\title{
VARIABILITY STUDY TO DETERMINE THE SOLUBILITY OF IMPURITIES IN PLUTONIUM- BEARING, LANTHANIDE BOROSILICATE GLASS
}

\author{
K.M. Fox \\ E.N. Hoffman \\ C.L. Crawford \\ T.B. Edwards \\ D.R. Best \\ J.C. Marra
}

September 2007

Materials Science and Technology Savannah River National Laboratory Aiken, SC 29808

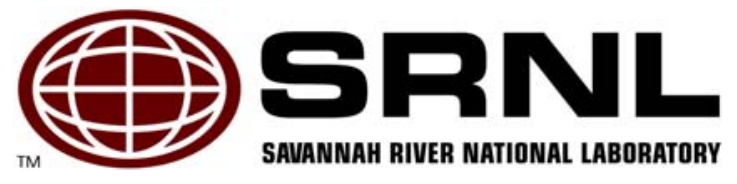


WSRC-STI-2007-00477

Revision 0

\section{DISCLAIMER}

This report was prepared by Washington Savannah River Company (WSRC) for the United States Department of Energy under Contract No. DE-AC09-96SR18500 and is an account of work performed under that contract. Neither the United States Department of Energy, nor WSRC, nor any of their employees makes any warranty, expressed or implied, or assumes any legal liability or responsibility for the accuracy, completeness, or usefulness, of any information, apparatus, or product or process disclosed herein or represents that its use will not infringe privately owned rights. Reference herein to any specific commercial product, process, or service by trademark, name, manufacturer or otherwise does not necessarily constitute or imply endorsement, recommendation, or favoring of same by WSRC or by the United States Government or any agency thereof. The views and opinions of the authors expressed herein do not necessarily state or reflect those of the United States Government or any agency thereof.

\section{Printed in the United States of America \\ Prepared For U.S. Department of Energy}

The Savannah River National Laboratory is operated for the U.S. Department of Energy by Washington Savannah River Company. 
Keywords: waste glass, variability study, Pu disposition

Retention: permanent

\section{VARIABILITY STUDY TO DETERMINE THE SOLUBILITY OF IMPURITIES IN PLUTONIUM- BEARING, LANTHANIDE BOROSILICATE GLASS}

K.M. Fox

E.N. Hoffman

C.L. Crawford

T.B. Edwards

D.R. Best

J.C. Marra

September 2007

Materials Science and Technology

Savannah River National Laboratory

Aiken, SC 29808

Prepared for the U.S. Department of Energy Under

Contract Number DEAC09-96SR18500

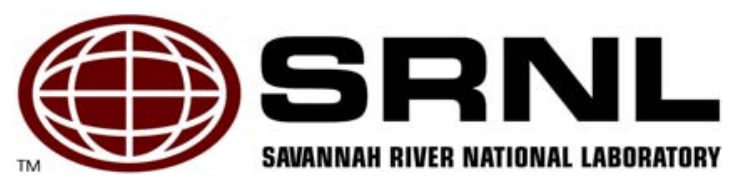




\section{REVIEWS AND APPROVALS}

\section{AUTHORS:}

K.M. Fox, Process Science and Engineering

Date

E.N. Hoffman, Materials Science and Technology

Date

C.L. Crawford, Process Science and Engineering

Date

T.B. Edwards, Statistical Consulting Section

Date

D.R. Best, Process Science and Engineering

Date

J.C. Marra, Materials Science and Technology

Date

\section{TECHNICAL REVIEWER:}

D.K. Peeler, Process Science and Engineering

Date

\section{APPROVERS}

G.T. Chandler, Manager, Materials Performance and Corrosion Technology Date

N.C. Iver, Director, Materials Science and Technology

Date

D.P. Eisele, Nuclear Materials Management Engineering

Date

R.H. Smith, Technology Manager

Date 


\section{EXECUTIVE SUMMARY}

This study focuses on the development of a compositional envelope that describes the retention of various impurities in lanthanide borosilicate (LaBS) glass for vitrification and immobilization of excess, defense-related plutonium. A limited amount of impurity data for the various plutonium sources is available and projections were made through analysis of the available information. These projections were used to define types and concentrations of impurities in the LaBS glass compositions to be fabricated and tested.

Sixty surrogate glass compositions were developed through a statistically designed approach to cover the anticipated ranges of concentrations for several impurity species expected in the plutonium feeds. An additional four glass compositions containing actual plutonium oxide were selected based on their targeted concentrations of metals and anions. The glasses were fabricated and characterized in the laboratory and shielded cells facility to determine the degree of retention of the impurity components, the impact of the impurities on the durability of each glass, and the degree of crystallization that occurred, both upon quenching and slow cooling.

Overall, the LaBS glass system appears to be very tolerant of most of the impurity types and concentrations projected in the plutonium waste stream. For the surrogate glasses, the measured $\mathrm{CuO}$, $\mathrm{Ga}_{2} \mathrm{O}_{3}, \mathrm{Na}_{2} \mathrm{O}, \mathrm{NiO}$, and $\mathrm{Ta}_{2} \mathrm{O}_{5}$ concentrations fell very close to their target values across the ranges of concentrations targeted in this study for each of these components. The measured $\mathrm{CaO}$ and $\mathrm{PbO}$ concentrations were consistently higher than the targeted values. The measured $\mathrm{Cr}_{2} \mathrm{O}_{3}$ and $\mathrm{Fe}_{2} \mathrm{O}_{3}$ concentrations were very close to the targets except for the one highest targeted value for each of these components. A solubility limit may have been approached in this glass system for $\mathrm{K}_{2} \mathrm{O}$ and $\mathrm{MgO}$. The measured $\mathrm{Cl}^{-}, \mathrm{F}^{-}, \mathrm{SeO}_{2}$ and $\mathrm{SO}_{4}{ }^{2-}$ concentrations were well below their target values for all of the study glasses. This is likely due to volatilization of these species during melting of the glass batch. Note that the degree of volatilization that occurred in this crucible-scale study may differ from the full-scale melter. The measured $\mathrm{HfO}_{2}$ concentrations were below their target values for all of the surrogate glasses. It is likely that for $\mathrm{HfO}_{2}$, the solubility limit in the glass was exceeded and some of the $\mathrm{HfO}_{2}$ batch material remained in the bottom of the crucibles after pouring the glasses.

X-ray diffraction and scanning electron microscopy (SEM) results indicated that some crystalline $\mathrm{HfO}_{2}$ remained in some of the surrogate glasses with the lowest concentration of impurities. No other crystalline phases were identified. The Product Consistency Test (PCT) results showed that all 60 of the surrogate glass compositions tested were very durable, regardless of thermal history, with the highest normalized release for boron being $0.041 \mathrm{~g} / \mathrm{L}$. The $\mathrm{pH}$ of the leachate solutions was generally lower than that of conventional waste glasses due to the lack of alkali in the LaBS glass, which likely impacted the PCT results. The normalized release rates for the elements measured were generally too small to attempt to correlate the results with the compositions of the test glasses. The Toxicity Characteristic Leaching Procedure results showed that no hazardous metals were leached from the surrogate glasses in any measurable concentration.

A plutonium-containing crystalline phase with a cross-shaped morphology was identified via SEM in the glasses fabricated with plutonium oxide. This phase was identified in a previous study of plutonium-bearing LaBS glasses and may provide an opportunity to intentionally crystallize some of the plutonium oxide into a highly insoluble form with an intrinsic neutron absorber. Additional work is necessary to better characterize the influence that this phase has on durability of the glass. 
The PCT results for the plutonium-containing LaBS glasses with impurities were similar to previous tests conducted on $\mathrm{PuO}_{2}$-containing glasses without impurities added. The highest normalized release for boron was $0.02 \mathrm{~g} / \mathrm{L}$, which bounded the highest normalized release for plutonium of $0.01 \mathrm{~g} / \mathrm{L}$. 


\section{TABLE OF CONTENTS}

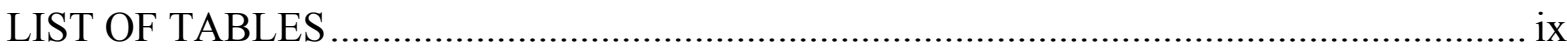

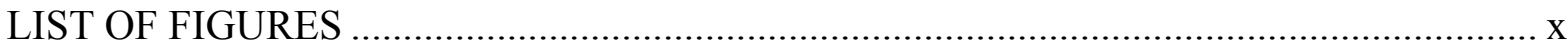

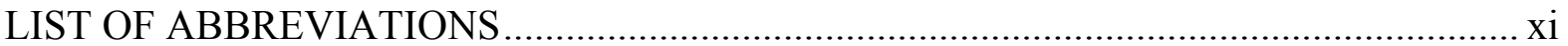

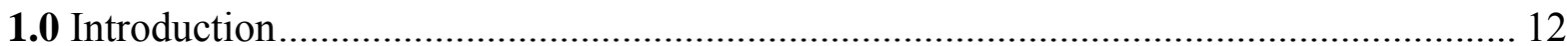

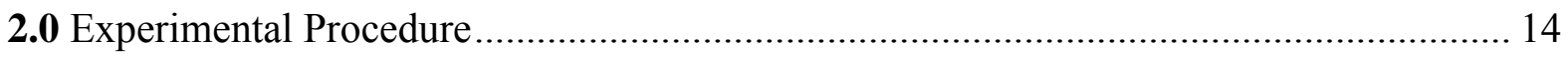

2.1 Target Compositions of Selected Glasses ........................................................... 15

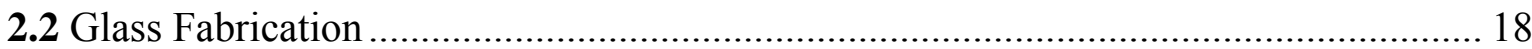

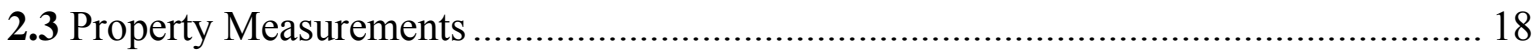

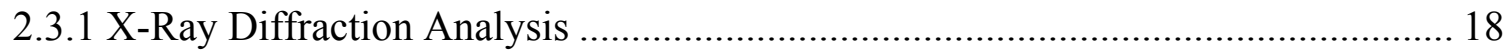

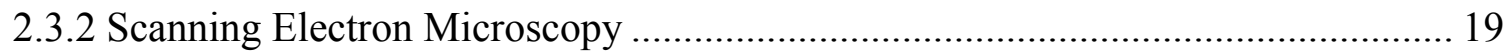

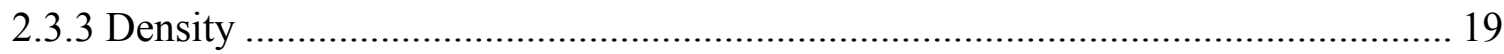

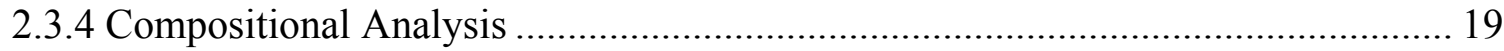

2.3.5 Product Consistency Test ....................................................................................... 19

2.3.6 Toxicity Characteristic Leaching Procedure (TCLP) ........................................ 20

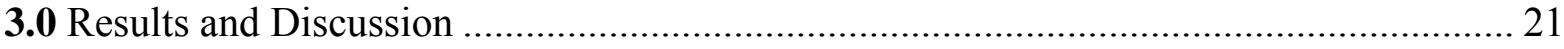

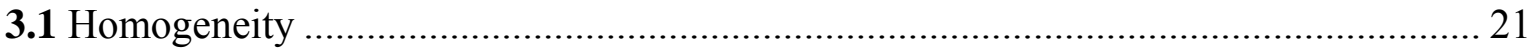

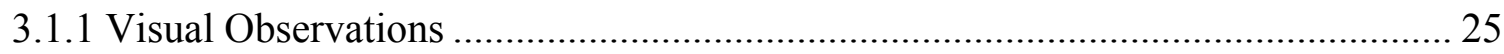

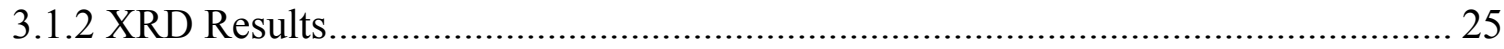

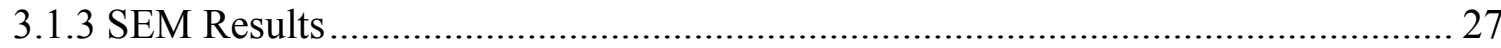

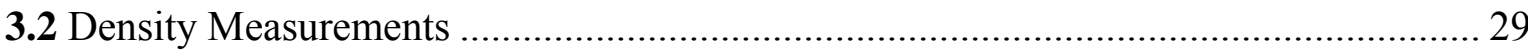

3.3 A Statistical Review of the Chemical Composition Measurements of the Pu Impurity

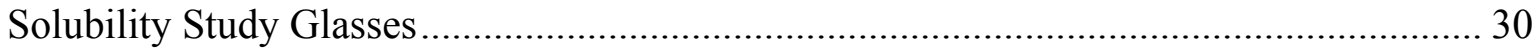

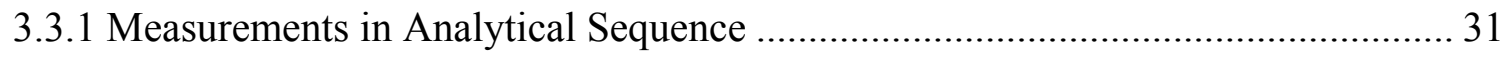

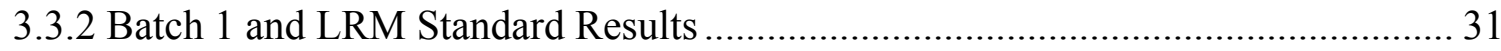

3.3.3 Composition Measurements by Glass Number.............................................. 32

3.3.4 Measured versus Targeted Compositions ............................................................ 32

3.4 A Statistical Review of the PCT Results for the Surrogate Glasses.......................... 35

3.4.1 Measurements in Analytical Sequence ............................................................. 36

3.4.2 Results for the Samples of the Multi-Element Solution Standard ......................... 36

3.4.3 Measurements by Glass Number.................................................................. 37 


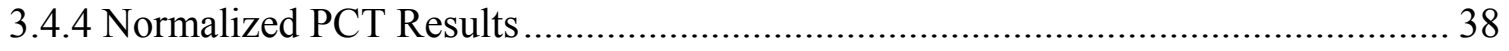

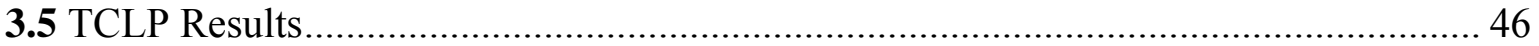

3.6 Results for the $\mathrm{PuO}_{2}$ Glasses .............................................................................. 46

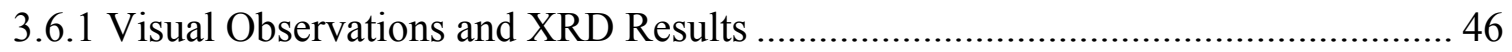

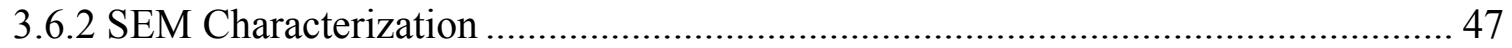

3.6.3 Normalized PCT Results .................................................................................. 56

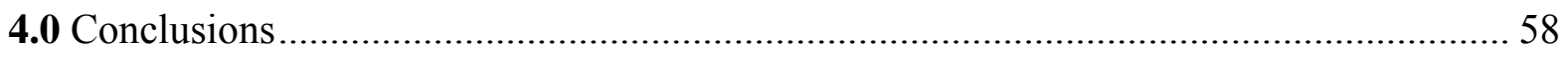

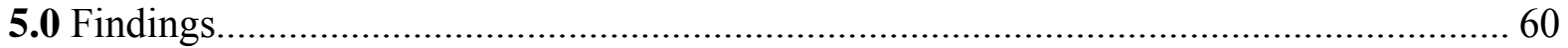

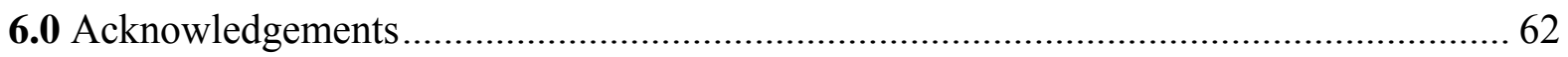

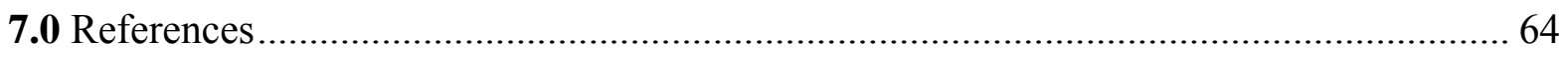

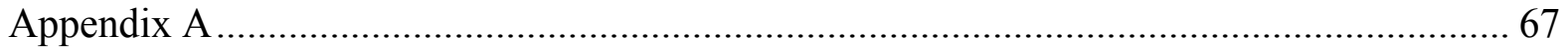

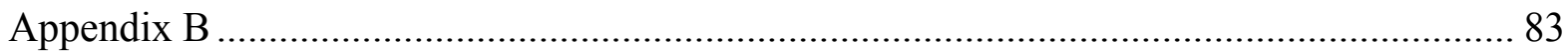

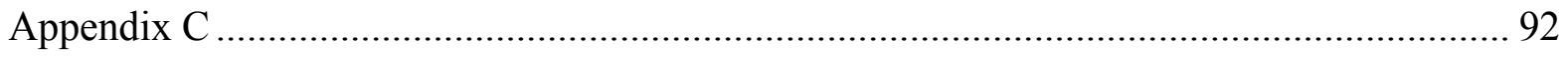

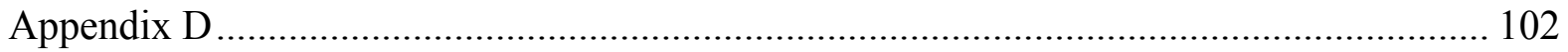

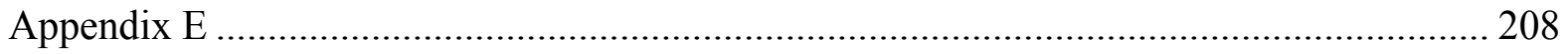

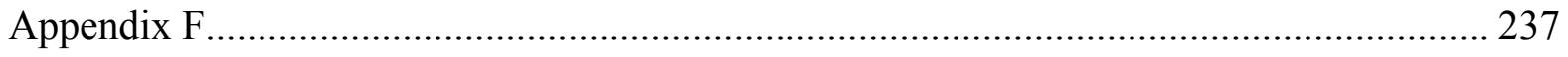




\section{LIST OF TABLES}

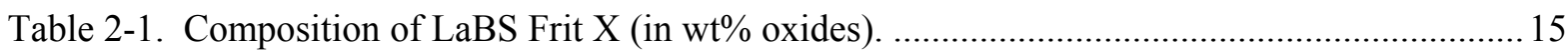

Table 2-2. Target compositions of the variability study surrogate glasses (in wt \% oxides)............. 16

Table 2-3. Target compositions of the variability study glasses containing $\mathrm{PuO}_{2}$ (in wt \% oxides)... 18

Table 3-1. Visual observations and XRD results for the variability study glasses...........................22

Table 3-2. Measured densities of the surrogate glasses................................................................... 30

Table 3-3. Results from samples of the multi-element solution standard by PCT plans..................... 37

Table 3-4. Normalized PCTs by Glass ID and compositional view................................................. 39

Table 3-5. Results of the TCLP for select surrogate glasses. …..................................................... 46

Table 3-6. Visual observations and $\mathrm{XRD}$ results for the glasses fabricated with $\mathrm{PuO}_{2} \ldots \ldots \ldots \ldots \ldots \ldots \ldots . . . . . . . . .64$

Table 3-7. PCT results for the ARM reference glass and multielement standard solution included

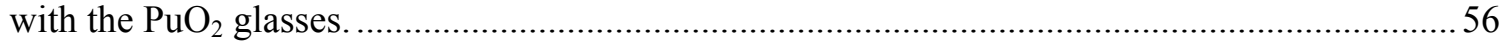

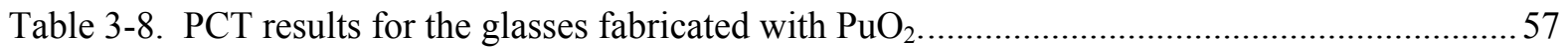




\section{LIST OF FIGURES}

Figure 3-1. XRD results for the CCC version of surrogate glass Pu35-14 .................................... 26

Figure 3-2. XRD results for the CCC version of surrogate glass Pu35-42 .................................... 27

Figure 3-3. SEM micrograph of a fracture surface in the CCC version of glass Pu04-03 showing an

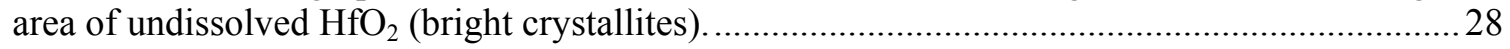

Figure 3-4. SEM micrograph of a fracture surface in the CCC version of glass Pu35-20_...............29

Figure 3-5. SEM micrograph of a fracture surface in the CCC version of glass Pu35-25 ...............29

Figure 3-6. Measured versus targeted concentrations for select analytes of the surrogate glasses. .... 34

Figure 3-7. Photograph of the four glasses fabricated with $\mathrm{PuO}_{2}$ in the $\mathrm{SRNL}$ shielded cells facility. The glasses are, from left to right, Pu35-03B, Pu35-06B, Pu04-04B and Pu35-17B.

Figure 3-8. SEM micrograph of glass Pu04-04B. This glass was generally free of any crystalline phases.

Figure 3-9. Higher magnification SEM micrograph of glass Pu04-04B, showing a small area of crystalline material.

Figure 3-10. SEM micrograph of the crystalline phase identified in glass Pu04-04B. The marked spots indicate areas where EDS spectra were recorded.

Figure 3-11. EDS spectrum collected at Spot-3 in Figure 3-10.

Figure 3-12. EDS spectrum recorded at Spot-4 in Figure 3-10.

Figure 3-13. SEM micrograph of glass Pu35-03B. The arrows indicate crystallization on the faces of some of the glass particles..

Figure 3-14. Higher magnification SEM micrograph of the two crystalline phases identified in glass

Pu35-03B. Areas analyzed by EDS are indicated.

Figure 3-15. EDS spectra corresponding to the spots identified in Figure 3-14.

Figure 3-16. SEM micrograph of glass Pu35-06B.

Figure 3-17. SEM micrograph of glass Pu35-17B. Some crystalline material is visible at the center of the image.

Figure 3-18. Higher magnification SEM micrograph of glass Pu35-06B, showing an area of crystallization on the face of a glass particle.

Figure 3-19. Higher magnification SEM micrograph of glass Pu35-17B, showing an area of crystallization on the face of a glass particle. 


\section{LIST OF ABBREVIATIONS}

\begin{tabular}{|c|c|}
\hline $\mathrm{AD}$ & Analytical Development \\
\hline ANOVA & ANalysis Of VAriance \\
\hline ARM & Approved Reference Material \\
\hline bc & bias-corrected \\
\hline $\mathrm{CCC}$ & Can-in-Canister Cooled \\
\hline DOE & Department Of Energy \\
\hline DOE-EM & Department Of Energy - Office of Environmental Management \\
\hline EA & Environmental Assessment \\
\hline EDS & Energy Dispersive Spectroscopy \\
\hline HLW & High Level Waste \\
\hline IC & Ion Chromatography \\
\hline ICP-AES & Inductively Coupled Plasma - Atomic Emission Spectroscopy \\
\hline ICP-MS & Inductively Coupled Plasma - Mass Spectroscopy \\
\hline LaBS & Lanthanide Borosilicate \\
\hline LM & Lithium Metaborate \\
\hline LRM & Low-activity Reference Material \\
\hline MFFF & Mixed oxide Fuel Fabrication Facility \\
\hline MOX & Mixed OXide \\
\hline MT & Metric Tons \\
\hline NL & Normalized Leachate \\
\hline NMM & Nuclear Materials Management \\
\hline PCT & Product Consistency Test \\
\hline PIP & Plutonium Immobilization Program \\
\hline $\mathrm{PF}$ & Peroxide Fusion \\
\hline ppm & parts per million \\
\hline PSAL & Process Science Analytical Laboratory \\
\hline RCRA & Resource Conservation and Recovery Act \\
\hline SEM & Scanning Electron Microscopy \\
\hline SRNL & Savannah River National Laboratory \\
\hline SRS & Savannah River Site \\
\hline TCLP & Toxicity Characteristic Leaching Procedure \\
\hline VPWF & Vitrified Plutonium Waste Form \\
\hline WSRC & Washington Savannah River Company \\
\hline XRD & X-Ray Diffraction \\
\hline
\end{tabular}


WSRC-STI-2007-00477

Revision 0

This page intentionally left blank. 


\subsection{Introduction}

In the aftermath of the Cold War, the United States has identified an excess of up to 50 metric tons (MT) of weapons-useable plutonium. The Department of Energy (DOE) was to construct both a Mixed Oxide Fuel Fabrication Facility (MFFF) and a Plutonium Immobilization Program (PIP) facility to disposition this material. In April 2002, DOE decided not to construct the PIP facility and to solely proceed with the construction of the MFFF facility with a focus only on the disposition of weapons-grade plutonium to meet the non-proliferation agreement between Russia and the United States. This action resulted in several metric tons of DOE-Office of Environmental Management (DOE-EM) owned, weapons usable, plutonium-bearing materials having no clear disposition path.

A vitrification technology utilizing a lanthanide borosilicate (LaBS) glass appears to be a viable option to disposition excess weapons-useable plutonium that is not suitable for processing into mixed oxide (MOX) fuel. A significant effort to develop a glass formulation and vitrification process to immobilize plutonium was completed in the mid-1990s to support the PIP. The LaBS glass formulation was found to be capable of immobilizing in excess of $10 \mathrm{wt} \% \mathrm{Pu}$ and to be tolerant of the impurities accompanying the plutonium material streams. ${ }^{1,2}$ Thus, this waste form could be suitable for the disposition of plutonium owned by the DOE-EM that may not be well characterized and that may contain high levels of impurities. However, the relative tolerance of the glass composition to the various feed impurities needs to be studied.

The can-in-canister technology demonstrated in the PIP $^{3,4}$ could be utilized to dispose of the vitrified plutonium in the federal radioactive waste repository. The can-in-canister technology involves placing small cans of the vitrified $\mathrm{Pu}$ form into a high level waste (HLW) glass canister fitted with a rack to hold the cans and then filling the canister with HLW glass to provide proliferation resistance. The completed assembly containing the plutonium glass and the HLW glass would be referred to as the Vitrified Plutonium Waste Form (VPWF).

This study focuses on the development of a composition envelope that describes the degree of retention of various impurities in the LaBS glass. A detailed analysis of the types and concentrations of the impurities expected in the $\mathrm{Pu}$ feed stream has recently been issued. ${ }^{5}$ A series of glass compositions was selected, as documented in a previous report, ${ }^{6}$ based on these projections. These glasses will provide further insight into the impurity tolerance of the LaBS glass.

The results of this glass selection process provided an array of glass compositions to be fabricated and characterized in the laboratory in order to evaluate the retention of various impurity elements, their effects on crystallization and durability response. The array was developed using a layered process to allow for an evaluation of both linear and non-linear effects of the impurities. The majority of the glasses were formulated with $\mathrm{Hf}$ as a surrogate for $\mathrm{Pu}$ on a mass basis to simplify laboratory experiments. Pu glass testing was implemented for select compositions for comparison with the results of the surrogate testing. This report describes the outcome of the experimental work, including the measured retention ${ }^{\mathrm{a}}$ of various impurity species in the test glasses, the durability of these glasses, and characterization of any crystallization in the glasses after both quenching and slow cooling.

This work was initiated by an Nuclear Materials Management (NMM) Technical Task Request ${ }^{7}$ and is performed under a Savannah River National Laboratory (SRNL) Task Technical and Quality Assurance Plan. ${ }^{8}$

\footnotetext{
a Note that "retention" is used here rather than "solubility" since true equilibrium conditions are not likely to be achieved in this crucible-scale study.
} 
WSRC-STI-2007-00477

Revision 0

This page intentionally left blank. 
WSRC-STI-2007-00477

Revision 0

\subsection{Experimental Procedure}

\subsection{Target Compositions of Selected Glasses}

The strategy used in selecting glasses for the impurity variability study is described in a previous report. ${ }^{6}$ The target compositions for the surrogate and $\mathrm{PuO}_{2}$ glasses will be briefly summarized here. Each variability study glass was fabricated with a lanthanide borosilicate glass frit termed LaBS Frit X. ${ }^{9}$ The nominal composition of this frit is given in Table 2-1.

Table 2-1. Composition of LaBS Frit $X$ (in wt\% oxides).

\begin{tabular}{||c|c|}
\hline \hline Component & wt \% \\
\hline $\mathrm{Al}_{2} \mathrm{O}_{3}$ & 10.0 \\
\hline $\mathrm{B}_{2} \mathrm{O}_{3}$ & 13.0 \\
\hline $\mathrm{Gd}_{2} \mathrm{O}_{3}$ & 13.5 \\
\hline $\mathrm{HfO}_{2}$ & 7.0 \\
\hline $\mathrm{La}_{2} \mathrm{O}_{3}$ & 19.0 \\
\hline $\mathrm{Nd}_{2} \mathrm{O}_{3}$ & 15.0 \\
\hline $\mathrm{SiO}_{2}$ & 20.0 \\
\hline $\mathrm{SrO}$ & 2.5 \\
\hline
\end{tabular}

A series of impurity elements and their concentrations was chosen based on an analysis of the anticipated $\mathrm{Pu}$ feeds provided by Moore and Allender. ${ }^{5}$ An array of 60 surrogate glass compositions was developed to examine the influence of these impurities on the performance of glasses fabricated with Frit $X$. The surrogate glasses contained $\mathrm{Hf}$ in place of $\mathrm{Pu}$ on a mass basis. The target compositions of the 60 surrogate glasses are given in Table 2-2. The Glass ID numbers were developed to indicate the concentration of impurities in the $\mathrm{Pu}$ feed. For example, Pu35-xx indicates $35 \mathrm{wt} \%$ impurities in the $\mathrm{Pu}$ feed. In addition, four glasses were fabricated with $\mathrm{PuO}_{2}$ for comparison with the surrogate glasses. These glass compositions were selected from the array of surrogate glasses, with the selection strategy being described in a previous report. ${ }^{6} \mathrm{~A}$ letter ' $\mathrm{B}$ ' was appended to the glass identifiers to distinguish the glasses made with $\mathrm{PuO}_{2}$ from the surrogates (i.e., Pu35-03B, Pu35-06B, Pu35-17B and Pu04-04B). The target compositions of the four glasses fabricated with $\mathrm{PuO}_{2}$ are given in Table 2-3. 
Table 2-2. Target compositions of the variability study surrogate glasses (in wt \% oxides).

\begin{tabular}{|c|c|c|c|c|c|c|c|c|c|c|c|c|c|}
\hline Glass ID & $\mathrm{Cl}^{-}$ & $\mathbf{T a}_{2} \mathbf{O}_{5}$ & MgO & $\overline{K_{2} \mathrm{O}}$ & $\mathrm{Fe}_{2} \mathrm{O}_{3}$ & $\mathrm{Na}_{2} \mathrm{O}$ & $\mathbf{F}^{-}$ & $\mathrm{CaO}$ & $\mathbf{G a}_{2} \mathbf{O}_{3}$ & NiO & $\mathrm{Cr}_{2} \mathrm{O}_{3}$ & $\mathrm{CuO}$ & $\mathrm{SOO}_{4}{ }^{2-}$ \\
\hline Pu35-01 & 0.58 & 0.07 & 1.62 & 0.26 & 0.39 & 0.80 & 0.00 & 0.00 & 0.95 & 0.21 & 0.00 & 0.15 & 0.00 \\
\hline $\mathrm{Pu} 35-02$ & 0.58 & 0.07 & 1.45 & 0.74 & 0.08 & 0.35 & 0.45 & 0.36 & 0.08 & 0.15 & 0.33 & 0.07 & 0.17 \\
\hline Pu35-03 & 0.57 & 0.18 & 0.54 & 0.31 & 0.14 & 1.48 & 0.00 & 0.77 & 0.45 & 0.07 & 0.64 & 0.00 & 0.00 \\
\hline Pu35-04 & 0.59 & 0.46 & 1.06 & 0.45 & 0.27 & 0.56 & 0.52 & 0.32 & 0.36 & 0.07 & 0.09 & 0.07 & 0.00 \\
\hline Pu35-05 & 0.58 & 0.09 & 0.52 & 0.78 & 1.32 & 0.35 & 0.00 & 0.13 & 0.29 & 0.00 & 0.64 & 0.29 & 0.00 \\
\hline Pu35-06 & 0.60 & 0.10 & 0.91 & 0.27 & 0.97 & 0.80 & 0.48 & 0.29 & 0.00 & 0.28 & 0.22 & 0.00 & 0.17 \\
\hline Pu35-07 & 0.62 & 1.30 & 0.54 & 0.42 & 0.09 & 0.61 & 0.19 & 0.20 & 0.08 & 0.37 & 0.13 & 0.16 & 0.17 \\
\hline Pu35-08 & 0.62 & 0.39 & 0.88 & 0.77 & 0.89 & 0.40 & 0.30 & 0.24 & 0.16 & 0.25 & 0.09 & 0.07 & 0.00 \\
\hline Pu35-09 & 0.64 & 0.11 & 0.53 & 1.54 & 0.00 & 1.13 & 0.00 & 0.10 & 0.13 & 0.19 & 0.08 & 0.25 & 0.17 \\
\hline Pu35-10 & 0.65 & 0.27 & 0.81 & 0.36 & 0.59 & 0.67 & 0.38 & 0.08 & 0.71 & 0.07 & 0.08 & 0.07 & 0.17 \\
\hline Pu35-11 & 0.69 & 0.69 & 0.99 & 0.38 & 0.08 & 0.69 & 0.06 & 0.40 & 0.21 & 0.17 & 0.40 & 0.00 & 0.17 \\
\hline $\mathrm{Pu} 35-12$ & 0.65 & 0.59 & 0.66 & 0.28 & 0.19 & 0.79 & 0.33 & 0.08 & 0.36 & 0.47 & 0.40 & 0.18 & 0.00 \\
\hline Pu35-13 & 0.77 & 0.84 & 0.76 & 0.44 & 0.37 & 1.09 & 0.06 & 0.00 & 0.08 & 0.00 & 0.37 & 0.15 & 0.00 \\
\hline Pu35-14 & 0.80 & 0.34 & 0.44 & 0.20 & 1.00 & 1.07 & 0.08 & 0.38 & 0.27 & 0.07 & 0.13 & 0.07 & 0.00 \\
\hline Pu35-15 & 1.00 & 0.00 & 0.54 & 0.59 & 0.00 & 0.88 & 0.00 & 0.00 & 1.27 & 0.60 & 0.00 & 0.00 & 0.00 \\
\hline Pu35-16 & 0.95 & 0.29 & 0.73 & 0.00 & 0.46 & 1.23 & 0.00 & 0.70 & 0.15 & 0.13 & 0.00 & 0.29 & 0.17 \\
\hline Pu35-17 & 1.11 & 0.55 & 0.40 & 0.43 & 0.00 & 1.04 & 0.06 & 0.08 & 0.68 & 0.07 & 0.31 & 0.10 & 0.17 \\
\hline Pu35-18 & 0.58 & 0.07 & 1.04 & 1.10 & 0.08 & 0.94 & 0.06 & 0.57 & 0.08 & 0.07 & 0.48 & 0.07 & 0.00 \\
\hline Pu35-19 & 0.58 & 0.07 & 1.38 & 0.37 & 0.78 & 0.78 & 0.38 & 0.08 & 0.08 & 0.07 & 0.48 & 0.07 & 0.00 \\
\hline Pu35-20 & 0.58 & 0.51 & 0.55 & 0.85 & 0.28 & 0.50 & 0.29 & 0.23 & 0.51 & 0.29 & 0.40 & 0.07 & 0.00 \\
\hline Pu35-21 & 0.58 & 1.14 & 1.28 & 0.41 & 0.08 & 0.59 & 0.06 & 0.08 & 0.62 & 0.07 & 0.09 & 0.07 & 0.00 \\
\hline Pu35-22 & 0.60 & 0.52 & 0.69 & 0.55 & 0.37 & 0.74 & 0.47 & 0.59 & 0.08 & 0.08 & 0.15 & 0.22 & 0.00 \\
\hline Pu35-23 & 0.59 & 0.83 & 0.67 & 0.16 & 0.56 & 0.93 & 0.09 & 0.16 & 0.53 & 0.12 & 0.29 & 0.22 & 0.00 \\
\hline Pu35-24 & 0.63 & 0.15 & 0.67 & 0.53 & 0.41 & 0.58 & 0.24 & 0.40 & 0.83 & 0.10 & 0.37 & 0.22 & 0.00 \\
\hline Pu35-25 & 0.67 & 0.59 & 0.48 & 0.70 & 0.83 & 0.48 & 0.07 & 0.28 & 0.26 & 0.35 & 0.17 & 0.22 & 0.00 \\
\hline Pu35-26 & 0.66 & 0.22 & 0.89 & 0.25 & 0.47 & 0.77 & 0.10 & 0.43 & 0.79 & 0.22 & 0.27 & 0.07 & 0.00 \\
\hline Pu35-27 & 0.72 & 0.67 & 0.61 & 0.52 & 0.46 & 0.65 & 0.24 & 0.32 & 0.27 & 0.07 & 0.48 & 0.07 & 0.00 \\
\hline Pu35-28 & 0.72 & 0.54 & 0.93 & 0.39 & 0.08 & 0.74 & 0.10 & 0.11 & 0.41 & 0.36 & 0.48 & 0.22 & 0.00 \\
\hline Pu35-29 & 0.84 & 0.34 & 0.47 & 0.84 & 0.18 & 0.95 & 0.36 & 0.08 & 0.70 & 0.07 & 0.09 & 0.07 & 0.00 \\
\hline Pu35-30 & 0.58 & 0.07 & 0.46 & 1.11 & 0.08 & 0.90 & 0.06 & 0.46 & 0.75 & 0.07 & 0.08 & 0.07 & 0.17 \\
\hline Pu35-31 & 0.58 & 0.07 & 0.60 & 1.12 & 0.83 & 0.47 & 0.47 & 0.08 & 0.08 & 0.17 & 0.09 & 0.07 & 0.17 \\
\hline Pu35-32 & 0.58 & 0.07 & 1.39 & 0.26 & 0.08 & 0.69 & 0.40 & 0.08 & 0.90 & 0.07 & 0.08 & 0.07 & 0.17 \\
\hline Pu35-33 & 0.57 & 0.07 & 1.37 & 0.08 & 0.56 & 0.90 & 0.13 & 0.44 & 0.08 & 0.07 & 0.48 & 0.07 & 0.17 \\
\hline Pu35-34 & 0.58 & 0.71 & 1.38 & 0.58 & 0.08 & 0.48 & 0.06 & 0.37 & 0.08 & 0.07 & 0.08 & 0.22 & 0.17 \\
\hline Pu35-35 & 0.58 & 1.12 & 0.46 & 0.07 & 0.82 & 0.93 & 0.06 & 0.08 & 0.39 & 0.07 & 0.08 & 0.07 & 0.17 \\
\hline Pu35-36 & 0.60 & 0.51 & 0.89 & 0.43 & 0.11 & 0.67 & 0.16 & 0.08 & 0.31 & 0.33 & 0.37 & 0.22 & 0.17 \\
\hline Pu35-37 & 0.60 & 0.35 & 1.02 & 0.36 & 0.28 & 0.65 & 0.10 & 0.17 & 0.36 & 0.37 & 0.40 & 0.07 & 0.17 \\
\hline Pu35-38 & 0.66 & 0.53 & 0.73 & 0.45 & 0.17 & 0.66 & 0.31 & 0.43 & 0.30 & 0.18 & 0.18 & 0.07 & 0.17 \\
\hline Pu35-39 & 0.69 & 0.50 & 0.70 & 0.77 & 0.29 & 0.70 & 0.18 & 0.08 & 0.31 & 0.07 & 0.31 & 0.07 & 0.17 \\
\hline Pu35-40 & 0.72 & 0.07 & 0.65 & 0.50 & 0.56 & 0.65 & 0.14 & 0.41 & 0.39 & 0.10 & 0.32 & 0.22 & 0.17 \\
\hline Pu35-41 & 0.93 & 0.07 & 1.39 & 0.34 & 0.08 & 0.94 & 0.06 & 0.08 & 0.08 & 0.44 & 0.08 & 0.15 & 0.17 \\
\hline $\mathrm{Pu} 35-42$ & 0.58 & 0.21 & 1.08 & 0.84 & 0.17 & 0.78 & 0.12 & 0.16 & 0.16 & 0.15 & 0.34 & 0.14 & 0.17 \\
\hline Pu35-43 & 0.58 & 0.49 & 0.65 & 0.21 & 0.57 & 0.74 & 0.20 & 0.35 & 0.35 & 0.20 & 0.25 & 0.14 & 0.17 \\
\hline Pu35-44 & 0.58 & 0.54 & 0.80 & 0.31 & 0.58 & 0.66 & 0.19 & 0.28 & 0.30 & 0.15 & 0.25 & 0.11 & 0.17 \\
\hline Pu35-45 & 0.58 & 0.70 & 0.75 & 0.20 & 0.46 & 0.73 & 0.12 & 0.23 & 0.48 & 0.22 & 0.17 & 0.11 & 0.17 \\
\hline Pu35-46 & 0.59 & 0.45 & 0.73 & 0.41 & 0.17 & 0.63 & 0.35 & 0.17 & 0.54 & 0.30 & 0.17 & 0.15 & 0.17 \\
\hline Pu35-47 & 0.61 & 0.85 & 0.61 & 0.25 & 0.17 & 0.73 & 0.12 & 0.40 & 0.19 & 0.29 & 0.34 & 0.14 & 0.17 \\
\hline Pu35-48 & 0.63 & & 0.79 & 0.29 & 0.50 & 0.73 & 0.20 & 0.37 & 0.34 & 0.19 & 0.23 & 0.11 & 0.17 \\
\hline $\mathrm{Pu} 35-49$ & 0.64 & 0.27 & 0.77 & 0.63 & 0.52 & 0.64 & 0.19 & 0.32 & 0.19 & 0.20 & 0.19 & 0.14 & 0.17 \\
\hline $\mathrm{Pu} 35-50$ & 0.64 & 0.18 & 0.66 & 0.69 & 0.49 & 0.65 & 0.20 & 0.26 & 0.32 & 0.24 & 0.25 & 0.11 & 0.17 \\
\hline Pu35-51 & 0.65 & 0.32 & 0.90 & 0.26 & 0.56 & 0.75 & 0.22 & 0.16 & 0.16 & 0.29 & 0.32 & 0.11 & 0.17 \\
\hline Pu35-52 & 0.69 & 0.14 & 0.82 & 0.37 & 0.39 & 0.71 & 0.14 & 0.17 & 0.58 & 0.23 & 0.33 & 0.14 & 0.17 \\
\hline Pu35-53 & 0.70 & 0.77 & 0.62 & 0.47 & 0.17 & 0.79 & 0.35 & 0.16 & 0.16 & 0.15 & 0.17 & 0.11 & 0.17 \\
\hline Pu35-54 & 0.64 & 0.46 & 0.81 & 0.57 & 0.42 & 0.70 & 0.21 & 0.28 & 0.41 & 0.16 & 0.30 & 0.13 & 0.00 \\
\hline Pu35-55 & 0.63 & 0.39 & 0.84 & 0.46 & 0.36 & 0.72 & 0.19 & 0.24 & 0.32 & 0.19 & 0.23 & 0.12 & 0.17 \\
\hline $\mathrm{Pu} 04-01$ & 0.12 & 0.00 & 0.00 & 0.21 & 0.00 & 0.24 & 0.00 & 0.00 & 0.00 & 0.00 & 0.00 & 0.00 & 0.00 \\
\hline Pu04-02 & 0.00 & 0.00 & 0.08 & 0.07 & 0.00 & 0.32 & 0.12 & 0.00 & 0.00 & 0.00 & 0.00 & 0.00 & 0.00 \\
\hline $\mathrm{Pu} 04-03$ & 0.06 & 0.00 & 0.16 & 0.00 & 0.17 & 0.16 & 0.06 & 0.00 & 0.00 & 0.00 & 0.00 & 0.00 & 0.00 \\
\hline $\mathrm{Pu} 04-04$ & 0.00 & 0.00 & 0.08 & 0.07 & 0.08 & 0.08 & 0.00 & 0.08 & 0.00 & 0.08 & 0.09 & 0.07 & 0.00 \\
\hline $\mathrm{Pu} 04-05$ & 0.12 & 0.00 & 0.00 & 0.00 & 0.00 & 0.32 & 0.12 & 0.00 & 0.00 & 0.00 & 0.00 & 0.00 & 0.00 \\
\hline
\end{tabular}


Table 2-2. Target compositions of the variability study surrogate glasses (in wt \% oxides). (continued)

\begin{tabular}{|c|c|c|c|c|c|c|c|c|c|c|c|c|c|}
\hline Glass ID & $\mathrm{C}$ & PbO & $\mathrm{SeO}_{2}$ & $\mathrm{Cs}_{2} \mathrm{O}$ & $\mathbf{H f O}_{2}$ & $\mathbf{A l}_{2} \mathbf{O}_{3}$ & $\mathbf{B}_{2} \mathbf{O}_{3}$ & $\mathrm{Gd}_{2} \mathrm{O}_{3}$ & $\mathrm{La}_{2} \mathrm{O}_{3}$ & $\mathrm{Nd}_{2} \mathrm{O}_{3}$ & $\mathrm{SiO}_{2}$ & SrO & Total \\
\hline Pu35-01 & 0.06 & 0.00 & 0.08 & 0.00 & 14.86 & 8.60 & 11.18 & 11.61 & 16.34 & 12.90 & 17.20 & 2.15 & 100 \\
\hline Pu35-02 & 0.00 & 0.06 & 0.08 & 0.06 & 14.92 & 8.60 & 11.18 & 11.61 & 16.34 & 12.90 & 17.20 & 2.15 & 100 \\
\hline Pu35-03 & 0.00 & 0.00 & 0.00 & 0.06 & 14.81 & 8.60 & 11.18 & 11.61 & 16.34 & 12.90 & 17.20 & 2.15 & 100 \\
\hline Pu35-04 & 0.06 & 0.08 & 0.08 & 0.00 & 15.00 & 8.60 & 11.18 & 11.61 & 16.34 & 12.90 & 17.20 & 2.15 & 100 \\
\hline Pu35-05 & 0.06 & 0.07 & 0.00 & 0.06 & 14.85 & 8.60 & 11.18 & 11.61 & 16.34 & 12.90 & 17.20 & 2.15 & 100 \\
\hline Pu35-06 & 0.06 & 0.00 & 0.00 & 0.00 & 14.87 & 8.60 & 11.18 & 11.61 & 16.34 & 12.90 & 17.20 & 2.15 & 100 \\
\hline Pu35-07 & 0.06 & 0.06 & 0.00 & 0.06 & 14.96 & 8.60 & 11.18 & 11.61 & 16.34 & 12.90 & 17.20 & 2.15 & 100 \\
\hline Pu35-08 & 0.00 & 0.00 & 0.00 & 0.00 & 14.95 & 8.60 & 11.18 & 11.61 & 16.34 & 12.90 & 17.20 & 2.15 & 100 \\
\hline Pu35-09 & 0.06 & 0.08 & 0.08 & 0.00 & 14.92 & 8.60 & 11.18 & 11.61 & 16.34 & 12.90 & 17.20 & 2.15 & 100 \\
\hline Pu35-10 & 0.00 & 0.06 & 0.08 & 0.06 & 14.90 & 8.60 & 11.18 & 11.61 & 16.34 & 12.90 & 17.20 & 2.15 & 100 \\
\hline Pu35-11 & 0.06 & 0.07 & 0.08 & 0.00 & 14.87 & 8.60 & 11.18 & 11.61 & 16.34 & 12.90 & 17.20 & 2.15 & 100 \\
\hline Pu35-12 & 0.00 & 0.00 & 0.08 & 0.00 & 14.96 & 8.60 & 11.18 & 11.61 & 16.34 & 12.90 & 17.20 & 2.15 & 100 \\
\hline Pu35-13 & 0.00 & 0.08 & 0.00 & 0.06 & 14.96 & 8.60 & 11.18 & 11.61 & 16.34 & 12.90 & 17.20 & 2.15 & 100 \\
\hline Pu35-14 & 0.06 & 0.06 & 0.08 & 0.06 & 14.90 & 8.60 & 11.18 & 11.61 & 16.34 & 12.90 & 17.20 & 2.15 & 100 \\
\hline Pu35-15 & 0.00 & 0.08 & 0.00 & 0.06 & 15.00 & 8.60 & 11.18 & 11.61 & 16.34 & 12.90 & 17.20 & 2.15 & 100 \\
\hline Pu35-16 & 0.00 & 0.06 & 0.00 & 0.00 & 14.85 & 8.60 & 11.18 & 11.61 & 16.34 & 12.90 & 17.20 & 2.15 & 100 \\
\hline Pu35-17 & 0.06 & 0.00 & 0.00 & 0.00 & 14.95 & 8.60 & 11.18 & 11.61 & 16.34 & 12.90 & 17.20 & 2.15 & 100 \\
\hline Pu35-18 & 0.00 & 0.00 & 0.00 & 0.00 & 14.88 & 8.60 & 11.18 & 11.61 & 16.34 & 12.90 & 17.20 & 2.15 & 100 \\
\hline Pu35-19 & 0.00 & 0.00 & 0.00 & 0.00 & 14.89 & 8.60 & 11.18 & 11.61 & 16.34 & 12.90 & 17.20 & 2.15 & 100 \\
\hline Pu35-20 & 0.00 & 0.00 & 0.00 & 0.00 & 14.95 & 8.60 & 11.18 & 11.61 & 16.34 & 12.90 & 17.20 & 2.15 & 100 \\
\hline Pu35-21 & 0.00 & 0.00 & 0.00 & 0.00 & 14.94 & 8.60 & 11.18 & 11.61 & 16.34 & 12.90 & 17.20 & 2.15 & 100 \\
\hline Pu35-22 & 0.00 & 0.00 & 0.00 & 0.00 & 14.98 & 8.60 & 11.18 & 11.61 & 16.34 & 12.90 & 17.20 & 2.15 & 100 \\
\hline Pu35-23 & 0.00 & 0.00 & 0.00 & 0.00 & 14.88 & 8.60 & 11.18 & 11.61 & 16.34 & 12.90 & 17.20 & 2.15 & 100 \\
\hline Pu35-24 & 0.00 & 0.00 & 0.00 & 0.00 & 14.90 & 8.60 & 11.18 & 11.61 & 16.34 & 12.90 & 17.20 & 2.15 & 100 \\
\hline Pu35-25 & 0.00 & 0.00 & 0.00 & 0.00 & 14.92 & 8.60 & 11.18 & 11.61 & 16.34 & 12.90 & 17.20 & 2.15 & 100 \\
\hline Pu35-26 & 0.00 & 0.00 & 0.00 & 0.00 & 14.87 & 8.60 & 11.18 & 11.61 & 16.34 & 12.90 & 17.20 & 2.15 & 100 \\
\hline Pu35-27 & 0.00 & 0.00 & 0.00 & 0.00 & 14.94 & 8.60 & 11.18 & 11.61 & 16.34 & 12.90 & 17.20 & 2.15 & 100 \\
\hline Pu35-28 & 0.00 & 0.00 & 0.00 & 0.00 & 14.93 & 8.60 & 11.18 & 11.61 & 16.34 & 12.90 & 17.20 & 2.15 & 100 \\
\hline Pu35-29 & 0.00 & 0.00 & 0.00 & 0.00 & 15.03 & 8.60 & 11.18 & 11.61 & 16.34 & 12.90 & 17.20 & 2.15 & 100 \\
\hline Pu35-30 & 0.06 & 0.06 & 0.08 & 0.06 & 14.88 & 8.60 & 11.18 & 11.61 & 16.34 & 12.90 & 17.20 & 2.15 & 100 \\
\hline Pu35-31 & 0.06 & 0.06 & 0.08 & 0.06 & 14.95 & 8.60 & 11.18 & 11.61 & 16.34 & 12.90 & 17.20 & 2.15 & 100 \\
\hline Pu35-32 & 0.06 & 0.06 & 0.08 & 0.06 & 14.90 & 8.60 & 11.18 & 11.61 & 16.34 & 12.90 & 17.20 & 2.15 & 100 \\
\hline Pu35-33 & 0.06 & 0.06 & 0.08 & 0.06 & 14.78 & 8.60 & 11.18 & 11.61 & 16.34 & 12.90 & 17.20 & 2.15 & 100 \\
\hline Pu35-34 & 0.06 & 0.06 & 0.08 & 0.06 & 14.89 & 8.60 & 11.18 & 11.61 & 16.34 & 12.90 & 17.20 & 2.15 & 100 \\
\hline Pu35-35 & 0.06 & 0.06 & 0.08 & 0.06 & 14.85 & 8.60 & 11.18 & 11.61 & 16.34 & 12.90 & 17.20 & 2.15 & 100 \\
\hline Pu35-36 & 0.06 & 0.06 & 0.08 & 0.06 & 14.89 & 8.60 & 11.18 & 11.61 & 16.34 & 12.90 & 17.20 & 2.15 & 100 \\
\hline Pu35-37 & 0.06 & 0.06 & 0.08 & 0.06 & 14.85 & 8.60 & 11.18 & 11.61 & 16.34 & 12.90 & 17.20 & 2.15 & 100 \\
\hline Pu35-38 & 0.06 & 0.06 & 0.08 & 0.06 & 14.93 & 8.60 & 11.18 & 11.61 & 16.34 & 12.90 & 17.20 & 2.15 & 100 \\
\hline Pu35-39 & 0.06 & 0.06 & 0.08 & 0.06 & 14.92 & 8.60 & 11.18 & 11.61 & 16.34 & 12.90 & 17.20 & 2.15 & 100 \\
\hline Pu35-40 & 0.06 & 0.06 & 0.08 & 0.06 & 14.86 & 8.60 & 11.18 & 11.61 & 16.34 & 12.90 & 17.20 & 2.15 & 100 \\
\hline Pu35-41 & 0.06 & 0.06 & 0.08 & 0.06 & 14.93 & 8.60 & 11.18 & 11.61 & 16.34 & 12.90 & 17.20 & 2.15 & 100 \\
\hline Pu35-42 & 0.06 & 0.06 & 0.08 & 0.06 & 14.88 & 8.60 & 11.18 & 11.61 & 16.34 & 12.90 & 17.20 & 2.15 & 100 \\
\hline Pu35-43 & 0.06 & 0.06 & 0.08 & 0.06 & 14.85 & 8.60 & 11.18 & 11.61 & 16.34 & 12.90 & 17.20 & 2.15 & 100 \\
\hline Pu35-44 & 0.06 & 0.06 & 0.08 & 0.06 & 14.86 & 8.60 & 11.18 & 11.61 & 16.34 & 12.90 & 17.20 & 2.15 & 100 \\
\hline Pu35-45 & 0.06 & 0.06 & 0.08 & 0.06 & 14.86 & 8.60 & 11.18 & 11.61 & 16.34 & 12.90 & 17.20 & 2.15 & 100 \\
\hline Pu35-46 & 0.06 & 0.06 & 0.08 & 0.06 & 14.92 & 8.60 & 11.18 & 11.61 & 16.34 & 12.90 & 17.20 & 2.15 & 100 \\
\hline Pu35-47 & 0.06 & 0.06 & 0.08 & 0.06 & 14.88 & 8.60 & 11.18 & 11.61 & 16.34 & 12.90 & 17.20 & 2.15 & 100 \\
\hline Pu35-48 & 0.06 & 0.06 & 0.08 & 0.06 & 14.86 & 8.60 & 11.18 & 11.61 & 16.34 & 12.90 & 17.20 & 2.15 & 100 \\
\hline Pu35-49 & 0.06 & 0.06 & 0.08 & 0.06 & 14.89 & 8.60 & 11.18 & 11.61 & 16.34 & 12.90 & 17.20 & 2.15 & 100 \\
\hline Pu35-50 & 0.06 & 0.06 & 0.08 & 0.06 & 14.89 & 8.60 & 11.18 & 11.61 & 16.34 & 12.90 & 17.20 & 2.15 & 100 \\
\hline Pu35-51 & 0.06 & 0.06 & 0.08 & 0.06 & 14.87 & 8.60 & 11.18 & 11.61 & 16.34 & 12.90 & 17.20 & 2.15 & 100 \\
\hline Pu35-52 & 0.06 & 0.06 & 0.08 & 0.06 & 14.86 & 8.60 & 11.18 & 11.61 & 16.34 & 12.90 & 17.20 & 2.15 & 100 \\
\hline Pu35-53 & 0.06 & 0.06 & 0.08 & 0.06 & 14.97 & 8.60 & 11.18 & 11.61 & 16.34 & 12.90 & 17.20 & 2.15 & 100 \\
\hline Pu35-54 & 0.00 & 0.00 & 0.00 & 0.00 & 14.93 & 8.60 & 11.18 & 11.61 & 16.34 & 12.90 & 17.20 & 2.15 & 100 \\
\hline Pu35-55 & 0.06 & 0.06 & 0.08 & 0.06 & 14.88 & 8.60 & 11.18 & 11.61 & 16.34 & 12.90 & 17.20 & 2.15 & 100 \\
\hline Pu04-01 & 0.00 & 0.00 & 0.00 & 0.00 & 19.45 & 8.60 & 11.18 & 11.61 & 16.34 & 12.90 & 17.20 & 2.15 & 100 \\
\hline Pu04-02 & 0.00 & 0.00 & 0.00 & 0.00 & 19.43 & 8.60 & 11.18 & 11.61 & 16.34 & 12.90 & 17.20 & 2.15 & 100 \\
\hline Pu04-03 & 0.00 & 0.00 & 0.00 & 0.00 & 19.42 & 8.60 & 11.18 & 11.61 & 16.34 & 12.90 & 17.20 & 2.15 & 100 \\
\hline Pu04-04 & 0.00 & 0.00 & 0.00 & 0.00 & 19.39 & 8.60 & 11.18 & 11.61 & 16.34 & 12.90 & 17.20 & 2.15 & 100 \\
\hline Pu04-05 & 0.00 & 0.00 & 0.00 & 0.00 & 19.46 & 8.60 & 11.18 & 11.61 & 16.34 & 12.90 & 17.20 & 2.15 & 100 \\
\hline
\end{tabular}


WSRC-STI-2007-00477

Revision 0

Table 2-3. Target compositions of the variability study glasses containing $\mathrm{PuO}_{2}$ (in wt \% oxides).

\begin{tabular}{|c|c|c|c|c|c|c|c|c|c|c|c|c|c|}
\hline Glass ID & $\mathrm{Cl}^{-}$ & $\mathbf{T a}_{2} \mathbf{O}_{5}$ & MgO & $\mathrm{K}_{2} \mathrm{O}$ & $\mathrm{Fe}_{2} \mathrm{O}_{3}$ & $\mathrm{Na}_{2} \mathrm{O}$ & $\mathbf{F}^{-}$ & $\mathrm{CaO}$ & $\mathrm{Ga}_{2} \mathrm{O}_{3}$ & NiO & $\mathrm{Cr}_{2} \mathrm{O}_{3}$ & $\mathrm{CuO}$ & $\mathrm{SO}_{4}$ \\
\hline Pu35-03B & 0.57 & 0.18 & 0.54 & 0.31 & 0.14 & 1.48 & 0.00 & 0.77 & 0.45 & 0.07 & 0.64 & 0.00 & 0.00 \\
\hline Pu35-06B & 0.60 & 0.10 & 0.91 & 0.27 & 0.97 & 0.80 & 0.48 & 0.29 & 0.00 & 0.28 & 0.22 & 0.00 & 0.17 \\
\hline Pu35-17B & 1.11 & 0.55 & 0.40 & 0.43 & 0.00 & 1.04 & 0.06 & 0.08 & 0.68 & 0.07 & 0.31 & 0.10 & 0.17 \\
\hline $\mathrm{Pu} 04-04 \mathrm{~B}$ & 0.00 & 0.00 & 0.08 & 0.07 & 0.08 & 0.08 & 0.00 & 0.08 & 0.00 & 0.08 & 0.09 & 0.07 & 0.00 \\
\hline Glass ID & $\mathrm{C}$ & PbO & $\mathrm{SeO}_{2}$ & $\mathrm{Cs}_{2} \mathrm{O}$ & $\mathrm{PuO}_{2}$ & $\mathrm{HfO}_{2}$ & $\overline{\mathrm{Al}_{2} \mathbf{O}_{3}}$ & $\mathbf{B}_{2} \mathbf{O}_{3}$ & $\mathbf{G d}_{2} \mathbf{O}_{3}$ & $\overline{\mathbf{L a}_{2} \mathbf{O}_{3}}$ & $\mathrm{Nd}_{2} \mathrm{O}_{3}$ & $\mathrm{SiO}_{2}$ & SrO \\
\hline $\mathrm{Pu} 35-03 \mathrm{~B}$ & 0.00 & 0.00 & 0.00 & 0.06 & 8.79 & 6.02 & 8.60 & 11.18 & 11.61 & 16.34 & 12.90 & 17.20 & 2.15 \\
\hline Pu35-06B & 0.06 & 0.00 & 0.00 & 0.00 & 8.85 & 6.02 & 8.60 & 11.18 & 11.61 & 16.34 & 12.90 & 17.20 & 2.15 \\
\hline Pu35-17B & 0.06 & 0.00 & 0.00 & 0.00 & 8.93 & 6.02 & 8.60 & 11.18 & 11.61 & 16.34 & 12.90 & 17.20 & 2.15 \\
\hline $\mathrm{Pu} 04-04 \mathrm{~B}$ & 0.00 & 0.00 & 0.00 & 0.00 & 9.07 & 6.02 & 8.60 & 11.18 & 11.61 & 16.34 & 12.90 & 17.20 & 2.15 \\
\hline
\end{tabular}

\subsection{Glass Fabrication}

Each variability study glass was prepared from the proper proportions of reagent-grade metal oxides, carbonates, fluorides, chlorides, $\mathrm{H}_{3} \mathrm{BO}_{3}$, and salts in $150 \mathrm{~g}$ batches. ${ }^{10}$ The batches were thoroughly mixed and then melted in $\mathrm{Pt} / \mathrm{Rh}$ crucibles at $1450{ }^{\circ} \mathrm{C}$ for 1 hour. The glass was quenched by pouring onto a stainless steel plate. The resulting glass patty and the remaining contents of the crucible were ground to a fine powder using a ring pulverizer to further aid in mixing. The glass powder was subsequently remelted at $1450{ }^{\circ} \mathrm{C}$ for one hour and quenched. The glass pour patty was used as a sampling stock for the various property measurements, including chemical composition and durability testing.

Fabrication of the four glasses containing $\mathrm{PuO}_{2}$ was slightly different since these glasses were prepared in the SRNL shielded cells facility and had to be produced using remotely operated equipment. The glasses were melted twice for 3 hours rather than 1 hour. Quenching after each melt was accomplished by partially submerging the crucibles in a tub of room temperature water rather than pouring onto a stainless steel plate. A hammer was used to pulverize the glasses in between the two melts instead of a ring pulverizer. These differences in fabrication technique should have no significant impact on the ability to compare the results of the surrogate and $\mathrm{PuO}_{2}$ glass testing. ${ }^{9}$

Approximately $25 \mathrm{~g}$ of each glass was heat-treated to simulate cooling within a DWPF-type canister (the can-in-canister disposal method) to gauge the effects of thermal history on the performance of the glass. This cooling schedule will be referred to as the can-in-canister cooled (CCC) heat treatment, and is described in detail in a report by Jones, et al. ${ }^{11}$ Note that this heat treatment schedule differs from the canister centerline cooled heat treatment typically performed for HLW glasses at the Savannah River Site (SRS). ${ }^{12}$ Visual observations on both quenched and CCC glasses were documented. The CCC was not performed on the glasses fabricated with $\mathrm{PuO}_{2}$. The analyses of these four glasses will be on the quenched versions only.

\subsection{Property Measurements}

This section provides a general discussion of the X-ray diffraction analyses, the chemical composition analyses and the Product Consistency Test (PCT) results of the impurity variability study glasses.

\subsubsection{X-Ray Diffraction Analysis}

Although visual observations for crystallization were performed and documented, representative samples for all quenched and CCC glasses were submitted to SRNL Analytical Development (AD) for X-ray diffraction (XRD) analysis. Samples were run under conditions providing a detection limit of approximately $0.5 \mathrm{vol} \%$. That is, if crystals (or undissolved solids) were present at $0.5 \mathrm{vol} \%$ or greater, the diffractometer would not only be capable of detecting the crystals but would also allow a qualitative 
determination of the type of crystal(s) present. Otherwise, a characteristically high background devoid of crystalline spectral peaks indicates that the glass product is amorphous, suggesting either a completely amorphous product or that the degree of crystallization is below the detection limit.

\subsubsection{Scanning Electron Microscopy}

Samples of select surrogate glasses were prepared for analysis by Scanning Electron Microscopy (SEM) and Energy Dispersive Spectroscopy (EDS). Four of the surrogate glasses (the CCC versions of glasses Pu04-03, Pu04-05, Pu35-20 and Pu35-25) were submitted for analysis since crystalline material was identified in these glasses by XRD. Each of the four glasses fabricated with $\mathrm{PuO}_{2}$ was also submitted for SEM and EDS analysis to identify any crystalline phases that may be present below the XRD detection limit.

\subsubsection{Density}

The density of each of the surrogate glasses was measured using the Archimedes method with de-ionized water. ${ }^{13}$ The density of the de-ionized water was corrected for temperature. To improve the accuracy of the measurements, relatively large chunks of each glass were used and an attempt was made to select samples with no visible cracking or porosity. In some cases, adequate samples of a particular glass were not available. Results of the density measurements for these glasses will be reported as " $\mathrm{n} / \mathrm{a}$ ". The densities of the glasses fabricated with $\mathrm{PuO}_{2}$ were not measured.

\subsubsection{Compositional Analysis}

To confirm that the as-fabricated glasses met the target compositions, a representative sample from each glass was submitted to the SRNL Process Science Analytical Laboratory (PSAL) for chemical analysis under the auspices of an analytical plan. The plan (see Appendix A) identified the cations and anions to be analyzed and was developed in such a way as to provide the opportunity to evaluate potential sources of bias and error. Samples prepared using lithium-metaborate (LM) were used to measure aluminum (Al), calcium $(\mathrm{Ca})$, chromium $(\mathrm{Cr})$, copper $(\mathrm{Cu})$, iron $(\mathrm{Fe})$, gallium $(\mathrm{Ga})$, gadolinium $(\mathrm{Gd})$, hafnium $(\mathrm{Hf})$, potassium $(\mathrm{K})$, lanthanum $(\mathrm{La})$, magnesium $(\mathrm{Mg})$, sodium $(\mathrm{Na})$, neodymium $(\mathrm{Nd})$, nickel $(\mathrm{Ni})$, lead $(\mathrm{Pb})$, sulfur (S), selenium (Se), silicon ( $\mathrm{Si})$, strontium (Sr), and tantalum (Ta) concentrations. Samples prepared using sodium peroxide fusion (PF) were used to measure for boron (B) concentrations. All of the prepared samples were analyzed twice for each element of interest by Inductively Coupled Plasma Atomic Emission Spectroscopy (ICP-AES), with the instrumentation being re-calibrated between the duplicate analyses. Two glass standards, (Waste Compliance Plan Batch $1^{14}$ and the Low-Activity Reference Material (LRM), ${ }^{15}$ were intermittently measured to assess the performance of the ICP-AES instrument over the course of these analyses. Samples of each glass were also prepared for Ion Chromatography (IC) analysis and were measured for the anions chlorine $\left(\mathrm{Cl}^{-}\right)$and fluorine $\left(\mathrm{F}^{-}\right)$. The LRM and Batch 1 standards were also included in the IC analysis. It should be noted that some of the glasses were batched with carbon (C) and/or cesium (Cs), but due to difficulty in measuring the concentrations of these elements, they were excluded from the compositional analysis. The chemical compositions of the four glasses fabricated with $\mathrm{PuO}_{2}$ were not measured due to difficulty in performing the necessary dissolutions in the shielded cells facility. Further analysis of these glasses will be based on their target compositions.

\subsubsection{Product Consistency Test}

The $\mathrm{PCT}^{16}$ was performed in triplicate on each quenched and $\mathrm{CCC}$ glass to assess chemical durability. Also included in the experimental test matrix was the Environmental Assessment (EA) reference glass, ${ }^{17}$ the Approved Reference Material (ARM) glass, and blanks from the sample cleaning batch. Samples were ground, washed, and prepared according to the standard procedure. ${ }^{16}$ The vessels were closed, sealed, and placed in an oven at $90 \pm 2{ }^{\circ} \mathrm{C}$ where the samples were maintained at temperature for seven days. Once cooled, the resulting solutions were sampled (filtered and acidified), then labeled and 
analyzed by PSAL under the auspices of an analytical plan (see Appendix B). The aim of the plan was to provide an opportunity to assess the consistency (repeatability) of the PCT and analytical procedures in evaluating the chemical durability of the glasses. Normalized release rates for the surrogate glasses were calculated based on target, measured, and bias-corrected (bc) compositions using the average of the common logarithms of the leachate concentrations. Normalized release rates for the $\mathrm{PuO}_{2}$ glasses were calculated based on target compositions only.

\subsubsection{Toxicity Characteristic Leaching Procedure (TCLP)}

The Toxicity Characteristic Leaching Procedure (TCLP) was performed for a select set of the surrogate glasses since some of the metal impurities included in this study are categorized as hazardous by the Resource Conservation and Recovery Act (RCRA). Eight of the surrogate glass compositions were selected for the TCLP based on their relatively high targeted concentrations of $\mathrm{Cr}, \mathrm{Pb}, \mathrm{Ni}$ and $\mathrm{Se}$. These are compositions Pu35-11, Pu35-36, Pu35-37, Pu35-41, Pu35-47, Pu35-50, Pu35-51, and Pu35-52. The samples were sent to Davis \& Floyd, Inc. (Greenwood, SC) for the TCLP analysis. The complete results provided by the laboratory will be included as an appendix to this report. 


\subsection{Results and Discussion}

This section provides analysis of the experimental data. The surrogate glasses will be discussed first, followed by a separate section for discussion of the glasses fabricated with $\mathrm{PuO}_{2}$.

\subsection{Homogeneity}

Table 3-1 lists the visual observations and XRD results for the quenched and CCC versions of the surrogate variability study glasses. ${ }^{\mathrm{a}}$ These results will be summarized below.

\footnotetext{
${ }^{\mathrm{a}}$ For a more detailed description of the visual observations and XRD results, see WSRC-NB-2007-00022.
} 
Table 3-1. Visual observations and XRD results for the variability study glasses.

\begin{tabular}{|c|c|c|c|}
\hline Glass ID & $\begin{array}{c}\text { Heat } \\
\text { Treatment }\end{array}$ & Visual Observations & XRD Results \\
\hline \multirow[t]{2}{*}{ Pu04-01 } & quenched & $\begin{array}{l}\text { patty: transparent purple with white streak on surface; crucible: } \\
\text { milky/purple with undissolved material }\end{array}$ & amorphous \\
\hline & $\mathrm{CCC}$ & clear, purple glass mixed with white/hazy pieces of glass & hafnium oxide \\
\hline \multirow[t]{2}{*}{ Pu04-02 } & quenched & $\begin{array}{l}\text { patty: transparent purple with three white streaks on surface; crucible: } \\
\text { milky/purple with undissolved material }\end{array}$ & amorphous \\
\hline & $\mathrm{CCC}$ & transparent, light purple glass with a few milky/white pieces & possible tungsten carbide \\
\hline \multirow[t]{2}{*}{$\mathrm{Pu} 04-03$} & quenched & $\begin{array}{l}\text { patty: transparent, brown color with large white streaks on surface; } \\
\text { crucible: white undissolved material }\end{array}$ & hafnium oxide \\
\hline & $\mathrm{CCC}$ & light purple glass with white spots of material melted together & hafnium oxide \\
\hline \multirow[t]{2}{*}{ Pu04-04 } & quenched & $\begin{array}{l}\text { patty: very dark green with some dark swirls on surface and bulk; } \\
\text { crucible: undissolved material along melt line and on bottom }\end{array}$ & amorphous \\
\hline & $\mathrm{CCC}$ & dark green glass, appear clean & amorphous \\
\hline \multirow[t]{2}{*}{ Pu04-05 } & quenched & $\begin{array}{l}\text { patty: purple, transparent with a large white swirl; crucible: a lot of } \\
\text { undissolved material on bottom }\end{array}$ & hafnium oxide \\
\hline & $\mathrm{CCC}$ & purple color glass with white pieces of material scattered throughout & hafnium oxide \\
\hline \multirow[t]{2}{*}{ Pu35-01 } & quenched & $\begin{array}{l}\text { patty: light brown, transparent, clean; crucible: undissolved material } \\
\text { on bottom }\end{array}$ & amorphous \\
\hline & $\mathrm{CCC}$ & mottled gray/purple colors in the glass & possible tungsten carbide \\
\hline \multirow[t]{2}{*}{ Pu35-02 } & quenched & $\begin{array}{l}\text { patty: very dark green with a light white streak on surface; crucible: } \\
\text { undissolved material along melt line and on bottom }\end{array}$ & amorphous \\
\hline & $\mathrm{CCC}$ & milky, green colored glass with possible crystals throughout & possible tungsten carbide \\
\hline \multirow{2}{*}{ Pu35-03 } & quenched & patty: very dark green, clean; crucible: clean & amorphous \\
\hline & $\mathrm{CCC}$ & milky, green colored glass with crystals throughout & amorphous \\
\hline \multirow[t]{2}{*}{ Pu35-04 } & quenched & $\begin{array}{l}\text { patty: green, transparent, clean; crucible: some undissolved material } \\
\text { on bottom }\end{array}$ & amorphous \\
\hline & $\mathrm{CCC}$ & aqua color with crystals throughout & amorphous \\
\hline \multirow[t]{2}{*}{ Pu35-05 } & quenched & $\begin{array}{l}\text { patty: dark green with milky green swirls on surface; crucible: } \\
\text { undissolved material on bottom }\end{array}$ & amorphous \\
\hline & $\mathrm{CCC}$ & aqua color with crystals throughout & amorphous \\
\hline \multirow[t]{2}{*}{ Pu35-06 } & quenched & $\begin{array}{l}\text { patty: dark brown, clean; crucible: very small amount of undissolved } \\
\text { material }\end{array}$ & amorphous \\
\hline & $\mathrm{CCC}$ & pea-green color with crystals throughout & amorphous \\
\hline \multirow{2}{*}{ Pu35-07 } & quenched & patty: dark green, clean; crucible: some undissolved material & amorphous \\
\hline & $\mathrm{CCC}$ & aqua color with crystals throughout & amorphous \\
\hline \multirow[t]{2}{*}{ Pu35-08 } & quenched & $\begin{array}{l}\text { patty: dark green with milky haze on surface; crucible: small amount } \\
\text { of undissolved material }\end{array}$ & amorphous \\
\hline & $\mathrm{CCC}$ & light aqua color with crystals throughout & amorphous \\
\hline \multirow{2}{*}{ Pu35-09 } & quenched & patty: aqua blue with creamy swirls on surface; crucible: clean & amorphous \\
\hline & $\mathrm{CCC}$ & very light aqua color with crystals throughout & amorphous \\
\hline \multirow{2}{*}{ Pu35-10 } & quenched & patty: green, clean; crucible: white undissolved material in bottom & amorphous \\
\hline & $\mathrm{CCC}$ & light aqua color with crystals throughout & possible tungsten carbide \\
\hline \multirow{2}{*}{ Pu35-11 } & quenched & patty: dark green, clean; crucible: a few undissolved solids & amorphous \\
\hline & $\mathrm{CCC}$ & aqua color with crystals throughout & amorphous \\
\hline \multirow[t]{2}{*}{ Pu35-12 } & quenched & $\begin{array}{l}\text { patty: dark green, clean; crucible: some undissolved material in } \\
\text { bottom }\end{array}$ & amorphous \\
\hline & $\mathrm{CCC}$ & aqua color with crystals throughout & amorphous \\
\hline \multirow[t]{2}{*}{ Pu35-13 } & quenched & $\begin{array}{l}\text { patty: clean; crucible: very small amount of undissolved material in } \\
\text { bottom }\end{array}$ & amorphous \\
\hline & $\mathrm{CCC}$ & aqua color with crystals throughout & amorphous \\
\hline \multirow{2}{*}{ Pu35-14 } & quenched & patty: clean; crucible: some undissolved material in bottom & amorphous \\
\hline & $\mathrm{CCC}$ & grayish/green color with crystals throughout & possible tungsten carbide \\
\hline
\end{tabular}


Table 3-1. Visual observations and XRD results for the variability study glasses. (continued)

\begin{tabular}{|c|c|c|c|}
\hline Glass ID & $\begin{array}{c}\text { Heat } \\
\text { Treatment }\end{array}$ & Visual Observations & XRD Results \\
\hline \multirow[t]{2}{*}{ Pu35-15 } & quenched & $\begin{array}{l}\text { patty: brown, transparent, clean; crucible: small amount of } \\
\text { undissolved material }\end{array}$ & amorphous \\
\hline & $\mathrm{CCC}$ & grayish/white color with crystals throughout & amorphous \\
\hline \multirow[t]{2}{*}{ Pu35-16 } & quenched & $\begin{array}{l}\text { patty: brown, transparent, clean; crucible: some undissolved material } \\
\text { on bottom }\end{array}$ & amorphous \\
\hline & $\mathrm{CCC}$ & light brown, transparent, clean & amorphous \\
\hline \multirow[t]{2}{*}{ Pu35-17 } & quenched & $\begin{array}{l}\text { patty: green, transparent, clean; crucible: some undissolved material } \\
\text { on bottom }\end{array}$ & amorphous \\
\hline & $\mathrm{CCC}$ & aqua color with crystals throughout & amorphous \\
\hline \multirow[t]{2}{*}{ Pu35-18 } & quenched & $\begin{array}{l}\text { patty: deep aqua marine color with streaks, bottom a deep mottled } \\
\text { color; crucible: undissolved material on bottom }\end{array}$ & amorphous \\
\hline & $\mathrm{CCC}$ & aqua color with crystals throughout & possible tungsten carbide \\
\hline \multirow{2}{*}{ Pu35-19 } & quenched & patty: dark green, clean; crucible: clean & amorphous \\
\hline & $\mathrm{CCC}$ & darker green color with crystals throughout & possible tungsten carbide \\
\hline \multirow[t]{2}{*}{ Pu35-20 } & quenched & $\begin{array}{l}\text { patty: dark green with some aqua colored streaks on surface; crucible: } \\
\text { some undissolved material }\end{array}$ & amorphous \\
\hline & $\mathrm{CCC}$ & green, crystals throughout & possible tungsten carbide \\
\hline \multirow{2}{*}{ Pu35-21 } & quenched & patty: green, transparent, clean; crucible: a lot of undissolved material & amorphous \\
\hline & $\mathrm{CCC}$ & light aqua color with crystals throughout & possible tungsten carbide \\
\hline \multirow[t]{2}{*}{ Pu35-22 } & quenched & $\begin{array}{l}\text { patty: dark green, clean; crucible: tiny white undissolved solids on } \\
\text { bottom and sides }\end{array}$ & amorphous \\
\hline & $\mathrm{CCC}$ & milky light green with crystals throughout & possible tungsten carbide \\
\hline \multirow[t]{2}{*}{ Pu35-23 } & quenched & $\begin{array}{l}\text { patty: dark green, clean; crucible: some undissolved material on } \\
\text { bottom and sides }\end{array}$ & amorphous \\
\hline & $\mathrm{CCC}$ & light green with darker swirls and crystals & amorphous \\
\hline \multirow{2}{*}{ Pu35-24 } & quenched & patty: dark green, clean; crucible: very few undissolved solids & amorphous \\
\hline & $\mathrm{CCC}$ & milky aqua color with crystals throughout & amorphous \\
\hline \multirow[t]{2}{*}{ Pu35-25 } & quenched & $\begin{array}{l}\text { patty: dark green with milky haze and swirls on surface; crucible: } \\
\text { undissolved material along melt line and some on bottom }\end{array}$ & amorphous \\
\hline & $\mathrm{CCC}$ & milky green with crystals throughout & possible tungsten carbide \\
\hline \multirow{2}{*}{ Pu35-26 } & quenched & patty: dark green, clean; crucible: very few undissolved solids & amorphous \\
\hline & $\mathrm{CCC}$ & medium green with milky swirls, crystals throughout & possible tungsten carbide \\
\hline \multirow{2}{*}{ Pu35-27 } & quenched & patty: dark green, clean; crucible: very few undissolved solids & amorphous \\
\hline & $\mathrm{CCC}$ & milky green with crystals throughout & possible tungsten carbide \\
\hline \multirow[t]{2}{*}{ Pu35-28 } & quenched & $\begin{array}{l}\text { patty: dark green, clean; crucible: a few tiny spots of undissolved } \\
\text { material on the bottom and along the melt line }\end{array}$ & amorphous \\
\hline & $\mathrm{CCC}$ & milky green with crystals throughout & possible tungsten carbide \\
\hline \multirow[t]{2}{*}{ Pu35-29 } & quenched & $\begin{array}{l}\text { patty: aqua green swirls on surface and through bulk, bottom had a } \\
\text { thin, dark green layer; crucible: aqua swirls and undissolved material } \\
\text { on the bottom and along the melt line }\end{array}$ & amorphous \\
\hline & $\mathrm{CCC}$ & creamy light green with crystals & possible tungsten carbide \\
\hline \multirow[t]{2}{*}{ Pu35-30 } & quenched & $\begin{array}{l}\text { patty: aqua with milky swirls, darker green on bottom; crucible: } \\
\text { undissolved material on bottom and along melt line }\end{array}$ & amorphous \\
\hline & $\mathrm{CCC}$ & creamy light green with crystals & possible tungsten carbide \\
\hline \multirow[t]{2}{*}{ Pu35-31 } & quenched & $\begin{array}{l}\text { patty: aqua with milky swirls, darker green on bottom; crucible: } \\
\text { undissolved material on bottom and along melt line }\end{array}$ & amorphous \\
\hline & $\mathrm{CCC}$ & light milky olive color with swirls, crystals throughout & possible tungsten carbide \\
\hline \multirow[t]{2}{*}{ Pu35-32 } & quenched & $\begin{array}{l}\text { patty: green, transparent, clean; crucible: undissolved material on } \\
\text { bottom and along melt line }\end{array}$ & amorphous \\
\hline & $\mathrm{CCC}$ & milky aqua color with darker swirls, crystals throughout & amorphous \\
\hline \multirow[t]{2}{*}{ Pu35-33 } & quenched & $\begin{array}{l}\text { patty: dark green, clean; crucible: clean, no visible undissolved } \\
\text { material }\end{array}$ & amorphous \\
\hline & $\mathrm{CCC}$ & milky aqua color with darker swirls, crystals throughout & possible tungsten carbide \\
\hline
\end{tabular}


Table 3-1. Visual observations and XRD results for the variability study glasses. (continued)

\begin{tabular}{|c|c|c|c|}
\hline Glass ID & $\begin{array}{c}\text { Heat } \\
\text { Treatment }\end{array}$ & Visual Observations & XRD Results \\
\hline \multirow[t]{2}{*}{ Pu35-34 } & quenched & $\begin{array}{l}\text { patty: green, transparent, clean; crucible: some undissolved material } \\
\text { on bottom }\end{array}$ & amorphous \\
\hline & $\mathrm{CCC}$ & aqua color, crystals throughout & possible tungsten carbide \\
\hline \multirow[t]{2}{*}{ Pu35-35 } & quenched & $\begin{array}{l}\text { patty: dark green, transparent, clean; crucible: tiny amount of } \\
\text { undissolved material }\end{array}$ & amorphous \\
\hline & $\mathrm{CCC}$ & milky green with swirls, crystals throughout & amorphous \\
\hline \multirow[t]{2}{*}{ Pu35-36 } & quenched & $\begin{array}{l}\text { patty: dark green, clean; crucible: small amount of undissolved } \\
\text { material on bottom }\end{array}$ & amorphous \\
\hline & $\mathrm{CCC}$ & light green with milky swirls & possible tungsten carbide \\
\hline \multirow[t]{2}{*}{ Pu35-37 } & quenched & $\begin{array}{l}\text { patty: dark green glass, clean; crucible: small amount of undissolved } \\
\text { material on bottom }\end{array}$ & amorphous \\
\hline & $\mathrm{CCC}$ & light green, crystals throughout & possible tungsten carbide \\
\hline \multirow[t]{2}{*}{ Pu35-38 } & quenched & $\begin{array}{l}\text { patty: transparent, medium green, clean; crucible: small amount of } \\
\text { undissolved material on the bottom }\end{array}$ & amorphous \\
\hline & $\mathrm{CCC}$ & milky green with swirls, crystals throughout & amorphous \\
\hline \multirow[t]{2}{*}{ Pu35-39 } & quenched & $\begin{array}{l}\text { patty: aqua swirls on surface, thin layer of dark green glass on } \\
\text { bottom; crucible: some undissolved material on bottom and along } \\
\text { melt line }\end{array}$ & amorphous \\
\hline & $\mathrm{CCC}$ & milky green with swirls, crystals throughout & amorphous \\
\hline \multirow[t]{2}{*}{ Pu35-40 } & quenched & $\begin{array}{l}\text { patty: very dark green, clean; crucible: some undissolved material on } \\
\text { bottom }\end{array}$ & amorphous \\
\hline & $\mathrm{CCC}$ & light green with swirls, crystals throughout & possible tungsten carbide \\
\hline \multirow[t]{2}{*}{ Pu35-41 } & quenched & $\begin{array}{l}\text { patty: very dark green glass, small amount of possibly undissolved } \\
\text { material on surface; crucible: undissolved material on bottom }\end{array}$ & amorphous \\
\hline & $\mathrm{CCC}$ & olive green with swirls, crystals throughout & possible tungsten carbide \\
\hline \multirow[t]{2}{*}{ Pu35-42 } & quenched & $\begin{array}{l}\text { patty: some aqua green swirls on surface, no undissolved material; } \\
\text { crucible: undissolved material on bottom and along melt line }\end{array}$ & amorphous \\
\hline & $\mathrm{CCC}$ & light creamy green with swirls, crystals throughout & possible tungsten carbide \\
\hline \multirow[t]{2}{*}{ Pu35-43 } & quenched & $\begin{array}{l}\text { patty: dark green, clean; crucible: undissolved material on bottom and } \\
\text { along melt line }\end{array}$ & amorphous \\
\hline & $\mathrm{CCC}$ & green with milky swirls, crystals throughout & possible tungsten carbide \\
\hline \multirow[t]{2}{*}{ Pu35-44 } & quenched & $\begin{array}{l}\text { patty: dark green, clean; crucible: undissolved material on bottom and } \\
\text { along melt line }\end{array}$ & amorphous \\
\hline & $\mathrm{CCC}$ & light green with swirls, crystals throughout & possible tungsten carbide \\
\hline \multirow[t]{2}{*}{ Pu35-45 } & quenched & $\begin{array}{l}\text { patty: green, transparent, clean; crucible: some undissolved material } \\
\text { on bottom }\end{array}$ & amorphous \\
\hline & $\mathrm{CCC}$ & dark green with milky swirls, crystals throughout & amorphous \\
\hline \multirow[t]{2}{*}{$\mathrm{Pu} 35-46$} & quenched & $\begin{array}{l}\text { patty: green, transparent, clean; crucible: some undissolved material } \\
\text { on bottom }\end{array}$ & amorphous \\
\hline & $\mathrm{CCC}$ & light green with milky swirls, crystals throughout & possible tungsten carbide \\
\hline \multirow[t]{2}{*}{ Pu35-47 } & quenched & $\begin{array}{l}\text { patty: green, transparent, clean; crucible: some undissolved material } \\
\text { on bottom }\end{array}$ & amorphous \\
\hline & $\mathrm{CCC}$ & light green, crystals throughout & possible tungsten carbide \\
\hline \multirow[t]{2}{*}{ Pu35-48 } & quenched & $\begin{array}{l}\text { patty: dark green, clean; crucible: small amount of undissolved } \\
\text { material on bottom and along melt line }\end{array}$ & amorphous \\
\hline & $\mathrm{CCC}$ & green with swirls, crystals throughout & amorphous \\
\hline \multirow[t]{2}{*}{ Pu35-49 } & quenched & $\begin{array}{l}\text { patty: dark green, clean; crucible: some undissolved material on } \\
\text { bottom and along melt line }\end{array}$ & amorphous \\
\hline & $\mathrm{CCC}$ & light green with milky swirls, crystals throughout & possible tungsten carbide \\
\hline \multirow[t]{2}{*}{ Pu35-50 } & quenched & $\begin{array}{l}\text { patty: dark green with milky/aqua swirls on surface; crucible: } \\
\text { undissolved material on bottom and along melt line }\end{array}$ & amorphous \\
\hline & $\mathrm{CCC}$ & green with swirls, crystals throughout & amorphous \\
\hline
\end{tabular}


Table 3-1. Visual observations and XRD results for the variability study glasses. (continued)

\begin{tabular}{||c|c|l|l||}
\hline \multirow{2}{*}{ Glass ID } & $\begin{array}{c}\text { Heat } \\
\text { Treatment }\end{array}$ & \multicolumn{1}{|c|}{ Visual Observations } & \multicolumn{1}{|c|}{ XRD Results } \\
\hline \multirow{3}{*}{ Pu35-51 } & quenched & $\begin{array}{l}\text { patty: dark green, clean; crucible: some undissolved material on } \\
\text { bottom and along melt line }\end{array}$ & amorphous \\
\cline { 2 - 5 } & CCC & light green with swirls, crystals throughout & possible tungsten carbide \\
\hline \multirow{3}{*}{ Pu35-52 } & quenched & $\begin{array}{l}\text { patty: dark green with light green streak on surface; crucible: } \\
\text { undissolved material on bottom and along melt line }\end{array}$ & amorphous \\
\cline { 2 - 5 } & CCC & light green with swirls, crystals throughout & possible tungsten carbide \\
\hline \multirow{3}{*}{ Pu35-53 } & quenched & $\begin{array}{l}\text { patty: dark green, clean; crucible: undissolved material on bottom and } \\
\text { along melt line }\end{array}$ & amorphous \\
\cline { 2 - 5 } & CCC & aqua, crystals throughout & possible tungsten carbide \\
\hline \multirow{2}{*}{ Pu35-55 } & quenched & $\begin{array}{l}\text { patty: dark green, clean; crucible: undissolved material on bottom and } \\
\text { along melt line }\end{array}$ & amorphous \\
\cline { 2 - 5 } & CCC & aqua, crystals throughout & possible tungsten carbide \\
\cline { 2 - 4 } & CCC & light green with swirls, crystals throughout & amorphous \\
\hline
\end{tabular}

\subsubsection{Visual Observations}

Prior to discussing the visual observations, a few words regarding the terminology used are warranted. The term "surface" refers to the surface of the quenched pour patty or glass sample after the CCC heat treatment. The term "bulk" refers to the cross-section of the quenched pour patty or glass sample after the CCC heat treatment. The use of "clean" indicates that the sample was classified as a single-phase system (i.e., no visible evidence of crystallization).

Visual observations of the quenched variability study glasses (see Table 3-1) indicated that they were generally homogeneous, with some glasses having a small amount of surface crystallization evident in the form of "streaks" or "swirls". Most of the glasses left some visible crystalline material behind in the crucible after pouring. This material is likely to be undissolved $\mathrm{HfO}_{2}$, which will be confirmed by the XRD results presented in the following section. No visible crystallization was observed in the glasses fabricated with $\mathrm{PuO}_{2}$.

Visual observations of the CCC variability study glasses identified what appeared to be crystalline material in the majority of the glasses after heat treatment. However, the XRD results, discussed in the following section, do not corroborate these observations. It is likely that the volume of crystallization in the glasses was below the detection limit for XRD.

\subsubsection{XRD Results}

The XRD results are included in Table 3-1 and provide qualitative results regarding crystallization in the surrogate variability study glasses.

All but two of the quenched glasses were amorphous by XRD. This indicates that the glasses were either free of crystalline material, or that any crystallization was below the XRD detection limit of $0.5 \mathrm{vol} \%$. Two of the quenched glasses formulated with 4\% impurities in the simulated $\mathrm{Pu}$ feed (Pu04-03 and $\mathrm{Pu} 04-05$ ) contained some crystalline $\mathrm{HfO}_{2}$. The target $\mathrm{HfO}_{2}$ concentration in these glasses was relatively high at $\sim 19.5 \mathrm{wt} \%$. For the CCC glasses, 3 of the 5 glasses with $4 \mathrm{wt} \%$ impurities in the simulated $\mathrm{Pu}$ feed (Pu04-01, Pu04-03 and Pu04-05) contained some crystalline $\mathrm{HfO}_{2}$. Again, this is not unexpected due to the high concentration of $\mathrm{HfO}_{2}$ in the $4 \mathrm{wt} \%$ impurity glasses (i.e., these glasses contain both $\mathrm{HfO}_{2}$ from the frit and a relatively high concentration of $\mathrm{HfO}_{2}$ as a surrogate for $\mathrm{PuO}_{2}$ ). 
The possible presence of trevorite $\left(\mathrm{NiFe}_{2} \mathrm{O}_{4}\right)$ was identified in several of the CCC glasses. However, later in the analysis, it became apparent that the XRD peak identified as trevorite might instead be tungsten carbide. For example, Figure 3-1 shows an XRD spectrum for the CCC version of glass Pu35-14. A peak at approximately 36 degrees $2 \theta$ has been identified as possible trevorite. Compare this with Figure 3-2, which shows an XRD spectrum for the CCC version of glass Pu35-42. For this glass, the peak at approximately 36 degrees $2 \theta$ has been identified as tungsten carbide (WC). It is likely that the peaks identified as trevorite are actually tungsten carbide. Tungsten carbide contamination in the glasses may have resulted from wear of the tungsten carbide grinder used between melting steps during fabrication. Also, as will be discussed below, no trevorite or other spinels were identified in the glass by SEM analysis. The presence of a small amount of tungsten carbide in the glasses should not affect the durability of the glasses or their ability to incorporate impurity species, and will therefore have no impact on the outcome of this study.

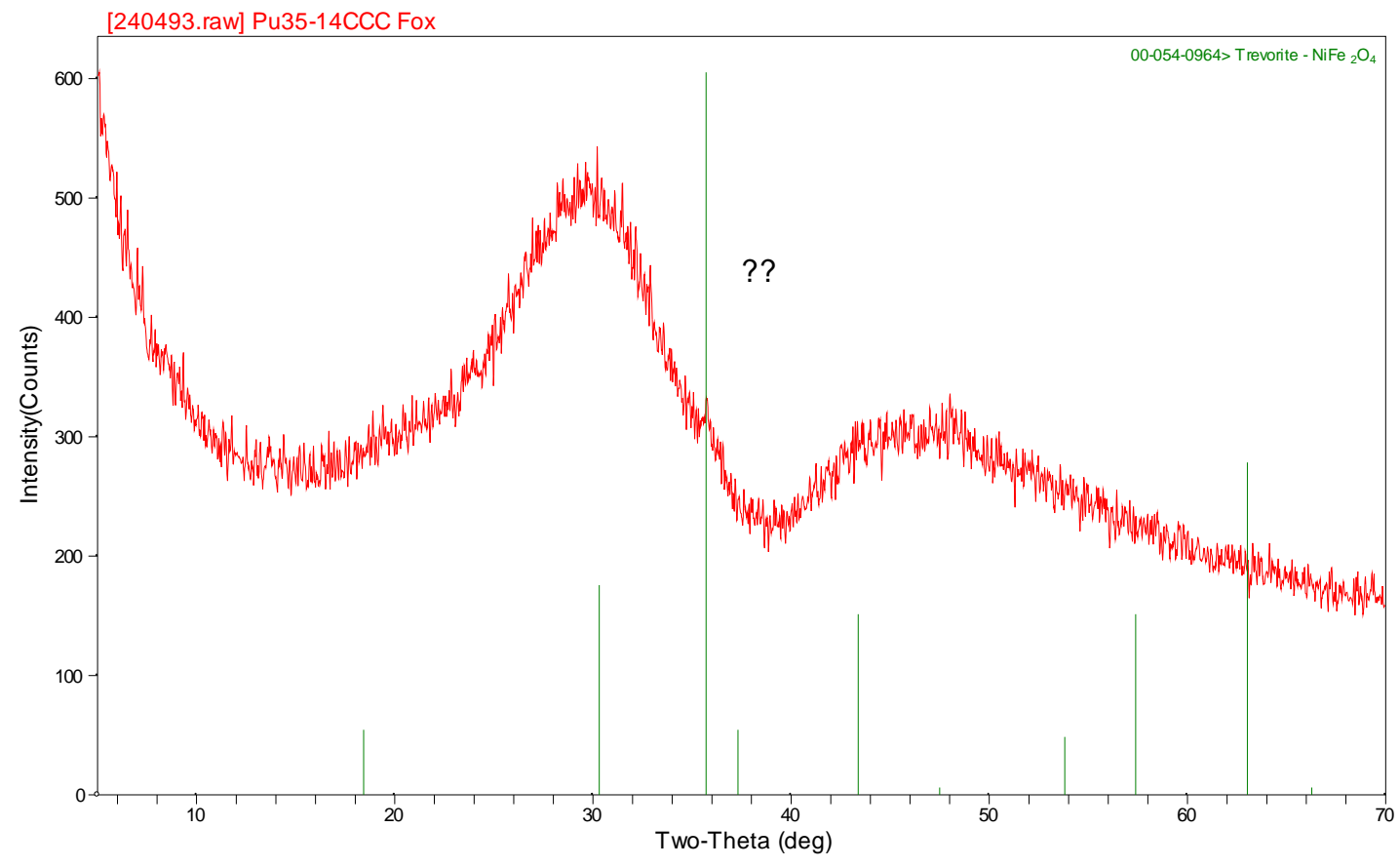

Figure 3-1. XRD results for the CCC version of surrogate glass Pu35-14. 


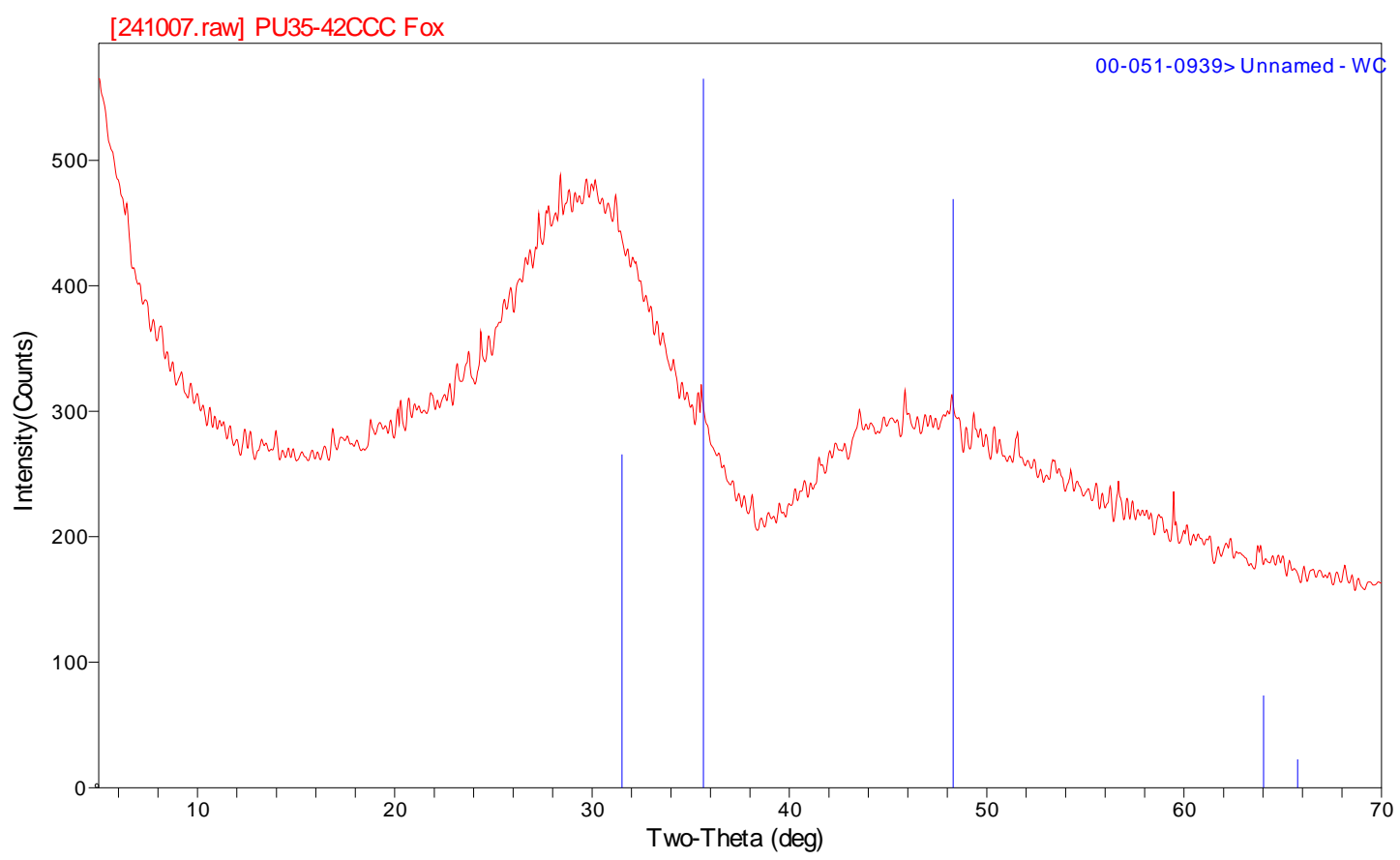

Figure 3-2. XRD results for the CCC version of surrogate glass Pu35-42.

\subsubsection{SEM Results}

SEM and EDS were used to provide further insight into the presence of any crystalline material in the surrogate glasses. Four of the surrogate glasses (the CCC versions of glasses Pu04-03, Pu04-05, Pu35-20 and Pu35-25) were submitted for analysis since crystalline material was identified in these glasses by XRD. Crystalline $\mathrm{HfO}_{2}$ was identified by XRD in the CCC versions of glasses Pu04-03 and Pu04-05.

This was confirmed by SEM and EDS. An example micrograph for glass Pu04-03 is given as Figure 3-3. Crystallites of $\mathrm{HfO}_{2}$ appear brighter in this backscattered electron image due to their higher average atom mass, and EDS confirmed that the concentration of $\mathrm{Hf}$ in these crystallites was much higher than in the surrounding glass matrix. Similar crystallites were observed in glass Pu04-05. 


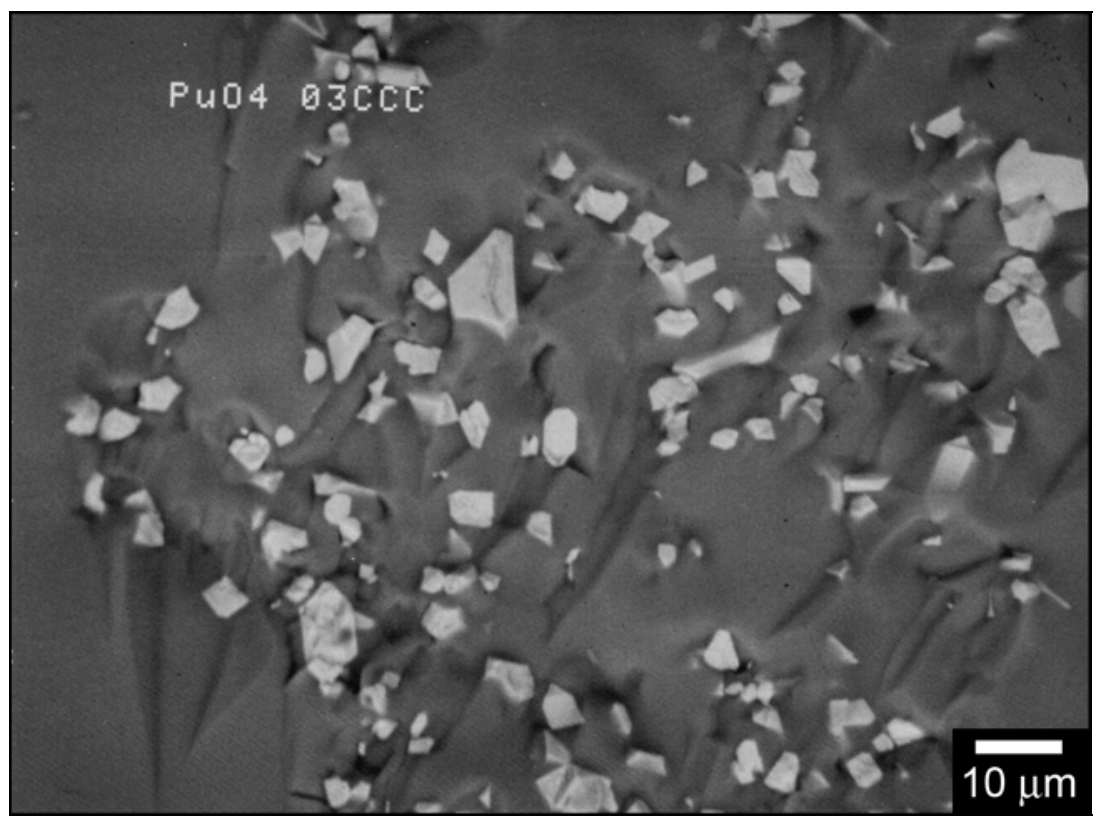

Figure 3-3. SEM micrograph of a fracture surface in the CCC version of glass Pu04-03 showing an area of undissolved $\mathrm{HfO}_{2}$ (bright crystallites).

For the other two glasses, Pu35-20 and Pu35-25, trevorite was identified as a possible crystalline phase in the $\mathrm{CCC}$ versions of these glasses by XRD. As discussed in the previous section, it is more likely that the XRD peak identified as possible trevorite was actually a small amount of tungsten carbide contamination picked up during grinding of the glass. Example micrographs are shown in Figure 3-4 and Figure 3-5 for the CCC versions of Pu35-20 and Pu35-25, respectively. No crystalline material is visible in either image. The small, dark spots are small bubbles or pores in the glass. It is likely that any tungsten carbide present in these samples occupies a very small volume of the glass, and was therefore not observed by SEM. 


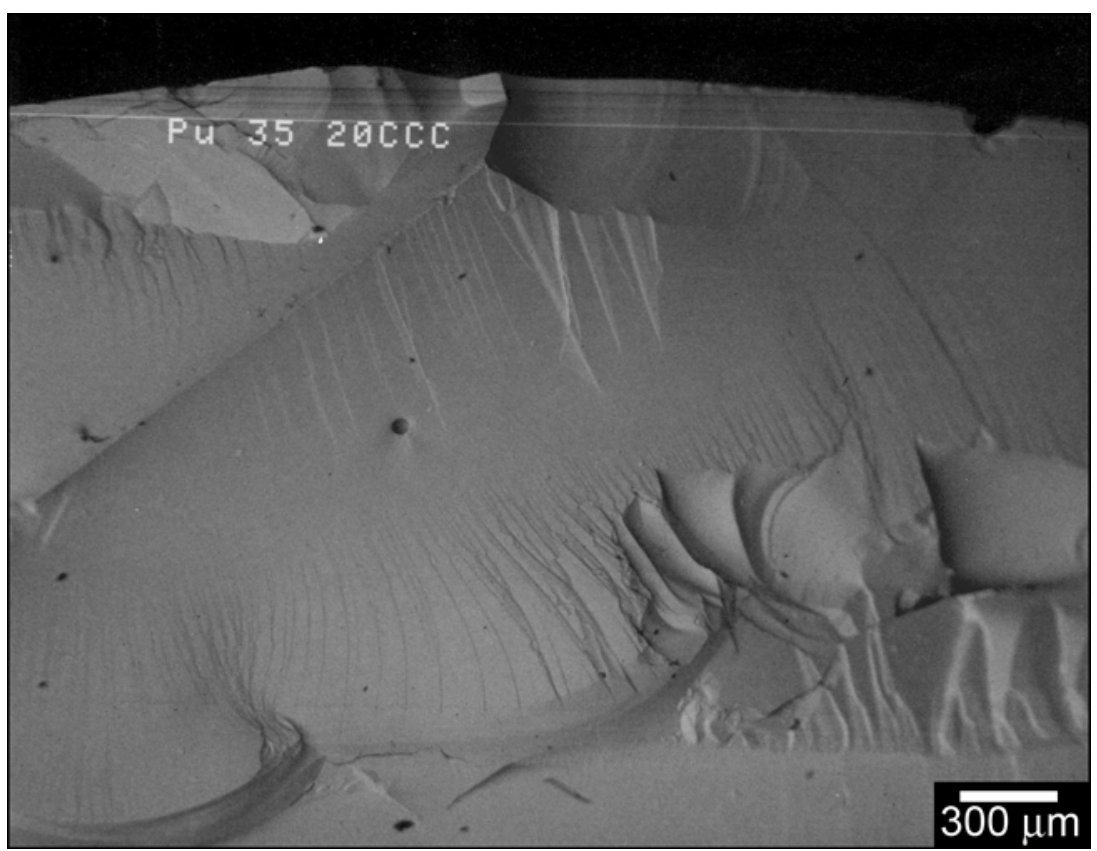

Figure 3-4. SEM micrograph of a fracture surface in the CCC version of glass Pu35-20.

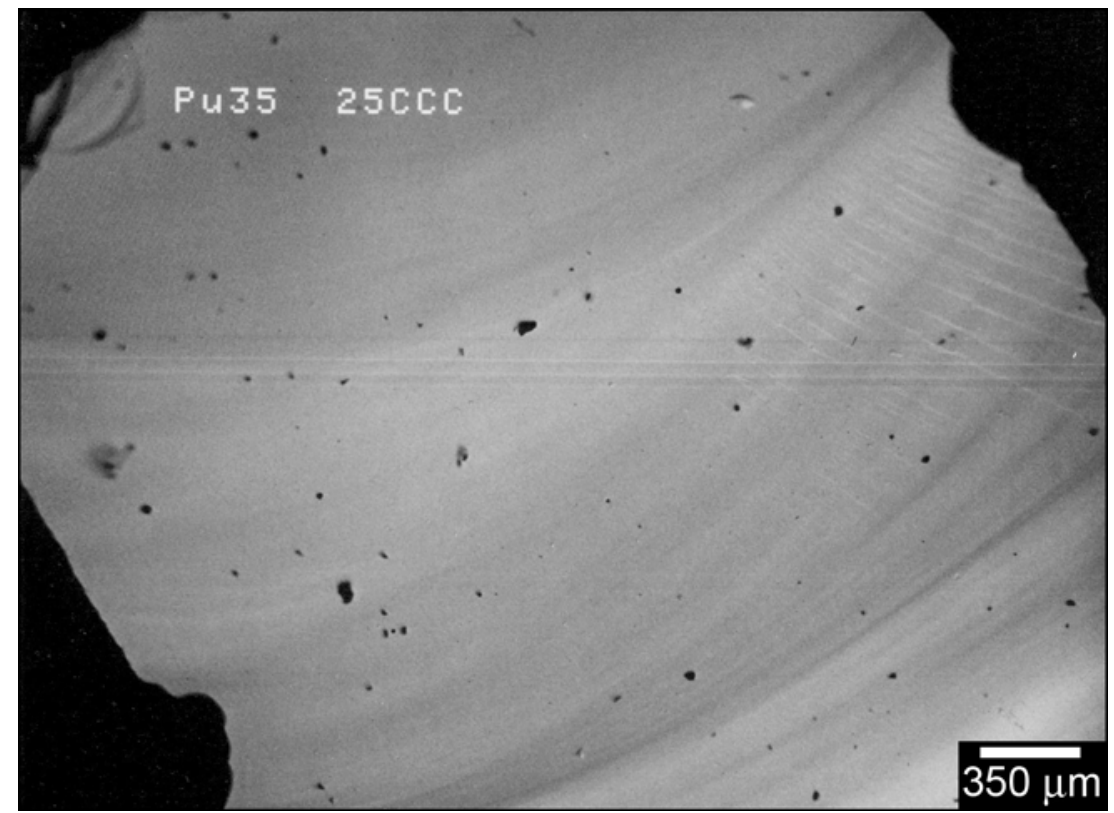

Figure 3-5. SEM micrograph of a fracture surface in the CCC version of glass Pu35-25.

\subsection{Density Measurements}

The results of the density measurements for the surrogate glasses are given in Table 3-2. In some cases, adequate samples of a particular glass were not available. Results of the density measurements for these glasses are reported as " $\mathrm{n} / \mathrm{a}$ ". 
WSRC-STI-2007-00477

Revision 0

Table 3-2. Measured densities of the surrogate glasses.

\begin{tabular}{|c|c|c|c|c|c|}
\hline Glass ID & $\begin{array}{l}\text { Density } \\
\left(\mathrm{g} / \mathrm{cm}^{3}\right)\end{array}$ & Glass ID & $\begin{array}{l}\text { Density } \\
\left(\mathrm{g} / \mathrm{cm}^{3}\right)\end{array}$ & Glass ID & $\begin{array}{l}\text { Density } \\
\left(\mathrm{g} / \mathrm{cm}^{3}\right)\end{array}$ \\
\hline Pu04-01 & 4.25 & Pu35-16 & $\mathrm{n} / \mathrm{a}$ & Pu35-36 & $\mathrm{n} / \mathrm{a}$ \\
\hline Pu04-02 & 4.27 & Pu35-17 & 4.21 & Pu35-37 & $\mathrm{n} / \mathrm{a}$ \\
\hline Pu04-03 & 4.32 & Pu35-18 & 4.20 & Pu35-38 & 4.24 \\
\hline $\mathrm{Pu} 04-04$ & $\mathrm{n} / \mathrm{a}$ & Pu35-19 & 4.24 & Pu35-39 & 4.23 \\
\hline Pu04-05 & 4.24 & Pu35-20 & 4.25 & $\mathrm{Pu} 35-40$ & 4.23 \\
\hline Pu35-01 & 4.24 & Pu35-21 & 4.26 & Pu35-41 & 4.22 \\
\hline Pu35-02 & 4.23 & Pu35-22 & 4.23 & Pu35-42 & 4.22 \\
\hline Pu35-03 & 4.19 & Pu35-23 & $\mathrm{n} / \mathrm{a}$ & Pu35-43 & 4.25 \\
\hline Pu35-04 & 4.24 & $\mathrm{Pu} 35-24$ & 4.25 & Pu35-44 & 4.23 \\
\hline Pu35-05 & 4.25 & $\mathrm{Pu} 35-25$ & 4.19 & $\mathrm{Pu} 35-45$ & 4.26 \\
\hline Pu35-06 & 4.25 & Pu35-26 & 4.25 & Pu35-46 & 4.24 \\
\hline Pu35-07 & 4.27 & Pu35-27 & 4.25 & Pu35-47 & 4.26 \\
\hline Pu35-08 & 4.25 & Pu35-28 & 4.23 & Pu35-48 & 4.23 \\
\hline Pu35-09 & 4.18 & Pu35-29 & 4.19 & Pu35-49 & 4.22 \\
\hline Pu35-10 & 4.23 & Pu35-30 & 4.21 & Pu35-50 & 4.21 \\
\hline Pu35-11 & $\mathrm{n} / \mathrm{a}$ & Pu35-31 & 4.23 & $\mathrm{Pu} 35-51$ & 4.24 \\
\hline Pu35-12 & 4.26 & Pu35-32 & 4.24 & Pu35-52 & 4.21 \\
\hline Pu35-13 & $\mathrm{n} / \mathrm{a}$ & Pu35-33 & 4.18 & Pu35-53 & 4.22 \\
\hline Pu35-14 & 4.25 & Pu35-34 & 4.17 & Pu35-54 & 4.22 \\
\hline Pu35-15 & 4.24 & Pu35-35 & 4.28 & Pu35-55 & $\mathrm{n} / \mathrm{a}$ \\
\hline
\end{tabular}

The measured densities of all of the surrogate glasses were quite similar, with an average density of $4.23 \mathrm{~g} / \mathrm{cm}^{3}$. Densities of the glasses fabricated with $\mathrm{PuO}_{2}$ were not measured, but are likely to be somewhat higher than those of the surrogate glasses due to the higher atomic mass of $\mathrm{Pu}$ as compared to Hf.

\subsection{A Statistical Review of the Chemical Composition Measurements of the Pu Impurity Solubility Study Glasses}

In this section, the measured versus targeted compositions of the 60 surrogate glasses are presented and compared. The targeted compositions for these glasses are provided in Table 2-2 and Table D1 of Appendix D. A sum of oxides column is provided in this table as well. Chemical composition measurements for the surrogate glasses were conducted by the PSAL following the analytical plans provided in Appendix A. Three dissolution methods were utilized in measuring these chemical compositions. All of the LM and PF prepared samples were analyzed (once for each element of interest) by ICP-AES. Each glass was prepared once for measurement by IC to determine the concentrations of $\mathrm{Cl}^{-}$ and $\mathrm{F}^{-}$. For each study glass, duplicate measurements on each of the analytes listed in this paragraph were obtained from the samples prepared by these dissolution methods.

Table D2 in Appendix D provides the elemental concentration measurements derived from the samples prepared using LM, Table D3 in Appendix D provides the measurements derived from the samples prepared using PF, and Table D4 in Appendix D provides the measurements derived from the samples prepared for measurement by the IC method. Measurements for standards (Batch 1 and LRM) that were included in the PSAL analytical plans along with the study glasses are also provided in these tables.

The measured concentrations of the cations listed above were converted to oxide concentrations by multiplying the values for each element by the gravimetric factor for the corresponding oxide. During this process, an elemental concentration that was determined to be below the detection limit of the 
analytical procedures used by the PSAL was reduced to half of that detection limit as the oxide concentration was determined.

While no conversion to oxides was necessary for $\mathrm{Cl}^{-}$and $\mathrm{F}^{-}$, if a reported measurement for either of these elements was below the detection limit, then the value was reduced to half of the detection limit for the subsequent analyses performed in this report.

In the sections that follow, the analytical sequences of the measurements are explored, the measurements of the standards are investigated and used for bias correction, the measurements for each surrogate glass are reviewed, the average chemical compositions (measured and bias-corrected) for each surrogate glass are determined, and comparisons are made between the measurements and the targeted compositions for the surrogate glasses.

\subsubsection{Measurements in Analytical Sequence}

Exhibit D1 in Appendix D provides plots of the measurements generated by the PSAL for samples prepared using the LM method. The plots are in analytical sequence with different symbols and colors being used to represent each of the surrogate and standard glasses. Similar plots for the samples prepared using the PF method and for the samples analyzed by IC are provided in Exhibit D2 in Appendix D. These plots include all of the measurement data from Tables D2, D3, and D4. There appear to be no obvious outliers or other problems in these chemical composition measurements.

\subsubsection{Batch 1 and LRM Standard Results}

In this section, the PSAL measurements of the chemical compositions of the Batch 1 and LRM standards are reviewed. These measurements are investigated across the ICP-AES analytical blocks (for Batch 1 and LRM) and across the IC analytical blocks (for LRM), and the results are used to bias correct the measurements for the study glasses.

Exhibit D3 in Appendix D provides statistical analyses of the Batch 1 and LRM results generated by the LM preparation method by block for each oxide of interest. The results include analysis of variance (ANOVA) investigations looking for statistically significant differences between the means of these groups for each of the oxides for each of the standards. The results from the statistical tests for the Batch 1 standard may be summarized as follows: $\mathrm{CaO}, \mathrm{Cr}_{2} \mathrm{O}_{3}, \mathrm{CuO}, \mathrm{Fe}_{2} \mathrm{O}_{3}, \mathrm{MgO}, \mathrm{Na}_{2} \mathrm{O}, \mathrm{NiO}, \mathrm{SiO}_{2}$, and $\mathrm{SrO}$ have measurements that indicate a significant ICP-AES calibration effect on the block averages at the 5\% significance level. The $\mathrm{SrO}$ differences are detection limit differences. For the LRM standard, $\mathrm{CaO}$, $\mathrm{Cr}_{2} \mathrm{O}_{3}, \mathrm{CuO}, \mathrm{Fe}_{2} \mathrm{O}_{3}, \mathrm{Gd}_{2} \mathrm{O}_{3}, \mathrm{MgO}, \mathrm{NiO}, \mathrm{PbO}, \mathrm{SO}_{4}{ }^{2-}$, and $\mathrm{SiO}_{2}$ have measurements that indicate a significant ICP-AES calibration effect on the block averages at the 5\% significance level. The $\mathrm{Gd}_{2} \mathrm{O}_{3}$ differences are detection limit differences. The reference values for the oxide concentrations of the standards are given in the header for each set of measurements in the exhibit.

Exhibit D4 in Appendix D provides a similar set of analyses for the ICP-AES measurements derived from samples prepared via the PF method. There is no indication of a significant ICP-AES calibration effects on the block averages for the $\mathrm{B}_{2} \mathrm{O}_{3}$ measurements at the $5 \%$ significance level. The reference values for the $\mathrm{B}_{2} \mathrm{O}_{3}$ concentration of the standards are given in the headers in the exhibit.

Exhibit D5 in Appendix D provides a similar set of analyses for the $\mathrm{Cl}^{-}$and $\mathrm{F}^{-}$measurements derived from LRM samples measured by IC. There is no indication of a significant IC calibration effects on the block averages for these measurements at the 5\% significance level. The reference values for the $\mathrm{Cl}^{-}$and $\mathrm{F}^{-}$ concentrations of the standard are given in the headers of the exhibit. 
Thus, some of these results provide incentive for adjusting the measurements by the effects of the ICPAES calibration and by the effects of the IC calibrations. Therefore, the oxide measurements of the surrogate glasses were bias corrected for the effect of the ICP-AES calibration on each of the analytical blocks, and the $\mathrm{F}^{-}$measurements of the surrogate glasses were bias corrected for the effect of the IC calibration on each of the analytical blocks. For the other oxides, bias-correction was conducted for an oxide as long as the oxide concentration in the Batch 1 glass was greater than or equal to $0.1 \mathrm{wt} \% \mathrm{with}$ the exception of $\mathrm{Nd}_{2} \mathrm{O}_{3}$. Although the Batch 1 reference value for $\mathrm{Nd}_{2} \mathrm{O}_{3}$ is $0.147 \mathrm{wt} \%$, the values reported by PSAL were $\sim 4$ times that amount. Increasing the $\mathrm{Nd}_{2} \mathrm{O}_{3}$ content of the surrogate glasses by a factor of 4 was not seen as being practical. Also, no bias correction was conducted for $\mathrm{Cl}^{-}$due to volatility issues for this element. The basis for the bias correction is presented as part of Exhibits D3, D4, and D5 - the average measurement for Batch 1 for each ICP block for $\mathrm{Al}_{2} \mathrm{O}_{3}, \mathrm{~B}_{2} \mathrm{O}_{3}, \mathrm{CaO}, \mathrm{Cr}_{2} \mathrm{O}_{3}, \mathrm{CuO}, \mathrm{Fe}_{2} \mathrm{O}_{3}, \mathrm{~K}_{2} \mathrm{O}$, $\mathrm{MgO}, \mathrm{Na}_{2} \mathrm{O}, \mathrm{NiO}$, and $\mathrm{SiO}_{2}$ and the average $\mathrm{F}^{-}$measurement for $\mathrm{LRM}$ for each IC block for $\mathrm{F}$. No bias correction was conducted for $\mathrm{Cl}^{-}, \mathrm{Ga}_{2} \mathrm{O}_{3}, \mathrm{Gd}_{2} \mathrm{O}_{3}, \mathrm{HfO}_{2}, \mathrm{La}_{2} \mathrm{O}_{3}, \mathrm{Nd}_{2} \mathrm{O}_{3}, \mathrm{PbO}, \mathrm{Nd}_{2} \mathrm{O}_{3}, \mathrm{SeO}_{2}$, and $\mathrm{Ta}_{2} \mathrm{O}_{5}$.

The bias correction was conducted as follows. For each oxide (or for $\mathrm{F}^{-}$), let $\overline{\mathrm{a}}_{\mathrm{ij}}$ be the average measurement for the $\mathrm{i}^{\text {th }}$ oxide (or $\mathrm{F}^{-}$) at analytical block $\mathrm{j}$ for Batch 1 (or LRM for $\mathrm{F}^{-}$), and let $\mathrm{t}_{\mathrm{i}}$ be the reference value for the $\mathrm{i}^{\text {th }}$ oxide for Batch 1 ( or for LRM for $\mathrm{F}^{-}$). (The averages and reference values are provided in Exhibits D3, D4, and D5.) Let $\bar{c}_{\mathrm{ijk}}$ be the average measurement for the $\mathrm{i}^{\text {th }}$ oxide (or for $\mathrm{F}^{-}$) at analytical block $\mathrm{j}$ for the $\mathrm{k}^{\text {th }}$ glass. The bias adjustment was conducted as follows:

$$
\overline{\mathrm{c}}_{\mathrm{ijk}} \bullet\left(1-\frac{\overline{\mathrm{a}}_{\mathrm{ij}}-\mathrm{t}_{\mathrm{i}}}{\overline{\mathrm{a}}_{\mathrm{ij}}}\right)=\overline{\mathrm{c}}_{\mathrm{ijk}} \bullet \frac{\mathrm{t}_{\mathrm{i}}}{\overline{\mathrm{a}}_{\mathrm{ij}}}
$$

Bias-corrected measurements are indicated by a "bc" suffix, and such adjustments were performed for all of the analytes of this study except for $\mathrm{Cl}^{-}, \mathrm{Ga}_{2} \mathrm{O}_{3}, \mathrm{Gd}_{2} \mathrm{O}_{3}, \mathrm{HfO}_{2}, \mathrm{La}_{2} \mathrm{O}_{3}, \mathrm{Nd}_{2} \mathrm{O}_{3}, \mathrm{PbO}, \mathrm{Nd}_{2} \mathrm{O}_{3}, \mathrm{SeO}_{2}$, and $\mathrm{Ta}_{2} \mathrm{O}_{5}$. Both measured and measured " $\mathrm{bc}$ " values are included in the discussion that follows. In these discussions, bias-corrected values for $\mathrm{Cl}^{-}, \mathrm{Ga}_{2} \mathrm{O}_{3}, \mathrm{Gd}_{2} \mathrm{O}_{3}, \mathrm{HfO}_{2}, \mathrm{La}_{2} \mathrm{O}_{3}, \mathrm{Nd}_{2} \mathrm{O}_{3}, \mathrm{PbO}, \mathrm{Nd}_{2} \mathrm{O}_{3}, \mathrm{SeO}_{2}$, and $\mathrm{Ta}_{2} \mathrm{O}_{5}$ are included for completeness (e.g., to allow a sum of oxides to be computed for the bias-corrected results). These bias-corrected values are the same as the original $\mathrm{Cl}^{-}, \mathrm{Ga}_{2} \mathrm{O}_{3}, \mathrm{Gd}_{2} \mathrm{O}_{3}, \mathrm{HfO}_{2}, \mathrm{La}_{2} \mathrm{O}_{3}, \mathrm{Nd}_{2} \mathrm{O}_{3}$, $\mathrm{PbO}, \mathrm{Nd}_{2} \mathrm{O}_{3}, \mathrm{SeO}_{2}$, and $\mathrm{Ta}_{2} \mathrm{O}_{5}$ values.

\subsubsection{Composition Measurements by Glass Number}

Exhibits D6 and D7 in Appendix D provide plots of the oxide concentration measurements by Glass ID (including Batch 1 and LRM) for the measured and bias-corrected (bc) values for the LM and PF preparation methods, respectively. Exhibit D8 provides similar plots for $\mathrm{Cl}^{-}$and $\mathrm{F}^{-}$for the IC measurements including the measurements for LRM. Different symbols and colors are used to represent the different glasses and the glasses are grouped by the targeted concentration of the particular analyte. These plots show the individual measurements across the duplicate measurements of each preparation method. A review of the plots presented in these exhibits reveals the repeatability of the individual values for each analyte for each glass. No significant issues in the repeatability of the measurements in these plots are evident. In comparing the measured values to their targeted concentrations, some differences are seen between the measured values and the targeted concentrations for some analytes for some of the glasses. A closer look at these comparisons is presented in the next section.

\subsubsection{Measured versus Targeted Compositions}

The duplicate measurements for each analyte for each surrogate glass (over all of the preparation methods) were averaged to determine a representative chemical composition for each glass. These determinations were conducted both for the measured and for the bias-corrected data. A sum of oxides 
was also computed for each glass based upon both the measured and bias-corrected values. Exhibit D9 in Appendix D provides plots showing results for each glass for each analyte to help highlight the comparisons among the measured, bias-corrected, and targeted values.

Some observations from the plots of Exhibit D9 are offered. For almost all of the study glasses (Pu35-33 is the only exception), the measured concentrations of $\mathrm{Al}_{2} \mathrm{O}_{3}$ are somewhat higher than the targeted value of $8.6 \mathrm{wt} \%$. For all of the study glasses, the measured concentrations of $\mathrm{CaO}$ are slightly higher than their targeted values. The $\mathrm{Cl}^{-}$measurements (for the study and standard glasses) suggest a high degree of volatility for this element. The $\mathrm{Cr}_{2} \mathrm{O}_{3}$ measurements for glasses that targeted the higher concentrations for this oxide appear to fall below the targets while the measurements for glasses targeting a lower concentration of $\mathrm{Cr}_{2} \mathrm{O}_{3}$ appear to more in line. For those study glasses with $\mathrm{F}^{-}$present, the measurements for $\mathrm{F}^{-}$appear to fall below the targeted concentrations, indicating volatility for this element. The $\mathrm{HfO}_{2}$ measurements were consistently below their targeted values, and the differences between the measured and targeted concentrations were greater for the Pu04-xx series of study glasses, which targeted higher levels of $\mathrm{HfO}_{2}$. A general problem with detection limits appears to be seen in the results for $\mathrm{PbO}$. Volatility appears to have reduced the measured concentrations of $\mathrm{SeO}_{2}$ and $\mathrm{SO}_{4}{ }^{2-}$ to values well below the targets.

Figure 3-6 provides a graphical look at the measured versus targeted concentrations for the surrogate glasses. A plot is shown for each of the elements (converted to an oxide) that was varied in the glass compositions (i.e., the anticipated impurity elements and the Pu surrogate Hf). 

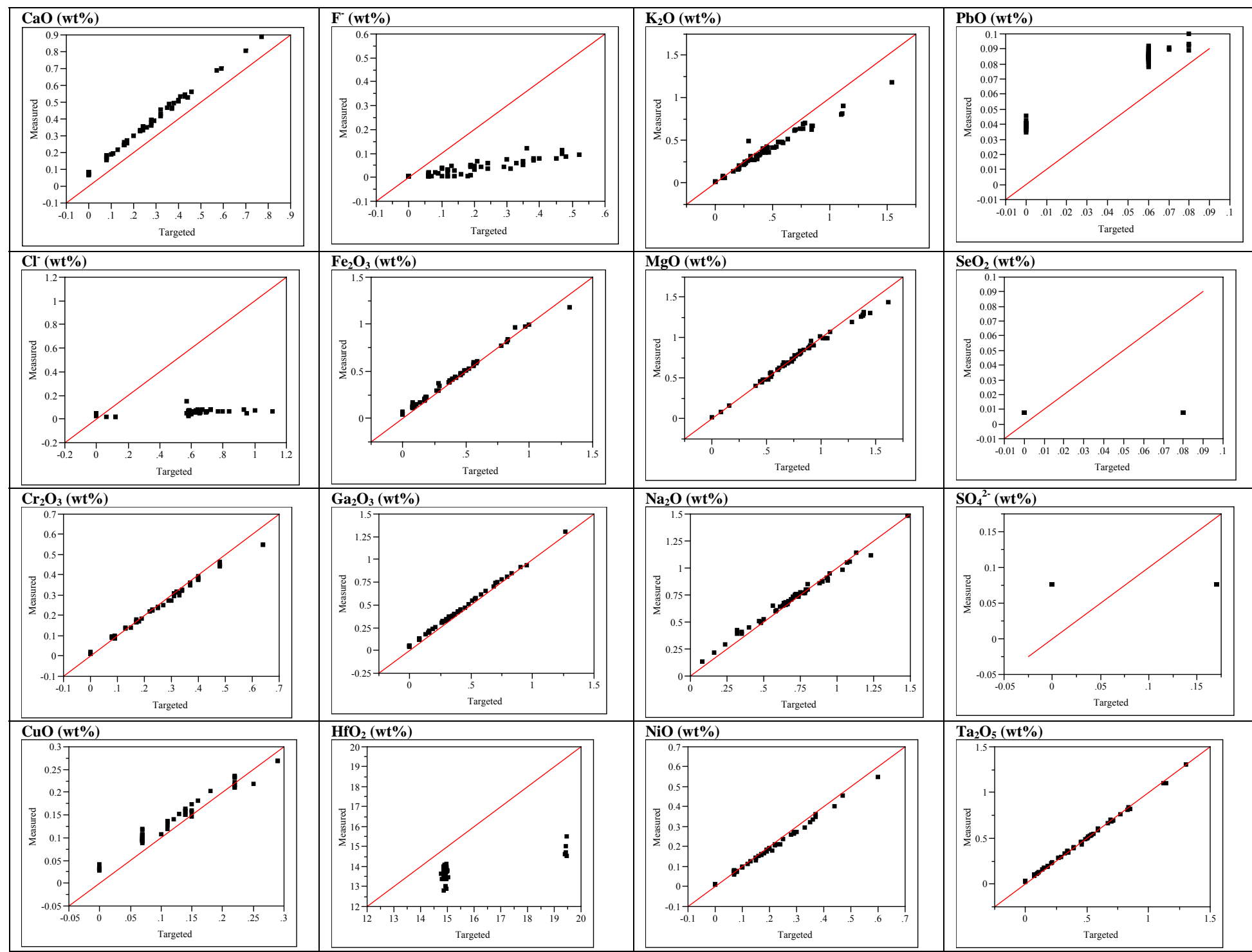

Figure 3-6. Measured versus targeted concentrations for select analytes of the surrogate glasses. 
Figure 3-6 shows that the measured $\mathrm{CaO}$ and $\mathrm{PbO}$ concentrations were consistently higher than the targeted values. The measured $\mathrm{Cr}_{2} \mathrm{O}_{3}$ and $\mathrm{Fe}_{2} \mathrm{O}_{3}$ concentrations were very close to the targets except for the one highest targeted value for each of these components. The measured $\mathrm{Cl}^{-}, \mathrm{F}^{-}$, $\mathrm{SeO}_{2}$ and $\mathrm{SO}_{4}{ }^{2-}$ concentrations were well below their target values for all of the study glasses. ${ }^{\mathrm{a}}$ This is likely due to volatilization of these species during melting of the glass batch. The measured $\mathrm{HfO}_{2}$ concentrations were below their target values for all of the study glasses. It is likely that for $\mathrm{HfO}_{2}$, the solubility limit in the glass was exceeded and some of the $\mathrm{HfO}_{2}$ batch material remained in the bottom of the crucibles after pouring the glasses. The measured $\mathrm{K}_{2} \mathrm{O}$ concentrations were very close to the target values up to a concentration of about $0.48 \mathrm{wt} \%$, after which the measured concentrations fall below the target values. The measured $\mathrm{MgO}$ concentrations were very close to the target values up to a concentration of about $1.1 \mathrm{wt} \%$, after which the measured concentrations fall below the target values. The measured $\mathrm{CuO}, \mathrm{Ga}_{2} \mathrm{O}_{3}$, $\mathrm{Na}_{2} \mathrm{O}, \mathrm{NiO}$, and $\mathrm{Ta}_{2} \mathrm{O}_{5}$ concentrations generally fell very close to their target values across the ranges of concentrations targeted in this study for each of these components.

In summary, these results indicate that a solubility limit may have been approached in this glass system for some components, including $\mathrm{K}_{2} \mathrm{O}$ and $\mathrm{MgO}$. Volatility is likely responsible for the low measured concentrations of $\mathrm{Cl}^{-}, \mathrm{F}^{-}, \mathrm{SO}_{4}{ }^{2-}$ and $\mathrm{SeO}_{2}$.

Table D5 in Appendix D provides a summary of the average compositions as well as the targeted compositions and some associated differences and relative differences. Notice that the targeted sums of oxides for the standard glasses do not sum to $100 \%$ due to an incomplete coverage of the oxides in the Batch 1 and LRM glasses. All of the sums of oxides (both measured and biascorrected) for the surrogate glasses fall within the interval of 95 to $105 \mathrm{wt} \%$. Entries in Table D5 show the relative differences between the measured or bias-corrected values and the targeted values. These differences are shaded when they are greater than or equal to $5 \%$.

Exhibit D10 in Appendix D provides an opportunity to review the outcomes for the impurities (whose measurements are provided here) for each of the surrogate glasses.

\subsection{A Statistical Review of the PCT Results for the Surrogate Glasses}

The surrogate glasses were subjected to the 7-day PCT Method A to assess their durabilities. ${ }^{16}$ Two heat treatments (quenched and CCC) were used during the fabrication of each of the study glasses. Both heat treatments for each surrogate glass were subjected to the PCT in triplicate. PCTs were also conducted in triplicate for samples of the EA glass and for samples of the ARM glass as part of each PCT plan. Blanks (samples consisting only of ASTM Type I water) were also submitted as part of each PCT plan. There were 6 plans in all (see Appendices B and C for details). The plans were provided to the PSAL to support the evaluation of the compositions of the solutions resulting from the PCTs. Samples of a multi-element, standard solution were also included in each analytical plan (as a check on the accuracy of the ICP-AES instrument used for the measurements). In this and the following sections, the measurements generated by the PSAL for these PCTs are presented and reviewed.

Table E1 in Appendix E provides the elemental leachate concentration measurements determined by the PSAL for the solution samples generated by the PCTs. The PCTs for the quenched versions of the glasses were conducted in 3 sets, and the PCTs for the CCC versions of the glasses were conducted in another set of 3 PCTs. One of the quality control checkpoints for the

\footnotetext{
${ }^{a}$ Note that because of detection limit issues, the measured concentrations of $\mathrm{SeO}_{2}$ and $\mathrm{SO}_{4}{ }^{2-}$ appear to be high when the target concentration was $0 \mathrm{wt} \%$. The measured concentrations of $\mathrm{SeO}_{2}$ and $\mathrm{SO}_{4}{ }^{2-}$ were below the detection limits for all of the surrogate glasses.
} 
PCT procedure is solution weight loss over the course of the 7-day test. None of the PCT results for any of the 6 sets of PCTs indicated a solution weight loss problem. Note that for these glasses, the PCT solutions were measured for boron (B), gadolinium (Gd), hafnium (Hf), sodium (Na), and silicon $(\mathrm{Si})$ concentrations. Any measurement in Table E1 below the detection limit of the analytical procedure (indicated by a " $<$ ") was replaced by one half of the detection limit in subsequent analyses. In addition to adjustments for detection limits, the values were adjusted for the dilution factors: the values for the surrogate glasses, the blanks, and the ARM glass in Table E1 were multiplied by 1.6667 to determine the values in parts per million (ppm) and the values for EA were multiplied by 16.6667. The last five columns of Table E1 provide the measurements resulting from these adjustments. Note that the measured values for the ARM glass all fall within the specified control limits. ${ }^{14}$

In the sections that follow, the analytical sequence of the measurements is explored, the measurements of the standards are investigated and used to assess the overall accuracy of the ICP-AES measurement process, the measurements for each surrogate glass are reviewed, and plots are provided that explore the effects of heat treatment on the PCTs for these glasses.

\subsubsection{Measurements in Analytical Sequence}

Exhibit E1 in Appendix E provides plots of the leachate (ppm) concentrations for the quenched results in analytical sequence as generated by the PSAL for all of the data as well as plots for the data from only the surrogate glasses. In these plots, ARM is represented by the symbol ":", EA is represented by a " $\times$ ", a blank is represented by a "+", and the multi-element solution standard is represented by a " $\diamond$ ". Each surrogate glass is represented by a "ø". Exhibit E2 in Appendix E provides plots of the leachate ( $\mathrm{ppm}$ ) concentrations for the $\mathrm{CCC}$ results in analytical sequence as generated by the PSAL for all of the data as well as plots for the data from only the surrogate glasses. As seen by these plots, the analyte concentrations for the elements of interest appear relatively low for most all of the surrogate glasses (quenched and CCC versions). A more detailed discussion of these results is provided below.

\subsubsection{Results for the Samples of the Multi-Element Solution Standard}

Exhibit E3 in Appendix E provides analyses of the PSAL measurements of the samples of the multi-element solution standard by ICP-AES analytical (or calibration) block and PCT set for the quenched glasses. An ANOVA investigating for statistically significant differences among the block averages for these samples for each element of interest is included in these exhibits. Exhibit E4 in Appendix E provides similar investigations for the CCC results. For both the quenched and CCC results, a statistically significant (at approximately a 5\% level) difference is seen among the B average measurements over the calibration blocks and PCT sets. However, no bias correction of the PCT results for the study glasses was conducted. This approach was taken since the triplicate PCTs for a single study glass were placed in different calibration blocks. Averaging the ppm values for each set of triplicates helps to minimize the impact of any bias in the ICP-AES measurements.

Table 3-3 summarizes the average measurements and the reference values for the 3 primary elements present in the multi-element solution. The results indicate consistent and accurate measurements from the PSAL processes used to conduct these analyses. 
Table 3-3. Results from samples of the multi-element solution standard by PCT plans.

\begin{tabular}{|c|c|c|c|c|c|c|c|}
\hline \multicolumn{4}{|c|}{ Quenched plans } & \multicolumn{4}{|c|}{ CCC plans } \\
\hline Set/Block & $\begin{array}{c}\mathrm{B} \\
(\mathrm{ppm})\end{array}$ & $\begin{array}{c}\mathrm{Na} \\
(\mathrm{ppm})\end{array}$ & $\begin{array}{c}\mathrm{Si} \\
(\mathrm{ppm})\end{array}$ & Set/Block & $\begin{array}{c}\mathrm{B} \\
(\mathrm{ppm})\end{array}$ & $\begin{array}{c}\mathrm{Na} \\
(\mathrm{ppm})\end{array}$ & $\begin{array}{c}\mathrm{Si} \\
(\mathrm{ppm})\end{array}$ \\
\hline $1 / 1$ & 21.8 & 83.2 & 49 & $1 / 1$ & 20.5 & 83.7 & 49.9 \\
\hline $1 / 1$ & 20.8 & 82.4 & 49.1 & $1 / 1$ & 20.8 & 84.8 & 50.7 \\
\hline $1 / 1$ & 21.6 & 85 & 51.8 & $1 / 1$ & 20 & 87.2 & 49.3 \\
\hline $1 / 2$ & 21.5 & 82.8 & 49.7 & $1 / 2$ & 21.2 & 84.2 & 50.4 \\
\hline $1 / 2$ & 19.2 & 83.3 & 49.3 & $1 / 2$ & 20.5 & 86.6 & 50.8 \\
\hline $1 / 2$ & 19.4 & 80.5 & 50 & $1 / 2$ & 20.2 & 88.3 & 49.1 \\
\hline $1 / 3$ & 20.4 & 84.7 & 51.1 & $1 / 3$ & 20.9 & 84.1 & 49.1 \\
\hline $1 / 3$ & 19.9 & 84.6 & 50.5 & $1 / 3$ & 20.1 & 86.9 & 50.5 \\
\hline $1 / 3$ & 20.3 & 85.6 & 50.9 & $1 / 3$ & 20 & 90 & 50 \\
\hline $2 / 1$ & 20.6 & 83.5 & 49.2 & $2 / 1$ & 20.8 & 82 & 49.5 \\
\hline $2 / 1$ & 20.1 & 84.8 & 47.5 & $2 / 1$ & 19.4 & 82.3 & 49.8 \\
\hline $2 / 1$ & 21.3 & 86 & 50.4 & $2 / 1$ & 19.7 & 87.2 & 48.8 \\
\hline $2 / 2$ & 20.4 & 85.2 & 49.4 & $2 / 2$ & 20.1 & 81.3 & 49.3 \\
\hline $2 / 2$ & 18.6 & 80.5 & 46.9 & $2 / 2$ & 19.1 & 80.8 & 48.4 \\
\hline $2 / 2$ & 18.9 & 84.3 & 47.8 & $2 / 2$ & 19.6 & 84.2 & 50.4 \\
\hline $2 / 3$ & 20.6 & 83.9 & 49.8 & $2 / 3$ & 20.5 & 82.4 & 50 \\
\hline $2 / 3$ & 18.7 & 82.7 & 46.4 & $2 / 3$ & 19.1 & 82.5 & 48.2 \\
\hline $2 / 3$ & 19.8 & 87.4 & 48.7 & $2 / 3$ & 19.3 & 84.1 & 48.4 \\
\hline $3 / 1$ & 19.6 & 80.2 & 47.6 & $3 / 1$ & 21.2 & 83.8 & 49.6 \\
\hline $3 / 1$ & 18.4 & 82.1 & 47.3 & $3 / 1$ & 20.4 & 89.3 & 48.9 \\
\hline $3 / 1$ & 18.8 & 80.2 & 48.7 & $3 / 1$ & 20.9 & 87.2 & 50.4 \\
\hline $3 / 2$ & 20 & 82.9 & 47.9 & $3 / 2$ & 21.7 & 85.1 & 51.2 \\
\hline $3 / 2$ & 19.5 & 83.9 & 48.5 & $3 / 2$ & 20.7 & 88.1 & 50 \\
\hline $3 / 2$ & 19.8 & 85.2 & 49.3 & $3 / 2$ & 21 & 84.1 & 51.4 \\
\hline $3 / 3$ & 20.1 & 82.6 & 48.6 & $3 / 3$ & 20.2 & 85.3 & 48.8 \\
\hline $3 / 3$ & 18.9 & 82.8 & 48.7 & $3 / 3$ & 20.4 & 85.7 & 51.7 \\
\hline $3 / 3$ & 19.7 & 83.8 & 49.4 & $3 / 3$ & 20.1 & 87.4 & 50.8 \\
\hline $\begin{array}{c}\text { Grand } \\
\text { Average }\end{array}$ & 19.95 & 83.49 & 49.02 & Grand Average & 20.31 & 85.13 & 49.83 \\
\hline $\begin{array}{c}\text { Reference } \\
\text { Value }\end{array}$ & 20 & 81 & 50 & $\begin{array}{c}\text { Reference } \\
\text { Value }\end{array}$ & 20 & 81 & 50 \\
\hline$\%$ difference & $-0.24 \%$ & $3.07 \%$ & $-1.96 \%$ & $\%$ difference & $1.56 \%$ & $5.10 \%$ & $-0.34 \%$ \\
\hline
\end{tabular}

\subsubsection{Measurements by Glass Number}

Exhibit E5 in Appendix E provide plots of the leachate concentrations for the two heat treatments (quenched and CCC) by study glass. These plots allow for the assessment of the repeatability of the measurements, which suggests minor scatter in the triplicate values for some analytes for some of the glasses. Also, note that some differences between the values for the two heat treatments for some glasses are evident for some of the elements of interest. In particular, the concentration of $\mathrm{Si}$ in the leachates of many of the $\mathrm{CCC}$ versions of the surrogate glasses tended to be somewhat higher than the concentration in the leachates for the quenched versions of the 
glasses. However, these differences are too small to have a practical impact on the durability performance of the glasses.

\subsubsection{Normalized PCT Results}

PCT leachate concentrations are typically normalized using the cation composition (expressed as a weight percent) in the glass to obtain a grams-per-liter $(\mathrm{g} / \mathrm{L})$ leachate concentration. The normalization of the PCTs is usually conducted using the measured compositions of the glasses. This is the preferred normalization process for the PCTs. For completeness, the targeted cation concentrations and the bias-corrected cation concentrations were also used to conduct this normalization.

As is the usual convention, the common logarithm of the normalized PCT (normalized leachate, $\mathrm{NL}$ ) for each element of interest was determined and used for comparison. To accomplish this computation, one must

1. Determine the common logarithm of the elemental parts per million (ppm) leachate concentration for each of the triplicates and each of the elements of interest (these values are provided in Table E2 of Appendix E),

2. Average the common logarithms over the triplicates for each element of interest, and then

Normalizing Using Measured Composition (preferred method)

3. Subtract a quantity equal to 1 plus the common logarithm of the average cation measured concentration (expressed as a weight percent of the glass) from the average computed in step 2 .

Or Normalizing Using Target Composition

3. Subtract a quantity equal to 1 plus the common logarithm of the target cation concentration (expressed as a weight percent of the glass) from the average computed in step 2.

Or Normalizing Using Measured Bias-Corrected Composition

3. Subtract a quantity equal to 1 plus the common logarithm of the measured bias-corrected cation concentration (expressed as a weight percent of the glass) from the average computed in step 2.

Table 3-4 summarizes the normalized PCTs for the surrogate glasses. 
WSRC-STI-2007-00477

Revision 0

Table 3-4. Normalized PCTs by Glass ID and compositional view.

\begin{tabular}{|c|c|c|c|c|c|c|c|c|c|c|c|c|c|}
\hline Set & Glass ID & $\begin{array}{c}\text { Heat } \\
\text { Treatment }\end{array}$ & Composition & \begin{tabular}{|c|}
$\log \mathrm{NL}$ \\
{$[\mathrm{B}(\mathrm{g} / \mathrm{L})]$} \\
\end{tabular} & \begin{tabular}{|c|}
$\log \mathrm{NL}$ \\
{$[\mathrm{Gd}(\mathrm{g} / \mathrm{L})]$}
\end{tabular} & $\begin{array}{c}\log \mathrm{NL} \\
{[\mathrm{Hf}(\mathrm{g} / \mathrm{L})]}\end{array}$ & $\begin{array}{c}\log \mathrm{NL} \\
{[\mathrm{Na}(\mathrm{g} / \mathrm{L})]}\end{array}$ & \begin{tabular}{|c|}
$\log \mathrm{NL}$ \\
{$[\mathrm{Si}(\mathrm{g} / \mathrm{L})]$}
\end{tabular} & $\begin{array}{c}\mathrm{NL} \\
\mathrm{B}(\mathrm{g} / \mathrm{L}) \\
\end{array}$ & $\begin{array}{c}\mathrm{NL} \\
\mathrm{Gd}(\mathrm{g} / \mathrm{L}) \\
\end{array}$ & $\begin{array}{c}\mathrm{NL} \\
\mathrm{Hf}(\mathrm{g} / \mathrm{L}) \\
\end{array}$ & $\begin{array}{c}\mathrm{NL} \\
\mathrm{Na}(\mathrm{g} / \mathrm{L})\end{array}$ & $\begin{array}{c}\mathrm{NL} \\
\mathrm{Si}(\mathrm{g} / \mathrm{L}) \\
\end{array}$ \\
\hline 1 & ARM-1 & - & reference & -0.3050 & - & - & -0.2755 & -0.5648 & 0.495 & - & - & 0.530 & 0.272 \\
\hline 1 & EA & - & reference & 1.2624 & - & - & 1.1634 & 0.6078 & 18.299 & - & - & 14.568 & 4.053 \\
\hline 2 & ARM-1 & - & reference & -0.3410 & - & - & -0.2569 & -0.5794 & 0.456 & - & - & 0.554 & 0.263 \\
\hline 2 & EA & - & reference & 1.2436 & - & - & 1.1343 & 0.5940 & 17.523 & - & - & 13.623 & 3.926 \\
\hline 3 & ARM-1 & - & reference & -0.2902 & - & - & -0.3009 & -0.5710 & 0.513 & - & - & 0.500 & 0.269 \\
\hline 3 & EA & - & reference & 1.2491 & - & - & 1.1334 & 0.5853 & 17.745 & - & - & 13.595 & 3.848 \\
\hline 1 & Pu04-01 & ccc & measured & -1.6433 & -2.1024 & -2.4701 & -0.2203 & -1.5790 & 0.023 & 0.008 & 0.003 & 0.602 & 0.026 \\
\hline 1 & $\mathrm{Pu} 04-02$ & $\mathrm{ccc}$ & measured & -1.6444 & -2.0983 & -2.4754 & -0.2775 & -1.9723 & 0.023 & 0.008 & 0.003 & 0.528 & 0.011 \\
\hline 1 & Pu04-03 & $\mathrm{ccc}$ & measured & -1.6379 & -2.1024 & -2.4840 & -0.4720 & -1.9110 & 0.023 & 0.008 & 0.003 & 0.337 & 0.012 \\
\hline 1 & $\mathrm{Pu} 04-04$ & $\mathrm{ccc}$ & measured & -1.6456 & -2.1106 & -2.4719 & -0.1077 & -1.9491 & 0.023 & 0.008 & 0.003 & 0.780 & 0.011 \\
\hline 1 & $\mathrm{Pu} 04-05$ & $\mathrm{ccc}$ & measured & -1.6456 & -2.1086 & -2.4975 & -0.6783 & -2.0105 & 0.023 & 0.008 & 0.003 & 0.210 & 0.010 \\
\hline 1 & Pu35-01 & ccc & measured & -1.6226 & -2.0835 & -2.4428 & -0.7389 & -1.5231 & 0.024 & 0.008 & 0.004 & 0.182 & 0.030 \\
\hline 1 & Pu35-02 & $\mathrm{ccc}$ & measured & -1.6421 & -2.0920 & -2.4428 & -0.5655 & -1.2546 & 0.023 & 0.008 & 0.004 & 0.272 & 0.056 \\
\hline 1 & Pu35-03 & ccc & measured & -1.4120 & -1.8531 & -2.4333 & -0.4161 & -1.0639 & 0.039 & 0.014 & 0.004 & 0.384 & 0.086 \\
\hline 1 & Pu35-04 & $\mathrm{ccc}$ & measured & -1.5263 & -1.9804 & -2.4465 & -0.5268 & -1.2954 & 0.030 & 0.010 & 0.004 & 0.297 & 0.051 \\
\hline 1 & Pu35-05 & $\mathrm{ccc}$ & measured & -1.6312 & -2.0822 & -2.4390 & -0.5352 & -1.1851 & 0.023 & 0.008 & 0.004 & 0.292 & 0.065 \\
\hline 1 & Pu35-06 & $\mathrm{ccc}$ & measured & -1.6113 & -2.0835 & -2.4390 & -0.7807 & -1.3269 & 0.024 & 0.008 & 0.004 & 0.166 & 0.047 \\
\hline 1 & Pu35-07 & $\mathrm{ccc}$ & measured & -1.6119 & -2.0856 & -2.4539 & -0.0274 & -1.2828 & 0.024 & 0.008 & 0.004 & 0.939 & 0.052 \\
\hline 1 & Pu35-08 & ccc & measured & -1.5050 & -1.9755 & -2.4352 & -0.6336 & -1.2553 & 0.031 & 0.011 & 0.004 & 0.233 & 0.056 \\
\hline 1 & Pu35-09 & $\mathrm{ccc}$ & measured & -1.4573 & -1.9245 & -2.4333 & -0.4370 & -1.0555 & 0.035 & 0.012 & 0.004 & 0.366 & 0.088 \\
\hline 1 & Pu35-10 & $\mathrm{ccc}$ & measured & -1.6170 & -2.0856 & -2.4352 & -0.4142 & -1.3381 & 0.024 & 0.008 & 0.004 & 0.385 & 0.046 \\
\hline 1 & Pu35-11 & $\mathrm{ccc}$ & measured & -1.4952 & -1.9604 & -2.4521 & -0.6850 & -1.2812 & 0.032 & 0.011 & 0.004 & 0.207 & 0.052 \\
\hline 1 & Pu35-12 & ccc & measured & -1.6245 & -2.0856 & -2.4521 & 0.0435 & -1.2828 & 0.024 & 0.008 & 0.004 & 1.105 & 0.052 \\
\hline 1 & Pu35-13 & $\mathrm{ccc}$ & measured & -1.5116 & -1.9853 & -2.4333 & -0.4723 & -1.1866 & 0.031 & 0.010 & 0.004 & 0.337 & 0.065 \\
\hline 1 & Pu35-14 & $\mathrm{ccc}$ & measured & -1.6062 & -2.0878 & -2.4484 & -1.1423 & -1.3215 & 0.025 & 0.008 & 0.004 & 0.072 & 0.048 \\
\hline 1 & Pu35-15 & $\mathrm{ccc}$ & measured & -1.6075 & -2.0899 & -2.4484 & -0.0602 & -1.2706 & 0.025 & 0.008 & 0.004 & 0.870 & 0.054 \\
\hline 2 & Pu35-16 & $\mathrm{ccc}$ & measured & -1.6263 & -2.0941 & -2.4539 & -1.5167 & -1.6161 & 0.024 & 0.008 & 0.004 & 0.030 & 0.024 \\
\hline 2 & Pu35-17 & $\mathrm{ccc}$ & measured & -1.6282 & -2.0920 & -2.4502 & -1.3060 & -1.2612 & 0.024 & 0.008 & 0.004 & 0.049 & 0.055 \\
\hline 2 & Pu35-18 & $\mathrm{ccc}$ & measured & -1.4824 & -1.9472 & -2.4521 & -1.0068 & -1.0850 & 0.033 & 0.011 & 0.004 & 0.098 & 0.082 \\
\hline 2 & Pu35-19 & $\mathrm{ccc}$ & measured & -1.6220 & -2.0920 & -2.4539 & -1.8331 & -1.3925 & 0.024 & 0.008 & 0.004 & 0.015 & 0.041 \\
\hline 2 & Pu35-20 & $\mathrm{ccc}$ & measured & -1.6195 & -2.0962 & -2.4576 & -0.3727 & -1.2324 & 0.024 & 0.008 & 0.003 & 0.424 & 0.059 \\
\hline 2 & Pu35-21 & $\mathrm{ccc}$ & measured & -1.6183 & -2.0920 & -2.4428 & -0.6757 & -1.3237 & 0.024 & 0.008 & 0.004 & 0.211 & 0.047 \\
\hline 2 & Pu35-22 & $\mathrm{ccc}$ & measured & -1.6245 & -2.0983 & -2.4521 & -1.0555 & -1.2552 & 0.024 & 0.008 & 0.004 & 0.088 & 0.056 \\
\hline 2 & Pu35-23 & $\mathrm{ccc}$ & measured & -1.6263 & -2.0920 & -2.4539 & -0.7569 & -1.3367 & 0.024 & 0.008 & 0.004 & 0.175 & 0.046 \\
\hline 2 & Pu35-24 & $\mathrm{ccc}$ & measured & -1.6288 & -2.0899 & -2.4484 & -1.7211 & -1.3431 & 0.024 & 0.008 & 0.004 & 0.019 & 0.045 \\
\hline 2 & Pu35-25 & $\mathrm{ccc}$ & measured & -1.6195 & -2.0899 & -2.3048 & -0.5231 & -1.2560 & 0.024 & 0.008 & 0.005 & 0.300 & 0.055 \\
\hline 2 & $\mathrm{Pu} 35-26$ & $\mathrm{ccc}$ & measured & -1.6214 & -2.0835 & -2.4447 & -1.0356 & -1.4432 & 0.024 & 0.008 & 0.004 & 0.092 & 0.036 \\
\hline 2 & Pu35-27 & $\mathrm{ccc}$ & measured & -1.6195 & -2.0816 & -2.4352 & -1.6278 & -1.6310 & 0.024 & 0.008 & 0.004 & 0.024 & 0.023 \\
\hline 2 & Pu35-28 & $\mathrm{ccc}$ & measured & -1.6276 & -2.0856 & -2.4428 & -1.1642 & -1.3488 & 0.024 & 0.008 & 0.004 & 0.069 & 0.045 \\
\hline 2 & Pu35-29 & $\mathrm{ccc}$ & measured & -1.6239 & -2.0813 & -2.4371 & -1.1820 & -1.2703 & 0.024 & 0.008 & 0.004 & 0.066 & 0.054 \\
\hline 2 & Pu35-30 & $\mathrm{ccc}$ & measured & -1.6132 & -2.0878 & -2.4465 & -1.4945 & -1.2017 & 0.024 & 0.008 & 0.004 & 0.032 & 0.063 \\
\hline 2 & $\mathrm{Pu} 35-31$ & $\mathrm{ccc}$ & measured & $\begin{array}{l}-1.6119 \\
\end{array}$ & -2.0856 & -2.4447 & $\begin{array}{l}-0.5469 \\
\end{array}$ & -1.2380 & 0.024 & 0.008 & 0.004 & 0.284 & 0.058 \\
\hline 2 & Pu35-32 & $\mathrm{ccc}$ & measured & -1.6195 & -2.0878 & -2.4539 & -1.7943 & -1.5383 & 0.024 & 0.008 & 0.004 & 0.016 & 0.029 \\
\hline 2 & Pu35-33 & ccc & measured & -1.6081 & -2.0733 & -2.4428 & -0.7097 & -1.5243 & 0.025 & 0.008 & 0.004 & 0.195 & 0.030 \\
\hline 2 & $\mathrm{Pu} 35-34$ & $\mathrm{ccc}$ & measured & -1.6094 & -2.0878 & -2.4428 & -0.4317 & -1.2852 & 0.025 & 0.008 & 0.004 & 0.370 & 0.052 \\
\hline 2 & Pu35-35 & $\mathrm{ccc}$ & measured & -1.6226 & -2.0835 & -2.2576 & -1.1668 & -1.4571 & 0.024 & 0.008 & 0.006 & 0.068 & 0.035 \\
\hline 3 & Pu35-36 & $\mathrm{ccc}$ & measured & -1.4574 & -1.9307 & -2.4558 & -0.4434 & -1.1565 & 0.035 & 0.012 & 0.004 & 0.360 & 0.070 \\
\hline 3 & Pu35-37 & $\mathrm{ccc}$ & measured & -1.6126 & -2.0798 & -2.4333 & -0.6118 & -1.2857 & 0.024 & 0.008 & 0.004 & 0.244 & 0.052 \\
\hline 3 & Pu35-38 & $\mathrm{ccc}$ & measured & -1.6132 & -2.0763 & -2.4447 & -0.6704 & -1.2679 & 0.024 & 0.008 & 0.004 & 0.214 & 0.054 \\
\hline 3 & Pu35-39 & $\mathrm{ccc}$ & measured & -1.6132 & -2.0878 & -2.4539 & -0.8807 & -1.2338 & 0.024 & 0.008 & 0.004 & 0.132 & 0.058 \\
\hline 3 & $\mathrm{Pu} 35-40$ & $\mathrm{ccc}$ & measured & -1.6151 & -2.0794 & -2.4352 & -1.0822 & -1.2690 & 0.024 & 0.008 & 0.004 & 0.083 & 0.054 \\
\hline 3 & Pu35-41 & $\mathrm{ccc}$ & measured & -1.4904 & -1.9544 & -2.4390 & -0.9575 & -1.2372 & 0.032 & 0.011 & 0.004 & 0.110 & 0.058 \\
\hline 3 & Pu35-42 & $\mathrm{ccc}$ & measured & -1.6094 & -2.0856 & -2.4465 & -0.7921 & -1.1717 & 0.025 & 0.008 & 0.004 & 0.161 & 0.067 \\
\hline 3 & Pu35-43 & $\mathrm{ccc}$ & measured & -1.4589 & -1.9233 & -2.4447 & -0.1069 & -1.3782 & 0.035 & 0.012 & 0.004 & 0.782 & 0.042 \\
\hline 3 & Pu35-44 & $\mathrm{ccc}$ & measured & -1.6100 & -2.0835 & -2.4447 & -0.6081 & -1.3446 & 0.025 & 0.008 & 0.004 & 0.247 & 0.045 \\
\hline 3 & Pu35-45 & $\mathrm{ccc}$ & measured & -1.6195 & -2.0768 & -2.4371 & -0.8120 & -1.4724 & 0.024 & 0.008 & 0.004 & 0.154 & 0.034 \\
\hline
\end{tabular}


WSRC-STI-2007-00477

Revision 0

Table 3-4. Normalized PCTs by Glass ID and compositional view (continued)

\begin{tabular}{|c|c|c|c|c|c|c|c|c|c|c|c|c|c|}
\hline Set & Glass ID & Heat Treatment & Composition & \begin{tabular}{|c|}
$\log \mathrm{NL}$ \\
{$[\mathrm{B}(\mathrm{g} / \mathrm{L})]$} \\
\end{tabular} & $\begin{array}{c}\log \mathrm{NL} \\
{[\mathrm{Gd}(\mathrm{g} / \mathrm{L})]}\end{array}$ & $\begin{array}{c}\log \mathrm{NL} \\
{[\mathrm{Hf}(\mathrm{g} / \mathrm{L})]}\end{array}$ & $\begin{array}{c}\log \mathrm{NL} \\
{[\mathrm{Na}(\mathrm{g} / \mathrm{L})]}\end{array}$ & \begin{tabular}{|c|}
$\log \mathrm{NL}$ \\
{$[\mathrm{Si}(\mathrm{g} / \mathrm{L})]$}
\end{tabular} & \begin{tabular}{|c|}
$\mathrm{NL}$ \\
$\mathrm{B}(\mathrm{g} / \mathrm{L})$ \\
\end{tabular} & \begin{tabular}{|c|}
$\mathrm{NL}$ \\
$\mathrm{Gd}(\mathrm{g} / \mathrm{L})$ \\
\end{tabular} & \begin{tabular}{|c|}
$\mathrm{NL}$ \\
$\mathrm{Hf}(\mathrm{g} / \mathrm{L})$ \\
\end{tabular} & $\begin{array}{c}\mathrm{NL} \\
\mathrm{Na}(\mathrm{g} / \mathrm{L}) \\
\end{array}$ & $\begin{array}{c}\mathrm{NL} \\
\mathrm{Si}(\mathrm{g} / \mathrm{L}) \\
\end{array}$ \\
\hline 3 & $\begin{array}{l}\text { Pu35-46 } \\
\end{array}$ & $\mathrm{ccc}$ & measured & \begin{tabular}{|l|}
-1.6300 \\
\end{tabular} & -2.0983 & -2.4502 & \begin{tabular}{|l|}
-1.0724 \\
\end{tabular} & -1.3078 & 0.023 & 0.008 & \begin{tabular}{|l|}
0.004 \\
\end{tabular} & 0.085 & 0.049 \\
\hline 3 & Pu35-47 & $\mathrm{ccc}$ & measured & -1.6282 & -2.0878 & -2.4502 & -0.8963 & -1.3595 & 0.024 & 0.008 & 0.004 & 0.127 & 0.044 \\
\hline 3 & Pu35-48 & $\mathrm{ccc}$ & measured & -1.6312 & -2.0899 & -2.4409 & -1.2891 & -1.3665 & 0.023 & 0.008 & 0.004 & 0.051 & 0.043 \\
\hline 3 & Pu35-49 & $\mathrm{ccc}$ & measured & -1.6300 & -2.0941 & -2.4409 & -1.2726 & -1.2955 & 0.023 & 0.008 & 0.004 & 0.053 & 0.051 \\
\hline 3 & Pu35-50 & $\mathrm{ccc}$ & measured & -1.6337 & -2.0920 & -2.4390 & -0.6251 & -1.2565 & 0.023 & 0.008 & 0.004 & 0.237 & 0.055 \\
\hline 3 & Pu35-51 & $\mathrm{ccc}$ & measured & -1.6325 & -2.0941 & -2.4371 & -0.9770 & -1.3373 & 0.023 & 0.008 & 0.004 & 0.105 & 0.046 \\
\hline 3 & Pu35-52 & $\mathrm{ccc}$ & measured & -1.5309 & -1.9917 & -2.4136 & -1.3927 & -1.2597 & 0.029 & 0.010 & 0.004 & 0.040 & 0.055 \\
\hline 3 & Pu35-53 & $\mathrm{ccc}$ & measured & -1.5247 & -1.9840 & -2.4176 & -0.4279 & -1.2424 & 0.030 & 0.010 & 0.004 & 0.373 & 0.057 \\
\hline 3 & Pu35-54 & $\mathrm{ccc}$ & measured & -1.6349 & -2.0962 & -2.4216 & -0.5350 & -1.1993 & 0.023 & 0.008 & 0.004 & 0.292 & 0.063 \\
\hline 3 & Pu35-55 & $\mathrm{ccc}$ & measured & -1.6444 & -2.0983 & -2.4333 & -1.0312 & -1.2742 & 0.023 & 0.008 & 0.004 & 0.093 & 0.053 \\
\hline 1 & Pu04-01 & $\mathrm{ccc}$ & measured bc & -1.6353 & -2.1024 & -2.4701 & -0.1811 & -1.5731 & 0.023 & 0.008 & 0.003 & 0.659 & 0.027 \\
\hline 1 & Pu04-02 & ccc & measured bc & -1.6365 & -2.0983 & -2.4754 & -0.2383 & -1.9664 & 0.023 & 0.008 & 0.003 & 0.578 & 0.011 \\
\hline 1 & \begin{tabular}{|l|}
$\mathrm{Pu} 04-03$ \\
\end{tabular} & $\mathrm{ccc}$ & measured bc & -1.6299 & -2.1024 & -2.4840 & -0.4328 & -1.9050 & 0.023 & 0.008 & 0.003 & 0.369 & 0.012 \\
\hline 1 & Pu04-04 & $\mathrm{ccc}$ & measured bc & -1.6376 & -2.1106 & -2.4719 & -0.0685 & -1.9431 & 0.023 & 0.008 & 0.003 & 0.854 & 0.011 \\
\hline 1 & Pu04-05 & $\mathrm{ccc}$ & measured bc & -1.6376 & -2.1086 & -2.4975 & -0.6391 & -2.0046 & 0.023 & 0.008 & 0.003 & 0.230 & 0.010 \\
\hline 1 & \begin{tabular}{|l} 
Pu35-01 \\
\end{tabular} & $\mathrm{ccc}$ & measured bc & -1.6147 & -2.0835 & -2.4428 & -0.6997 & -1.5172 & 0.024 & 0.008 & 0.004 & 0.200 & 0.030 \\
\hline 1 & \begin{tabular}{|l|} 
Pu35-02 \\
\end{tabular} & $\mathrm{ccc}$ & measured bc & -1.6341 & -2.0920 & -2.4428 & -0.5263 & -1.2486 & 0.023 & 0.008 & 0.004 & 0.298 & 0.056 \\
\hline 1 & Pu35-03 & $\mathrm{ccc}$ & measured bc & -1.4041 & -1.8531 & -2.4333 & -0.3769 & -1.0580 & 0.039 & 0.014 & 0.004 & 0.420 & 0.088 \\
\hline 1 & Pu35-04 & ccc & measured bc & -1.5183 & -1.9804 & -2.4465 & -0.4876 & -1.2894 & 0.030 & 0.010 & 0.004 & 0.325 & 0.051 \\
\hline 1 & \begin{tabular}{|l|} 
Pu35-05 \\
\end{tabular} & $\mathrm{ccc}$ & measured bc & -1.6233 & -2.0822 & -2.4390 & -0.4960 & -1.1792 & 0.024 & 0.008 & 0.004 & 0.319 & 0.066 \\
\hline 1 & Pu35-06 & $\mathrm{ccc}$ & measured bc & -1.6232 & -2.0835 & -2.4390 & -0.7416 & -1.3301 & 0.024 & 0.008 & 0.004 & 0.181 & 0.047 \\
\hline 1 & Pu35-07 & $\mathrm{ccc}$ & measured bc & -1.6238 & -2.0856 & -2.4539 & 0.0116 & -1.2861 & 0.024 & 0.008 & 0.004 & 1.027 & 0.052 \\
\hline 1 & Pu35-08 & $\mathrm{ccc}$ & measured bc & -1.5169 & -1.9755 & -2.4352 & -0.5945 & -1.2586 & 0.030 & 0.011 & 0.004 & 0.254 & 0.055 \\
\hline 1 & \begin{tabular}{|l|} 
Pu35-09 \\
\end{tabular} & $\mathrm{ccc}$ & measured bc & -1.4692 & -1.9245 & -2.4333 & -0.3980 & -1.0588 & 0.034 & 0.012 & 0.004 & 0.400 & 0.087 \\
\hline 1 & Pu35-10 & $\mathrm{ccc}$ & measured bc & -1.6289 & -2.0856 & -2.4352 & -0.3752 & -1.3413 & 0.024 & 0.008 & 0.004 & 0.422 & 0.046 \\
\hline 1 & Pu35-11 & $\mathrm{ccc}$ & measured bc & -1.5071 & -1.9604 & -2.4521 & -0.6460 & -1.2844 & 0.031 & 0.011 & 0.004 & 0.226 & 0.052 \\
\hline 1 & Pu35-12 & $\mathrm{ccc}$ & measured bc & -1.6364 & -2.0856 & -2.4521 & 0.0825 & -1.2861 & 0.023 & 0.008 & 0.004 & 1.209 & 0.052 \\
\hline 1 & Pu35-13 & $\mathrm{ccc}$ & measured bc & -1.5235 & -1.9853 & -2.4333 & -0.4333 & -1.1899 & 0.030 & 0.010 & 0.004 & 0.369 & 0.065 \\
\hline 1 & Pu35-14 & $\mathrm{ccc}$ & measured bc & -1.6181 & -2.0878 & -2.4484 & -1.1033 & -1.3247 & 0.024 & 0.008 & 0.004 & 0.079 & 0.047 \\
\hline 1 & Pu35-15 & $\mathrm{ccc}$ & measured bc & -1.6194 & -2.0899 & -2.4484 & -0.0212 & -1.2738 & 0.024 & 0.008 & 0.004 & 0.952 & 0.053 \\
\hline 2 & \begin{tabular}{|l|} 
Pu35-16 \\
\end{tabular} & $\mathrm{ccc}$ & measured bc & -1.6237 & -2.0941 & -2.4539 & -1.4735 & -1.6053 & 0.024 & 0.008 & 0.004 & 0.034 & 0.025 \\
\hline 2 & Pu35-17 & ccc & measured bc & -1.6255 & -2.0920 & -2.4502 & -1.2628 & -1.2504 & 0.024 & 0.008 & 0.004 & 0.055 & 0.056 \\
\hline 2 & Pu35-18 & $\mathrm{ccc}$ & measured bc & -1.4798 & -1.9472 & -2.4521 & -0.9636 & -1.0742 & 0.033 & 0.011 & 0.004 & 0.109 & 0.084 \\
\hline 2 & \begin{tabular}{|l} 
Pu35-19 \\
\end{tabular} & $\mathrm{ccc}$ & measured bc & -1.6194 & -2.0920 & -2.4539 & -1.7900 & -1.3817 & 0.024 & 0.008 & 0.004 & 0.016 & 0.042 \\
\hline 2 & \begin{tabular}{|l} 
Pu35-20 \\
\end{tabular} & $\mathrm{ccc}$ & measured bc & -1.6169 & -2.0962 & -2.4576 & -0.3296 & -1.2215 & 0.024 & 0.008 & 0.003 & 0.468 & 0.060 \\
\hline 2 & Pu35-21 & $\mathrm{ccc}$ & measured bc & -1.6156 & -2.0920 & -2.4428 & -0.6325 & -1.3129 & 0.024 & 0.008 & 0.004 & 0.233 & 0.049 \\
\hline 2 & Pu35-22 & $\mathrm{ccc}$ & measured bc & -1.6218 & -2.0983 & -2.4521 & -1.0123 & -1.2444 & 0.024 & 0.008 & 0.004 & 0.097 & 0.057 \\
\hline 2 & \begin{tabular}{|l|} 
Pu35-23 \\
\end{tabular} & $\mathrm{ccc}$ & measured bc & -1.6237 & -2.0920 & -2.4539 & -0.7137 & -1.3259 & 0.024 & 0.008 & 0.004 & 0.193 & 0.047 \\
\hline 2 & \begin{tabular}{|l} 
Pu35-24 \\
\end{tabular} & $\mathrm{ccc}$ & measured bc & -1.6262 & -2.0899 & -2.4484 & -1.6780 & -1.3323 & 0.024 & 0.008 & 0.004 & 0.021 & 0.047 \\
\hline 2 & Pu35-25 & $\mathrm{ccc}$ & measured bc & -1.6169 & -2.0899 & -2.3048 & -0.4799 & -1.2452 & 0.024 & 0.008 & 0.005 & 0.331 & 0.057 \\
\hline 2 & Pu35-26 & $\mathrm{ccc}$ & measured bc & -1.6181 & -2.0835 & -2.4447 & -1.0122 & -1.4477 & 0.024 & 0.008 & 0.004 & 0.097 & 0.036 \\
\hline 2 & Pu35-27 & $\mathrm{ccc}$ & measured bc & -1.6163 & -2.0816 & -2.4352 & -1.6043 & -1.6355 & 0.024 & 0.008 & 0.004 & 0.025 & 0.023 \\
\hline 2 & Pu35-28 & $\mathrm{ccc}$ & measured bc & -1.6243 & -2.0856 & -2.4428 & -1.1407 & -1.3533 & 0.024 & 0.008 & 0.004 & 0.072 & 0.044 \\
\hline 2 & \begin{tabular}{|l|} 
Pu35-29 \\
\end{tabular} & ccc & measured bc & -1.6206 & -2.0813 & -2.4371 & -1.1585 & -1.2748 & 0.024 & 0.008 & 0.004 & 0.069 & 0.053 \\
\hline 2 & \begin{tabular}{|l|} 
Pu35-30 \\
\end{tabular} & $\mathrm{ccc}$ & measured bc & -1.6100 & -2.0878 & -2.4465 & -1.4710 & -1.2062 & 0.025 & 0.008 & 0.004 & 0.034 & 0.062 \\
\hline 2 & \begin{tabular}{|l|} 
Pu35-31 \\
\end{tabular} & $\mathrm{ccc}$ & measured bc & -1.6087 & -2.0856 & -2.4447 & -0.5234 & -1.2425 & 0.025 & 0.008 & 0.004 & 0.300 & 0.057 \\
\hline 2 & \begin{tabular}{|l|} 
Pu35-32 \\
\end{tabular} & $\mathrm{ccc}$ & measured bc & -1.6163 & -2.0878 & -2.4539 & $\begin{array}{l}-1.7709 \\
\end{array}$ & -1.5428 & 0.024 & 0.008 & 0.004 & 0.017 & 0.029 \\
\hline 2 & Pu35-33 & $\mathrm{ccc}$ & measured bc & -1.6049 & -2.0733 & -2.4428 & -0.6862 & -1.5288 & 0.025 & 0.008 & 0.004 & 0.206 & 0.030 \\
\hline 2 & Pu35-34 & $\mathrm{ccc}$ & measured bc & -1.6061 & -2.0878 & -2.4428 & -0.4082 & -1.2897 & 0.025 & 0.008 & 0.004 & 0.391 & 0.051 \\
\hline 2 & Pu35-35 & $\mathrm{ccc}$ & measured bc & -1.6194 & -2.0835 & -2.2576 & -1.1433 & -1.4616 & 0.024 & 0.008 & 0.006 & 0.072 & 0.035 \\
\hline 3 & Pu35-36 & $\mathrm{ccc}$ & measured bc & -1.4699 & -1.9307 & -2.4558 & -0.4063 & -1.1604 & 0.034 & 0.012 & 0.004 & 0.392 & 0.069 \\
\hline 3 & Pu35-37 & $\mathrm{ccc}$ & measured bc & -1.6251 & -2.0798 & -2.4333 & -0.5748 & -1.2895 & 0.024 & 0.008 & 0.004 & 0.266 & 0.051 \\
\hline 3 & Pu35-38 & $\mathrm{ccc}$ & measured bc & -1.6257 & -2.0763 & -2.4447 & -0.6333 & -1.2717 & 0.024 & 0.008 & 0.004 & 0.233 & 0.053 \\
\hline 3 & \begin{tabular}{|l|} 
Pu35-39 \\
\end{tabular} & $\mathrm{ccc}$ & measured bc & -1.6257 & -2.0878 & -2.4539 & -0.8437 & -1.2377 & 0.024 & 0.008 & 0.004 & 0.143 & 0.058 \\
\hline 3 & Pu35-40 & $\mathrm{ccc}$ & measured bc & -1.6276 & -2.0794 & -2.4352 & -1.0452 & -1.2728 & 0.024 & 0.008 & 0.004 & 0.090 & 0.053 \\
\hline 3 & Pu35-41 & $\mathrm{ccc}$ & measured bc & -1.5029 & -1.9544 & -2.4390 & -0.9205 & -1.2410 & 0.031 & 0.011 & 0.004 & 0.120 & 0.057 \\
\hline
\end{tabular}


WSRC-STI-2007-00477

Revision 0

Table 3-4. Normalized PCTs by Glass ID and compositional view (continued)

\begin{tabular}{|c|c|c|c|c|c|c|c|c|c|c|c|c|c|}
\hline Set & Glass ID & Heat Treatment & Composition & \begin{tabular}{|c|}
$\log \mathrm{NL}$ \\
{$[\mathrm{B}(\mathrm{g} / \mathrm{L})]$} \\
\end{tabular} & $\begin{array}{c}\log \mathrm{NL} \\
{[\mathrm{Gd}(\mathrm{g} / \mathrm{L})]}\end{array}$ & $\begin{array}{c}\log \mathrm{NL} \\
{[\mathrm{Hf}(\mathrm{g} / \mathrm{L})]}\end{array}$ & $\begin{array}{c}\log \mathrm{NL} \\
{[\mathrm{Na}(\mathrm{g} / \mathrm{L})]}\end{array}$ & \begin{tabular}{|c|}
$\log \mathrm{NL}$ \\
{$[\mathrm{Si}(\mathrm{g} / \mathrm{L})]$}
\end{tabular} & \begin{tabular}{|c|}
$\mathrm{NL}$ \\
$\mathrm{B}(\mathrm{g} / \mathrm{L})$ \\
\end{tabular} & \begin{tabular}{|c|}
$\mathrm{NL}$ \\
$\mathrm{Gd}(\mathrm{g} / \mathrm{L})$ \\
\end{tabular} & \begin{tabular}{|c|}
$\mathrm{NL}$ \\
$\mathrm{Hf}(\mathrm{g} / \mathrm{L})$ \\
\end{tabular} & $\begin{array}{c}\mathrm{NL} \\
\mathrm{Na}(\mathrm{g} / \mathrm{L}) \\
\end{array}$ & $\begin{array}{c}\mathrm{NL} \\
\mathrm{Si}(\mathrm{g} / \mathrm{L}) \\
\end{array}$ \\
\hline 3 & $\begin{array}{l}\mathrm{Pu} 35-42 \\
\end{array}$ & $\mathrm{ccc}$ & measured bc & \begin{tabular}{|l|}
-1.6219 \\
\end{tabular} & -2.0856 & -2.4465 & -0.7551 & -1.1756 & 0.024 & 0.008 & \begin{tabular}{|l|}
0.004 \\
\end{tabular} & 0.176 & 0.067 \\
\hline 3 & Pu35-43 & $\mathrm{ccc}$ & measured bc & -1.4714 & -1.9233 & -2.4447 & -0.0699 & -1.3820 & 0.034 & 0.012 & 0.004 & 0.851 & 0.041 \\
\hline 3 & Pu35-44 & $\mathrm{ccc}$ & measured bc & -1.6225 & -2.0835 & -2.4447 & -0.5711 & -1.3485 & 0.024 & 0.008 & 0.004 & 0.268 & 0.045 \\
\hline 3 & Pu35-45 & $\mathrm{ccc}$ & measured bc & -1.6320 & -2.0768 & -2.4371 & -0.7750 & -1.4762 & 0.023 & 0.008 & 0.004 & 0.168 & 0.033 \\
\hline 3 & Pu35-46 & $\mathrm{ccc}$ & measured bc & -1.6268 & -2.0983 & -2.4502 & -1.0467 & -1.3013 & 0.024 & 0.008 & 0.004 & 0.090 & 0.050 \\
\hline 3 & \begin{tabular}{|l|} 
Pu35-47 \\
\end{tabular} & $\mathrm{ccc}$ & measured bc & -1.6249 & -2.0878 & -2.4502 & -0.8705 & -1.3529 & 0.024 & 0.008 & 0.004 & 0.135 & 0.044 \\
\hline 3 & Pu35-48 & $\mathrm{ccc}$ & measured bc & -1.6280 & -2.0899 & -2.4409 & -1.2633 & -1.3599 & 0.024 & 0.008 & 0.004 & 0.055 & 0.044 \\
\hline 3 & Pu35-49 & $\mathrm{ccc}$ & measured bc & -1.6268 & -2.0941 & -2.4409 & -1.2469 & -1.2889 & 0.024 & 0.008 & 0.004 & 0.057 & 0.051 \\
\hline 3 & Pu35-50 & $\mathrm{ccc}$ & measured bc & -1.6304 & -2.0920 & -2.4390 & -0.5994 & -1.2499 & 0.023 & 0.008 & 0.004 & 0.252 & 0.056 \\
\hline 3 & Pu35-51 & ccc & measured bc & -1.6292 & -2.0941 & -2.4371 & -0.9513 & -1.3308 & 0.023 & 0.008 & 0.004 & 0.112 & 0.047 \\
\hline 3 & Pu35-52 & $\mathrm{ccc}$ & measured bc & -1.5277 & -1.9917 & -2.4136 & -1.3669 & -1.2531 & 0.030 & 0.010 & 0.004 & 0.043 & 0.056 \\
\hline 3 & Pu35-53 & ccc & measured bc & -1.5215 & -1.9840 & -2.4176 & -0.4021 & -1.2358 & 0.030 & 0.010 & 0.004 & 0.396 & 0.058 \\
\hline 3 & \begin{tabular}{|l|} 
Pu35-54 \\
\end{tabular} & $\mathrm{ccc}$ & measured bc & -1.6316 & -2.0962 & -2.4216 & -0.5093 & -1.1927 & 0.023 & 0.008 & 0.004 & 0.310 & 0.064 \\
\hline 3 & Pu35-55 & $\mathrm{ccc}$ & measured bc & -1.6412 & -2.0983 & -2.4333 & -1.0054 & -1.2677 & 0.023 & 0.008 & 0.004 & 0.099 & 0.054 \\
\hline 1 & Pu04-01 & $\mathrm{ccc}$ & targeted & -1.6198 & -2.0823 & -2.5975 & -0.1456 & -1.5443 & 0.024 & 0.008 & 0.003 & 0.715 & 0.029 \\
\hline 1 & \begin{tabular}{|l} 
Pu04-02 \\
\end{tabular} & $\mathrm{ccc}$ & targeted & \begin{tabular}{|l}
-1.6198 \\
\end{tabular} & -2.0823 & -2.5971 & -0.1651 & -1.9353 & 0.024 & 0.008 & 0.003 & 0.684 & 0.012 \\
\hline 1 & \begin{tabular}{|l|} 
Pu04-03 \\
\end{tabular} & $\mathrm{ccc}$ & targeted & \begin{tabular}{|l|}
-1.6198 \\
\end{tabular} & -2.0823 & -2.5968 & -0.3660 & -1.8782 & 0.024 & 0.008 & 0.003 & 0.430 & 0.013 \\
\hline 1 & Pu04-04 & $\mathrm{ccc}$ & targeted & -1.6198 & -2.0823 & -2.5962 & 0.0897 & -1.9133 & 0.024 & 0.008 & 0.003 & 1.229 & 0.012 \\
\hline 1 & Pu04-05 & ccc & targeted & \begin{tabular}{|l|}
-1.6198 \\
\end{tabular} & -2.0823 & -2.5977 & -0.5981 & -1.9748 & 0.024 & 0.008 & 0.003 & 0.252 & 0.011 \\
\hline 1 & \begin{tabular}{|l|} 
Pu35-01 \\
\end{tabular} & $\mathrm{ccc}$ & targeted & -1.6198 & -2.0823 & -2.4806 & -0.7154 & -1.5026 & 0.024 & 0.008 & 0.003 & 0.193 & 0.031 \\
\hline 1 & Pu35-02 & $\mathrm{ccc}$ & targeted & \begin{tabular}{|l|}
-1.6198 \\
\end{tabular} & -2.0823 & -2.4824 & -0.5115 & -1.2428 & 0.024 & 0.008 & 0.003 & 0.308 & 0.057 \\
\hline 1 & Pu35-03 & $\mathrm{ccc}$ & targeted & -1.3915 & -1.8541 & -2.4791 & -0.4171 & -1.0618 & 0.041 & 0.014 & 0.003 & 0.383 & 0.087 \\
\hline 1 & Pu35-04 & $\mathrm{ccc}$ & targeted & \begin{tabular}{|l|}
-1.5124 \\
\end{tabular} & -1.9749 & -2.4847 & -0.4677 & -1.2803 & 0.031 & 0.011 & 0.003 & 0.341 & 0.052 \\
\hline 1 & \begin{tabular}{|l|} 
Pu35-05 \\
\end{tabular} & $\mathrm{ccc}$ & targeted & \begin{tabular}{|l|}
-1.6198 \\
\end{tabular} & -2.0823 & -2.4803 & -0.4963 & -1.1779 & 0.024 & 0.008 & 0.003 & 0.319 & 0.066 \\
\hline 1 & Pu35-06 & $\mathrm{ccc}$ & targeted & -1.6198 & -2.0823 & -2.4809 & -0.7869 & -1.3218 & 0.024 & 0.008 & 0.003 & 0.163 & 0.048 \\
\hline 1 & Pu35-07 & $\mathrm{ccc}$ & targeted & \begin{tabular}{|l|}
-1.6198 \\
\end{tabular} & -2.0823 & -2.4835 & -0.0091 & -1.2745 & 0.024 & 0.008 & 0.003 & 0.979 & 0.053 \\
\hline 1 & Pu35-08 & $\mathrm{ccc}$ & targeted & -1.5096 & -1.9722 & -2.4832 & -0.5894 & -1.2516 & 0.031 & 0.011 & 0.003 & 0.257 & 0.056 \\
\hline 1 & Pu35-09 & $\mathrm{ccc}$ & targeted & $\begin{array}{l}-1.4607 \\
\end{array}$ & -1.9233 & -2.4824 & -0.4366 & -1.0449 & 0.035 & 0.012 & 0.003 & 0.366 & 0.090 \\
\hline 1 & Pu35-10 & $\mathrm{ccc}$ & targeted & \begin{tabular}{|l|}
-1.6198 \\
\end{tabular} & -2.0823 & -2.4818 & -0.4073 & -1.3279 & 0.024 & 0.008 & 0.003 & 0.391 & 0.047 \\
\hline 1 & Pu35-11 & $\mathrm{ccc}$ & targeted & \begin{tabular}{|l|}
-1.4967 \\
\end{tabular} & -1.9593 & -2.4809 & -0.6811 & -1.2700 & 0.032 & 0.011 & 0.003 & 0.208 & 0.054 \\
\hline 1 & \begin{tabular}{|l|} 
Pu35-12 \\
\end{tabular} & $\mathrm{ccc}$ & targeted & \begin{tabular}{|l|}
-1.6198 \\
\end{tabular} & -2.0823 & -2.4835 & 0.0413 & -1.2714 & 0.024 & 0.008 & 0.003 & 1.100 & 0.054 \\
\hline 1 & Pu35-13 & $\mathrm{ccc}$ & targeted & \begin{tabular}{|l|}
-1.5194 \\
\end{tabular} & -1.9820 & -2.4835 & -0.4888 & -1.1778 & 0.030 & 0.010 & 0.003 & 0.325 & 0.066 \\
\hline 1 & Pu35-14 & $\mathrm{ccc}$ & targeted & \begin{tabular}{|l|}
-1.6198 \\
\end{tabular} & -2.0823 & -2.4818 & -1.1555 & -1.3098 & 0.024 & 0.008 & 0.003 & 0.070 & 0.049 \\
\hline 1 & Pu35-15 & $\mathrm{ccc}$ & targeted & -1.6198 & -2.0823 & -2.4847 & -0.0747 & -1.2557 & 0.024 & 0.008 & 0.003 & 0.842 & 0.056 \\
\hline 2 & \begin{tabular}{|l} 
Pu35-16 \\
\end{tabular} & $\mathrm{ccc}$ & targeted & \begin{tabular}{|l|}
-1.6198 \\
\end{tabular} & -2.0823 & -2.4803 & -1.5612 & -1.5983 & 0.024 & 0.008 & 0.003 & 0.027 & 0.025 \\
\hline 2 & Pu35-17 & $\mathrm{ccc}$ & targeted & $\begin{array}{l}-1.6198 \\
\end{array}$ & -2.0823 & -2.4832 & -1.3342 & -1.2388 & 0.024 & 0.008 & 0.003 & 0.046 & 0.058 \\
\hline 2 & Pu35-18 & $\mathrm{ccc}$ & targeted & \begin{tabular}{|l|}
-1.4771 \\
\end{tabular} & -1.9396 & -2.4812 & -1.0277 & -1.0673 & 0.033 & 0.011 & 0.003 & 0.094 & 0.086 \\
\hline 2 & \begin{tabular}{|l|} 
Pu35-19 \\
\end{tabular} & $\mathrm{ccc}$ & targeted & \begin{tabular}{|l|}
-1.6198 \\
\end{tabular} & -2.0823 & -2.4815 & -1.8416 & -1.3771 & 0.024 & 0.008 & 0.003 & 0.014 & 0.042 \\
\hline 2 & \begin{tabular}{|l} 
Pu35-20 \\
\end{tabular} & $\mathrm{ccc}$ & targeted & \begin{tabular}{|l}
-1.6198 \\
\end{tabular} & -2.0823 & -2.4832 & -0.3577 & -1.2090 & 0.024 & 0.008 & 0.003 & 0.439 & 0.062 \\
\hline 2 & \begin{tabular}{|l|} 
Pu35-21 \\
\end{tabular} & $\mathrm{ccc}$ & targeted & -1.6198 & -2.0823 & -2.4829 & -0.6665 & -1.3047 & 0.024 & 0.008 & 0.003 & 0.216 & 0.050 \\
\hline 2 & $\begin{array}{l}\text { Pu35-22 } \\
\end{array}$ & $\mathrm{ccc}$ & targeted & \begin{tabular}{|l}
-1.6198 \\
\end{tabular} & -2.0823 & -2.4841 & -1.0484 & -1.2316 & 0.024 & 0.008 & 0.003 & 0.089 & 0.059 \\
\hline 2 & Pu35-23 & $\mathrm{ccc}$ & targeted & \begin{tabular}{|l}
-1.6198 \\
\end{tabular} & -2.0823 & -2.4812 & -0.7702 & -1.3208 & 0.024 & 0.008 & 0.003 & 0.170 & 0.048 \\
\hline 2 & Pu35-24 & $\mathrm{ccc}$ & targeted & -1.6198 & -2.0823 & -2.4818 & -1.7129 & -1.3238 & 0.024 & 0.008 & 0.003 & 0.019 & 0.047 \\
\hline 2 & Pu35-25 & ccc & targeted & \begin{tabular}{|l|}
-1.6198 \\
\end{tabular} & -2.0823 & -2.3388 & -0.5112 & -1.1996 & 0.024 & 0.008 & 0.005 & 0.308 & 0.063 \\
\hline 2 & \begin{tabular}{|l|} 
Pu35-26 \\
\end{tabular} & $\mathrm{ccc}$ & targeted & -1.6198 & -2.0823 & -2.4809 & -1.0431 & -1.4349 & 0.024 & 0.008 & 0.003 & 0.091 & 0.037 \\
\hline 2 & Pu35-27 & $\mathrm{ccc}$ & targeted & \begin{tabular}{|l|}
-1.6198 \\
\end{tabular} & -2.0823 & -2.4829 & $\begin{array}{l}-1.6298 \\
\end{array}$ & -1.6254 & 0.024 & 0.008 & 0.003 & 0.023 & 0.024 \\
\hline 2 & \begin{tabular}{|l|} 
Pu35-28 \\
\end{tabular} & $\mathrm{ccc}$ & targeted & \begin{tabular}{|l|}
-1.6198 \\
\end{tabular} & -2.0823 & -2.4826 & -1.1673 & -1.3456 & 0.024 & 0.008 & 0.003 & 0.068 & 0.045 \\
\hline 2 & Pu35-29 & $\mathrm{ccc}$ & targeted & \begin{tabular}{|l|}
-1.6198 \\
\end{tabular} & -2.0823 & -2.4855 & -1.1847 & -1.2647 & 0.024 & 0.008 & 0.003 & 0.065 & 0.054 \\
\hline 2 & Pu35-30 & $\mathrm{ccc}$ & targeted & \begin{tabular}{|l|}
-1.6198 \\
\end{tabular} & -2.0823 & -2.4812 & -1.5115 & -1.1937 & 0.024 & 0.008 & 0.003 & 0.031 & 0.064 \\
\hline 2 & Pu35-31 & $\mathrm{ccc}$ & targeted & -1.6198 & -2.0823 & -2.4832 & -0.5228 & -1.2295 & 0.024 & 0.008 & 0.003 & 0.300 & 0.059 \\
\hline 2 & Pu35-32 & $\mathrm{ccc}$ & targeted & -1.6198 & -2.0823 & -2.4818 & -1.7883 & -1.5300 & 0.024 & 0.008 & 0.003 & 0.016 & 0.030 \\
\hline 2 & Pu35-33 & ccc & targeted & \begin{tabular}{|l|}
-1.6198 \\
\end{tabular} & -2.0823 & -2.4783 & -0.7244 & -1.4866 & 0.024 & 0.008 & 0.003 & 0.189 & 0.033 \\
\hline 2 & Pu35-34 & $\mathrm{ccc}$ & targeted & \begin{tabular}{|c|}
-1.6198 \\
\end{tabular} & -2.0823 & -2.4815 & -0.4264 & -1.2343 & 0.024 & 0.008 & 0.003 & 0.375 & 0.058 \\
\hline 2 & Pu35-35 & $\mathrm{ccc}$ & targeted & -1.6198 & -2.0823 & -2.2840 & -1.1814 & -1.4552 & 0.024 & 0.008 & 0.005 & 0.066 & 0.035 \\
\hline 3 & Pu35-36 & $\mathrm{ccc}$ & targeted & \begin{tabular}{|l|}
-1.4627 \\
\end{tabular} & -1.9252 & -2.4815 & -0.4326 & -1.1430 & 0.034 & 0.012 & 0.003 & 0.369 & 0.072 \\
\hline 3 & Pu35-37 & $\mathrm{ccc}$ & targeted & -1.6198 & -2.0823 & -2.4803 & -0.6000 & -1.2806 & 0.024 & 0.008 & 0.003 & 0.251 & 0.052 \\
\hline
\end{tabular}


Table 3-4. Normalized PCTs by Glass ID and compositional view (continued)

\begin{tabular}{|c|c|c|c|c|c|c|c|c|c|c|c|c|c|}
\hline Set & Glass ID & Heat Treatment & Composition & \begin{tabular}{|c|}
$\log \mathrm{NL}$ \\
{$[\mathrm{B}(\mathrm{g} / \mathrm{L})]$} \\
\end{tabular} & $\begin{array}{c}\log \mathrm{NL} \\
{[\mathrm{Gd}(\mathrm{g} / \mathrm{L})]}\end{array}$ & $\begin{array}{c}\log \mathrm{NL} \\
{[\mathrm{Hf}(\mathrm{g} / \mathrm{L})]}\end{array}$ & $\begin{array}{c}\log \mathrm{NL} \\
{[\mathrm{Na}(\mathrm{g} / \mathrm{L})]}\end{array}$ & \begin{tabular}{|c|}
$\log \mathrm{NL}$ \\
{$[\mathrm{Si}(\mathrm{g} / \mathrm{L})]$}
\end{tabular} & \begin{tabular}{|c|}
$\mathrm{NL}$ \\
$\mathrm{B}(\mathrm{g} / \mathrm{L})$ \\
\end{tabular} & \begin{tabular}{|c|}
$\mathrm{NL}$ \\
$\mathrm{Gd}(\mathrm{g} / \mathrm{L})$ \\
\end{tabular} & \begin{tabular}{|c|}
$\mathrm{NL}$ \\
$\mathrm{Hf}(\mathrm{g} / \mathrm{L})$ \\
\end{tabular} & $\begin{array}{c}\mathrm{NL} \\
\mathrm{Na}(\mathrm{g} / \mathrm{L}) \\
\end{array}$ & $\begin{array}{c}\mathrm{NL} \\
\mathrm{Si}(\mathrm{g} / \mathrm{L}) \\
\end{array}$ \\
\hline 3 & $\begin{array}{l}\text { Pu35-38 } \\
\end{array}$ & $\mathrm{ccc}$ & targeted & \begin{tabular}{|l|}
-1.6198 \\
\end{tabular} & -2.0823 & -2.4826 & \begin{tabular}{|c|}
-0.6709 \\
\end{tabular} & -1.2636 & 0.024 & 0.008 & \begin{tabular}{|l|}
0.003 \\
\end{tabular} & 0.213 & 0.055 \\
\hline 3 & Pu35-39 & $\mathrm{ccc}$ & targeted & -1.6198 & -2.0823 & -2.4824 & -0.8633 & -1.2197 & 0.024 & 0.008 & 0.003 & 0.137 & 0.060 \\
\hline 3 & Pu35-40 & $\mathrm{ccc}$ & targeted & -1.6198 & -2.0823 & -2.4806 & -1.0792 & -1.2631 & 0.024 & 0.008 & 0.003 & 0.083 & 0.055 \\
\hline 3 & Pu35-41 & ccc & targeted & -1.4906 & -1.9532 & -2.4826 & -0.9884 & -1.2321 & 0.032 & 0.011 & 0.003 & 0.103 & 0.059 \\
\hline 3 & Pu35-42 & $\mathrm{ccc}$ & targeted & -1.6198 & -2.0823 & -2.4812 & -0.8024 & -1.1603 & 0.024 & 0.008 & 0.003 & 0.158 & 0.069 \\
\hline 3 & \begin{tabular}{|l|} 
Pu35-43 \\
\end{tabular} & $\mathrm{ccc}$ & targeted & -1.4617 & -1.9243 & -2.4803 & -0.1141 & -1.3704 & 0.035 & 0.012 & 0.003 & 0.769 & 0.043 \\
\hline 3 & Pu35-44 & $\mathrm{ccc}$ & targeted & -1.6198 & -2.0823 & -2.4806 & -0.6069 & -1.3353 & 0.024 & 0.008 & 0.003 & 0.247 & 0.046 \\
\hline 3 & Pu35-45 & $\mathrm{ccc}$ & targeted & -1.6198 & -2.0823 & -2.4806 & -0.8112 & -1.4710 & 0.024 & 0.008 & 0.003 & 0.154 & 0.034 \\
\hline 3 & Pu35-46 & $\mathrm{ccc}$ & targeted & -1.6198 & -2.0823 & -2.4824 & -1.0649 & -1.2850 & 0.024 & 0.008 & 0.003 & 0.086 & 0.052 \\
\hline 3 & Pu35-47 & ccc & targeted & \begin{tabular}{|l|}
-1.6198 \\
\end{tabular} & -2.0823 & -2.4812 & -0.8892 & -1.3426 & 0.024 & 0.008 & 0.003 & 0.129 & 0.045 \\
\hline 3 & Pu35-48 & $\mathrm{ccc}$ & targeted & -1.6198 & -2.0823 & -2.4806 & -1.2788 & -1.3537 & 0.024 & 0.008 & 0.003 & 0.053 & 0.044 \\
\hline 3 & Pu35-49 & ccc & targeted & -1.6198 & -2.0823 & -2.4815 & -1.2567 & -1.2716 & 0.024 & 0.008 & 0.003 & 0.055 & 0.054 \\
\hline 3 & Pu35-50 & $\mathrm{ccc}$ & targeted & -1.6198 & -2.0823 & -2.4815 & -0.6072 & -1.2398 & 0.024 & 0.008 & 0.003 & 0.247 & 0.058 \\
\hline 3 & Pu35-51 & $\mathrm{ccc}$ & targeted & $\begin{array}{l}-1.6198 \\
\end{array}$ & -2.0823 & -2.4809 & -0.9688 & -1.3165 & 0.024 & 0.008 & 0.003 & 0.107 & 0.048 \\
\hline 3 & Pu35-52 & $\mathrm{ccc}$ & targeted & -1.5194 & -1.9820 & -2.4806 & -1.3727 & -1.2412 & 0.030 & 0.010 & 0.003 & 0.042 & 0.057 \\
\hline 3 & $\begin{array}{l}\text { Pu35-53 } \\
\end{array}$ & $\mathrm{ccc}$ & targeted & -1.5096 & -1.9722 & -2.4838 & -0.4268 & -1.2231 & 0.031 & 0.011 & 0.003 & 0.374 & 0.060 \\
\hline 3 & \begin{tabular}{|l|} 
Pu35-54 \\
\end{tabular} & $\mathrm{ccc}$ & targeted & \begin{tabular}{|l|}
-1.6198 \\
\end{tabular} & -2.0823 & -2.4826 & -0.5245 & -1.1749 & 0.024 & 0.008 & 0.003 & 0.299 & 0.067 \\
\hline 3 & Pu35-55 & $\mathrm{ccc}$ & targeted & -1.6198 & -2.0823 & -2.4812 & -1.0157 & -1.2442 & 0.024 & 0.008 & 0.003 & 0.096 & 0.057 \\
\hline 1 & ARM-1 & - & reference & -0.3146 & - & - & -0.2942 & -0.5701 & 0.485 & - & - & 0.508 & 0.269 \\
\hline 1 & EA & - & reference & 1.2650 & - & - & 1.1486 & 0.6083 & 18.406 & - & - & 14.080 & 4.058 \\
\hline 2 & ARM-1 & - & reference & -0.3348 & - & - & -0.3272 & -0.5969 & 0.463 & - & - & 0.471 & 0.253 \\
\hline 2 & EA & - & reference & 1.2316 & - & - & 1.1266 & 0.5669 & 17.046 & - & - & 13.384 & 3.689 \\
\hline 3 & ARM-1 & - & reference & -0.3525 & - & - & -0.3209 & -0.5895 & 0.444 & - & - & 0.478 & 0.257 \\
\hline 3 & EA & - & reference & 1.2479 & - & - & 1.1415 & 0.5967 & 17.696 & - & - & 13.853 & 3.951 \\
\hline 1 & \begin{tabular}{|l|} 
Pu04-01 \\
\end{tabular} & quenched & measured & -1.6433 & -2.1024 & -2.4701 & -0.2755 & -2.6166 & 0.023 & 0.008 & 0.003 & 0.530 & 0.002 \\
\hline 1 & \begin{tabular}{|l|}
$\mathrm{Pu} 04-02$ \\
\end{tabular} & quenched & measured & -1.6444 & -2.0983 & -2.4754 & -0.9291 & -3.0214 & 0.023 & 0.008 & 0.003 & 0.118 & 0.001 \\
\hline 1 & Pu04-03 & quenched & measured & -1.6379 & -2.1024 & -2.4840 & -1.2596 & -3.0172 & 0.023 & 0.008 & 0.003 & 0.055 & 0.001 \\
\hline 1 & Pu04-04 & quenched & measured & -1.6456 & -2.1106 & -2.4719 & -1.0500 & -2.9142 & 0.023 & 0.008 & 0.003 & 0.089 & 0.001 \\
\hline 1 & Pu04-05 & quenched & measured & -1.6456 & -2.1086 & -2.4975 & -1.5348 & -3.0202 & 0.023 & 0.008 & 0.003 & 0.029 & 0.001 \\
\hline 1 & Pu35-01 & quenched & measured & \begin{tabular}{|l|}
-1.4983 \\
\end{tabular} & -1.9592 & -2.4428 & -1.8761 & -3.0050 & 0.032 & 0.011 & 0.004 & 0.013 & 0.001 \\
\hline 1 & \begin{tabular}{|l|} 
Pu35-02 \\
\end{tabular} & quenched & measured & -1.6421 & -2.0920 & -2.4428 & -1.5475 & -2.1433 & 0.023 & 0.008 & 0.004 & 0.028 & 0.007 \\
\hline 1 & Pu35-03 & quenched & measured & \begin{tabular}{|l|}
-1.6403 \\
\end{tabular} & -2.0813 & -2.4333 & -2.1188 & -2.1621 & 0.023 & 0.008 & 0.004 & 0.008 & 0.007 \\
\hline 1 & \begin{tabular}{|l|} 
Pu35-04 \\
\end{tabular} & quenched & measured & -1.5195 & -1.9736 & -2.4465 & -1.7568 & -2.9996 & 0.030 & 0.011 & 0.004 & 0.018 & 0.001 \\
\hline 1 & Pu35-05 & quenched & measured & -1.6312 & -2.0822 & -2.4390 & -0.3195 & -1.4066 & 0.023 & 0.008 & 0.004 & 0.479 & 0.039 \\
\hline 1 & \begin{tabular}{|l} 
Pu35-06 \\
\end{tabular} & quenched & measured & -1.6113 & -2.0835 & -2.4390 & -1.6683 & -2.9895 & 0.024 & 0.008 & 0.004 & 0.021 & 0.001 \\
\hline 1 & Pu35-07 & quenched & measured & \begin{tabular}{|l|}
-1.6119 \\
\end{tabular} & -2.0856 & -2.4539 & -1.7531 & -2.4360 & 0.024 & 0.008 & 0.004 & 0.018 & 0.004 \\
\hline 1 & \begin{tabular}{|l|} 
Pu35-08 \\
\end{tabular} & quenched & measured & \begin{tabular}{|l}
-1.4984 \\
\end{tabular} & -1.9689 & -2.4352 & -1.5957 & -2.2966 & 0.032 & 0.011 & 0.004 & 0.025 & 0.005 \\
\hline 1 & \begin{tabular}{|l|} 
Pu35-09 \\
\end{tabular} & quenched & measured & \begin{tabular}{|l|}
-1.4334 \\
\end{tabular} & -1.9005 & -2.4333 & -1.5291 & -1.2420 & 0.037 & 0.013 & 0.004 & 0.030 & 0.057 \\
\hline 1 & Pu35-10 & quenched & measured & -1.6170 & -2.0856 & -2.4352 & -1.5775 & -2.9946 & 0.024 & 0.008 & 0.004 & 0.026 & 0.001 \\
\hline 1 & \begin{tabular}{|l|} 
Pu35-11 \\
\end{tabular} & quenched & measured & -1.6183 & -2.0835 & -2.4521 & -1.7922 & -2.9956 & 0.024 & 0.008 & 0.004 & 0.016 & 0.001 \\
\hline 1 & $\begin{array}{l}\text { Pu35-12 } \\
\end{array}$ & quenched & measured & \begin{tabular}{|l}
-1.6245 \\
\end{tabular} & -2.0856 & -2.4521 & -1.4460 & -2.9959 & 0.024 & 0.008 & 0.004 & 0.036 & 0.001 \\
\hline 1 & Pu35-13 & quenched & measured & $\begin{array}{l}-1.5101 \\
\end{array}$ & -1.9839 & -2.4333 & -1.1520 & -2.1021 & 0.031 & 0.010 & 0.004 & 0.070 & 0.008 \\
\hline 1 & Pu35-14 & quenched & measured & -1.6062 & -2.0878 & -2.4484 & -1.9657 & -2.9962 & 0.025 & 0.008 & 0.004 & 0.011 & 0.001 \\
\hline 1 & Pu35-15 & quenched & measured & -1.6075 & -2.0899 & -2.4484 & -1.8796 & -2.8892 & 0.025 & 0.008 & 0.004 & 0.013 & 0.001 \\
\hline 2 & \begin{tabular}{|l|} 
Pu35-16 \\
\end{tabular} & quenched & measured & -1.6263 & -2.0941 & -2.4539 & -1.9948 & -2.1515 & 0.024 & 0.008 & 0.004 & 0.010 & 0.007 \\
\hline 2 & \begin{tabular}{|l|} 
Pu35-17 \\
\end{tabular} & quenched & measured & $\begin{array}{l}-1.6282 \\
\end{array}$ & -2.0920 & -2.4502 & -1.9383 & -1.7594 & 0.024 & 0.008 & 0.004 & 0.012 & 0.017 \\
\hline 2 & \begin{tabular}{|l|} 
Pu35-18 \\
\end{tabular} & quenched & measured & -1.5205 & -1.9853 & -2.4521 & -1.9017 & -1.3572 & 0.030 & 0.010 & 0.004 & 0.013 & 0.044 \\
\hline 2 & Pu35-19 & quenched & measured & \begin{tabular}{|l|}
-1.6220 \\
\end{tabular} & -2.0920 & -2.4539 & -1.8331 & -2.2149 & 0.024 & 0.008 & 0.004 & 0.015 & 0.006 \\
\hline 2 & Pu35-20 & quenched & measured & \begin{tabular}{|l|}
-1.6195 \\
\end{tabular} & -2.0962 & -2.4576 & -1.6635 & -1.6366 & 0.024 & 0.008 & 0.003 & 0.022 & 0.023 \\
\hline 2 & Pu35-21 & quenched & measured & -1.6183 & -2.0920 & -2.4428 & -1.7295 & -2.2770 & 0.024 & 0.008 & 0.004 & 0.019 & 0.005 \\
\hline 2 & Pu35-22 & quenched & measured & -1.6245 & -2.0983 & -2.4521 & -1.8258 & -2.1771 & 0.024 & 0.008 & 0.004 & 0.015 & 0.007 \\
\hline 2 & Pu35-23 & quenched & measured & -1.6263 & -2.0920 & -2.4539 & -1.9046 & -2.2643 & 0.024 & 0.008 & 0.004 & 0.012 & 0.005 \\
\hline 2 & Pu35-24 & quenched & measured & -1.6288 & -2.0899 & -2.4484 & -1.7211 & -2.2611 & 0.024 & 0.008 & 0.004 & 0.019 & 0.005 \\
\hline 2 & Pu35-25 & quenched & measured & -1.6195 & -2.0899 & -2.4484 & -1.6427 & -1.5638 & 0.024 & 0.008 & 0.004 & 0.023 & 0.027 \\
\hline 2 & Pu35-26 & quenched & measured & -1.6214 & -2.0835 & -2.4447 & -1.0859 & -2.3150 & 0.024 & 0.008 & 0.004 & 0.082 & 0.005 \\
\hline 2 & Pu35-27 & quenched & measured & -1.6195 & -2.0816 & -2.4352 & -1.7604 & -2.1915 & 0.024 & 0.008 & 0.004 & 0.017 & 0.006 \\
\hline
\end{tabular}


WSRC-STI-2007-00477

Revision 0

Table 3-4. Normalized PCTs by Glass ID and compositional view (continued)

\begin{tabular}{|c|c|c|c|c|c|c|c|c|c|c|c|c|c|}
\hline Set & Glass ID & Heat Treatment & Composition & \begin{tabular}{|c|}
$\log \mathrm{NL}$ \\
{$[\mathrm{B}(\mathrm{g} / \mathrm{L})]$} \\
\end{tabular} & $\begin{array}{c}\log \mathrm{NL} \\
{[\mathrm{Gd}(\mathrm{g} / \mathrm{L})]}\end{array}$ & $\begin{array}{c}\log \mathrm{NL} \\
{[\mathrm{Hf}(\mathrm{g} / \mathrm{L})]}\end{array}$ & $\begin{array}{c}\log \mathrm{NL} \\
{[\mathrm{Na}(\mathrm{g} / \mathrm{L})]}\end{array}$ & \begin{tabular}{|c|}
$\log \mathrm{NL}$ \\
{$[\mathrm{Si}(\mathrm{g} / \mathrm{L})]$}
\end{tabular} & \begin{tabular}{|c|}
$\mathrm{NL}$ \\
$\mathrm{B}(\mathrm{g} / \mathrm{L})$ \\
\end{tabular} & \begin{tabular}{|c|}
$\mathrm{NL}$ \\
$\mathrm{Gd}(\mathrm{g} / \mathrm{L})$ \\
\end{tabular} & \begin{tabular}{|c|}
$\mathrm{NL}$ \\
$\mathrm{Hf}(\mathrm{g} / \mathrm{L})$ \\
\end{tabular} & $\begin{array}{c}\mathrm{NL} \\
\mathrm{Na}(\mathrm{g} / \mathrm{L}) \\
\end{array}$ & $\begin{array}{c}\mathrm{NL} \\
\mathrm{Si}(\mathrm{g} / \mathrm{L}) \\
\end{array}$ \\
\hline 2 & $\begin{array}{l}\text { Pu35-28 } \\
\end{array}$ & quenched & measured & -1.6276 & -2.0856 & -2.4428 & \begin{tabular}{|l}
-1.8156 \\
\end{tabular} & -2.2246 & 0.024 & 0.008 & \begin{tabular}{|l|}
0.004 \\
\end{tabular} & 0.015 & 0.006 \\
\hline 2 & Pu35-29 & quenched & measured & -1.6239 & -2.0813 & -2.4371 & -1.5444 & -1.5344 & 0.024 & 0.008 & 0.004 & 0.029 & 0.029 \\
\hline 2 & Pu35-30 & quenched & measured & -1.6132 & -2.0878 & -2.4465 & -1.8867 & -1.3349 & 0.024 & 0.008 & 0.004 & 0.013 & 0.046 \\
\hline 2 & Pu35-31 & quenched & measured & -1.6119 & -2.0856 & -2.4447 & -1.6456 & -1.4413 & 0.024 & 0.008 & 0.004 & 0.023 & 0.036 \\
\hline 2 & Pu35-32 & quenched & measured & -1.6195 & -2.0878 & -2.4539 & -1.7943 & -2.3262 & 0.024 & 0.008 & 0.004 & 0.016 & 0.005 \\
\hline 2 & Pu35-33 & quenched & measured & -1.6081 & -2.0733 & -2.4428 & -1.8891 & -2.3110 & 0.025 & 0.008 & 0.004 & 0.013 & 0.005 \\
\hline 2 & Pu35-34 & quenched & measured & -1.6094 & -2.0878 & -2.4428 & -1.6361 & -1.8766 & 0.025 & 0.008 & 0.004 & 0.023 & 0.013 \\
\hline 2 & Pu35-35 & quenched & measured & -1.6226 & -2.0835 & -2.4539 & -1.9033 & -2.2923 & 0.024 & 0.008 & 0.004 & 0.012 & 0.005 \\
\hline 3 & Pu35-36 & quenched & measured & -1.6145 & -2.0878 & -2.4558 & -1.7863 & -1.6514 & 0.024 & 0.008 & 0.004 & 0.016 & 0.022 \\
\hline 3 & Pu35-37 & quenched & measured & -1.6126 & -2.0798 & -2.4333 & -1.7742 & -1.8016 & 0.024 & 0.008 & 0.004 & 0.017 & 0.016 \\
\hline 3 & Pu35-38 & quenched & measured & -1.6132 & -2.0763 & -2.4447 & -1.7685 & -1.9211 & 0.024 & 0.008 & 0.004 & 0.017 & 0.012 \\
\hline 3 & Pu35-39 & quenched & measured & -1.6132 & -2.0878 & -2.4539 & -1.8120 & -1.4495 & 0.024 & 0.008 & 0.004 & 0.015 & 0.036 \\
\hline 3 & Pu35-40 & quenched & measured & -1.6151 & -2.0794 & -2.4352 & -1.7654 & -1.9304 & 0.024 & 0.008 & 0.004 & 0.017 & 0.012 \\
\hline 3 & Pu35-41 & quenched & measured & -1.4790 & -1.9430 & -2.4390 & -1.8918 & -1.9329 & 0.033 & 0.011 & 0.004 & 0.013 & 0.012 \\
\hline 3 & Pu35-42 & quenched & measured & -1.6094 & -2.0856 & -2.4465 & -1.8312 & -1.5103 & 0.025 & 0.008 & 0.004 & 0.015 & 0.031 \\
\hline 3 & $\begin{array}{l}\text { Pu35-43 } \\
\end{array}$ & quenched & measured & -1.6170 & -2.0813 & -2.4447 & -1.8116 & -2.0247 & 0.024 & 0.008 & 0.004 & 0.015 & 0.009 \\
\hline 3 & \begin{tabular}{|l|} 
Pu35-44 \\
\end{tabular} & quenched & measured & $\begin{array}{l}-1.6100 \\
\end{array}$ & -2.0835 & -2.4447 & -1.7703 & -2.0504 & 0.025 & 0.008 & 0.004 & 0.017 & 0.009 \\
\hline 3 & Pu35-45 & quenched & measured & -1.6195 & -2.0768 & -2.4371 & -1.8136 & -1.7813 & 0.024 & 0.008 & 0.004 & 0.015 & 0.017 \\
\hline 3 & Pu35-46 & quenched & measured & -1.6300 & -2.0983 & -2.4502 & -1.7563 & -1.8745 & 0.023 & 0.008 & 0.004 & 0.018 & 0.013 \\
\hline 3 & \begin{tabular}{|l|} 
Pu35-47 \\
\end{tabular} & quenched & measured & -1.6282 & -2.0878 & -2.4502 & -1.8199 & -1.9942 & 0.024 & 0.008 & 0.004 & 0.015 & 0.010 \\
\hline 3 & Pu35-48 & quenched & measured & -1.6312 & -2.0899 & -2.4409 & 8231 & -1.9962 & 0.023 & 0.008 & 0.004 & 0.015 & 0.010 \\
\hline 3 & Pu35-49 & quenched & measured & -1.6300 & -2.0941 & -2.4409 & -1.7716 & -1.7153 & 0.023 & 0.008 & 0.004 & 0.017 & 0.019 \\
\hline 3 & Pu35-50 & quenched & measured & \begin{tabular}{|l|}
-1.6337 \\
\end{tabular} & -2.0920 & -2.4390 & -1.7803 & -1.5296 & 0.023 & 0.008 & 0.004 & 0.017 & 0.030 \\
\hline 3 & \begin{tabular}{|l|} 
Pu35-51 \\
\end{tabular} & quenched & measured & -1.5021 & -1.9638 & -2.4371 & -1.8328 & -1.9245 & 0.031 & 0.011 & 0.004 & 0.015 & 0.012 \\
\hline 3 & $\begin{array}{l}\text { Pu35-52 } \\
\end{array}$ & quenched & measured & -1.6312 & -2.0920 & -2.4136 & -1.8207 & -1.5755 & 0.023 & 0.008 & 0.004 & 0.015 & 0.027 \\
\hline 3 & Pu35-53 & quenched & measured & \begin{tabular}{|l|}
-1.6349 \\
\end{tabular} & -2.0941 & -2.4176 & -1.8482 & -1.7489 & 0.023 & 0.008 & 0.004 & 0.014 & 0.018 \\
\hline 3 & Pu35-54 & quenched & measured & -1.6349 & -2.0962 & -2.4216 & & -1.7853 & 0.023 & 0.008 & 0.004 & 0.016 & 0.016 \\
\hline 3 & Pu35-55 & quenched & measured & -1.6444 & -2.0983 & -2.4333 & -1.8223 & -1.6452 & 0.023 & 0.008 & 0.004 & 0.015 & 0.023 \\
\hline 1 & Pu04-01 & quenched & measured bc & -1.6353 & -2.1024 & -2.4701 & -0.2363 & -2.6106 & 0.023 & 0.008 & 0.003 & 0.580 & 0.002 \\
\hline 1 & Pu04-02 & quenched & measured bc & -1.6365 & -2.0983 & -2.4754 & -0.8899 & -3.0155 & 0.023 & 0.008 & 0.003 & 0.129 & 0.001 \\
\hline 1 & \begin{tabular}{|l|}
$\mathrm{Pu} 04-03$ \\
\end{tabular} & quenched & measured bc & -1.6299 & -2.1024 & -2.4840 & 204 & 112 & 0.023 & 0.008 & 0.003 & 0.060 & 0.001 \\
\hline 1 & \begin{tabular}{|l|} 
Pu04-04 \\
\end{tabular} & quenched & measured bc & -1.6376 & -2.1106 & -2.4719 & -1.0108 & -2.9082 & 0.023 & 0.008 & 0.003 & 0.098 & 0.001 \\
\hline 1 & Pu04-05 & quenched & measured bc & -1.6376 & -2.1086 & -2.4975 & -1.4956 & -3.0142 & 0.023 & 0.008 & 0.003 & 0.032 & 0.001 \\
\hline 1 & \begin{tabular}{|l} 
Pu35-01 \\
\end{tabular} & quenched & measured bc & -1.4904 & -1.9592 & -2.4428 & -1.8369 & -2.9990 & 0.032 & 0.011 & 0.004 & 0.015 & 0.001 \\
\hline 1 & \begin{tabular}{|l} 
Pu35-02 \\
\end{tabular} & quenched & measured bc & -1.6341 & -2.0920 & -2.4428 & -1.5083 & -2.1373 & 0.023 & 0.008 & 0.004 & 0.031 & 0.007 \\
\hline 1 & Pu35-03 & quenched & measured bc & -1.6323 & -2.0813 & -2.4333 & -2.0796 & -2.1562 & 0.023 & 0.008 & 0.004 & 0.008 & 0.007 \\
\hline 1 & Pu35-04 & quenched & measured bc & -1.5116 & -1.9736 & -2.4465 & -1.7176 & -2.9936 & 0.031 & 0.011 & 0.004 & 0.019 & 0.001 \\
\hline 1 & \begin{tabular}{|l|} 
Pu35-05 \\
\end{tabular} & quenched & measured bc & -1.6233 & & & & -1.4007 & 0.024 & 0.008 & 0.004 & 0.524 & 0.040 \\
\hline 1 & Pu35-06 & quenched & measured bc & -1.6232 & -2.0835 & -2.4390 & -1.6293 & -2.9928 & 0.024 & 0.008 & 0.004 & 0.023 & 0.001 \\
\hline 1 & Pu35-07 & quenched & measured bc & -1.6238 & -2.0856 & -2.4539 & -1.7141 & -2.4392 & 0.024 & 0.008 & 0.004 & 0.019 & 0.004 \\
\hline 1 & $\begin{array}{l}\text { Pu35-08 } \\
\end{array}$ & quenched & measured bc & & & & & & 0.031 & 0.011 & 0.004 & 0.028 & 0.005 \\
\hline 1 & Pu35-09 & quenched & measured bc & $\begin{array}{l}-1.4453 \\
\end{array}$ & -1.9005 & -2.4333 & -1.4900 & -1.2452 & 0.036 & 0.013 & 0.004 & 0.032 & 0.057 \\
\hline 1 & Pu35-10 & quenched & measured bc & -1.6289 & -2.0856 & -2.4352 & -1.5385 & -2.9978 & 0.024 & 0.008 & 0.004 & 0.029 & 0.001 \\
\hline 1 & Pu35-11 & quenched & measured bc & -1.6302 & -2.0835 & -2.4521 & -1.7532 & -2.9989 & 0.023 & 0.008 & 0.004 & 0.018 & 0.001 \\
\hline 1 & \begin{tabular}{|l|} 
Pu35-12 \\
\end{tabular} & quenched & measured bc & -1.6364 & -2.0856 & -2.4521 & -1.4070 & -2.9991 & 0.023 & 0.008 & 0.004 & 0.039 & 0.001 \\
\hline 1 & \begin{tabular}{|l} 
Pu35-13 \\
\end{tabular} & quenched & measured bc & -1.5220 & -1.9839 & -2.4333 & -1.1129 & -2.1053 & 0.030 & 0.010 & 0.004 & 0.077 & 0.008 \\
\hline 1 & \begin{tabular}{|l|} 
Pu35-14 \\
\end{tabular} & quenched & measured bc & -1.6181 & -2.0878 & -2.4484 & -1.9266 & -2.9994 & 0.024 & 0.008 & 0.004 & 0.012 & 0.001 \\
\hline 1 & Pu35-15 & quenched & measured bc & $\begin{array}{l}-1.6194 \\
\end{array}$ & -2.0899 & -2.4484 & -1.8405 & -2.8924 & 0.024 & 0.008 & 0.004 & 0.014 & 0.001 \\
\hline 2 & Pu35-16 & quenched & measured bc & -1.6237 & -2.0941 & -2.4539 & -1.9517 & -2.1407 & 0.024 & 0.008 & 0.004 & 0.011 & 0.007 \\
\hline 2 & Pu35-17 & quenched & measured bc & -1.6255 & -2.0920 & -2.4502 & -1.8952 & -1.7485 & 0.024 & 0.008 & 0.004 & 0.013 & 0.018 \\
\hline 2 & Pu35-18 & quenched & measured bc & -1.5178 & -1.9853 & -2.4521 & -1.8585 & -1.3464 & 0.030 & 0.010 & 0.004 & 0.014 & 0.045 \\
\hline 2 & Pu35-19 & quenched & measured bc & -1.6194 & -2.0920 & -2.4539 & -1.7900 & -2.2041 & 0.024 & 0.008 & 0.004 & 0.016 & 0.006 \\
\hline 2 & Pu35-20 & quenched & measured bc & -1.6169 & -2.0962 & -2.4576 & -1.6203 & -1.6258 & 0.024 & 0.008 & 0.003 & 0.024 & 0.024 \\
\hline 2 & Pu35-21 & quenched & measured bc & -1.6156 & -2.0920 & -2.4428 & -1.6863 & -2.2661 & 0.024 & 0.008 & 0.004 & 0.021 & 0.005 \\
\hline 2 & Pu35-22 & quenched & measured bc & -1.6218 & -2.0983 & -2.4521 & -1.7826 & -2.1663 & 0.024 & 0.008 & 0.004 & 0.016 & 0.007 \\
\hline 2 & Pu35-23 & quenched & measured bc & -1.6237 & -2.0920 & -2.4539 & -1.8614 & -2.2535 & 0.024 & 0.008 & 0.004 & 0.014 & 0.006 \\
\hline
\end{tabular}


WSRC-STI-2007-00477

Revision 0

Table 3-4. Normalized PCTs by Glass ID and compositional view (continued)

\begin{tabular}{|c|c|c|c|c|c|c|c|c|c|c|c|c|c|}
\hline Set & Glass ID & Heat Treatment & Composition & $\begin{array}{c}\log \mathrm{NL} \\
{[\mathrm{B}(\mathrm{g} / \mathrm{L})]}\end{array}$ & $\begin{array}{c}\log \mathrm{NL} \\
{[\mathrm{Gd}(\mathrm{g} / \mathrm{L})]}\end{array}$ & $\begin{array}{c}\log \mathrm{NL} \\
{[\mathrm{Hf}(\mathrm{g} / \mathrm{L})]}\end{array}$ & $\begin{array}{c}\log \mathrm{NL} \\
{[\mathrm{Na}(\mathrm{g} / \mathrm{L})]}\end{array}$ & \begin{tabular}{|c|}
$\log \mathrm{NL}$ \\
{$[\mathrm{Si}(\mathrm{g} / \mathrm{L})]$}
\end{tabular} & \begin{tabular}{|c|}
$\mathrm{NL}$ \\
$\mathrm{B}(\mathrm{g} / \mathrm{L})$ \\
\end{tabular} & \begin{tabular}{|c|}
$\mathrm{NL}$ \\
$\mathrm{Gd}(\mathrm{g} / \mathrm{L})$ \\
\end{tabular} & \begin{tabular}{|c|}
$\mathrm{NL}$ \\
$\mathrm{Hf}(\mathrm{g} / \mathrm{L})$ \\
\end{tabular} & $\begin{array}{c}\mathrm{NL} \\
\mathrm{Na}(\mathrm{g} / \mathrm{L}) \\
\end{array}$ & $\begin{array}{c}\mathrm{NL} \\
\mathrm{Si}(\mathrm{g} / \mathrm{L}) \\
\end{array}$ \\
\hline 2 & $\begin{array}{l}\mathrm{Pu} 35-24 \\
\end{array}$ & quenched & measured bc & -1.6262 & -2.0899 & -2.4484 & \begin{tabular}{|l|}
-1.6780 \\
\end{tabular} & -2.2503 & 0.024 & 0.008 & \begin{tabular}{|l|}
0.004 \\
\end{tabular} & 0.021 & 0.006 \\
\hline 2 & Pu35-25 & quenched & measured bc & -1.6169 & -2.0899 & -2.4484 & -1.5995 & -1.5529 & 0.024 & 0.008 & 0.004 & 0.025 & 0.028 \\
\hline 2 & Pu35-26 & quenched & measured bc & -1.6181 & -2.0835 & -2.4447 & -1.0624 & -2.3195 & 0.024 & 0.008 & 0.004 & 0.087 & 0.005 \\
\hline 2 & Pu35-27 & quenched & measured bc & -1.6163 & -2.0816 & -2.4352 & -1.7369 & -2.1960 & 0.024 & 0.008 & 0.004 & 0.018 & 0.006 \\
\hline 2 & Pu35-28 & quenched & measured bc & -1.6243 & -2.0856 & -2.4428 & -1.7921 & -2.2291 & 0.024 & 0.008 & 0.004 & 0.016 & 0.006 \\
\hline 2 & \begin{tabular}{|l|} 
Pu35-29 \\
\end{tabular} & quenched & measured bc & -1.6206 & -2.0813 & -2.4371 & -1.5209 & -1.5389 & 0.024 & 0.008 & 0.004 & 0.030 & 0.029 \\
\hline 2 & Pu35-30 & quenched & measured bc & -1.6100 & -2.0878 & -2.4465 & -1.8632 & -1.3394 & 0.025 & 0.008 & 0.004 & 0.014 & 0.046 \\
\hline 2 & Pu35-31 & quenched & measured bc & -1.6087 & -2.0856 & -2.4447 & -1.6221 & -1.4457 & 0.025 & 0.008 & 0.004 & 0.024 & 0.036 \\
\hline 2 & Pu35-32 & quenched & measured bc & -1.6163 & -2.0878 & -2.4539 & -1.7709 & -2.3307 & 0.024 & 0.008 & 0.004 & 0.017 & 0.005 \\
\hline 2 & Pu35-33 & quenched & measured bc & $\begin{array}{l}-1.6049 \\
\end{array}$ & -2.0733 & -2.4428 & -1.8656 & -2.3155 & 0.025 & 0.008 & 0.004 & 0.014 & 0.005 \\
\hline 2 & Pu35-34 & quenched & measured bc & -1.6061 & -2.0878 & -2.4428 & -1.6126 & -1.8811 & 0.025 & 0.008 & 0.004 & 0.024 & 0.013 \\
\hline 2 & Pu35-35 & quenched & measured bc & -1.6194 & -2.0835 & -2.4539 & -1.8798 & -2.2968 & 0.024 & 0.008 & 0.004 & 0.013 & 0.005 \\
\hline 3 & \begin{tabular}{|l|} 
Pu35-36 \\
\end{tabular} & quenched & measured bc & -1.6270 & -2.0878 & -2.4558 & -1.7493 & -1.6552 & 0.024 & 0.008 & 0.004 & 0.018 & 0.022 \\
\hline 3 & Pu35-37 & quenched & measured bc & -1.6251 & -2.0798 & -2.4333 & -1.7372 & -1.8054 & 0.024 & 0.008 & 0.004 & 0.018 & 0.016 \\
\hline 3 & Pu35-38 & quenched & measured bc & -1.6257 & -2.0763 & -2.4447 & -1.7315 & -1.9250 & 0.024 & 0.008 & 0.004 & 0.019 & 0.012 \\
\hline 3 & $\begin{array}{l}\text { Pu35-39 } \\
\end{array}$ & quenched & measured bc & -1.6257 & -2.0878 & -2.4539 & -1.7749 & -1.4534 & 0.024 & 0.008 & 0.004 & 0.017 & 0.035 \\
\hline 3 & \begin{tabular}{|l|} 
Pu35-40 \\
\end{tabular} & quenched & measured bc & -1.6276 & -2.0794 & -2.4352 & -1.7283 & -1.9343 & 0.024 & 0.008 & 0.004 & 0.019 & 0.012 \\
\hline 3 & Pu35-41 & quenched & measured bc & -1.4915 & -1.9430 & -2.4390 & -1.8547 & -1.9367 & 0.032 & 0.011 & 0.004 & 0.014 & 0.012 \\
\hline 3 & Pu35-42 & quenched & measured bc & -1.6219 & -2.0856 & -2.4465 & -1.7942 & -1.5142 & 0.024 & 0.008 & 0.004 & 0.016 & 0.031 \\
\hline 3 & \begin{tabular}{|l|} 
Pu35-43 \\
\end{tabular} & quenched & measured bc & -1.6295 & -2.0813 & -2.4447 & -1.7745 & -2.0286 & 0.023 & 0.008 & 0.004 & 0.017 & 0.009 \\
\hline 3 & Pu35-44 & quenched & measured bc & -1.6225 & -2.0835 & -2.4447 & -1.7332 & -2.0542 & 0.024 & 0.008 & 0.004 & 0.018 & 0.009 \\
\hline 3 & Pu35-45 & quenched & measured bc & -1.6320 & -2.0768 & -2.4371 & -1.7765 & -1.7852 & 0.023 & 0.008 & 0.004 & 0.017 & 0.016 \\
\hline 3 & Pu35-46 & quenched & measured bc & -1.6268 & -2.0983 & -2.4502 & -1.7306 & -1.8679 & 0.024 & 0.008 & 0.004 & 0.019 & 0.014 \\
\hline 3 & \begin{tabular}{|l|} 
Pu35-47 \\
\end{tabular} & quenched & measured bc & -1.6249 & -2.0878 & -2.4502 & -1.7942 & -1.9876 & 0.024 & 0.008 & 0.004 & 0.016 & 0.010 \\
\hline 3 & $\begin{array}{l}\text { Pu35-48 } \\
\end{array}$ & quenched & measured bc & -1.6280 & -2.0899 & -2.4409 & -1.7973 & -1.9897 & 0.024 & 0.008 & 0.004 & 0.016 & 0.010 \\
\hline 3 & \begin{tabular}{|l} 
Pu35-49 \\
\end{tabular} & quenched & measured bc & -1.6268 & -2.0941 & -2.4409 & -1.7458 & -1.7088 & 0.024 & 0.008 & 0.004 & 0.018 & 0.020 \\
\hline 3 & Pu35-50 & quenched & measured bc & -1.6304 & -2.0920 & -2.4390 & -1.7546 & -1.5230 & 0.023 & 0.008 & 0.004 & 0.018 & 0.030 \\
\hline 3 & Pu35-51 & quenched & measured bc & -1.4989 & -1.9638 & -2.4371 & -1.8070 & -1.9179 & 0.032 & 0.011 & 0.004 & 0.016 & 0.012 \\
\hline 3 & $\begin{array}{l}\text { Pu35-52 } \\
\end{array}$ & quenched & measured bc & -1.6280 & -2.0920 & -2.4136 & -1.7950 & -1.5689 & 0.024 & 0.008 & 0.004 & 0.016 & 0.027 \\
\hline 3 & Pu35-53 & quenched & measured bc & -1.6316 & -2.0941 & -2.4176 & -1.8224 & -1.7423 & 0.023 & 0.008 & 0.004 & 0.015 & 0.018 \\
\hline 3 & \begin{tabular}{|l|} 
Pu35-54 \\
\end{tabular} & quenched & measured bc & -1.6316 & -2.0962 & -2.4216 & -1.7793 & -1.7787 & 0.023 & 0.008 & 0.004 & 0.017 & 0.017 \\
\hline 3 & \begin{tabular}{|l} 
Pu35-55 \\
\end{tabular} & quenched & measured bc & -1.6412 & -2.0983 & -2.4333 & -1.7966 & -1.6386 & 0.023 & 0.008 & 0.004 & 0.016 & 0.023 \\
\hline 1 & Pu04-01 & quenched & targeted & -1.6198 & -2.0823 & -2.5975 & -0.2007 & -2.5818 & 0.024 & 0.008 & 0.003 & 0.630 & 0.003 \\
\hline 1 & $\begin{array}{l}\text { Pu04-02 } \\
\end{array}$ & quenched & targeted & -1.6198 & -2.0823 & -2.5971 & -0.8167 & -2.9844 & 0.024 & 0.008 & 0.003 & 0.153 & 0.001 \\
\hline 1 & \begin{tabular}{|l|} 
Pu04-03 \\
\end{tabular} & quenched & targeted & \begin{tabular}{|l}
-1.6198 \\
\end{tabular} & -2.0823 & -2.5968 & -1.1536 & -2.9844 & 0.024 & 0.008 & 0.003 & 0.070 & 0.001 \\
\hline 1 & $\mathrm{Pu04-04}$ & quenched & targeted & \begin{tabular}{|l|}
-1.6198 \\
\end{tabular} & -2.0823 & -2.5962 & -0.8526 & -2.8784 & 0.024 & 0.008 & 0.003 & 0.140 & 0.001 \\
\hline 1 & Pu04-05 & quenched & targeted & -1.6198 & -2.0823 & -2.5977 & -1.4546 & -2.9844 & 0.024 & 0.008 & 0.003 & 0.035 & 0.001 \\
\hline 1 & \begin{tabular}{|l|} 
Pu35-01 \\
\end{tabular} & quenched & targeted & -1.4955 & & -2.4806 & & -2.9844 & 0.032 & 0.011 & 0.003 & 0.014 & 0.001 \\
\hline 1 & \begin{tabular}{|l|} 
Pu35-02 \\
\end{tabular} & quenched & targeted & \begin{tabular}{|l}
-1.6198 \\
\end{tabular} & -2.0823 & -2.4824 & -1.4936 & -2.1315 & 0.024 & 0.008 & 0.003 & 0.032 & 0.007 \\
\hline 1 & $\begin{array}{l}\mathrm{Pu} 35-03 \\
\end{array}$ & quenched & targeted & -1.6198 & -2.0823 & -2.4791 & -2.1197 & -2.1600 & 0.024 & 0.008 & 0.003 & 0.008 & 0.007 \\
\hline 1 & \begin{tabular}{|l} 
Pu35-04 \\
\end{tabular} & quenched & targeted & -1.5056 & & -2.4847 & & & 0.031 & 0.011 & 0.003 & 0.020 & 0.001 \\
\hline 1 & Pu35-05 & quenched & targeted & \begin{tabular}{|l|}
-1.6198 \\
\end{tabular} & -2.0823 & -2.4803 & -0.2806 & -1.3994 & 0.024 & 0.008 & 0.003 & 0.524 & 0.040 \\
\hline 1 & Pu35-06 & quenched & targeted & -1.6198 & -2.0823 & -2.4809 & -1.6746 & -2.9844 & 0.024 & 0.008 & 0.003 & 0.021 & 0.001 \\
\hline 1 & Pu35-07 & quenched & targeted & \begin{tabular}{|l|}
-1.6198 \\
\end{tabular} & -2.0823 & -2.4835 & -1.7348 & -2.4277 & 0.024 & 0.008 & 0.003 & 0.018 & 0.004 \\
\hline 1 & \begin{tabular}{|l|} 
Pu35-08 \\
\end{tabular} & quenched & targeted & -1.5030 & -1.9656 & -2.4832 & -1.5515 & -2.2929 & 0.031 & 0.011 & 0.003 & 0.028 & 0.005 \\
\hline 1 & \begin{tabular}{|l} 
Pu35-09 \\
\end{tabular} & quenched & targeted & \begin{tabular}{|l}
-1.4368 \\
\end{tabular} & -1.8993 & -2.4824 & -1.5287 & -1.2313 & 0.037 & 0.013 & 0.003 & 0.030 & 0.059 \\
\hline 1 & \begin{tabular}{|l|} 
Pu35-10 \\
\end{tabular} & quenched & targeted & \begin{tabular}{|l|}
-1.6198 \\
\end{tabular} & -2.0823 & -2.4818 & -1.5706 & -2.9844 & 0.024 & 0.008 & 0.003 & 0.027 & 0.001 \\
\hline 1 & Pu35-11 & quenched & targeted & \begin{tabular}{|l|}
-1.6198 \\
\end{tabular} & -2.0823 & -2.4809 & -1.7883 & -2.9844 & 0.024 & 0.008 & 0.003 & 0.016 & 0.001 \\
\hline 1 & Pu35-12 & quenched & targeted & \begin{tabular}{|l|}
-1.6198 \\
\end{tabular} & -2.0823 & -2.4835 & -1.4483 & -2.9844 & 0.024 & 0.008 & 0.003 & 0.036 & 0.001 \\
\hline 1 & Pu35-13 & quenched & targeted & -1.5180 & -1.9805 & -2.4835 & -1.1684 & -2.0933 & 0.030 & 0.010 & 0.003 & 0.068 & 0.008 \\
\hline 1 & Pu35-14 & quenched & targeted & -1.6198 & -2.0823 & -2.4818 & -1.9789 & -2.9844 & 0.024 & 0.008 & 0.003 & 0.010 & 0.001 \\
\hline 1 & Pu35-15 & quenched & targeted & -1.6198 & -2.0823 & -2.4847 & -1.8940 & -2.8743 & 0.024 & 0.008 & 0.003 & 0.013 & 0.001 \\
\hline 2 & Pu35-16 & quenched & targeted & -1.6198 & -2.0823 & -2.4803 & -2.0394 & -2.1338 & 0.024 & 0.008 & 0.003 & 0.009 & 0.007 \\
\hline 2 & \begin{tabular}{|l|}
$\mathrm{Pu} 35-17$ \\
\end{tabular} & quenched & targeted & -1.6198 & -2.0823 & -2.4832 & -1.9665 & -1.7370 & 0.024 & 0.008 & 0.003 & 0.011 & 0.018 \\
\hline 2 & Pu35-18 & quenched & targeted & -1.5152 & -1.9777 & -2.4812 & -1.9226 & -1.3395 & 0.031 & 0.011 & 0.003 & 0.012 & 0.046 \\
\hline 2 & $\begin{array}{l}\text { Pu35-19 } \\
\end{array}$ & quenched & targeted & -1.6198 & -2.0823 & -2.4815 & -1.8416 & -2.1995 & 0.024 & 0.008 & 0.003 & 0.014 & 0.006 \\
\hline
\end{tabular}


WSRC-STI-2007-00477

Revision 0

Table 3-4. Normalized PCTs by Glass ID and compositional view (continued)

\begin{tabular}{|c|c|c|c|c|c|c|c|c|c|c|c|c|c|}
\hline Set & Glass ID & Heat Treatment & Composition & $\begin{array}{c}\log N L \\
{[\mathrm{~B}(\mathrm{~g} / \mathrm{L})]} \\
\end{array}$ & $\begin{array}{c}\log \mathrm{NL} \\
{[\mathrm{Gd}(\mathrm{g} / \mathrm{L})]}\end{array}$ & $\begin{array}{c}\log \mathrm{NL} \\
{[\mathrm{Hf}(\mathrm{g} / \mathrm{L})]}\end{array}$ & $\begin{array}{c}\log \mathrm{NL} \\
{[\mathrm{Na}(\mathrm{g} / \mathrm{L})]}\end{array}$ & $\begin{array}{c}\log \mathrm{NL} \\
{[\mathrm{Si}(\mathrm{g} / \mathrm{L})]}\end{array}$ & $\begin{array}{c}\mathrm{NL} \\
\mathrm{B}(\mathrm{g} / \mathrm{L}) \\
\end{array}$ & \begin{tabular}{|c|}
$\mathrm{NL}$ \\
$\mathrm{Gd}(\mathrm{g} / \mathrm{L})$ \\
\end{tabular} & $\begin{array}{c}\mathrm{NL} \\
\mathrm{Hf}(\mathrm{g} / \mathrm{L}) \\
\end{array}$ & $\begin{array}{c}\mathrm{NL} \\
\mathrm{Na}(\mathrm{g} / \mathrm{L}) \\
\end{array}$ & \begin{tabular}{|c}
$\mathrm{NL}$ \\
$\mathrm{Si}(\mathrm{g} / \mathrm{L})$ \\
\end{tabular} \\
\hline 2 & \begin{tabular}{|l|} 
Pu35-20 \\
\end{tabular} & quenched & targeted & -1.6198 & -2.0823 & -2.4832 & -1.6485 & -1.6132 & 0.024 & \begin{tabular}{|l|}
0.008 \\
\end{tabular} & 0.003 & 0.022 & 0.024 \\
\hline 2 & Pu35-21 & quenched & targeted & -1.6198 & -2.0823 & -2.4829 & -1.7203 & -2.2579 & 0.024 & 0.008 & 0.003 & 0.019 & 0.006 \\
\hline 2 & Pu35-22 & quenched & targeted & -1.6198 & -2.0823 & -2.4841 & -1.8187 & -2.1534 & 0.024 & 0.008 & 0.003 & 0.015 & 0.007 \\
\hline 2 & $\mathrm{Pu} 35-23$ & quenched & targeted & -1.6198 & -2.0823 & -2.4812 & -1.9180 & -2.2484 & 0.024 & 0.008 & 0.003 & 0.012 & 0.006 \\
\hline 2 & $\mathrm{Pu} 35-24$ & quenched & targeted & -1.6198 & -2.0823 & -2.4818 & -1.7129 & -2.2418 & 0.024 & 0.008 & 0.003 & 0.019 & 0.006 \\
\hline 2 & Pu35-25 & quenched & targeted & -1.6198 & -2.0823 & -2.4824 & -1.6307 & -1.5074 & 0.024 & 0.008 & 0.003 & 0.023 & 0.031 \\
\hline 2 & \begin{tabular}{|l} 
Pu35-26 \\
\end{tabular} & quenched & targeted & -1.6198 & -2.0823 & -2.4809 & -1.0933 & -2.3068 & 0.024 & 0.008 & 0.003 & 0.081 & 0.005 \\
\hline 2 & \begin{tabular}{|l|}
$\mathrm{Pu} 35-27$ \\
\end{tabular} & quenched & targeted & -1.6198 & -2.0823 & -2.4829 & -1.7624 & -2.1859 & 0.024 & 0.008 & 0.003 & 0.017 & 0.007 \\
\hline 2 & Pu35-28 & quenched & targeted & -1.6198 & -2.0823 & -2.4826 & -1.8187 & -2.2213 & 0.024 & 0.008 & 0.003 & 0.015 & 0.006 \\
\hline 2 & Pu35-29 & quenched & targeted & -1.6198 & -2.0823 & -2.4855 & 5470 & -1.5288 & 0.024 & 0.008 & 0.003 & 0.028 & 0.030 \\
\hline 2 & $\mathrm{Pu} 35-30$ & quenched & targeted & -1.6198 & -2.0823 & -2.4812 & -1.9037 & -1.3269 & 0.024 & 0.008 & 0.003 & 0.012 & 0.047 \\
\hline 2 & Pu35-31 & quenched & targeted & -1.6198 & -2.0823 & -2.4832 & -1.6216 & -1.4327 & 0.024 & 0.008 & 0.003 & 0.024 & 0.037 \\
\hline 2 & \begin{tabular}{|l|}
$\mathrm{Pu} 35-32$ \\
\end{tabular} & & targeted & -1.6198 & -2.08 & -2.4818 & 883 & 179 & 0.024 & 0.008 & 0.003 & 0.016 & 0.005 \\
\hline 2 & \begin{tabular}{|l} 
Pu35-33 \\
\end{tabular} & quenched & targeted & -1.6198 & -2.0823 & -2.4783 & 9037 & -2.2733 & 0.024 & 0.008 & 0.003 & 0.012 & 0.005 \\
\hline 2 & \begin{tabular}{|l|}
$\mathrm{Pu} 35-34$ \\
\end{tabular} & quenched & targeted & -1.6198 & -2.0823 & -2.4815 & -1.6307 & -1.8257 & 0.024 & 0.008 & 0.003 & 0.023 & 0.015 \\
\hline 2 & Pu35-35 & quenched & targeted & $\begin{array}{l}-1.6198 \\
\end{array}$ & -2.0823 & -2.4803 & 180 & 904 & 0.024 & 0.008 & 0.003 & 0.012 & 0.005 \\
\hline 3 & Pu35-36 & quenched & targeted & -1.6198 & -2.0823 & -2.4815 & 7756 & 6378 & 0.024 & 0.008 & 0.003 & 0.017 & 0.023 \\
\hline 3 & Pu35-37 & quenched & geted & -1.6198 & -2.0823 & -2.4803 & -1.7624 & -1.7965 & 0.024 & 0.008 & 0.003 & 0.017 & 0.016 \\
\hline 3 & Pu35-38 & quenched & targeted & -1.6198 & -2.0823 & -2.4826 & -1.7690 & -1.9168 & 0.024 & 0.008 & 0.003 & 0.017 & 0.012 \\
\hline 3 & Pu35-39 & & targeted & -1.6198 & -2.0 & -2. & -1.7946 & 355 & 0.024 & 0.008 & 0.003 & 0.016 & 0.037 \\
\hline 3 & Pu35-40 & quenched & targeted & \begin{tabular}{|l}
-1.6198 \\
\end{tabular} & -2.0823 & -2.4806 & -1.7624 & -1.9245 & 0.024 & 0.008 & 0.003 & 0.017 & 0.012 \\
\hline 3 & \begin{tabular}{|l|}
$\mathrm{Pu} 35-41$ \\
\end{tabular} & quenched & targeted & -1.4792 & -1.9418 & -2.4826 & -1.9226 & -1.9278 & 0.033 & 0.011 & 0.003 & 0.012 & 0.012 \\
\hline 3 & Pu35-42 & quenched & targeted & & & & & -1.4989 & 0.024 & & 0.003 & 0.014 & 0.032 \\
\hline 3 & Pu35-43 & quenched & targeted & -1.6198 & -2.0823 & -2.4803 & -1.8187 & -2.0169 & 0.024 & 0.008 & 0.003 & 0.015 & 0.010 \\
\hline 3 & Pu35-44 & quenched & targeted & -1.6198 & -2.0823 & -2.4806 & -1.7690 & -2.0410 & 0.024 & 0.008 & 0.003 & 0.017 & 0.009 \\
\hline 3 & Pu35-45 & quenched & targeted & -1.6198 & -2.0823 & -2.4806 & -1.8128 & -1.7800 & 0.024 & 0.008 & 0.003 & 0.015 & 0.017 \\
\hline 3 & Pu35-46 & quenched & targeted & \begin{tabular}{|l|}
-1.6198 \\
\end{tabular} & -2.0823 & -2.4824 & -1.7488 & -1.8516 & 0.024 & 0.008 & 0.003 & 0.018 & 0.014 \\
\hline 3 & Pu35-47 & quenched & targeted & \begin{tabular}{|l|}
-1.6198 \\
\end{tabular} & -2.0823 & -2.4812 & -1.8128 & -1.9772 & 0.024 & 0.008 & 0.003 & 0.015 & 0.011 \\
\hline 3 & Pu35-48 & quenched & targeted & -1.6198 & -2.0823 & -2.4806 & -1.8128 & -1.9835 & 0.024 & 0.008 & 0.003 & 0.015 & 0.010 \\
\hline 3 & Pu35-49 & quenched & targeted & -1.6198 & -2.0823 & -2.4815 & & -1.6914 & 0.024 & 0.008 & 0.003 & 0.018 & 0.020 \\
\hline 3 & Pu35-50 & quenched & targeted & -1.6198 & -2.0823 & -2.4815 & -1.7624 & -1.5129 & 0.024 & 0.008 & 0.003 & 0.017 & 0.031 \\
\hline 3 & \begin{tabular}{|l|}
$\mathrm{Pu} 35-51$ \\
\end{tabular} & quenched & targeted & -1.4895 & -1.9520 & -2.4809 & -1.8245 & -1.9037 & 0.032 & 0.011 & 0.003 & 0.015 & 0.012 \\
\hline 3 & Pu35-52 & quenched & targeted & -1.6198 & -2.0823 & -2.4806 & -1.8007 & -1.5570 & 0.024 & 0.008 & 0.003 & 0.016 & 0.028 \\
\hline 3 & \begin{tabular}{|l|} 
Pu35-53 \\
\end{tabular} & quenched & targeted & -1.6198 & -2.0823 & -2.4838 & -1.8471 & -1.7296 & 0.024 & 0.008 & 0.003 & 0.014 & 0.019 \\
\hline 3 & \begin{tabular}{|l|} 
Pu35-54 \\
\end{tabular} & quenched & targeted & -1.6198 & -2.0823 & -2.4826 & -1.7946 & -1.7609 & 0.024 & 0.008 & 0.003 & 0.016 & 0.017 \\
\hline 3 & Pu35-55 & quenched & targeted & -1.6198 & -2.0823 & -2.4812 & -1.8068 & -1.6152 & 0.024 & 0.008 & 0.003 & 0.016 & 0.024 \\
\hline
\end{tabular}

The results of the PCTs indicate that each of the surrogate glasses was highly durable as compared to the EA glass, which is used as a benchmark for defense-related waste glasses destined for the U.S. federal repository. ${ }^{17}$ Boron has been found to be released at the same maximum normalized concentration as some high-activity radionuclides, and is therefore typically used to gauge the performance of simulated waste glasses. The concentration of boron in the PCT leachates was below the detection limit of the ICP-AES instrument for most of the surrogate glasses. The highest normalized release for boron measured was $0.041 \mathrm{~g} / \mathrm{L}$, which is considerably lower than that of the EA glass $(16.695 \mathrm{~g} / \mathrm{L}) .{ }^{17}$ The maximum normalized release rates among the 60 surrogate glasses for the other elements measured were also quite low: 0.005 $\mathrm{g} / \mathrm{L}$ for Hf, $0.014 \mathrm{~g} / \mathrm{L}$ for $\mathrm{Gd}, 1.229 \mathrm{~g} / \mathrm{L}$ for $\mathrm{Na}$ and $0.090 \mathrm{~g} / \mathrm{L}$ for Si. The normalized release rates for the elements measured were generally too small to attempt to correlate the results with the compositions of the test glasses. Note that the $\mathrm{pH}$ of the leachate solutions (typically $\sim 8.0$ ) was generally lower than that of conventional HLW glasses developed for defense-related radioactive waste sludges (typically 10.5) due to the lack of alkali in the LaBS glass. The leachate solution is less corrosive to the glass matrix at a lower $\mathrm{pH}$, so it is likely that this impacted the PCT results 
(i.e., a poorer PCT response may be measured if a higher $\mathrm{pH}$ solution, more typical of alkaliborosilicate HLW glasses, is used).

\subsection{TCLP Results}

The results of the TCLP for the selected surrogate glasses are summarized in Table 3-5. For all of the glasses submitted, none of the RCRA hazardous metals were detectable in the leachates at the completion of the test (i.e., the measurements were all below the analytical detection limits). The complete report provided by Davis \& Floyd, Inc. is included as Appendix F.

Table 3-5. Results of the TCLP for select surrogate glasses.

\begin{tabular}{|c|c|c|c|c||}
\hline Glass ID & Cr (mg/L) & Pb (mg/L) & Ni (mg/L) & Se (mg/L) \\
\hline $\mathrm{Pu} 35-11$ & $<0.10$ & $<0.050$ & $<0.20$ & $<0.050$ \\
\hline $\mathrm{Pu} 35-36$ & $<0.10$ & $<0.050$ & $<0.20$ & $<0.050$ \\
\hline $\mathrm{Pu} 35-37$ & $<0.10$ & $<0.050$ & $<0.20$ & $<0.050$ \\
\hline $\mathrm{Pu} 35-41$ & $<0.10$ & $<0.050$ & $<0.20$ & $<0.050$ \\
\hline $\mathrm{Pu} 35-47$ & $<0.10$ & $<0.050$ & $<0.20$ & $<0.050$ \\
\hline $\mathrm{Pu} 35-50$ & $<0.10$ & $<0.050$ & $<0.20$ & $<0.050$ \\
\hline $\mathrm{Pu} 35-51$ & $<0.10$ & $<0.050$ & $<0.20$ & $<0.050$ \\
\hline $\mathrm{Pu} 35-52$ & $<0.10$ & $<0.050$ & $<0.20$ & $<0.050$ \\
\hline \hline
\end{tabular}

\subsection{Results for the $\mathrm{PuO}_{2}$ Glasses}

An analysis of the experimental data for the glasses fabricated with $\mathrm{PuO}_{2}$ is provided in the following sections.

\subsubsection{Visual Observations and XRD Results}

The visual observations and XRD results for the $\mathrm{PuO}_{2}$-containing glasses are summarized in Table 3-6. No crystallization was visible on the surface of the glass after melting. Figure 3-7 is a photograph of these four glasses after being removed from the platinum crucibles in the SRNL shielded cells facility. In addition, all of the glasses were amorphous by XRD. This indicates that the glasses were either free of crystalline material, or that any crystallization was below the XRD detection limit of $0.5 \mathrm{vol} \%$. These results suggest complete dissolution of $\mathrm{PuO}_{2}$ in the glass matrix.

Table 3-6. Visual observations and XRD results for the glasses fabricated with $\mathrm{PuO}_{2}$.

\begin{tabular}{|l|l|l|l||}
\hline Glass ID & $\begin{array}{c}\text { Heat } \\
\text { Treatment }\end{array}$ & \multicolumn{1}{|c||}{ Visual Observations } & \multicolumn{1}{||}{ XRD Results } \\
\hline Pu35-03B & quenched & no visible crystallization on surface & amorphous \\
\hline Pu35-06B & quenched & no visible crystallization on surface & amorphous \\
\hline Pu35-17B & quenched & no visible crystallization on surface & amorphous \\
\hline Pu04-04B & quenched & no visible crystallization on surface & amorphous \\
\hline
\end{tabular}




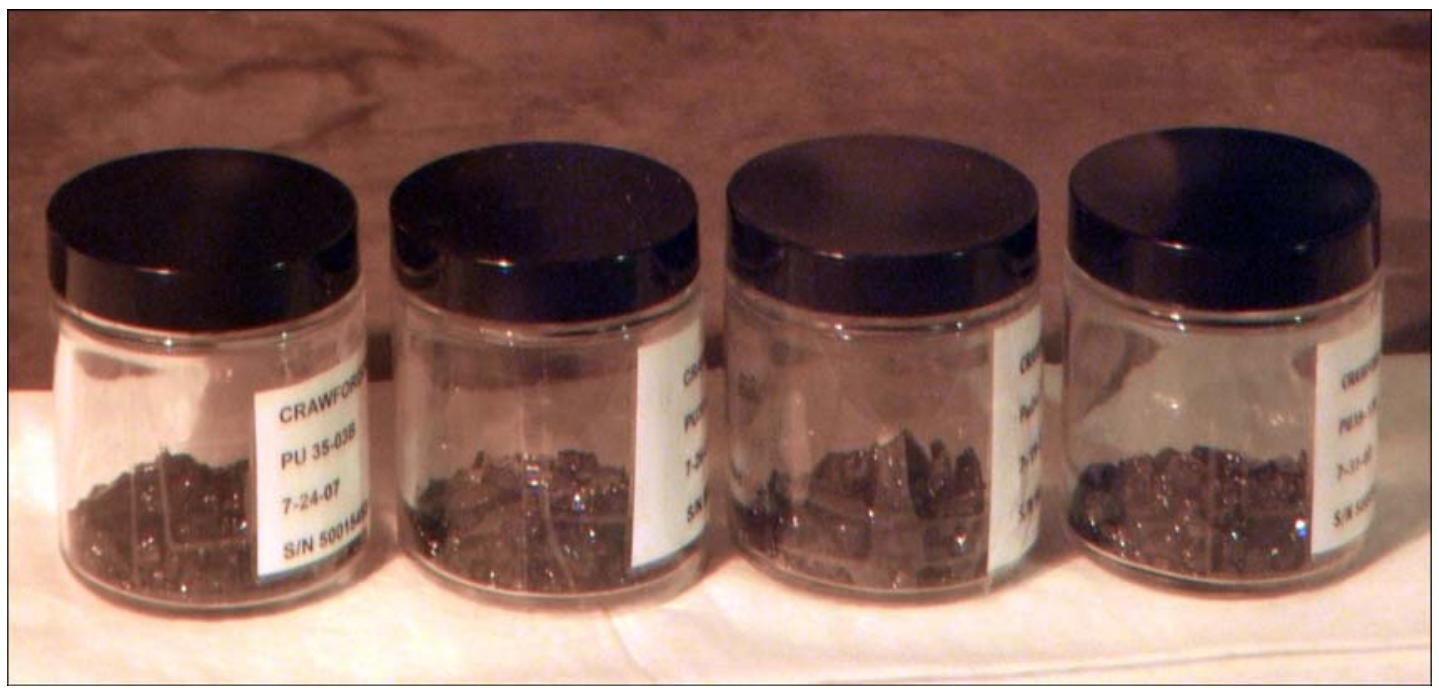

Figure 3-7. Photograph of the four glasses fabricated with $\mathrm{PuO}_{2}$ in the SRNL shielded cells facility. The glasses are, from left to right, Pu35-03B, Pu35-06B, Pu04-04B and Pu35-17B.

\subsubsection{SEM Characterization}

Each of the glasses fabricated with $\mathrm{PuO}_{2}$ was submitted to AD for SEM and EDS analysis. Ground samples were used to provide an increased amount of surface area for analysis. Glass Pu04-04B was generally free of any crystalline phases, as shown in Figure 3-8. However, some small areas of crystalline material were located, as shown in Figure 3-9.

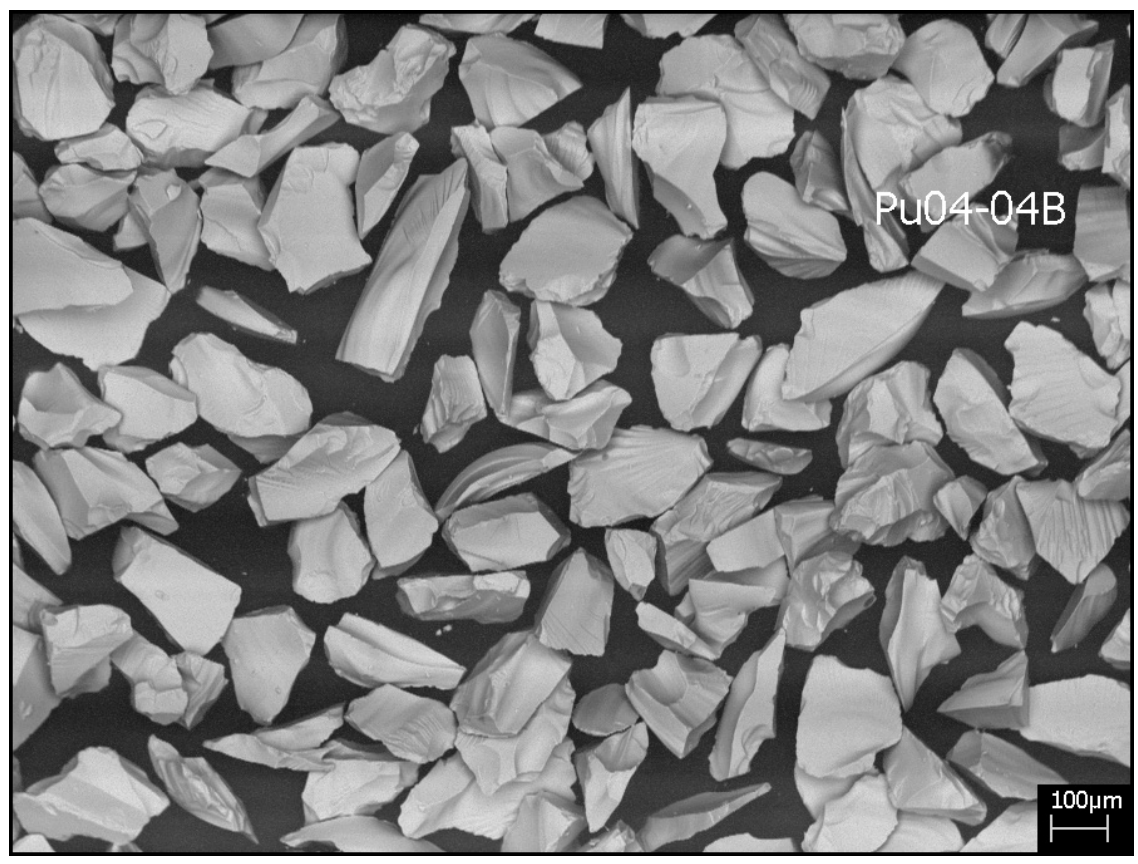

Figure 3-8. SEM micrograph of glass Pu04-04B. This glass was generally free of any crystalline phases. 


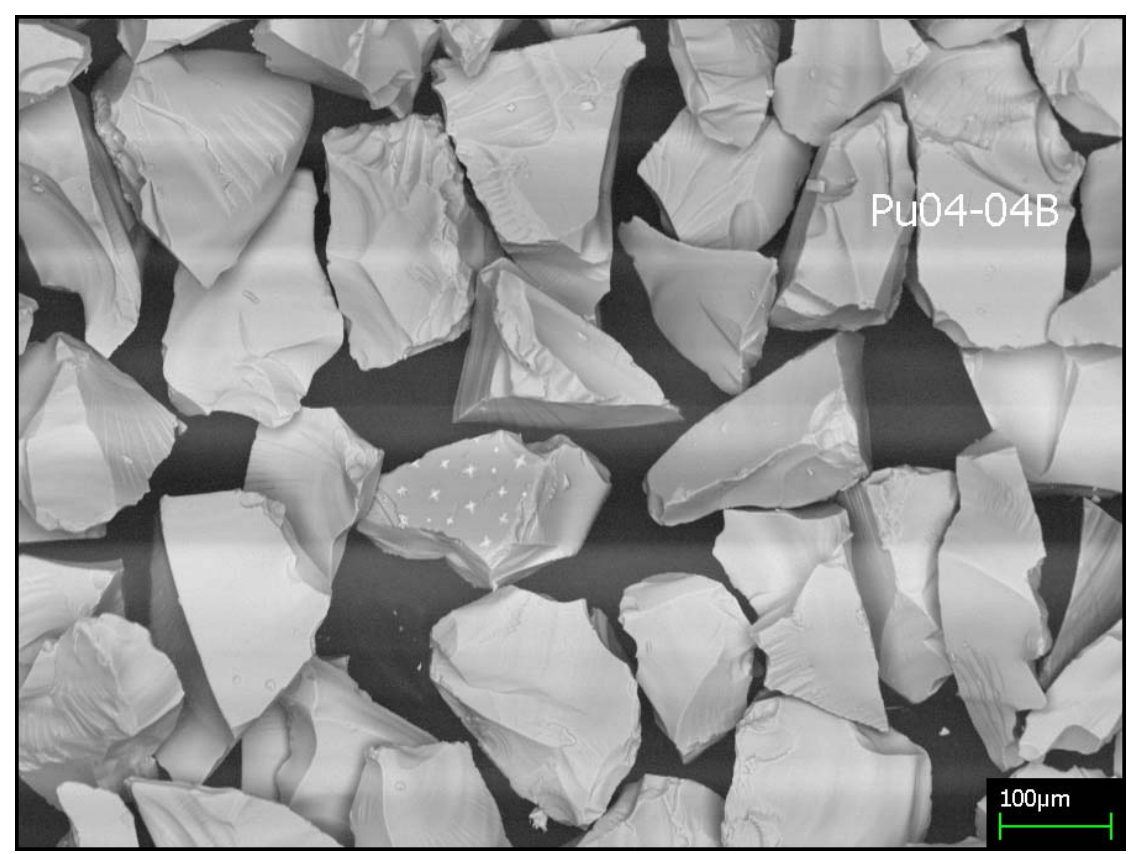

Figure 3-9. Higher magnification SEM micrograph of glass Pu04-04B, showing a small area of crystalline material.

EDS was used to identify the composition of the crystalline phase in Figure 3-9. A higher magnification image of this region is shown in Figure 3-10. The areas evaluated with EDS are also indicated in this micrograph. The EDS results for Spot-3 are shown in Figure 3-11 and the EDS results for Spot-4 are shown in Figure 3-12. The relative intensities for $\mathrm{Pu}$ and $\mathrm{Hf}$ are higher in the EDS spectrum for the crystalline phase (Spot-3, Figure 3-11) than in the glass matrix (Spot4, Figure 3-12), indicating that the crystalline phase is composed mainly of these elements. 


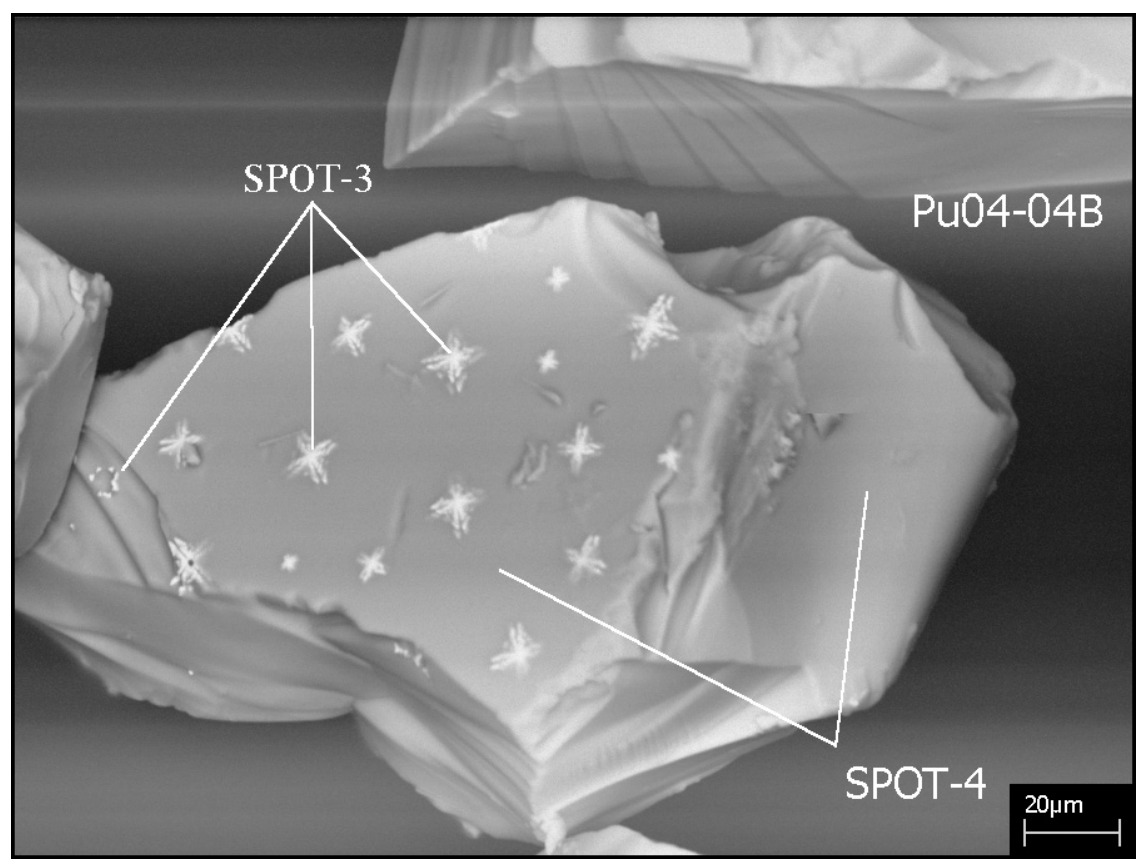

Figure 3-10. SEM micrograph of the crystalline phase identified in glass Pu04-04B. The marked spots indicate areas where EDS spectra were recorded.

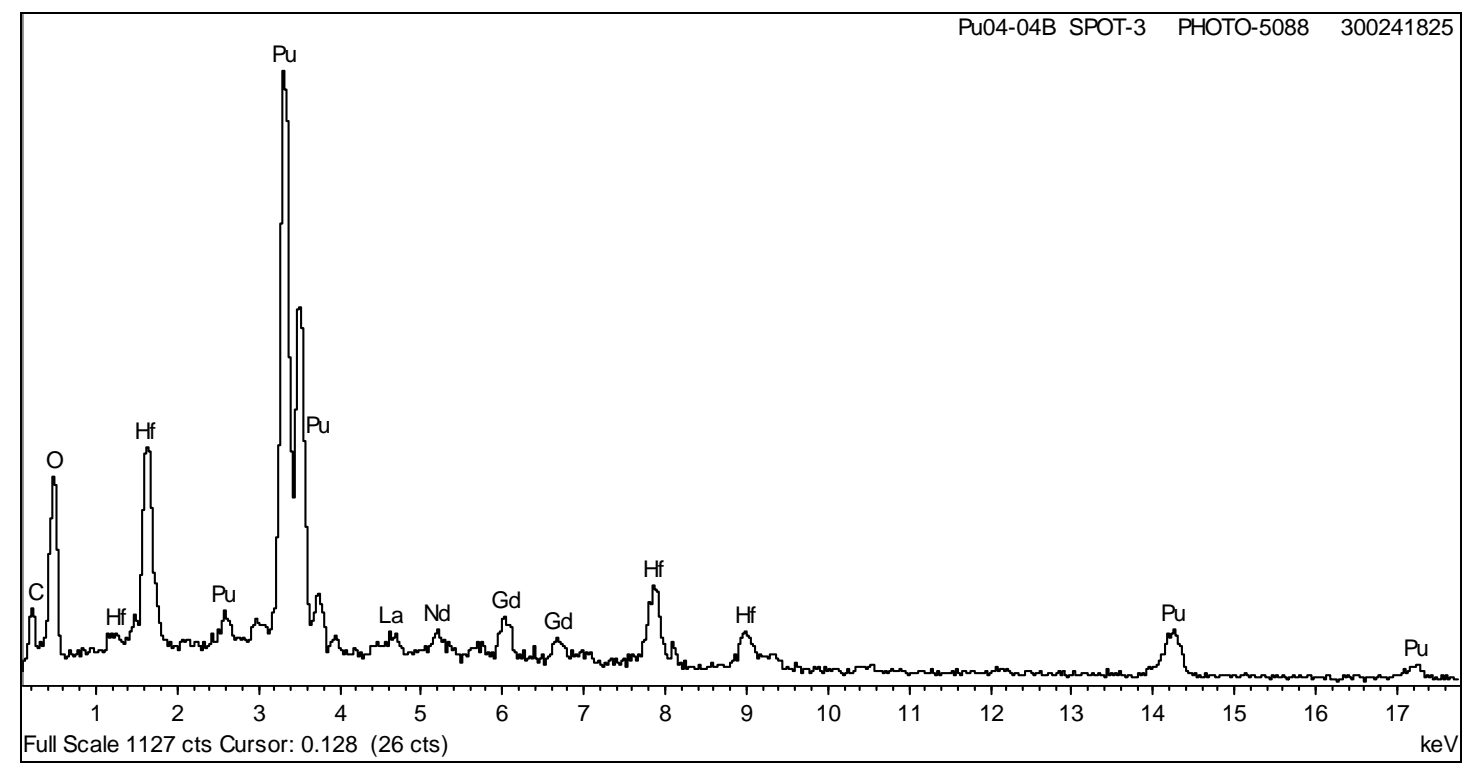

Figure 3-11. EDS spectrum collected at Spot-3 in Figure 3-10. 


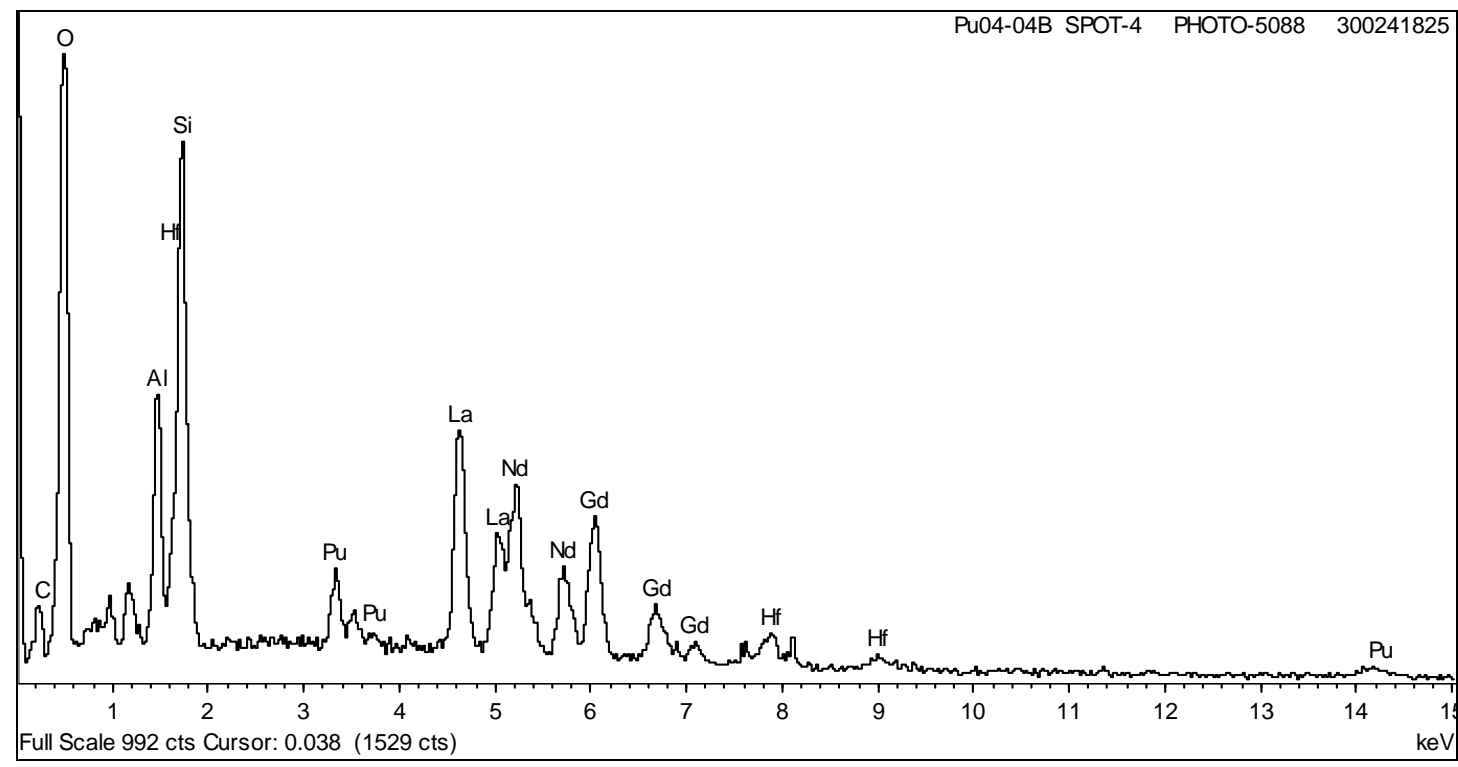

Figure 3-12. EDS spectrum recorded at Spot-4 in Figure 3-10.

A Pu-containing crystalline phase with the morphology shown in Figure 3-10 has been identified in a previous study of Pu-bearing LaBS glasses. ${ }^{9}$ The authors of that study identified this phase as a solid solution of $\mathrm{PuO}_{2}$ and $\mathrm{HfO}_{2}{ }^{9}$. Additional work is necessary to better characterize the effect that this phase has, if any, on durability of the glass.

A small amount of crystallization was identified in glass Pu35-03B via SEM. The crystallization appeared to be confined to the faces of individual particles of the glass, as indicated by the arrows in Figure 3-13. It is possible that these crystals were nucleated at the interface between the glass and the platinum crucible, which may explain why they are limited to only single faces of a small number of glass particles. Alternatively, some $\mathrm{PuO}_{2}$ may have sunk to the bottom of the crucible, exceeding the solubility limit of the glass at the bottom and resulting in crystallization of a small amount of $\mathrm{PuO}_{2}$. 


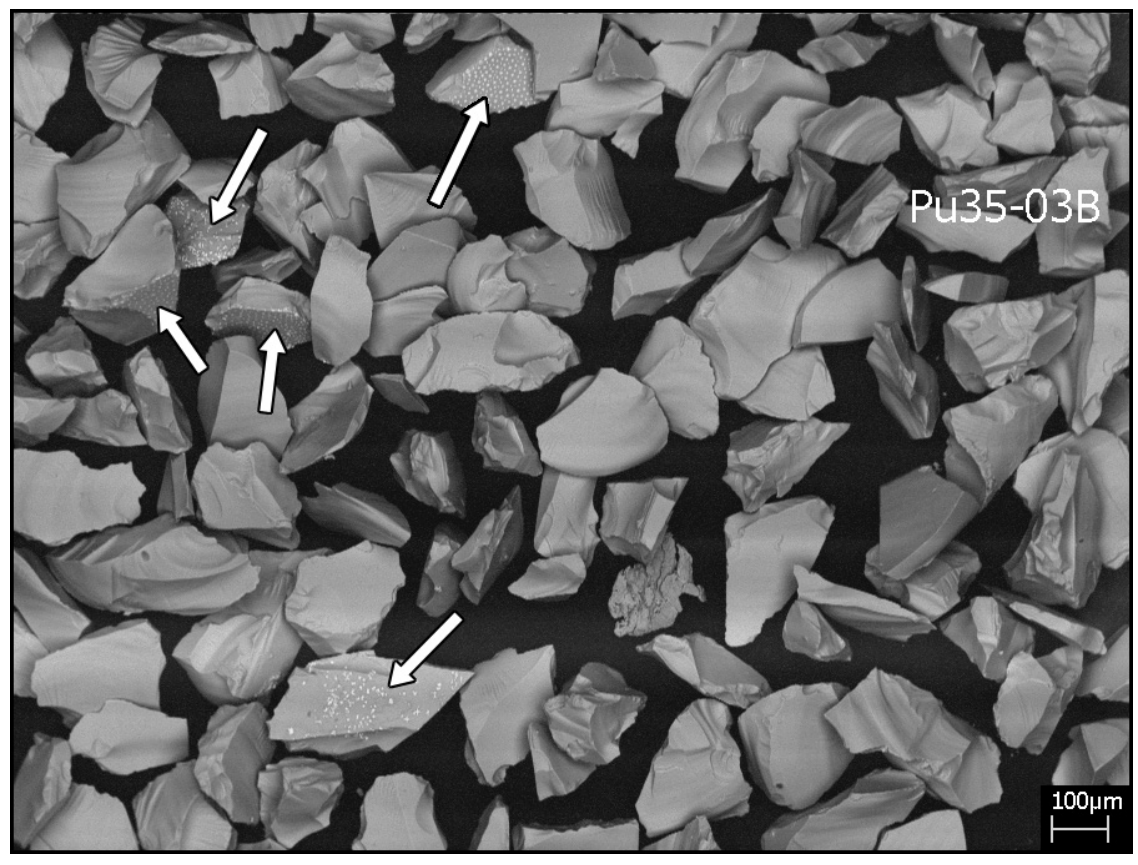

Figure 3-13. SEM micrograph of glass Pu35-03B. The arrows indicate crystallization on the faces of some of the glass particles.

The crystalline phases in this glass included two morphologies, a simple cube or sphere shape, and a cross shape (as seen in glass Pu04-04B). These morphologies are shown at higher magnification in Figure 3-14. EDS was used to compare the composition of each of these phases (Spot-1 and Spot-3) with the glass matrix (Spot-2).

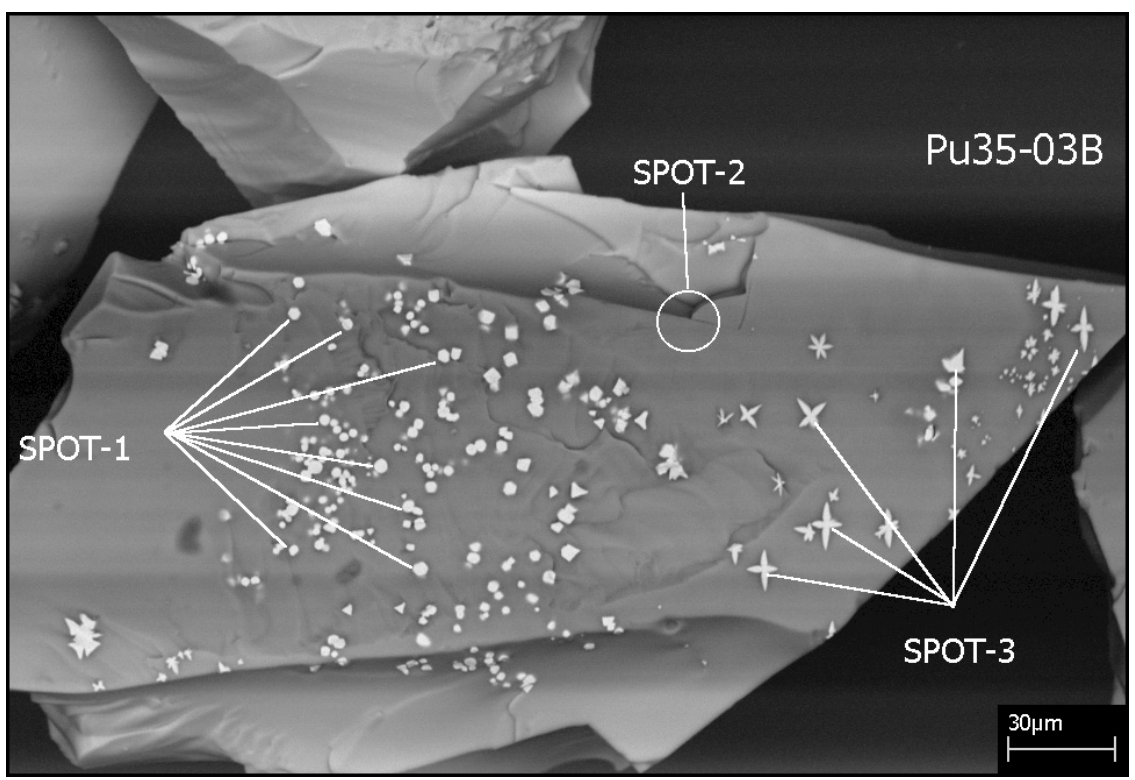

Figure 3-14. Higher magnification SEM micrograph of the two crystalline phases identified in glass Pu35-03B. Areas analyzed by EDS are indicated. 
The EDS spectra are shown in Figure 3-15. The relative intensities of the EDS peaks for Spot-1 indicate that this phase consists mainly of $\mathrm{Pu}$. The EDS spectrum collected at Spot-3 indicates that this phase consists mainly of $\mathrm{Hf}$ and $\mathrm{Pu}$, similar to the crystalline phase in glass Pu04-04B. 


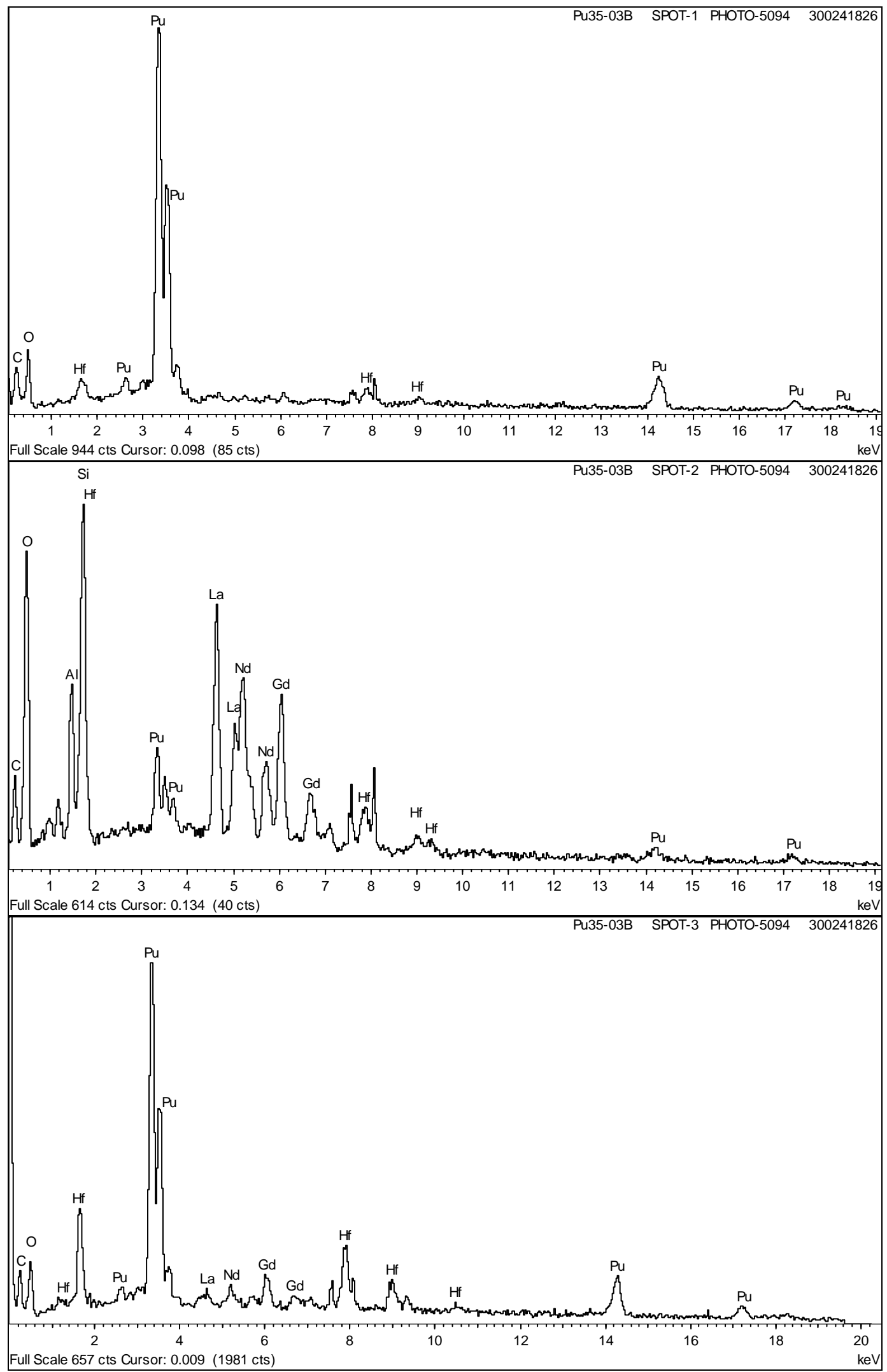

Figure 3-15. EDS spectra corresponding to the spots identified in Figure 3-14. 
The SEM results for glasses Pu35-06B and Pu35-17B were similar to each other. Both glasses were generally free of crystallization (Figure 3-16 and Figure 3-17), but a small amount of the cross-shaped phase was identified in each glass (Figure 3-18 and Figure 3-19). EDS spectra were collected for each glass, and the results were similar to those for the cross-shaped phases identified in glasses Pu04-04B and Pu35-03B. Again, additional work needs to be performed to characterize the influence of this crystalline phase on the performance of the glass.

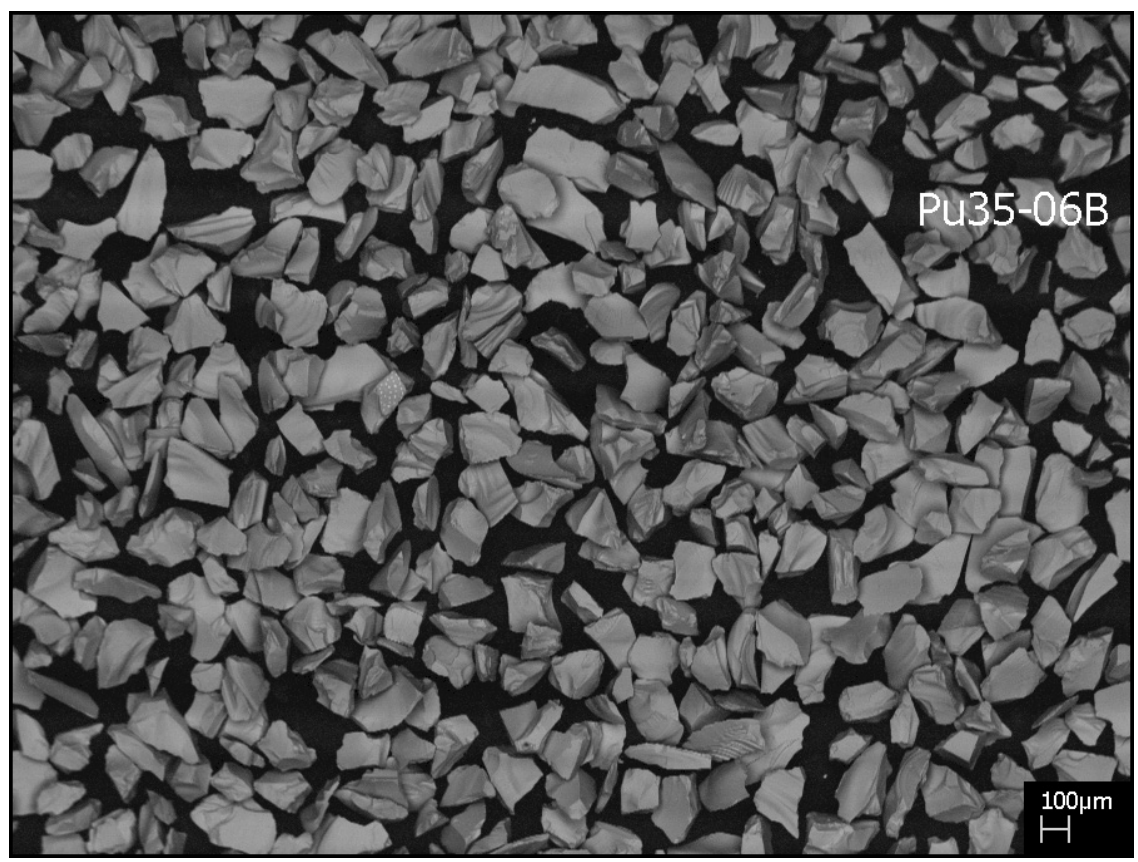

Figure 3-16. SEM micrograph of glass Pu35-06B. 


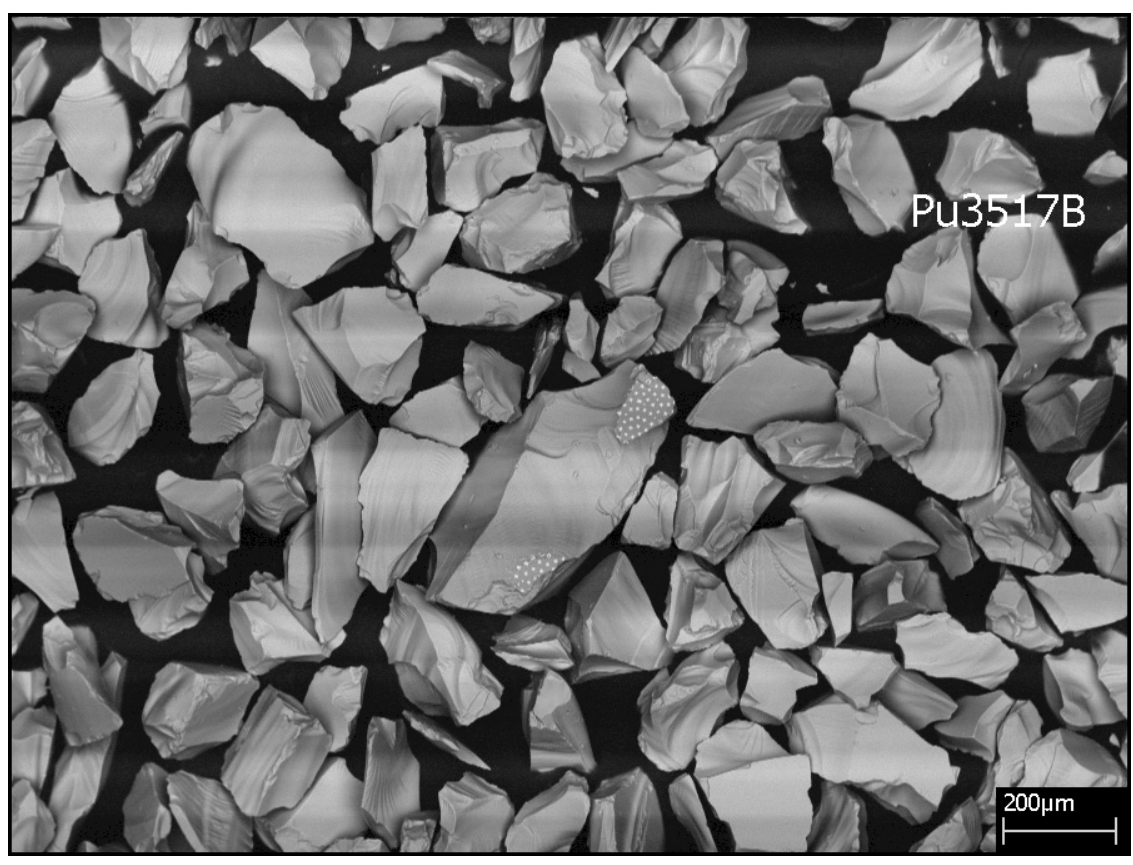

Figure 3-17. SEM micrograph of glass Pu35-17B. Some crystalline material is visible at the center of the image.

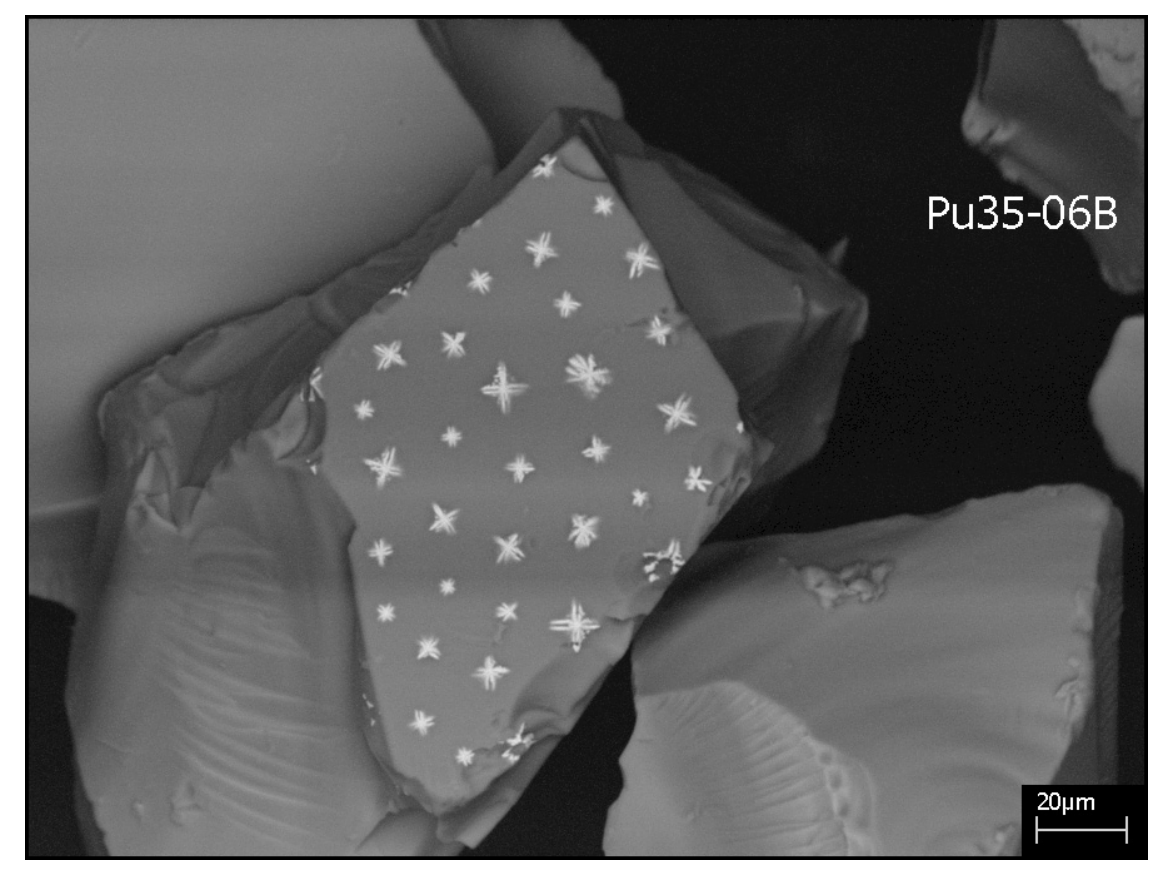

Figure 3-18. Higher magnification SEM micrograph of glass Pu35-06B, showing an area of crystallization on the face of a glass particle. 


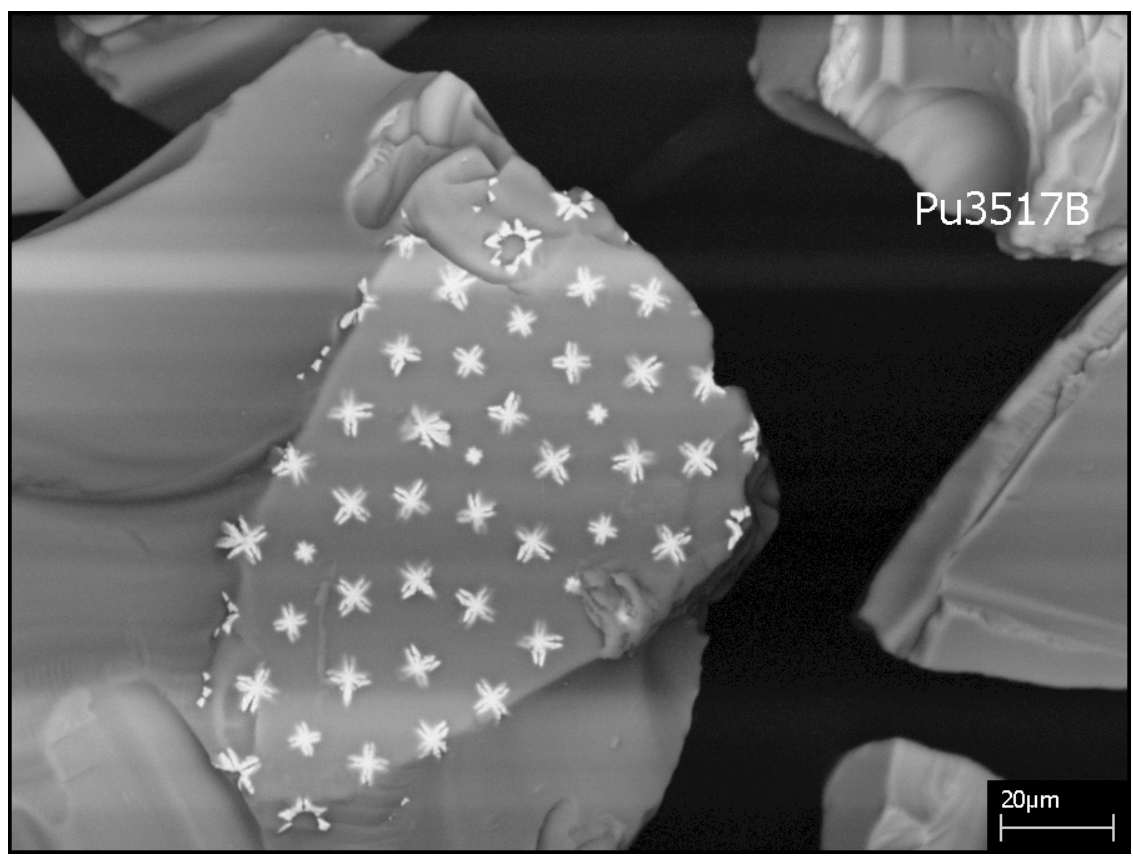

Figure 3-19. Higher magnification SEM micrograph of glass Pu35-17B, showing an area of crystallization on the face of a glass particle.

\subsubsection{Normalized PCT Results}

The four different $\mathrm{PuO}_{2}$-containing glasses were leach tested in two separate PCTs via remote handling in the SRNL shielded cells facility. The PCT Method $\mathrm{A}^{16}$ was followed using a 10:1 mass ratio of leachant to glass. Each PCT included two $\mathrm{PuO}_{2}$-containing glasses and the EA and ARM reference glasses, all in triplicate. Two blanks (ASTM Type I water only) were also included with each PCT. Leachates for the $\mathrm{PuO}_{2}$-containing glasses were analyzed by both ICPAES (for B, Na and Si concentrations) and Inductively Coupled Plasma - Mass Spectroscopy (ICP-MS) (for $\mathrm{La}, \mathrm{Nd}, \mathrm{Gd}, \mathrm{Hf}$ and Pu concentrations). Samples of a multielement standard solution were included with the leachates submitted for ICP-AES analysis.

The measured ARM glass leachate concentrations for PCT \#1 and PCT \#2 and the control range values are given in Table 3-7. The measured values for the ARM glass for both PCTs all fell within the specified control limits. ${ }^{14}$ All of the multielement standard solution concentrations, also shown in Table 3-7, agreed with the standard values to within $\pm 4 \%$.

Table 3-7. PCT results for the ARM reference glass and multielement standard solution included with the $\mathrm{PuO}_{2}$ glasses.

\begin{tabular}{||c|c|c|c||}
\hline & B (ppm) & Na (ppm) & Si (ppm) \\
\hline Control values & $12.9-22.7$ & $28.9-43.6$ & $49.0-73.4$ \\
\hline ARM (PCT \#1) & $16.8 \pm 0.8$ & $35.9 \pm 1.5$ & $62.2 \pm 1.8$ \\
\hline ARM (PCT \#2) & $17.7 \pm 0.1$ & $37.5 \pm 0.3$ & $64.2 \pm 0.4$ \\
\hline & & & 50.0 \\
\hline Standard values & 20.0 & 81.0 & 50.3 \\
\hline Standard Sol'n (PCT \#1) & 19.3 & 79.6 & 51.2 \\
\hline Standard Sol'n (PCT \#2) & 19.6 & 80.8 & \\
\hline
\end{tabular}


The leachate concentrations for the $\mathrm{PuO}_{2}$-containing glasses were normalized using the target compositions as described in Section 3.4.4. The average normalized release values for PCT \#1 (Pu04-04B and Pu35-03B) and PCT \#2 (Pu35-06B and Pu35-17B) are summarized in Table 3-8. Data for the EA glass are also shown. Measurements that were below the analytical detection limit are indicated by a "<". Comparison of the EA glass results from the two different PCTs to the reference values indicates that $\mathrm{NL}(\mathrm{B})$ and $\mathrm{NL}(\mathrm{Na})$ average values were slightly below the range of EA reference values for PCT \#1. The NL(Si) average is within the (average - one standard deviation) of the reference $\mathrm{NL}(\mathrm{Si})$. All of the measured EA values for PCT \#2 are in good agreement with the EA reference values.

Table 3-8. PCT results for the glasses fabricated with $\mathrm{PuO}_{2}$.

\begin{tabular}{||c|c|c|c|c|c|c|c|c|c||}
\hline Glass ID & $\begin{array}{c}\text { NL B } \\
(\mathbf{g} / \mathbf{L})\end{array}$ & $\begin{array}{c}\text { NL Na } \\
(\mathbf{g} / \mathbf{L})\end{array}$ & $\begin{array}{c}\text { NL Si } \\
(\mathbf{g} / \mathbf{L})\end{array}$ & $\begin{array}{c}\text { NL La } \\
(\mathbf{g} / \mathbf{L})\end{array}$ & $\begin{array}{c}\text { NL Nd } \\
(\mathbf{g} / \mathbf{L})\end{array}$ & $\begin{array}{c}\text { NL Gd } \\
(\mathbf{g} / \mathbf{L})\end{array}$ & $\begin{array}{c}\text { NL Hf } \\
(\mathbf{g} / \mathbf{L})\end{array}$ & $\begin{array}{c}\text { NL Pu } \\
(\mathbf{g} / \mathbf{L})\end{array}$ & $\mathbf{p H}$ \\
\hline Pu04-04B & 0.020 & $<1.587$ & 0.022 & 0.0003 & 0.0001 & 0.0002 & $<0.0001$ & 0.0096 & $7.15 \pm 0.4$ \\
\hline Pu35-03B & 0.014 & $<0.085$ & 0.017 & 0.0001 & 0.0000 & 0.0000 & $<0.0001$ & 0.0061 & $7.56 \pm 0.3$ \\
\hline Pu35-06B & 0.017 & $<0.158$ & 0.017 & 0.0002 & 0.0001 & 0.0001 & $<0.0001$ & 0.0061 & $6.91 \pm 0.4$ \\
\hline Pu35-17B & 0.015 & $<0.122$ & 0.016 & 0.0002 & 0.0001 & 0.0001 & $<0.0001$ & 0.0074 & $6.57 \pm 0.2$ \\
\hline EA (PCT \#1) & 15.171 & 11.885 & 3.649 & - & - & - & - & - & $11.49 \pm 0.05$ \\
\hline EA (PCT \#2) & 16.943 & 13.119 & 3.968 & - & - & - & - & - & $11.64 \pm 0.01$ \\
\hline
\end{tabular}

${ }^{*}$ The reference NL values for the EA glass are $16.695 \pm 1.222 \mathrm{~g} / \mathrm{L}$ for B, $13.346 \pm 0.902 \mathrm{~g} / \mathrm{L}$ for Na, $3.922 \pm 0.376 \mathrm{~g} / \mathrm{L}$ for $\mathrm{Si}$, and a $\mathrm{pH}$ of $11.85 \pm 0.1 .^{17}$

The $\mathrm{NL}(\mathrm{B})$ values for the $\mathrm{PuO}_{2}$-containing glasses are considerably lower than the $\mathrm{EA}$ reference value of 16.695. ${ }^{17}$ Overall, the normalized release results for the $\mathrm{PuO}_{2}$-containing glasses with impurities are similar in magnitude to previous testing performed on $\mathrm{PuO}_{2}$-containing glasses without any impurities present. ${ }^{18,19}$

Average $\mathrm{pH}$ values for the leachates are shown in the last column of Table 3-8, with the precisions indicating the standard deviation of the three triplicate measurements. Note that, as was observed for the surrogate glasses, the $\mathrm{pH}$ of the leachate solutions was generally lower than that of conventional HLW glasses developed for defense-related radioactive waste sludges (typically 10.5) due to the lack of alkali in the LaBS glass. The leachate solution is less corrosive to the glass matrix at a lower $\mathrm{pH}$, so it is likely that this impacted the PCT results (i.e., a poorer PCT response may be measured if a higher $\mathrm{pH}$ solution, more typical of alkaliborosilicate HLW glasses, is used). 
WSRC-STI-2007-00477

Revision 0

This page intentionally left blank. 
WSRC-STI-2007-00477

Revision 0

\subsection{Conclusions}

Sixty surrogate glass compositions were developed through a statistically designed approach to cover the anticipated ranges of concentrations for several impurity species expected in the Pu feed. An additional four glass compositions containing actual $\mathrm{PuO}_{2}$ were selected based on their targeted concentrations of metals and anions. The glasses were fabricated and characterized in the laboratory and shielded cells facility to determine the degree of retention of the impurity components, the impact of the impurities on the durability of each glass, and the degree of crystallization that occurred, both upon quenching and slow cooling.

Overall, the LaBS glass system appears to be very tolerant of most of the impurity types and concentrations projected in the $\mathrm{Pu}$ waste stream. For the surrogate glasses, the measured $\mathrm{CuO}$, $\mathrm{Ga}_{2} \mathrm{O}_{3}, \mathrm{Na}_{2} \mathrm{O}, \mathrm{NiO}$, and $\mathrm{Ta}_{2} \mathrm{O}_{5}$ concentrations fell very close to their target values across the ranges of concentrations targeted in this study for each of these components. The measured $\mathrm{CaO}$ and $\mathrm{PbO}$ concentrations were consistently higher than the targeted values. The measured $\mathrm{Cr}_{2} \mathrm{O}_{3}$ and $\mathrm{Fe}_{2} \mathrm{O}_{3}$ concentrations were very close to the targets except for the one highest targeted value for each of these components. A solubility limit may have been approached in this glass system for $\mathrm{K}_{2} \mathrm{O}$ and $\mathrm{MgO}$. The measured $\mathrm{Cl}^{-}, \mathrm{F}^{-}, \mathrm{SeO}_{2}$ and $\mathrm{SO}_{4}{ }^{2-}$ concentrations were well below their target values for all of the study glasses. This is likely due to volatilization of these species during melting of the glass batch. Note that the degree of volatilization that occurred in this crucible-scale study may differ from the full-scale melter. The measured $\mathrm{HfO}_{2}$ concentrations were below their target values for all of the surrogate glasses. It is likely that for $\mathrm{HfO}_{2}$, the solubility limit in the glass was exceeded and some of the $\mathrm{HfO}_{2}$ batch material remained in the bottom of the crucibles after pouring the glasses.

XRD and SEM results indicated that some crystalline $\mathrm{HfO}_{2}$ remained in some of the surrogate glasses with the lowest concentration of impurities. No other crystalline phases were identified. The PCT results showed that all 60 of the surrogate glass compositions tested were very durable, with the highest normalized release for boron being $0.041 \mathrm{~g} / \mathrm{L}$. Note that the $\mathrm{pH}$ of the leachate solutions (typically $\sim 8.0$ ) was generally lower than that of conventional HLW glasses developed for defense-related radioactive waste sludges (typically 10.5 ) due to the lack of alkali in the LaBS glass. The leachate solution is less corrosive to the glass matrix at a lower $\mathrm{pH}$, so it is likely that this impacted the PCT results (i.e., a poorer PCT response may be measured if a higher $\mathrm{pH}$ solution, more typical of alkaliborosilicate HLW glasses, is used). The normalized release rates for the elements measured were generally too small to attempt to correlate the results with the compositions of the test glasses. The TCLP results showed that no RCRA hazardous metals were leached from the surrogate glasses in any measurable concentration.

A Pu-containing crystalline phase with a cross-shaped morphology was identified via SEM in the glasses fabricated with $\mathrm{PuO}_{2}$. This phase was identified in a previous study of Pu-bearing $\mathrm{LaBS}$ glasses and may provide an opportunity to intentionally crystallize some of the $\mathrm{PuO}_{2}$ into a highly insoluble form with an intrinsic neutron absorber. ${ }^{9}$ Additional work is necessary to better characterize the influence that this phase has on durability of the glass.

The PCT results for the plutonium-containing LaBS glasses with impurities were similar to previous tests conducted on $\mathrm{PuO}_{2}$-containing glasses without impurities added. The highest normalized release for boron was $0.02 \mathrm{~g} / \mathrm{L}$, which bounded the highest normalized release for plutonium of $0.01 \mathrm{~g} / \mathrm{L}$. 
WSRC-STI-2007-00477

Revision 0

This page intentionally left blank. 


\subsection{Findings}

- The LaBS glass system appears to be a viable solution for vitrification and immobilization of impure Pu feeds.

- The downstream impacts of the impurities that were identified in this study as being volatile should be further examined.

- Future updates to the impurity projections in the expected $\mathrm{Pu}$ feed streams will likely require additional experimental work.

- It may be beneficial for the future studies to consider equilibrium conditions and oxidation/reduction in determining solubility limits.

- It may be appropriate for additional durability studies to examine the effects of higher $\mathrm{pH}$ leaching solutions on the performance of the LaBS glass.

- Further characterization should be performed on the $\mathrm{Pu} / \mathrm{Hf}$ crystalline phase identified in the glasses fabricated with $\mathrm{PuO}_{2}$. 
WSRC-STI-2007-00477

Revision 0

This page intentionally left blank. 


\subsection{Acknowledgements}

The authors would like to thank several individuals at SRNL, including: Steve Beard, Phyllis Burkhalter, Vicki Dukes, Jack Durden, Eddie Estochen, Jim Gillam Jr., David Healy, Art Jurgenson, David Missimer, Irene Reamer, Whitney Thomas, Pat Toole, Rodney Walker, Dee Wheeler, Frances Williams, and Phyllis Workman, all of whom made significant contributions to this study. 
WSRC-STI-2007-00477

Revision 0

This page intentionally left blank. 
WSRC-STI-2007-00477

Revision 0

\subsection{References}

1. Vienna, J. D., D. L. Alexander, H. Li, M. J. Schweiger, D. K. Peeler and T. F. Meaker, "Plutonium Dioxide Dissolution in Glass," U.S. Department of Energy Report PNNL-11346, Pacific Northwest National Laboratory, Richland, WA (1996).

2. Meaker, T. F. and D. K. Peeler, "Solubility of Independent Plutonium Bearing Feed Streams in a Hf-Based LaBS Frit, contained in: Plutonium Immobilization: The Glass Option - A Compendium of Reports and Presentations," U.S. Department of Energy Report WSRC-RP-9700902, Revision 0, Westinghouse Savannah River Company, Aiken, SC (1997).

3. Smith, M. E. and G. L. Hovis, "Phase 1 Can-in-Canister Cold Pour Tests for the Plutonium Immobilization Project," U.S. Department of Energy Report WSRC-TR-99-337, Revision 0, Westinghouse Savannah River Company, Aiken, SC (1999).

4. Smith, M. E., G. L. Hovis and E. L. Hamilton, "Phase 2 Can-in-Canister Cold Pour Tests for the Plutonium Immobilization Project," U.S. Department of Energy Report WSRC-TR-2000-408, Revision 0, Westinghouse Savannah River Company, Aiken, SC (2000).

5. Moore, E. N. and J. S. Allender, "Projected Characteristics of Nominal Feeds to Plutonium Disposition Project," U.S. Department of Energy Report SRNL-OPD-2007-00008, Washington Savannah River Company, Aiken, SC (2007).

6. Fox, K. M., E. N. Hoffman, T. B. Edwards and J. C. Marra, "Defining a Glass Composition Envelope for an Impurity Variability Study to Support Plutonium Disposition," U.S. Department of Energy Report WSRC-STI-2007-00368, Revision 0, Washington Savannah River Company, Aiken, SC (2007).

7. Eisele, D. P., "Technical Task Request: Glass Formulation and Performance Testing to Support Pu Disposition," U.S. Department of Energy Report M09A-SRNL-010, Washington Savannah River Company, Aiken, SC (2007).

8. Marra, J. C., K. M. Fox and E. N. Hoffman, "Task Technical and QA Plan: Glass Formulation and Performance Testing to Support Pu Disposition," U.S. Department of Energy Report WSRCSTI-2007-00076, Revision 0, Washington Savannah River Company, Aiken, SC (2007).

9. Marra, J. C., D. K. Peeler and C. M. Jantzen, "Development of Alternative Glass Formulations for Vitrification of Excess Plutonium," U.S. Department of Energy Report WSRC-TR-2006-00031, Revision 0, Washington Savannah River Company, Aiken, SC (2006).

10. SRNL, "Glass Batching," U.S. Department of Energy Report SRTC Procedure Manual, L29, ITS-0001, Westinghouse Savannah River Company, Aiken, SC (2002).

11. Jones, T. M., J. C. Marra, D. M. Immel and B. Z. Meers, "Glass Macrocracking Determination in Prototypic Canisters Containing Lanthanide Borosilicate Glass," U.S. Department of Energy Report WSRC-TR-2006-00015, Revision 0, Washington Savannah River Company, Aiken, SC (2006). 
WSRC-STI-2007-00477

Revision 0

12. Marra, S. L. and C. M. Jantzen, "Characterization of Projected DWPF Glass Heat Treated to Simulate Canister Centerline Cooling," U.S. Department of Energy Report WSRC-TR-92-142, Revision 1, Westinghouse Savannah River Company, Aiken, SC (1993).

13. SRNL, "Glass Density Using the Mettler AT400 or Equivalent Balance," U.S. Department of Energy Report SRTC Procedure Manual, L29, ITS-0057, Washington Savannah River Company, Aiken, SC (2002).

14. Jantzen, C. M., J. B. Picket, K. G. Brown, T. B. Edwards and D. C. Beam, "Process/Product Models for the Defense Waste Processing Facility (DWPF): Part I. Predicting Glass Durability from Composition Using a Thermodynamic Hydration Energy Reaction Model (THERMO)," U.S. Department of Energy Report WSRC-TR-93-672, Revision 1, Westinghouse Savannah River Company, Aiken, SC (1995).

15. Ebert, W. L. and S. F. Wolfe, "Round-robin Testing of a Reference Glass for Low-Activity Waste Forms," U.S. Department of Energy Report ANL-99/22, Argonne National Laboratory, Argonne, IL (1999).

16. ASTM, "Standard Test Methods for Determining Chemical Durability of Nuclear Waste Glasses: The Product Consistency Test (PCT)," ASTM C-1285, (2002).

17. Jantzen, C. M., N. E. Bibler, D. C. Beam, C. L. Crawford and M. A. Pickett, "Characterization of the Defense Waste Processing Facility (DWPF) Environmental Assessment (EA) Glass Standard Reference Material," U.S. Department of Energy Report WSRC-TR-92-346, Revision 1, Westinghouse Savannah River Company, Aiken, SC (1993).

18. Marra, J. C., C. L. Crawford and N. E. Bibler, "Glass Fabrication and Product Consistency Testing of Lanthanide Borosilicate Frit B Composition for Plutonium Disposition," U.S. Department of Energy Report WSRC-TR-2006-00033, Revision 0, Washington Savannah River Company, Aiken, SC (2006).

19. Marra, J. C., C. L. Crawford and N. E. Bibler, "Glass Fabrication and Product Consistency Testing of Lanthanide Borosilicate Frit X Composition for Plutonium Disposition," U.S. Department of Energy Report WSRC-STI-2006-00318, Revision 0, Washington Savannah River Company, Aiken, SC (2006). 


\section{Appendix A}

\section{SRNL-SCS-2007-00014}

An Analytical Plan for Measuring the Chemical Composition of Glasses Fabricated as Part of the Study of Impurity Solubility

During Pu Vitrification 
From:

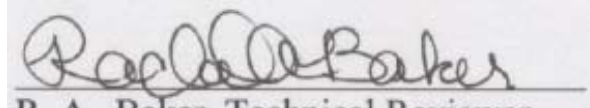

R. A. Baker, Technical Reviewer

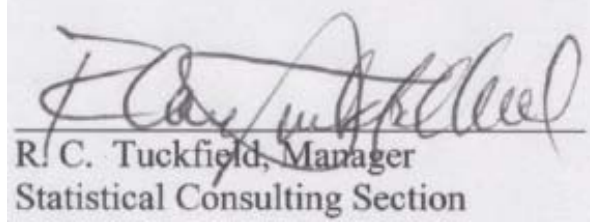

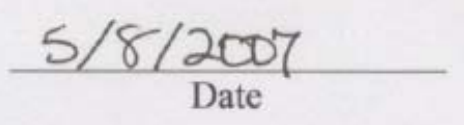

Date

Date

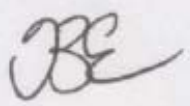

\section{An Analytical Plan for Measuring the Chemical Composition of Glasses Fabricated as Part of the Study of Impurity Solubility During Pu Vitrification (U)}




\subsection{EXECUTIVE SUMMARY}

A glass study (WSRC-STI-2007-00076) is underway at the Savannah River National Laboratory (SRNL) to investigate glass formulations and to conduct performance testing to support plutonium $(\mathrm{Pu})$ disposition. Sixty (60) glasses have been selected to be batched and fabricated as part of this study. The selection of these 60 compositions is to be addressed in a separate report. The chemical compositions of the study glasses are to be measured by SRNL's Process Science Analytical Laboratory (PSAL). The measurements for each glass are to be reviewed to assess their closeness to the intended target composition for the glass. This memorandum provides an analytical plan to direct and support the measurement of the chemical compositions of the samples at PSAL. 
WSRC-STI-2007-00477

Revision 0

Appendix A (SNRL-SCS-2007-00014)

\subsection{INTRODUCTION}

A glass study is underway at the Savannah River National Laboratory (SRNL) to investigate glass formulations and to conduct performance testing to support plutonium $(\mathrm{Pu})$ disposition [1]. Sixty (60) glasses have been selected to be batched and fabricated as part of this study. The selection of these 60 compositions is to be addressed in a separate report. The chemical compositions of these glasses are to be measured by SRNL's Process Science Analytical Laboratory (PSAL). The measurements for each glass are to be reviewed to assess their closeness to the intended target composition for the glass. This memorandum provides an analytical plan to direct and support the measurement of the chemical compositions of the samples at PSAL.

Due to the large number of glasses in this study, the glasses are to be grouped into six sets for chemical composition measurements with each group being handled separately. This memorandum provides an analytical plan structured in a manner that facilitates these measurements in sets by PSAL.

\subsection{Anal ytical Plan}

Two preparation methods, lithium metaborate fusion (LM) and sodium peroxide fusion (PF), are to be used by PSAL to determine cation concentrations for each glass sample using Inductively Coupled Plasma - Atomic Emission Spectrometry (ICP-AES). The anion concentrations of interest for these glasses are to be measured using Ion Chromatography (IC). The preparation method for this analytical procedure will be designated as "ic" in this plan. Each glass is to be prepared in duplicate by the LM, PF, and "ic" methods.

Since this is an impurity solubility study, targeting and measuring small concentrations of several analytes (both cations and anions) in glass are of interest. Table A1 in the Appendix (in 2 parts) provides the target compositions for each of the study glasses. These compositions are being provided to PSAL to assist them in adjusting dilution factors and/or other aspects of their analytical approach to allow better sensitivity to the small concentrations being targeted for some of the analytes. As a consequence, there will be no use of "blind" sample identifiers in this study.

The measurements of interest for this study are to be acquired as follows. The samples prepared by $\mathrm{LM}$ are to be measured for aluminum $(\mathrm{Al})$, calcium $(\mathrm{Ca})$, chromium $(\mathrm{Cr})$, copper $(\mathrm{Cu})$, iron $(\mathrm{Fe})$, gallium $(\mathrm{Ga})$, gadolinium $(\mathrm{Gd})$, hafnium $(\mathrm{Hf})$, potassium $(\mathrm{K})$, lanthanum $(\mathrm{La})$, magnesium $(\mathrm{Mg})$, sodium $(\mathrm{Na})$, neodymium $(\mathrm{Nd})$, nickel $(\mathrm{Ni})$, lead $(\mathrm{Pb})$, sulfur $(\mathrm{S})$, selenium $(\mathrm{Se})$, silicon $(\mathrm{Si})$, strontium ( $\mathrm{Sr}$ ), and tantalum (Ta) concentrations. Samples prepared by PF are to be measured for boron (B) concentrations. Samples dissolved by both of these preparation methods are to be measured using ICP-AES. Samples prepared for IC are to be measured for the following anions: chlorine $(\mathrm{Cl})$ and fluorine $(\mathrm{F})$. It should also be noted that some of the glasses were batched with carbon (C) and/or cesium (Cs), so these components may be present in some of the study glasses as well.

Randomizing the preparation steps and randomizing the measurements by ICP-AES and by IC are of primary concern in the development of this analytical plan. The sources of uncertainty for the analytical procedure used by PSAL to determine the cation concentrations for the submitted glass samples are dominated by the dissolution step in the preparation of the sample and by instrument calibrations. 
WSRC-STI-2007-00477

Revision 0

Appendix A (SNRL-SCS-2007-00014)

Samples of glass standards will be included in the analytical plan to provide an opportunity for checking the performance of the instrumentation over the course of the analyses and for potential bias correction for each set of results. Specifically, samples of Waste Compliance Plan (WCP) Batch 1 (BCH) [2] (see Table 1 for the reference composition of Batch 1) and samples of the Low-Activity Reference Material (LRM) standard glass (which contains some of the anions of interest - see [3] for details on the chemical composition of this glass) are to be included in the sets of samples submitted to PSAL.

Table 1: Oxide Compositions of WCP Batch 1 (BCH)

\begin{tabular}{|c|c|}
\hline $\begin{array}{c}\text { Oxide/ } \\
\text { Anion }\end{array}$ & $\begin{array}{c}\text { BCH } \\
\text { (wt \%) }\end{array}$ \\
\hline $\mathrm{Al}_{2} \mathrm{O}_{3}$ & 4.877 \\
\hline $\mathrm{B}_{2} \mathrm{O}_{3}$ & 7.777 \\
\hline $\mathrm{BaO}$ & 0.151 \\
\hline $\mathrm{CaO}$ & 1.22 \\
\hline $\mathrm{Cr}_{2} \mathrm{O}_{3}$ & 0.107 \\
\hline $\mathrm{Cs}_{2} \mathrm{O}$ & 0.06 \\
\hline $\mathrm{CuO}$ & 0.399 \\
\hline $\mathrm{Fe}_{2} \mathrm{O}_{3}$ & 12.839 \\
\hline $\mathrm{K}_{2} \mathrm{O}$ & 3.327 \\
\hline $\mathrm{Li}_{2} \mathrm{O}$ & 4.429 \\
\hline $\mathrm{MgO}$ & 1.419 \\
\hline $\mathrm{MnO}_{\mathrm{Na} O}$ & 1.726 \\
\hline $\mathrm{Na}_{2} \mathrm{O}$ & 9.003 \\
\hline $\mathrm{Nd}_{2} \mathrm{O}_{3}$ & 0.147 \\
\hline $\mathrm{NiO}_{20}$ & 0.751 \\
\hline $\mathrm{RuO}_{2}$ & 0.0214 \\
\hline $\mathrm{SiO}_{2}$ & 50.22 \\
\hline $\mathrm{SO}_{4}$ & $\sim 0$ \\
\hline $\mathrm{TiO}_{2}$ & 0.677 \\
\hline $\mathrm{U}_{3} \mathrm{O}_{8}$ & $\sim 0$ \\
\hline $\mathrm{ZrO}_{2}$ & 0.098 \\
\hline
\end{tabular}

Each glass sample submitted to PSAL will be prepared twice by the LM, the PF, and the "ic" dissolution methods. Every LM- and PF-prepared sample will be read only once by ICP-AES, and every sample prepared by the "ic" method will read only once by IC. This will lead to two measurements for each cation and anion of interest for each submitted glass.

Table 2 presents identifying codes, B01 through B60, for the 60 glass samples (by glass set) developed for this study. The table provides a short-hand naming convention (randomization as part of this naming convention was not used) that is to be employed in analyzing the glasses and reporting the measurements of their compositions. 
Table 2: "Short-Hand" Sample Identifiers for Use at PSAL for All Six Sets of Analyses

\begin{tabular}{|c|c|c|c|c|c|c|c|c|c|c|c|}
\hline \multicolumn{2}{|c|}{ SET 1} & \multicolumn{2}{|c|}{ SET 2} & \multicolumn{2}{|c|}{ SET 3} & \multicolumn{2}{|c|}{ SET 4} & \multicolumn{2}{|c|}{ SET 5} & \multicolumn{2}{|c|}{ SET 6} \\
\hline $\begin{array}{c}\text { Glass } \\
\text { ID }\end{array}$ & $\begin{array}{c}\text { Sample } \\
\text { ID }\end{array}$ & $\begin{array}{c}\text { Glass } \\
\text { ID }\end{array}$ & $\begin{array}{c}\text { Sample } \\
\text { ID }\end{array}$ & $\begin{array}{c}\text { Glass } \\
\text { ID }\end{array}$ & $\begin{array}{c}\text { Sample } \\
\text { ID }\end{array}$ & $\begin{array}{c}\text { Glass } \\
\text { ID }\end{array}$ & $\begin{array}{c}\text { Sample } \\
\text { ID }\end{array}$ & $\begin{array}{c}\text { Glass } \\
\text { ID }\end{array}$ & $\begin{array}{c}\text { Sample } \\
\text { ID }\end{array}$ & $\begin{array}{c}\text { Glass } \\
\text { ID }\end{array}$ & $\begin{array}{c}\text { Sample } \\
\text { ID }\end{array}$ \\
\hline $\mathrm{Pu} 04-01$ & B01 & Pu35-06 & B11 & Pu35-16 & B21 & $\mathrm{Pu} 35-26$ & B31 & Pu35-36 & B41 & Pu35-46 & B51 \\
\hline $\mathrm{Pu04-02}$ & $\mathrm{B} 02$ & Pu35-07 & B12 & Pu35-17 & $\mathrm{B} 22$ & Pu35-27 & B32 & Pu35-37 & B42 & Pu35-47 & B52 \\
\hline $\mathrm{Pu04-03}$ & B03 & Pu35-08 & B13 & Pu35-18 & B23 & Pu35-28 & B33 & Pu35-38 & B43 & $\mathrm{Pu} 35-48$ & B53 \\
\hline $\mathrm{Pu04-04}$ & B04 & Pu35-09 & B14 & Pu35-19 & B24 & Pu35-29 & B34 & Pu35-39 & B44 & Pu35-49 & B54 \\
\hline $\mathrm{Pu04-05}$ & B05 & Pu35-10 & B15 & Pu35-20 & $\mathrm{B} 25$ & $\mathrm{Pu} 35-30$ & B35 & $\mathrm{Pu} 35-40$ & B45 & Pu35-50 & B55 \\
\hline Pu35-01 & B06 & Pu35-11 & B16 & Pu35-21 & B26 & Pu35-31 & B36 & Pu35-41 & B46 & Pu35-51 & B56 \\
\hline Pu35-02 & B07 & Pu35-12 & $\mathrm{B} 17$ & Pu35-22 & B27 & $\mathrm{Pu} 35-32$ & B37 & $\mathrm{Pu} 35-42$ & B47 & Pu35-52 & B57 \\
\hline Pu35-03 & B08 & Pu35-13 & B18 & Pu35-23 & B28 & Pu35-33 & B38 & $\mathrm{Pu} 35-43$ & B48 & Pu35-53 & B58 \\
\hline Pu35-04 & B09 & Pu35-14 & B19 & Pu35-24 & B29 & Pu35-34 & B39 & Pu35-44 & B49 & Pu35-54 & B59 \\
\hline Pu35-05 & B10 & Pu35-15 & B20 & Pu35-25 & B30 & $\mathrm{Pu} 35-35$ & B40 & $\mathrm{Pu} 35-45$ & $\mathrm{~B} 50$ & Pu35-55 & B60 \\
\hline
\end{tabular}


WSRC-STI-2007-00477

Revision 0

Appendix A (SNRL-SCS-2007-00014)

\subsection{PREPARATION OF THE SAMPLES}

Each glass in each of the six sets of glasses covered in this analytical plan is to be prepared twice by the LM, twice by the PF, and twice by the "ic" dissolution methods. Thus, the total number of prepared glass samples in each of the six sets is determined by $10 \times 3 \times 2=60$; this does not include the samples of the $\mathrm{BCH}$ and LRM glass standards that are to be prepared.

Table 3 provides blocking and (random) sequencing schema for conducting the preparation steps of the analytical procedures for each set of glasses. One block of preparation work is provided for each preparation method to facilitate the scheduling of activities by work shift for a set of glasses. The identifier for each of the prepared samples indicates the sample identifier (ID) and preparation method along with the number to indicate the preparation number for the sample.

Table 3a: Preparation Blocks by Method for Sets 1, 2, and 3

\begin{tabular}{|c|c|c|c|c|c|c|c|c|}
\hline \multicolumn{3}{|c|}{$\begin{array}{l}\text { SET } 1 \\
\end{array}$} & \multicolumn{3}{|c|}{ SET 2} & \multicolumn{3}{|c|}{ SET 3} \\
\hline LM & PF & “ic" & LM & PF & "ic" & LM & PF & "ic" \\
\hline$\overline{\text { B01LM1 }}$ & B04PF1 & B09ic1 & $\overline{\mathrm{B} 17 \mathrm{LM} 1}$ & B13PF1 & B13ic1 & B27LM1 & $\mathrm{B} 27 \mathrm{PF} 1$ & B25ic1 \\
\hline B10LM1 & B08PF1 & B06ic1 & B17LM2 & $\mathrm{B} 17 \mathrm{PF} 1$ & B20ic1 & B27LM2 & B27PF2 & B22ic1 \\
\hline B10LM2 & B06PF1 & B07ic1 & B11LM1 & $\mathrm{B} 15 \mathrm{PF} 1$ & B18ic1 & B30LM1 & $\mathrm{B} 30 \mathrm{PF} 1$ & B30ic1 \\
\hline B02LM1 & B07PF1 & B10ic1 & B15LM1 & B17PF2 & B19ic1 & B28LM1 & B28PF1 & \\
\hline B06LM1 & B02PF1 & B05ic1 & B20LM1 & B19PF1 & B14ic1 & B29LM1 & B29PF1 & B27ic1 \\
\hline B01LM2 & B07PF2 & B08ic1 & B18LM1 & B12PF1 & B16ic1 & B29LM2 & B29PF2 & B28ic2 \\
\hline B07LM1 & B02PF2 & B05ic2 & B18LM2 & B13PF2 & B13ic2 & B30LM2 & B30PF2 & B25ic2 \\
\hline B09LM1 & $\mathrm{B} 05 \mathrm{PF} 1$ & B06ic2 & B16LM1 & $\mathrm{B} 19 \mathrm{PF} 2$ & B20ic2 & B28LM2 & $\mathrm{B} 28 \mathrm{PF} 2$ & B23ic1 \\
\hline B06LM2 & B05PF2 & B03ic1 & B20LM2 & B20PF1 & B11ic1 & B26LM1 & B26PF1 & B22ic2 \\
\hline B02LM2 & B10PF1 & B04ic1 & B14LM1 & B14PF1 & B15ic1 & B24LM1 & B24PF1 & B30ic2 \\
\hline B04LM1 & B03PF1 & B07ic2 & B12LM1 & B16PF1 & B17ic1 & B23LM1 & B23PF1 & B27ic2 \\
\hline B03LM1 & B01PF1 & B02ic1 & B15LM2 & $\mathrm{B} 15 \mathrm{PF} 2$ & B18ic2 & B21LM1 & $\mathrm{B} 21 \mathrm{PF} 1$ & B26ic1 \\
\hline B07LM2 & B04PF2 & B09ic2 & B12LM2 & B20PF2 & B19ic2 & B21LM2 & B21PF2 & B21ic1 \\
\hline B08LM1 & B10PF2 & B10ic2 & B16LM2 & B12PF2 & B16ic2 & B22LM1 & B22PF1 & B23ic2 \\
\hline B03LM2 & B06PF2 & B08ic2 & B11LM2 & B16PF2 & B12ic1 & B25LM1 & B25PF1 & B29ic1 \\
\hline B09LM2 & B08PF2 & B03ic2 & B13LM1 & B11PF1 & B14ic2 & B26LM2 & B26PF2 & B24ic1 \\
\hline B05LM1 & B01PF2 & B01ic1 & B14LM2 & B18PF1 & B11ic2 & B23LM2 & B23PF2 & B24ic2 \\
\hline B04LM2 & B03PF2 & B04ic2 & B19LM1 & B14PF2 & B12ic2 & B25LM2 & B25PF2 & B21ic2 \\
\hline B08LM2 & B09PF1 & B02ic2 & B19LM2 & B11PF2 & B15ic2 & B24LM2 & B24PF2 & B26ic2 \\
\hline B05LM2 & B09PF2 & B01ic2 & B13LM2 & $\mathrm{B} 18 \mathrm{PF} 2$ & B17ic2 & B22LM2 & $\mathrm{B} 22 \mathrm{PF} 2$ & B29ic2 \\
\hline
\end{tabular}


WSRC-STI-2007-00477

Revision 0

Appendix A (SNRL-SCS-2007-00014)

Table 3b: Preparation Blocks by Method for Sets 4, 5, and 6

\begin{tabular}{|c|c|c|c|c|c|c|c|c|}
\hline \multicolumn{3}{|c|}{ SET 4} & \multicolumn{3}{|c|}{ SET 5} & \multicolumn{3}{|c|}{ SET 6} \\
\hline LM & PF & “ic" & LM & PF & “ic" & LM & PF & “ic" \\
\hline B35LM1 & B40PF1 & B38ic1 & B45LM1 & B46PF1 & B46ic1 & B53LM1 & B52PF1 & B60ic1 \\
\hline B37LM1 & B31PF1 & B33ic1 & B43LM1 & B46PF2 & B46ic2 & B60LM1 & B58PF1 & B56ic1 \\
\hline B37LM2 & B32PF1 & B32ic1 & B42LM1 & B44PF1 & B50ic1 & B56LM1 & B57PF1 & B54ic1 \\
\hline B35LM2 & B34PF1 & B37ic1 & B41LM1 & B48PF1 & B48ic1 & B54LM1 & B51PF1 & B59ic1 \\
\hline B33LM1 & B35PF1 & B35ic1 & B48LM1 & B41PF1 & B45ic1 & B57LM1 & B58PF2 & B58ic1 \\
\hline B32LM1 & B40PF2 & B39ic1 & B45LM2 & B43PF1 & B47ic1 & B54LM2 & B54PF1 & B53ic1 \\
\hline B34LM1 & B31PF2 & B38ic2 & B47LM1 & B44PF2 & B49ic1 & B53LM2 & B52PF2 & B60ic2 \\
\hline B33LM2 & $\mathrm{B} 32 \mathrm{PF} 2$ & B35ic2 & B43LM2 & B47PF1 & B50ic2 & B60LM2 & B54PF2 & B54ic2 \\
\hline B34LM2 & $\mathrm{B} 35 \mathrm{PF} 2$ & B32ic2 & B42LM2 & $\mathrm{B} 45 \mathrm{PF} 1$ & B43ic1 & B58LM1 & B55PF1 & B56ic2 \\
\hline B31LM1 & B37PF1 & B36ic1 & B46LM1 & B41PF2 & B48ic2 & B56LM2 & B57PF2 & B55ic1 \\
\hline B36LM1 & B34PF2 & B34ic1 & B41LM2 & B43PF2 & B42ic1 & B55LM1 & B55PF2 & B58ic2 \\
\hline B40LM1 & B33PF1 & B33ic2 & B50LM1 & $\mathrm{B} 42 \mathrm{PF} 1$ & B47ic2 & B57LM2 & B51PF2 & B52ic1 \\
\hline B39LM1 & B38PF1 & B31ic1 & B49LM1 & B48PF2 & B45ic2 & B59LM1 & B60PF1 & B51ic1 \\
\hline B38LM1 & B36PF1 & B37ic2 & $\overline{B 47 L M 2}$ & B47PF2 & B44ic1 & B51LM1 & B53PF1 & B53ic2 \\
\hline B38LM2 & B39PF1 & B34ic2 & B48LM2 & B49PF1 & B43ic2 & B58LM2 & B59PF1 & B59ic2 \\
\hline B32LM2 & B37PF2 & B40ic1 & B44LM1 & B50PF1 & B41ic1 & B51LM2 & B53PF2 & B57ic1 \\
\hline B40LM2 & B39PF2 & B40ic2 & B44LM2 & $\mathrm{B} 45 \mathrm{PF} 2$ & B42ic2 & B55LM2 & B56PF1 & B55ic2 \\
\hline$\overline{\text { B31LM2 }}$ & B33PF2 & B39ic2 & $\overline{\text { B46LM2 }}$ & $\mathrm{B} 42 \mathrm{PF} 2$ & $\bar{B} 44 i c 2$ & B52LM1 & B60PF2 & $\overline{\text { B52ic2 }}$ \\
\hline B36LM2 & $\mathrm{B} 38 \mathrm{PF} 2$ & B36ic2 & B50LM2 & B49PF2 & B49ic2 & B59LM2 & B59PF2 & B51ic2 \\
\hline B39LM2 & B36PF2 & B31ic2 & B49LM2 & $\mathrm{B} 50 \mathrm{PF} 2$ & B41ic2 & B52LM2 & B56PF2 & B57ic2 \\
\hline
\end{tabular}

\subsection{ICP-AES Calibration Blocks}

Cations of interest are to be measured in those glass samples prepared by the LM and PF dissolution methods using ICP-AES instrumentation calibrated for the particular preparation method. Similarly, the IC instrumentation is to be used to measure the glasses prepared by the "ic" method for anions of interest.

Randomized plans for measuring cation concentrations in the LM-prepared and PF-prepared samples and anions in the "ic"-prepared samples are provided in Table 4 for each of the sets of glasses. The identifiers for the BCH and LRM samples have been modified to indicate the set of glasses to which they correspond and that each of these prepared standards is to be read 3 times (mirrored in the corresponding suffix of 1,2 , or 3 ) per analytical set. 
Table 4a: ICP-AES Blocks by Preparation Method \& IC Block for Set 1

\begin{tabular}{|c|c|c|}
\hline LM ICP-AES & PF ICP-AES & IC \\
\hline BCHLM11 & BCHPF11 & BCHic11 \\
\hline LRMLM11 & LRMPF11 & LRMic11 \\
\hline B09LM1 & B10PF1 & B02ic2 \\
\hline B06LM1 & B01PF1 & B06ic1 \\
\hline B03LM1 & B01PF2 & B01ic2 \\
\hline B07LM2 & B02PF2 & B10ic1 \\
\hline B02LM1 & B04PF2 & B08ic2 \\
\hline B08LM2 & B07PF1 & B03ic1 \\
\hline B10LM1 & B06PF1 & B09ic2 \\
\hline B09LM2 & $\mathrm{B} 06 \mathrm{PF} 2$ & B04ic2 \\
\hline B05LM2 & B04PF1 & B08ic1 \\
\hline B05LM1 & B05PF1 & B09ic1 \\
\hline BCHLM12 & BCHPF12 & BCHic12 \\
\hline LRMLM12 & LRMPF12 & LRMic12 \\
\hline B10LM2 & B07PF2 & B04ic1 \\
\hline B01LM1 & B03PF1 & B01ic1 \\
\hline B08LM1 & B10PF2 & B07ic2 \\
\hline B02LM2 & B05PF2 & B02ic1 \\
\hline B04LM1 & B08PF2 & B03ic2 \\
\hline B07LM1 & B09PF1 & B07ic1 \\
\hline B01LM2 & B02PF1 & B06ic2 \\
\hline B06LM2 & B08PF1 & B05ic2 \\
\hline B04LM2 & B03PF2 & B05ic1 \\
\hline B03LM2 & B09PF2 & B10ic2 \\
\hline LRMLM13 & BCHPF13 & BCHic13 \\
\hline BCHLM13 & LRMPF13 & LRMic13 \\
\hline
\end{tabular}

Table 4b: ICP-AES Blocks by Preparation Method \& IC Block for Set 2

\begin{tabular}{|c|c|c|}
\hline LM ICP-AES & PF ICP-AES & IC \\
\hline BCHLM21 & BCHPF21 & BCHic21 \\
\hline LRMLM21 & LRMPF21 & LRMic21 \\
\hline B18LM1 & B17PF2 & B13ic1 \\
\hline B19LM1 & B16PF1 & B17ic2 \\
\hline B20LM1 & B17PF1 & B16ic1 \\
\hline B20LM2 & B13PF2 & B18ic1 \\
\hline B12LM1 & B15PF1 & B14ic2 \\
\hline B16LM2 & B20PF2 & B19ic1 \\
\hline B15LM2 & B15PF2 & B15ic1 \\
\hline B14LM2 & B19PF1 & B16ic2 \\
\hline B13LM2 & B16PF2 & B11ic2 \\
\hline B17LM1 & B14PF1 & B12ic1 \\
\hline BCHLM22 & BCHPF22 & BCHic22 \\
\hline LRMLM22 & LRMPF22 & LRMic22 \\
\hline B18LM2 & B14PF2 & B12ic2 \\
\hline B19LM2 & B12PF1 & B18ic2 \\
\hline B15LM1 & B13PF1 & B20ic2 \\
\hline B13LM1 & B18PF2 & B20ic1 \\
\hline B17LM2 & B11PF1 & B13ic2 \\
\hline B16LM1 & B11PF2 & B15ic2 \\
\hline B11LM1 & B12PF2 & B17ic1 \\
\hline B11LM2 & B18PF1 & B19ic2 \\
\hline B12LM2 & B20PF1 & B14ic1 \\
\hline B14LM1 & B19PF2 & B11ic1 \\
\hline LRMLM23 & BCHPF23 & BCHic23 \\
\hline BCHLM23 & LRMPF23 & LRMic23 \\
\hline
\end{tabular}

1.1.1.1.1.1.1.1.2 
Table 4c: ICP-AES Blocks by Preparation Method \& IC Block for Set 3

\begin{tabular}{||c|c|c||}
\hline LM ICP-AES & PF ICP-AES & IC \\
\hline BCHLM31 & BCHPF31 & BCHic31 \\
\hline LRMLM31 & LRMPF31 & LRMic31 \\
\hline B29LM1 & B21PF1 & B29ic2 \\
\hline B30LM2 & B30PF1 & B25ic2 \\
\hline B23LM1 & B24PF1 & B21ic2 \\
\hline B27LM2 & B26PF2 & B28ic2 \\
\hline B30LM1 & B28PF1 & B28ic1 \\
\hline B25LM1 & B27PF1 & B30ic1 \\
\hline B21LM2 & B26PF1 & B23ic2 \\
\hline B23LM2 & B23PF2 & B26ic2 \\
\hline B27LM1 & B25PF2 & B25ic1 \\
\hline B25LM2 & B30PF2 & B27ic2 \\
\hline BCHLM32 & BCHPF32 & BCHic32 \\
\hline LRMLM32 & LRMPF32 & LRMic32 \\
\hline B26LM1 & B23PF1 & B27ic1 \\
\hline B28LM1 & B29PF1 & B26ic1 \\
\hline B26LM2 & B21PF2 & B23ic1 \\
\hline B29LM2 & B22PF1 & B24ic1 \\
\hline B22LM1 & B25PF1 & B22ic2 \\
\hline B21LM1 & B22PF2 & B24ic2 \\
\hline B22LM2 & B28PF2 & B29ic1 \\
\hline B24LM1 & B29PF2 & B30ic2 \\
\hline B24LM2 & B27PF2 & B21ic1 \\
\hline B28LM2 & B24PF2 & B22ic1 \\
\hline LRMLM33 & BCHPF33 & BCHic33 \\
\hline BCHLM33 & LRMPF33 & LRMic33 \\
\hline \hline
\end{tabular}

Table 4d: ICP-AES Blocks by Preparation Method \& IC Block for Set 4

\begin{tabular}{|c|c|c||}
\hline LM ICP-AES & PF ICP-AES & IC \\
\hline BCHLM41 & BCHPF41 & BCHic41 \\
\hline LRMLM41 & LRMPF41 & LRMic41 \\
\hline B32LM1 & B34PF2 & B33ic2 \\
\hline B38LM1 & B31PF2 & B33ic1 \\
\hline B33LM1 & B33PF2 & B37ic2 \\
\hline B35LM1 & B38PF2 & B31ic1 \\
\hline B31LM1 & B34PF1 & B32ic2 \\
\hline B39LM2 & B37PF2 & B40ic1 \\
\hline B37LM1 & B35PF2 & B39ic1 \\
\hline B39LM1 & B37PF1 & B35ic2 \\
\hline B33LM2 & B39PF2 & B34ic2 \\
\hline B40LM2 & B39PF1 & B37ic1 \\
\hline BCHLM42 & BCHPF42 & BCHic42 \\
\hline LRMLM42 & LRMPF42 & LRMic42 \\
\hline B36LM2 & B40PF1 & B35ic1 \\
\hline B31LM2 & B36PF1 & B39ic2 \\
\hline B38LM2 & B35PF1 & B38ic2 \\
\hline B40LM1 & B36PF2 & B40ic2 \\
\hline B37LM2 & B32PF1 & B31ic2 \\
\hline B36LM1 & B38PF1 & B32ic1 \\
\hline B34LM1 & B32PF2 & B36ic2 \\
\hline B32LM2 & B31PF1 & B36ic1 \\
\hline B35LM2 & B40PF2 & B34ic1 \\
\hline B34LM2 & B33PF1 & B38ic1 \\
\hline LRMLM43 & BCHPF43 & BCHic43 \\
\hline BCHLM43 & LRMPF43 & LRMic43 \\
\hline
\end{tabular}

1.1.1.1.1.1.1.4 
Table 4e: ICP-AES Blocks by Preparation Method \& IC Block for Set 5

\begin{tabular}{|c|c|c|}
\hline LM ICP-AES & PF ICP-AES & IC \\
\hline BCHLM51 & BCHPF51 & BCHic51 \\
\hline LRMLM51 & LRMPF51 & LRMic51 \\
\hline B45LM2 & B46PF2 & B44ic1 \\
\hline B49LM2 & B44PF1 & B48ic1 \\
\hline B43LM2 & B45PF1 & B41ic1 \\
\hline B50LM2 & B47PF1 & B50ic2 \\
\hline B45LM1 & B46PF1 & B45ic2 \\
\hline B43LM1 & B49PF2 & B49ic1 \\
\hline B41LM2 & B43PF2 & B46ic2 \\
\hline B49LM1 & B45PF2 & B42ic1 \\
\hline B42LM2 & B41PF1 & B47ic1 \\
\hline B44LM2 & B42PF1 & B43ic2 \\
\hline BCHLM52 & BCHPF52 & BCHic52 \\
\hline LRMLM52 & LRMPF52 & LRMic52 \\
\hline B42LM1 & B50PF2 & B41ic2 \\
\hline B48LM2 & B48PF2 & B49ic2 \\
\hline B50LM1 & B44PF2 & B47ic2 \\
\hline B47LM1 & B47PF2 & B48ic2 \\
\hline B48LM1 & B43PF1 & B42ic2 \\
\hline B41LM1 & B50PF1 & B45ic1 \\
\hline B46LM2 & B41PF2 & B43ic1 \\
\hline B44LM1 & B42PF2 & B50ic1 \\
\hline B47LM2 & B49PF1 & B46ic1 \\
\hline B46LM1 & B48PF1 & B44ic2 \\
\hline LRMLM53 & BCHPF53 & BCHic53 \\
\hline BCHLM53 & LRMPF53 & LRMic53 \\
\hline
\end{tabular}

Table 4f: ICP-AES Blocks by Preparation Method \& IC Block for Set 6

\begin{tabular}{|c|c|c||}
\hline LM ICP-AES & PF ICP-AES & IC \\
\hline BCHLM61 & BCHPF61 & BCHic61 \\
\hline LRMLM61 & LRMPF61 & LRMic61 \\
\hline B58LM2 & B59PF1 & B53ic1 \\
\hline B56LM2 & B53PF1 & B60ic2 \\
\hline B53LM2 & B60PF2 & B51ic1 \\
\hline B52LM1 & B58PF2 & B52ic1 \\
\hline B59LM1 & B54PF1 & B60ic1 \\
\hline B58LM1 & B55PF1 & B56ic2 \\
\hline B57LM2 & B59PF2 & B56ic1 \\
\hline B54LM2 & B52PF2 & B59ic1 \\
\hline B55LM1 & B54PF2 & B54ic2 \\
\hline B59LM2 & B53PF2 & B57ic2 \\
\hline BCHLM62 & BCHPF62 & BCHic62 \\
\hline LRMLM62 & LRMPF62 & LRMic62 \\
\hline B51LM1 & B60PF1 & B58ic1 \\
\hline B51LM2 & B55PF2 & B52ic2 \\
\hline B54LM1 & B51PF1 & B57ic1 \\
\hline B57LM1 & B56PF2 & B53ic2 \\
\hline B60LM2 & B56PF1 & B55ic2 \\
\hline B56LM1 & B51PF2 & B51ic2 \\
\hline B55LM2 & B58PF1 & B58ic2 \\
\hline B53LM1 & B52PF1 & B54ic1 \\
\hline B60LM1 & B57PF1 & B59ic2 \\
\hline B52LM2 & B57PF2 & B55ic1 \\
\hline LRMLM63 & BCHPF63 & BCHic63 \\
\hline BCHLM63 & LRMPF63 & LRMic63 \\
\hline \hline
\end{tabular}

1.1.1.1.1.1.1.1.6 
WSRC-STI-2007-00477

Revision 0

Appendix A (SNRL-SCS-2007-00014)

\subsection{CONCLUding COMMENTS}

In summary, this analytical plan identifies for each of the six sets of glasses: three preparation blocks in Table 3 and two ICP-AES blocks and one IC block in Table 4 for use by PSAL. The sequencing of the activities associated with each of the steps in the analytical procedures has been randomized. The size of each of the blocks was selected so that it could be completed in a single work shift.

If a problem is discovered while measuring samples in a calibration block, the instrument should be re-calibrated and the block of samples re-measured in its entirety. If for some reason the measurements are not conducted in the sequences presented in this report, a record should be made of the actual order used along with any explanative comments.

The analytical plan indicated in the preceding tables should be modified by the personnel of PSAL to include any calibration check standards and/or other standards that are part of their routine operating procedures. It is also recommended that the solutions resulting from each of the prepared samples be archived for some period, considering the "shelf-life" of the solutions, in case questions arise during data analysis. This would allow for the solutions to be rerun without additional preparations, thus minimizing cost.

\subsection{REFERENCES}

[1] Marra, J.C., K.M. Fox, and E.N. Hoffman, "Task Technical \& QA Plan: Glass Formulation and Performance Testing to Support Pu Disposition," WSRC-STI-200700076 , February 2007.

[2] Jantzen, C.M., J.B. Pickett, K.G. Brown, T.B. Edwards, and D.C. Beam, "Process/ Product Models for the Defense Waste Processing Facility (DWPF): Part I. Predicting Glass Durability from Composition Using a Thermodynamic Hydration Energy Reaction Model (THERMO ${ }^{\mathrm{TM}}$ ) (U)," WSRC-TR-93-673, Revision 1, Volume 2, Table B.1, pp. B.9, 1995.

[3] Ebert, W.L. and S.F. Wolf, "Round-Robin Testing of a Reference Glass for Low-Activity Waste Forms," ANL-99/22, Argonne National Laboratory, Argonne, IL, October 1999. 


\section{Appendix}

Table A1. Selected Compositions for Study Glasses (part 1)

\begin{tabular}{|c|c|c|c|c|c|c|c|c|c|c|c|c|c|c|c|c|c|}
\hline Glass ID & $\mathrm{Cl}$ & Ta2O5 & MgO & $\mathrm{K} 2 \mathrm{O}$ & Fe2O3 & $\mathrm{Na2O}$ & $\mathbf{F}$ & $\mathrm{CaO}$ & Ga2O3 & $\mathrm{NiO}$ & Cr2O3 & $\mathrm{CuO}$ & SO4 & C & PbO & $\mathrm{SeO} 2$ & Cs2O \\
\hline Pu04-01 & 0.30 & 0.00 & 0.00 & 0.54 & 0.00 & 0.60 & 0.00 & 0.00 & 0.00 & 0.00 & 0.00 & 0.00 & 0.00 & 0.00 & 0.00 & 0.00 & 0.00 \\
\hline Pu04-02 & 0.00 & 0.00 & 0.20 & 0.18 & 0.00 & 0.80 & 0.30 & 0.00 & 0.00 & 0.00 & 0.00 & 0.00 & 0.00 & 0.00 & 0.00 & 0.00 & 0.00 \\
\hline $\begin{array}{l}\mathrm{Pu} 04-03 \\
\end{array}$ & 0.15 & 0.00 & 0.39 & 0.00 & 0.42 & 0.40 & 0.15 & 0.00 & 0.00 & 0.00 & 0.00 & 0.00 & 0.00 & 0.00 & 0.00 & 0.00 & 0.00 \\
\hline Pu04-04 & 0.00 & 0.00 & 0.20 & 0.18 & 0.21 & 0.20 & 0.00 & 0.21 & 0.00 & 0.19 & 0.22 & 0.18 & 0.00 & 0.00 & 0.00 & 0.00 & 0.00 \\
\hline Pu04-05 & 0.30 & 0.00 & 0.00 & 0.00 & 0.00 & 0.80 & 0.30 & 0.00 & 0.00 & 0.00 & 0.00 & 0.00 & 0.00 & 0.00 & 0.00 & 0.00 & 0.00 \\
\hline Pu35-01 & 1.44 & 0.18 & 4.05 & 0.66 & 0.98 & 1.99 & 0.00 & 0.00 & 2.36 & 0.52 & 0.00 & 0.37 & 0.00 & 0.14 & 0.00 & 0.20 & 0.00 \\
\hline Pu35-02 & 1.45 & 0.18 & 3.62 & 1.85 & 0.21 & 0.89 & 1.12 & 0.91 & 0.20 & 0.38 & 0.83 & 0.18 & 0.43 & 0.00 & 0.16 & 0.20 & 0.15 \\
\hline Pu35-03 & 1.43 & 0.46 & 1.35 & 0.76 & 0.34 & 3.71 & 0.00 & 1.93 & 1.12 & 0.18 & 1.59 & 0.00 & 0.00 & 0.00 & 0.00 & 0.00 & 0.15 \\
\hline Pu35-04 & 1.46 & 1.14 & 2.64 & 1.12 & 0.67 & 1.39 & 1.29 & 0.80 & 0.90 & 0.19 & 0.21 & 0.18 & 0.00 & 0.15 & 0.19 & 0.21 & 0.00 \\
\hline Pu35-05 & 1.44 & 0.23 & 1.31 & 1.95 & 3.29 & 0.87 & 0.00 & 0.31 & 0.73 & 0.00 & 1.60 & 0.72 & 0.00 & 0.14 & 0.19 & 0.00 & 0.15 \\
\hline Pu35-06 & 1.50 & 0.25 & 2.28 & 0.68 & 2.43 & 2.00 & 1.21 & 0.72 & 0.00 & 0.69 & 0.56 & 0.00 & 0.43 & 0.14 & 0.00 & 0.00 & 0.00 \\
\hline Pu35-07 & 1.55 & 3.24 & 1.35 & 1.06 & 0.22 & 1.53 & 0.47 & 0.49 & 0.20 & 0.94 & 0.33 & 0.39 & 0.44 & 0.15 & 0.16 & 0.00 & 0.15 \\
\hline Pu35-08 & 1.56 & 0.96 & 2.20 & 1.92 & 2.23 & 1.01 & 0.75 & 0.61 & 0.41 & 0.63 & 0.21 & 0.18 & 0.00 & 0.00 & 0.00 & 0.00 & 0.00 \\
\hline $\begin{array}{l}\text { Pu35-09 } \\
\end{array}$ & 1.60 & 0.26 & 1.33 & 3.85 & 0.00 & 2.83 & 0.00 & 0.26 & 0.34 & 0.47 & 0.21 & 0.62 & 0.44 & 0.15 & 0.19 & 0.20 & 0.00 \\
\hline Pu35-10 & 1.62 & 0.67 & 2.02 & 0.91 & 1.46 & 1.67 & 0.95 & 0.20 & 1.77 & 0.18 & 0.21 & 0.18 & 0.43 & 0.00 & 0.16 & 0.20 & 0.15 \\
\hline Pu35-11 & 1.71 & 1.74 & 2.49 & 0.95 & 0.21 & 1.72 & 0.14 & 1.01 & 0.53 & 0.42 & 1.00 & 0.00 & 0.43 & 0.14 & 0.19 & 0.20 & 0.00 \\
\hline Pu35-12 & 1.61 & 1.49 & 1.66 & 0.71 & 0.48 & 1.97 & 0.82 & 0.20 & 0.89 & 1.18 & 0.99 & 0.45 & 0.00 & 0.00 & 0.00 & 0.20 & 0.00 \\
\hline Pu35-13 & 1.94 & 2.11 & 1.89 & 1.09 & 0.94 & 2.72 & 0.15 & 0.00 & 0.20 & 0.00 & 0.92 & 0.37 & 0.00 & 0.00 & 0.19 & 0.00 & 0.15 \\
\hline Pu35-14 & 2.00 & 0.86 & 1.10 & 0.49 & 2.49 & 2.67 & 0.20 & 0.95 & 0.67 & 0.18 & 0.33 & 0.18 & 0.00 & 0.14 & 0.16 & 0.20 & 0.15 \\
\hline Pu35-15 & 2.51 & 0.00 & 1.35 & 1.46 & 0.00 & 2.21 & 0.00 & 0.00 & 3.19 & 1.49 & 0.00 & 0.00 & 0.00 & 0.00 & 0.19 & 0.00 & 0.16 \\
\hline $\begin{array}{l}\text { Pu35-16 } \\
\end{array}$ & 2.37 & 0.73 & 1.83 & 0.00 & 1.16 & 3.06 & 0.00 & 1.75 & 0.38 & 0.33 & 0.00 & 0.72 & 0.43 & 0.00 & 0.16 & 0.00 & 0.00 \\
\hline Pu35-17 & 2.76 & 1.38 & 1.00 & 1.08 & 0.00 & 2.59 & 0.15 & 0.20 & 1.71 & 0.19 & 0.79 & 0.24 & 0.44 & 0.15 & 0.00 & 0.00 & 0.00 \\
\hline Pu35-18 & 1.45 & 0.18 & 2.60 & 2.74 & 0.21 & 2.34 & 0.14 & 1.42 & 0.19 & 0.18 & 1.20 & 0.18 & 0.00 & 0.00 & 0.00 & 0.00 & 0.00 \\
\hline Pu35-19 & 1.45 & 0.18 & 3.46 & 0.93 & 1.95 & 1.94 & 0.95 & 0.20 & 0.19 & 0.18 & 1.21 & 0.18 & 0.00 & 0.00 & 0.00 & 0.00 & 0.00 \\
\hline Pu35-20 & 1.46 & 1.29 & 1.37 & 2.11 & 0.71 & 1.24 & 0.72 & 0.57 & 1.27 & 0.73 & 1.00 & 0.18 & 0.00 & 0.00 & 0.00 & 0.00 & 0.00 \\
\hline Pu35-21 & 1.45 & 2.84 & 3.20 & 1.03 & 0.21 & 1.48 & 0.15 & 0.20 & 1.56 & 0.19 & 0.21 & 0.18 & 0.00 & 0.00 & 0.00 & 0.00 & 0.00 \\
\hline Pu35-22 & 1.49 & 1.30 & 1.71 & 1.38 & 0.93 & 1.85 & 1.17 & 1.47 & 0.20 & 0.20 & 0.36 & 0.55 & 0.00 & 0.00 & 0.00 & 0.00 & 0.00 \\
\hline Pu35-23 & 1.47 & 2.06 & 1.67 & 0.39 & 1.41 & 2.34 & 0.22 & 0.39 & 1.33 & 0.29 & 0.73 & 0.54 & 0.00 & 0.00 & 0.00 & 0.00 & 0.00 \\
\hline Pu35-24 & 1.58 & 0.39 & 1.67 & 1.31 & 1.01 & 1.45 & 0.61 & 1.00 & 2.06 & 0.24 & 0.92 & 0.54 & 0.00 & 0.00 & 0.00 & 0.00 & 0.00 \\
\hline Pu35-25 & 1.66 & 1.48 & 1.21 & 1.75 & 2.07 & 1.19 & 0.18 & 0.70 & 0.65 & 0.86 & 0.43 & 0.54 & 0.00 & 0.00 & 0.00 & 0.00 & 0.00 \\
\hline Pu35-26 & 1.66 & 0.55 & 2.24 & 0.63 & 1.18 & 1.93 & 0.25 & 1.07 & 1.97 & 0.56 & 0.66 & 0.18 & 0.00 & 0.00 & 0.00 & 0.00 & 0.00 \\
\hline Pu35-27 & 1.79 & 1.67 & 1.52 & 1.31 & 1.15 & 1.62 & 0.59 & 0.81 & 0.68 & 0.19 & 1.21 & 0.18 & 0.00 & 0.00 & 0.00 & 0.00 & 0.00 \\
\hline Pu35-28 & 1.80 & 1.35 & 2.33 & 0.98 & 0.21 & 1.84 & 0.25 & 0.28 & 1.02 & 0.90 & 1.21 & 0.55 & 0.00 & 0.00 & 0.00 & 0.00 & 0.00 \\
\hline Pu35-29 & 2.10 & 0.85 & 1.17 & 2.10 & 0.45 & 2.38 & 0.89 & 0.21 & 1.75 & 0.19 & 0.21 & 0.18 & 0.00 & 0.00 & 0.00 & 0.00 & 0.00 \\
\hline Pu35-30 & 1.44 & 0.18 & 1.15 & 2.78 & 0.21 & 2.26 & 0.14 & 1.14 & 1.89 & 0.18 & 0.21 & 0.18 & 0.43 & 0.14 & 0.16 & 0.20 & 0.15 \\
\hline Pu35-31 & 1.46 & 0.18 & 1.49 & 2.81 & 2.08 & 1.18 & 1.17 & 0.20 & 0.20 & 0.43 & 0.21 & 0.18 & 0.44 & 0.15 & 0.16 & 0.20 & 0.15 \\
\hline
\end{tabular}




\section{Appendix (continued)}

Table A1. Selected Compositions for Study Glasses (part 1)

(continued)

\begin{tabular}{|c|c|c|c|c|c|c|c|c|c|c|c|c|c|c|c|c|c|}
\hline Glass ID & $\mathrm{Cl}$ & Ta2O5 & MgO & $\mathrm{K} 2 \mathrm{O}$ & Fe2O3 & $\mathrm{Na2O}$ & $\mathbf{F}$ & $\mathrm{CaO}$ & Ga2O3 & NiO & Cr2O3 & $\mathrm{CuO}$ & SO4 & C & PbO & $\mathrm{SeO} 2$ & Cs2O \\
\hline $\begin{array}{l}\text { Pu35-32 } \\
\end{array}$ & 1.45 & 0.18 & 3.47 & 0.65 & 0.21 & 1.73 & 0.99 & 0.20 & 2.26 & 0.18 & 0.21 & 0.18 & 0.43 & 0.14 & 0.16 & 0.20 & 0.15 \\
\hline Pu35-33 & 1.43 & 0.17 & 3.42 & 0.19 & 1.39 & 2.25 & 0.32 & 1.10 & 0.19 & 0.18 & 1.19 & 0.18 & 0.43 & 0.14 & 0.15 & 0.20 & 0.15 \\
\hline Pu35-34 & 1.45 & 1.78 & 3.46 & 1.44 & 0.21 & 1.20 & 0.14 & 0.91 & 0.19 & 0.18 & 0.21 & 0.54 & 0.43 & 0.14 & 0.16 & 0.20 & 0.15 \\
\hline Pu35-35 & 1.44 & 2.81 & 1.15 & 0.17 & 2.06 & 2.33 & 0.14 & 0.20 & 0.97 & 0.18 & 0.21 & 0.18 & 0.43 & 0.14 & 0.16 & 0.20 & 0.15 \\
\hline Pu35-36 & 1.50 & 1.28 & 2.23 & 1.08 & 0.27 & 1.68 & 0.41 & 0.20 & 0.77 & 0.81 & 0.93 & 0.54 & 0.43 & 0.14 & 0.16 & 0.20 & 0.15 \\
\hline Pu35-37 & 1.50 & 0.87 & 2.54 & 0.91 & 0.69 & 1.64 & 0.25 & 0.43 & 0.90 & 0.93 & 0.99 & 0.18 & 0.43 & 0.14 & 0.16 & 0.20 & 0.15 \\
\hline Pu35-38 & 1.65 & 1.31 & 1.82 & 1.12 & 0.43 & 1.65 & 0.77 & 1.07 & 0.75 & 0.45 & 0.44 & 0.18 & 0.44 & 0.15 & 0.16 & 0.20 & 0.15 \\
\hline $\begin{array}{l}\text { Pu35-39 } \\
\end{array}$ & 1.72 & 1.26 & 1.74 & 1.92 & 0.72 & 1.75 & 0.44 & 0.20 & 0.77 & 0.18 & 0.76 & 0.18 & 0.43 & 0.15 & 0.16 & 0.20 & 0.15 \\
\hline $\begin{array}{l}\text { Pu35-40 } \\
\end{array}$ & 1.80 & 0.18 & 1.61 & 1.25 & 1.40 & 1.63 & 0.36 & 1.02 & 0.97 & 0.26 & 0.80 & 0.54 & 0.43 & 0.14 & 0.16 & 0.20 & 0.15 \\
\hline Pu35-41 & 2.32 & 0.18 & 3.48 & 0.86 & 0.21 & 2.35 & 0.15 & 0.20 & 0.20 & 1.11 & 0.21 & 0.38 & 0.44 & 0.15 & 0.16 & 0.20 & 0.15 \\
\hline Pu35-42 & 1.44 & 0.53 & 2.69 & 2.09 & 0.41 & 1.95 & 0.29 & 0.40 & 0.39 & 0.37 & 0.84 & 0.36 & 0.43 & 0.14 & 0.16 & 0.20 & 0.15 \\
\hline Pu35-43 & 1.44 & 1.22 & 1.62 & 0.53 & 1.43 & 1.86 & 0.50 & 0.88 & 0.87 & 0.50 & 0.62 & 0.36 & 0.43 & 0.14 & 0.16 & 0.20 & 0.15 \\
\hline $\begin{array}{l}\text { Pu35-44 } \\
\end{array}$ & 1.44 & 1.36 & 1.99 & 0.77 & 1.45 & 1.64 & 0.47 & 0.69 & 0.75 & 0.37 & 0.62 & 0.27 & 0.43 & 0.14 & 0.16 & 0.20 & 0.15 \\
\hline Pu35-45 & 1.44 & 1.75 & 1.87 & 0.51 & 1.14 & 1.83 & 0.29 & 0.57 & 1.19 & 0.54 & 0.42 & 0.27 & 0.43 & 0.14 & 0.16 & 0.20 & 0.15 \\
\hline $\begin{array}{l}\text { Pu35-46 } \\
\end{array}$ & 1.46 & 1.13 & 1.83 & 1.03 & 0.43 & 1.57 & 0.87 & 0.43 & 1.36 & 0.74 & 0.42 & 0.36 & 0.44 & 0.15 & 0.16 & 0.20 & 0.15 \\
\hline $\begin{array}{l}\text { Pu35-47 } \\
\end{array}$ & 1.54 & 2.12 & 1.54 & 0.62 & 0.41 & 1.82 & 0.29 & 1.01 & 0.48 & 0.74 & 0.84 & 0.36 & 0.43 & 0.14 & 0.16 & 0.20 & 0.15 \\
\hline Pu35-48 & 1.57 & 0.86 & 1.99 & 0.71 & 1.24 & 1.82 & 0.51 & 0.92 & 0.85 & 0.49 & 0.57 & 0.27 & 0.43 & 0.14 & 0.16 & 0.20 & 0.15 \\
\hline $\begin{array}{l}\text { Pu35-49 } \\
\end{array}$ & 1.61 & 0.67 & 1.92 & 1.58 & 1.30 & 1.60 & 0.47 & 0.79 & 0.47 & 0.50 & 0.47 & 0.36 & 0.43 & 0.14 & 0.16 & 0.20 & 0.15 \\
\hline $\begin{array}{l}\text { Pu35-50 } \\
\end{array}$ & 1.61 & 0.45 & 1.66 & 1.72 & 1.22 & 1.64 & 0.49 & 0.66 & 0.81 & 0.59 & 0.63 & 0.27 & 0.43 & 0.14 & 0.16 & 0.20 & 0.15 \\
\hline Pu35-51 & 1.62 & 0.81 & 2.26 & 0.66 & 1.41 & 1.87 & 0.56 & 0.40 & 0.39 & 0.73 & 0.80 & 0.27 & 0.43 & 0.14 & 0.16 & 0.20 & 0.15 \\
\hline Pu35-52 & 1.73 & 0.35 & 2.04 & 0.93 & 0.98 & 1.78 & 0.35 & 0.43 & 1.45 & 0.58 & 0.81 & 0.36 & 0.43 & 0.14 & 0.16 & 0.20 & 0.15 \\
\hline Pu35-53 & 1.75 & 1.93 & 1.55 & 1.17 & 0.42 & 1.97 & 0.88 & 0.41 & 0.39 & 0.37 & 0.43 & 0.27 & 0.44 & 0.15 & 0.16 & 0.21 & 0.15 \\
\hline Pu35-54 & 1.61 & 1.16 & 2.03 & 1.43 & 1.06 & 1.74 & 0.53 & 0.69 & 1.02 & 0.41 & 0.74 & 0.32 & 0.00 & 0.00 & 0.00 & 0.00 & 0.00 \\
\hline $\begin{array}{l}\text { Pu35-55 } \\
\end{array}$ & 1.58 & 0.98 & 2.10 & 1.15 & 0.91 & 1.79 & 0.47 & 0.60 & 0.81 & 0.48 & 0.58 & 0.30 & 0.43 & 0.14 & 0.16 & 0.20 & 0.15 \\
\hline
\end{tabular}


WSRC-STI-2007-00477

Revision 0

Appendix A (SNRL-SCS-2007-00014)

\section{Appendix (continued)}

Table A1. Selected Compositions for Study Glasses (part 2)

\begin{tabular}{|c|c|c|c|c|c|c|c|c|}
\hline Glass ID & HfO2 & Al2O3 & B2O3 & Gd2O3 & La2O3 & Nd2O3 & "SiO2 & $\overline{\mathrm{SrO}}$ \\
\hline Pu04-01 & 38.12 & 6.50 & 8.45 & 8.78 & 12.35 & 9.75 & 13.00 & 1.63 \\
\hline $\mathrm{Pu} 04-02$ & 38.08 & 6.50 & 8.45 & 8.78 & 12.35 & 9.75 & 13.00 & 1.63 \\
\hline $\mathrm{Pu} 04-03$ & 38.04 & 6.50 & 8.45 & 8.78 & 12.35 & 9.75 & 13.00 & 1.63 \\
\hline $\mathrm{Pu} 04-04$ & 37.97 & 6.50 & 8.45 & 8.78 & 12.35 & 9.75 & 13.00 & 1.63 \\
\hline $\mathrm{Pu} 04-05$ & 38.16 & 6.50 & 8.45 & 8.78 & 12.35 & 9.75 & 13.00 & 1.63 \\
\hline Pu35-01 & 26.65 & 6.50 & 8.45 & 8.78 & 12.35 & 9.75 & 13.00 & 1.63 \\
\hline Pu35-02 & 26.80 & 6.50 & 8.45 & 8.78 & 12.35 & 9.75 & 13.00 & 1.63 \\
\hline Pu35-03 & 26.52 & 6.50 & 8.45 & 8.78 & 12.35 & 9.75 & 13.00 & 1.63 \\
\hline $\mathrm{Pu} 35-04$ & 27.01 & 6.50 & 8.45 & 8.78 & 12.35 & 9.75 & 13.00 & 1.63 \\
\hline Pu35-05 & 26.62 & 6.50 & 8.45 & 8.78 & 12.35 & 9.75 & 13.00 & 1.63 \\
\hline Pu35-06 & 26.66 & 6.50 & 8.45 & 8.78 & 12.35 & 9.75 & 13.00 & 1.63 \\
\hline Pu35-07 & 26.90 & 6.50 & 8.45 & 8.78 & 12.35 & 9.75 & 13.00 & 1.63 \\
\hline Pu35-08 & 26.87 & 6.50 & 8.45 & 8.78 & 12.35 & 9.75 & 13.00 & 1.63 \\
\hline Pu35-09 & 26.81 & 6.50 & 8.45 & 8.78 & 12.35 & 9.75 & 13.00 & 1.63 \\
\hline Pu35-10 & 26.75 & 6.50 & 8.45 & 8.78 & 12.35 & 9.75 & 13.00 & 1.63 \\
\hline Pu35-11 & 26.66 & 6.50 & 8.45 & 8.78 & 12.35 & 9.75 & 13.00 & 1.63 \\
\hline $\mathrm{Pu} 35-12$ & 26.89 & 6.50 & 8.45 & 8.78 & 12.35 & 9.75 & 13.00 & 1.63 \\
\hline Pu35-13 & 26.89 & 6.50 & 8.45 & 8.78 & 12.35 & 9.75 & 13.00 & 1.63 \\
\hline Pu35-14 & 26.76 & 6.50 & 8.45 & 8.78 & 12.35 & 9.75 & 13.00 & 1.63 \\
\hline Pu35-15 & 26.99 & 6.50 & 8.45 & 8.78 & 12.35 & 9.75 & 13.00 & 1.63 \\
\hline Pu35-16 & 26.63 & 6.50 & 8.45 & 8.78 & 12.35 & 9.75 & 13.00 & 1.63 \\
\hline Pu35-17 & 26.88 & 6.50 & 8.45 & 8.78 & 12.35 & 9.75 & 13.00 & 1.63 \\
\hline Pu35-18 & 26.71 & 6.50 & 8.45 & 8.78 & 12.35 & 9.75 & 13.00 & 1.63 \\
\hline Pu35-19 & 26.73 & 6.50 & 8.45 & 8.78 & 12.35 & 9.75 & 13.00 & 1.63 \\
\hline Pu35-20 & 26.89 & 6.50 & 8.45 & 8.78 & 12.35 & 9.75 & 13.00 & 1.63 \\
\hline Pu35-21 & 26.84 & 6.50 & 8.45 & 8.78 & 12.35 & 9.75 & 13.00 & 1.63 \\
\hline Pu35-22 & 26.94 & 6.50 & 8.45 & 8.78 & 12.35 & 9.75 & 13.00 & 1.63 \\
\hline Pu35-23 & 26.70 & 6.50 & 8.45 & 8.78 & 12.35 & 9.75 & 13.00 & 1.63 \\
\hline $\mathrm{Pu} 35-24$ & 26.76 & 6.50 & 8.45 & 8.78 & 12.35 & 9.75 & 13.00 & 1.63 \\
\hline Pu35-25 & 26.80 & 6.50 & 8.45 & 8.78 & 12.35 & 9.75 & 13.00 & 1.63 \\
\hline Pu35-26 & 26.66 & 6.50 & 8.45 & 8.78 & 12.35 & 9.75 & 13.00 & 1.63 \\
\hline Pu35-27 & 26.84 & 6.50 & 8.45 & 8.78 & 12.35 & 9.75 & 13.00 & 1.63 \\
\hline Pu35-28 & 26.83 & 6.50 & 8.45 & 8.78 & 12.35 & 9.75 & 13.00 & 1.63 \\
\hline Pu35-29 & 27.07 & 6.50 & 8.45 & 8.78 & 12.35 & 9.75 & 13.00 & 1.63 \\
\hline Pu35-30 & 26.69 & 6.50 & 8.45 & 8.78 & 12.35 & 9.75 & 13.00 & 1.63 \\
\hline Pu35-31 & 26.88 & 6.50 & 8.45 & 8.78 & 12.35 & 9.75 & 13.00 & 1.63 \\
\hline Pu35-32 & 26.76 & 6.50 & 8.45 & 8.78 & 12.35 & 9.75 & 13.00 & 1.63 \\
\hline Pu35-33 & 26.46 & 6.50 & 8.45 & 8.78 & 12.35 & 9.75 & 13.00 & 1.63 \\
\hline Pu35-34 & 26.73 & 6.50 & 8.45 & 8.78 & 12.35 & 9.75 & 13.00 & 1.63 \\
\hline Pu35-35 & 26.62 & 6.50 & 8.45 & 8.78 & 12.35 & 9.75 & 13.00 & 1.63 \\
\hline Pu35-36 & 26.73 & 6.50 & 8.45 & 8.78 & 12.35 & 9.75 & 13.00 & 1.63 \\
\hline Pu35-37 & 26.63 & 6.50 & 8.45 & 8.78 & 12.35 & 9.75 & 13.00 & 1.63 \\
\hline Pu35-38 & 26.82 & 6.50 & 8.45 & 8.78 & 12.35 & 9.75 & 13.00 & 1.63 \\
\hline Pu35-39 & 26.80 & 6.50 & 8.45 & 8.78 & 12.35 & 9.75 & 13.00 & 1.63 \\
\hline Pu35-40 & 26.65 & 6.50 & 8.45 & 8.78 & 12.35 & 9.75 & 13.00 & 1.63 \\
\hline Pu35-41 & 26.82 & 6.50 & 8.45 & 8.78 & 12.35 & 9.75 & 13.00 & 1.63 \\
\hline Pu35-42 & 26.70 & 6.50 & 8.45 & 8.78 & 12.35 & 9.75 & 13.00 & 1.63 \\
\hline Pu35-43 & 26.63 & 6.50 & 8.45 & 8.78 & 12.35 & 9.75 & 13.00 & 1.63 \\
\hline $\mathrm{Pu} 35-44$ & 26.65 & 6.50 & 8.45 & 8.78 & 12.35 & 9.75 & 13.00 & 1.63 \\
\hline Pu35-45 & 26.64 & 6.50 & 8.45 & 8.78 & 12.35 & 9.75 & 13.00 & 1.63 \\
\hline Pu35-46 & 26.81 & 6.50 & 8.45 & 8.78 & 12.35 & 9.75 & 13.00 & 1.63 \\
\hline Pu35-47 & 26.70 & 6.50 & 8.45 & 8.78 & 12.35 & 9.75 & 13.00 & 1.63 \\
\hline Pu35-48 & 26.66 & 6.50 & 8.45 & 8.78 & 12.35 & 9.75 & 13.00 & 1.63 \\
\hline Pu35-49 & 26.72 & 6.50 & 8.45 & 8.78 & 12.35 & 9.75 & 13.00 & 1.63 \\
\hline Pu35-50 & 26.71 & 6.50 & 8.45 & 8.78 & 12.35 & 9.75 & 13.00 & 1.63 \\
\hline
\end{tabular}


WSRC-STI-2007-00477

Revision 0

Appendix A (SNRL-SCS-2007-00014)

\section{Appendix (continued)}

Table A1. Selected Compositions for Study Glasses (part 2) (continued)

\begin{tabular}{||c|c|c|c|c|c|c|c|c||}
\hline \hline Glass ID & HfO2 & Al2O3 & B2O3 & Gd2O3 & La2O3 & Nd2O3 & SiO2 & SrO \\
\hline Pu35-51 & 26.68 & 6.50 & 8.45 & 8.78 & 12.35 & 9.75 & 13.00 & 1.63 \\
\hline Pu35-52 & 26.66 & 6.50 & 8.45 & 8.78 & 12.35 & 9.75 & 13.00 & 1.63 \\
\hline Pu35-53 & 26.92 & 6.50 & 8.45 & 8.78 & 12.35 & 9.75 & 13.00 & 1.63 \\
\hline Pu35-54 & 26.82 & 6.50 & 8.45 & 8.78 & 12.35 & 9.75 & 13.00 & 1.63 \\
\hline Pu35-55 & 26.71 & 6.50 & 8.45 & 8.78 & 12.35 & 9.75 & 13.00 & 1.63 \\
\hline
\end{tabular}




\section{Appendix B}

SRNL-SCS-2007-00019

Analytical Plans for Measuring the PCT Solutions for the Quenched Glasses Fabricated as Part of the Study of Impurity Solubility during $\mathrm{Pu}$ Vitrification 


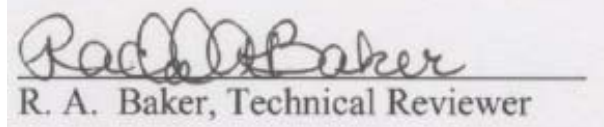

R. A. Baker, Technical Reviewer

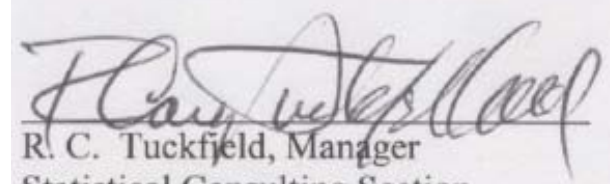

Statistical Consulting Section
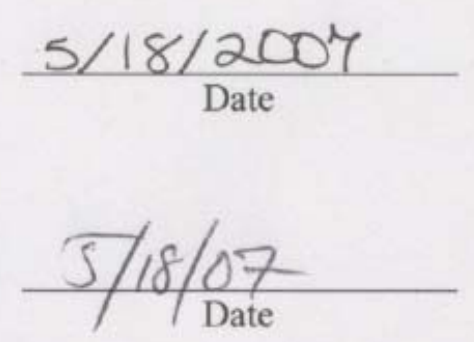

\section{Analytical Plans for Measuring the PCT Solutions for the Quenched Glasses Fabricated as Part of the Study of Impurity Solubility during Pu Vitrification (U)}


WSRC-STI-2007-00477

Revision 0

Appendix B (SRNL-SCS-2007-00019)

\subsection{EXECUTIVE SUMMARY}

A glass study (WSRC-STI-2007-00076) is underway at the Savannah River National Laboratory (SRNL) to investigate glass formulations and to conduct performance testing to support plutonium $(\mathrm{Pu})$ disposition. Sixty (60) glasses have been selected to be batched and fabricated as part of this study. The selection of these 60 compositions is to be addressed in a separate report. The durabilities of the glasses are to be measured using the Product Consistency Test (PCT) as defined in ASTM C-1285-2002. Two heat treatments are to be utilized during the fabrication of each of these glasses. Specifically, each of the glasses is to be quenched (i.e., rapidly cooled) and cooled in accordance with the centerline-canister-cooling (ccc) regime. Both heat treatments of each glass are to be subjected to the PCT. The PCT solutions are to be analyzed by SRNL's Process Science Analytical Laboratory (PSAL).

Due to the large number of glasses in this study (60 quenched and $60 \mathrm{ccc}$ glasses in total), the PCTs are to be conducted in 6 sets. Twenty glasses are to be included in each set starting with the quenched and then working through the ccc glasses. This memorandum provides analytical plans for the PCTs for the 3 sets of quenched glasses, which are labeled as Pu04-01 through Pu04-05 and Pu35-01 through Pu35-55, that are to be measured by PSAL. 
WSRC-STI-2007-00477

Revision 0

Appendix B (SRNL-SCS-2007-00019)

\subsection{INTRODUCTION}

A glass study is underway at the Savannah River National Laboratory (SRNL) to investigate glass formulations and to conduct performance testing to support plutonium $(\mathrm{Pu})$ disposition [1]. Sixty (60) glasses have been selected to be batched and fabricated as part of this study. The selection of these 60 compositions is to be addressed in a separate report. The durabilities of the glasses are to be measured using the Product Consistency Test (PCT) as defined in ASTM C-1285-2002 [2]. Two heat treatments are to be utilized during the fabrication of each of these glasses. Specifically, each of the glasses is to be quenched (i.e., rapidly cooled) and cooled in accordance with the centerline-canister-cooling (ccc) regime. Both heat treatments of each glass are to be subjected to the PCT. The PCT solutions are to be analyzed by SRNL's Process Science Analytical Laboratory (PSAL).

Due to the large number of glasses in this study (60 quenched and $60 \mathrm{ccc}$ glasses in total), the PCTs are to be conducted in 6 sets. Twenty glasses are to be included in each set starting with the quenched and then working through the ccc glasses. This memorandum provides analytical plans for the PCTs for the 3 sets of quenched glasses. The glass identifiers for each of the 3 sets of PCTs are provided in Table 1.

Table 1: Three Sets of Quenched Glass Identifiers Covered in These Plans

\begin{tabular}{||c|c|c|}
\hline Set 1 & Set 2 & Set 3 \\
\hline Pu04-01 & Pu35-16 & Pu35-36 \\
\hline Pu04-02 & Pu35-17 & Pu35-37 \\
\hline Pu04-03 & Pu35-18 & Pu35-38 \\
\hline Pu04-04 & Pu35-19 & Pu35-39 \\
\hline Pu04-05 & Pu35-20 & Pu35-40 \\
\hline Pu35-01 & Pu35-21 & Pu35-41 \\
\hline Pu35-02 & Pu35-22 & Pu35-42 \\
\hline Pu35-03 & Pu35-23 & Pu35-43 \\
\hline Pu35-04 & Pu35-24 & Pu35-44 \\
\hline Pu35-05 & Pu35-25 & Pu35-45 \\
\hline Pu35-06 & Pu35-26 & Pu35-46 \\
\hline Pu35-07 & Pu35-27 & Pu35-47 \\
\hline Pu35-08 & Pu35-28 & Pu35-48 \\
\hline Pu35-09 & Pu35-29 & Pu35-49 \\
\hline Pu35-10 & Pu35-30 & Pu35-50 \\
\hline Pu35-11 & Pu35-31 & Pu35-51 \\
\hline Pu35-12 & Pu35-32 & Pu35-52 \\
\hline Pu35-13 & Pu35-33 & Pu35-53 \\
\hline Pu35-14 & Pu35-34 & Pu35-54 \\
\hline Pu35-15 & Pu35-35 & Pu35-55 \\
\hline
\end{tabular}


WSRC-STI-2007-00477

Revision 0

Appendix B (SRNL-SCS-2007-00019)

\subsection{DISCUSSION}

Each of the 20 study glasses in each set of Table 1 is to be subjected to the PCT in triplicate. In addition to PCTs for the study glasses of the set, triplicate PCTs are to be conducted on a sample of the Approved Reference Material - One (ARM-1) glass and a sample of the Environmental Assessment (EA) glass. Two reagent blank samples are also to be included in these tests. This results in 68 sample solutions being required to complete the PCTs for each of the 3 sets of quenched glasses.

For all 3 sets, the leachates from the PCTs will be diluted by adding $4 \mathrm{~mL}$ of $0.4 \mathrm{M} \mathrm{HNO}_{3}$ to 6 $\mathrm{mL}$ of the leachate (a $6: 10$ volume to volume, v:v, dilution) before being submitted to PSAL. The leachates of EA will be further diluted $(1: 10 \mathrm{v}: \mathrm{v})$ with deionized water prior to submission to PSAL in order to prevent problems with the nebulizer. Note that additional dilutions for the ccc versions of one or more of the study glasses may be needed due to a possible low durability of some of the glasses. Upon termination of the PCT, a decision is to be made (by the technicians and a PSAL representative, if called by the technician) as to whether additional dilutions are needed for these solutions to mitigate any potential gelling issues. Any extra dilutions are to be reported, and guidance is to be given as to how the dilutions are to be handled in the statistical assessment of the measurement data. More specifically, PSAL will be responsible for indicating if any additional dilutions were made and how they were, or how they should be, accounted for in the reported measurements.

Table 2 presents identifying codes for the individual solutions required for the PCTs of the study glasses and of the standards (EA, ARM-1, and blanks) for each of the 3 sets of quenched PCTs: C01 through C68 for Set \#1, D01 through D68 for Set \#2, and E01 through E68 for Set \#3. This provides a naming convention for each set of PCTs that is to be used by PSAL in analyzing the solutions and reporting the relevant concentration measurements. ${ }^{\mathrm{a}}$

Renaming these samples ensures that they will be processed as blind samples by PSAL. This table does not contain the solution identifiers for those on the distribution list with a "wo" following their names. 
Table 2: Identifiers for the PCT Solutions for Each Set

\begin{tabular}{|c|c|c|c|c|c|c|c|c|c|c|c|}
\hline \multicolumn{4}{|c|}{ Set \#1 } & \multicolumn{4}{|c|}{ Set \#2 } & \multicolumn{4}{|c|}{ Set \#3 } \\
\hline Original & Solution & Original & Solution & Original & Solution & Original & Solution & Original & Solution & Original & Solution \\
\hline Sample & Identifier & Sample & Identifier & Sample & Identifier & Sample & Identifier & Sample & Identifier & Sample & Identifier \\
\hline Pu04-01 & C04 & Pu35-08 & $\mathrm{C} 08$ & Pu35-16 & D51 & Pu35-28 & D19 & Pu35-36 & E42 & Pu35-48 & E64 \\
\hline Pu04-01 & $\mathrm{C} 41$ & Pu35-08 & $\mathrm{C} 17$ & Pu35-16 & D05 & Pu35-28 & D26 & Pu35-36 & E12 & Pu35-48 & E60 \\
\hline $\mathrm{Pu} 04-01$ & $\mathrm{C} 44$ & Pu35-08 & $\mathrm{C} 01$ & Pu35-16 & D46 & $\mathrm{Pu} 35-28$ & D41 & Pu35-36 & E23 & Pu35-48 & E58 \\
\hline Pu04-02 & $\mathrm{C} 27$ & Pu35-09 & $\mathrm{C} 50$ & Pu35-17 & D37 & Pu35-29 & D44 & Pu35-37 & E16 & Pu35-49 & E43 \\
\hline $\mathrm{Pu} 04-02$ & $\mathrm{C} 48$ & Pu35-09 & $\mathrm{C} 18$ & Pu35-17 & D68 & Pu35-29 & D61 & Pu35-37 & E25 & Pu35-49 & E04 \\
\hline $\mathrm{Pu} 04-02$ & $\mathrm{C} 15$ & Pu35-09 & $\mathrm{C} 40$ & Pu35-17 & D47 & Pu35-29 & D43 & Pu35-37 & E39 & Pu35-49 & E17 \\
\hline Pu04-03 & $\mathrm{C} 26$ & Pu35-10 & C33 & Pu35-18 & D67 & Pu35-30 & D27 & Pu35-38 & E06 & Pu35-50 & E27 \\
\hline Pu04-03 & C61 & Pu35-10 & $\mathrm{C} 23$ & Pu35-18 & D24 & Pu35-30 & D53 & Pu35-38 & E02 & Pu35-50 & E52 \\
\hline Pu04-03 & $\mathrm{C} 65$ & Pu35-10 & $\mathrm{C} 06$ & Pu35-18 & D38 & Pu35-30 & D10 & Pu35-38 & E13 & Pu35-50 & E05 \\
\hline $\mathrm{Pu} 04-04$ & C59 & Pu35-11 & $\mathrm{C} 47$ & Pu35-19 & D54 & Pu35-31 & D32 & Pu35-39 & E33 & Pu35-51 & E08 \\
\hline $\mathrm{Pu} 04-04$ & $\mathrm{C} 53$ & Pu35-11 & C51 & Pu35-19 & D40 & Pu35-31 & D29 & Pu35-39 & E36 & Pu35-51 & E10 \\
\hline Pu04-04 & $\mathrm{C} 55$ & Pu35-11 & C66 & Pu35-19 & D20 & Pu35-31 & D17 & Pu35-39 & E07 & Pu35-51 & E67 \\
\hline $\mathrm{Pu} 04-05$ & $\mathrm{C} 10$ & Pu35-12 & C34 & Pu35-20 & D36 & Pu35-32 & D13 & $\mathrm{Pu} 35-40$ & E55 & Pu35-52 & E32 \\
\hline Pu04-05 & $\mathrm{C} 03$ & Pu35-12 & $\mathrm{C} 20$ & Pu35-20 & D07 & Pu35-32 & D31 & Pu35-40 & E41 & Pu35-52 & E14 \\
\hline $\mathrm{Pu} 04-05$ & C49 & Pu35-12 & $\mathrm{C} 42$ & Pu35-20 & D22 & Pu35-32 & D25 & Pu35-40 & E44 & Pu35-52 & E61 \\
\hline Pu35-01 & C67 & Pu35-13 & $\mathrm{C} 09$ & Pu35-21 & D64 & Pu35-33 & D02 & Pu35-41 & E31 & Pu35-53 & E37 \\
\hline Pu35-01 & C39 & Pu35-13 & C68 & Pu35-21 & D30 & Pu35-33 & D60 & Pu35-41 & E34 & Pu35-53 & E09 \\
\hline Pu35-01 & C62 & Pu35-13 & $\mathrm{C} 12$ & Pu35-21 & D23 & Pu35-33 & D59 & Pu35-41 & E18 & Pu35-53 & E49 \\
\hline Pu35-02 & $\mathrm{C} 11$ & Pu35-14 & C64 & Pu35-22 & D15 & Pu35-34 & D56 & Pu35-42 & E68 & $\mathrm{Pu} 35-54$ & E63 \\
\hline Pu35-02 & $\mathrm{C} 57$ & Pu35-14 & $\mathrm{C} 29$ & Pu35-22 & D33 & Pu35-34 & D39 & Pu35-42 & E47 & Pu35-54 & E45 \\
\hline Pu35-02 & C19 & Pu35-14 & C46 & Pu35-22 & D45 & $\mathrm{Pu} 35-34$ & D04 & Pu35-42 & E20 & Pu35-54 & E57 \\
\hline Pu35-03 & C14 & $\mathrm{Pu} 35-15$ & $\mathrm{C} 07$ & Pu35-23 & D57 & Pu35-35 & D65 & Pu35-43 & E51 & $\mathrm{Pu} 35-55$ & E59 \\
\hline Pu35-03 & C58 & Pu35-15 & $\mathrm{C} 02$ & Pu35-23 & D42 & Pu35-35 & D52 & Pu35-43 & E11 & Pu35-55 & E15 \\
\hline Pu35-03 & $\mathrm{C} 30$ & Pu35-15 & C37 & Pu35-23 & D14 & Pu35-35 & D49 & Pu35-43 & E03 & Pu35-55 & E48 \\
\hline Pu35-04 & C38 & EA & $\mathrm{C} 05$ & Pu35-24 & D12 & EA & D66 & Pu35-44 & E38 & EA & E62 \\
\hline Pu35-04 & C52 & EA & C36 & Pu35-24 & D06 & EA & D08 & Pu35-44 & E56 & EA & E29 \\
\hline Pu35-04 & C24 & EA & C54 & $\mathrm{Pu} 35-24$ & D50 & EA & D09 & Pu35-44 & E53 & EA & E30 \\
\hline Pu35-05 & $\mathrm{C} 13$ & ARM-1 & $\mathrm{C} 28$ & Pu35-25 & D16 & ARM-1 & D34 & Pu35-45 & E22 & ARM-1 & E46 \\
\hline Pu35-05 & C32 & ARM-1 & $\mathrm{C} 43$ & Pu35-25 & D35 & ARM-1 & D63 & Pu35-45 & E40 & ARM-1 & E26 \\
\hline Pu35-05 & C60 & ARM-1 & $\mathrm{C} 16$ & $\mathrm{Pu} 35-25$ & D01 & ARM-1 & D58 & Pu35-45 & E19 & ARM-1 & E01 \\
\hline Pu35-06 & C31 & blank & $\mathrm{C} 21$ & Pu35-26 & D48 & blank & D21 & Pu35-46 & E50 & blank & E54 \\
\hline Pu35-06 & C56 & blank & C63 & $\mathrm{Pu} 35-26$ & D18 & blank & D28 & $\mathrm{Pu} 35-46$ & E24 & blank & E21 \\
\hline Pu35-06 & $\mathrm{C} 45$ & & & Pu35-26 & D55 & & & Pu35-46 & E28 & & \\
\hline Pu35-07 & $\mathrm{C} 25$ & & & Pu35-27 & D62 & & & Pu35-47 & E35 & & \\
\hline Pu35-07 & $\mathrm{C} 22$ & & & Pu35-27 & D11 & & & Pu35-47 & E66 & & \\
\hline Pu35-07 & C35 & & & Pu35-27 & D03 & & & Pu35-47 & E65 & & \\
\hline
\end{tabular}




\subsection{Anal ytical Plans}

The analytical plans for PSAL are provided in this section. Each of the solution samples in each of the sets submitted to PSAL is to be analyzed only once for each of the following: boron (B), gadolinium $(\mathrm{Gd})$, hafnium $(\mathrm{Hf})$, sodium $(\mathrm{Na})$, and silicon $(\mathrm{Si})$. The measurements are to be made in parts per million ( $\mathrm{ppm})$. The analytical procedure used by PSAL to determine the concentrations utilizes an Inductively Coupled Plasma - Atomic Emission Spectrometer (ICPAES). The PCT solutions for each set (as identified in Table 2) are grouped in three ICP-AES blocks for processing by PSAL in Table 3. Each block requires a different calibration of the ICPAES. 
Table 3: ICP-AES Calibration Blocks for the Leachate Measurements for Each Set

\begin{tabular}{|c|c|c|c|c|c|c|c|c|}
\hline \multicolumn{3}{|c|}{ Set \#1 } & \multicolumn{3}{|c|}{ Set \#2 } & \multicolumn{3}{|c|}{ Set \#3 } \\
\hline Block 1 & Block 2 & Block 3 & Block 1 & Block 2 & Block 3 & Block 1 & Block 2 & Block 3 \\
\hline std-11-1 & std-12-1 & std-13-1 & std-21-1 & std-22-1 & std-23-1 & std-31-1 & std-32-1 & std-33-1 \\
\hline C62 & $\mathrm{C} 40$ & C44 & D47 & D43 & D09 & E61 & E31 & E14 \\
\hline $\mathrm{C} 45$ & $\mathrm{C} 12$ & $\mathrm{C} 28$ & D30 & D20 & D24 & E23 & E37 & E38 \\
\hline C49 & $\mathrm{C} 35$ & $\mathrm{C} 30$ & D38 & D62 & D01 & E21 & E33 & E44 \\
\hline $\mathrm{C08}$ & $\mathrm{C} 02$ & C63 & D21 & D05 & D28 & E04 & E01 & E10 \\
\hline C55 & C53 & C68 & D26 & D60 & D34 & E30 & E40 & E62 \\
\hline C32 & C56 & $\mathrm{C} 07$ & D56 & D64 & D59 & E41 & E51 & E05 \\
\hline $\mathrm{C} 21$ & C57 & C67 & D65 & D48 & D51 & E67 & E47 & E59 \\
\hline C37 & C47 & C52 & D12 & D08 & D37 & E46 & E48 & E26 \\
\hline $\mathrm{C} 42$ & C39 & C19 & D10 & D58 & D39 & E49 & E29 & E58 \\
\hline C51 & C34 & $\mathrm{C} 20$ & D03 & D35 & D41 & E07 & E45 & E25 \\
\hline C50 & $\mathrm{C} 03$ & C18 & D55 & D22 & D25 & E64 & E60 & E54 \\
\hline std-11-2 & std-12-2 & std-13-2 & std-21-2 & std-22-2 & std-23-2 & std-31-2 & std-32-2 & std-33-2 \\
\hline $\mathrm{C} 24$ & $\mathrm{C} 17$ & $\mathrm{C} 25$ & D29 & D27 & D32 & E52 & E08 & E02 \\
\hline $\mathrm{C} 23$ & $\mathrm{C} 14$ & C54 & D13 & D31 & D18 & E34 & E27 & E18 \\
\hline C15 & $\mathrm{C} 43$ & C31 & D14 & D15 & D40 & E20 & E24 & E57 \\
\hline C58 & C33 & C66 & D63 & D06 & D45 & E03 & E32 & E09 \\
\hline $\mathrm{C} 11$ & $\mathrm{C} 46$ & $\mathrm{C} 13$ & D46 & D67 & D23 & E63 & E43 & E68 \\
\hline C36 & $\mathrm{C} 41$ & C64 & D16 & D04 & D57 & E56 & E55 & E42 \\
\hline $\mathrm{C} 16$ & C60 & C61 & D02 & D52 & D49 & E35 & E16 & E36 \\
\hline $\mathrm{C} 09$ & $\mathrm{C} 27$ & $\mathrm{C} 48$ & D66 & D19 & D07 & E22 & E53 & E28 \\
\hline $\mathrm{C} 29$ & $\mathrm{C05}$ & $\mathrm{C} 01$ & D33 & D42 & D11 & E39 & E65 & E17 \\
\hline $\mathrm{C} 04$ & C65 & C59 & D54 & D17 & D53 & E15 & E06 & E66 \\
\hline $\mathrm{C} 22$ & C38 & $\mathrm{C} 06$ & D36 & D68 & D50 & E13 & E12 & E11 \\
\hline $\mathrm{C} 26$ & std-12-3 & $\mathrm{C} 10$ & D61 & std-22-3 & D44 & E50 & std-32-3 & E19 \\
\hline std-11-3 & & std-13-3 & std-21-3 & & std-23-3 & std-31-3 & & std-33-3 \\
\hline
\end{tabular}


WSRC-STI-2007-00477

Revision 0

Appendix C (SRNL-SCS-2007-00028)

A multi-element solution standard (denoted by "std-ij-k" where $\mathrm{i}=1,2$, and 3 represents the set number, $\mathrm{j}=1,2$, and 3 represents the block number for the set, and $\mathrm{k}=1,2$, and 3 represents the position in the block) was added at the beginning, middle, and end of each of the three blocks for each of the three sets. This standard may be useful in checking and correcting for bias in the concentration measurements arising from the ICP calibrations.

\subsection{SUMMARY}

In summary, these analytical plans provide identifiers for the PCT solutions for each set in Table 2 and three ICP-AES calibration blocks for each set of quenched PCTs in Table 3 for PSAL to use in conducting the boron (B), gadolinium (Gd), hafnium (Hf), sodium (Na), and silicon ( $\mathrm{Si}$ ) concentration measurements. The sequencing of the activities associated with each of the steps in the analytical procedure for each set has been randomized. The size of the blocks for each set of PCTs was selected so that each block could be completed in a single work shift. If for some reason the measurements are not conducted in the sequence presented in this memorandum, the actual order should be recorded along with any explanative comments.

The analytical plans indicated in the preceding tables should be modified by the personnel of PSAL to include any calibration check standards and/or other standards that are part of their standard operating procedures.

\subsection{REFERENCES}

[1] J.C. Marra, K.M. Fox, and E.N. Hoffman, "Task Technical \& QA Plan: Glass Formulation and Performance Testing to Support Pu Disposition," WSRC-STI-200700076, February 2007.

[2] ASTM C-1285-2002, "Standard Test Methods for Determining Chemical Durability of Nuclear Waste Glasses: The Product Consistency Test (PCT)," ASTM, 2002. 


\section{Appendix C}

SRNL-SCS-2007-00028

Analytical Plans for Measuring the PCT Solutions for the CCC Glasses Fabricated as Part of the Study of Impurity Solubility during Pu Vitrification 
WSRC-STI-2007-00477

Revision 0

Appendix C (SRNL-SCS-2007-00028) 
SRNL-SCS-2007-00028

June 6, 2007

To:

K. M. Fox, SRNL

cc:

D. R. Best, 786-1A (wo)

I. A. Reamer, 999-1W

C. C. Herman, 999-W

P. A. Toole, 786-1A (wo)

E. N. Hoffman, 730-A

R. C. Tuckfield, 773-42A

M. D. Joner, 999-W

R. J. Workman, 999-1W

J. C. Marra, 773-42A

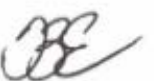

From: T. B. Edwards, 999-W (819-8464)

Statistical Consulting Section

wo - without glass identifiers
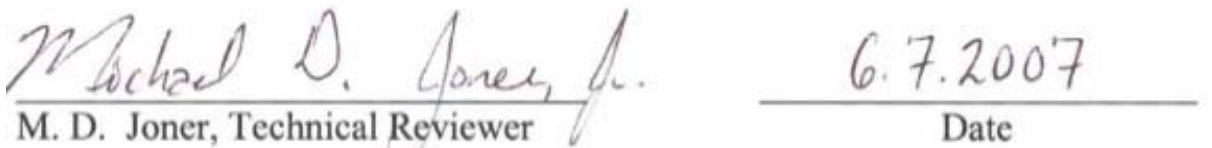

R. C. Tuckfielo, Maneger

Statistical Consulting Section
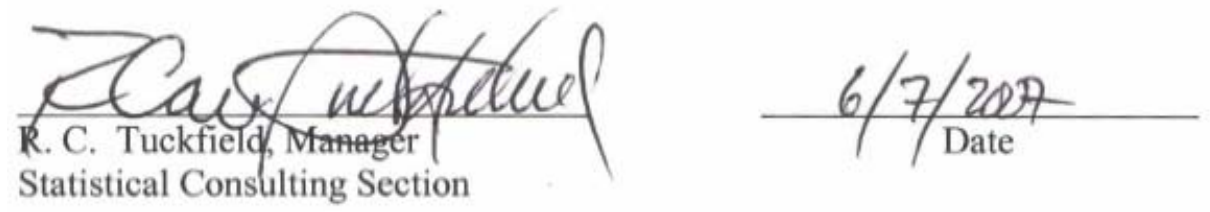

\section{Analytical Plans for Measuring the PCT Solutions for the CCC Glasses Fabricated as Part of the Study of Impurity Solubility during $\mathrm{Pu}$ Vitrification (U)}


WSRC-STI-2007-00477

Revision 0

Appendix C (SRNL-SCS-2007-00028)

\subsection{EXECUTIVE SUMMARY}

A glass study (WSRC-STI-2007-00076) is underway at the Savannah River National Laboratory (SRNL) to investigate glass formulations and to conduct performance testing to support plutonium $(\mathrm{Pu})$ disposition. Sixty $(60)$ glasses have been selected to be batched and fabricated as part of this study. The selection of these 60 compositions is to be addressed in a separate report. The durabilities of the glasses are to be measured using the Product Consistency Test (PCT) as defined in ASTM C-1285-2002. Two heat treatments are to be utilized during the fabrication of each of these glasses. Specifically, each of the glasses is to be (1) quenched (i.e., rapidly cooled) and (2) cooled in accordance with the centerline-canister-cooling (ccc) regime. Both heat treatments of each glass are to be subjected to the PCT. The PCT solutions are to be analyzed by SRNL's Process Science Analytical Laboratory (PSAL).

Due to the large number of glasses in this study (60 quenched and $60 \mathrm{ccc}$ glasses in total), the PCTs are to be conducted in 6 sets. Twenty glasses are to be included in each set starting with the quenched and then working through the ccc glasses. This memorandum provides analytical plans for the PCTs for the 3 sets of ccc glasses, which are labeled as Pu04-01 through Pu04-05 and Pu35-01 through Pu35-55, that are to be measured by PSAL. 
WSRC-STI-2007-00477

Revision 0

Appendix C (SRNL-SCS-2007-00028)

\subsection{INTRODUCTION}

A glass study is underway at the Savannah River National Laboratory (SRNL) to investigate glass formulations and to conduct performance testing to support plutonium $(\mathrm{Pu})$ disposition [1]. Sixty (60) glasses have been selected to be batched and fabricated as part of this study. The selection of these 60 compositions is to be addressed in a separate report. The durabilities of the glasses are to be measured using the Product Consistency Test (PCT) as defined in ASTM C-1285-2002 [2]. Two heat treatments are to be utilized during the fabrication of each of these glasses. Specifically, each of the glasses is to be (1) quenched (i.e., rapidly cooled) and (2) cooled in accordance with the centerline-canister-cooling (ccc) regime. Both heat treatments of each glass are to be subjected to the PCT. The PCT solutions are to be analyzed by SRNL's Process Science Analytical Laboratory (PSAL).

Due to the large number of glasses in this study (60 quenched and $60 \mathrm{ccc}$ glasses in total), the PCTs are to be conducted in 6 sets. Twenty glasses are to be included in each set starting with the quenched and then working through the ccc glasses. This memorandum provides analytical plans for the PCTs for the 3 sets of ccc glasses. The glass identifiers for each of the 3 sets of PCTs are provided in Table 1.

Table 1: Three Sets of CCC Glass Identifiers Covered in These Plans

\begin{tabular}{||c|c|c|}
\hline Set 1 & Set 2 & Set 3 \\
\hline Pu04-01 & Pu35-16 & Pu35-36 \\
\hline Pu04-02 & Pu35-17 & Pu35-37 \\
\hline Pu04-03 & Pu35-18 & Pu35-38 \\
\hline Pu04-04 & Pu35-19 & Pu35-39 \\
\hline Pu04-05 & Pu35-20 & Pu35-40 \\
\hline Pu35-01 & Pu35-21 & Pu35-41 \\
\hline Pu35-02 & Pu35-22 & Pu35-42 \\
\hline Pu35-03 & Pu35-23 & Pu35-43 \\
\hline Pu35-04 & Pu35-24 & Pu35-44 \\
\hline Pu35-05 & Pu35-25 & Pu35-45 \\
\hline Pu35-06 & Pu35-26 & Pu35-46 \\
\hline Pu35-07 & Pu35-27 & Pu35-47 \\
\hline Pu35-08 & Pu35-28 & Pu35-48 \\
\hline Pu35-09 & Pu35-29 & Pu35-49 \\
\hline Pu35-10 & Pu35-30 & Pu35-50 \\
\hline Pu35-11 & Pu35-31 & Pu35-51 \\
\hline Pu35-12 & Pu35-32 & Pu35-52 \\
\hline Pu35-13 & Pu35-33 & Pu35-53 \\
\hline Pu35-14 & Pu35-34 & Pu35-54 \\
\hline Pu35-15 & Pu35-35 & Pu35-55 \\
\hline
\end{tabular}


WSRC-STI-2007-00477

Revision 0

Appendix C (SRNL-SCS-2007-00028)

\subsection{DISCUSSION}

Each of the 20 study glasses in each set of Table 1 is to be subjected to the PCT in triplicate. In addition to PCTs for the study glasses of the set, triplicate PCTs are to be conducted on a sample of the Approved Reference Material - One (ARM-1) glass and a sample of the Environmental Assessment (EA) glass. Two reagent blank samples are also to be included in these tests. This results in 68 sample solutions being required to complete the PCTs for each of the 3 sets of ccc glasses.

For all 3 sets, the leachates from the PCTs will be diluted by adding $4 \mathrm{~mL}$ of $0.4 \mathrm{M} \mathrm{HNO}_{3}$ to 6 $\mathrm{mL}$ of the leachate (a $6: 10$ volume to volume, v:v, dilution) before being submitted to PSAL. The leachates of EA will be further diluted $(1: 10 \mathrm{v}: \mathrm{v})$ with deionized water prior to submission to PSAL in order to prevent problems with the nebulizer. Note that additional dilutions for the ccc versions of one or more of the study glasses may be needed due to a possible low durability of some of the glasses. Upon termination of the PCT, a decision is to be made (by the technicians and a PSAL representative, if called by the technician) as to whether additional dilutions are needed for these solutions to mitigate any potential gelling issues. Any extra dilutions are to be reported, and guidance is to be given as to how the dilutions are to be handled in the statistical assessment of the measurement data. More specifically, PSAL will be responsible for indicating if any additional dilutions were made and how they were, or how they should be, accounted for in the reported measurements.

Table 2 presents identifying codes for the individual solutions required for the PCTs of the study glasses and of the standards (EA, ARM-1, and blanks) for each of the 3 sets of ccc PCTs: L01 through L68 for Set \#1, M01 through M68 for Set \#2, and N01 through N68 for Set \#3. This provides a naming convention for each set of PCTs that is to be used by PSAL in analyzing the solutions and reporting the relevant concentration measurements. ${ }^{\mathrm{a}}$

Renaming these samples ensures that they will be processed as blind samples by PSAL. This table does not contain the solution identifiers for those on the distribution list with a "wo" following their names. 
Table 2: Identifiers for the PCT Solutions for Each Set

\begin{tabular}{|c|c|c|c|c|c|c|c|c|c|c|c|}
\hline \multicolumn{4}{|c|}{ Set \#1 } & \multicolumn{4}{|c|}{ Set \#2 } & \multicolumn{4}{|c|}{ Set \#3 } \\
\hline Original & Solution & Original & Solution & Original & Solution & Original & Solution & Original & Solution & Original & Solution \\
\hline Sample & Identifier & Sample & Identifier & Sample & Identifier & Sample & Identifier & Sample & Identifier & Sample & Identifier \\
\hline Pu04-01 & L04 & Pu35-08 & L08 & Pu35-16 & M51 & Pu35-28 & M19 & Pu35-36 & N42 & Pu35-48 & N64 \\
\hline $\mathrm{Pu} 04-01$ & L41 & $\mathrm{Pu} 35-08$ & L17 & Pu35-16 & M05 & Pu35-28 & M26 & $\mathrm{Pu} 35-36$ & $\mathrm{~N} 12$ & $\mathrm{Pu} 35-48$ & N60 \\
\hline Pu04-01 & L44 & Pu35-08 & L01 & Pu35-16 & M46 & Pu35-28 & M41 & Pu35-36 & N23 & Pu35-48 & N58 \\
\hline Pu04-02 & L27 & Pu35-09 & L50 & Pu35-17 & M37 & Pu35-29 & M44 & Pu35-37 & N16 & Pu35-49 & N43 \\
\hline $\mathrm{Pu} 04-02$ & L48 & Pu35-09 & L18 & Pu35-17 & M68 & Pu35-29 & M61 & $\mathrm{Pu} 35-37$ & N25 & Pu35-49 & N04 \\
\hline Pu04-02 & L15 & Pu35-09 & L40 & Pu35-17 & M47 & Pu35-29 & M43 & Pu35-37 & N39 & Pu35-49 & N17 \\
\hline $\mathrm{Pu} 04-03$ & L26 & Pu35-10 & L33 & Pu35-18 & M67 & Pu35-30 & M27 & $\mathrm{Pu} 35-38$ & N06 & Pu35-50 & N27 \\
\hline Pu04-03 & L61 & Pu35-10 & L23 & Pu35-18 & M24 & Pu35-30 & M53 & Pu35-38 & N02 & Pu35-50 & N52 \\
\hline $\mathrm{Pu} 04-03$ & L65 & Pu35-10 & L06 & Pu35-18 & M38 & Pu35-30 & M10 & Pu35-38 & N13 & Pu35-50 & N05 \\
\hline $\mathrm{Pu} 04-04$ & L59 & Pu35-11 & L47 & Pu35-19 & M54 & Pu35-31 & M32 & Pu35-39 & N33 & Pu35-51 & N08 \\
\hline Pu04-04 & L53 & Pu35-11 & L51 & Pu35-19 & M40 & Pu35-31 & M29 & Pu35-39 & N36 & Pu35-51 & N10 \\
\hline $\mathrm{Pu} 04-04$ & L55 & Pu35-11 & L66 & Pu35-19 & M20 & $\mathrm{Pu} 35-31$ & M17 & Pu35-39 & N07 & Pu35-51 & N67 \\
\hline $\mathrm{Pu} 04-05$ & L10 & Pu35-12 & L34 & Pu35-20 & M36 & Pu35-32 & M13 & $\mathrm{Pu} 35-40$ & N55 & Pu35-52 & N32 \\
\hline $\mathrm{Pu} 04-05$ & L03 & Pu35-12 & L20 & $\mathrm{Pu} 35-20$ & M07 & $\mathrm{Pu} 35-32$ & M31 & $\mathrm{Pu} 35-40$ & N41 & Pu35-52 & N14 \\
\hline Pu04-05 & L49 & Pu35-12 & L42 & Pu35-20 & M22 & Pu35-32 & M25 & Pu35-40 & N44 & Pu35-52 & N61 \\
\hline Pu35-01 & L67 & Pu35-13 & L09 & Pu35-21 & M64 & Pu35-33 & M02 & Pu35-41 & N31 & Pu35-53 & N37 \\
\hline Pu35-01 & L39 & Pu35-13 & L68 & Pu35-21 & M30 & $\mathrm{Pu} 35-33$ & M60 & Pu35-41 & N34 & Pu35-53 & N09 \\
\hline Pu35-01 & L62 & Pu35-13 & L12 & Pu35-21 & M23 & Pu35-33 & M59 & Pu35-41 & N18 & Pu35-53 & N49 \\
\hline Pu35-02 & L11 & Pu35-14 & L64 & Pu35-22 & M15 & Pu35-34 & M56 & Pu35-42 & N68 & Pu35-54 & N63 \\
\hline Pu35-02 & L57 & Pu35-14 & L29 & Pu35-22 & M33 & Pu35-34 & M39 & Pu35-42 & N47 & Pu35-54 & N45 \\
\hline Pu35-02 & L19 & Pu35-14 & L46 & Pu35-22 & M45 & Pu35-34 & M04 & Pu35-42 & N20 & Pu35-54 & N57 \\
\hline Pu35-03 & L14 & Pu35-15 & L07 & Pu35-23 & M57 & Pu35-35 & M65 & Pu35-43 & N51 & Pu35-55 & N59 \\
\hline Pu35-03 & L58 & Pu35-15 & L02 & Pu35-23 & M42 & Pu35-35 & M52 & Pu35-43 & N11 & Pu35-55 & N15 \\
\hline Pu35-03 & L30 & Pu35-15 & L37 & $\mathrm{Pu} 35-23$ & M14 & $\mathrm{Pu} 35-35$ & M49 & $\mathrm{Pu} 35-43$ & N03 & $\mathrm{Pu} 35-55$ & N48 \\
\hline Pu35-04 & L38 & EA & L05 & $\mathrm{Pu} 35-24$ & M12 & EA & M66 & $\mathrm{Pu} 35-44$ & N38 & EA & N62 \\
\hline Pu35-04 & L52 & EA & L36 & Pu35-24 & M06 & EA & M08 & Pu35-44 & N56 & EA & N29 \\
\hline Pu35-04 & L24 & EA & L54 & $\mathrm{Pu} 35-24$ & M50 & EA & M09 & $\mathrm{Pu} 35-44$ & N53 & EA & N30 \\
\hline Pu35-05 & L13 & ARM-1 & L28 & Pu35-25 & M16 & ARM-1 & M34 & Pu35-45 & N22 & ARM-1 & N46 \\
\hline Pu35-05 & L32 & ARM-1 & L43 & $\mathrm{Pu} 35-25$ & M35 & ARM-1 & M63 & $\mathrm{Pu} 35-45$ & N40 & ARM-1 & N26 \\
\hline Pu35-05 & L60 & ARM-1 & L16 & $\mathrm{Pu} 35-25$ & M01 & ARM-1 & M58 & $\mathrm{Pu} 35-45$ & N19 & ARM-1 & N01 \\
\hline Pu35-06 & L31 & blank & L21 & $\mathrm{Pu} 35-26$ & M48 & blank & M21 & $\mathrm{Pu} 35-46$ & N50 & blank & N54 \\
\hline Pu35-06 & L56 & blank & L63 & Pu35-26 & M18 & blank & M28 & $\mathrm{Pu} 35-46$ & N24 & blank & $\mathrm{N} 21$ \\
\hline Pu35-06 & L45 & & & Pu35-26 & M55 & & & Pu35-46 & N28 & & \\
\hline Pu35-07 & L25 & & & $\mathrm{Pu} 35-27$ & M62 & & & Pu35-47 & N35 & & \\
\hline Pu35-07 & L22 & & & Pu35-27 & M11 & & & Pu35-47 & N66 & & \\
\hline Pu35-07 & L35 & & & Pu35-27 & M03 & & & Pu35-47 & N65 & & \\
\hline
\end{tabular}


WSRC-STI-2007-00477

Revision 0

Appendix C (SRNL-SCS-2007-00028)

\subsection{Anal ytical Plans}

The analytical plans for PSAL are provided in this section. Each of the solution samples in each of the sets submitted to PSAL is to be analyzed only once for each of the following: boron (B), gadolinium $(\mathrm{Gd})$, hafnium $(\mathrm{Hf})$, sodium $(\mathrm{Na})$, and silicon $(\mathrm{Si})$. The measurements are to be made in parts per million ( $\mathrm{ppm})$. The analytical procedure used by PSAL to determine the concentrations utilizes an Inductively Coupled Plasma - Atomic Emission Spectrometer (ICPAES). The PCT solutions for each set (as identified in Table 2) are grouped in three ICP-AES blocks for processing by PSAL in Table 3. Each block requires a different calibration of the ICPAES.

A multi-element solution standard (denoted by "std-ij-k" where $\mathrm{i}=1,2$, and 3 represents the set number, $\mathrm{j}=1,2$, and 3 represents the block number for the set, and $\mathrm{k}=1,2$, and 3 represents the position in the block) was added at the beginning, middle, and end of each of the three blocks for each of the three sets. This standard may be useful in checking and correcting for bias in the concentration measurements arising from the ICP calibrations. 
Table 3: ICP-AES Calibration Blocks for the Leachate Measurements for Each Set

\begin{tabular}{|c|c|c|c|c|c|c|c|c|}
\hline \multicolumn{3}{|c|}{ Set \#1 } & \multicolumn{3}{|c|}{ Set \#2 } & \multicolumn{3}{|c|}{ Set \#3 } \\
\hline Block 1 & Block 2 & Block 3 & Block 1 & Block 2 & Block 3 & Block 1 & Block 2 & Block 3 \\
\hline std-11-1 & std-12-1 & std-13-1 & std-21-1 & std-22-1 & std-23-1 & std-31-1 & std-32-1 & std-33-1 \\
\hline L62 & L40 & L44 & M47 & M43 & M09 & N61 & N31 & N14 \\
\hline L45 & L12 & L28 & M30 & M20 & M24 & $\mathrm{N} 23$ & N37 & N38 \\
\hline L49 & L35 & L30 & M38 & M62 & M01 & N21 & N33 & N44 \\
\hline L08 & L02 & L63 & M21 & M05 & M28 & N04 & N01 & N10 \\
\hline L55 & L53 & L68 & M26 & M60 & M34 & N30 & $\mathrm{N} 40$ & N62 \\
\hline L32 & L56 & L07 & M56 & M64 & M59 & N41 & N51 & N05 \\
\hline L21 & L57 & L67 & M65 & M48 & M51 & N67 & N47 & N59 \\
\hline L37 & L47 & L52 & M12 & M08 & M37 & N46 & $\mathrm{N} 48$ & N26 \\
\hline L42 & L39 & L19 & M10 & M58 & M39 & N49 & $\mathrm{N} 29$ & N58 \\
\hline L51 & L34 & L20 & M03 & M35 & M41 & N07 & $\mathrm{N} 45$ & N25 \\
\hline L50 & L03 & L18 & M55 & M22 & M25 & N64 & N60 & N54 \\
\hline std-11-2 & std-12-2 & std-13-2 & std-21-2 & std-22-2 & std-23-2 & std-31-2 & std-32-2 & std-33-2 \\
\hline L24 & L17 & L25 & M29 & M27 & M32 & N52 & N08 & N02 \\
\hline L23 & L14 & L54 & M13 & M31 & M18 & N34 & $\mathrm{N} 27$ & N18 \\
\hline L15 & L43 & L31 & M14 & M15 & M40 & N20 & N24 & N57 \\
\hline L58 & L33 & L66 & M63 & M06 & M45 & N03 & N32 & N09 \\
\hline L11 & L46 & L13 & M46 & M67 & M23 & N63 & $\mathrm{N} 43$ & N68 \\
\hline L36 & L41 & L64 & M16 & M04 & M57 & N56 & N55 & N42 \\
\hline L16 & L60 & L61 & M02 & M52 & M49 & N35 & N16 & N36 \\
\hline L09 & L27 & L48 & M66 & M19 & M07 & $\mathrm{N} 22$ & N53 & N28 \\
\hline L29 & L05 & L01 & M33 & M42 & M11 & N39 & N65 & N17 \\
\hline L04 & L65 & L59 & M54 & M17 & M53 & N15 & N06 & N66 \\
\hline L22 & L38 & L06 & M36 & M68 & M50 & N13 & N12 & N11 \\
\hline L26 & std-12-3 & L10 & M61 & std-22-3 & M44 & N50 & std-32-3 & N19 \\
\hline std-11-3 & & std-13-3 & std-21-3 & & std-23-3 & std-31-3 & & std-33-3 \\
\hline
\end{tabular}


WSRC-STI-2007-00477

Revision 0

Appendix C (SRNL-SCS-2007-00028)

\subsection{SUMMARY}

In summary, these analytical plans provide identifiers for the PCT solutions for each set in Table 2 and three ICP-AES calibration blocks for each set of ccc PCTs in Table 3 for PSAL to use in conducting the boron (B), gadolinium $(\mathrm{Gd})$, hafnium $(\mathrm{Hf})$, sodium $(\mathrm{Na})$, and silicon $(\mathrm{Si})$ concentration measurements. The sequencing of the activities associated with each of the steps in the analytical procedure for each set has been randomized. The size of the blocks for each set of PCTs was selected so that each block could be completed in a single work shift. If for some reason the measurements are not conducted in the sequence presented in this memorandum, the actual order should be recorded along with any explanative comments.

The analytical plans indicated in the preceding tables should be modified by the personnel of PSAL to include any calibration check standards and/or other standards that are part of their standard operating procedures.

\subsection{REFERENCES}

[1] J.C. Marra, K.M. Fox, and E.N. Hoffman, "Task Technical \& QA Plan: Glass Formulation and Performance Testing to Support Pu Disposition," WSRC-STI-200700076, February 2007.

[2] ASTM C-1285-2002, "Standard Test Methods for Determining Chemical Durability of Nuclear Waste Glasses: The Product Consistency Test (PCT),” ASTM, 2002. 


\section{Appendix D}

Tables and Exhibits Supporting the Analysis of the Chemical Composition Measurements of the Surrogate Pu Impurity Variability Study Glasses 
Table D1. Targeted Oxide Concentrations (as wt \% oxides) for the Pu/Impurity Solubility Study Glasses (part 1)

\begin{tabular}{|c|c|c|c|c|c|c|c|c|c|c|c|c|c|c|c|c|c|}
\hline Glass ID & $\mathbf{C l}$ & $\mathbf{T a}_{2} \mathbf{O}_{5}$ & MgO & $\mathrm{K}_{2} \mathrm{O}$ & $\mathrm{Fe}_{2} \mathrm{O}_{3}$ & $\mathrm{Na}_{2} \mathrm{O}$ & $\mathbf{F}$ & $\mathrm{CaO}$ & $\mathbf{G a}_{2} \mathbf{O}_{3}$ & $\mathrm{NiO}$ & $\mathrm{Cr}_{2} \mathrm{O}_{3}$ & $\mathrm{CuO}$ & $\mathrm{SO}_{4}$ & C & PbO & $\mathrm{SeO}_{2}$ & $\mathrm{Cs}_{2} \mathrm{O}$ \\
\hline Pu35-01 & 0.58 & 0.07 & 1.62 & 0.26 & 0.39 & 0.80 & 0.00 & 0.00 & 0.95 & 0.21 & 0.00 & 0.15 & 0.00 & 0.06 & 0.00 & 0.08 & 0.00 \\
\hline $\begin{array}{l}\text { Pu35-02 } \\
\end{array}$ & 0.58 & 0.07 & 1.45 & 0.74 & 0.08 & 0.35 & 0.45 & 0.36 & 0.08 & 0.15 & 0.33 & 0.07 & 0.17 & 0.00 & 0.06 & 0.08 & 0.06 \\
\hline Pu35-03 & 0.57 & 0.18 & 0.54 & 0.31 & 0.14 & 1.48 & 0.00 & 0.77 & 0.45 & 0.07 & 0.64 & 0.00 & 0.00 & 0.00 & 0.00 & 0.00 & 0.06 \\
\hline $\begin{array}{l}\text { Pu35-04 } \\
\end{array}$ & 0.59 & 0.46 & 1.06 & 0.45 & 0.27 & 0.56 & 0.52 & 0.32 & 0.36 & 0.07 & 0.09 & 0.07 & 0.00 & 0.06 & 0.08 & 0.08 & 0.00 \\
\hline Pu35-05 & 0.58 & 0.09 & 0.52 & 0.78 & 1.32 & 0.35 & 0.00 & 0.13 & 0.29 & 0.00 & 0.64 & 0.29 & 0.00 & 0.06 & 0.07 & 0.00 & 0.06 \\
\hline $\begin{array}{l}\text { Pu35-06 } \\
\end{array}$ & 0.60 & 0.10 & 0.91 & 0.27 & 0.97 & 0.80 & 0.48 & 0.29 & 0.00 & 0.28 & 0.22 & 0.00 & 0.17 & 0.06 & 0.00 & 0.00 & 0.00 \\
\hline Pu35-07 & 0.62 & 1.30 & 0.54 & 0.42 & 0.09 & 0.61 & 0.19 & 0.20 & 0.08 & 0.37 & 0.13 & 0.16 & 0.17 & 0.06 & 0.06 & 0.00 & 0.06 \\
\hline $\begin{array}{l}\text { Pu35-08 } \\
\end{array}$ & 0.62 & 0.39 & 0.88 & 0.77 & 0.89 & 0.40 & 0.30 & 0.24 & 0.16 & 0.25 & 0.09 & 0.07 & 0.00 & 0.00 & 0.00 & 0.00 & 0.00 \\
\hline $\begin{array}{l}\text { Pu35-09 } \\
\end{array}$ & 0.64 & 0.11 & 0.53 & 1.54 & 0.00 & 1.13 & 0.00 & 0.10 & 0.13 & 0.19 & 0.08 & 0.25 & 0.17 & 0.06 & 0.08 & 0.08 & 0.00 \\
\hline Pu35-10 & 0.65 & 0.27 & 0.81 & 0.36 & 0.59 & 0.67 & 0.38 & 0.08 & 0.71 & 0.07 & 0.08 & 0.07 & 0.17 & 0.00 & 0.06 & 0.08 & 0.06 \\
\hline $\begin{array}{l}\text { Pu35-11 } \\
\end{array}$ & 0.69 & 0.69 & 0.99 & 0.38 & 0.08 & 0.69 & 0.06 & 0.40 & 0.21 & 0.17 & 0.40 & 0.00 & 0.17 & 0.06 & 0.07 & 0.08 & 0.00 \\
\hline Pu35-12 & 0.65 & 0.59 & 0.66 & 0.28 & 0.19 & 0.79 & 0.33 & 0.08 & 0.36 & 0.47 & 0.40 & 0.18 & 0.00 & 0.00 & 0.00 & 0.08 & 0.00 \\
\hline Pu35-13 & 0.77 & 0.84 & 0.76 & 0.44 & 0.37 & 1.09 & 0.06 & 0.00 & 0.08 & 0.00 & 0.37 & 0.15 & 0.00 & 0.00 & 0.08 & 0.00 & 0.06 \\
\hline Pu35-14 & 0.80 & 0.34 & 0.44 & 0.20 & 1.00 & 1.07 & 0.08 & 0.38 & 0.27 & 0.07 & 0.13 & 0.07 & 0.00 & 0.06 & 0.06 & 0.08 & 0.06 \\
\hline Pu35-15 & 1.00 & 0.00 & 0.54 & 0.59 & 0.00 & 0.88 & 0.00 & 0.00 & 1.27 & 0.60 & 0.00 & 0.00 & 0.00 & 0.00 & 0.08 & 0.00 & 0.06 \\
\hline Pu35-16 & 0.95 & 0.29 & 0.73 & 0.00 & 0.46 & 1.23 & 0.00 & 0.70 & 0.15 & 0.13 & 0.00 & 0.29 & 0.17 & 0.00 & 0.06 & 0.00 & 0.00 \\
\hline $\begin{array}{l}\text { Pu35-17 } \\
\end{array}$ & 1.11 & 0.55 & 0.40 & 0.43 & 0.00 & 1.04 & 0.06 & 0.08 & 0.68 & 0.07 & 0.31 & 0.10 & 0.17 & 0.06 & 0.00 & 0.00 & 0.00 \\
\hline Pu35-18 & 0.58 & 0.07 & 1.04 & 1.10 & 0.08 & 0.94 & 0.06 & 0.57 & 0.08 & 0.07 & 0.48 & 0.07 & 0.00 & 0.00 & 0.00 & 0.00 & 0.00 \\
\hline $\begin{array}{l}\text { Pu35-19 } \\
\end{array}$ & 0.58 & 0.07 & 1.38 & 0.37 & 0.78 & 0.78 & 0.38 & 0.08 & 0.08 & 0.07 & 0.48 & 0.07 & 0.00 & 0.00 & 0.00 & 0.00 & 0.00 \\
\hline Pu35-20 & 0.58 & 0.51 & 0.55 & 0.85 & 0.28 & 0.50 & 0.29 & 0.23 & 0.51 & 0.29 & 0.40 & 0.07 & 0.00 & 0.00 & 0.00 & 0.00 & 0.00 \\
\hline Pu35-21 & 0.58 & 1.14 & 1.28 & $\begin{array}{l}0.41 \\
\end{array}$ & 0.08 & 0.59 & 0.06 & 0.08 & 0.62 & 0.07 & 0.09 & 0.07 & 0.00 & 0.00 & 0.00 & 0.00 & 0.00 \\
\hline Pu35-22 & 0.60 & 0.52 & 0.69 & 0.55 & 0.37 & 0.74 & 0.47 & 0.59 & 0.08 & 0.08 & 0.15 & 0.22 & 0.00 & 0.00 & 0.00 & 0.00 & 0.00 \\
\hline Pu35-23 & 0.59 & 0.83 & 0.67 & 0.16 & 0.56 & 0.93 & 0.09 & 0.16 & 0.53 & 0.12 & 0.29 & 0.22 & 0.00 & 0.00 & 0.00 & 0.00 & 0.00 \\
\hline $\begin{array}{l}\text { Pu35-24 } \\
\end{array}$ & 0.63 & 0.15 & 0.67 & 0.53 & 0.41 & 0.58 & 0.24 & 0.40 & 0.83 & 0.10 & 0.37 & 0.22 & 0.00 & 0.00 & 0.00 & 0.00 & 0.00 \\
\hline Pu35-25 & 0.67 & 0.59 & 0.48 & 0.70 & 0.83 & 0.48 & 0.07 & 0.28 & 0.26 & 0.35 & 0.17 & 0.22 & 0.00 & 0.00 & 0.00 & 0.00 & 0.00 \\
\hline Pu35-26 & 0.66 & 0.22 & 0.89 & 0.25 & 0.47 & 0.77 & 0.10 & 0.43 & 0.79 & 0.22 & 0.27 & 0.07 & 0.00 & 0.00 & 0.00 & 0.00 & 0.00 \\
\hline Pu35-27 & 0.72 & 0.67 & 0.61 & 0.52 & 0.46 & 0.65 & 0.24 & 0.32 & 0.27 & 0.07 & 0.48 & 0.07 & 0.00 & 0.00 & 0.00 & 0.00 & 0.00 \\
\hline $\begin{array}{l}\text { Pu35-28 } \\
\end{array}$ & 0.72 & 0.54 & 0.93 & 0.39 & 0.08 & 0.74 & 0.10 & 0.11 & 0.41 & 0.36 & 0.48 & 0.22 & 0.00 & 0.00 & 0.00 & 0.00 & 0.00 \\
\hline $\begin{array}{l}\text { Pu35-29 } \\
\end{array}$ & 0.84 & 0.34 & 0.47 & 0.84 & 0.18 & 0.95 & 0.36 & 0.08 & 0.70 & 0.07 & 0.09 & 0.07 & 0.00 & 0.00 & 0.00 & 0.00 & 0.00 \\
\hline $\begin{array}{l}\text { Pu35-30 } \\
\end{array}$ & 0.58 & 0.07 & 0.46 & 1.11 & 0.08 & 0.90 & 0.06 & 0.46 & 0.75 & 0.07 & 0.08 & 0.07 & 0.17 & 0.06 & 0.06 & 0.08 & 0.06 \\
\hline Pu35-31 & 0.58 & 0.07 & 0.60 & 1.12 & 0.83 & 0.47 & 0.47 & 0.08 & 0.08 & 0.17 & 0.09 & 0.07 & 0.17 & 0.06 & 0.06 & 0.08 & 0.06 \\
\hline $\begin{array}{l}\text { Pu35-32 } \\
\end{array}$ & 0.58 & 0.07 & 1.39 & 0.26 & 0.08 & 0.69 & 0.40 & 0.08 & 0.90 & 0.07 & 0.08 & 0.07 & 0.17 & 0.06 & 0.06 & 0.08 & 0.06 \\
\hline $\begin{array}{l}\text { Pu35-33 } \\
\end{array}$ & 0.57 & 0.07 & 1.37 & 0.08 & 0.56 & 0.90 & 0.13 & 0.44 & 0.08 & 0.07 & 0.48 & 0.07 & 0.17 & 0.06 & 0.06 & 0.08 & 0.06 \\
\hline Pu35-34 & 0.58 & 0.71 & 1.38 & 0.58 & 0.08 & 0.48 & 0.06 & 0.37 & 0.08 & 0.07 & 0.08 & 0.22 & 0.17 & 0.06 & 0.06 & 0.08 & 0.06 \\
\hline $\begin{array}{l}\text { Pu35-35 } \\
\end{array}$ & 0.58 & 1.12 & 0.46 & 0.07 & 0.82 & 0.93 & 0.06 & 0.08 & 0.39 & 0.07 & 0.08 & 0.07 & 0.17 & 0.06 & 0.06 & 0.08 & 0.06 \\
\hline Pu35-36 & 0.60 & 0.51 & 0.89 & 0.43 & 0.11 & 0.67 & 0.16 & 0.08 & 0.31 & 0.33 & 0.37 & 0.22 & 0.17 & 0.06 & 0.06 & 0.08 & 0.06 \\
\hline $\begin{array}{l}\text { Pu35-37 } \\
\end{array}$ & 0.60 & 0.35 & 1.02 & 0.36 & 0.28 & 0.65 & 0.10 & 0.17 & 0.36 & 0.37 & 0.40 & 0.07 & 0.17 & 0.06 & 0.06 & 0.08 & 0.06 \\
\hline $\begin{array}{l}\text { Pu35-38 } \\
\end{array}$ & 0.66 & 0.53 & 0.73 & 0.45 & 0.17 & 0.66 & 0.31 & 0.43 & 0.30 & 0.18 & 0.18 & 0.07 & 0.17 & 0.06 & 0.06 & 0.08 & 0.06 \\
\hline $\begin{array}{l}\text { Pu35-39 } \\
\end{array}$ & 0.69 & 0.50 & 0.70 & 0.77 & 0.29 & 0.70 & 0.18 & 0.08 & 0.31 & 0.07 & 0.31 & 0.07 & 0.17 & 0.06 & 0.06 & 0.08 & 0.06 \\
\hline $\begin{array}{l}\text { Pu35-40 } \\
\end{array}$ & 0.72 & 0.07 & 0.65 & 0.50 & 0.56 & 0.65 & 0.14 & 0.41 & 0.39 & 0.10 & 0.32 & 0.22 & 0.17 & 0.06 & 0.06 & 0.08 & 0.06 \\
\hline $\begin{array}{l}\text { Pu35-41 } \\
\end{array}$ & 0.93 & 0.07 & 1.39 & 0.34 & 0.08 & 0.94 & 0.06 & 0.08 & 0.08 & 0.44 & 0.08 & 0.15 & 0.17 & 0.06 & 0.06 & 0.08 & 0.06 \\
\hline $\begin{array}{l}\text { Pu35-42 } \\
\end{array}$ & 0.58 & 0.21 & 1.08 & 0.84 & 0.17 & 0.78 & 0.12 & 0.16 & 0.16 & 0.15 & 0.34 & 0.14 & 0.17 & 0.06 & 0.06 & 0.08 & 0.06 \\
\hline $\begin{array}{l}\text { Pu35-43 } \\
\end{array}$ & 0.58 & 0.49 & 0.65 & 0.21 & 0.57 & 0.74 & 0.20 & 0.35 & 0.35 & 0.20 & 0.25 & 0.14 & 0.17 & 0.06 & 0.06 & 0.08 & 0.06 \\
\hline $\begin{array}{l}\text { Pu35-44 } \\
\end{array}$ & 0.58 & 0.54 & 0.80 & 0.31 & 0.58 & 0.66 & 0.19 & 0.28 & 0.30 & 0.15 & 0.25 & 0.11 & 0.17 & 0.06 & 0.06 & 0.08 & 0.06 \\
\hline $\begin{array}{l}\text { Pu35-45 } \\
\end{array}$ & 0.58 & 0.70 & 0.75 & 0.20 & 0.46 & 0.73 & 0.12 & 0.23 & 0.48 & 0.22 & 0.17 & 0.11 & 0.17 & 0.06 & 0.06 & 0.08 & 0.06 \\
\hline
\end{tabular}


Table D1. Targeted Oxide Concentrations (as wt \% oxides) for the Pu/Impurity Solubility Study Glasses (part 1, continued)

\begin{tabular}{|c|c|c|c|c|c|c|c|c|c|c|c|c|c|c|c|c|c|}
\hline Glass ID & $\begin{array}{l}\mathrm{Cl} \\
\end{array}$ & $\mathbf{T a}_{2} \mathbf{O}_{5}$ & MgO & $\overline{\mathrm{K}_{2} \mathbf{O}}$ & $\mathrm{Fe}_{2} \mathrm{O}_{3}$ & $\mathrm{Na}_{2} \mathrm{O}$ & $\bar{F}$ & $\mathrm{CaO}$ & $\mathrm{Ga}_{2} \mathrm{O}_{3}$ & $\mathrm{NiO}$ & $\mathrm{Cr}_{2} \mathrm{O}_{3}$ & $\mathrm{CuO}$ & $\mathrm{SO}_{4}$ & C & PbO & $\mathrm{SeO}_{2}$ & $\mathrm{Cs}_{2} \mathrm{O}$ \\
\hline Pu35-46 & 0.59 & 0.45 & 0.73 & 0.41 & 0.17 & 0.63 & 0.35 & 0.17 & 0.54 & 0.30 & 0.17 & 0.15 & 0.17 & 0.06 & 0.06 & 0.08 & 0.06 \\
\hline Pu35-47 & 0.61 & 0.85 & 0.61 & 0.25 & 0.17 & 0.73 & 0.12 & 0.40 & 0.19 & 0.29 & 0.34 & 0.14 & 0.17 & 0.06 & 0.06 & 0.08 & 0.06 \\
\hline Pu35-48 & 0.63 & 0.35 & 0.79 & 0.29 & 0.50 & 0.73 & 0.20 & 0.37 & 0.34 & 0.19 & 0.23 & 0.11 & 0.17 & 0.06 & 0.06 & 0.08 & 0.06 \\
\hline $\begin{array}{l}\text { Pu35-49 } \\
\end{array}$ & 0.64 & 0.27 & 0.77 & 0.63 & 0.52 & 0.64 & 0.19 & 0.32 & 0.19 & 0.20 & 0.19 & 0.14 & 0.17 & 0.06 & 0.06 & 0.08 & 0.06 \\
\hline Pu35-50 & 0.64 & 0.18 & 0.66 & 0.69 & 0.49 & 0.65 & 0.20 & 0.26 & 0.32 & 0.24 & 0.25 & 0.11 & 0.17 & 0.06 & 0.06 & 0.08 & 0.06 \\
\hline Pu35-51 & 0.65 & 0.32 & 0.90 & 0.26 & 0.56 & 0.75 & 0.22 & 0.16 & 0.16 & 0.29 & 0.32 & 0.11 & 0.17 & 0.06 & 0.06 & 0.08 & 0.06 \\
\hline Pu35-52 & 0.69 & 0.14 & 0.82 & 0.37 & 0.39 & 0.71 & 0.14 & 0.17 & 0.58 & 0.23 & 0.33 & 0.14 & 0.17 & 0.06 & 0.06 & 0.08 & 0.06 \\
\hline Pu35-53 & 0.70 & 0.77 & 0.62 & 0.47 & 0.17 & 0.79 & 0.35 & 0.16 & 0.16 & 0.15 & 0.17 & 0.11 & 0.17 & 0.06 & 0.06 & 0.08 & 0.06 \\
\hline \begin{tabular}{|l} 
Pu35-54 \\
\end{tabular} & 0.64 & 0.46 & 0.81 & 0.57 & 0.42 & 0.70 & 0.21 & 0.28 & 0.41 & 0.16 & 0.30 & 0.13 & 0.00 & 0.00 & 0.00 & 0.00 & 0.00 \\
\hline Pu35-55 & 0.63 & 0.39 & 0.84 & 0.46 & 0.36 & 0.72 & 0.19 & 0.24 & 0.32 & 0.19 & 0.23 & 0.12 & 0.17 & 0.06 & 0.06 & 0.08 & 0.06 \\
\hline Pu04-01 & 0.00 & 0.00 & 0.00 & 0.00 & 0.00 & 0.00 & 0.00 & 0.00 & 0.00 & 0.00 & 0.00 & 0.00 & 0.00 & 0.00 & 0.00 & 0.00 & 0.00 \\
\hline Pu04-02 & 0.12 & 0.00 & 0.00 & 0.21 & 0.00 & 0.24 & 0.00 & 0.00 & 0.00 & 0.00 & 0.00 & 0.00 & 0.00 & 0.00 & 0.00 & 0.00 & 0.00 \\
\hline Pu04-03 & 0.00 & 0.00 & 0.08 & 0.07 & 0.00 & 0.32 & 0.12 & 0.00 & 0.00 & 0.00 & 0.00 & 0.00 & 0.00 & 0.00 & 0.00 & 0.00 & 0.00 \\
\hline Pu04-04 & 0.06 & 0.00 & 0.16 & 0.00 & 0.17 & 0.16 & 0.06 & 0.00 & 0.00 & 0.00 & 0.00 & 0.00 & 0.00 & 0.00 & 0.00 & 0.00 & 0.00 \\
\hline Pu04-05 & 0.00 & 0.00 & 0.08 & 0.07 & 0.08 & 0.08 & 0.00 & 0.08 & 0.00 & 0.08 & 0.09 & 0.07 & 0.00 & 0.00 & 0.00 & 0.00 & 0.00 \\
\hline
\end{tabular}


WSRC-STI-2007-00477

Revision 0

Appendix D

Table D1. Targeted Oxide Concentrations (as wt\%'s) for the Pu/Impurity Solubility Study Glasses (part 2)

\begin{tabular}{|c|c|c|c|c|c|c|c|c|}
\hline Glass ID & $\mathrm{HfO}_{2}$ & $\mathbf{A l}_{2} \mathbf{O}_{3}$ & $\mathrm{~B}_{2} \mathbf{O}_{3}$ & $\mathbf{G d}_{2} \mathbf{O}_{3}$ & $\mathbf{L a}_{2} \mathbf{O}_{3}$ & $\mathbf{N d}_{2} \mathbf{O}_{3}$ & $\mathrm{SiO}_{2}$ & SrO \\
\hline Pu35-01 & 14.86 & 8.60 & 11.18 & 11.61 & 16.34 & 12.90 & 17.20 & 2.15 \\
\hline $\mathrm{Pu} 35-02$ & 14.92 & 8.60 & 11.18 & 11.61 & 16.34 & 12.90 & 17.20 & 2.15 \\
\hline Pu35-03 & 14.81 & 8.60 & 11.18 & 11.61 & 16.34 & 12.90 & 17.20 & 2.15 \\
\hline Pu35-04 & 15.00 & 8.60 & 11.18 & 11.61 & 16.34 & 12.90 & 17.20 & 2.15 \\
\hline Pu35-05 & 14.85 & 8.60 & 11.18 & 11.61 & 16.34 & 12.90 & 17.20 & 2.15 \\
\hline Pu35-06 & 14.87 & 8.60 & 11.18 & 11.61 & 16.34 & 12.90 & 17.20 & 2.15 \\
\hline Pu35-07 & 14.96 & 8.60 & 11.18 & 11.61 & 16.34 & 12.90 & 17.20 & 2.15 \\
\hline Pu35-08 & 14.95 & 8.60 & 11.18 & 11.61 & 16.34 & 12.90 & 17.20 & 2.15 \\
\hline Pu35-09 & 14.92 & 8.60 & 11.18 & 11.61 & 16.34 & 12.90 & 17.20 & 2.15 \\
\hline $\mathrm{Pu} 35-10$ & 14.90 & 8.60 & 11.18 & 11.61 & 16.34 & 12.90 & 17.20 & 2.15 \\
\hline Pu35-11 & 14.87 & 8.60 & 11.18 & 11.61 & 16.34 & 12.90 & 17.20 & 2.15 \\
\hline Pu35-12 & 14.96 & 8.60 & 11.18 & 11.61 & 16.34 & 12.90 & 17.20 & 2.15 \\
\hline Pu35-13 & 14.96 & 8.60 & 11.18 & 11.61 & 16.34 & 12.90 & 17.20 & 2.15 \\
\hline Pu35-14 & 14.90 & 8.60 & 11.18 & 11.61 & 16.34 & 12.90 & 17.20 & 2.15 \\
\hline Pu35-15 & 15.00 & 8.60 & 11.18 & 11.61 & 16.34 & 12.90 & 17.20 & 2.15 \\
\hline Pu35-16 & 14.85 & 8.60 & 11.18 & 11.61 & 16.34 & 12.90 & 17.20 & 2.15 \\
\hline Pu35-17 & 14.95 & 8.60 & 11.18 & 11.61 & 16.34 & 12.90 & 17.20 & 2.15 \\
\hline Pu35-18 & 14.88 & 8.60 & 11.18 & 11.61 & 16.34 & 12.90 & 17.20 & 2.15 \\
\hline Pu35-19 & 14.89 & 8.60 & 11.18 & 11.61 & 16.34 & 12.90 & 17.20 & 2.15 \\
\hline Pu35-20 & 14.95 & 8.60 & 11.18 & 11.61 & 16.34 & 12.90 & 17.20 & 2.15 \\
\hline Pu35-21 & 14.94 & 8.60 & 11.18 & 11.61 & 16.34 & 12.90 & 17.20 & 2.15 \\
\hline Pu35-22 & 14.98 & 8.60 & 11.18 & 11.61 & 16.34 & 12.90 & 17.20 & 2.15 \\
\hline Pu35-23 & 14.88 & 8.60 & 11.18 & 11.61 & 16.34 & 12.90 & 17.20 & 2.15 \\
\hline Pu35-24 & 14.90 & 8.60 & 11.18 & 11.61 & 16.34 & 12.90 & 17.20 & 2.15 \\
\hline Pu35-25 & 14.92 & 8.60 & 11.18 & 11.61 & 16.34 & 12.90 & 17.20 & 2.15 \\
\hline Pu35-26 & 14.87 & 8.60 & 11.18 & 11.61 & 16.34 & 12.90 & 17.20 & 2.15 \\
\hline Pu35-27 & 14.94 & 8.60 & 11.18 & 11.61 & 16.34 & 12.90 & 17.20 & 2.15 \\
\hline Pu35-28 & 14.93 & 8.60 & 11.18 & 11.61 & 16.34 & 12.90 & 17.20 & 2.15 \\
\hline Pu35-29 & 15.03 & 8.60 & 11.18 & 11.61 & 16.34 & 12.90 & 17.20 & 2.15 \\
\hline Pu35-30 & 14.88 & 8.60 & 11.18 & 11.61 & 16.34 & 12.90 & 17.20 & 2.15 \\
\hline Pu35-31 & 14.95 & 8.60 & 11.18 & 11.61 & 16.34 & 12.90 & 17.20 & 2.15 \\
\hline Pu35-32 & 14.90 & 8.60 & 11.18 & 11.61 & 16.34 & 12.90 & 17.20 & 2.15 \\
\hline Pu35-33 & 14.78 & 8.60 & 11.18 & 11.61 & 16.34 & 12.90 & 17.20 & 2.15 \\
\hline Pu35-34 & 14.89 & 8.60 & 11.18 & 11.61 & 16.34 & 12.90 & 17.20 & 2.15 \\
\hline Pu35-35 & 14.85 & 8.60 & 11.18 & 11.61 & 16.34 & 12.90 & 17.20 & 2.15 \\
\hline Pu35-36 & 14.89 & 8.60 & 11.18 & 11.61 & 16.34 & 12.90 & 17.20 & 2.15 \\
\hline Pu35-37 & 14.85 & 8.60 & 11.18 & 11.61 & 16.34 & 12.90 & 17.20 & 2.15 \\
\hline Pu35-38 & 14.93 & 8.60 & 11.18 & 11.61 & 16.34 & 12.90 & 17.20 & 2.15 \\
\hline Pu35-39 & 14.92 & 8.60 & 11.18 & 11.61 & 16.34 & 12.90 & 17.20 & 2.15 \\
\hline Pu35-40 & 14.86 & 8.60 & 11.18 & 11.61 & 16.34 & 12.90 & 17.20 & 2.15 \\
\hline Pu35-41 & 14.93 & 8.60 & 11.18 & 11.61 & 16.34 & 12.90 & 17.20 & 2.15 \\
\hline Pu35-42 & 14.88 & 8.60 & 11.18 & 11.61 & 16.34 & 12.90 & 17.20 & 2.15 \\
\hline Pu35-43 & 14.85 & 8.60 & 11.18 & 11.61 & 16.34 & 12.90 & 17.20 & 2.15 \\
\hline Pu35-44 & 14.86 & 8.60 & 11.18 & 11.61 & 16.34 & 12.90 & 17.20 & 2.15 \\
\hline Pu35-45 & 14.86 & 8.60 & 11.18 & 11.61 & 16.34 & 12.90 & 17.20 & 2.15 \\
\hline Pu35-46 & 14.92 & 8.60 & 11.18 & 11.61 & 16.34 & 12.90 & 17.20 & 2.15 \\
\hline Pu35-47 & 14.88 & 8.60 & 11.18 & 11.61 & 16.34 & 12.90 & 17.20 & 2.15 \\
\hline Pu35-48 & 14.86 & 8.60 & 11.18 & 11.61 & 16.34 & 12.90 & 17.20 & 2.15 \\
\hline Pu35-49 & 14.89 & 8.60 & 11.18 & 11.61 & 16.34 & 12.90 & 17.20 & 2.15 \\
\hline Pu35-50 & 14.89 & 8.60 & 11.18 & 11.61 & 16.34 & 12.90 & 17.20 & 2.15 \\
\hline Pu35-51 & 14.87 & 8.60 & 11.18 & 11.61 & 16.34 & 12.90 & 17.20 & 2.15 \\
\hline Pu35-52 & 14.86 & 8.60 & 11.18 & 11.61 & 16.34 & 12.90 & 17.20 & 2.15 \\
\hline Pu35-53 & 14.97 & 8.60 & 11.18 & 11.61 & 16.34 & 12.90 & 17.20 & 2.15 \\
\hline Pu35-54 & 14.93 & 8.60 & 11.18 & 11.61 & 16.34 & 12.90 & 17.20 & 2.15 \\
\hline Pu35-55 & 14.88 & 8.60 & 11.18 & 11.61 & 16.34 & 12.90 & 17.20 & 2.15 \\
\hline Pu04-01 & 6.02 & 8.60 & 11.18 & 11.61 & 16.34 & 12.90 & 17.20 & 2.15 \\
\hline Pu04-02 & 19.45 & 8.60 & 11.18 & 11.61 & 16.34 & 12.90 & 17.20 & 2.15 \\
\hline Pu04-03 & 19.43 & 8.60 & 11.18 & 11.61 & 16.34 & 12.90 & 17.20 & 2.15 \\
\hline Pu04-04 & 19.42 & 8.60 & 11.18 & 11.61 & 16.34 & 12.90 & 17.20 & 2.15 \\
\hline Pu04-05 & 19.39 & 8.60 & 11.18 & 11.61 & 16.34 & 12.90 & 17.20 & 2.15 \\
\hline
\end{tabular}


Table D2. Measured Elemental Concentrations (wt \%) for Samples Prepared Using Lithium Metaborate

\begin{tabular}{|c|c|c|c|c|c|c|c|c|c|c|c|c|c|c|c|c|c|c|c|c|c|c|c|}
\hline Glass ID & Block & Seq. & Lab ID & $\begin{array}{c}\text { Al } \\
\text { (wt \%) }\end{array}$ & $\begin{array}{c}\text { Ca } \\
\text { (wt \%) }\end{array}$ & $\begin{array}{c}\mathrm{Cr} \\
\text { (wt \%) }\end{array}$ & $\begin{array}{c}\mathrm{Cu} \\
\text { (wt \%) }\end{array}$ & $\begin{array}{c}\mathbf{F e} \\
(w t \%)\end{array}$ & $\begin{array}{c}\text { Ga } \\
\text { (wt \%) }\end{array}$ & $\begin{array}{c}\text { Gd } \\
\text { (wt \%) }\end{array}$ & $\begin{array}{c}\text { Hf } \\
\text { (wt \%) }\end{array}$ & $\begin{array}{c}\mathrm{K} \\
\text { (wt \%) }\end{array}$ & $\begin{array}{c}\text { La } \\
\text { (wt \%) }\end{array}$ & $\begin{array}{c}\text { Mg } \\
\text { (wt \%) }\end{array}$ & $\begin{array}{c}\mathrm{Na} \\
\text { (wt \%) }\end{array}$ & $\begin{array}{c}\text { Nd } \\
\text { (wt \%) }\end{array}$ & $\begin{array}{c}\mathrm{Ni} \\
\text { (wt \%) }\end{array}$ & $\begin{array}{c}\mathbf{P b} \\
\text { (wt \%) }\end{array}$ & $\begin{array}{c}\mathrm{S} \\
\text { (wt \%) }\end{array}$ & $\begin{array}{c}\text { Se } \\
\text { (wt \%) }\end{array}$ & $\begin{array}{c}\mathrm{Si} \\
\text { (wt \%) }\end{array}$ & $\begin{array}{c}\text { Sr } \\
\text { (wt \%) }\end{array}$ & $\begin{array}{c}\text { Ta } \\
\text { (wt \%) }\end{array}$ \\
\hline Batch 1 & 1 & 1 & BCHLM11 & 2.62 & 0.883 & 0.074 & 0.302 & 8.95 & $<0.010$ & 0.319 & 0.115 & 3.17 & 0.637 & 0.845 & 7.34 & 0.539 & 0.52 & $<0.010$ & $<0.050$ & $<0.010$ & 23.9 & 0.037 & $<0.010$ \\
\hline LRM & 1 & 2 & LRMLM11 & 5.35 & 0.359 & 0.131 & 0.012 & 0.893 & $<0.010$ & 0.005 & 0.015 & 1.29 & 0.011 & 0.055 & 15.9 & $<0.010$ & 0.13 & 0.079 & 0.081 & $<<0.010$ & 25.4 & $<0.010$ & $<0.010$ \\
\hline Pu35-04 & 1 & 3 & B09LM1 & 4.82 & 0.333 & 0.055 & 0.079 & 0.199 & 0.287 & 10.2 & 11.5 & 0.353 & 14 & 0.595 & 0.493 & 11.3 & 0.055 & 0.086 & $<0.050$ & $<0.010$ & 8.36 & 1.9 & 0.353 \\
\hline Pu35-01 & 1 & 4 & B06LM1 & 4.74 & 0.058 & 0.006 & 0.124 & 0.296 & 0.692 & 10 & 11.6 & 0.197 & 13.7 & 0.861 & 0.62 & 11.1 & 0.139 & 0.034 & $<0.050$ & $<<0.010$ & 8.39 & 1.88 & 0.065 \\
\hline $\mathrm{Pu} 04-03$ & 1 & 5 & B03LM1 & 4.97 & 0.044 & 0.006 & 0.023 & 0.126 & 0.027 & 10.5 & 12.8 & $<0.010$ & 14.3 & 0.088 & 0.148 & 11.6 & $<0.010$ & 0.035 & $<0.050$ & $<0.010$ & 8.67 & 1.97 & 0.016 \\
\hline Pu35-02 & 1 & 6 & B07LM2 & 4.82 & 0.344 & 0.199 & 0.071 & 0.076 & 0.082 & 10.2 & 11.4 & 0.519 & 13.6 & 0.782 & 0.288 & 11.2 & 0.097 & 0.079 & $<0.050$ & $<<0.010$ & 8.2 & 1.92 & 0.066 \\
\hline $\mathrm{Pu} 04-02$ & 1 & 7 & B02LM1 & 4.98 & 0.053 & 0.006 & 0.024 & 0.025 & 0.027 & 10.4 & 12.4 & 0.067 & 14.1 & 0.042 & 0.34 & 11.4 & $<0.010$ & 0.035 & $<0.050$ & $<0.010$ & 8.75 & 1.95 & 0.016 \\
\hline Pu35-03 & 1 & 8 & B08LM2 & 4.63 & 0.629 & 0.37 & 0.025 & 0.11 & 0.34 & 10 & 11.2 & 0.25 & 13.7 & 0.304 & 1.08 & 11 & 0.044 & 0.033 & $<0.050$ & $<0.010$ & 8.03 & 1.83 & 0.143 \\
\hline Pu35-05 & 1 & 9 & B10LM1 & 4.82 & 0.155 & 0.383 & 0.218 & 0.835 & 0.242 & 10.3 & 11.9 & 0.591 & 13.8 & 0.293 & 0.291 & 11.3 & $<0.010$ & 0.085 & $<0.050$ & $<<0.010$ & 8.4 & 1.94 & 0.081 \\
\hline Pu35-04 & 1 & 10 & B09LM2 & 4.79 & 0.311 & 0.055 & 0.075 & 0.199 & 0.281 & 10.2 & 11.8 & 0.346 & 14 & 0.585 & 0.459 & 11.3 & 0.056 & 0.084 & $<0.050$ & $<0.010$ & 8.29 & 1.89 & 0.343 \\
\hline Pu04-05 & 1 & 11 & B05LM2 & 4.98 & 0.045 & 0.006 & 0.023 & 0.019 & 0.027 & 10.7 & 13.3 & $<0.010$ & 14 & $<0.010$ & 0.274 & 11.8 & $<0.010$ & 0.035 & $<0.050$ & $<<0.010$ & 8.77 & 1.94 & 0.016 \\
\hline Pu04-05 & 1 & 12 & $\begin{array}{l}\text { B05LM1 } \\
\end{array}$ & 4.94 & 0.05 & 0.006 & 0.023 & 0.019 & 0.027 & 10.7 & 12.9 & $<0.010$ & 13.9 & $<0.010$ & 0.297 & 11.7 & $<0.010$ & 0.036 & $<0.050$ & $<0.010$ & 8.69 & 1.92 & 0.016 \\
\hline Batch 1 & 1 & 13 & BCHLM12 & 2.62 & 0.885 & 0.073 & 0.299 & 8.98 & $<0.010$ & 0.313 & 0.138 & 3.11 & 0.623 & 0.846 & 7.22 & 0.529 & 0.517 & $<0.010$ & $<0.050$ & $<0.010$ & 23.8 & 0.038 & $<0.010$ \\
\hline LRM & 1 & 14 & LRMLM12 & 5.04 & 0.361 & 0.13 & 0.012 & 0.882 & $<0.010$ & 0.005 & 0.043 & 1.21 & 0.01 & 0.055 & 15.4 & $<0.010$ & 0.128 & 0.078 & 0.085 & $<0.010$ & 24.8 & $<0.010$ & $<0.010$ \\
\hline Pu35-05 & 1 & 15 & B10LM2 & 4.59 & 0.145 & 0.363 & 0.208 & 0.799 & 0.231 & 9.84 & 11 & 0.558 & 13.3 & 0.281 & 0.277 & 10.9 & $<0.010$ & 0.082 & $<0.050$ & $<<0.010$ & 7.95 & 1.83 & 0.078 \\
\hline Pu04-01 & 1 & 16 & B01LM1 & 5.03 & 0.051 & 0.008 & 0.023 & 0.031 & 0.028 & 10.6 & 12.3 & 0.166 & 14.5 & $<0.010$ & 0.214 & 11.7 & $<0.010$ & 0.036 & $<0.050$ & $<0.010$ & 8.74 & 1.97 & 0.015 \\
\hline Pu35-03 & 1 & 17 & B08LM1 & 4.74 & 0.637 & 0.373 & 0.025 & 0.109 & 0.343 & 10.1 & 11.4 & 0.257 & 13.7 & 0.3 & 1.111 & 11.2 & 0.044 & 0.032 & $<0.050$ & $<0.010$ & 8.13 & 1.89 & 0.147 \\
\hline $\mathrm{Pu} 04-02$ & 1 & 18 & B02LM2 & 4.99 & 0.056 & 0.006 & 0.023 & 0.021 & 0.028 & 10.5 & 12.5 & 0.049 & 14.4 & 0.041 & 0.275 & 11.6 & $<0.010$ & 0.035 & $<0.050$ & $<0.010$ & 8.76 & 1.96 & 0.015 \\
\hline Pu04-04 & 1 & 19 & B04LM1 & 5.03 & 0.119 & 0.057 & 0.085 & 0.076 & 0.027 & 10.7 & 12.6 & 0.051 & 13.8 & 0.041 & 0.083 & 11.8 & 0.055 & 0.036 & $<0.050$ & $<0.010$ & 8.7 & 1.93 & 0.015 \\
\hline Pu35-02 & 1 & 20 & B07LM1 & 4.88 & 0.349 & 0.205 & 0.075 & 0.082 & 0.083 & 10.4 & 11.7 & 0.522 & 13.9 & 0.782 & 0.3 & 11.5 & 0.099 & 0.081 & $<0.050$ & $<<0.010$ & 8.32 & 1.95 & 0.068 \\
\hline Pu04-01 & 1 & 21 & B01LM2 & 5.05 & 0.047 & 0.012 & 0.024 & 0.044 & 0.027 & 10.5 & 12.3 & 0.152 & 14.3 & $<0.010$ & 0.209 & 11.7 & $<0.010$ & 0.036 & $<0.050$ & $<0.010$ & 8.68 & 1.98 & 0.015 \\
\hline Pu35-01 & 1 & 22 & B06LM2 & 4.82 & 0.057 & 0.005 & 0.122 & 0.278 & 0.69 & 10.2 & 11.5 & 0.203 & 13.9 & 0.857 & 0.633 & 11.3 & 0.138 & 0.033 & $<0.050$ & $<0.010$ & 8.47 & 1.9 & 0.061 \\
\hline $\mathrm{Pu} 04-04$ & 1 & 23 & B04LM2 & 5.08 & 0.128 & 0.056 & 0.08 & 0.081 & 0.025 & 10.8 & 12.1 & 0.054 & 13.9 & 0.041 & 0.104 & 12 & 0.053 & 0.034 & $<0.050$ & $<0.010$ & 8.76 & 1.96 & 0.014 \\
\hline Pu04-03 & 1 & 24 & B03LM2 & 5 & 0.05 & 0.005 & 0.026 & 0.126 & 0.029 & 10.6 & 12.6 & $<0.010$ & 14.4 & 0.09 & 0.155 & 11.7 & $<0.010$ & 0.035 & $<0.050$ & $<0.010$ & 8.67 & 1.95 & 0.016 \\
\hline Batch 1 & 1 & 25 & BCHLM13 & 2.63 & 0.894 & 0.071 & 0.3 & 8.81 & $<0.010$ & 0.312 & 0.147 & 3.2 & 0.619 & 0.809 & 7.37 & 0.527 & 0.508 & $<0.010$ & $<0.050$ & $<0.010$ & 23.7 & 0.038 & $<0.010$ \\
\hline LRM & 1 & 26 & LRMLM13 & 5.17 & 0.365 & 0.13 & 0.012 & 0.88 & $<0.010$ & 0.005 & 0.05 & 1.25 & 0.011 & 0.054 & 15.8 & $<0.010$ & 0.127 & 0.079 & 0.082 & $<0.010$ & 24.7 & $<0.010$ & $<0.010$ \\
\hline Batch 1 & 2 & 1 & BCHLM21 & 2.56 & 0.882 & 0.077 & 0.306 & 8.73 & $<0.010$ & 0.33 & 0.117 & 3.09 & 0.662 & 0.892 & 7.13 & 0.552 & 0.541 & $<0.010$ & $<0.050$ & $<0.010$ & 23.2 & 0.034 & $<0.010$ \\
\hline LRM & 2 & 2 & LRMLM11 & 5.16 & 0.355 & 0.138 & 0.009 & 0.943 & $<0.010$ & 0.005 & 0.011 & 1.27 & 0.011 & 0.057 & 15.6 & $<0.010$ & 0.135 & 0.082 & 0.081 & $<0.010$ & 24.5 & $<0.010$ & $<0.010$ \\
\hline Pu35-13 & 2 & 3 & B18LM1 & 4.75 & 0.042 & 0.246 & 0.139 & 0.272 & 0.087 & 10.2 & 11.4 & 0.299 & 13.8 & 0.467 & 0.781 & 11.2 & $<0.010$ & 0.092 & $<0.050$ & $<0.010$ & 8.28 & 1.89 & 0.687 \\
\hline Pu35-14 & 2 & 4 & B19LM1 & 4.83 & 0.352 & 0.091 & 0.074 & 0.676 & 0.227 & 10.2 & 11.7 & 0.127 & 13.8 & 0.266 & 0.765 & 11.3 & 0.052 & 0.078 & $<0.050$ & $<0.010$ & 8.23 & 1.94 & 0.288 \\
\hline Pu35-15 & 2 & 5 & B20LM1 & 4.89 & 0.046 & 0.006 & 0.02 & 0.024 & 0.967 & 10.3 & 11.9 & 0.385 & 14 & 0.327 & 0.632 & 11.5 & 0.431 & 0.083 & $<<0.050$ & $<0.010$ & 8.39 & 1.96 & 0.014 \\
\hline Pu35-15 & 2 & 6 & B20LM2 & 4.84 & 0.044 & 0.005 & 0.021 & 0.02 & 0.957 & 10.2 & 11.5 & 0.382 & 13.8 & 0.322 & 0.631 & 11.3 & 0.422 & 0.081 & $<0.050$ & $<0.010$ & 8.25 & 1.93 & 0.014 \\
\hline Pu35-07 & 2 & 7 & B12LM1 & 4.82 & 0.216 & 0.088 & 0.142 & 0.078 & 0.083 & 10.2 & 11.9 & 0.334 & 13.8 & 0.331 & 0.469 & 11.3 & 0.277 & 0.081 & $<0.050$ & $<0.010$ & 8.27 & 1.94 & 1.049 \\
\hline Pu35-11 & 2 & 8 & B16LM2 & 4.74 & 0.36 & 0.265 & 0.032 & 0.08 & 0.183 & 10.1 & 11.8 & 0.257 & 13.6 & 0.603 & 0.516 & 11.1 & 0.125 & 0.081 & $<0.050$ & $<0.010$ & 8.28 & 1.91 & 0.568 \\
\hline Pu35-10 & 2 & 9 & B15LM2 & 4.78 & 0.109 & 0.06 & 0.075 & 0.417 & 0.557 & 10.2 & 11.6 & 0.267 & 13.8 & 0.502 & 0.514 & 11.3 & 0.053 & 0.077 & $<0.050$ & $<0.010$ & 8.31 & 1.91 & 0.226 \\
\hline Pu35-09 & 2 & 10 & B14LM2 & 4.88 & 0.131 & 0.06 & 0.176 & 0.019 & 0.128 & 10.3 & 11.7 & 0.986 & 14 & 0.334 & 0.852 & 11.4 & 0.135 & 0.086 & $<0.050$ & $<0.010$ & 8.43 & 1.95 & 0.099 \\
\hline Pu35-08 & 2 & 11 & B13LM2 & 4.8 & 0.246 & 0.074 & 0.079 & 0.713 & 0.151 & 10.2 & 11.7 & 0.548 & 13.9 & 0.546 & 0.325 & 11.3 & 0.196 & 0.034 & $<0.050$ & $<0.010$ & 8.36 & 1.91 & 0.323 \\
\hline Pu35-12 & 2 & 12 & B17LM1 & 4.82 & 0.114 & 0.259 & 0.162 & 0.153 & 0.295 & 10.2 & 11.8 & 0.205 & 13.7 & 0.411 & 0.589 & 11.3 & 0.354 & 0.037 & $<0.050$ & $<0.010$ & 8.21 & 1.94 & 0.493 \\
\hline Batch 1 & 2 & 13 & BCHLM21 & 2.65 & 0.893 & 0.077 & 0.311 & 8.52 & $<0.010$ & 0.337 & 0.122 & 3.27 & 0.675 & 0.906 & 7.39 & 0.563 & 0.55 & $<0.010$ & $<0.050$ & $<0.010$ & 23.3 & 0.035 & $<0.010$ \\
\hline LRM & 2 & 14 & LRMLM21 & 5.16 & 0.36 & 0.136 & 0.009 & 0.922 & $<0.010$ & 0.006 & 0.077 & 1.3 & 0.015 & 0.056 & 15.7 & $<0.010$ & 0.132 & 0.08 & 0.08 & $<0.010$ & 24.2 & $<0.010$ & $<0.010$ \\
\hline Pu35-13 & 2 & 15 & B18LM2 & 4.81 & 0.044 & 0.243 & 0.136 & 0.27 & 0.086 & 10.1 & 11.2 & 0.29 & 13.5 & 0.464 & 0.776 & 11.2 & $<0.010$ & 0.092 & $<0.050$ & $<0.010$ & 8.13 & 1.94 & 0.679 \\
\hline Pu35-14 & 2 & 16 & B19LM2 & 4.83 & 0.349 & 0.095 & 0.075 & 0.702 & 0.23 & 10.2 & 11.7 & 0.125 & 13.8 & 0.276 & 0.775 & 11.3 & 0.054 & 0.083 & $<<0.050$ & $<0.010$ & 8.29 & 1.94 & 0.295 \\
\hline
\end{tabular}


Table D2. Measured Elemental Concentrations (wt \%) for Samples Prepared Using Lithium Metaborate (continued)

\begin{tabular}{|c|c|c|c|c|c|c|c|c|c|c|c|c|c|c|c|c|c|c|c|c|c|c|c|}
\hline Glass ID & Block & Seq. & Lab ID & $\begin{array}{c}\mathrm{Al} \\
\text { (wt \%) }\end{array}$ & $\begin{array}{c}\text { Ca } \\
\text { (wt \%) }\end{array}$ & $\begin{array}{c}\mathrm{Cr} \\
\text { (wt \%) }\end{array}$ & $\begin{array}{c}\mathrm{Cu} \\
\text { (wt \%) }\end{array}$ & $\begin{array}{c}\mathbf{F e} \\
\text { (wt \%) }\end{array}$ & $\begin{array}{c}\text { Ga } \\
\text { (wt \%) }\end{array}$ & $\begin{array}{c}\text { Gd } \\
\text { (wt \%) }\end{array}$ & $\begin{array}{c}\text { Hf } \\
\text { (wt \%) }\end{array}$ & $\begin{array}{c}\mathrm{K} \\
\text { (wt \%) }\end{array}$ & $\begin{array}{c}\text { La } \\
\text { (wt \%) }\end{array}$ & $\begin{array}{c}\text { Mg } \\
\text { (wt \%) }\end{array}$ & $\begin{array}{c}\mathrm{Na} \\
\text { (wt \%) }\end{array}$ & $\begin{array}{c}\text { Nd } \\
\text { (wt \%) }\end{array}$ & $\begin{array}{c}\mathrm{Ni} \\
\text { (wt \%) }\end{array}$ & $\begin{array}{c}\mathbf{P b} \\
\text { (wt \%) }\end{array}$ & $\begin{array}{c}\mathrm{S} \\
\text { (wt \%) }\end{array}$ & $\begin{array}{c}\text { Se } \\
\text { (wt \%) }\end{array}$ & $\begin{array}{c}\mathrm{Si} \\
\text { (wt \%) }\end{array}$ & $\begin{array}{c}\mathrm{Sr} \\
\text { (wt \%) }\end{array}$ & $\begin{array}{c}\text { Ta } \\
\text { (wt \%) } \\
\end{array}$ \\
\hline Pu35-10 & 2 & 17 & B15LM1 & 4.76 & 0.105 & 0.058 & 0.072 & 0.412 & 0.544 & 10.1 & 11.1 & 0.258 & 13.6 & 0.499 & 0.496 & 11.1 & 0.055 & 0.077 & $<0.050$ & $<0.010$ & 8.15 & 1.91 & 0.217 \\
\hline Pu35-08 & 2 & 18 & B13LM1 & 4.73 & 0.257 & 0.056 & 0.082 & 0.628 & 0.157 & 10.1 & 11 & 0.593 & 13.9 & 0.495 & 0.332 & 11.3 & 0.172 & 0.05 & $<0.050$ & $<0.010$ & 7.86 & 1.91 & 0.307 \\
\hline Pu35-12 & 2 & 19 & B17LM2 & 4.85 & 0.11 & 0.257 & 0.159 & 0.152 & 0.289 & 10.1 & 11.8 & 0.201 & 13.6 & 0.411 & 0.577 & 11.3 & 0.352 & 0.037 & $<0.050$ & $<0.010$ & 8.3 & 1.98 & 0.489 \\
\hline Pu35-11 & 2 & 20 & B16LM1 & 4.78 & 0.359 & 0.266 & 0.03 & 0.074 & 0.185 & 10.1 & 11.8 & 0.26 & 13.6 & 0.614 & 0.517 & 11.2 & 0.126 & 0.084 & $<0.050$ & $<0.010$ & 8.22 & 1.93 & 0.569 \\
\hline Pu35-06 & 2 & 21 & B11LM1 & 4.77 & 0.274 & 0.148 & 0.022 & 0.673 & 0.024 & 10.1 & 11.5 & 0.189 & 13.7 & 0.568 & 0.579 & 11.1 & 0.201 & 0.036 & $<0.050$ & $<0.010$ & 8.15 & 1.92 & 0.091 \\
\hline Pu35-06 & 2 & 22 & B11LM2 & 4.79 & 0.276 & 0.148 & 0.021 & 0.68 & 0.024 & 10.1 & 11.4 & 0.189 & 13.6 & 0.575 & 0.591 & 11.2 & 0.203 & 0.037 & $<0.050$ & $<0.010$ & 8.12 & 1.93 & 0.09 \\
\hline Pu35-07 & 2 & 23 & B12LM2 & 4.73 & 0.201 & 0.093 & 0.144 & 0.088 & 0.084 & 10.1 & 11.8 & 0.325 & 13.7 & 0.341 & 0.475 & 11.1 & 0.285 & 0.083 & $<0.050$ & $<0.010$ & 8.12 & 1.92 & 1.066 \\
\hline Pu35-09 & 2 & 24 & B14LM1 & 4.68 & 0.128 & 0.06 & 0.17 & 0.035 & 0.124 & 9.9 & 10.9 & 0.953 & 13.5 & 0.329 & 0.826 & 11 & 0.135 & 0.086 & $<0.050$ & $<0.010$ & 8.05 & 1.89 & 0.092 \\
\hline Batch 1 & 2 & 25 & BCHLM23 & 2.63 & 0.879 & 0.079 & 0.306 & 8.65 & $<0.010$ & 0.336 & 0.123 & 3.21 & 0.678 & 0.927 & 7.4 & 0.559 & 0.561 & $<0.010$ & $<0.050$ & $<0.010$ & 23.4 & 0.034 & $<0.010$ \\
\hline LRM & 2 & 26 & LRMLM23 & 5.15 & 0.35 & 0.138 & 0.008 & 0.946 & $<0.010$ & 0.005 & 0.074 & 1.28 & 0.011 & 0.058 & 15.8 & $<0.010$ & 0.136 & 0.082 & 0.084 & $<0.010$ & 24.7 & $<0.010$ & $<0.010$ \\
\hline Batch 1 & 3 & 1 & BCHLM31 & 2.63 & 0.868 & 0.073 & 0.303 & 9.13 & $<0.010$ & 0.324 & 0.116 & 3.16 & 0.646 & 0.836 & 7.35 & 0.548 & 0.524 & $<0.010$ & $<0.050$ & $<0.010$ & 24.1 & 0.035 & $<0.010$ \\
\hline LRM & 3 & 2 & LRMLM31 & 5.35 & 0.357 & 0.132 & 0.011 & 0.905 & $<0.010$ & 0.005 & 0.01 & 1.27 & 0.011 & 0.054 & 15.8 & $<0.010$ & 0.129 & 0.078 & 0.075 & $<0.010$ & 25.7 & $<0.010$ & $<0.010$ \\
\hline Pu35-24 & 3 & 3 & B29LM1 & 4.71 & 0.359 & 0.232 & 0.173 & 0.282 & 0.628 & 10.2 & 11.5 & 0.353 & 14.1 & 0.391 & 0.44 & 11.2 & 0.068 & 0.036 & $<0.050$ & $<0.010$ & 8.43 & 1.84 & 0.138 \\
\hline Pu35-25 & 3 & 4 & B30LM2 & $\begin{array}{ll}4.7 \\
\end{array}$ & 0.266 & 0.116 & 0.183 & 0.57 & 0.218 & 10.2 & 11.7 & 0.516 & 13.9 & 0.285 & 0.365 & 11.2 & 0.249 & 0.035 & $<0.050$ & $<0.010$ & 9.16 & 1.85 & 0.472 \\
\hline Pu35-18 & 3 & 5 & B23LM1 & 4.62 & 0.481 & 0.328 & 0.075 & 0.144 & 0.085 & 10.1 & 11.7 & 0.663 & 13.8 & 0.592 & 0.669 & 11 & 0.062 & 0.036 & $<0.050$ & $<0.010$ & 8.27 & 1.81 & 0.068 \\
\hline Pu35-22 & 3 & 6 & B27LM2 & 4.75 & 0.495 & 0.094 & 0.185 & 0.26 & 0.085 & 10.4 & 11.7 & 0.385 & 14.3 & 0.407 & 0.56 & 11.2 & 0.057 & 0.035 & $<0.050$ & $<0.010$ & 8.44 & 1.85 & 0.42 \\
\hline Pu35-25 & 3 & 7 & B30LM1 & 4.71 & 0.269 & 0.124 & 0.183 & 0.581 & 0.216 & 10.3 & 11.7 & 0.516 & 14 & 0.278 & 0.367 & 11.1 & 0.249 & 0.033 & $<0.050$ & $<0.010$ & 9.15 & 1.84 & 0.468 \\
\hline Pu35-20 & 3 & 8 & B25LM1 & 4.81 & 0.228 & 0.25 & 0.082 & 0.198 & 0.399 & 10.4 & 11.9 & 0.55 & 14.3 & 0.319 & 0.381 & 11.4 & 0.206 & 0.036 & $<0.050$ & $<0.010$ & 8.48 & 1.88 & 0.416 \\
\hline Pu35-16 & 3 & 9 & B21LM2 & 4.69 & 0.568 & 0.004 & 0.214 & 0.306 & 0.14 & 10.2 & 11.6 & $<0.010$ & 13.8 & 0.413 & 0.815 & 11.1 & 0.093 & 0.071 & $<0.050$ & $<0.010$ & 8.26 & 1.82 & 0.231 \\
\hline Pu35-18 & 3 & 10 & B23LM2 & 4.77 & 0.496 & 0.303 & 0.075 & 0.076 & 0.084 & 10.4 & 11.9 & 0.665 & 14.3 & 0.591 & 0.66 & 11.4 & 0.051 & 0.035 & $<0.050$ & $<0.010$ & 8.48 & 1.86 & 0.066 \\
\hline Pu35-22 & 3 & 11 & B27LM1 & 4.84 & 0.501 & 0.093 & 0.185 & 0.263 & 0.086 & 10.5 & 11.9 & 0.391 & 14.4 & 0.408 & 0.556 & 11.5 & 0.057 & 0.035 & $<0.050$ & $<0.010$ & 8.54 & 1.9 & 0.421 \\
\hline Pu35-20 & 3 & 12 & B25LM2 & 4.8 & 0.229 & 0.256 & 0.083 & 0.203 & 0.404 & 10.4 & 12 & 0.553 & 14.4 & 0.328 & 0.387 & 11.4 & 0.213 & 0.037 & $<0.050$ & $<0.010$ & 8.49 & 1.88 & 0.421 \\
\hline Batch 1 & 3 & 13 & BCHLM32 & 2.63 & 0.866 & 0.075 & 0.305 & 9.1 & $<0.010$ & 0.33 & 0.147 & 3.11 & 0.657 & 0.856 & 7.24 & 0.551 & 0.533 & $<0.010$ & $<0.050$ & $<0.010$ & 24 & 0.035 & $<0.010$ \\
\hline LRM & 3 & 14 & LRMLM32 & 5.1 & 0.349 & 0.133 & 0.01 & 0.917 & $<0.010$ & 0.005 & 0.056 & 1.22 & 0.01 & 0.055 & 15.5 & $<0.010$ & 0.131 & 0.08 & 0.078 & $<0.010$ & 25 & $<0.010$ & $<0.010$ \\
\hline Pu35-21 & 3 & 15 & B26LM1 & 4.75 & 0.145 & 0.055 & 0.096 & 0.071 & 0.483 & 10.3 & $\begin{array}{ll}11.4 \\
\end{array}$ & 0.295 & 14.1 & 0.712 & 0.451 & 11.3 & 0.056 & 0.036 & $<0.050$ & $<0.010$ & 8.39 & 1.86 & 0.893 \\
\hline Pu35-23 & 3 & 16 & B28LM1 & 4.74 & 0.173 & 0.186 & 0.189 & 0.387 & 0.418 & 10.3 & 11.9 & 0.107 & 14.2 & 0.395 & 0.672 & 11.3 & 0.086 & 0.036 & $<0.050$ & $<0.010$ & 8.38 & 1.87 & 0.658 \\
\hline Pu35-21 & 3 & 17 & B26LM2 & 4.74 & 0.112 & 0.056 & 0.092 & 0.074 & 0.48 & 10.3 & 11.7 & 0.293 & 14.1 & 0.718 & 0.443 & 11.3 & 0.056 & 0.036 & $<0.050$ & $<0.010$ & 8.41 & 1.87 & 0.894 \\
\hline Pu35-24 & 3 & 18 & B29LM2 & 4.73 & 0.361 & 0.238 & 0.17 & 0.319 & 0.621 & 10.3 & 11.9 & 0.342 & 14.1 & 0.392 & 0.437 & 11.2 & 0.072 & 0.037 & $<0.050$ & $<0.010$ & 8.38 & 1.85 & 0.139 \\
\hline Pu35-17 & 3 & 19 & B22LM1 & 4.71 & 0.117 & 0.202 & 0.085 & 0.026 & 0.52 & 10.3 & 11.8 & 0.287 & 14.1 & 0.236 & 0.725 & 11.2 & 0.052 & 0.038 & $<0.050$ & $<0.010$ & 8.47 & 1.84 & 0.439 \\
\hline Pu35-16 & 3 & 20 & B21LM1 & 4.87 & 0.574 & 0.004 & 0.214 & 0.32 & 0.144 & 10.5 & 12.1 & $<0.010$ & 14.2 & 0.43 & 0.832 & 11.5 & 0.097 & 0.075 & $<0.050$ & $<0.010$ & 8.49 & 1.91 & 0.237 \\
\hline Pu35-17 & 3 & 21 & B22LM2 & 4.76 & 0.114 & 0.215 & 0.085 & 0.06 & 0.518 & 10.3 & 11.7 & 0.286 & 14 & 0.236 & 0.721 & 11.3 & 0.059 & 0.037 & $<0.050$ & $<0.010$ & 8.46 & 1.86 & 0.44 \\
\hline Pu35-19 & 3 & 22 & B24LM1 & 4.72 & 0.112 & 0.298 & 0.073 & 0.52 & 0.084 & 10.3 & 11.8 & 0.23 & 14.1 & 0.771 & 0.57 & 11.2 & 0.048 & 0.035 & $<0.050$ & $<0.010$ & 8.33 & 1.86 & 0.068 \\
\hline Pu35-19 & 3 & 23 & B24LM2 & 4.76 & 0.11 & 0.307 & 0.073 & 0.541 & 0.084 & 10.3 & 11.9 & 0.226 & 14 & 0.763 & 0.565 & 11.2 & 0.056 & 0.035 & $<0.050$ & $<0.010$ & 8.33 & 1.88 & 0.067 \\
\hline Pu35-23 & 3 & 24 & B28LM2 & 4.77 & 0.167 & 0.184 & 0.185 & 0.392 & 0.411 & 10.3 & 11.8 & 0.103 & 14 & 0.389 & 0.666 & 11.2 & 0.087 & 0.036 & $<0.050$ & $<0.010$ & 8.3 & 1.9 & 0.647 \\
\hline Batch 1 & 3 & 25 & BCHLM33 & 2.7 & 0.857 & 0.073 & 0.3 & 8.95 & $<0.010$ & 0.324 & 0.143 & 3.26 & 0.647 & 0.848 & 7.54 & 0.542 & 0.527 & $<0.010$ & $<0.050$ & $<0.010$ & 24.1 & 0.035 & $<0.010$ \\
\hline LRM & 3 & 26 & LRMLM33 & 5.23 & 0.345 & 0.132 & 0.01 & 0.91 & $<0.010$ & 0.005 & 0.053 & 1.3 & 0.01 & 0.055 & 16.2 & $<0.010$ & 0.13 & 0.079 & 0.078 & $<0.010$ & 25.3 & $<0.010$ & $<0.010$ \\
\hline Batch 1 & 4 & 1 & BCHLM41 & 2.58 & 0.865 & 0.076 & 0.305 & 8.8 & $<0.010$ & 0.331 & 0.118 & 3.1 & 0.66 & 0.87 & 7.04 & 0.551 & 0.536 & $<0.010$ & $<0.050$ & $<0.010$ & 23.4 & 0.035 & $<0.010$ \\
\hline LRM & 4 & 2 & LRMLM41 & 5.17 & 0.348 & 0.137 & 0.011 & 0.926 & $<0.010$ & 0.006 & 0.012 & 1.24 & 0.012 & 0.058 & 15.5 & $<0.010$ & 0.134 & 0.083 & 0.081 & $<0.010$ & 24.7 & $<0.010$ & $<0.010$ \\
\hline Pu35-27 & 4 & 3 & B32LM1 & 4.69 & 0.303 & 0.305 & 0.085 & 0.322 & 0.233 & 10.2 & 11.3 & 0.342 & 13.9 & 0.359 & 0.48 & 11.2 & 0.056 & 0.037 & $<0.050$ & $<0.010$ & 8.25 & 1.82 & 0.54 \\
\hline Pu35-33 & 4 & 4 & B38LM1 & 4.51 & 0.372 & 0.296 & 0.074 & 0.37 & 0.084 & 9.94 & 11.5 & 0.042 & 13.6 & 0.746 & 0.652 & 10.8 & 0.053 & 0.079 & $<0.050$ & $<0.010$ & 8.79 & 1.78 & 0.07 \\
\hline Pu35-28 & 4 & 5 & B33LM1 & 4.69 & 0.136 & 0.308 & 0.18 & 0.079 & 0.322 & 10.2 & 11.6 & 0.271 & 13.7 & 0.545 & 0.543 & 11.2 & 0.262 & 0.038 & $<0.050$ & $<0.010$ & 8.15 & 1.88 & 0.436 \\
\hline Pu35-30 & 4 & 6 & B35LM1 & 4.74 & 0.398 & 0.062 & 0.069 & 0.08 & 0.578 & 10.3 & 11.7 & 0.666 & 14.1 & 0.275 & 0.644 & 11.3 & 0.05 & 0.081 & $<0.050$ & $<0.010$ & 8.22 & 1.88 & 0.073 \\
\hline Pu35-26 & 4 & 7 & B31LM1 & 4.72 & 0.374 & 0.169 & 0.077 & 0.33 & 0.595 & 10.2 & 11.6 & 0.171 & 13.8 & 0.522 & 0.558 & 11.3 & 0.161 & 0.037 & $<0.050$ & $<0.010$ & 8.22 & 1.86 & 0.187 \\
\hline Pu35-34 & 4 & 8 & B39LM2 & 4.68 & 0.327 & 0.058 & 0.167 & 0.076 & 0.087 & 10.2 & 11.6 & 0.397 & 13.9 & 0.772 & 0.361 & 11.2 & 0.051 & 0.086 & $<0.050$ & $<0.010$ & 9.06 & 1.86 & 0.563 \\
\hline
\end{tabular}


Table D2. Measured Elemental Concentrations (wt \%) for Samples Prepared Using Lithium Metaborate (continued)

\begin{tabular}{|c|c|c|c|c|c|c|c|c|c|c|c|c|c|c|c|c|c|c|c|c|c|c|c|}
\hline Glass ID & Block & Seq. & Lab ID & $\begin{array}{c}\text { Al } \\
\text { (wt \%) }\end{array}$ & $\begin{array}{c}\mathrm{Ca} \\
\text { (wt \%) }\end{array}$ & $\begin{array}{c}\mathrm{Cr} \\
\text { (wt \%) }\end{array}$ & $\begin{array}{c}\mathrm{Cu} \\
\text { (wt \%) }\end{array}$ & $\begin{array}{c}\mathbf{F e} \\
\text { (wt \%) }\end{array}$ & $\begin{array}{c}\text { Ga } \\
\text { (wt \%) }\end{array}$ & $\begin{array}{c}\text { Gd } \\
\text { (wt \%) }\end{array}$ & $\begin{array}{c}\text { Hf } \\
\text { (wt \%) }\end{array}$ & $\begin{array}{c}\mathrm{K} \\
\text { (wt \%) }\end{array}$ & $\begin{array}{c}\text { La } \\
\text { (wt \%) }\end{array}$ & $\begin{array}{c}\text { Mg } \\
\text { (wt \%) }\end{array}$ & $\begin{array}{c}\text { Na } \\
\text { (wt \%) }\end{array}$ & $\begin{array}{c}\text { Nd } \\
\text { (wt \%) }\end{array}$ & $\begin{array}{c}\mathrm{Ni} \\
\text { (wt \%) }\end{array}$ & $\begin{array}{c}\mathbf{P b} \\
\text { (wt \%) }\end{array}$ & $\begin{array}{c}\mathrm{S} \\
\text { (wt \%) }\end{array}$ & $\begin{array}{c}\begin{array}{c}\text { Se } \\
\text { (wt \%) }\end{array} \\
\end{array}$ & $\begin{array}{c}\mathrm{Si} \\
\text { (wt \%) }\end{array}$ & $\begin{array}{c}\mathrm{Sr} \\
\text { (wt \%) }\end{array}$ & $\begin{array}{c}\text { Ta } \\
\text { (wt \%) } \\
\end{array}$ \\
\hline Pu35-32 & 4 & 9 & B37LM1 & 4.75 & 0.11 & 0.058 & 0.072 & 0.073 & 0.675 & 10.4 & 11.9 & 0.184 & 14.1 & 0.768 & 0.515 & 11.4 & 0.053 & 0.083 & $<0.050$ & $<0.010$ & 8.25 & 1.88 & 0.07 \\
\hline Pu35-34 & 4 & 10 & B39LM1 & 4.71 & 0.326 & 0.065 & 0.167 & 0.104 & 0.087 & 10.2 & 11.5 & 0.396 & 13.8 & 0.753 & 0.36 & 11.2 & 0.056 & 0.084 & $<0.050$ & $<0.010$ & 9.02 & 1.85 & 0.557 \\
\hline Pu35-28 & 4 & 11 & B33LM2 & 4.69 & 0.134 & 0.302 & 0.173 & 0.075 & 0.315 & 10.1 & 11.5 & 0.27 & 13.7 & 0.532 & 0.547 & 11.2 & 0.257 & 0.037 & $<0.050$ & $<0.010$ & 8.05 & 1.82 & 0.429 \\
\hline Pu35-35 & 4 & 12 & B40LM2 & 4.61 & 0.109 & 0.066 & 0.093 & 0.569 & 0.307 & 10.2 & 11.9 & 0.038 & 13.9 & 0.266 & 0.67 & 11.2 & 0.061 & 0.081 & $<0.050$ & $<0.010$ & 8.09 & 1.82 & 0.891 \\
\hline Batch 1 & 4 & 13 & BCHLM42 & 2.53 & 0.865 & 0.075 & 0.301 & 8.98 & $<0.010$ & 0.325 & 0.149 & 3.01 & 0.65 & 0.859 & 6.91 & 0.551 & 0.535 & $<0.010$ & $<0.050$ & $<0.010$ & 23.2 & 0.035 & $<0.010$ \\
\hline LRM & 4 & 14 & LRMLM42 & 4.98 & 0.351 & 0.134 & 0.011 & 0.914 & $<0.010$ & 0.006 & 0.065 & 1.17 & 0.012 & 0.057 & 14.9 & $<0.010$ & 0.133 & 0.081 & 0.081 & $<0.010$ & 24.3 & $<0.010$ & $<0.010$ \\
\hline Pu35-31 & 4 & 15 & B36LM2 & 4.68 & 0.11 & 0.066 & 0.071 & 0.587 & 0.086 & 10.2 & 11.4 & 0.747 & 14 & 0.352 & 0.367 & 11.4 & 0.121 & 0.082 & $<0.050$ & $<0.010$ & 8.23 & 1.86 & 0.069 \\
\hline Pu35-26 & 4 & 16 & B31LM2 & 4.59 & 0.377 & 0.167 & 0.077 & 0.33 & 0.594 & 10 & 11.6 & 0.171 & 13.7 & 0.515 & 0.565 & 11.1 & 0.161 & 0.036 & $<0.050$ & $<0.010$ & 8.17 & 1.78 & 0.186 \\
\hline Pu35-33 & 4 & 17 & B38LM2 & 4.48 & 0.375 & 0.302 & 0.072 & 0.393 & 0.086 & 9.79 & 11.6 & 0.042 & 13.5 & 0.76 & 0.639 & 10.9 & 0.056 & 0.08 & $<0.050$ & $<0.010$ & 8.75 & 1.78 & 0.069 \\
\hline Pu35-35 & 4 & 18 & B40LM1 & 4.57 & 0.121 & 0.06 & 0.091 & 0.555 & 0.307 & 10 & 11.8 & 0.038 & 13.8 & 0.269 & 0.664 & 11.1 & 0.059 & 0.082 & $<0.050$ & $<0.010$ & 8.06 & 1.83 & 0.892 \\
\hline Pu35-32 & 4 & 19 & B37LM2 & 4.65 & 0.109 & 0.058 & 0.071 & 0.074 & 0.679 & 10 & 11.8 & 0.182 & 13.8 & 0.786 & 0.523 & 11.2 & 0.054 & 0.085 & $<0.050$ & $<0.010$ & 8.14 & 1.87 & 0.07 \\
\hline Pu35-31 & 4 & 20 & B36LM1 & 4.68 & 0.128 & 0.059 & 0.072 & 0.578 & 0.087 & 10.1 & 11.8 & 0.738 & 13.8 & 0.36 & 0.37 & 11.2 & 0.12 & 0.084 & $<0.050$ & $<0.010$ & 8.17 & 1.89 & 0.07 \\
\hline Pu35-29 & 4 & 21 & B34LM1 & 4.65 & 0.119 & 0.059 & 0.084 & 0.154 & 0.54 & 10 & 11.4 & 0.553 & 13.8 & 0.283 & 0.699 & 11.1 & 0.056 & 0.039 & $<0.050$ & $<0.010$ & 8.12 & 1.87 & 0.282 \\
\hline Pu35-27 & 4 & 22 & B32LM2 & 4.63 & 0.302 & 0.304 & 0.084 & 0.339 & 0.23 & 9.91 & 11.4 & 0.335 & 13.4 & 0.358 & 0.48 & 11 & 0.058 & 0.038 & $<0.050$ & $<0.010$ & 8.04 & 1.83 & 0.533 \\
\hline Pu35-30 & 4 & 23 & B35LM2 & 4.7 & 0.398 & 0.061 & 0.068 & 0.076 & 0.571 & 10.1 & 11.6 & 0.663 & 13.8 & 0.273 & 0.64 & 11.1 & 0.05 & 0.081 & $<0.050$ & $<0.010$ & 8.16 & 1.9 & 0.072 \\
\hline Pu35-29 & 4 & 24 & B34LM2 & 4.77 & 0.122 & 0.059 & 0.086 & 0.155 & 0.544 & 10.1 & 11.4 & 0.55 & 13.8 & 0.282 & 0.702 & 11.2 & 0.054 & 0.039 & $<0.050$ & $<0.010$ & 8.17 & 1.94 & 0.284 \\
\hline Batch 1 & 4 & 25 & BCHLM43 & 2.57 & 0.866 & 0.076 & 0.302 & 8.63 & $<0.010$ & 0.328 & 0.12 & 3.16 & 0.655 & 0.871 & 7.2 & 0.551 & 0.542 & $<0.010$ & $<0.050$ & $<0.010$ & 23.1 & 0.035 & $<0.010$ \\
\hline LRM & 4 & 26 & LRMLM43 & 5.06 & 0.342 & 0.132 & 0.011 & 0.91 & $<0.010$ & 0.007 & 0.09 & 1.23 & 0.014 & 0.057 & 15.5 & $<0.010$ & 0.132 & 0.08 & 0.079 & $<0.010$ & 24.2 & $<0.010$ & $<0.010$ \\
\hline Batch 1 & 5 & 1 & BCHLM51 & 2.61 & 0.878 & 0.076 & 0.305 & 8.83 & $<0.010$ & 0.328 & 0.117 & 3.16 & 0.655 & 0.878 & 7.34 & 0.551 & 0.537 & $<0.010$ & $<0.050$ & $<0.010$ & 23.5 & 0.04 & $<0.010$ \\
\hline LRM & 5 & 2 & LRMLM51 & 5.2 & 0.36 & 0.137 & 0.013 & 0.931 & $<0.010$ & 0.006 & 0.01 & 1.28 & 0.012 & 0.057 & 15.5 & $<0.010$ & 0.134 & 0.082 & 0.088 & $<0.010$ & 24.8 & $<0.010$ & $<0.010$ \\
\hline Pu35-40 & 5 & 3 & B45LM2 & 4.67 & 0.377 & 0.217 & 0.166 & 0.423 & 0.313 & 10.1 & 11.2 & 0.341 & 13.8 & 0.393 & 0.487 & 11.1 & 0.078 & 0.079 & $<0.050$ & $<0.010$ & 8.21 & 1.86 & 0.071 \\
\hline Pu35-44 & 5 & 4 & B49LM2 & 4.62 & 0.274 & 0.161 & 0.106 & 0.403 & 0.245 & 10 & 11.4 & 0.217 & 13.7 & 0.475 & 0.489 & 11 & 0.109 & 0.079 & $<0.050$ & $<0.010$ & 8.14 & 1.86 & 0.437 \\
\hline Pu35-38 & 5 & 5 & B43LM2 & 4.58 & 0.384 & 0.115 & 0.078 & 0.14 & 0.242 & 9.87 & 11.4 & 0.307 & 13.5 & 0.432 & 0.486 & 10.8 & 0.126 & 0.079 & $<0.050$ & $<0.010$ & 8.02 & 1.83 & 0.422 \\
\hline Pu35-45 & 5 & 6 & B50LM2 & 4.53 & 0.233 & 0.109 & 0.107 & 0.316 & 0.368 & 9.79 & 11.3 & 0.125 & 13.4 & 0.439 & 0.542 & 10.8 & 0.158 & 0.078 & $<0.050$ & $<0.010$ & 8.01 & 1.81 & 0.552 \\
\hline Pu35-40 & 5 & 7 & B45LM1 & 4.58 & 0.376 & 0.21 & 0.166 & 0.397 & 0.31 & 9.91 & 11.5 & 0.341 & 13.6 & 0.387 & 0.484 & 10.9 & 0.075 & 0.077 & $<0.050$ & $<0.010$ & 8.09 & 1.82 & 0.07 \\
\hline Pu35-38 & 5 & 8 & B43LM1 & 4.67 & 0.386 & 0.115 & 0.079 & 0.139 & 0.243 & 10 & 11.8 & 0.314 & 13.9 & 0.435 & 0.492 & 11 & 0.126 & 0.077 & $<0.050$ & $<0.010$ & 8.22 & 1.88 & 0.424 \\
\hline Pu35-36 & 5 & 9 & B41LM2 & 4.68 & 0.115 & 0.239 & 0.17 & 0.101 & 0.248 & 10.1 & 11.8 & 0.302 & 13.8 & 0.522 & 0.505 & 11.1 & 0.229 & 0.077 & $<0.050$ & $<0.010$ & 8.21 & 1.88 & 0.409 \\
\hline Pu35-44 & 5 & 10 & B49LM1 & 4.75 & 0.282 & 0.16 & 0.106 & 0.4 & 0.245 & 10.2 & 11.8 & 0.221 & 14 & 0.47 & 0.493 & 11.2 & 0.109 & 0.08 & $<0.050$ & $<0.010$ & 8.29 & 1.91 & 0.433 \\
\hline Pu35-37 & 5 & 11 & B42LM2 & 4.71 & 0.192 & 0.264 & 0.078 & 0.276 & 0.284 & 10.1 & 11.6 & 0.243 & 13.8 & 0.587 & 0.504 & 11.1 & 0.271 & 0.077 & $<0.050$ & $<0.010$ & 8.19 & 1.88 & 0.282 \\
\hline Pu35-39 & 5 & 12 & B44LM2 & 4.72 & 0.117 & 0.196 & 0.077 & 0.228 & 0.248 & 10.1 & 11.7 & 0.515 & 13.8 & 0.407 & 0.536 & 11.1 & 0.053 & 0.075 & $<0.050$ & $<0.010$ & 8.2 & 1.9 & 0.398 \\
\hline Batch 1 & 5 & 13 & BCHLM52 & 2.62 & 0.883 & 0.075 & 0.3 & 8.64 & $<0.010$ & 0.322 & 0.147 & 3.19 & 0.647 & 0.868 & 7.21 & 0.546 & 0.534 & $<0.010$ & $<0.050$ & $<0.010$ & 23.2 & 0.04 & $<0.010$ \\
\hline LRM & 5 & 14 & LRMLM52 & 5.2 & 0.364 & 0.134 & 0.012 & 0.923 & $<0.010$ & 0.006 & 0.066 & 1.29 & 0.012 & 0.056 & 15.8 & $<0.010$ & 0.132 & 0.08 & 0.081 & $<0.010$ & 24.6 & $<0.010$ & $<0.010$ \\
\hline Pu35-37 & 5 & 15 & B42LM1 & 4.62 & 0.189 & 0.253 & 0.074 & 0.226 & 0.282 & 9.93 & 11 & 0.233 & 13.6 & 0.597 & 0.487 & 10.9 & 0.267 & 0.076 & $<0.050$ & $<0.010$ & 8.08 & 1.85 & 0.282 \\
\hline Pu35-43 & 5 & 16 & B48LM2 & 4.72 & 0.331 & 0.163 & 0.127 & 0.401 & 0.28 & 10.1 & 11.6 & 0.138 & 13.7 & 0.39 & 0.543 & 11.2 & 0.149 & 0.079 & $<0.050$ & $<0.010$ & 8.22 & 1.9 & 0.397 \\
\hline Pu35-45 & 5 & 17 & B50LM1 & 4.7 & 0.233 & 0.112 & 0.108 & 0.321 & 0.372 & 10.1 & 11.5 & 0.125 & 13.6 & 0.445 & 0.543 & 11.1 & 0.161 & 0.079 & $<0.050$ & $<0.010$ & 8.12 & 1.89 & 0.556 \\
\hline Pu35-42 & 5 & 18 & B47LM1 & 4.71 & 0.181 & 0.221 & 0.118 & 0.131 & 0.142 & 10.1 & 11.6 & 0.503 & 13.7 & 0.639 & 0.562 & 11.2 & 0.109 & 0.08 & $<0.050$ & $<0.010$ & 8.22 & 1.9 & 0.18 \\
\hline Pu35-43 & 5 & 19 & B48LM1 & 4.71 & 0.329 & 0.162 & 0.124 & 0.402 & 0.278 & 10 & 11.6 & 0.137 & 13.6 & 0.387 & 0.537 & 11 & 0.148 & 0.078 & $<0.050$ & $<0.010$ & 8.15 & 1.88 & 0.394 \\
\hline Pu35-36 & 5 & 20 & B41LM1 & 4.82 & 0.121 & 0.242 & 0.172 & 0.1 & 0.252 & 10.3 & 12 & 0.311 & 14 & 0.527 & 0.514 & 11.3 & 0.232 & 0.079 & $<0.050$ & $<0.010$ & 8.38 & 1.94 & 0.412 \\
\hline Pu35-41 & 5 & 21 & B46LM2 & 4.8 & 0.12 & 0.06 & 0.117 & 0.074 & 0.083 & 10.2 & 11.5 & 0.223 & 13.7 & 0.784 & 0.653 & 11.1 & 0.311 & 0.072 & $<0.050$ & $<0.010$ & 8.22 & 1.95 & 0.07 \\
\hline Pu35-39 & 5 & 22 & B44LM1 & 4.85 & 0.119 & 0.201 & 0.079 & 0.234 & 0.253 & 10.3 & 12 & 0.525 & 14 & 0.42 & 0.545 & 11.4 & 0.054 & 0.078 & $<0.050$ & $<0.010$ & 8.41 & 1.95 & 0.409 \\
\hline Pu35-42 & 5 & 23 & B47LM2 & 4.78 & 0.186 & 0.22 & 0.118 & 0.131 & 0.143 & 10.2 & 11.7 & 0.517 & 13.8 & 0.638 & 0.568 & 11.3 & 0.114 & 0.081 & $<0.050$ & $<0.010$ & 8.29 & 1.93 & 0.181 \\
\hline Pu35-41 & 5 & 24 & B46LM1 & 4.69 & 0.116 & 0.061 & 0.115 & 0.076 & 0.083 & 10 & 11.4 & 0.216 & 13.6 & 0.784 & 0.646 & 11.1 & 0.311 & 0.072 & $<0.050$ & $<0.010$ & 8.05 & 1.89 & 0.07 \\
\hline Batch 1 & 5 & 25 & BCHLM53 & 2.57 & 0.897 & 0.075 & 0.303 & 8.59 & $<0.010$ & 0.324 & 0.148 & 3.18 & 0.651 & 0.872 & 7.27 & 0.55 & 0.539 & $<0.010$ & $<0.050$ & $<0.010$ & 23.1 & 0.04 & $<0.010$ \\
\hline LRM & 5 & 26 & LRMLM53 & 5.1 & 0.364 & 0.135 & 0.012 & 0.932 & $<0.010$ & 0.006 & 0.07 & 1.27 & 0.012 & 0.057 & 15.6 & $<0.010$ & 0.133 & 0.08 & 0.088 & $<0.010$ & 24.3 & $<0.010$ & $<0.010$ \\
\hline
\end{tabular}


Table D2. Measured Elemental Concentrations (wt \%) for Samples Prepared Using Lithium Metaborate (continued)

\begin{tabular}{|c|c|c|c|c|c|c|c|c|c|c|c|c|c|c|c|c|c|c|c|c|c|c|c|}
\hline Glass ID & Block & Seq. & Lab ID & $\begin{array}{c}\mathrm{Al} \\
\text { (wt \%) }\end{array}$ & $\begin{array}{c}\mathrm{Ca} \\
\text { (wt \%) }\end{array}$ & $\begin{array}{c}\mathrm{Cr} \\
\text { (wt \%) }\end{array}$ & $\begin{array}{c}\mathrm{Cu} \\
\text { (wt \%) }\end{array}$ & $\begin{array}{c}\mathbf{F e} \\
\text { (wt \%) }\end{array}$ & $\begin{array}{c}\text { Ga } \\
\text { (wt \%) }\end{array}$ & $\begin{array}{c}\text { Gd } \\
\text { (wt \%) }\end{array}$ & $\begin{array}{c}\text { Hf } \\
\text { (wt \%) }\end{array}$ & $\begin{array}{c}\mathrm{K} \\
\text { (wt \%) }\end{array}$ & $\begin{array}{c}\begin{array}{c}\text { La } \\
\text { (wt \%) }\end{array} \\
\text {. }\end{array}$ & $\begin{array}{c}\text { Mg } \\
\text { (wt \%) }\end{array}$ & $\begin{array}{c}\mathrm{Na} \\
\text { (wt \%) }\end{array}$ & $\begin{array}{c}\text { Nd } \\
\text { (wt \%) }\end{array}$ & $\begin{array}{c}\mathrm{Ni} \\
\text { (wt \%) }\end{array}$ & $\begin{array}{c}\mathbf{P b} \\
\text { (wt \%) }\end{array}$ & $\begin{array}{c}\mathrm{S} \\
\text { (wt \%) }\end{array}$ & $\begin{array}{c}\mathrm{Se} \\
\text { (wt \%) }\end{array}$ & $\begin{array}{c}\mathrm{Si} \\
\text { (wt \%) }\end{array}$ & $\begin{array}{c}\mathrm{Sr} \\
\text { (wt \%) }\end{array}$ & $\begin{array}{c}\begin{array}{c}\text { Ta } \\
\text { (wt \%) }\end{array} \\
\end{array}$ \\
\hline Batch 1 & 6 & 1 & BCHLM61 & 2.6 & 0.856 & 0.076 & 0.3 & 8.96 & $<0.010$ & 0.326 & 0.118 & 3.08 & 0.653 & 0.879 & 7.07 & 0.548 & 0.537 & $<0.010$ & $<0.050$ & $<0.010$ & 23.7 & 0.035 & $<0.010$ \\
\hline LRM & 6 & 2 & LRMLM61 & 5.17 & 0.35 & 0.136 & 0.012 & 0.925 & $<0.010$ & 0.005 & 0.013 & 1.25 & 0.012 & 0.057 & 15.3 & $<0.010$ & 0.134 & 0.08 & 0.081 & $<0.010$ & 24.9 & $<0.010$ & $<0.010$ \\
\hline Pu35-53 & 6 & 3 & B58LM2 & 4.87 & 0.174 & 0.113 & 0.11 & 0.128 & 0.144 & 10.4 & 10.8 & 0.297 & 14.4 & 0.372 & 0.579 & 11.4 & 0.106 & 0.074 & $<0.050$ & $<0.010$ & 8.46 & 1.98 & 0.617 \\
\hline Pu35-51 & 6 & 4 & B56LM2 & 4.9 & 0.169 & 0.21 & 0.102 & 0.393 & 0.144 & 10.4 & 11.3 & 0.174 & 14.4 & 0.538 & 0.556 & 11.3 & 0.212 & 0.077 & $<0.050$ & $<0.010$ & 8.49 & 1.99 & 0.269 \\
\hline Pu35-48 & 6 & 5 & B53LM2 & 4.83 & 0.33 & 0.154 & $\begin{array}{ll}0.1 \\
\end{array}$ & 0.351 & 0.274 & 10.3 & 11.4 & 0.614 & 13.9 & 0.475 & 0.563 & 11.2 & 0.141 & 0.081 & $<0.050$ & $<0.010$ & 8.28 & 1.96 & 0.265 \\
\hline Pu35-47 & 6 & 6 & B52LM1 & 4.84 & 0.352 & 0.222 & 0.13 & 0.131 & 0.168 & 10.4 & 11.9 & 0.166 & 14.2 & 0.369 & 0.544 & 11.3 & 0.211 & 0.078 & $<0.050$ & $<0.010$ & 8.45 & 1.95 & 0.673 \\
\hline Pu35-54 & 6 & 7 & B59LM1 & 4.83 & 0.255 & 0.185 & 0.12 & 0.295 & 0.323 & 10.3 & 10.9 & 0.394 & 14.3 & 0.477 & 0.532 & 11.3 & 0.115 & 0.031 & $<0.050$ & $<0.010$ & 8.42 & 1.97 & 0.368 \\
\hline Pu35-53 & 6 & 8 & B58LM1 & 4.83 & 0.171 & 0.115 & 0.106 & 0.129 & 0.142 & 10.3 & 11 & 0.276 & 14.3 & 0.376 & 0.596 & 11.3 & 0.113 & 0.077 & $<0.050$ & $<0.010$ & 8.35 & 1.96 & 0.621 \\
\hline Pu35-52 & 6 & 9 & B57LM2 & 4.81 & 0.177 & 0.209 & 0.119 & 0.279 & 0.447 & 10.1 & 10.6 & 0.251 & 14 & 0.482 & 0.549 & 11.2 & 0.163 & 0.078 & $<0.050$ & $<0.010$ & 8.26 & 1.96 & 0.119 \\
\hline Pu35-49 & 6 & 10 & B54LM2 & 4.91 & 0.294 & 0.125 & 0.124 & 0.365 & 0.166 & 10.3 & 11.5 & 0.41 & 14.2 & 0.462 & 0.497 & 11.4 & 0.147 & 0.077 & $<0.050$ & $<0.010$ & 8.47 & 1.99 & 0.226 \\
\hline Pu35-50 & 6 & 11 & B55LM1 & 4.88 & 0.25 & 0.161 & 0.094 & 0.352 & 0.26 & 10.3 & 11.5 & 0.498 & 14.1 & 0.393 & 0.51 & 11.2 & 0.165 & 0.075 & $<0.050$ & $<0.010$ & 8.36 & 1.99 & 0.151 \\
\hline Pu35-54 & 6 & 12 & B59LM2 & 4.95 & 0.256 & 0.185 & 0.121 & 0.294 & 0.326 & 10.5 & 11.1 & 0.399 & 14.5 & 0.478 & 0.532 & 11.5 & 0.116 & 0.032 & $<0.050$ & $<0.010$ & 8.59 & 2.03 & 0.371 \\
\hline Batch 1 & 6 & 13 & BCHLM62 & 2.66 & 0.858 & 0.076 & 0.3 & 9.02 & $<0.010$ & 0.234 & 0.122 & 3.22 & 0.466 & 0.852 & 7.09 & 0.422 & 0.535 & $<0.010$ & $<0.050$ & $<0.010$ & 24 & 0.023 & $<0.010$ \\
\hline LRM & 6 & 14 & LRMLM62 & 5.4 & 0.342 & 0.137 & 0.011 & 0.938 & $<0.010$ & 0.005 & 0.079 & 1.32 & 0.012 & 0.058 & 15.5 & $<0.010$ & 0.134 & 0.081 & 0.082 & $<0.010$ & 25.6 & $<0.010$ & $<0.010$ \\
\hline Pu35-46 & 6 & 15 & B51LM1 & 4.87 & 0.188 & 0.111 & 0.126 & 0.133 & 0.423 & 10.4 & 11.6 & 0.287 & 14.2 & 0.44 & 0.471 & 11.3 & 0.213 & 0.079 & $<0.050$ & $<0.010$ & 8.43 & 1.99 & 0.367 \\
\hline Pu35-46 & 6 & 16 & B51LM2 & 4.95 & 0.189 & 0.109 & 0.128 & 0.147 & 0.422 & 10.5 & 11.9 & 0.294 & 14.3 & 0.432 & 0.48 & 11.5 & 0.209 & 0.076 & $<0.050$ & $<0.010$ & 8.52 & 2.03 & 0.364 \\
\hline Pu35-49 & 6 & 17 & B54LM1 & 4.91 & 0.295 & 0.122 & 0.124 & 0.36 & 0.168 & 10.4 & 11.5 & 0.434 & 14.3 & 0.453 & 0.488 & 11.4 & 0.142 & 0.08 & $<0.050$ & $<0.010$ & 8.52 & 2 & 0.222 \\
\hline Pu35-52 & 6 & 18 & B57LM1 & 4.91 & 0.178 & 0.211 & 0.119 & 0.28 & 0.448 & 10.5 & 11 & 0.258 & 14.5 & 0.485 & 0.554 & 11.4 & 0.163 & 0.077 & $<0.050$ & $<0.010$ & 8.52 & 2 & 0.122 \\
\hline Pu35-55 & 6 & 19 & B60LM2 & 4.88 & 0.229 & 0.152 & 0.108 & 0.262 & 0.264 & 10.4 & 11.2 & 0.327 & 14.4 & 0.503 & 0.54 & 11.4 & 0.14 & 0.078 & $<0.050$ & $<0.010$ & 8.59 & 1.98 & 0.316 \\
\hline Pu35-51 & 6 & 20 & B56LM1 & 4.86 & 0.17 & 0.21 & 0.1 & 0.397 & 0.144 & 10.3 & 11.5 & 0.18 & 14.2 & 0.545 & 0.578 & 11.3 & 0.214 & 0.078 & $<0.050$ & $<0.010$ & 8.38 & 1.97 & 0.269 \\
\hline Pu35-50 & 6 & 21 & B55LM2 & 4.9 & 0.245 & 0.161 & 0.094 & 0.344 & 0.26 & 10.3 & 11.4 & 0.509 & 14.2 & 0.392 & 0.495 & 11.3 & 0.162 & 0.076 & $<0.050$ & $<0.010$ & 8.35 & 2.01 & 0.15 \\
\hline Pu35-48 & 6 & 22 & B53LM1 & 4.86 & 0.329 & 0.15 & 0.099 & 0.345 & 0.271 & 10.2 & 11.6 & 0.192 & 13.8 & 0.464 & 0.546 & 11.3 & 0.136 & 0.079 & $<0.050$ & $<0.010$ & 8.28 & 2.01 & 0.276 \\
\hline Pu35-55 & 6 & 23 & B60LM1 & 5.02 & 0.242 & 0.153 & 0.113 & 0.263 & 0.27 & 10.5 & 11.4 & 0.346 & 14.6 & 0.508 & 0.567 & 11.7 & 0.142 & 0.077 & $<0.050$ & $<0.010$ & 8.64 & 2.06 & 0.321 \\
\hline Pu35-47 & 6 & 24 & B52LM2 & 4.83 & 0.364 & 0.21 & 0.129 & 0.125 & 0.165 & 10 & 11.6 & 0.176 & 13.6 & 0.351 & 0.557 & 11.1 & 0.198 & 0.071 & $<0.050$ & $<0.010$ & 8.27 & 2 & 0.65 \\
\hline Batch 1 & 6 & 25 & BCHLM63 & 2.64 & 0.863 & 0.076 & 0.299 & 8.76 & $<0.010$ & 0.146 & 0.086 & 3.25 & 0.291 & 0.827 & 7.1 & 0.303 & 0.529 & $<0.010$ & $<0.050$ & $<0.010$ & 23.8 & 0.011 & $<0.010$ \\
\hline LRM & 6 & 26 & LRMLM63 & 5.38 & 0.345 & 0.136 & 0.011 & 0.926 & $<0.010$ & 0.005 & 0.071 & 1.36 & 0.011 & 0.057 & 15.8 & $<0.010$ & 0.133 & 0.08 & 0.086 & $<0.010$ & 25.2 & $<0.010$ & $<0.010$ \\
\hline
\end{tabular}


WSRC-STI-2007-00477

Revision 0

Appendix D

Table D3. Measured Elemental Concentrations (wt \%) for Samples Prepared Using Peroxide Fusion

\begin{tabular}{|c|c|c|c|c|}
\hline Glass ID & Block & " Sequence & Lab ID & B (wt \%) \\
\hline Batch 1 & 1 & 1 & BCHPF11 & 2.48 \\
\hline LRM & 1 & 2 & LRMPF11 & 2.46 \\
\hline Pu35-05 & 1 & 3 & B10PF1 & 3.58 \\
\hline $\mathrm{Pu} 04-01$ & 1 & 4 & B01PF1 & 3.68 \\
\hline $\mathrm{Pu} 04-01$ & 1 & 5 & B01PF2 & 3.65 \\
\hline $\mathrm{Pu} 04-02$ & 1 & 6 & B02PF2 & 3.64 \\
\hline Pu04-04 & 1 & 7 & B04PF2 & 3.71 \\
\hline $\mathrm{Pu} 35-02$ & 1 & 8 & B07PF1 & 3.62 \\
\hline Pu35-01 & 1 & 9 & B06PF1 & 3.52 \\
\hline $\mathrm{Pu} 35-01$ & 1 & 10 & B06PF2 & 3.47 \\
\hline Pu04-04 & 1 & 11 & B04PF1 & 3.66 \\
\hline $\mathrm{Pu} 04-05$ & 1 & 12 & B05PF1 & 3.67 \\
\hline Batch 1 & 1 & 13 & BCHPF12 & 2.44 \\
\hline LRM & 1 & 14 & LRMPF12 & 2.47 \\
\hline Pu35-02 & 1 & 15 & B07PF2 & 3.69 \\
\hline $\mathrm{Pu} 04-03$ & 1 & 16 & B03PF1 & 3.59 \\
\hline $\mathrm{Pu} 35-05$ & 1 & 17 & B10PF2 & 3.55 \\
\hline $\mathrm{Pu} 04-05$ & 1 & 18 & B05PF2 & 3.7 \\
\hline Pu35-03 & 1 & 19 & B08PF2 & 3.61 \\
\hline $\mathrm{Pu} 35-04$ & 1 & 20 & B09PF1 & 3.58 \\
\hline $\mathrm{Pu} 04-02$ & 1 & 21 & B02PF1 & 3.71 \\
\hline $\mathrm{Pu} 35-03$ & 1 & 22 & B08PF1 & 3.67 \\
\hline $\mathrm{Pu} 04-03$ & 1 & 23 & B03PF2 & 3.65 \\
\hline $\mathrm{Pu} 35-04$ & 1 & 24 & B09PF2 & 3.59 \\
\hline Batch 1 & 1 & 25 & BCHPF13 & 2.46 \\
\hline LRM & 1 & 26 & LRMPF13 & 2.45 \\
\hline Batch 1 & 2 & 1 & BCHPF21 & 2.47 \\
\hline LRM & 2 & 2 & LRMPF11 & 2.4 \\
\hline Pu35-12 & 2 & 3 & B17PF2 & 3.53 \\
\hline Pu35-11 & 2 & 4 & B16PF1 & 3.51 \\
\hline Pu35-12 & 2 & 5 & B17PF1 & 3.49 \\
\hline Pu35-08 & 2 & 6 & B13PF2 & 3.49 \\
\hline Pu35-10 & 2 & 7 & B15PF1 & 3.45 \\
\hline Pu35-15 & 2 & 8 & B20PF2 & 3.4 \\
\hline Pu35-10 & 2 & 9 & B15PF2 & 3.45 \\
\hline Pu35-14 & 2 & 10 & B19PF1 & 3.38 \\
\hline Pu35-11 & 2 & 11 & B16PF2 & 3.41 \\
\hline Pu35-09 & 2 & 12 & B14PF1 & 3.43 \\
\hline Batch 1 & 2 & 13 & BCHPF21 & 2.29 \\
\hline LRM & 2 & 14 & LRMPF21 & 2.34 \\
\hline Pu35-09 & 2 & 15 & B14PF2 & 3.46 \\
\hline Pu35-07 & 2 & 16 & B12PF1 & 3.37 \\
\hline Pu35-08 & 2 & 17 & B13PF1 & 3.38 \\
\hline $\mathrm{Pu} 35-13$ & 2 & 18 & B18PF2 & 3.42 \\
\hline Pu35-06 & 2 & 19 & B11PF1 & 3.41 \\
\hline Pu35-06 & 2 & 20 & B11PF2 & 3.4 \\
\hline $\mathrm{Pu} 35-07$ & 2 & 21 & B12PF2 & 3.45 \\
\hline $\mathrm{Pu} 35-13$ & 2 & 22 & B18PF1 & 3.4 \\
\hline $\mathrm{Pu} 35-15$ & 2 & 23 & B20PF1 & 3.35 \\
\hline Pu35-14 & 2 & 24 & B19PF2 & 3.35 \\
\hline Batch 1 & 2 & 25 & BCHPF23 & 2.29 \\
\hline LRM & 2 & 26 & LRMPF23 & 2.34 \\
\hline Batch 1 & 3 & 1 & BCHPF31 & 2.48 \\
\hline LRM & 3 & 2 & LRMPF31 & 2.43 \\
\hline Pu35-16 & 3 & 3 & B21PF1 & 3.52 \\
\hline $\mathrm{Pu} 35-25$ & 3 & 4 & B30PF1 & 3.47 \\
\hline Pu35-19 & 3 & 5 & B24PF1 & 3.46 \\
\hline Pu35-21 & 3 & 6 & B26PF2 & 3.46 \\
\hline $\mathrm{Pu} 35-23$ & 3 & 7 & B28PF1 & 3.5 \\
\hline $\mathrm{Pu} 35-22$ & 3 & 8 & B27PF1 & 3.46 \\
\hline Pu35-21 & 3 & 9 & B26PF1 & 3.46 \\
\hline Pu35-18 & 3 & 10 & B23PF2 & 3.43 \\
\hline Pu35-20 & 3 & 11 & B25PF2 & 3.42 \\
\hline Pu35-25 & 3 & 12 & B30PF2 & 3.47 \\
\hline
\end{tabular}


WSRC-STI-2007-00477

Revision 0

Appendix D

Table D3. Measured Elemental Concentrations (wt \%)

for Samples Prepared Using Peroxide Fusion (continued)

\begin{tabular}{|c|c|c|c|c|}
\hline Glass ID & "Block & " Sequence & Lab ID & B (wt\%) \\
\hline Batch 1 & 3 & 13 & BCHPF32 & 2.43 \\
\hline LRM & 3 & 14 & LRMPF32 & 2.41 \\
\hline Pu35-18 & 3 & 15 & B23PF1 & 3.6 \\
\hline $\mathrm{Pu} 35-24$ & 3 & 16 & B29PF1 & 3.54 \\
\hline Pu35-16 & 3 & 17 & B21PF2 & 3.53 \\
\hline Pu35-17 & 3 & 18 & B22PF1 & 3.55 \\
\hline Pu35-20 & 3 & 19 & B25PF1 & 3.52 \\
\hline $\mathrm{Pu} 35-17$ & 3 & 20 & B22PF2 & 3.53 \\
\hline Pu35-23 & 3 & 21 & B28PF2 & 3.55 \\
\hline Pu35-24 & 3 & 22 & B29PF2 & 3.55 \\
\hline Pu35-22 & 3 & 23 & B27PF2 & 3.56 \\
\hline Pu35-19 & 3 & 24 & B24PF2 & 3.52 \\
\hline Batch 1 & 3 & 25 & BCHPF33 & 2.38 \\
\hline LRM & 3 & 26 & LRMPF33 & 2.42 \\
\hline Batch 1 & 4 & 1 & BCHPF41 & 2.52 \\
\hline LRM & 4 & 2 & LRMPF41 & 2.44 \\
\hline Pu35-29 & 4 & 3 & B34PF2 & 3.48 \\
\hline Pu35-26 & 4 & 4 & B31PF2 & 3.44 \\
\hline Pu35-28 & 4 & 5 & B33PF2 & 3.51 \\
\hline Pu35-33 & 4 & 6 & B38PF2 & 3.38 \\
\hline Pu35-29 & 4 & 7 & B34PF1 & 3.53 \\
\hline Pu35-32 & 4 & 8 & B37PF2 & 3.39 \\
\hline $\mathrm{Pu} 35-30$ & 4 & 9 & B35PF2 & 3.41 \\
\hline Pu35-32 & 4 & 10 & B37PF1 & 3.55 \\
\hline $\mathrm{Pu} 35-34$ & 4 & 11 & B39PF2 & 3.39 \\
\hline $\mathrm{Pu} 35-34$ & 4 & 12 & B39PF1 & 3.39 \\
\hline Batch 1 & 4 & 13 & BCHPF42 & 2.38 \\
\hline LRM & 4 & 14 & LRMPF42 & 2.34 \\
\hline $\mathrm{Pu} 35-35$ & 4 & 15 & B40PF1 & 3.46 \\
\hline Pu35-31 & 4 & 16 & B36PF1 & 3.43 \\
\hline Pu35-30 & 4 & 17 & B35PF1 & 3.43 \\
\hline Pu35-31 & 4 & 18 & B36PF2 & 3.39 \\
\hline Pu35-27 & 4 & 19 & B32PF1 & 3.47 \\
\hline Pu35-33 & 4 & 20 & B38PF1 & 3.38 \\
\hline Pu35-27 & 4 & 21 & B32PF2 & 3.47 \\
\hline Pu35-26 & 4 & 22 & B31PF1 & 3.53 \\
\hline Pu35-35 & 4 & 23 & B40PF2 & 3.53 \\
\hline $\mathrm{Pu} 35-28$ & 4 & 24 & B33PF1 & 3.56 \\
\hline Batch 1 & 4 & 25 & BCHPF43 & 2.4 \\
\hline LRM & 4 & 26 & LRMPF43 & 2.47 \\
\hline Batch 1 & 5 & 1 & BCHPF51 & 2.42 \\
\hline LRM & 5 & 2 & LRMPF51 & 2.41 \\
\hline Pu35-41 & 5 & 3 & B46PF2 & 3.54 \\
\hline Pu35-39 & 5 & 4 & B44PF1 & 3.44 \\
\hline Pu35-40 & 5 & 5 & B45PF1 & 3.45 \\
\hline Pu35-42 & 5 & 6 & B47PF1 & 3.38 \\
\hline $\mathrm{Pu} 35-41$ & 5 & 7 & B46PF1 & 3.4 \\
\hline $\mathrm{Pu} 35-44$ & 5 & 8 & B49PF2 & 3.46 \\
\hline Pu35-38 & 5 & 9 & B43PF2 & 3.44 \\
\hline $\mathrm{Pu} 35-40$ & 5 & 10 & B45PF2 & 3.42 \\
\hline Pu35-36 & 5 & 11 & B41PF1 & 3.44 \\
\hline Pu35-37 & 5 & 12 & B42PF1 & 3.41 \\
\hline Batch 1 & 5 & 13 & BCHPF52 & 2.31 \\
\hline LRM & 5 & 14 & LRMPF52 & 2.35 \\
\hline $\mathrm{Pu} 35-45$ & 5 & 15 & B50PF2 & 3.53 \\
\hline $\mathrm{Pu} 35-43$ & 5 & 16 & B48PF2 & 3.52 \\
\hline Pu35-39 & 5 & 17 & B44PF2 & 3.4 \\
\hline $\mathrm{Pu} 35-42$ & 5 & 18 & B47PF2 & 3.4 \\
\hline Pu35-38 & 5 & 19 & B43PF1 & 3.4 \\
\hline $\mathrm{Pu} 35-45$ & 5 & 20 & B50PF1 & 3.41 \\
\hline Pu35-36 & 5 & 21 & B41PF2 & 3.42 \\
\hline Pu35-37 & 5 & 22 & B42PF2 & 3.42 \\
\hline $\mathrm{Pu} 35-44$ & 5 & 23 & B49PF1 & 3.33 \\
\hline Pu35-43 & 5 & 24 & B48PF1 & 3.38 \\
\hline Batch 1 & 5 & 25 & BCHPF53 & 2.31 \\
\hline LRM & 5 & 26 & LRMPF53 & 2.34 \\
\hline
\end{tabular}


WSRC-STI-2007-00477

Revision 0

Appendix D

Table D3. Measured Elemental Concentrations (wt \%)

for Samples Prepared Using Peroxide Fusion (continued)

\begin{tabular}{|c|c|c|c|c||}
\hline Glass ID & Block & Sequence & Lab ID & B (wt\%) \\
\hline Batch 1 & 6 & 1 & BCHPF61 & 2.48 \\
\hline LRM & 6 & 2 & LRMPF61 & 2.51 \\
\hline Pu35-54 & 6 & 3 & B59PF1 & 3.63 \\
\hline Pu35-48 & 6 & 4 & B53PF1 & 3.6 \\
\hline Pu35-55 & 6 & 5 & B60PF2 & 3.65 \\
\hline Pu35-53 & 6 & 6 & B58PF2 & 3.57 \\
\hline Pu35-49 & 6 & 7 & B54PF1 & 3.56 \\
\hline Pu35-50 & 6 & 8 & B55PF1 & 3.58 \\
\hline Pu35-54 & 6 & 9 & B59PF2 & 3.56 \\
\hline Pu35-47 & 6 & 10 & B52PF2 & 3.53 \\
\hline Pu35-49 & 6 & 11 & B54PF2 & 3.55 \\
\hline Pu35-48 & 6 & 12 & B53PF2 & 3.53 \\
\hline Batch 1 & 6 & 13 & BCHPF62 & 2.41 \\
\hline LRM & 6 & 14 & LRMPF62 & 2.4 \\
\hline Pu35-55 & 6 & 15 & B60PF1 & 3.7 \\
\hline Pu35-50 & 6 & 16 & B55PF2 & 3.59 \\
\hline Pu35-46 & 6 & 17 & B51PF1 & 3.53 \\
\hline Pu35-51 & 6 & 18 & B56PF2 & 3.58 \\
\hline Pu35-51 & 6 & 19 & B56PF1 & 3.57 \\
\hline Pu35-46 & 6 & 20 & B51PF2 & 3.58 \\
\hline Pu35-53 & 6 & 21 & B58PF1 & 3.62 \\
\hline Pu35-47 & 6 & 22 & B52PF1 & 3.55 \\
\hline Pu35-52 & 6 & 23 & B57PF1 & 3.58 \\
\hline Pu35-52 & 6 & 24 & B57PF2 & 3.55 \\
\hline Batch 1 & 6 & 25 & BCHPF63 & 2.41 \\
\hline LRM & 6 & 26 & LRMPF63 & 2.4 \\
\hline \hline
\end{tabular}


WSRC-STI-2007-00477

Revision 0

Appendix D

Table D4. Measured Elemental Concentrations (wt \%) for Samples Prepared for Analysis by IC

\begin{tabular}{|c|c|c|c|c|c|}
\hline Glass ID & Block & " Sequence & Lab ID & F (wt \%) ar & Cl (wt \%) ar \\
\hline LRM & 1 & 1 & LRMIC11 & 0.84 & $<0.100$ \\
\hline $\mathrm{Pu04-02}$ & 1 & 2 & B02IC2 & 0.016 & 0.025 \\
\hline Pu35-01 & 1 & 3 & B06IC1 & 0 & 0.059 \\
\hline $\mathrm{Pu} 04-01$ & 1 & 4 & B01IC2 & 0 & 0.012 \\
\hline Pu35-05 & 1 & 5 & B10IC1 & 0 & 0.048 \\
\hline Pu35-03 & 1 & 6 & B08IC2 & 0 & 0.137 \\
\hline Pu04-03 & 1 & 7 & B03IC1 & 0 & 0.009 \\
\hline Pu35-04 & 1 & 8 & B09IC2 & 0.09 & 0.035 \\
\hline $\mathrm{Pu04-04}$ & 1 & 9 & B04IC2 & 0 & 0.041 \\
\hline Pu35-03 & 1 & 10 & B08IC1 & 0 & 0.142 \\
\hline Pu35-04 & 1 & 11 & B09IC1 & 0.092 & 0.027 \\
\hline LRM & 1 & 12 & LRMIC12 & 0.818 & $<0.100$ \\
\hline $\mathrm{Pu04-04}$ & 1 & 13 & B04IC1 & 0 & 0.034 \\
\hline Pu04-01 & 1 & 14 & B01IC1 & 0 & 0.01 \\
\hline Pu35-02 & 1 & 15 & B07IC2 & 0.07 & 0.018 \\
\hline $\mathrm{Pu} 04-02$ & 1 & 16 & B02IC1 & 0.024 & 0.011 \\
\hline $\mathrm{Pu} 04-03$ & 1 & 17 & B03IC2 & 0 & 0.011 \\
\hline Pu35-02 & 1 & 18 & B07IC1 & 0.079 & 0.019 \\
\hline Pu35-01 & 1 & 19 & B06IC2 & 0 & 0.056 \\
\hline $\mathrm{Pu} 04-05$ & 1 & 20 & B05IC1 & & \\
\hline $\mathrm{Pu} 04-05$ & 1 & 21 & B05IC2 & 0.027 & 0.012 \\
\hline Pu35-05 & 1 & 22 & B10IC2 & 0 & 0.038 \\
\hline LRM & 1 & 23 & LRMIC13 & 0.819 & $<0.100$ \\
\hline LRM & 2 & 1 & LRMIC21 & 0.812 & $<0.100$ \\
\hline Pu35-08 & 2 & 2 & B13IC1 & 0.071 & 0.05 \\
\hline Pu35-12 & 2 & 3 & B17IC2 & 0.055 & 0.042 \\
\hline Pu35-11 & 2 & 4 & B16IC1 & 0.011 & 0.042 \\
\hline Pu35-13 & 2 & 5 & B18IC1 & 0.012 & 0.055 \\
\hline Pu35-09 & 2 & 6 & B14IC2 & 0 & 0.048 \\
\hline Pu35-14 & 2 & 7 & B19IC1 & 0.017 & 0.058 \\
\hline Pu35-10 & 2 & 8 & B15IC1 & 0.048 & 0.047 \\
\hline Pu35-11 & 2 & 9 & B16IC2 & 0.014 & 0.052 \\
\hline Pu35-06 & 2 & 10 & B11IC2 & 0.077 & 0.034 \\
\hline Pu35-07 & 2 & 11 & B12IC1 & 0.04 & 0.051 \\
\hline LRM & 2 & 12 & LRMIC22 & 0.812 & $<0.100$ \\
\hline Pu35-07 & 2 & 13 & B12IC2 & 0.051 & 0.053 \\
\hline Pu35-13 & 2 & 14 & B18IC2 & 0.012 & 0.055 \\
\hline Pu35-15 & 2 & 15 & B20IC2 & 0 & 0.055 \\
\hline Pu35-15 & 2 & 16 & B20IC1 & 0 & 0.068 \\
\hline Pu35-08 & 2 & 17 & B13IC2 & 0.071 & 0.042 \\
\hline Pu35-10 & 2 & 18 & B15IC2 & 0.083 & 0.054 \\
\hline Pu35-12 & 2 & 19 & B17IC1 & 0.053 & 0.039 \\
\hline Pu35-14 & 2 & 20 & B19IC2 & 0.014 & 0.059 \\
\hline Pu35-09 & 2 & 21 & B14IC1 & 0 & 0.05 \\
\hline Pu35-06 & 2 & 22 & B11IC1 & 0.089 & 0.035 \\
\hline LRM & 2 & 23 & LRMIC23 & 0.806 & $<0.100$ \\
\hline LRM & 3 & 1 & LRMIC31 & 0.811 & $<0.100$ \\
\hline Pu35-24 & 3 & 2 & B29IC2 & 0.033 & 0.073 \\
\hline Pu35-20 & 3 & 3 & B25IC2 & 0.04 & 0.048 \\
\hline Pu35-16 & 3 & 4 & B21IC2 & 0 & 0.036 \\
\hline Pu35-23 & 3 & 5 & B28IC1 & & \\
\hline Pu35-23 & 3 & 6 & B28IC2 & 0.011 & 0.063 \\
\hline Pu35-25 & 3 & 7 & B30IC1 & 0 & 0.083 \\
\hline Pu35-18 & 3 & 8 & B23IC2 & 0 & 0.033 \\
\hline Pu35-21 & 3 & 9 & B26IC2 & 0 & 0.039 \\
\hline Pu35-20 & 3 & 10 & B25IC1 & 0.04 & 0.049 \\
\hline Pu35-22 & 3 & 11 & $\mathrm{~B} 27 \mathrm{IC} 2$ & 0.091 & 0.049 \\
\hline LRM & 3 & 12 & LRMIC32 & 0.811 & $<0.100$ \\
\hline Pu35-22 & 3 & 13 & B27IC1 & 0.099 & 0.062 \\
\hline Pu35-21 & 3 & 14 & B26IC1 & 0 & 0.087 \\
\hline Pu35-18 & 3 & 15 & B23IC1 & 0 & 0.033 \\
\hline Pu35-19 & 3 & 16 & B24IC1 & 0.077 & 0.056 \\
\hline Pu35-17 & 3 & 17 & B22IC2 & 0 & 0.067 \\
\hline Pu35-19 & 3 & 18 & B24IC2 & 0.075 & 0.047 \\
\hline
\end{tabular}


Table D4. Measured Elemental Concentrations (wt \%) for Samples Prepared for Analysis by IC (continued)

\begin{tabular}{|c|c|c|c|c|c|}
\hline Glass ID & Block & "Sequence & Lab ID & F (wt \%) ar & CCl (wt \%) ar \\
\hline Pu35-24 & 3 & 19 & B29IC1 & 0.029 & 0.037 \\
\hline Pu35-25 & 3 & 20 & B30IC2 & 0 & 0.064 \\
\hline Pu35-16 & 3 & 21 & B21IC1 & 0 & 0.049 \\
\hline Pu35-17 & 3 & 22 & B22IC1 & 0 & 0.051 \\
\hline LRM & 3 & 23 & LRMIC33 & 0.809 & $<0.100$ \\
\hline LRM & 4 & 1 & LRMIC41 & 0.812 & $<0.100$ \\
\hline Pu35-28 & 4 & 2 & B33IC2 & 0.03 & 0.082 \\
\hline Pu35-28 & 4 & 3 & B33IC1 & 0.039 & 0.064 \\
\hline Pu35-32 & 4 & 4 & B37IC2 & 0.073 & 0.04 \\
\hline Pu35-26 & 4 & 5 & B31IC1 & 0.032 & 0.047 \\
\hline $\mathrm{Pu} 35-27$ & 4 & 6 & B32IC2 & 0.062 & 0.049 \\
\hline Pu35-35 & 4 & 7 & B40IC1 & 0.016 & 0.051 \\
\hline Pu35-34 & 4 & 8 & B39IC1 & 0 & 0.059 \\
\hline Pu35-30 & 4 & 9 & B35IC2 & 0 & 0.032 \\
\hline Pu35-29 & 4 & 10 & B34IC2 & 0.115 & 0.063 \\
\hline Pu35-32 & 4 & 11 & B37IC1 & 0.076 & 0.043 \\
\hline LRM & 4 & 12 & LRMIC42 & 0.821 & $<0.100$ \\
\hline Pu35-30 & 4 & 13 & B35IC1 & 0 & 0.034 \\
\hline Pu35-34 & 4 & 14 & B39IC2 & 0.014 & 0.044 \\
\hline Pu35-33 & 4 & 15 & B38IC2 & 0.044 & 0.047 \\
\hline Pu35-35 & 4 & 16 & B40IC2 & 0.016 & 0.046 \\
\hline $\mathrm{Pu} 35-26$ & 4 & 17 & B31IC2 & 0.033 & 0.048 \\
\hline Pu35-27 & 4 & 18 & B32IC1 & 0.048 & 0.09 \\
\hline Pu35-31 & 4 & 19 & B36IC2 & 0.114 & 0.037 \\
\hline Pu35-31 & 4 & 20 & B36IC1 & 0.104 & 0.04 \\
\hline Pu35-29 & 4 & 21 & B34IC1 & 0.117 & 0.058 \\
\hline Pu35-33 & 4 & 22 & B38IC1 & 0.04 & 0.04 \\
\hline LRM & 4 & 23 & LRMIC43 & 0.824 & $<0.100$ \\
\hline LRM & 5 & 1 & LRMIC51 & 0.809 & $<0.100$ \\
\hline Pu35-39 & 5 & 2 & B44IC1 & 0 & 0.05 \\
\hline Pu35-43 & 5 & 3 & B48IC1 & 0.021 & 0.042 \\
\hline Pu35-36 & 5 & 4 & B41IC1 & 0 & 0.061 \\
\hline Pu35-45 & 5 & 5 & B50IC2 & 0 & 0.048 \\
\hline Pu35-40 & 5 & 6 & B45IC2 & 0 & 0.077 \\
\hline Pu35-44 & 5 & 7 & B49IC1 & 0 & 0.046 \\
\hline Pu35-41 & 5 & 8 & B46IC2 & 0 & 0.082 \\
\hline Pu35-37 & 5 & 9 & B42IC1 & 0 & 0.046 \\
\hline Pu35-42 & 5 & 10 & B47IC1 & 0 & 0.034 \\
\hline Pu35-38 & 5 & 11 & B43IC2 & 0.037 & 0.051 \\
\hline LRM & 5 & 12 & LRMIC52 & 0.805 & $<0.100$ \\
\hline Pu35-36 & 5 & 13 & B41IC2 & 0.02 & 0.051 \\
\hline Pu35-44 & 5 & 14 & B49IC2 & 0.011 & 0.049 \\
\hline Pu35-42 & 5 & 15 & B47IC2 & 0 & 0.035 \\
\hline Pu35-43 & 5 & 16 & B48IC2 & 0.033 & 0.043 \\
\hline Pu35-37 & 5 & 17 & B42IC2 & 0 & 0.043 \\
\hline Pu35-40 & 5 & 18 & B45IC1 & 0 & 0.061 \\
\hline Pu35-38 & 5 & 19 & B43IC1 & 0.029 & 0.055 \\
\hline Pu35-45 & 5 & 20 & B50IC1 & 0 & 0.047 \\
\hline Pu35-41 & 5 & 21 & B46IC1 & 0 & 0.063 \\
\hline Pu35-39 & 5 & 22 & B44IC2 & 0 & 0.056 \\
\hline LRM & 5 & 23 & LRMIC53 & 0.813 & $<0.100$ \\
\hline LRM & 6 & 1 & LRMIC61 & 0.815 & $<0.100$ \\
\hline Pu35-48 & 6 & 2 & B53IC1 & 0.037 & 0.054 \\
\hline Pu35-55 & 6 & 3 & B60IC2 & 0.044 & 0.055 \\
\hline Pu35-46 & 6 & 4 & B51IC1 & 0.06 & 0.075 \\
\hline Pu35-47 & 6 & 5 & B52IC1 & 0.028 & 0.055 \\
\hline Pu35-55 & 6 & 6 & B60IC1 & 0.05 & 0.078 \\
\hline Pu35-51 & 6 & 7 & B56IC2 & 0.04 & 0.047 \\
\hline Pu35-51 & 6 & 8 & B56IC1 & 0.041 & 0.056 \\
\hline Pu35-54 & 6 & 9 & B59IC1 & 0.083 & 0.053 \\
\hline Pu35-49 & 6 & 10 & B54IC2 & 0.054 & 0.054 \\
\hline Pu35-52 & 6 & 11 & B57IC2 & 0.023 & 0.061 \\
\hline LRM & 6 & 12 & LRMIC62 & 0.822 & $<0.100$ \\
\hline Pu35-53 & 6 & 13 & B58IC1 & 0.048 & 0.054 \\
\hline Pu35-47 & 6 & 14 & B52IC2 & 0.025 & 0.046 \\
\hline Pu35-52 & 6 & 15 & B57IC1 & 0.028 & 0.043 \\
\hline
\end{tabular}


WSRC-STI-2007-00477

Revision 0

Appendix D

Table D4. Measured Elemental Concentrations (wt \%)

for Samples Prepared for Analysis by IC (continued)

\begin{tabular}{|c|c|c|c|c|c||}
\hline Glass ID & Block & Sequence & Lab ID & F (wt \%) ar & Cl (wt \%) ar \\
\hline Pu35-48 & 6 & 16 & B53IC2 & 0.036 & 0.058 \\
\hline Pu35-50 & 6 & 17 & B55IC2 & 0.043 & 0.081 \\
\hline $\mathrm{Pu} 35-46$ & 6 & 18 & B51IC2 & 0.068 & 0.054 \\
\hline $\mathrm{Pu} 35-53$ & 6 & 19 & B58IC2 & 0.048 & 0.057 \\
\hline $\mathrm{Pu} 35-49$ & 6 & 20 & B54IC1 & 0.028 & 0.059 \\
\hline $\mathrm{Pu} 35-54$ & 6 & 21 & B59IC2 & 0.041 & 0.076 \\
\hline $\mathrm{Pu} 35-50$ & 6 & 22 & B55IC1 & 0.041 & 0.058 \\
\hline LRM & 6 & 23 & LRMIC63 & 0.812 & $<0.100$ \\
\hline
\end{tabular}


Table D5. Average Measured and Bias-Corrected Chemical Compositions Versus Targeted Compositions by Oxide by Study Glass

\begin{tabular}{|c|c|c|c|c|c|c|c|c|}
\hline Glass ID & Oxide & \begin{tabular}{|c|}
$\begin{array}{c}\text { Measured } \\
(\text { wt \%) }\end{array}$ \\
\end{tabular} & \begin{tabular}{|c|} 
Measured Bias- \\
Corrected (wt \%)
\end{tabular} & \begin{tabular}{|c|} 
Targeted \\
$(\mathrm{wt} \%)$
\end{tabular} & $\begin{array}{c}\text { Diff of } \\
\text { Measured }\end{array}$ & \begin{tabular}{|c|} 
Diff of Meas \\
BC \\
\end{tabular} & $\begin{array}{l}\text { \% Diff of } \\
\text { Measured }\end{array}$ & $\begin{array}{c}\text { \% Diff of Meas } \\
\text { BC } \\
\end{array}$ \\
\hline Batch 1 & $\mathrm{Al}_{2} \mathrm{O}_{3}(\mathrm{wt} \%)$ & 4.9389 & 4.8770 & \begin{tabular}{|l|}
4.8770 \\
\end{tabular} & 0.0619 & \begin{tabular}{|l|}
0.0000 \\
\end{tabular} & $1.3 \%$ & $0.0 \%$ \\
\hline Batch 1 & $\mathrm{~B}_{2} \mathrm{O}_{3}(\mathrm{wt} \%)$ & 7.7564 & 7.7770 & 7.7770 & -0.0206 & 0.0000 & $-0.3 \%$ & $0.0 \%$ \\
\hline Batch 1 & $\mathrm{CaO}($ wt $\%)$ & 1.2234 & 1.2200 & 1.2200 & 0.0034 & 0.0000 & $0.3 \%$ & $0.0 \%$ \\
\hline Batch 1 & $\mathrm{Cl}(\mathrm{wt} \%)$ & & & & 0.0000 & 0.0000 & & \\
\hline Batch 1 & $\mathrm{Cr}_{2} \mathrm{O}_{3}(\mathrm{wt} \%)$ & 0.1099 & 0.1070 & 0.1070 & 0.0029 & 0.0000 & $2.7 \%$ & $0.0 \%$ \\
\hline Batch 1 & $\mathrm{CuO}(\mathrm{wt} \%)$ & 0.3788 & 0.3990 & 0.3990 & -0.0202 & 0.0000 & $-5.1 \%$ & $0.0 \%$ \\
\hline Batch 1 & $\mathrm{~F}(\mathrm{wt} \%)$ & & & & 0.0000 & 0.0000 & & \\
\hline Batch 1 & $\mathrm{Fe}_{2} \mathrm{O}_{3}(\mathrm{wt} \%)$ & 12.6314 & 12.8390 & 12.8390 & -0.2076 & 0.0000 & $-1.6 \%$ & $0.0 \%$ \\
\hline Batch 1 & $\mathrm{Ga}_{2} \mathrm{O}_{3}(\mathrm{wt} \%)$ & 0.0067 & 0.0067 & 0.0000 & & & & \\
\hline Batch 1 & $\mathrm{Gd}_{2} \mathrm{O}_{3}(\mathrm{wt} \%)$ & 0.3579 & 0.3579 & 0.0000 & 0.3579 & 0.3579 & & \\
\hline Batch 1 & $\mathrm{HfO}_{2}(\mathrm{wt} \%)$ & 0.1502 & 0.1502 & 0.0000 & 0.1502 & 0.1502 & & \\
\hline Batch 1 & $\mathrm{~K}_{2} \mathrm{O}(\mathrm{wt} \%)$ & 3.8099 & 3.3270 & 3.3270 & 0.4829 & 0.0000 & $14.5 \%$ & $0.0 \%$ \\
\hline Batch 1 & $\mathrm{La}_{2} \mathrm{O}_{3}(\mathrm{wt} \%)$ & 0.7279 & 0.7279 & 0.0000 & 0.7279 & 0.7279 & & \\
\hline Batch 1 & $\mathrm{MgO}(\mathrm{wt} \%)$ & 1.4318 & 1.4190 & 1.4190 & 0.0128 & 0.0000 & $0.9 \%$ & $0.0 \%$ \\
\hline Batch 1 & $\mathrm{Na}_{2} \mathrm{O}(\mathrm{wt} \%)$ & 9.7513 & 9.0030 & 9.0030 & 0.7483 & 0.0000 & $8.3 \%$ & $0.0 \%$ \\
\hline Batch 1 & $\mathrm{Nd}_{2} \mathrm{O}_{3}(\mathrm{wt} \%)$ & 0.6145 & 0.6145 & 0.1470 & 0.4675 & 0.4675 & $318.0 \%$ & $318.0 \%$ \\
\hline Batch 1 & $\mathrm{NiO}(\mathrm{wt} \%)$ & 0.6790 & 0.7510 & 0.7510 & -0.0720 & 0.0000 & $-9.6 \%$ & $0.0 \%$ \\
\hline Batch 1 & $\mathrm{PbO}($ wt \%) & 0.0054 & 0.0054 & 0.0000 & 0.0054 & 0.0054 & & \\
\hline Batch 1 & $\mathrm{SeO}_{2}(\mathrm{wt} \%)$ & 0.0070 & 0.0070 & 0.0000 & 0.0070 & 0.0070 & & \\
\hline Batch 1 & $\mathrm{Si}_{2} \mathrm{O}_{3}(\mathrm{wt} \%)$ & 50.4518 & 50.2200 & 50.2200 & 0.2318 & 0.0000 & $0.5 \%$ & $0.0 \%$ \\
\hline Batch 1 & $\mathrm{SO}_{4}(\mathrm{wt} \%)$ & 0.0749 & 0.0749 & 0.0000 & 0.0749 & 0.0749 & & \\
\hline Batch 1 & SrO (wt \%) & 0.0404 & 0.0404 & 0.0000 & 0.0404 & 0.0404 & & \\
\hline Batch 1 & $\mathrm{Ta}_{2} \mathrm{O}_{5}(\mathrm{wt} \%)$ & 0.0061 & 0.0061 & 0.0000 & 0.0061 & 0.0061 & & \\
\hline Batch 1 & Sum (wt \%) & 95.1536 & 93.9301 & 92.0860 & 3.0676 & 1.8441 & $3.3 \%$ & $2.0 \%$ \\
\hline LRM & $\mathrm{Al}_{2} \mathrm{O}_{3}($ wt $\%)$ & 9.8013 & 9.6783 & 10.0000 & -0.1987 & -0.3217 & $-2.0 \%$ & $-3.2 \%$ \\
\hline LRM & $\mathrm{B}_{2} \mathrm{O}_{3}(\mathrm{wt} \%)$ & 7.7600 & 7.7811 & 8.0000 & -0.2400 & -0.2189 & $-3.0 \%$ & $-2.7 \%$ \\
\hline LRM & $\mathrm{CaO}(\mathrm{wt} \%)$ & 0.4949 & 0.4935 & 0.5000 & -0.0051 & -0.0065 & $-1.0 \%$ & $-1.3 \%$ \\
\hline LRM & $\mathrm{Cl}(\mathrm{wt} \%)$ & 0.0500 & 0.0500 & 0.8000 & -0.7500 & -0.7500 & $-93.8 \%$ & $-93.8 \%$ \\
\hline LRM & $\mathrm{Cr}_{2} \mathrm{O}_{3}(\mathrm{wt} \%)$ & 0.1963 & 0.1912 & 0.2000 & -0.0037 & -0.0088 & $-1.8 \%$ & $-4.4 \%$ \\
\hline LRM & $\mathrm{CuO}(\mathrm{wt} \%)$ & 0.0137 & 0.0144 & 0.0000 & 0.0137 & 0.0144 & & \\
\hline LRM & $\mathrm{F}(\mathrm{wt} \%)$ & 0.8151 & 1.0000 & 1.0000 & -0.1849 & 0.0000 & $-18.5 \%$ & $0.0 \%$ \\
\hline LRM & $\mathrm{Fe}_{2} \mathrm{O}_{3}(\mathrm{wt} \%)$ & 1.3124 & 1.3346 & 1.0000 & 0.3124 & 0.3346 & $31.2 \%$ & $33.5 \%$ \\
\hline LRM & $\mathrm{Ga}_{2} \mathrm{O}_{3}(\mathrm{wt} \%)$ & 0.0067 & 0.0067 & 0.0000 & 0.0067 & 0.0067 & & \\
\hline LRM & $\mathrm{Gd}_{2} \mathrm{O}_{3}(\mathrm{wt} \%)$ & 0.0063 & 0.0063 & 0.0000 & 0.0063 & 0.0063 & & \\
\hline LRM & $\mathrm{HfO}_{2}(\mathrm{wt} \%)$ & 0.0567 & 0.0567 & 0.0000 & 0.0567 & 0.0567 & & \\
\hline LRM & $\mathrm{K}_{2} \mathrm{O}($ wt $\%)$ & 1.5258 & 1.3323 & 1.5000 & 0.0258 & -0.1677 & $1.7 \%$ & $-11.2 \%$ \\
\hline LRM & $\mathrm{La}_{2} \mathrm{O}_{3}(\mathrm{wt} \%)$ & 0.0136 & 0.0136 & 0.0000 & 0.0136 & 0.0136 & & \\
\hline LRM & $\mathrm{MgO}(\mathrm{wt} \%)$ & 0.0933 & 0.0925 & 0.1000 & -0.0067 & -0.0075 & $-6.7 \%$ & $-7.5 \%$ \\
\hline LRM & $\mathrm{Na}_{2} \mathrm{O}(\mathrm{wt} \%)$ & 21.0513 & 19.4381 & 20.0000 & 1.0513 & -0.5619 & $5.3 \%$ & $-2.8 \%$ \\
\hline LRM & $\mathrm{Nd}_{2} \mathrm{O}_{3}(\mathrm{wt} \%)$ & 0.0058 & 0.0058 & 0.0000 & 0.0058 & 0.0058 & & \\
\hline LRM & $\mathrm{NiO}($ wt \%) & 0.1680 & 0.1859 & 0.1000 & 0.0680 & 0.0859 & $68.0 \%$ & $85.9 \%$ \\
\hline LRM & $\mathrm{PbO}(\mathrm{wt} \%)$ & 0.0864 & 0.0864 & 0.1000 & -0.0136 & -0.0136 & $-13.6 \%$ & $-13.6 \%$ \\
\hline LRM & $\mathrm{SeO}_{2}(\mathrm{wt} \%)$ & 0.0070 & 0.0070 & 0.0000 & 0.0070 & 0.0070 & & \\
\hline LRM & $\mathrm{Si}_{2} \mathrm{O}_{3}($ wt $\%)$ & 53.1141 & 52.8695 & 54.3700 & -1.2559 & -1.5005 & $-2.3 \%$ & $-2.8 \%$ \\
\hline LRM & $\mathrm{SO}_{4}(\mathrm{wt} \%)$ & 0.2448 & 0.2448 & 0.2400 & 0.0048 & 0.0048 & $2.0 \%$ & $2.0 \%$ \\
\hline LRM & $\mathrm{SrO}($ wt \%) & 0.0059 & 0.0059 & 0.0000 & 0.0059 & 0.0059 & & \\
\hline LRM & $\mathrm{Ta}_{2} \mathrm{O}_{5}(\mathrm{wt} \%)$ & 0.0061 & 0.0061 & 0.0000 & 0.0061 & 0.0061 & & \\
\hline \begin{tabular}{|l|} 
LRM \\
\end{tabular} & Sum (wt \%) & 96.8356 & 94.9009 & 97.9100 & -1.0744 & -3.0091 & $-1.1 \%$ & $-3.1 \%$ \\
\hline Pu04-01 & $\mathrm{Al}_{2} \mathrm{O}_{3}(\mathrm{wt} \%)$ & 9.5231 & 9.3698 & 8.6000 & 0.9231 & 0.7698 & $10.7 \%$ & $9.0 \%$ \\
\hline Pu04-01 & $\mathrm{B}_{2} \mathrm{O}_{3}(\mathrm{wt} \%)$ & 11.8009 & 11.5865 & 11.1800 & 0.6209 & 0.4065 & $5.6 \%$ & $3.6 \%$ \\
\hline Pu04-01 & $\mathrm{CaO}(\mathrm{wt} \%)$ & 0.0686 & 0.0674 & 0.0000 & 0.0686 & 0.0674 & & \\
\hline Pu04-01 & $\mathrm{Cl}(\mathrm{wt} \%)$ & 0.0110 & 0.0110 & 0.1200 & -0.1090 & -0.1090 & $-90.8 \%$ & $-90.8 \%$ \\
\hline Pu04-01 & $\mathrm{Cr}_{2} \mathrm{O}_{3}(\mathrm{wt} \%)$ & 0.0146 & 0.0147 & 0.0000 & 0.0146 & 0.0147 & & \\
\hline Pu04-01 & $\mathrm{CuO}($ wt $\%)$ & 0.0294 & 0.0312 & 0.0000 & 0.0294 & 0.0312 & & \\
\hline Pu04-01 & $\mathrm{F}(\mathrm{wt} \%)$ & 0.0000 & 0.0000 & 0.0000 & 0.0000 & 0.0000 & & \\
\hline Pu04-01 & $\mathrm{Fe}_{2} \mathrm{O}_{3}(\mathrm{wt} \%)$ & 0.0536 & 0.0540 & 0.0000 & 0.0536 & 0.0540 & & \\
\hline
\end{tabular}


Table D5. Average Measured and Bias-Corrected Chemical Compositions Versus Targeted Compositions by Oxide by Study Glass (continued)

\begin{tabular}{|c|c|c|c|c|c|c|c|c|}
\hline Glass ID & Oxide & $\begin{array}{c}\text { Measured } \\
\text { (wt \%) }\end{array}$ & \begin{tabular}{|c} 
Measured Bias- \\
Corrected (wt \%)
\end{tabular} & $\begin{array}{c}\text { Targeted } \\
\text { (wt \%) }\end{array}$ & $\begin{array}{c}\text { Diff of } \\
\text { Measured }\end{array}$ & \begin{tabular}{|c|} 
Diff of Meas \\
BC
\end{tabular} & $\begin{array}{l}\text { \% Diff of } \\
\text { Measured }\end{array}$ & $\begin{array}{c}\% \text { Diff of Meas } \\
\text { BC }\end{array}$ \\
\hline Pu04-01 & $\mathrm{Ga}_{2} \mathrm{O}_{3}(\mathrm{wt} \%)$ & 0.0370 & \begin{tabular}{|c|}
0.0370 \\
\end{tabular} & 0.0000 & 0.0370 & \begin{tabular}{|l|}
0.0370 \\
\end{tabular} & & \\
\hline Pu04-01 & $\mathrm{Gd}_{2} \mathrm{O}_{3}(\mathrm{wt} \%)$ & 12.1599 & 12.1599 & 11.6100 & 0.5499 & 0.5499 & $4.7 \%$ & $4.7 \%$ \\
\hline Pu04-01 & $\mathrm{HfO}_{2}(\mathrm{wt} \%)$ & 14.5054 & 14.5054 & 19.4500 & -4.9446 & -4.9446 & $-25.4 \%$ & $-25.4 \%$ \\
\hline $\mathrm{Pu} 04-01$ & $\mathrm{~K}_{2} \mathrm{O}(\mathrm{wt} \%)$ & 0.1915 & 0.1674 & 0.2100 & -0.0185 & -0.0426 & $-8.8 \%$ & $-20.3 \%$ \\
\hline Pu04-01 & $\mathrm{La}_{2} \mathrm{O}_{3}($ wt $\%)$ & 16.8883 & 16.8883 & 16.3400 & 0.5483 & 0.5483 & $3.4 \%$ & $3.4 \%$ \\
\hline Pu04-01 & $\mathrm{MgO}(\mathrm{wt} \%)$ & 0.0083 & 0.0085 & 0.0000 & 0.0083 & 0.0085 & & \\
\hline Pu04-01 & $\mathrm{Na}_{2} \mathrm{O}($ wt $\%)$ & 0.2851 & 0.2605 & 0.2400 & 0.0451 & 0.0205 & $18.8 \%$ & $8.5 \%$ \\
\hline Pu04-01 & $\mathrm{Nd}_{2} \mathrm{O}_{3}($ wt $\%)$ & 13.6469 & 13.6469 & 12.9000 & 0.7469 & 0.7469 & $5.8 \%$ & $5.8 \%$ \\
\hline $\mathrm{Pu} 04-01$ & $\mathrm{NiO}(\mathrm{wt} \%)$ & 0.0064 & 0.0073 & 0.0000 & 0.0064 & 0.0073 & & \\
\hline \begin{tabular}{|l|}
$\mathrm{Pu} 04-01$ \\
\end{tabular} & $\mathrm{PbO}(\mathrm{wt} \%)$ & 0.0388 & 0.0388 & 0.0000 & 0.0388 & 0.0388 & & \\
\hline Pu04-01 & $\mathrm{SeO}_{2}(\mathrm{wt} \%)$ & 0.0070 & 0.0070 & 0.0000 & 0.0070 & 0.0070 & & \\
\hline Pu04-01 & $\mathrm{Si}_{2} \mathrm{O}_{3}($ wt $\%)$ & 18.6333 & 18.3788 & 17.2000 & 1.4333 & 1.1788 & $8.3 \%$ & $6.9 \%$ \\
\hline \begin{tabular}{|l|}
$\mathrm{Pu} 04-01$ \\
\end{tabular} & $\mathrm{SO}_{4}(\mathrm{wt} \%)$ & 0.0749 & 0.0749 & 0.0000 & 0.0749 & 0.0749 & & \\
\hline $\mathrm{Pu} 04-01$ & $\mathrm{SrO}(\mathrm{wt} \%)$ & 2.3356 & 2.3356 & 2.1500 & 0.1856 & 0.1856 & $8.6 \%$ & $8.6 \%$ \\
\hline $\mathrm{Pu} 04-01$ & $\mathrm{Ta}_{2} \mathrm{O}_{5}(\mathrm{wt} \%)$ & 0.0183 & 0.0183 & 0.0000 & 0.0183 & 0.0183 & & \\
\hline \begin{tabular}{|l|}
$\mathrm{Pu} 04-01$ \\
\end{tabular} & Sum (wt \%) & 100.3380 & 99.6693 & 100.0000 & 0.3380 & -0.3307 & $0.3 \%$ & $-0.3 \%$ \\
\hline $\mathrm{Pu} 04-02$ & $\mathrm{Al}_{2} \mathrm{O}_{3}(\mathrm{wt} \%)$ & 9.4192 & 9.2675 & 8.6000 & 0.8192 & 0.6675 & $9.5 \%$ & $7.8 \%$ \\
\hline $\mathrm{Pu} 04-02$ & $\mathrm{~B}_{2} \mathrm{O}_{3}(\mathrm{wt} \%)$ & 11.8331 & 11.6181 & 11.1800 & 0.6531 & 0.4381 & $5.8 \%$ & $3.9 \%$ \\
\hline $\mathrm{Pu} 04-02$ & $\mathrm{CaO}($ wt $\%)$ & 0.0763 & 0.0749 & 0.0000 & 0.0763 & 0.0749 & & \\
\hline $\mathrm{Pu} 04-02$ & $\mathrm{Cl}(\mathrm{wt} \%)$ & 0.0180 & 0.0180 & 0.0000 & 0.0180 & 0.0180 & & \\
\hline \begin{tabular}{|l|}
$\mathrm{Pu} 04-02$ \\
\end{tabular} & $\mathrm{Cr}_{2} \mathrm{O}_{3}(\mathrm{wt} \%)$ & 0.0088 & 0.0088 & 0.0000 & 0.0088 & 0.0088 & & \\
\hline Pu04-02 & $\mathrm{CuO}($ wt $\%)$ & 0.0294 & 0.0312 & 0.0000 & 0.0294 & 0.0312 & & \\
\hline $\mathrm{Pu} 04-02$ & $\mathrm{~F}(\mathrm{wt} \%)$ & 0.0200 & 0.0242 & 0.1200 & -0.1000 & -0.0958 & $-83.3 \%$ & $-79.8 \%$ \\
\hline Pu04-02 & $\mathrm{Fe}_{2} \mathrm{O}_{3}(\mathrm{wt} \%)$ & 0.0329 & 0.0331 & 0.0000 & 0.0329 & 0.0331 & & \\
\hline Pu04-02 & $\mathrm{Ga}_{2} \mathrm{O}_{3}(\mathrm{wt} \%)$ & 0.0370 & 0.0370 & 0.0000 & 0.0370 & 0.0370 & & \\
\hline $\mathrm{Pu} 04-02$ & $\mathrm{Gd}_{2} \mathrm{O}_{3}(\mathrm{wt} \%)$ & 12.0447 & 12.0447 & 11.6100 & 0.4347 & 0.4347 & $3.7 \%$ & $3.7 \%$ \\
\hline $\mathrm{Pu} 04-02$ & $\mathrm{HfO}_{2}(\mathrm{wt} \%)$ & 14.6823 & 14.6823 & 19.4300 & -4.7477 & -4.7477 & $-24.4 \%$ & $-24.4 \%$ \\
\hline $\mathrm{Pu} 04-02$ & $\mathrm{~K}_{2} \mathrm{O}(\mathrm{wt} \%)$ & 0.0699 & 0.0611 & 0.0700 & -0.0001 & -0.0089 & $-0.2 \%$ & $-12.8 \%$ \\
\hline \begin{tabular}{|l|}
$\mathrm{Pu} 04-02$ \\
\end{tabular} & $\mathrm{La}_{2} \mathrm{O}_{3}(\mathrm{wt} \%)$ & 16.7124 & 16.7124 & 16.3400 & 0.3724 & 0.3724 & $2.3 \%$ & $2.3 \%$ \\
\hline $\mathrm{Pu} 04-02$ & $\mathrm{MgO}(\mathrm{wt} \%)$ & 0.0688 & 0.0707 & 0.0800 & -0.0112 & -0.0093 & $-14.0 \%$ & $-11.7 \%$ \\
\hline \begin{tabular}{|l|}
$\mathrm{Pu} 04-02$ \\
\end{tabular} & $\mathrm{Na}_{2} \mathrm{O}($ wt $\%)$ & 0.4145 & 0.3787 & 0.3200 & 0.0945 & 0.0587 & $29.5 \%$ & $18.3 \%$ \\
\hline \begin{tabular}{|l|}
$\mathrm{Pu} 04-02$ \\
\end{tabular} & $\mathrm{Nd}_{2} \mathrm{O}_{3}(\mathrm{wt} \%)$ & 13.4136 & 13.4136 & 12.9000 & 0.5136 & 0.5136 & $4.0 \%$ & $4.0 \%$ \\
\hline $\mathrm{Pu} 04-02$ & $\mathrm{NiO}(\mathrm{wt} \%)$ & 0.0064 & 0.0073 & 0.0000 & 0.0064 & 0.0073 & & \\
\hline $\mathrm{Pu} 04-02$ & $\mathrm{PbO}($ wt $\%)$ & 0.0377 & 0.0377 & 0.0000 & 0.0377 & 0.0377 & & \\
\hline $\mathrm{Pu} 04-02$ & $\mathrm{SeO}_{2}(\mathrm{wt} \%)$ & 0.0070 & 0.0070 & 0.0000 & 0.0070 & 0.0070 & & \\
\hline $\mathrm{Pu} 04-02$ & $\mathrm{Si}_{2} \mathrm{O}_{3}($ wt $\%)$ & 18.7296 & 18.4738 & 17.2000 & 1.5296 & 1.2738 & $8.9 \%$ & $7.4 \%$ \\
\hline \begin{tabular}{|l|}
$\mathrm{Pu} 04-02$ \\
\end{tabular} & $\mathrm{SO}_{4}(\mathrm{wt} \%)$ & 0.0749 & 0.0749 & 0.0000 & 0.0749 & 0.0749 & & \\
\hline $\mathrm{Pu} 04-02$ & $\mathrm{SrO}(\mathrm{wt} \%)$ & 2.3120 & 2.3120 & 2.1500 & 0.1620 & 0.1620 & $7.5 \%$ & $7.5 \%$ \\
\hline $\mathrm{Pu} 04-02$ & $\mathrm{Ta}_{2} \mathrm{O}_{5}(\mathrm{wt} \%)$ & 0.0189 & 0.0189 & 0.0000 & 0.0189 & 0.0189 & & \\
\hline \begin{tabular}{|l|}
$\mathrm{Pu} 04-02$ \\
\end{tabular} & Sum (wt \%) & 100.0672 & 99.4079 & 100.0000 & 0.0672 & -0.5921 & $0.1 \%$ & $-0.6 \%$ \\
\hline \begin{tabular}{|l|}
$\mathrm{Pu} 04-03$ \\
\end{tabular} & $\mathrm{Al}_{2} \mathrm{O}_{3}($ wt $\%)$ & 9.4192 & 9.2675 & 8.6000 & 0.8192 & 0.6675 & $9.5 \%$ & $7.8 \%$ \\
\hline Pu04-03 & $\mathrm{B}_{2} \mathrm{O}_{3}(\mathrm{wt} \%)$ & 11.6560 & 11.4442 & 11.1800 & 0.4760 & 0.2642 & $4.3 \%$ & $2.4 \%$ \\
\hline \begin{tabular}{|l|}
$\mathrm{Pu} 04-03$ \\
\end{tabular} & $\mathrm{CaO}($ wt \%) & 0.0658 & 0.0646 & 0.0000 & 0.0658 & 0.0646 & & \\
\hline \begin{tabular}{|l|}
$\mathrm{Pu} 04-03$ \\
\end{tabular} & $\mathrm{Cl}(\mathrm{wt} \%)$ & 0.0100 & 0.0100 & 0.0600 & -0.0500 & -0.0500 & $-83.3 \%$ & $-83.3 \%$ \\
\hline \begin{tabular}{|l|}
$\mathrm{Pu} 04-03$ \\
\end{tabular} & $\mathrm{Cr}_{2} \mathrm{O}_{3}(\mathrm{wt} \%)$ & 0.0080 & 0.0081 & 0.0000 & 0.0080 & 0.0081 & & \\
\hline \begin{tabular}{|l|}
$\mathrm{Pu} 04-03$ \\
\end{tabular} & $\mathrm{CuO}($ wt $\%)$ & 0.0307 & 0.0325 & 0.0000 & 0.0307 & 0.0325 & & \\
\hline \begin{tabular}{|l|}
$\mathrm{Pu} 04-03$ \\
\end{tabular} & $\mathrm{~F}(\mathrm{wt} \%)$ & 0.0000 & 0.0000 & 0.0600 & -0.0600 & -0.0600 & $-100.0 \%$ & $-100.0 \%$ \\
\hline Pu04-03 & $\mathrm{Fe}_{2} \mathrm{O}_{3}(\mathrm{wt} \%)$ & 0.1801 & 0.1815 & 0.1700 & 0.0101 & 0.0115 & $6.0 \%$ & $6.8 \%$ \\
\hline Pu04-03 & $\mathrm{Ga}_{2} \mathrm{O}_{3}(\mathrm{wt} \%)$ & 0.0376 & 0.0376 & 0.0000 & 0.0376 & 0.0376 & & \\
\hline Pu04-03 & $\mathrm{Gd}_{2} \mathrm{O}_{3}(\mathrm{wt} \%)$ & 12.1599 & 12.1599 & 11.6100 & 0.5499 & 0.5499 & $4.7 \%$ & $4.7 \%$ \\
\hline Pu04-03 & $\mathrm{HfO}_{2}(\mathrm{wt} \%)$ & 14.9771 & 14.9771 & 19.4200 & -4.4429 & -4.4429 & $-22.9 \%$ & $-22.9 \%$ \\
\hline Pu04-03 & $\mathrm{K}_{2} \mathrm{O}(\mathrm{wt} \%)$ & 0.0060 & 0.0053 & 0.0000 & 0.0060 & 0.0053 & & \\
\hline Pu04-03 & $\mathrm{La}_{2} \mathrm{O}_{3}(\mathrm{wt} \%)$ & 16.8297 & 16.8297 & 16.3400 & 0.4897 & 0.4897 & $3.0 \%$ & $3.0 \%$ \\
\hline Pu04-03 & $\mathrm{MgO}(\mathrm{wt} \%)$ & 0.1476 & 0.1515 & 0.1600 & -0.0124 & -0.0085 & $-7.8 \%$ & $-5.3 \%$ \\
\hline Pu04-03 & $\mathrm{Na}_{2} \mathrm{O}($ wt $\%)$ & 0.2042 & 0.1866 & 0.1600 & 0.0442 & 0.0266 & $27.6 \%$ & $16.6 \%$ \\
\hline Pu04-03 & $\mathrm{Nd}_{2} \mathrm{O}_{3}(\mathrm{wt} \%)$ & 13.5886 & 13.5886 & 12.9000 & 0.6886 & 0.6886 & $5.3 \%$ & $5.3 \%$ \\
\hline \begin{tabular}{|l|}
$\mathrm{Pu} 04-03$ \\
\end{tabular} & $\mathrm{NiO}(\mathrm{wt} \%)$ & 0.0064 & 0.0073 & 0.0000 & 0.0064 & 0.0073 & & \\
\hline $\mathrm{Pu} 04-03$ & $\mathrm{PbO}(\mathrm{wt} \%)$ & 0.0377 & 0.0377 & 0.0000 & 0.0377 & 0.0377 & & \\
\hline
\end{tabular}


WSRC-STI-2007-00477

Revision 0

Appendix D

Table D5. Average Measured and Bias-Corrected Chemical Compositions Versus Targeted Compositions by Oxide by Study Glass (continued)

\begin{tabular}{|c|c|c|c|c|c|c|c|c|}
\hline Glass ID & Oxide & $\begin{array}{c}\text { Measured } \\
\text { (wt \%) }\end{array}$ & \begin{tabular}{|c|} 
Measured Bias- \\
Corrected (wt \%)
\end{tabular} & $\begin{array}{c}\text { Targeted } \\
\text { (wt \%) }\end{array}$ & $\begin{array}{c}\text { Diff of } \\
\text { Measured }\end{array}$ & $\begin{array}{c}\text { Diff of Meas } \\
\text { BC }\end{array}$ & $\begin{array}{l}\text { \% Diff of } \\
\text { Measured }\end{array}$ & $\begin{array}{c}\text { \% Diff of Meas } \\
\text { BC }\end{array}$ \\
\hline $\mathrm{Pu} 04-03$ & $\mathrm{SeO}_{2}($ wt $\%)$ & 0.0070 & \begin{tabular}{|l|}
0.0070 \\
\end{tabular} & 0.0000 & 0.0070 & 0.0070 & & \\
\hline \begin{tabular}{|l|}
$\mathrm{Pu} 04-03$ \\
\end{tabular} & $\mathrm{Si}_{2} \mathrm{O}_{3}($ wt $\%)$ & 18.5477 & 18.2944 & 17.2000 & 1.3477 & 1.0944 & $7.8 \%$ & $6.4 \%$ \\
\hline \begin{tabular}{|l|}
$\mathrm{Pu} 04-03$ \\
\end{tabular} & $\mathrm{SO}_{4}(\mathrm{wt} \%)$ & 0.0749 & 0.0749 & 0.0000 & 0.0749 & 0.0749 & & \\
\hline $\mathrm{Pu} 04-03$ & $\mathrm{SrO}($ wt $\%)$ & 2.3179 & 2.3179 & 2.1500 & 0.1679 & 0.1679 & $7.8 \%$ & $7.8 \%$ \\
\hline $\mathrm{Pu} 04-03$ & $\mathrm{Ta}_{2} \mathrm{O}_{5}(\mathrm{wt} \%)$ & 0.0195 & 0.0195 & 0.0000 & 0.0195 & 0.0195 & & \\
\hline Pu04-03 & Sum (wt \%) & 100.3317 & 99.7036 & 100.0100 & 0.3217 & -0.3064 & $0.3 \%$ & $-0.3 \%$ \\
\hline \begin{tabular}{|l|}
$\mathrm{Pu} 04-04$ \\
\end{tabular} & $\mathrm{Al}_{2} \mathrm{O}_{3}(\mathrm{wt} \%)$ & 9.5514 & 9.3977 & 8.6000 & 0.9514 & 0.7977 & $11.1 \%$ & $9.3 \%$ \\
\hline Pu04-04 & $\mathrm{B}_{2} \mathrm{O}_{3}(\mathrm{wt} \%)$ & 11.8653 & 11.6497 & 11.1800 & 0.6853 & 0.4697 & $6.1 \%$ & $4.2 \%$ \\
\hline $\mathrm{Pu} 04-04$ & $\mathrm{CaO}(\mathrm{wt} \%)$ & 0.1728 & 0.1698 & 0.0800 & 0.0928 & 0.0898 & $116.0 \%$ & $112.3 \%$ \\
\hline \begin{tabular}{|l|}
$\mathrm{Pu} 04-04$ \\
\end{tabular} & $\mathrm{Cl}(\mathrm{wt} \%)$ & 0.0375 & 0.0375 & 0.0000 & 0.0375 & 0.0375 & & \\
\hline \begin{tabular}{|l|}
$\mathrm{Pu} 04-04$ \\
\end{tabular} & $\mathrm{Cr}_{2} \mathrm{O}_{3}(\mathrm{wt} \%)$ & 0.0826 & 0.0832 & 0.0900 & -0.0074 & -0.0068 & $-8.2 \%$ & $-7.6 \%$ \\
\hline \begin{tabular}{|l|}
$\mathrm{Pu} 04-04$ \\
\end{tabular} & $\mathrm{CuO}(\mathrm{wt} \%)$ & 0.1033 & 0.1096 & 0.0700 & 0.0333 & 0.0396 & $47.5 \%$ & $56.6 \%$ \\
\hline \begin{tabular}{|l|}
$\mathrm{Pu} 04-04$ \\
\end{tabular} & $\mathrm{~F}(\mathrm{wt} \%)$ & 0.0000 & 0.0000 & 0.0000 & 0.0000 & 0.0000 & & \\
\hline Pu04-04 & $\mathrm{Fe}_{2} \mathrm{O}_{3}(\mathrm{wt} \%)$ & 0.1122 & 0.1131 & 0.0800 & 0.0322 & 0.0331 & $40.3 \%$ & $41.3 \%$ \\
\hline Pu04-04 & $\mathrm{Ga}_{2} \mathrm{O}_{3}($ wt $\%)$ & 0.0349 & 0.0349 & 0.0000 & 0.0349 & 0.0349 & & \\
\hline \begin{tabular}{|l|}
$\mathrm{Pu} 04-04$ \\
\end{tabular} & $\mathrm{Gd}_{2} \mathrm{O}_{3}(\mathrm{wt} \%)$ & 12.3905 & 12.3905 & 11.6100 & 0.7805 & 0.7805 & $6.7 \%$ & $6.7 \%$ \\
\hline $\mathrm{Pu} 04-04$ & $\mathrm{HfO}_{2}(\mathrm{wt} \%)$ & 14.5644 & 14.5644 & 19.3900 & -4.8256 & -4.8256 & $-24.9 \%$ & $-24.9 \%$ \\
\hline Pu04-04 & $\mathrm{K}_{2} \mathrm{O}(\mathrm{wt} \%)$ & 0.0632 & 0.0553 & 0.0700 & -0.0068 & -0.0147 & $-9.7 \%$ & $-21.0 \%$ \\
\hline Pu04-04 & $\mathrm{La}_{2} \mathrm{O}_{3}(\mathrm{wt} \%)$ & 16.2433 & 16.2433 & 16.3400 & -0.0967 & -0.0967 & $-0.6 \%$ & $-0.6 \%$ \\
\hline \begin{tabular}{|l|}
$\mathrm{Pu} 04-04$ \\
\end{tabular} & $\mathrm{MgO}(\mathrm{wt} \%)$ & 0.0680 & 0.0698 & 0.0800 & -0.0120 & -0.0102 & $-15.0 \%$ & $-12.7 \%$ \\
\hline \begin{tabular}{|l|}
$\mathrm{Pu} 04-04$ \\
\end{tabular} & $\mathrm{Na}_{2} \mathrm{O}($ wt $\%)$ & 0.1260 & 0.1152 & 0.0800 & 0.0460 & 0.0352 & $57.5 \%$ & $43.9 \%$ \\
\hline Pu04-04 & $\mathrm{Nd}_{2} \mathrm{O}_{3}(\mathrm{wt} \%)$ & 13.8802 & 13.8802 & 12.9000 & 0.9802 & 0.9802 & $7.6 \%$ & $7.6 \%$ \\
\hline \begin{tabular}{|l|}
$\mathrm{Pu} 04-04$ \\
\end{tabular} & $\mathrm{NiO}(\mathrm{wt} \%)$ & 0.0687 & 0.0787 & 0.0800 & -0.0113 & -0.0013 & $-14.1 \%$ & $-1.6 \%$ \\
\hline $\mathrm{Pu} 04-04$ & $\mathrm{PbO}(\mathrm{wt} \%)$ & 0.0377 & 0.0377 & 0.0000 & 0.0377 & 0.0377 & & \\
\hline \begin{tabular}{|l|}
$\mathrm{Pu} 04-04$ \\
\end{tabular} & $\mathrm{SeO}_{2}(\mathrm{wt} \%)$ & 0.0070 & 0.0070 & 0.0000 & 0.0070 & 0.0070 & & \\
\hline $\mathrm{Pu} 04-04$ & $\mathrm{Si}_{2} \mathrm{O}_{3}($ wt $\%)$ & 18.6761 & 18.4210 & 17.2000 & 1.4761 & 1.2210 & $8.6 \%$ & $7.1 \%$ \\
\hline \begin{tabular}{|l|}
$\mathrm{Pu} 04-04$ \\
\end{tabular} & $\mathrm{SO}_{4}(\mathrm{wt} \%)$ & 0.0749 & 0.0749 & 0.0000 & 0.0749 & 0.0749 & & \\
\hline $\mathrm{Pu} 04-04$ & $\mathrm{SrO}(\mathrm{wt} \%)$ & 2.3002 & 2.3002 & 2.1500 & 0.1502 & 0.1502 & $7.0 \%$ & $7.0 \%$ \\
\hline \begin{tabular}{|l|}
$\mathrm{Pu} 04-04$ \\
\end{tabular} & $\mathrm{Ta}_{2} \mathrm{O}_{5}(\mathrm{wt} \%)$ & 0.0177 & 0.0177 & 0.0000 & 0.0177 & 0.0177 & & \\
\hline $\mathrm{Pu} 04-04$ & Sum (wt \%) & 100.4779 & 99.8513 & 100.0000 & 0.4779 & -0.1487 & $0.5 \%$ & $-0.1 \%$ \\
\hline \begin{tabular}{|l|}
$\mathrm{Pu} 04-05$ \\
\end{tabular} & $\mathrm{Al}_{2} \mathrm{O}_{3}(\mathrm{wt} \%)$ & 9.3719 & 9.2211 & 8.6000 & 0.7719 & 0.6211 & $9.0 \%$ & $7.2 \%$ \\
\hline $\mathrm{Pu} 04-05$ & $\mathrm{~B}_{2} \mathrm{O}_{3}(\mathrm{wt} \%)$ & 11.8653 & 11.6497 & 11.1800 & 0.6853 & 0.4697 & $6.1 \%$ & $4.2 \%$ \\
\hline $\mathrm{Pu} 04-05$ & $\mathrm{CaO}($ wt \%) & 0.0665 & 0.0653 & 0.0000 & 0.0665 & 0.0653 & & \\
\hline $\mathrm{Pu} 04-05$ & $\mathrm{Cl}(\mathrm{wt} \%)$ & 0.0120 & 0.0120 & 0.1200 & -0.1080 & -0.1080 & $-90.0 \%$ & $-90.0 \%$ \\
\hline $\mathrm{Pu} 04-05$ & $\mathrm{Cr}_{2} \mathrm{O}_{3}(\mathrm{wt} \%)$ & 0.0088 & 0.0088 & 0.0000 & 0.0088 & 0.0088 & & \\
\hline Pu04-05 & $\mathrm{CuO}(\mathrm{wt} \%)$ & 0.0288 & 0.0306 & 0.0000 & 0.0288 & 0.0306 & & \\
\hline $\mathrm{Pu} 04-05$ & $\mathrm{~F}(\mathrm{wt} \%)$ & 0.0270 & 0.0327 & 0.1200 & -0.0930 & -0.0873 & $-77.5 \%$ & $-72.7 \%$ \\
\hline $\mathrm{Pu} 04-05$ & $\mathrm{Fe}_{2} \mathrm{O}_{3}(\mathrm{wt} \%)$ & 0.0272 & 0.0274 & 0.0000 & 0.0272 & 0.0274 & & \\
\hline Pu04-05 & $\mathrm{Ga}_{2} \mathrm{O}_{3}(\mathrm{wt} \%)$ & 0.0363 & 0.0363 & 0.0000 & 0.0363 & 0.0363 & & \\
\hline \begin{tabular}{|l|}
$\mathrm{Pu} 04-05$ \\
\end{tabular} & $\mathrm{Gd}_{2} \mathrm{O}_{3}(\mathrm{wt} \%)$ & 12.3328 & 12.3328 & 11.6100 & 0.7228 & 0.7228 & $6.2 \%$ & $6.2 \%$ \\
\hline Pu04-05 & $\mathrm{HfO}_{2}(\mathrm{wt} \%)$ & 15.4488 & 15.4488 & 19.4600 & -4.0112 & -4.0112 & $-20.6 \%$ & $-20.6 \%$ \\
\hline \begin{tabular}{|l|}
$\mathrm{Pu} 04-05$ \\
\end{tabular} & $\mathrm{~K}_{2} \mathrm{O}(\mathrm{wt} \%)$ & 0.0060 & 0.0053 & 0.0000 & 0.0060 & 0.0053 & & \\
\hline $\mathrm{Pu} 04-05$ & $\mathrm{La}_{2} \mathrm{O}_{3}(\mathrm{wt} \%)$ & 16.3606 & 16.3606 & 16.3400 & 0.0206 & 0.0206 & $0.1 \%$ & $0.1 \%$ \\
\hline $\mathrm{Pu} 04-05$ & $\mathrm{MgO}(\mathrm{wt} \%)$ & 0.0083 & 0.0085 & 0.0000 & 0.0083 & 0.0085 & & \\
\hline \begin{tabular}{|l|}
$\mathrm{Pu} 04-05$ \\
\end{tabular} & $\mathrm{Na}_{2} \mathrm{O}$ (wt \%) & 0.3849 & 0.3516 & 0.3200 & 0.0649 & 0.0316 & $20.3 \%$ & $9.9 \%$ \\
\hline $\mathrm{Pu} 04-05$ & $\mathrm{Nd}_{2} \mathrm{O}_{3}($ wt $\%)$ & 13.7052 & 13.7052 & 12.9000 & 0.8052 & 0.8052 & $6.2 \%$ & $6.2 \%$ \\
\hline $\mathrm{Pu} 04-05$ & $\mathrm{NiO}($ wt \%) & 0.0064 & 0.0073 & 0.0000 & 0.0064 & 0.0073 & & \\
\hline $\mathrm{Pu} 04-05$ & $\mathrm{PbO}(\mathrm{wt} \%)$ & 0.0382 & 0.0382 & 0.0000 & 0.0382 & 0.0382 & & \\
\hline $\mathrm{Pu} 04-05$ & $\mathrm{SeO}_{2}($ wt $\%)$ & 0.0070 & 0.0070 & 0.0000 & 0.0070 & 0.0070 & & \\
\hline $\mathrm{Pu} 04-05$ & $\mathrm{Si}_{2} \mathrm{O}_{3}($ wt $\%)$ & 18.6761 & 18.4210 & 17.2000 & 1.4761 & 1.2210 & $8.6 \%$ & $7.1 \%$ \\
\hline $\mathrm{Pu} 04-05$ & $\mathrm{SO}_{4}(\mathrm{wt} \%)$ & 0.0749 & 0.0749 & 0.0000 & 0.0749 & 0.0749 & & \\
\hline $\mathrm{Pu} 04-05$ & $\mathrm{SrO}(\mathrm{wt} \%)$ & 2.2824 & 2.2824 & 2.1500 & 0.1324 & 0.1324 & $6.2 \%$ & $6.2 \%$ \\
\hline Pu04-05 & $\mathrm{Ta}_{2} \mathrm{O}_{5}(\mathrm{wt} \%)$ & 0.0195 & 0.0195 & 0.0000 & 0.0195 & 0.0195 & & \\
\hline \begin{tabular}{|l|}
$\mathrm{Pu} 04-05$ \\
\end{tabular} & \begin{tabular}{|l|} 
Sum (wt \%) \\
\end{tabular} & 100.7949 & 100.1471 & 100.0000 & 0.7949 & 0.1471 & $0.8 \%$ & $0.1 \%$ \\
\hline Pu35-01 & $\mathrm{Al}_{2} \mathrm{O}_{3}(\mathrm{wt} \%)$ & 9.0318 & 8.8864 & 8.6000 & 0.4318 & 0.2864 & $5.0 \%$ & $3.3 \%$ \\
\hline Pu35-01 & $\mathrm{B}_{2} \mathrm{O}_{3}(\mathrm{wt} \%)$ & 11.2536 & 11.0490 & 11.1800 & 0.0736 & -0.1310 & $0.7 \%$ & $-1.2 \%$ \\
\hline Pu35-01 & $\mathrm{CaO}(\mathrm{wt} \%)$ & 0.0805 & 0.0791 & 0.0000 & 0.0805 & 0.0791 & & \\
\hline Pu35-01 & $\mathrm{Cl}(\mathrm{wt} \%)$ & 0.0575 & 0.0575 & 0.5800 & -0.5225 & -0.5225 & $-90.1 \%$ & $-90.1 \%$ \\
\hline
\end{tabular}


Table D5. Average Measured and Bias-Corrected Chemical Compositions Versus Targeted Compositions by Oxide by Study Glass (continued)

\begin{tabular}{|c|c|c|c|c|c|c|c|c|}
\hline Glass ID & Oxide & $\begin{array}{c}\text { Measured } \\
\text { (wt \%) }\end{array}$ & \begin{tabular}{|c|} 
Measured Bias- \\
Corrected (wt \%) \\
\end{tabular} & $\begin{array}{c}\text { Targeted } \\
\text { (wt \%) }\end{array}$ & $\begin{array}{c}\text { Diff of } \\
\text { Measured }\end{array}$ & $\begin{array}{c}\text { Diff of Meas } \\
\text { BC } \\
\end{array}$ & $\begin{array}{l}\text { \% Diff of } \\
\text { Measured }\end{array}$ & \begin{tabular}{|c} 
\% Diff of Meas \\
BC \\
\end{tabular} \\
\hline Pu35-01 & $\mathrm{Cr}_{2} \mathrm{O}_{3}(\mathrm{wt} \%)$ & 0.0080 & \begin{tabular}{|l|}
0.0081 \\
\end{tabular} & 0.0000 & 0.0080 & 0.0081 & & \\
\hline \begin{tabular}{|l|} 
Pu35-01 \\
\end{tabular} & $\mathrm{CuO}(\mathrm{wt} \%)$ & 0.1540 & 0.1634 & 0.1500 & 0.0040 & 0.0134 & $2.6 \%$ & $8.9 \%$ \\
\hline Pu35-01 & $\mathrm{F}(\mathrm{wt} \%)$ & 0.0000 & 0.0000 & 0.0000 & 0.0000 & 0.0000 & & \\
\hline Pu35-01 & $\mathrm{Fe}_{2} \mathrm{O}_{3}(\mathrm{wt} \%)$ & 0.4103 & 0.4134 & 0.3900 & 0.0203 & 0.0234 & $5.2 \%$ & $6.0 \%$ \\
\hline Pu35-01 & $\mathrm{Ga}_{2} \mathrm{O}_{3}(\mathrm{wt} \%)$ & 0.9288 & 0.9288 & 0.9500 & -0.0212 & -0.0212 & $-2.2 \%$ & $-2.2 \%$ \\
\hline Pu35-01 & $\mathrm{Gd}_{2} \mathrm{O}_{3}(\mathrm{wt} \%)$ & 11.6413 & 11.6413 & 11.6100 & 0.0313 & 0.0313 & $0.3 \%$ & $0.3 \%$ \\
\hline Pu35-01 & $\mathrm{HfO}_{2}(\mathrm{wt} \%)$ & 13.6209 & 13.6209 & 14.8600 & -1.2391 & -1.2391 & $-8.3 \%$ & $-8.3 \%$ \\
\hline Pu35-01 & $\mathrm{K}_{2} \mathrm{O}(\mathrm{wt} \%)$ & 0.2409 & 0.2106 & 0.2600 & -0.0191 & -0.0494 & $-7.3 \%$ & $-19.0 \%$ \\
\hline Pu35-01 & $\mathrm{La}_{2} \mathrm{O}_{3}(\mathrm{wt} \%)$ & 16.1846 & 16.1846 & 16.3400 & -0.1554 & -0.1554 & $-1.0 \%$ & $-1.0 \%$ \\
\hline \begin{tabular}{|l|}
$\mathrm{Pu} 35-01$ \\
\end{tabular} & $\mathrm{MgO}(\mathrm{wt} \%)$ & 1.4245 & 1.4627 & 1.6200 & -0.1955 & -0.1573 & $-12.1 \%$ & $-9.7 \%$ \\
\hline \begin{tabular}{|l|}
$\mathrm{Pu} 35-01$ \\
\end{tabular} & $\mathrm{Na}_{2} \mathrm{O}(\mathrm{wt} \%)$ & 0.8445 & 0.7716 & 0.8000 & 0.0445 & -0.0284 & $5.6 \%$ & $-3.6 \%$ \\
\hline \begin{tabular}{|l|} 
Pu35-01 \\
\end{tabular} & $\mathrm{Nd}_{2} \mathrm{O}_{3}(\mathrm{wt} \%)$ & 13.0637 & 13.0637 & 12.9000 & 0.1637 & 0.1637 & $1.3 \%$ & $1.3 \%$ \\
\hline \begin{tabular}{|l|} 
Pu35-01 \\
\end{tabular} & $\mathrm{NiO}(\mathrm{wt} \%)$ & 0.1762 & 0.2020 & 0.2100 & -0.0338 & -0.0080 & $-16.1 \%$ & $-3.8 \%$ \\
\hline Pu35-01 & $\mathrm{PbO}($ wt \%) & 0.0361 & 0.0361 & 0.0000 & 0.0361 & 0.0361 & & \\
\hline Pu35-01 & $\mathrm{SeO}_{2}(\mathrm{wt} \%)$ & 0.0070 & 0.0070 & 0.0800 & -0.0730 & -0.0730 & $-91.2 \%$ & $-91.2 \%$ \\
\hline \begin{tabular}{|l|} 
Pu35-01 \\
\end{tabular} & $\mathrm{Si}_{2} \mathrm{O}_{3}($ wt $\%)$ & 18.0343 & 17.7880 & 17.2000 & 0.8343 & 0.5880 & $4.9 \%$ & $3.4 \%$ \\
\hline Pu35-01 & $\mathrm{SO}_{4}(\mathrm{wt} \%)$ & 0.0749 & 0.0749 & 0.0000 & 0.0749 & 0.0749 & & \\
\hline Pu35-01 & $\mathrm{SrO}(\mathrm{wt} \%)$ & 2.2351 & 2.2351 & 2.1500 & 0.0851 & 0.0851 & $4.0 \%$ & $4.0 \%$ \\
\hline \begin{tabular}{|l|}
$\mathrm{Pu} 35-01$ \\
\end{tabular} & $\mathrm{Ta}_{2} \mathrm{O}_{5}(\mathrm{wt} \%)$ & 0.0769 & 0.0769 & 0.0700 & 0.0069 & 0.0069 & $9.9 \%$ & $9.9 \%$ \\
\hline Pu35-01 & Sum (wt \%) & 99.5855 & 98.9612 & 99.9500 & -0.3645 & -0.9888 & $-0.4 \%$ & $-1.0 \%$ \\
\hline \begin{tabular}{|l|}
$\mathrm{Pu} 35-02$ \\
\end{tabular} & $\mathrm{Al}_{2} \mathrm{O}_{3}(\mathrm{wt} \%)$ & 9.1641 & 9.0166 & 8.6000 & 0.5641 & 0.4166 & $6.6 \%$ & $4.8 \%$ \\
\hline Pu35-02 & $\mathrm{B}_{2} \mathrm{O}_{3}($ wt $\%)$ & 11.7687 & 11.5549 & 11.1800 & 0.5887 & 0.3749 & $5.3 \%$ & $3.4 \%$ \\
\hline \begin{tabular}{|l|}
$\mathrm{Pu} 35-02$ \\
\end{tabular} & $\mathrm{CaO}$ (wt \%) & 0.4848 & 0.4764 & 0.3600 & 0.1248 & 0.1164 & $34.7 \%$ & $32.3 \%$ \\
\hline \begin{tabular}{|l|}
$\mathrm{Pu} 35-02$ \\
\end{tabular} & $\mathrm{Cl}(\mathrm{wt} \%)$ & 0.0185 & 0.0185 & 0.5800 & -0.5615 & -0.5615 & $-96.8 \%$ & $-96.8 \%$ \\
\hline \begin{tabular}{|l|}
$\mathrm{Pu} 35-02$ \\
\end{tabular} & $\mathrm{Cr}_{2} \mathrm{O}_{3}(\mathrm{wt} \%)$ & 0.2952 & 0.2974 & 0.3300 & -0.0348 & -0.0326 & $-10.5 \%$ & $-9.9 \%$ \\
\hline \begin{tabular}{|l|}
$\mathrm{Pu} 35-02$ \\
\end{tabular} & $\mathrm{CuO}(\mathrm{wt} \%)$ & 0.0914 & 0.0970 & 0.0700 & 0.0214 & 0.0270 & $30.5 \%$ & $38.5 \%$ \\
\hline Pu35-02 & $\mathrm{F}(\mathrm{wt} \%)$ & 0.0745 & 0.0902 & 0.4500 & -0.3755 & -0.3598 & $-83.4 \%$ & $-79.9 \%$ \\
\hline \begin{tabular}{|l|}
$\mathrm{Pu} 35-02$ \\
\end{tabular} & $\mathrm{Fe}_{2} \mathrm{O}_{3}(\mathrm{wt} \%)$ & 0.1129 & 0.1138 & 0.0800 & 0.0329 & 0.0338 & $41.2 \%$ & $42.2 \%$ \\
\hline \begin{tabular}{|l|}
$\mathrm{Pu} 35-02$ \\
\end{tabular} & $\mathrm{Ga}_{2} \mathrm{O}_{3}(\mathrm{wt} \%)$ & 0.1109 & 0.1109 & 0.0800 & 0.0309 & 0.0309 & $38.6 \%$ & $38.6 \%$ \\
\hline Pu35-02 & $\mathrm{Gd}_{2} \mathrm{O}_{3}(\mathrm{wt} \%)$ & 11.8718 & 11.8718 & 11.6100 & 0.2618 & 0.2618 & $2.3 \%$ & $2.3 \%$ \\
\hline \begin{tabular}{|l|}
$\mathrm{Pu} 35-02$ \\
\end{tabular} & $\mathrm{HfO}_{2}(\mathrm{wt} \%)$ & 13.6209 & 13.6209 & 14.9200 & -1.2991 & -1.2991 & $-8.7 \%$ & $-8.7 \%$ \\
\hline Pu35-02 & $\mathrm{K}_{2} \mathrm{O}(\mathrm{wt} \%)$ & 0.6270 & 0.5480 & 0.7400 & -0.1130 & -0.1920 & $-15.3 \%$ & $-25.9 \%$ \\
\hline Pu35-02 & $\mathrm{La}_{2} \mathrm{O}_{3}(\mathrm{wt} \%)$ & 16.1260 & 16.1260 & 16.3400 & -0.2140 & -0.2140 & $-1.3 \%$ & $-1.3 \%$ \\
\hline Pu35-02 & $\mathrm{MgO}($ wt $\%)$ & 1.2968 & 1.3316 & 1.4500 & -0.1532 & -0.1184 & $-10.6 \%$ & $-8.2 \%$ \\
\hline Pu35-02 & $\mathrm{Na}_{2} \mathrm{O}(\mathrm{wt} \%)$ & 0.3963 & 0.3621 & 0.3500 & 0.0463 & 0.0121 & $13.2 \%$ & $3.5 \%$ \\
\hline \begin{tabular}{|l|}
$\mathrm{Pu} 35-02$ \\
\end{tabular} & $\mathrm{Nd}_{2} \mathrm{O}_{3}(\mathrm{wt} \%)$ & 13.2386 & 13.2386 & 12.9000 & 0.3386 & 0.3386 & $2.6 \%$ & $2.6 \%$ \\
\hline Pu35-02 & $\mathrm{NiO}($ wt $\%)$ & 0.1247 & 0.1429 & 0.1500 & -0.0253 & -0.0071 & $-16.9 \%$ & $-4.7 \%$ \\
\hline Pu35-02 & $\mathrm{PbO}$ (wt \%) & 0.0862 & 0.0862 & 0.0600 & 0.0262 & 0.0262 & $43.6 \%$ & $43.6 \%$ \\
\hline Pu35-02 & $\mathrm{SeO}_{2}($ wt $\%)$ & 0.0070 & 0.0070 & 0.0800 & -0.0730 & -0.0730 & $-91.2 \%$ & $-91.2 \%$ \\
\hline \begin{tabular}{|l|}
$\mathrm{Pu} 35-02$ \\
\end{tabular} & $\mathrm{Si}_{2} \mathrm{O}_{3}($ wt $\%)$ & 17.6706 & 17.4293 & 17.2000 & 0.4706 & 0.2293 & $2.7 \%$ & $1.3 \%$ \\
\hline Pu35-02 & $\mathrm{SO}_{4}(\mathrm{wt} \%)$ & 0.0749 & 0.0749 & 0.1700 & -0.0951 & -0.0951 & $-55.9 \%$ & $-55.9 \%$ \\
\hline \begin{tabular}{|l|} 
Pu35-02 \\
\end{tabular} & SrO (wt \%) & 2.2883 & 2.2883 & 2.1500 & 0.1383 & 0.1383 & $6.4 \%$ & $6.4 \%$ \\
\hline Pu35-02 & $\mathrm{Ta}_{2} \mathrm{O}_{5}(\mathrm{wt} \%)$ & 0.0818 & 0.0818 & 0.0700 & 0.0118 & 0.0118 & $16.9 \%$ & $16.9 \%$ \\
\hline Pu35-02 & Sum (wt \%) & 99.6321 & 98.9851 & 99.9200 & -0.2879 & -0.9349 & $-0.3 \%$ & $-0.9 \%$ \\
\hline Pu35-03 & $\mathrm{Al}_{2} \mathrm{O}_{3}(\mathrm{wt} \%)$ & 8.8523 & 8.7098 & 8.6000 & 0.2523 & 0.1098 & $2.9 \%$ & $1.3 \%$ \\
\hline Pu35-03 & $\mathrm{B}_{2} \mathrm{O}_{3}(\mathrm{wt} \%)$ & 11.7204 & 11.5074 & 11.1800 & 0.5404 & 0.3274 & $4.8 \%$ & $2.9 \%$ \\
\hline Pu35-03 & $\mathrm{CaO}(w \mathrm{t} \%)$ & 0.8857 & 0.8703 & 0.7700 & 0.1157 & 0.1003 & $15.0 \%$ & $13.0 \%$ \\
\hline Pu35-03 & $\mathrm{Cl}(\mathrm{wt} \%)$ & 0.1395 & 0.1395 & 0.5700 & -0.4305 & -0.4305 & $-75.5 \%$ & $-75.5 \%$ \\
\hline Pu35-03 & $\mathrm{Cr}_{2} \mathrm{O}_{3}(\mathrm{wt} \%)$ & 0.5430 & 0.5470 & 0.6400 & -0.0970 & -0.0930 & $-15.2 \%$ & $-14.5 \%$ \\
\hline \begin{tabular}{|l|}
$\mathrm{Pu} 35-03$ \\
\end{tabular} & $\mathrm{CuO}(\mathrm{wt} \%)$ & 0.0313 & 0.0332 & 0.0000 & 0.0313 & 0.0332 & & \\
\hline Pu35-03 & $\mathrm{F}(\mathrm{wt} \%)$ & 0.0000 & 0.0000 & 0.0000 & 0.0000 & 0.0000 & & \\
\hline Pu35-03 & $\mathrm{Fe}_{2} \mathrm{O}_{3}($ wt $\%)$ & 0.1566 & 0.1577 & 0.1400 & 0.0166 & 0.0177 & $11.8 \%$ & $12.7 \%$ \\
\hline Pu35-03 & $\mathrm{Ga}_{2} \mathrm{O}_{3}(\mathrm{wt} \%)$ & 0.4590 & 0.4590 & 0.4500 & 0.0090 & 0.0090 & $2.0 \%$ & $2.0 \%$ \\
\hline Pu35-03 & $\mathrm{Gd}_{2} \mathrm{O}_{3}(\mathrm{wt} \%)$ & 11.5836 & 11.5836 & 11.6100 & -0.0264 & -0.0264 & $-0.2 \%$ & $-0.2 \%$ \\
\hline Pu35-03 & $\mathrm{HfO}_{2}(\mathrm{wt} \%)$ & 13.3261 & 13.3261 & 14.8100 & -1.4839 & -1.4839 & $-10.0 \%$ & $-10.0 \%$ \\
\hline Pu35-03 & $\mathrm{K}_{2} \mathrm{O}(\mathrm{wt} \%)$ & 0.3054 & 0.2669 & 0.3100 & -0.0046 & -0.0431 & $-1.5 \%$ & $-13.9 \%$ \\
\hline Pu35-03 & $\mathrm{La}_{2} \mathrm{O}_{3}(\mathrm{wt} \%)$ & 16.0674 & 16.0674 & 16.3400 & -0.2726 & -0.2726 & $-1.7 \%$ & $-1.7 \%$ \\
\hline Pu35-03 & $\mathrm{MgO}(\mathrm{wt} \%)$ & 0.5008 & 0.5142 & 0.5400 & -0.0392 & -0.0258 & $-7.3 \%$ & $-4.8 \%$ \\
\hline
\end{tabular}


Table D5. Average Measured and Bias-Corrected Chemical Compositions Versus Targeted Compositions by Oxide by Study Glass (continued)

\begin{tabular}{|c|c|c|c|c|c|c|c|c|}
\hline Glass ID & Oxide & $\begin{array}{c}\text { Measured } \\
\text { (wt \%) }\end{array}$ & \begin{tabular}{|c|} 
Measured Bias- \\
Corrected (wt \%)
\end{tabular} & $\begin{array}{c}\text { Targeted } \\
\text { (wt \%) }\end{array}$ & $\begin{array}{c}\text { Diff of } \\
\text { Measured }\end{array}$ & $\begin{array}{c}\text { Diff of Meas } \\
\text { BC }\end{array}$ & $\begin{array}{l}\text { \% Diff of } \\
\text { Measured }\end{array}$ & $\begin{array}{c}\text { \% Diff of Meas } \\
\text { BC }\end{array}$ \\
\hline $\mathrm{Pu} 35-03$ & $\mathrm{Na}_{2} \mathrm{O}($ wt $\%)$ & 1.4767 & 1.3492 & 1.4800 & -0.0033 & -0.1308 & $-0.2 \%$ & $-8.8 \%$ \\
\hline \begin{tabular}{|l|}
$\mathrm{Pu} 35-03$ \\
\end{tabular} & $\mathrm{Nd}_{2} \mathrm{O}_{3}(\mathrm{wt} \%)$ & 12.9470 & 12.9470 & 12.9000 & 0.0470 & 0.0470 & $0.4 \%$ & $0.4 \%$ \\
\hline Pu35-03 & $\mathrm{NiO}(\mathrm{wt} \%)$ & 0.0560 & 0.0642 & 0.0700 & -0.0140 & -0.0058 & $-20.0 \%$ & $-8.3 \%$ \\
\hline Pu35-03 & $\mathrm{PbO}(\mathrm{wt} \%)$ & 0.0350 & 0.0350 & 0.0000 & 0.0350 & 0.0350 & & \\
\hline Pu35-03 & $\mathrm{SeO}_{2}(\mathrm{wt} \%)$ & 0.0070 & 0.0070 & 0.0000 & 0.0070 & 0.0070 & & \\
\hline Pu35-03 & $\mathrm{Si}_{2} \mathrm{O}_{3}(\mathrm{wt} \%)$ & 17.2855 & 17.0495 & 17.2000 & 0.0855 & -0.1505 & $0.5 \%$ & $-0.9 \%$ \\
\hline Pu35-03 & $\mathrm{SO}_{4}(\mathrm{wt} \%)$ & 0.0749 & 0.0749 & 0.0000 & 0.0749 & 0.0749 & & \\
\hline Pu35-03 & $\mathrm{SrO}($ wt $\%)$ & 2.1996 & 2.1996 & 2.1500 & 0.0496 & 0.0496 & $2.3 \%$ & $2.3 \%$ \\
\hline Pu35-03 & $\mathrm{Ta}_{2} \mathrm{O}_{5}(\mathrm{wt} \%)$ & 0.1770 & 0.1770 & 0.1800 & -0.0030 & -0.0030 & $-1.6 \%$ & $-1.6 \%$ \\
\hline \begin{tabular}{|l|}
$\mathrm{Pu} 35-03$ \\
\end{tabular} & Sum (wt \%) & 98.8300 & 98.0858 & 99.9400 & -1.1100 & -1.8542 & $-1.1 \%$ & $-1.9 \%$ \\
\hline \begin{tabular}{|l|}
$\mathrm{Pu} 35-04$ \\
\end{tabular} & $\mathrm{Al}_{2} \mathrm{O}_{3}(\mathrm{wt} \%)$ & 9.0790 & 8.9329 & 8.6000 & 0.4790 & 0.3329 & $5.6 \%$ & $3.9 \%$ \\
\hline Pu35-04 & $\mathrm{B}_{2} \mathrm{O}_{3}(\mathrm{wt} \%)$ & 11.5433 & 11.3336 & 11.1800 & 0.3633 & 0.1536 & $3.2 \%$ & $1.4 \%$ \\
\hline \begin{tabular}{|l|} 
Pu35-04 \\
\end{tabular} & $\mathrm{CaO}(\mathrm{wt} \%)$ & 0.4505 & 0.4427 & 0.3200 & 0.1305 & 0.1227 & $40.8 \%$ & $38.3 \%$ \\
\hline Pu35-04 & $\mathrm{Cl}(\mathrm{wt} \%)$ & 0.0310 & 0.0310 & 0.5900 & -0.5590 & -0.5590 & $-94.7 \%$ & $-94.7 \%$ \\
\hline \begin{tabular}{|l|}
$\mathrm{Pu} 35-04$ \\
\end{tabular} & $\mathrm{Cr}_{2} \mathrm{O}_{3}(\mathrm{wt} \%)$ & 0.0804 & 0.0810 & 0.0900 & -0.0096 & -0.0090 & $-10.7 \%$ & $-10.0 \%$ \\
\hline \begin{tabular}{|l|}
$\mathrm{Pu} 35-04$ \\
\end{tabular} & $\mathrm{CuO}(\mathrm{wt} \%)$ & 0.0964 & 0.1023 & 0.0700 & 0.0264 & 0.0323 & $37.7 \%$ & $46.1 \%$ \\
\hline Pu35-04 & $\mathrm{F}(\mathrm{wt} \%)$ & 0.0910 & 0.1102 & 0.5200 & -0.4290 & -0.4098 & $-82.5 \%$ & $-78.8 \%$ \\
\hline Pu35-04 & $\mathrm{Fe}_{2} \mathrm{O}_{3}(\mathrm{wt} \%)$ & 0.2845 & 0.2866 & 0.2700 & 0.0145 & 0.0166 & $5.4 \%$ & $6.2 \%$ \\
\hline Pu35-04 & $\mathrm{Ga}_{2} \mathrm{O}_{3}($ wt $\%)$ & 0.3818 & 0.3818 & 0.3600 & 0.0218 & 0.0218 & $6.0 \%$ & $6.0 \%$ \\
\hline Pu35-04 & $\mathrm{Gd}_{2} \mathrm{O}_{3}(\mathrm{wt} \%)$ & 11.7565 & 11.7565 & 11.6100 & 0.1465 & 0.1465 & $1.3 \%$ & $1.3 \%$ \\
\hline \begin{tabular}{|l|}
$\mathrm{Pu} 35-04$ \\
\end{tabular} & $\mathrm{HfO}_{2}(\mathrm{wt} \%)$ & 13.7388 & 13.7388 & 15.0000 & -1.2612 & -1.2612 & $-8.4 \%$ & $-8.4 \%$ \\
\hline Pu35-04 & $\mathrm{K}_{2} \mathrm{O}(\mathrm{wt} \%)$ & 0.4210 & 0.3680 & 0.4500 & -0.0290 & -0.0820 & $-6.4 \%$ & $-18.2 \%$ \\
\hline Pu35-04 & $\mathrm{La}_{2} \mathrm{O}_{3}(\mathrm{wt} \%)$ & 16.4192 & 16.4192 & 16.3400 & 0.0792 & 0.0792 & $0.5 \%$ & $0.5 \%$ \\
\hline \begin{tabular}{|l|}
$\mathrm{Pu} 35-04$ \\
\end{tabular} & $\mathrm{MgO}(\mathrm{wt} \%)$ & 0.9784 & 1.0047 & 1.0600 & -0.0816 & -0.0553 & $-7.7 \%$ & $-5.2 \%$ \\
\hline \begin{tabular}{|l|}
$\mathrm{Pu} 35-04$ \\
\end{tabular} & $\mathrm{Na}_{2} \mathrm{O}(\mathrm{wt} \%)$ & 0.6416 & 0.5862 & 0.5600 & 0.0816 & 0.0262 & $14.6 \%$ & $4.7 \%$ \\
\hline \begin{tabular}{|l|}
$\mathrm{Pu} 35-04$ \\
\end{tabular} & $\mathrm{Nd}_{2} \mathrm{O}_{3}(\mathrm{wt} \%)$ & 13.1803 & 13.1803 & 12.9000 & 0.2803 & 0.2803 & $2.2 \%$ & $2.2 \%$ \\
\hline Pu35-04 & $\mathrm{NiO}(\mathrm{wt} \%)$ & 0.0706 & 0.0809 & 0.0700 & 0.0006 & 0.0109 & $0.9 \%$ & $15.6 \%$ \\
\hline Pu35-04 & $\mathrm{PbO}(\mathrm{wt} \%)$ & 0.0916 & 0.0916 & 0.0800 & 0.0116 & 0.0116 & $14.5 \%$ & $14.5 \%$ \\
\hline Pu35-04 & $\mathrm{SeO}_{2}(\mathrm{wt} \%)$ & 0.0070 & 0.0070 & 0.0800 & -0.0730 & -0.0730 & $-91.2 \%$ & $-91.2 \%$ \\
\hline Pu35-04 & $\mathrm{Si}_{2} \mathrm{O}_{3}($ wt $\%)$ & 17.8097 & 17.5664 & 17.2000 & 0.6097 & 0.3664 & $3.5 \%$ & $2.1 \%$ \\
\hline Pu35-04 & $\mathrm{SO}_{4}(\mathrm{wt} \%)$ & 0.0749 & 0.0749 & 0.0000 & 0.0749 & 0.0749 & & \\
\hline Pu35-04 & $\mathrm{SrO}(\mathrm{wt} \%)$ & 2.2410 & 2.2410 & 2.1500 & 0.0910 & 0.0910 & $4.2 \%$ & $4.2 \%$ \\
\hline Pu35-04 & $\mathrm{Ta}_{2} \mathrm{O}_{5}(\mathrm{wt} \%)$ & 0.4249 & 0.4249 & 0.4600 & -0.0351 & -0.0351 & $-7.6 \%$ & $-7.6 \%$ \\
\hline Pu35-04 & Sum (wt \%) & 99.8936 & 99.2426 & 99.9600 & -0.0664 & -0.7174 & $-0.1 \%$ & $-0.7 \%$ \\
\hline Pu35-05 & $\mathrm{Al}_{2} \mathrm{O}_{3}(\mathrm{wt} \%)$ & 8.8901 & 8.7470 & 8.6000 & 0.2901 & 0.1470 & $3.4 \%$ & $1.7 \%$ \\
\hline $\mathrm{Pu} 35-05$ & $\mathrm{~B}_{2} \mathrm{O}_{3}(\mathrm{wt} \%)$ & 11.4789 & 11.2703 & 11.1800 & 0.2989 & 0.0903 & $2.7 \%$ & $0.8 \%$ \\
\hline Pu35-05 & $\mathrm{CaO}($ wt \%) & 0.2099 & 0.2062 & 0.1300 & 0.0799 & 0.0762 & $61.4 \%$ & $58.6 \%$ \\
\hline Pu35-05 & $\mathrm{Cl}(\mathrm{wt} \%)$ & 0.0430 & 0.0430 & 0.5800 & -0.5370 & -0.5370 & $-92.6 \%$ & $-92.6 \%$ \\
\hline Pu35-05 & $\mathrm{Cr}_{2} \mathrm{O}_{3}(\mathrm{wt} \%)$ & 0.5452 & 0.5492 & 0.6400 & -0.0948 & -0.0908 & $-14.8 \%$ & $-14.2 \%$ \\
\hline \begin{tabular}{|l|}
$\mathrm{Pu} 35-05$ \\
\end{tabular} & $\mathrm{CuO}(\mathrm{wt} \%)$ & 0.2666 & 0.2830 & 0.2900 & -0.0234 & -0.0070 & $-8.1 \%$ & $-2.4 \%$ \\
\hline \begin{tabular}{|l|}
$\mathrm{Pu} 35-05$ \\
\end{tabular} & $\mathrm{~F}(\mathrm{wt} \%)$ & 0.0000 & 0.0000 & 0.0000 & 0.0000 & 0.0000 & & \\
\hline Pu35-05 & $\mathrm{Fe}_{2} \mathrm{O}_{3}(\mathrm{wt} \%)$ & 1.1681 & 1.1768 & 1.3200 & -0.1519 & -0.1432 & $-11.5 \%$ & $-10.8 \%$ \\
\hline Pu35-05 & $\mathrm{Ga}_{2} \mathrm{O}_{3}(\mathrm{wt} \%)$ & 0.3179 & 0.3179 & 0.2900 & 0.0279 & 0.0279 & $9.6 \%$ & $9.6 \%$ \\
\hline Pu35-05 & $\mathrm{Gd}_{2} \mathrm{O}_{3}(\mathrm{wt} \%)$ & 11.6067 & 11.6067 & 11.6100 & -0.0033 & -0.0033 & $0.0 \%$ & $0.0 \%$ \\
\hline Pu35-05 & $\mathrm{HfO}_{2}(\mathrm{wt} \%)$ & 13.5030 & 13.5030 & 14.8500 & -1.3470 & -1.3470 & $-9.1 \%$ & $-9.1 \%$ \\
\hline Pu35-05 & $\mathrm{K}_{2} \mathrm{O}(\mathrm{wt} \%)$ & 0.6920 & 0.6049 & 0.7800 & -0.0880 & -0.1751 & $-11.3 \%$ & $-22.5 \%$ \\
\hline Pu35-05 & $\mathrm{La}_{2} \mathrm{O}_{3}(\mathrm{wt} \%)$ & 15.8914 & 15.8914 & 16.3400 & -0.4486 & -0.4486 & $-2.7 \%$ & $-2.7 \%$ \\
\hline Pu35-05 & $\mathrm{MgO}(\mathrm{wt} \%)$ & 0.4759 & 0.4887 & 0.5200 & -0.0441 & -0.0313 & $-8.5 \%$ & $-6.0 \%$ \\
\hline Pu35-05 & $\mathrm{Na}_{2} \mathrm{O}($ wt $\%)$ & 0.3828 & 0.3498 & 0.3500 & 0.0328 & -0.0002 & $9.4 \%$ & $-0.1 \%$ \\
\hline \begin{tabular}{|l|}
$\mathrm{Pu} 35-05$ \\
\end{tabular} & $\mathrm{Nd}_{2} \mathrm{O}_{3}(\mathrm{wt} \%)$ & 12.9470 & 12.9470 & 12.9000 & 0.0470 & 0.0470 & $0.4 \%$ & $0.4 \%$ \\
\hline $\mathrm{Pu} 35-05$ & $\mathrm{NiO}(\mathrm{wt} \%)$ & 0.0064 & 0.0073 & 0.0000 & 0.0064 & 0.0073 & & \\
\hline Pu35-05 & $\mathrm{PbO}(\mathrm{wt} \%)$ & 0.0899 & 0.0899 & 0.0700 & 0.0199 & 0.0199 & $28.5 \%$ & $28.5 \%$ \\
\hline Pu35-05 & $\mathrm{SeO}_{2}($ wt $\%)$ & 0.0070 & 0.0070 & 0.0000 & 0.0070 & 0.0070 & & \\
\hline Pu35-05 & $\mathrm{Si}_{2} \mathrm{O}_{3}($ wt $\%)$ & 17.4888 & 17.2499 & 17.2000 & 0.2888 & 0.0499 & $1.7 \%$ & $0.3 \%$ \\
\hline Pu35-05 & $\mathrm{SO}_{4}(\mathrm{wt} \%)$ & 0.0749 & 0.0749 & 0.0000 & 0.0749 & 0.0749 & & \\
\hline Pu35-05 & SrO (wt \%) & 2.2292 & 2.2292 & 2.1500 & 0.0792 & 0.0792 & $3.7 \%$ & $3.7 \%$ \\
\hline Pu35-05 & $\mathrm{Ta}_{2} \mathrm{O}_{5}(\mathrm{wt} \%)$ & 0.0971 & 0.0971 & 0.0900 & 0.0071 & 0.0071 & $7.9 \%$ & $7.9 \%$ \\
\hline Pu35-05 & Sum (wt \%) & 98.4119 & 97.7404 & 99.8900 & -1.4781 & -2.1496 & $-1.5 \%$ & $-2.2 \%$ \\
\hline
\end{tabular}


Table D5. Average Measured and Bias-Corrected Chemical Compositions Versus Targeted Compositions by Oxide by Study Glass (continued)

\begin{tabular}{|c|c|c|c|c|c|c|c|c|}
\hline Glass ID & Oxide & $\begin{array}{c}\text { Measured } \\
\text { (wt \%) }\end{array}$ & \begin{tabular}{|c|} 
Measured Bias- \\
Corrected (wt \%)
\end{tabular} & $\begin{array}{c}\text { Targeted } \\
\text { (wt \%) }\end{array}$ & $\begin{array}{c}\text { Diff of } \\
\text { Measured }\end{array}$ & $\begin{array}{c}\text { Diff of Meas } \\
\text { BC }\end{array}$ & $\begin{array}{l}\text { \% Diff of } \\
\text { Measured }\end{array}$ & $\begin{array}{c}\text { \% Diff of Meas } \\
\text { BC }\end{array}$ \\
\hline $\mathrm{Pu} 35-06$ & $\mathrm{Al}_{2} \mathrm{O}_{3}(\mathrm{wt} \%)$ & 9.0318 & 8.9204 & 8.6000 & 0.4318 & 0.3204 & $5.0 \%$ & $3.7 \%$ \\
\hline Pu35-06 & $\mathrm{B}_{2} \mathrm{O}_{3}(\mathrm{wt} \%)$ & 10.9638 & 11.2684 & 11.1800 & -0.2162 & 0.0884 & $-1.9 \%$ & $0.8 \%$ \\
\hline Pu35-06 & $\mathrm{CaO}(\mathrm{wt} \%)$ & 0.3848 & 0.3792 & 0.2900 & 0.0948 & 0.0892 & $32.7 \%$ & $30.8 \%$ \\
\hline Pu35-06 & $\mathrm{Cl}(\mathrm{wt} \%)$ & 0.0345 & 0.0345 & 0.6000 & -0.5655 & -0.5655 & $-94.3 \%$ & $-94.3 \%$ \\
\hline Pu35-06 & $\mathrm{Cr}_{2} \mathrm{O}_{3}(\mathrm{wt} \%)$ & 0.2163 & 0.2039 & 0.2200 & -0.0037 & -0.0161 & $-1.7 \%$ & $-7.3 \%$ \\
\hline Pu35-06 & $\mathrm{CuO}(\mathrm{wt} \%)$ & 0.0269 & 0.0279 & 0.0000 & 0.0269 & 0.0279 & & \\
\hline Pu35-06 & $\mathrm{F}(\mathrm{wt} \%)$ & 0.0830 & 0.1025 & 0.4800 & -0.3970 & -0.3775 & $-82.7 \%$ & $-78.7 \%$ \\
\hline Pu35-06 & $\mathrm{Fe}_{2} \mathrm{O}_{3}(\mathrm{wt} \%)$ & 0.9672 & 1.0061 & 0.9700 & -0.0028 & 0.0361 & $-0.3 \%$ & $3.7 \%$ \\
\hline $\mathrm{Pu} 35-06$ & $\mathrm{Ga}_{2} \mathrm{O}_{3}(\mathrm{wt} \%)$ & 0.0323 & 0.0323 & 0.0000 & 0.0323 & 0.0323 & & \\
\hline Pu35-06 & $\mathrm{Gd}_{2} \mathrm{O}_{3}(\mathrm{wt} \%)$ & 11.6413 & 11.6413 & 11.6100 & 0.0313 & 0.0313 & $0.3 \%$ & $0.3 \%$ \\
\hline Pu35-06 & $\mathrm{HfO}_{2}(\mathrm{wt} \%)$ & 13.5030 & 13.5030 & 14.8700 & -1.3670 & -1.3670 & $-9.2 \%$ & $-9.2 \%$ \\
\hline Pu35-06 & $\mathrm{K}_{2} \mathrm{O}(\mathrm{wt} \%)$ & 0.2277 & 0.1971 & 0.2700 & -0.0423 & -0.0729 & $-15.7 \%$ & $-27.0 \%$ \\
\hline \begin{tabular}{|l|} 
Pu35-06 \\
\end{tabular} & $\mathrm{La}_{2} \mathrm{O}_{3}(\mathrm{wt} \%)$ & 16.0087 & 16.0087 & 16.3400 & -0.3313 & -0.3313 & $-2.0 \%$ & $-2.0 \%$ \\
\hline Pu35-06 & $\mathrm{MgO}($ wt $\%)$ & 0.9477 & 0.8928 & 0.9100 & 0.0377 & -0.0172 & $4.1 \%$ & $-1.9 \%$ \\
\hline Pu35-06 & $\mathrm{Na}_{2} \mathrm{O}($ wt $\%)$ & 0.7886 & 0.7208 & 0.8000 & -0.0114 & -0.0792 & $-1.4 \%$ & $-9.9 \%$ \\
\hline \begin{tabular}{|l|} 
Pu35-06 \\
\end{tabular} & $\mathrm{Nd}_{2} \mathrm{O}_{3}(\mathrm{wt} \%)$ & 13.0054 & 13.0054 & 12.9000 & 0.1054 & 0.1054 & $0.8 \%$ & $0.8 \%$ \\
\hline Pu35-06 & $\mathrm{NiO}($ wt \%) & 0.2570 & 0.2755 & 0.2800 & -0.0230 & -0.0045 & $-8.2 \%$ & $-1.6 \%$ \\
\hline Pu35-06 & $\mathrm{PbO}(\mathrm{wt} \%)$ & 0.0393 & 0.0393 & 0.0000 & 0.0393 & 0.0393 & & \\
\hline Pu35-06 & $\mathrm{SeO}_{2}(\mathrm{wt} \%)$ & 0.0070 & 0.0070 & 0.0000 & 0.0070 & 0.0070 & & \\
\hline Pu35-06 & $\mathrm{Si}_{2} \mathrm{O}_{3}($ wt $\%)$ & 17.4032 & 17.5339 & 17.2000 & 0.2032 & 0.3339 & $1.2 \%$ & $1.9 \%$ \\
\hline \begin{tabular}{|l|}
$\mathrm{Pu} 35-06$ \\
\end{tabular} & $\mathrm{SO}_{4}(\mathrm{wt} \%)$ & 0.0749 & 0.0749 & 0.1700 & -0.0951 & -0.0951 & $-55.9 \%$ & $-55.9 \%$ \\
\hline Pu35-06 & $\mathrm{SrO}(\mathrm{wt} \%)$ & 2.2765 & 2.2765 & 2.1500 & 0.1265 & 0.1265 & $5.9 \%$ & $5.9 \%$ \\
\hline Pu35-06 & $\mathrm{Ta}_{2} \mathrm{O}_{5}(\mathrm{wt} \%)$ & 0.1105 & 0.1105 & 0.1000 & 0.0105 & 0.0105 & $10.5 \%$ & $10.5 \%$ \\
\hline Pu35-06 & Sum (wt \%) & 98.0313 & 98.2618 & 99.9400 & -1.9087 & -1.6782 & $-1.9 \%$ & $-1.7 \%$ \\
\hline \begin{tabular}{|l|}
$\mathrm{Pu} 35-07$ \\
\end{tabular} & $\mathrm{Al}_{2} \mathrm{O}_{3}(\mathrm{wt} \%)$ & 9.0224 & 8.9111 & 8.6000 & 0.4224 & 0.3111 & $4.9 \%$ & $3.6 \%$ \\
\hline \begin{tabular}{|l|} 
Pu35-07 \\
\end{tabular} & $\mathrm{B}_{2} \mathrm{O}_{3}(\mathrm{wt} \%)$ & 10.9799 & 11.2849 & 11.1800 & -0.2001 & 0.1049 & $-1.8 \%$ & $0.9 \%$ \\
\hline Pu35-07 & $\mathrm{CaO}($ wt \%) & 0.2917 & 0.2875 & 0.2000 & 0.0917 & 0.0875 & $45.9 \%$ & $43.8 \%$ \\
\hline \begin{tabular}{|l|}
$\mathrm{Pu} 35-07$ \\
\end{tabular} & $\mathrm{Cl}(\mathrm{wt} \%)$ & 0.0520 & 0.0520 & 0.6200 & -0.5680 & -0.5680 & $-91.6 \%$ & $-91.6 \%$ \\
\hline \begin{tabular}{|l|}
$\mathrm{Pu} 35-07$ \\
\end{tabular} & $\mathrm{Cr}_{2} \mathrm{O}_{3}(\mathrm{wt} \%)$ & 0.1323 & 0.1247 & 0.1300 & 0.0023 & -0.0053 & $1.7 \%$ & $-4.1 \%$ \\
\hline Pu35-07 & $\mathrm{CuO}(\mathrm{wt} \%)$ & 0.1790 & 0.1855 & 0.1600 & 0.0190 & 0.0255 & $11.9 \%$ & $15.9 \%$ \\
\hline \begin{tabular}{|l|}
$\mathrm{Pu} 35-07$ \\
\end{tabular} & $\mathrm{~F}(\mathrm{wt} \%)$ & 0.0455 & 0.0562 & 0.1900 & -0.1445 & -0.1338 & $-76.1 \%$ & $-70.4 \%$ \\
\hline Pu35-07 & $\mathrm{Fe}_{2} \mathrm{O}_{3}(\mathrm{wt} \%)$ & 0.1187 & 0.1234 & 0.0900 & 0.0287 & 0.0334 & $31.9 \%$ & $37.1 \%$ \\
\hline \begin{tabular}{|l|}
$\mathrm{Pu} 35-07$ \\
\end{tabular} & $\mathrm{Ga}_{2} \mathrm{O}_{3}($ wt $\%)$ & 0.1122 & 0.1122 & 0.0800 & 0.0322 & 0.0322 & $40.3 \%$ & $40.3 \%$ \\
\hline \begin{tabular}{|l|}
$\mathrm{Pu} 35-07$ \\
\end{tabular} & $\mathrm{Gd}_{2} \mathrm{O}_{3}(\mathrm{wt} \%)$ & 11.6989 & 11.6989 & 11.6100 & 0.0889 & 0.0889 & $0.8 \%$ & $0.8 \%$ \\
\hline Pu35-07 & $\mathrm{HfO}_{2}(\mathrm{wt} \%)$ & 13.9747 & 13.9747 & 14.9600 & -0.9853 & -0.9853 & $-6.6 \%$ & $-6.6 \%$ \\
\hline \begin{tabular}{|l|}
$\mathrm{Pu} 35-07$ \\
\end{tabular} & $\mathrm{~K}_{2} \mathrm{O}(\mathrm{wt} \%)$ & 0.3969 & 0.3437 & 0.4200 & -0.0231 & -0.0763 & $-5.5 \%$ & $-18.2 \%$ \\
\hline \begin{tabular}{|l|}
$\mathrm{Pu} 35-07$ \\
\end{tabular} & $\mathrm{La}_{2} \mathrm{O}_{3}(\mathrm{wt} \%)$ & 16.1260 & 16.1260 & 16.3400 & -0.2140 & -0.2140 & $-1.3 \%$ & $-1.3 \%$ \\
\hline Pu35-07 & $\mathrm{MgO}($ wt $\%)$ & 0.5572 & 0.5249 & 0.5400 & 0.0172 & -0.0151 & $3.2 \%$ & $-2.8 \%$ \\
\hline Pu35-07 & $\mathrm{Na}_{2} \mathrm{O}($ wt $\%)$ & 0.6363 & 0.5816 & 0.6100 & 0.0263 & -0.0284 & $4.3 \%$ & $-4.7 \%$ \\
\hline \begin{tabular}{|l|}
$\mathrm{Pu} 35-07$ \\
\end{tabular} & $\mathrm{Nd}_{2} \mathrm{O}_{3}(\mathrm{wt} \%)$ & 13.0637 & 13.0637 & 12.9000 & 0.1637 & 0.1637 & $1.3 \%$ & $1.3 \%$ \\
\hline \begin{tabular}{|l|}
$\mathrm{Pu} 35-07$ \\
\end{tabular} & $\mathrm{NiO}($ wt \%) & 0.3576 & 0.3832 & 0.3700 & -0.0124 & 0.0132 & $-3.4 \%$ & $3.6 \%$ \\
\hline Pu35-07 & $\mathrm{PbO}$ (wt \%) & 0.0883 & 0.0883 & 0.0600 & 0.0283 & 0.0283 & $47.2 \%$ & $47.2 \%$ \\
\hline Pu35-07 & $\mathrm{SeO}_{2}($ wt $\%)$ & 0.0070 & 0.0070 & 0.0000 & 0.0070 & 0.0070 & & \\
\hline Pu35-07 & $\mathrm{Si}_{2} \mathrm{O}_{3}($ wt $\%)$ & 17.5316 & 17.6632 & 17.2000 & 0.3316 & 0.4632 & $1.9 \%$ & $2.7 \%$ \\
\hline Pu35-07 & $\mathrm{SO}_{4}(\mathrm{wt} \%)$ & 0.0749 & 0.0749 & 0.1700 & -0.0951 & -0.0951 & $-55.9 \%$ & $-55.9 \%$ \\
\hline Pu35-07 & SrO (wt \%) & 2.2824 & 2.2824 & 2.1500 & 0.1324 & 0.1324 & $6.2 \%$ & $6.2 \%$ \\
\hline Pu35-07 & $\mathrm{Ta}_{2} \mathrm{O}_{5}(\mathrm{wt} \%)$ & 1.2912 & 1.2912 & 1.3000 & -0.0088 & -0.0088 & $-0.7 \%$ & $-0.7 \%$ \\
\hline Pu35-07 & Sum (wt \%) & 99.0203 & 99.2413 & 99.8800 & -0.8597 & -0.6387 & $-0.9 \%$ & $-0.6 \%$ \\
\hline Pu35-08 & $\mathrm{Al}_{2} \mathrm{O}_{3}(\mathrm{wt} \%)$ & 9.0035 & 8.8924 & 8.6000 & 0.4035 & 0.2924 & $4.7 \%$ & $3.4 \%$ \\
\hline \begin{tabular}{|l|}
$\mathrm{Pu} 35-08$ \\
\end{tabular} & $\mathrm{~B}_{2} \mathrm{O}_{3}(\mathrm{wt} \%)$ & 11.0604 & 11.3676 & 11.1800 & -0.1196 & 0.1876 & $-1.1 \%$ & $1.7 \%$ \\
\hline Pu35-08 & $\mathrm{CaO}($ wt \%) & 0.3519 & 0.3468 & 0.2400 & 0.1119 & 0.1068 & $46.6 \%$ & $44.5 \%$ \\
\hline Pu35-08 & $\mathrm{Cl}(\mathrm{wt} \%)$ & 0.0460 & 0.0460 & 0.6200 & -0.5740 & -0.5740 & $-92.6 \%$ & $-92.6 \%$ \\
\hline Pu35-08 & $\mathrm{Cr}_{2} \mathrm{O}_{3}($ wt $\%)$ & 0.0950 & 0.0895 & 0.0900 & 0.0050 & -0.0005 & $5.6 \%$ & $-0.5 \%$ \\
\hline Pu35-08 & $\mathrm{CuO}(\mathrm{wt} \%)$ & 0.1008 & 0.1044 & 0.0700 & 0.0308 & 0.0344 & $44.0 \%$ & $49.1 \%$ \\
\hline \begin{tabular}{|l|}
$\mathrm{Pu} 35-08$ \\
\end{tabular} & $\mathrm{~F}(\mathrm{wt} \%)$ & 0.0710 & 0.0877 & 0.3000 & -0.2290 & -0.2123 & $-76.3 \%$ & $-70.8 \%$ \\
\hline Pu35-08 & $\mathrm{Fe}_{2} \mathrm{O}_{3}(\mathrm{wt} \%)$ & 0.9586 & 0.9971 & 0.8900 & 0.0686 & 0.1071 & $7.7 \%$ & $12.0 \%$ \\
\hline Pu35-08 & $\mathrm{Ga}_{2} \mathrm{O}_{3}(\mathrm{wt} \%)$ & 0.2070 & 0.2070 & 0.1600 & 0.0470 & 0.0470 & $29.4 \%$ & $29.4 \%$ \\
\hline Pu35-08 & $\mathrm{Gd}_{2} \mathrm{O}_{3}(\mathrm{wt} \%)$ & 11.6989 & 11.6989 & 11.6100 & 0.0889 & 0.0889 & $0.8 \%$ & $0.8 \%$ \\
\hline
\end{tabular}


Table D5. Average Measured and Bias-Corrected Chemical Compositions Versus Targeted Compositions by Oxide by Study Glass (continued)

\begin{tabular}{|c|c|c|c|c|c|c|c|c|}
\hline Glass ID & Oxide & $\begin{array}{c}\text { Measured } \\
(\mathrm{wt} \%)\end{array}$ & \begin{tabular}{|c|} 
Measured Bias- \\
Corrected (wt \%)
\end{tabular} & $\begin{array}{c}\text { Targeted } \\
\text { (wt \%) }\end{array}$ & $\begin{array}{c}\text { Diff of } \\
\text { Measured }\end{array}$ & $\begin{array}{c}\text { Diff of Meas } \\
\text { BC }\end{array}$ & $\begin{array}{l}\text { \% Diff of } \\
\text { Measured }\end{array}$ & $\begin{array}{c}\text { \% Diff of Meas } \\
\text { BC }\end{array}$ \\
\hline Pu35-08 & $\mathrm{HfO}_{2}(\mathrm{wt} \%)$ & 13.3851 & \begin{tabular}{|l|}
13.3851 \\
\end{tabular} & 14.9500 & -1.5649 & -1.5649 & $-10.5 \%$ & $-10.5 \%$ \\
\hline \begin{tabular}{|l|} 
Pu35-08 \\
\end{tabular} & $\mathrm{K}_{2} \mathrm{O}(\mathrm{wt} \%)$ & 0.6872 & 0.5950 & 0.7700 & -0.0828 & -0.1750 & $-10.8 \%$ & $-22.7 \%$ \\
\hline Pu35-08 & $\mathrm{La}_{2} \mathrm{O}_{3}(\mathrm{wt} \%)$ & 16.3019 & 16.3019 & 16.3400 & -0.0381 & -0.0381 & $-0.2 \%$ & $-0.2 \%$ \\
\hline Pu35-08 & $\mathrm{MgO}(\mathrm{wt} \%)$ & 0.8631 & 0.8131 & 0.8800 & -0.0169 & -0.0669 & $-1.9 \%$ & $-7.6 \%$ \\
\hline Pu35-08 & $\mathrm{Na}_{2} \mathrm{O}(\mathrm{wt} \%)$ & 0.4428 & 0.4048 & 0.4000 & 0.0428 & 0.0048 & $10.7 \%$ & $1.2 \%$ \\
\hline Pu35-08 & $\mathrm{Nd}_{2} \mathrm{O}_{3}(\mathrm{wt} \%)$ & 13.1803 & 13.1803 & 12.9000 & 0.2803 & 0.2803 & $2.2 \%$ & $2.2 \%$ \\
\hline Pu35-08 & $\mathrm{NiO}(\mathrm{wt} \%)$ & 0.2341 & 0.2509 & 0.2500 & -0.0159 & 0.0009 & $-6.3 \%$ & $0.4 \%$ \\
\hline Pu35-08 & $\mathrm{PbO}(\mathrm{wt} \%)$ & 0.0452 & 0.0452 & 0.0000 & 0.0452 & 0.0452 & & \\
\hline Pu35-08 & $\mathrm{SeO}_{2}(\mathrm{wt} \%)$ & 0.0070 & 0.0070 & 0.0000 & 0.0070 & 0.0070 & & \\
\hline Pu35-08 & $\mathrm{Si}_{2} \mathrm{O}_{3}(\mathrm{wt} \%)$ & 17.3497 & 17.4800 & 17.2000 & 0.1497 & 0.2800 & $0.9 \%$ & $1.6 \%$ \\
\hline Pu35-08 & $\mathrm{SO}_{4}(\mathrm{wt} \%)$ & 0.0749 & 0.0749 & 0.0000 & 0.0749 & 0.0749 & & \\
\hline \begin{tabular}{|l|} 
Pu35-08 \\
\end{tabular} & $\mathrm{SrO}(\mathrm{wt} \%)$ & 2.2588 & 2.2588 & 2.1500 & 0.1088 & 0.1088 & $5.1 \%$ & $5.1 \%$ \\
\hline \begin{tabular}{|l|} 
Pu35-08 \\
\end{tabular} & $\mathrm{Ta}_{2} \mathrm{O}_{5}(\mathrm{wt} \%)$ & 0.3846 & 0.3846 & 0.3900 & -0.0054 & -0.0054 & $-1.4 \%$ & $-1.4 \%$ \\
\hline Pu35-08 & Sum (wt \%) & 98.8079 & 99.0192 & 99.9900 & -1.1821 & -0.9708 & $-1.2 \%$ & $-1.0 \%$ \\
\hline Pu35-09 & $\mathrm{Al}_{2} \mathrm{O}_{3}(\mathrm{wt} \%)$ & 9.0318 & 8.9204 & 8.6000 & 0.4318 & 0.3204 & $5.0 \%$ & $3.7 \%$ \\
\hline \begin{tabular}{|l|} 
Pu35-09 \\
\end{tabular} & $\mathrm{B}_{2} \mathrm{O}_{3}(\mathrm{wt} \%)$ & 11.0926 & 11.4007 & 11.1800 & -0.0874 & 0.2207 & $-0.8 \%$ & $2.0 \%$ \\
\hline Pu35-09 & $\mathrm{CaO}($ wt \%) & 0.1812 & 0.1786 & 0.1000 & 0.0812 & 0.0786 & $81.2 \%$ & $78.6 \%$ \\
\hline Pu35-09 & $\mathrm{Cl}(\mathrm{wt} \%)$ & 0.0490 & 0.0490 & 0.6400 & -0.5910 & -0.5910 & $-92.3 \%$ & $-92.3 \%$ \\
\hline Pu35-09 & $\mathrm{Cr}_{2} \mathrm{O}_{3}(\mathrm{wt} \%)$ & 0.0877 & 0.0827 & 0.0800 & 0.0077 & 0.0027 & $9.6 \%$ & $3.3 \%$ \\
\hline Pu35-09 & $\mathrm{CuO}(\mathrm{wt} \%)$ & 0.2166 & 0.2244 & 0.2500 & -0.0334 & -0.0256 & $-13.4 \%$ & $-10.3 \%$ \\
\hline \begin{tabular}{|l|} 
Pu35-09 \\
\end{tabular} & $\mathrm{F}(\mathrm{wt} \%)$ & 0.0000 & 0.0000 & 0.0000 & 0.0000 & 0.0000 & & \\
\hline Pu35-09 & $\mathrm{Fe}_{2} \mathrm{O}_{3}(\mathrm{wt} \%)$ & 0.0386 & 0.0402 & 0.0000 & 0.0386 & 0.0402 & & \\
\hline Pu35-09 & $\mathrm{Ga}_{2} \mathrm{O}_{3}(\mathrm{wt} \%)$ & 0.1694 & 0.1694 & 0.1300 & 0.0394 & 0.0394 & $30.3 \%$ & $30.3 \%$ \\
\hline Pu35-09 & $\mathrm{Gd}_{2} \mathrm{O}_{3}(\mathrm{wt} \%)$ & 11.6413 & 11.6413 & 11.6100 & 0.0313 & 0.0313 & $0.3 \%$ & $0.3 \%$ \\
\hline Pu35-09 & $\mathrm{HfO}_{2}(\mathrm{wt} \%)$ & 13.3261 & 13.3261 & 14.9200 & -1.5939 & -1.5939 & $-10.7 \%$ & $-10.7 \%$ \\
\hline \begin{tabular}{|l|} 
Pu35-09 \\
\end{tabular} & $\mathrm{K}_{2} \mathrm{O}(\mathrm{wt} \%)$ & 1.1679 & 1.0111 & 1.5400 & -0.3721 & -0.5289 & $-24.2 \%$ & $-34.3 \%$ \\
\hline Pu35-09 & $\mathrm{La}_{2} \mathrm{O}_{3}(\mathrm{wt} \%)$ & 16.1260 & 16.1260 & 16.3400 & -0.2140 & -0.2140 & $-1.3 \%$ & $-1.3 \%$ \\
\hline Pu35-09 & $\mathrm{MgO}(\mathrm{wt} \%)$ & 0.5497 & 0.5179 & 0.5300 & 0.0197 & -0.0121 & $3.7 \%$ & $-2.3 \%$ \\
\hline Pu35-09 & $\mathrm{Na}_{2} \mathrm{O}($ wt $\%)$ & 1.1310 & 1.0338 & 1.1300 & 0.0010 & -0.0962 & $0.1 \%$ & $-8.5 \%$ \\
\hline Pu35-09 & $\mathrm{Nd}_{2} \mathrm{O}_{3}(\mathrm{wt} \%)$ & 13.0637 & 13.0637 & 12.9000 & 0.1637 & 0.1637 & $1.3 \%$ & $1.3 \%$ \\
\hline \begin{tabular}{|l|} 
Pu35-09 \\
\end{tabular} & $\mathrm{NiO}($ wt \%) & 0.1718 & 0.1841 & 0.1900 & -0.0182 & -0.0059 & $-9.6 \%$ & $-3.1 \%$ \\
\hline \begin{tabular}{|l|}
$\mathrm{Pu} 35-09$ \\
\end{tabular} & $\mathrm{PbO}(\mathrm{wt} \%)$ & 0.0926 & 0.0926 & 0.0800 & 0.0126 & 0.0126 & $15.8 \%$ & $15.8 \%$ \\
\hline Pu35-09 & $\mathrm{SeO}_{2}($ wt $\%)$ & 0.0070 & 0.0070 & 0.0800 & -0.0730 & -0.0730 & $-91.2 \%$ & $-91.2 \%$ \\
\hline Pu35-09 & $\mathrm{Si}_{2} \mathrm{O}_{3}($ wt $\%)$ & 17.6278 & 17.7602 & 17.2000 & 0.4278 & 0.5602 & $2.5 \%$ & $3.3 \%$ \\
\hline Pu35-09 & $\mathrm{SO}_{4}(\mathrm{wt} \%)$ & 0.0749 & 0.0749 & 0.1700 & -0.0951 & -0.0951 & $-55.9 \%$ & $-55.9 \%$ \\
\hline Pu35-09 & $\mathrm{SrO}(\mathrm{wt} \%)$ & 2.2706 & 2.2706 & 2.1500 & 0.1206 & 0.1206 & $5.6 \%$ & $5.6 \%$ \\
\hline Pu35-09 & $\mathrm{Ta}_{2} \mathrm{O}_{5}(\mathrm{wt} \%)$ & 0.1166 & 0.1166 & 0.1100 & 0.0066 & 0.0066 & $6.0 \%$ & $6.0 \%$ \\
\hline Pu35-09 & Sum (wt \%) & 98.2338 & 98.2912 & 99.9300 & -1.6962 & -1.6388 & $-1.7 \%$ & $-1.6 \%$ \\
\hline Pu35-10 & $\mathrm{Al}_{2} \mathrm{O}_{3}(\mathrm{wt} \%)$ & 9.0129 & 8.9018 & 8.6000 & 0.4129 & 0.3018 & $4.8 \%$ & $3.5 \%$ \\
\hline Pu35-10 & $\mathrm{B}_{2} \mathrm{O}_{3}(\mathrm{wt} \%)$ & 11.1087 & 11.4173 & 11.1800 & -0.0713 & 0.2373 & $-0.6 \%$ & $2.1 \%$ \\
\hline Pu35-10 & $\mathrm{CaO}($ wt \%) & 0.1497 & 0.1476 & 0.0800 & 0.0697 & 0.0676 & $87.1 \%$ & $84.4 \%$ \\
\hline \begin{tabular}{|l|} 
Pu35-10 \\
\end{tabular} & $\mathrm{Cl}(\mathrm{wt} \%)$ & 0.0505 & 0.0505 & 0.6500 & -0.5995 & -0.5995 & $-92.2 \%$ & $-92.2 \%$ \\
\hline Pu35-10 & $\mathrm{Cr}_{2} \mathrm{O}_{3}(\mathrm{wt} \%)$ & 0.0862 & 0.0813 & 0.0800 & 0.0062 & 0.0013 & $7.8 \%$ & $1.6 \%$ \\
\hline Pu35-10 & $\mathrm{CuO}(\mathrm{wt} \%)$ & 0.0920 & 0.0953 & 0.0700 & 0.0220 & 0.0253 & $31.4 \%$ & $36.2 \%$ \\
\hline Pu35-10 & $\mathrm{F}(\mathrm{wt} \%)$ & 0.0655 & 0.0809 & 0.3800 & -0.3145 & -0.2991 & $-82.8 \%$ & $-78.7 \%$ \\
\hline Pu35-10 & $\mathrm{Fe}_{2} \mathrm{O}_{3}(\mathrm{wt} \%)$ & 0.5926 & 0.6164 & 0.5900 & 0.0026 & 0.0264 & $0.4 \%$ & $4.5 \%$ \\
\hline Pu35-10 & $\mathrm{Ga}_{2} \mathrm{O}_{3}(\mathrm{wt} \%)$ & 0.7400 & 0.7400 & 0.7100 & 0.0300 & 0.0300 & $4.2 \%$ & $4.2 \%$ \\
\hline Pu35-10 & $\mathrm{Gd}_{2} \mathrm{O}_{3}(\mathrm{wt} \%)$ & 11.6989 & 11.6989 & 11.6100 & 0.0889 & 0.0889 & $0.8 \%$ & $0.8 \%$ \\
\hline Pu35-10 & $\mathrm{HfO}_{2}(\mathrm{wt} \%)$ & 13.3851 & 13.3851 & 14.9000 & -1.5149 & -1.5149 & $-10.2 \%$ & $-10.2 \%$ \\
\hline Pu35-10 & $\mathrm{K}_{2} \mathrm{O}(\mathrm{wt} \%)$ & 0.3162 & 0.2738 & 0.3600 & -0.0438 & -0.0862 & $-12.2 \%$ & $-24.0 \%$ \\
\hline Pu35-10 & $\mathrm{La}_{2} \mathrm{O}_{3}(\mathrm{wt} \%)$ & 16.0674 & 16.0674 & 16.3400 & -0.2726 & -0.2726 & $-1.7 \%$ & $-1.7 \%$ \\
\hline Pu35-10 & $\mathrm{MgO}(\mathrm{wt} \%)$ & 0.8300 & 0.7819 & 0.8100 & 0.0200 & -0.0281 & $2.5 \%$ & $-3.5 \%$ \\
\hline Pu35-10 & $\mathrm{Na}_{2} \mathrm{O}$ (wt \%) & 0.6807 & 0.6222 & 0.6700 & 0.0107 & -0.0478 & $1.6 \%$ & $-7.1 \%$ \\
\hline Pu35-10 & $\mathrm{Nd}_{2} \mathrm{O}_{3}(\mathrm{wt} \%)$ & 13.0637 & 13.0637 & 12.9000 & 0.1637 & 0.1637 & $1.3 \%$ & $1.3 \%$ \\
\hline \begin{tabular}{|l|} 
Pu35-10 \\
\end{tabular} & $\mathrm{NiO}(\mathrm{wt} \%)$ & 0.0687 & 0.0736 & 0.0700 & -0.0013 & 0.0036 & $-1.8 \%$ & $5.2 \%$ \\
\hline Pu35-10 & $\mathrm{PbO}(\mathrm{wt} \%)$ & 0.0829 & 0.0829 & 0.0600 & 0.0229 & 0.0229 & $38.2 \%$ & $38.2 \%$ \\
\hline Pu35-10 & $\mathrm{SeO}_{2}($ wt $\%)$ & 0.0070 & 0.0070 & 0.0800 & -0.0730 & -0.0730 & $-91.2 \%$ & $-91.2 \%$ \\
\hline Pu35-10 & $\mathrm{Si}_{2} \mathrm{O}_{3}(\mathrm{wt} \%)$ & 17.6064 & 17.7387 & 17.2000 & 0.4064 & 0.5387 & $2.4 \%$ & $3.1 \%$ \\
\hline
\end{tabular}


Table D5. Average Measured and Bias-Corrected Chemical Compositions Versus Targeted Compositions by Oxide by Study Glass (continued)

\begin{tabular}{|c|c|c|c|c|c|c|c|c|}
\hline Glass ID & Oxide & $\begin{array}{c}\text { Measured } \\
(\mathrm{wt} \%)\end{array}$ & \begin{tabular}{|c|} 
Measured Bias- \\
Corrected (wt \%)
\end{tabular} & $\begin{array}{c}\text { Targeted } \\
\text { (wt \%) }\end{array}$ & $\begin{array}{c}\text { Diff of } \\
\text { Measured }\end{array}$ & $\begin{array}{c}\text { Diff of Meas } \\
\text { BC }\end{array}$ & $\begin{array}{l}\text { \% Diff of } \\
\text { Measured }\end{array}$ & $\begin{array}{c}\text { \% Diff of Meas } \\
\text { BC }\end{array}$ \\
\hline Pu35-10 & $\mathrm{SO}_{4}(\mathrm{wt} \%)$ & 0.0749 & \begin{tabular}{|l|}
0.0749 \\
\end{tabular} & 0.1700 & -0.0951 & -0.0951 & $-55.9 \%$ & $-55.9 \%$ \\
\hline Pu35-10 & $\mathrm{SrO}($ wt $\%)$ & 2.2588 & 2.2588 & 2.1500 & 0.1088 & 0.1088 & $5.1 \%$ & $5.1 \%$ \\
\hline Pu35-10 & $\mathrm{Ta}_{2} \mathrm{O}_{5}(\mathrm{wt} \%)$ & 0.2705 & 0.2705 & 0.2700 & 0.0005 & 0.0005 & $0.2 \%$ & $0.2 \%$ \\
\hline Pu35-10 & Sum (wt \%) & 98.3093 & 98.5303 & 99.9300 & -1.6207 & -1.3997 & $-1.6 \%$ & $-1.4 \%$ \\
\hline Pu35-11 & $\mathrm{Al}_{2} \mathrm{O}_{3}(\mathrm{wt} \%)$ & 8.9940 & 8.8831 & 8.6000 & 0.3940 & 0.2831 & $4.6 \%$ & $3.3 \%$ \\
\hline Pu35-11 & $\mathrm{B}_{2} \mathrm{O}_{3}(\mathrm{wt} \%)$ & 11.1409 & 11.4504 & 11.1800 & -0.0391 & 0.2704 & $-0.4 \%$ & $2.4 \%$ \\
\hline Pu35-11 & $\mathrm{CaO}(\mathrm{wt} \%)$ & 0.5030 & 0.4958 & 0.4000 & 0.1030 & 0.0958 & $25.8 \%$ & $23.9 \%$ \\
\hline Pu35-11 & $\mathrm{Cl}(\mathrm{wt} \%)$ & 0.0470 & 0.0470 & 0.6900 & -0.6430 & -0.6430 & $-93.2 \%$ & $-93.2 \%$ \\
\hline Pu35-11 & $\mathrm{Cr}_{2} \mathrm{O}_{3}(\mathrm{wt} \%)$ & 0.3881 & 0.3658 & 0.4000 & -0.0119 & -0.0342 & $-3.0 \%$ & $-8.6 \%$ \\
\hline \begin{tabular}{|l|}
$\mathrm{Pu} 35-11$ \\
\end{tabular} & $\mathrm{CuO}(\mathrm{wt} \%)$ & 0.0388 & 0.0402 & 0.0000 & 0.0388 & 0.0402 & & \\
\hline \begin{tabular}{|l|}
$\mathrm{Pu} 35-11$ \\
\end{tabular} & $\mathrm{~F}(\mathrm{wt} \%)$ & 0.0125 & 0.0154 & 0.0600 & -0.0475 & -0.0446 & $-79.2 \%$ & $-74.3 \%$ \\
\hline \begin{tabular}{|l|} 
Pu35-11 \\
\end{tabular} & $\mathrm{Fe}_{2} \mathrm{O}_{3}(\mathrm{wt} \%)$ & 0.1101 & 0.1145 & 0.0800 & 0.0301 & 0.0345 & $37.6 \%$ & $43.1 \%$ \\
\hline \begin{tabular}{|l|} 
Pu35-11 \\
\end{tabular} & $\mathrm{Ga}_{2} \mathrm{O}_{3}(\mathrm{wt} \%)$ & 0.2473 & 0.2473 & 0.2100 & 0.0373 & 0.0373 & $17.8 \%$ & $17.8 \%$ \\
\hline Pu35-11 & $\mathrm{Gd}_{2} \mathrm{O}_{3}(\mathrm{wt} \%)$ & 11.6413 & 11.6413 & 11.6100 & 0.0313 & 0.0313 & $0.3 \%$ & $0.3 \%$ \\
\hline Pu35-11 & $\mathrm{HfO}_{2}(\mathrm{wt} \%)$ & 13.9157 & 13.9157 & 14.8700 & -0.9543 & -0.9543 & $-6.4 \%$ & $-6.4 \%$ \\
\hline \begin{tabular}{|l|}
$\mathrm{Pu} 35-11$ \\
\end{tabular} & $\mathrm{~K}_{2} \mathrm{O}(\mathrm{wt} \%)$ & 0.3114 & 0.2696 & 0.3800 & -0.0686 & -0.1104 & $-18.1 \%$ & $-29.1 \%$ \\
\hline Pu35-11 & $\mathrm{La}_{2} \mathrm{O}_{3}(\mathrm{wt} \%)$ & 15.9501 & 15.9501 & 16.3400 & -0.3899 & -0.3899 & $-2.4 \%$ & $-2.4 \%$ \\
\hline Pu35-11 & $\mathrm{MgO}($ wt $\%)$ & 1.0091 & 0.9506 & 0.9900 & 0.0191 & -0.0394 & $1.9 \%$ & $-4.0 \%$ \\
\hline Pu35-11 & $\mathrm{Na}_{2} \mathrm{O}(\mathrm{wt} \%)$ & 0.6962 & 0.6364 & 0.6900 & 0.0062 & -0.0536 & $0.9 \%$ & $-7.8 \%$ \\
\hline Pu35-11 & $\mathrm{Nd}_{2} \mathrm{O}_{3}(\mathrm{wt} \%)$ & 13.0054 & 13.0054 & 12.9000 & 0.1054 & 0.1054 & $0.8 \%$ & $0.8 \%$ \\
\hline \begin{tabular}{|l|}
$\mathrm{Pu} 35-11$ \\
\end{tabular} & $\mathrm{NiO}($ wt \%) & 0.1597 & 0.1712 & 0.1700 & -0.0103 & 0.0012 & $-6.1 \%$ & $0.7 \%$ \\
\hline Pu35-11 & $\mathrm{PbO}(\mathrm{wt} \%)$ & 0.0889 & 0.0889 & 0.0700 & 0.0189 & 0.0189 & $27.0 \%$ & $27.0 \%$ \\
\hline \begin{tabular}{|l|}
$\mathrm{Pu} 35-11$ \\
\end{tabular} & $\mathrm{SeO}_{2}(\mathrm{wt} \%)$ & 0.0070 & 0.0070 & 0.0800 & -0.0730 & -0.0730 & $-91.2 \%$ & $-91.2 \%$ \\
\hline Pu35-11 & $\mathrm{Si}_{2} \mathrm{O}_{3}($ wt $\%)$ & 17.6492 & 17.7818 & 17.2000 & 0.4492 & 0.5818 & $2.6 \%$ & $3.4 \%$ \\
\hline \begin{tabular}{|l|}
$\mathrm{Pu} 35-11$ \\
\end{tabular} & $\mathrm{SO}_{4}(\mathrm{wt} \%)$ & 0.0749 & 0.0749 & 0.1700 & -0.0951 & -0.0951 & $-55.9 \%$ & $-55.9 \%$ \\
\hline Pu35-11 & SrO (wt \%) & 2.2706 & 2.2706 & 2.1500 & 0.1206 & 0.1206 & $5.6 \%$ & $5.6 \%$ \\
\hline Pu35-11 & $\mathrm{Ta}_{2} \mathrm{O}_{5}(\mathrm{wt} \%)$ & 0.6941 & 0.6941 & 0.6900 & 0.0041 & 0.0041 & $0.6 \%$ & $0.6 \%$ \\
\hline Pu35-11 & Sum (wt \%) & 98.9553 & 99.1170 & 99.9300 & -0.9747 & -0.8130 & $-1.0 \%$ & $-0.8 \%$ \\
\hline Pu35-12 & $\mathrm{Al}_{2} \mathrm{O}_{3}(\mathrm{wt} \%)$ & 9.1357 & 9.0231 & 8.6000 & 0.5357 & 0.4231 & $6.2 \%$ & $4.9 \%$ \\
\hline Pu35-12 & $\mathrm{B}_{2} \mathrm{O}_{3}(\mathrm{wt} \%)$ & 11.3018 & 11.6159 & 11.1800 & 0.1218 & 0.4359 & $1.1 \%$ & $3.9 \%$ \\
\hline \begin{tabular}{|l|}
$\mathrm{Pu} 35-12$ \\
\end{tabular} & $\mathrm{CaO}(\mathrm{wt} \%)$ & 0.1567 & 0.1545 & 0.0800 & 0.0767 & 0.0745 & $95.9 \%$ & $93.1 \%$ \\
\hline \begin{tabular}{|l|} 
Pu35-12 \\
\end{tabular} & $\mathrm{Cl}(\mathrm{wt} \%)$ & 0.0405 & 0.0405 & 0.6500 & -0.6095 & -0.6095 & $-93.8 \%$ & $-93.8 \%$ \\
\hline Pu35-12 & $\mathrm{Cr}_{2} \mathrm{O}_{3}(\mathrm{wt} \%)$ & 0.3771 & 0.3554 & 0.4000 & -0.0229 & -0.0446 & $-5.7 \%$ & $-11.1 \%$ \\
\hline Pu35-12 & $\mathrm{CuO}(\mathrm{wt} \%)$ & 0.2009 & 0.2081 & 0.1800 & 0.0209 & 0.0281 & $11.6 \%$ & $15.6 \%$ \\
\hline Pu35-12 & $\mathrm{F}(\mathrm{wt} \%)$ & 0.0540 & 0.0667 & 0.3300 & -0.2760 & -0.2633 & $-83.6 \%$ & $-79.8 \%$ \\
\hline Pu35-12 & $\mathrm{Fe}_{2} \mathrm{O}_{3}(\mathrm{wt} \%)$ & 0.2180 & 0.2268 & 0.1900 & 0.0280 & 0.0368 & $14.8 \%$ & $19.4 \%$ \\
\hline Pu35-12 & $\mathrm{Ga}_{2} \mathrm{O}_{3}(\mathrm{wt} \%)$ & 0.3925 & 0.3925 & 0.3600 & 0.0325 & 0.0325 & $9.0 \%$ & $9.0 \%$ \\
\hline Pu35-12 & $\mathrm{Gd}_{2} \mathrm{O}_{3}(\mathrm{wt} \%)$ & 11.6989 & 11.6989 & 11.6100 & 0.0889 & 0.0889 & $0.8 \%$ & $0.8 \%$ \\
\hline Pu35-12 & $\mathrm{HfO}_{2}(\mathrm{wt} \%)$ & 13.9157 & 13.9157 & 14.9600 & -1.0443 & -1.0443 & $-7.0 \%$ & $-7.0 \%$ \\
\hline Pu35-12 & $\mathrm{K}_{2} \mathrm{O}(\mathrm{wt} \%)$ & 0.2445 & 0.2117 & 0.2800 & -0.0355 & -0.0683 & $-12.7 \%$ & $-24.4 \%$ \\
\hline \begin{tabular}{|l|}
$\mathrm{Pu} 35-12$ \\
\end{tabular} & $\mathrm{La}_{2} \mathrm{O}_{3}(\mathrm{wt} \%)$ & 16.0087 & 16.0087 & 16.3400 & -0.3313 & -0.3313 & $-2.0 \%$ & $-2.0 \%$ \\
\hline \begin{tabular}{|l|} 
Pu35-12 \\
\end{tabular} & $\mathrm{MgO}(\mathrm{wt} \%)$ & 0.6816 & 0.6421 & 0.6600 & 0.0216 & -0.0179 & $3.3 \%$ & $-2.7 \%$ \\
\hline Pu35-12 & $\mathrm{Na}_{2} \mathrm{O}($ wt $\%)$ & 0.7859 & 0.7184 & 0.7900 & -0.0041 & -0.0716 & $-0.5 \%$ & $-9.1 \%$ \\
\hline Pu35-12 & $\mathrm{Nd}_{2} \mathrm{O}_{3}(\mathrm{wt} \%)$ & 13.1803 & 13.1803 & 12.9000 & 0.2803 & 0.2803 & $2.2 \%$ & $2.2 \%$ \\
\hline Pu35-12 & $\mathrm{NiO}($ wt \%) & 0.4492 & 0.4814 & 0.4700 & -0.0208 & 0.0114 & $-4.4 \%$ & $2.4 \%$ \\
\hline Pu35-12 & $\mathrm{PbO}$ (wt \%) & 0.0399 & 0.0399 & 0.0000 & 0.0399 & 0.0399 & & \\
\hline Pu35-12 & $\mathrm{SeO}_{2}($ wt $\%)$ & 0.0070 & 0.0070 & 0.0800 & -0.0730 & -0.0730 & $-91.2 \%$ & $-91.2 \%$ \\
\hline Pu35-12 & $\mathrm{Si}_{2} \mathrm{O}_{3}(\mathrm{wt} \%)$ & 17.6599 & 17.7925 & 17.2000 & 0.4599 & 0.5925 & $2.7 \%$ & $3.4 \%$ \\
\hline Pu35-12 & $\mathrm{SO}_{4}(\mathrm{wt} \%)$ & 0.0749 & 0.0749 & 0.0000 & 0.0749 & 0.0749 & & \\
\hline \begin{tabular}{|l|}
$\mathrm{Pu} 35-12$ \\
\end{tabular} & $\mathrm{SrO}(\mathrm{wt} \%)$ & 2.3179 & 2.3179 & 2.1500 & 0.1679 & 0.1679 & $7.8 \%$ & $7.8 \%$ \\
\hline Pu35-12 & $\mathrm{Ta}_{2} \mathrm{O}_{5}(\mathrm{wt} \%)$ & 0.5995 & 0.5995 & 0.5900 & 0.0095 & 0.0095 & $1.6 \%$ & $1.6 \%$ \\
\hline Pu35-12 & Sum (wt \%) & 99.5413 & 99.7724 & 100.0000 & -0.4587 & -0.2276 & $-0.5 \%$ & $-0.2 \%$ \\
\hline Pu35-13 & $\mathrm{Al}_{2} \mathrm{O}_{3}($ wt $\%)$ & 9.0318 & 8.9204 & 8.6000 & 0.4318 & 0.3204 & $5.0 \%$ & $3.7 \%$ \\
\hline Pu35-13 & $\mathrm{B}_{2} \mathrm{O}_{3}(\mathrm{wt} \%)$ & 10.9799 & 11.2849 & 11.1800 & -0.2001 & 0.1049 & $-1.8 \%$ & $0.9 \%$ \\
\hline Pu35-13 & $\mathrm{CaO}(w \mathrm{t} \%)$ & 0.0602 & 0.0593 & 0.0000 & 0.0602 & 0.0593 & & \\
\hline Pu35-13 & $\mathrm{Cl}(\mathrm{wt} \%)$ & 0.0550 & 0.0550 & 0.7700 & -0.7150 & -0.7150 & $-92.9 \%$ & $-92.9 \%$ \\
\hline Pu35-13 & $\mathrm{Cr}_{2} \mathrm{O}_{3}(\mathrm{wt} \%)$ & 0.3574 & 0.3368 & 0.3700 & -0.0126 & -0.0332 & $-3.4 \%$ & $-9.0 \%$ \\
\hline Pu35-13 & $\mathrm{CuO}(\mathrm{wt} \%)$ & 0.1721 & 0.1783 & 0.1500 & 0.0221 & 0.0283 & $14.7 \%$ & $18.9 \%$ \\
\hline
\end{tabular}


Table D5. Average Measured and Bias-Corrected Chemical Compositions Versus Targeted Compositions by Oxide by Study Glass (continued)

\begin{tabular}{|c|c|c|c|c|c|c|c|c|}
\hline Glass ID & Oxide & \begin{tabular}{|c|} 
Measured \\
(wt \%)
\end{tabular} & \begin{tabular}{|c|} 
Measured Bias- \\
Corrected (wt \%)
\end{tabular} & $\begin{array}{c}\text { Targeted } \\
\text { (wt \%) }\end{array}$ & $\begin{array}{c}\text { Diff of } \\
\text { Measured }\end{array}$ & $\begin{array}{c}\text { Diff of Meas } \\
\text { BC }\end{array}$ & $\begin{array}{l}\text { \% Diff of } \\
\text { Measured }\end{array}$ & $\begin{array}{c}\text { \% Diff of Meas } \\
\text { BC }\end{array}$ \\
\hline $\mathrm{Pu} 35-13$ & $\mathrm{~F}(\mathrm{wt} \%)$ & \begin{tabular}{|l|}
0.0120 \\
\end{tabular} & \begin{tabular}{|l|}
0.0148 \\
\end{tabular} & 0.0600 & -0.0480 & -0.0452 & $-80.0 \%$ & $-75.3 \%$ \\
\hline \begin{tabular}{|l|} 
Pu35-13 \\
\end{tabular} & $\mathrm{Fe}_{2} \mathrm{O}_{3}(\mathrm{wt} \%)$ & 0.3874 & 0.4030 & 0.3700 & 0.0174 & 0.0330 & $4.7 \%$ & $8.9 \%$ \\
\hline Pu35-13 & $\mathrm{Ga}_{2} \mathrm{O}_{3}(\mathrm{wt} \%)$ & 0.1163 & 0.1163 & 0.0800 & 0.0363 & 0.0363 & $45.3 \%$ & $45.3 \%$ \\
\hline Pu35-13 & $\mathrm{Gd}_{2} \mathrm{O}_{3}(\mathrm{wt} \%)$ & 11.6989 & 11.6989 & 11.6100 & 0.0889 & 0.0889 & $0.8 \%$ & $0.8 \%$ \\
\hline Pu35-13 & $\mathrm{HfO}_{2}(\mathrm{wt} \%)$ & 13.3261 & 13.3261 & 14.9600 & -1.6339 & -1.6339 & $-10.9 \%$ & $-10.9 \%$ \\
\hline Pu35-13 & $\mathrm{K}_{2} \mathrm{O}(\mathrm{wt} \%)$ & 0.3548 & 0.3071 & 0.4400 & -0.0852 & -0.1329 & $-19.4 \%$ & $-30.2 \%$ \\
\hline Pu35-13 & $\mathrm{La}_{2} \mathrm{O}_{3}(\mathrm{wt} \%)$ & 16.0087 & 16.0087 & 16.3400 & -0.3313 & -0.3313 & $-2.0 \%$ & $-2.0 \%$ \\
\hline Pu35-13 & $\mathrm{MgO}(\mathrm{wt} \%)$ & 0.7719 & 0.7272 & 0.7600 & 0.0119 & -0.0328 & $1.6 \%$ & $-4.3 \%$ \\
\hline Pu35-13 & $\mathrm{Na}_{2} \mathrm{O}(\mathrm{wt} \%)$ & 1.0494 & 0.9592 & 1.0900 & -0.0406 & -0.1308 & $-3.7 \%$ & $-12.0 \%$ \\
\hline \begin{tabular}{|l|}
$\mathrm{Pu} 35-13$ \\
\end{tabular} & $\mathrm{Nd}_{2} \mathrm{O}_{3}(\mathrm{wt} \%)$ & 13.0637 & 13.0637 & 12.9000 & 0.1637 & 0.1637 & $1.3 \%$ & $1.3 \%$ \\
\hline \begin{tabular}{|l|}
$\mathrm{Pu} 35-13$ \\
\end{tabular} & $\mathrm{NiO}(\mathrm{wt} \%)$ & 0.0064 & 0.0068 & 0.0000 & 0.0064 & 0.0068 & & \\
\hline Pu35-13 & $\mathrm{PbO}$ (wt \%) & 0.0991 & 0.0991 & 0.0800 & 0.0191 & 0.0191 & $23.9 \%$ & $23.9 \%$ \\
\hline Pu35-13 & $\mathrm{SeO}_{2}($ wt $\%)$ & 0.0070 & 0.0070 & 0.0000 & 0.0070 & 0.0070 & & \\
\hline Pu35-13 & $\mathrm{Si}_{2} \mathrm{O}_{3}(\mathrm{wt} \%)$ & 17.5530 & 17.6848 & 17.2000 & 0.3530 & 0.4848 & $2.1 \%$ & $2.8 \%$ \\
\hline Pu35-13 & $\mathrm{SO}_{4}(\mathrm{wt} \%)$ & 0.0749 & 0.0749 & 0.0000 & 0.0749 & 0.0749 & & \\
\hline \begin{tabular}{|l|}
$\mathrm{Pu} 35-13$ \\
\end{tabular} & $\mathrm{SrO}(\mathrm{wt} \%)$ & 2.2647 & 2.2647 & 2.1500 & 0.1147 & 0.1147 & $5.3 \%$ & $5.3 \%$ \\
\hline Pu35-13 & $\mathrm{Ta}_{2} \mathrm{O}_{5}(\mathrm{wt} \%)$ & 0.8339 & 0.8339 & 0.8400 & -0.0061 & -0.0061 & $-0.7 \%$ & $-0.7 \%$ \\
\hline Pu35-13 & Sum (wt \%) & 98.2845 & 98.4311 & 99.9500 & -1.6655 & -1.5189 & $-1.7 \%$ & $-1.5 \%$ \\
\hline Pu35-14 & $\mathrm{Al}_{2} \mathrm{O}_{3}(\mathrm{wt} \%)$ & 9.1263 & 9.0137 & 8.6000 & 0.5263 & 0.4137 & $6.1 \%$ & $4.8 \%$ \\
\hline Pu35-14 & $\mathrm{B}_{2} \mathrm{O}_{3}(\mathrm{wt} \%)$ & 10.8350 & 11.1360 & 11.1800 & -0.3450 & -0.0440 & $-3.1 \%$ & $-0.4 \%$ \\
\hline Pu35-14 & $\mathrm{CaO}($ wt \%) & 0.4904 & 0.4834 & 0.3800 & 0.1104 & 0.1034 & $29.1 \%$ & $27.2 \%$ \\
\hline Pu35-14 & $\mathrm{Cl}(\mathrm{wt} \%)$ & 0.0585 & 0.0585 & 0.8000 & -0.7415 & -0.7415 & $-92.7 \%$ & $-92.7 \%$ \\
\hline Pu35-14 & $\mathrm{Cr}_{2} \mathrm{O}_{3}(\mathrm{wt} \%)$ & 0.1359 & 0.1281 & 0.1300 & 0.0059 & -0.0019 & $4.6 \%$ & $-1.4 \%$ \\
\hline Pu35-14 & $\mathrm{CuO}(\mathrm{wt} \%)$ & 0.0933 & 0.0966 & 0.0700 & 0.0233 & 0.0266 & $33.2 \%$ & $38.0 \%$ \\
\hline Pu35-14 & $\mathrm{F}(\mathrm{wt} \%)$ & 0.0155 & 0.0191 & 0.0800 & -0.0645 & -0.0609 & $-80.6 \%$ & $-76.1 \%$ \\
\hline \begin{tabular}{|l|} 
Pu35-14 \\
\end{tabular} & $\mathrm{Fe}_{2} \mathrm{O}_{3}(\mathrm{wt} \%)$ & 0.9851 & 1.0246 & 1.0000 & -0.0149 & 0.0246 & $-1.5 \%$ & $2.5 \%$ \\
\hline Pu35-14 & $\mathrm{Ga}_{2} \mathrm{O}_{3}(\mathrm{wt} \%)$ & 0.3071 & 0.3071 & 0.2700 & 0.0371 & 0.0371 & $13.8 \%$ & $13.8 \%$ \\
\hline \begin{tabular}{|l|} 
Pu35-14 \\
\end{tabular} & $\mathrm{Gd}_{2} \mathrm{O}_{3}(\mathrm{wt} \%)$ & 11.7565 & 11.7565 & 11.6100 & 0.1465 & 0.1465 & $1.3 \%$ & $1.3 \%$ \\
\hline Pu35-14 & $\mathrm{HfO}_{2}(\mathrm{wt} \%)$ & 13.7978 & 13.7978 & 14.9000 & -1.1022 & -1.1022 & $-7.4 \%$ & $-7.4 \%$ \\
\hline Pu35-14 & $\mathrm{K}_{2} \mathrm{O}(\mathrm{wt} \%)$ & 0.1518 & 0.1314 & 0.2000 & -0.0482 & -0.0686 & $-24.1 \%$ & $-34.3 \%$ \\
\hline Pu35-14 & $\mathrm{La}_{2} \mathrm{O}_{3}(\mathrm{wt} \%)$ & 16.1846 & 16.1846 & 16.3400 & -0.1554 & -0.1554 & $-1.0 \%$ & $-1.0 \%$ \\
\hline Pu35-14 & $\mathrm{MgO}(\mathrm{wt} \%)$ & 0.4494 & 0.4234 & 0.4400 & 0.0094 & -0.0166 & $2.1 \%$ & $-3.8 \%$ \\
\hline Pu35-14 & $\mathrm{Na}_{2} \mathrm{O}(\mathrm{wt} \%)$ & 1.0380 & 0.9488 & 1.0700 & -0.0320 & -0.1212 & $-3.0 \%$ & $-11.3 \%$ \\
\hline Pu35-14 & $\mathrm{Nd}_{2} \mathrm{O}_{3}(\mathrm{wt} \%)$ & 13.1803 & 13.1803 & 12.9000 & 0.2803 & 0.2803 & $2.2 \%$ & $2.2 \%$ \\
\hline Pu35-14 & $\mathrm{NiO}(\mathrm{wt} \%)$ & 0.0674 & 0.0723 & 0.0700 & -0.0026 & 0.0023 & $-3.7 \%$ & $3.3 \%$ \\
\hline Pu35-14 & $\mathrm{PbO}(\mathrm{wt} \%)$ & 0.0867 & 0.0867 & 0.0600 & 0.0267 & 0.0267 & $44.5 \%$ & $44.5 \%$ \\
\hline Pu35-14 & $\mathrm{SeO}_{2}($ wt $\%)$ & 0.0070 & 0.0070 & 0.0800 & -0.0730 & -0.0730 & $-91.2 \%$ & $-91.2 \%$ \\
\hline Pu35-14 & $\mathrm{Si}_{2} \mathrm{O}_{3}(\mathrm{wt} \%)$ & 17.6706 & 17.8033 & 17.2000 & 0.4706 & 0.6033 & $2.7 \%$ & $3.5 \%$ \\
\hline Pu35-14 & $\mathrm{SO}_{4}(\mathrm{wt} \%)$ & 0.0749 & 0.0749 & 0.0000 & 0.0749 & 0.0749 & & \\
\hline Pu35-14 & $\mathrm{SrO}(\mathrm{wt} \%)$ & 2.2942 & 2.2942 & 2.1500 & 0.1442 & 0.1442 & $6.7 \%$ & $6.7 \%$ \\
\hline Pu35-14 & $\mathrm{Ta}_{2} \mathrm{O}_{5}(\mathrm{wt} \%)$ & 0.3559 & 0.3559 & 0.3400 & 0.0159 & 0.0159 & $4.7 \%$ & $4.7 \%$ \\
\hline Pu35-14 & Sum (wt \%) & 99.1624 & 99.3845 & 99.8700 & -0.7076 & -0.4855 & $-0.7 \%$ & $-0.5 \%$ \\
\hline Pu35-15 & $\mathrm{Al}_{2} \mathrm{O}_{3}(\mathrm{wt} \%)$ & 9.1924 & 9.0791 & 8.6000 & 0.5924 & 0.4791 & $6.9 \%$ & $5.6 \%$ \\
\hline Pu35-15 & $\mathrm{B}_{2} \mathrm{O}_{3}(\mathrm{wt} \%)$ & 10.8672 & 11.1691 & 11.1800 & -0.3128 & -0.0109 & $-2.8 \%$ & $-0.1 \%$ \\
\hline Pu35-15 & $\mathrm{CaO}(\mathrm{wt} \%)$ & 0.0630 & 0.0621 & 0.0000 & 0.0630 & 0.0621 & & \\
\hline Pu35-15 & $\mathrm{Cl}(\mathrm{wt} \%)$ & 0.0615 & 0.0615 & 1.0000 & -0.9385 & -0.9385 & $-93.9 \%$ & $-93.9 \%$ \\
\hline Pu35-15 & $\mathrm{Cr}_{2} \mathrm{O}_{3}(\mathrm{wt} \%)$ & 0.0080 & 0.0076 & 0.0000 & 0.0080 & 0.0076 & & \\
\hline Pu35-15 & $\mathrm{CuO}(\mathrm{wt} \%)$ & 0.0257 & 0.0266 & 0.0000 & 0.0257 & 0.0266 & & \\
\hline Pu35-15 & $\mathrm{F}(\mathrm{wt} \%)$ & 0.0000 & 0.0000 & 0.0000 & 0.0000 & 0.0000 & & \\
\hline \begin{tabular}{|l|}
$\mathrm{Pu} 35-15$ \\
\end{tabular} & $\mathrm{Fe}_{2} \mathrm{O}_{3}(\mathrm{wt} \%)$ & 0.0315 & 0.0327 & 0.0000 & 0.0315 & 0.0327 & & \\
\hline Pu35-15 & $\mathrm{Ga}_{2} \mathrm{O}_{3}(\mathrm{wt} \%)$ & 1.2931 & 1.2931 & 1.2700 & 0.0231 & 0.0231 & $1.8 \%$ & $1.8 \%$ \\
\hline Pu35-15 & $\mathrm{Gd}_{2} \mathrm{O}_{3}(\mathrm{wt} \%)$ & 11.8142 & 11.8142 & 11.6100 & 0.2042 & 0.2042 & $1.8 \%$ & $1.8 \%$ \\
\hline Pu35-15 & $\mathrm{HfO}_{2}(\mathrm{wt} \%)$ & 13.7978 & 13.7978 & 15.0000 & -1.2022 & -1.2022 & $-8.0 \%$ & $-8.0 \%$ \\
\hline Pu35-15 & $\mathrm{K}_{2} \mathrm{O}(\mathrm{wt} \%)$ & 0.4620 & 0.4000 & 0.5900 & -0.1280 & -0.1900 & $-21.7 \%$ & $-32.2 \%$ \\
\hline Pu35-15 & $\mathrm{La}_{2} \mathrm{O}_{3}(\mathrm{wt} \%)$ & 16.3019 & 16.3019 & 16.3400 & -0.0381 & -0.0381 & $-0.2 \%$ & $-0.2 \%$ \\
\hline Pu35-15 & $\mathrm{MgO}($ wt $\%)$ & 0.5381 & 0.5069 & 0.5400 & -0.0019 & -0.0331 & $-0.3 \%$ & $-6.1 \%$ \\
\hline Pu35-15 & $\mathrm{Na}_{2} \mathrm{O}($ wt $\%)$ & 0.8513 & 0.7781 & 0.8800 & -0.0287 & -0.1019 & $-3.3 \%$ & $-11.6 \%$ \\
\hline Pu35-15 & $\mathrm{Nd}_{2} \mathrm{O}_{3}(\mathrm{wt} \%)$ & 13.2970 & 13.2970 & 12.9000 & 0.3970 & 0.3970 & $3.1 \%$ & $3.1 \%$ \\
\hline
\end{tabular}


Table D5. Average Measured and Bias-Corrected Chemical Compositions Versus Targeted Compositions by Oxide by Study Glass (continued)

\begin{tabular}{|c|c|c|c|c|c|c|c|c|}
\hline Glass ID & Oxide & $\begin{array}{c}\text { Measured } \\
\text { (wt \%) }\end{array}$ & \begin{tabular}{|c|} 
Measured Bias- \\
Corrected (wt \%)
\end{tabular} & $\begin{array}{c}\text { Targeted } \\
\text { (wt \%) }\end{array}$ & $\begin{array}{c}\text { Diff of } \\
\text { Measured }\end{array}$ & $\begin{array}{c}\text { Diff of Meas } \\
\text { BC }\end{array}$ & $\begin{array}{l}\text { \% Diff of } \\
\text { Measured }\end{array}$ & $\begin{array}{c}\text { \% Diff of Meas } \\
\text { BC }\end{array}$ \\
\hline Pu35-15 & $\mathrm{NiO}(w \mathrm{t} \%)$ & 0.5427 & 0.5817 & 0.6000 & -0.0573 & -0.0183 & $-9.5 \%$ & $-3.1 \%$ \\
\hline Pu35-15 & $\mathrm{PbO}$ (wt \%) & 0.0883 & 0.0883 & 0.0800 & 0.0083 & 0.0083 & $10.4 \%$ & $10.4 \%$ \\
\hline Pu35-15 & $\mathrm{SeO}_{2}(\mathrm{wt} \%)$ & 0.0070 & 0.0070 & 0.0000 & 0.0070 & 0.0070 & & \\
\hline Pu35-15 & $\mathrm{Si}_{2} \mathrm{O}_{3}(\mathrm{wt} \%)$ & 17.7990 & 17.9326 & 17.2000 & 0.5990 & 0.7326 & $3.5 \%$ & $4.3 \%$ \\
\hline $\mathrm{Pu} 35-15$ & $\mathrm{SO}_{4}(\mathrm{wt} \%)$ & 0.0749 & 0.0749 & 0.0000 & 0.0749 & 0.0749 & & \\
\hline Pu35-15 & $\mathrm{SrO}(\mathrm{wt} \%)$ & 2.3002 & 2.3002 & 2.1500 & 0.1502 & 0.1502 & $7.0 \%$ & $7.0 \%$ \\
\hline $\mathrm{Pu} 35-15$ & $\mathrm{Ta}_{2} \mathrm{O}_{5}(\mathrm{wt} \%)$ & 0.0171 & 0.0171 & 0.0000 & 0.0171 & 0.0171 & & \\
\hline $\mathrm{Pu} 35-15$ & Sum (wt \%) & 99.4337 & 99.6294 & 99.9400 & -0.5063 & -0.3106 & $-0.5 \%$ & $-0.3 \%$ \\
\hline $\mathrm{Pu} 35-16$ & $\mathrm{Al}_{2} \mathrm{O}_{3}(\mathrm{wt} \%)$ & 9.0318 & 8.7860 & 8.6000 & 0.4318 & 0.1860 & $5.0 \%$ & $2.2 \%$ \\
\hline Pu35-16 & $\mathrm{B}_{2} \mathrm{O}_{3}(\mathrm{wt} \%)$ & 11.3501 & 11.2814 & 11.1800 & 0.1701 & 0.1014 & $1.5 \%$ & $0.9 \%$ \\
\hline Pu35-16 & $\mathrm{CaO}($ wt \%) & 0.7989 & 0.8066 & 0.7000 & 0.0989 & 0.1066 & $14.1 \%$ & $15.2 \%$ \\
\hline Pu35-16 & $\mathrm{Cl}(\mathrm{wt} \%)$ & 0.0425 & 0.0425 & 0.9500 & -0.9075 & -0.9075 & $-95.5 \%$ & $-95.5 \%$ \\
\hline Pu35-16 & $\mathrm{Cr}_{2} \mathrm{O}_{3}(\mathrm{wt} \%)$ & 0.0058 & 0.0058 & 0.0000 & 0.0058 & 0.0058 & & \\
\hline Pu35-16 & $\mathrm{CuO}($ wt $\%)$ & 0.2679 & 0.2821 & 0.2900 & -0.0221 & -0.0079 & $-7.6 \%$ & $-2.7 \%$ \\
\hline Pu35-16 & $\mathrm{F}(\mathrm{wt} \%)$ & 0.0000 & 0.0000 & 0.0000 & 0.0000 & 0.0000 & & \\
\hline Pu35-16 & $\mathrm{Fe}_{2} \mathrm{O}_{3}(\mathrm{wt} \%)$ & 0.4475 & 0.4436 & 0.4600 & -0.0125 & -0.0164 & $-2.7 \%$ & $-3.6 \%$ \\
\hline Pu35-16 & $\mathrm{Ga}_{2} \mathrm{O}_{3}(\mathrm{wt} \%)$ & 0.1909 & 0.1909 & 0.1500 & 0.0409 & 0.0409 & $27.3 \%$ & $27.3 \%$ \\
\hline Pu35-16 & $\mathrm{Gd}_{2} \mathrm{O}_{3}(\mathrm{wt} \%)$ & 11.9294 & 11.9294 & 11.6100 & 0.3194 & 0.3194 & $2.8 \%$ & $2.8 \%$ \\
\hline Pu35-16 & $\mathrm{HfO}_{2}(\mathrm{wt} \%)$ & 13.9747 & 13.9747 & 14.8500 & -0.8753 & -0.8753 & $-5.9 \%$ & $-5.9 \%$ \\
\hline Pu35-16 & $\mathrm{K}_{2} \mathrm{O}(\mathrm{wt} \%)$ & 0.0060 & 0.0052 & 0.0000 & 0.0060 & 0.0052 & & \\
\hline Pu35-16 & $\mathrm{La}_{2} \mathrm{O}_{3}(\mathrm{wt} \%)$ & 16.4192 & 16.4192 & 16.3400 & 0.0792 & 0.0792 & $0.5 \%$ & $0.5 \%$ \\
\hline Pu35-16 & $\mathrm{MgO}(\mathrm{wt} \%)$ & 0.6990 & 0.7064 & 0.7300 & -0.0310 & -0.0236 & $-4.3 \%$ & $-3.2 \%$ \\
\hline Pu35-16 & $\mathrm{Na}_{2} \mathrm{O}(\mathrm{wt} \%)$ & 1.1101 & 1.0051 & 1.2300 & -0.1199 & -0.2249 & $-9.7 \%$ & $-18.3 \%$ \\
\hline Pu35-16 & $\mathrm{Nd}_{2} \mathrm{O}_{3}(\mathrm{wt} \%)$ & 13.1803 & 13.1803 & 12.9000 & 0.2803 & 0.2803 & $2.2 \%$ & $2.2 \%$ \\
\hline Pu35-16 & $\mathrm{NiO}(\mathrm{wt} \%)$ & 0.1209 & 0.1351 & 0.1300 & -0.0091 & 0.0051 & $-7.0 \%$ & $3.9 \%$ \\
\hline \begin{tabular}{|l|} 
Pu35-16 \\
\end{tabular} & $\mathrm{PbO}(\mathrm{wt} \%)$ & 0.0786 & 0.0786 & 0.0600 & 0.0186 & 0.0186 & $31.1 \%$ & $31.1 \%$ \\
\hline Pu35-16 & $\mathrm{SeO}_{2}(\mathrm{wt} \%)$ & 0.0070 & 0.0070 & 0.0000 & 0.0070 & 0.0070 & & \\
\hline \begin{tabular}{|l|} 
Pu35-16 \\
\end{tabular} & $\mathrm{Si}_{2} \mathrm{O}_{3}$ (wt \%) & 17.9166 & 17.4761 & 17.2000 & 0.7166 & 0.2761 & $4.2 \%$ & $1.6 \%$ \\
\hline Pu35-16 & $\mathrm{SO}_{4}(\mathrm{wt} \%)$ & 0.0749 & 0.0749 & 0.1700 & -0.0951 & -0.0951 & $-55.9 \%$ & $-55.9 \%$ \\
\hline Pu35-16 & SrO (wt \%) & 2.2055 & 2.2055 & 2.1500 & 0.0555 & 0.0555 & $2.6 \%$ & $2.6 \%$ \\
\hline Pu35-16 & $\mathrm{Ta}_{2} \mathrm{O}_{5}(\mathrm{wt} \%)$ & 0.2857 & 0.2857 & 0.2900 & -0.0043 & -0.0043 & $-1.5 \%$ & $-1.5 \%$ \\
\hline Pu35-16 & Sum (wt \%) & 100.1436 & 99.3223 & 99.9900 & 0.1536 & -0.6677 & $0.2 \%$ & $-0.7 \%$ \\
\hline Pu35-17 & $\mathrm{Al}_{2} \mathrm{O}_{3}(\mathrm{wt} \%)$ & 8.9468 & 8.7032 & 8.6000 & 0.3468 & 0.1032 & $4.0 \%$ & $1.2 \%$ \\
\hline Pu35-17 & $\mathrm{B}_{2} \mathrm{O}_{3}(\mathrm{wt} \%)$ & 11.3984 & 11.3295 & 11.1800 & 0.2184 & 0.1495 & $2.0 \%$ & $1.3 \%$ \\
\hline Pu35-17 & $\mathrm{CaO}($ wt \%) & 0.1616 & 0.1632 & 0.0800 & 0.0816 & 0.0832 & $102.0 \%$ & $103.9 \%$ \\
\hline Pu35-17 & $\mathrm{Cl}(\mathrm{wt} \%)$ & 0.0590 & 0.0590 & 1.1100 & -1.0510 & -1.0510 & $-94.7 \%$ & $-94.7 \%$ \\
\hline Pu35-17 & $\mathrm{Cr}_{2} \mathrm{O}_{3}(\mathrm{wt} \%)$ & 0.3047 & 0.3028 & 0.3100 & -0.0053 & -0.0072 & $-1.7 \%$ & $-2.3 \%$ \\
\hline Pu35-17 & $\mathrm{CuO}(\mathrm{wt} \%)$ & 0.1064 & 0.1121 & 0.1000 & 0.0064 & 0.0121 & $6.4 \%$ & $12.1 \%$ \\
\hline Pu35-17 & $\mathrm{F}(\mathrm{wt} \%)$ & 0.0000 & 0.0000 & 0.0600 & -0.0600 & -0.0600 & $-100.0 \%$ & $-100.0 \%$ \\
\hline Pu35-17 & $\mathrm{Fe}_{2} \mathrm{O}_{3}(\mathrm{wt} \%)$ & 0.0615 & 0.0609 & 0.0000 & 0.0615 & 0.0609 & & \\
\hline Pu35-17 & $\mathrm{Ga}_{2} \mathrm{O}_{3}(\mathrm{wt} \%)$ & 0.6976 & 0.6976 & 0.6800 & 0.0176 & 0.0176 & $2.6 \%$ & $2.6 \%$ \\
\hline \begin{tabular}{|l|}
$\mathrm{Pu} 35-17$ \\
\end{tabular} & $\mathrm{Gd}_{2} \mathrm{O}_{3}(\mathrm{wt} \%)$ & 11.8718 & 11.8718 & 11.6100 & 0.2618 & 0.2618 & $2.3 \%$ & $2.3 \%$ \\
\hline Pu35-17 & $\mathrm{HfO}_{2}(\mathrm{wt} \%)$ & 13.8568 & 13.8568 & 14.9500 & -1.0932 & -1.0932 & $-7.3 \%$ & $-7.3 \%$ \\
\hline Pu35-17 & $\mathrm{K}_{2} \mathrm{O}(\mathrm{wt} \%)$ & 0.3451 & 0.3001 & 0.4300 & -0.0849 & -0.1299 & $-19.7 \%$ & $-30.2 \%$ \\
\hline \begin{tabular}{|l|} 
Pu35-17 \\
\end{tabular} & $\mathrm{La}_{2} \mathrm{O}_{3}(\mathrm{wt} \%)$ & 16.4778 & 16.4778 & 16.3400 & 0.1378 & 0.1378 & $0.8 \%$ & $0.8 \%$ \\
\hline Pu35-17 & $\mathrm{MgO}(\mathrm{wt} \%)$ & 0.3914 & 0.3955 & 0.4000 & -0.0086 & -0.0045 & $-2.2 \%$ & $-1.1 \%$ \\
\hline Pu35-17 & $\mathrm{Na}_{2} \mathrm{O}($ wt $\%)$ & 0.9746 & 0.8824 & 1.0400 & -0.0654 & -0.1576 & $-6.3 \%$ & $-15.2 \%$ \\
\hline Pu35-17 & $\mathrm{Nd}_{2} \mathrm{O}_{3}(\mathrm{wt} \%)$ & 13.1220 & 13.1220 & 12.9000 & 0.2220 & 0.2220 & $1.7 \%$ & $1.7 \%$ \\
\hline Pu35-17 & $\mathrm{NiO}(\mathrm{wt} \%)$ & 0.0706 & 0.0789 & 0.0700 & 0.0006 & 0.0089 & $0.9 \%$ & $12.8 \%$ \\
\hline \begin{tabular}{|l|} 
Pu35-17 \\
\end{tabular} & $\mathrm{PbO}($ wt \%) & 0.0404 & 0.0404 & 0.0000 & 0.0404 & 0.0404 & & \\
\hline Pu35-17 & $\mathrm{SeO}_{2}(\mathrm{wt} \%)$ & 0.0070 & 0.0070 & 0.0000 & 0.0070 & 0.0070 & & \\
\hline Pu35-17 & $\mathrm{Si}_{2} \mathrm{O}_{3}($ wt $\%)$ & 18.1092 & 17.6639 & 17.2000 & 0.9092 & 0.4639 & $5.3 \%$ & $2.7 \%$ \\
\hline Pu35-17 & $\mathrm{SO}_{4}(\mathrm{wt} \%)$ & 0.0749 & 0.0749 & 0.1700 & -0.0951 & -0.0951 & $-55.9 \%$ & $-55.9 \%$ \\
\hline Pu35-17 & $\mathrm{SrO}(\mathrm{wt} \%)$ & 2.1878 & 2.1878 & 2.1500 & 0.0378 & 0.0378 & $1.8 \%$ & $1.8 \%$ \\
\hline Pu35-17 & $\mathrm{Ta}_{2} \mathrm{O}_{5}(\mathrm{wt} \%)$ & 0.5366 & 0.5366 & 0.5500 & -0.0134 & -0.0134 & $-2.4 \%$ & $-2.4 \%$ \\
\hline $\mathrm{Pu} 35-17$ & Sum (wt \%) & 99.8021 & 98.9243 & 99.9300 & -0.1279 & -1.0057 & $-0.1 \%$ & $-1.0 \%$ \\
\hline Pu35-18 & $\mathrm{Al}_{2} \mathrm{O}_{3}(\mathrm{wt} \%)$ & 8.8712 & 8.6297 & 8.6000 & 0.2712 & 0.0297 & $3.2 \%$ & $0.3 \%$ \\
\hline Pu35-18 & $\mathrm{B}_{2} \mathrm{O}_{3}(\mathrm{wt} \%)$ & 11.3179 & 11.2494 & 11.1800 & 0.1379 & 0.0694 & $1.2 \%$ & $0.6 \%$ \\
\hline
\end{tabular}


Table D5. Average Measured and Bias-Corrected Chemical Compositions Versus Targeted Compositions by Oxide by Study Glass (continued)

\begin{tabular}{|c|c|c|c|c|c|c|c|c|}
\hline Glass ID & Oxide & $\begin{array}{c}\text { Measured } \\
\text { (wt \%) }\end{array}$ & \begin{tabular}{|c|} 
Measured Bias- \\
Corrected (wt \%)
\end{tabular} & $\begin{array}{c}\text { Targeted } \\
\text { (wt \%) }\end{array}$ & $\begin{array}{c}\text { Diff of } \\
\text { Measured }\end{array}$ & $\begin{array}{c}\text { Diff of Meas } \\
\text { BC }\end{array}$ & $\begin{array}{l}\text { \% Diff of } \\
\text { Measured }\end{array}$ & $\begin{array}{c}\text { \% Diff of Meas } \\
\text { BC }\end{array}$ \\
\hline Pu35-18 & $\mathrm{CaO}(\mathrm{wt} \%)$ & 0.6835 & \begin{tabular}{|l|}
0.6900 \\
\end{tabular} & 0.5700 & 0.1135 & 0.1200 & $19.9 \%$ & $21.1 \%$ \\
\hline Pu35-18 & $\mathrm{Cl}(\mathrm{wt} \%)$ & 0.0330 & 0.0330 & 0.5800 & -0.5470 & -0.5470 & $-94.3 \%$ & $-94.3 \%$ \\
\hline Pu35-18 & $\mathrm{Cr}_{2} \mathrm{O}_{3}(\mathrm{wt} \%)$ & 0.4611 & 0.4583 & 0.4800 & -0.0189 & -0.0217 & $-3.9 \%$ & $-4.5 \%$ \\
\hline Pu35-18 & $\mathrm{CuO}(\mathrm{wt} \%)$ & 0.0939 & 0.0989 & 0.0700 & 0.0239 & 0.0289 & $34.1 \%$ & $41.2 \%$ \\
\hline Pu35-18 & $\mathrm{F}(\mathrm{wt} \%)$ & 0.0000 & 0.0000 & 0.0600 & -0.0600 & -0.0600 & $-100.0 \%$ & $-100.0 \%$ \\
\hline Pu35-18 & $\mathrm{Fe}_{2} \mathrm{O}_{3}(\mathrm{wt} \%)$ & 0.1573 & 0.1559 & 0.0800 & 0.0773 & 0.0759 & $96.6 \%$ & $94.9 \%$ \\
\hline Pu35-18 & $\mathrm{Ga}_{2} \mathrm{O}_{3}(\mathrm{wt} \%)$ & 0.1136 & 0.1136 & 0.0800 & 0.0336 & 0.0336 & $42.0 \%$ & $42.0 \%$ \\
\hline Pu35-18 & $\mathrm{Gd}_{2} \mathrm{O}_{3}(\mathrm{wt} \%)$ & 11.8142 & 11.8142 & 11.6100 & 0.2042 & 0.2042 & $1.8 \%$ & $1.8 \%$ \\
\hline Pu35-18 & $\mathrm{HfO}_{2}(\mathrm{wt} \%)$ & 13.9157 & 13.9157 & 14.8800 & -0.9643 & -0.9643 & $-6.5 \%$ & $-6.5 \%$ \\
\hline Pu35-18 & $\mathrm{K}_{2} \mathrm{O}(\mathrm{wt} \%)$ & 0.7999 & 0.6954 & 1.1000 & -0.3001 & -0.4046 & $-27.3 \%$ & $-36.8 \%$ \\
\hline \begin{tabular}{|l|}
$\mathrm{Pu} 35-18$ \\
\end{tabular} & $\mathrm{La}_{2} \mathrm{O}_{3}(\mathrm{wt} \%)$ & 16.4778 & 16.4778 & 16.3400 & 0.1378 & 0.1378 & $0.8 \%$ & $0.8 \%$ \\
\hline Pu35-18 & $\mathrm{MgO}(\mathrm{wt} \%)$ & 0.9809 & 0.9913 & 1.0400 & -0.0591 & -0.0487 & $-5.7 \%$ & $-4.7 \%$ \\
\hline \begin{tabular}{|l|} 
Pu35-18 \\
\end{tabular} & $\mathrm{Na}_{2} \mathrm{O}$ (wt \%) & 0.8957 & 0.8110 & 0.9400 & -0.0443 & -0.1290 & $-4.7 \%$ & $-13.7 \%$ \\
\hline Pu35-18 & $\mathrm{Nd}_{2} \mathrm{O}_{3}(\mathrm{wt} \%)$ & 13.0637 & 13.0637 & 12.9000 & 0.1637 & 0.1637 & $1.3 \%$ & $1.3 \%$ \\
\hline Pu35-18 & $\mathrm{NiO}(\mathrm{wt} \%)$ & 0.0719 & 0.0804 & 0.0700 & 0.0019 & 0.0104 & $2.7 \%$ & $14.8 \%$ \\
\hline \begin{tabular}{|l|} 
Pu35-18 \\
\end{tabular} & $\mathrm{PbO}(\mathrm{wt} \%)$ & 0.0382 & 0.0382 & 0.0000 & 0.0382 & 0.0382 & & \\
\hline Pu35-18 & $\mathrm{SeO}_{2}($ wt $\%)$ & 0.0070 & 0.0070 & 0.0000 & 0.0070 & 0.0070 & & \\
\hline Pu35-18 & $\mathrm{Si}_{2} \mathrm{O}_{3}($ wt $\%)$ & 17.9166 & 17.4761 & 17.2000 & 0.7166 & 0.2761 & $4.2 \%$ & $1.6 \%$ \\
\hline Pu35-18 & $\mathrm{SO}_{4}(\mathrm{wt} \%)$ & 0.0749 & 0.0749 & 0.0000 & 0.0749 & 0.0749 & & \\
\hline Pu35-18 & $\mathrm{SrO}(\mathrm{wt} \%)$ & 2.1701 & 2.1701 & 2.1500 & 0.0201 & 0.0201 & $0.9 \%$ & $0.9 \%$ \\
\hline \begin{tabular}{|l|}
$\mathrm{Pu} 35-18$ \\
\end{tabular} & $\mathrm{Ta}_{2} \mathrm{O}_{5}(\mathrm{wt} \%)$ & 0.0818 & 0.0818 & 0.0700 & 0.0118 & 0.0118 & $16.9 \%$ & $16.9 \%$ \\
\hline Pu35-18 & Sum (wt \%) & 100.0400 & 99.1265 & 100.0000 & 0.0400 & -0.8735 & $0.0 \%$ & $-0.9 \%$ \\
\hline \begin{tabular}{|l|}
$\mathrm{Pu} 35-19$ \\
\end{tabular} & $\mathrm{Al}_{2} \mathrm{O}_{3}(\mathrm{wt} \%)$ & 8.9562 & 8.7124 & 8.6000 & 0.3562 & 0.1124 & $4.1 \%$ & $1.3 \%$ \\
\hline Pu35-19 & $\mathrm{B}_{2} \mathrm{O}_{3}(\mathrm{wt} \%)$ & 11.2375 & 11.1694 & 11.1800 & 0.0575 & -0.0106 & $0.5 \%$ & $-0.1 \%$ \\
\hline \begin{tabular}{|l|}
$\mathrm{Pu} 35-19$ \\
\end{tabular} & $\mathrm{CaO}($ wt \%) & 0.1553 & 0.1568 & 0.0800 & 0.0753 & 0.0768 & $94.1 \%$ & $96.0 \%$ \\
\hline \begin{tabular}{|l|} 
Pu35-19 \\
\end{tabular} & $\mathrm{Cl}(\mathrm{wt} \%)$ & 0.0515 & 0.0515 & 0.5800 & -0.5285 & -0.5285 & $-91.1 \%$ & $-91.1 \%$ \\
\hline Pu35-19 & $\mathrm{Cr}_{2} \mathrm{O}_{3}(\mathrm{wt} \%)$ & 0.4421 & 0.4394 & 0.4800 & -0.0379 & -0.0406 & $-7.9 \%$ & $-8.5 \%$ \\
\hline Pu35-19 & $\mathrm{CuO}(\mathrm{wt} \%)$ & 0.0914 & 0.0962 & 0.0700 & 0.0214 & 0.0262 & $30.5 \%$ & $37.5 \%$ \\
\hline \begin{tabular}{|l|} 
Pu35-19 \\
\end{tabular} & $\mathrm{F}(\mathrm{wt} \%)$ & 0.0760 & 0.0938 & 0.3800 & -0.3040 & -0.2862 & $-80.0 \%$ & $-75.3 \%$ \\
\hline Pu35-19 & $\mathrm{Fe}_{2} \mathrm{O}_{3}(\mathrm{wt} \%)$ & 0.7585 & 0.7518 & 0.7800 & -0.0215 & -0.0282 & $-2.8 \%$ & $-3.6 \%$ \\
\hline \begin{tabular}{|l|}
$\mathrm{Pu} 35-19$ \\
\end{tabular} & $\mathrm{Ga}_{2} \mathrm{O}_{3}(\mathrm{wt} \%)$ & 0.1129 & 0.1129 & 0.0800 & 0.0329 & 0.0329 & $41.1 \%$ & $41.1 \%$ \\
\hline \begin{tabular}{|l|}
$\mathrm{Pu} 35-19$ \\
\end{tabular} & $\mathrm{Gd}_{2} \mathrm{O}_{3}(\mathrm{wt} \%)$ & 11.8718 & 11.8718 & 11.6100 & 0.2618 & 0.2618 & $2.3 \%$ & $2.3 \%$ \\
\hline Pu35-19 & $\mathrm{HfO}_{2}(\mathrm{wt} \%)$ & 13.9747 & 13.9747 & 14.8900 & -0.9153 & -0.9153 & $-6.1 \%$ & $-6.1 \%$ \\
\hline Pu35-19 & $\mathrm{K}_{2} \mathrm{O}(\mathrm{wt} \%)$ & 0.2746 & 0.2388 & 0.3700 & -0.0954 & -0.1312 & $-25.8 \%$ & $-35.5 \%$ \\
\hline Pu35-19 & $\mathrm{La}_{2} \mathrm{O}_{3}(\mathrm{wt} \%)$ & 16.4778 & 16.4778 & 16.3400 & 0.1378 & 0.1378 & $0.8 \%$ & $0.8 \%$ \\
\hline \begin{tabular}{|l|}
$\mathrm{Pu} 35-19$ \\
\end{tabular} & $\mathrm{MgO}(\mathrm{wt} \%)$ & 1.2719 & 1.2855 & 1.3800 & -0.1081 & -0.0945 & $-7.8 \%$ & $-6.8 \%$ \\
\hline \begin{tabular}{|l|}
$\mathrm{Pu} 35-19$ \\
\end{tabular} & $\mathrm{Na}_{2} \mathrm{O}($ wt $\%)$ & 0.7650 & 0.6926 & 0.7800 & -0.0150 & -0.0874 & $-1.9 \%$ & $-11.2 \%$ \\
\hline Pu35-19 & $\mathrm{Nd}_{2} \mathrm{O}_{3}($ wt $\%)$ & 13.0637 & 13.0637 & 12.9000 & 0.1637 & 0.1637 & $1.3 \%$ & $1.3 \%$ \\
\hline \begin{tabular}{|l|}
$\mathrm{Pu} 35-19$ \\
\end{tabular} & $\mathrm{NiO}(\mathrm{wt} \%)$ & 0.0662 & 0.0740 & 0.0700 & -0.0038 & 0.0040 & $-5.5 \%$ & $5.7 \%$ \\
\hline Pu35-19 & $\mathrm{PbO}(\mathrm{wt} \%)$ & 0.0377 & 0.0377 & 0.0000 & 0.0377 & 0.0377 & & \\
\hline \begin{tabular}{|l|}
$\mathrm{Pu} 35-19$ \\
\end{tabular} & $\mathrm{SeO}_{2}(\mathrm{wt} \%)$ & 0.0070 & 0.0070 & 0.0000 & 0.0070 & 0.0070 & & \\
\hline \begin{tabular}{|l|}
$\mathrm{Pu} 35-19$ \\
\end{tabular} & $\mathrm{Si}_{2} \mathrm{O}_{3}(\mathrm{wt} \%)$ & 17.8204 & 17.3822 & 17.2000 & 0.6204 & 0.1822 & $3.6 \%$ & $1.1 \%$ \\
\hline \begin{tabular}{|l|}
$\mathrm{Pu} 35-19$ \\
\end{tabular} & $\mathrm{SO}_{4}(\mathrm{wt} \%)$ & 0.0749 & 0.0749 & 0.0000 & 0.0749 & 0.0749 & & \\
\hline Pu35-19 & $\mathrm{SrO}(\mathrm{wt} \%)$ & 2.2115 & 2.2115 & 2.1500 & 0.0615 & 0.0615 & $2.9 \%$ & $2.9 \%$ \\
\hline Pu35-19 & $\mathrm{Ta}_{2} \mathrm{O}_{5}(\mathrm{wt} \%)$ & 0.0824 & 0.0824 & 0.0700 & 0.0124 & 0.0124 & $17.7 \%$ & $17.7 \%$ \\
\hline \begin{tabular}{|l|}
$\mathrm{Pu} 35-19$ \\
\end{tabular} & Sum (wt \%) & 99.8810 & 99.0589 & 99.9900 & -0.1090 & -0.9311 & $-0.1 \%$ & $-0.9 \%$ \\
\hline Pu35-20 & $\mathrm{Al}_{2} \mathrm{O}_{3}(\mathrm{wt} \%)$ & 9.0790 & 8.8319 & 8.6000 & 0.4790 & 0.2319 & $5.6 \%$ & $2.7 \%$ \\
\hline Pu35-20 & $\mathrm{B}_{2} \mathrm{O}_{3}(\mathrm{wt} \%)$ & 11.1731 & 11.1054 & 11.1800 & -0.0069 & -0.0746 & $-0.1 \%$ & $-0.7 \%$ \\
\hline Pu35-20 & $\mathrm{CaO}(w \mathrm{t} \%)$ & 0.3197 & 0.3228 & 0.2300 & 0.0897 & 0.0928 & $39.0 \%$ & $40.3 \%$ \\
\hline Pu35-20 & $\mathrm{Cl}(\mathrm{wt} \%)$ & 0.0485 & 0.0485 & 0.5800 & -0.5315 & -0.5315 & $-91.6 \%$ & $-91.6 \%$ \\
\hline Pu35-20 & $\mathrm{Cr}_{2} \mathrm{O}_{3}(\mathrm{wt} \%)$ & 0.3698 & 0.3675 & 0.4000 & -0.0302 & -0.0325 & $-7.6 \%$ & $-8.1 \%$ \\
\hline $\mathrm{Pu} 35-20$ & $\mathrm{CuO}(\mathrm{wt} \%)$ & 0.1033 & 0.1088 & 0.0700 & 0.0333 & 0.0388 & $47.5 \%$ & $55.4 \%$ \\
\hline Pu35-20 & $\mathrm{F}(\mathrm{wt} \%)$ & 0.0400 & 0.0494 & 0.2900 & -0.2500 & -0.2406 & $-86.2 \%$ & $-83.0 \%$ \\
\hline Pu35-20 & $\mathrm{Fe}_{2} \mathrm{O}_{3}(\mathrm{wt} \%)$ & 0.2867 & 0.2841 & 0.2800 & 0.0067 & 0.0041 & $2.4 \%$ & $1.5 \%$ \\
\hline Pu35-20 & $\mathrm{Ga}_{2} \mathrm{O}_{3}($ wt $\%)$ & 0.5397 & 0.5397 & 0.5100 & 0.0297 & 0.0297 & $5.8 \%$ & $5.8 \%$ \\
\hline $\mathrm{Pu} 35-20$ & $\mathrm{Gd}_{2} \mathrm{O}_{3}(\mathrm{wt} \%)$ & 11.9870 & 11.9870 & 11.6100 & 0.3770 & 0.3770 & $3.2 \%$ & $3.2 \%$ \\
\hline Pu35-20 & $\mathrm{HfO}_{2}(\mathrm{wt} \%)$ & 14.0926 & 14.0926 & 14.9500 & -0.8574 & -0.8574 & $-5.7 \%$ & $-5.7 \%$ \\
\hline $\mathrm{Pu} 35-20$ & $\mathrm{~K}_{2} \mathrm{O}(\mathrm{wt} \%)$ & 0.6643 & 0.5776 & 0.8500 & -0.1857 & -0.2724 & $-21.8 \%$ & $-32.0 \%$ \\
\hline
\end{tabular}


Table D5. Average Measured and Bias-Corrected Chemical Compositions Versus Targeted Compositions by Oxide by Study Glass (continued)

\begin{tabular}{|c|c|c|c|c|c|c|c|c|}
\hline Glass ID & Oxide & $\begin{array}{c}\text { Measured } \\
(\text { wt \%) }\end{array}$ & \begin{tabular}{|c} 
Measured Bias- \\
Corrected (wt \%)
\end{tabular} & $\begin{array}{c}\text { Targeted } \\
\text { (wt \%) }\end{array}$ & $\begin{array}{c}\text { Diff of } \\
\text { Measured }\end{array}$ & $\begin{array}{c}\text { Diff of Meas } \\
\text { BC } \\
\end{array}$ & $\begin{array}{l}\% \text { Diff of } \\
\text { Measured }\end{array}$ & $\begin{array}{c}\text { \% Diff of Meas } \\
\text { BC }\end{array}$ \\
\hline $\mathrm{Pu} 35-20$ & $\mathrm{La}_{2} \mathrm{O}_{3}(\mathrm{wt} \%)$ & 16.8297 & \begin{tabular}{|l|}
16.8297 \\
\end{tabular} & 16.3400 & 0.4897 & 0.4897 & $3.0 \%$ & $3.0 \%$ \\
\hline Pu35-20 & $\mathrm{MgO}(\mathrm{wt} \%)$ & 0.5365 & 0.5422 & 0.5500 & -0.0135 & -0.0078 & $-2.5 \%$ & $-1.4 \%$ \\
\hline Pu35-20 & $\mathrm{Na}_{2} \mathrm{O}($ wt \%) & 0.5176 & 0.4687 & 0.5000 & 0.0176 & -0.0313 & $3.5 \%$ & $-6.3 \%$ \\
\hline Pu35-20 & $\mathrm{Nd}_{2} \mathrm{O}_{3}(\mathrm{wt} \%)$ & 13.2970 & 13.2970 & 12.9000 & 0.3970 & 0.3970 & $3.1 \%$ & $3.1 \%$ \\
\hline $\mathrm{Pu} 35-20$ & $\mathrm{NiO}(\mathrm{wt} \%)$ & 0.2666 & 0.2980 & 0.2900 & -0.0234 & 0.0080 & $-8.1 \%$ & $2.8 \%$ \\
\hline Pu35-20 & $\mathrm{PbO}($ wt \%) & 0.0393 & 0.0393 & 0.0000 & 0.0393 & 0.0393 & & \\
\hline $\mathrm{Pu} 35-20$ & $\mathrm{SeO}_{2}(\mathrm{wt} \%)$ & 0.0070 & 0.0070 & 0.0000 & 0.0070 & 0.0070 & & \\
\hline Pu35-20 & $\mathrm{Si}_{2} \mathrm{O}_{3}($ wt $\%)$ & 18.1520 & 17.7057 & 17.2000 & 0.9520 & 0.5057 & $5.5 \%$ & $2.9 \%$ \\
\hline $\mathrm{Pu} 35-20$ & $\mathrm{SO}_{4}(\mathrm{wt} \%)$ & 0.0749 & 0.0749 & 0.0000 & 0.0749 & 0.0749 & & \\
\hline Pu35-20 & $\mathrm{SrO}(\mathrm{wt} \%)$ & 2.2233 & 2.2233 & 2.1500 & 0.0733 & 0.0733 & $3.4 \%$ & $3.4 \%$ \\
\hline $\mathrm{Pu} 35-20$ & $\mathrm{Ta}_{2} \mathrm{O}_{5}(\mathrm{wt} \%)$ & 0.5110 & 0.5110 & 0.5100 & 0.0010 & 0.0010 & $0.2 \%$ & $0.2 \%$ \\
\hline Pu35-20 & Sum (wt \%) & 101.1585 & 100.3120 & 99.9900 & 1.1685 & 0.3220 & $1.2 \%$ & $0.3 \%$ \\
\hline Pu35-21 & $\mathrm{Al}_{2} \mathrm{O}_{3}(\mathrm{wt} \%)$ & 8.9657 & 8.7216 & 8.6000 & 0.3657 & 0.1216 & $4.3 \%$ & $1.4 \%$ \\
\hline Pu35-21 & $\mathrm{B}_{2} \mathrm{O}_{3}(\mathrm{wt} \%)$ & 11.1409 & 11.0734 & 11.1800 & -0.0391 & -0.1066 & $-0.4 \%$ & $-1.0 \%$ \\
\hline $\mathrm{Pu} 35-21$ & $\mathrm{CaO}($ wt \%) & 0.1798 & 0.1815 & 0.0800 & 0.0998 & 0.1015 & $124.7 \%$ & $126.9 \%$ \\
\hline $\mathrm{Pu} 35-21$ & $\mathrm{Cl}(\mathrm{wt} \%)$ & 0.0630 & 0.0630 & 0.5800 & -0.5170 & -0.5170 & $-89.1 \%$ & $-89.1 \%$ \\
\hline Pu35-21 & $\mathrm{Cr}_{2} \mathrm{O}_{3}(\mathrm{wt} \%)$ & 0.0811 & 0.0806 & 0.0900 & -0.0089 & -0.0094 & $-9.9 \%$ & $-10.4 \%$ \\
\hline Pu35-21 & $\mathrm{CuO}(\mathrm{wt} \%)$ & 0.1177 & 0.1239 & 0.0700 & 0.0477 & 0.0539 & $68.1 \%$ & $77.0 \%$ \\
\hline $\mathrm{Pu} 35-21$ & $\mathrm{~F}(\mathrm{wt} \%)$ & 0.0000 & 0.0000 & 0.0600 & -0.0600 & -0.0600 & $-100.0 \%$ & $-100.0 \%$ \\
\hline $\mathrm{Pu} 35-21$ & $\mathrm{Fe}_{2} \mathrm{O}_{3}(\mathrm{wt} \%)$ & 0.1037 & 0.1027 & 0.0800 & 0.0237 & 0.0227 & $29.6 \%$ & $28.4 \%$ \\
\hline Pu35-21 & $\mathrm{Ga}_{2} \mathrm{O}_{3}(\mathrm{wt} \%)$ & 0.6472 & 0.6472 & 0.6200 & 0.0272 & 0.0272 & $4.4 \%$ & $4.4 \%$ \\
\hline Pu35-21 & $\mathrm{Gd}_{2} \mathrm{O}_{3}(\mathrm{wt} \%)$ & 11.8718 & 11.8718 & 11.6100 & 0.2618 & 0.2618 & $2.3 \%$ & $2.3 \%$ \\
\hline Pu35-21 & $\mathrm{HfO}_{2}(\mathrm{wt} \%)$ & 13.6209 & 13.6209 & 14.9400 & -1.3191 & -1.3191 & $-8.8 \%$ & $-8.8 \%$ \\
\hline $\mathrm{Pu} 35-21$ & $\mathrm{~K}_{2} \mathrm{O}(\mathrm{wt} \%)$ & 0.3542 & 0.3079 & 0.4100 & -0.0558 & -0.1021 & $-13.6 \%$ & $-24.9 \%$ \\
\hline Pu35-21 & $\mathrm{La}_{2} \mathrm{O}_{3}(\mathrm{wt} \%)$ & 16.5365 & 16.5365 & 16.3400 & 0.1965 & 0.1965 & $1.2 \%$ & $1.2 \%$ \\
\hline Pu35-21 & $\mathrm{MgO}(\mathrm{wt} \%)$ & 1.1857 & 1.1983 & 1.2800 & -0.0943 & -0.0817 & $-7.4 \%$ & $-6.4 \%$ \\
\hline Pu35-21 & $\mathrm{Na}_{2} \mathrm{O}($ wt $\%)$ & 0.6026 & 0.5456 & 0.5900 & 0.0126 & -0.0444 & $2.1 \%$ & $-7.5 \%$ \\
\hline Pu35-21 & $\mathrm{Nd}_{2} \mathrm{O}_{3}(\mathrm{wt} \%)$ & 13.1803 & 13.1803 & 12.9000 & 0.2803 & 0.2803 & $2.2 \%$ & $2.2 \%$ \\
\hline Pu35-21 & $\mathrm{NiO}(\mathrm{wt} \%)$ & 0.0713 & 0.0797 & 0.0700 & 0.0013 & 0.0097 & $1.8 \%$ & $13.8 \%$ \\
\hline Pu35-21 & $\mathrm{PbO}($ wt \%) & 0.0388 & 0.0388 & 0.0000 & 0.0388 & 0.0388 & & \\
\hline Pu35-21 & $\mathrm{SeO}_{2}($ wt $\%)$ & 0.0070 & 0.0070 & 0.0000 & 0.0070 & 0.0070 & & \\
\hline Pu35-21 & $\mathrm{Si}_{2} \mathrm{O}_{3}(\mathrm{wt} \%)$ & 17.9701 & 17.5283 & 17.2000 & 0.7701 & 0.3283 & $4.5 \%$ & $1.9 \%$ \\
\hline Pu35-21 & $\mathrm{SO}_{4}(\mathrm{wt} \%)$ & 0.0749 & 0.0749 & 0.0000 & 0.0749 & 0.0749 & & \\
\hline Pu35-21 & SrO (wt \%) & 2.2055 & 2.2055 & 2.1500 & 0.0555 & 0.0555 & $2.6 \%$ & $2.6 \%$ \\
\hline Pu35-21 & $\mathrm{Ta}_{2} \mathrm{O}_{5}(\mathrm{wt} \%)$ & 1.0910 & 1.0910 & 1.1400 & -0.0490 & -0.0490 & $-4.3 \%$ & $-4.3 \%$ \\
\hline $\mathrm{Pu} 35-21$ & Sum (wt \%) & 100.1095 & 99.2805 & 99.9900 & 0.1195 & -0.7095 & $0.1 \%$ & $-0.7 \%$ \\
\hline $\mathrm{Pu} 35-22$ & $\mathrm{Al}_{2} \mathrm{O}_{3}(\mathrm{wt} \%)$ & 9.0602 & 8.8135 & 8.6000 & 0.4602 & 0.2135 & $5.4 \%$ & $2.5 \%$ \\
\hline $\mathrm{Pu} 35-22$ & $\mathrm{~B}_{2} \mathrm{O}_{3}(\mathrm{wt} \%)$ & 11.3018 & 11.2334 & 11.1800 & 0.1218 & 0.0534 & $1.1 \%$ & $0.5 \%$ \\
\hline Pu35-22 & $\mathrm{CaO}($ wt \%) & 0.6968 & 0.7035 & 0.5900 & 0.1068 & 0.1135 & $18.1 \%$ & $19.2 \%$ \\
\hline $\mathrm{Pu} 35-22$ & $\mathrm{Cl}(\mathrm{wt} \%)$ & 0.0555 & 0.0555 & 0.6000 & -0.5445 & -0.5445 & $-90.8 \%$ & $-90.8 \%$ \\
\hline $\mathrm{Pu} 35-22$ & $\mathrm{Cr}_{2} \mathrm{O}_{3}(\mathrm{wt} \%)$ & 0.1367 & 0.1358 & 0.1500 & -0.0133 & -0.0142 & $-8.9 \%$ & $-9.5 \%$ \\
\hline $\mathrm{Pu} 35-22$ & $\mathrm{CuO}(\mathrm{wt} \%)$ & 0.2316 & 0.2439 & 0.2200 & 0.0116 & 0.0239 & $5.3 \%$ & $10.9 \%$ \\
\hline $\mathrm{Pu} 35-22$ & $\mathrm{~F}(\mathrm{wt} \%)$ & 0.0950 & 0.1172 & 0.4700 & -0.3750 & -0.3528 & $-79.8 \%$ & $-75.1 \%$ \\
\hline Pu35-22 & $\mathrm{Fe}_{2} \mathrm{O}_{3}(\mathrm{wt} \%)$ & 0.3739 & 0.3706 & 0.3700 & 0.0039 & 0.0006 & $1.0 \%$ & $0.2 \%$ \\
\hline $\mathrm{Pu} 35-22$ & $\mathrm{Ga}_{2} \mathrm{O}_{3}(\mathrm{wt} \%)$ & 0.1149 & 0.1149 & 0.0800 & 0.0349 & 0.0349 & $43.7 \%$ & $43.7 \%$ \\
\hline $\mathrm{Pu} 35-22$ & $\mathrm{Gd}_{2} \mathrm{O}_{3}(\mathrm{wt} \%)$ & 12.0447 & 12.0447 & 11.6100 & 0.4347 & 0.4347 & $3.7 \%$ & $3.7 \%$ \\
\hline Pu35-22 & $\mathrm{HfO}_{2}(\mathrm{wt} \%)$ & 13.9157 & 13.9157 & 14.9800 & -1.0643 & -1.0643 & $-7.1 \%$ & $-7.1 \%$ \\
\hline Pu35-22 & $\mathrm{K}_{2} \mathrm{O}(\mathrm{wt} \%)$ & 0.4674 & 0.4064 & 0.5500 & -0.0826 & -0.1436 & $-15.0 \%$ & $-26.1 \%$ \\
\hline $\mathrm{Pu} 35-22$ & $\mathrm{La}_{2} \mathrm{O}_{3}(\mathrm{wt} \%)$ & 16.8297 & 16.8297 & 16.3400 & 0.4897 & 0.4897 & $3.0 \%$ & $3.0 \%$ \\
\hline $\mathrm{Pu} 35-22$ & $\mathrm{MgO}(\mathrm{wt} \%)$ & 0.6758 & 0.6830 & 0.6900 & -0.0142 & -0.0070 & $-2.1 \%$ & $-1.0 \%$ \\
\hline Pu35-22 & $\mathrm{Na}_{2} \mathrm{O}($ wt $\%)$ & 0.7522 & 0.6810 & 0.7400 & 0.0122 & -0.0590 & $1.6 \%$ & $-8.0 \%$ \\
\hline $\mathrm{Pu} 35-22$ & $\mathrm{Nd}_{2} \mathrm{O}_{3}(\mathrm{wt} \%)$ & 13.2386 & 13.2386 & 12.9000 & 0.3386 & 0.3386 & $2.6 \%$ & $2.6 \%$ \\
\hline $\mathrm{Pu} 35-22$ & $\mathrm{NiO}($ wt \%) & 0.0725 & 0.0811 & 0.0800 & -0.0075 & 0.0011 & $-9.3 \%$ & $1.3 \%$ \\
\hline Pu35-22 & $\mathrm{PbO}(\mathrm{wt} \%)$ & 0.0377 & 0.0377 & 0.0000 & 0.0377 & 0.0377 & & \\
\hline Pu35-22 & $\mathrm{SeO}_{2}(\mathrm{wt} \%)$ & 0.0070 & 0.0070 & 0.0000 & 0.0070 & 0.0070 & & \\
\hline Pu35-22 & $\mathrm{Si}_{2} \mathrm{O}_{3}($ wt $\%)$ & 18.1627 & 17.7161 & 17.2000 & 0.9627 & 0.5161 & $5.6 \%$ & $3.0 \%$ \\
\hline Pu35-22 & $\mathrm{SO}_{4}(\mathrm{wt} \%)$ & 0.0749 & 0.0749 & 0.0000 & 0.0749 & 0.0749 & & \\
\hline $\mathrm{Pu} 35-22$ & $\mathrm{SrO}($ wt $\%)$ & 2.2174 & 2.2174 & 2.1500 & 0.0674 & 0.0674 & $3.1 \%$ & $3.1 \%$ \\
\hline
\end{tabular}


Table D5. Average Measured and Bias-Corrected Chemical Compositions Versus Targeted Compositions by Oxide by Study Glass (continued)

\begin{tabular}{|c|c|c|c|c|c|c|c|c|}
\hline Glass ID & Oxide & $\begin{array}{c}\text { Measured } \\
(\text { wt \%) }\end{array}$ & $\begin{array}{c}\text { Measured Bias- } \\
\text { Corrected (wt \%) }\end{array}$ & $\begin{array}{c}\text { Targeted } \\
\text { (wt \%) }\end{array}$ & $\begin{array}{c}\text { Diff of } \\
\text { Measured }\end{array}$ & $\begin{array}{c}\text { Diff of Meas } \\
\text { BC }\end{array}$ & $\begin{array}{l}\% \text { Diff of } \\
\text { Measured }\end{array}$ & $\begin{array}{c}\% \text { Diff of Meas } \\
\text { BC }\end{array}$ \\
\hline Pu35-22 & $\mathrm{Ta}_{2} \mathrm{O}_{5}(\mathrm{wt} \%)$ & 0.5134 & 0.5134 & 0.5200 & -0.0066 & -0.0066 & $-1.3 \%$ & $-1.3 \%$ \\
\hline Pu35-22 & Sum (wt \%) & 101.0760 & 100.2351 & 100.0200 & 1.0560 & 0.2151 & $1.1 \%$ & $0.2 \%$ \\
\hline Pu35-23 & $\mathrm{Al}_{2} \mathrm{O}_{3}(\mathrm{wt} \%)$ & 8.9846 & 8.7400 & 8.6000 & 0.3846 & 0.1400 & $4.5 \%$ & $1.6 \%$ \\
\hline Pu35-23 & $\mathrm{B}_{2} \mathrm{O}_{3}($ wt $\%)$ & 11.3501 & 11.2814 & 11.1800 & 0.1701 & 0.1014 & $1.5 \%$ & $0.9 \%$ \\
\hline Pu35-23 & $\mathrm{CaO}(\mathrm{wt} \%)$ & 0.2379 & 0.2401 & 0.1600 & 0.0779 & 0.0801 & $48.7 \%$ & $50.1 \%$ \\
\hline Pu35-23 & $\mathrm{Cl}(\mathrm{wt} \%)$ & 0.0630 & 0.0630 & 0.5900 & -0.5270 & -0.5270 & $-89.3 \%$ & $-89.3 \%$ \\
\hline Pu35-23 & $\mathrm{Cr}_{2} \mathrm{O}_{3}(\mathrm{wt} \%)$ & 0.2704 & 0.2687 & 0.2900 & -0.0196 & -0.0213 & $-6.8 \%$ & $-7.3 \%$ \\
\hline $\mathrm{Pu} 35-23$ & $\mathrm{CuO}(\mathrm{wt} \%)$ & 0.2341 & 0.2465 & 0.2200 & 0.0141 & 0.0265 & $6.4 \%$ & $12.1 \%$ \\
\hline $\mathrm{Pu} 35-23$ & $\mathrm{~F}(\mathrm{wt} \%)$ & 0.0110 & 0.0136 & 0.0900 & -0.0790 & -0.0764 & $-87.8 \%$ & $-84.9 \%$ \\
\hline Pu35-23 & $\mathrm{Fe}_{2} \mathrm{O}_{3}(\mathrm{wt} \%)$ & 0.5569 & 0.5520 & 0.5600 & -0.0031 & -0.0080 & $-0.6 \%$ & $-1.4 \%$ \\
\hline $\mathrm{Pu} 35-23$ & $\mathrm{Ga}_{2} \mathrm{O}_{3}(\mathrm{wt} \%)$ & 0.5572 & 0.5572 & 0.5300 & 0.0272 & 0.0272 & $5.1 \%$ & $5.1 \%$ \\
\hline Pu35-23 & $\mathrm{Gd}_{2} \mathrm{O}_{3}(\mathrm{wt} \%)$ & 11.8718 & 11.8718 & 11.6100 & 0.2618 & 0.2618 & $2.3 \%$ & $2.3 \%$ \\
\hline $\mathrm{Pu} 35-23$ & $\mathrm{HfO}_{2}(\mathrm{wt} \%)$ & 13.9747 & 13.9747 & 14.8800 & -0.9053 & -0.9053 & $-6.1 \%$ & $-6.1 \%$ \\
\hline Pu35-23 & $\mathrm{K}_{2} \mathrm{O}(\mathrm{wt} \%)$ & 0.1265 & 0.1100 & 0.1600 & -0.0335 & -0.0500 & $-20.9 \%$ & $-31.3 \%$ \\
\hline Pu35-23 & $\mathrm{La}_{2} \mathrm{O}_{3}(\mathrm{wt} \%)$ & 16.5365 & 16.5365 & 16.3400 & 0.1965 & 0.1965 & $1.2 \%$ & $1.2 \%$ \\
\hline Pu35-23 & $\mathrm{MgO}(\mathrm{wt} \%)$ & 0.6501 & 0.6570 & 0.6700 & -0.0199 & -0.0130 & $-3.0 \%$ & $-1.9 \%$ \\
\hline Pu35-23 & $\mathrm{Na}_{2} \mathrm{O}$ (wt \%) & 0.9018 & 0.8165 & 0.9300 & -0.0282 & -0.1135 & $-3.0 \%$ & $-12.2 \%$ \\
\hline $\mathrm{Pu} 35-23$ & $\mathrm{Nd}_{2} \mathrm{O}_{3}(\mathrm{wt} \%)$ & 13.1220 & 13.1220 & 12.9000 & 0.2220 & 0.2220 & $1.7 \%$ & $1.7 \%$ \\
\hline $\mathrm{Pu} 35-23$ & $\mathrm{NiO}($ wt \%) & 0.1101 & 0.1230 & 0.1200 & -0.0099 & 0.0030 & $-8.3 \%$ & $2.5 \%$ \\
\hline Pu35-23 & $\mathrm{PbO}(\mathrm{wt} \%)$ & 0.0388 & 0.0388 & 0.0000 & 0.0388 & 0.0388 & & \\
\hline $\mathrm{Pu} 35-23$ & $\mathrm{SeO}_{2}($ wt $\%)$ & 0.0070 & 0.0070 & 0.0000 & 0.0070 & 0.0070 & & \\
\hline $\mathrm{Pu} 35-23$ & $\mathrm{Si}_{2} \mathrm{O}_{3}($ wt $\%)$ & 17.8418 & 17.4031 & 17.2000 & 0.6418 & 0.2031 & $3.7 \%$ & $1.2 \%$ \\
\hline $\mathrm{Pu} 35-23$ & $\mathrm{SO}_{4}(\mathrm{wt} \%)$ & 0.0749 & 0.0749 & 0.0000 & 0.0749 & 0.0749 & & \\
\hline Pu35-23 & $\mathrm{SrO}(\mathrm{wt} \%)$ & 2.2292 & 2.2292 & 2.1500 & 0.0792 & 0.0792 & $3.7 \%$ & $3.7 \%$ \\
\hline $\mathrm{Pu} 35-23$ & $\mathrm{Ta}_{2} \mathrm{O}_{5}(\mathrm{wt} \%)$ & 0.7967 & 0.7967 & 0.8300 & -0.0333 & -0.0333 & $-4.0 \%$ & $-4.0 \%$ \\
\hline Pu35-23 & Sum (wt \%) & 100.5469 & 99.7237 & 100.0100 & 0.5369 & -0.2863 & $0.5 \%$ & $-0.3 \%$ \\
\hline Pu35-24 & $\mathrm{Al}_{2} \mathrm{O}_{3}(\mathrm{wt} \%)$ & 8.9184 & 8.6757 & 8.6000 & 0.3184 & 0.0757 & $3.7 \%$ & $0.9 \%$ \\
\hline Pu35-24 & $\mathrm{B}_{2} \mathrm{O}_{3}(\mathrm{wt} \%)$ & 11.4145 & 11.3455 & 11.1800 & 0.2345 & 0.1655 & $2.1 \%$ & $1.5 \%$ \\
\hline Pu35-24 & $\mathrm{CaO}($ wt \%) & 0.5037 & 0.5085 & 0.4000 & 0.1037 & 0.1085 & $25.9 \%$ & $27.1 \%$ \\
\hline Pu35-24 & $\mathrm{Cl}(\mathrm{wt} \%)$ & 0.0550 & 0.0550 & 0.6300 & -0.5750 & -0.5750 & $-91.3 \%$ & $-91.3 \%$ \\
\hline Pu35-24 & $\mathrm{Cr}_{2} \mathrm{O}_{3}(\mathrm{wt} \%)$ & 0.3435 & 0.3413 & 0.3700 & -0.0265 & -0.0287 & $-7.2 \%$ & $-7.7 \%$ \\
\hline Pu35-24 & $\mathrm{CuO}(\mathrm{wt} \%)$ & 0.2147 & 0.2261 & 0.2200 & -0.0053 & 0.0061 & $-2.4 \%$ & $2.8 \%$ \\
\hline $\mathrm{Pu} 35-24$ & $\mathrm{~F}(\mathrm{wt} \%)$ & 0.0310 & 0.0383 & 0.2400 & -0.2090 & -0.2017 & $-87.1 \%$ & $-84.1 \%$ \\
\hline Pu35-24 & $\mathrm{Fe}_{2} \mathrm{O}_{3}(\mathrm{wt} \%)$ & 0.4296 & 0.4258 & 0.4100 & 0.0196 & 0.0158 & $4.8 \%$ & $3.9 \%$ \\
\hline Pu35-24 & $\mathrm{Ga}_{2} \mathrm{O}_{3}($ wt $\%)$ & 0.8395 & 0.8395 & 0.8300 & 0.0095 & 0.0095 & $1.1 \%$ & $1.1 \%$ \\
\hline Pu35-24 & $\mathrm{Gd}_{2} \mathrm{O}_{3}(\mathrm{wt} \%)$ & 11.8142 & 11.8142 & 11.6100 & 0.2042 & 0.2042 & $1.8 \%$ & $1.8 \%$ \\
\hline $\mathrm{Pu} 35-24$ & $\mathrm{HfO}_{2}(\mathrm{wt} \%)$ & 13.7978 & 13.7978 & 14.9000 & -1.1022 & -1.1022 & $-7.4 \%$ & $-7.4 \%$ \\
\hline $\mathrm{Pu} 35-24$ & $\mathrm{~K}_{2} \mathrm{O}(\mathrm{wt} \%)$ & 0.4186 & 0.3639 & 0.5300 & -0.1114 & -0.1661 & $-21.0 \%$ & $-31.3 \%$ \\
\hline $\mathrm{Pu} 35-24$ & $\mathrm{La}_{2} \mathrm{O}_{3}(\mathrm{wt} \%)$ & 16.5365 & 16.5365 & 16.3400 & 0.1965 & 0.1965 & $1.2 \%$ & $1.2 \%$ \\
\hline $\mathrm{Pu} 35-24$ & $\mathrm{MgO}(\mathrm{wt} \%)$ & 0.6492 & 0.6561 & 0.6700 & -0.0208 & -0.0139 & $-3.1 \%$ & $-2.1 \%$ \\
\hline $\mathrm{Pu} 35-24$ & $\mathrm{Na}_{2} \mathrm{O}($ wt $\%)$ & 0.5911 & 0.5352 & 0.5800 & 0.0111 & -0.0448 & $1.9 \%$ & $-7.7 \%$ \\
\hline Pu35-24 & $\mathrm{Nd}_{2} \mathrm{O}_{3}(\mathrm{wt} \%)$ & 13.0637 & 13.0637 & 12.9000 & 0.1637 & 0.1637 & $1.3 \%$ & $1.3 \%$ \\
\hline $\mathrm{Pu} 35-24$ & $\mathrm{NiO}($ wt \%) & 0.0891 & 0.0996 & 0.1000 & -0.0109 & -0.0004 & $-10.9 \%$ & $-0.4 \%$ \\
\hline $\mathrm{Pu} 35-24$ & $\mathrm{PbO}(\mathrm{wt} \%)$ & 0.0393 & 0.0393 & 0.0000 & 0.0393 & 0.0393 & & \\
\hline $\mathrm{Pu} 35-24$ & $\mathrm{SeO}_{2}(\mathrm{wt} \%)$ & 0.0070 & 0.0070 & 0.0000 & 0.0070 & 0.0070 & & \\
\hline Pu35-24 & $\mathrm{Si}_{2} \mathrm{O}_{3}($ wt $\%)$ & 17.9808 & 17.5387 & 17.2000 & 0.7808 & 0.3387 & $4.5 \%$ & $2.0 \%$ \\
\hline Pu35-24 & $\mathrm{SO}_{4}(\mathrm{wt} \%)$ & 0.0749 & 0.0749 & 0.0000 & 0.0749 & 0.0749 & & \\
\hline Pu35-24 & $\mathrm{SrO}($ wt $\%)$ & 2.1819 & 2.1819 & 2.1500 & 0.0319 & 0.0319 & $1.5 \%$ & $1.5 \%$ \\
\hline Pu35-24 & $\mathrm{Ta}_{2} \mathrm{O}_{5}($ wt $\%)$ & 0.1691 & 0.1691 & 0.1500 & 0.0191 & 0.0191 & $12.7 \%$ & $12.7 \%$ \\
\hline $\mathrm{Pu} 35-24$ & Sum (wt \%) & 100.1631 & 99.3336 & 100.0100 & 0.1531 & -0.6764 & $0.2 \%$ & $-0.7 \%$ \\
\hline $\mathrm{Pu} 35-25$ & $\mathrm{Al}_{2} \mathrm{O}_{3}(\mathrm{wt} \%)$ & 8.8901 & 8.6481 & 8.6000 & 0.2901 & 0.0481 & $3.4 \%$ & $0.6 \%$ \\
\hline Pu35-25 & $\mathrm{B}_{2} \mathrm{O}_{3}(\mathrm{wt} \%)$ & 11.1731 & 11.1054 & 11.1800 & -0.0069 & -0.0746 & $-0.1 \%$ & $-0.7 \%$ \\
\hline Pu35-25 & $\mathrm{CaO}(\mathrm{wt} \%)$ & 0.3743 & 0.3779 & 0.2800 & 0.0943 & 0.0979 & $33.7 \%$ & $35.0 \%$ \\
\hline $\mathrm{Pu} 35-25$ & $\mathrm{Cl}(\mathrm{wt} \%)$ & 0.0735 & 0.0735 & 0.6700 & -0.5965 & -0.5965 & $-89.0 \%$ & $-89.0 \%$ \\
\hline $\mathrm{Pu} 35-25$ & $\mathrm{Cr}_{2} \mathrm{O}_{3}(\mathrm{wt} \%)$ & 0.1754 & 0.1743 & 0.1700 & 0.0054 & 0.0043 & $3.2 \%$ & $2.5 \%$ \\
\hline $\mathrm{Pu} 35-25$ & $\mathrm{CuO}(\mathrm{wt} \%)$ & 0.2291 & 0.2412 & 0.2200 & 0.0091 & 0.0212 & $4.1 \%$ & $9.7 \%$ \\
\hline Pu35-25 & $\mathrm{F}(\mathrm{wt} \%)$ & 0.0000 & 0.0000 & 0.0700 & -0.0700 & -0.0700 & $-100.0 \%$ & $-100.0 \%$ \\
\hline Pu35-25 & $\mathrm{Fe}_{2} \mathrm{O}_{3}($ wt $\%)$ & 0.8228 & 0.8155 & 0.8300 & -0.0072 & -0.0145 & $-0.9 \%$ & $-1.7 \%$ \\
\hline
\end{tabular}


Table D5. Average Measured and Bias-Corrected Chemical Compositions Versus Targeted Compositions by Oxide by Study Glass (continued)

\begin{tabular}{|c|c|c|c|c|c|c|c|c|}
\hline Glass ID & Oxide & $\begin{array}{c}\text { Measured } \\
\text { (wt \%) }\end{array}$ & \begin{tabular}{|c} 
Measured Bias- \\
Corrected (wt \%)
\end{tabular} & $\begin{array}{c}\text { Targeted } \\
\text { (wt \%) }\end{array}$ & $\begin{array}{c}\text { Diff of } \\
\text { Measured }\end{array}$ & \begin{tabular}{|c|} 
Diff of Meas \\
BC
\end{tabular} & $\begin{array}{l}\text { \% Diff of } \\
\text { Measured }\end{array}$ & $\begin{array}{c}\% \text { Diff of Meas } \\
\text { BC }\end{array}$ \\
\hline Pu35-25 & $\mathrm{Ga}_{2} \mathrm{O}_{3}(\mathrm{wt} \%)$ & 0.2917 & 0.2917 & 0.2600 & 0.0317 & \begin{tabular}{|l|}
0.0317 \\
\end{tabular} & $12.2 \%$ & $12.2 \%$ \\
\hline Pu35-25 & $\mathrm{Gd}_{2} \mathrm{O}_{3}(\mathrm{wt} \%)$ & 11.8142 & 11.8142 & 11.6100 & 0.2042 & 0.2042 & $1.8 \%$ & $1.8 \%$ \\
\hline Pu35-25 & $\mathrm{HfO}_{2}(\mathrm{wt} \%)$ & 13.7978 & 13.7978 & 14.9200 & -1.1222 & -1.1222 & $-7.5 \%$ & $-7.5 \%$ \\
\hline Pu35-25 & $\mathrm{K}_{2} \mathrm{O}(\mathrm{wt} \%)$ & 0.6216 & 0.5404 & 0.7000 & -0.0784 & -0.1596 & $-11.2 \%$ & $-22.8 \%$ \\
\hline Pu35-25 & $\mathrm{La}_{2} \mathrm{O}_{3}($ wt $\%)$ & 16.3606 & 16.3606 & 16.3400 & 0.0206 & 0.0206 & $0.1 \%$ & $0.1 \%$ \\
\hline Pu35-25 & $\mathrm{MgO}(\mathrm{wt} \%)$ & 0.4668 & 0.4718 & 0.4800 & -0.0132 & -0.0082 & $-2.7 \%$ & $-1.7 \%$ \\
\hline Pu35-25 & $\mathrm{Na}_{2} \mathrm{O}($ wt $\%)$ & 0.4934 & 0.4467 & 0.4800 & 0.0134 & -0.0333 & $2.8 \%$ & $-6.9 \%$ \\
\hline Pu35-25 & $\mathrm{Nd}_{2} \mathrm{O}_{3}($ wt $\%)$ & 13.0054 & 13.0054 & 12.9000 & 0.1054 & 0.1054 & $0.8 \%$ & $0.8 \%$ \\
\hline Pu35-25 & $\mathrm{NiO}(\mathrm{wt} \%)$ & 0.3169 & 0.3542 & 0.3500 & -0.0331 & 0.0042 & $-9.5 \%$ & $1.2 \%$ \\
\hline Pu35-25 & $\mathrm{PbO}(\mathrm{wt} \%)$ & 0.0366 & 0.0366 & 0.0000 & 0.0366 & 0.0366 & & \\
\hline Pu35-25 & $\mathrm{SeO}_{2}(\mathrm{wt} \%)$ & 0.0070 & 0.0070 & 0.0000 & 0.0070 & 0.0070 & & \\
\hline Pu35-25 & $\mathrm{Si}_{2} \mathrm{O}_{3}($ wt $\%)$ & 19.5853 & 19.1038 & 17.2000 & 2.3853 & 1.9038 & $13.9 \%$ & $11.1 \%$ \\
\hline \begin{tabular}{|l|} 
Pu35-25 \\
\end{tabular} & $\mathrm{SO}_{4}(\mathrm{wt} \%)$ & 0.0749 & 0.0749 & 0.0000 & 0.0749 & 0.0749 & & \\
\hline Pu35-25 & $\mathrm{SrO}(\mathrm{wt} \%)$ & 2.1819 & 2.1819 & 2.1500 & 0.0319 & 0.0319 & $1.5 \%$ & $1.5 \%$ \\
\hline Pu35-25 & $\mathrm{Ta}_{2} \mathrm{O}_{5}(\mathrm{wt} \%)$ & 0.5739 & 0.5739 & 0.5900 & -0.0161 & -0.0161 & $-2.7 \%$ & $-2.7 \%$ \\
\hline Pu35-25 & Sum (wt \%) & 101.3660 & 100.4967 & 100.0000 & 1.3660 & 0.4967 & $1.4 \%$ & $0.5 \%$ \\
\hline Pu35-26 & $\mathrm{Al}_{2} \mathrm{O}_{3}(\mathrm{wt} \%)$ & 8.7956 & 8.8681 & 8.6000 & 0.1956 & 0.2681 & $2.3 \%$ & $3.1 \%$ \\
\hline Pu35-26 & $\mathrm{B}_{2} \mathrm{O}_{3}(\mathrm{wt} \%)$ & 11.2214 & 11.1382 & 11.1800 & 0.0414 & -0.0418 & $0.4 \%$ & $-0.4 \%$ \\
\hline Pu35-26 & $\mathrm{CaO}$ (wt \%) & 0.5254 & 0.5294 & 0.4300 & 0.0954 & 0.0994 & $22.2 \%$ & $23.1 \%$ \\
\hline Pu35-26 & $\mathrm{Cl}(\mathrm{wt} \%)$ & 0.0475 & 0.0475 & 0.6600 & -0.6125 & -0.6125 & $-92.8 \%$ & $-92.8 \%$ \\
\hline Pu35-26 & $\mathrm{Cr}_{2} \mathrm{O}_{3}(\mathrm{wt} \%)$ & 0.2455 & 0.2376 & 0.2700 & -0.0245 & -0.0324 & $-9.1 \%$ & $-12.0 \%$ \\
\hline Pu35-26 & $\mathrm{CuO}($ wt $\%)$ & 0.0964 & 0.1015 & 0.0700 & 0.0264 & 0.0315 & $37.7 \%$ & $45.0 \%$ \\
\hline Pu35-26 & $\mathrm{F}(\mathrm{wt} \%)$ & 0.0325 & 0.0397 & 0.1000 & -0.0675 & -0.0603 & $-67.5 \%$ & $-60.3 \%$ \\
\hline Pu35-26 & $\mathrm{Fe}_{2} \mathrm{O}_{3}(\mathrm{wt} \%)$ & 0.4718 & 0.4813 & 0.4700 & 0.0018 & 0.0113 & $0.4 \%$ & $2.4 \%$ \\
\hline Pu35-26 & $\mathrm{Ga}_{2} \mathrm{O}_{3}(\mathrm{wt} \%)$ & 0.7991 & 0.7991 & 0.7900 & 0.0091 & 0.0091 & $1.2 \%$ & $1.2 \%$ \\
\hline Pu35-26 & $\mathrm{Gd}_{2} \mathrm{O}_{3}(\mathrm{wt} \%)$ & 11.6413 & 11.6413 & 11.6100 & 0.0313 & 0.0313 & $0.3 \%$ & $0.3 \%$ \\
\hline Pu35-26 & $\mathrm{HfO}_{2}(\mathrm{wt} \%)$ & 13.6799 & 13.6799 & 14.8700 & -1.1901 & -1.1901 & $-8.0 \%$ & $-8.0 \%$ \\
\hline Pu35-26 & $\mathrm{K}_{2} \mathrm{O}(\mathrm{wt} \%)$ & 0.2060 & 0.1841 & 0.2500 & -0.0440 & -0.0659 & $-17.6 \%$ & $-26.4 \%$ \\
\hline Pu35-26 & $\mathrm{La}_{2} \mathrm{O}_{3}(\mathrm{wt} \%)$ & 16.1260 & 16.1260 & 16.3400 & -0.2140 & -0.2140 & $-1.3 \%$ & $-1.3 \%$ \\
\hline Pu35-26 & $\mathrm{MgO}(\mathrm{wt} \%)$ & 0.8598 & 0.8489 & 0.8900 & -0.0302 & -0.0411 & $-3.4 \%$ & $-4.6 \%$ \\
\hline \begin{tabular}{|l|} 
Pu35-26 \\
\end{tabular} & $\mathrm{Na}_{2} \mathrm{O}($ wt $\%)$ & 0.7569 & 0.7170 & 0.7700 & -0.0131 & -0.0530 & $-1.7 \%$ & $-6.9 \%$ \\
\hline Pu35-26 & $\mathrm{Nd}_{2} \mathrm{O}_{3}($ wt $\%)$ & 13.0637 & 13.0637 & 12.9000 & 0.1637 & 0.1637 & $1.3 \%$ & $1.3 \%$ \\
\hline Pu35-26 & $\mathrm{NiO}(\mathrm{wt} \%)$ & 0.2049 & 0.2249 & 0.2200 & -0.0151 & 0.0049 & $-6.9 \%$ & $2.2 \%$ \\
\hline Pu35-26 & $\mathrm{PbO}($ wt $\%)$ & 0.0393 & 0.0393 & 0.0000 & 0.0393 & 0.0393 & & \\
\hline Pu35-26 & $\mathrm{SeO}_{2}(\mathrm{wt} \%)$ & 0.0070 & 0.0070 & 0.0000 & 0.0070 & 0.0070 & & \\
\hline Pu35-26 & $\mathrm{Si}_{2} \mathrm{O}_{3}($ wt $\%)$ & 17.5316 & 17.7139 & 17.2000 & 0.3316 & 0.5139 & $1.9 \%$ & $3.0 \%$ \\
\hline \begin{tabular}{|l|} 
Pu35-26 \\
\end{tabular} & $\mathrm{SO}_{4}(\mathrm{wt} \%)$ & 0.0749 & 0.0749 & 0.0000 & 0.0749 & 0.0749 & & \\
\hline Pu35-26 & $\mathrm{SrO}(\mathrm{wt} \%)$ & 2.1523 & 2.1523 & 2.1500 & 0.0023 & 0.0023 & $0.1 \%$ & $0.1 \%$ \\
\hline Pu35-26 & $\mathrm{Ta}_{2} \mathrm{O}_{5}(\mathrm{wt} \%)$ & 0.2277 & 0.2277 & 0.2200 & 0.0077 & 0.0077 & $3.5 \%$ & $3.5 \%$ \\
\hline Pu35-26 & Sum (wt \%) & 98.8065 & 98.9434 & 99.9900 & -1.1835 & -1.0466 & $-1.2 \%$ & $-1.0 \%$ \\
\hline Pu35-27 & $\mathrm{Al}_{2} \mathrm{O}_{3}($ wt $\%)$ & 8.8051 & 8.8777 & 8.6000 & 0.2051 & 0.2777 & $2.4 \%$ & $3.2 \%$ \\
\hline Pu35-27 & $\mathrm{B}_{2} \mathrm{O}_{3}(\mathrm{wt} \%)$ & 11.1731 & 11.0902 & 11.1800 & -0.0069 & -0.0898 & $-0.1 \%$ & $-0.8 \%$ \\
\hline \begin{tabular}{|l|}
$\mathrm{Pu} 35-27$ \\
\end{tabular} & $\mathrm{CaO}($ wt \%) & 0.4233 & 0.4265 & 0.3200 & 0.1033 & 0.1065 & $32.3 \%$ & $33.3 \%$ \\
\hline \begin{tabular}{|l|}
$\mathrm{Pu} 35-27$ \\
\end{tabular} & $\mathrm{Cl}(\mathrm{wt} \%)$ & 0.0695 & 0.0695 & 0.7200 & -0.6505 & -0.6505 & $-90.3 \%$ & $-90.3 \%$ \\
\hline \begin{tabular}{|l|} 
Pu35-27 \\
\end{tabular} & $\mathrm{Cr}_{2} \mathrm{O}_{3}(\mathrm{wt} \%)$ & 0.4451 & 0.4306 & 0.4800 & -0.0349 & -0.0494 & $-7.3 \%$ & $-10.3 \%$ \\
\hline \begin{tabular}{|l|} 
Pu35-27 \\
\end{tabular} & $\mathrm{CuO}($ wt $\%)$ & 0.1058 & 0.1114 & 0.0700 & 0.0358 & 0.0414 & $51.1 \%$ & $59.1 \%$ \\
\hline \begin{tabular}{|l|}
$\mathrm{Pu} 35-27$ \\
\end{tabular} & $\mathrm{~F}(\mathrm{wt} \%)$ & 0.0550 & 0.0672 & 0.2400 & -0.1850 & -0.1728 & $-77.1 \%$ & $-72.0 \%$ \\
\hline Pu35-27 & $\mathrm{Fe}_{2} \mathrm{O}_{3}(\mathrm{wt} \%)$ & 0.4725 & 0.4820 & 0.4600 & 0.0125 & 0.0220 & $2.7 \%$ & $4.8 \%$ \\
\hline Pu35-27 & $\mathrm{Ga}_{2} \mathrm{O}_{3}(\mathrm{wt} \%)$ & 0.3112 & 0.3112 & 0.2700 & 0.0412 & 0.0412 & $15.3 \%$ & $15.3 \%$ \\
\hline Pu35-27 & $\mathrm{Gd}_{2} \mathrm{O}_{3}(\mathrm{wt} \%)$ & 11.5894 & 11.5894 & 11.6100 & -0.0206 & -0.0206 & $-0.2 \%$ & $-0.2 \%$ \\
\hline Pu35-27 & $\mathrm{HfO}_{2}(\mathrm{wt} \%)$ & 13.3851 & 13.3851 & 14.9400 & -1.5549 & -1.5549 & $-10.4 \%$ & $-10.4 \%$ \\
\hline Pu35-27 & $\mathrm{K}_{2} \mathrm{O}(\mathrm{wt} \%)$ & 0.4078 & 0.3645 & 0.5200 & -0.1122 & -0.1555 & $-21.6 \%$ & $-29.9 \%$ \\
\hline Pu35-27 & $\mathrm{La}_{2} \mathrm{O}_{3}(\mathrm{wt} \%)$ & 16.0087 & 16.0087 & 16.3400 & -0.3313 & -0.3313 & $-2.0 \%$ & $-2.0 \%$ \\
\hline Pu35-27 & $\mathrm{MgO}(\mathrm{wt} \%)$ & 0.5945 & 0.5870 & 0.6100 & -0.0155 & -0.0230 & $-2.5 \%$ & $-3.8 \%$ \\
\hline Pu35-27 & $\mathrm{Na}_{2} \mathrm{O}($ wt $\%)$ & 0.6470 & 0.6130 & 0.6500 & -0.0030 & -0.0370 & $-0.5 \%$ & $-5.7 \%$ \\
\hline Pu35-27 & $\mathrm{Nd}_{2} \mathrm{O}_{3}(\mathrm{wt} \%)$ & 12.9470 & 12.9470 & 12.9000 & 0.0470 & 0.0470 & $0.4 \%$ & $0.4 \%$ \\
\hline Pu35-27 & $\mathrm{NiO}(\mathrm{wt} \%$ ) & 0.0725 & 0.0796 & 0.0700 & 0.0025 & 0.0096 & $3.6 \%$ & $13.7 \%$ \\
\hline Pu35-27 & $\mathrm{PbO}(\mathrm{wt} \%)$ & 0.0404 & 0.0404 & 0.0000 & 0.0404 & 0.0404 & & \\
\hline
\end{tabular}


Table D5. Average Measured and Bias-Corrected Chemical Compositions Versus Targeted Compositions by Oxide by Study Glass (continued)

\begin{tabular}{|c|c|c|c|c|c|c|c|c|}
\hline Glass ID & Oxide & $\begin{array}{c}\text { Measured } \\
\text { (wt \%) }\end{array}$ & \begin{tabular}{|c|} 
Measured Bias- \\
Corrected (wt \%) \\
\end{tabular} & $\begin{array}{c}\text { Targeted } \\
\text { (wt \%) }\end{array}$ & $\begin{array}{c}\text { Diff of } \\
\text { Measured }\end{array}$ & $\begin{array}{c}\text { Diff of Meas } \\
\text { BC } \\
\end{array}$ & $\begin{array}{l}\text { \% Diff of } \\
\text { Measured }\end{array}$ & \begin{tabular}{|c} 
\% Diff of Meas \\
BC \\
\end{tabular} \\
\hline $\mathrm{Pu} 35-27$ & $\mathrm{SeO}_{2}(\mathrm{wt} \%)$ & 0.0070 & \begin{tabular}{|l|}
0.0070 \\
\end{tabular} & 0.0000 & 0.0070 & 0.0070 & & \\
\hline \begin{tabular}{|l|}
$\mathrm{Pu} 35-27$ \\
\end{tabular} & $\mathrm{Si}_{2} \mathrm{O}_{3}($ wt $\%)$ & 17.4246 & 17.6058 & 17.2000 & 0.2246 & 0.4058 & $1.3 \%$ & $2.4 \%$ \\
\hline Pu35-27 & $\mathrm{SO}_{4}(\mathrm{wt} \%)$ & 0.0749 & 0.0749 & 0.0000 & 0.0749 & 0.0749 & & \\
\hline Pu35-27 & $\mathrm{SrO}($ wt $\%)$ & 2.1582 & 2.1582 & 2.1500 & 0.0082 & 0.0082 & $0.4 \%$ & $0.4 \%$ \\
\hline $\mathrm{Pu} 35-27$ & $\mathrm{Ta}_{2} \mathrm{O}_{5}(\mathrm{wt} \%)$ & 0.6551 & 0.6551 & 0.6700 & -0.0149 & -0.0149 & $-2.2 \%$ & $-2.2 \%$ \\
\hline \begin{tabular}{|l|} 
Pu35-27 \\
\end{tabular} & Sum (wt \%) & 97.8727 & 97.9819 & 100.0000 & -2.1273 & -2.0181 & $-2.1 \%$ & $-2.0 \%$ \\
\hline Pu35-28 & $\mathrm{Al}_{2} \mathrm{O}_{3}(\mathrm{wt} \%)$ & 8.8618 & 8.9348 & 8.6000 & 0.2618 & 0.3348 & $3.0 \%$ & $3.9 \%$ \\
\hline Pu35-28 & $\mathrm{B}_{2} \mathrm{O}_{3}(\mathrm{wt} \%)$ & 11.3823 & 11.2980 & 11.1800 & 0.2023 & 0.1180 & $1.8 \%$ & $1.1 \%$ \\
\hline Pu35-28 & $\mathrm{CaO}(\mathrm{wt} \%)$ & 0.1889 & 0.1903 & 0.1100 & 0.0789 & 0.0803 & $71.7 \%$ & $73.0 \%$ \\
\hline Pu35-28 & $\mathrm{Cl}(\mathrm{wt} \%)$ & 0.0730 & 0.0730 & 0.7200 & -0.6470 & -0.6470 & $-89.9 \%$ & $-89.9 \%$ \\
\hline \begin{tabular}{|l|}
$\mathrm{Pu} 35-28$ \\
\end{tabular} & $\mathrm{Cr}_{2} \mathrm{O}_{3}(\mathrm{wt} \%)$ & 0.4458 & 0.4313 & 0.4800 & -0.0342 & -0.0487 & $-7.1 \%$ & $-10.1 \%$ \\
\hline Pu35-28 & $\mathrm{CuO}(\mathrm{wt} \%)$ & 0.2209 & 0.2327 & 0.2200 & 0.0009 & 0.0127 & $0.4 \%$ & $5.8 \%$ \\
\hline \begin{tabular}{|l|} 
Pu35-28 \\
\end{tabular} & $\mathrm{F}(\mathrm{wt} \%)$ & 0.0345 & 0.0421 & 0.1000 & -0.0655 & -0.0579 & $-65.5 \%$ & $-57.9 \%$ \\
\hline Pu35-28 & $\mathrm{Fe}_{2} \mathrm{O}_{3}(\mathrm{wt} \%)$ & 0.1101 & 0.1123 & 0.0800 & 0.0301 & 0.0323 & $37.6 \%$ & $40.4 \%$ \\
\hline Pu35-28 & $\mathrm{Ga}_{2} \mathrm{O}_{3}($ wt $\%)$ & 0.4281 & 0.4281 & 0.4100 & 0.0181 & 0.0181 & $4.4 \%$ & $4.4 \%$ \\
\hline \begin{tabular}{|l|}
$\mathrm{Pu} 35-28$ \\
\end{tabular} & $\mathrm{Gd}_{2} \mathrm{O}_{3}(\mathrm{wt} \%)$ & 11.6989 & 11.6989 & 11.6100 & 0.0889 & 0.0889 & $0.8 \%$ & $0.8 \%$ \\
\hline Pu35-28 & $\mathrm{HfO}_{2}(\mathrm{wt} \%)$ & 13.6209 & 13.6209 & 14.9300 & -1.3091 & -1.3091 & $-8.8 \%$ & $-8.8 \%$ \\
\hline Pu35-28 & $\mathrm{K}_{2} \mathrm{O}(\mathrm{wt} \%)$ & 0.3258 & 0.2912 & 0.3900 & -0.0642 & -0.0988 & $-16.5 \%$ & $-25.3 \%$ \\
\hline Pu35-28 & $\mathrm{La}_{2} \mathrm{O}_{3}(\mathrm{wt} \%)$ & 16.0674 & 16.0674 & 16.3400 & -0.2726 & -0.2726 & $-1.7 \%$ & $-1.7 \%$ \\
\hline Pu35-28 & $\mathrm{MgO}(\mathrm{wt} \%)$ & 0.8930 & 0.8817 & 0.9300 & -0.0370 & -0.0483 & $-4.0 \%$ & $-5.2 \%$ \\
\hline \begin{tabular}{|l|}
$\mathrm{Pu} 35-28$ \\
\end{tabular} & $\mathrm{Na}_{2} \mathrm{O}($ wt $\%)$ & 0.7347 & 0.6960 & 0.7400 & -0.0053 & -0.0440 & $-0.7 \%$ & $-5.9 \%$ \\
\hline Pu35-28 & $\mathrm{Nd}_{2} \mathrm{O}_{3}($ wt $\%)$ & 13.0637 & 13.0637 & 12.9000 & 0.1637 & 0.1637 & $1.3 \%$ & $1.3 \%$ \\
\hline Pu35-28 & $\mathrm{NiO}(\mathrm{wt} \%)$ & 0.3302 & 0.3625 & 0.3600 & -0.0298 & 0.0025 & $-8.3 \%$ & $0.7 \%$ \\
\hline Pu35-28 & $\mathrm{PbO}(\mathrm{wt} \%)$ & 0.0404 & 0.0404 & 0.0000 & 0.0404 & 0.0404 & & \\
\hline \begin{tabular}{|l|}
$\mathrm{Pu} 35-28$ \\
\end{tabular} & $\mathrm{SeO}_{2}(\mathrm{wt} \%)$ & 0.0070 & 0.0070 & 0.0000 & 0.0070 & 0.0070 & & \\
\hline Pu35-28 & $\mathrm{Si}_{2} \mathrm{O}_{3}($ wt $\%)$ & 17.3283 & 17.5086 & 17.2000 & 0.1283 & 0.3086 & $0.7 \%$ & $1.8 \%$ \\
\hline Pu35-28 & $\mathrm{SO}_{4}(\mathrm{wt} \%)$ & 0.0749 & 0.0749 & 0.0000 & 0.0749 & 0.0749 & & \\
\hline Pu35-28 & $\mathrm{SrO}(\mathrm{wt} \%)$ & 2.1878 & 2.1878 & 2.1500 & 0.0378 & 0.0378 & $1.8 \%$ & $1.8 \%$ \\
\hline \begin{tabular}{|l|} 
Pu35-28 \\
\end{tabular} & $\mathrm{Ta}_{2} \mathrm{O}_{5}(\mathrm{wt} \%)$ & 0.5281 & 0.5281 & 0.5400 & -0.0119 & -0.0119 & $-2.2 \%$ & $-2.2 \%$ \\
\hline Pu35-28 & Sum (wt \%) & 98.6465 & 98.7716 & 99.9900 & -1.3435 & -1.2184 & $-1.3 \%$ & $-1.2 \%$ \\
\hline \begin{tabular}{|l|}
$\mathrm{Pu} 35-29$ \\
\end{tabular} & $\mathrm{Al}_{2} \mathrm{O}_{3}(\mathrm{wt} \%)$ & 8.8995 & 8.9729 & 8.6000 & 0.2995 & 0.3729 & $3.5 \%$ & $4.3 \%$ \\
\hline \begin{tabular}{|l|}
$\mathrm{Pu} 35-29$ \\
\end{tabular} & $\mathrm{~B}_{2} \mathrm{O}_{3}(\mathrm{wt} \%)$ & 11.2857 & 11.2021 & 11.1800 & 0.1057 & 0.0221 & $0.9 \%$ & $0.2 \%$ \\
\hline Pu35-29 & $\mathrm{CaO}($ wt \%) & 0.1686 & 0.1699 & 0.0800 & 0.0886 & 0.0899 & $110.8 \%$ & $112.4 \%$ \\
\hline \begin{tabular}{|l|}
$\mathrm{Pu} 35-29$ \\
\end{tabular} & $\mathrm{Cl}(\mathrm{wt} \%)$ & 0.0605 & 0.0605 & 0.8400 & -0.7795 & -0.7795 & $-92.8 \%$ & $-92.8 \%$ \\
\hline Pu35-29 & $\mathrm{Cr}_{2} \mathrm{O}_{3}(\mathrm{wt} \%)$ & 0.0862 & 0.0834 & 0.0900 & -0.0038 & -0.0066 & $-4.2 \%$ & $-7.3 \%$ \\
\hline \begin{tabular}{|l|}
$\mathrm{Pu} 35-29$ \\
\end{tabular} & $\mathrm{CuO}(\mathrm{wt} \%)$ & 0.1064 & 0.1121 & 0.0700 & 0.0364 & 0.0421 & $52.0 \%$ & $60.1 \%$ \\
\hline \begin{tabular}{|l|}
$\mathrm{Pu} 35-29$ \\
\end{tabular} & $\mathrm{~F}(\mathrm{wt} \%)$ & 0.1160 & 0.1416 & 0.3600 & -0.2440 & -0.2184 & $-67.8 \%$ & $-60.7 \%$ \\
\hline Pu35-29 & $\mathrm{Fe}_{2} \mathrm{O}_{3}(\mathrm{wt} \%)$ & 0.2209 & 0.2253 & 0.1800 & 0.0409 & 0.0453 & $22.7 \%$ & $25.2 \%$ \\
\hline Pu35-29 & $\mathrm{Ga}_{2} \mathrm{O}_{3}(\mathrm{wt} \%)$ & 0.7286 & 0.7286 & 0.7000 & 0.0286 & 0.0286 & $4.1 \%$ & $4.1 \%$ \\
\hline \begin{tabular}{|l|}
$\mathrm{Pu} 35-29$ \\
\end{tabular} & $\mathrm{Gd}_{2} \mathrm{O}_{3}(\mathrm{wt} \%)$ & 11.5836 & 11.5836 & 11.6100 & -0.0264 & -0.0264 & $-0.2 \%$ & $-0.2 \%$ \\
\hline Pu35-29 & $\mathrm{HfO}_{2}(\mathrm{wt} \%)$ & 13.4440 & 13.4440 & 15.0300 & -1.5860 & -1.5860 & $-10.6 \%$ & $-10.6 \%$ \\
\hline \begin{tabular}{|l|}
$\mathrm{Pu} 35-29$ \\
\end{tabular} & $\mathrm{~K}_{2} \mathrm{O}(\mathrm{wt} \%)$ & 0.6643 & 0.5938 & 0.8400 & -0.1757 & -0.2462 & $-20.9 \%$ & $-29.3 \%$ \\
\hline \begin{tabular}{|l|}
$\mathrm{Pu} 35-29$ \\
\end{tabular} & $\mathrm{La}_{2} \mathrm{O}_{3}(\mathrm{wt} \%)$ & 16.1846 & 16.1846 & 16.3400 & -0.1554 & -0.1554 & $-1.0 \%$ & $-1.0 \%$ \\
\hline \begin{tabular}{|l|}
$\mathrm{Pu} 35-29$ \\
\end{tabular} & $\mathrm{MgO}(\mathrm{wt} \%)$ & 0.4685 & 0.4625 & 0.4700 & -0.0015 & -0.0075 & $-0.3 \%$ & $-1.6 \%$ \\
\hline \begin{tabular}{|l|}
$\mathrm{Pu} 35-29$ \\
\end{tabular} & $\mathrm{Na}_{2} \mathrm{O}($ wt $\%)$ & 0.9443 & 0.8946 & 0.9500 & -0.0057 & -0.0554 & $-0.6 \%$ & $-5.8 \%$ \\
\hline \begin{tabular}{|l|}
$\mathrm{Pu} 35-29$ \\
\end{tabular} & $\mathrm{Nd}_{2} \mathrm{O}_{3}($ wt $\%)$ & 13.0054 & 13.0054 & 12.9000 & 0.1054 & 0.1054 & $0.8 \%$ & $0.8 \%$ \\
\hline \begin{tabular}{|l|}
$\mathrm{Pu} 35-29$ \\
\end{tabular} & $\mathrm{NiO}($ wt \%) & 0.0700 & 0.0768 & 0.0700 & 0.0000 & 0.0068 & $0.0 \%$ & $9.7 \%$ \\
\hline Pu35-29 & $\mathrm{PbO}(\mathrm{wt} \%)$ & 0.0420 & 0.0420 & 0.0000 & 0.0420 & 0.0420 & & \\
\hline \begin{tabular}{|l|}
$\mathrm{Pu} 35-29$ \\
\end{tabular} & $\mathrm{SeO}_{2}($ wt $\%)$ & 0.0070 & 0.0070 & 0.0000 & 0.0070 & 0.0070 & & \\
\hline Pu35-29 & $\mathrm{Si}_{2} \mathrm{O}_{3}($ wt $\%)$ & 17.4246 & 17.6058 & 17.2000 & 0.2246 & 0.4058 & $1.3 \%$ & $2.4 \%$ \\
\hline \begin{tabular}{|l|}
$\mathrm{Pu} 35-29$ \\
\end{tabular} & $\mathrm{SO}_{4}(\mathrm{wt} \%)$ & 0.0749 & 0.0749 & 0.0000 & 0.0749 & 0.0749 & & \\
\hline Pu35-29 & $\mathrm{SrO}(\mathrm{wt} \%)$ & 2.2529 & 2.2529 & 2.1500 & 0.1029 & 0.1029 & $4.8 \%$ & $4.8 \%$ \\
\hline Pu35-29 & $\mathrm{Ta}_{2} \mathrm{O}_{5}(\mathrm{wt} \%)$ & 0.3455 & 0.3455 & 0.3400 & 0.0055 & 0.0055 & $1.6 \%$ & $1.6 \%$ \\
\hline Pu35-29 & Sum (wt \%) & 98.1841 & 98.2699 & 100.0000 & -1.8159 & -1.7301 & $-1.8 \%$ & $-1.7 \%$ \\
\hline Pu35-30 & $\mathrm{Al}_{2} \mathrm{O}_{3}(\mathrm{wt} \%)$ & 8.9184 & 8.9920 & 8.6000 & 0.3184 & 0.3920 & $3.7 \%$ & $4.6 \%$ \\
\hline Pu35-30 & $\mathrm{B}_{2} \mathrm{O}_{3}(\mathrm{wt} \%)$ & 11.0121 & 10.9304 & 11.1800 & -0.1679 & -0.2496 & $-1.5 \%$ & $-2.2 \%$ \\
\hline Pu35-30 & $\mathrm{CaO}(w \mathrm{t} \%)$ & 0.5569 & 0.5611 & 0.4600 & 0.0969 & 0.1011 & $21.1 \%$ & $22.0 \%$ \\
\hline Pu35-30 & $\mathrm{Cl}(\mathrm{wt} \%)$ & 0.0330 & 0.0330 & 0.5800 & -0.5470 & -0.5470 & $-94.3 \%$ & $-94.3 \%$ \\
\hline
\end{tabular}


Table D5. Average Measured and Bias-Corrected Chemical Compositions Versus Targeted Compositions by Oxide by Study Glass (continued)

\begin{tabular}{|c|c|c|c|c|c|c|c|c|}
\hline Glass ID & Oxide & $\begin{array}{c}\text { Measured } \\
\text { (wt \%) }\end{array}$ & \begin{tabular}{|c|} 
Measured Bias- \\
Corrected (wt \%) \\
\end{tabular} & $\begin{array}{c}\text { Targeted } \\
\text { (wt \%) }\end{array}$ & $\begin{array}{c}\text { Diff of } \\
\text { Measured }\end{array}$ & $\begin{array}{c}\text { Diff of Meas } \\
\text { BC } \\
\end{array}$ & $\begin{array}{l}\text { \% Diff of } \\
\text { Measured }\end{array}$ & $\begin{array}{c}\text { \% Diff of Meas } \\
\text { BC }\end{array}$ \\
\hline $\mathrm{Pu} 35-30$ & $\mathrm{Cr}_{2} \mathrm{O}_{3}(\mathrm{wt} \%)$ & 0.0899 & \begin{tabular}{|l|}
0.0870 \\
\end{tabular} & 0.0800 & 0.0099 & 0.0070 & $12.4 \%$ & $8.7 \%$ \\
\hline \begin{tabular}{|l|}
$\mathrm{Pu} 35-30$ \\
\end{tabular} & $\mathrm{CuO}(\mathrm{wt} \%)$ & 0.0857 & 0.0903 & 0.0700 & 0.0157 & 0.0203 & $22.5 \%$ & $29.0 \%$ \\
\hline Pu35-30 & $\mathrm{F}(\mathrm{wt} \%)$ & 0.0000 & 0.0000 & 0.0600 & -0.0600 & -0.0600 & $-100.0 \%$ & $-100.0 \%$ \\
\hline Pu35-30 & $\mathrm{Fe}_{2} \mathrm{O}_{3}(\mathrm{wt} \%)$ & 0.1115 & 0.1138 & 0.0800 & 0.0315 & 0.0338 & $39.4 \%$ & $42.2 \%$ \\
\hline Pu35-30 & $\mathrm{Ga}_{2} \mathrm{O}_{3}(\mathrm{wt} \%)$ & 0.7722 & 0.7722 & 0.7500 & 0.0222 & 0.0222 & $3.0 \%$ & $3.0 \%$ \\
\hline Pu35-30 & $\mathrm{Gd}_{2} \mathrm{O}_{3}(\mathrm{wt} \%)$ & 11.7565 & 11.7565 & 11.6100 & 0.1465 & 0.1465 & $1.3 \%$ & $1.3 \%$ \\
\hline Pu35-30 & $\mathrm{HfO}_{2}(\mathrm{wt} \%)$ & 13.7388 & 13.7388 & 14.8800 & -1.1412 & -1.1412 & $-7.7 \%$ & $-7.7 \%$ \\
\hline Pu35-30 & $\mathrm{K}_{2} \mathrm{O}(\mathrm{wt} \%)$ & 0.8005 & 0.7155 & 1.1100 & -0.3095 & -0.3945 & $-27.9 \%$ & $-35.5 \%$ \\
\hline Pu35-30 & $\mathrm{La}_{2} \mathrm{O}_{3}(\mathrm{wt} \%)$ & 16.3606 & 16.3606 & 16.3400 & 0.0206 & 0.0206 & $0.1 \%$ & $0.1 \%$ \\
\hline Pu35-30 & $\mathrm{MgO}(\mathrm{wt} \%)$ & 0.4544 & 0.4486 & 0.4600 & -0.0056 & -0.0114 & $-1.2 \%$ & $-2.5 \%$ \\
\hline \begin{tabular}{|l|}
$\mathrm{Pu} 35-30$ \\
\end{tabular} & $\mathrm{Na}_{2} \mathrm{O}(\mathrm{wt} \%)$ & 0.8654 & 0.8198 & 0.9000 & -0.0346 & -0.0802 & $-3.8 \%$ & $-8.9 \%$ \\
\hline \begin{tabular}{|l|} 
Pu35-30 \\
\end{tabular} & $\mathrm{Nd}_{2} \mathrm{O}_{3}(\mathrm{wt} \%)$ & 13.0637 & 13.0637 & 12.9000 & 0.1637 & 0.1637 & $1.3 \%$ & $1.3 \%$ \\
\hline \begin{tabular}{|l|} 
Pu35-30 \\
\end{tabular} & $\mathrm{NiO}($ wt \%) & 0.0636 & 0.0698 & 0.0700 & -0.0064 & -0.0002 & $-9.1 \%$ & $-0.2 \%$ \\
\hline Pu35-30 & $\mathrm{PbO}($ wt \%) & 0.0873 & 0.0873 & 0.0600 & 0.0273 & 0.0273 & $45.4 \%$ & $45.4 \%$ \\
\hline Pu35-30 & $\mathrm{SeO}_{2}(\mathrm{wt} \%)$ & 0.0070 & 0.0070 & 0.0800 & -0.0730 & -0.0730 & $-91.2 \%$ & $-91.2 \%$ \\
\hline \begin{tabular}{|l|} 
Pu35-30 \\
\end{tabular} & $\mathrm{Si}_{2} \mathrm{O}_{3}($ wt $\%)$ & 17.5209 & 17.7031 & 17.2000 & 0.3209 & 0.5031 & $1.9 \%$ & $2.9 \%$ \\
\hline Pu35-30 & $\mathrm{SO}_{4}(\mathrm{wt} \%)$ & 0.0749 & 0.0749 & 0.1700 & -0.0951 & -0.0951 & $-55.9 \%$ & $-55.9 \%$ \\
\hline Pu35-30 & $\mathrm{SrO}(\mathrm{wt} \%)$ & 2.2351 & 2.2351 & 2.1500 & 0.0851 & 0.0851 & $4.0 \%$ & $4.0 \%$ \\
\hline Pu35-30 & $\mathrm{Ta}_{2} \mathrm{O}_{5}(\mathrm{wt} \%)$ & 0.0885 & 0.0885 & 0.0700 & 0.0185 & 0.0185 & $26.5 \%$ & $26.5 \%$ \\
\hline Pu35-30 & Sum (wt \%) & 98.6969 & 98.7491 & 99.8600 & -1.1631 & -1.1109 & $-1.2 \%$ & $-1.1 \%$ \\
\hline \begin{tabular}{|l|}
$\mathrm{Pu} 35-31$ \\
\end{tabular} & $\mathrm{Al}_{2} \mathrm{O}_{3}(\mathrm{wt} \%)$ & 8.8429 & 8.9158 & 8.6000 & 0.2429 & 0.3158 & $2.8 \%$ & $3.7 \%$ \\
\hline Pu35-31 & $\mathrm{B}_{2} \mathrm{O}_{3}(\mathrm{wt} \%)$ & 10.9799 & 10.8985 & 11.1800 & -0.2001 & -0.2815 & $-1.8 \%$ & $-2.5 \%$ \\
\hline Pu35-31 & $\mathrm{CaO}($ wt \%) & 0.1665 & 0.1678 & 0.0800 & 0.0865 & 0.0878 & $108.1 \%$ & $109.7 \%$ \\
\hline \begin{tabular}{|l|}
$\mathrm{Pu} 35-31$ \\
\end{tabular} & $\mathrm{Cl}(\mathrm{wt} \%)$ & 0.0385 & 0.0385 & 0.5800 & -0.5415 & -0.5415 & $-93.4 \%$ & $-93.4 \%$ \\
\hline \begin{tabular}{|l|}
$\mathrm{Pu} 35-31$ \\
\end{tabular} & $\mathrm{Cr}_{2} \mathrm{O}_{3}(\mathrm{wt} \%)$ & 0.0914 & 0.0884 & 0.0900 & 0.0014 & -0.0016 & $1.5 \%$ & $-1.8 \%$ \\
\hline \begin{tabular}{|l|} 
Pu35-31 \\
\end{tabular} & $\mathrm{CuO}(\mathrm{wt} \%)$ & 0.0895 & 0.0943 & 0.0700 & 0.0195 & 0.0243 & $27.9 \%$ & $34.7 \%$ \\
\hline Pu35-31 & $\mathrm{F}(\mathrm{wt} \%)$ & 0.1090 & 0.1331 & 0.4700 & -0.3610 & -0.3369 & $-76.8 \%$ & $-71.7 \%$ \\
\hline \begin{tabular}{|l|}
$\mathrm{Pu} 35-31$ \\
\end{tabular} & $\mathrm{Fe}_{2} \mathrm{O}_{3}(\mathrm{wt} \%)$ & 0.8328 & 0.8495 & 0.8300 & 0.0028 & 0.0195 & $0.3 \%$ & $2.4 \%$ \\
\hline \begin{tabular}{|l|}
$\mathrm{Pu} 35-31$ \\
\end{tabular} & $\mathrm{Ga}_{2} \mathrm{O}_{3}(\mathrm{wt} \%)$ & 0.1163 & 0.1163 & 0.0800 & 0.0363 & 0.0363 & $45.3 \%$ & $45.3 \%$ \\
\hline Pu35-31 & $\mathrm{Gd}_{2} \mathrm{O}_{3}(\mathrm{wt} \%)$ & 11.6989 & 11.6989 & 11.6100 & 0.0889 & 0.0889 & $0.8 \%$ & $0.8 \%$ \\
\hline \begin{tabular}{|l|}
$\mathrm{Pu} 35-31$ \\
\end{tabular} & $\mathrm{HfO}_{2}(\mathrm{wt} \%)$ & 13.6799 & 13.6799 & 14.9500 & -1.2701 & -1.2701 & $-8.5 \%$ & $-8.5 \%$ \\
\hline \begin{tabular}{|l|}
$\mathrm{Pu} 35-31$ \\
\end{tabular} & $\mathrm{~K}_{2} \mathrm{O}(\mathrm{wt} \%)$ & 0.8944 & 0.7994 & 1.1200 & -0.2256 & -0.3206 & $-20.1 \%$ & $-28.6 \%$ \\
\hline \begin{tabular}{|l|}
$\mathrm{Pu} 35-31$ \\
\end{tabular} & $\mathrm{La}_{2} \mathrm{O}_{3}(\mathrm{wt} \%)$ & 16.3019 & 16.3019 & 16.3400 & -0.0381 & -0.0381 & $-0.2 \%$ & $-0.2 \%$ \\
\hline Pu35-31 & $\mathrm{MgO}($ wt $\%)$ & 0.5904 & 0.5829 & 0.6000 & -0.0096 & -0.0171 & $-1.6 \%$ & $-2.9 \%$ \\
\hline Pu35-31 & $\mathrm{Na}_{2} \mathrm{O}(\mathrm{wt} \%)$ & 0.4967 & 0.4706 & 0.4700 & 0.0267 & 0.0006 & $5.7 \%$ & $0.1 \%$ \\
\hline \begin{tabular}{|l|}
$\mathrm{Pu} 35-31$ \\
\end{tabular} & $\mathrm{Nd}_{2} \mathrm{O}_{3}(\mathrm{wt} \%)$ & 13.1803 & 13.1803 & 12.9000 & 0.2803 & 0.2803 & $2.2 \%$ & $2.2 \%$ \\
\hline Pu35-31 & $\mathrm{NiO}($ wt $\%)$ & 0.1533 & 0.1683 & 0.1700 & -0.0167 & -0.0017 & $-9.8 \%$ & $-1.0 \%$ \\
\hline Pu35-31 & $\mathrm{PbO}$ (wt \%) & 0.0894 & 0.0894 & 0.0600 & 0.0294 & 0.0294 & $49.0 \%$ & $49.0 \%$ \\
\hline Pu35-31 & $\mathrm{SeO}_{2}($ wt $\%)$ & 0.0070 & 0.0070 & 0.0800 & -0.0730 & -0.0730 & $-91.2 \%$ & $-91.2 \%$ \\
\hline \begin{tabular}{|l|}
$\mathrm{Pu} 35-31$ \\
\end{tabular} & $\mathrm{Si}_{2} \mathrm{O}_{3}($ wt $\%)$ & 17.5423 & 17.7247 & 17.2000 & 0.3423 & 0.5247 & $2.0 \%$ & $3.1 \%$ \\
\hline Pu35-31 & $\mathrm{SO}_{4}(\mathrm{wt} \%)$ & 0.0749 & 0.0749 & 0.1700 & -0.0951 & -0.0951 & $-55.9 \%$ & $-55.9 \%$ \\
\hline \begin{tabular}{|l|} 
Pu35-31 \\
\end{tabular} & SrO (wt \%) & 2.2174 & 2.2174 & 2.1500 & 0.0674 & 0.0674 & $3.1 \%$ & $3.1 \%$ \\
\hline Pu35-31 & $\mathrm{Ta}_{2} \mathrm{O}_{5}(\mathrm{wt} \%)$ & 0.0849 & 0.0849 & 0.0700 & 0.0149 & 0.0149 & $21.2 \%$ & $21.2 \%$ \\
\hline $\mathrm{Pu} 35-31$ & Sum (wt \%) & 98.2783 & 98.3825 & 99.8700 & -1.5917 & -1.4875 & $-1.6 \%$ & $-1.5 \%$ \\
\hline \begin{tabular}{|l|} 
Pu35-32 \\
\end{tabular} & $\mathrm{Al}_{2} \mathrm{O}_{3}$ (wt \%) & 8.8807 & 8.9539 & 8.6000 & 0.2807 & 0.3539 & $3.3 \%$ & $4.1 \%$ \\
\hline Pu35-32 & $\mathrm{B}_{2} \mathrm{O}_{3}(\mathrm{wt} \%)$ & 11.1731 & 11.0902 & 11.1800 & -0.0069 & -0.0898 & $-0.1 \%$ & $-0.8 \%$ \\
\hline Pu35-32 & $\mathrm{CaO}(w \mathrm{t} \%)$ & 0.1532 & 0.1544 & 0.0800 & 0.0732 & 0.0744 & $91.5 \%$ & $93.0 \%$ \\
\hline Pu35-32 & $\mathrm{Cl}(\mathrm{wt} \%)$ & 0.0415 & 0.0415 & 0.5800 & -0.5385 & -0.5385 & $-92.8 \%$ & $-92.8 \%$ \\
\hline Pu35-32 & $\mathrm{Cr}_{2} \mathrm{O}_{3}(\mathrm{wt} \%)$ & 0.0848 & 0.0820 & 0.0800 & 0.0048 & 0.0020 & $6.0 \%$ & $2.5 \%$ \\
\hline \begin{tabular}{|l|}
$\mathrm{Pu} 35-32$ \\
\end{tabular} & $\mathrm{CuO}(\mathrm{wt} \%)$ & 0.0895 & 0.0943 & 0.0700 & 0.0195 & 0.0243 & $27.9 \%$ & $34.7 \%$ \\
\hline Pu35-32 & $\mathrm{F}(\mathrm{wt} \%)$ & 0.0745 & 0.0910 & 0.4000 & -0.3255 & -0.3090 & $-81.4 \%$ & $-77.3 \%$ \\
\hline Pu35-32 & $\mathrm{Fe}_{2} \mathrm{O}_{3}($ wt $\%)$ & 0.1051 & 0.1072 & 0.0800 & 0.0251 & 0.0272 & $31.4 \%$ & $34.0 \%$ \\
\hline Pu35-32 & $\mathrm{Ga}_{2} \mathrm{O}_{3}(\mathrm{wt} \%)$ & 0.9100 & 0.9100 & 0.9000 & 0.0100 & 0.0100 & $1.1 \%$ & $1.1 \%$ \\
\hline Pu35-32 & $\mathrm{Gd}_{2} \mathrm{O}_{3}(\mathrm{wt} \%)$ & 11.7565 & 11.7565 & 11.6100 & 0.1465 & 0.1465 & $1.3 \%$ & $1.3 \%$ \\
\hline $\mathrm{Pu} 35-32$ & $\mathrm{HfO}_{2}(\mathrm{wt} \%)$ & 13.9747 & 13.9747 & 14.9000 & -0.9253 & -0.9253 & $-6.2 \%$ & $-6.2 \%$ \\
\hline Pu35-32 & $\mathrm{K}_{2} \mathrm{O}(\mathrm{wt} \%)$ & 0.2204 & 0.1970 & 0.2600 & -0.0396 & -0.0630 & $-15.2 \%$ & $-24.2 \%$ \\
\hline Pu35-32 & $\mathrm{La}_{2} \mathrm{O}_{3}(\mathrm{wt} \%)$ & 16.3606 & 16.3606 & 16.3400 & 0.0206 & 0.0206 & $0.1 \%$ & $0.1 \%$ \\
\hline Pu35-32 & $\mathrm{MgO}(\mathrm{wt} \%)$ & 1.2885 & 1.2722 & 1.3900 & -0.1015 & -0.1178 & $-7.3 \%$ & $-8.5 \%$ \\
\hline
\end{tabular}


Table D5. Average Measured and Bias-Corrected Chemical Compositions Versus Targeted Compositions by Oxide by Study Glass (continued)

\begin{tabular}{|c|c|c|c|c|c|c|c|c|}
\hline Glass ID & Oxide & \begin{tabular}{|c|} 
Measured \\
(wt \%)
\end{tabular} & \begin{tabular}{|c|} 
Measured Bias- \\
Corrected (wt \%) \\
\end{tabular} & $\begin{array}{c}\text { Targeted } \\
(\mathrm{wt} \%)\end{array}$ & $\begin{array}{c}\text { Diff of } \\
\text { Measured }\end{array}$ & $\begin{array}{c}\text { Diff of Meas } \\
\text { BC } \\
\end{array}$ & $\begin{array}{l}\text { \% Diff of } \\
\text { Measured }\end{array}$ & $\begin{array}{c}\text { \% Diff of Meas } \\
\text { BC } \\
\end{array}$ \\
\hline $\mathrm{Pu} 35-32$ & $\mathrm{Na}_{2} \mathrm{O}($ wt \%) & 0.6996 & \begin{tabular}{|l|}
0.6628 \\
\end{tabular} & 0.6900 & 0.0096 & -0.0272 & $1.4 \%$ & $-3.9 \%$ \\
\hline \begin{tabular}{|l|}
$\mathrm{Pu} 35-32$ \\
\end{tabular} & $\mathrm{Nd}_{2} \mathrm{O}_{3}(\mathrm{wt} \%)$ & 13.1803 & 13.1803 & 12.9000 & 0.2803 & 0.2803 & $2.2 \%$ & $2.2 \%$ \\
\hline Pu35-32 & $\mathrm{NiO}(\mathrm{wt} \%)$ & 0.0681 & 0.0747 & 0.0700 & -0.0019 & 0.0047 & $-2.7 \%$ & $6.8 \%$ \\
\hline Pu35-32 & $\mathrm{PbO}(\mathrm{wt} \%)$ & 0.0905 & 0.0905 & 0.0600 & 0.0305 & 0.0305 & $50.8 \%$ & $50.8 \%$ \\
\hline Pu35-32 & $\mathrm{SeO}_{2}(\mathrm{wt} \%)$ & 0.0070 & 0.0070 & 0.0800 & -0.0730 & -0.0730 & $-91.2 \%$ & $-91.2 \%$ \\
\hline Pu35-32 & $\mathrm{Si}_{2} \mathrm{O}_{3}(\mathrm{wt} \%)$ & 17.5316 & 17.7139 & 17.2000 & 0.3316 & 0.5139 & $1.9 \%$ & $3.0 \%$ \\
\hline Pu35-32 & $\mathrm{SO}_{4}(\mathrm{wt} \%)$ & 0.0749 & 0.0749 & 0.1700 & -0.0951 & -0.0951 & $-55.9 \%$ & $-55.9 \%$ \\
\hline Pu35-32 & $\mathrm{SrO}(\mathrm{wt} \%)$ & 2.2174 & 2.2174 & 2.1500 & 0.0674 & 0.0674 & $3.1 \%$ & $3.1 \%$ \\
\hline $\mathrm{Pu} 35-32$ & $\mathrm{Ta}_{2} \mathrm{O}_{5}(\mathrm{wt} \%)$ & 0.0855 & 0.0855 & 0.0700 & 0.0155 & 0.0155 & $22.1 \%$ & $22.1 \%$ \\
\hline \begin{tabular}{|l|}
$\mathrm{Pu} 35-32$ \\
\end{tabular} & Sum (wt \%) & 99.0679 & 99.1924 & 99.8600 & -0.7921 & -0.6676 & $-0.8 \%$ & $-0.7 \%$ \\
\hline \begin{tabular}{|l|}
$\mathrm{Pu} 35-33$ \\
\end{tabular} & $\mathrm{Al}_{2} \mathrm{O}_{3}(\mathrm{wt} \%)$ & 8.4933 & 8.5633 & 8.6000 & -0.1067 & -0.0367 & $-1.2 \%$ & $-0.4 \%$ \\
\hline \begin{tabular}{|l|} 
Pu35-33 \\
\end{tabular} & $\mathrm{B}_{2} \mathrm{O}_{3}(\mathrm{wt} \%)$ & 10.8833 & 10.8026 & 11.1800 & -0.2967 & -0.3774 & $-2.7 \%$ & $-3.4 \%$ \\
\hline \begin{tabular}{|l|} 
Pu35-33 \\
\end{tabular} & $\mathrm{CaO}(\mathrm{wt} \%)$ & 0.5226 & 0.5266 & 0.4400 & 0.0826 & 0.0866 & $18.8 \%$ & $19.7 \%$ \\
\hline Pu35-33 & $\mathrm{Cl}(\mathrm{wt} \%)$ & 0.0435 & 0.0435 & 0.5700 & -0.5265 & -0.5265 & $-92.4 \%$ & $-92.4 \%$ \\
\hline Pu35-33 & $\mathrm{Cr}_{2} \mathrm{O}_{3}(\mathrm{wt} \%)$ & 0.4370 & 0.4228 & 0.4800 & -0.0430 & -0.0572 & $-9.0 \%$ & $-11.9 \%$ \\
\hline \begin{tabular}{|l|}
$\mathrm{Pu} 35-33$ \\
\end{tabular} & $\mathrm{CuO}(\mathrm{wt} \%)$ & 0.0914 & 0.0962 & 0.0700 & 0.0214 & 0.0262 & $30.5 \%$ & $37.5 \%$ \\
\hline Pu35-33 & $\mathrm{F}(\mathrm{wt} \%)$ & 0.0420 & 0.0513 & 0.1300 & -0.0880 & -0.0787 & $-67.7 \%$ & $-60.6 \%$ \\
\hline Pu35-33 & $\mathrm{Fe}_{2} \mathrm{O}_{3}(\mathrm{wt} \%)$ & 0.5454 & 0.5564 & 0.5600 & -0.0146 & -0.0036 & $-2.6 \%$ & $-0.6 \%$ \\
\hline Pu35-33 & $\mathrm{Ga}_{2} \mathrm{O}_{3}(\mathrm{wt} \%)$ & 0.1143 & 0.1143 & 0.0800 & 0.0343 & 0.0343 & $42.8 \%$ & $42.8 \%$ \\
\hline \begin{tabular}{|l|}
$\mathrm{Pu} 35-33$ \\
\end{tabular} & $\mathrm{Gd}_{2} \mathrm{O}_{3}(\mathrm{wt} \%)$ & 11.3704 & 11.3704 & 11.6100 & -0.2396 & -0.2396 & $-2.1 \%$ & $-2.1 \%$ \\
\hline \begin{tabular}{|l|}
$\mathrm{Pu} 35-33$ \\
\end{tabular} & $\mathrm{HfO}_{2}(\mathrm{wt} \%)$ & 13.6209 & 13.6209 & 14.7800 & -1.1591 & -1.1591 & $-7.8 \%$ & $-7.8 \%$ \\
\hline \begin{tabular}{|l|}
$\mathrm{Pu} 35-33$ \\
\end{tabular} & $\mathrm{~K}_{2} \mathrm{O}(\mathrm{wt} \%)$ & 0.0506 & 0.0452 & 0.0800 & -0.0294 & -0.0348 & $-36.8 \%$ & $-43.5 \%$ \\
\hline \begin{tabular}{|l|}
$\mathrm{Pu} 35-33$ \\
\end{tabular} & $\mathrm{La}_{2} \mathrm{O}_{3}(\mathrm{wt} \%)$ & 15.8914 & 15.8914 & 16.3400 & -0.4486 & -0.4486 & $-2.7 \%$ & $-2.7 \%$ \\
\hline \begin{tabular}{|l|}
$\mathrm{Pu} 35-33$ \\
\end{tabular} & $\mathrm{MgO}(\mathrm{wt} \%)$ & 1.2487 & 1.2329 & 1.3700 & -0.1213 & -0.1371 & $-8.9 \%$ & $-10.0 \%$ \\
\hline \begin{tabular}{|l|}
$\mathrm{Pu} 35-33$ \\
\end{tabular} & $\mathrm{Na}_{2} \mathrm{O}(\mathrm{wt} \%)$ & 0.8701 & 0.8243 & 0.9000 & -0.0299 & -0.0757 & $-3.3 \%$ & $-8.4 \%$ \\
\hline Pu35-33 & $\mathrm{Nd}_{2} \mathrm{O}_{3}(\mathrm{wt} \%)$ & 12.6554 & 12.6554 & 12.9000 & -0.2446 & -0.2446 & $-1.9 \%$ & $-1.9 \%$ \\
\hline Pu35-33 & $\mathrm{NiO}(\mathrm{wt} \%)$ & 0.0694 & 0.0761 & 0.0700 & -0.0006 & 0.0061 & $-0.9 \%$ & $8.7 \%$ \\
\hline Pu35-33 & $\mathrm{PbO}(\mathrm{wt} \%)$ & 0.0856 & 0.0856 & 0.0600 & 0.0256 & 0.0256 & $42.7 \%$ & $42.7 \%$ \\
\hline \begin{tabular}{|l|}
$\mathrm{Pu} 35-33$ \\
\end{tabular} & $\mathrm{SeO}_{2}(\mathrm{wt} \%)$ & 0.0070 & 0.0070 & 0.0800 & -0.0730 & -0.0730 & $-91.2 \%$ & $-91.2 \%$ \\
\hline Pu35-33 & $\mathrm{Si}_{2} \mathrm{O}_{3}(\mathrm{wt} \%)$ & 18.7617 & 18.9568 & 17.2000 & 1.5617 & 1.7568 & $9.1 \%$ & $10.2 \%$ \\
\hline \begin{tabular}{|l|} 
Pu35-33 \\
\end{tabular} & $\mathrm{SO}_{4}(\mathrm{wt} \%)$ & 0.0749 & 0.0749 & 0.1700 & -0.0951 & -0.0951 & $-55.9 \%$ & $-55.9 \%$ \\
\hline Pu35-33 & $\mathrm{SrO}(\mathrm{wt} \%)$ & 2.1050 & 2.1050 & 2.1500 & -0.0450 & -0.0450 & $-2.1 \%$ & $-2.1 \%$ \\
\hline Pu35-33 & $\mathrm{Ta}_{2} \mathrm{O}_{5}(\mathrm{wt} \%)$ & 0.0849 & 0.0849 & 0.0700 & 0.0149 & 0.0149 & $21.2 \%$ & $21.2 \%$ \\
\hline Pu35-33 & Sum (wt \%) & 98.0688 & 98.2079 & 99.8900 & -1.8212 & -1.6821 & $-1.8 \%$ & $-1.7 \%$ \\
\hline Pu35-34 & $\mathrm{Al}_{2} \mathrm{O}_{3}(\mathrm{wt} \%)$ & 8.8712 & 8.9443 & 8.6000 & 0.2712 & 0.3443 & $3.2 \%$ & $4.0 \%$ \\
\hline Pu35-34 & $\mathrm{B}_{2} \mathrm{O}_{3}(\mathrm{wt} \%)$ & 10.9155 & 10.8345 & 11.1800 & -0.2645 & -0.3455 & $-2.4 \%$ & $-3.1 \%$ \\
\hline Pu35-34 & $\mathrm{CaO}($ wt \%) & 0.4568 & 0.4603 & 0.3700 & 0.0868 & 0.0903 & $23.5 \%$ & $24.4 \%$ \\
\hline Pu35-34 & $\mathrm{Cl}(\mathrm{wt} \%)$ & 0.0515 & 0.0515 & 0.5800 & -0.5285 & -0.5285 & $-91.1 \%$ & $-91.1 \%$ \\
\hline Pu35-34 & $\mathrm{Cr}_{2} \mathrm{O}_{3}(\mathrm{wt} \%)$ & 0.0899 & 0.0870 & 0.0800 & 0.0099 & 0.0070 & $12.4 \%$ & $8.7 \%$ \\
\hline \begin{tabular}{|l|}
$\mathrm{Pu} 35-34$ \\
\end{tabular} & $\mathrm{CuO}(\mathrm{wt} \%)$ & 0.2091 & 0.2202 & 0.2200 & -0.0109 & 0.0002 & $-5.0 \%$ & $0.1 \%$ \\
\hline \begin{tabular}{|l|}
$\mathrm{Pu} 35-34$ \\
\end{tabular} & $\mathrm{~F}(\mathrm{wt} \%)$ & 0.0070 & 0.0085 & 0.0600 & -0.0530 & -0.0515 & $-88.3 \%$ & $-85.8 \%$ \\
\hline \begin{tabular}{|l|}
$\mathrm{Pu} 35-34$ \\
\end{tabular} & $\mathrm{Fe}_{2} \mathrm{O}_{3}(\mathrm{wt} \%)$ & 0.1287 & 0.1313 & 0.0800 & 0.0487 & 0.0513 & $60.8 \%$ & $64.1 \%$ \\
\hline Pu35-34 & $\mathrm{Ga}_{2} \mathrm{O}_{3}(\mathrm{wt} \%)$ & 0.1169 & 0.1169 & 0.0800 & 0.0369 & 0.0369 & $46.2 \%$ & $46.2 \%$ \\
\hline $\mathrm{Pu} 35-34$ & $\mathrm{Gd}_{2} \mathrm{O}_{3}(\mathrm{wt} \%)$ & 11.7565 & 11.7565 & 11.6100 & 0.1465 & 0.1465 & $1.3 \%$ & $1.3 \%$ \\
\hline Pu35-34 & $\mathrm{HfO}_{2}(\mathrm{wt} \%)$ & 13.6209 & 13.6209 & 14.8900 & -1.2691 & -1.2691 & $-8.5 \%$ & $-8.5 \%$ \\
\hline Pu35-34 & $\mathrm{K}_{2} \mathrm{O}(\mathrm{wt} \%)$ & 0.4776 & 0.4269 & 0.5800 & -0.1024 & -0.1531 & $-17.7 \%$ & $-26.4 \%$ \\
\hline Pu35-34 & $\mathrm{La}_{2} \mathrm{O}_{3}(\mathrm{wt} \%)$ & 16.2433 & 16.2433 & 16.3400 & -0.0967 & -0.0967 & $-0.6 \%$ & $-0.6 \%$ \\
\hline Pu35-34 & $\mathrm{MgO}(\mathrm{wt} \%)$ & 1.2645 & 1.2484 & 1.3800 & -0.1155 & -0.1316 & $-8.4 \%$ & $-9.5 \%$ \\
\hline $\mathrm{Pu} 35-34$ & $\mathrm{Na}_{2} \mathrm{O}($ wt $\%)$ & 0.4860 & 0.4604 & 0.4800 & 0.0060 & -0.0196 & $1.2 \%$ & $-4.1 \%$ \\
\hline \begin{tabular}{|l|}
$\mathrm{Pu} 35-34$ \\
\end{tabular} & $\mathrm{Nd}_{2} \mathrm{O}_{3}(\mathrm{wt} \%)$ & 13.0637 & 13.0637 & 12.9000 & 0.1637 & 0.1637 & $1.3 \%$ & $1.3 \%$ \\
\hline Pu35-34 & $\mathrm{NiO}(\mathrm{wt} \%)$ & 0.0681 & 0.0747 & 0.0700 & -0.0019 & 0.0047 & $-2.7 \%$ & $6.8 \%$ \\
\hline Pu35-34 & $\mathrm{PbO}(\mathrm{wt} \%)$ & 0.0916 & 0.0916 & 0.0600 & 0.0316 & 0.0316 & $52.6 \%$ & $52.6 \%$ \\
\hline Pu35-34 & $\mathrm{SeO}_{2}($ wt $\%)$ & 0.0070 & 0.0070 & 0.0800 & -0.0730 & -0.0730 & $-91.2 \%$ & $-91.2 \%$ \\
\hline Pu35-34 & $\mathrm{Si}_{2} \mathrm{O}_{3}($ wt $\%)$ & 19.3393 & 19.5404 & 17.2000 & 2.1393 & 2.3404 & $12.4 \%$ & $13.6 \%$ \\
\hline Pu35-34 & $\mathrm{SO}_{4}(\mathrm{wt} \%)$ & 0.0749 & 0.0749 & 0.1700 & -0.0951 & -0.0951 & $-55.9 \%$ & $-55.9 \%$ \\
\hline Pu35-34 & SrO (wt \%) & 2.1937 & 2.1937 & 2.1500 & 0.0437 & 0.0437 & $2.0 \%$ & $2.0 \%$ \\
\hline Pu35-34 & $\mathrm{Ta}_{2} \mathrm{O}_{5}(\mathrm{wt} \%)$ & 0.6838 & 0.6838 & 0.7100 & -0.0262 & -0.0262 & $-3.7 \%$ & $-3.7 \%$ \\
\hline Pu35-34 & Sum (wt \%) & 100.2173 & 100.3408 & 99.8700 & 0.3473 & 0.4708 & $0.3 \%$ & $0.5 \%$ \\
\hline
\end{tabular}


Table D5. Average Measured and Bias-Corrected Chemical Compositions Versus Targeted Compositions by Oxide by Study Glass (continued)

\begin{tabular}{|c|c|c|c|c|c|c|c|c|}
\hline Glass ID & Oxide & $\begin{array}{c}\text { Measured } \\
(\mathrm{wt} \%)\end{array}$ & \begin{tabular}{|c|} 
Measured Bias- \\
Corrected (wt \%)
\end{tabular} & $\begin{array}{c}\text { Targeted } \\
\text { (wt \%) }\end{array}$ & $\begin{array}{c}\text { Diff of } \\
\text { Measured }\end{array}$ & $\begin{array}{c}\text { Diff of Meas } \\
\text { BC }\end{array}$ & $\begin{array}{l}\text { \% Diff of } \\
\text { Measured }\end{array}$ & $\begin{array}{c}\text { \% Diff of Meas } \\
\text { BC }\end{array}$ \\
\hline $\mathrm{Pu} 35-35$ & $\mathrm{Al}_{2} \mathrm{O}_{3}($ wt $\%)$ & 8.6728 & 8.7443 & 8.6000 & 0.0728 & 0.1443 & $0.8 \%$ & $1.7 \%$ \\
\hline \begin{tabular}{|l|}
$\mathrm{Pu} 35-35$ \\
\end{tabular} & $\mathrm{~B}_{2} \mathrm{O}_{3}(\mathrm{wt} \%)$ & 11.2536 & 11.1701 & 11.1800 & 0.0736 & -0.0099 & $0.7 \%$ & $-0.1 \%$ \\
\hline Pu35-35 & $\mathrm{CaO}(\mathrm{wt} \%)$ & 0.1609 & 0.1621 & 0.0800 & 0.0809 & 0.0821 & $101.1 \%$ & $102.7 \%$ \\
\hline $\mathrm{Pu} 35-35$ & $\mathrm{Cl}(\mathrm{wt} \%)$ & 0.0485 & 0.0485 & 0.5800 & -0.5315 & -0.5315 & $-91.6 \%$ & $-91.6 \%$ \\
\hline $\mathrm{Pu} 35-35$ & $\mathrm{Cr}_{2} \mathrm{O}_{3}(\mathrm{wt} \%)$ & 0.0921 & 0.0891 & 0.0800 & 0.0121 & 0.0091 & $15.1 \%$ & $11.4 \%$ \\
\hline Pu35-35 & $\mathrm{CuO}(\mathrm{wt} \%)$ & 0.1152 & 0.1213 & 0.0700 & 0.0452 & 0.0513 & $64.5 \%$ & $73.3 \%$ \\
\hline Pu35-35 & $\mathrm{F}(\mathrm{wt} \%)$ & 0.0160 & 0.0195 & 0.0600 & -0.0440 & -0.0405 & $-73.3 \%$ & $-67.4 \%$ \\
\hline $\mathrm{Pu} 35-35$ & $\mathrm{Fe}_{2} \mathrm{O}_{3}(\mathrm{wt} \%)$ & 0.8035 & 0.8196 & 0.8200 & -0.0165 & -0.0004 & $-2.0 \%$ & $0.0 \%$ \\
\hline $\mathrm{Pu} 35-35$ & $\mathrm{Ga}_{2} \mathrm{O}_{3}(\mathrm{wt} \%)$ & 0.4127 & 0.4127 & 0.3900 & 0.0227 & 0.0227 & $5.8 \%$ & $5.8 \%$ \\
\hline Pu35-35 & $\mathrm{Gd}_{2} \mathrm{O}_{3}(\mathrm{wt} \%)$ & 11.6413 & 11.6413 & 11.6100 & 0.0313 & 0.0313 & $0.3 \%$ & $0.3 \%$ \\
\hline \begin{tabular}{|l|}
$\mathrm{Pu} 35-35$ \\
\end{tabular} & $\mathrm{HfO}_{2}(\mathrm{wt} \%)$ & 13.9747 & 13.9747 & 14.8500 & -0.8753 & -0.8753 & $-5.9 \%$ & $-5.9 \%$ \\
\hline Pu35-35 & $\mathrm{K}_{2} \mathrm{O}(\mathrm{wt} \%)$ & 0.0458 & 0.0409 & 0.0700 & -0.0242 & -0.0291 & $-34.6 \%$ & $-41.6 \%$ \\
\hline \begin{tabular}{|l|}
$\mathrm{Pu} 35-35$ \\
\end{tabular} & $\mathrm{La}_{2} \mathrm{O}_{3}(\mathrm{wt} \%)$ & 16.2433 & 16.2433 & 16.3400 & -0.0967 & -0.0967 & $-0.6 \%$ & $-0.6 \%$ \\
\hline Pu35-35 & $\mathrm{MgO}($ wt $\%)$ & 0.4436 & 0.4380 & 0.4600 & -0.0164 & -0.0220 & $-3.6 \%$ & $-4.8 \%$ \\
\hline $\mathrm{Pu} 35-35$ & $\mathrm{Na}_{2} \mathrm{O}(\mathrm{wt} \%)$ & 0.8991 & 0.8518 & 0.9300 & -0.0309 & -0.0782 & $-3.3 \%$ & $-8.4 \%$ \\
\hline \begin{tabular}{|l|}
$\mathrm{Pu} 35-35$ \\
\end{tabular} & $\mathrm{Nd}_{2} \mathrm{O}_{3}(\mathrm{wt} \%)$ & 13.0054 & 13.0054 & 12.9000 & 0.1054 & 0.1054 & $0.8 \%$ & $0.8 \%$ \\
\hline $\mathrm{Pu} 35-35$ & $\mathrm{NiO}($ wt \%) & 0.0764 & 0.0838 & 0.0700 & 0.0063 & 0.0138 & $9.1 \%$ & $19.7 \%$ \\
\hline Pu35-35 & $\mathrm{PbO}(\mathrm{wt} \%)$ & 0.0878 & 0.0878 & 0.0600 & 0.0278 & 0.0278 & $46.3 \%$ & $46.3 \%$ \\
\hline Pu35-35 & $\mathrm{SeO}_{2}(\mathrm{wt} \%)$ & 0.0070 & 0.0070 & 0.0800 & -0.0730 & -0.0730 & $-91.2 \%$ & $-91.2 \%$ \\
\hline Pu35-35 & $\mathrm{Si}_{2} \mathrm{O}_{3}($ wt $\%)$ & 17.2748 & 17.4545 & 17.2000 & 0.0748 & 0.2545 & $0.4 \%$ & $1.5 \%$ \\
\hline \begin{tabular}{|l|}
$\mathrm{Pu} 35-35$ \\
\end{tabular} & $\mathrm{SO}_{4}(\mathrm{wt} \%)$ & 0.0749 & 0.0749 & 0.1700 & -0.0951 & -0.0951 & $-55.9 \%$ & $-55.9 \%$ \\
\hline Pu35-35 & SrO (wt \%) & 2.1582 & 2.1582 & 2.1500 & 0.0082 & 0.0082 & $0.4 \%$ & $0.4 \%$ \\
\hline \begin{tabular}{|l|}
$\mathrm{Pu} 35-35$ \\
\end{tabular} & $\mathrm{Ta}_{2} \mathrm{O}_{5}(\mathrm{wt} \%)$ & 1.0885 & 1.0885 & 1.1200 & -0.0315 & -0.0315 & $-2.8 \%$ & $-2.8 \%$ \\
\hline \begin{tabular}{|l|}
$\mathrm{Pu} 35-35$ \\
\end{tabular} & Sum (wt \%) & 98.5959 & 98.7373 & 99.8700 & -1.2741 & -1.1327 & $-1.3 \%$ & $-1.1 \%$ \\
\hline Pu35-36 & $\mathrm{Al}_{2} \mathrm{O}_{3}(\mathrm{wt} \%)$ & 8.9751 & 8.9099 & 8.6000 & 0.3751 & 0.3099 & $4.4 \%$ & $3.6 \%$ \\
\hline \begin{tabular}{|l|} 
Pu35-36 \\
\end{tabular} & $\mathrm{B}_{2} \mathrm{O}_{3}(\mathrm{wt} \%)$ & 11.0443 & 11.3672 & 11.1800 & -0.1357 & 0.1872 & $-1.2 \%$ & $1.7 \%$ \\
\hline Pu35-36 & $\mathrm{CaO}($ wt \%) & 0.1651 & 0.1625 & 0.0800 & 0.0851 & 0.0825 & $106.4 \%$ & $103.1 \%$ \\
\hline \begin{tabular}{|l|}
$\mathrm{Pu} 35-36$ \\
\end{tabular} & $\mathrm{Cl}(\mathrm{wt} \%)$ & 0.0560 & 0.0560 & 0.6000 & -0.5440 & -0.5440 & $-90.7 \%$ & $-90.7 \%$ \\
\hline Pu35-36 & $\mathrm{Cr}_{2} \mathrm{O}_{3}(\mathrm{wt} \%)$ & 0.3515 & 0.3416 & 0.3700 & -0.0185 & -0.0284 & $-5.0 \%$ & $-7.7 \%$ \\
\hline Pu35-36 & $\mathrm{CuO}(\mathrm{wt} \%)$ & 0.2141 & 0.2254 & 0.2200 & -0.0059 & 0.0054 & $-2.7 \%$ & $2.5 \%$ \\
\hline Pu35-36 & $\mathrm{F}(\mathrm{wt} \%)$ & 0.0100 & 0.0124 & 0.1600 & -0.1500 & -0.1476 & $-93.8 \%$ & $-92.3 \%$ \\
\hline Pu35-36 & $\mathrm{Fe}_{2} \mathrm{O}_{3}(\mathrm{wt} \%)$ & 0.1437 & 0.1485 & 0.1100 & 0.0337 & 0.0385 & $30.6 \%$ & $35.0 \%$ \\
\hline Pu35-36 & $\mathrm{Ga}_{2} \mathrm{O}_{3}($ wt $\%)$ & 0.3361 & 0.3361 & 0.3100 & 0.0261 & 0.0261 & $8.4 \%$ & $8.4 \%$ \\
\hline Pu35-36 & $\mathrm{Gd}_{2} \mathrm{O}_{3}(\mathrm{wt} \%)$ & 11.7565 & 11.7565 & 11.6100 & 0.1465 & 0.1465 & $1.3 \%$ & $1.3 \%$ \\
\hline Pu35-36 & $\mathrm{HfO}_{2}(\mathrm{wt} \%)$ & 14.0337 & 14.0337 & 14.8900 & -0.8563 & -0.8563 & $-5.8 \%$ & $-5.8 \%$ \\
\hline $\mathrm{Pu} 35-36$ & $\mathrm{~K}_{2} \mathrm{O}(\mathrm{wt} \%)$ & 0.3692 & 0.3210 & 0.4300 & -0.0608 & -0.1090 & $-14.1 \%$ & $-25.3 \%$ \\
\hline Pu35-36 & $\mathrm{La}_{2} \mathrm{O}_{3}(\mathrm{wt} \%)$ & 16.3019 & 16.3019 & 16.3400 & -0.0381 & -0.0381 & $-0.2 \%$ & $-0.2 \%$ \\
\hline Pu35-36 & $\mathrm{MgO}($ wt $\%)$ & 0.8698 & 0.8529 & 0.8900 & -0.0202 & -0.0371 & $-2.3 \%$ & $-4.2 \%$ \\
\hline Pu35-36 & $\mathrm{Na}_{2} \mathrm{O}($ wt $\%)$ & 0.6868 & 0.6307 & 0.6700 & 0.0168 & -0.0393 & $2.5 \%$ & $-5.9 \%$ \\
\hline Pu35-36 & $\mathrm{Nd}_{2} \mathrm{O}_{3}(\mathrm{wt} \%)$ & 13.0637 & 13.0637 & 12.9000 & 0.1637 & 0.1637 & $1.3 \%$ & $1.3 \%$ \\
\hline $\mathrm{Pu} 35-36$ & $\mathrm{NiO}($ wt \%) & 0.2933 & 0.3226 & 0.3300 & -0.0367 & -0.0074 & $-11.1 \%$ & $-2.3 \%$ \\
\hline \begin{tabular}{|l|} 
Pu35-36 \\
\end{tabular} & $\mathrm{PbO}(\mathrm{wt} \%)$ & 0.0840 & 0.0840 & 0.0600 & 0.0240 & 0.0240 & $40.0 \%$ & $40.0 \%$ \\
\hline Pu35-36 & $\mathrm{SeO}_{2}($ wt $\%)$ & 0.0070 & 0.0070 & 0.0800 & -0.0730 & -0.0730 & $-91.2 \%$ & $-91.2 \%$ \\
\hline Pu35-36 & $\mathrm{Si}_{2} \mathrm{O}_{3}(\mathrm{wt} \%)$ & 17.7455 & 17.9044 & 17.2000 & 0.5455 & 0.7044 & $3.2 \%$ & $4.1 \%$ \\
\hline Pu35-36 & $\mathrm{SO}_{4}(\mathrm{wt} \%)$ & 0.0749 & 0.0749 & 0.1700 & -0.0951 & -0.0951 & $-55.9 \%$ & $-55.9 \%$ \\
\hline Pu35-36 & $\mathrm{SrO}(\mathrm{wt} \%)$ & 2.2588 & 2.2588 & 2.1500 & 0.1088 & 0.1088 & $5.1 \%$ & $5.1 \%$ \\
\hline Pu35-36 & $\mathrm{Ta}_{2} \mathrm{O}_{5}(\mathrm{wt} \%)$ & 0.5012 & 0.5012 & 0.5100 & -0.0088 & -0.0088 & $-1.7 \%$ & $-1.7 \%$ \\
\hline $\mathrm{Pu} 35-36$ & Sum (wt \%) & 99.3421 & 99.6728 & 99.8600 & -0.5179 & -0.1872 & $-0.5 \%$ & $-0.2 \%$ \\
\hline Pu35-37 & $\mathrm{Al}_{2} \mathrm{O}_{3}(\mathrm{wt} \%)$ & 8.8145 & 8.7505 & 8.6000 & 0.2145 & 0.1505 & $2.5 \%$ & $1.7 \%$ \\
\hline Pu35-37 & $\mathrm{B}_{2} \mathrm{O}_{3}(\mathrm{wt} \%)$ & 10.9960 & 11.3175 & 11.1800 & -0.1840 & 0.1375 & $-1.6 \%$ & $1.2 \%$ \\
\hline Pu35-37 & $\mathrm{CaO}($ wt \%) & 0.2665 & 0.2623 & 0.1700 & 0.0965 & 0.0923 & $56.8 \%$ & $54.3 \%$ \\
\hline Pu35-37 & $\mathrm{Cl}(\mathrm{wt} \%)$ & 0.0445 & 0.0445 & 0.6000 & -0.5555 & -0.5555 & $-92.6 \%$ & $-92.6 \%$ \\
\hline Pu35-37 & $\mathrm{Cr}_{2} \mathrm{O}_{3}(\mathrm{wt} \%)$ & 0.3778 & 0.3672 & 0.4000 & -0.0222 & -0.0328 & $-5.5 \%$ & $-8.2 \%$ \\
\hline Pu35-37 & $\mathrm{CuO}(\mathrm{wt} \%)$ & 0.0951 & 0.1002 & 0.0700 & 0.0251 & 0.0302 & $35.9 \%$ & $43.1 \%$ \\
\hline Pu35-37 & $\mathrm{F}(\mathrm{wt} \%)$ & 0.0000 & 0.0000 & 0.1000 & -0.1000 & -0.1000 & $-100.0 \%$ & $-100.0 \%$ \\
\hline Pu35-37 & $\mathrm{Fe}_{2} \mathrm{O}_{3}(\mathrm{wt} \%)$ & 0.3589 & 0.3710 & 0.2800 & 0.0789 & 0.0910 & $28.2 \%$ & $32.5 \%$ \\
\hline \begin{tabular}{|l|}
$\mathrm{Pu} 35-37$ \\
\end{tabular} & $\mathrm{Ga}_{2} \mathrm{O}_{3}(\mathrm{wt} \%)$ & 0.3804 & 0.3804 & 0.3600 & 0.0204 & 0.0204 & $5.7 \%$ & $5.7 \%$ \\
\hline Pu35-37 & $\mathrm{Gd}_{2} \mathrm{O}_{3}(\mathrm{wt} \%)$ & 11.5433 & 11.5433 & 11.6100 & -0.0667 & -0.0667 & $-0.6 \%$ & $-0.6 \%$ \\
\hline
\end{tabular}


Table D5. Average Measured and Bias-Corrected Chemical Compositions Versus Targeted Compositions by Oxide by Study Glass (continued)

\begin{tabular}{|c|c|c|c|c|c|c|c|c|}
\hline Glass ID & Oxide & $\begin{array}{c}\text { Measured } \\
(\mathrm{wt} \%)\end{array}$ & \begin{tabular}{|c|} 
Measured Bias- \\
Corrected (wt \%)
\end{tabular} & $\begin{array}{c}\text { Targeted } \\
\text { (wt \%) }\end{array}$ & $\begin{array}{c}\text { Diff of } \\
\text { Measured }\end{array}$ & $\begin{array}{c}\text { Diff of Meas } \\
\text { BC }\end{array}$ & $\begin{array}{l}\text { \% Diff of } \\
\text { Measured }\end{array}$ & $\begin{array}{c}\text { \% Diff of Meas } \\
\text { BC }\end{array}$ \\
\hline $\mathrm{Pu} 35-37$ & $\mathrm{HfO}_{2}(\mathrm{wt} \%)$ & 13.3261 & \begin{tabular}{|l|}
13.3261 \\
\end{tabular} & 14.8500 & -1.5239 & -1.5239 & $-10.3 \%$ & $-10.3 \%$ \\
\hline \begin{tabular}{|l|}
$\mathrm{Pu} 35-37$ \\
\end{tabular} & $\mathrm{~K}_{2} \mathrm{O}(\mathrm{wt} \%)$ & 0.2867 & 0.2493 & 0.3600 & -0.0733 & -0.1107 & $-20.4 \%$ & $-30.8 \%$ \\
\hline Pu35-37 & $\mathrm{La}_{2} \mathrm{O}_{3}(\mathrm{wt} \%)$ & 16.0674 & 16.0674 & 16.3400 & -0.2726 & -0.2726 & $-1.7 \%$ & $-1.7 \%$ \\
\hline Pu35-37 & $\mathrm{MgO}(\mathrm{wt} \%)$ & 0.9817 & 0.9626 & 1.0200 & -0.0383 & -0.0574 & $-3.8 \%$ & $-5.6 \%$ \\
\hline Pu35-37 & $\mathrm{Na}_{2} \mathrm{O}($ wt $\%)$ & 0.6679 & 0.6133 & 0.6500 & 0.0179 & -0.0367 & $2.8 \%$ & $-5.6 \%$ \\
\hline Pu35-37 & $\mathrm{Nd}_{2} \mathrm{O}_{3}(\mathrm{wt} \%)$ & 12.8304 & 12.8304 & 12.9000 & -0.0696 & -0.0696 & $-0.5 \%$ & $-0.5 \%$ \\
\hline Pu35-37 & $\mathrm{NiO}($ wt \%) & 0.3423 & 0.3764 & 0.3700 & -0.0277 & 0.0064 & $-7.5 \%$ & $1.7 \%$ \\
\hline Pu35-37 & $\mathrm{PbO}(\mathrm{wt} \%)$ & 0.0824 & 0.0824 & 0.0600 & 0.0224 & 0.0224 & $37.3 \%$ & $37.3 \%$ \\
\hline Pu35-37 & $\mathrm{SeO}_{2}(\mathrm{wt} \%)$ & 0.0070 & 0.0070 & 0.0800 & -0.0730 & -0.0730 & $-91.2 \%$ & $-91.2 \%$ \\
\hline \begin{tabular}{|l|}
$\mathrm{Pu} 35-37$ \\
\end{tabular} & $\mathrm{Si}_{2} \mathrm{O}_{3}($ wt $\%)$ & 17.4032 & 17.5590 & 17.2000 & 0.2032 & 0.3590 & $1.2 \%$ & $2.1 \%$ \\
\hline \begin{tabular}{|l|}
$\mathrm{Pu} 35-37$ \\
\end{tabular} & $\mathrm{SO}_{4}(\mathrm{wt} \%)$ & 0.0749 & 0.0749 & 0.1700 & -0.0951 & -0.0951 & $-55.9 \%$ & $-55.9 \%$ \\
\hline \begin{tabular}{|l|} 
Pu35-37 \\
\end{tabular} & $\mathrm{SrO}(\mathrm{wt} \%)$ & 2.2055 & 2.2055 & 2.1500 & 0.0555 & 0.0555 & $2.6 \%$ & $2.6 \%$ \\
\hline \begin{tabular}{|l|} 
Pu35-37 \\
\end{tabular} & $\mathrm{Ta}_{2} \mathrm{O}_{5}(\mathrm{wt} \%)$ & 0.3443 & 0.3443 & 0.3500 & -0.0057 & -0.0057 & $-1.6 \%$ & $-1.6 \%$ \\
\hline Pu35-37 & Sum (wt \%) & 97.4969 & 97.8355 & 99.8700 & -2.3731 & -2.0345 & $-2.4 \%$ & $-2.0 \%$ \\
\hline \begin{tabular}{|l|}
$\mathrm{Pu} 35-38$ \\
\end{tabular} & $\mathrm{Al}_{2} \mathrm{O}_{3}(\mathrm{wt} \%)$ & 8.7389 & 8.6754 & 8.6000 & 0.1389 & 0.0754 & $1.6 \%$ & $0.9 \%$ \\
\hline \begin{tabular}{|l|}
$\mathrm{Pu} 35-38$ \\
\end{tabular} & $\mathrm{~B}_{2} \mathrm{O}_{3}(\mathrm{wt} \%)$ & 11.0121 & 11.3341 & 11.1800 & -0.1679 & 0.1541 & $-1.5 \%$ & $1.4 \%$ \\
\hline Pu35-38 & $\mathrm{CaO}($ wt \%) & 0.5387 & 0.5301 & 0.4300 & 0.1087 & 0.1001 & $25.3 \%$ & $23.3 \%$ \\
\hline Pu35-38 & $\mathrm{Cl}(\mathrm{wt} \%)$ & 0.0530 & 0.0530 & 0.6600 & -0.6070 & -0.6070 & $-92.0 \%$ & $-92.0 \%$ \\
\hline Pu35-38 & $\mathrm{Cr}_{2} \mathrm{O}_{3}(\mathrm{wt} \%)$ & 0.1681 & 0.1633 & 0.1800 & -0.0119 & -0.0167 & $-6.6 \%$ & $-9.3 \%$ \\
\hline Pu35-38 & $\mathrm{CuO}(\mathrm{wt} \%)$ & 0.0983 & 0.1035 & 0.0700 & 0.0283 & 0.0335 & $40.4 \%$ & $47.8 \%$ \\
\hline \begin{tabular}{|l|}
$\mathrm{Pu} 35-38$ \\
\end{tabular} & $\mathrm{~F}(\mathrm{wt} \%)$ & 0.0330 & 0.0408 & 0.3100 & -0.2770 & -0.2692 & $-89.4 \%$ & $-86.8 \%$ \\
\hline Pu35-38 & $\mathrm{Fe}_{2} \mathrm{O}_{3}($ wt $\%)$ & 0.1994 & 0.2062 & 0.1700 & 0.0294 & 0.0362 & $17.3 \%$ & $21.3 \%$ \\
\hline \begin{tabular}{|l|}
$\mathrm{Pu} 35-38$ \\
\end{tabular} & $\mathrm{Ga}_{2} \mathrm{O}_{3}($ wt $\%)$ & 0.3260 & 0.3260 & 0.3000 & 0.0260 & 0.0260 & $8.7 \%$ & $8.7 \%$ \\
\hline \begin{tabular}{|l|}
$\mathrm{Pu} 35-38$ \\
\end{tabular} & $\mathrm{Gd}_{2} \mathrm{O}_{3}(\mathrm{wt} \%)$ & 11.4511 & 11.4511 & 11.6100 & -0.1589 & -0.1589 & $-1.4 \%$ & $-1.4 \%$ \\
\hline \begin{tabular}{|l|}
$\mathrm{Pu} 35-38$ \\
\end{tabular} & $\mathrm{HfO}_{2}(\mathrm{wt} \%)$ & 13.6799 & 13.6799 & 14.9300 & -1.2501 & -1.2501 & $-8.4 \%$ & $-8.4 \%$ \\
\hline Pu35-38 & $\mathrm{K}_{2} \mathrm{O}(\mathrm{wt} \%)$ & 0.3740 & 0.3252 & 0.4500 & -0.0760 & -0.1248 & $-16.9 \%$ & $-27.7 \%$ \\
\hline Pu35-38 & $\mathrm{La}_{2} \mathrm{O}_{3}(\mathrm{wt} \%)$ & 16.0674 & 16.0674 & 16.3400 & -0.2726 & -0.2726 & $-1.7 \%$ & $-1.7 \%$ \\
\hline Pu35-38 & $\mathrm{MgO}(\mathrm{wt} \%)$ & 0.7189 & 0.7049 & 0.7300 & -0.0111 & -0.0251 & $-1.5 \%$ & $-3.4 \%$ \\
\hline Pu35-38 & $\mathrm{Na}_{2} \mathrm{O}($ wt $\%)$ & 0.6592 & 0.6053 & 0.6600 & -0.0008 & -0.0547 & $-0.1 \%$ & $-8.3 \%$ \\
\hline Pu35-38 & $\mathrm{Nd}_{2} \mathrm{O}_{3}($ wt $\%)$ & 12.7138 & 12.7138 & 12.9000 & -0.1862 & -0.1862 & $-1.4 \%$ & $-1.4 \%$ \\
\hline \begin{tabular}{|l|}
$\mathrm{Pu} 35-38$ \\
\end{tabular} & $\mathrm{NiO}(\mathrm{wt} \%)$ & 0.1603 & 0.1763 & 0.1800 & -0.0197 & -0.0037 & $-10.9 \%$ & $-2.0 \%$ \\
\hline Pu35-38 & $\mathrm{PbO}(\mathrm{wt} \%)$ & 0.0840 & 0.0840 & 0.0600 & 0.0240 & 0.0240 & $40.0 \%$ & $40.0 \%$ \\
\hline Pu35-38 & $\mathrm{SeO}_{2}(\mathrm{wt} \%)$ & 0.0070 & 0.0070 & 0.0800 & -0.0730 & -0.0730 & $-91.2 \%$ & $-91.2 \%$ \\
\hline Pu35-38 & $\mathrm{Si}_{2} \mathrm{O}_{3}(\mathrm{wt} \%)$ & 17.3711 & 17.5266 & 17.2000 & 0.1711 & 0.3266 & $1.0 \%$ & $1.9 \%$ \\
\hline Pu35-38 & $\mathrm{SO}_{4}(\mathrm{wt} \%)$ & 0.0749 & 0.0749 & 0.1700 & -0.0951 & -0.0951 & $-55.9 \%$ & $-55.9 \%$ \\
\hline Pu35-38 & $\mathrm{SrO}(\mathrm{wt} \%)$ & 2.1937 & 2.1937 & 2.1500 & 0.0437 & 0.0437 & $2.0 \%$ & $2.0 \%$ \\
\hline Pu35-38 & $\mathrm{Ta}_{2} \mathrm{O}_{5}(\mathrm{wt} \%)$ & 0.5165 & 0.5165 & 0.5300 & -0.0135 & -0.0135 & $-2.6 \%$ & $-2.6 \%$ \\
\hline Pu35-38 & Sum (wt \%) & 97.2392 & 97.5590 & 99.8900 & -2.6508 & -2.3310 & $-2.7 \%$ & $-2.3 \%$ \\
\hline Pu35-39 & $\mathrm{Al}_{2} \mathrm{O}_{3}($ wt $\%)$ & 9.0413 & 8.9756 & 8.6000 & 0.4413 & 0.3756 & $5.1 \%$ & $4.4 \%$ \\
\hline Pu35-39 & $\mathrm{B}_{2} \mathrm{O}_{3}(\mathrm{wt} \%)$ & 11.0121 & 11.3341 & 11.1800 & -0.1679 & 0.1541 & $-1.5 \%$ & $1.4 \%$ \\
\hline Pu35-39 & $\mathrm{CaO}(\mathrm{wt} \%)$ & 0.1651 & 0.1625 & 0.0800 & 0.0851 & 0.0825 & $106.4 \%$ & $103.1 \%$ \\
\hline \begin{tabular}{|l|} 
Pu35-39 \\
\end{tabular} & $\mathrm{Cl}(\mathrm{wt} \%)$ & 0.0530 & 0.0530 & 0.6900 & -0.6370 & -0.6370 & $-92.3 \%$ & $-92.3 \%$ \\
\hline \begin{tabular}{|l|}
$\mathrm{Pu} 35-39$ \\
\end{tabular} & $\mathrm{Cr}_{2} \mathrm{O}_{3}(\mathrm{wt} \%)$ & 0.2901 & 0.2819 & 0.3100 & -0.0199 & -0.0281 & $-6.4 \%$ & $-9.1 \%$ \\
\hline \begin{tabular}{|l|}
$\mathrm{Pu} 35-39$ \\
\end{tabular} & $\mathrm{CuO}(\mathrm{wt} \%)$ & 0.0976 & 0.1028 & 0.0700 & 0.0276 & 0.0328 & $39.5 \%$ & $46.9 \%$ \\
\hline \begin{tabular}{|l|}
$\mathrm{Pu} 35-39$ \\
\end{tabular} & $\mathrm{~F}(\mathrm{wt} \%)$ & 0.0000 & 0.0000 & 0.1800 & -0.1800 & -0.1800 & $-100.0 \%$ & $-100.0 \%$ \\
\hline \begin{tabular}{|l|}
$\mathrm{Pu} 35-39$ \\
\end{tabular} & $\mathrm{Fe}_{2} \mathrm{O}_{3}(\mathrm{wt} \%)$ & 0.3303 & 0.3414 & 0.2900 & 0.0403 & 0.0514 & $13.9 \%$ & $17.7 \%$ \\
\hline \begin{tabular}{|l|}
$\mathrm{Pu} 35-39$ \\
\end{tabular} & $\mathrm{Ga}_{2} \mathrm{O}_{3}($ wt $\%)$ & 0.3367 & 0.3367 & 0.3100 & 0.0267 & 0.0267 & $8.6 \%$ & $8.6 \%$ \\
\hline \begin{tabular}{|l|}
$\mathrm{Pu} 35-39$ \\
\end{tabular} & $\mathrm{Gd}_{2} \mathrm{O}_{3}(\mathrm{wt} \%)$ & 11.7565 & 11.7565 & 11.6100 & 0.1465 & 0.1465 & $1.3 \%$ & $1.3 \%$ \\
\hline \begin{tabular}{|l|}
$\mathrm{Pu} 35-39$ \\
\end{tabular} & $\mathrm{HfO}_{2}(\mathrm{wt} \%)$ & 13.9747 & 13.9747 & 14.9200 & -0.9453 & -0.9453 & $-6.3 \%$ & $-6.3 \%$ \\
\hline \begin{tabular}{|l|}
$\mathrm{Pu} 35-39$ \\
\end{tabular} & $\mathrm{~K}_{2} \mathrm{O}(\mathrm{wt} \%)$ & 0.6264 & 0.5446 & 0.7700 & -0.1436 & -0.2254 & $-18.7 \%$ & $-29.3 \%$ \\
\hline \begin{tabular}{|l|}
$\mathrm{Pu} 35-39$ \\
\end{tabular} & $\mathrm{La}_{2} \mathrm{O}_{3}(\mathrm{wt} \%)$ & 16.3019 & 16.3019 & 16.3400 & -0.0381 & -0.0381 & $-0.2 \%$ & $-0.2 \%$ \\
\hline Pu35-39 & $\mathrm{MgO}(\mathrm{wt} \%)$ & 0.6857 & 0.6724 & 0.7000 & -0.0143 & -0.0276 & $-2.0 \%$ & $-3.9 \%$ \\
\hline Pu35-39 & $\mathrm{Na}_{2} \mathrm{O}$ (wt \%) & 0.7286 & 0.6690 & 0.7000 & 0.0286 & -0.0310 & $4.1 \%$ & $-4.4 \%$ \\
\hline \begin{tabular}{|l|}
$\mathrm{Pu} 35-39$ \\
\end{tabular} & $\mathrm{Nd}_{2} \mathrm{O}_{3}(\mathrm{wt} \%)$ & 13.1220 & 13.1220 & 12.9000 & 0.2220 & 0.2220 & $1.7 \%$ & $1.7 \%$ \\
\hline \begin{tabular}{|l|} 
Pu35-39 \\
\end{tabular} & $\mathrm{NiO}(\mathrm{wt} \%)$ & 0.0681 & 0.0749 & 0.0700 & -0.0019 & 0.0049 & $-2.7 \%$ & $7.0 \%$ \\
\hline Pu35-39 & $\mathrm{PbO}(\mathrm{wt} \%)$ & 0.0824 & 0.0824 & 0.0600 & 0.0224 & 0.0224 & $37.3 \%$ & $37.3 \%$ \\
\hline \begin{tabular}{|l|} 
Pu35-39 \\
\end{tabular} & $\mathrm{SeO}_{2}(\mathrm{wt} \%)$ & 0.0070 & 0.0070 & 0.0800 & -0.0730 & -0.0730 & $-91.2 \%$ & $-91.2 \%$ \\
\hline Pu35-39 & $\mathrm{Si}_{2} \mathrm{O}_{3}($ wt $\%)$ & 17.7669 & 17.9259 & 17.2000 & 0.5669 & 0.7259 & $3.3 \%$ & $4.2 \%$ \\
\hline
\end{tabular}


Table D5. Average Measured and Bias-Corrected Chemical Compositions Versus Targeted Compositions by Oxide by Study Glass (continued)

\begin{tabular}{|c|c|c|c|c|c|c|c|c|}
\hline Glass ID & Oxide & $\begin{array}{c}\text { Measured } \\
(\mathrm{wt} \%)\end{array}$ & \begin{tabular}{|c|} 
Measured Bias- \\
Corrected (wt \%)
\end{tabular} & $\begin{array}{c}\text { Targeted } \\
\text { (wt \%) }\end{array}$ & $\begin{array}{c}\text { Diff of } \\
\text { Measured }\end{array}$ & $\begin{array}{c}\text { Diff of Meas } \\
\text { BC }\end{array}$ & $\begin{array}{l}\text { \% Diff of } \\
\text { Measured }\end{array}$ & $\begin{array}{c}\text { \% Diff of Meas } \\
\text { BC }\end{array}$ \\
\hline Pu35-39 & $\mathrm{SO}_{4}(\mathrm{wt} \%)$ & 0.0749 & \begin{tabular}{|l|}
0.0749 \\
\end{tabular} & 0.1700 & -0.0951 & -0.0951 & $-55.9 \%$ & $-55.9 \%$ \\
\hline \begin{tabular}{|l|} 
Pu35-39 \\
\end{tabular} & $\mathrm{SrO}(\mathrm{wt} \%)$ & 2.2765 & 2.2765 & 2.1500 & 0.1265 & 0.1265 & $5.9 \%$ & $5.9 \%$ \\
\hline \begin{tabular}{|l|}
$\mathrm{Pu} 35-39$ \\
\end{tabular} & $\mathrm{Ta}_{2} \mathrm{O}_{5}(\mathrm{wt} \%)$ & 0.4927 & 0.4927 & 0.5000 & -0.0073 & -0.0073 & $-1.5 \%$ & $-1.5 \%$ \\
\hline Pu35-39 & Sum (wt \%) & 99.2905 & 99.5635 & 99.8800 & -0.5895 & -0.3165 & $-0.6 \%$ & $-0.3 \%$ \\
\hline $\mathrm{Pu} 35-40$ & $\mathrm{Al}_{2} \mathrm{O}_{3}(\mathrm{wt} \%)$ & 8.7389 & 8.6754 & 8.6000 & 0.1389 & 0.0754 & $1.6 \%$ & $0.9 \%$ \\
\hline Pu35-40 & $\mathrm{B}_{2} \mathrm{O}_{3}(\mathrm{wt} \%)$ & 11.0604 & 11.3838 & 11.1800 & -0.1196 & 0.2038 & $-1.1 \%$ & $1.8 \%$ \\
\hline Pu35-40 & $\mathrm{CaO}($ wt \%) & 0.5268 & 0.5184 & 0.4100 & 0.1168 & 0.1084 & $28.5 \%$ & $26.4 \%$ \\
\hline Pu35-40 & $\mathrm{Cl}(\mathrm{wt} \%)$ & 0.0690 & 0.0690 & 0.7200 & -0.6510 & -0.6510 & $-90.4 \%$ & $-90.4 \%$ \\
\hline $\mathrm{Pu} 35-40$ & $\mathrm{Cr}_{2} \mathrm{O}_{3}(\mathrm{wt} \%)$ & 0.3121 & 0.3032 & 0.3200 & -0.0079 & -0.0168 & $-2.5 \%$ & $-5.2 \%$ \\
\hline Pu35-40 & $\mathrm{CuO}(\mathrm{wt} \%)$ & 0.2078 & 0.2188 & 0.2200 & -0.0122 & -0.0012 & $-5.5 \%$ & $-0.5 \%$ \\
\hline Pu35-40 & $\mathrm{F}(\mathrm{wt} \%)$ & 0.0000 & 0.0000 & 0.1400 & -0.1400 & -0.1400 & $-100.0 \%$ & $-100.0 \%$ \\
\hline Pu35-40 & $\mathrm{Fe}_{2} \mathrm{O}_{3}(\mathrm{wt} \%)$ & 0.5862 & 0.6060 & 0.5600 & 0.0262 & 0.0460 & $4.7 \%$ & $8.2 \%$ \\
\hline \begin{tabular}{|l|}
$\mathrm{Pu} 35-40$ \\
\end{tabular} & $\mathrm{Ga}_{2} \mathrm{O}_{3}(\mathrm{wt} \%)$ & 0.4187 & 0.4187 & 0.3900 & 0.0287 & 0.0287 & $7.4 \%$ & $7.4 \%$ \\
\hline Pu35-40 & $\mathrm{Gd}_{2} \mathrm{O}_{3}(\mathrm{wt} \%)$ & 11.5318 & 11.5318 & 11.6100 & -0.0782 & -0.0782 & $-0.7 \%$ & $-0.7 \%$ \\
\hline $\mathrm{Pu} 35-40$ & $\mathrm{HfO}_{2}(\mathrm{wt} \%)$ & 13.3851 & 13.3851 & 14.8600 & -1.4749 & -1.4749 & $-9.9 \%$ & $-9.9 \%$ \\
\hline \begin{tabular}{|l|}
$\mathrm{Pu} 35-40$ \\
\end{tabular} & $\mathrm{~K}_{2} \mathrm{O}(\mathrm{wt} \%)$ & 0.4108 & 0.3571 & 0.5000 & -0.0892 & -0.1429 & $-17.8 \%$ & $-28.6 \%$ \\
\hline Pu35-40 & $\mathrm{La}_{2} \mathrm{O}_{3}(\mathrm{wt} \%)$ & 16.0674 & 16.0674 & 16.3400 & -0.2726 & -0.2726 & $-1.7 \%$ & $-1.7 \%$ \\
\hline $\mathrm{Pu} 35-40$ & $\mathrm{MgO}($ wt $\%)$ & 0.6467 & 0.6342 & 0.6500 & -0.0033 & -0.0158 & $-0.5 \%$ & $-2.4 \%$ \\
\hline $\mathrm{Pu} 35-40$ & $\mathrm{Na}_{2} \mathrm{O}(\mathrm{wt} \%)$ & 0.6545 & 0.6010 & 0.6500 & 0.0045 & -0.0490 & $0.7 \%$ & $-7.5 \%$ \\
\hline Pu35-40 & $\mathrm{Nd}_{2} \mathrm{O}_{3}(\mathrm{wt} \%)$ & 12.8304 & 12.8304 & 12.9000 & -0.0696 & -0.0696 & $-0.5 \%$ & $-0.5 \%$ \\
\hline \begin{tabular}{|l|}
$\mathrm{Pu} 35-40$ \\
\end{tabular} & $\mathrm{NiO}($ wt \%) & 0.0973 & 0.1071 & 0.1000 & -0.0027 & 0.0071 & $-2.7 \%$ & $7.1 \%$ \\
\hline Pu35-40 & $\mathrm{PbO}($ wt \%) & 0.0840 & 0.0840 & 0.0600 & 0.0240 & 0.0240 & $40.0 \%$ & $40.0 \%$ \\
\hline Pu35-40 & $\mathrm{SeO}_{2}(\mathrm{wt} \%)$ & 0.0070 & 0.0070 & 0.0800 & -0.0730 & -0.0730 & $-91.2 \%$ & $-91.2 \%$ \\
\hline \begin{tabular}{|l|} 
Pu35-40 \\
\end{tabular} & $\mathrm{Si}_{2} \mathrm{O}_{3}$ (wt \%) & 17.4353 & 17.5914 & 17.2000 & 0.2353 & 0.3914 & $1.4 \%$ & $2.3 \%$ \\
\hline \begin{tabular}{|l|}
$\mathrm{Pu} 35-40$ \\
\end{tabular} & $\mathrm{SO}_{4}(\mathrm{wt} \%)$ & 0.0749 & 0.0749 & 0.1700 & -0.0951 & -0.0951 & $-55.9 \%$ & $-55.9 \%$ \\
\hline \begin{tabular}{|l|}
$\mathrm{Pu} 35-40$ \\
\end{tabular} & $\mathrm{SrO}(\mathrm{wt} \%)$ & 2.1760 & 2.1760 & 2.1500 & 0.0260 & 0.0260 & $1.2 \%$ & $1.2 \%$ \\
\hline Pu35-40 & $\mathrm{Ta}_{2} \mathrm{O}_{5}(\mathrm{wt} \%)$ & 0.0861 & 0.0861 & 0.0700 & 0.0161 & 0.0161 & $23.0 \%$ & $23.0 \%$ \\
\hline $\mathrm{Pu} 35-40$ & Sum (wt \%) & 97.4070 & 97.7267 & 99.8800 & -2.4730 & -2.1533 & $-2.5 \%$ & $-2.2 \%$ \\
\hline Pu35-41 & $\mathrm{Al}_{2} \mathrm{O}_{3}(\mathrm{wt} \%)$ & 8.9657 & 8.9005 & 8.6000 & 0.3657 & 0.3005 & $4.3 \%$ & $3.5 \%$ \\
\hline Pu35-41 & $\mathrm{B}_{2} \mathrm{O}_{3}(\mathrm{wt} \%)$ & 11.1731 & 11.4998 & 11.1800 & -0.0069 & 0.3198 & $-0.1 \%$ & $2.9 \%$ \\
\hline \begin{tabular}{|l|}
$\mathrm{Pu} 35-41$ \\
\end{tabular} & $\mathrm{CaO}(\mathrm{wt} \%)$ & 0.1651 & 0.1625 & 0.0800 & 0.0851 & 0.0825 & $106.4 \%$ & $103.1 \%$ \\
\hline Pu35-41 & $\mathrm{Cl}(\mathrm{wt} \%)$ & 0.0725 & 0.0725 & 0.9300 & -0.8575 & -0.8575 & $-92.2 \%$ & $-92.2 \%$ \\
\hline Pu35-41 & $\mathrm{Cr}_{2} \mathrm{O}_{3}(\mathrm{wt} \%)$ & 0.0884 & 0.0859 & 0.0800 & 0.0084 & 0.0059 & $10.5 \%$ & $7.4 \%$ \\
\hline Pu35-41 & $\mathrm{CuO}(\mathrm{wt} \%)$ & 0.1452 & 0.1529 & 0.1500 & -0.0048 & 0.0029 & $-3.2 \%$ & $1.9 \%$ \\
\hline Pu35-41 & $\mathrm{F}(\mathrm{wt} \%)$ & 0.0000 & 0.0000 & 0.0600 & -0.0600 & -0.0600 & $-100.0 \%$ & $-100.0 \%$ \\
\hline Pu35-41 & $\mathrm{Fe}_{2} \mathrm{O}_{3}(\mathrm{wt} \%)$ & 0.1072 & 0.1109 & 0.0800 & 0.0272 & 0.0309 & $34.0 \%$ & $38.6 \%$ \\
\hline $\mathrm{Pu} 35-41$ & $\mathrm{Ga}_{2} \mathrm{O}_{3}(\mathrm{wt} \%)$ & 0.1116 & 0.1116 & 0.0800 & 0.0316 & 0.0316 & $39.5 \%$ & $39.5 \%$ \\
\hline Pu35-41 & $\mathrm{Gd}_{2} \mathrm{O}_{3}(\mathrm{wt} \%)$ & 11.6413 & 11.6413 & 11.6100 & 0.0313 & 0.0313 & $0.3 \%$ & $0.3 \%$ \\
\hline Pu35-41 & $\mathrm{HfO}_{2}(\mathrm{wt} \%)$ & 13.5030 & 13.5030 & 14.9300 & -1.4270 & -1.4270 & $-9.6 \%$ & $-9.6 \%$ \\
\hline $\mathrm{Pu} 35-41$ & $\mathrm{~K}_{2} \mathrm{O}(\mathrm{wt} \%)$ & 0.2644 & 0.2299 & 0.3400 & -0.0756 & -0.1101 & $-22.2 \%$ & $-32.4 \%$ \\
\hline \begin{tabular}{|l|}
$\mathrm{Pu} 35-41$ \\
\end{tabular} & $\mathrm{La}_{2} \mathrm{O}_{3}(\mathrm{wt} \%)$ & 16.0087 & 16.0087 & 16.3400 & -0.3313 & -0.3313 & $-2.0 \%$ & $-2.0 \%$ \\
\hline \begin{tabular}{|l|} 
Pu35-41 \\
\end{tabular} & $\mathrm{MgO}(\mathrm{wt} \%)$ & 1.3001 & 1.2748 & 1.3900 & -0.0899 & -0.1152 & $-6.5 \%$ & $-8.3 \%$ \\
\hline Pu35-41 & $\mathrm{Na}_{2} \mathrm{O}($ wt $\%)$ & 0.8755 & 0.8040 & 0.9400 & -0.0645 & -0.1360 & $-6.9 \%$ & $-14.5 \%$ \\
\hline $\mathrm{Pu} 35-41$ & $\mathrm{Nd}_{2} \mathrm{O}_{3}(\mathrm{wt} \%)$ & 12.9470 & 12.9470 & 12.9000 & 0.0470 & 0.0470 & $0.4 \%$ & $0.4 \%$ \\
\hline Pu35-41 & $\mathrm{NiO}($ wt \%) & 0.3957 & 0.4352 & 0.4400 & -0.0443 & -0.0048 & $-10.1 \%$ & $-1.1 \%$ \\
\hline Pu35-41 & $\mathrm{PbO}$ (wt \%) & 0.0776 & 0.0776 & 0.0600 & 0.0176 & 0.0176 & $29.3 \%$ & $29.3 \%$ \\
\hline Pu35-41 & $\mathrm{SeO}_{2}($ wt $\%)$ & 0.0070 & 0.0070 & 0.0800 & -0.0730 & -0.0730 & $-91.2 \%$ & $-91.2 \%$ \\
\hline Pu35-41 & $\mathrm{Si}_{2} \mathrm{O}_{3}(\mathrm{wt} \%)$ & 17.4032 & 17.5590 & 17.2000 & 0.2032 & 0.3590 & $1.2 \%$ & $2.1 \%$ \\
\hline Pu35-41 & $\mathrm{SO}_{4}(\mathrm{wt} \%)$ & 0.0749 & 0.0749 & 0.1700 & -0.0951 & -0.0951 & $-55.9 \%$ & $-55.9 \%$ \\
\hline \begin{tabular}{|l|}
$\mathrm{Pu} 35-41$ \\
\end{tabular} & $\mathrm{SrO}(\mathrm{wt} \%)$ & 2.2706 & 2.2706 & 2.1500 & 0.1206 & 0.1206 & $5.6 \%$ & $5.6 \%$ \\
\hline Pu35-41 & $\mathrm{Ta}_{2} \mathrm{O}_{5}(\mathrm{wt} \%)$ & 0.0855 & 0.0855 & 0.0700 & 0.0155 & 0.0155 & $22.1 \%$ & $22.1 \%$ \\
\hline Pu35-41 & Sum (wt \%) & 97.6833 & 98.0150 & 99.8600 & -2.1767 & -1.8450 & $-2.2 \%$ & $-1.8 \%$ \\
\hline Pu35-42 & $\mathrm{Al}_{2} \mathrm{O}_{3}($ wt $\%)$ & 8.9657 & 8.9005 & 8.6000 & 0.3657 & 0.3005 & $4.3 \%$ & $3.5 \%$ \\
\hline Pu35-42 & $\mathrm{B}_{2} \mathrm{O}_{3}(\mathrm{wt} \%)$ & 10.9155 & 11.2347 & 11.1800 & -0.2645 & 0.0547 & $-2.4 \%$ & $0.5 \%$ \\
\hline Pu35-42 & $\mathrm{CaO}(w \mathrm{t} \%)$ & 0.2568 & 0.2527 & 0.1600 & 0.0968 & 0.0927 & $60.5 \%$ & $57.9 \%$ \\
\hline $\mathrm{Pu} 35-42$ & $\mathrm{Cl}(\mathrm{wt} \%)$ & 0.0345 & 0.0345 & 0.5800 & -0.5455 & -0.5455 & $-94.1 \%$ & $-94.1 \%$ \\
\hline Pu35-42 & $\mathrm{Cr}_{2} \mathrm{O}_{3}(\mathrm{wt} \%)$ & 0.3223 & 0.3132 & 0.3400 & -0.0177 & -0.0268 & $-5.2 \%$ & $-7.9 \%$ \\
\hline $\mathrm{Pu} 35-42$ & $\mathrm{CuO}(\mathrm{wt} \%)$ & 0.1477 & 0.1556 & 0.1400 & 0.0077 & 0.0156 & $5.5 \%$ & $11.1 \%$ \\
\hline
\end{tabular}


Table D5. Average Measured and Bias-Corrected Chemical Compositions Versus Targeted Compositions by Oxide by Study Glass (continued)

\begin{tabular}{|c|c|c|c|c|c|c|c|c|}
\hline Glass ID & Oxide & $\begin{array}{c}\text { Measured } \\
(\text { wt \%) }\end{array}$ & \begin{tabular}{|c} 
Measured Bias- \\
Corrected (wt \%)
\end{tabular} & $\begin{array}{c}\text { Targeted } \\
\text { (wt \%) }\end{array}$ & $\begin{array}{c}\text { Diff of } \\
\text { Measured }\end{array}$ & $\begin{array}{c}\text { Diff of Meas } \\
\text { BC }\end{array}$ & $\begin{array}{l}\% \text { Diff of } \\
\text { Measured }\end{array}$ & $\begin{array}{c}\text { \% Diff of Meas } \\
\text { BC }\end{array}$ \\
\hline $\mathrm{Pu} 35-42$ & $\mathrm{~F}(\mathrm{wt} \%)$ & \begin{tabular}{|l|}
0.0000 \\
\end{tabular} & \begin{tabular}{|l|}
0.0000 \\
\end{tabular} & 0.1200 & -0.1200 & -0.1200 & $-100.0 \%$ & $-100.0 \%$ \\
\hline Pu35-42 & $\mathrm{Fe}_{2} \mathrm{O}_{3}(\mathrm{wt} \%)$ & 0.1873 & 0.1936 & 0.1700 & 0.0173 & 0.0236 & $10.2 \%$ & $13.9 \%$ \\
\hline Pu35-42 & $\mathrm{Ga}_{2} \mathrm{O}_{3}(\mathrm{wt} \%)$ & 0.1915 & 0.1915 & 0.1600 & 0.0315 & 0.0315 & $19.7 \%$ & $19.7 \%$ \\
\hline Pu35-42 & $\mathrm{Gd}_{2} \mathrm{O}_{3}(\mathrm{wt} \%)$ & 11.6989 & 11.6989 & 11.6100 & 0.0889 & 0.0889 & $0.8 \%$ & $0.8 \%$ \\
\hline $\mathrm{Pu} 35-42$ & $\mathrm{HfO}_{2}(\mathrm{wt} \%)$ & 13.7388 & 13.7388 & 14.8800 & -1.1412 & -1.1412 & $-7.7 \%$ & $-7.7 \%$ \\
\hline $\mathrm{Pu} 35-42$ & $\mathrm{~K}_{2} \mathrm{O}(\mathrm{wt} \%)$ & 0.6143 & 0.5341 & 0.8400 & -0.2257 & -0.3059 & $-26.9 \%$ & $-36.4 \%$ \\
\hline Pu35-42 & $\mathrm{La}_{2} \mathrm{O}_{3}(\mathrm{wt} \%)$ & 16.1260 & 16.1260 & 16.3400 & -0.2140 & -0.2140 & $-1.3 \%$ & $-1.3 \%$ \\
\hline $\mathrm{Pu} 35-42$ & $\mathrm{MgO}(\mathrm{wt} \%)$ & 1.0588 & 1.0382 & 1.0800 & -0.0212 & -0.0418 & $-2.0 \%$ & $-3.9 \%$ \\
\hline $\mathrm{Pu} 35-42$ & $\mathrm{Na}_{2} \mathrm{O}($ wt \%) & 0.7616 & 0.6994 & 0.7800 & -0.0184 & -0.0806 & $-2.4 \%$ & $-10.3 \%$ \\
\hline Pu35-42 & $\mathrm{Nd}_{2} \mathrm{O}_{3}(\mathrm{wt} \%)$ & 13.1220 & 13.1220 & 12.9000 & 0.2220 & 0.2220 & $1.7 \%$ & $1.7 \%$ \\
\hline $\mathrm{Pu} 35-42$ & $\mathrm{NiO}(\mathrm{wt} \%)$ & 0.1419 & 0.1560 & 0.1500 & -0.0081 & 0.0060 & $-5.4 \%$ & $4.0 \%$ \\
\hline Pu35-42 & $\mathrm{PbO}(\mathrm{wt} \%)$ & 0.0867 & 0.0867 & 0.0600 & 0.0267 & 0.0267 & $44.5 \%$ & $44.5 \%$ \\
\hline Pu35-42 & $\mathrm{SeO}_{2}(\mathrm{wt} \%)$ & 0.0070 & 0.0070 & 0.0800 & -0.0730 & -0.0730 & $-91.2 \%$ & $-91.2 \%$ \\
\hline Pu35-42 & $\mathrm{Si}_{2} \mathrm{O}_{3}($ wt $\%)$ & 17.6599 & 17.8180 & 17.2000 & 0.4599 & 0.6180 & $2.7 \%$ & $3.6 \%$ \\
\hline Pu35-42 & $\mathrm{SO}_{4}(\mathrm{wt} \%)$ & 0.0749 & 0.0749 & 0.1700 & -0.0951 & -0.0951 & $-55.9 \%$ & $-55.9 \%$ \\
\hline Pu35-42 & $\mathrm{SrO}(\mathrm{wt} \%)$ & 2.2647 & 2.2647 & 2.1500 & 0.1147 & 0.1147 & $5.3 \%$ & $5.3 \%$ \\
\hline $\mathrm{Pu} 35-42$ & $\mathrm{Ta}_{2} \mathrm{O}_{5}(\mathrm{wt} \%)$ & 0.2204 & 0.2204 & 0.2100 & 0.0104 & 0.0104 & $4.9 \%$ & $4.9 \%$ \\
\hline Pu35-42 & Sum (wt \%) & 98.5973 & 98.8615 & 99.9000 & -1.3027 & -1.0385 & $-1.3 \%$ & $-1.0 \%$ \\
\hline $\mathrm{Pu} 35-43$ & $\mathrm{Al}_{2} \mathrm{O}_{3}(\mathrm{wt} \%)$ & 8.9090 & 8.8443 & 8.6000 & 0.3090 & 0.2443 & $3.6 \%$ & $2.8 \%$ \\
\hline $\mathrm{Pu} 35-43$ & $\mathrm{~B}_{2} \mathrm{O}_{3}(\mathrm{wt} \%)$ & 11.1087 & 11.4335 & 11.1800 & -0.0713 & 0.2535 & $-0.6 \%$ & $2.3 \%$ \\
\hline $\mathrm{Pu} 35-43$ & $\mathrm{CaO}(\mathrm{wt} \%)$ & 0.4617 & 0.4544 & 0.3500 & 0.1117 & 0.1044 & $31.9 \%$ & $29.8 \%$ \\
\hline $\mathrm{Pu} 35-43$ & $\mathrm{Cl}(\mathrm{wt} \%)$ & 0.0425 & 0.0425 & 0.5800 & -0.5375 & -0.5375 & $-92.7 \%$ & $-92.7 \%$ \\
\hline $\mathrm{Pu} 35-43$ & $\mathrm{Cr}_{2} \mathrm{O}_{3}(\mathrm{wt} \%)$ & 0.2375 & 0.2308 & 0.2500 & -0.0125 & -0.0192 & $-5.0 \%$ & $-7.7 \%$ \\
\hline $\mathrm{Pu} 35-43$ & $\mathrm{CuO}(\mathrm{wt} \%)$ & 0.1571 & 0.1654 & 0.1400 & 0.0171 & 0.0254 & $12.2 \%$ & $18.2 \%$ \\
\hline Pu35-43 & $\mathrm{F}(\mathrm{wt} \%)$ & 0.0270 & 0.0334 & 0.2000 & -0.1730 & -0.1666 & $-86.5 \%$ & $-83.3 \%$ \\
\hline Pu35-43 & $\mathrm{Fe}_{2} \mathrm{O}_{3}(\mathrm{wt} \%)$ & 0.5740 & 0.5934 & 0.5700 & 0.0040 & 0.0234 & $0.7 \%$ & $4.1 \%$ \\
\hline Pu35-43 & $\mathrm{Ga}_{2} \mathrm{O}_{3}($ wt $\%)$ & 0.3750 & 0.3750 & 0.3500 & 0.0250 & 0.0250 & $7.2 \%$ & $7.2 \%$ \\
\hline Pu35-43 & $\mathrm{Gd}_{2} \mathrm{O}_{3}(\mathrm{wt} \%)$ & 11.5836 & 11.5836 & 11.6100 & -0.0264 & -0.0264 & $-0.2 \%$ & $-0.2 \%$ \\
\hline Pu35-43 & $\mathrm{HfO}_{2}(\mathrm{wt} \%)$ & 13.6799 & 13.6799 & 14.8500 & -1.1701 & -1.1701 & $-7.9 \%$ & $-7.9 \%$ \\
\hline Pu35-43 & $\mathrm{K}_{2} \mathrm{O}(\mathrm{wt} \%)$ & 0.1656 & 0.1440 & 0.2100 & -0.0444 & -0.0660 & $-21.1 \%$ & $-31.4 \%$ \\
\hline Pu35-43 & $\mathrm{La}_{2} \mathrm{O}_{3}(\mathrm{wt} \%)$ & 16.0087 & 16.0087 & 16.3400 & -0.3313 & -0.3313 & $-2.0 \%$ & $-2.0 \%$ \\
\hline $\mathrm{Pu} 35-43$ & $\mathrm{MgO}(\mathrm{wt} \%)$ & 0.6442 & 0.6317 & 0.6500 & -0.0058 & -0.0183 & $-0.9 \%$ & $-2.8 \%$ \\
\hline $\mathrm{Pu} 35-43$ & $\mathrm{Na}_{2} \mathrm{O}(\mathrm{wt} \%)$ & 0.7279 & 0.6684 & 0.7400 & -0.0121 & -0.0716 & $-1.6 \%$ & $-9.7 \%$ \\
\hline Pu35-43 & $\mathrm{Nd}_{2} \mathrm{O}_{3}(\mathrm{wt} \%)$ & 12.9470 & 12.9470 & 12.9000 & 0.0470 & 0.0470 & $0.4 \%$ & $0.4 \%$ \\
\hline $\mathrm{Pu} 35-43$ & $\mathrm{NiO}($ wt \%) & 0.1890 & 0.2078 & 0.2000 & -0.0110 & 0.0078 & $-5.5 \%$ & $3.9 \%$ \\
\hline Pu35-43 & $\mathrm{PbO}(\mathrm{wt} \%)$ & 0.0846 & 0.0846 & 0.0600 & 0.0246 & 0.0246 & $40.9 \%$ & $40.9 \%$ \\
\hline $\mathrm{Pu} 35-43$ & $\mathrm{SeO}_{2}(\mathrm{wt} \%)$ & 0.0070 & 0.0070 & 0.0800 & -0.0730 & -0.0730 & $-91.2 \%$ & $-91.2 \%$ \\
\hline $\mathrm{Pu} 35-43$ & $\mathrm{Si}_{2} \mathrm{O}_{3}(\mathrm{wt} \%)$ & 17.5102 & 17.6669 & 17.2000 & 0.3102 & 0.4669 & $1.8 \%$ & $2.7 \%$ \\
\hline $\mathrm{Pu} 35-43$ & $\mathrm{SO}_{4}(\mathrm{wt} \%)$ & 0.0749 & 0.0749 & 0.1700 & -0.0951 & -0.0951 & $-55.9 \%$ & $-55.9 \%$ \\
\hline $\mathrm{Pu} 35-43$ & $\mathrm{SrO}(\mathrm{wt} \%)$ & 2.2351 & 2.2351 & 2.1500 & 0.0851 & 0.0851 & $4.0 \%$ & $4.0 \%$ \\
\hline $\mathrm{Pu} 35-43$ & $\mathrm{Ta}_{2} \mathrm{O}_{5}(\mathrm{wt} \%)$ & 0.4829 & 0.4829 & 0.4900 & -0.0071 & -0.0071 & $-1.4 \%$ & $-1.4 \%$ \\
\hline $\mathrm{Pu} 35-43$ & Sum (wt \%) & 98.2333 & 98.5954 & 99.8700 & -1.6367 & -1.2746 & $-1.6 \%$ & $-1.3 \%$ \\
\hline $\mathrm{Pu} 35-44$ & $\mathrm{Al}_{2} \mathrm{O}_{3}(\mathrm{wt} \%)$ & 8.8523 & 8.7880 & 8.6000 & 0.2523 & 0.1880 & $2.9 \%$ & $2.2 \%$ \\
\hline Pu35-44 & $\mathrm{B}_{2} \mathrm{O}_{3}(\mathrm{wt} \%)$ & 10.9316 & 11.2512 & 11.1800 & -0.2484 & 0.0712 & $-2.2 \%$ & $0.6 \%$ \\
\hline Pu35-44 & $\mathrm{CaO}($ wt \%) & 0.3890 & 0.3828 & 0.2800 & 0.1090 & 0.1028 & $38.9 \%$ & $36.7 \%$ \\
\hline Pu35-44 & $\mathrm{Cl}(\mathrm{wt} \%)$ & 0.0475 & 0.0475 & 0.5800 & -0.5325 & -0.5325 & $-91.8 \%$ & $-91.8 \%$ \\
\hline Pu35-44 & $\mathrm{Cr}_{2} \mathrm{O}_{3}($ wt $\%)$ & 0.2346 & 0.2280 & 0.2500 & -0.0154 & -0.0220 & $-6.2 \%$ & $-8.8 \%$ \\
\hline Pu35-44 & $\mathrm{CuO}($ wt \%) & 0.1327 & 0.1397 & 0.1100 & 0.0227 & 0.0297 & $20.6 \%$ & $27.0 \%$ \\
\hline $\mathrm{Pu} 35-44$ & F (wt \%) & 0.0055 & 0.0068 & 0.1900 & -0.1845 & -0.1832 & $-97.1 \%$ & $-96.4 \%$ \\
\hline $\mathrm{Pu} 35-44$ & $\mathrm{Fe}_{2} \mathrm{O}_{3}(\mathrm{wt} \%)$ & 0.5740 & 0.5934 & 0.5800 & -0.0060 & 0.0134 & $-1.0 \%$ & $2.3 \%$ \\
\hline $\mathrm{Pu} 35-44$ & $\mathrm{Ga}_{2} \mathrm{O}_{3}(\mathrm{wt} \%)$ & 0.3293 & 0.3293 & 0.3000 & 0.0293 & 0.0293 & $9.8 \%$ & $9.8 \%$ \\
\hline $\mathrm{Pu} 35-44$ & $\mathrm{Gd}_{2} \mathrm{O}_{3}(\mathrm{wt} \%)$ & 11.6413 & 11.6413 & 11.6100 & 0.0313 & 0.0313 & $0.3 \%$ & $0.3 \%$ \\
\hline Pu35-44 & $\mathrm{HfO}_{2}(\mathrm{wt} \%)$ & 13.6799 & 13.6799 & 14.8600 & -1.1801 & -1.1801 & $-7.9 \%$ & $-7.9 \%$ \\
\hline $\mathrm{Pu} 35-44$ & $\mathrm{~K}_{2} \mathrm{O}(\mathrm{wt} \%)$ & 0.2638 & 0.2294 & 0.3100 & -0.0462 & -0.0806 & $-14.9 \%$ & $-26.0 \%$ \\
\hline $\mathrm{Pu} 35-44$ & $\mathrm{La}_{2} \mathrm{O}_{3}(\mathrm{wt} \%)$ & 16.2433 & 16.2433 & 16.3400 & -0.0967 & -0.0967 & $-0.6 \%$ & $-0.6 \%$ \\
\hline Pu35-44 & $\mathrm{MgO}(\mathrm{wt} \%)$ & 0.7835 & 0.7683 & 0.8000 & -0.0165 & -0.0317 & $-2.1 \%$ & $-4.0 \%$ \\
\hline Pu35-44 & $\mathrm{Na}_{2} \mathrm{O}$ (wt \%) & 0.6619 & 0.6078 & 0.6600 & 0.0019 & -0.0522 & $0.3 \%$ & $-7.9 \%$ \\
\hline $\mathrm{Pu} 35-44$ & $\mathrm{Nd}_{2} \mathrm{O}_{3}(\mathrm{wt} \%)$ & 12.9470 & 12.9470 & 12.9000 & 0.0470 & 0.0470 & $0.4 \%$ & $0.4 \%$ \\
\hline
\end{tabular}


Table D5. Average Measured and Bias-Corrected Chemical Compositions Versus Targeted Compositions by Oxide by Study Glass (continued)

\begin{tabular}{|c|c|c|c|c|c|c|c|c|}
\hline Glass ID & Oxide & $\begin{array}{c}\text { Measured } \\
(\mathrm{wt} \%)\end{array}$ & \begin{tabular}{|c|} 
Measured Bias- \\
Corrected (wt \%)
\end{tabular} & $\begin{array}{c}\text { Targeted } \\
\text { (wt \%) }\end{array}$ & $\begin{array}{c}\text { Diff of } \\
\text { Measured }\end{array}$ & $\begin{array}{c}\text { Diff of Meas } \\
\text { BC }\end{array}$ & $\begin{array}{l}\text { \% Diff of } \\
\text { Measured }\end{array}$ & $\begin{array}{c}\text { \% Diff of Meas } \\
\text { BC }\end{array}$ \\
\hline Pu35-44 & $\mathrm{NiO}(\mathrm{wt} \%)$ & 0.1387 & 0.1525 & 0.1500 & -0.0113 & 0.0025 & $-7.5 \%$ & $1.7 \%$ \\
\hline Pu35-44 & $\mathrm{PbO}(\mathrm{wt} \%)$ & 0.0856 & 0.0856 & 0.0600 & 0.0256 & 0.0256 & $42.7 \%$ & $42.7 \%$ \\
\hline Pu35-44 & $\mathrm{SeO}_{2}(\mathrm{wt} \%)$ & 0.0070 & 0.0070 & 0.0800 & -0.0730 & -0.0730 & $-91.2 \%$ & $-91.2 \%$ \\
\hline Pu35-44 & $\mathrm{Si}_{2} \mathrm{O}_{3}(\mathrm{wt} \%)$ & 17.5743 & 17.7317 & 17.2000 & 0.3743 & 0.5317 & $2.2 \%$ & $3.1 \%$ \\
\hline $\mathrm{Pu} 35-44$ & $\mathrm{SO}_{4}(\mathrm{wt} \%)$ & 0.0749 & 0.0749 & 0.1700 & -0.0951 & -0.0951 & $-55.9 \%$ & $-55.9 \%$ \\
\hline Pu35-44 & $\mathrm{SrO}(\mathrm{wt} \%)$ & 2.2292 & 2.2292 & 2.1500 & 0.0792 & 0.0792 & $3.7 \%$ & $3.7 \%$ \\
\hline Pu35-44 & $\mathrm{Ta}_{2} \mathrm{O}_{5}(\mathrm{wt} \%)$ & 0.5311 & 0.5311 & 0.5400 & -0.0089 & -0.0089 & $-1.6 \%$ & $-1.6 \%$ \\
\hline $\mathrm{Pu} 35-44$ & Sum (wt \%) & 98.3581 & 98.6958 & 99.9000 & -1.5419 & -1.2042 & $-1.5 \%$ & $-1.2 \%$ \\
\hline $\mathrm{Pu} 35-45$ & $\mathrm{Al}_{2} \mathrm{O}_{3}(\mathrm{wt} \%)$ & 8.7200 & 8.6567 & 8.6000 & 0.1200 & 0.0567 & $1.4 \%$ & $0.7 \%$ \\
\hline \begin{tabular}{|l|}
$\mathrm{Pu} 35-45$ \\
\end{tabular} & $\mathrm{~B}_{2} \mathrm{O}_{3}(\mathrm{wt} \%)$ & 11.1731 & 11.4998 & 11.1800 & -0.0069 & 0.3198 & $-0.1 \%$ & $2.9 \%$ \\
\hline Pu35-45 & $\mathrm{CaO}($ wt \%) & 0.3260 & 0.3208 & 0.2300 & 0.0960 & 0.0908 & $41.7 \%$ & $39.5 \%$ \\
\hline Pu35-45 & $\mathrm{Cl}(\mathrm{wt} \%)$ & 0.0475 & 0.0475 & 0.5800 & -0.5325 & -0.5325 & $-91.8 \%$ & $-91.8 \%$ \\
\hline \begin{tabular}{|l|}
$\mathrm{Pu} 35-45$ \\
\end{tabular} & $\mathrm{Cr}_{2} \mathrm{O}_{3}(\mathrm{wt} \%)$ & 0.1615 & 0.1569 & 0.1700 & -0.0085 & -0.0131 & $-5.0 \%$ & $-7.7 \%$ \\
\hline $\mathrm{Pu} 35-45$ & $\mathrm{CuO}(\mathrm{wt} \%)$ & 0.1346 & 0.1417 & 0.1100 & 0.0246 & 0.0317 & $22.3 \%$ & $28.8 \%$ \\
\hline $\mathrm{Pu} 35-45$ & $\mathrm{~F}(\mathrm{wt} \%)$ & 0.0000 & 0.0000 & 0.1200 & -0.1200 & -0.1200 & $-100.0 \%$ & $-100.0 \%$ \\
\hline \begin{tabular}{|l|}
$\mathrm{Pu} 35-45$ \\
\end{tabular} & $\mathrm{Fe}_{2} \mathrm{O}_{3}(\mathrm{wt} \%)$ & 0.4554 & 0.4707 & 0.4600 & -0.0046 & 0.0107 & $-1.0 \%$ & $2.3 \%$ \\
\hline $\mathrm{Pu} 35-45$ & $\mathrm{Ga}_{2} \mathrm{O}_{3}($ wt $\%)$ & 0.4974 & 0.4974 & 0.4800 & 0.0174 & 0.0174 & $3.6 \%$ & $3.6 \%$ \\
\hline $\mathrm{Pu} 35-45$ & $\mathrm{Gd}_{2} \mathrm{O}_{3}(\mathrm{wt} \%)$ & 11.4626 & 11.4626 & 11.6100 & -0.1474 & -0.1474 & $-1.3 \%$ & $-1.3 \%$ \\
\hline $\mathrm{Pu} 35-45$ & $\mathrm{HfO}_{2}(\mathrm{wt} \%)$ & 13.4440 & 13.4440 & 14.8600 & -1.4160 & -1.4160 & $-9.5 \%$ & $-9.5 \%$ \\
\hline $\mathrm{Pu} 35-45$ & $\mathrm{~K}_{2} \mathrm{O}(\mathrm{wt} \%)$ & 0.1506 & 0.1309 & 0.2000 & -0.0494 & -0.0691 & $-24.7 \%$ & $-34.5 \%$ \\
\hline \begin{tabular}{|l|}
$\mathrm{Pu} 35-45$ \\
\end{tabular} & $\mathrm{La}_{2} \mathrm{O}_{3}($ wt $\%)$ & 15.8328 & 15.8328 & 16.3400 & -0.5072 & -0.5072 & $-3.1 \%$ & $-3.1 \%$ \\
\hline Pu35-45 & $\mathrm{MgO}(\mathrm{wt} \%)$ & 0.7330 & 0.7187 & 0.7500 & -0.0170 & -0.0313 & $-2.3 \%$ & $-4.2 \%$ \\
\hline \begin{tabular}{|l|}
$\mathrm{Pu} 35-45$ \\
\end{tabular} & $\mathrm{Na}_{2} \mathrm{O}($ wt $\%)$ & 0.7313 & 0.6715 & 0.7300 & 0.0013 & -0.0585 & $0.2 \%$ & $-8.0 \%$ \\
\hline \begin{tabular}{|l|}
$\mathrm{Pu} 35-45$ \\
\end{tabular} & $\mathrm{Nd}_{2} \mathrm{O}_{3}(\mathrm{wt} \%)$ & 12.7721 & 12.7721 & 12.9000 & -0.1279 & -0.1279 & $-1.0 \%$ & $-1.0 \%$ \\
\hline \begin{tabular}{|l|}
$\mathrm{Pu} 35-45$ \\
\end{tabular} & $\mathrm{NiO}(w t \%)$ & 0.2030 & 0.2232 & 0.2200 & -0.0170 & 0.0032 & $-7.7 \%$ & $1.5 \%$ \\
\hline \begin{tabular}{|l|}
$\mathrm{Pu} 35-45$ \\
\end{tabular} & $\mathrm{PbO}(\mathrm{wt} \%)$ & 0.0846 & 0.0846 & 0.0600 & 0.0246 & 0.0246 & $40.9 \%$ & $40.9 \%$ \\
\hline Pu35-45 & $\mathrm{SeO}_{2}(\mathrm{wt} \%)$ & 0.0070 & 0.0070 & 0.0800 & -0.0730 & -0.0730 & $-91.2 \%$ & $-91.2 \%$ \\
\hline \begin{tabular}{|l|} 
Pu35-45 \\
\end{tabular} & $\mathrm{Si}_{2} \mathrm{O}_{3}($ wt $\%)$ & 17.2535 & 17.4079 & 17.2000 & 0.0535 & 0.2079 & $0.3 \%$ & $1.2 \%$ \\
\hline Pu35-45 & $\mathrm{SO}_{4}(\mathrm{wt} \%)$ & 0.0749 & 0.0749 & 0.1700 & -0.0951 & -0.0951 & $-55.9 \%$ & $-55.9 \%$ \\
\hline Pu35-45 & SrO (wt \%) & 2.1878 & 2.1878 & 2.1500 & 0.0378 & 0.0378 & $1.8 \%$ & $1.8 \%$ \\
\hline \begin{tabular}{|l|}
$\mathrm{Pu} 35-45$ \\
\end{tabular} & $\mathrm{Ta}_{2} \mathrm{O}_{5}(\mathrm{wt} \%)$ & 0.6764 & 0.6764 & 0.7000 & -0.0236 & -0.0236 & $-3.4 \%$ & $-3.4 \%$ \\
\hline $\mathrm{Pu} 35-45$ & Sum (wt \%) & 97.1289 & 97.4861 & 99.9000 & -2.7711 & -2.4139 & $-2.8 \%$ & $-2.4 \%$ \\
\hline $\mathrm{Pu} 35-46$ & $\mathrm{Al}_{2} \mathrm{O}_{3}(\mathrm{wt} \%)$ & 9.2774 & 9.0934 & 8.6000 & 0.6774 & 0.4934 & $7.9 \%$ & $5.7 \%$ \\
\hline $\mathrm{Pu} 35-46$ & $\mathrm{~B}_{2} \mathrm{O}_{3}(\mathrm{wt} \%)$ & 11.4467 & 11.3619 & 11.1800 & 0.2667 & 0.1819 & $2.4 \%$ & $1.6 \%$ \\
\hline Pu35-46 & $\mathrm{CaO}($ wt \%) & 0.2637 & 0.2677 & 0.1700 & 0.0937 & 0.0977 & $55.1 \%$ & $57.5 \%$ \\
\hline $\mathrm{Pu} 35-46$ & $\mathrm{Cl}(\mathrm{wt} \%)$ & 0.0645 & 0.0645 & 0.5900 & -0.5255 & -0.5255 & $-89.1 \%$ & $-89.1 \%$ \\
\hline Pu35-46 & $\mathrm{Cr}_{2} \mathrm{O}_{3}(\mathrm{wt} \%)$ & 0.1608 & 0.1549 & 0.1700 & -0.0092 & -0.0151 & $-5.4 \%$ & $-8.9 \%$ \\
\hline Pu35-46 & $\mathrm{CuO}(\mathrm{wt} \%)$ & 0.1590 & 0.1691 & 0.1500 & 0.0090 & 0.0191 & $6.0 \%$ & $12.7 \%$ \\
\hline $\mathrm{Pu} 35-46$ & F (wt \%) & 0.0640 & 0.0784 & 0.3500 & -0.2860 & -0.2716 & $-81.7 \%$ & $-77.6 \%$ \\
\hline Pu35-46 & $\mathrm{Fe}_{2} \mathrm{O}_{3}(\mathrm{wt} \%)$ & 0.2002 & 0.2017 & 0.1700 & 0.0302 & 0.0317 & $17.7 \%$ & $18.6 \%$ \\
\hline $\mathrm{Pu} 35-46$ & $\mathrm{Ga}_{2} \mathrm{O}_{3}(\mathrm{wt} \%)$ & 0.5679 & 0.5679 & 0.5400 & 0.0279 & 0.0279 & $5.2 \%$ & $5.2 \%$ \\
\hline Pu35-46 & $\mathrm{Gd}_{2} \mathrm{O}_{3}(\mathrm{wt} \%)$ & 12.0447 & 12.0447 & 11.6100 & 0.4347 & 0.4347 & $3.7 \%$ & $3.7 \%$ \\
\hline $\mathrm{Pu} 35-46$ & $\mathrm{HfO}_{2}(\mathrm{wt} \%)$ & 13.8568 & 13.8568 & 14.9200 & -1.0632 & -1.0632 & $-7.1 \%$ & $-7.1 \%$ \\
\hline Pu35-46 & $\mathrm{K}_{2} \mathrm{O}(\mathrm{wt} \%)$ & 0.3499 & 0.3036 & 0.4100 & -0.0601 & -0.1064 & $-14.6 \%$ & $-25.9 \%$ \\
\hline \begin{tabular}{|l|} 
Pu35-46 \\
\end{tabular} & $\mathrm{La}_{2} \mathrm{O}_{3}$ (wt \%) & 16.7124 & 16.7124 & 16.3400 & 0.3724 & 0.3724 & $2.3 \%$ & $2.3 \%$ \\
\hline $\mathrm{Pu} 35-46$ & $\mathrm{MgO}(\mathrm{wt} \%)$ & 0.7230 & 0.7256 & 0.7300 & -0.0070 & -0.0044 & $-1.0 \%$ & $-0.6 \%$ \\
\hline $\mathrm{Pu} 35-46$ & $\mathrm{Na}_{2} \mathrm{O}($ wt $\%)$ & 0.6410 & 0.6041 & 0.6300 & 0.0110 & -0.0259 & $1.7 \%$ & $-4.1 \%$ \\
\hline Pu35-46 & $\mathrm{Nd}_{2} \mathrm{O}_{3}(\mathrm{wt} \%)$ & 13.2970 & 13.2970 & 12.9000 & 0.3970 & 0.3970 & $3.1 \%$ & $3.1 \%$ \\
\hline $\mathrm{Pu} 35-46$ & $\mathrm{NiO}(w \mathrm{t} \%)$ & 0.2685 & 0.2969 & 0.3000 & -0.0315 & -0.0031 & $-10.5 \%$ & $-1.0 \%$ \\
\hline \begin{tabular}{|l|}
$\mathrm{Pu} 35-46$ \\
\end{tabular} & $\mathrm{PbO}($ wt \%) & 0.0835 & 0.0835 & 0.0600 & 0.0235 & 0.0235 & $39.1 \%$ & $39.1 \%$ \\
\hline Pu35-46 & $\mathrm{SeO}_{2}(\mathrm{wt} \%)$ & 0.0070 & 0.0070 & 0.0800 & -0.0730 & -0.0730 & $-91.2 \%$ & $-91.2 \%$ \\
\hline Pu35-46 & $\mathrm{Si}_{2} \mathrm{O}_{3}($ wt $\%)$ & 18.1306 & 17.8580 & 17.2000 & 0.9306 & 0.6580 & $5.4 \%$ & $3.8 \%$ \\
\hline $\mathrm{Pu} 35-46$ & $\mathrm{SO}_{4}(\mathrm{wt} \%)$ & 0.0749 & 0.0749 & 0.1700 & -0.0951 & -0.0951 & $-55.9 \%$ & $-55.9 \%$ \\
\hline Pu35-46 & $\mathrm{SrO}(\mathrm{wt} \%)$ & 2.3770 & 2.3770 & 2.1500 & 0.2270 & 0.2270 & $10.6 \%$ & $10.6 \%$ \\
\hline $\mathrm{Pu} 35-46$ & $\mathrm{Ta}_{2} \mathrm{O}_{5}(\mathrm{wt} \%)$ & 0.4463 & 0.4463 & 0.4500 & -0.0037 & -0.0037 & $-0.8 \%$ & $-0.8 \%$ \\
\hline $\mathrm{Pu} 35-46$ & Sum (wt \%) & 101.2168 & 100.6472 & 99.8700 & 1.3468 & 0.7772 & $1.3 \%$ & $0.8 \%$ \\
\hline Pu35-47 & $\mathrm{Al}_{2} \mathrm{O}_{3}($ wt $\%)$ & 9.1357 & 8.9545 & 8.6000 & 0.5357 & 0.3545 & $6.2 \%$ & $4.1 \%$ \\
\hline $\mathrm{Pu} 35-47$ & $\mathrm{~B}_{2} \mathrm{O}_{3}(\mathrm{wt} \%)$ & 11.3984 & 11.3139 & 11.1800 & 0.2184 & 0.1339 & $2.0 \%$ & $1.2 \%$ \\
\hline
\end{tabular}


Table D5. Average Measured and Bias-Corrected Chemical Compositions Versus Targeted Compositions by Oxide by Study Glass (continued)

\begin{tabular}{|c|c|c|c|c|c|c|c|c|}
\hline Glass ID & Oxide & $\begin{array}{c}\text { Measured } \\
(\text { wt \%) }\end{array}$ & \begin{tabular}{|c} 
Measured Bias- \\
Corrected (wt \%)
\end{tabular} & $\begin{array}{c}\text { Targeted } \\
\text { (wt \%) }\end{array}$ & $\begin{array}{c}\text { Diff of } \\
\text { Measured }\end{array}$ & $\begin{array}{c}\text { Diff of Meas } \\
\text { BC }\end{array}$ & $\begin{array}{l}\% \text { Diff of } \\
\text { Measured }\end{array}$ & $\begin{array}{c}\text { \% Diff of Meas } \\
\text { BC }\end{array}$ \\
\hline $\mathrm{Pu} 35-47$ & $\mathrm{CaO}(w t \%)$ & \begin{tabular}{|l|}
0.5009 \\
\end{tabular} & \begin{tabular}{|l|}
0.5085 \\
\end{tabular} & 0.4000 & 0.1009 & 0.1085 & $25.2 \%$ & $27.1 \%$ \\
\hline \begin{tabular}{|l|} 
Pu35-47 \\
\end{tabular} & $\mathrm{Cl}(\mathrm{wt} \%)$ & 0.0505 & 0.0505 & 0.6100 & -0.5595 & -0.5595 & $-91.7 \%$ & $-91.7 \%$ \\
\hline Pu35-47 & $\mathrm{Cr}_{2} \mathrm{O}_{3}(\mathrm{wt} \%)$ & 0.3157 & 0.3041 & 0.3400 & -0.0243 & -0.0359 & $-7.1 \%$ & $-10.6 \%$ \\
\hline Pu35-47 & $\mathrm{CuO}(\mathrm{wt} \%)$ & 0.1621 & 0.1724 & 0.1400 & 0.0221 & 0.0324 & $15.8 \%$ & $23.2 \%$ \\
\hline $\mathrm{Pu} 35-47$ & $\mathrm{~F}(\mathrm{wt} \%)$ & 0.0265 & 0.0325 & 0.1200 & -0.0935 & -0.0875 & $-77.9 \%$ & $-72.9 \%$ \\
\hline $\mathrm{Pu} 35-47$ & $\mathrm{Fe}_{2} \mathrm{O}_{3}(\mathrm{wt} \%)$ & 0.1830 & 0.1844 & 0.1700 & 0.0130 & 0.0144 & $7.6 \%$ & $8.5 \%$ \\
\hline $\mathrm{Pu} 35-47$ & $\mathrm{Ga}_{2} \mathrm{O}_{3}(\mathrm{wt} \%)$ & 0.2238 & 0.2238 & 0.1900 & 0.0338 & 0.0338 & $17.8 \%$ & $17.8 \%$ \\
\hline $\mathrm{Pu} 35-47$ & $\mathrm{Gd}_{2} \mathrm{O}_{3}(\mathrm{wt} \%)$ & 11.7565 & 11.7565 & 11.6100 & 0.1465 & 0.1465 & $1.3 \%$ & $1.3 \%$ \\
\hline $\mathrm{Pu} 35-47$ & $\mathrm{HfO}_{2}(\mathrm{wt} \%)$ & 13.8568 & 13.8568 & 14.8800 & -1.0232 & -1.0232 & $-6.9 \%$ & $-6.9 \%$ \\
\hline $\mathrm{Pu} 35-47$ & $\mathrm{~K}_{2} \mathrm{O}(\mathrm{wt} \%)$ & 0.2060 & 0.1787 & 0.2500 & -0.0440 & -0.0713 & $-17.6 \%$ & $-28.5 \%$ \\
\hline $\mathrm{Pu} 35-47$ & $\mathrm{La}_{2} \mathrm{O}_{3}(\mathrm{wt} \%)$ & 16.3019 & 16.3019 & 16.3400 & -0.0381 & -0.0381 & $-0.2 \%$ & $-0.2 \%$ \\
\hline Pu35-47 & $\mathrm{MgO}(\mathrm{wt} \%)$ & 0.5970 & 0.5991 & 0.6100 & -0.0130 & -0.0109 & $-2.1 \%$ & $-1.8 \%$ \\
\hline Pu35-47 & $\mathrm{Na}_{2} \mathrm{O}($ wt $\%)$ & 0.7421 & 0.6994 & 0.7300 & 0.0121 & -0.0306 & $1.7 \%$ & $-4.2 \%$ \\
\hline Pu35-47 & $\mathrm{Nd}_{2} \mathrm{O}_{3}(\mathrm{wt} \%)$ & 13.0637 & 13.0637 & 12.9000 & 0.1637 & 0.1637 & $1.3 \%$ & $1.3 \%$ \\
\hline $\mathrm{Pu} 35-47$ & $\mathrm{NiO}($ wt \%) & 0.2602 & 0.2878 & 0.2900 & -0.0298 & -0.0022 & $-10.3 \%$ & $-0.8 \%$ \\
\hline Pu35-47 & $\mathrm{PbO}(\mathrm{wt} \%)$ & 0.0803 & 0.0803 & 0.0600 & 0.0203 & 0.0203 & $33.8 \%$ & $33.8 \%$ \\
\hline Pu35-47 & $\mathrm{SeO}_{2}($ wt $\%)$ & 0.0070 & 0.0070 & 0.0800 & -0.0730 & -0.0730 & $-91.2 \%$ & $-91.2 \%$ \\
\hline Pu35-47 & $\mathrm{Si}_{2} \mathrm{O}_{3}($ wt $\%)$ & 17.8845 & 17.6156 & 17.2000 & 0.6845 & 0.4156 & $4.0 \%$ & $2.4 \%$ \\
\hline $\mathrm{Pu} 35-47$ & $\mathrm{SO}_{4}(\mathrm{wt} \%)$ & 0.0749 & 0.0749 & 0.1700 & -0.0951 & -0.0951 & $-55.9 \%$ & $-55.9 \%$ \\
\hline $\mathrm{Pu} 35-47$ & $\mathrm{SrO}(\mathrm{wt} \%)$ & 2.3356 & 2.3356 & 2.1500 & 0.1856 & 0.1856 & $8.6 \%$ & $8.6 \%$ \\
\hline $\mathrm{Pu} 35-47$ & $\mathrm{Ta}_{2} \mathrm{O}_{5}(\mathrm{wt} \%)$ & 0.8077 & 0.8077 & 0.8500 & -0.0423 & -0.0423 & $-5.0 \%$ & $-5.0 \%$ \\
\hline $\mathrm{Pu} 35-47$ & Sum (wt \%) & 99.9709 & 99.4096 & 99.8700 & 0.1009 & -0.4604 & $0.1 \%$ & $-0.5 \%$ \\
\hline Pu35-48 & $\mathrm{Al}_{2} \mathrm{O}_{3}(\mathrm{wt} \%)$ & 9.1546 & 8.9731 & 8.6000 & 0.5546 & 0.3731 & $6.4 \%$ & $4.3 \%$ \\
\hline $\mathrm{Pu} 35-48$ & $\mathrm{~B}_{2} \mathrm{O}_{3}(\mathrm{wt} \%)$ & 11.4789 & 11.3938 & 11.1800 & 0.2989 & 0.2138 & $2.7 \%$ & $1.9 \%$ \\
\hline Pu35-48 & $\mathrm{CaO}(\mathrm{wt} \%)$ & 0.4610 & 0.4680 & 0.3700 & 0.0910 & 0.0980 & $24.6 \%$ & $26.5 \%$ \\
\hline Pu35-48 & $\mathrm{Cl}(\mathrm{wt} \%)$ & 0.0560 & 0.0560 & 0.6300 & -0.5740 & -0.5740 & $-91.1 \%$ & $-91.1 \%$ \\
\hline Pu35-48 & $\mathrm{Cr}_{2} \mathrm{O}_{3}(\mathrm{wt} \%)$ & 0.2222 & 0.2140 & 0.2300 & -0.0078 & -0.0160 & $-3.4 \%$ & $-7.0 \%$ \\
\hline Pu35-48 & $\mathrm{CuO}(\mathrm{wt} \%)$ & 0.1246 & 0.1325 & 0.1100 & 0.0146 & 0.0225 & $13.2 \%$ & $20.4 \%$ \\
\hline Pu35-48 & $\mathrm{F}(\mathrm{wt} \%)$ & 0.0365 & 0.0447 & 0.2000 & -0.1635 & -0.1553 & $-81.8 \%$ & $-77.6 \%$ \\
\hline Pu35-48 & $\mathrm{Fe}_{2} \mathrm{O}_{3}(\mathrm{wt} \%)$ & 0.4975 & 0.5013 & 0.5000 & -0.0025 & 0.0013 & $-0.5 \%$ & $0.3 \%$ \\
\hline Pu35-48 & $\mathrm{Ga}_{2} \mathrm{O}_{3}($ wt $\%)$ & 0.3663 & 0.3663 & 0.3400 & 0.0263 & 0.0263 & $7.7 \%$ & $7.7 \%$ \\
\hline $\mathrm{Pu} 35-48$ & $\mathrm{Gd}_{2} \mathrm{O}_{3}(\mathrm{wt} \%)$ & 11.8142 & 11.8142 & 11.6100 & 0.2042 & 0.2042 & $1.8 \%$ & $1.8 \%$ \\
\hline $\mathrm{Pu} 35-48$ & $\mathrm{HfO}_{2}(\mathrm{wt} \%)$ & 13.5620 & 13.5620 & 14.8600 & -1.2981 & -1.2981 & $-8.7 \%$ & $-8.7 \%$ \\
\hline Pu35-48 & $\mathrm{K}_{2} \mathrm{O}$ (wt \%) & 0.4855 & 0.4212 & 0.2900 & 0.1955 & 0.1312 & $67.4 \%$ & $45.2 \%$ \\
\hline Pu35-48 & $\mathrm{La}_{2} \mathrm{O}_{3}(\mathrm{wt} \%)$ & 16.2433 & 16.2433 & 16.3400 & -0.0967 & -0.0967 & $-0.6 \%$ & $-0.6 \%$ \\
\hline $\mathrm{Pu} 35-48$ & $\mathrm{MgO}(\mathrm{wt} \%)$ & 0.7786 & 0.7813 & 0.7900 & -0.0114 & -0.0087 & $-1.4 \%$ & $-1.1 \%$ \\
\hline $\mathrm{Pu} 35-48$ & $\mathrm{Na}_{2} \mathrm{O}($ wt $\%)$ & 0.7475 & 0.7044 & 0.7300 & 0.0175 & -0.0256 & $2.4 \%$ & $-3.5 \%$ \\
\hline Pu35-48 & $\mathrm{Nd}_{2} \mathrm{O}_{3}(\mathrm{wt} \%)$ & 13.1220 & 13.1220 & 12.9000 & 0.2220 & 0.2220 & $1.7 \%$ & $1.7 \%$ \\
\hline $\mathrm{Pu} 35-48$ & $\mathrm{NiO}($ wt \%) & 0.1762 & 0.1949 & 0.1900 & -0.0138 & 0.0049 & $-7.2 \%$ & $2.6 \%$ \\
\hline Pu35-48 & $\mathrm{PbO}(\mathrm{wt} \%)$ & 0.0862 & 0.0862 & 0.0600 & 0.0262 & 0.0262 & $43.6 \%$ & $43.6 \%$ \\
\hline $\mathrm{Pu} 35-48$ & $\mathrm{SeO}_{2}(\mathrm{wt} \%)$ & 0.0070 & 0.0070 & 0.0800 & -0.0730 & -0.0730 & $-91.2 \%$ & $-91.2 \%$ \\
\hline Pu35-48 & $\mathrm{Si}_{2} \mathrm{O}_{3}($ wt $\%)$ & 17.7134 & 17.4471 & 17.2000 & 0.5134 & 0.2471 & $3.0 \%$ & $1.4 \%$ \\
\hline Pu35-48 & $\mathrm{SO}_{4}(\mathrm{wt} \%)$ & 0.0749 & 0.0749 & 0.1700 & -0.0951 & -0.0951 & $-55.9 \%$ & $-55.9 \%$ \\
\hline Pu35-48 & $\mathrm{SrO}(\mathrm{wt} \%)$ & 2.3475 & 2.3475 & 2.1500 & 0.1975 & 0.1975 & $9.2 \%$ & $9.2 \%$ \\
\hline Pu35-48 & $\mathrm{Ta}_{2} \mathrm{O}_{5}(\mathrm{wt} \%)$ & 0.3303 & 0.3303 & 0.3500 & -0.0197 & -0.0197 & $-5.6 \%$ & $-5.6 \%$ \\
\hline Pu35-48 & Sum (wt \%) & 99.8860 & 99.2858 & 99.8800 & 0.0060 & -0.5942 & $0.0 \%$ & $-0.6 \%$ \\
\hline Pu35-49 & $\mathrm{Al}_{2} \mathrm{O}_{3}(\mathrm{wt} \%)$ & 9.2774 & 9.0934 & 8.6000 & 0.6774 & 0.4934 & $7.9 \%$ & $5.7 \%$ \\
\hline Pu35-49 & $\mathrm{B}_{2} \mathrm{O}_{3}(\mathrm{wt} \%)$ & 11.4467 & 11.3619 & 11.1800 & 0.2667 & 0.1819 & $2.4 \%$ & $1.6 \%$ \\
\hline Pu35-49 & $\mathrm{CaO}($ wt \%) & 0.4121 & 0.4183 & 0.3200 & 0.0921 & 0.0983 & $28.8 \%$ & $30.7 \%$ \\
\hline Pu35-49 & $\mathrm{Cl}(\mathrm{wt} \%)$ & 0.0565 & 0.0565 & 0.6400 & -0.5835 & -0.5835 & $-91.2 \%$ & $-91.2 \%$ \\
\hline Pu35-49 & $\mathrm{Cr}_{2} \mathrm{O}_{3}(\mathrm{wt} \%)$ & 0.1805 & 0.1739 & 0.1900 & -0.0095 & -0.0161 & $-5.0 \%$ & $-8.5 \%$ \\
\hline $\mathrm{Pu} 35-49$ & $\mathrm{CuO}(\mathrm{wt} \%)$ & 0.1552 & 0.1651 & 0.1400 & 0.0152 & 0.0251 & $10.9 \%$ & $17.9 \%$ \\
\hline $\mathrm{Pu} 35-49$ & $\mathrm{~F}(\mathrm{wt} \%)$ & 0.0410 & 0.0502 & 0.1900 & -0.1490 & -0.1398 & $-78.4 \%$ & $-73.6 \%$ \\
\hline Pu35-49 & $\mathrm{Fe}_{2} \mathrm{O}_{3}(\mathrm{wt} \%)$ & 0.5183 & 0.5222 & 0.5200 & -0.0017 & 0.0022 & $-0.3 \%$ & $0.4 \%$ \\
\hline $\mathrm{Pu} 35-49$ & $\mathrm{Ga}_{2} \mathrm{O}_{3}(\mathrm{wt} \%)$ & 0.2245 & 0.2245 & 0.1900 & 0.0345 & 0.0345 & $18.1 \%$ & $18.1 \%$ \\
\hline Pu35-49 & $\mathrm{Gd}_{2} \mathrm{O}_{3}(\mathrm{wt} \%)$ & 11.9294 & 11.9294 & 11.6100 & 0.3194 & 0.3194 & $2.8 \%$ & $2.8 \%$ \\
\hline Pu35-49 & $\mathrm{HfO}_{2}(\mathrm{wt} \%)$ & 13.5620 & 13.5620 & 14.8900 & -1.3281 & -1.3281 & $-8.9 \%$ & $-8.9 \%$ \\
\hline $\mathrm{Pu} 35-49$ & $\mathrm{~K}_{2} \mathrm{O}(\mathrm{wt} \%)$ & 0.5083 & 0.4410 & 0.6300 & -0.1217 & -0.1890 & $-19.3 \%$ & $-30.0 \%$ \\
\hline
\end{tabular}


Table D5. Average Measured and Bias-Corrected Chemical Compositions Versus Targeted Compositions by Oxide by Study Glass (continued)

\begin{tabular}{|c|c|c|c|c|c|c|c|c|}
\hline Glass ID & Oxide & $\begin{array}{c}\text { Measured } \\
\text { (wt \%) }\end{array}$ & \begin{tabular}{|c|} 
Measured Bias- \\
Corrected (wt \%)
\end{tabular} & $\begin{array}{c}\text { Targeted } \\
\text { (wt \%) }\end{array}$ & $\begin{array}{c}\text { Diff of } \\
\text { Measured }\end{array}$ & $\begin{array}{c}\text { Diff of Meas } \\
\text { BC }\end{array}$ & $\begin{array}{l}\text { \% Diff of } \\
\text { Measured }\end{array}$ & $\begin{array}{c}\text { \% Diff of Meas } \\
\text { BC }\end{array}$ \\
\hline $\mathrm{Pu} 35-49$ & $\mathrm{La}_{2} \mathrm{O}_{3}(\mathrm{wt} \%)$ & 16.7124 & 16.7124 & 16.3400 & 0.3724 & 0.3724 & $2.3 \%$ & $2.3 \%$ \\
\hline \begin{tabular}{|l|} 
Pu35-49 \\
\end{tabular} & $\mathrm{MgO}(\mathrm{wt} \%)$ & 0.7587 & 0.7614 & 0.7700 & -0.0113 & -0.0086 & $-1.5 \%$ & $-1.1 \%$ \\
\hline \begin{tabular}{|l|}
$\mathrm{Pu} 35-49$ \\
\end{tabular} & $\mathrm{Na}_{2} \mathrm{O}($ wt $\%)$ & 0.6639 & 0.6257 & 0.6400 & 0.0239 & -0.0143 & $3.7 \%$ & $-2.2 \%$ \\
\hline Pu35-49 & $\mathrm{Nd}_{2} \mathrm{O}_{3}(\mathrm{wt} \%)$ & 13.2970 & 13.2970 & 12.9000 & 0.3970 & 0.3970 & $3.1 \%$ & $3.1 \%$ \\
\hline Pu35-49 & $\mathrm{NiO}(\mathrm{wt} \%)$ & 0.1839 & 0.2033 & 0.2000 & -0.0161 & 0.0033 & $-8.1 \%$ & $1.7 \%$ \\
\hline Pu35-49 & $\mathrm{PbO}(\mathrm{wt} \%)$ & 0.0846 & 0.0846 & 0.0600 & 0.0246 & 0.0246 & $40.9 \%$ & $40.9 \%$ \\
\hline \begin{tabular}{|l|}
$\mathrm{Pu} 35-49$ \\
\end{tabular} & $\mathrm{SeO}_{2}(\mathrm{wt} \%)$ & 0.0070 & 0.0070 & 0.0800 & -0.0730 & -0.0730 & $-91.2 \%$ & $-91.2 \%$ \\
\hline Pu35-49 & $\mathrm{Si}_{2} \mathrm{O}_{3}(\mathrm{wt} \%)$ & 18.1734 & 17.9001 & 17.2000 & 0.9734 & 0.7001 & $5.7 \%$ & $4.1 \%$ \\
\hline Pu35-49 & $\mathrm{SO}_{4}(\mathrm{wt} \%)$ & 0.0749 & 0.0749 & 0.1700 & -0.0951 & -0.0951 & $-55.9 \%$ & $-55.9 \%$ \\
\hline Pu35-49 & $\mathrm{SrO}(\mathrm{wt} \%)$ & 2.3593 & 2.3593 & 2.1500 & 0.2093 & 0.2093 & $9.7 \%$ & $9.7 \%$ \\
\hline \begin{tabular}{|l|}
$\mathrm{Pu} 35-49$ \\
\end{tabular} & $\mathrm{Ta}_{2} \mathrm{O}_{5}(\mathrm{wt} \%)$ & 0.2735 & 0.2735 & 0.2700 & 0.0035 & 0.0035 & $1.3 \%$ & $1.3 \%$ \\
\hline \begin{tabular}{|l|} 
Pu35-49 \\
\end{tabular} & Sum (wt \%) & 100.9004 & 100.2975 & 99.8800 & 1.0204 & 0.4175 & $1.0 \%$ & $0.4 \%$ \\
\hline \begin{tabular}{|l|}
$\mathrm{Pu} 35-50$ \\
\end{tabular} & $\mathrm{Al}_{2} \mathrm{O}_{3}(\mathrm{wt} \%)$ & 9.2397 & 9.0564 & 8.6000 & 0.6397 & 0.4564 & $7.4 \%$ & $5.3 \%$ \\
\hline Pu35-50 & $\mathrm{B}_{2} \mathrm{O}_{3}(\mathrm{wt} \%)$ & 11.5433 & 11.4578 & 11.1800 & 0.3633 & 0.2778 & $3.2 \%$ & $2.5 \%$ \\
\hline Pu35-50 & $\mathrm{CaO}($ wt \%) & 0.3463 & 0.3515 & 0.2600 & 0.0863 & 0.0915 & $33.2 \%$ & $35.2 \%$ \\
\hline \begin{tabular}{|l|}
$\mathrm{Pu} 35-50$ \\
\end{tabular} & $\mathrm{Cl}(\mathrm{wt} \%)$ & 0.0695 & 0.0695 & 0.6400 & -0.5705 & -0.5705 & $-89.1 \%$ & $-89.1 \%$ \\
\hline Pu35-50 & $\mathrm{Cr}_{2} \mathrm{O}_{3}(\mathrm{wt} \%)$ & 0.2353 & 0.2267 & 0.2500 & -0.0147 & -0.0233 & $-5.9 \%$ & $-9.3 \%$ \\
\hline Pu35-50 & $\mathrm{CuO}(\mathrm{wt} \%)$ & 0.1177 & 0.1252 & 0.1100 & 0.0077 & 0.0152 & $7.0 \%$ & $13.8 \%$ \\
\hline \begin{tabular}{|l|} 
Pu35-50 \\
\end{tabular} & $\mathrm{F}(\mathrm{wt} \%)$ & 0.0420 & 0.0515 & 0.2000 & -0.1580 & -0.1485 & $-79.0 \%$ & $-74.3 \%$ \\
\hline Pu35-50 & $\mathrm{Fe}_{2} \mathrm{O}_{3}(\mathrm{wt} \%)$ & 0.4975 & 0.5013 & 0.4900 & 0.0075 & 0.0113 & $1.5 \%$ & $2.3 \%$ \\
\hline \begin{tabular}{|l|}
$\mathrm{Pu} 35-50$ \\
\end{tabular} & $\mathrm{Ga}_{2} \mathrm{O}_{3}($ wt $\%)$ & 0.3495 & 0.3495 & 0.3200 & 0.0295 & 0.0295 & $9.2 \%$ & $9.2 \%$ \\
\hline Pu35-50 & $\mathrm{Gd}_{2} \mathrm{O}_{3}(\mathrm{wt} \%)$ & 11.8718 & 11.8718 & 11.6100 & 0.2618 & 0.2618 & $2.3 \%$ & $2.3 \%$ \\
\hline \begin{tabular}{|l|}
$\mathrm{Pu} 35-50$ \\
\end{tabular} & $\mathrm{HfO}_{2}(\mathrm{wt} \%)$ & 13.5030 & 13.5030 & 14.8900 & -1.3870 & -1.3870 & $-9.3 \%$ & $-9.3 \%$ \\
\hline \begin{tabular}{|l|}
$\mathrm{Pu} 35-50$ \\
\end{tabular} & $\mathrm{~K}_{2} \mathrm{O}(\mathrm{wt} \%)$ & 0.6065 & 0.5262 & 0.6900 & -0.0835 & -0.1638 & $-12.1 \%$ & $-23.7 \%$ \\
\hline \begin{tabular}{|l|}
$\mathrm{Pu} 35-50$ \\
\end{tabular} & $\mathrm{La}_{2} \mathrm{O}_{3}(\mathrm{wt} \%)$ & 16.5951 & 16.5951 & 16.3400 & 0.2551 & 0.2551 & $1.6 \%$ & $1.6 \%$ \\
\hline \begin{tabular}{|l|} 
Pu35-50 \\
\end{tabular} & $\mathrm{MgO}(\mathrm{wt} \%)$ & 0.6509 & 0.6532 & 0.6600 & -0.0091 & -0.0068 & $-1.4 \%$ & $-1.0 \%$ \\
\hline \begin{tabular}{|l|}
$\mathrm{Pu} 35-50$ \\
\end{tabular} & $\mathrm{Na}_{2} \mathrm{O}(\mathrm{wt} \%)$ & 0.6774 & 0.6384 & 0.6500 & 0.0274 & -0.0116 & $4.2 \%$ & $-1.8 \%$ \\
\hline \begin{tabular}{|l|}
$\mathrm{Pu} 35-50$ \\
\end{tabular} & $\mathrm{Nd}_{2} \mathrm{O}_{3}(\mathrm{wt} \%)$ & 13.1220 & 13.1220 & 12.9000 & 0.2220 & 0.2220 & $1.7 \%$ & $1.7 \%$ \\
\hline Pu35-50 & $\mathrm{NiO}($ wt \%) & 0.2081 & 0.2301 & 0.2400 & -0.0319 & -0.0099 & $-13.3 \%$ & $-4.1 \%$ \\
\hline Pu35-50 & $\mathrm{PbO}($ wt $\%)$ & 0.0813 & 0.0813 & 0.0600 & 0.0213 & 0.0213 & $35.5 \%$ & $35.5 \%$ \\
\hline \begin{tabular}{|l|}
$\mathrm{Pu} 35-50$ \\
\end{tabular} & $\mathrm{SeO}_{2}($ wt $\%)$ & 0.0070 & 0.0070 & 0.0800 & -0.0730 & -0.0730 & $-91.2 \%$ & $-91.2 \%$ \\
\hline Pu35-50 & $\mathrm{Si}_{2} \mathrm{O}_{3}($ wt $\%)$ & 17.8739 & 17.6051 & 17.2000 & 0.6739 & 0.4051 & $3.9 \%$ & $2.4 \%$ \\
\hline Pu35-50 & $\mathrm{SO}_{4}(\mathrm{wt} \%)$ & 0.0749 & 0.0749 & 0.1700 & -0.0951 & -0.0951 & $-55.9 \%$ & $-55.9 \%$ \\
\hline Pu35-50 & SrO (wt \%) & 2.3652 & 2.3652 & 2.1500 & 0.2152 & 0.2152 & $10.0 \%$ & $10.0 \%$ \\
\hline Pu35-50 & $\mathrm{Ta}_{2} \mathrm{O}_{5}(\mathrm{wt} \%)$ & 0.1838 & 0.1838 & 0.1800 & 0.0038 & 0.0038 & $2.1 \%$ & $2.1 \%$ \\
\hline Pu35-50 & Sum (wt \%) & 100.2616 & 99.6463 & 99.8700 & 0.3916 & -0.2237 & $0.4 \%$ & $-0.2 \%$ \\
\hline \begin{tabular}{|l|}
$\mathrm{Pu} 35-51$ \\
\end{tabular} & $\mathrm{Al}_{2} \mathrm{O}_{3}(\mathrm{wt} \%)$ & 9.2208 & 9.0379 & 8.6000 & 0.6208 & 0.4379 & $7.2 \%$ & $5.1 \%$ \\
\hline Pu35-51 & $\mathrm{B}_{2} \mathrm{O}_{3}(\mathrm{wt} \%)$ & 11.5111 & 11.4258 & 11.1800 & 0.3311 & 0.2458 & $3.0 \%$ & $2.2 \%$ \\
\hline Pu35-51 & $\mathrm{CaO}(w \mathrm{t} \%)$ & 0.2372 & 0.2407 & 0.1600 & 0.0772 & 0.0807 & $48.2 \%$ & $50.5 \%$ \\
\hline \begin{tabular}{|l|}
$\mathrm{Pu} 35-51$ \\
\end{tabular} & $\mathrm{Cl}(\mathrm{wt} \%)$ & 0.0515 & 0.0515 & 0.6500 & -0.5985 & -0.5985 & $-92.1 \%$ & $-92.1 \%$ \\
\hline \begin{tabular}{|l|}
$\mathrm{Pu} 35-51$ \\
\end{tabular} & $\mathrm{Cr}_{2} \mathrm{O}_{3}(\mathrm{wt} \%)$ & 0.3069 & 0.2957 & 0.3200 & -0.0131 & -0.0243 & $-4.1 \%$ & $-7.6 \%$ \\
\hline \begin{tabular}{|l|}
$\mathrm{Pu} 35-51$ \\
\end{tabular} & $\mathrm{CuO}(\mathrm{wt} \%)$ & 0.1264 & 0.1345 & 0.1100 & 0.0164 & 0.0245 & $14.9 \%$ & $22.3 \%$ \\
\hline \begin{tabular}{|l|}
$\mathrm{Pu} 35-51$ \\
\end{tabular} & $\mathrm{~F}(\mathrm{wt} \%)$ & 0.0405 & 0.0496 & 0.2200 & -0.1795 & -0.1704 & $-81.6 \%$ & $-77.4 \%$ \\
\hline Pu35-51 & $\mathrm{Fe}_{2} \mathrm{O}_{3}(\mathrm{wt} \%)$ & 0.5647 & 0.5690 & 0.5600 & 0.0047 & 0.0090 & $0.8 \%$ & $1.6 \%$ \\
\hline \begin{tabular}{|l|}
$\mathrm{Pu} 35-51$ \\
\end{tabular} & $\mathrm{Ga}_{2} \mathrm{O}_{3}(\mathrm{wt} \%)$ & 0.1936 & 0.1936 & 0.1600 & 0.0336 & 0.0336 & $21.0 \%$ & $21.0 \%$ \\
\hline Pu35-51 & $\mathrm{Gd}_{2} \mathrm{O}_{3}(\mathrm{wt} \%)$ & 11.9294 & 11.9294 & 11.6100 & 0.3194 & 0.3194 & $2.8 \%$ & $2.8 \%$ \\
\hline \begin{tabular}{|l|}
$\mathrm{Pu} 35-51$ \\
\end{tabular} & $\mathrm{HfO}_{2}(\mathrm{wt} \%)$ & 13.4440 & 13.4440 & 14.8700 & -1.4260 & -1.4260 & $-9.6 \%$ & $-9.6 \%$ \\
\hline Pu35-51 & $\mathrm{K}_{2} \mathrm{O}(\mathrm{wt} \%)$ & 0.2132 & 0.1850 & 0.2600 & -0.0468 & -0.0750 & $-18.0 \%$ & $-28.9 \%$ \\
\hline Pu35-51 & $\mathrm{La}_{2} \mathrm{O}_{3}(\mathrm{wt} \%)$ & 16.7710 & 16.7710 & 16.3400 & 0.4310 & 0.4310 & $2.6 \%$ & $2.6 \%$ \\
\hline \begin{tabular}{|l|}
$\mathrm{Pu} 35-51$ \\
\end{tabular} & $\mathrm{MgO}(\mathrm{wt} \%)$ & 0.8980 & 0.9012 & 0.9000 & -0.0020 & 0.0012 & $-0.2 \%$ & $0.1 \%$ \\
\hline Pu35-51 & $\mathrm{Na}_{2} \mathrm{O}($ wt $\%)$ & 0.7643 & 0.7203 & 0.7500 & 0.0143 & -0.0297 & $1.9 \%$ & $-4.0 \%$ \\
\hline Pu35-51 & $\mathrm{Nd}_{2} \mathrm{O}_{3}(\mathrm{wt} \%)$ & 13.1803 & 13.1803 & 12.9000 & 0.2803 & 0.2803 & $2.2 \%$ & $2.2 \%$ \\
\hline Pu35-51 & $\mathrm{NiO}($ wt \%) & 0.2710 & 0.2997 & 0.2900 & -0.0190 & 0.0097 & $-6.5 \%$ & $3.4 \%$ \\
\hline Pu35-51 & $\mathrm{PbO}(\mathrm{wt} \%)$ & 0.0835 & 0.0835 & 0.0600 & 0.0235 & 0.0235 & $39.1 \%$ & $39.1 \%$ \\
\hline Pu35-51 & $\mathrm{SeO}_{2}(\mathrm{wt} \%)$ & 0.0070 & 0.0070 & 0.0800 & -0.0730 & -0.0730 & $-91.2 \%$ & $-91.2 \%$ \\
\hline $\mathrm{Pu} 35-51$ & $\mathrm{Si}_{2} \mathrm{O}_{3}(\mathrm{wt} \%)$ & 18.0450 & 17.7737 & 17.2000 & 0.8450 & 0.5737 & $4.9 \%$ & $3.3 \%$ \\
\hline \begin{tabular}{|l|}
$\mathrm{Pu} 35-51$ \\
\end{tabular} & $\mathrm{SO}_{4}(\mathrm{wt} \%)$ & 0.0749 & 0.0749 & 0.1700 & -0.0951 & -0.0951 & $-55.9 \%$ & $-55.9 \%$ \\
\hline Pu35-51 & $\mathrm{SrO}(\mathrm{wt} \%)$ & 2.3415 & 2.3415 & 2.1500 & 0.1915 & 0.1915 & $8.9 \%$ & $8.9 \%$ \\
\hline
\end{tabular}


Table D5. Average Measured and Bias-Corrected Chemical Compositions Versus Targeted Compositions by Oxide by Study Glass (continued)

\begin{tabular}{|c|c|c|c|c|c|c|c|c|}
\hline Glass ID & Oxide & $\begin{array}{c}\text { Measured } \\
(\mathrm{wt} \%)\end{array}$ & \begin{tabular}{|c|} 
Measured Bias- \\
Corrected (wt \%)
\end{tabular} & $\begin{array}{c}\text { Targeted } \\
\text { (wt \%) }\end{array}$ & $\begin{array}{c}\text { Diff of } \\
\text { Measured }\end{array}$ & $\begin{array}{c}\text { Diff of Meas } \\
\text { BC }\end{array}$ & $\begin{array}{l}\text { \% Diff of } \\
\text { Measured }\end{array}$ & $\begin{array}{c}\text { \% Diff of Meas } \\
\text { BC }\end{array}$ \\
\hline $\mathrm{Pu} 35-51$ & $\mathrm{Ta}_{2} \mathrm{O}_{5}(\mathrm{wt} \%)$ & 0.3284 & \begin{tabular}{|l|}
0.3284 \\
\end{tabular} & 0.3200 & 0.0084 & 0.0084 & $2.6 \%$ & $2.6 \%$ \\
\hline \begin{tabular}{|l|}
$\mathrm{Pu} 35-51$ \\
\end{tabular} & Sum (wt \%) & 100.6045 & 100.0383 & 99.8600 & 0.7445 & 0.1783 & $0.7 \%$ & $0.2 \%$ \\
\hline Pu35-52 & $\mathrm{Al}_{2} \mathrm{O}_{3}(\mathrm{wt} \%)$ & 9.1830 & 9.0008 & 8.6000 & 0.5830 & 0.4008 & $6.8 \%$ & $4.7 \%$ \\
\hline Pu35-52 & $\mathrm{B}_{2} \mathrm{O}_{3}(\mathrm{wt} \%)$ & 11.4789 & 11.3938 & 11.1800 & 0.2989 & 0.2138 & $2.7 \%$ & $1.9 \%$ \\
\hline Pu35-52 & $\mathrm{CaO}(\mathrm{wt} \%)$ & 0.2484 & 0.2521 & 0.1700 & 0.0784 & 0.0821 & $46.1 \%$ & $48.3 \%$ \\
\hline Pu35-52 & $\mathrm{Cl}(\mathrm{wt} \%)$ & 0.0520 & 0.0520 & 0.6900 & -0.6380 & -0.6380 & $-92.5 \%$ & $-92.5 \%$ \\
\hline Pu35-52 & $\mathrm{Cr}_{2} \mathrm{O}_{3}(\mathrm{wt} \%)$ & 0.3069 & 0.2957 & 0.3300 & -0.0231 & -0.0343 & $-7.0 \%$ & $-10.4 \%$ \\
\hline Pu35-52 & $\mathrm{CuO}(\mathrm{wt} \%)$ & 0.1490 & 0.1584 & 0.1400 & 0.0090 & 0.0184 & $6.4 \%$ & $13.2 \%$ \\
\hline Pu35-52 & $\mathrm{F}(\mathrm{wt} \%)$ & 0.0255 & 0.0312 & 0.1400 & -0.1145 & -0.1088 & $-81.8 \%$ & $-77.7 \%$ \\
\hline Pu35-52 & $\mathrm{Fe}_{2} \mathrm{O}_{3}(\mathrm{wt} \%)$ & 0.3996 & 0.4026 & 0.3900 & 0.0096 & 0.0126 & $2.5 \%$ & $3.2 \%$ \\
\hline \begin{tabular}{|l|}
$\mathrm{Pu} 35-52$ \\
\end{tabular} & $\mathrm{Ga}_{2} \mathrm{O}_{3}(\mathrm{wt} \%)$ & 0.6015 & 0.6015 & 0.5800 & 0.0215 & 0.0215 & $3.7 \%$ & $3.7 \%$ \\
\hline \begin{tabular}{|l|} 
Pu35-52 \\
\end{tabular} & $\mathrm{Gd}_{2} \mathrm{O}_{3}(\mathrm{wt} \%)$ & 11.8718 & 11.8718 & 11.6100 & 0.2618 & 0.2618 & $2.3 \%$ & $2.3 \%$ \\
\hline \begin{tabular}{|l|} 
Pu35-52 \\
\end{tabular} & $\mathrm{HfO}_{2}(\mathrm{wt} \%)$ & 12.7364 & 12.7364 & 14.8600 & -2.1236 & -2.1236 & $-14.3 \%$ & $-14.3 \%$ \\
\hline Pu35-52 & $\mathrm{K}_{2} \mathrm{O}(\mathrm{wt} \%)$ & 0.3066 & 0.2660 & 0.3700 & -0.0634 & -0.1040 & $-17.1 \%$ & $-28.1 \%$ \\
\hline Pu35-52 & $\mathrm{La}_{2} \mathrm{O}_{3}(\mathrm{wt} \%)$ & 16.7124 & 16.7124 & 16.3400 & 0.3724 & 0.3724 & $2.3 \%$ & $2.3 \%$ \\
\hline \begin{tabular}{|l|}
$\mathrm{Pu} 35-52$ \\
\end{tabular} & $\mathrm{MgO}(\mathrm{wt} \%)$ & 0.8018 & 0.8046 & 0.8200 & -0.0182 & -0.0154 & $-2.2 \%$ & $-1.9 \%$ \\
\hline Pu35-52 & $\mathrm{Na}_{2} \mathrm{O}(\mathrm{wt} \%)$ & 0.7434 & 0.7006 & 0.7100 & 0.0334 & -0.0094 & $4.7 \%$ & $-1.3 \%$ \\
\hline Pu35-52 & $\mathrm{Nd}_{2} \mathrm{O}_{3}(\mathrm{wt} \%)$ & 13.1803 & 13.1803 & 12.9000 & 0.2803 & 0.2803 & $2.2 \%$ & $2.2 \%$ \\
\hline Pu35-52 & $\mathrm{NiO}(\mathrm{wt} \%)$ & 0.2074 & 0.2294 & 0.2300 & -0.0226 & -0.0006 & $-9.8 \%$ & $-0.3 \%$ \\
\hline Pu35-52 & $\mathrm{PbO}(\mathrm{wt} \%)$ & 0.0835 & 0.0835 & 0.0600 & 0.0235 & 0.0235 & $39.1 \%$ & $39.1 \%$ \\
\hline \begin{tabular}{|l|}
$\mathrm{Pu} 35-52$ \\
\end{tabular} & $\mathrm{SeO}_{2}(\mathrm{wt} \%)$ & 0.0070 & 0.0070 & 0.0800 & -0.0730 & -0.0730 & $-91.2 \%$ & $-91.2 \%$ \\
\hline Pu35-52 & $\mathrm{Si}_{2} \mathrm{O}_{3}($ wt $\%)$ & 17.9487 & 17.6788 & 17.2000 & 0.7487 & 0.4788 & $4.4 \%$ & $2.8 \%$ \\
\hline \begin{tabular}{|l|}
$\mathrm{Pu} 35-52$ \\
\end{tabular} & $\mathrm{SO}_{4}(\mathrm{wt} \%)$ & 0.0749 & 0.0749 & 0.1700 & -0.0951 & -0.0951 & $-55.9 \%$ & $-55.9 \%$ \\
\hline \begin{tabular}{|l|}
$\mathrm{Pu} 35-52$ \\
\end{tabular} & SrO (wt \%) & 2.3415 & 2.3415 & 2.1500 & 0.1915 & 0.1915 & $8.9 \%$ & $8.9 \%$ \\
\hline \begin{tabular}{|l|}
$\mathrm{Pu} 35-52$ \\
\end{tabular} & $\mathrm{Ta}_{2} \mathrm{O}_{5}(\mathrm{wt} \%)$ & 0.1471 & 0.1471 & 0.1400 & 0.0071 & 0.0071 & $5.1 \%$ & $5.1 \%$ \\
\hline \begin{tabular}{|l|}
$\mathrm{Pu} 35-52$ \\
\end{tabular} & Sum (wt \%) & 99.6078 & 99.0228 & 99.8600 & -0.2522 & -0.8372 & $-0.3 \%$ & $-0.8 \%$ \\
\hline \begin{tabular}{|l|}
$\mathrm{Pu} 35-53$ \\
\end{tabular} & $\mathrm{Al}_{2} \mathrm{O}_{3}(\mathrm{wt} \%)$ & 9.1641 & 8.9823 & 8.6000 & 0.5641 & 0.3823 & $6.6 \%$ & $4.4 \%$ \\
\hline \begin{tabular}{|l|} 
Pu35-53 \\
\end{tabular} & $\mathrm{B}_{2} \mathrm{O}_{3}(\mathrm{wt} \%)$ & 11.5755 & 11.4897 & 11.1800 & 0.3955 & 0.3097 & $3.5 \%$ & $2.8 \%$ \\
\hline \begin{tabular}{|l|} 
Pu35-53 \\
\end{tabular} & $\mathrm{CaO}(\mathrm{wt} \%)$ & 0.2414 & 0.2450 & 0.1600 & 0.0814 & 0.0850 & $50.9 \%$ & $53.1 \%$ \\
\hline Pu35-53 & $\mathrm{Cl}(\mathrm{wt} \%)$ & 0.0555 & 0.0555 & 0.7000 & -0.6445 & -0.6445 & $-92.1 \%$ & $-92.1 \%$ \\
\hline \begin{tabular}{|l|}
$\mathrm{Pu} 35-53$ \\
\end{tabular} & $\mathrm{Cr}_{2} \mathrm{O}_{3}(\mathrm{wt} \%)$ & 0.1666 & 0.1605 & 0.1700 & -0.0034 & -0.0095 & $-2.0 \%$ & $-5.6 \%$ \\
\hline \begin{tabular}{|l|}
$\mathrm{Pu} 35-53$ \\
\end{tabular} & $\mathrm{CuO}(\mathrm{wt} \%)$ & 0.1352 & 0.1438 & 0.1100 & 0.0252 & 0.0338 & $22.9 \%$ & $30.7 \%$ \\
\hline \begin{tabular}{|l|}
$\mathrm{Pu} 35-53$ \\
\end{tabular} & $\mathrm{~F}(\mathrm{wt} \%)$ & 0.0480 & 0.0588 & 0.3500 & -0.3020 & -0.2912 & $-86.3 \%$ & $-83.2 \%$ \\
\hline \begin{tabular}{|l|}
$\mathrm{Pu} 35-53$ \\
\end{tabular} & $\mathrm{Fe}_{2} \mathrm{O}_{3}(\mathrm{wt} \%)$ & 0.1837 & 0.1851 & 0.1700 & 0.0137 & 0.0151 & $8.1 \%$ & $8.9 \%$ \\
\hline Pu35-53 & $\mathrm{Ga}_{2} \mathrm{O}_{3}(\mathrm{wt} \%)$ & 0.1922 & 0.1922 & 0.1600 & 0.0322 & 0.0322 & $20.1 \%$ & $20.1 \%$ \\
\hline \begin{tabular}{|l|}
$\mathrm{Pu} 35-53$ \\
\end{tabular} & $\mathrm{Gd}_{2} \mathrm{O}_{3}(\mathrm{wt} \%)$ & 11.9294 & 11.9294 & 11.6100 & 0.3194 & 0.3194 & $2.8 \%$ & $2.8 \%$ \\
\hline Pu35-53 & $\mathrm{HfO}_{2}(\mathrm{wt} \%)$ & 12.8544 & 12.8544 & 14.9700 & -2.1156 & -2.1156 & $-14.1 \%$ & $-14.1 \%$ \\
\hline Pu35-53 & $\mathrm{K}_{2} \mathrm{O}(\mathrm{wt} \%)$ & 0.3451 & 0.2994 & 0.4700 & -0.1249 & -0.1706 & $-26.6 \%$ & $-36.3 \%$ \\
\hline Pu35-53 & $\mathrm{La}_{2} \mathrm{O}_{3}(\mathrm{wt} \%)$ & 16.8297 & 16.8297 & 16.3400 & 0.4897 & 0.4897 & $3.0 \%$ & $3.0 \%$ \\
\hline Pu35-53 & $\mathrm{MgO}(\mathrm{wt} \%)$ & 0.6202 & 0.6224 & 0.6200 & 0.0002 & 0.0024 & $0.0 \%$ & $0.4 \%$ \\
\hline \begin{tabular}{|l|}
$\mathrm{Pu} 35-53$ \\
\end{tabular} & $\mathrm{Na}_{2} \mathrm{O}(\mathrm{wt} \%)$ & 0.7920 & 0.7464 & 0.7900 & 0.0020 & -0.0436 & $0.2 \%$ & $-5.5 \%$ \\
\hline \begin{tabular}{|l|}
$\mathrm{Pu} 35-53$ \\
\end{tabular} & $\mathrm{Nd}_{2} \mathrm{O}_{3}(\mathrm{wt} \%)$ & 13.2386 & 13.2386 & 12.9000 & 0.3386 & 0.3386 & $2.6 \%$ & $2.6 \%$ \\
\hline \begin{tabular}{|l|}
$\mathrm{Pu} 35-53$ \\
\end{tabular} & $\mathrm{NiO}($ wt \%) & 0.1393 & 0.1541 & 0.1500 & -0.0107 & 0.0041 & $-7.1 \%$ & $2.7 \%$ \\
\hline Pu35-53 & $\mathrm{PbO}(\mathrm{wt} \%)$ & 0.0813 & 0.0813 & 0.0600 & 0.0213 & 0.0213 & $35.5 \%$ & $35.5 \%$ \\
\hline \begin{tabular}{|l|} 
Pu35-53 \\
\end{tabular} & $\mathrm{SeO}_{2}(\mathrm{wt} \%)$ & 0.0070 & 0.0070 & 0.0800 & -0.0730 & -0.0730 & $-91.2 \%$ & $-91.2 \%$ \\
\hline Pu35-53 & $\mathrm{Si}_{2} \mathrm{O}_{3}(\mathrm{wt} \%)$ & 17.9808 & 17.7105 & 17.2000 & 0.7808 & 0.5105 & $4.5 \%$ & $3.0 \%$ \\
\hline \begin{tabular}{|l|}
$\mathrm{Pu} 35-53$ \\
\end{tabular} & $\mathrm{SO}_{4}(\mathrm{wt} \%)$ & 0.0749 & 0.0749 & 0.1700 & -0.0951 & -0.0951 & $-55.9 \%$ & $-55.9 \%$ \\
\hline Pu35-53 & $\mathrm{SrO}(\mathrm{wt} \%)$ & 2.3297 & 2.3297 & 2.1500 & 0.1797 & 0.1797 & $8.4 \%$ & $8.4 \%$ \\
\hline Pu35-53 & $\mathrm{Ta}_{2} \mathrm{O}_{5}(\mathrm{wt} \%)$ & 0.7558 & 0.7558 & 0.7700 & -0.0142 & -0.0142 & $-1.8 \%$ & $-1.8 \%$ \\
\hline \begin{tabular}{|l|}
$\mathrm{Pu} 35-53$ \\
\end{tabular} & Sum (wt \%) & 99.7405 & 99.1466 & 99.8800 & -0.1395 & -0.7334 & $-0.1 \%$ & $-0.7 \%$ \\
\hline Pu35-54 & $\mathrm{Al}_{2} \mathrm{O}_{3}(\mathrm{wt} \%)$ & 9.2397 & 9.0564 & 8.6000 & 0.6397 & 0.4564 & $7.4 \%$ & $5.3 \%$ \\
\hline Pu35-54 & $\mathrm{B}_{2} \mathrm{O}_{3}($ wt $\%)$ & 11.5755 & 11.4897 & 11.1800 & 0.3955 & 0.3097 & $3.5 \%$ & $2.8 \%$ \\
\hline Pu35-54 & $\mathrm{CaO}(\mathrm{wt} \%)$ & 0.3575 & 0.3629 & 0.2800 & 0.0775 & 0.0829 & $27.7 \%$ & $29.6 \%$ \\
\hline Pu35-54 & $\mathrm{Cl}(\mathrm{wt} \%)$ & 0.0645 & 0.0645 & 0.6400 & -0.5755 & -0.5755 & $-89.9 \%$ & $-89.9 \%$ \\
\hline Pu35-54 & $\mathrm{Cr}_{2} \mathrm{O}_{3}(\mathrm{wt} \%)$ & 0.2704 & 0.2605 & 0.3000 & -0.0296 & -0.0395 & $-9.9 \%$ & $-13.2 \%$ \\
\hline Pu35-54 & $\mathrm{CuO}(\mathrm{wt} \%)$ & 0.1508 & 0.1604 & 0.1300 & 0.0208 & 0.0304 & $16.0 \%$ & $23.4 \%$ \\
\hline Pu35-54 & $\mathrm{F}(\mathrm{wt} \%)$ & 0.0620 & 0.0760 & 0.2100 & -0.1480 & -0.1340 & $-70.5 \%$ & $-63.8 \%$ \\
\hline Pu35-54 & $\mathrm{Fe}_{2} \mathrm{O}_{3}(\mathrm{wt} \%)$ & 0.4210 & 0.4242 & 0.4200 & 0.0010 & 0.0042 & $0.2 \%$ & $1.0 \%$ \\
\hline
\end{tabular}


Table D5. Average Measured and Bias-Corrected Chemical Compositions Versus Targeted Compositions by Oxide by Study Glass (continued)

\begin{tabular}{|c|c|c|c|c|c|c|c|c|}
\hline Glass ID & Oxide & $\begin{array}{c}\text { Measured } \\
\text { (wt \%) }\end{array}$ & \begin{tabular}{|c|} 
Measured Bias- \\
Corrected (wt \%)
\end{tabular} & $\begin{array}{c}\text { Targeted } \\
\text { (wt \%) }\end{array}$ & $\begin{array}{c}\text { Diff of } \\
\text { Measured }\end{array}$ & $\begin{array}{c}\text { Diff of Meas } \\
\text { BC }\end{array}$ & $\begin{array}{l}\text { \% Diff of } \\
\text { Measured }\end{array}$ & $\begin{array}{c}\text { \% Diff of Meas } \\
\text { BC }\end{array}$ \\
\hline $\mathrm{Pu} 35-54$ & $\mathrm{Ga}_{2} \mathrm{O}_{3}(\mathrm{wt} \%)$ & 0.4362 & 0.4362 & 0.4100 & 0.0262 & 0.0262 & $6.4 \%$ & $6.4 \%$ \\
\hline Pu35-54 & $\mathrm{Gd}_{2} \mathrm{O}_{3}(\mathrm{wt} \%)$ & 11.9870 & 11.9870 & 11.6100 & 0.3770 & 0.3770 & $3.2 \%$ & $3.2 \%$ \\
\hline $\mathrm{Pu} 35-54$ & $\mathrm{HfO}_{2}(\mathrm{wt} \%)$ & 12.9723 & 12.9723 & 14.9300 & -1.9577 & -1.9577 & $-13.1 \%$ & $-13.1 \%$ \\
\hline $\mathrm{Pu} 35-54$ & $\mathrm{~K}_{2} \mathrm{O}(\mathrm{wt} \%)$ & 0.4776 & 0.4144 & 0.5700 & -0.0924 & -0.1556 & $-16.2 \%$ & $-27.3 \%$ \\
\hline $\mathrm{Pu} 35-54$ & $\mathrm{La}_{2} \mathrm{O}_{3}(\mathrm{wt} \%)$ & 16.8883 & 16.8883 & 16.3400 & 0.5483 & 0.5483 & $3.4 \%$ & $3.4 \%$ \\
\hline \begin{tabular}{|l|}
$\mathrm{Pu} 35-54$ \\
\end{tabular} & $\mathrm{MgO}(\mathrm{wt} \%)$ & 0.7918 & 0.7947 & 0.8100 & -0.0182 & -0.0153 & $-2.2 \%$ & $-1.9 \%$ \\
\hline Pu35-54 & $\mathrm{Na}_{2} \mathrm{O}(\mathrm{wt} \%)$ & 0.7171 & 0.6759 & 0.7000 & 0.0171 & -0.0241 & $2.4 \%$ & $-3.4 \%$ \\
\hline Pu35-54 & $\mathrm{Nd}_{2} \mathrm{O}_{3}(\mathrm{wt} \%)$ & 13.2970 & 13.2970 & 12.9000 & 0.3970 & 0.3970 & $3.1 \%$ & $3.1 \%$ \\
\hline Pu35-54 & $\mathrm{NiO}(\mathrm{wt} \%)$ & 0.1470 & 0.1625 & 0.1600 & -0.0130 & 0.0025 & $-8.1 \%$ & $1.6 \%$ \\
\hline Pu35-54 & $\mathrm{PbO}(\mathrm{wt} \%)$ & 0.0339 & 0.0339 & 0.0000 & 0.0339 & 0.0339 & & \\
\hline \begin{tabular}{|l|}
$\mathrm{Pu} 35-54$ \\
\end{tabular} & $\mathrm{SeO}_{2}($ wt $\%)$ & 0.0070 & 0.0070 & 0.0000 & 0.0070 & 0.0070 & & \\
\hline Pu35-54 & $\mathrm{Si}_{2} \mathrm{O}_{3}(\mathrm{wt} \%)$ & 18.1947 & 17.9212 & 17.2000 & 0.9947 & 0.7212 & $5.8 \%$ & $4.2 \%$ \\
\hline Pu35-54 & $\mathrm{SO}_{4}(\mathrm{wt} \%)$ & 0.0749 & 0.0749 & 0.0000 & 0.0749 & 0.0749 & & \\
\hline Pu35-54 & $\mathrm{SrO}(\mathrm{wt} \%)$ & 2.3652 & 2.3652 & 2.1500 & 0.2152 & 0.2152 & $10.0 \%$ & $10.0 \%$ \\
\hline $\mathrm{Pu} 35-54$ & $\mathrm{Ta}_{2} \mathrm{O}_{5}(\mathrm{wt} \%)$ & 0.4512 & 0.4512 & 0.4600 & -0.0088 & -0.0088 & $-1.9 \%$ & $-1.9 \%$ \\
\hline Pu35-54 & Sum (wt \%) & 100.9828 & 100.3762 & 100.0000 & 0.9828 & 0.3762 & $1.0 \%$ & $0.4 \%$ \\
\hline Pu35-55 & $\mathrm{Al}_{2} \mathrm{O}_{3}(\mathrm{wt} \%)$ & 9.3530 & 9.1675 & 8.6000 & 0.7530 & 0.5675 & $8.8 \%$ & $6.6 \%$ \\
\hline Pu35-55 & $\mathrm{B}_{2} \mathrm{O}_{3}(\mathrm{wt} \%)$ & 11.8331 & 11.7454 & 11.1800 & 0.6531 & 0.5654 & $5.8 \%$ & $5.1 \%$ \\
\hline Pu35-55 & $\mathrm{CaO}$ (wt \%) & 0.3295 & 0.3345 & 0.2400 & 0.0895 & 0.0945 & $37.3 \%$ & $39.4 \%$ \\
\hline $\mathrm{Pu} 35-55$ & $\mathrm{Cl}(\mathrm{wt} \%)$ & 0.0665 & 0.0665 & 0.6300 & -0.5635 & -0.5635 & $-89.4 \%$ & $-89.4 \%$ \\
\hline $\mathrm{Pu} 35-55$ & $\mathrm{Cr}_{2} \mathrm{O}_{3}(\mathrm{wt} \%)$ & 0.2229 & 0.2147 & 0.2300 & -0.0071 & -0.0153 & $-3.1 \%$ & $-6.7 \%$ \\
\hline Pu35-55 & $\mathrm{CuO}($ wt $\%)$ & 0.1383 & 0.1471 & 0.1200 & 0.0183 & 0.0271 & $15.3 \%$ & $22.6 \%$ \\
\hline $\mathrm{Pu} 35-55$ & $\mathrm{~F}(\mathrm{wt} \%)$ & 0.0470 & 0.0576 & 0.1900 & -0.1430 & -0.1324 & $-75.3 \%$ & $-69.7 \%$ \\
\hline Pu35-55 & $\mathrm{Fe}_{2} \mathrm{O}_{3}(\mathrm{wt} \%)$ & 0.3753 & 0.3781 & 0.3600 & 0.0153 & 0.0181 & $4.2 \%$ & $5.0 \%$ \\
\hline Pu35-55 & $\mathrm{Ga}_{2} \mathrm{O}_{3}(\mathrm{wt} \%)$ & 0.3589 & 0.3589 & 0.3200 & 0.0389 & 0.0389 & $12.2 \%$ & $12.2 \%$ \\
\hline \begin{tabular}{|l|}
$\mathrm{Pu} 35-55$ \\
\end{tabular} & $\mathrm{Gd}_{2} \mathrm{O}_{3}(\mathrm{wt} \%)$ & 12.0447 & 12.0447 & 11.6100 & 0.4347 & 0.4347 & $3.7 \%$ & $3.7 \%$ \\
\hline \begin{tabular}{|l|}
$\mathrm{Pu} 35-55$ \\
\end{tabular} & $\mathrm{HfO}_{2}(\mathrm{wt} \%)$ & 13.3261 & 13.3261 & 14.8800 & -1.5539 & -1.5539 & $-10.4 \%$ & $-10.4 \%$ \\
\hline Pu35-55 & $\mathrm{K}_{2} \mathrm{O}(\mathrm{wt} \%)$ & 0.4053 & 0.3517 & 0.4600 & -0.0547 & -0.1083 & $-11.9 \%$ & $-23.5 \%$ \\
\hline Pu35-55 & $\mathrm{La}_{2} \mathrm{O}_{3}(\mathrm{wt} \%)$ & 17.0056 & 17.0056 & 16.3400 & 0.6656 & 0.6656 & $4.1 \%$ & $4.1 \%$ \\
\hline Pu35-55 & $\mathrm{MgO}(\mathrm{wt} \%)$ & 0.8383 & 0.8412 & 0.8400 & -0.0017 & 0.0012 & $-0.2 \%$ & $0.1 \%$ \\
\hline Pu35-55 & $\mathrm{Na}_{2} \mathrm{O}($ wt $\%)$ & 0.7461 & 0.7032 & 0.7200 & 0.0261 & -0.0168 & $3.6 \%$ & $-2.3 \%$ \\
\hline Pu35-55 & $\mathrm{Nd}_{2} \mathrm{O}_{3}(\mathrm{wt} \%)$ & 13.4719 & 13.4719 & 12.9000 & 0.5719 & 0.5719 & $4.4 \%$ & $4.4 \%$ \\
\hline Pu35-55 & $\mathrm{NiO}(\mathrm{wt} \%)$ & 0.1794 & 0.1984 & 0.1900 & -0.0106 & 0.0084 & $-5.6 \%$ & $4.4 \%$ \\
\hline Pu35-55 & $\mathrm{PbO}($ wt $\%)$ & 0.0835 & 0.0835 & 0.0600 & 0.0235 & 0.0235 & $39.1 \%$ & $39.1 \%$ \\
\hline Pu35-55 & $\mathrm{SeO}_{2}(\mathrm{wt} \%)$ & 0.0070 & 0.0070 & 0.0800 & -0.0730 & -0.0730 & $-91.2 \%$ & $-91.2 \%$ \\
\hline \begin{tabular}{|l|}
$\mathrm{Pu} 35-55$ \\
\end{tabular} & $\mathrm{Si}_{2} \mathrm{O}_{3}(\mathrm{wt} \%)$ & 18.4301 & 18.1529 & 17.2000 & 1.2301 & 0.9529 & $7.2 \%$ & $5.5 \%$ \\
\hline Pu35-55 & $\mathrm{SO}_{4}(\mathrm{wt} \%)$ & 0.0749 & 0.0749 & 0.1700 & -0.0951 & -0.0951 & $-55.9 \%$ & $-55.9 \%$ \\
\hline Pu35-55 & $\mathrm{SrO}(\mathrm{wt} \%)$ & 2.3889 & 2.3889 & 2.1500 & 0.2389 & 0.2389 & $11.1 \%$ & $11.1 \%$ \\
\hline Pu35-55 & $\mathrm{Ta}_{2} \mathrm{O}_{5}($ wt $\%)$ & 0.3889 & 0.3889 & 0.3900 & -0.0011 & -0.0011 & $-0.3 \%$ & $-0.3 \%$ \\
\hline $\mathrm{Pu} 35-55$ & Sum (wt \%) & 102.1152 & 101.5092 & 99.8600 & 2.2552 & 1.6492 & $2.3 \%$ & $1.7 \%$ \\
\hline
\end{tabular}




\section{Exhibit D1. Oxide Measurements in Analytical Sequence for Samples Prepared Using the LM Method}
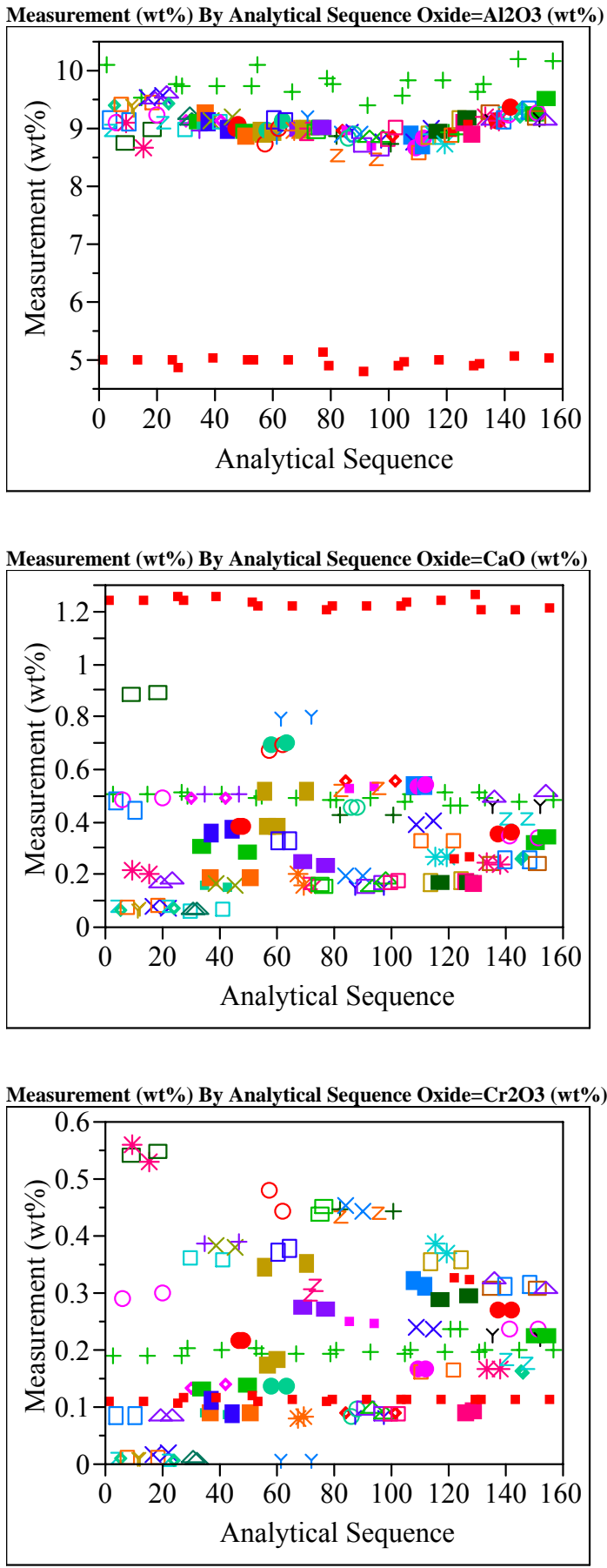
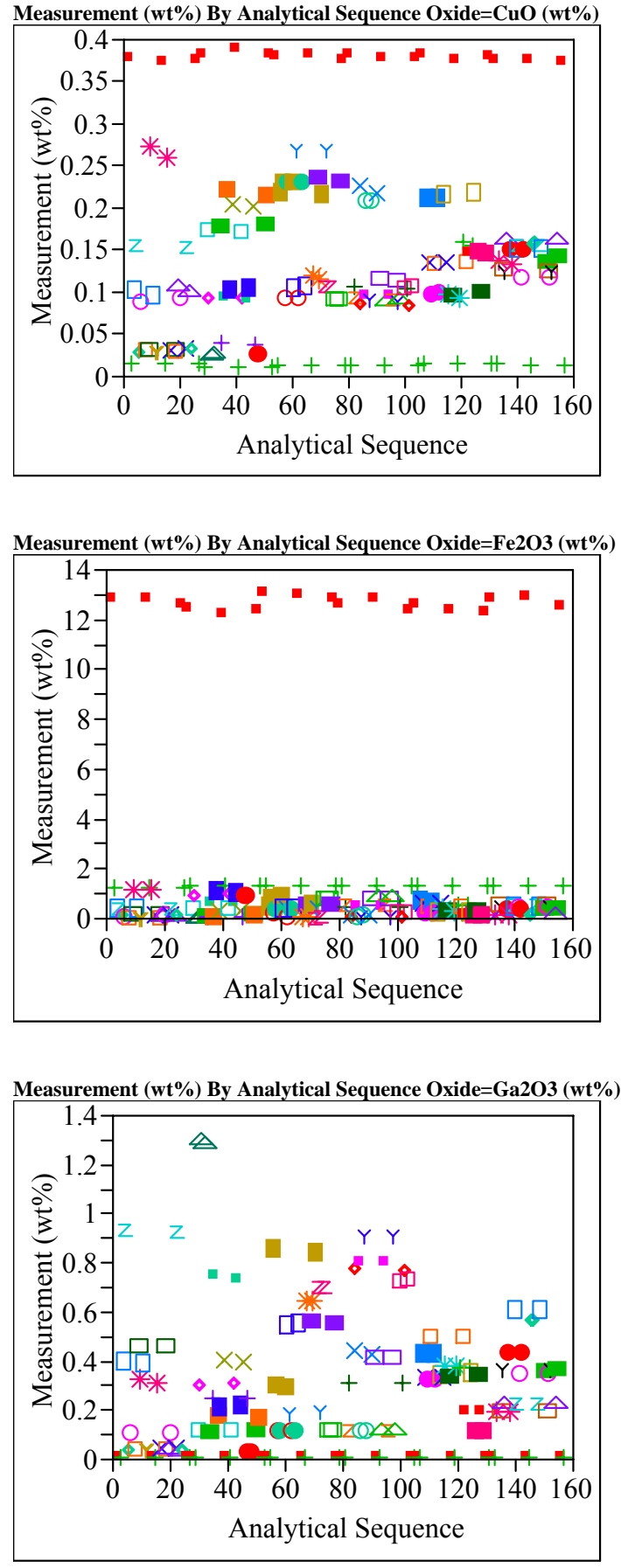


\section{Exhibit D1. Oxide Measurements in Analytical Sequence for Samples Prepared Using the LM Method (continued)}
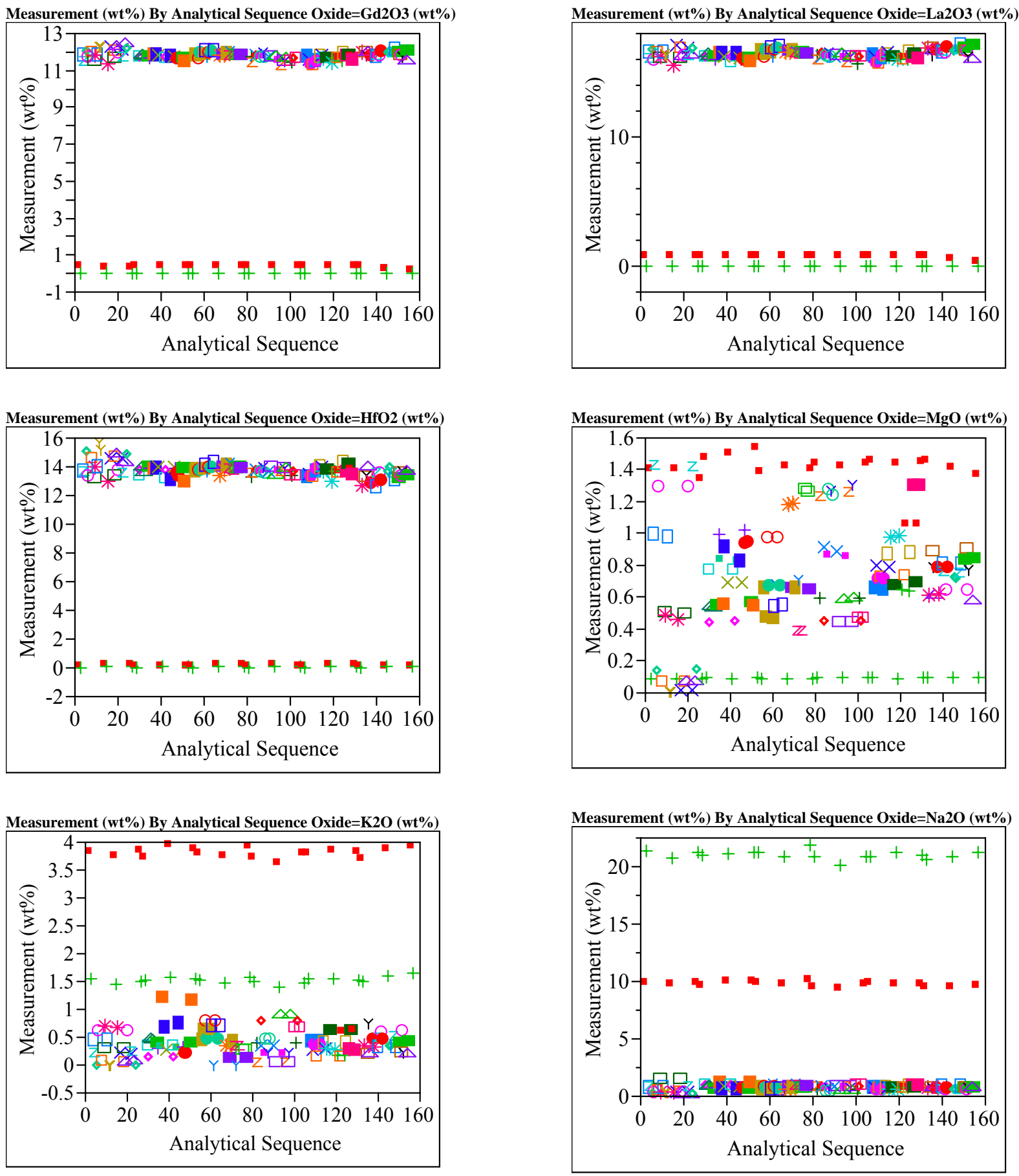


\section{Exhibit D1. Oxide Measurements in Analytical Sequence for Samples Prepared Using the LM Method (continued)}
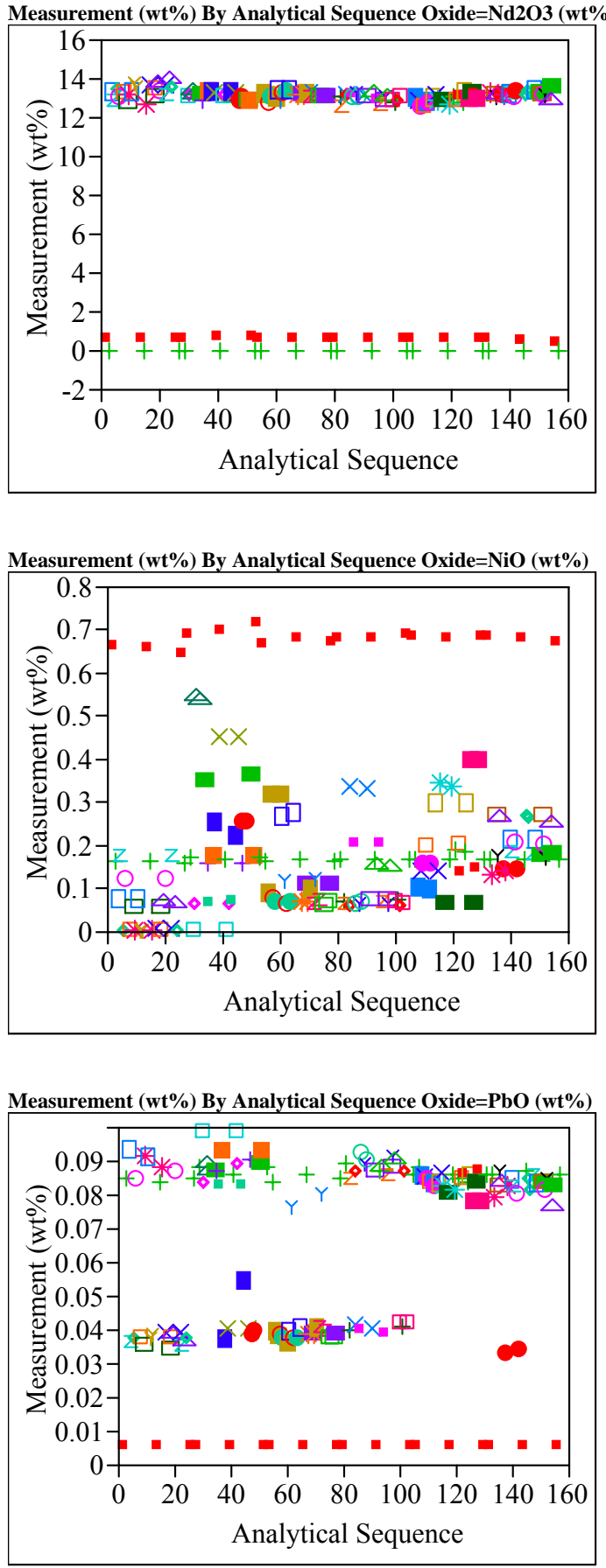
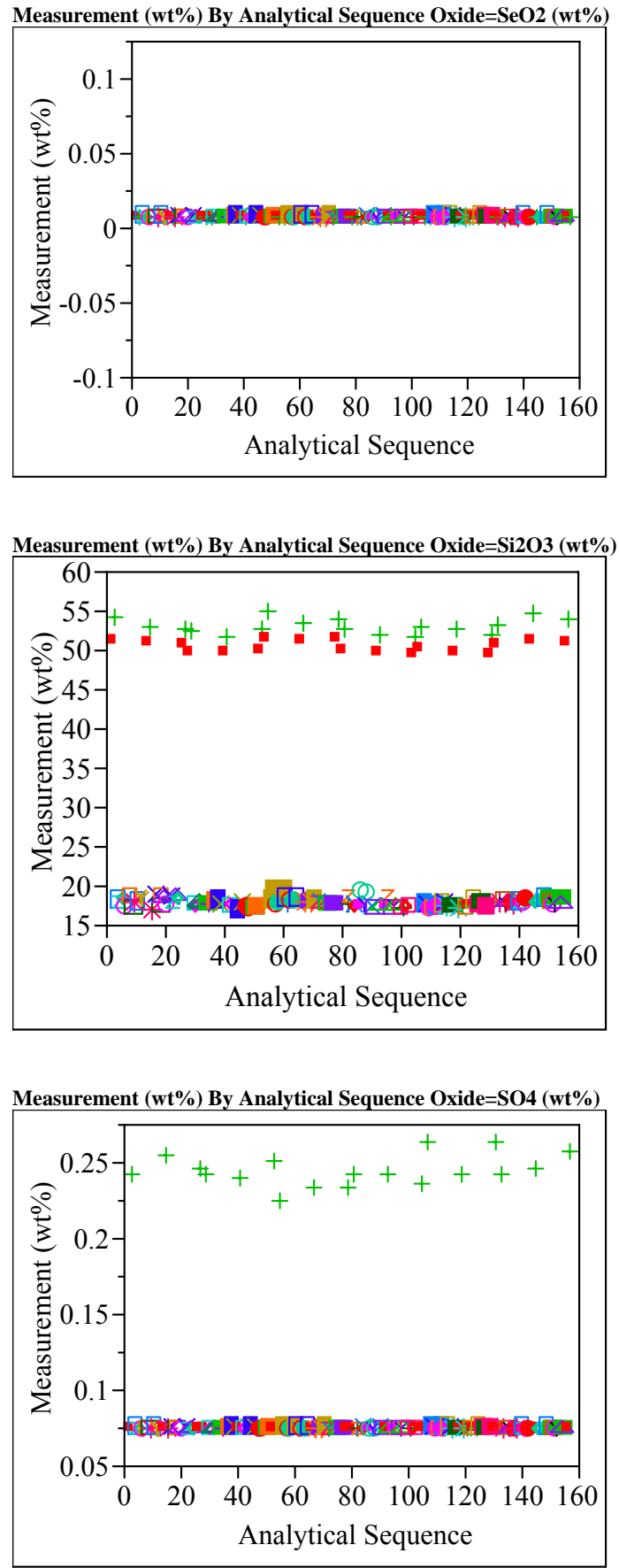
WSRC-STI-2007-00477

Revision 0

Appendix D

Exhibit D1. Oxide Measurements in Analytical Sequence for Samples Prepared Using the LM Method (continued)
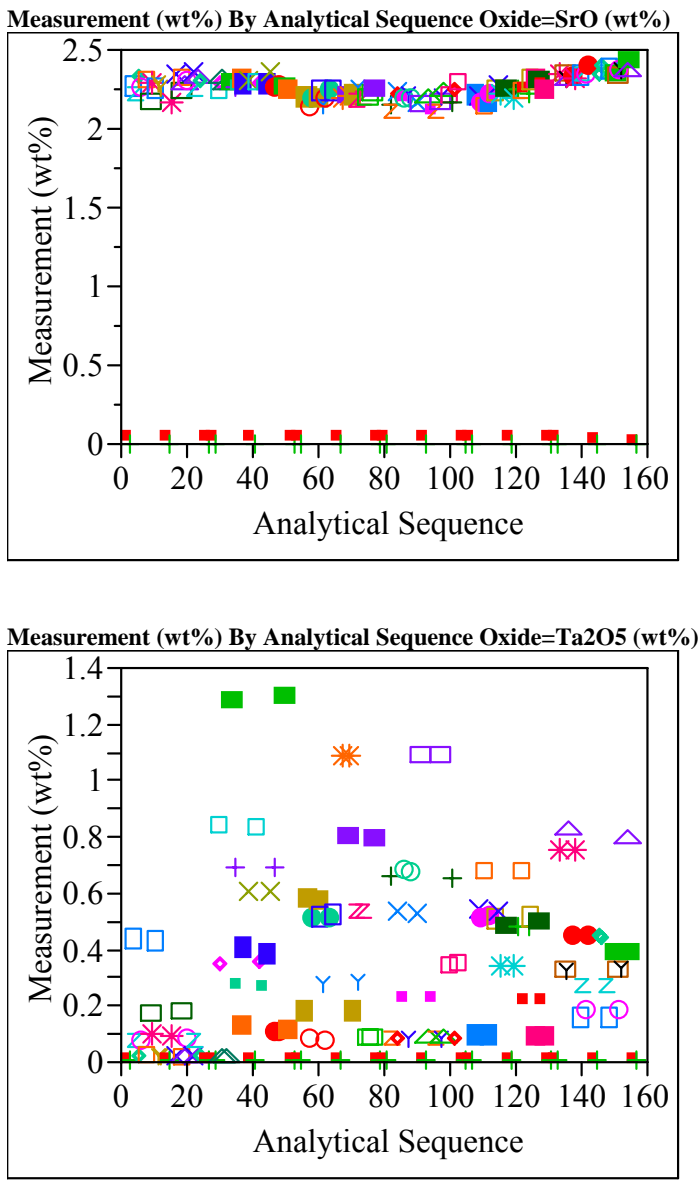
Exhibit D2. Measurements in Analytical Sequence for Samples Prepared Using the PF Method and for Samples Prepared for Measurements by IC

\section{PF Preparation}

B2O3 (wt \%) By Analytical Sequence

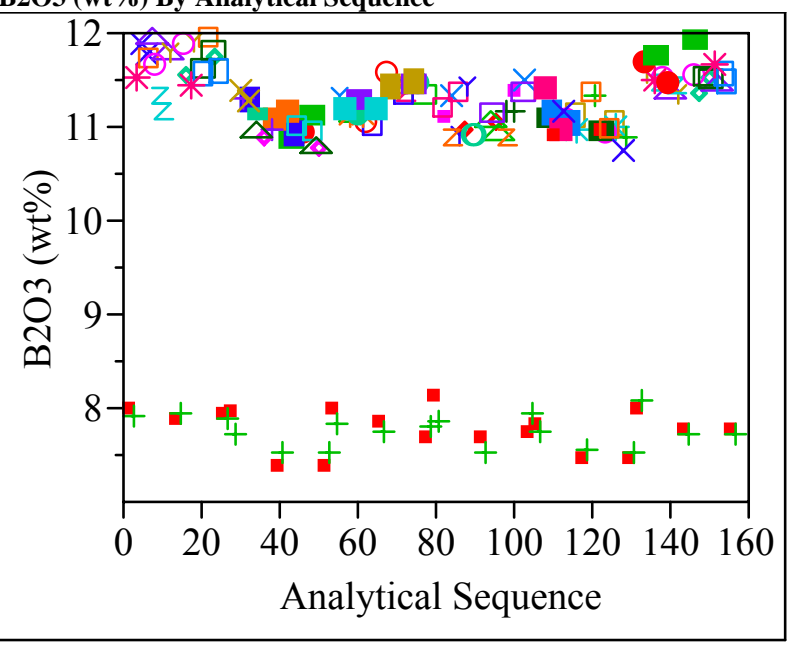

\section{Measurements by IC}

$\mathrm{Cl}(\mathrm{wt} \%)$ By Analytical Sequence

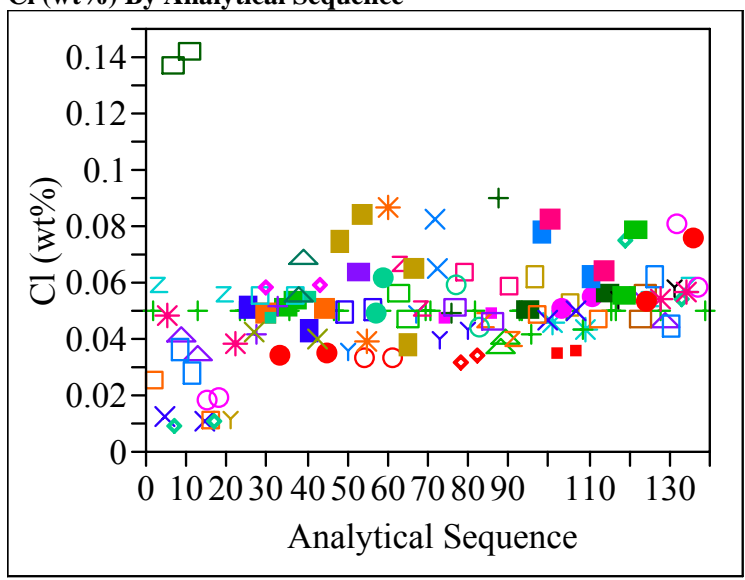

F (wt \%) By Analytical Sequence

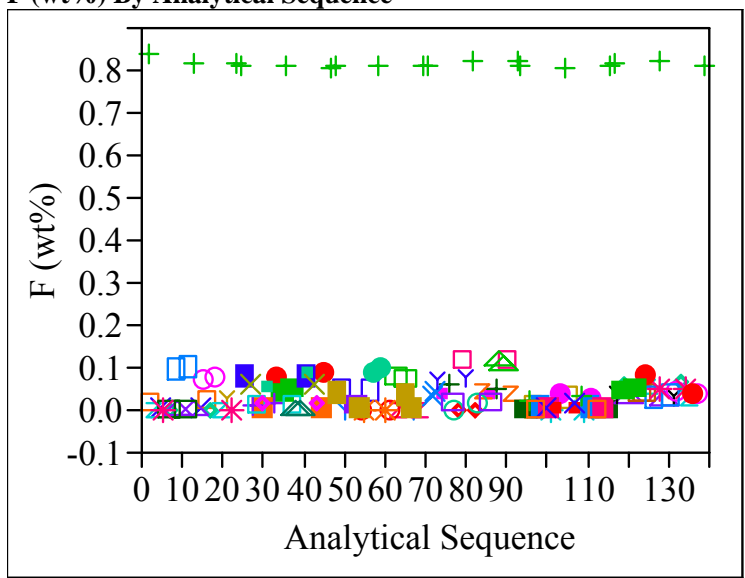




\section{Exhibit D3. PSAL Measurements by Analytical Block for Samples of the} Standard Glasses Prepared Using the LM Method

Oneway Analysis of Measurement (wt \%) By Block Glass ID=Batch 1, Oxide $=\mathrm{Al} 2 \mathrm{O} 3(\mathrm{wt} \%)$

Reference Value $=4.877 \mathrm{wt} \%$

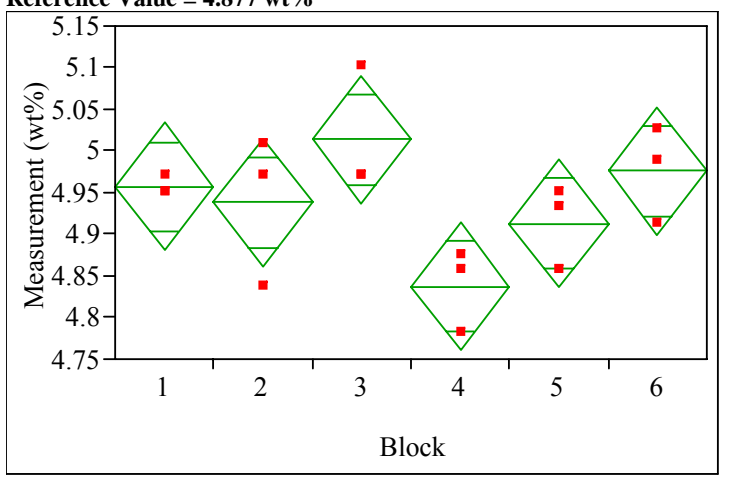

\section{Oneway Anova}

Summary of Fit

$\begin{array}{lr}\text { Rsquare } & 0.552006 \\ \text { Adj Rsquare } & 0.365342 \\ \text { Root Mean Square Error } & 0.060902 \\ \text { Mean of Response } & 4.938943 \\ \text { Observations (or Sum Wgts) } & 18\end{array}$

Observations (or Sum Wgts)

18

Analysis of Variance

Source DF Sum of Squares Mean Square F Ratio Prob $>$ F

$\begin{array}{llllll}\text { Block } & 5 & 0.05484240 & 0.010968 & 2.9572 & 0.0575\end{array}$

$\begin{array}{lll}\text { Error } \quad 12 & 0.04450862\end{array}$

0.003709

Means for Oneway Anova

Level Number Mean Std Error Lower 95\% Upper 95\%

\begin{tabular}{rrrrrr}
1 & 3 & 4.95679 & 0.03516 & 4.8802 & 5.0334 \\
\hline
\end{tabular}

$\begin{array}{lllll}3 & 4.93789 & 0.03516 & 4.8802 & 5.0334 \\ & & 4.8613 & 5.0145\end{array}$

$\begin{array}{lllll}3 & 5.01347 & 0.03516 & 4.9369 & 5.0901\end{array}$

$\begin{array}{lllll}3 & 4.83712 & 0.03516 & 4.7605 & 4.9137\end{array}$

$\begin{array}{lllll}3 & 4.91270 & 0.03516 & 4.8361 & 4.9893\end{array}$

Std Error uses a pooled estimate of error variance
Oneway Analysis of Measurement (wt\%) By Block Glass ID $=$ Batch 1, Oxide $=\mathrm{CaO}(w t \%)$

Reference Value $=1.200 \mathrm{wt} \%$

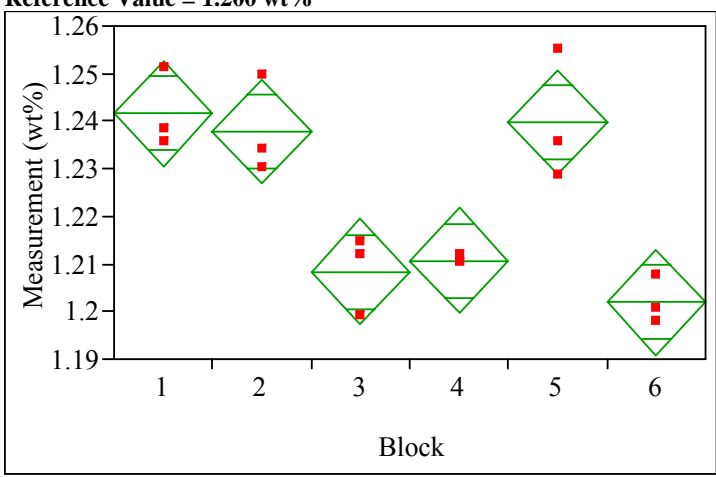

\section{Oneway Anova}

Summary of Fit

\section{Adj Rsquare \\ Root Mean Squa \\ 0.844029 \\ 0.77904 \\ Mean of Respons \\ 1.223367}

Observations (or Sum Wgts)

Analysis of Variance

Source DF Sum of Squares Mean Square F Ratio Prob $>$ F

$\begin{array}{lllllll}\text { Block } & 5 & 0.00494400 & 0.000989 & 12.9874 & 0.0002\end{array}$

$\begin{array}{llll}\text { Error } & 12 & 0.00091362 & 0.000076\end{array}$

C. Total $17 \quad 0.00585762$

Means for Oneway Anova

Level Number Mean Std Error Lower 95\% Upper 95\%

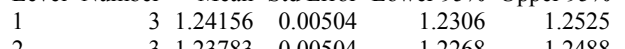

$\begin{array}{llllll}2 & 3 & 1.23783 & 0.00504 & 1.2268 & 1.2488 \\ 3 & 3 & 1.20844 & 0.00504 & 1.1975 & 1.2194\end{array}$

$\begin{array}{llll}3 & 1.20844 & 0.00504 \\ 3 & 1.21077 & 0.00504\end{array}$

$\begin{array}{lll}3 & 1.23969 & 0.00504\end{array}$

$\begin{array}{lll}3 & 1.20191 \quad 0.00504\end{array}$

$\begin{array}{ll}1.1998 & 1.2218 \\ 1.2287 & 1.2507\end{array}$

$\begin{array}{ll}1.2287 & 1.2507 \\ 1.1909 & 1.2129\end{array}$

Std Error uses a pooled estimate of error variance
Oneway Analysis of Measurement (wt\%) By Block Glass ID=Batch 1, Oxide $=$ Cr2O3 $(w t \%)$

Reference Value $=0.107 \mathrm{wt} \%$

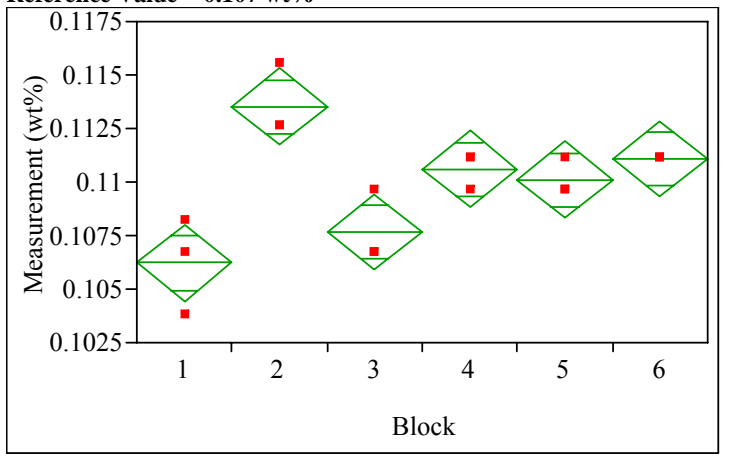

Oneway Anova

Summary of Fit

Adj R 0.806268

Root Mean Square Eror $\quad 0.725546$

Root Mean Square Ero

Observations (or Sum Wga) 0.109864

Analysis of Variance

Source DF Sum of Squares Mean Square F Ratio Prob $>$ F $\begin{array}{llrrrr}\text { Block } & 5 & 0.00010076 & 0.000020 & 9.9882 & 0.0006\end{array}$ $\begin{array}{lrll}\text { Error } & 12 & 0.00002421 & 2.018 \mathrm{e}-6\end{array}$

$\begin{array}{lll}\text { C. Total } & 17 & 0.00012497\end{array}$

Means for Oneway Anova

Level Number Mean Std Error Lower 95\% Upper 95\% $\begin{array}{llllll}1 & 3 & 0.106210 & 0.00082 & 0.10442 & 0.10800\end{array}$ $\begin{array}{llllll}2 & 3 & 0.113518 & 0.00082 & 0.11173 & 0.11530 \\ 3 & 3 & 0.107671 & 0.00082 & 0.10588 & 0.10946\end{array}$ $\begin{array}{llllll}4 & 3 & 0.110594 & 0.00082 & 0.10881 & 0.11238\end{array}$

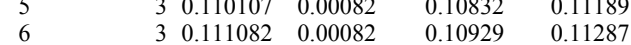

Std Error uses a pooled estimate of error variance 


\section{Exhibit D3. PSAL Measurements by Analytical Block for Samples of the}

Standard Glasses Prepared Using the LM Method (continued)

Oneway Analysis of Measurement (wt \%) By Block Glass ID=Batch 1, Oxide $=\mathrm{CuO}(\mathrm{wt} \%)$

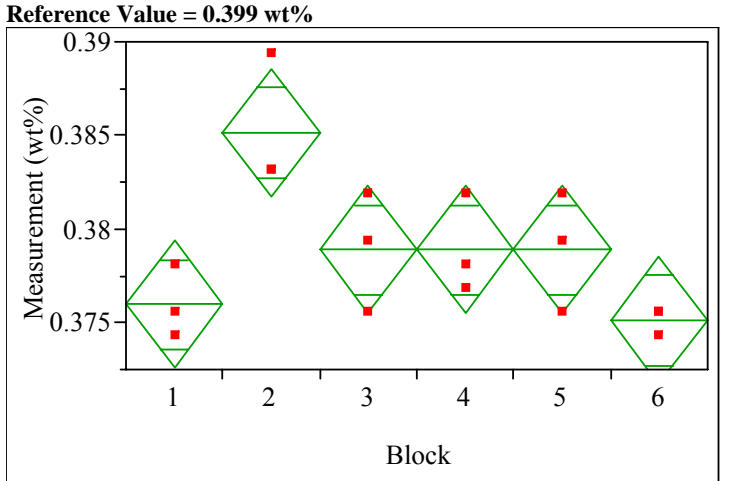

Oneway Anova
Summary of Fit

$\begin{array}{lr}\text { Rsquare } & 0.678674 \\ \text { Adj Rsquare } & 0.544788 \\ \text { Root Mean Square Error } & 0.002704 \\ \text { Mean of Response } & 0.378809 \\ \text { Observations (or Sum Wgts) } & 18\end{array}$

\section{Analysis of Variance}

Source DF Sum of Squares Mean Square F Ratio Prob $>$ F $\begin{array}{llllll}\text { Block } & 5 & 0.00018534 & 0.000037 & 5.0690 & 0.0100\end{array}$ Error $\quad 12 \quad 0.00008775 \quad 7.313 \mathrm{e}-6$

C. Total $17 \quad 0.00027309$

\section{Means for Oneway Anova}

Level Number Mean Std Error Lower 95\% Upper 95\%

\begin{tabular}{|c|c|c|c|c|}
\hline & $\begin{array}{ll}3 & 0.375957\end{array}$ & 0.00156 & 0.37256 & 0.37936 \\
\hline 2 & 30.385137 & 0.00156 & 0.38174 & 0.38854 \\
\hline 3 & 30.378878 & 0.00156 & 0.37548 & 0.38228 \\
\hline & 30.378878 & 0.00156 & 0.37548 & 0.38228 \\
\hline 5 & 30.378878 & 0.00156 & 0.37548 & 0.38228 \\
\hline & $\begin{array}{ll}30.375123 \\
\end{array}$ & 0.00156 & 0.37172 & 0.378 \\
\hline
\end{tabular}

Std Error uses a pooled estimate of error variance
Oneway Analysis of Measurement (wt\%) By Block Glass ID=Batch 1, Oxide=Fe2O3 (wt\%)

Reference Value $=12.839 \mathrm{wt} \%$

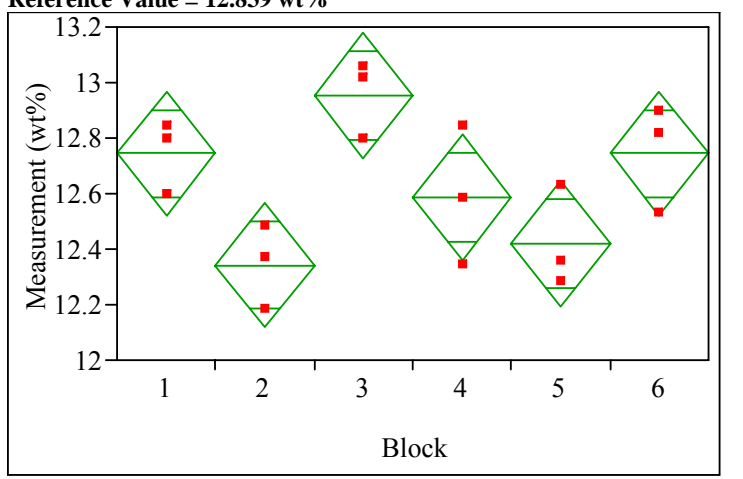

\section{Oneway Anova}

Summary of Fit

Rsquare

Adj Rsquare

Root Mean Square

Mean of Response

0.668927

0.530981
0.178919

0.178919
12.6314

Observations (or Sum Wgts)

Analysis of Variance

Source DF Sum of Squares Mean Square F Ratio Prob $>$ F $\begin{array}{llllll}\text { Block } & 5 & 0.7761568 & 0.155231 & 4.8492 & 0.0117\end{array}$

$\begin{array}{lll}\text { Error } & 12 & 0.3841436\end{array}$

0.032012

Means for Oneway Anova

Means for Oneway Anova
Level Number Mean Std Error Lower 95\% Upper 95\%

Level Number Mean Std Error Lower 95\% Upper 95\%

$\begin{array}{llllll}1 & 3 & 12.7434 & 0.10330 & 12.518 & 12.968 \\ 2 & 3 & 12.3431 & 0.10330 & 12.118 & 12.568 \\ 3 & 3 & 12.9531 & 0.10330 & 12.728 & 13.178\end{array}$

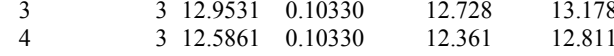

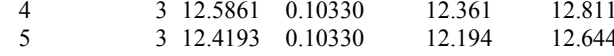

$\begin{array}{llllll}5 & 3 & 12.4193 & 0.10330 & 12.194 & 12.644 \\ 6 & 3 & 12.7434 & 0.10330 & 12.518 & 12.968\end{array}$

Std Error uses a pooled estimate of error variance
Oneway Analysis of Measurement (wt\%) By Block Glass ID=Batch 1, Oxide=Ga2O3 (wt \%)

Reference Value $=0.0 \mathrm{wt} \%$

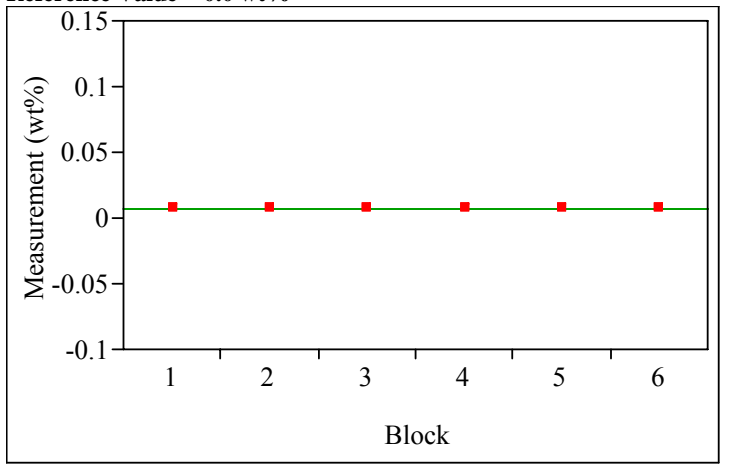

Oneway Anova

Summary of Fit

Rsquare

Adj Rsquare

$\begin{array}{lr}\text { Root Mean Square Error } & 0 \\ \text { Mean of Response } & 0.006721\end{array}$

Observations (or Sum Wgts) $\quad 18$

Analysis of Variance

Source DF Sum of Squares Mean Square F Ratio Prob $>$ F $\begin{array}{lrll}\text { Block } & 5 & 0 & 0 \\ \text { Error } & 12 & 0 & 0\end{array}$

C. Total 17

Means for Oneway Anova

Level Number Mean Std Error Lower 95\% Upper 95\% $\begin{array}{llllll}1 & 3 & 0.006721 & 0 & 0.00672 & 0.00672\end{array}$ $\begin{array}{llllll}2 & 3 & 0.006721 & 0 & 0.00672 & 0.00672\end{array}$ $\begin{array}{llllll}3 & 3 & 0.006721 & 0 & 0.00672 & 0.00672 \\ 4 & 3 & 0.006721 & 0 & 0.00672 & 0.00672\end{array}$ $\begin{array}{llllll}5 & 3 & 0.006721 & 0 & 0.00672 & 0.00672 \\ 6 & 3 & 0.006721 & 0 & 0.00672 & 0.00672\end{array}$

Std Error uses a pooled estimate of error variance 


\section{Exhibit D3. PSAL Measurements by Analytical Block for Samples of the}

Standard Glasses Prepared Using the LM Method (continued)

Oneway Analysis of Measurement (wt \%) By Block Glass ID=Batch 1, Oxide $=$ Gd2O3 (wt $\%)$

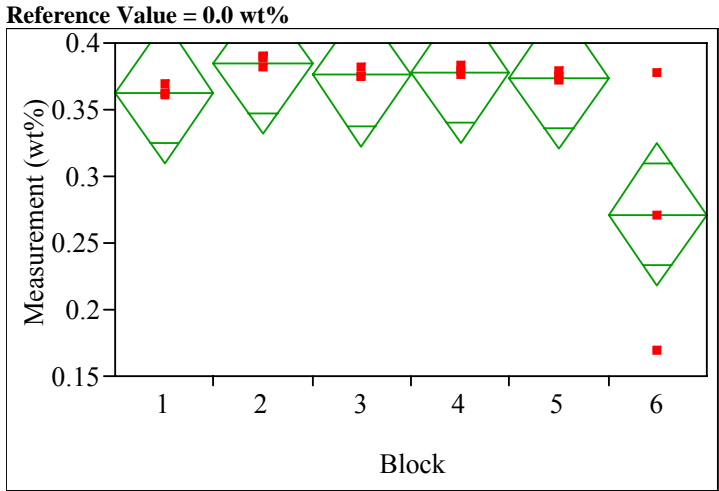

\section{Oneway Anova}

Summary of Fit

$\begin{array}{lr}\text { Rsquare } & 0.562079 \\ \text { Adj Rsquare } & 0.379612 \\ \text { Root Mean Square Error } & 0.042507 \\ \text { Mean of Response } & 0.357882 \\ \text { Observations (or Sum Wgts) } & 18\end{array}$

Observations (or Sum Wgts)

Analysis of Variance

Source DF Sum of Squares Mean Square F Ratio Prob $>$ F

$\begin{array}{llllll}\text { Block } & 5 & 0.02782892 & 0.005566 & 3.0804 & 0.0512\end{array}$

$\begin{array}{llll}\text { Error } \quad 12 & 0.02168179 & 0.001807\end{array}$

C. Total $17 \quad 0.04951071$

Means for Oneway Anova

Level Number Mean Std Error Lower 95\% Upper 95\%

$\begin{array}{llllll}1 & 3 & 0.362685 & 0.02454 & 0.30921 & 0.41616\end{array}$

$\begin{array}{llllll}2 & 3 & 0.385353 & 0.02454 & 0.33188 & 0.43882\end{array}$

$\begin{array}{llllll}3 & 3 & 0.375748 & 0.02454 & 0.32228 & 0.42922 \\ 4 & 3 & 0.378053 & 0.02254 & 0.32458 & 0.43152\end{array}$

$\begin{array}{llllll}4 & 3 & 0.378053 & 0.02454 & 0.32458 & 0.43152 \\ 5 & 3 & 0.374211 & 0.02454 & 0.32074 & 0.42768\end{array}$

$\begin{array}{llllll}5 & 3 & 0.374211 & 0.02454 & 0.32074 & 0.42768 \\ 6 & 3 & 0.271245 & 0.02454 & 0.21777 & 0.32472\end{array}$

Std Error uses a pooled estimate of error variance
Oneway Analysis of Measurement (wt \%) By Block Glass ID=Batch 1, Oxide=HfO2 (wt\%)

Reference Value $=0.0 \mathrm{wt} \%$

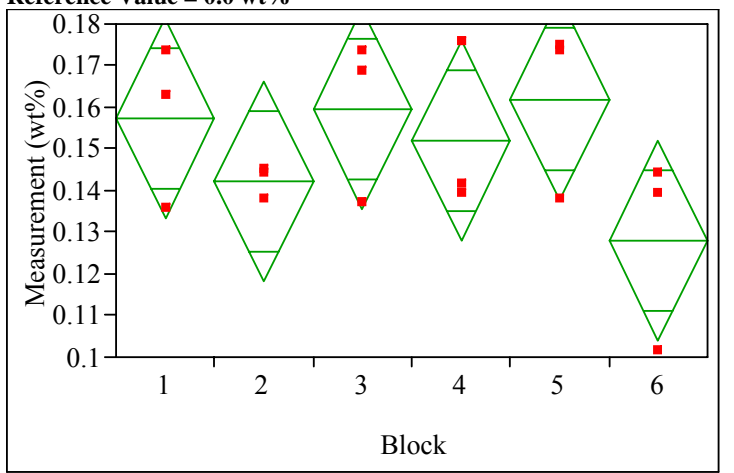

\section{Oneway Anova}

Summary of Fit

Rsquare

$\begin{array}{ll}\text { Adj Rsquare } & 0.097629 \\ \text { Rot } & 0.019062\end{array}$

\subsection{2}

Root Mean Square Error $\quad 0.019062$

Observations (or Sum Wgts)

18

Analysis of Variance

Source DF Sum of Squares Mean Square F Ratio Prob $>$ F $\begin{array}{lrrrrr}\text { Block } & 5 & 0.00248519 & 0.000497 & 1.3679 & 0.3029\end{array}$

$\begin{array}{lll}\text { Error } \quad 12 & 0.00436046\end{array}$

0.000363

C. Total $17 \quad 0.00684565$

Means for Oneway Anova

Level Number Mean Std Error Lower 95\% Upper 95\%

$\begin{array}{llllll}1 & 3 & 0.157240 & 0.01101 & 0.13326 & 0.18122\end{array}$

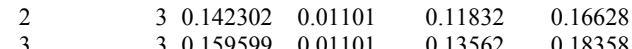

$\begin{array}{llllll}3 & 3 & 0.15959 & 0.01101 & 0.13562 & 0.18358 \\ 4 & 3 & 0.152130 & 0.01101 & 0.12815 & 0.17611\end{array}$

$\begin{array}{llllll}3 & 3 & 0.15959 & 0.01101 & 0.13562 & 0.18358 \\ 5 & 3 & 0.152130 & 0.01101 & 0.12815 & 0.17611 \\ 6 & 3 & 0.121957 & 0.01101 & 0.13798 & 0.18594\end{array}$

$\begin{array}{llllll}5 & 3 & 0.161957 & 0.01101 & 0.13798 & 0.18594 \\ 6 & 3 & 0.128151 & 0.01101 & 0.10417 & 0.15213\end{array}$

Std Error uses a pooled estimate of error variance
Oneway Analysis of Measurement (wt \%) By Block Glass ID=Batch 1, Oxide $=K 20(w t \%)$ Reference Value $=3.327 \mathrm{wt} \%$

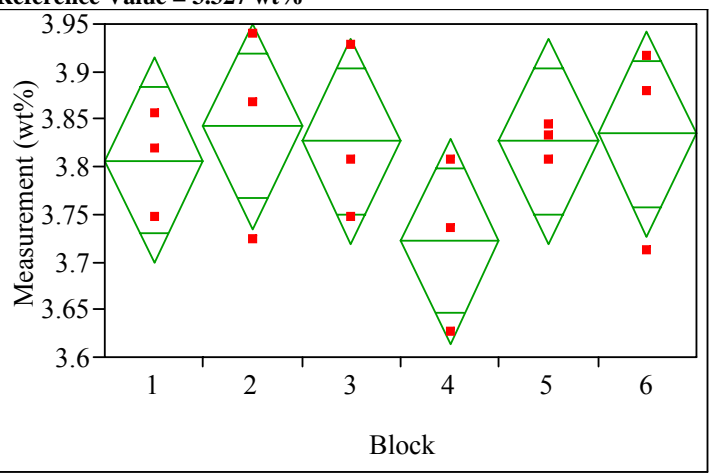

\section{Oneway Anova}

Summary of Fit

Rsquare

Root Mean Square Error $\quad \begin{array}{r}-0.05953 \\ 0.085885\end{array}$

Mean of Response $\quad 3.080988$

Observations (or Sum Wgts)

Analysis of Variance

Source DF Sum of Squares Mean Square F Ratio Prob $>$ F $\begin{array}{lrrrrr}\text { Block } & 5 & 0.02983543 & 0.005967 & 0.8090 & 0.5651\end{array}$

$\begin{array}{lrrr}\text { Elock } & 5 & 0.02983543 & 0.005967 \\ \text { Error } & 12 & 0.08851473 & 0.007376\end{array}$

C. Total $17 \quad 0.11835016$

\section{Means for Oneway Anova}

Level Number Mean Std Error Lower 95\% Upper 95\%

$\begin{array}{llllll}1 & 3 & 3.80654 & 0.04959 & 3.6985 & 3.9146 \\ 2 & 3 & 3.84267 & 0.04959 & 3.7346 & 3.9507\end{array}$

$\begin{array}{llllll}1 & 3 & 3.84267 & 0.04959 & 3.7346 & 3.9507 \\ 3 & 3 & 3.82661 & 0.04959 & 3.7186 & 3.9347\end{array}$

$\begin{array}{llllll}4 & 33.72221 & 0.04959 & 3.6142 & 3.8303\end{array}$

$\begin{array}{llllll}5 & 3 & 3.82661 & 0.04959 & 3.7186 & 3.9347 \\ 6 & 3 & 3.83464 & 0.04959 & 3.7266 & 3.9427\end{array}$

Std Error uses a pooled estimate of error variance 


\section{Exhibit D3. PSAL Measurements by Analytical Block for Samples of the}

Standard Glasses Prepared Using the LM Method (continued)

Oneway Analysis of Measurement (wt \%) By Block Glass ID=Batch 1, Oxide=La2O3 (wt \%)

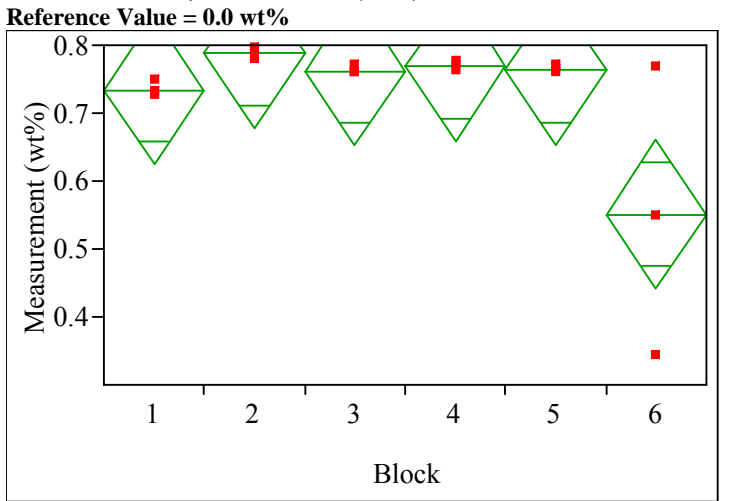

Oneway Anova

Summary of Fit

$\begin{array}{ll} & 0.562468 \\ \text { Adj Rsquare } & 0.380163\end{array}$

$\begin{array}{ll}\text { Adj Rsquare } & 0.380163 \\ \text { Root Mean Square Error } & 0.086994\end{array}$

Mean of Response

Observations (or Sum Wgts)

Analysis of Variance

Source DF Sum of Squares Mean Square F Ratio Prob $>$ F

$\begin{array}{lrrrrr}\text { Block } & 5 & 0.11674720 & 0.023349 & 3.0853 & 0.0510\end{array}$

$\begin{array}{lll}\text { Error } & 12 & 0.09081519 \\ \text { C. Total } & 17 & 0.20756239\end{array}$

\section{Means for Oneway Anova}

Level Number Mean Std Error Lower 95\% Upper 95\%

\begin{tabular}{|c|c|c|c|c|}
\hline 1 & $\begin{array}{ll}3 & 0.734564\end{array}$ & 0.05023 & 0.62513 & 0.84400 \\
\hline & $\begin{array}{ll}3 & 0.787731\end{array}$ & 0.05023 & 0.67830 & 0.89716 \\
\hline 3 & 30.762320 & 0.05023 & 0.65289 & 0.87175 \\
\hline 4 & 30.768184 & 0.05023 & 0.65875 & 0.87762 \\
\hline 5 & 30.763493 & 0.05023 & 0.65406 & 0.87293 \\
\hline
\end{tabular}

Std Error uses a pooled estimate of error variance
Oneway Analysis of Measurement (wt\%) By Block Glass ID=Batch 1, Oxide=MgO (wt \%)

Reference Value $=1.419 \mathrm{wt} \%$

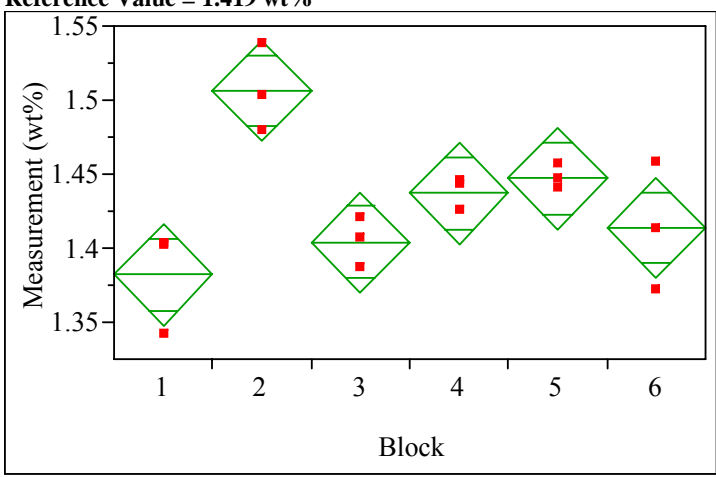

\section{Oneway Anova}

Summary of Fit

Rsquare

$\begin{array}{ll}\text { Adj Rsquare } & 0.662485 \\ \text { Root Mean Square Error } & 0.027097\end{array}$

Mean of Response $\quad 1.031758$

Analysis of Variance

Source DF Sum of Squares Mean Square F Ratio Prob $>$ F $\begin{array}{lrrrrr}\text { Block } & 5 & 0.02817134 & 0.005634 & 7.6736 & 0.0019\end{array}$ $\begin{array}{lrrr}\text { Block } & 5 & 0.02817134 & 0.005634 \\ \text { Error } & 12 & 0.00881087 & 0.000734\end{array}$

C. Total $17-0.03698221$$$
0.000734
$$

\section{Means for Oneway Anova}

Level Number Mean Std Error Lower 95\% Upper 95\%

$$
\begin{array}{lllll}
3 & 1.38192 & 0.01564 & 1.3478 & 1.4160 \\
3 & 1.50629 & 0.01564 & 1.4722 & 1.5404 \\
3 & 1.40403 & 0.01564 & 1.3699 & 1.4381 \\
3 & 1.43719 & 0.01564 & 1.4031 & 1.4713 \\
3 & 1.44714 & 0.01564 & 1.4131 & 1.4812 \\
3 & 1.41398 & 0.01564 & 1.3799 & 1.4481
\end{array}
$$$$
\begin{array}{llll}
3 & 1.41398 & 0.01564
\end{array}
$$

Std Error uses a pooled estimate of error variance
Oneway Analysis of Measurement (wt\%) By Block Glass ID=Batch 1, Oxide=Na2O (wt \%) Reference Value $=9.003 \mathrm{wt} \%$

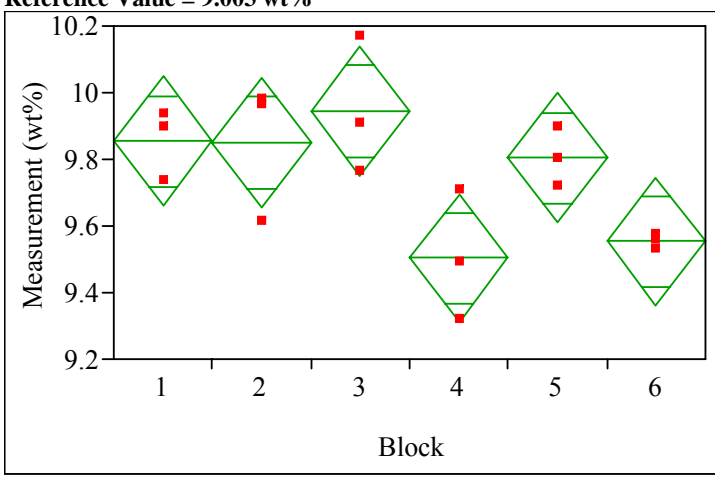

\section{Oneway Anova}

Summary of Fit

Rsquare

$\begin{array}{ll}\text { Adj Rsquare } & 0.474349 \\ \text { Rot } & 0.154024\end{array}$

0.628952

Root Mean Square Error $\quad 0.154024$

Observations (or Sum Wgts)

Analysis of Variance

Source DF Sum of Squares Mean Square F Ratio Prob > F $\begin{array}{lrrrrr}\text { Block } & 5 & 0.48255216 & 0.096510 & 4.0682 & 0.0216\end{array}$

$\begin{array}{llll}\text { Error } & 12 & 0.28467963 & 0.023723\end{array}$

C. Total $17 \quad 0.76723178$

\section{Means for Oneway Anova}

Level Number Mean Std Error Lower 95\% Upper 95\%

$\begin{array}{llllll}1 & 3 & 9.85388 & 0.08893 & 9.6601 & 10.048\end{array}$

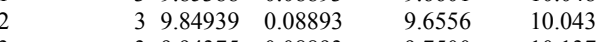

$\begin{array}{rrrrrr}3 & 3 & 9.94375 & 0.08893 & 9.7500 & 10.137 \\ 4 & 3 & 9.50340 & 0.08893 & 9.3096 & 9.697\end{array}$

$\begin{array}{llllll}4 & 3 & 9.50340 & 0.08893 & 9.3096 & 9.697 \\ 5 & 3 & 9.80445 & 0.08893 & 9.6107 & 9.998\end{array}$

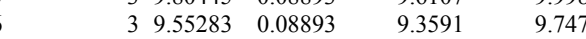

Std Error uses a pooled estimate of error variance 


\section{Exhibit D3. PSAL Measurements by Analytical Block for Samples of the}

Standard Glasses Prepared Using the LM Method (continued)

Oneway Analysis of Measurement (wt \%) By Block Glass ID=Batch 1, Oxide=Nd2O3 (wt \%)

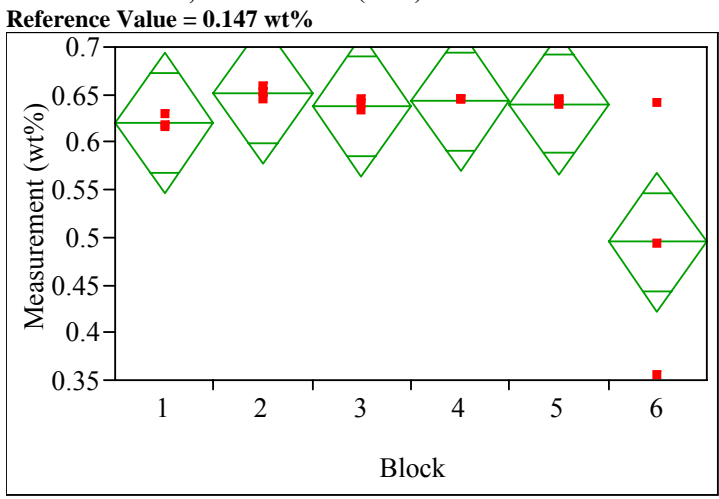

\section{Oneway Anova}

Summary of Fit

$\begin{array}{lr}\text { Rsquare } & 0.563089 \\ \text { Adj Rsquare } & 0.381043 \\ \text { Root Mean Square Error } & 0.058535 \\ \text { Mean of Response } & 0.614498 \\ \text { Observations (or Sum Wgts) } & 18\end{array}$

Analysis of Variance

Source DF Sum of Squares Mean Square F Ratio Prob $>$ F

$\begin{array}{llllll}\text { Block } & 5 & 0.05298991 & 0.010598 & 3.0931 & 0.0506\end{array}$

$\begin{array}{llll}\text { Error } & 12 & 0.04111579 & 0.003426\end{array}$

C. Total $17 \quad 0.09410570$

\section{Means for Oneway Anova}

Level Number Mean Std Error Lower 95\% Upper 95\%

$\begin{array}{lllllr}1 & 3 & 0.620136 & 0.03380 & 0.54650 & 0.69377\end{array}$

$\begin{array}{lllll}3 & 0.650851 & 0.03380 & 0.57722 & 0.69374\end{array}$

$\begin{array}{lllll}3 & 0.638021 & 0.03380 & 0.56439 & 0.71165\end{array}$

$\begin{array}{lllll}3 & 0.642686 & 0.03380 & 0.56905 & 0.71632\end{array}$

$\begin{array}{lllll}3 & 0.640354 & 0.03380 & 0.56672 & 0.71399\end{array}$

$\begin{array}{lllll}3 & 0.494942 & 0.03380 & 0.42131 & 0.56858\end{array}$

Std Error uses a pooled estimate of error variance
Oneway Analysis of Measurement (wt \%) By Block Glass ID=Batch 1, Oxide=NiO (wt \%)

Reference Value $=0.751 \mathrm{wt} \%$

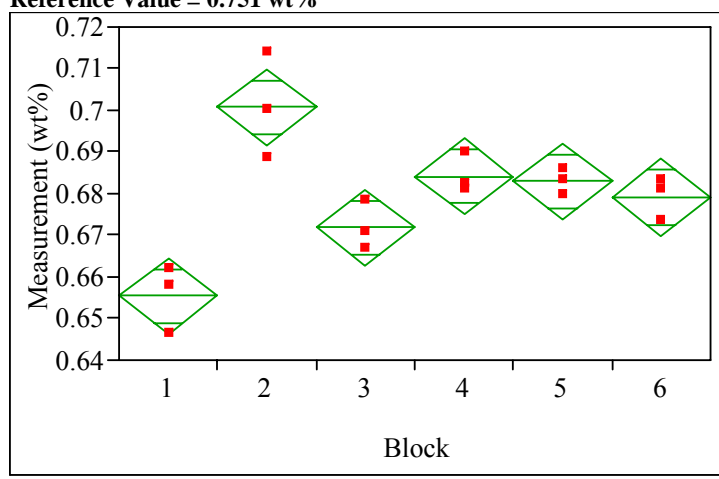

\section{Oneway Anova}

Summary of Fit

$\begin{array}{ll}\text { Rsquare } & 0.840072 \\ \text { Adj Rsquare } & 0.773435 \\ \text { Root Mean Square Error } & 0.007316\end{array}$

Root Mean Square Error $\quad 0.007316$

Observations (or Sum Wgts)

Analysis of Variance

Source DF Sum of Squares Mean Square F Ratio Prob $>$ F

$\begin{array}{lllllll}\text { Block } & 5 & 0.00337390 & 0.000675 & 12.6067 & 0.0002\end{array}$

$\begin{array}{lrrr}\text { Block } & 5 & 0.00337390 & 0.000675 \\ \text { Error } & 12 & 0.00064230 & 0.000054\end{array}$

C. Total $17 \quad 0.0040162$

\section{Means for Oneway Anova}

Level Number Mean Std Error Lower 95\% Upper 95\%

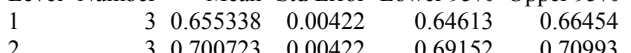

$\begin{array}{llllll}1 & 3 & 0.700723 & 0.00422 & 0.69152 & 0.70993 \\ 3 & 3 & 0.671880 & 0.00422 & 0.66268 & 0.68108\end{array}$

$\begin{array}{llllll}3 & 3 & 0.671880 & 0.00422 & 0.66268 & 0.68108 \\ 4 & 3 & 0.684181 & 0.00422 & 0.67498 & 0.69338\end{array}$

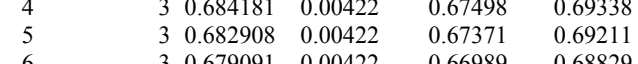

Std Error uses a pooled estimate of error variance
Oneway Analysis of Measurement (wt \%) By Block Glass ID=Batch 1, Oxide=PbO (wt \%)

Reference Value $=0.0 \mathrm{wt} \%$

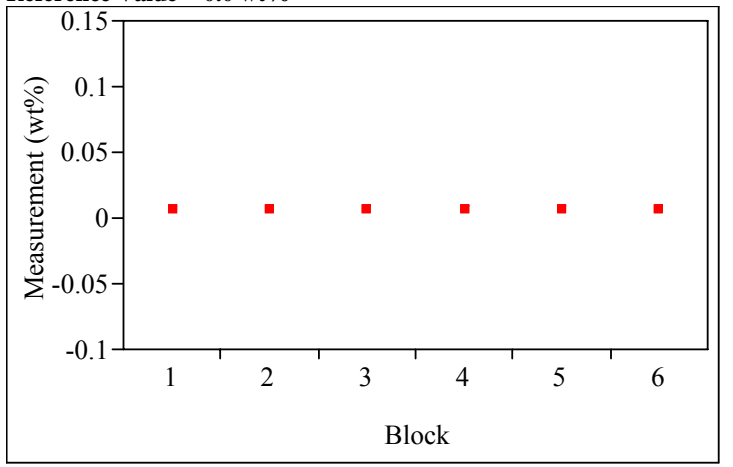

Oneway Anova

Summary of Fit

Rsquare

Adj Rsquare

Root Mean Square Error

$\begin{array}{lr}\text { Mean of Response } & 0.005386 \\ \text { Observations (or Sum Wgts) } & 18\end{array}$

\section{Analysis of Variance}

Source DF Sum of Squares Mean Square F Ratio Prob $>$ F $\begin{array}{llllll}\text { Block } & 5 & 1.3542 \mathrm{e}-35 & 2.708 \mathrm{e}-36 & -2.4000 & 0.0000\end{array}$ $\begin{array}{llll}\text { Error } & 12 & -1.354 \mathrm{e}-35 & -1.13 \mathrm{e}-36\end{array}$

Means for Oneway Anova

Level Number Mean Std Error Lower 95\% Upper 95\%

$\begin{array}{lll}1 & 3 & 0.005386 \\ 2 & 3 & 0.005386\end{array}$

$\begin{array}{lll}3 & 0.005386 \\ 3 & 0.00586\end{array}$

$\begin{array}{ll}3 & 0.005386 \\ 3 & 0.005386\end{array}$

30.005386

30.005386

Std Error uses a pooled estimate of error variance 
Exhibit D3. PSAL Measurements by Analytical Block for Samples of the Standard Glasses Prepared Using the LM Method (continued)

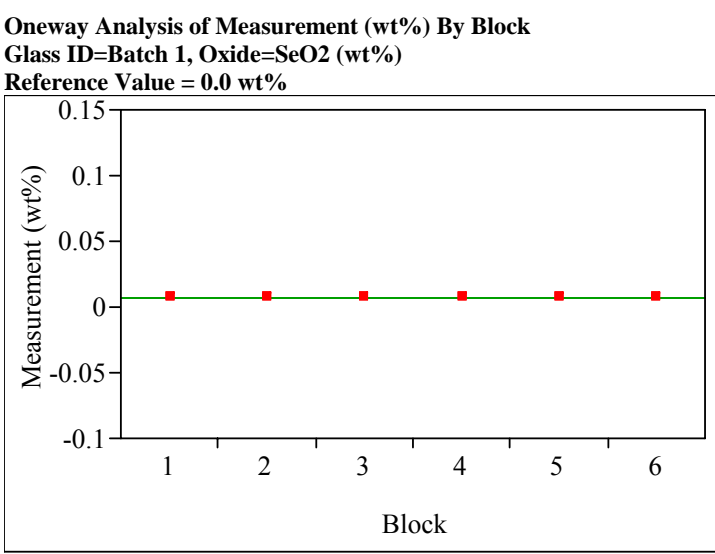

Oneway Anova

Summary of Fit

Rsquare

Adj Rsquare $\quad-0.41667$

Root Mean Square Error $\quad 1.06 \mathrm{e}-18$

Observations (or Sum Wgts) $\quad 18$

\section{Analysis of Variance}

Source DF Sum of Squares Mean Square F Ratio Prob $>$ F

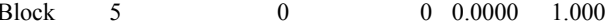
$\begin{array}{llll}\text { Error } & 12 & 1.3542 \mathrm{e}-35 & 1.128 \mathrm{e}-36\end{array}$

C. Total $17 \quad 1.3542 \mathrm{e}-35$

Means for Oneway Anova

Level Number Mean Std Error Lower 95\% Upper 95\%

\begin{tabular}{|c|c|c|c|}
\hline & $\begin{array}{ll}3 & 0.007027\end{array}$ & $6.133 \mathrm{e}-19$ & 0.00703 \\
\hline 2 & $\begin{array}{ll}3 & 0.007027\end{array}$ & $6.133 \mathrm{e}-19$ & 0.00703 \\
\hline & $\begin{array}{ll}3 & 0.007027\end{array}$ & $6.133 \mathrm{e}-19$ & 0.00703 \\
\hline 4 & $\begin{array}{ll}3 & 0.007027\end{array}$ & $6.133 \mathrm{e}-19$ & 0.00703 \\
\hline 5 & 30.007027 & $6.133 \mathrm{e}-19$ & 0.00703 \\
\hline & $\begin{array}{ll}3 & 0.007027\end{array}$ & $6.133 \mathrm{e}-19$ & 0.00703 \\
\hline
\end{tabular}

Std Error uses a pooled estimate of error variance
Oneway Analysis of Measurement (wt\%) By Block Glass ID=Batch 1, Oxide=Si2O3 (wt \%)

Reference Value $=\mathbf{5 0 . 2 2} \mathbf{w t} \%$

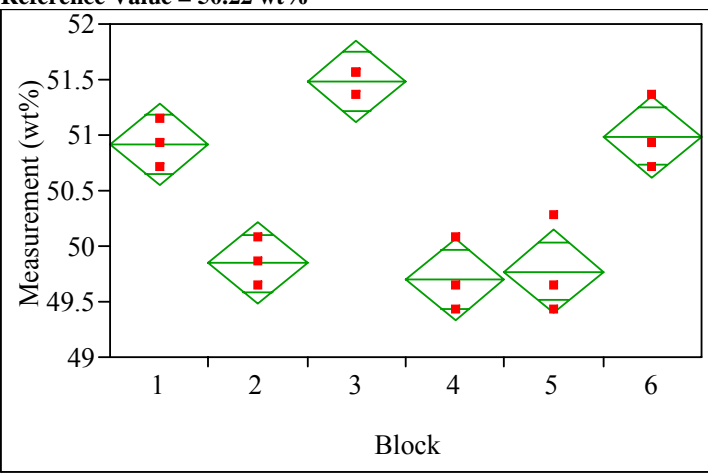

\section{Oneway Anova}

Summary of Fit

Rsquare

Adj Rsquare

Root Mean Square Error

0.851681

Dean Square Error $\quad 0.294019$

Observations (or Sum Wgts)

Analysis of Variance

Source DF Sum of Squares Mean Square F Ratio Prob $>$ F

$\begin{array}{lllllll}\text { Block } & 5 & 8.8709850 & 1.77420 & 20.5235 & <.0001\end{array}$

$\begin{array}{lll}\text { Error } \quad 12 & 1.870373637\end{array}$

0.08645

C. Total $17 \quad 9.9083487$

Means for Oneway Anova

Level Number Mean Std Error Lower 95\% Upper 95\%

1
2

$\begin{array}{lll}3 & 50.9153 & 0.16975 \\ 3 & 49.8457 & 0.16975\end{array}$

$\begin{array}{lll}3 & 49.8457 & 0.16975 \\ 3 & 51.4858 & 0.16975 \\ 3 & 49.7031 & 0.16975\end{array}$

$\begin{array}{lll}3 & 49.7031 & 0.16975 \\ 3 & 4.774 & 0.16975\end{array}$

$349.7744 \quad 0.16975$

$30.9867 \quad 0.16975$

$50.545 \quad 51.285$

$49.476 \quad 50.216$

$\begin{array}{ll}51.116 & 51.85 \\ 49.333 & 50.073\end{array}$

$49.405-50.144$

$\begin{array}{ll}49.405 & 50.144 \\ 50.617 & 51.357\end{array}$

Std Error uses a pooled estimate of error variance
Oneway Analysis of Measurement (wt \%) By Block Glass ID=Batch 1, Oxide=SO4 (wt \%) Reference Value $=0.0 \mathrm{w} \%$

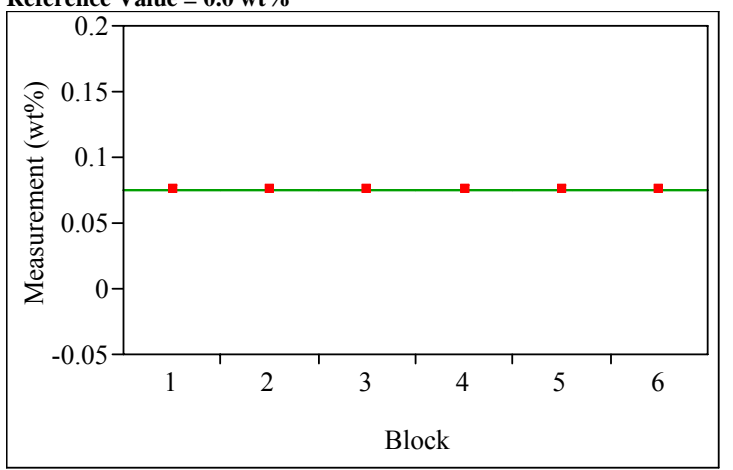

Oneway Anova

Summary of Fit

Rsquare

Adj Rsquare

$\begin{array}{lr}\text { Root Mean Square Error } & 0 \\ \text { Mean of Response } & 0.074898\end{array}$

Observations (or Sum Wgts) 18

Analysis of Variance

Source DF Sum of Squares Mean Square F Ratio Prob $>$ F $\begin{array}{lrll}\text { Block } & 5 & 0 & 0 \\ \text { Error } & 12 & 0 & 0\end{array}$

C. Total 17

Means for Oneway Anova

Level Number Mean Std Error Lower 95\% Upper 95\%

\begin{tabular}{|c|c|c|c|c|}
\hline & $\begin{array}{ll}3 & 0.074898\end{array}$ & 0 & 0.07490 & 0.07490 \\
\hline 2 & 30.074898 & 0 & 0.07490 & 0.07490 \\
\hline 3 & $\begin{array}{ll}3 & 0.074898\end{array}$ & 0 & 0.07490 & 0.07490 \\
\hline 4 & $\begin{array}{ll}30.074898\end{array}$ & 0 & 0.07490 & 0.07490 \\
\hline 5 & $\begin{array}{ll}30.074898\end{array}$ & 0 & 0.07490 & 0.07490 \\
\hline & 30.074898 & 0 & 0.07490 & 0.07490 \\
\hline
\end{tabular}

Std Error uses a pooled estimate of error variance 


\section{Exhibit D3. PSAL Measurements by Analytical Block for Samples of the}

Standard Glasses Prepared Using the LM Method (continued)

Oneway Analysis of Measurement (wt \%) By Block Glass ID=Batch 1, Oxide $=\mathrm{SrO}(\mathrm{wt} \%)$

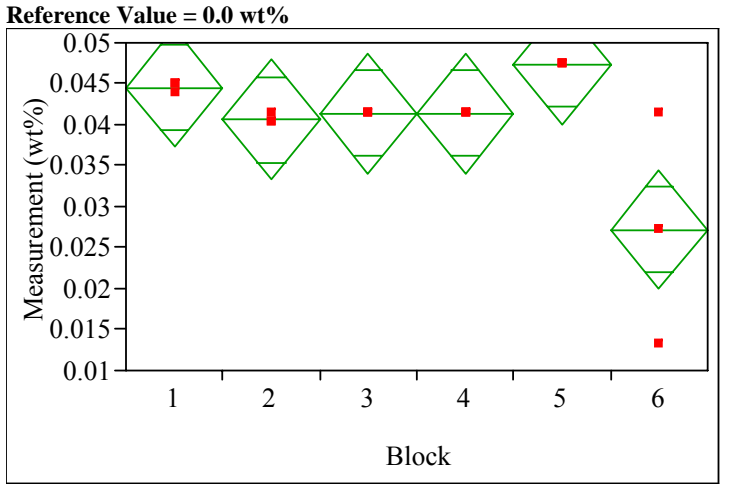

Oneway Anova

Summary of Fit

$\begin{array}{lr}\text { Rsquare } & 0.641248 \\ \text { Adj Rsquare } & 0.491768 \\ \text { Root Mean Square Error } & 0.005807 \\ \text { Mean of Response } & 0.040406 \\ \text { Observations (or Sum Wgts) } & 18\end{array}$

\section{Analysis of Variance}

Source DF Sum of Squares Mean Square F Ratio Prob $>$ F $\begin{array}{llllll}\text { Block } & 5 & 0.00072328 & 0.000145 & 4.2899 & 0.0180\end{array}$ Error $\quad 12 \quad 0.00040465 \quad 0.000034$

C. Total $17 \quad 0.00112792$

\section{Means for Oneway Anova}

Level Number Mean Std Error Lower 95\% Upper 95\%

\begin{tabular}{|c|c|c|c|c|}
\hline & $\begin{array}{ll}30.044545 \\
\end{array}$ & 0.00335 & 0.03724 & 0.05185 \\
\hline 2 & 30.040603 & 0.00335 & 0.03330 & 0.04791 \\
\hline 3 & $\begin{array}{ll}3 & 0.041391\end{array}$ & 0.00335 & 0.03409 & 0.0487 \\
\hline & 30.041391 & 0.00335 & 0.03409 & 0.04870 \\
\hline 5 & 0.047304 & 0.00335 & 0.04000 & 0.054 \\
\hline & 0.027200 & 0.00335 & 0.01990 & 0.03 \\
\hline
\end{tabular}

Std Error uses a pooled estimate of error variance
Oneway Analysis of Measurement ( $w t \%)$ By Block Glass ID=Batch 1, Oxide=Ta2O5 (wt \%)

Reference Value $=0.0 \mathrm{wt} \%$

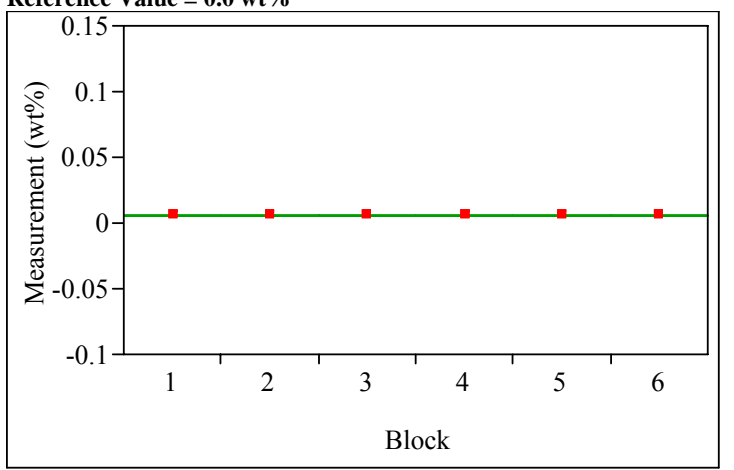

Oneway Anova
Summary of Fit

Rsquare

Adj Rsquare

$\begin{array}{lr}\text { Root Mean Square Error } & 0 \\ \text { Mean of Response } & 0.006105\end{array}$

Observations (or Sum Wgts) 18

Analysis of Variance

Source DF Sum of Squares Mean Square F Ratio Prob > F Block 5

Error 12

$\begin{array}{ll}0 & 0 \\ 0 & 0\end{array}$

Means for Oneway Anova

Level Number Mean Std Error Lower 95\% Upper 95\%

$\begin{array}{llllll}1 & 3 & 0.006105 & 0 & 0.00611 & 0.00611\end{array}$

$\begin{array}{llllll}2 & 3 & 0.006105 & 0 & 0.00611 & 0.00611 \\ 3 & 3 & 0.006105 & 0 & 0.00611 & 0.00611\end{array}$

$\begin{array}{llllll}3 & 3 & 0.006105 & 0 & 0.00611 & 0.00611 \\ 4 & 3 & 0.006105 & 0 & 0.00611 & 0.00611\end{array}$

$\begin{array}{llllll}5 & 3 & 0.006105 & 0 & 0.00611 & 0.00611 \\ 6 & 3 & 0.006105 & 0 & 0.00611 & 0.00611\end{array}$

Std Error uses a pooled estimate of error variance
Oneway Analysis of Measurement (wt \%) By Block Glass ID=LRM, Oxide=Al2O3 (wt \%)

Reference Value $=10.0 \mathrm{wt} \%$

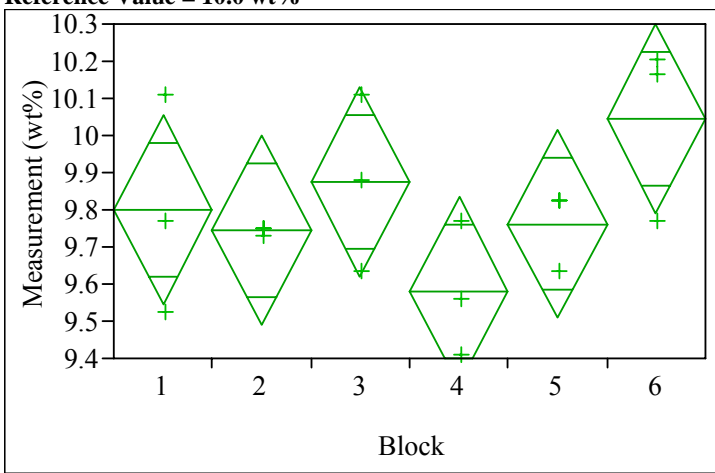

\section{Oneway Anova}

Summary of Fit

$\begin{array}{ll}\text { Rsquare } & 0.422259 \\ \text { Adj Rsquare } & 0.181533\end{array}$

$\begin{array}{ll}\text { Adj Rsquare } & 0.181533 \\ \text { Root Mean Square Error } & 0.201989\end{array}$

Root Mean Square Error $\quad 0.201989$

Mean of Respons Sum Wgts) 9.801256

Analysis of Variance

Analysis of Variance
Source DF Sum of Squares Mean Square F Ratio Prob $>$ F

$\begin{array}{lrrrrr}\text { Source } & \text { DF } & \text { Sum of Squares } & \text { Mean Square } & \text { F Ratio } & \text { Prob }>\text { F } \\ \text { Block } & 5 & 0.35783424 & 0.071567 & 1.7541 & 0.1970\end{array}$

$\begin{array}{lrll}\text { Block } & 5 & 0.35783424 & 0.071567 \\ \text { Error } & 12 & 0.48959483 & 0.040800\end{array}$

$\begin{array}{lll}\text { C. Total } & 17 & 0.84742907\end{array}$

Means for Oneway Anova

Level Number Mean Std Error Lower 95\% Upper 95\%

$\begin{array}{rrrrrr}1 & 3 & 9.8002 & 0.11662 & 9.5461 & 10.054 \\ 1 & 3 & 9.7435 & 0.1162 & 9.464 & 9.998\end{array}$

$\begin{array}{rrrrrr}1 & 3 & 9.8002 & 0.11662 & 9.5461 & 10.054 \\ 2 & 3 & 9.7435 & 0.11662 & 9.4894 & 9.998 \\ 3 & 3 & 9.8758 & 0.11662 & 9.6217 & 10.130\end{array}$

$\begin{array}{rrrrrr}3 & 3 & 9.8758 & 0.11662 & 9.6217 & 10.130 \\ 4 & 3 & 9.5798 & 0.11662 & 9.3257 & 9.834 \\ 5 & 3 & 9.7624 & 0.11662 & 9.5083 & 10.017\end{array}$

$\begin{array}{rrrrrr}4 & 3 & 9.5798 & 0.11662 & 9.3257 & 9.834 \\ 5 & 3 & 9.7624 & 0.11662 & 9.5083 & 10.017\end{array}$

$\begin{array}{rrrrrr}5 & 3 & 9.7624 & 0.11662 & 9.5083 & 10.017 \\ 6 & 3 & 10.0458 & 0.11662 & 9.7918 & 10.300\end{array}$

Std Error uses a pooled estimate of error variance 


\section{Exhibit D3. PSAL Measurements by Analytical Block for Samples of the}

Standard Glasses Prepared Using the LM Method (continued)

Oneway Analysis of Measurement (wt \%) By Block Glass ID $=$ LRM, Oxide $=\mathrm{CaO}$ (wt $\%$ )

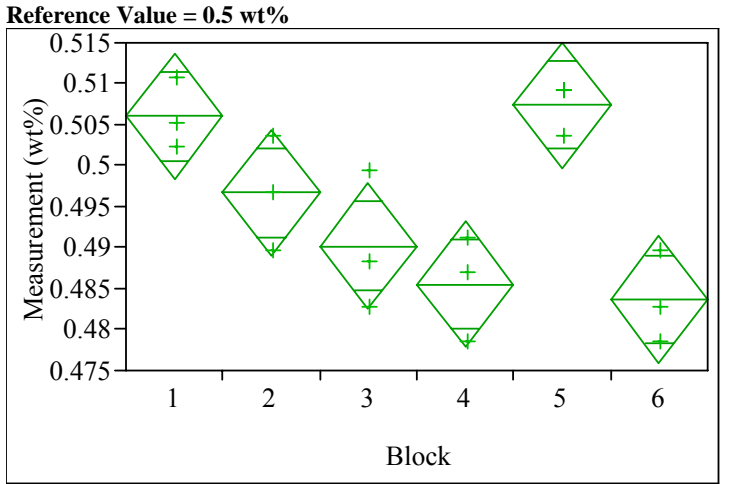

Oneway Anova

Summary of Fit

$\begin{array}{lr}\text { Rsquare } & 0.777477 \\ \text { Adj Rsquare } & 0.68476 \\ \text { Root Mean Square Error } & 0.006108 \\ \text { Mean of Response } & 0.494928 \\ \text { Observations (or Sum Wgts) } & 18\end{array}$

\section{Analysis of Variance}

Source DF Sum of Squares Mean Square F Ratio Prob $>$ F $\begin{array}{llllll}\text { Block } & 5 & 0.00156414 & 0.000313 & 8.3854 & 0.0013\end{array}$ $\begin{array}{llll}\text { Error } & 12 & 0.00044767 & 0.000037\end{array}$

C. Total $17 \quad 0.00201182$

\section{Means for Oneway Anova}

Level Number Mean Std Error Lower 95\% Upper 95\%

\begin{tabular}{|c|c|c|c|c|}
\hline & $\begin{array}{ll}3 & 0.506044\end{array}$ & 0.00353 & 0.49836 & 0.51373 \\
\hline 2 & 30.496716 & 0.00353 & 0.48903 & 0.50440 \\
\hline 3 & $\begin{array}{ll}3 & 0.490186\end{array}$ & 0.00353 & 0.48250 & 0.49787 \\
\hline & 30.485522 & 0.00353 & 0.47784 & 0.49321 \\
\hline 5 & 0.507443 & 0.00353 & 0.49976 & 0.515 \\
\hline & 0.483657 & 0.00353 & 0.47597 & 0.491 . \\
\hline
\end{tabular}

Std Error uses a pooled estimate of error variance
Oneway Analysis of Measurement (wt \%) By Block Glass ID=LRM, Oxide $=\mathrm{Cr} 2 \mathrm{O} 3(\mathrm{wt} \%)$

Reference Value $=0.2 \mathrm{wt} \%$

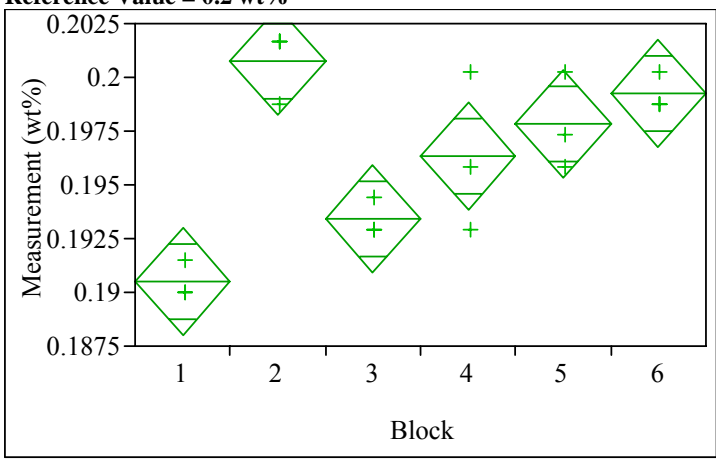

\section{Oneway Anova}

Summary of Fit

$\begin{array}{lr}\text { Rsquare } & 0.822581 \\ \text { Adj Rsquare } & 0.748656 \\ \text { Root Mean Square Error } & 0.001979 \\ \text { Mean of Response } & 0.196342 \\ \text { Observations (or Sum Wgts) } & 18\end{array}$

Analysis of Variance

Source DF Sum of Squares Mean Square F Ratio Prob $>$ F $\begin{array}{lllllll}\text { Block } & 5 & 0.00021790 & 0.000044 & 11.1273 & 0.0004\end{array}$ $\begin{array}{llll}\text { Error } & 12 & 0.00004700 & 3.917 \mathrm{e}-6\end{array}$

C. Total $17 \quad 0.00026490$

\section{Means for Oneway Anova}

Level Number Mean Std Error Lower 95\% Upper 95\%

$\begin{array}{lllllll}1 & 3 & 0.190495 & 0.00114 & 0.18801 & 0.19298\end{array}$

$\begin{array}{lllll}3 & 0.200726 & 0.00114 & 0.19824 & 0.20322\end{array}$

$\begin{array}{lllll}3 & 0.193418 & 0.00114 & 0.19093 & 0.19591\end{array}$

$\begin{array}{llllll}3 & 0.196342 & 0.00114 & 0.19385 & 0.19883\end{array}$

$\begin{array}{lllll}3 & 0.197803 & 0.00114 & 0.19531 & 0.20029 \\ 3 & 0.199265 & 0.00114 & 0.19678 & 0.20175\end{array}$

Std Error uses a pooled estimate of error variance
Oneway Analysis of Measurement (wt \%) By Block Glass ID=LRM, Oxide $=\mathbf{C u O}(w t \%)$

Reference Value $=\mathbf{0 . 0} \mathrm{wt} \%$

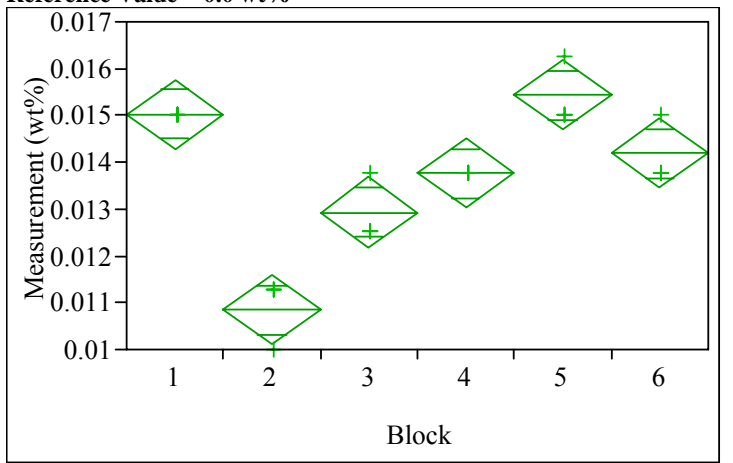

Oneway Anova

Summary of Fit

$\begin{array}{lr}\text { Rsquare } & 0.907869 \\ \text { Adj Rsquare } & 0.869482 \\ \text { Root Mean Square Error } & 0.00059 \\ \text { Mean of Response } & 0.0137 \\ \text { Observations (or Sum Wgts) } & 18\end{array}$

Source DF Sum of Squares Mean Square F Ratio Prob $>$ F $\begin{array}{lllllll}\text { Block } & 5 & 0.00004118 & 8.2355 \mathrm{e}-6 & 23.6500 & <.000\end{array}$ $\begin{array}{llll}\text { Error } & 12 & 0.00000418 & 3.4822 \mathrm{e}-7\end{array}$

C. Total $17 \quad 0.00004536$

Means for Oneway Anova

Level Number Mean Std Error Lower 95\% Upper 95\%

$\begin{array}{llllll}1 & 3 & 0.015022 & 0.00034 & 0.01428 & 0.01576\end{array}$

$\begin{array}{lllll}3 & 0.010849 & 0.00034 & 0.01011 & 0.01159\end{array}$

$\begin{array}{lllll}3 & 0.012935 & 0.00034 & 0.01219 & 0.01368\end{array}$

$\begin{array}{lllll}3 & 0.013770 & 0.00034 & 0.01303 & 0.01451\end{array}$

$\begin{array}{lllll}3 & 0.015439 & 0.00034 & 0.01470 & 0.01618\end{array}$

$\begin{array}{lllll}3 & 0.014187 & 0.00034 & 0.01344 & 0.01493\end{array}$

Std Error uses a pooled estimate of error variance 


\section{Exhibit D3. PSAL Measurements by Analytical Block for Samples of the}

Standard Glasses Prepared Using the LM Method (continued)

Oneway Analysis of Measurement (wt \%) By Block Glass ID=LRM, Oxide=Fe2O3 (wt \%)

Reference Value $=\mathbf{1 . 0} \mathbf{w t} \%$

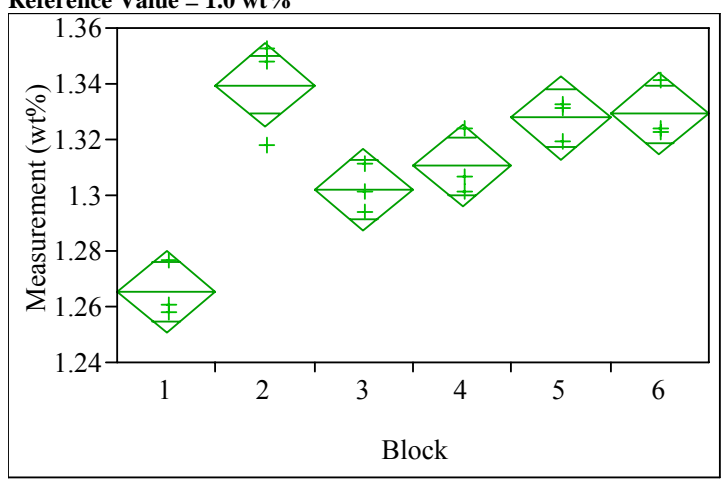

Oneway Anova

Summary of Fit

Rsquare
Adj Rsquare

0.867456

$\begin{array}{ll}0.812229 \\ \text { Adj Rsquare } & 0.011707\end{array}$

Root Mean Square Error $\quad 0.011707$

Observations (or Sum Wgts)

\section{18}

Analysis of Variance

Source DF Sum of Squares Mean Square F Ratio Prob $>$ F

$\begin{array}{lllllll}\text { Block } & 5 & 0.01076449 & 0.002153 & 15.7072 & <.0001\end{array}$

$\begin{array}{llll}\text { Error } & 12 & 0.00164477 & 0.000137\end{array}$

C. Total $17 \quad 0.01240927$

Means for Oneway Anova

Level Number Mean Std Error Lower 95\% Upper 95\%

$\begin{array}{llllll}1 & 3 & 1.26528 & 0.00676 & 1.2506 & 1.2800\end{array}$

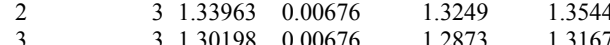

$\begin{array}{llllll}4 & 3 & 1.31056 & 0.00676 & 1.2958 & 1.3253 \\ 5 & 3 & 1.32771 & 0.00676 & 1.3130 & 1.3424\end{array}$

$\begin{array}{llllll}5 & 3 & 1.32771 & 0.00676 & 1.3130 & 1.3424 \\ 6 & 3 & 1.32914 & 0.00676 & 1.3144 & 1.3439\end{array}$

Std Error uses a pooled estimate of error variance
Oneway Analysis of Measurement (wt \%) By Block Glass ID=LRM, Oxide $=$ Ga2O3 (wt $\%$ )

Reference Value $=0.0 \mathrm{wt} \%$

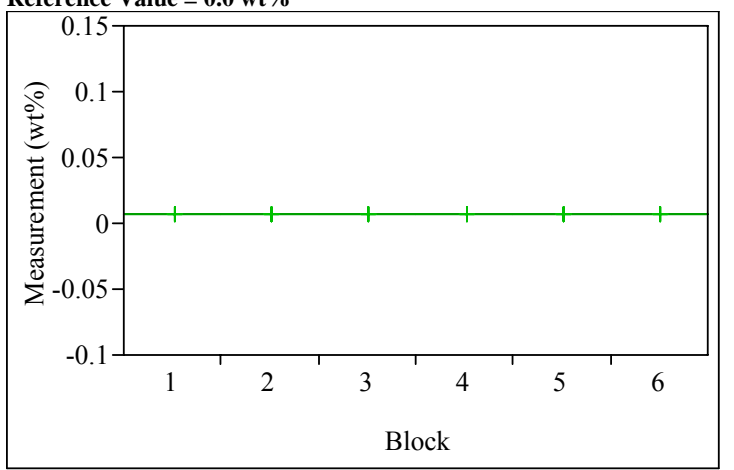

Oneway Anova

Summary of Fit

Rsquare

Adj Rsquare

$\begin{array}{lr}\text { Root Mean Square Error } & 0 \\ \text { Mean of Response } & 0.006721\end{array}$

Observations (or Sum Wgts) 18

Analysis of Variance

Source DF Sum of Squares Mean Square F Ratio Prob $>$ F $\begin{array}{lrll}\text { Block } & 5 & 0 & 0 \\ \text { Error } & 12 & 0 & 0 \\ \text { C. } & 17 & 0 & \end{array}$

C. Total 17

Means for Oneway Anova

Level Number Mean Std Error Lower 95\% Upper 95\%

$\begin{array}{llllll}1 & 3 & 0.006721 & 0 & 0.00672 & 0.00672 \\ 2 & 3 & 0.006721 & 0 & 0.00672 & 0.00672 \\ 3 & 3 & 0.006721 & 0 & 0.00672 & 0.00672 \\ 4 & 3 & 0.006721 & 0 & 0.00672 & 0.00672 \\ 5 & 3 & 0.006721 & 0 & 0.00672 & 0.00672 \\ 6 & 3 & 0.006721 & 0 & 0.00672 & 0.00672\end{array}$

Std Error uses a pooled estimate of error variance
Oneway Analysis of Measurement (wt \%) By Block Glass ID=LRM, Oxide $=\mathbf{G d 2 O}$ ( $w t \%)$ Reference Value $=\mathbf{0 . 0} \mathbf{w t} \%$

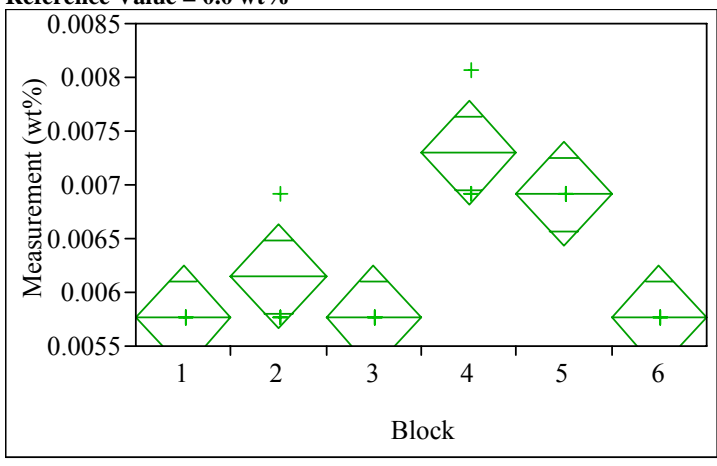

Oneway Anova

Summary of Fit

Rsquare

Adj Rsquare

0.793103

Root Mean Square Error $\quad 0.706897$

quare Error $\quad 0.000384$

\begin{tabular}{lr} 
Observations (or Sum Wgts) & 0.006275 \\
\hline
\end{tabular}

Analysis of Variance

Source DF Sum of Squares Mean Square F Ratio Prob > F $\begin{array}{llllll}\text { Block } & 5 & 0.00000679 & 1.358 \mathrm{e}-6 & 9.2000 & 0.000\end{array}$ $\begin{array}{llll}\text { Error } & 12 & 1.77132 \mathrm{e}-6 & 1.4761 \mathrm{e}-7\end{array}$

C. Total $17 \quad 8.56136 \mathrm{e}-6$

Means for Oneway Anova

Level Number Mean Std Error Lower 95\% Upper 95\%

$\begin{array}{llrrrr}1 & 3 & 0.005763 & 0.00022 & 0.00528 & 0.00625\end{array}$

$\begin{array}{llllll}2 & 3 & 0.006147 & 0.00022 & 0.00566 & 0.00663 \\ 3 & 3 & 0.005763 & 0.00022 & 0.00528 & 0.00625\end{array}$

$\begin{array}{lllll}3 & 0.005763 & 0.00022 & 0.00528 & 0.00625\end{array}$

$\begin{array}{lllll}3 & 0.007300 & 0.00022 & 0.00682 & 0.00778 \\ 3 & 0.006916 & 0.00022 & 0.00643 & 0.0740\end{array}$

$\begin{array}{lllll}3 & 0.006916 & 0.00022 & 0.00643 & 0.00740 \\ 3 & 0.005763 & 0.00022 & 0.00528 & 0.00625\end{array}$

Std Error uses a pooled estimate of error varianc 


\section{Exhibit D3. PSAL Measurements by Analytical Block for Samples of the}

Standard Glasses Prepared Using the LM Method (continued)

Oneway Analysis of Measurement (wt \%) By Block Glass ID=LRM, Oxide $=$ HfO2 $(\mathrm{wt} \%)$

Reference Value $=0.0 \mathrm{wt} \%$

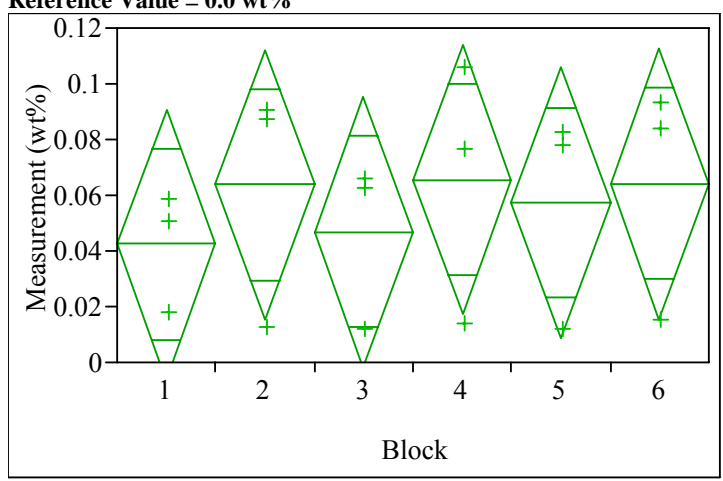

Oneway Anova

Summary of Fit

$\begin{array}{ll} & 0.075527 \\ \text { Adj Rsquare } & -0.30967\end{array}$

-0.30967
Root Mean Square Error $\quad 0.038526$

Reot 0.038526

0.056672
18

Analysis of Variance

Source DF Sum of Squares Mean Square F Ratio Prob $>$ F

$\begin{array}{lrrrrr}\text { Source } & \text { DF } & \text { Sum of Squares } & \text { Mean Square } & & \\ \text { Block } & 5 & 0.00145511 & 0.000291 & 0.1961 & 0.9581\end{array}$

$\begin{array}{lrrr}\text { Block } & 5 & 0.0014511 & 0.000291 \\ \text { Error } & 12 & 0.01781085 & 0.001484\end{array}$

C. Total $17-0.01926596$

\section{Means for Oneway Anova}

Level Number Mean Std Error Lower 95\% Upper 95\%

$\begin{array}{lrrrrr}1 & 3 & 0.042455 & 0.02224 & -0.0060 & 0.09092 \\ 2 & 3 & 0.063682 & 0.02224 & 0.0152 & 0.11215 \\ 3 & 3 & 0.046779 & 0.02224 & -0.0017 & 0.0524\end{array}$

$\begin{array}{rrrrr}3 & 0.063682 & 0.02224 & 0.0152 & 0.11215 \\ 3 & 0.046779 & 0.02224 & -0.0017 & 0.09524\end{array}$

$\begin{array}{rrrrrr}3 & 0.046779 & 0.02224 & -0.0017 & 0.09524 \\ 3 & 0.065648 & 0.02224 & 0.0172 & 0.11411\end{array}$

$\begin{array}{lllll}3 & 0.065648 & 0.02224 & 0.0172 & 0.11411 \\ 3 & 0.057393 & 0.02224 & 0.0089 & 0.10586\end{array}$

$\begin{array}{lllll}3 & 0.064075 & 0.02224 & 0.0156 & 0.11254\end{array}$

Std Error uses a pooled estimate of error variance
Oneway Analysis of Measurement (wt \%) By Block Glass ID=LRM, Oxide $=$ K2O $(w t \%)$

Reference Value $=1.5 \mathrm{wt} \%$

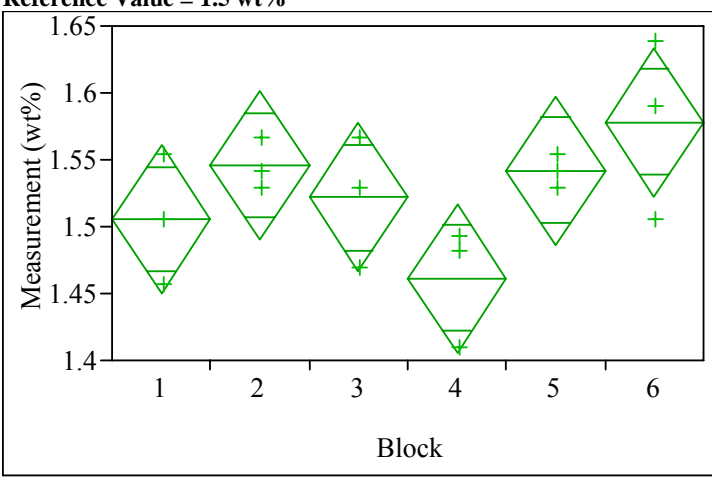

\section{Oneway Anova}

Summary of Fit

Rsquare

$\begin{array}{lr}\text { Rsquare } & 0.503067 \\ \text { Adj Rsquare } & 0.296012\end{array}$

$$
0.503067
$$

Root Mean Square Error $\quad \begin{array}{r}0.04426 \\ \text { Mean of Response }\end{array}$

Observations (or Sum Wgts)

18

Analysis of Variance

Source DF Sum of Squares Mean Square F Ratio Prob $>$ F

$\begin{array}{lrrrrr}\text { Source } & \text { DF } & \text { Sum of Squares } & \text { Mean Square } & \text { Ratio } & \text { Prob }>\text { F } \\ \text { Block } & 5 & 0.02379740 & 0.004759 & 2.4296 & 0.0964\end{array}$

$\begin{array}{lll}\text { Error } & 12 & 0.02350719\end{array}$

C. Total $17 \quad 0.045045$

Means for Oneway Anova

Level Number Mean Std Error Lower 95\% Upper 95\%

$\begin{array}{rrrrrr}1 & 3 & 1.50575 & 0.02555 & 1.4501 & 1.5614\end{array}$

$\begin{array}{llllll}1 & 3 & 1.50575 & 0.02555 & 1.4501 & 1.5614 \\ 2 & 3 & 1.54590 & 0.02555 & 1.4902 & 1.6016 \\ 3 & 3 & 1.52181 & 0.02555 & 1.4661 & 1.5775\end{array}$

$\begin{array}{llllll}3 & 3 & 1.52181 & 0.02555 & 1.4661 & 1.5775 \\ 4 & 3 & 1.46158 & 0.02555 & 1.4059 & 1.5173\end{array}$

$\begin{array}{llllll}4 & 3 & 1.46158 & 0.02555 & 1.4059 & 1.5173 \\ 5 & 3 & 1.54189 & 0.02555 & 1.4862 & 1.5976 \\ 6 & & 1.57803 & 0.02555 & 1.5223 & 1.6337\end{array}$

$\begin{array}{llllll}6 & 3 & 1.54189 & 0.02555 & 1.4862 & 1.5976 \\ & 3 & 1.57803 & 0.02555 & 1.5223 & 1.6337\end{array}$

Std Error uses a pooled estimate of error variance
Oneway Analysis of Measurement (wt \%) By Block Glass ID=LRM, Oxide=La2O3 (wt $\%$ )

Reference Value $=0.0 \mathrm{wt} \%$

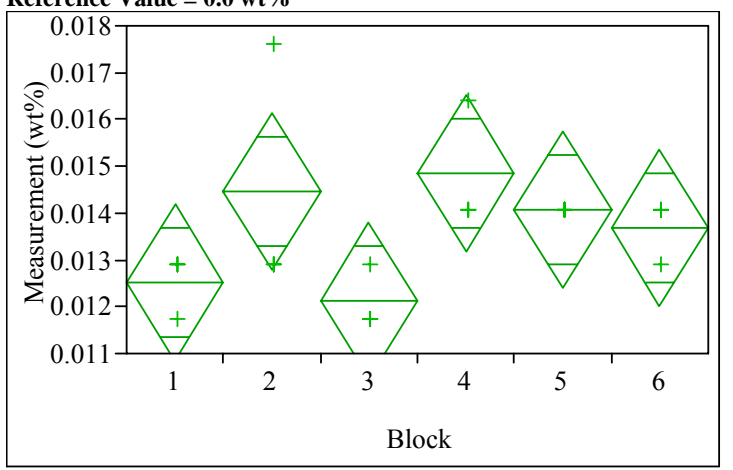

Oneway Anova

Summary of Fit

$\begin{array}{lr}\text { Rsquare } & 0.45776 \\ \text { Adj Rsquare } & 0.231827 \\ \text { Root Mean Square Error } & 0.001326 \\ \text { Mean of Response } & 0.013618 \\ \text { Observations (or Sum Wgts) } & 18\end{array}$

Source DF Sum of Squares Mean Square F Ratio Prob $>$ F $\begin{array}{llllll}\text { Block } & 5 & 0.00001780 & 3.5609 \mathrm{e}-6 & 2.0261 & 0.1468\end{array}$ Error $\quad 12 \quad 0.00002109 \quad 1.7575 \mathrm{e}-6$

C. Total $17 \quad 0.00003889$

Means for Oneway Anova

Level Number Mean Std Error Lower 95\% Upper 95\% $\begin{array}{lllllll}1 & 3 & 0.012510 & 0.00077 & 0.01084 & 0.01418 \\ 2 & & 3 & 0.014465 & 0.00077 & 0.01280 & 0.01613\end{array}$

$\begin{array}{llllll}2 & 3 & 0.014465 & 0.00077 & 0.01280 & 0.01613 \\ 3 & 3 & 0.012119 & 0.00077 & 0.01045 & 0.01379\end{array}$

$\begin{array}{llllll}4 & 3 & 0.014855 & 0.00077 & 0.01319 & 0.01652\end{array}$

$\begin{array}{llllll}5 & 3 & 0.014074 & 0.00077 & 0.01241 & 0.01574 \\ 6 & 3 & 0.013683 & 0.00077 & 0.01201 & 0.01535\end{array}$

Std Error uses a pooled estimate of error variance 


\section{Exhibit D3. PSAL Measurements by Analytical Block for Samples of the}

Standard Glasses Prepared Using the LM Method (continued)

Oneway Analysis of Measurement (wt \%) By Block Glass ID=LRM, Oxide $=\mathbf{M g O}(w t \%)$

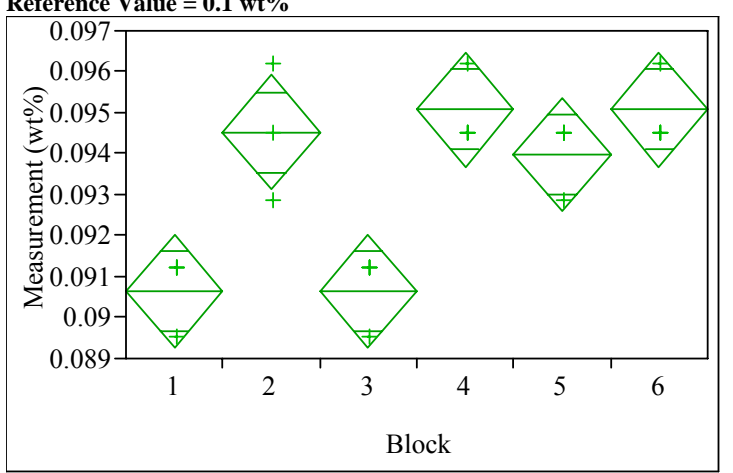

Oneway Anova

Summary of Fit

$\begin{array}{lr}\text { Rsquare } & 0.819887 \\ \text { Adj Rsquare } & 0.744841 \\ \text { Root Mean Square Error } & 0.001106 \\ \text { Mean of Response } & 0.093325 \\ \text { Observations (or Sum Wgts) } & 18\end{array}$

Observations (or Sum Wgts) $\begin{array}{r}0.093325 \\ 18\end{array}$

Analysis of Variance

Source DF Sum of Squares Mean Square F Ratio Prob > F

$\begin{array}{lllllll}\text { Block } & 5 & 0.00006676 & 0.000013 & 10.9250 & 0.0004\end{array}$

Error $\quad 12 \quad 0.00001467 \quad 1.222 \mathrm{e}-6$

C. Total $17 \quad 0.00008143$

Means for Oneway Anova

Level Number Mean Std Error Lower 95\% Upper 95\%

\begin{tabular}{|c|c|c|c|c|}
\hline & $\begin{array}{ll}30.090654 \\
\end{array}$ & 0.00064 & 0.08926 & 0.09204 \\
\hline 2 & 30.094523 & 0.00064 & 0.09313 & 0.09591 \\
\hline 3 & $\begin{array}{ll}3 & 0.090654\end{array}$ & 0.00064 & 0.08926 & 0.09204 \\
\hline & 30.095076 & 0.00064 & 0.09369 & 0.09647 \\
\hline 5 & $\begin{array}{ll}3 & 0.093970\end{array}$ & 0.00064 & 0.09258 & 0.095 \\
\hline & 0.095076 & 0.00064 & 0.09369 & 0.09 \\
\hline
\end{tabular}

Std Error uses a pooled estimate of error variance
Oneway Analysis of Measurement (wt\%) By Block Glass ID $=$ LRM, Oxide $=\mathrm{Na2O}$ (wt \%)

Reference Value $=20.0 \mathrm{wt} \%$

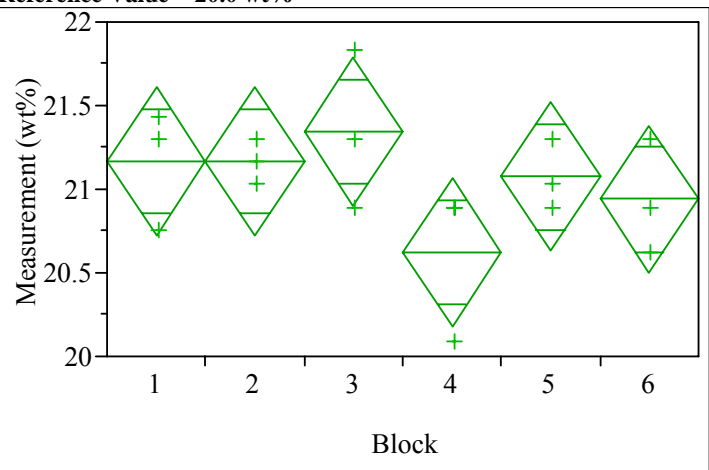

\section{Oneway Anova}

Summary of Fit

Rsquare

Adj Rsquare

$$
\begin{array}{r}
0.381132 \\
0.12327
\end{array}
$$

$\begin{array}{lr}\text { Adj Rsquare } & 0.12327 \\ \text { Root Mean Square Error } & 0.352376\end{array}$

Root Mean Square Error $\quad 0.352376$

21.05127
18

Analysis of Variance

Source DF Sum of Squares Mean Square F Ratio Prob $>$ F

$\begin{array}{lrrrrr}\text { Source } & \text { DF } & \text { Sum of Squares } & \text { Mean Square } & & \\ \text { Block } & 5 & 0.9176375 & 0.183528 & 1.4780 & 0.2676\end{array}$

$\begin{array}{lrr}\text { Error } & 12 & 0.9176375 \\ \text { Clo } & 1.4900253\end{array}$

0.124169

C. Total $17 \quad 2.4076628$

Means for Oneway Anova

Level Number Mean Std Error Lower 95\% Upper 95\%

1
2

$$
\begin{array}{rrrrr}
3 & 21.1636 & 0.20344 & 20.720 & 21.607 \\
3 & 21.1636 & 0.20344 & 20.720 & 21.607 \\
3 & 21.3433 & 0.20344 & 20.900 & 21.787 \\
3 & 20.6244 & 0.20344 & 20.181 & 21.068 \\
3 & 21.0737 & 0.20344 & 20.630 & 21.517 \\
3 & 20.9389 & 0.20344 & 20.496 & 21.382
\end{array}
$$

Std Error uses a pooled estimate of error variance
Oneway Analysis of Measurement (wt \%) By Block Glass ID=LRM, Oxide $=\mathrm{Nd} 2 \mathrm{O} 3(\mathrm{wt} \%)$ Reference Value $=\mathbf{0 . 0} \mathrm{wt} \%$

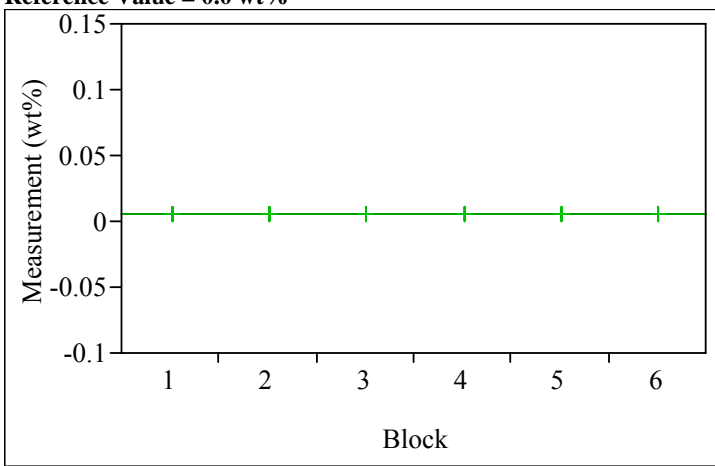

Oneway Anova

Summary of Fit

Rsquare

Adj Rsquare

$\begin{array}{lr}\text { Root Mean Square Error } & 0 \\ \text { Mean of Response } & 0.005832\end{array}$

Observations (or Sum Wgts) $\quad 18$

Analysis of Variance

Source DF Sum of Squares Mean Square F Ratio Prob $>$ F $\begin{array}{lrll}\text { Block } & 5 & 0 & 0 \\ \text { Error } & 12 & 0 & 0\end{array}$

C. Total 17

Means for Oneway Anova

Level Number Mean Std Error Lower 95\% Upper 95\%

$\begin{array}{llllll}1 & 3 & 0.005832 & 0 & 0.00583 & 0.00583 \\ 2 & 3 & 0.005832 & 0 & 0.00583 & 0.00583 \\ 3 & 3 & 0.005832 & 0 & 0.00583 & 0.00583 \\ 4 & 3 & 0.005832 & 0 & 0.00583 & 0.00583 \\ 5 & 3 & 0.005832 & 0 & 0.00583 & 0.00583 \\ 6 & 3 & 0.005832 & 0 & 0.00583 & 0.00583\end{array}$

Std Error uses a pooled estimate of error variance 
Exhibit D3. PSAL Measurements by Analytical Block for Samples of the Standard Glasses Prepared Using the LM Method (continued)

Oneway Analysis of Measurement (wt \%) By Block Glass ID=LRM, Oxide=NiO $(w t \%)$

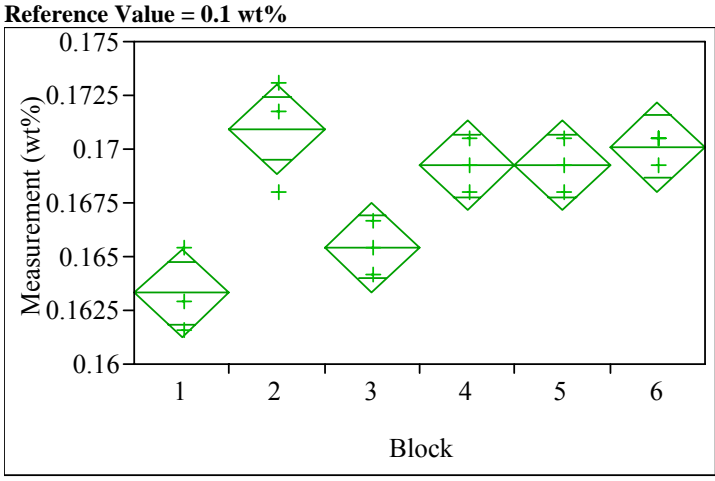

Oneway Anova

Summary of Fit

Rsquare

Adj Rsquare

Root Mean Square Emor 0.724771

are Error $\quad 0.001643$

0.168041
Observations (or Sum Wgts)

Analysis of Variance

Source DF Sum of Squares Mean Square F Ratio Prob $>$ $\begin{array}{llllll}\text { Block } & 5 & 0.00013431 & 0.000027 & 9.9533 & 0.0006\end{array}$ $\begin{array}{llll}\text { Error } & 12 & 0.00003239 & 2.699 \mathrm{e}-6\end{array}$

C. Total $17 \quad 0.00016669$

Means for Oneway Anova

Level Number Mean Std Error Lower 95\% Upper 95\%

$\begin{array}{lllllll}1 & 3 & 0.163304 & 0.00095 & 0.16124 & 0.16537\end{array}$

$\begin{array}{lllll}3 & 0.170939 & 0.00095 & 0.16887 & 0.17301\end{array}$

$\begin{array}{lllll}3 & 0.165425 & 0.00095 & 0.16336 & 0.16749\end{array}$

$\begin{array}{lllll}3 & 0.169243 & 0.00095 & 0.16718 & 0.17131\end{array}$

$\begin{array}{lllll}3 & 0.169243 & 0.00095 & 0.16718 & 0.17131 \\ 3 & 0.170091 & 0.00095 & 0.16802 & 0.17216\end{array}$

Std Error uses a pooled estimate of error variance
Oneway Analysis of Measurement (wt \%) By Block Glass ID=LRM, Oxide $=\mathbf{P b O}(\mathrm{wt} \%)$

Reference Value $=0.1 \mathrm{wt} \%$

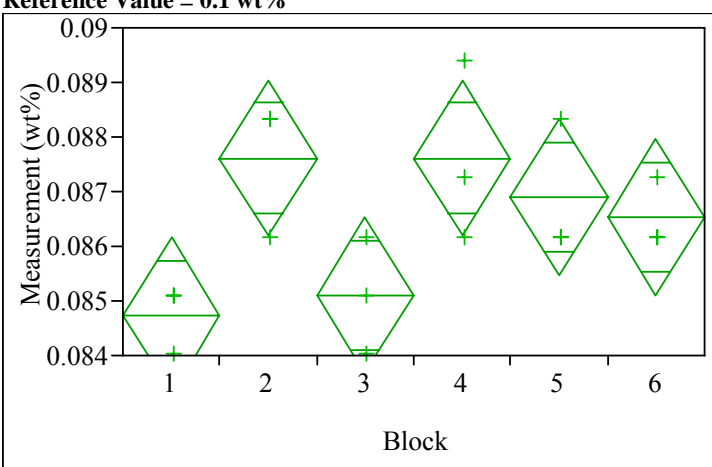

Oneway Anova

Summary of Fit

$\begin{array}{lr}\text { Rsquare } & 0.597315 \\ \text { Adj Rsquare } & 0.42953 \\ \text { Root Mean Square Error } & 0.001135 \\ \text { Mean of Response } & 0.086415 \\ \text { Observations (or Sum Wgts) } & 18\end{array}$

Analysis of Variance

Source DF Sum of Squares Mean Square F Ratio Prob > F $\begin{array}{lllllll}\text { Block } & 5 & 0.00002295 & 4.5899 \mathrm{e}-6 & 3.5600 & 0.0332\end{array}$ Error $\quad \begin{array}{lll}12 & 0.00001547 & 1.2893 \mathrm{e}-6\end{array}$

C. Total $17 \quad 0.00003842$

Means for Oneway Anova

Level Number Mean Std Error Lower 95\% Upper 95\%

$\begin{array}{llllll}1 & 3 & 0.084740 & 0.00066 & 0.08331 & 0.08617\end{array}$

$\begin{array}{lllll}3 & 0.087612 & 0.00066 & 0.08618 & 0.086904\end{array}$

$\begin{array}{lllll}3 & 0.085099 & 0.00066 & 0.08367 & 0.08653\end{array}$

$\begin{array}{lllll}3 & 0.087612 & 0.00066 & 0.08618 & 0.08904\end{array}$

$\begin{array}{lllll}3 & 0.086894 & 0.00066 & 0.08547 & 0.08832\end{array}$

$\begin{array}{lllll}3 & 0.086535 & 0.00066 & 0.08511 & 0.08796\end{array}$

Std Error uses a pooled estimate of error variance
Oneway Analysis of Measurement (wt\%) By Block Glass ID=LRM, Oxide $=\mathrm{SeO} 2$ (wt $\%)$

Reference Value $=0.0 \mathrm{wt} \%$

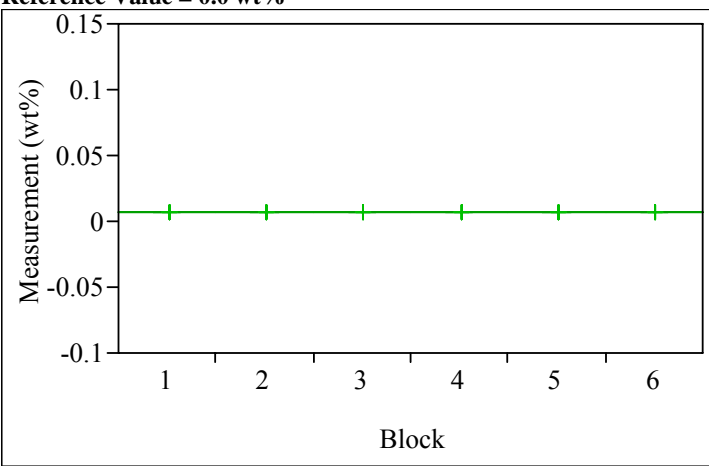

Oneway Anova

Summary of Fit

Rsquare

Adj Rsquare

-0.41667
$\quad 0.06 \mathrm{e}-18$ $\begin{array}{lr}\text { Mean of Response } & 0.007027 \\ \text { Observations (or Sum Wgts) } & 18\end{array}$

Analysis of Variance

Source DF Sum of Squares Mean Square F Ratio Prob $>$ F $\begin{array}{llllll}\text { Block } & 5 & 0 & 0 & 0.0000 & 1.0000\end{array}$ $\begin{array}{llll}\text { Error } & 12 & 1.3542 \mathrm{e}-35 & 1.128 \mathrm{e}-36\end{array}$

C. Total $17 \quad 1.3542 \mathrm{e}-35$

Means for Oneway Anova

Level Number Mean Std Error Lower 95\% Upper 95\% $\begin{array}{llllll}1 & 3 & 0.007027 & 6.133 \mathrm{e}-19 & 0.00703 & 0.00703\end{array}$

$\begin{array}{llllll}2 & 3 & 0.007027 & 6.133 \mathrm{e}-19 & 0.00703 & 0.00703\end{array}$

$\begin{array}{lllll}3 & 0.007027 & 6.133 \mathrm{e}-19 & 0.00703 & 0.00703\end{array}$

$\begin{array}{lllll}3 & 0.007027 & 6.133 \mathrm{e}-19 & 0.00703 & 0.00703\end{array}$

$\begin{array}{lllll}3 & 0.007027 & 6.133 \mathrm{e}-19 & 0.00703 & 0.00703\end{array}$

$\begin{array}{lllll}3 & 0.007027 & 6.133 \mathrm{e}-19 & 0.00703 & 0.00703\end{array}$

Std Error uses a pooled estimate of error variance 


\section{Exhibit D3. PSAL Measurements by Analytical Block for Samples of the}

Standard Glasses Prepared Using the LM Method (continued)

Oneway Analysis of Measurement (wt \%) By Block Glass ID $=$ LRM, Oxide $=\mathrm{Si2O} 3(\mathrm{wt} \%)$

Reference Value $=54.37 \mathrm{wt} \%$

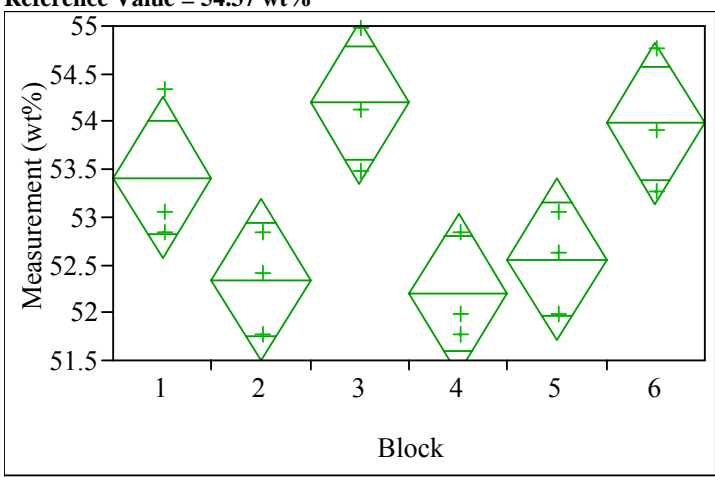

Oneway Anova

Summary of Fit

Rsquare

Adj Rsquare

$$
0.677311
$$

0.542857

Root Mean Square Error $\quad 0.668947$

Mean of Response

53.11407
18

Observations (or Sum Wgts)

Analysis of Variance

Source DF Sum of Squares Mean Square F Ratio Prob $>$ F

$\begin{array}{llllll}\text { Block } & 5 & 11.271160 & 2.25423 & 5.0375 & 0.0102\end{array}$

Error $12 \quad 5.369883$

0.44749

C. Total $17 \quad 16.641042$

Means for Oneway Anova

Level Number Mean Std Error Lower 95\% Upper 95\%

$\begin{array}{rrrrrr}1 & 3 & 53.4112 & 0.38622 & 52.570 & 54.253 \\ 2 & 3 & 52.3415 & 0.3862 & 51.500 & 53.183\end{array}$

$\begin{array}{lllll}3 & 52.3415 & 0.38622 & 51.500 & 53.183 \\ 3 & 54.1956 & 0.38622 & 53.354 & 55.037\end{array}$

$\begin{array}{lllll}3 & 54.1956 & 0.38622 & 53.354 & 55.037 \\ 3 & 52.1989 & 0.38622 & 51.357 & 53.040\end{array}$

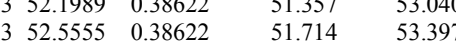

$\begin{array}{lllll}3 & 53.9817 & 0.38622 & 53.140 & 54.823\end{array}$

Std Error uses a pooled estimate of error variance
Oneway Analysis of Measurement (wt \%) By Block Glass ID=LRM, Oxide $=\mathrm{SO} 4$ (wt \%)

Reference Value $=0.24 \mathbf{w t} \%$

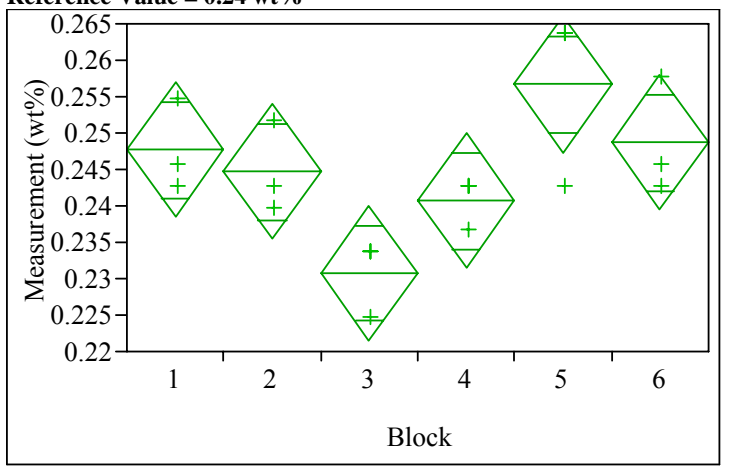

Oneway Anova

Summary of Fit

$\begin{array}{lr}\text { Rsquare } & 0.635959 \\ \text { Adj Rsquare } & 0.484275 \\ \text { Root Mean Square Error } & 0.007372 \\ \text { Mean of Response } & 0.244832 \\ \text { Observations (or Sum Wgts) } & 18\end{array}$

Analysis of Variance

Source DF Sum of Squares Mean Square F Ratio Prob $>$ F $\begin{array}{llllll}\text { Block } & 5 & 0.00113938 & 0.000228 & 4.1927 & 0.0195\end{array}$ $\begin{array}{llll}\text { Error } & 12 & 0.00065221 & 0.000054\end{array}$

C. Total $17 \quad 0.00179159$

Means for Oneway Anova

Level Number Mean Std Error Lower 95\% Upper 95\% $\begin{array}{llllll}1 & 3 & 0.247661 & 0.00426 & 0.23839 & 0.25693\end{array}$

$\begin{array}{llllll}2 & 3 & 0.244665 & 0.00426 & 0.23539 & 0.25394\end{array}$

$\begin{array}{llllll}3 & 3 & 0.230684 & 0.00426 & 0.22141 & 0.23996 \\ 4 & 3 & 0.240671 & 0.00426 & 0.23140 & 0.24994\end{array}$

$\begin{array}{llllll}5 & 3 & 0.256649 & 0.00426 & 0.24737 & 0.26592 \\ 6 & 3 & 0.24660 & 0.0426 & 0.23939 & 0.2593\end{array}$

$\begin{array}{lllll}3 & 0.248660 & 0.00426 & 0.23939 & 0.25793\end{array}$

Std Error uses a pooled estimate of error variance
Oneway Analysis of Measurement (wt \%) By Block Glass ID=LRM, Oxide $=\mathrm{SrO}$ ( $w t \%)$

Reference Value $=0.0 \mathrm{wt} \%$

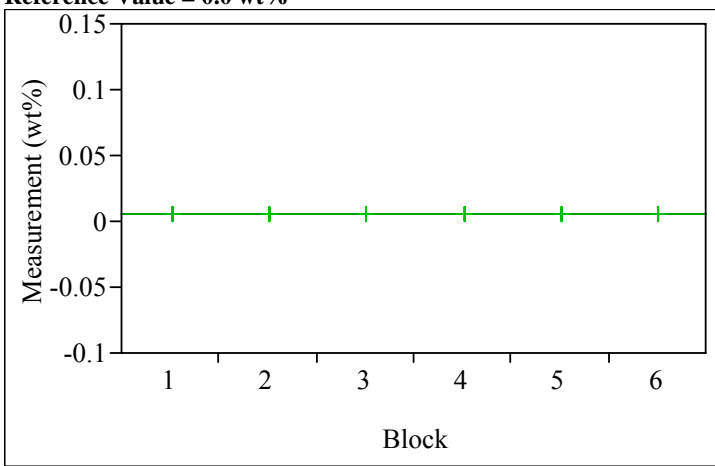

Oneway Anova

Summary of Fit

Rsquare

Adj Rsquare

$\begin{array}{lr}\text { Root Mean Square Error } & 0 \\ \text { Mean of Response } & 0.005913\end{array}$

Observations (or Sum Wgts) $\quad 18$

Analysis of Variance

Source DF Sum of Squares Mean Square F Ratio Prob $>$ F $\begin{array}{lrrr}\text { Block } & 5 & 0 & 0 \\ \text { Error } & 12 & 0 & 0\end{array}$

C. Total 17

Means for Oneway Anova

Level Number Mean Std Error Lower 95\% Upper 95\% $\begin{array}{llllll}1 & 3 & 0.005913 & 0 & 0.00591 & 0.00591\end{array}$ $\begin{array}{llllll}2 & 3 & 0.005913 & 0 & 0.00591 & 0.00591 \\ 3 & 3 & 0.005913 & 0 & 0.00591 & 0.00591\end{array}$ $\begin{array}{llllll}4 & 3 & 0.005913 & 0 & 0.00591 & 0.00591\end{array}$ $\begin{array}{llllll}5 & 3 & 0.005913 & 0 & 0.00591 & 0.00591 \\ 6 & 3 & 0.005913 & 0 & 0.00591 & 0.00591\end{array}$

Std Error uses a pooled estimate of error variance 
Exhibit D3. PSAL Measurements by Analytical Block for Samples of the Standard Glasses Prepared Using the LM Method (continued)

Oneway Analysis of Measurement (wt \%) By Block Glass ID $=$ LRM, Oxide $=$ Ta2O5 ( $w$ t $\%)$

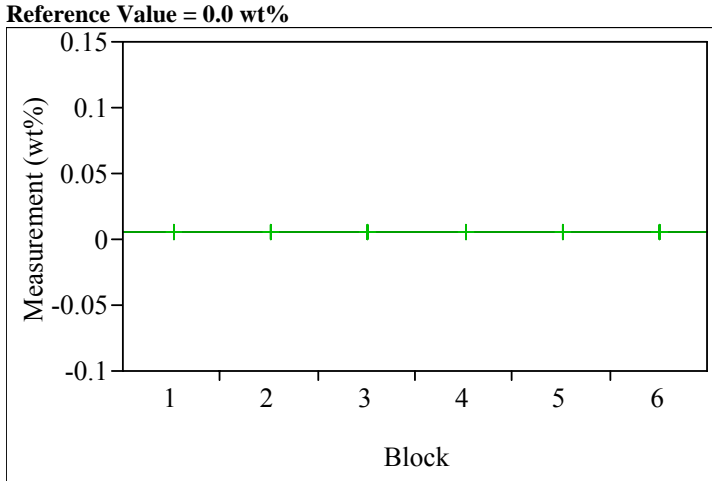

Oneway Anova

Summary of Fit

Rsquare
Adj Rsqua

Root Mean Square Error

Mean of Response

Observations (or Sum Wgts)

Analysis of Variance

Source DF Sum of Squares Mean Square F Ratio Prob $>$ F

$\begin{array}{lrll}\text { Block } & 5 & 0 & 0 \\ \text { Error } & 12 & 0 & 0\end{array}$

C. Total 17

Means for Oneway Anova

Level Number Mean Std Error Lower 95\% Upper 95\%

$\begin{array}{llllll}1 & 3 & 0.006105 & 0 & 0.00611 & 0.00611 \\ 2 & 3 & 0.006105 & 0 & 0.00611 & 0.00611\end{array}$

$\begin{array}{lllll}3 & 0.006105 & 0 & 0.00611 & 0.00611\end{array}$

$\begin{array}{lllll}3 & 0.006105 & 0 & 0.00611 & 0.00611\end{array}$

$\begin{array}{lllll}3 & 0.006105 & 0 & 0.00611 & 0.00611 \\ 3 & 0.006105 & 0 & 0.00611 & 0.00611\end{array}$

Std Error uses a pooled estimate of error variance 


\section{Exhibit D4: PSAL Measurements by Analytical Block for Samples of the} Standard Glasses Prepared Using the PF Method

Oneway Analysis of B2O3 (wt\%) By Block Glass ID=Batch 1 Reference Value $=7.777 \mathrm{wt} \%$

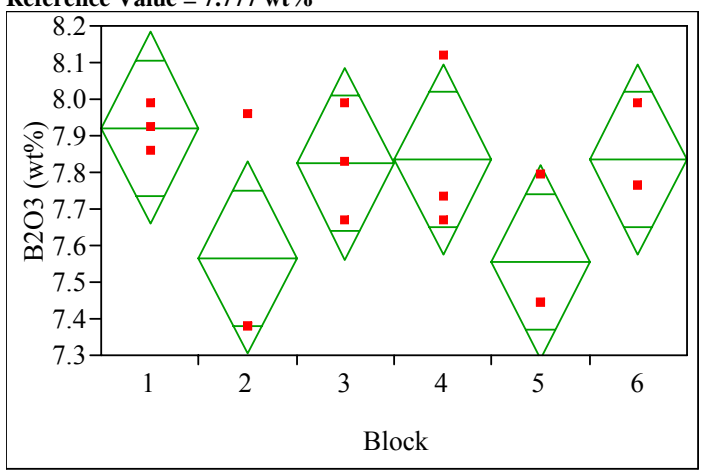

Oneway Anova

Summary of Fit

$\begin{array}{lr}\text { Rsquare } & 0.409257 \\ \text { Adj Rsquare } & 0.163115 \\ \text { Root Mean Square Error } & 0.208259 \\ \text { Mean of Response } & 7.756381 \\ \text { Observations (or Sum Wgts) } & 18\end{array}$

\section{Analysis of Variance}

Source DF Sum of Squares Mean Square F Ratio Prob $>$ F $\begin{array}{llllll}\text { Block } & 5 & 0.36056751 & 0.072114 & 1.6627 & 0.2179\end{array}$ $\begin{array}{llll}\text { Error } & 12 & 0.52046135 & 0.043372\end{array}$

C. Total $17 \quad 0.88102887$

Means for Oneway Anova

Level Number Mean Std Error Lower 95\% Upper 95\%

$\begin{array}{lrrrrr}1 & 3 & 7.92095 & 0.12024 & 7.6590 & 8.1829 \\ 2 & 3 & 7.56677 & 0.12024 & 7.3048 & 7.8287 \\ 3 & 3 & 7.82436 & 0.12024 & 7.5624 & 8.0863 \\ 4 & 3 & 7.83509 & 0.12024 & 7.5731 & 8.0971 \\ 5 & 3 & 7.55603 & 0.12024 & 7.2941 & 7.8180 \\ 6 & 3 & 7.83509 & 0.12024 & 7.5731 & 8.0971\end{array}$

Std Error uses a pooled estimate of error variance
Oneway Analysis of B2O3 (wt\%) By Block Glass ID=LRM Reference Value $=8.0 \mathrm{wt}$

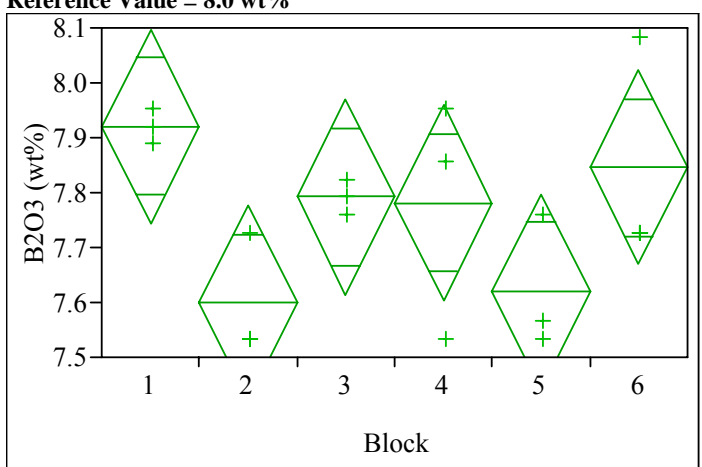

Oneway Anova

Summary of Fit

Rsquare

Adj Rsquare

0.502165

0.294733
Root Mean Square Error $\quad 0.140966$

Mean of Response $\quad 7.759959$

Observations (or Sum Wgts) 18

\section{Analysis of Variance}

Source DF Sum of Squares Mean Square F Ratio Prob $>$ F

$\begin{array}{lllllll}\text { Block } & 5 & 0.24053194 & 0.048106 & 2.4209 & 0.0973\end{array}$

$\begin{array}{llll}\text { Error } & 12 & 0.23845839 & 0.019872\end{array}$

C. Total $17 \quad 0.47899033$

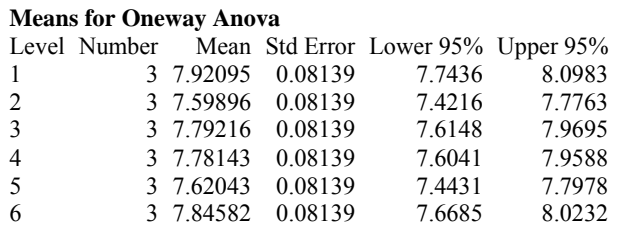

Std Error uses a pooled estimate of error variance 


\section{Exhibit D5: PSAL IC Measurements by Analytical Block for Samples of the LRM Standard Glass}

Oneway Analysis of $\mathrm{Cl}(\mathrm{wt} \%)$ By Block Glass ID=LRM

Reference Value $=0.8 \mathrm{wt} \%$

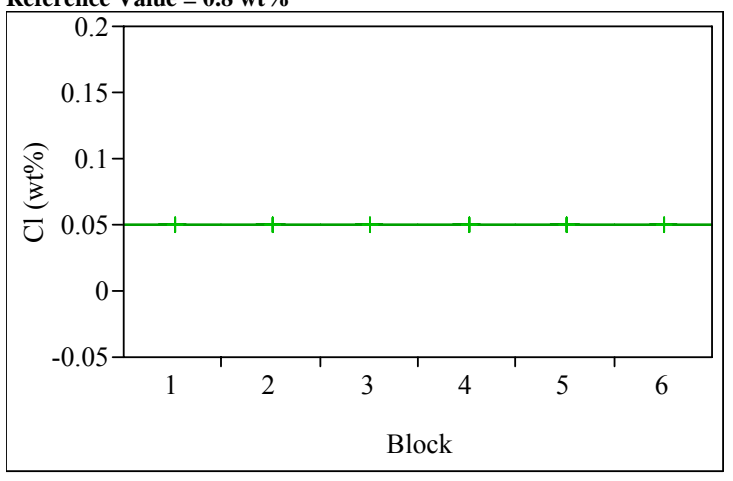

Oneway Anova

Summary of Fit

Rsquare

Adj Rsquare

Root Mean Square Error $\quad-0.41667$

Mean of Response

Observations (or Sun Whe 0.05

Analysis of Variance

Source DF Sum of Squares Mean Square F Ratio Prob $>$ F $\begin{array}{lrrrrr}\text { Block } & 5 & 0 & 0 & 0.0000 & 1.0000\end{array}$ $\begin{array}{llll}\text { Error } & 12 & 8.6667 \mathrm{e}-34 & 7.222 \mathrm{e}-35\end{array}$

C. Total $17 \quad 8.6667 \mathrm{e}-3$

Means for Oneway Ano

$\begin{array}{lrrrrr}\text { Level } & \text { Number } & \text { Mean } & \text { Std Error } & \text { Lower } 95 \% & \text { Upper } 95 \% \\ 1 & 3 & 0.050000 & 4.907 \mathrm{e}-18 & 0.05000 & 0.05000 \\ 2 & 3 & 0.050000 & 4.907 \mathrm{e}-18 & 0.05000 & 0.05000 \\ 3 & 3 & 0.050000 & 4.907 \mathrm{e}-18 & 0.05000 & 0.05000 \\ 4 & 3 & 0.050000 & 4.907 \mathrm{e}-18 & 0.05000 & 0.05000 \\ 5 & 3 & 0.050000 & 4.907 \mathrm{e}-18 & 0.05000 & 0.05000 \\ 6 & 3 & 0.050000 & 4.907 \mathrm{e}-18 & 0.05000 & 0.05000\end{array}$

Std Error uses a pooled estimate of error variance
Oneway Analysis of F (wt\%) By Block Glass ID=LRM

Reference Value $=1.0 \mathrm{wt} \%$

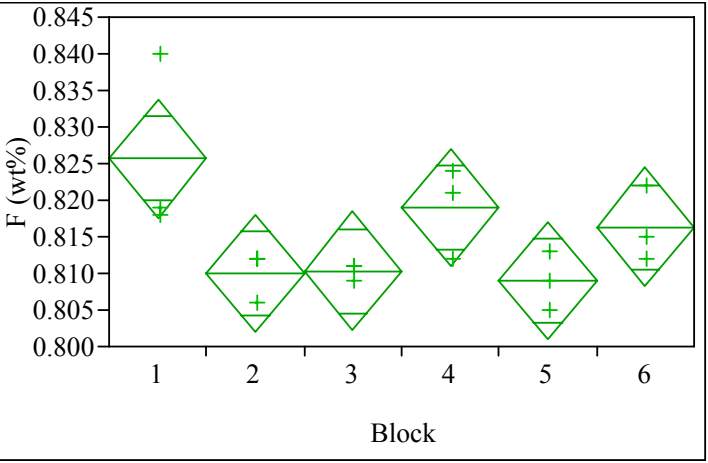

Oneway Anova

Summary of Fi

Rsquare

Adj Rsquare $\quad 0.56352$

Adj Rsquare $\quad 0.381653$

Root Mean Square Error $\quad 0.006442$

Mean of Response

0.815056

Analysis of Variance

Source DF Sum of Squares Mean Square F Ratio Prob $>$ F

$\begin{array}{llllll}\text { Block } & 5 & 0.00064294 & 0.000129 & 3.0985 & 0.0503\end{array}$

0.000041
.0049800

0.00114094

\section{Means for Oneway Anova}

Level Nur Onew Std Error Lower 95\% Upper 95\%

$\begin{array}{llllll}1 & 3 & 0.825667 & 0.00372 & 0.81756 & 0.83377\end{array}$

$\begin{array}{lllll}3 & 0.810000 & 0.00372 & 0.80190 & 0.81810\end{array}$

$\begin{array}{lllll}3 & 0.810333 & 0.00372 & 0.80223 & 0.81844 \\ 3 & 0.819000 & 0.00372 & 0.81090 & 0.82710\end{array}$

$\begin{array}{lllll}3 & 0.819000 & 0.00372 & 0.81090 & 0.82710 \\ 3 & 0.809000 & 0.00372 & 0.80090 & 0.81710\end{array}$

$\begin{array}{lllll}3 & 0.809000 & 0.00372 & 0.80090 & 0.81710 \\ 3 & 0.816333 & 0.00372 & 0.80823 & 0.82444\end{array}$

Std Error uses a pooled estimate of error variance 
Exhibit D6. Measured and Measured Bias-Corrected Oxide Weight Percents by Glass ID by Targeted Value for the Glasses Prepared Using the LM Method

Oxide=Al2O3 (wt\%) Variability Chart for measured

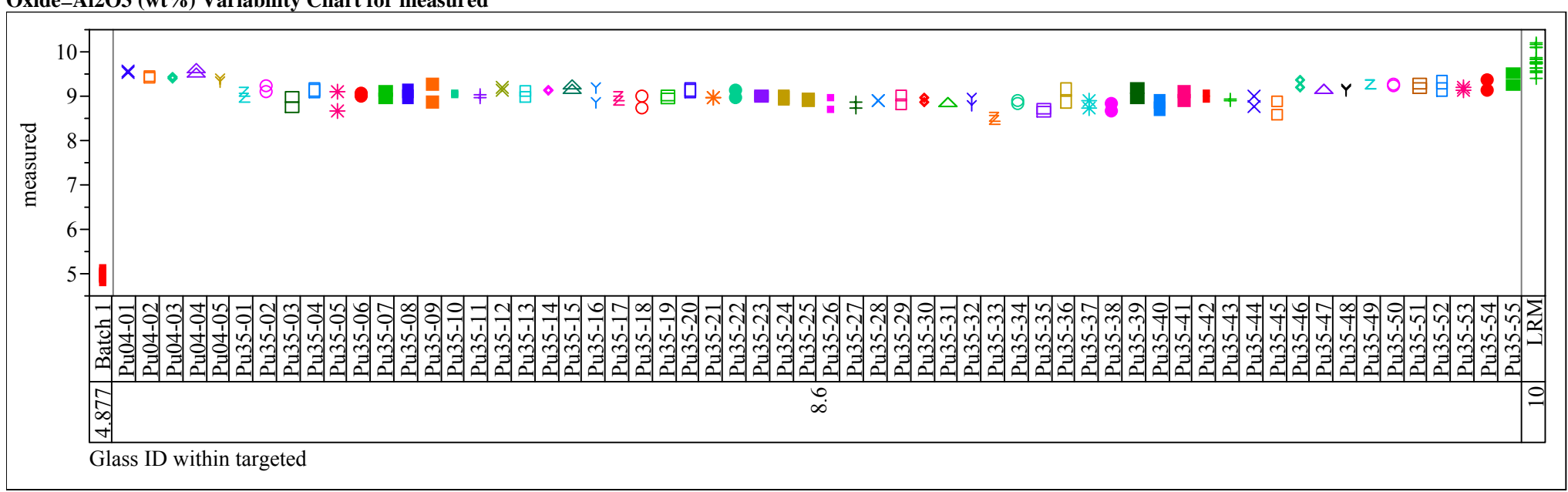

Oxide=Al2O3 (wt\%) Variability Chart for measured bc

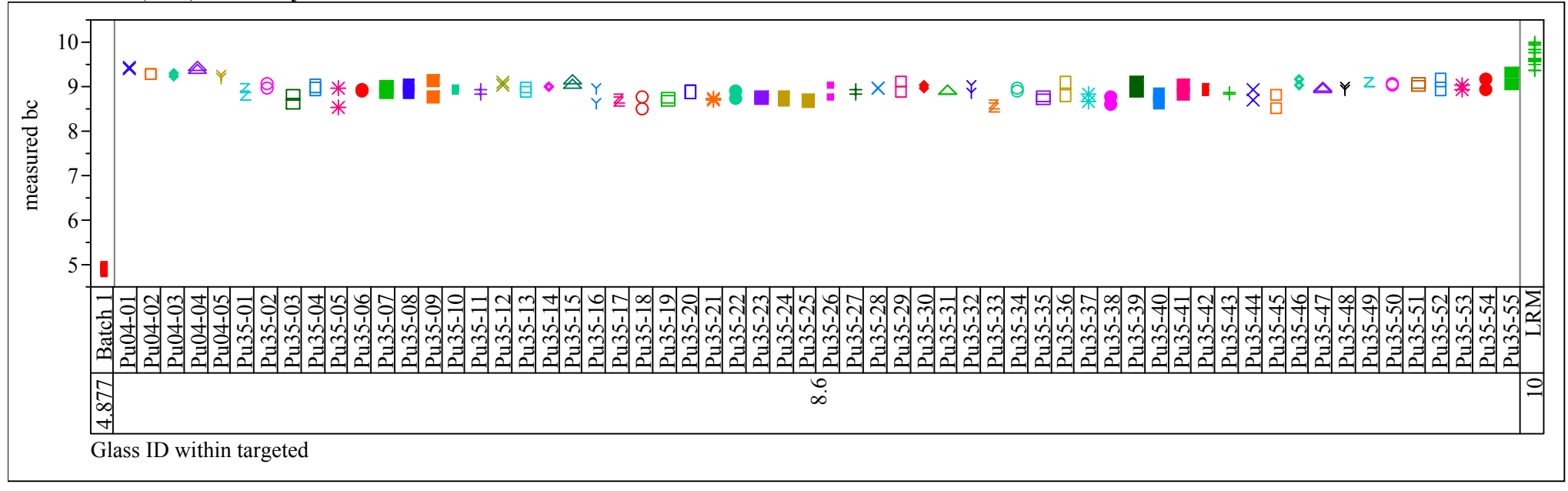


Exhibit D6. Measured and Measured Bias-Corrected Oxide Weight Percents

by Glass ID by Targeted Value for the Glasses Prepared Using the LM Method (continued)

Oxide $=\mathrm{CaO}(\mathrm{wt} \%)$ Variability Chart for measured

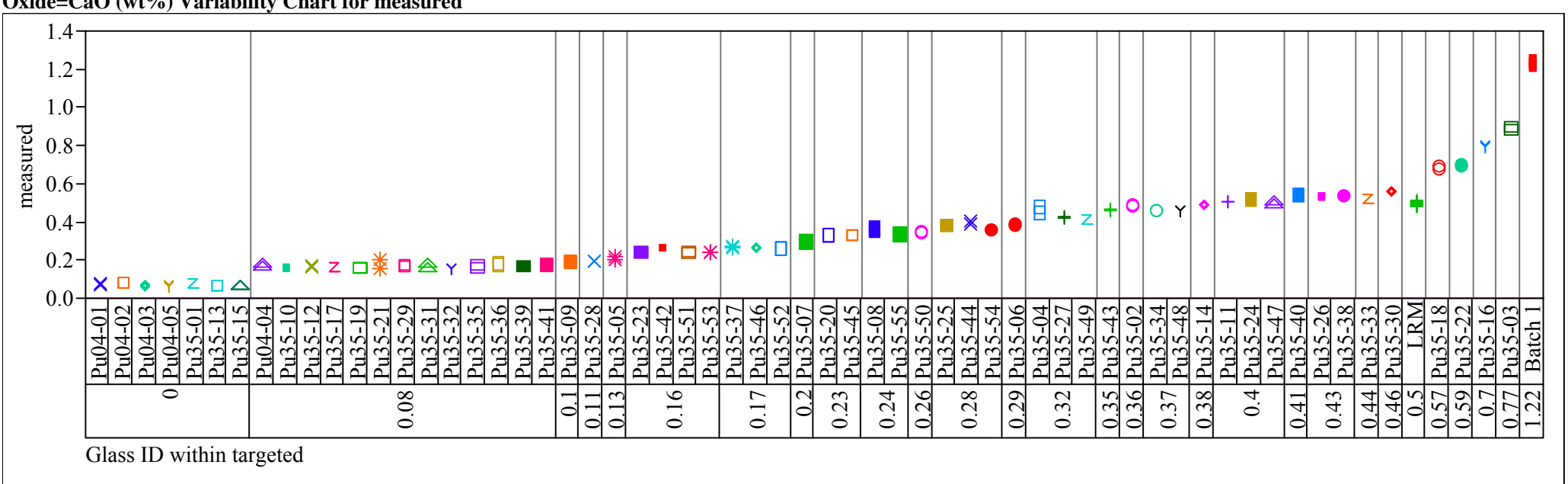

Oxide=CaO (wt\%) Variability Chart for measured bc

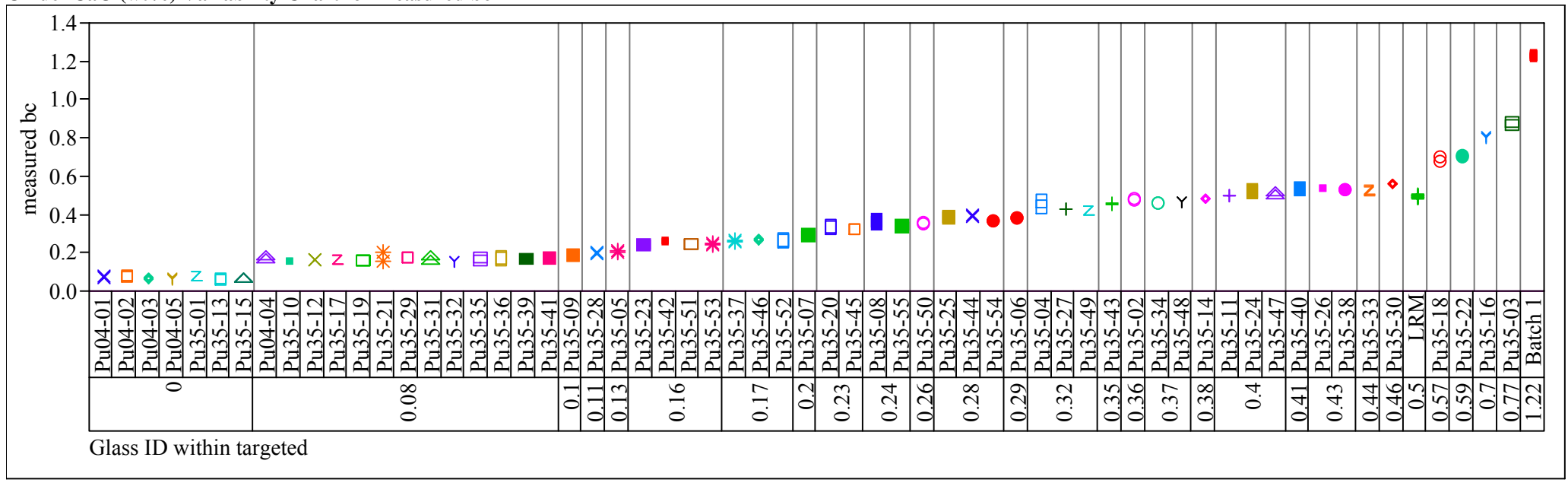


Exhibit D6. Measured and Measured Bias-Corrected Oxide Weight Percents

by Glass ID by Targeted Value for the Glasses Prepared Using the LM Method (continued)

Oxide $=\mathrm{Cr} 2 \mathrm{O} 3(\mathrm{wt} \%)$ Variability Chart for measured

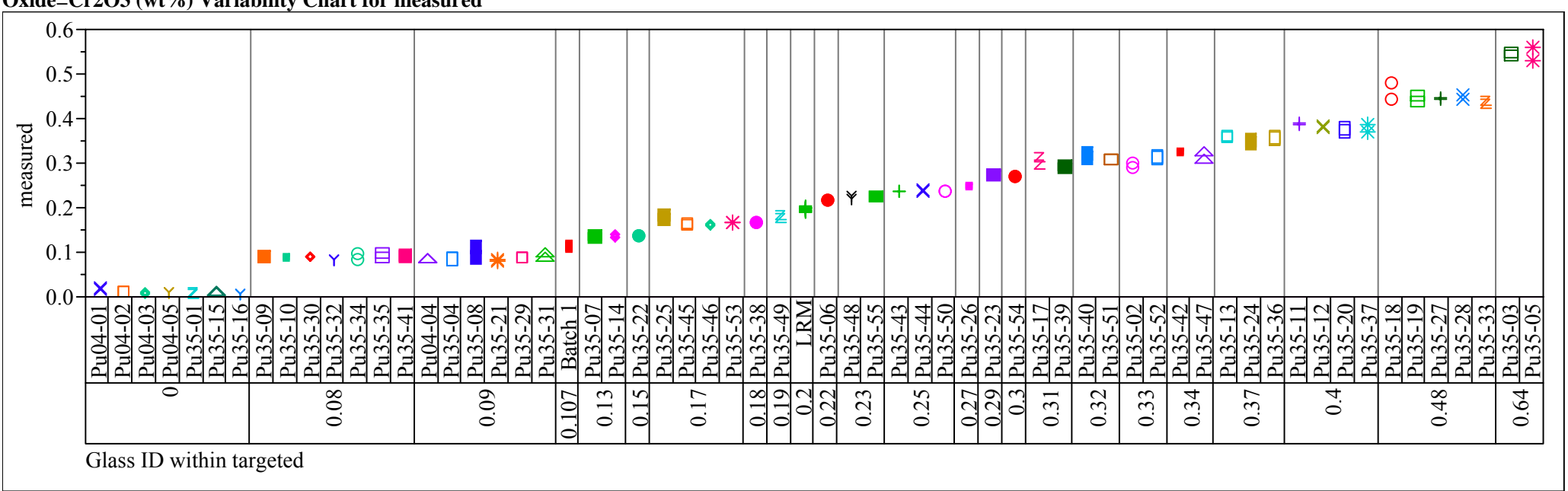

Oxide $=\mathrm{Cr} 2 \mathrm{O} 3(\mathrm{wt} \%)$ Variability Chart for measured bc

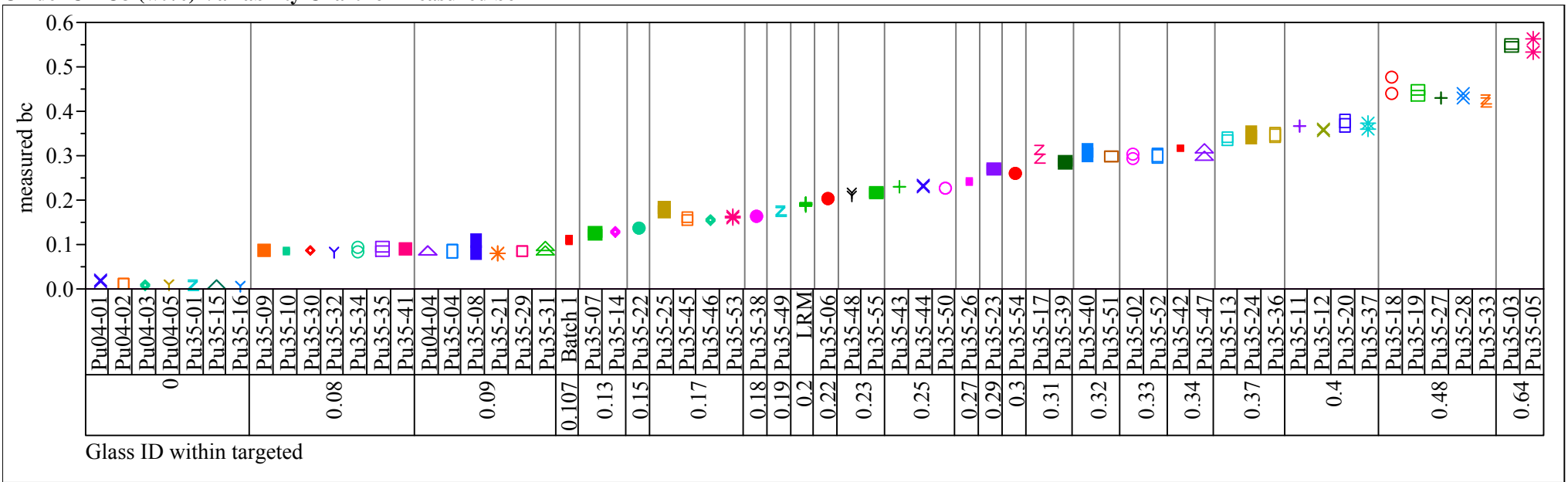


Exhibit D6. Measured and Measured Bias-Corrected Oxide Weight Percents

by Glass ID by Targeted Value for the Glasses Prepared Using the LM Method (continued)

Oxide $=\mathrm{CuO}($ wt $\%)$ Variability Chart for measured

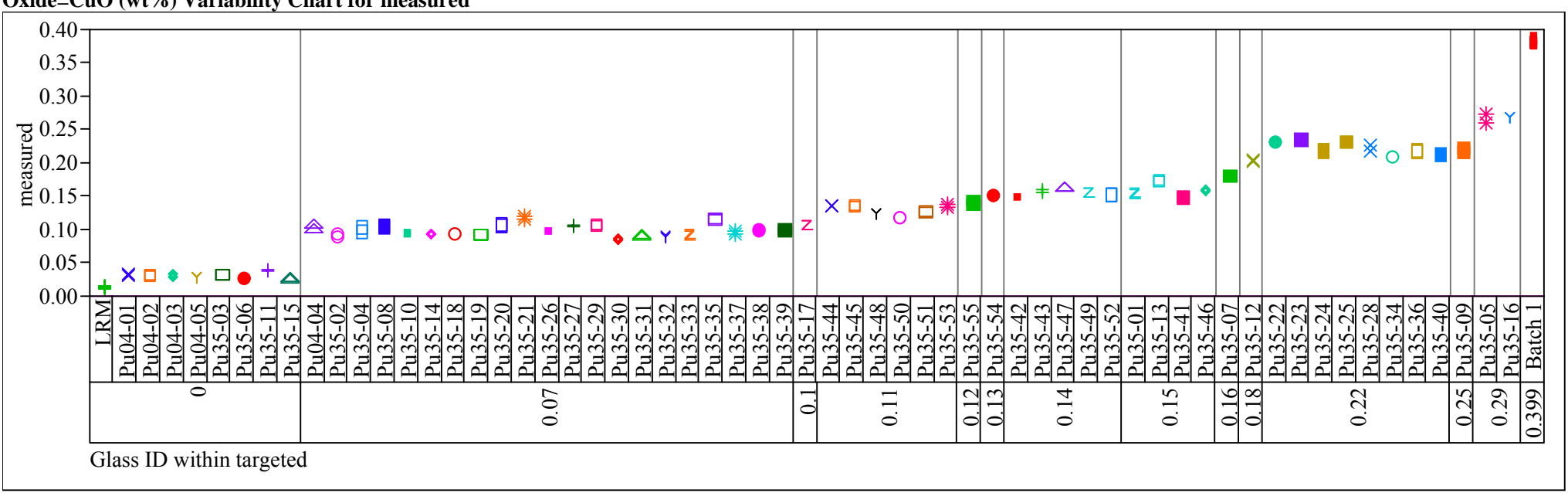

Oxide $=\mathrm{CuO}(\mathrm{wt} \%)$ Variability Chart for measured bc

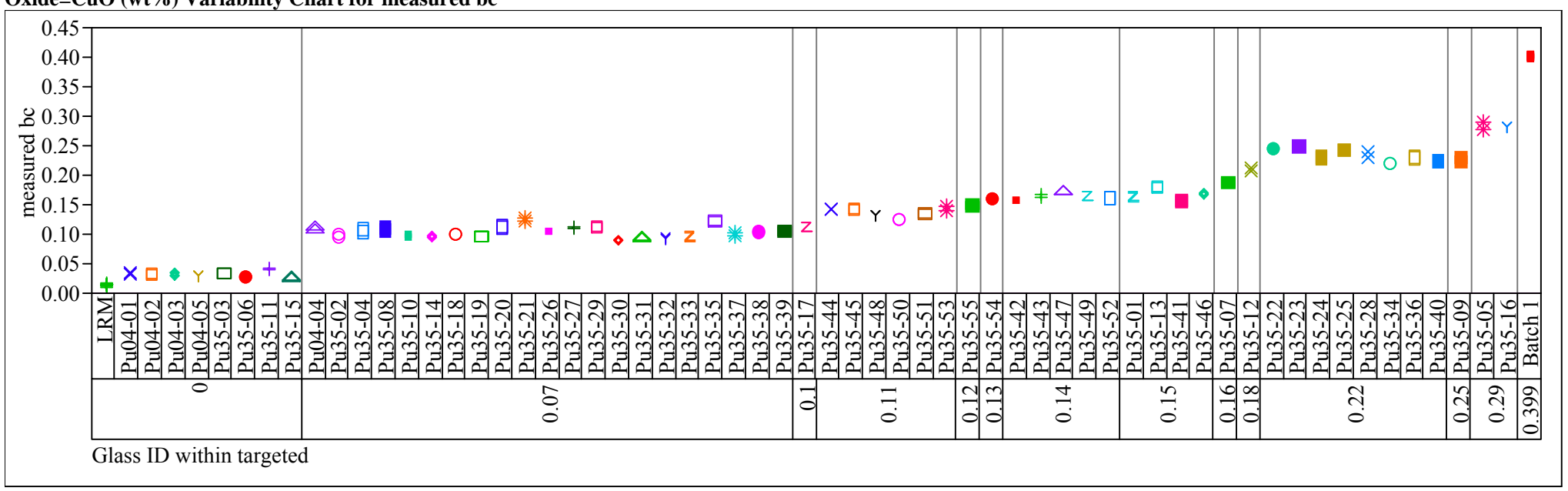


Exhibit D6. Measured and Measured Bias-Corrected Oxide Weight Percents

by Glass ID by Targeted Value for the Glasses Prepared Using the LM Method (continued)

Oxide=Fe2O3 (wt\%) Variability Chart for measured

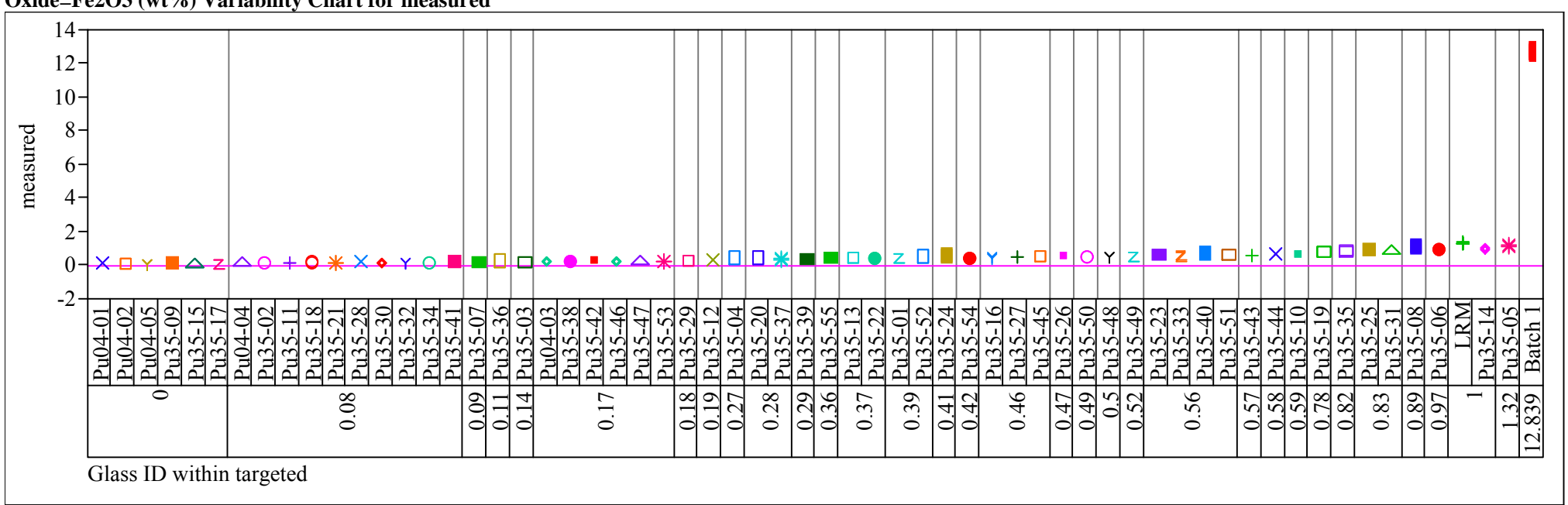

Oxide=Fe2O3 (wt\%) Variability Chart for measured bc

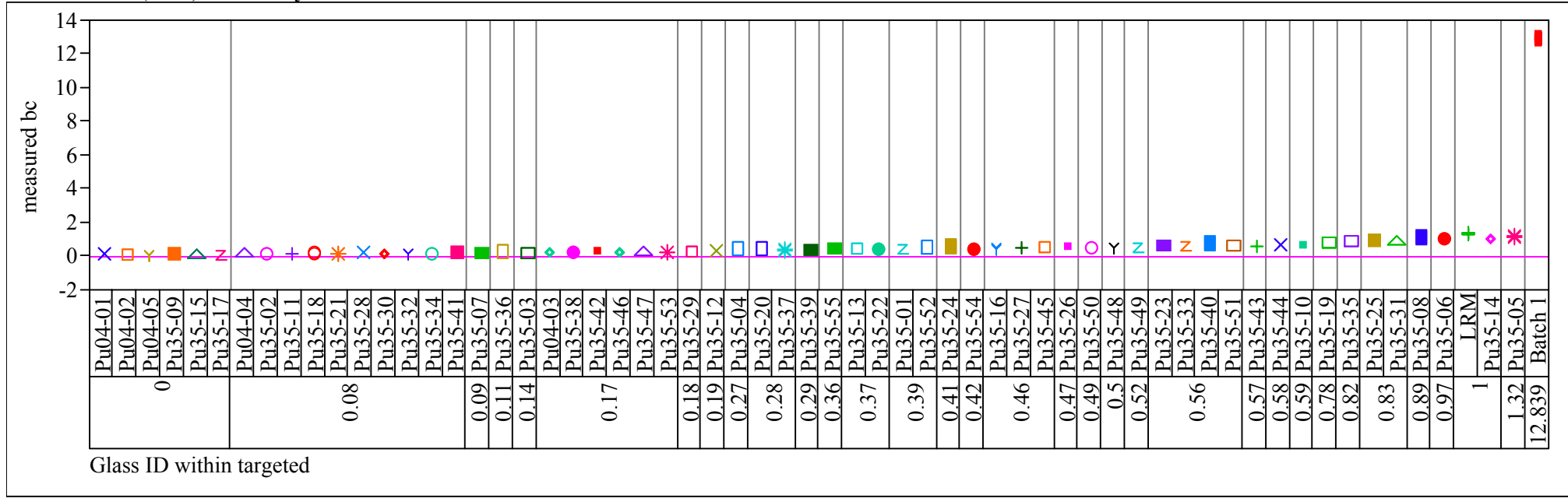


Exhibit D6. Measured and Measured Bias-Corrected Oxide Weight Percents

by Glass ID by Targeted Value for the Glasses Prepared Using the LM Method (continued)

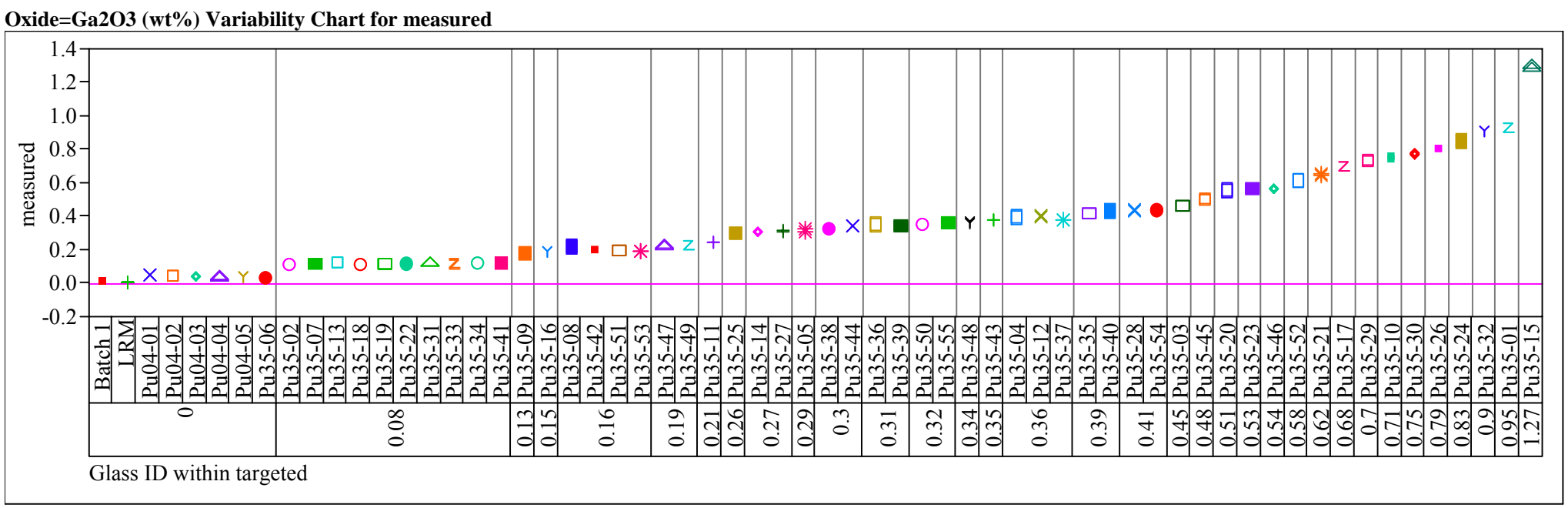

Oxide=Ga2O3 (wt\%) Variability Chart for measured bc

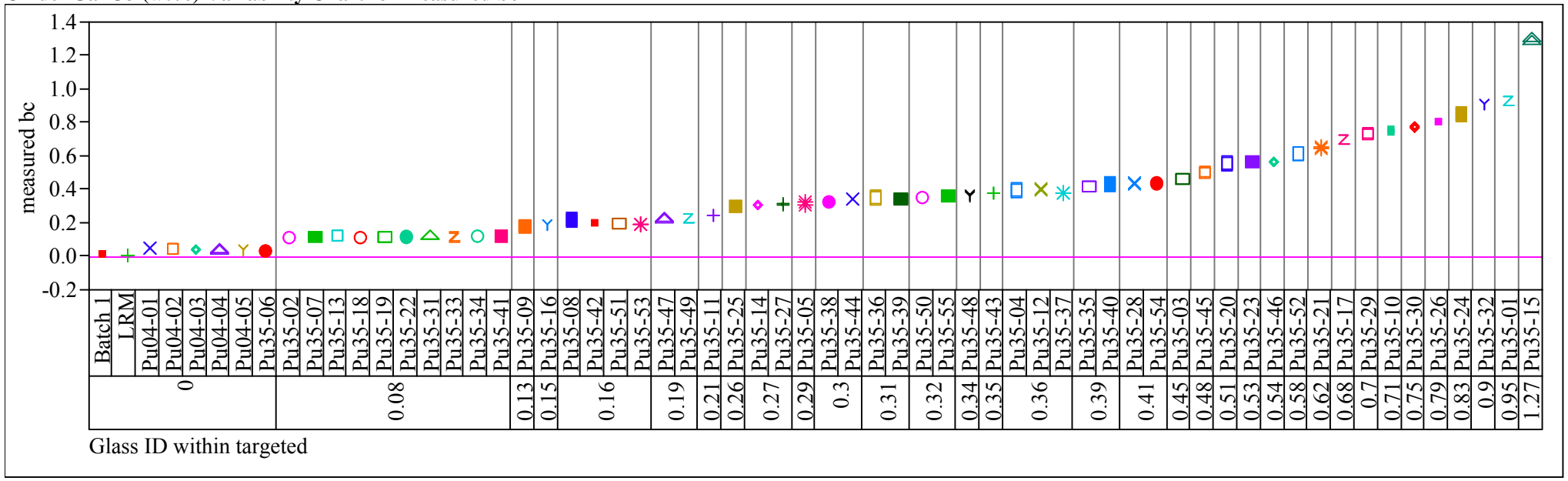


Exhibit D6. Measured and Measured Bias-Corrected Oxide Weight Percents

by Glass ID by Targeted Value for the Glasses Prepared Using the LM Method (continued)

Oxide $=$ Gd2O3 (wt \%) Variability Chart for measured

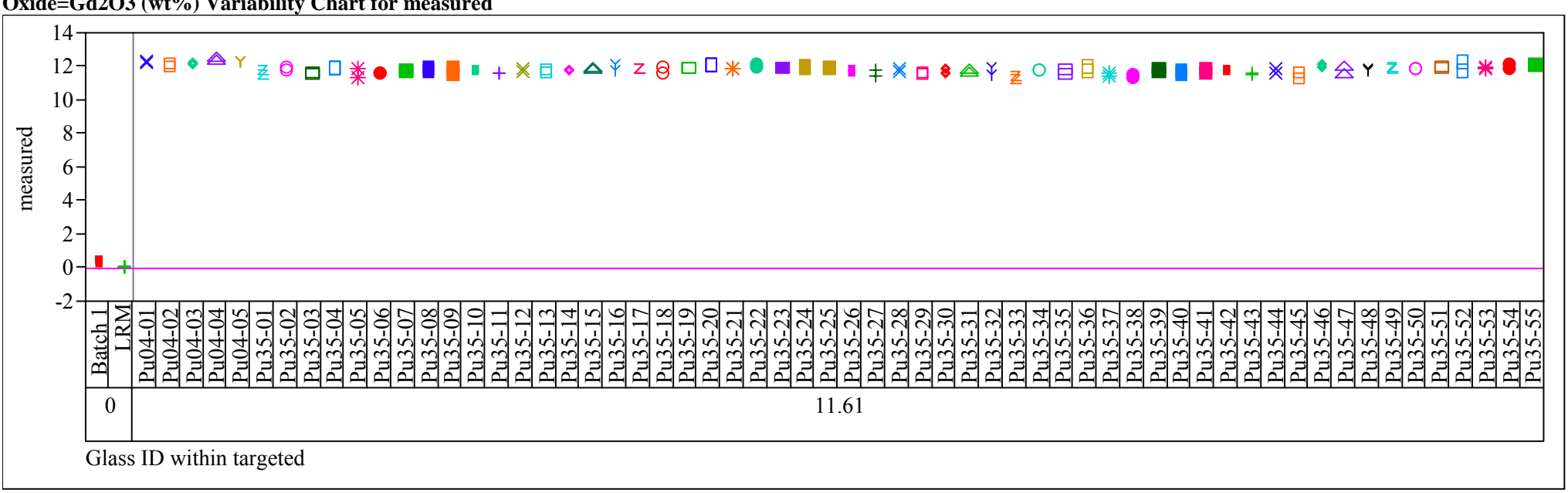

Oxide=Gd2O3 (wt\%) Variability Chart for measured bc

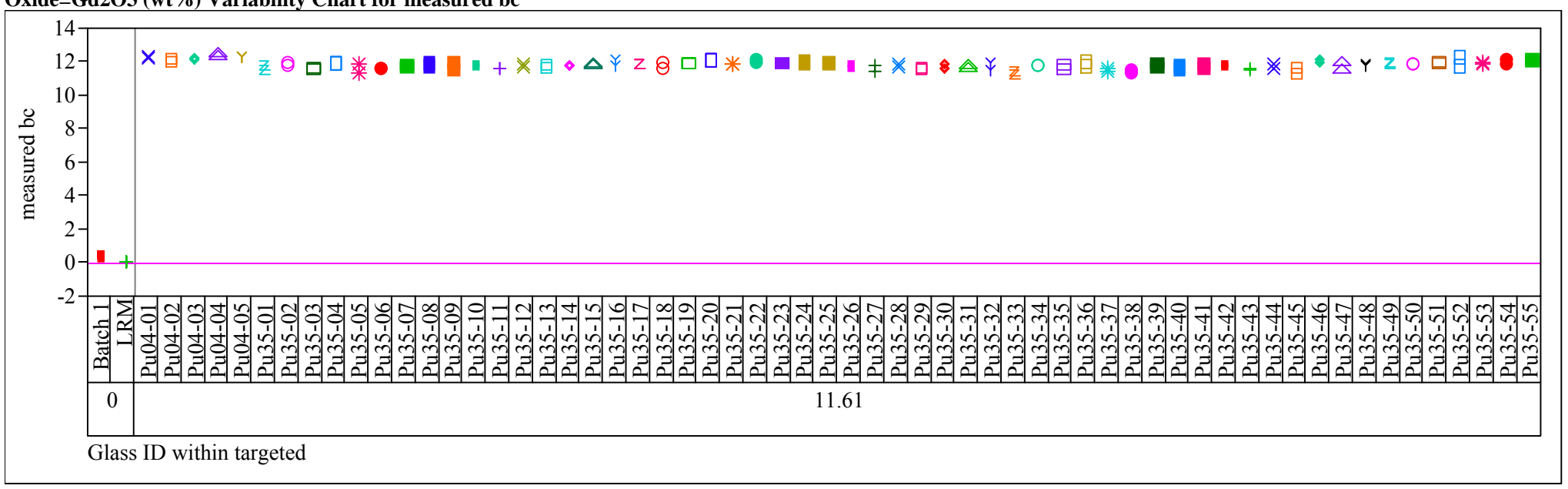


Exhibit D6. Measured and Measured Bias-Corrected Oxide Weight Percents

by Glass ID by Targeted Value for the Glasses Prepared Using the LM Method (continued)

Oxide=HfO2 (wt \%) Variability Chart for measured

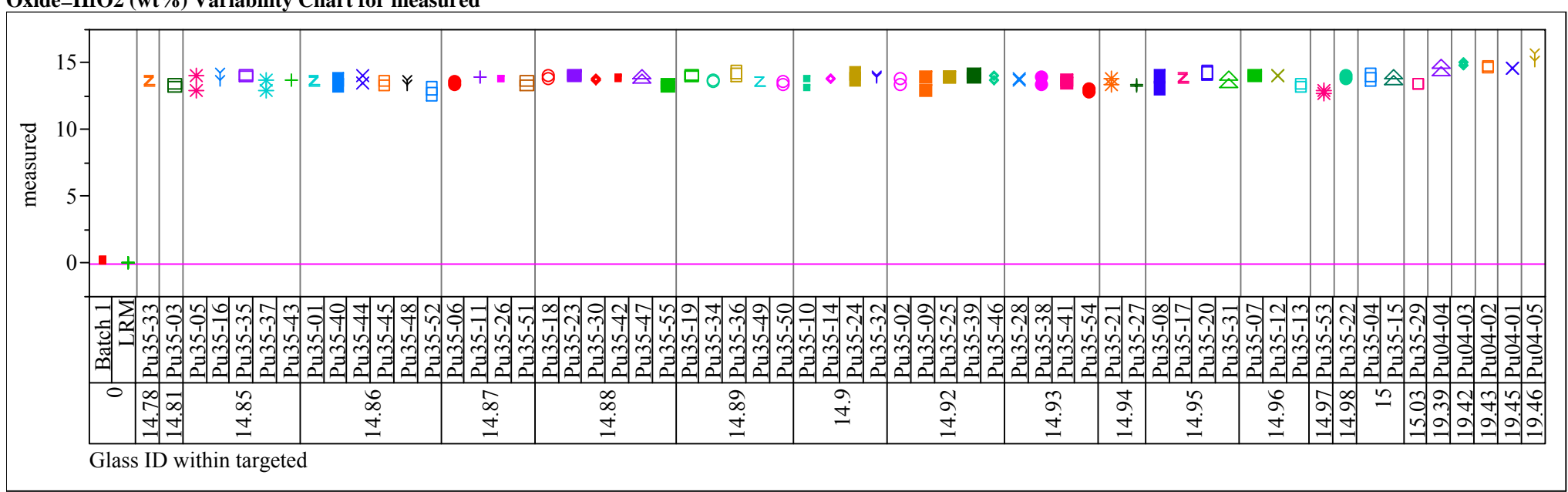

Oxide=HfO2 (wt\%) Variability Chart for measured bc

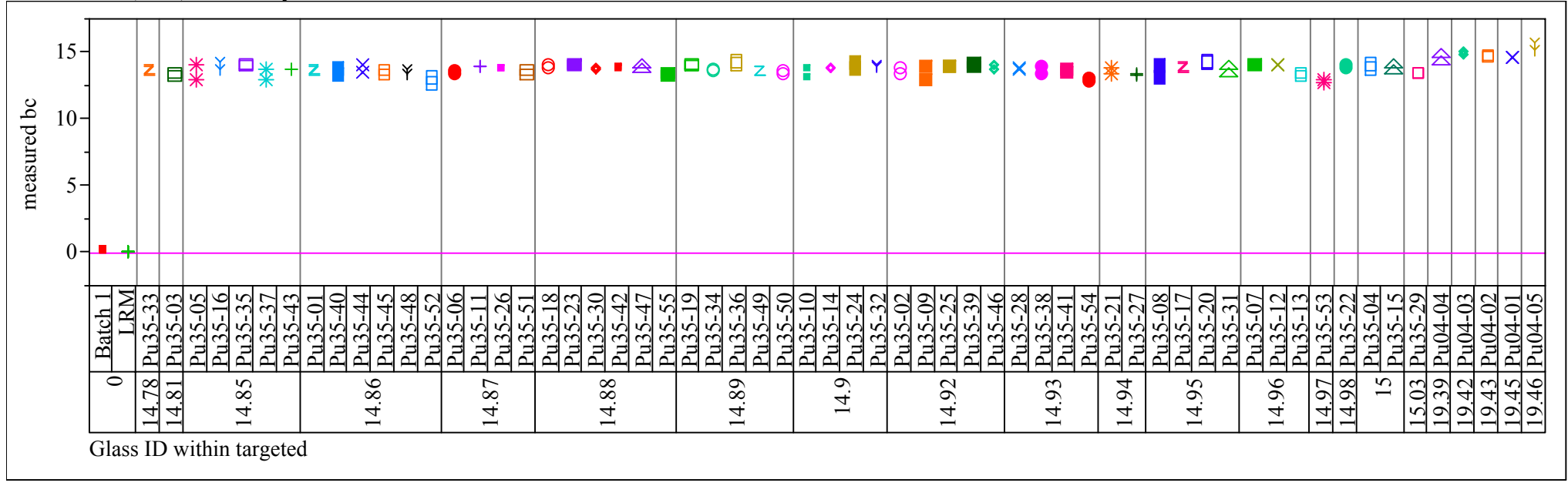


Exhibit D6. Measured and Measured Bias-Corrected Oxide Weight Percents

by Glass ID by Targeted Value for the Glasses Prepared Using the LM Method (continued)

Oxide=K2O (wt\%) Variability Chart for measured

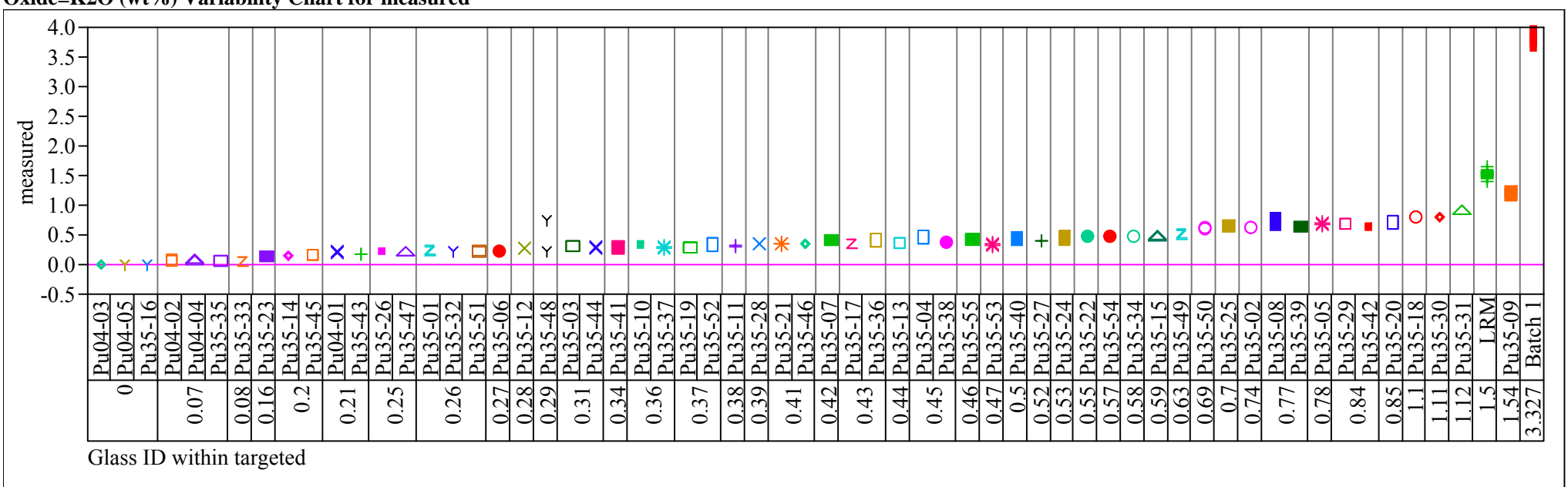

Oxide=K2O (wt\%) Variability Chart for measured bc

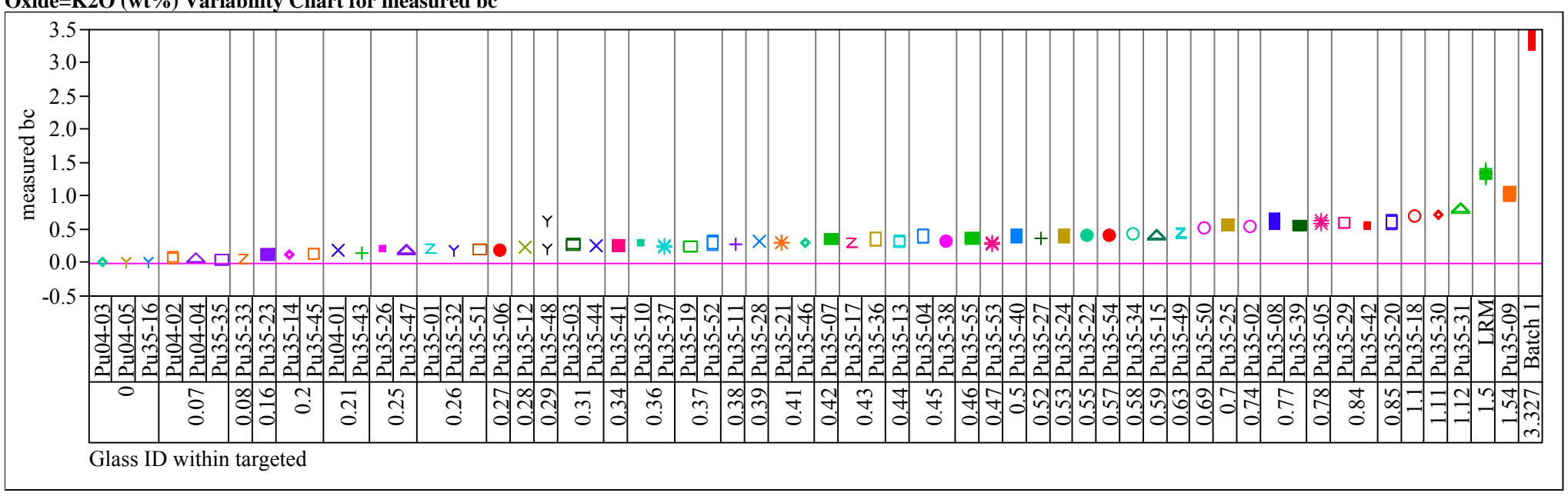


Exhibit D6. Measured and Measured Bias-Corrected Oxide Weight Percents

by Glass ID by Targeted Value for the Glasses Prepared Using the LM Method (continued)

Oxide=La2O3 (wt \%) Variability Chart for measured

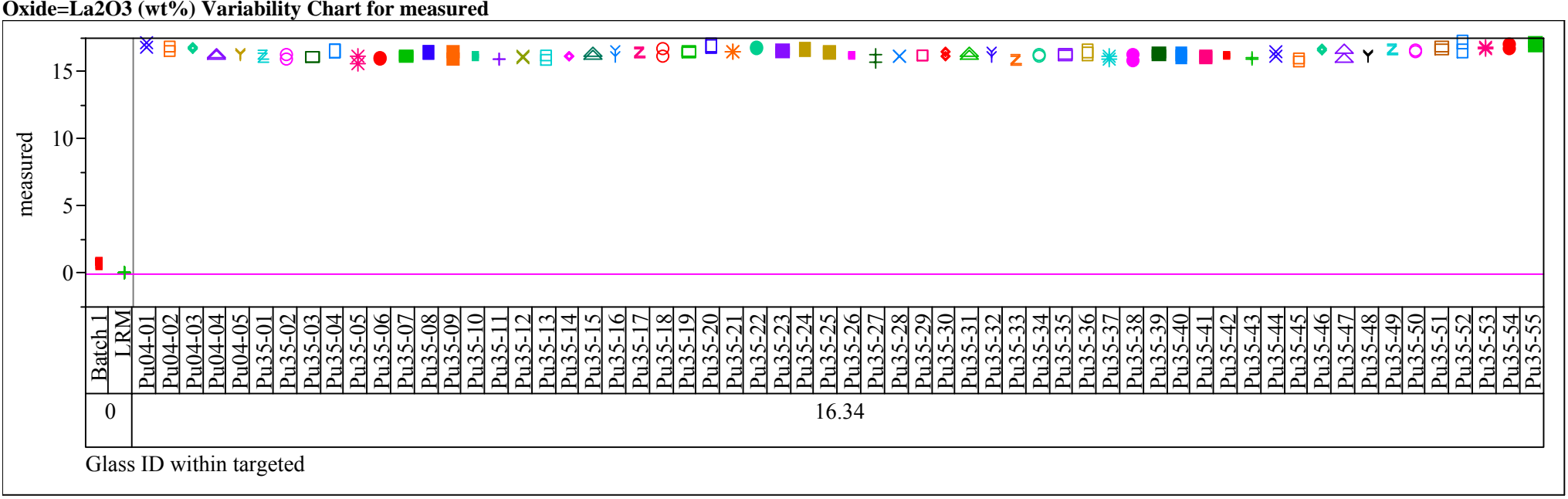

Oxide=La2O3 (wt\%) Variability Chart for measured bc

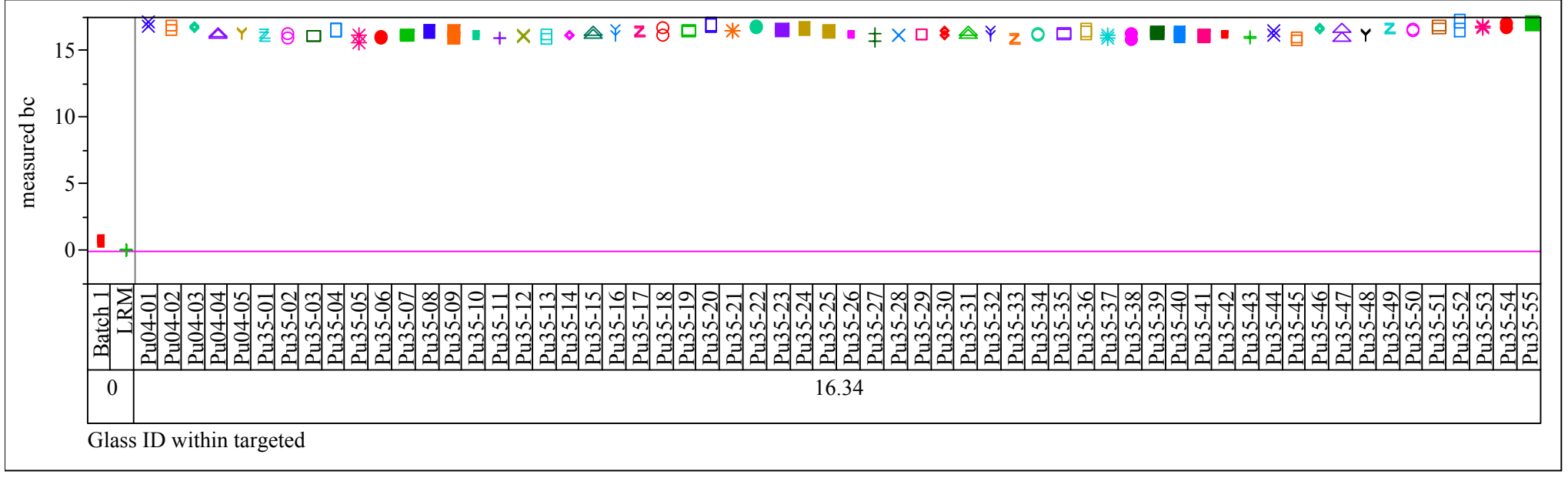


Exhibit D6. Measured and Measured Bias-Corrected Oxide Weight Percents

by Glass ID by Targeted Value for the Glasses Prepared Using the LM Method (continued)

Oxide=MgO (wt \%) Variability Chart for measured

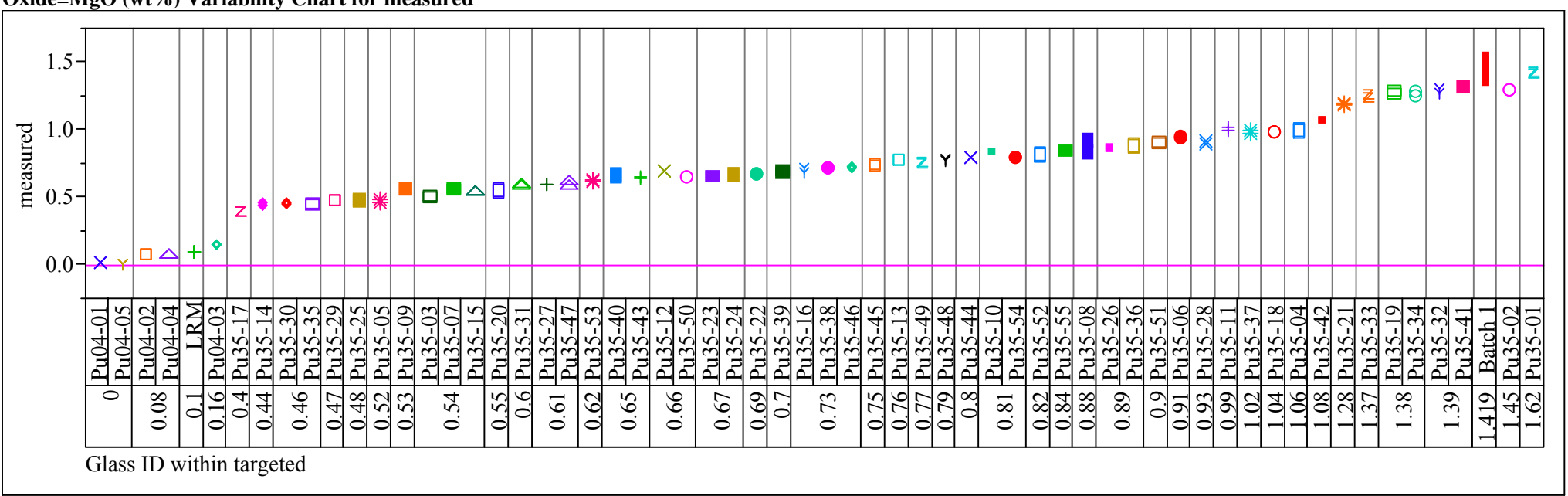

Oxide=MgO (wt\%) Variability Chart for measured bc

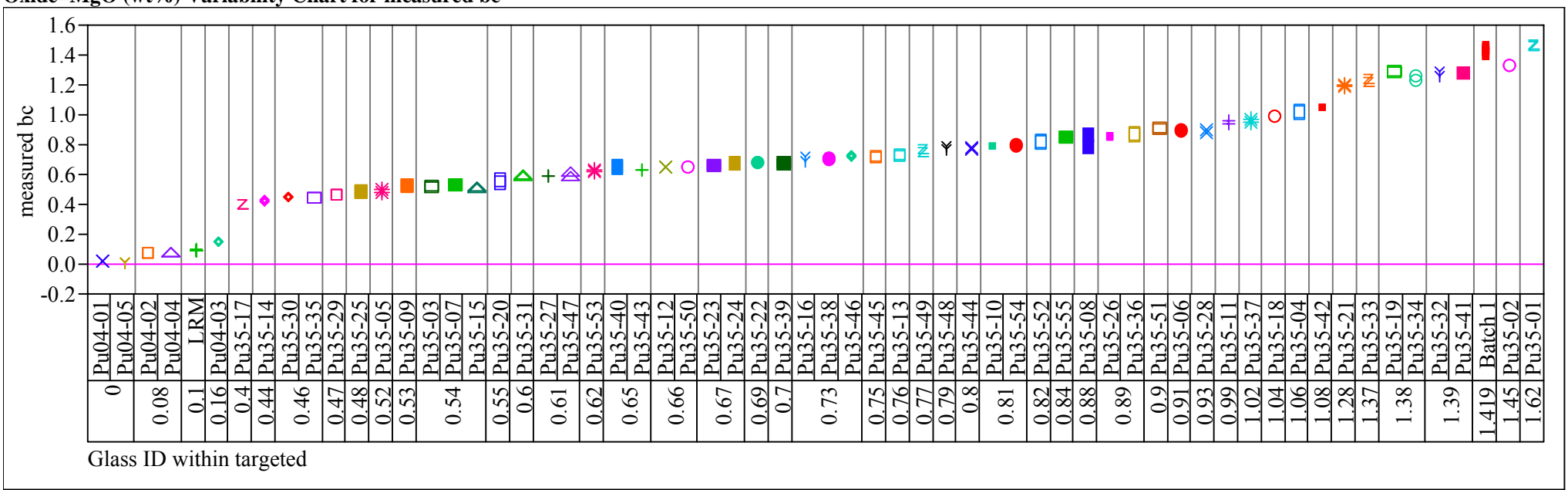


Exhibit D6. Measured and Measured Bias-Corrected Oxide Weight Percents

by Glass ID by Targeted Value for the Glasses Prepared Using the LM Method (continued)

Oxide=Na2O (wt \%) Variability Chart for measured

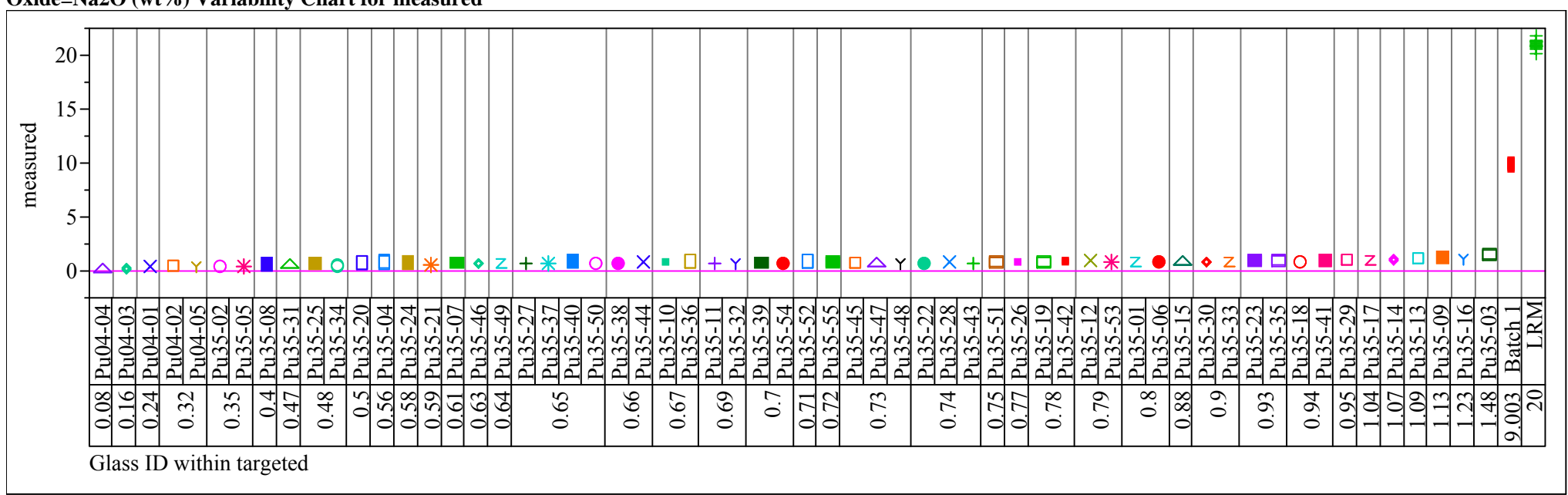

Oxide $=\mathrm{Na2O}(\mathrm{wt} \%)$ Variability Chart for measured bc

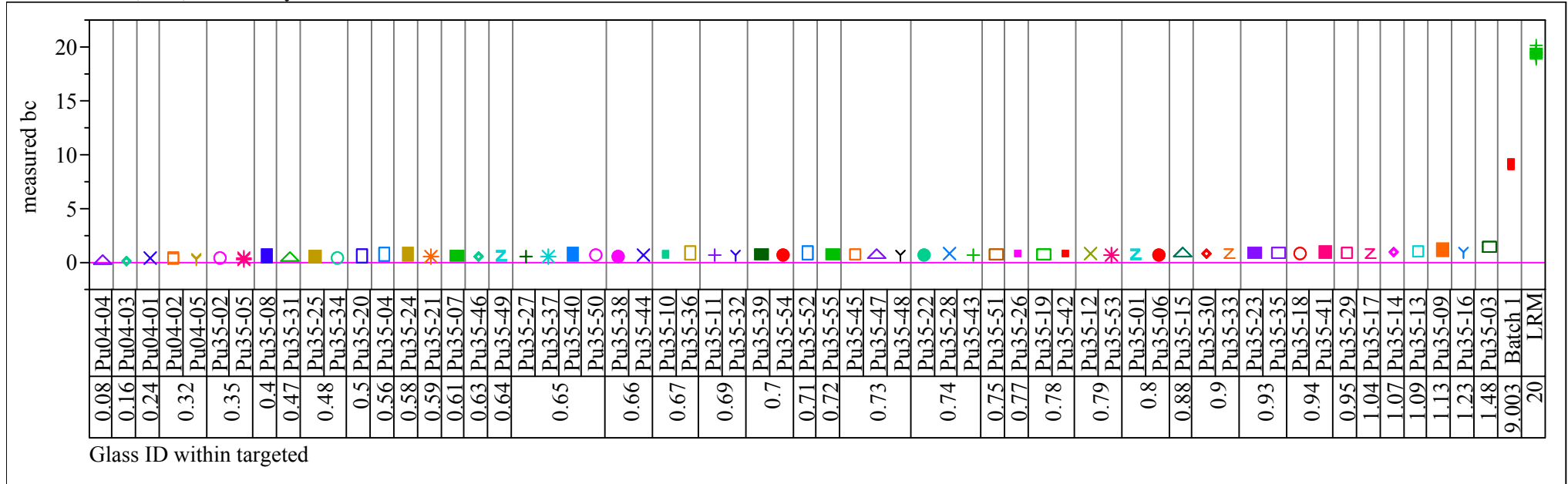


Exhibit D6. Measured and Measured Bias-Corrected Oxide Weight Percents

by Glass ID by Targeted Value for the Glasses Prepared Using the LM Method (continued)

Oxide=Nd2O3 (wt\%) Variability Chart for measured

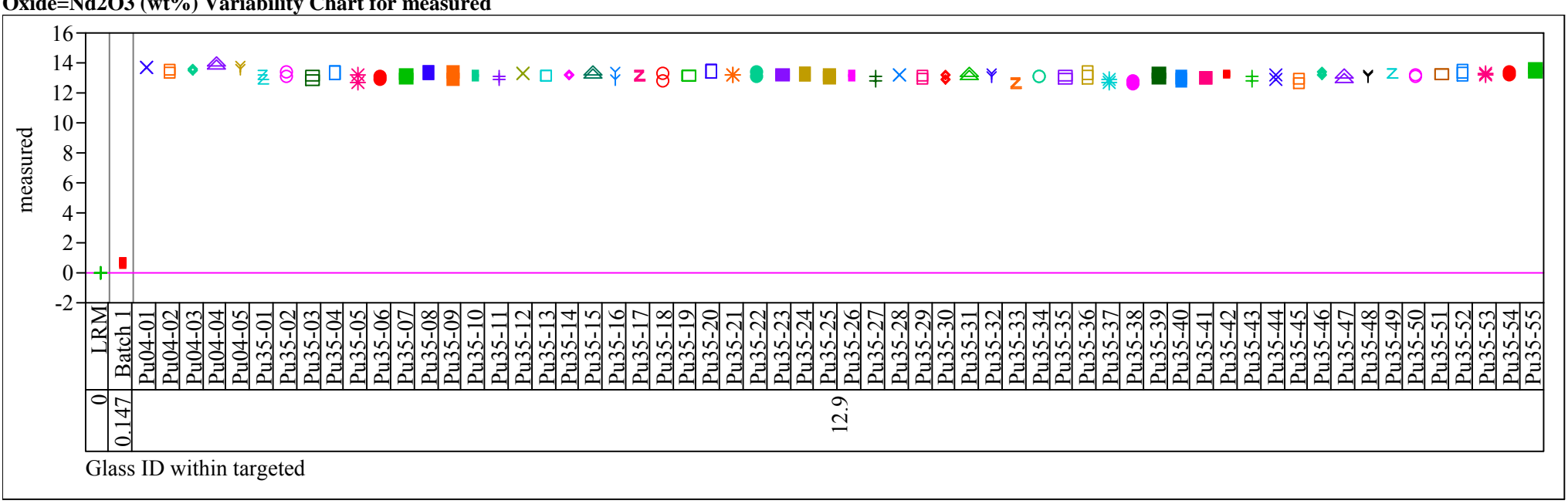

Oxide=Nd2O3 (wt\%) Variability Chart for measured bc

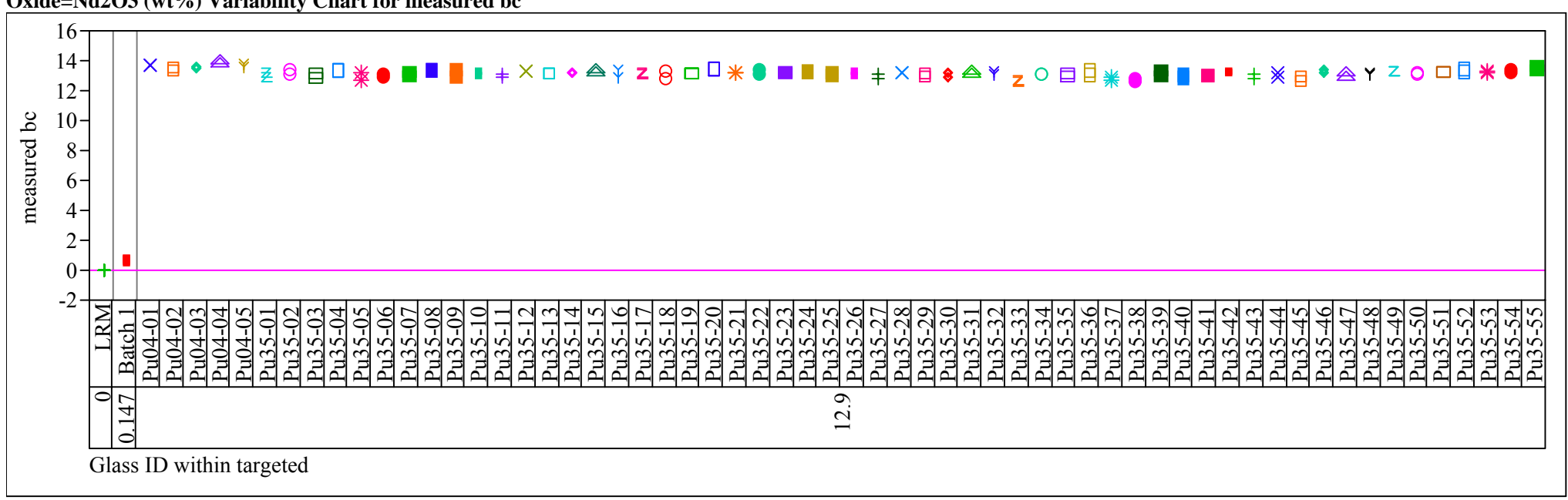


Exhibit D6. Measured and Measured Bias-Corrected Oxide Weight Percents

by Glass ID by Targeted Value for the Glasses Prepared Using the LM Method (continued)

Oxide=NiO (wt\%) Variability Chart for measured

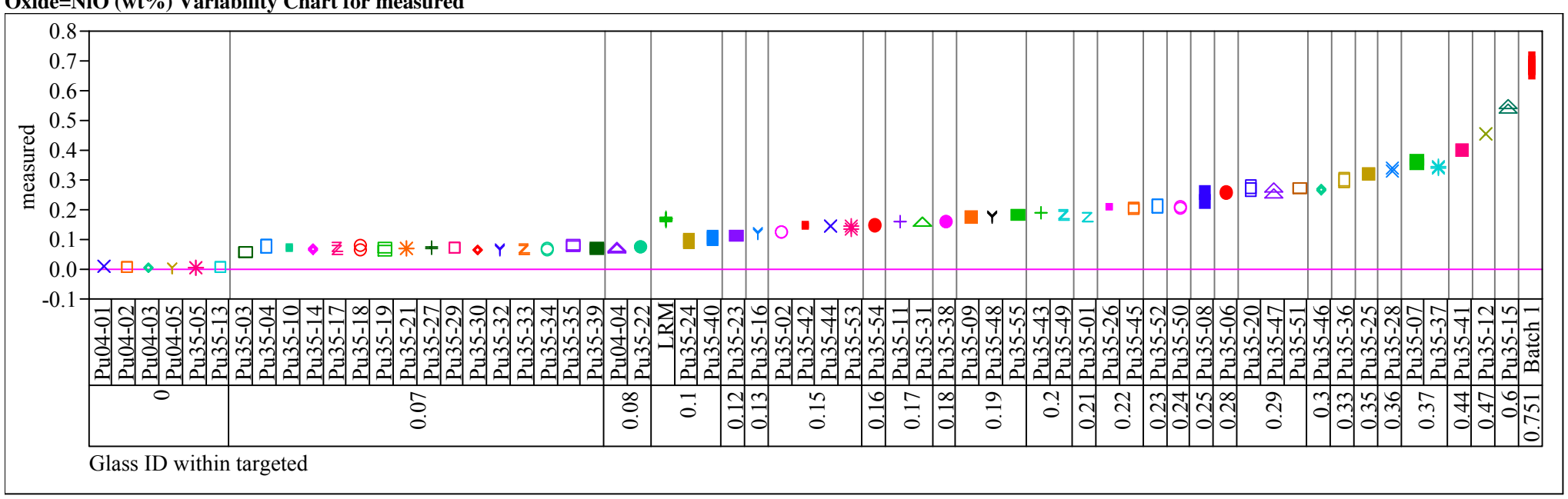

Oxide $=\mathrm{NiO}(\mathrm{wt} \%)$ Variability Chart for measured bc

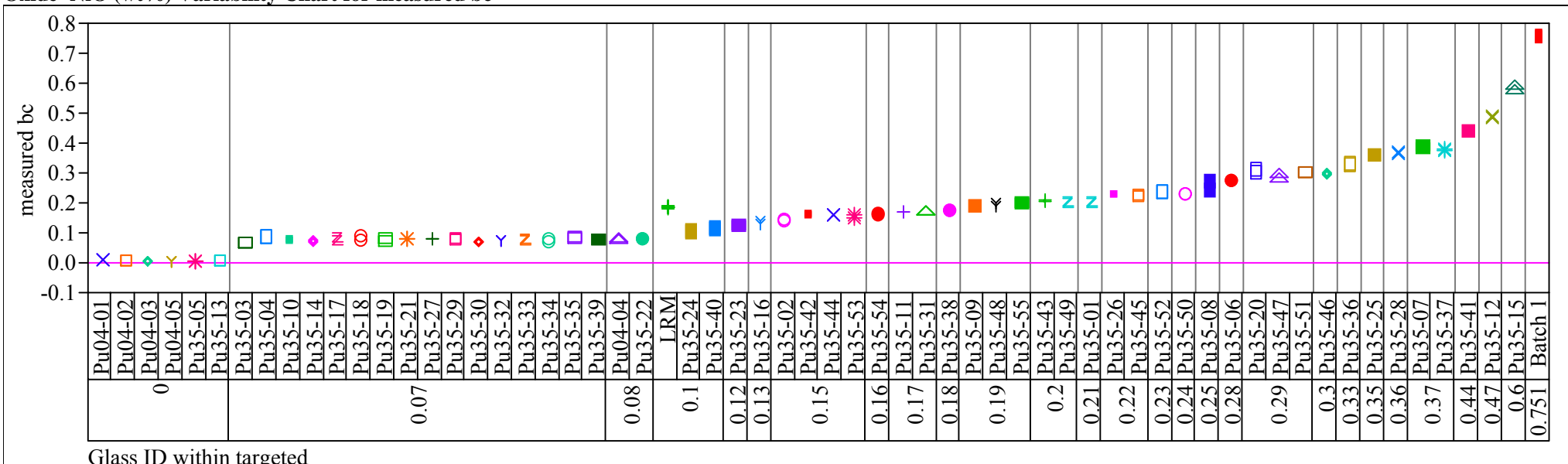


Exhibit D6. Measured and Measured Bias-Corrected Oxide Weight Percents

by Glass ID by Targeted Value for the Glasses Prepared Using the LM Method (continued)

Oxide=PbO (wt\%) Variability Chart for measured

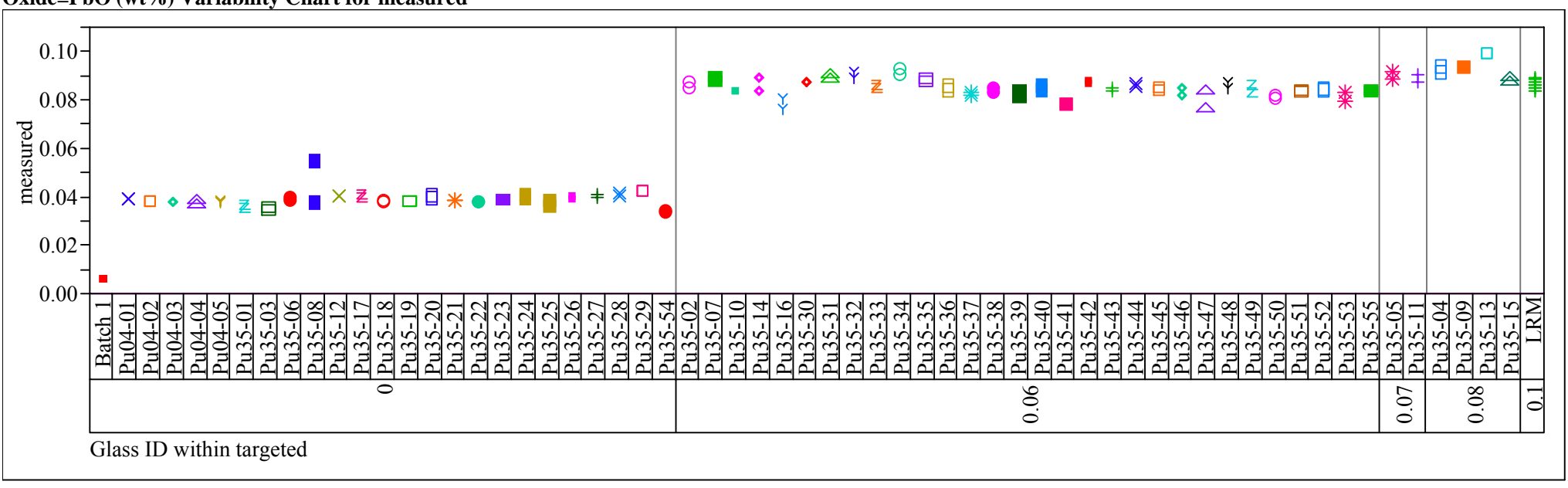

Oxide $=\mathbf{P b O}(\mathrm{wt} \%)$ Variability Chart for measured bc

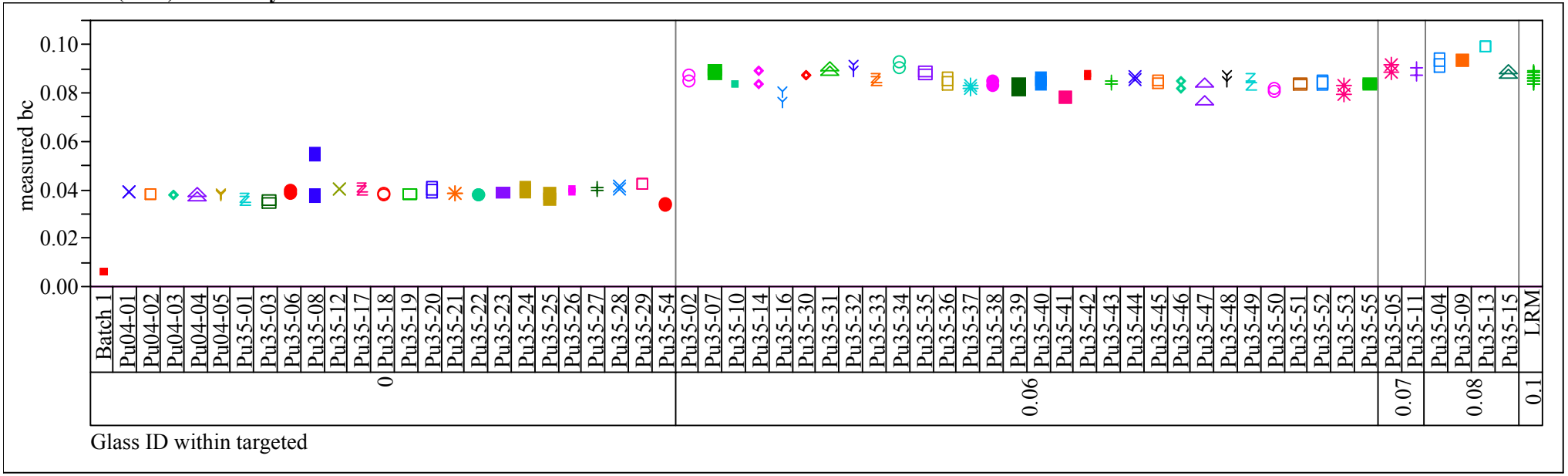


Exhibit D6. Measured and Measured Bias-Corrected Oxide Weight Percents

by Glass ID by Targeted Value for the Glasses Prepared Using the LM Method (continued)

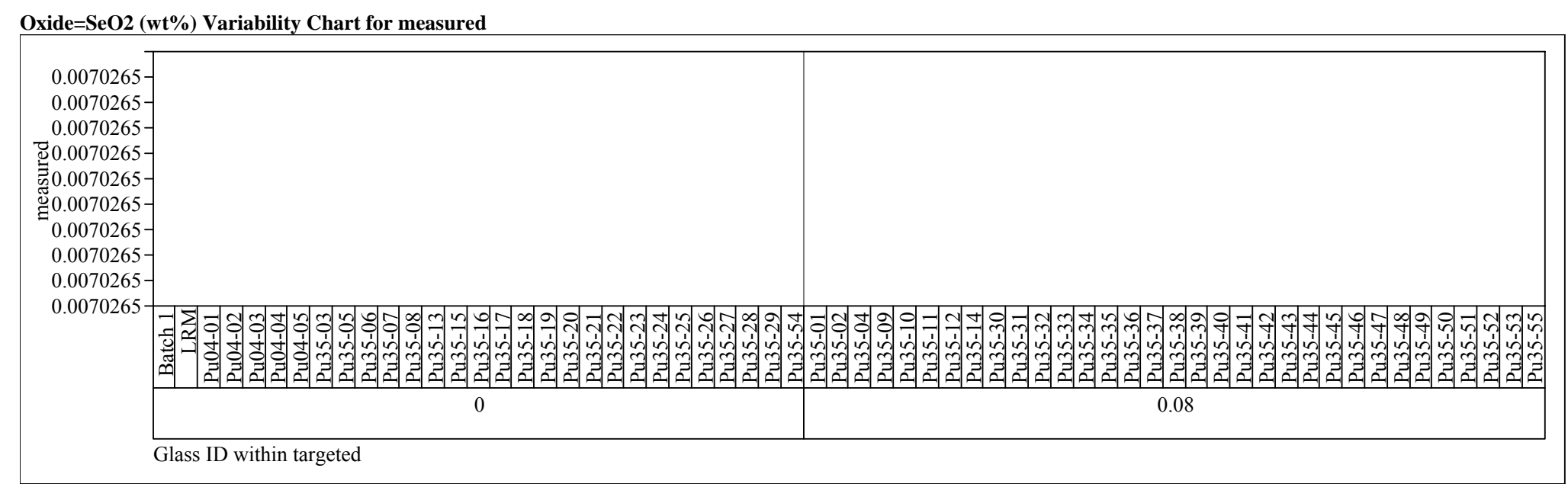

Oxide=SeO2 (wt\%) Variability Chart for measured bc

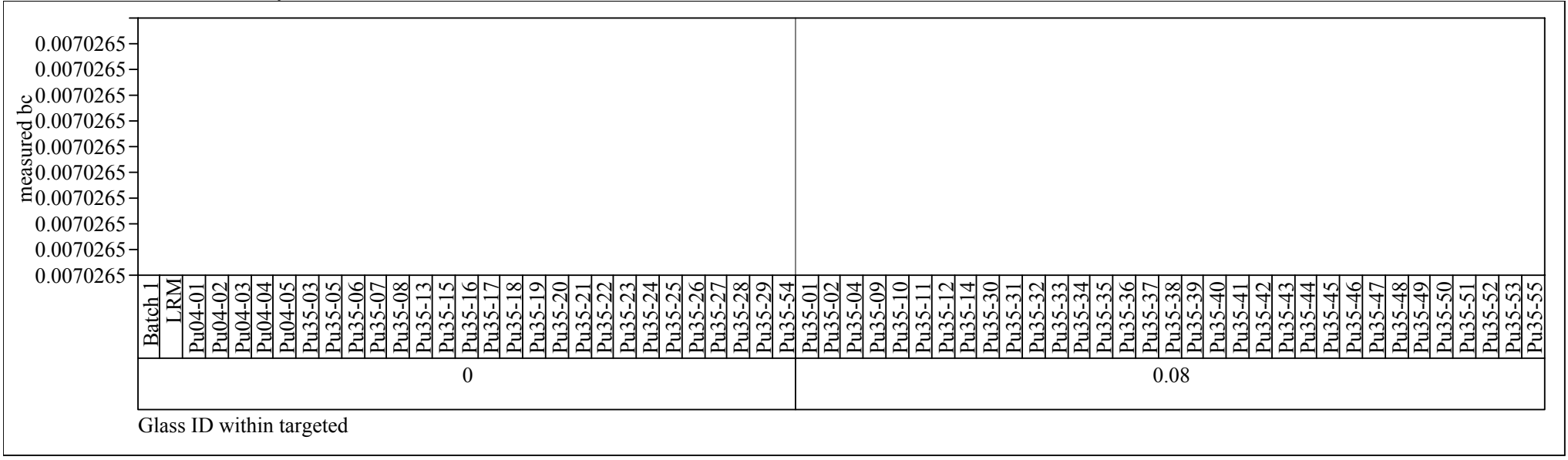


Exhibit D6. Measured and Measured Bias-Corrected Oxide Weight Percents

by Glass ID by Targeted Value for the Glasses Prepared Using the LM Method (continued)

Oxide=Si2O3 (wt\%) Variability Chart for measured

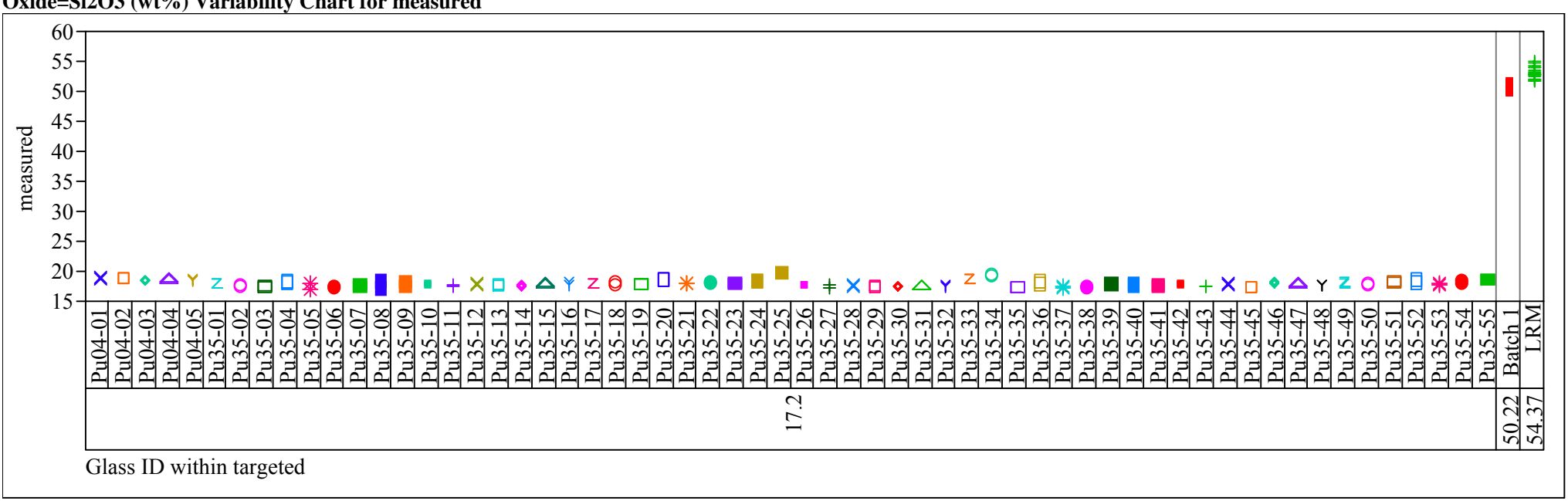

Oxide=Si2O3 (wt \%) Variability Chart for measured bc

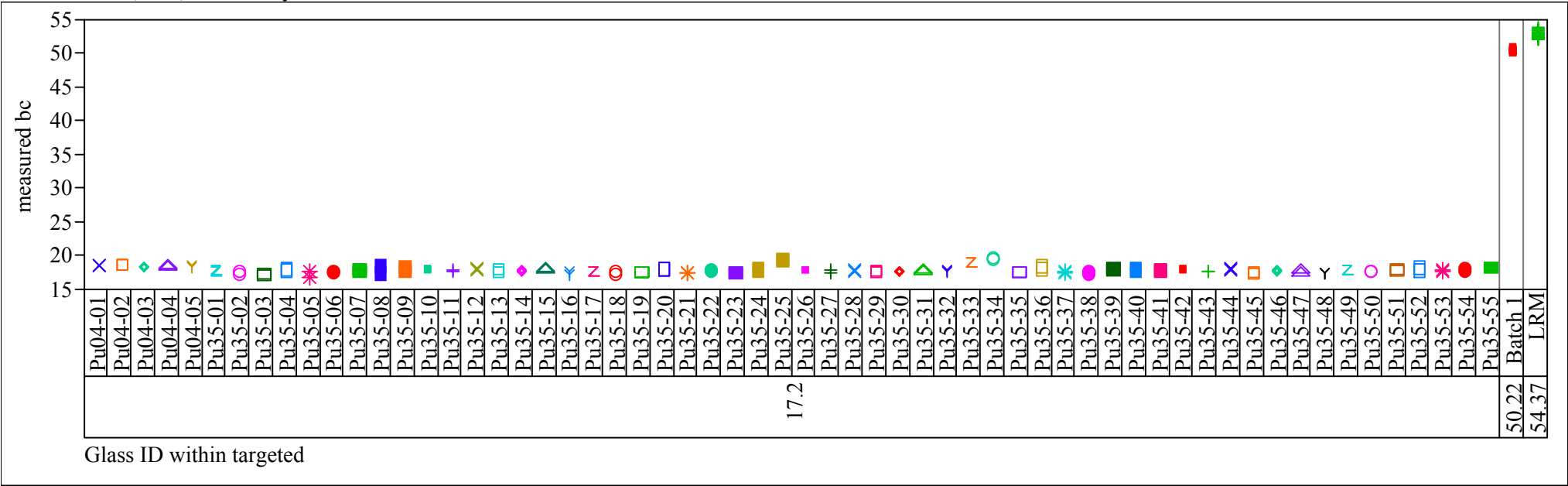


Exhibit D6. Measured and Measured Bias-Corrected Oxide Weight Percents

by Glass ID by Targeted Value for the Glasses Prepared Using the LM Method (continued)

Oxide $=\mathrm{SO} 4$ (wt \%) Variability Chart for measured

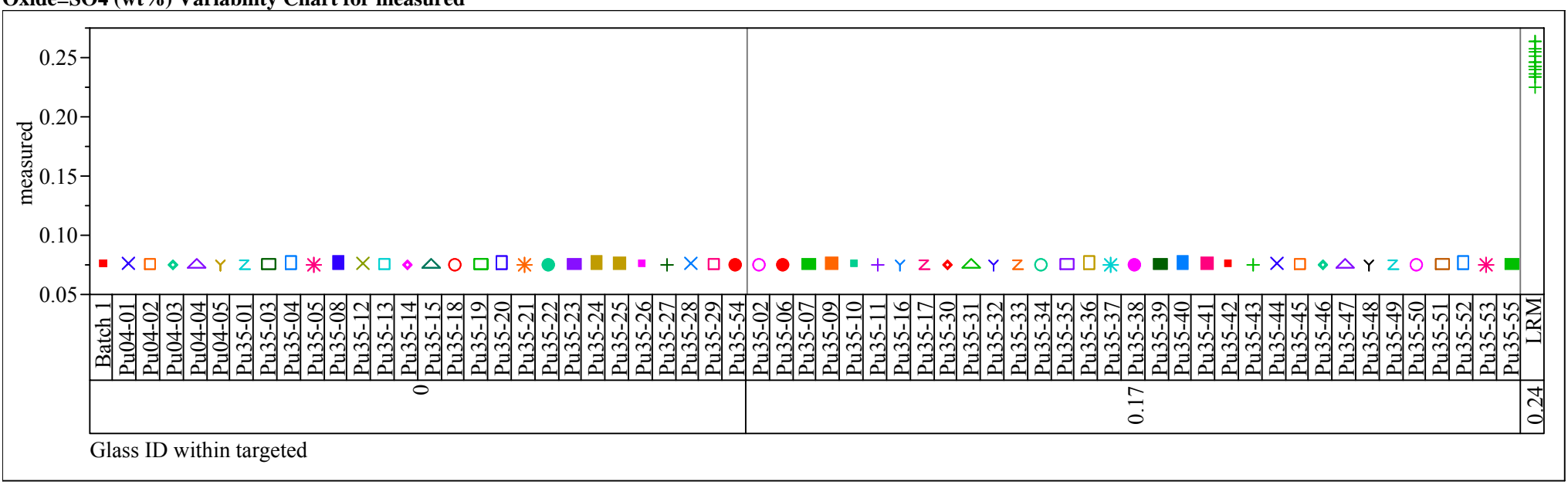

Oxide=SO4 (wt\%) Variability Chart for measured bc

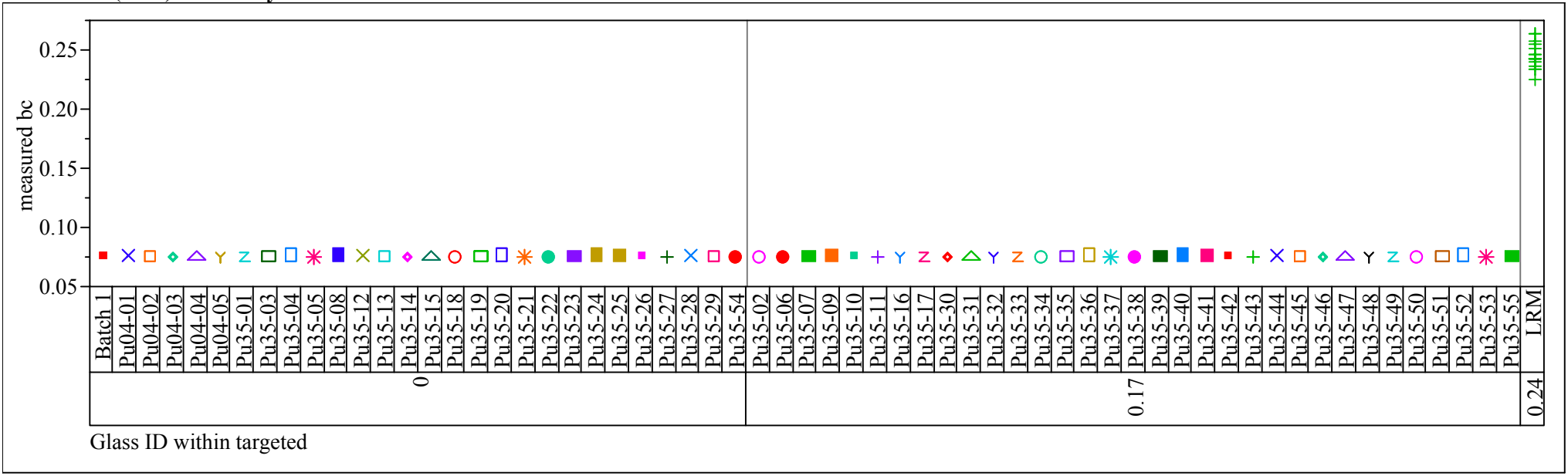


Exhibit D6. Measured and Measured Bias-Corrected Oxide Weight Percents

by Glass ID by Targeted Value for the Glasses Prepared Using the LM Method (continued)

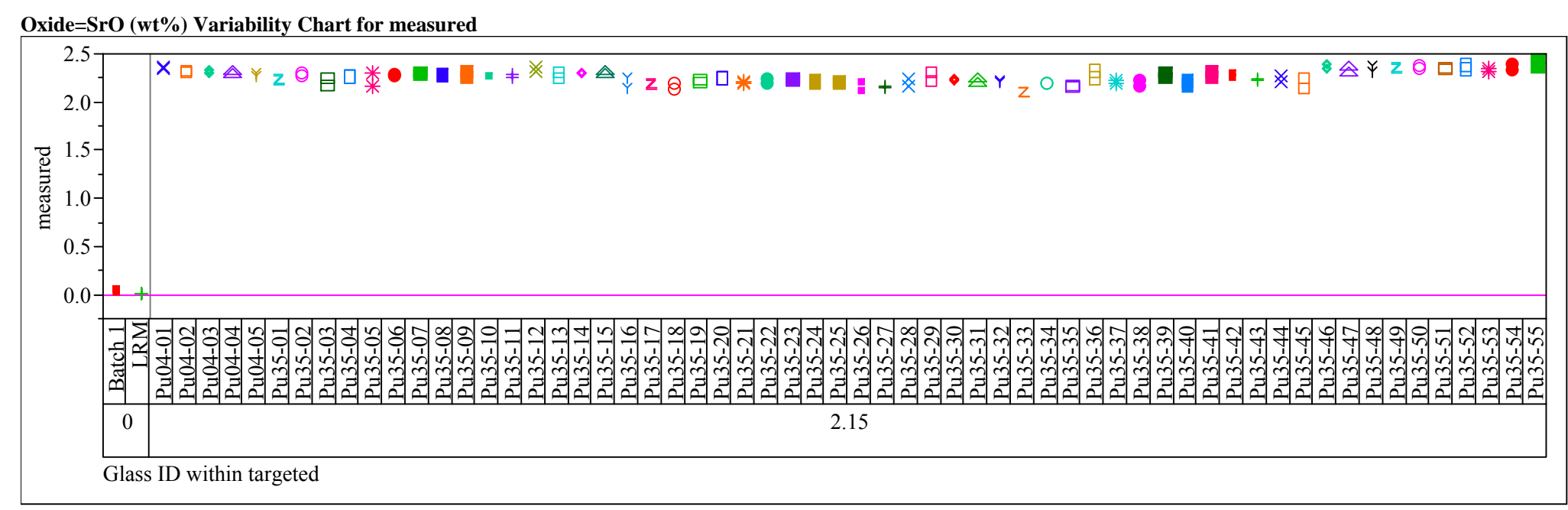

Oxide $=\mathrm{SrO}(\mathrm{wt} \%)$ Variability Chart for measured bc

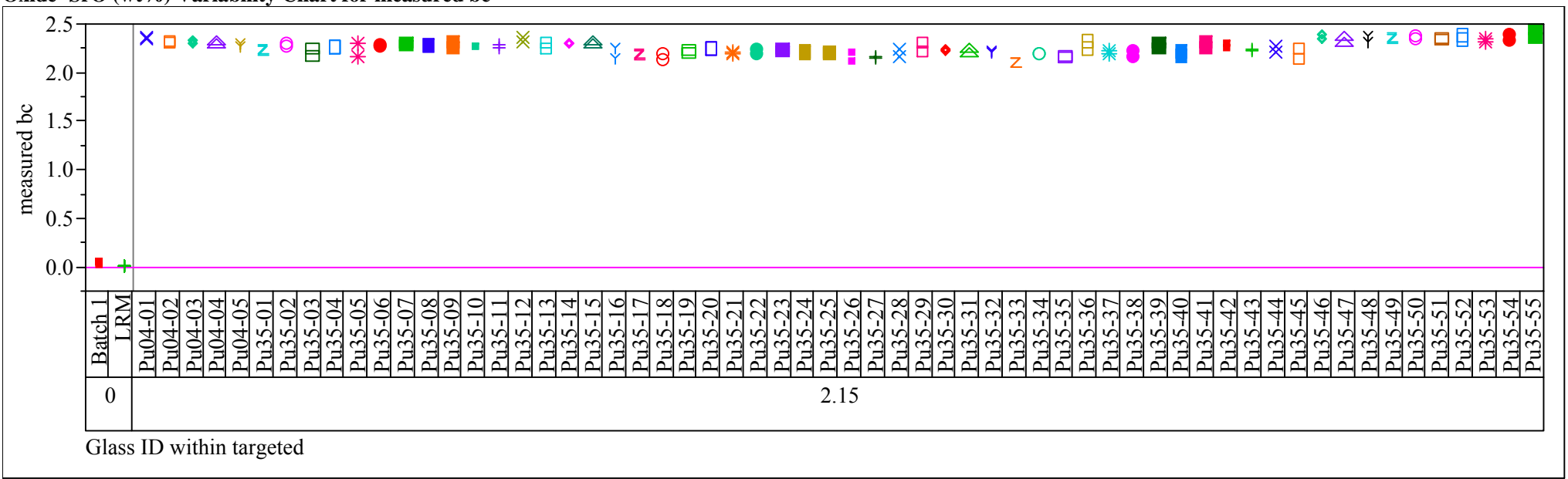


Exhibit D6. Measured and Measured Bias-Corrected Oxide Weight Percents

by Glass ID by Targeted Value for the Glasses Prepared Using the LM Method (continued)

Oxide=Ta2O5 (wt\%) Variability Chart for measured

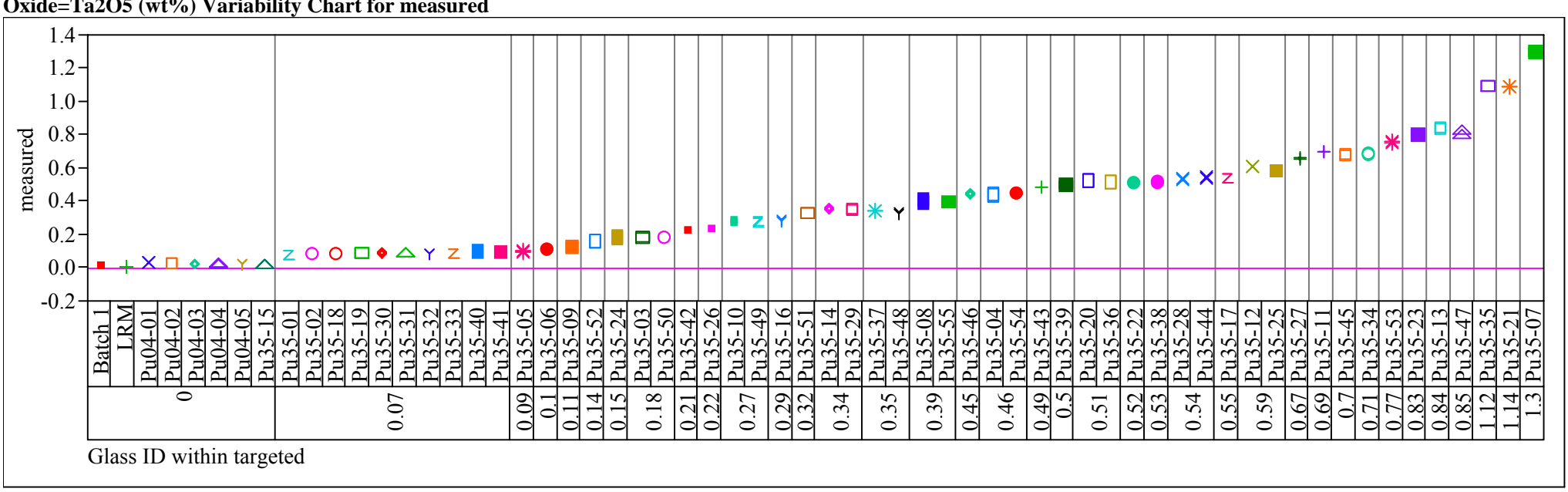

Oxide=Ta2O5 (wt \%) Variability Chart for measured bc

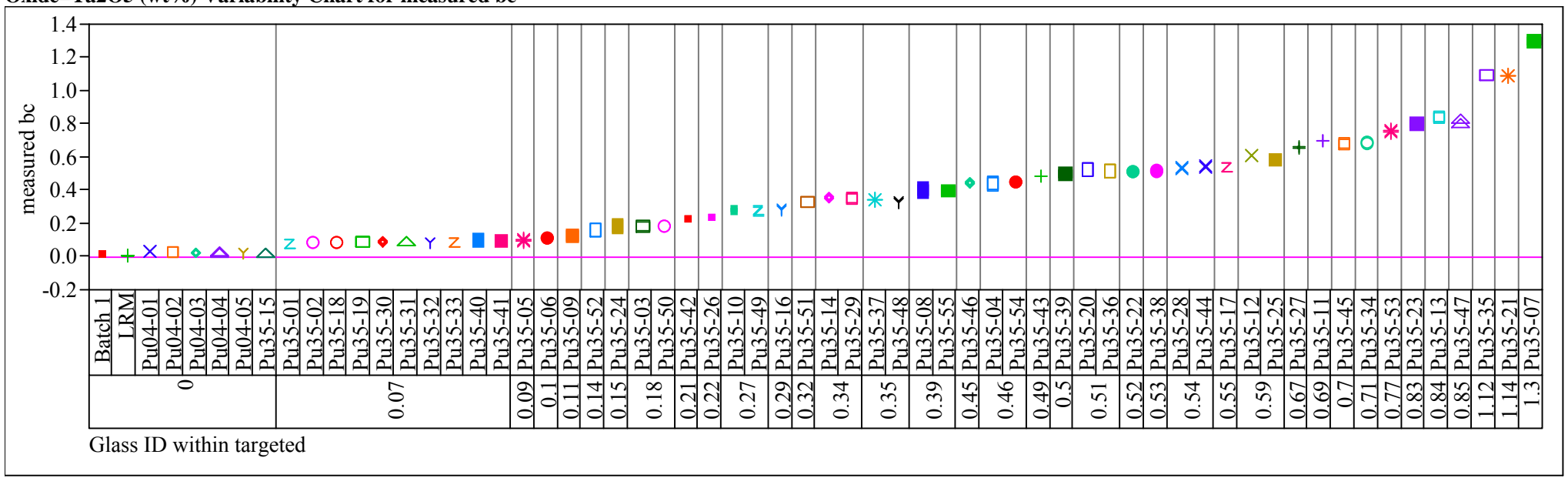


Exhibit D7. Measured and Measured Bias-Corrected Oxide Weight Percents by Glass ID by Targeted Value for the Glasses Prepared Using the PF Method

Variability Chart for B2O3 (wt\%)

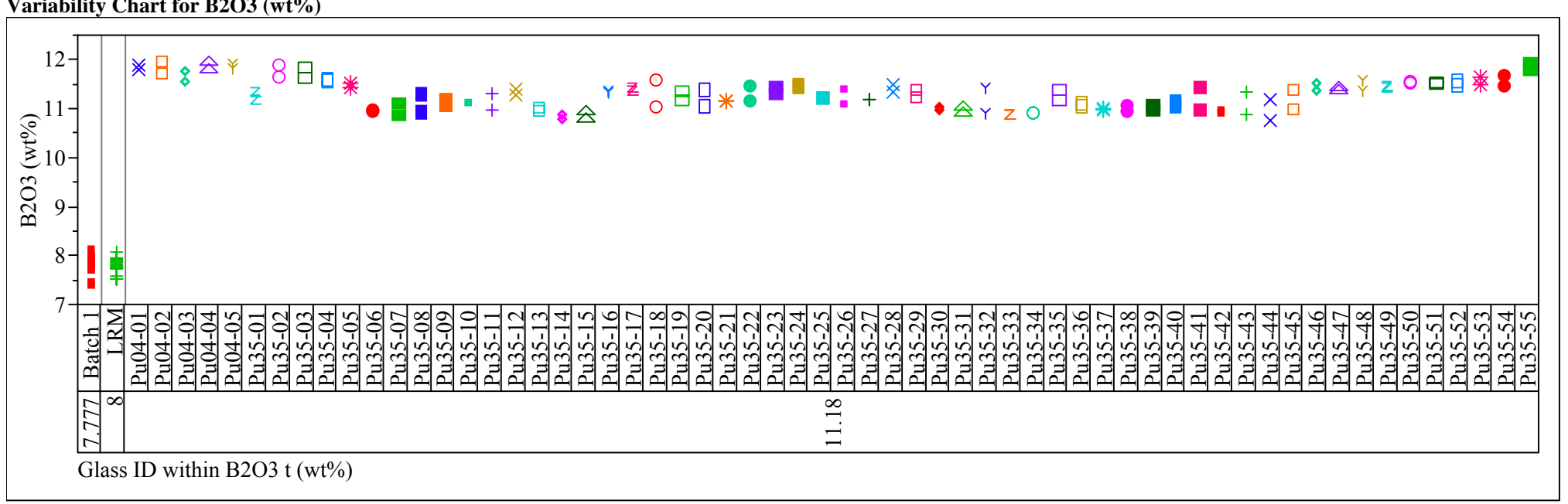

Variability Chart for B2O3 bc (wt\%)

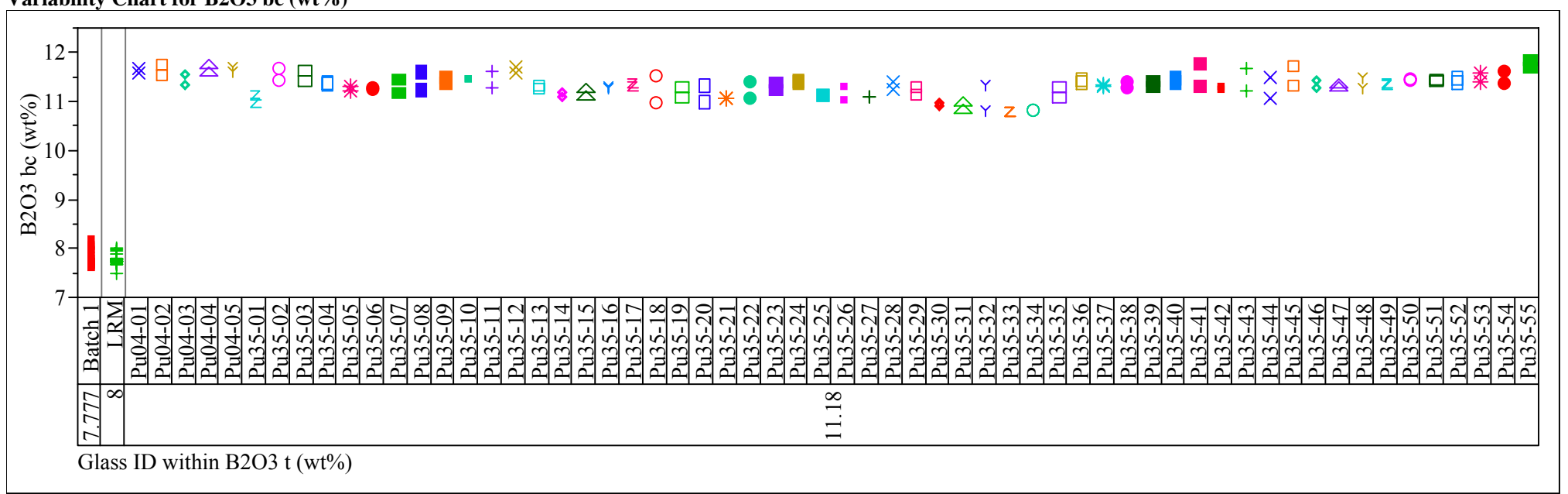




\section{Exhibit D8. IC Measured and Measured Bias-Corrected Weight Percents by Glass ID by Targeted Concentration}

Variability Chart for Cl (wt \%)

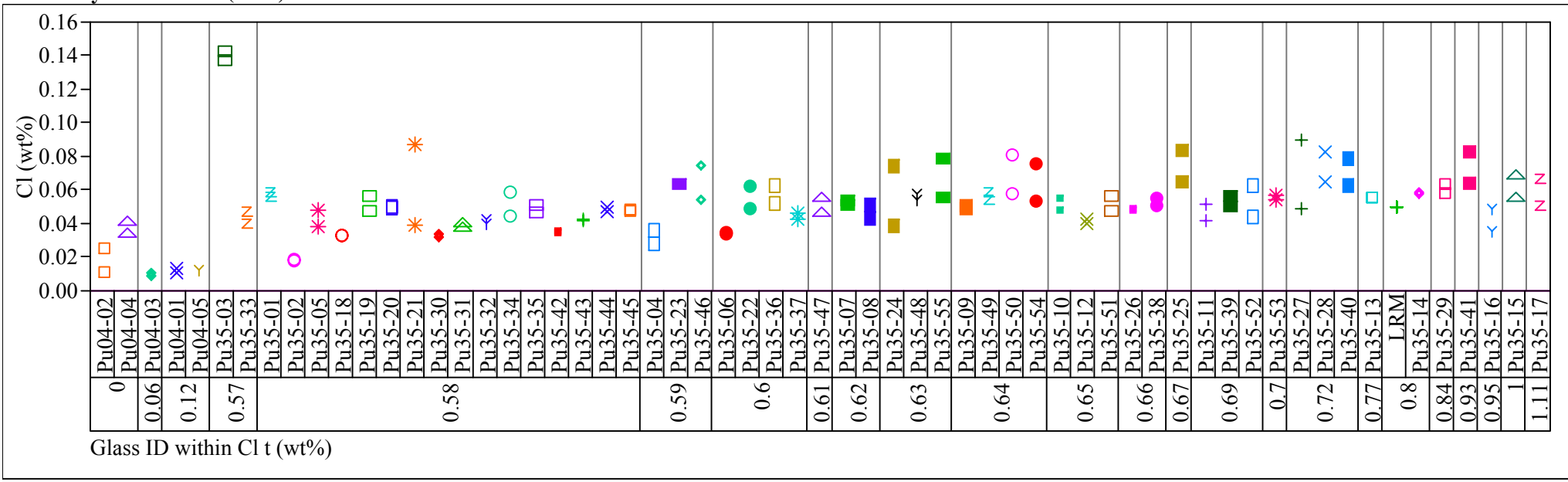

Variability Chart for $\mathrm{Cl} \mathrm{bc} \mathrm{(wt} \mathrm{\% )}$

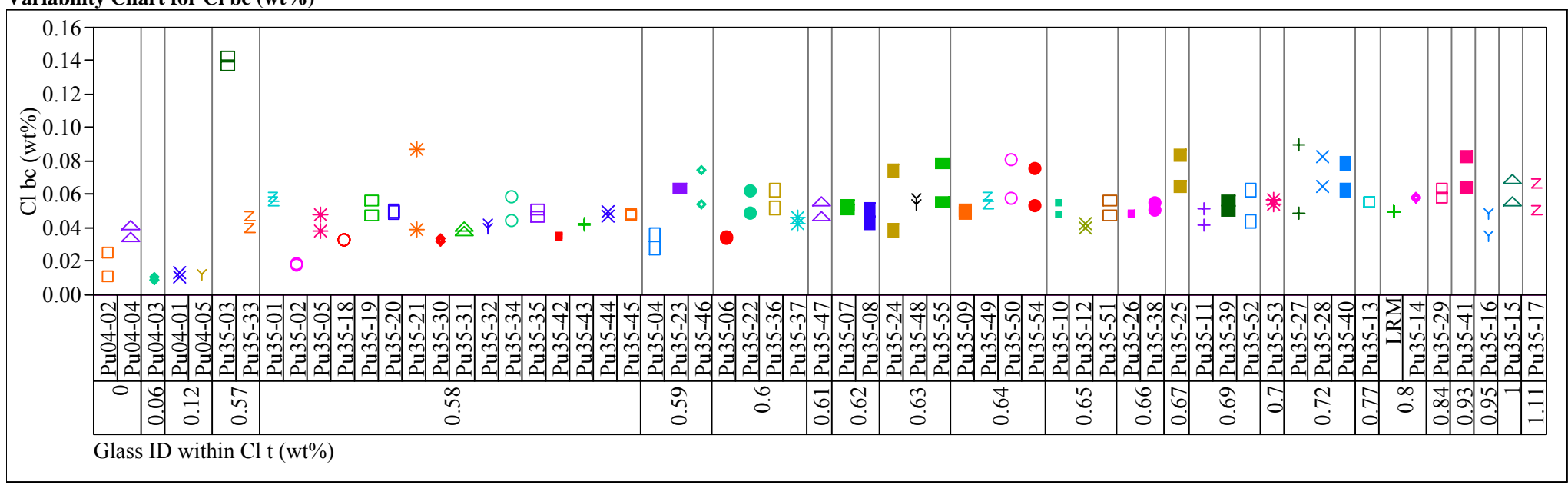


Exhibit D8. IC Measured and Measured Bias-Corrected Weight Percents by Glass ID by Targeted Concentration (continued) Variability Chart for F (wt\%)

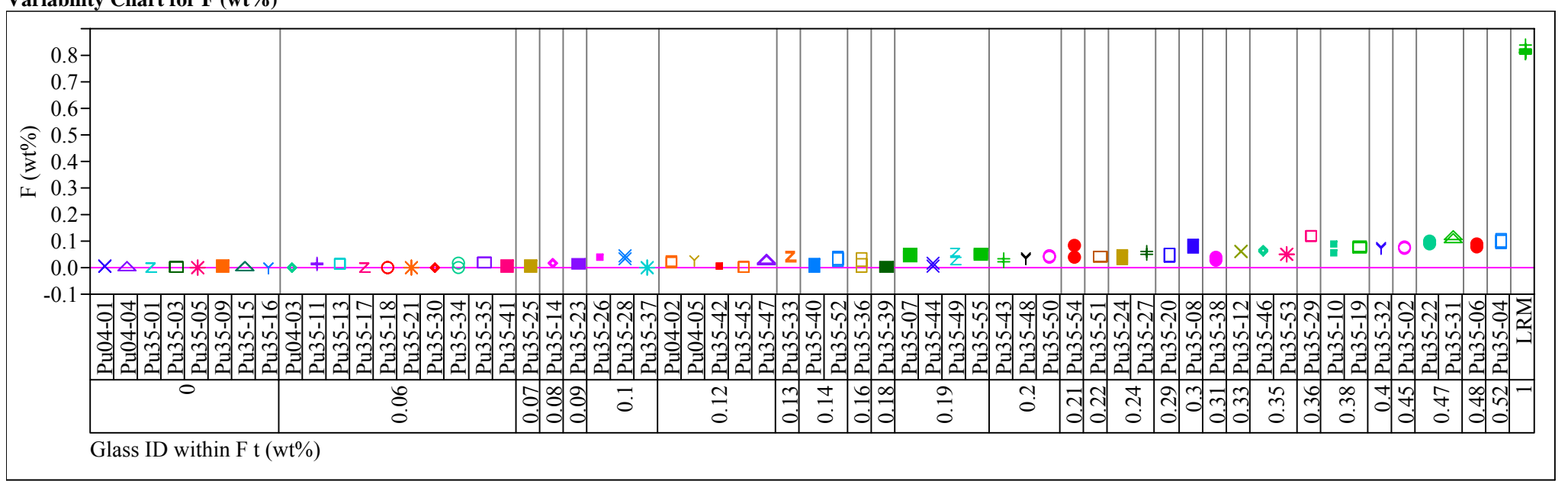

Variability Chart for F bc (wt\%)

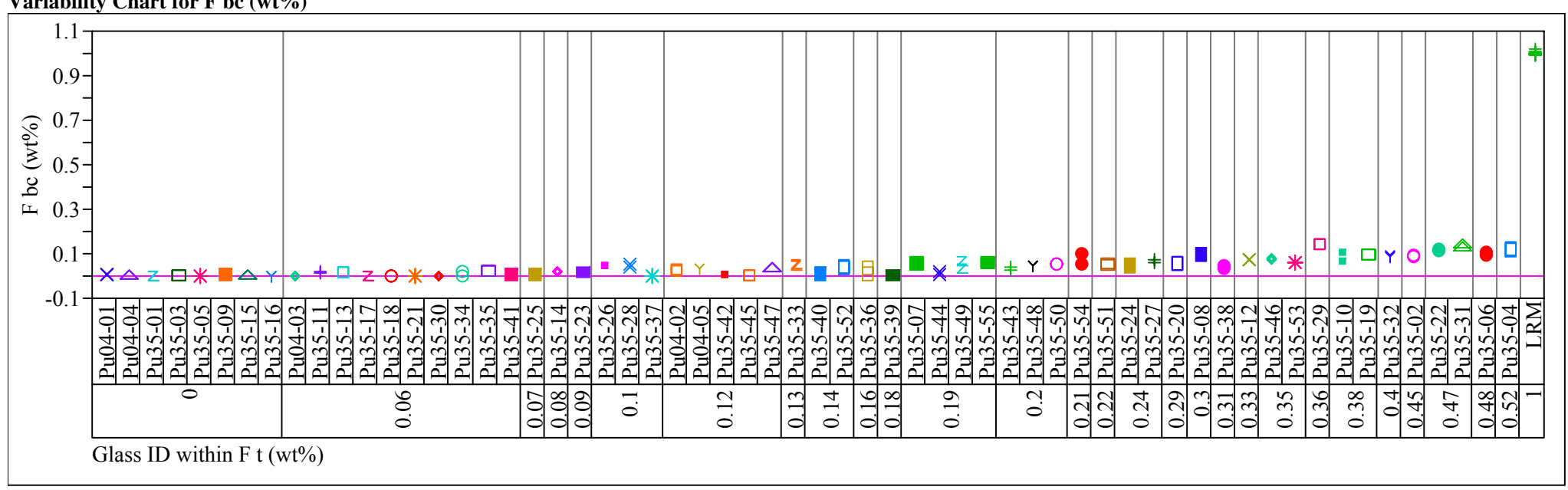




\section{Exhibit D9. Average Measured and Bias-Corrected (bc) Versus Targeted Compositions by Glass ID by Analyte}

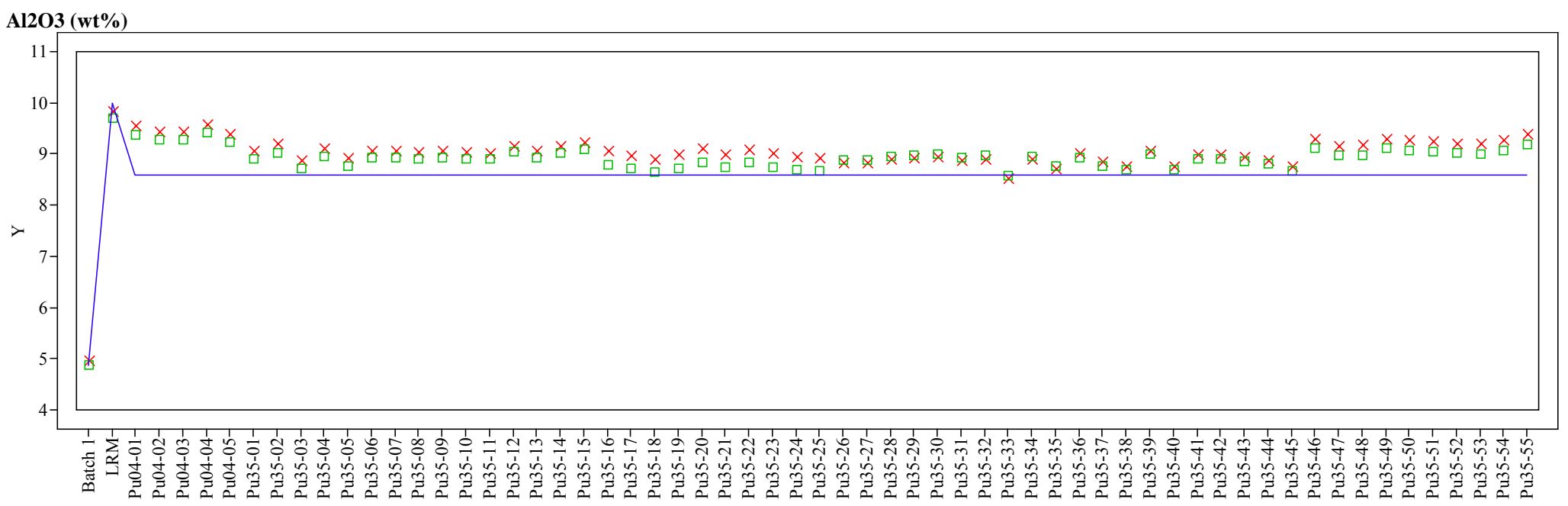
B2O3 (wt\%) Glass ID

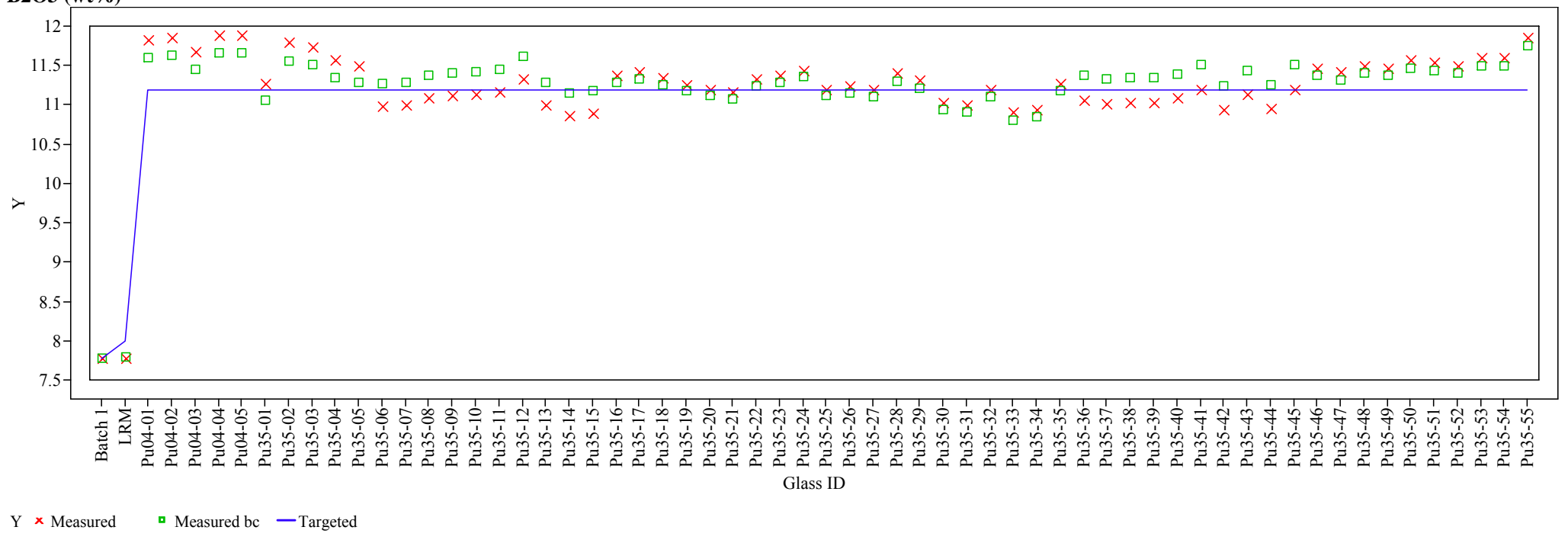


Exhibit D9. Average Measured and Bias-Corrected (bc) Versus Targeted Compositions by Glass ID by Analyte (continued)
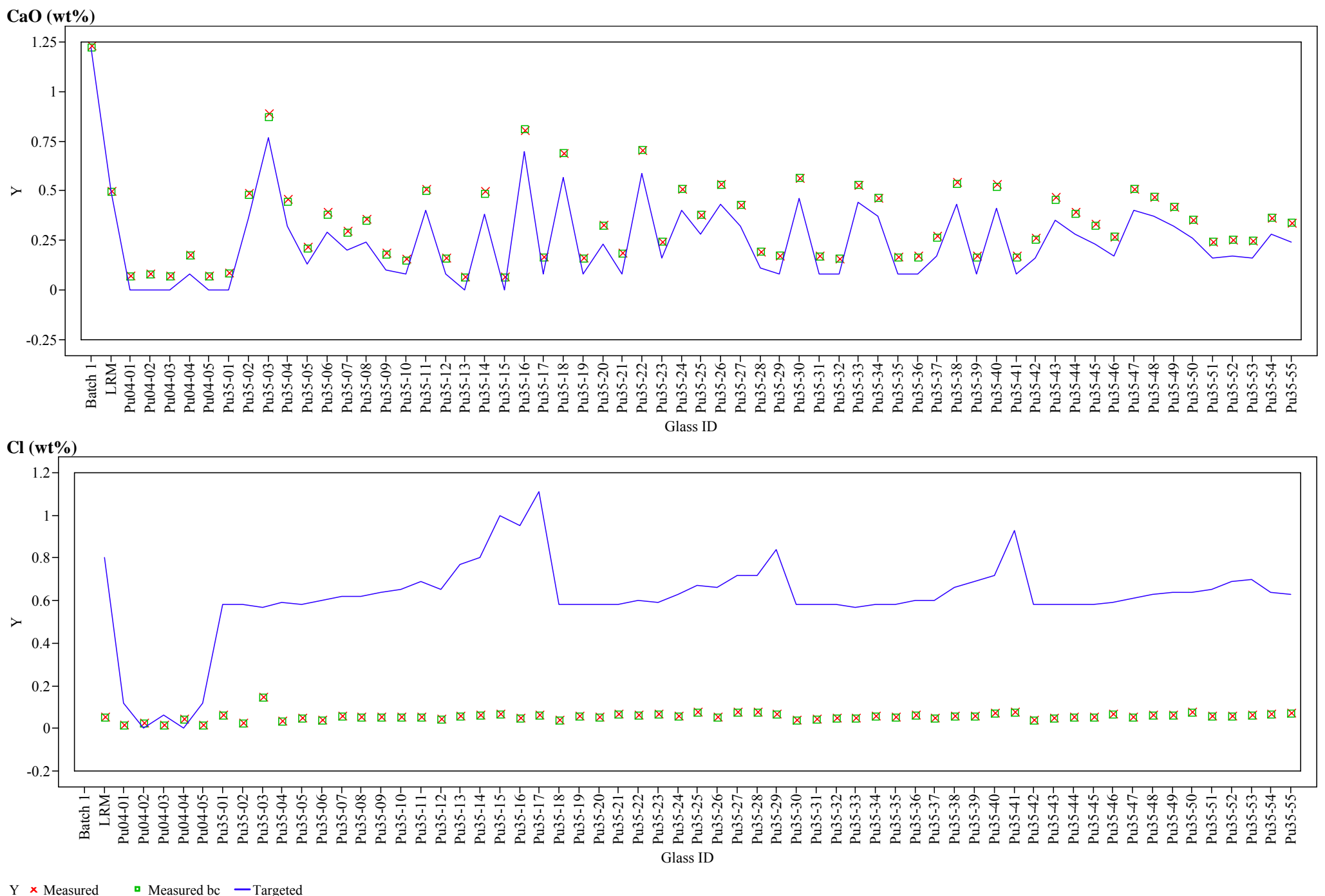
Exhibit D9. Average Measured and Bias-Corrected (bc) Versus Targeted Compositions by Glass ID by Analyte (continued)

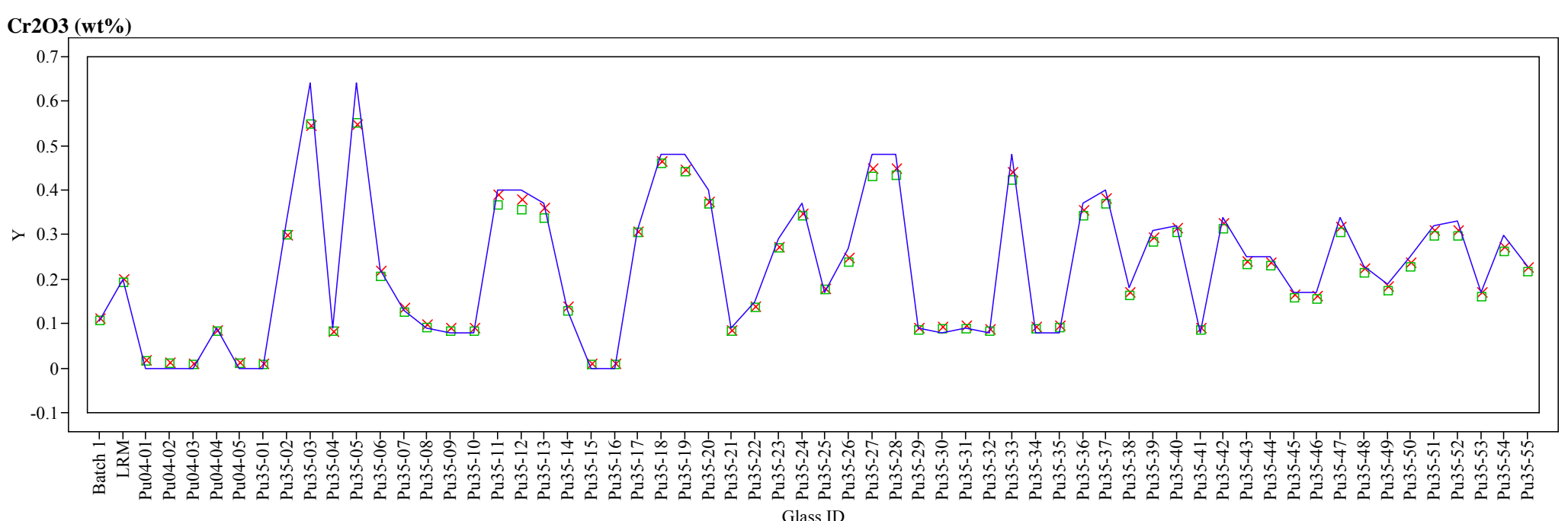

CuO (wt\%)

Glass ID

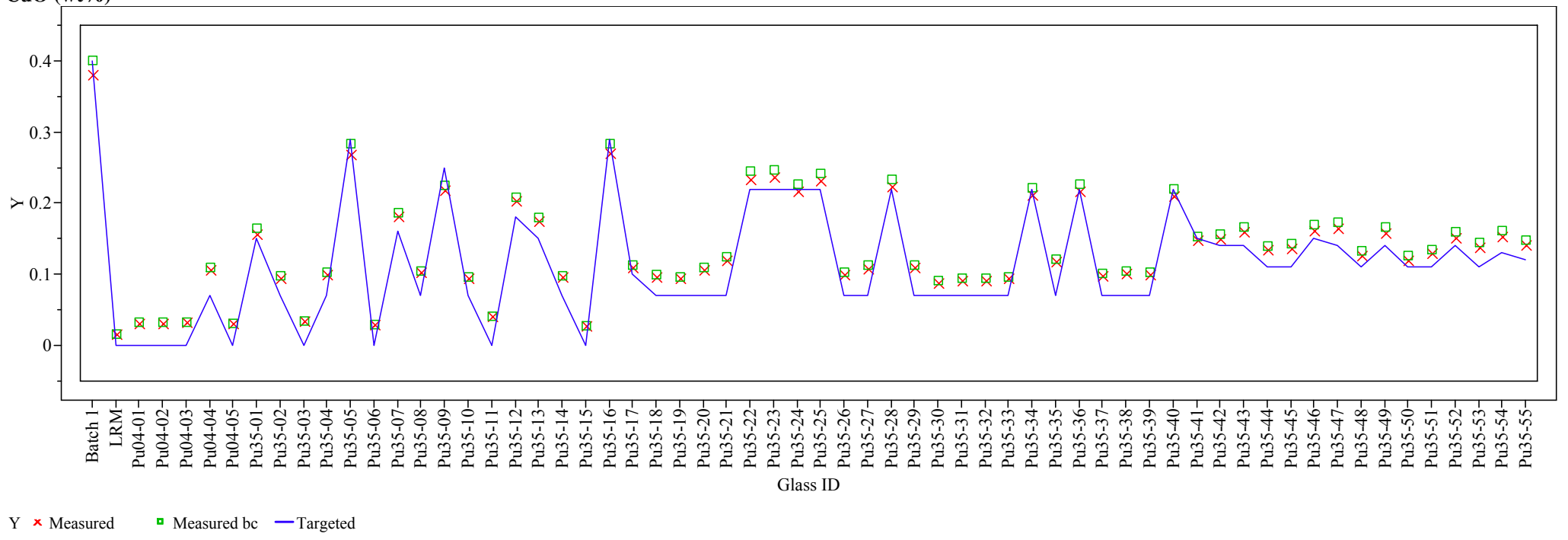


Exhibit D9. Average Measured and Bias-Corrected (bc) Versus Targeted Compositions by Glass ID by Analyte (continued)

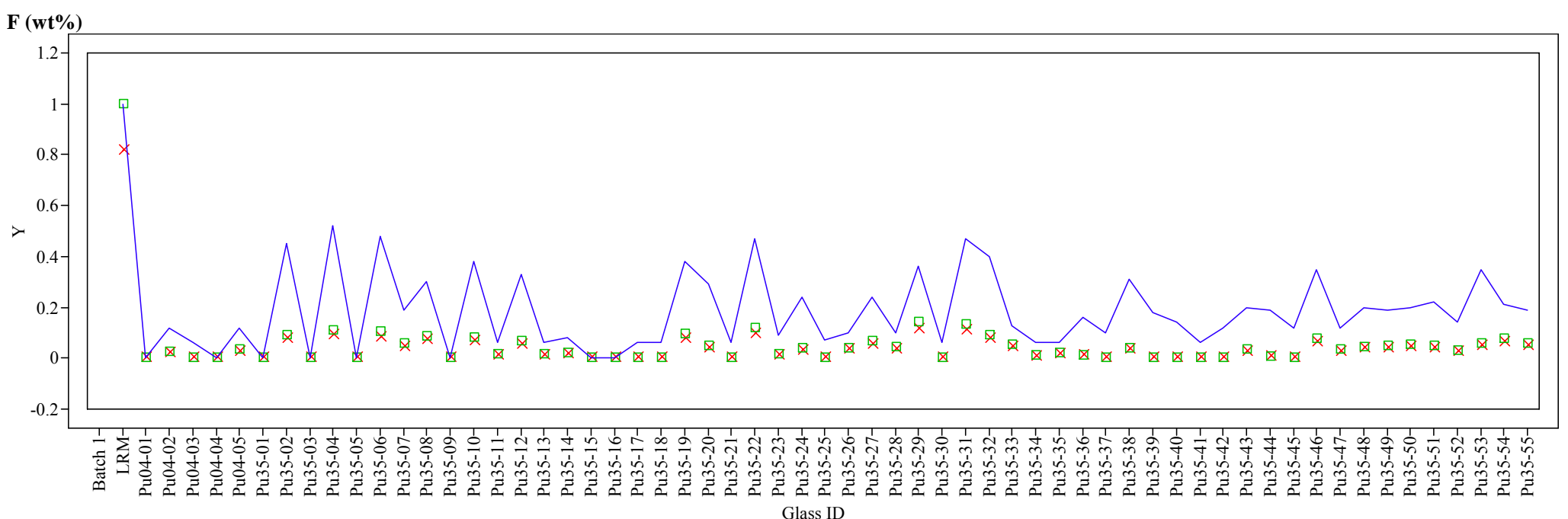
$\mathrm{Fe} 2 \mathrm{O} 3(\mathrm{wt} \%)$

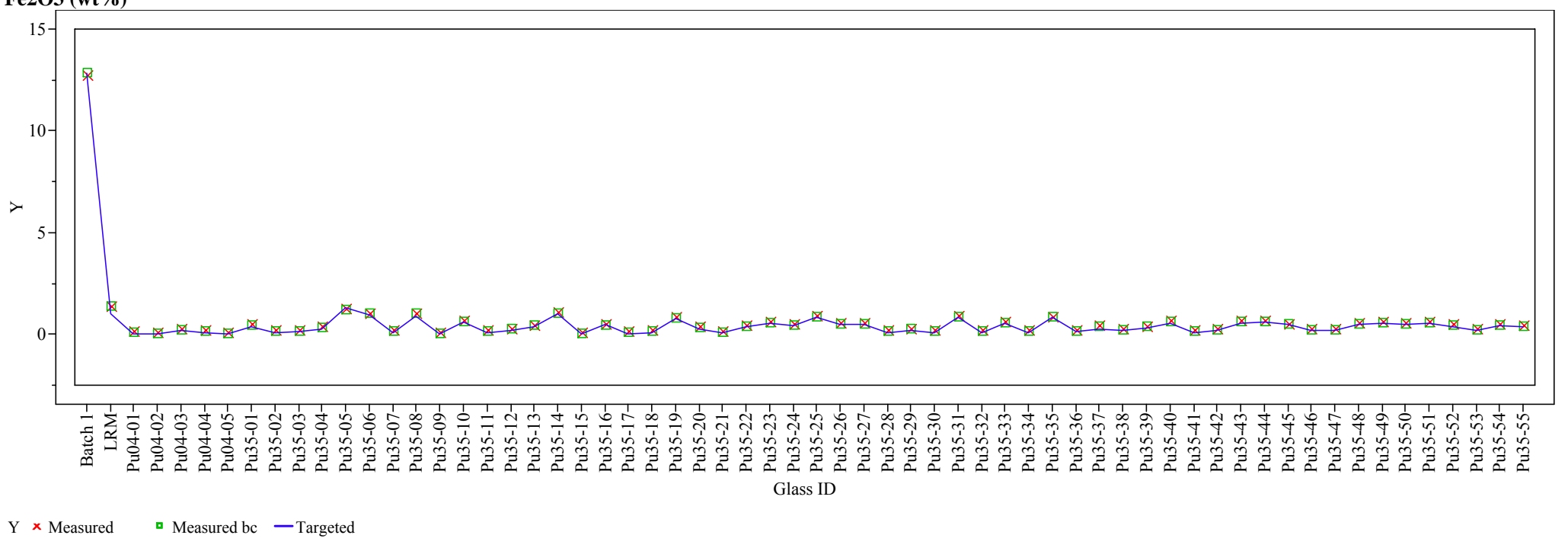


Exhibit D9. Average Measured and Bias-Corrected (bc) Versus Targeted Compositions by Glass ID by Analyte (continued)

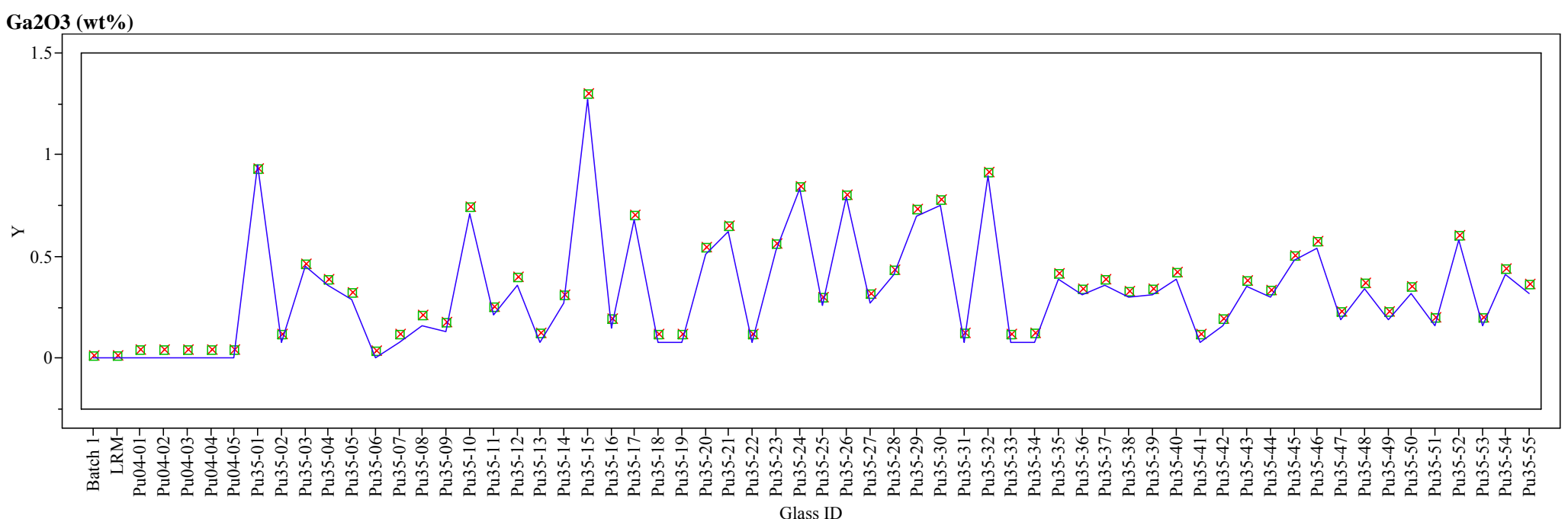

Gd2O3 (wt\%)

Glass ID

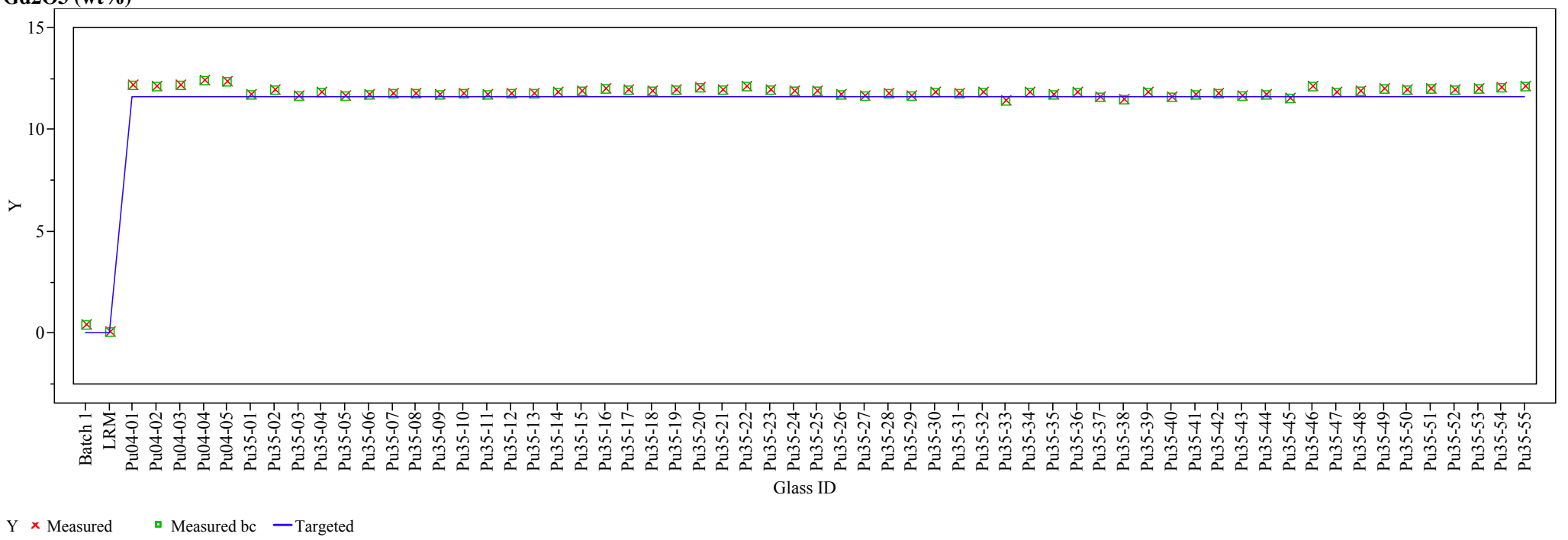


Exhibit D9. Average Measured and Bias-Corrected (bc) Versus Targeted Compositions by Glass ID by Analyte (continued)

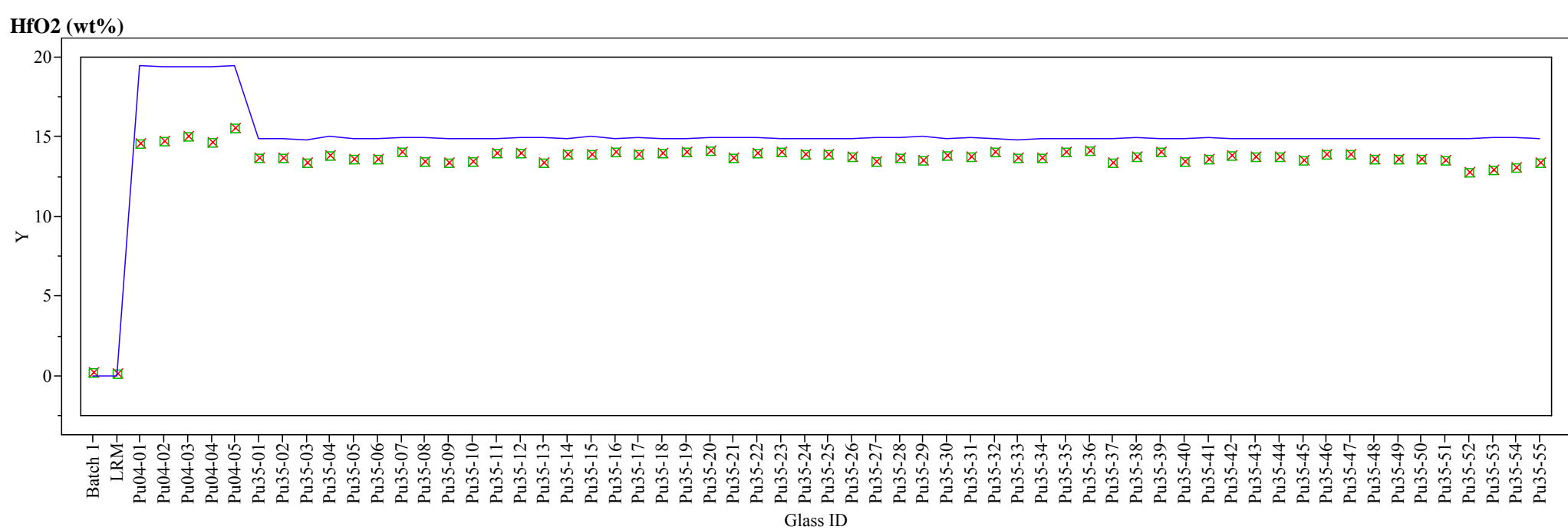

$$
\text { K2O (wt\%) }
$$

$$
\text { Glass ID }
$$

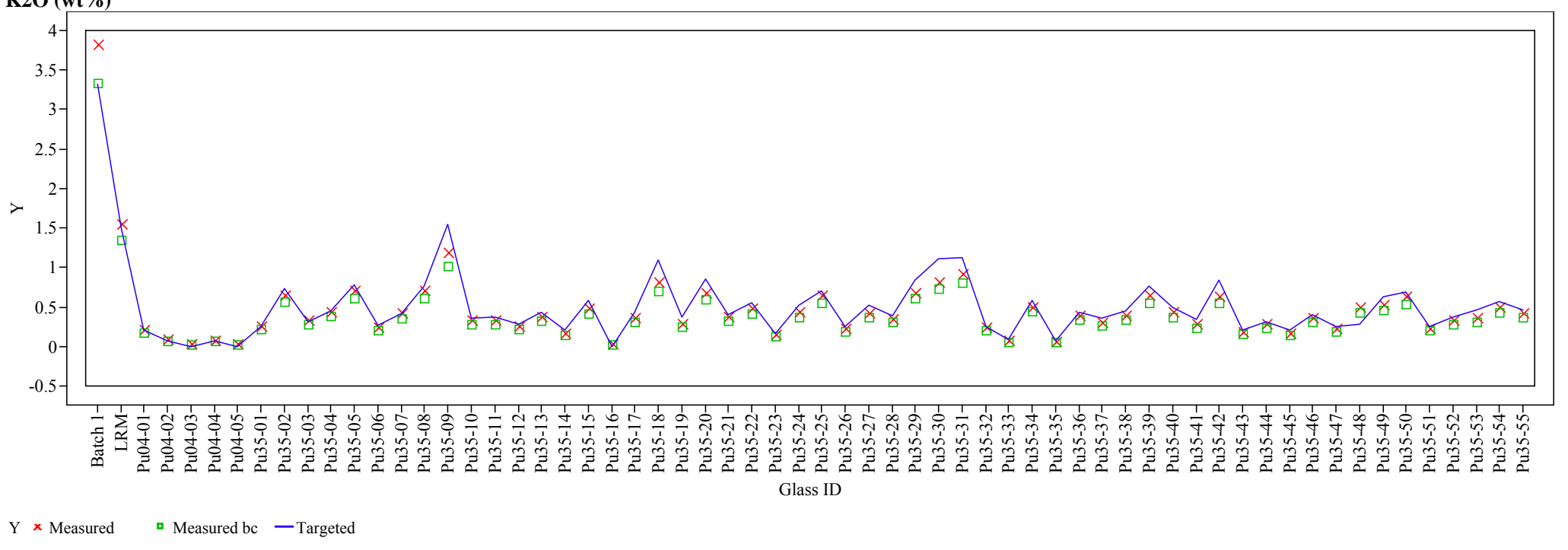


Exhibit D9. Average Measured and Bias-Corrected (bc) Versus Targeted Compositions by Glass ID by Analyte (continued) La2O3 (wt\%)

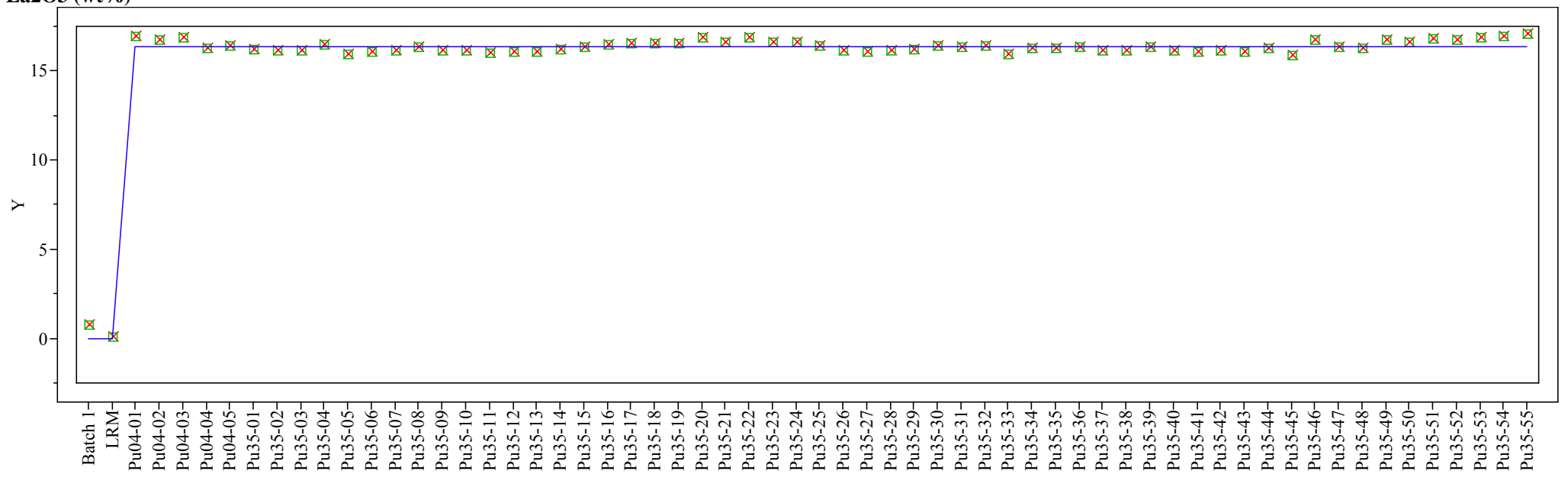
MgO (wt\%) Glass ID

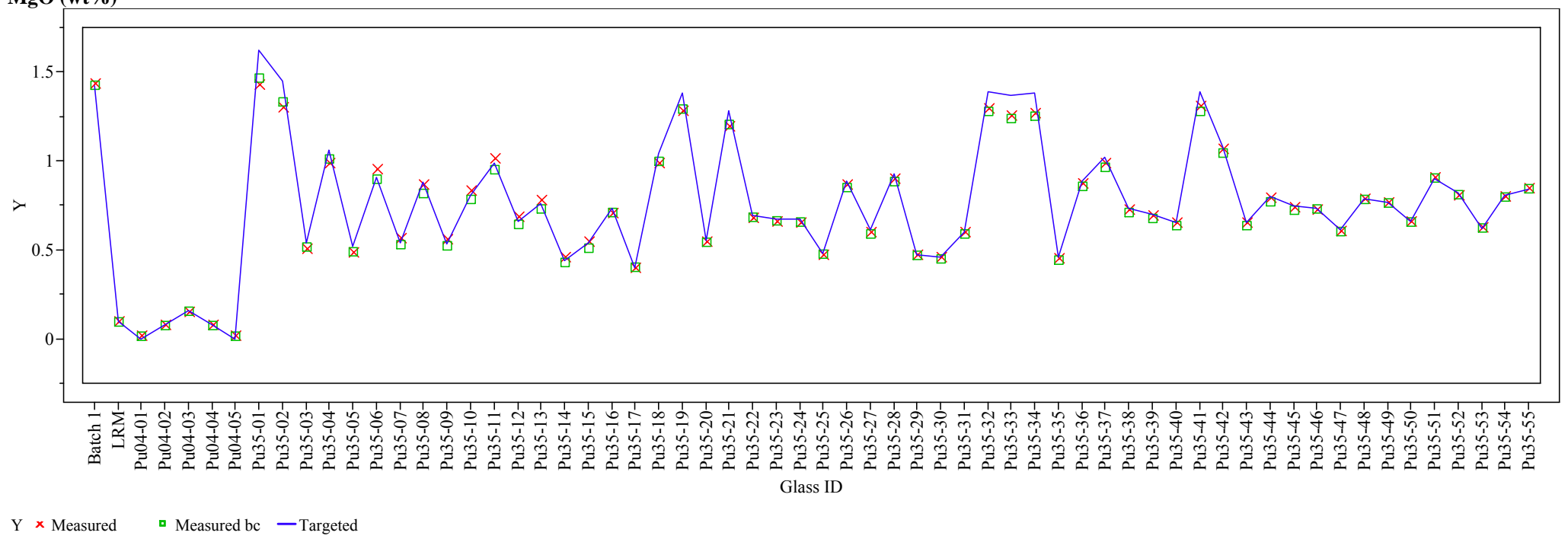


Exhibit D9. Average Measured and Bias-Corrected (bc) Versus Targeted Compositions by Glass ID by Analyte (continued)

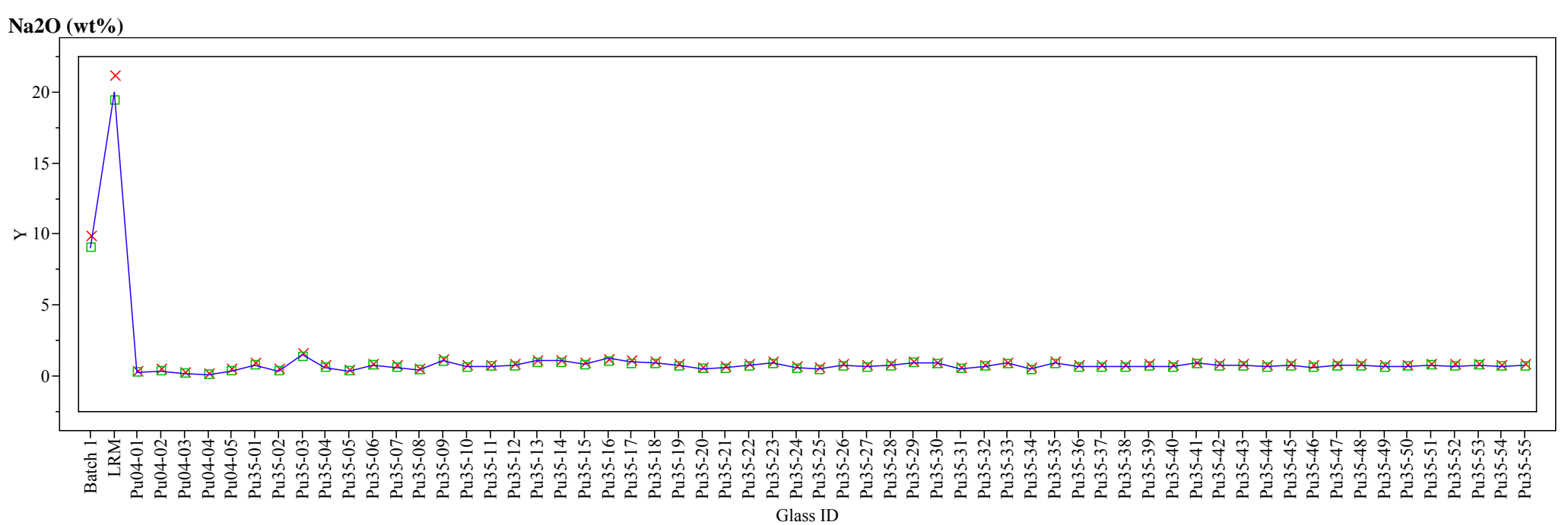

Nd2O3 (wt\%)

$$
\text { Glass ID }
$$

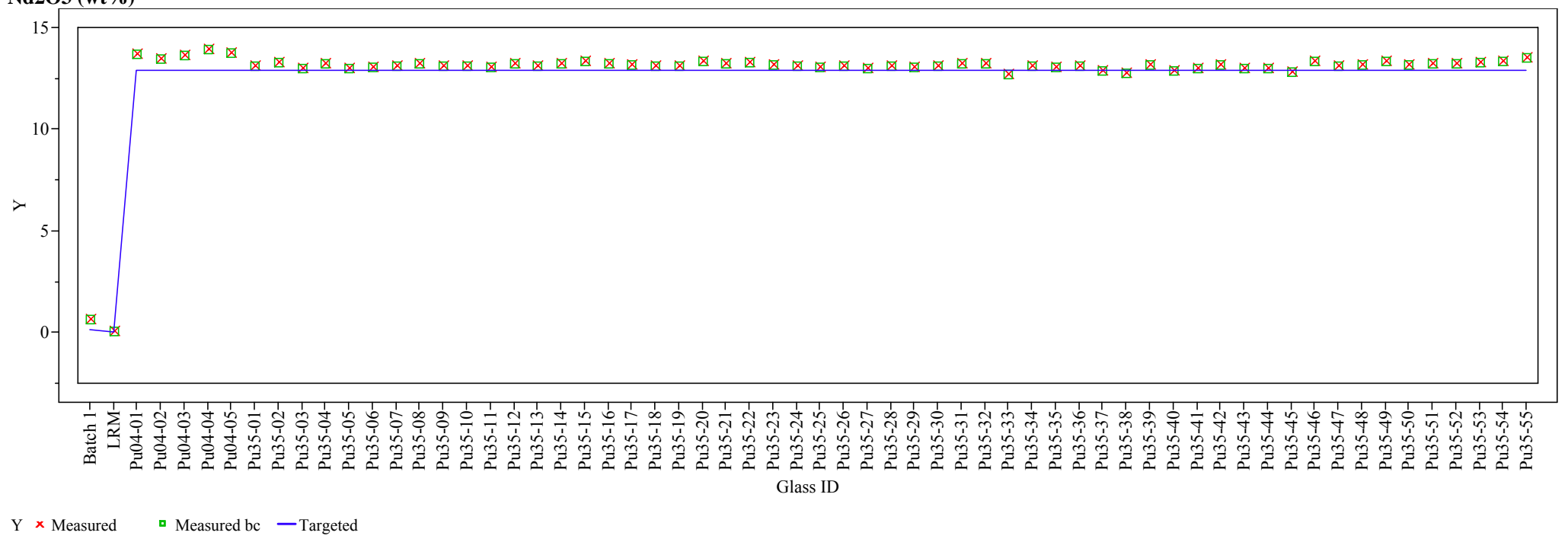


Exhibit D9. Average Measured and Bias-Corrected (bc) Versus Targeted Compositions by Glass ID by Analyte (continued)
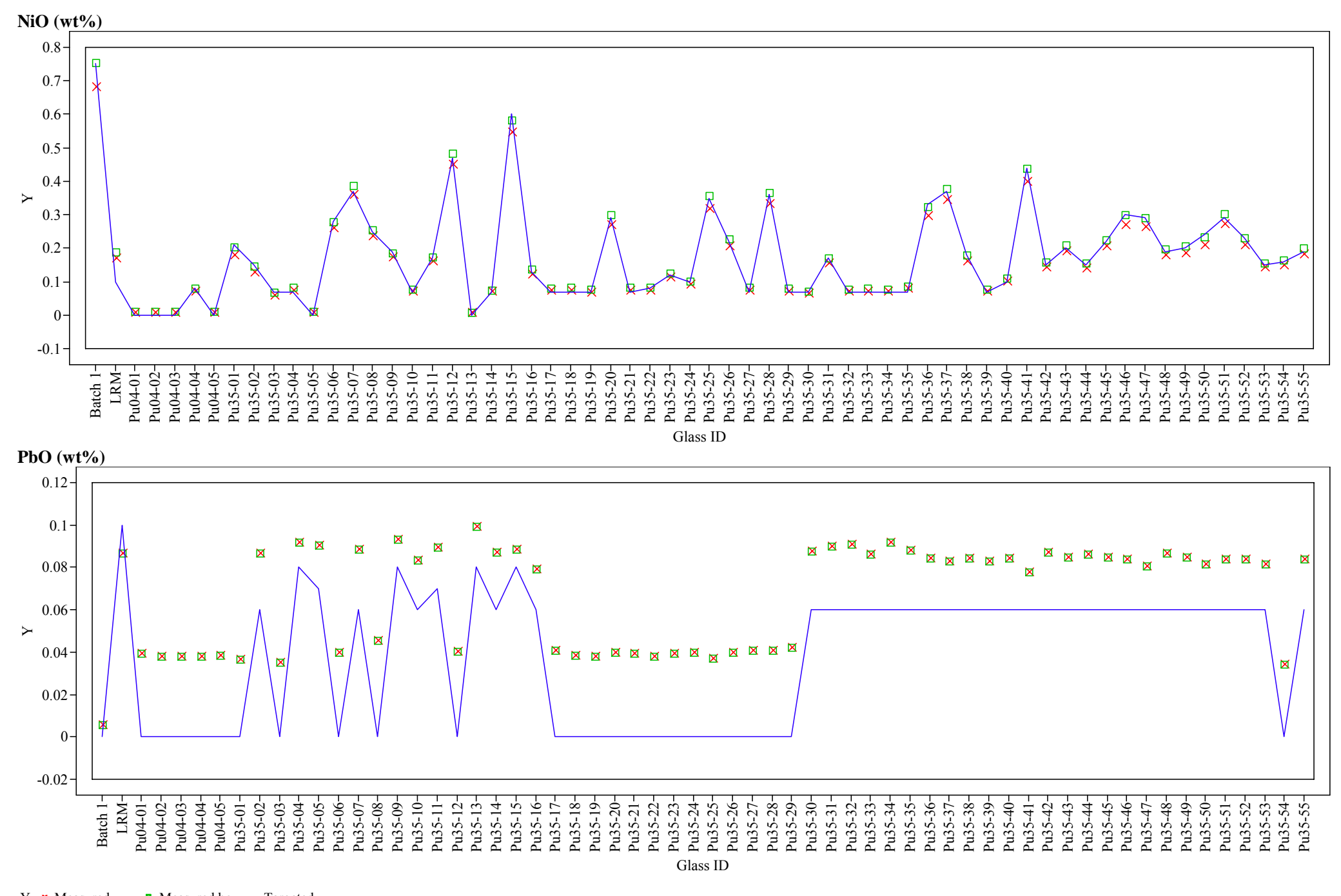

$\mathrm{Y} \times$ Measured $\quad \square$ Measured bc - Targeted 
Exhibit D9. Average Measured and Bias-Corrected (bc) Versus Targeted Compositions by Glass ID by Analyte (continued)
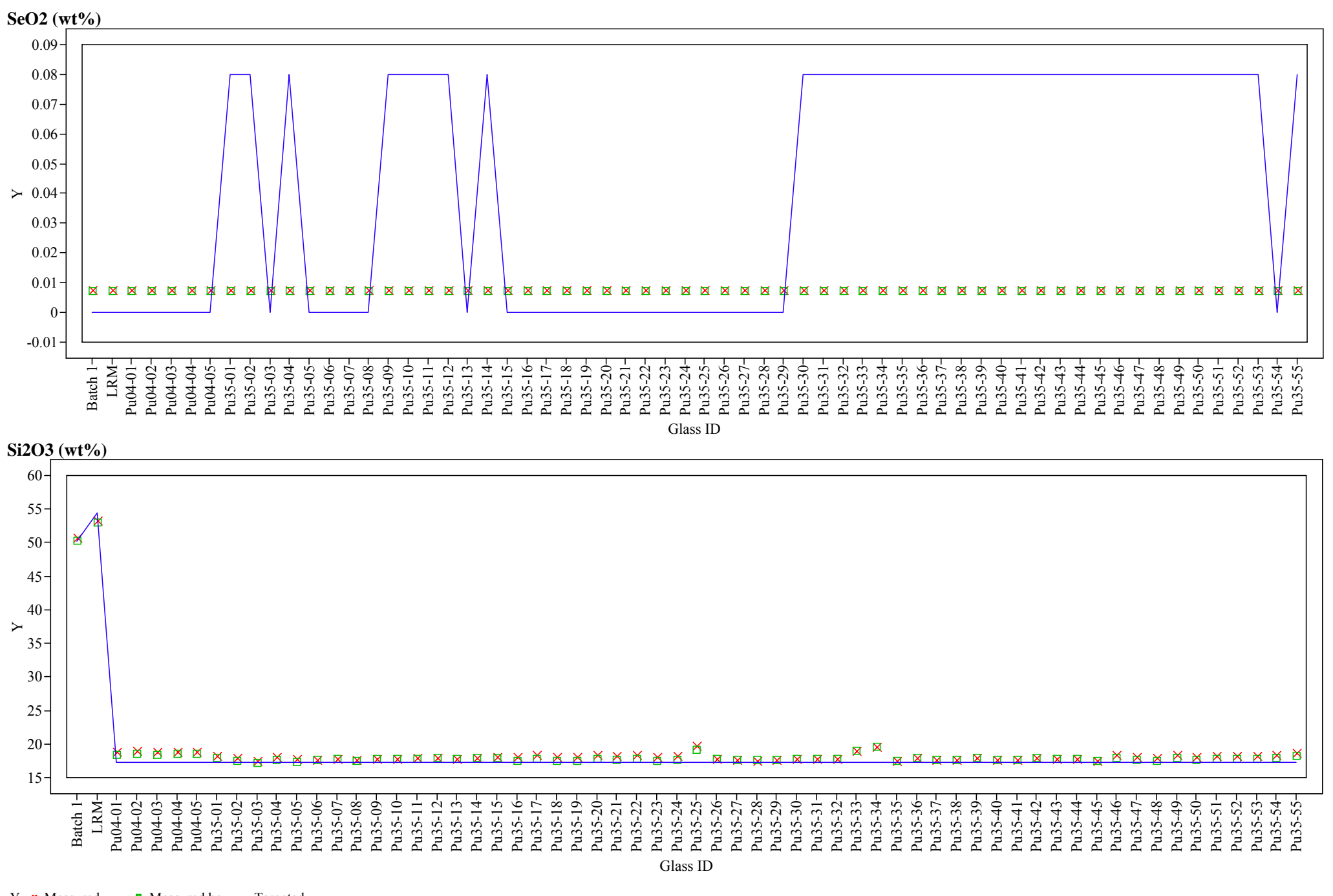

$\mathrm{Y} \times$ Measured $\quad \square$ Measured bc $\quad$ Targeted 
Exhibit D9. Average Measured and Bias-Corrected (bc) Versus Targeted Compositions by Glass ID by Analyte (continued)
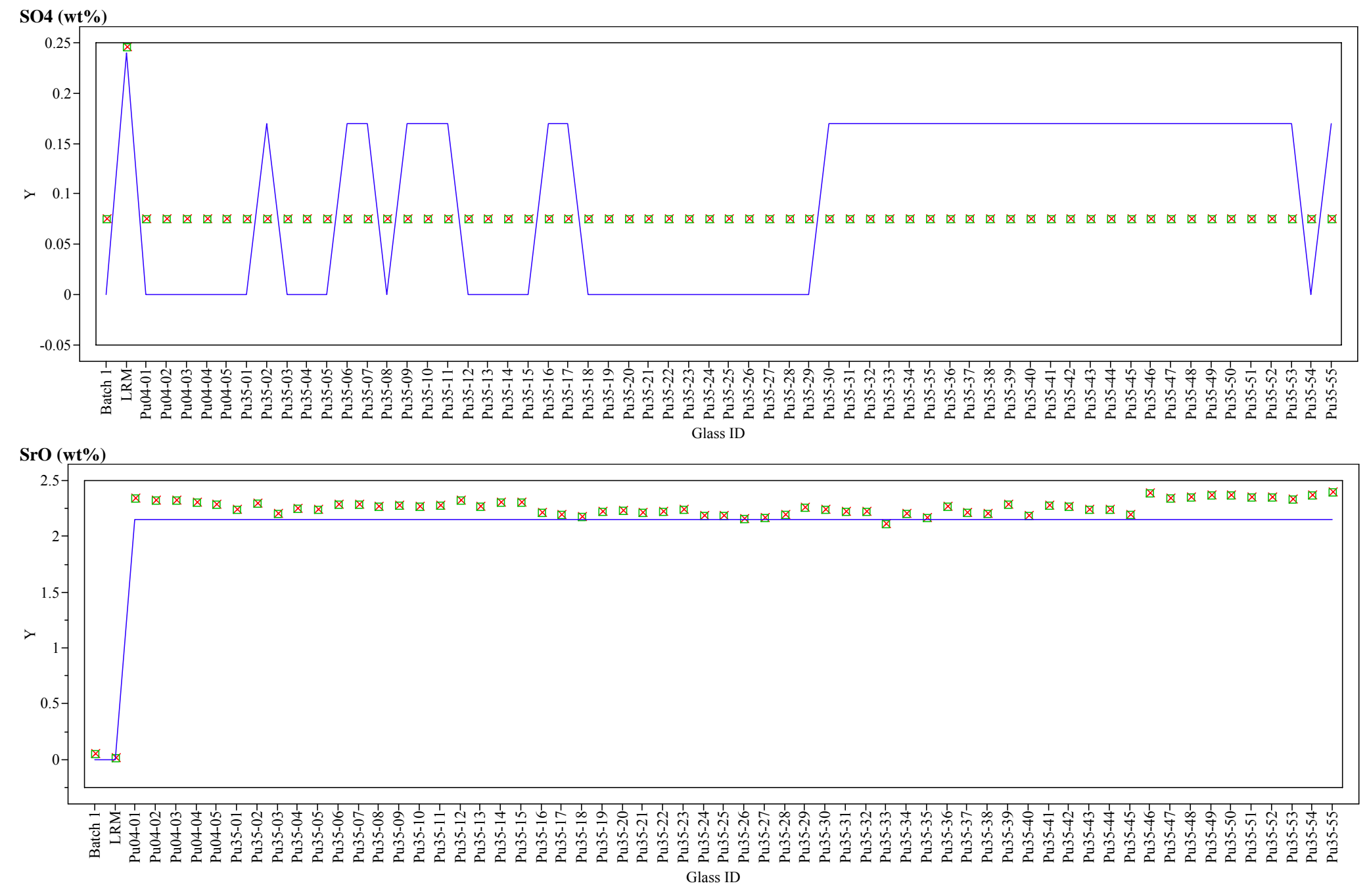

Y X Measured $\square$ Measured bc - Targeted 
Exhibit D9. Average Measured and Bias-Corrected (bc) Versus Targeted Compositions by Glass ID by Analyte (continued)

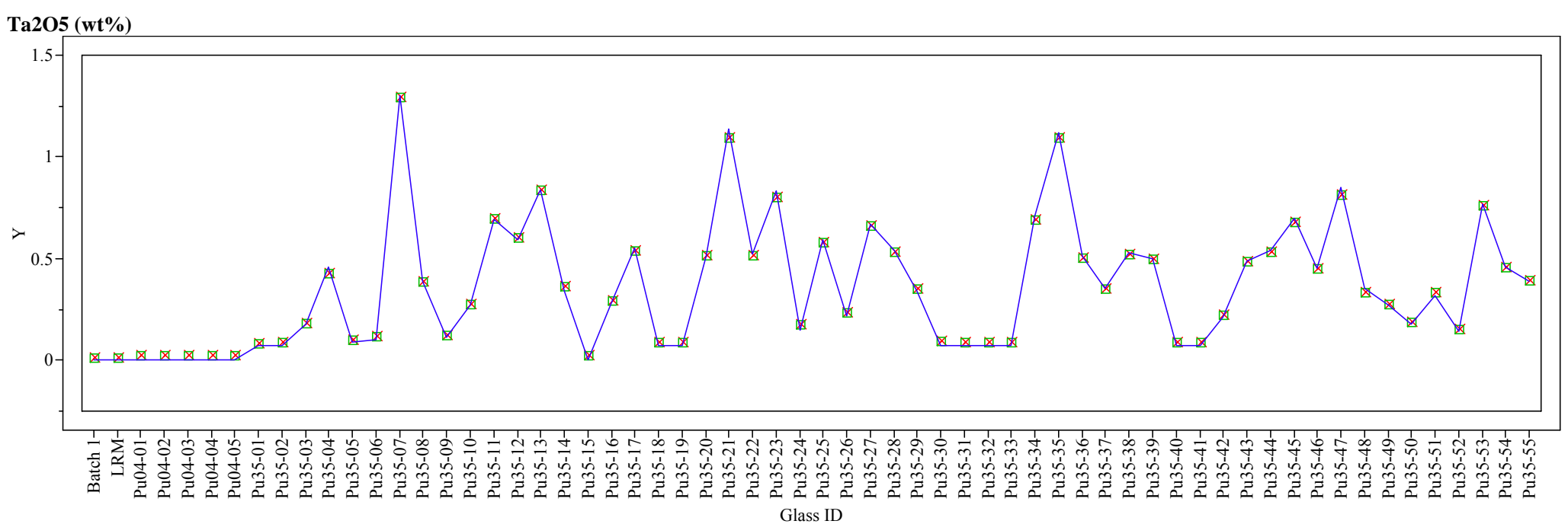

Sum of Oxides

Glass ID

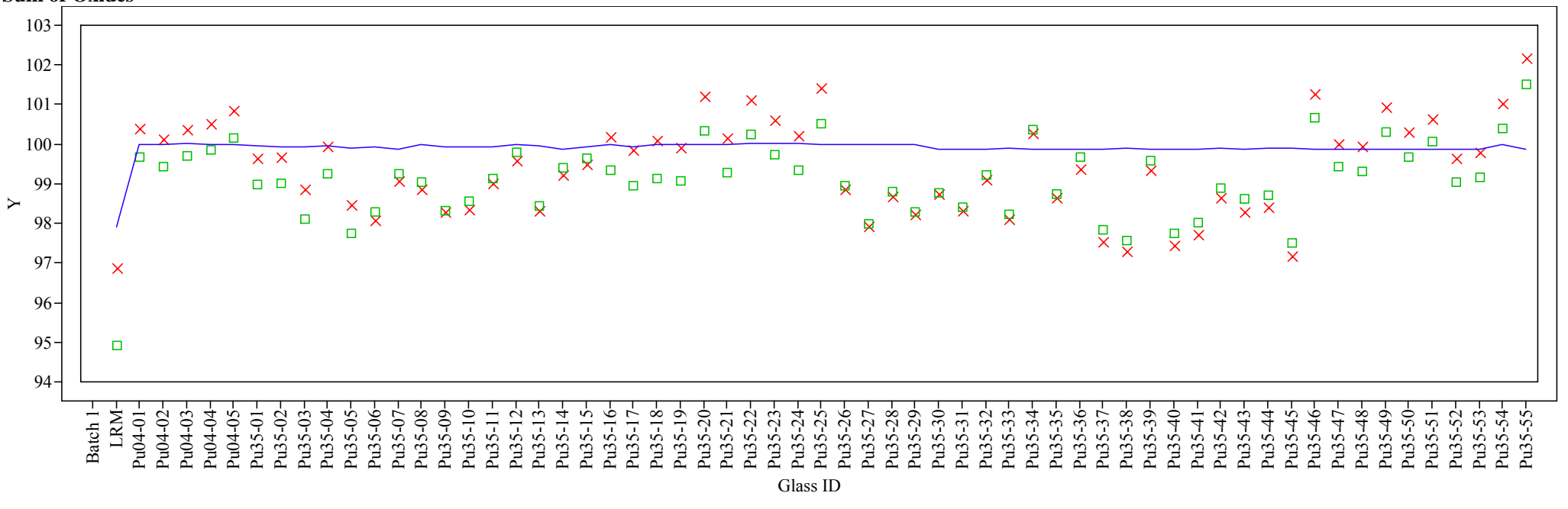

$\mathrm{Y} \times$ Measured $\square$ Measured bc - Targeted 
Exhibit D10. Measured Impurity Levels by Study Glass Sorted by Targeted Concentrations

Pu04-01: Variability Chart for Measured

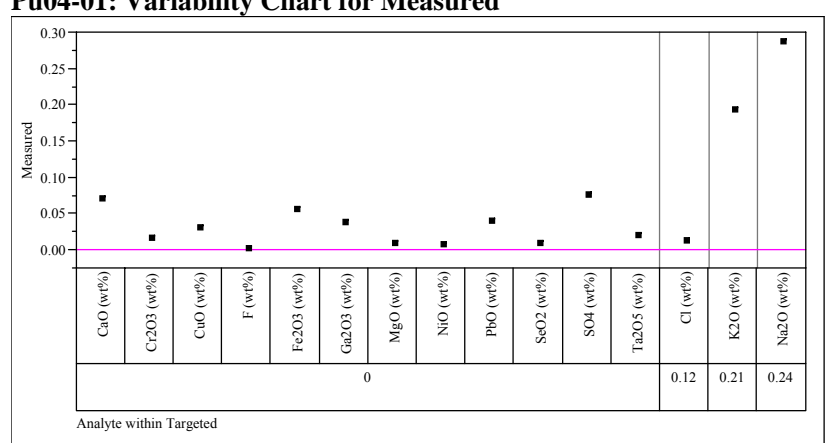

Pu04-02: Variability Chart for Measured

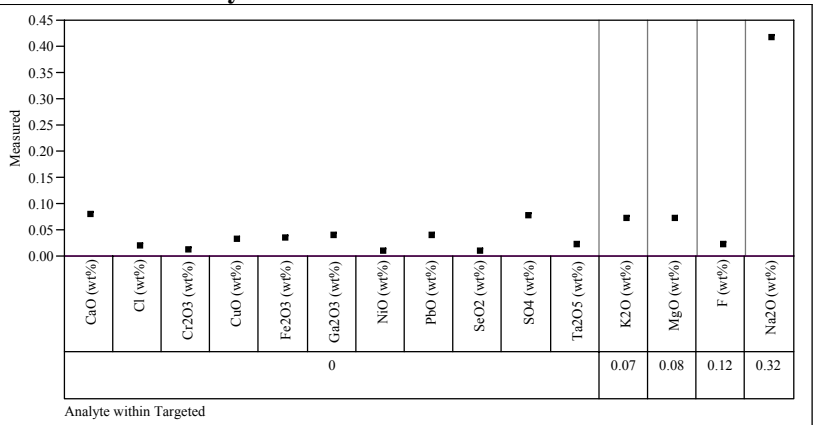

Pu04-03: Variability Chart for Measured

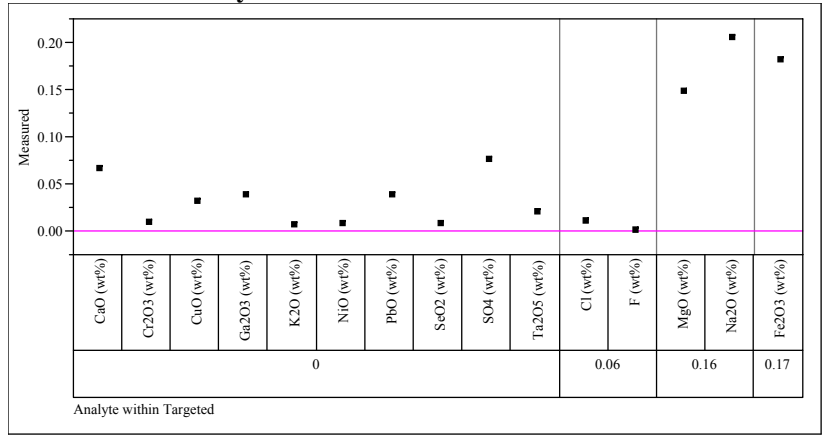

Pu04-04: Variability Chart for Measured

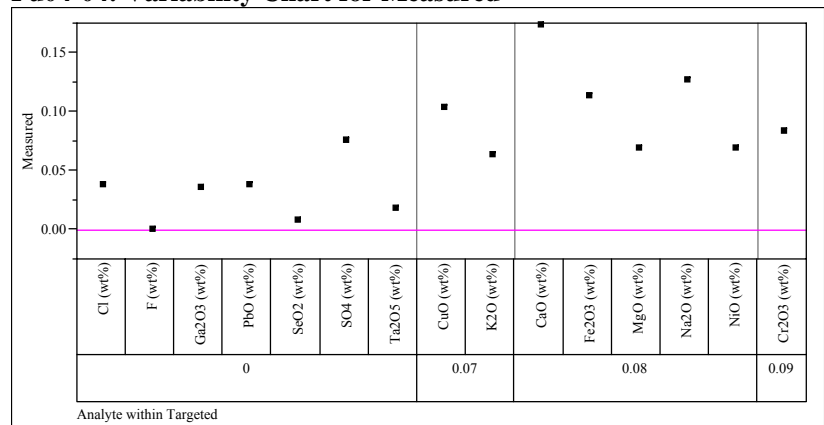

Pu04-05: Variability Chart for Measured

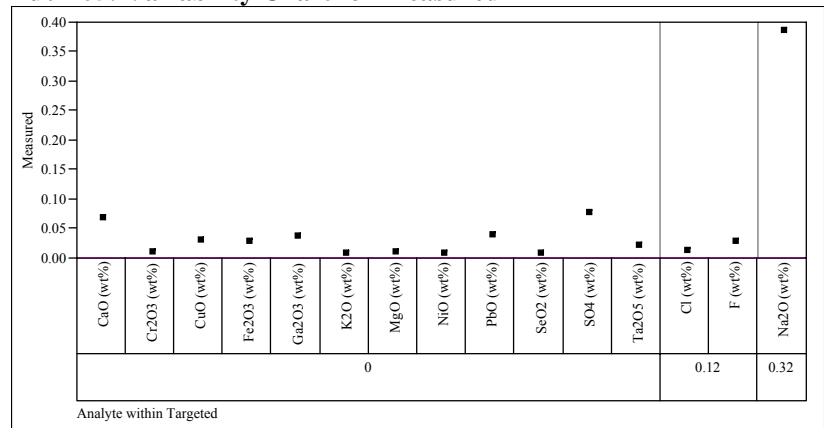

Pu35-01: Variability Chart for Measured

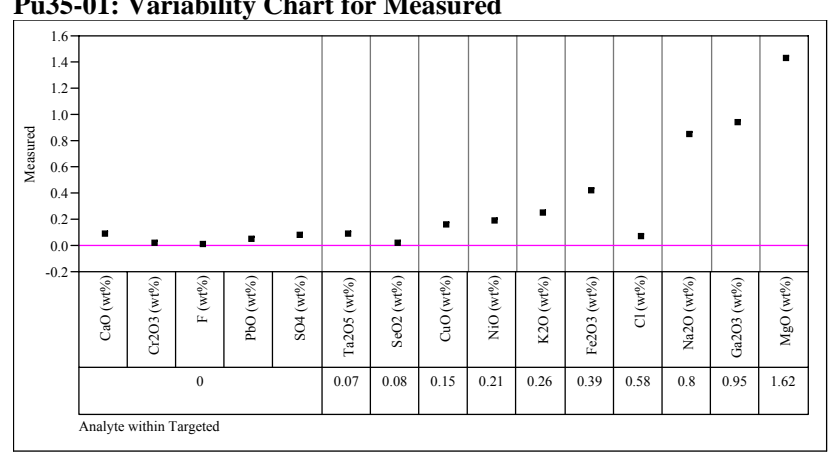


Exhibit D10. Measured Impurity Levels by Study Glass Sorted by Targeted Concentrations (continued)

Pu35-02: Variability Chart for Measured

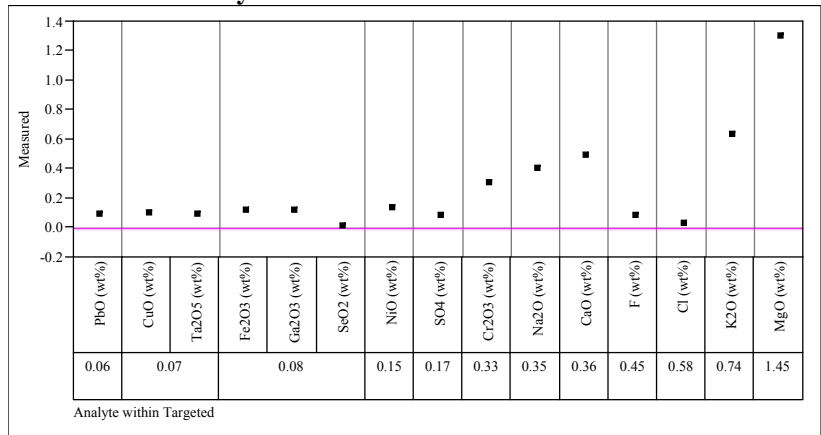

Pu35-03: Variability Chart for Measured

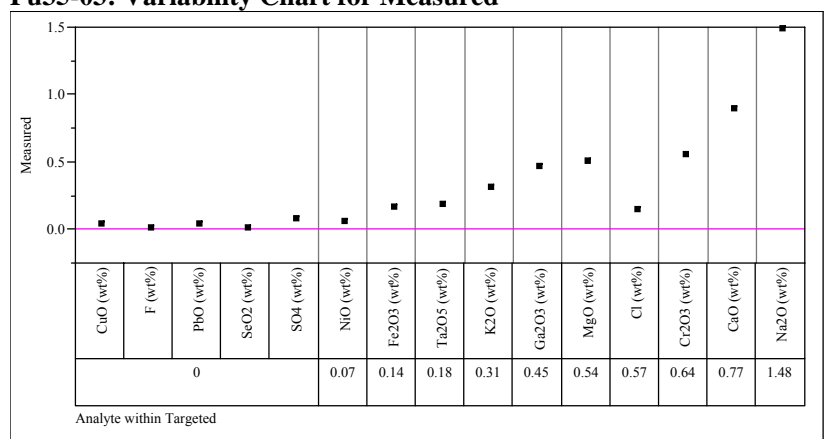

Pu35-04: Variability Chart for Measured

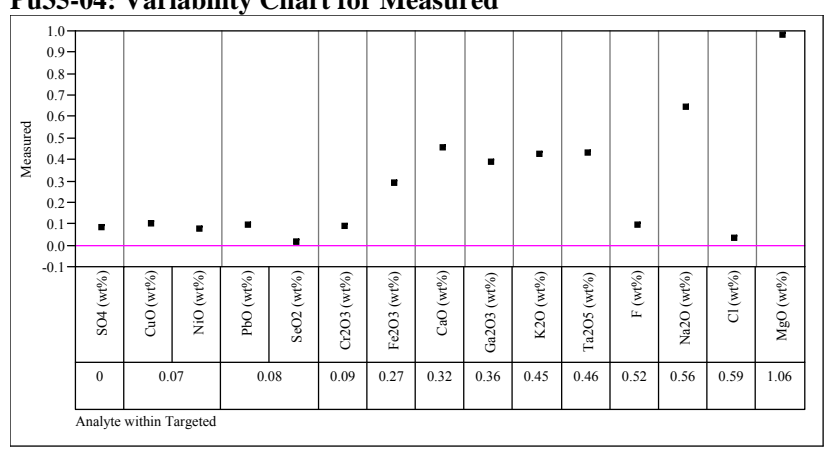

Pu35-05: Variability Chart for Measured

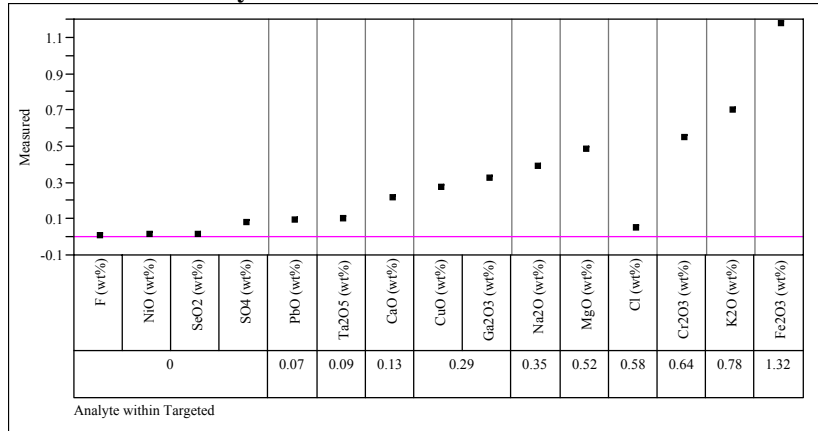

Pu35-06: Variability Chart for Measured

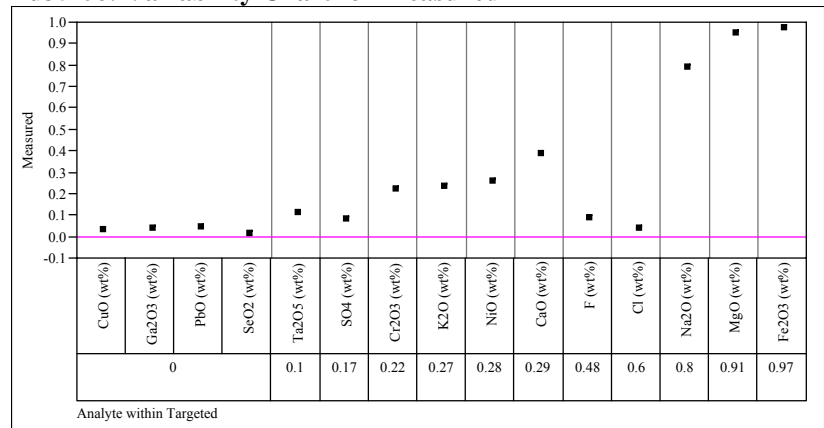

Pu35-07: Variability Chart for Measured

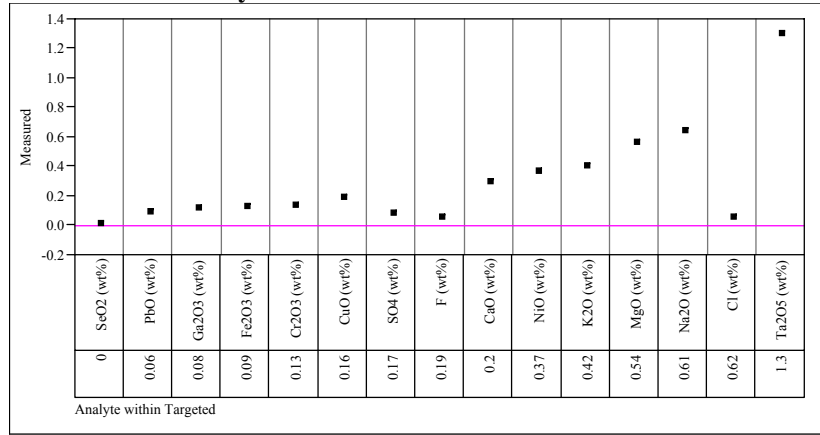


Exhibit D10. Measured Impurity Levels by Study Glass Sorted by Targeted Concentrations (continued)

Pu35-08: Variability Chart for Measured

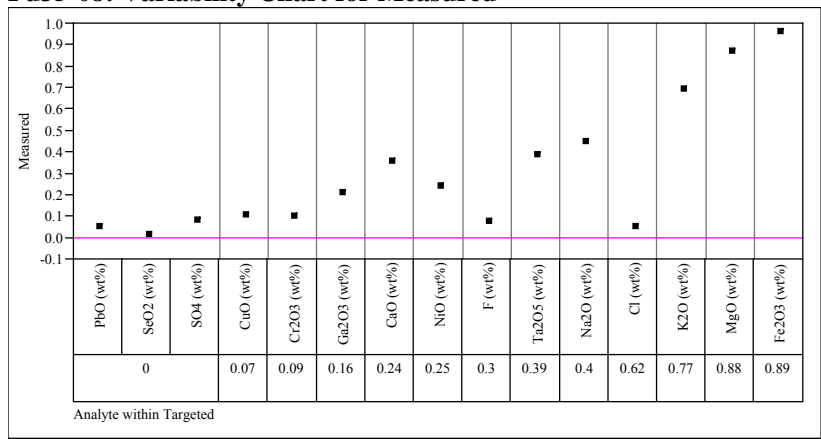

Pu35-09: Variability Chart for Measured

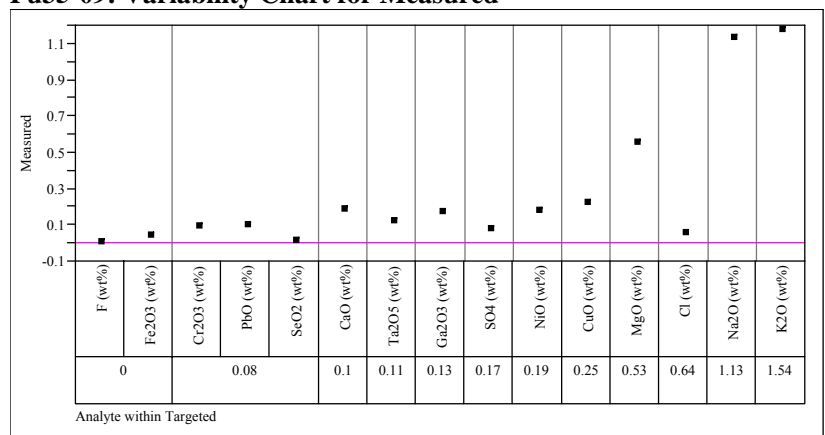

Pu35-10: Variability Chart for Measured

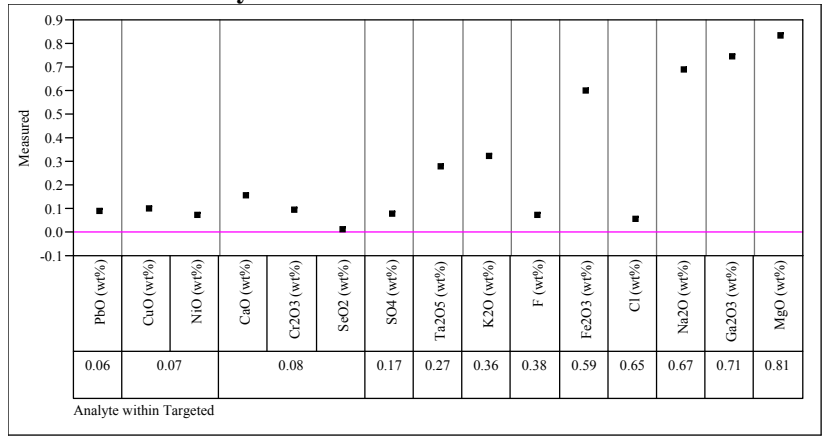

Pu35-11: Variability Chart for Measured

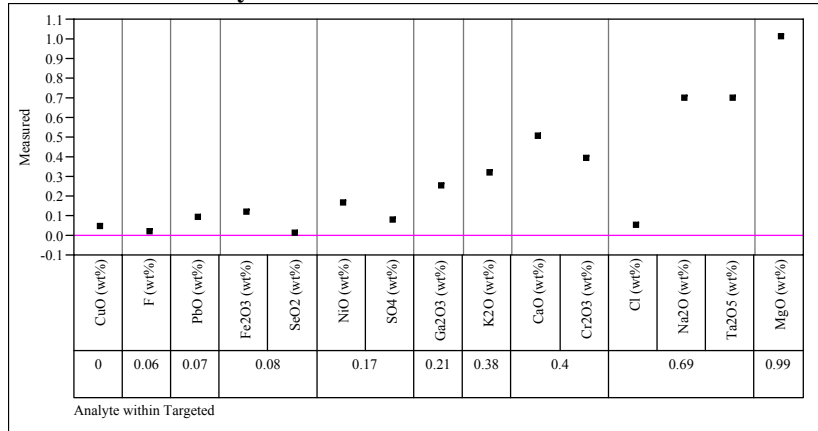

Pu35-12: Variability Chart for Measured

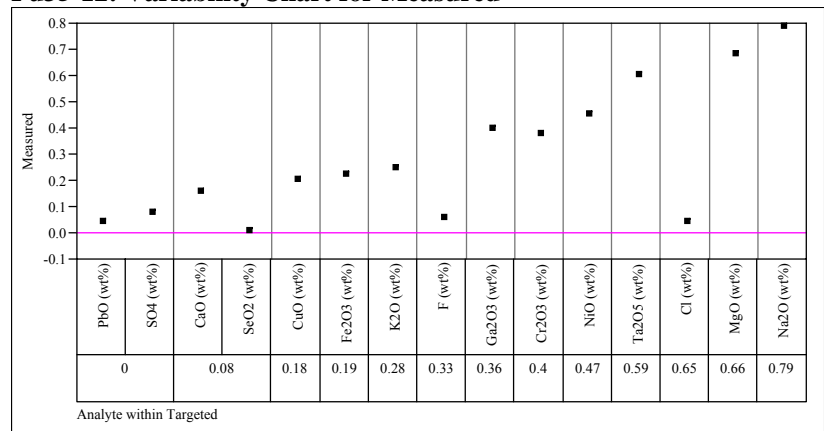

Pu35-13: Variability Chart for Measured

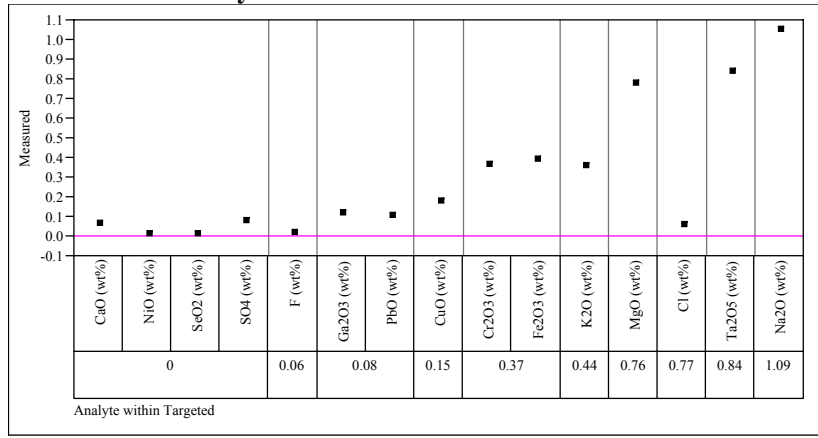


Exhibit D10. Measured Impurity Levels by Study Glass Sorted by Targeted Concentrations (continued)

Pu35-14: Variability Chart for Measured

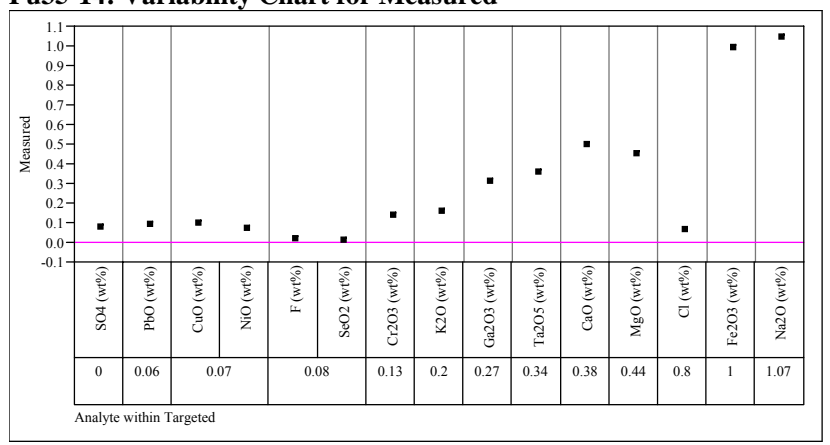

Pu35-15: Variability Chart for Measured

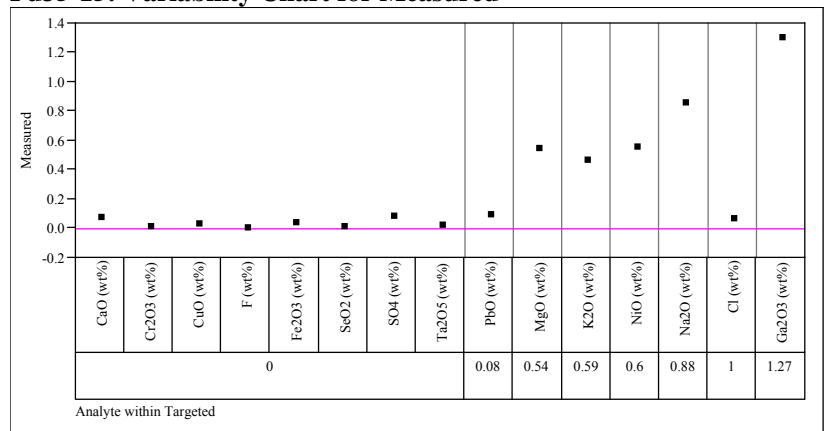

Pu35-16: Variability Chart for Measured

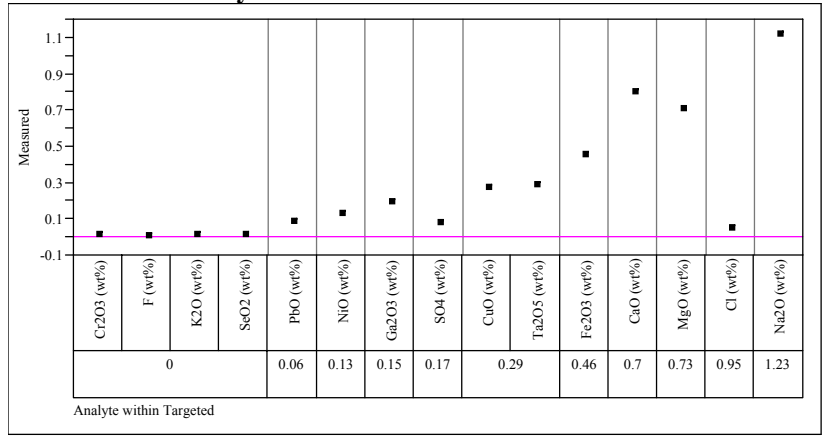

Pu35-17: Variability Chart for Measured

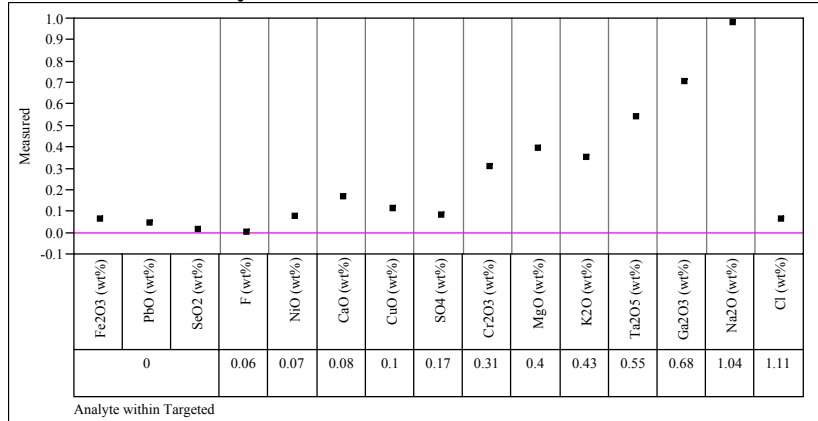

Pu35-18: Variability Chart for Measured

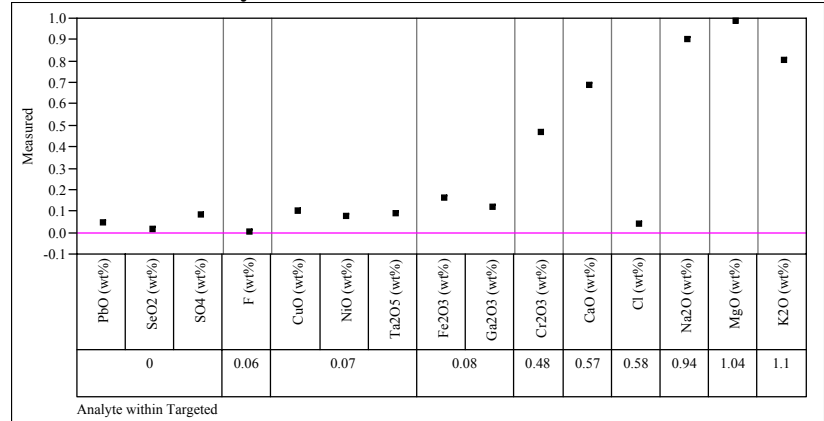

Pu35-19: Variability Chart for Measured

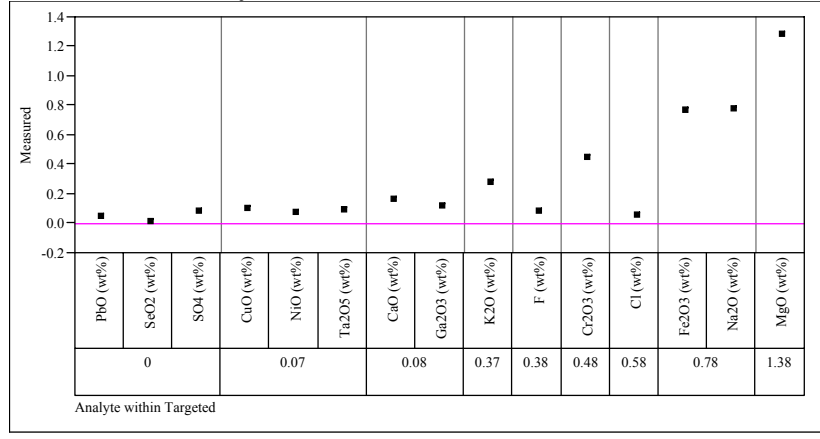


Exhibit D10. Measured Impurity Levels by Study Glass Sorted by Targeted Concentrations (continued)

Pu35-20: Variability Chart for Measured

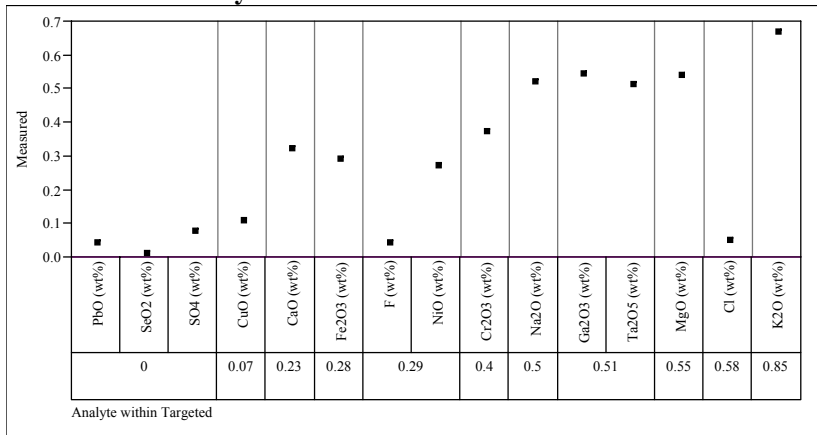

Pu35-21: Variability Chart for Measured

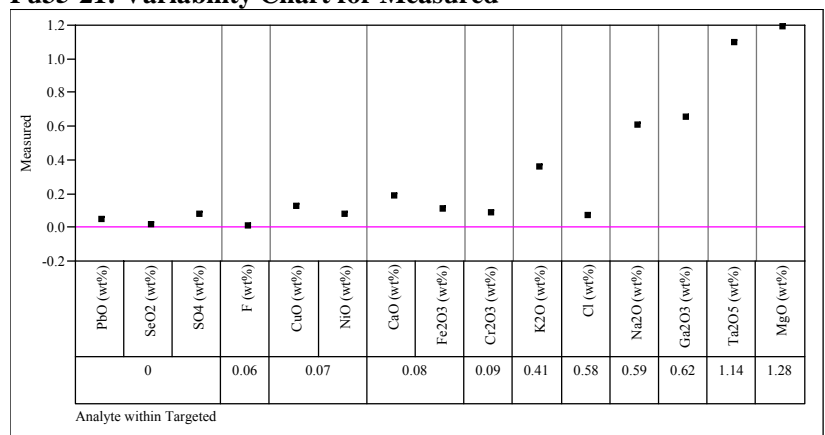

Pu35-22: Variability Chart for Measured

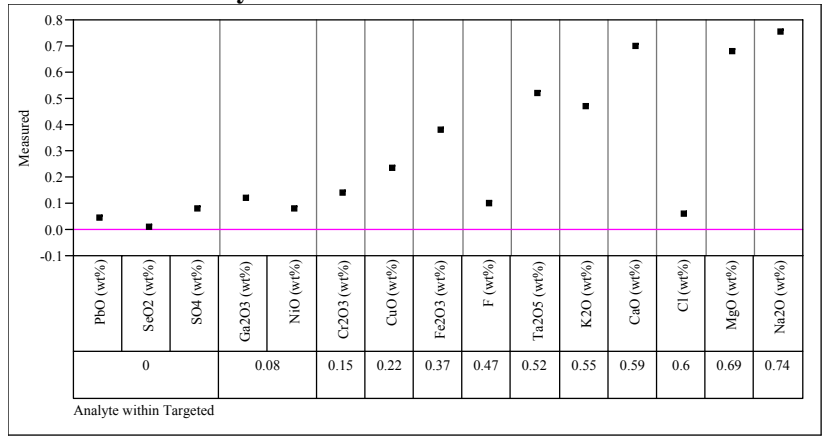

Pu35-23: Variability Chart for Measured

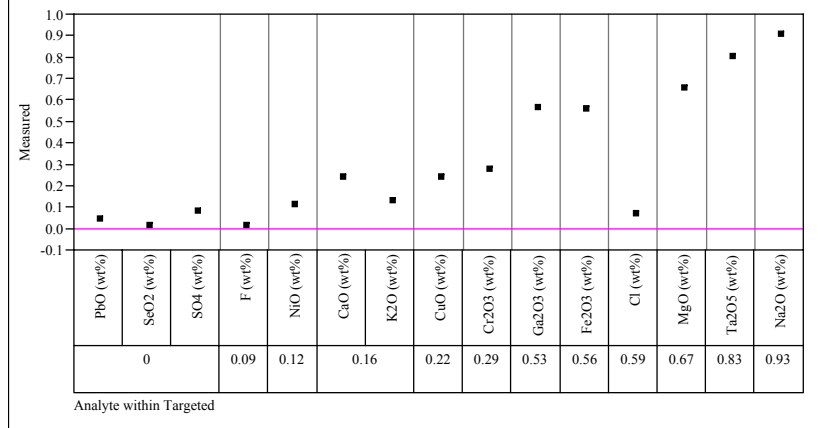

Pu35-24: Variability Chart for Measured

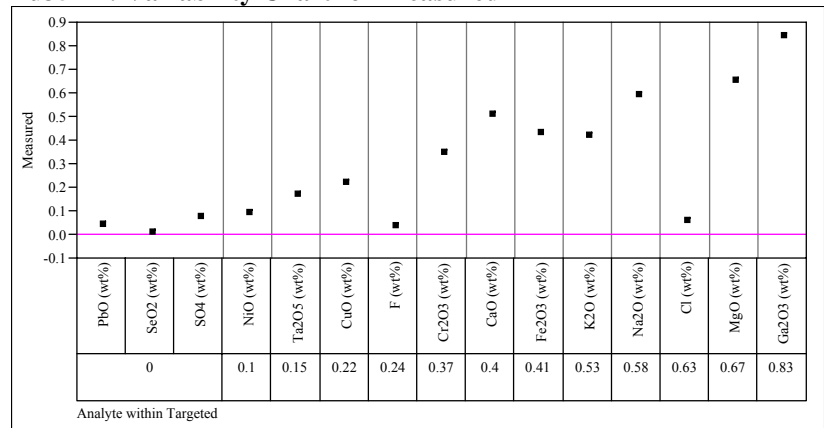

Pu35-25: Variability Chart for Measured

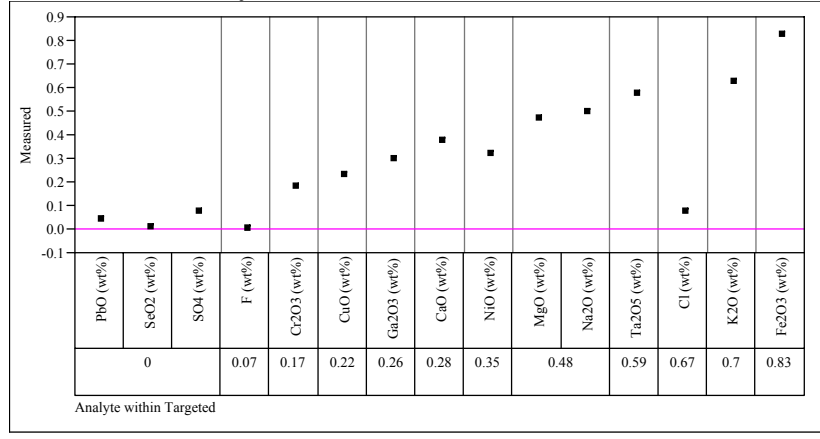


Exhibit D10. Measured Impurity Levels by Study Glass Sorted by Targeted Concentrations (continued)

Pu35-26: Variability Chart for Measured

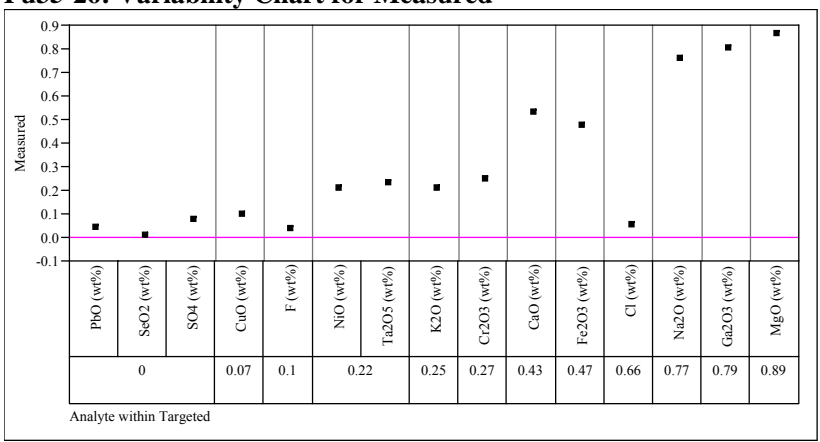

Pu35-27: Variability Chart for Measured

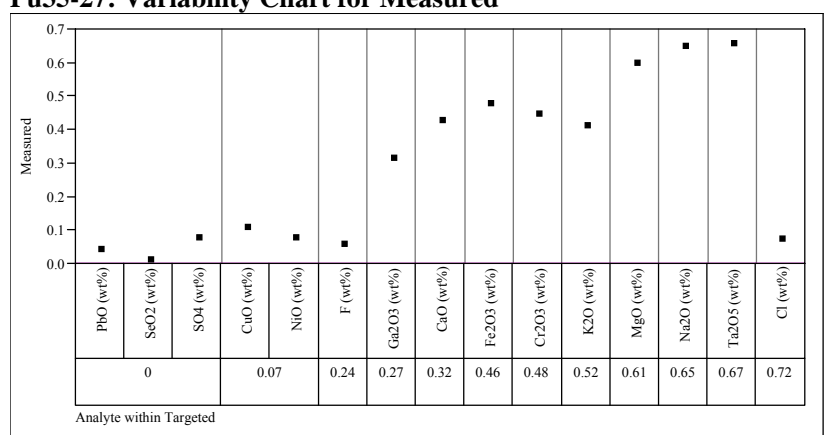

Pu35-28: Variability Chart for Measured

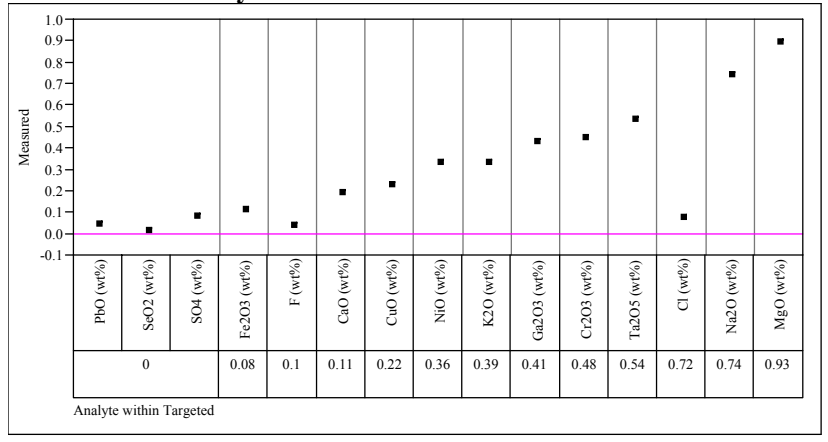

Pu35-29: Variability Chart for Measured

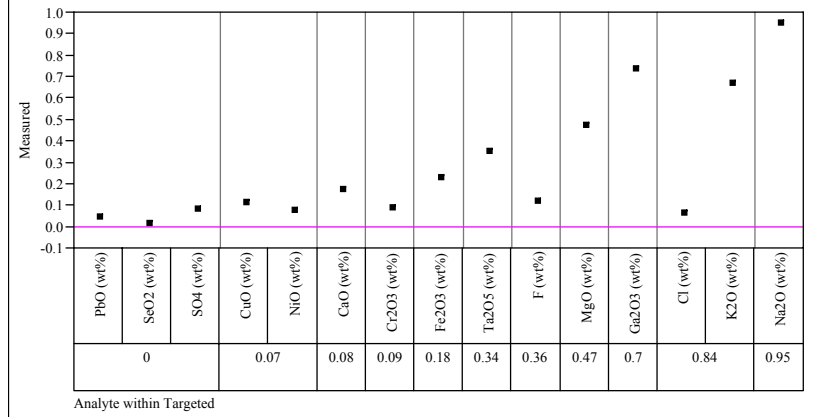

Pu35-30: Variability Chart for Measured

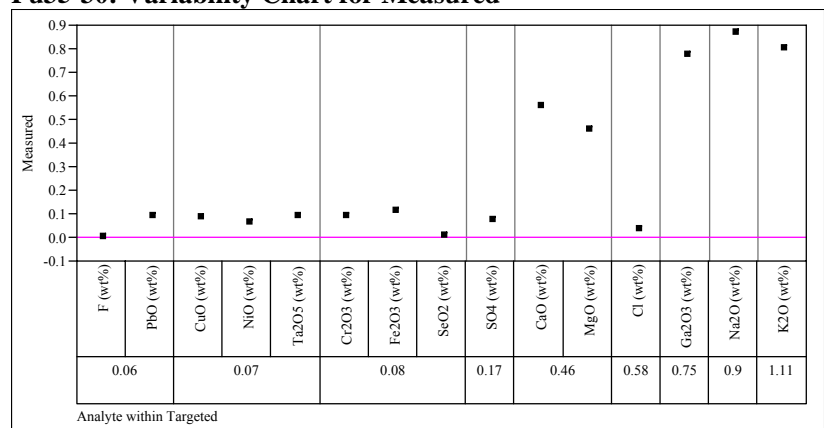

Pu35-31: Variability Chart for Measured

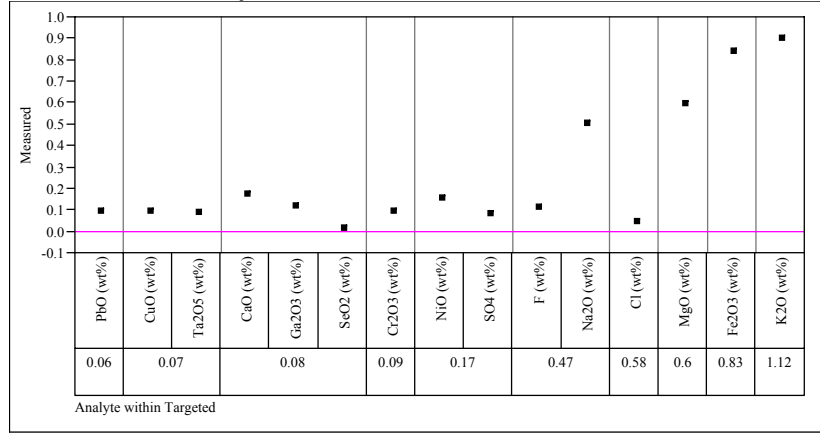


Exhibit D10. Measured Impurity Levels by Study Glass Sorted by Targeted Concentrations (continued)

Pu35-32: Variability Chart for Measured

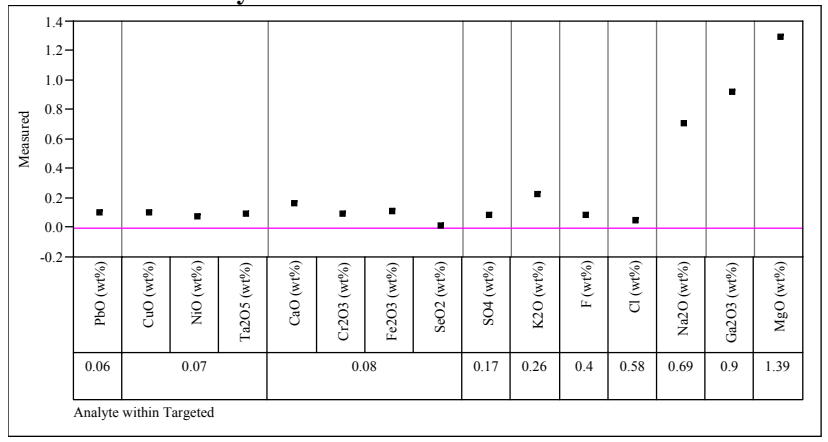

Pu35-33: Variability Chart for Measured

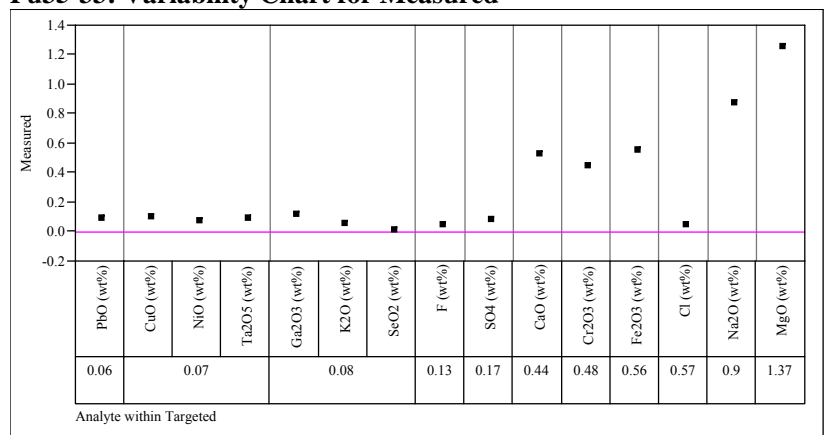

Pu35-34: Variability Chart for Measured

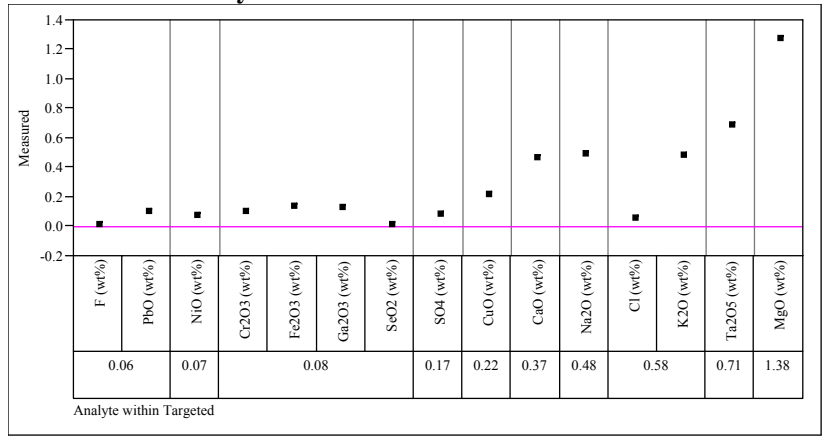

Pu35-35: Variability Chart for Measured

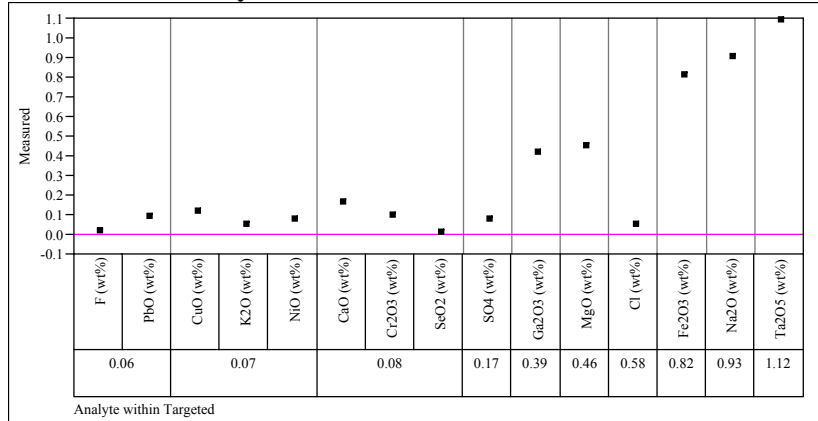

Pu35-36: Variability Chart for Measured

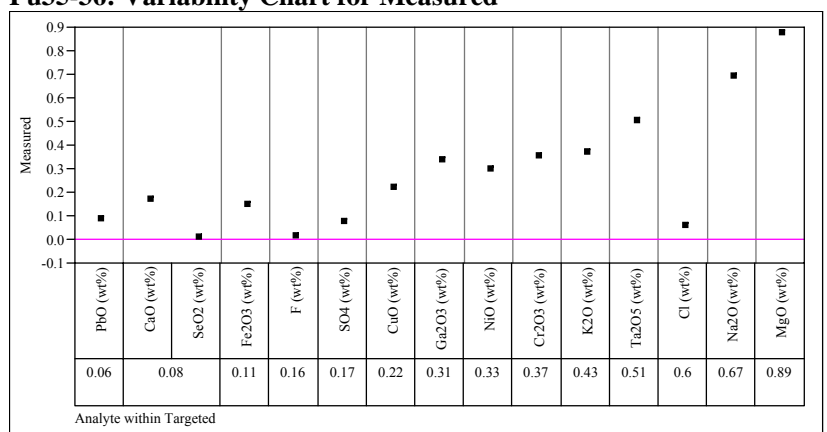

Pu35-37: Variability Chart for Measured

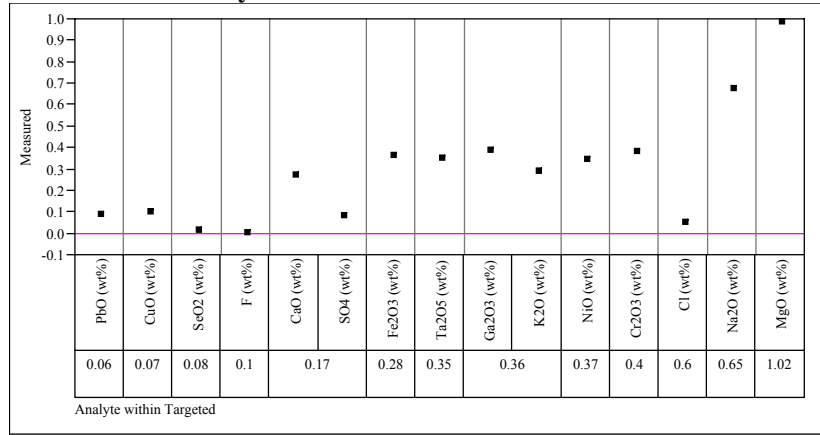


Exhibit D10. Measured Impurity Levels by Study Glass Sorted by Targeted Concentrations (continued)

Pu35-38: Variability Chart for Measured

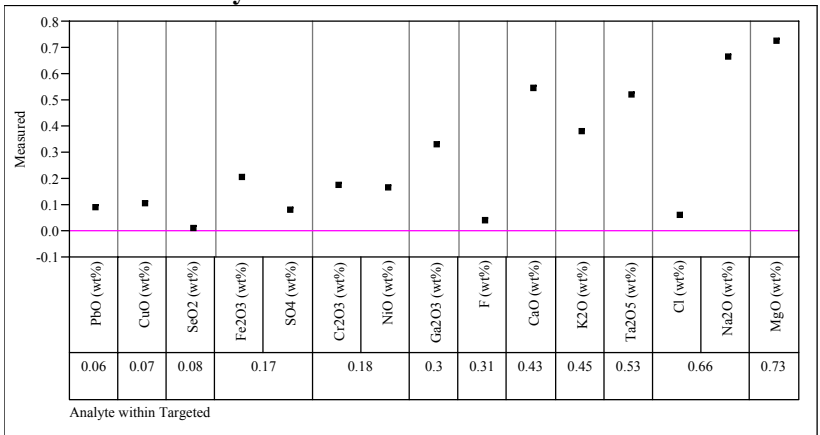

Pu35-39: Variability Chart for Measured

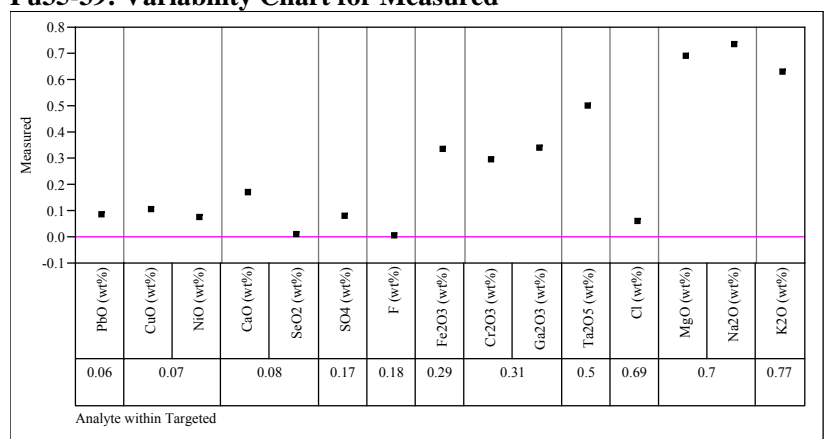

Pu35-40: Variability Chart for Measured

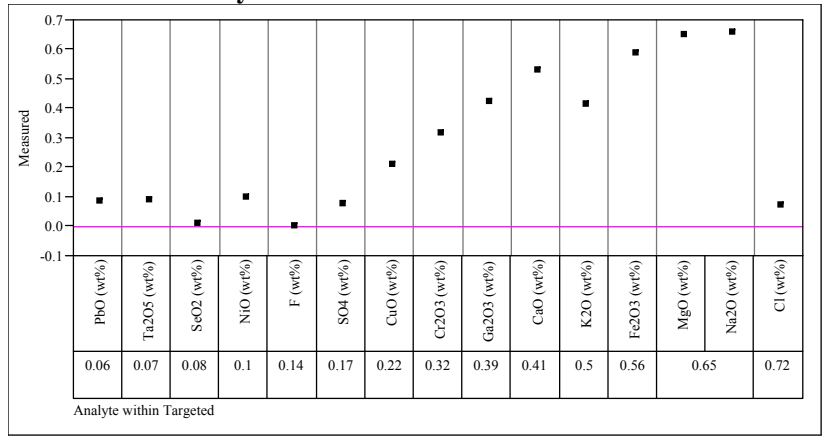

Pu35-41: Variability Chart for Measured

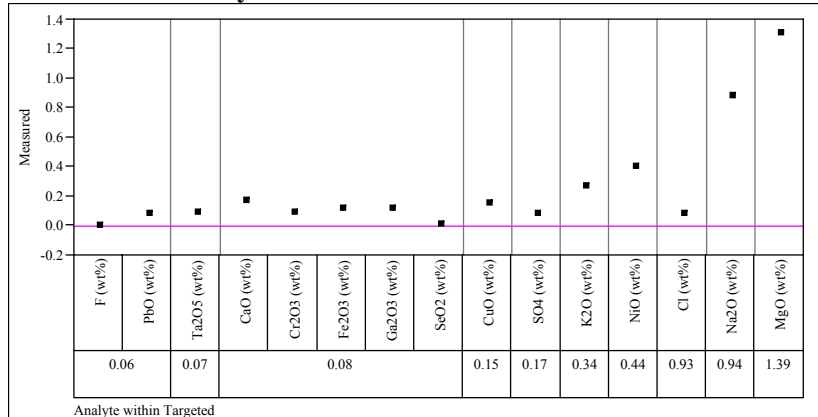

Pu35-42: Variability Chart for Measured

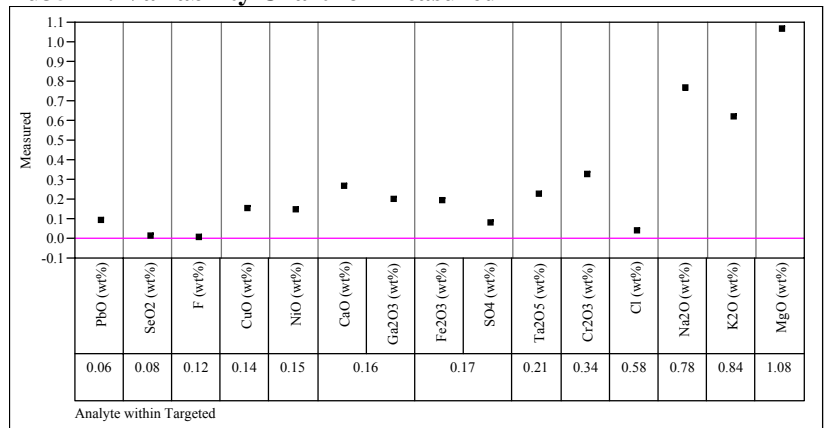

Pu35-43: Variability Chart for Measured

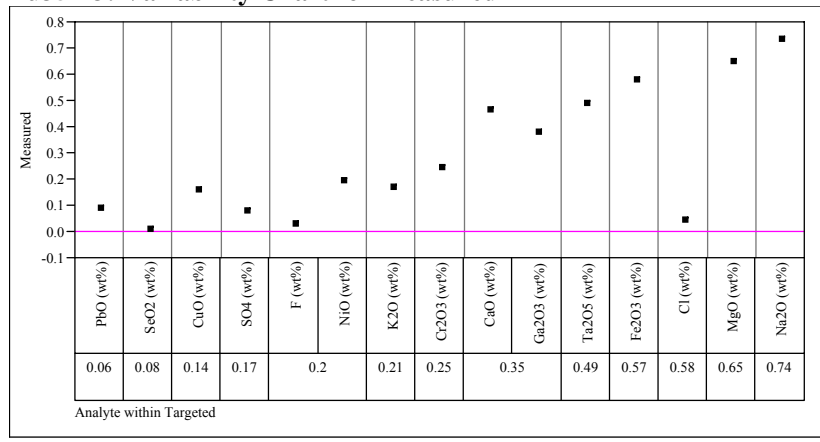


Exhibit D10. Measured Impurity Levels by Study Glass Sorted by Targeted Concentrations (continued)

Pu35-44: Variability Chart for Measured

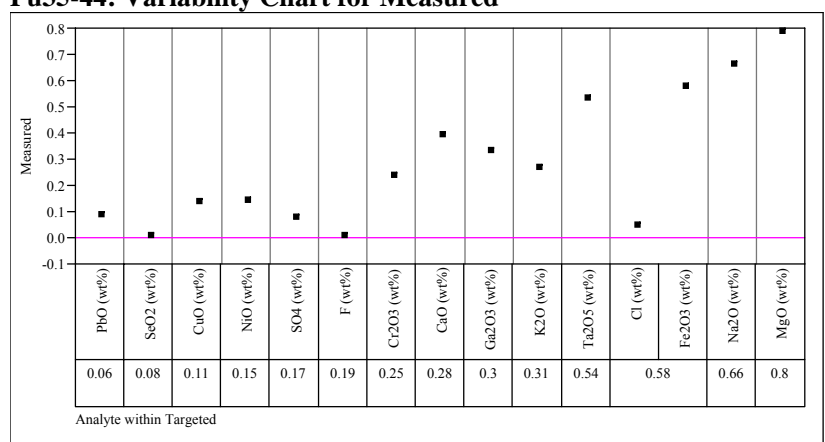

Pu35-45: Variability Chart for Measured

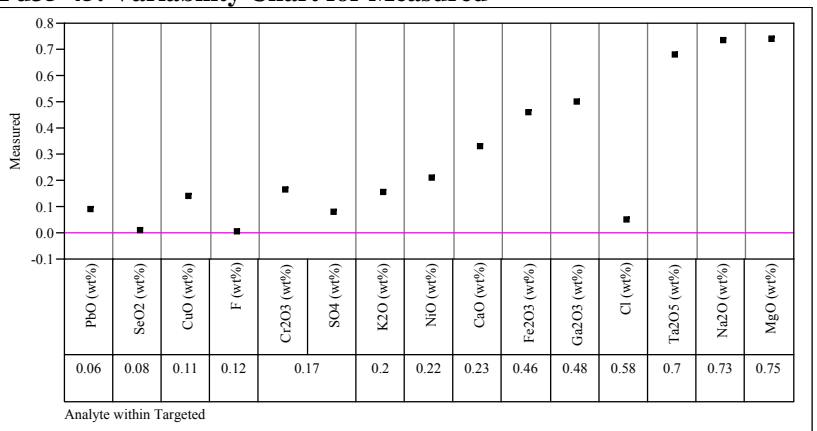

Pu35-46: Variability Chart for Measured

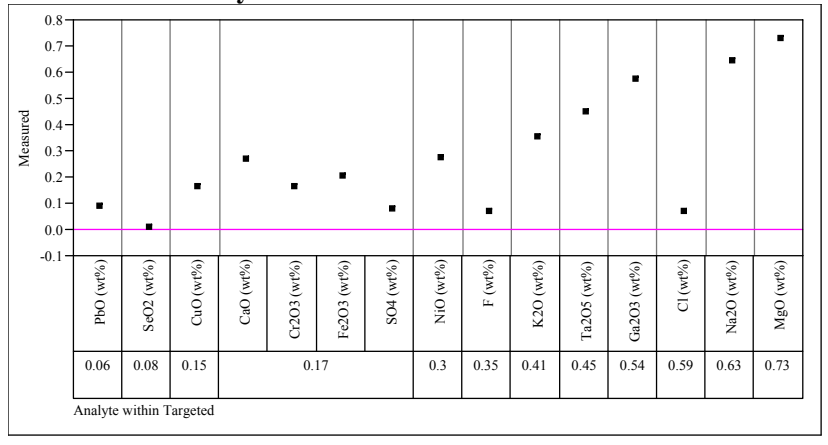

Pu35-47: Variability Chart for Measured

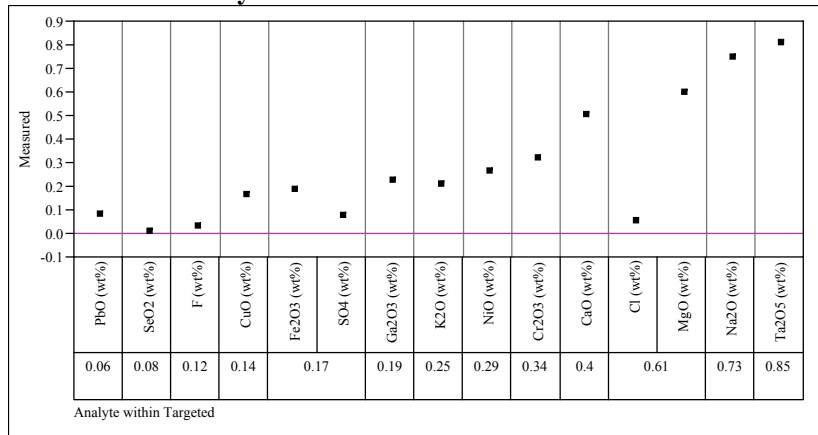

Pu35-48: Variability Chart for Measured

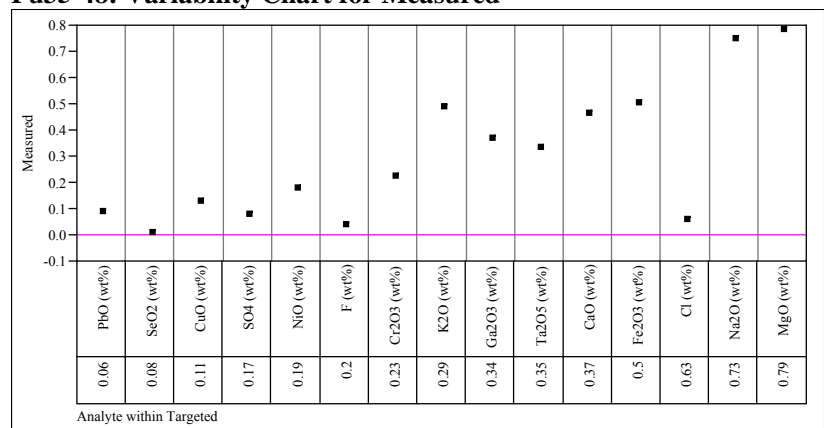

Pu35-49: Variability Chart for Measured

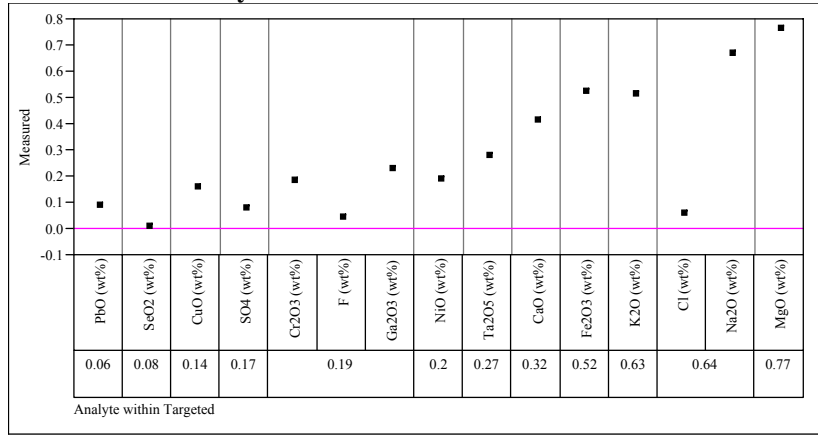


Exhibit D10. Measured Impurity Levels by Study Glass Sorted by Targeted Concentrations (continued)

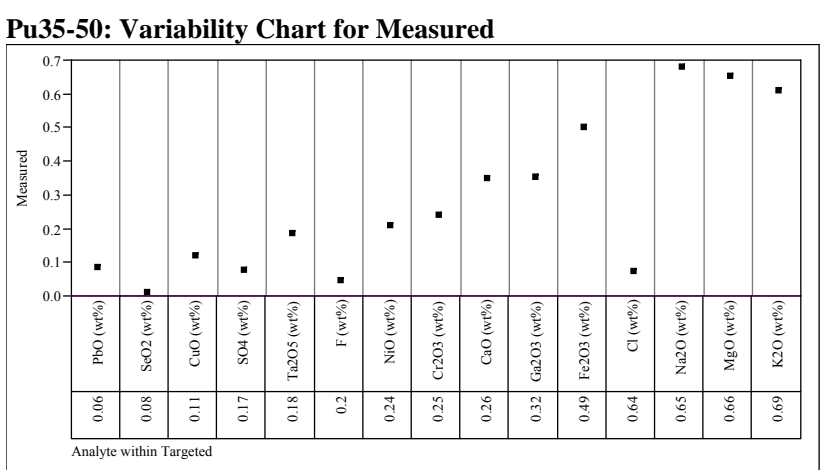

Pu35-51: Variability Chart for Measured

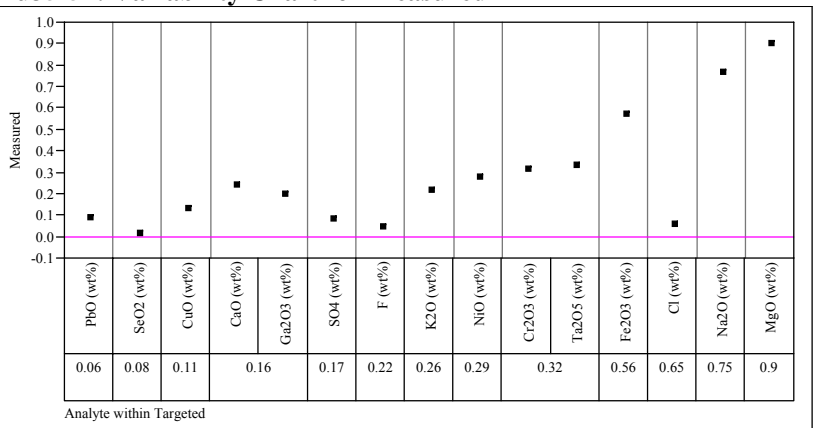

Pu35-52: Variability Chart for Measured

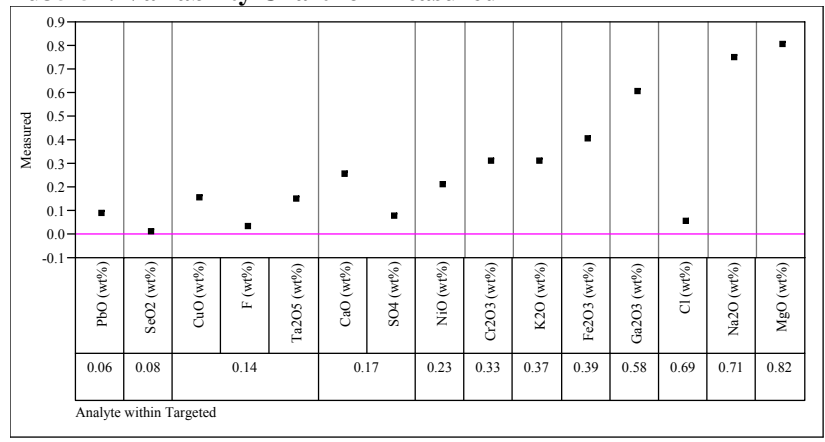

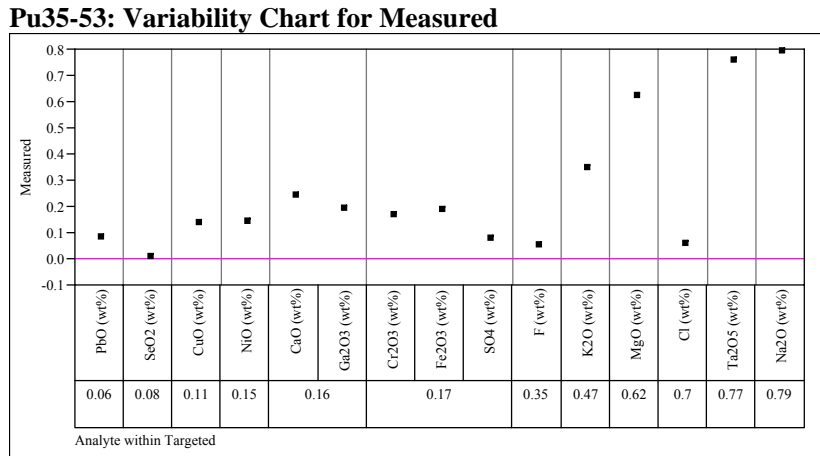

Pu35-54: Variability Chart for Measured

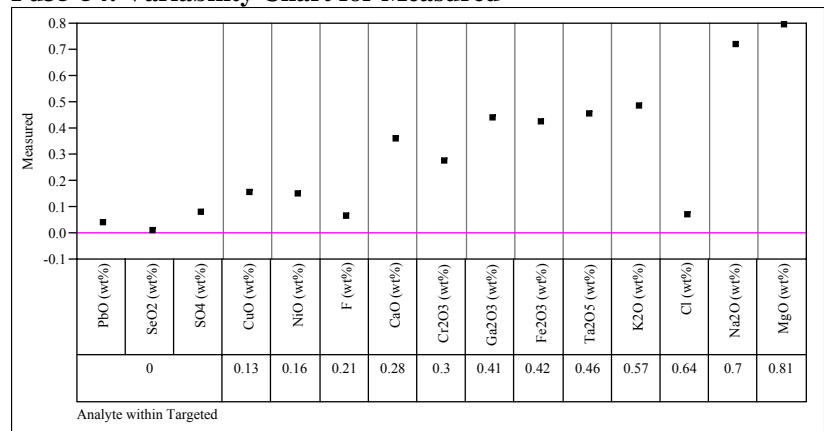

Pu35-55: Variability Chart for Measured

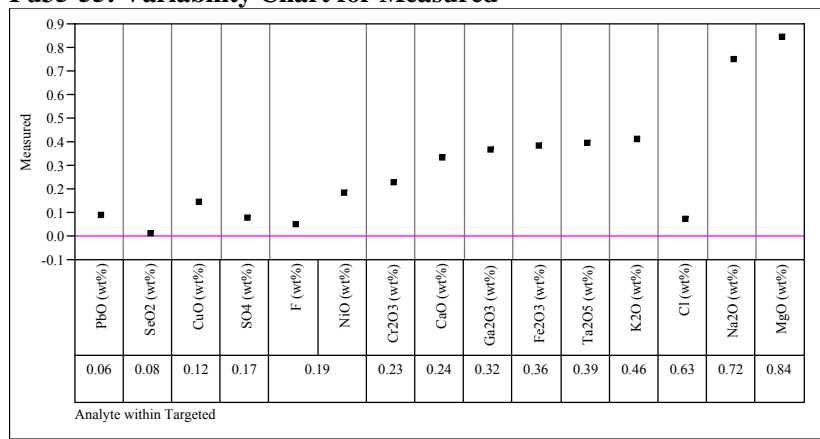




\section{Appendix E}

Tables and Exhibits Supporting the Analysis of the PCT Results for the Surrogate Pu Impurity Variability Study Glasses 
Table E1. Laboratory Measurements of the PCT Solutions for the Pu Study Glasses As Reported (ar) and After the Appropriate Adjustments (in parts per million, ppm)

\begin{tabular}{|c|c|c|c|c|c|c|c|c|c|c|c|c|c|c|c|}
\hline Heat Treament & Set & Glass ID & Block & Seq & SRNL-ML ID & B ar & Gd ar & Hf ar & Na ar & Si ar & B (ppm) & Gd (ppm) & Hf (ppm) & $\mathrm{Na}$ (ppm) & Si (ppm) \\
\hline & 1 & Soln Std & 1 & 1 & STD-11-1 & 21.8 & $<0.100$ & $<0.500$ & 83.2 & 49 & 21.8 & 0.05 & 0.25 & 83.2 & 49 \\
\hline quenched & 1 & Pu35-01 & 1 & 2 & C62 & 1.18 & $<0.100$ & $<0.500$ & $<0.100$ & $<0.100$ & 1.966706 & 0.083335 & 0.416675 & 0.083335 & 0.083335 \\
\hline quenched & 1 & Pu35-06 & 1 & 3 & $\mathrm{C} 45$ & $<1.00$ & $<0.100$ & $<0.500$ & $<0.100$ & $<0.100$ & 0.83335 & 0.083335 & 0.416675 & 0.083335 & 0.083335 \\
\hline quenched & 1 & $\mathrm{Pu} 04-05$ & 1 & 4 & C49 & $<1.00$ & $<0.100$ & $<0.500$ & $<0.100$ & $<0.100$ & 0.83335 & 0.083335 & 0.416675 & 0.083335 & 0.083335 \\
\hline quenched & 1 & Pu35-08 & 1 & 5 & $\mathrm{C} 08$ & $<1.00$ & $<0.100$ & $<0.500$ & $<0.100$ & $<0.100$ & 0.83335 & 0.083335 & 0.416675 & 0.083335 & 0.083335 \\
\hline quenched & 1 & $\mathrm{Pu} 04-04$ & 1 & 6 & C55 & $<1.00$ & $<0.100$ & $<0.500$ & $<0.100$ & $<0.100$ & 0.83335 & 0.083335 & 0.416675 & 0.083335 & 0.083335 \\
\hline \multirow[t]{2}{*}{ quenched } & 1 & Pu35-05 & 1 & 7 & $\mathrm{C} 32$ & $<1.00$ & $<0.100$ & $<0.500$ & $<0.100$ & 2.39 & 0.83335 & 0.083335 & 0.416675 & 0.083335 & 3.983413 \\
\hline & 1 & blank & 1 & 8 & $\mathrm{C} 21$ & $<1.00$ & $<0.100$ & $<0.500$ & $<0.100$ & $<0.100$ & 0.83335 & 0.083335 & 0.416675 & 0.083335 & 0.083335 \\
\hline quenched & 1 & Pu35-15 & 1 & 9 & $\mathrm{C} 37$ & $<1.00$ & $<0.100$ & $<0.500$ & $<0.100$ & $<0.100$ & 0.83335 & 0.083335 & 0.416675 & 0.083335 & 0.083335 \\
\hline quenched & 1 & Pu35-12 & 1 & 10 & $\mathrm{C} 42$ & $<1.00$ & $<0.100$ & $<0.500$ & $<0.100$ & $<0.100$ & 0.83335 & 0.083335 & 0.416675 & 0.083335 & 0.083335 \\
\hline quenched & 1 & Pu35-11 & 1 & 11 & $\mathrm{C} 51$ & $<1.00$ & $<0.100$ & $<0.500$ & $<0.100$ & $<0.100$ & 0.83335 & 0.083335 & 0.416675 & 0.083335 & 0.083335 \\
\hline \multirow[t]{2}{*}{ quenched } & 1 & Pu35-09 & 1 & 12 & $\mathrm{C} 50$ & $<1.00$ & $<0.100$ & $<0.500$ & $<0.100$ & 2.15 & 0.83335 & 0.083335 & 0.416675 & 0.083335 & 3.583405 \\
\hline & 1 & Soln Std & 1 & 13 & STD-11-2 & 20.8 & $<0.100$ & $<0.500$ & 82.4 & 49.1 & 20.8 & 0.05 & 0.25 & 82.4 & 49.1 \\
\hline quenched & 1 & Pu35-04 & 1 & 14 & $\mathrm{C} 24$ & 1.1 & $<0.100$ & $<0.500$ & $<0.100$ & $<0.100$ & 1.83337 & 0.083335 & 0.416675 & 0.083335 & 0.083335 \\
\hline quenched & 1 & Pu35-10 & 1 & 15 & $\mathrm{C} 23$ & $<1.00$ & $<0.100$ & $<0.500$ & $<0.100$ & $<0.100$ & 0.83335 & 0.083335 & 0.416675 & 0.083335 & 0.083335 \\
\hline quenched & 1 & $\mathrm{Pu} 04-02$ & 1 & 16 & $\mathrm{C} 15$ & $<1.00$ & $<0.100$ & $<0.500$ & $<0.100$ & $<0.100$ & 0.83335 & 0.083335 & 0.416675 & 0.083335 & 0.083335 \\
\hline quenched & 1 & Pu35-03 & 1 & 17 & C58 & $<1.00$ & $<0.100$ & $<0.500$ & $<0.100$ & $<0.100$ & 0.83335 & 0.083335 & 0.416675 & 0.083335 & 0.083335 \\
\hline \multirow[t]{3}{*}{ quenched } & 1 & Pu35-02 & 1 & 18 & $\mathrm{C} 11$ & $<1.00$ & $<0.100$ & $<0.500$ & $<0.100$ & 2.09 & 0.83335 & 0.083335 & 0.416675 & 0.083335 & 3.483403 \\
\hline & 1 & EA & 1 & 19 & $\mathrm{C} 36$ & 41.3 & $<0.100$ & $<0.500$ & \begin{tabular}{|l|}
108 \\
\end{tabular} & 58.3 & 688.33471 & 0.833335 & 4.166675 & 1800.0036 & 971.66861 \\
\hline & 1 & ARM-1 & 1 & 20 & $\mathrm{C} 16$ & 11.1 & $<0.100$ & $<0.500$ & 21.3 & 35.5 & 18.50037 & 0.083335 & 0.416675 & 35.50071 & 59.16785 \\
\hline quenched & 1 & Pu35-13 & 1 & 21 & $\mathrm{C} 09$ & $<1.00$ & $<0.100$ & $<0.500$ & $<0.100$ & $<0.100$ & 0.83335 & 0.083335 & 0.416675 & 0.083335 & 0.083335 \\
\hline quenched & 1 & Pu35-14 & 1 & 22 & $\mathrm{C} 29$ & $<1.00$ & $<0.100$ & $<0.500$ & $<0.100$ & $<0.100$ & 0.83335 & 0.083335 & 0.416675 & 0.083335 & 0.083335 \\
\hline quenched & 1 & Pu04-01 & 1 & 23 & $\mathrm{C} 04$ & $<1.00$ & $<0.100$ & $<0.500$ & $<0.100$ & $<0.100$ & 0.83335 & 0.083335 & 0.416675 & 0.083335 & 0.083335 \\
\hline quenched & 1 & Pu35-07 & 1 & 24 & $\mathrm{C} 22$ & $<1.00$ & $<0.100$ & $<0.500$ & $<0.100$ & $<0.100$ & 0.83335 & 0.083335 & 0.416675 & 0.083335 & 0.083335 \\
\hline \multirow[t]{3}{*}{ quenched } & 1 & Pu04-03 & 1 & 25 & $\mathrm{C} 26$ & $<1.00$ & $<0.100$ & $<0.500$ & $<0.100$ & $<0.100$ & 0.83335 & 0.083335 & 0.416675 & 0.083335 & 0.083335 \\
\hline & 1 & Soln Std & 1 & 26 & STD-11-3 & 21.6 & $<0.100$ & $<0.500$ & 85 & 51.8 & 21.6 & 0.05 & 0.25 & 85 & 51.8 \\
\hline & 1 & Soln Std & 2 & 1 & STD-12-1 & 21.5 & $<0.100$ & $<0.500$ & 82.8 & 49.7 & 21.5 & 0.05 & 0.25 & 82.8 & 49.7 \\
\hline quenched & 1 & Pu35-09 & 2 & 2 & $\mathrm{C} 40$ & 1.77 & $<0.100$ & $<0.500$ & $<0.100$ & 3.01 & 2.950059 & 0.083335 & 0.416675 & 0.083335 & 5.016767 \\
\hline quenched & 1 & Pu35-13 & 2 & 3 & $\mathrm{C} 12$ & 1.01 & $<0.100$ & $<0.500$ & 1.16 & 0.564 & 1.683367 & 0.083335 & 0.416675 & 1.933372 & 0.9400188 \\
\hline quenched & 1 & Pu35-07 & 2 & 4 & $\mathrm{C} 35$ & $<1.00$ & $<0.100$ & $<0.500$ & $<0.100$ & 0.1 & 0.83335 & 0.083335 & 0.416675 & 0.083335 & 0.16667 \\
\hline quenched & 1 & Pu35-15 & 2 & 5 & $\mathrm{C} 02$ & $<1.00$ & $<0.100$ & $<0.500$ & $<0.100$ & 0.107 & 0.83335 & 0.083335 & 0.416675 & 0.083335 & 0.1783369 \\
\hline quenched & 1 & $\mathrm{Pu} 04-04$ & 2 & 6 & C53 & $<1.00$ & $<0.100$ & $<0.500$ & $<0.100$ & $<0.100$ & 0.83335 & 0.083335 & 0.416675 & 0.083335 & 0.083335 \\
\hline quenched & 1 & Pu35-06 & 2 & 7 & C56 & $<1.00$ & $<0.100$ & $<0.500$ & $<0.100$ & $<0.100$ & 0.83335 & 0.083335 & 0.416675 & 0.083335 & 0.083335 \\
\hline
\end{tabular}


Table E1. Laboratory Measurements of the PCT Solutions for the Pu Study Glasses As Reported (ar) and After the Appropriate Adjustments (in parts per million, ppm)

(continued)

\begin{tabular}{|c|c|c|c|c|c|c|c|c|c|c|c|c|c|c|c|}
\hline Heat Treament & Set & Glass ID & Block & Seq & SRNL-ML ID & B ar & Gd ar & Hf ar & Na ar & Si ar & B (ppm) & Gd (ppm) & Hf (ppm) & $\mathrm{Na}$ (ppm) & Si (ppm) \\
\hline quenched & 1 & Pu35-02 & 2 & 8 & C57 & $<1.00$ & $<0.100$ & $<0.500$ & $<0.100$ & $<0.100$ & 0.83335 & 0.083335 & 0.416675 & 0.083335 & 0.083335 \\
\hline quenched & 1 & Pu35-11 & 2 & 9 & $\mathrm{C} 47$ & $<1.00$ & $<0.100$ & $<0.500$ & $<0.100$ & $<0.100$ & 0.83335 & 0.083335 & 0.416675 & 0.083335 & 0.083335 \\
\hline quenched & 1 & Pu35-01 & 2 & 10 & C39 & $<1.00$ & $<0.100$ & $<0.500$ & $<0.100$ & $<0.100$ & 0.83335 & 0.083335 & 0.416675 & 0.083335 & 0.083335 \\
\hline quenched & 1 & Pu35-12 & 2 & 11 & $\mathrm{C} 34$ & $<1.00$ & $<0.100$ & $<0.500$ & $<0.100$ & $<0.100$ & 0.83335 & 0.083335 & 0.416675 & 0.083335 & 0.083335 \\
\hline \multirow[t]{2}{*}{ quenched } & 1 & $\mathrm{Pu} 04-05$ & 2 & 12 & $\mathrm{C} 03$ & $<1.00$ & $<0.100$ & $<0.500$ & $<0.100$ & $<0.100$ & 0.83335 & 0.083335 & 0.416675 & 0.083335 & 0.083335 \\
\hline & 1 & Soln Std & 2 & 13 & STD-12-2 & 19.2 & $<0.100$ & $<0.500$ & 83.3 & 49.3 & 19.2 & 0.05 & 0.25 & 83.3 & 49.3 \\
\hline quenched & 1 & Pu35-08 & 2 & 14 & $\mathrm{C} 17$ & 1.12 & $<0.100$ & $<0.500$ & $<0.100$ & 0.827 & 1.866704 & 0.083335 & 0.416675 & 0.083335 & 1.3783609 \\
\hline \multirow[t]{2}{*}{ quenched } & 1 & Pu35-03 & 2 & 15 & $\mathrm{C} 14$ & $<1.00$ & $<0.100$ & $<0.500$ & $<0.100$ & 0.44 & 0.83335 & 0.083335 & 0.416675 & 0.083335 & 0.733348 \\
\hline & 1 & ARM-1 & 2 & 16 & $\mathrm{C} 43$ & 9.57 & $<0.100$ & $<0.500$ & 20.7 & 35.4 & 15.950319 & 0.083335 & 0.416675 & 34.50069 & 59.00118 \\
\hline quenched & 1 & Pu35-10 & 2 & 17 & $\mathrm{C} 33$ & $<1.00$ & $<0.100$ & $<0.500$ & 0.206 & $<0.100$ & 0.83335 & 0.083335 & 0.416675 & 0.3433402 & 0.083335 \\
\hline quenched & 1 & Pu35-14 & 2 & 18 & $\mathrm{C} 46$ & $<1.00$ & $<0.100$ & $<0.500$ & $<0.100$ & $<0.100$ & 0.83335 & 0.083335 & 0.416675 & 0.083335 & 0.083335 \\
\hline quenched & 1 & Pu04-01 & 2 & 19 & $\mathrm{C} 41$ & $<1.00$ & $<0.100$ & $<0.500$ & 10.9 & $<0.100$ & 0.83335 & 0.083335 & 0.416675 & 18.16703 & 0.083335 \\
\hline quenched & 1 & Pu35-05 & 2 & 20 & C60 & $<1.00$ & $<0.100$ & $<0.500$ & 8.57 & 1.55 & 0.83335 & 0.083335 & 0.416675 & 14.283619 & 2.583385 \\
\hline \multirow[t]{2}{*}{ quenched } & 1 & $\mathrm{Pu} 04-02$ & 2 & 21 & $\mathrm{C} 27$ & $<1.00$ & $<0.100$ & $<0.500$ & 4.1 & $<0.100$ & 0.83335 & 0.083335 & 0.416675 & 6.83347 & 0.083335 \\
\hline & 1 & EA & 2 & 22 & $\mathrm{C} 05$ & 36.9 & $<0.100$ & $<0.500$ & 101 & 53.8 & 615.00123 & 0.833335 & 4.166675 & 1683.3367 & 896.66846 \\
\hline quenched & 1 & $\mathrm{Pu} 04-03$ & 2 & 23 & $\mathrm{C} 65$ & $<1.00$ & $<0.100$ & $<0.500$ & $<0.100$ & $<0.100$ & 0.83335 & 0.083335 & 0.416675 & 0.083335 & 0.083335 \\
\hline \multirow[t]{3}{*}{ quenched } & 1 & Pu35-04 & 2 & 24 & C38 & $<1.00$ & $<0.100$ & $<0.500$ & $<0.100$ & $<0.100$ & 0.83335 & 0.083335 & 0.416675 & 0.083335 & 0.083335 \\
\hline & 1 & Soln Std & 2 & 25 & STD-12-3 & 19.4 & $<0.100$ & $<0.500$ & \begin{tabular}{|l|}
80.5 \\
\end{tabular} & \begin{tabular}{|l|}
50 \\
\end{tabular} & 19.4 & 0.05 & 0.25 & 80.5 & 50 \\
\hline & 1 & Soln Std & 3 & 1 & STD-13-1 & 20.4 & $<0.100$ & $<0.500$ & 84.7 & 51.1 & 20.4 & 0.05 & 0.25 & 84.7 & 51.1 \\
\hline \multirow[t]{2}{*}{ quenched } & 1 & Pu04-01 & 3 & 2 & $\mathrm{C} 44$ & $<1.00$ & $<0.100$ & $<0.500$ & 0.559 & 0.807 & 0.83335 & 0.083335 & 0.416675 & 0.9316853 & 1.3450269 \\
\hline & 1 & ARM-1 & 3 & 3 & $\mathrm{C} 28$ & 10 & $<0.100$ & $<0.500$ & 23.7 & 34.4 & 16.667 & 0.083335 & 0.416675 & 39.50079 & 57.33448 \\
\hline \multirow[t]{2}{*}{ quenched } & 1 & Pu35-03 & 3 & 4 & $\mathrm{C} 30$ & $<1.00$ & $<0.100$ & $<0.500$ & $<0.100$ & 1.69 & 0.83335 & 0.083335 & 0.416675 & 0.083335 & 2.816723 \\
\hline & 1 & blank & 3 & 5 & C63 & $<1.00$ & $<0.100$ & $<0.500$ & $<0.100$ & $<0.100$ & 0.83335 & 0.083335 & 0.416675 & 0.083335 & 0.083335 \\
\hline quenched & 1 & Pu35-13 & 3 & 6 & C68 & $<1.00$ & $<0.100$ & $<0.500$ & 0.615 & \begin{tabular}{|l|}
2.09 \\
\end{tabular} & 0.83335 & 0.083335 & 0.416675 & 1.0250205 & 3.483403 \\
\hline quenched & 1 & Pu35-15 & 3 & 7 & $\mathrm{C} 07$ & $<1.00$ & $<0.100$ & $<0.500$ & $<0.100$ & $<0.100$ & 0.83335 & 0.083335 & 0.416675 & 0.083335 & 0.083335 \\
\hline quenched & 1 & Pu35-01 & 3 & 8 & C67 & $<1.00$ & $<0.100$ & $<0.500$ & $<0.100$ & $<0.100$ & 0.83335 & 0.083335 & 0.416675 & 0.083335 & 0.083335 \\
\hline quenched & 1 & Pu35-04 & 3 & 9 & C52 & \begin{tabular}{|l|}
$<1.00$ \\
\end{tabular} & $<0.100$ & $<0.500$ & $<0.100$ & $<0.100$ & 0.83335 & 0.083335 & 0.416675 & 0.083335 & 0.083335 \\
\hline quenched & 1 & Pu35-02 & 3 & 10 & $\mathrm{C} 19$ & $<1.00$ & $<0.100$ & $<0.500$ & $<0.100$ & 0.433 & 0.83335 & 0.083335 & 0.416675 & 0.083335 & 0.7216811 \\
\hline quenched & 1 & Pu35-12 & 3 & 11 & $\mathrm{C} 20$ & $<1.00$ & $<0.100$ & $<0.500$ & 0.786 & $<0.100$ & 0.83335 & 0.083335 & 0.416675 & 1.3100262 & 0.083335 \\
\hline \multirow[t]{2}{*}{ quenched } & 1 & Pu35-09 & 3 & 12 & $\mathrm{C} 18$ & $<1.00$ & $<0.100$ & $<0.500$ & 1.32 & 3.51 & 0.83335 & 0.083335 & 0.416675 & 2.200044 & 5.850117 \\
\hline & 1 & Soln Std & 3 & 13 & STD-13-2 & 19.9 & $<0.100$ & $<0.500$ & 84.6 & 50.5 & 19.9 & 0.05 & 0.25 & 84.6 & 50.5 \\
\hline \multirow[t]{2}{*}{ quenched } & 1 & Pu35-07 & 3 & 14 & $\mathrm{C} 25$ & $<1.00$ & $<0.100$ & $<0.500$ & $<0.100$ & 1.17 & 0.83335 & 0.083335 & 0.416675 & 0.083335 & 1.950039 \\
\hline & 1 & EA & 3 & 15 & C54 & 38.2 & $<0.100$ & $<0.500$ & 107 & 54.4 & 636.66794 & 0.833335 & 4.166675 & 1783.3369 & 906.66848 \\
\hline quenched & 1 & Pu35-06 & 3 & 16 & $\mathrm{C} 31$ & $<1.00$ & $<0.100$ & $<0.500$ & 0.171 & $<0.100$ & 0.83335 & 0.083335 & 0.416675 & 0.2850057 & 0.083335 \\
\hline
\end{tabular}


Table E1. Laboratory Measurements of the PCT Solutions for the Pu Study Glasses As Reported (ar) and After the Appropriate Adjustments (in parts per million, ppm)

(continued)

\begin{tabular}{|c|c|c|c|c|c|c|c|c|c|c|c|c|c|c|c|}
\hline Heat Treament & Set & Glass ID & Block & Seq & SRNL-ML ID & B ar & Gd ar & Hf ar & Na ar & Si ar & B (ppm) & Gd (ppm) & Hf (ppm) & $\mathrm{Na}$ (ppm) & Si (ppm) \\
\hline quenched & \begin{tabular}{|l|l}
1 \\
\end{tabular} & Pu35-11 & 3 & 17 & C66 & $<1.00$ & $<0.100$ & $<0.500$ & $<0.100$ & $<0.100$ & 0.83335 & 0.083335 & 0.416675 & 0.083335 & 0.083335 \\
\hline quenched & 1 & Pu35-05 & 3 & 18 & $\mathrm{C} 13$ & $<1.00$ & $<0.100$ & $<0.500$ & 1.27 & 1.92 & 0.83335 & 0.083335 & 0.416675 & 2.116709 & 3.200064 \\
\hline quenched & 1 & Pu35-14 & 3 & 19 & C64 & $<1.00$ & $<0.100$ & $<0.500$ & $<0.100$ & $<0.100$ & 0.83335 & 0.083335 & 0.416675 & 0.083335 & 0.083335 \\
\hline quenched & 1 & Pu04-03 & 3 & 20 & C61 & $<1.00$ & $<0.100$ & $<0.500$ & $<0.100$ & $<0.100$ & 0.83335 & 0.083335 & 0.416675 & 0.083335 & 0.083335 \\
\hline quenched & 1 & $\mathrm{Pu} 04-02$ & 3 & 21 & $\mathrm{C} 48$ & $<1.00$ & $<0.100$ & $<0.500$ & $<0.100$ & $<0.100$ & 0.83335 & 0.083335 & 0.416675 & 0.083335 & 0.083335 \\
\hline quenched & 1 & Pu35-08 & 3 & 22 & $\mathrm{C} 01$ & $<1.00$ & $<0.100$ & $<0.500$ & $<0.100$ & 0.359 & 0.83335 & 0.083335 & 0.416675 & 0.083335 & 0.5983453 \\
\hline quenched & 1 & $\mathrm{Pu} 04-04$ & 3 & 23 & C59 & $<1.00$ & $<0.100$ & $<0.500$ & $<0.100$ & 0.104 & 0.83335 & 0.083335 & 0.416675 & 0.083335 & 0.1733368 \\
\hline quenched & 1 & Pu35-10 & 3 & 24 & $\mathrm{C} 06$ & $<1.00$ & $<0.100$ & $<0.500$ & $<0.100$ & $<0.100$ & 0.83335 & 0.083335 & 0.416675 & 0.083335 & 0.083335 \\
\hline \multirow[t]{3}{*}{ quenched } & 1 & $\mathrm{Pu} 04-05$ & 3 & 25 & $\mathrm{C} 10$ & $<1.00$ & $<0.100$ & $<0.500$ & $<0.100$ & $<0.100$ & 0.83335 & 0.083335 & 0.416675 & 0.083335 & 0.083335 \\
\hline & 1 & Soln Std & 3 & 26 & STD-13-3 & 20.3 & $<0.100$ & $<0.500$ & 85.6 & 50.9 & 20.3 & 0.05 & 0.25 & 85.6 & 50.9 \\
\hline & 2 & Soln Std & 1 & 1 & STD-21-1 & 20.6 & $<0.100$ & $<0.500$ & 83.5 & 49.2 & 20.6 & 0.05 & 0.25 & 83.5 & 49.2 \\
\hline quenched & 2 & Pu35-17 & 1 & 2 & D47 & $<1.00$ & $<0.100$ & $<0.500$ & $<0.100$ & 0.496 & 0.83335 & 0.083335 & 0.416675 & 0.083335 & 0.8266832 \\
\hline quenched & 2 & Pu35-21 & 1 & 3 & D30 & $<1.00$ & $<0.100$ & $<0.500$ & $<0.100$ & $<0.100$ & 0.83335 & 0.083335 & 0.416675 & 0.083335 & 0.083335 \\
\hline \multirow[t]{2}{*}{ quenched } & 2 & Pu35-18 & 1 & 4 & D38 & $<1.00$ & $<0.100$ & $<0.500$ & $<0.100$ & 1.73 & 0.83335 & 0.083335 & 0.416675 & 0.083335 & 2.883391 \\
\hline & 2 & blank & 1 & 5 & D21 & $<1.00$ & $<0.100$ & $<0.500$ & $<0.100$ & $<0.100$ & 0.83335 & 0.083335 & 0.416675 & 0.083335 & 0.083335 \\
\hline quenched & 2 & Pu35-28 & 1 & 6 & $\mathrm{D} 26$ & $<1.00$ & $<0.100$ & $<0.500$ & $<0.100$ & $<0.100$ & 0.83335 & 0.083335 & 0.416675 & 0.083335 & 0.083335 \\
\hline quenched & 2 & Pu35-34 & 1 & 7 & D56 & $<1.00$ & $<0.100$ & $<0.500$ & $<0.100$ & \begin{tabular}{|l|}
0.369 \\
\end{tabular} & 0.83335 & 0.083335 & 0.416675 & 0.083335 & 0.6150123 \\
\hline quenched & 2 & Pu35-35 & 1 & 8 & D65 & $<1.00$ & $<0.100$ & $<0.500$ & $<0.100$ & $<0.100$ & 0.83335 & 0.083335 & 0.416675 & 0.083335 & 0.083335 \\
\hline quenched & 2 & Pu35-24 & 1 & 9 & D12 & $<1.00$ & $<0.100$ & $<0.500$ & $<0.100$ & $<0.100$ & 0.83335 & 0.083335 & 0.416675 & 0.083335 & 0.083335 \\
\hline quenched & 2 & Pu35-30 & 1 & 10 & D10 & $<1.00$ & $<0.100$ & $<0.500$ & $<0.100$ & 2.46 & 0.83335 & 0.083335 & 0.416675 & 0.083335 & 4.100082 \\
\hline quenched & 2 & Pu35-27 & 1 & 11 & $\mathrm{D} 03$ & $<1.00$ & $<0.100$ & $<0.500$ & $<0.100$ & $<0.100$ & 0.83335 & 0.083335 & 0.416675 & 0.083335 & 0.083335 \\
\hline \multirow[t]{2}{*}{ quenched } & 2 & Pu35-26 & 1 & 12 & D55 & $<1.00$ & $<0.100$ & $<0.500$ & $<0.100$ & $<0.100$ & 0.83335 & 0.083335 & 0.416675 & 0.083335 & 0.083335 \\
\hline & 2 & Soln Std & 1 & 13 & STD-21-2 & 20.1 & $<0.100$ & $<0.500$ & 84.8 & 47.5 & 20.1 & 0.05 & 0.25 & 84.8 & 47.5 \\
\hline quenched & 2 & Pu35-31 & 1 & 14 & D29 & $<1.00$ & $<0.100$ & $<0.500$ & $<0.100$ & 1.05 & 0.83335 & 0.083335 & 0.416675 & 0.083335 & 1.750035 \\
\hline quenched & 2 & Pu35-32 & 1 & 15 & D13 & $<1.00$ & $<0.100$ & $<0.500$ & $<0.100$ & $<0.100$ & 0.83335 & 0.083335 & 0.416675 & 0.083335 & 0.083335 \\
\hline \multirow[t]{2}{*}{ quenched } & 2 & Pu35-23 & 1 & 16 & D14 & $<1.00$ & $<0.100$ & $<0.500$ & $<0.100$ & $<0.100$ & 0.83335 & 0.083335 & 0.416675 & 0.083335 & 0.083335 \\
\hline & 2 & ARM-1 & 1 & 17 & D63 & 10.1 & $<0.100$ & $<0.500$ & 19.9 & 33.2 & 16.83367 & 0.083335 & 0.416675 & 33.16733 & 55.33444 \\
\hline quenched & 2 & Pu35-16 & 1 & 18 & $\mathrm{D} 46$ & $<1.00$ & $<0.100$ & $<0.500$ & $<0.100$ & $<0.100$ & 0.83335 & 0.083335 & 0.416675 & 0.083335 & 0.083335 \\
\hline quenched & 2 & Pu35-25 & 1 & 19 & D16 & $<1.00$ & $<0.100$ & $<0.500$ & $<0.100$ & 0.762 & 0.83335 & 0.083335 & 0.416675 & 0.083335 & 1.2700254 \\
\hline \multirow[t]{2}{*}{ quenched } & 2 & Pu35-33 & 1 & 20 & D02 & $<1.00$ & $<0.100$ & $<0.500$ & $<0.100$ & $<0.100$ & 0.83335 & 0.083335 & 0.416675 & 0.083335 & 0.083335 \\
\hline & 2 & EA & 1 & 21 & D66 & 38.3 & $<0.100$ & $<0.500$ & 106 & \begin{tabular}{|l|}
52.2 \\
\end{tabular} & 638.33461 & 0.833335 & 4.166675 & 1766.6702 & 870.00174 \\
\hline quenched & 2 & Pu35-22 & 1 & 22 & D33 & $<1.00$ & $<0.100$ & $<0.500$ & $<0.100$ & $<0.100$ & 0.83335 & 0.083335 & 0.416675 & 0.083335 & 0.083335 \\
\hline quenched & 2 & Pu35-19 & 1 & 23 & D54 & $<1.00$ & $<0.100$ & $<0.500$ & $<0.100$ & $<0.100$ & 0.83335 & 0.083335 & 0.416675 & 0.083335 & 0.083335 \\
\hline quenched & 2 & Pu35-20 & 1 & 24 & D36 & $<1.00$ & $<0.100$ & $<0.500$ & $<0.100$ & 0.559 & 0.83335 & 0.083335 & 0.416675 & 0.083335 & 0.9316853 \\
\hline
\end{tabular}


Table E1. Laboratory Measurements of the PCT Solutions for the Pu Study Glasses As Reported (ar) and After the Appropriate Adjustments (in parts per million, ppm)

(continued)

\begin{tabular}{|c|c|c|c|c|c|c|c|c|c|c|c|c|c|c|c|}
\hline Heat Treament & Set & Glass ID & Block & Seq & SRNL-ML ID & B ar & Gd ar & Hf ar & Na ar & Si ar & B (ppm) & Gd (ppm) & Hf (ppm) & Na (ppm) & Si (ppm) \\
\hline \multirow[t]{3}{*}{ quenched } & \begin{tabular}{|l|}
2 \\
\end{tabular} & Pu35-29 & 1 & 25 & D61 & $<1.00$ & $<0.100$ & $<0.500$ & $<0.100$ & 0.815 & 0.83335 & 0.083335 & 0.416675 & 0.083335 & 1.3583605 \\
\hline & 2 & Soln Std & 1 & 26 & STD-21-3 & 21.3 & $<0.100$ & $<0.500$ & 86 & 50.4 & 21.3 & 0.05 & 0.25 & 86 & 50.4 \\
\hline & 2 & Soln Std & 2 & 1 & STD-22-1 & 20.4 & $<0.100$ & $<0.500$ & 85.2 & 49.4 & 20.4 & 0.05 & 0.25 & 85.2 & 49.4 \\
\hline quenched & 2 & Pu35-29 & 2 & 2 & D43 & $<1.00$ & $<0.100$ & $<0.500$ & $<0.100$ & 1.85 & 0.83335 & 0.083335 & 0.416675 & 0.083335 & 3.083395 \\
\hline quenched & 2 & Pu35-19 & 2 & 3 & D20 & $<1.00$ & $<0.100$ & $<0.500$ & $<0.100$ & 0.635 & 0.83335 & 0.083335 & 0.416675 & 0.083335 & 1.0583545 \\
\hline quenched & 2 & Pu35-27 & 2 & 4 & D62 & $<1.00$ & $<0.100$ & $<0.500$ & $<0.100$ & 0.799 & 0.83335 & 0.083335 & 0.416675 & 0.083335 & 1.3316933 \\
\hline quenched & 2 & Pu35-16 & 2 & 5 & D05 & $<1.00$ & $<0.100$ & $<0.500$ & $<0.100$ & 0.901 & 0.83335 & 0.083335 & 0.416675 & 0.083335 & 1.5016967 \\
\hline quenched & 2 & Pu35-33 & 2 & 6 & D60 & $<1.00$ & $<0.100$ & $<0.500$ & $<0.100$ & 0.625 & 0.83335 & 0.083335 & 0.416675 & 0.083335 & 1.0416875 \\
\hline quenched & 2 & Pu35-21 & 2 & 7 & D64 & $<1.00$ & $<0.100$ & $<0.500$ & $<0.100$ & 0.599 & 0.83335 & 0.083335 & 0.416675 & 0.083335 & 0.9983533 \\
\hline \multirow[t]{3}{*}{ quenched } & 2 & Pu35-26 & 2 & 8 & D48 & $<1.00$ & $<0.100$ & $<0.500$ & $<0.100$ & 0.48 & 0.83335 & 0.083335 & 0.416675 & 0.083335 & 0.800016 \\
\hline & 2 & EA & 2 & 9 & D08 & 34.3 & $<0.100$ & $<0.500$ & 97.2 & 49.5 & 571.66781 & 0.833335 & 4.166675 & 1620.00324 & 825.00165 \\
\hline & 2 & ARM-1 & 2 & 10 & D58 & 9.6 & $<0.100$ & $<0.500$ & 20.2 & 33.7 & 16.00032 & 0.083335 & 0.416675 & 33.66734 & 56.16779 \\
\hline quenched & 2 & Pu35-25 & 2 & 11 & D35 & $<1.00$ & $<0.100$ & $<0.500$ & $<0.100$ & 2.16 & 0.83335 & 0.083335 & 0.416675 & 0.083335 & 3.600072 \\
\hline \multirow[t]{2}{*}{ quenched } & 2 & Pu35-20 & 2 & 12 & D22 & $<1.00$ & $<0.100$ & $<0.500$ & $<0.100$ & 1.67 & 0.83335 & 0.083335 & 0.416675 & 0.083335 & 2.783389 \\
\hline & 2 & Soln Std & 2 & 13 & STD-22-2 & 18.6 & $<0.100$ & $<0.500$ & 80.5 & 46.9 & 18.6 & 0.05 & 0.25 & 80.5 & 46.9 \\
\hline quenched & 2 & Pu35-30 & 2 & 14 & D27 & $<1.00$ & $<0.100$ & $<0.500$ & $<0.100$ & 2.12 & 0.83335 & 0.083335 & 0.416675 & 0.083335 & 3.533404 \\
\hline quenched & 2 & Pu35-32 & 2 & 15 & D31 & $<1.00$ & $<0.100$ & $<0.500$ & $<0.100$ & 0.417 & 0.83335 & 0.083335 & 0.416675 & 0.083335 & 0.6950139 \\
\hline quenched & 2 & Pu35-22 & 2 & 16 & D15 & $<1.00$ & $<0.100$ & $<0.500$ & $<0.100$ & 0.911 & 0.83335 & 0.083335 & 0.416675 & 0.083335 & 1.5183637 \\
\hline quenched & 2 & Pu35-24 & 2 & 17 & D06 & $<1.00$ & $<0.100$ & $<0.500$ & $<0.100$ & 0.591 & 0.83335 & 0.083335 & 0.416675 & 0.083335 & 0.9850197 \\
\hline quenched & 2 & Pu35-18 & 2 & 18 & D67 & $<1.00$ & $<0.100$ & $<0.500$ & $<0.100$ & 2.42 & 0.83335 & 0.083335 & 0.416675 & 0.083335 & 4.033414 \\
\hline quenched & 2 & Pu35-34 & 2 & 19 & D04 & $<1.00$ & $<0.100$ & $<0.500$ & $<0.100$ & 0.948 & 0.83335 & 0.083335 & 0.416675 & 0.083335 & 1.5800316 \\
\hline quenched & 2 & Pu35-35 & 2 & 20 & D52 & $<1.00$ & $<0.100$ & $<0.500$ & $<0.100$ & 0.519 & 0.83335 & 0.083335 & 0.416675 & 0.083335 & 0.8650173 \\
\hline quenched & 2 & Pu35-28 & 2 & 21 & D19 & $<1.00$ & $<0.100$ & $<0.500$ & $<0.100$ & 0.655 & 0.83335 & 0.083335 & 0.416675 & 0.083335 & 1.0916885 \\
\hline quenched & 2 & Pu35-23 & 2 & 22 & $\mathrm{D} 42$ & $<1.00$ & $<0.100$ & $<0.500$ & $<0.100$ & 0.541 & 0.83335 & 0.083335 & 0.416675 & 0.083335 & 0.9016847 \\
\hline quenched & 2 & Pu35-31 & 2 & 23 & D17 & $<1.00$ & $<0.100$ & $<0.500$ & $<0.100$ & 2.34 & 0.83335 & 0.083335 & 0.416675 & 0.083335 & 3.900078 \\
\hline \multirow[t]{4}{*}{ quenched } & 2 & Pu35-17 & 2 & 24 & D68 & $<1.00$ & $<0.100$ & $<0.500$ & $<0.100$ & 1.18 & 0.83335 & 0.083335 & 0.416675 & 0.083335 & 1.966706 \\
\hline & 2 & Soln Std & 2 & 25 & STD-22-3 & 18.9 & $<0.100$ & $<0.500$ & 84.3 & 47.8 & 18.9 & 0.05 & 0.25 & 84.3 & 47.8 \\
\hline & 2 & Soln Std & 3 & 1 & STD-23-1 & 20.6 & $<0.100$ & $<0.500$ & 83.9 & 49.8 & 20.6 & 0.05 & 0.25 & 83.9 & 49.8 \\
\hline & 2 & EA & 3 & 2 & D09 & 35.2 & $<0.100$ & $<0.500$ & 97.3 & 49.6 & 586.66784 & 0.833335 & 4.166675 & 1621.66991 & 826.66832 \\
\hline quenched & 2 & Pu35-18 & 3 & 3 & D24 & 1.03 & $<0.100$ & $<0.500$ & $<0.100$ & 2.57 & 1.716701 & 0.083335 & 0.416675 & 0.083335 & 4.283419 \\
\hline \multirow[t]{3}{*}{ quenched } & 2 & Pu35-25 & 3 & 4 & D01 & $<1.00$ & $<0.100$ & $<0.500$ & $<0.100$ & 2.05 & 0.83335 & 0.083335 & 0.416675 & 0.083335 & 3.416735 \\
\hline & 2 & blank & 3 & 5 & $\mathrm{D} 28$ & $<1.00$ & $<0.100$ & $<0.500$ & $<0.100$ & 0.0629 & 0.83335 & 0.083335 & 0.416675 & 0.083335 & 0.10483543 \\
\hline & 2 & ARM-1 & 3 & 6 & D34 & 9.53 & $<0.100$ & $<0.500$ & 20.7 & 32.1 & 15.883651 & 0.083335 & 0.416675 & 34.50069 & 53.50107 \\
\hline quenched & 2 & Pu35-33 & 3 & 7 & D59 & $<1.00$ & $<0.100$ & $<0.500$ & $<0.100$ & 0.544 & 0.83335 & 0.083335 & 0.416675 & 0.083335 & 0.9066848 \\
\hline
\end{tabular}


Table E1. Laboratory Measurements of the PCT Solutions for the Pu Study Glasses As Reported (ar) and After the Appropriate Adjustments (in parts per million, ppm)

(continued)

\begin{tabular}{|c|c|c|c|c|c|c|c|c|c|c|c|c|c|c|c|}
\hline Heat Treament & Set & Glass ID & Block & Seq & SRNL-ML ID & B ar & Gd ar & Hf ar & Na ar & Si ar & B (ppm) & Gd (ppm) & Hf (ppm) & $\mathrm{Na}(\mathrm{ppm})$ & Si (ppm) \\
\hline quenched & 2 & Pu35-16 & 3 & 8 & D51 & $<1.00$ & $<0.100$ & $<0.500$ & $<0.100$ & 0.989 & 0.83335 & 0.083335 & 0.416675 & 0.083335 & 1.6483663 \\
\hline quenched & 2 & Pu35-17 & 3 & 9 & D37 & $<1.00$ & $<0.100$ & $<0.500$ & $<0.100$ & 1.18 & 0.83335 & 0.083335 & 0.416675 & 0.083335 & 1.966706 \\
\hline quenched & 2 & Pu35-34 & 3 & 10 & D39 & $<1.00$ & $<0.100$ & $<0.500$ & $<0.100$ & 1.07 & 0.83335 & 0.083335 & 0.416675 & 0.083335 & 1.783369 \\
\hline quenched & 2 & Pu35-28 & 3 & 11 & D41 & $<1.00$ & $<0.100$ & $<0.500$ & $<0.100$ & 0.743 & 0.83335 & 0.083335 & 0.416675 & 0.083335 & 1.2383581 \\
\hline \multirow[t]{2}{*}{ quenched } & 2 & Pu35-32 & 3 & 12 & D25 & $<1.00$ & $<0.100$ & $<0.500$ & $<0.100$ & 0.599 & 0.83335 & 0.083335 & 0.416675 & 0.083335 & 0.9983533 \\
\hline & 2 & Soln Std & 3 & 13 & STD23-2 & 18.7 & $<0.100$ & $<0.500$ & 82.7 & 46.4 & 18.7 & 0.05 & 0.25 & 82.7 & 46.4 \\
\hline quenched & 2 & Pu35-31 & 3 & 14 & D32 & $<1.00$ & $<0.100$ & $<0.500$ & $<0.100$ & 2.3 & 0.83335 & 0.083335 & 0.416675 & 0.083335 & 3.83341 \\
\hline quenched & 2 & Pu35-26 & 3 & 15 & D18 & $<1.00$ & $<0.100$ & $<0.500$ & 8.45 & 0.562 & 0.83335 & 0.083335 & 0.416675 & 14.083615 & 0.9366854 \\
\hline quenched & 2 & Pu35-19 & 3 & 16 & $\mathrm{D} 40$ & $<1.00$ & 0.213 & $<0.500$ & $<0.100$ & 0.891 & 0.83335 & 0.3550071 & 0.416675 & 0.083335 & 1.4850297 \\
\hline quenched & 2 & Pu35-22 & 3 & 17 & $\mathrm{D} 45$ & $<1.00$ & $<0.100$ & $<0.500$ & $<0.100$ & 0.854 & 0.83335 & 0.083335 & 0.416675 & 0.083335 & 1.4233618 \\
\hline quenched & 2 & Pu35-21 & 3 & 18 & $\mathrm{D} 23$ & $<1.00$ & $<0.100$ & $<0.500$ & $<0.100$ & 0.631 & 0.83335 & 0.083335 & 0.416675 & 0.083335 & 1.0516877 \\
\hline quenched & 2 & Pu35-23 & 3 & 19 & D57 & $<1.00$ & $<0.100$ & $<0.500$ & $<0.100$ & 0.746 & 0.83335 & 0.083335 & 0.416675 & 0.083335 & 1.2433582 \\
\hline quenched & 2 & Pu35-35 & 3 & 20 & $\mathrm{D} 49$ & $<1.00$ & $<0.100$ & $<0.500$ & $<0.100$ & 0.582 & 0.83335 & 0.083335 & 0.416675 & 0.083335 & 0.9700194 \\
\hline quenched & 2 & Pu35-20 & 3 & 21 & D07 & $<1.00$ & $<0.100$ & $<0.500$ & $<0.100$ & 1.74 & 0.83335 & 0.083335 & 0.416675 & 0.083335 & 2.900058 \\
\hline quenched & 2 & Pu35-27 & 3 & 22 & D11 & $<1.00$ & $<0.100$ & $<0.500$ & $<0.100$ & 0.778 & 0.83335 & 0.083335 & 0.416675 & 0.083335 & 1.2966926 \\
\hline quenched & 2 & Pu35-30 & 3 & 23 & D53 & $<1.00$ & $<0.100$ & $<0.500$ & $<0.100$ & 2.25 & 0.83335 & 0.083335 & 0.416675 & 0.083335 & 3.750075 \\
\hline quenched & 2 & Pu35-24 & 3 & 24 & D50 & $<1.00$ & $<0.100$ & $<0.500$ & $<0.100$ & 0.715 & 0.83335 & 0.083335 & 0.416675 & 0.083335 & 1.1916905 \\
\hline \multirow[t]{3}{*}{ quenched } & 2 & Pu35-29 & 3 & 25 & D44 & $<1.00$ & $<0.100$ & $<0.500$ & 0.691 & 1.93 & 0.83335 & 0.083335 & 0.416675 & 1.1516897 & 3.216731 \\
\hline & 2 & Soln Std & 3 & 26 & STD-23-3 & 19.8 & $<0.100$ & $<0.500$ & 87.4 & 48.7 & 19.8 & 0.05 & 0.25 & 87.4 & 48.7 \\
\hline & 3 & Soln Std & 1 & 1 & STD-11-1 & 19.6 & $<0.100$ & $<0.500$ & 80.2 & 47.6 & 19.6 & 0.05 & 0.25 & 80.2 & 47.6 \\
\hline quenched & 3 & Pu35-52 & 1 & 2 & E61 & $<1.00$ & $<0.100$ & $<0.500$ & $<0.100$ & 1.14 & 0.83335 & 0.083335 & 0.416675 & 0.083335 & 1.900038 \\
\hline \multirow[t]{2}{*}{ quenched } & 3 & Pu35-36 & 1 & 3 & E23 & $<1.00$ & $<0.100$ & $<0.500$ & $<0.100$ & 0.985 & 0.83335 & 0.083335 & 0.416675 & 0.083335 & 1.6416995 \\
\hline & 3 & blank & 1 & 4 & E21 & $<1.00$ & $<0.100$ & $<0.500$ & $<0.100$ & $<0.100$ & 0.83335 & 0.083335 & 0.416675 & 0.083335 & 0.083335 \\
\hline quenched & 3 & Pu35-49 & 1 & 5 & E04 & $<1.00$ & $<0.100$ & $<0.500$ & $<0.100$ & 0.823 & 0.83335 & 0.083335 & 0.416675 & 0.083335 & 1.3716941 \\
\hline quenched & 3 & EA & 1 & 6 & E30 & 36.7 & $<0.100$ & $<0.500$ & 102.3 & 53.5 & 611.66789 & 0.833335 & 4.166675 & 1705.00341 & 891.66845 \\
\hline quenched & 3 & Pu35-40 & 1 & 7 & E41 & $<1.00$ & $<0.100$ & $<0.500$ & $<0.100$ & 0.399 & 0.83335 & 0.083335 & 0.416675 & 0.083335 & 0.6650133 \\
\hline \multirow[t]{2}{*}{ quenched } & 3 & Pu35-51 & 1 & 8 & E67 & $<1.00$ & $<0.100$ & $<0.500$ & $<0.100$ & 0.487 & 0.83335 & 0.083335 & 0.416675 & 0.083335 & 0.8116829 \\
\hline & 3 & ARM-1 & 1 & 9 & E46 & 8.86 & $<0.100$ & $<0.500$ & 19.7 & 33.1 & 14.766962 & 0.083335 & 0.416675 & 32.83399 & 55.16777 \\
\hline quenched & 3 & Pu35-53 & 1 & 10 & E49 & $<1.00$ & $<0.100$ & $<0.500$ & $<0.100$ & 0.666 & 0.83335 & 0.083335 & 0.416675 & 0.083335 & 1.1100222 \\
\hline quenched & 3 & Pu35-39 & 1 & 11 & E07 & $<1.00$ & $<0.100$ & $<0.500$ & $<0.100$ & 1.59 & 0.83335 & 0.083335 & 0.416675 & 0.083335 & 2.650053 \\
\hline \multirow[t]{2}{*}{ quenched } & 3 & Pu35-48 & 1 & 12 & E64 & $<1.00$ & $<0.100$ & $<0.500$ & $<0.100$ & 0.348 & 0.83335 & 0.083335 & 0.416675 & 0.083335 & 0.5800116 \\
\hline & 3 & Soln Std & 1 & 13 & STD-11-2 & 18.4 & $<0.100$ & $<0.500$ & 82.1 & 47.3 & 18.4 & 0.05 & 0.25 & 82.1 & 47.3 \\
\hline quenched & 3 & Pu35-50 & 1 & 14 & E52 & $<1.00$ & $<0.100$ & $<0.500$ & $<0.100$ & 1.32 & 0.83335 & 0.083335 & 0.416675 & 0.083335 & 2.200044 \\
\hline quenched & 3 & Pu35-41 & 1 & 15 & E34 & $<1.00$ & $<0.100$ & $<0.500$ & $<0.100$ & 0.44 & 0.83335 & 0.083335 & 0.416675 & 0.083335 & 0.733348 \\
\hline
\end{tabular}


Table E1. Laboratory Measurements of the PCT Solutions for the Pu Study Glasses As Reported (ar) and After the Appropriate Adjustments (in parts per million, ppm)

(continued)

\begin{tabular}{|c|c|c|c|c|c|c|c|c|c|c|c|c|c|c|c|}
\hline Heat Treament & Set & Glass ID & Block & Seq & SRNL-ML ID & B ar & Gd ar & Hf ar & Na ar & Si ar & B (ppm) & Gd (ppm) & Hf (ppm) & $\mathrm{Na}(\mathrm{ppm})$ & Si (ppm) \\
\hline quenched & 3 & Pu35-42 & 1 & 16 & E20 & $<1.00$ & $<0.100$ & $<0.500$ & $<0.100$ & 1.25 & 0.83335 & 0.083335 & 0.416675 & 0.083335 & 2.083375 \\
\hline quenched & 3 & Pu35-43 & 1 & 17 & E03 & $<1.00$ & $<0.100$ & $<0.500$ & $<0.100$ & 0.28 & 0.83335 & 0.083335 & 0.416675 & 0.083335 & 0.466676 \\
\hline quenched & 3 & Pu35-54 & 1 & 18 & E63 & $<1.00$ & $<0.100$ & $<0.500$ & $<0.100$ & 0.562 & 0.83335 & 0.083335 & 0.416675 & 0.083335 & 0.9366854 \\
\hline quenched & 3 & Pu35-44 & 1 & 19 & E56 & $<1.00$ & $<0.100$ & $<0.500$ & $<0.100$ & 0.243 & 0.83335 & 0.083335 & 0.416675 & 0.083335 & 0.4050081 \\
\hline quenched & 3 & Pu35-47 & 1 & 20 & E35 & $<1.00$ & $<0.100$ & $<0.500$ & $<0.100$ & 0.34 & 0.83335 & 0.083335 & 0.416675 & 0.083335 & 0.566678 \\
\hline quenched & 3 & Pu35-45 & 1 & 21 & E22 & $<1.00$ & $<0.100$ & $<0.500$ & $<0.100$ & 0.541 & 0.83335 & 0.083335 & 0.416675 & 0.083335 & 0.9016847 \\
\hline quenched & 3 & Pu35-37 & 1 & 22 & E39 & $<1.00$ & $<0.100$ & $<0.500$ & $<0.100$ & 0.58 & 0.83335 & 0.083335 & 0.416675 & 0.083335 & 0.966686 \\
\hline quenched & 3 & Pu35-55 & 1 & 23 & E15 & $<1.00$ & $<0.100$ & $<0.500$ & $<0.100$ & 0.604 & 0.83335 & 0.083335 & 0.416675 & 0.083335 & 1.0066868 \\
\hline quenched & 3 & Pu35-38 & 1 & 24 & E13 & $<1.00$ & $<0.100$ & $<0.500$ & $<0.100$ & 0.362 & 0.83335 & 0.083335 & 0.416675 & 0.083335 & 0.6033454 \\
\hline \multirow[t]{3}{*}{ quenched } & 3 & Pu35-46 & 1 & 25 & $\mathrm{E} 50$ & $<1.00$ & $<0.100$ & $<0.500$ & $<0.100$ & 0.557 & 0.83335 & 0.083335 & 0.416675 & 0.083335 & 0.9283519 \\
\hline & 3 & Soln Std & 1 & 26 & STD-11-3 & 18.8 & $<0.100$ & $<0.500$ & 80.2 & 48.7 & 18.8 & 0.05 & 0.25 & 80.2 & 48.7 \\
\hline & 3 & Soln Std & 2 & 1 & STD-12-1 & 20 & $<0.100$ & $<0.500$ & 82.9 & 47.9 & 20 & 0.05 & 0.25 & 82.9 & 47.9 \\
\hline quenched & 3 & Pu35-41 & 2 & 2 & E31 & 1.32 & $<0.100$ & $<0.500$ & $<0.100$ & 0.764 & 2.200044 & 0.083335 & 0.416675 & 0.083335 & 1.2733588 \\
\hline quenched & 3 & Pu35-53 & 2 & 3 & E37 & $<1.00$ & $<0.100$ & $<0.500$ & $<0.100$ & 1.21 & 0.83335 & 0.083335 & 0.416675 & 0.083335 & 2.016707 \\
\hline \multirow[t]{2}{*}{ quenched } & 3 & Pu35-39 & 2 & 4 & E33 & $<1.00$ & $<0.100$ & $<0.500$ & $<0.100$ & 1.97 & 0.83335 & 0.083335 & 0.416675 & 0.083335 & 3.283399 \\
\hline & 3 & ARM-1 & 2 & 5 & E01 & 10 & $<0.100$ & $<0.500$ & 21.1 & 34.4 & 16.667 & 0.083335 & 0.416675 & 35.16737 & 57.33448 \\
\hline quenched & 3 & Pu35-45 & 2 & 6 & $\mathrm{E} 40$ & $<1.00$ & $<0.100$ & $<0.500$ & $<0.100$ & 1.25 & 0.83335 & 0.083335 & 0.416675 & 0.083335 & 2.083375 \\
\hline quenched & 3 & Pu35-43 & 2 & 7 & E51 & $<1.00$ & $<0.100$ & $<0.500$ & $<0.100$ & 0.698 & 0.83335 & 0.083335 & 0.416675 & 0.083335 & 1.1633566 \\
\hline quenched & 3 & Pu35-42 & 2 & 8 & E47 & $<1.00$ & $<0.100$ & $<0.500$ & $<0.100$ & 1.8 & 0.83335 & 0.083335 & 0.416675 & 0.083335 & 3.00006 \\
\hline \multirow[t]{2}{*}{ quenched } & 3 & Pu35-55 & 2 & 9 & $\mathrm{E} 48$ & $<1.00$ & $<0.100$ & $<0.500$ & $<0.100$ & 1.56 & 0.83335 & 0.083335 & 0.416675 & 0.083335 & 2.600052 \\
\hline & 3 & EA & 2 & 10 & E29 & 38.2 & $<0.100$ & $<0.500$ & 105.7 & 55 & 636.66794 & 0.833335 & 4.166675 & 1761.67019 & 916.6685 \\
\hline quenched & 3 & Pu35-54 & 2 & 11 & $\mathrm{E} 45$ & $<1.00$ & $<0.100$ & $<0.500$ & $<0.100$ & 1.21 & 0.83335 & 0.083335 & 0.416675 & 0.083335 & 2.016707 \\
\hline \multirow[t]{2}{*}{ quenched } & 3 & Pu35-48 & 2 & 12 & E60 & $<1.00$ & $<0.100$ & $<0.500$ & $<0.100$ & 0.744 & 0.83335 & 0.083335 & 0.416675 & 0.083335 & 1.2400248 \\
\hline & 3 & Soln Std & 2 & 13 & STD-12-2 & 19.5 & $<0.100$ & $<0.500$ & \begin{tabular}{|l|}
83.9 \\
\end{tabular} & 48.5 & 19.5 & 0.05 & 0.25 & 83.9 & 48.5 \\
\hline quenched & 3 & Pu35-51 & 2 & 14 & E08 & 1.23 & $<0.100$ & $<0.500$ & $<0.100$ & 0.869 & 2.050041 & 0.083335 & 0.416675 & 0.083335 & 1.4483623 \\
\hline quenched & 3 & Pu35-50 & 2 & 15 & E27 & $<1.00$ & $<0.100$ & $<0.500$ & $<0.100$ & 1.72 & 0.83335 & 0.083335 & 0.416675 & 0.083335 & 2.866724 \\
\hline quenched & 3 & Pu35-46 & 2 & 16 & E24 & $<1.00$ & $<0.100$ & $<0.500$ & $<0.100$ & 0.886 & 0.83335 & 0.083335 & 0.416675 & 0.083335 & 1.4766962 \\
\hline quenched & 3 & Pu35-52 & 2 & 17 & $\mathrm{E} 32$ & $<1.00$ & $<0.100$ & $<0.500$ & $<0.100$ & 1.49 & 0.83335 & 0.083335 & 0.416675 & 0.083335 & 2.483383 \\
\hline quenched & 3 & Pu35-49 & 2 & 18 & $\mathrm{E} 43$ & $<1.00$ & $<0.100$ & $<0.500$ & $<0.100$ & 1.19 & 0.83335 & 0.083335 & 0.416675 & 0.083335 & 1.983373 \\
\hline quenched & 3 & Pu35-40 & 2 & 19 & E55 & $<1.00$ & $<0.100$ & $<0.500$ & $<0.100$ & 0.813 & 0.83335 & 0.083335 & 0.416675 & 0.083335 & 1.3550271 \\
\hline quenched & 3 & Pu35-37 & 2 & 20 & E16 & $<1.00$ & $<0.100$ & $<0.500$ & $<0.100$ & 0.917 & 0.83335 & 0.083335 & 0.416675 & 0.083335 & 1.5283639 \\
\hline quenched & 3 & Pu35-44 & 2 & 21 & E53 & $<1.00$ & $<0.100$ & $<0.500$ & $<0.100$ & 0.617 & 0.83335 & 0.083335 & 0.416675 & 0.083335 & 1.0283539 \\
\hline quenched & 3 & Pu35-47 & 2 & 22 & E65 & $<1.00$ & $<0.100$ & $<0.500$ & $<0.100$ & 0.736 & 0.83335 & 0.083335 & 0.416675 & 0.083335 & 1.2266912 \\
\hline quenched & 3 & Pu35-38 & 2 & 23 & E06 & $<1.00$ & $<0.100$ & $<0.500$ & $<0.100$ & 0.854 & 0.83335 & 0.083335 & 0.416675 & 0.083335 & 1.4233618 \\
\hline
\end{tabular}


Table E1. Laboratory Measurements of the PCT Solutions for the Pu Study Glasses As Reported (ar) and After the Appropriate Adjustments (in parts per million, ppm)

(continued)

\begin{tabular}{|c|c|c|c|c|c|c|c|c|c|c|c|c|c|c|c|}
\hline Heat Treament & Set & Glass ID & Block & Seq & SRNL-ML ID & B ar & Gd ar & Hf ar & Na ar & Si ar & B (ppm) & Gd (ppm) & Hf (ppm) & Na (ppm) & Si (ppm) \\
\hline \multirow[t]{3}{*}{ quenched } & \begin{tabular}{|l|}
3 \\
\end{tabular} & Pu35-36 & 2 & 24 & E12 & $<1.00$ & $<0.100$ & $<0.500$ & $<0.100$ & 1.3 & 0.83335 & 0.083335 & 0.416675 & 0.083335 & 2.16671 \\
\hline & 3 & Soln Std & 2 & 25 & STD-12-3 & 19.8 & $<0.100$ & $<0.500$ & 85.2 & 49.3 & 19.8 & 0.05 & 0.25 & 85.2 & 49.3 \\
\hline & 3 & Soln Std & 3 & 1 & STD-13-1 & 20.1 & $<0.100$ & $<0.500$ & 82.6 & 48.6 & 20.1 & 0.05 & 0.25 & 82.6 & 48.6 \\
\hline quenched & 3 & Pu35-52 & 3 & 2 & E14 & $<1.00$ & $<0.100$ & $<0.500$ & $<0.100$ & 1.41 & 0.83335 & 0.083335 & 0.416675 & 0.083335 & 2.350047 \\
\hline quenched & 3 & Pu35-44 & 3 & 3 & E38 & $<1.00$ & $<0.100$ & $<0.500$ & $<0.100$ & 0.564 & 0.83335 & 0.083335 & 0.416675 & 0.083335 & 0.9400188 \\
\hline quenched & 3 & Pu35-40 & 3 & 4 & E44 & $<1.00$ & $<0.100$ & $<0.500$ & $<0.100$ & 0.583 & 0.83335 & 0.083335 & 0.416675 & 0.083335 & 0.9716861 \\
\hline \multirow[t]{2}{*}{ quenched } & 3 & Pu35-51 & 3 & 5 & E10 & $<1.00$ & $<0.100$ & $<0.500$ & $<0.100$ & 0.516 & 0.83335 & 0.083335 & 0.416675 & 0.083335 & 0.8600172 \\
\hline & 3 & EA & 3 & 6 & E62 & 36.9 & $<0.100$ & $<0.500$ & 102.8 & 53.5 & 615.00123 & 0.833335 & 4.166675 & 1713.33676 & 891.66845 \\
\hline quenched & 3 & Pu35-50 & 3 & 7 & E05 & $<1.00$ & $<0.100$ & $<0.500$ & $<0.100$ & 1.43 & 0.83335 & 0.083335 & 0.416675 & 0.083335 & 2.383381 \\
\hline \multirow[t]{2}{*}{ quenched } & 3 & Pu35-55 & 3 & 8 & E59 & $<1.00$ & $<0.100$ & $<0.500$ & $<0.100$ & 1.7 & 0.83335 & 0.083335 & 0.416675 & 0.083335 & 2.83339 \\
\hline & 3 & ARM-1 & 3 & 9 & E26 & 9.23 & $<0.100$ & $<0.500$ & 20.9 & 33.2 & 15.383641 & 0.083335 & 0.416675 & 34.83403 & 55.33444 \\
\hline quenched & 3 & Pu35-48 & 3 & 10 & E58 & $<1.00$ & $<0.100$ & $<0.500$ & $<0.100$ & 0.486 & 0.83335 & 0.083335 & 0.416675 & 0.083335 & 0.8100162 \\
\hline \multirow[t]{3}{*}{ quenched } & 3 & Pu35-37 & 3 & 11 & E25 & $<1.00$ & $<0.100$ & $<0.500$ & $<0.100$ & 0.861 & 0.83335 & 0.083335 & 0.416675 & 0.083335 & 1.4350287 \\
\hline & 3 & blank & 3 & 12 & E54 & $<1.00$ & $<0.100$ & $<0.500$ & $<0.100$ & $<0.100$ & 0.83335 & 0.083335 & 0.416675 & 0.083335 & 0.083335 \\
\hline & 3 & Soln Std & 3 & 13 & STD-13-2 & 18.9 & $<0.100$ & $<0.500$ & 82.8 & 48.7 & 18.9 & 0.05 & 0.25 & 82.8 & 48.7 \\
\hline quenched & 3 & Pu35-38 & 3 & 14 & E02 & $<1.00$ & $<0.100$ & $<0.500$ & $<0.100$ & 0.645 & 0.83335 & 0.083335 & 0.416675 & 0.083335 & 1.0750215 \\
\hline quenched & 3 & Pu35-41 & 3 & 15 & E18 & $<1.00$ & $<0.100$ & $<0.500$ & $<0.100$ & 0.55 & 0.83335 & 0.083335 & 0.416675 & 0.083335 & 0.916685 \\
\hline quenched & 3 & Pu35-54 & 3 & 16 & E57 & $<1.00$ & $<0.100$ & $<0.500$ & $<0.100$ & 0.861 & 0.83335 & 0.083335 & 0.416675 & 0.083335 & 1.4350287 \\
\hline quenched & 3 & Pu35-53 & 3 & 17 & E09 & $<1.00$ & $<0.100$ & $<0.500$ & $<0.100$ & 0.902 & 0.83335 & 0.083335 & 0.416675 & 0.083335 & 1.5033634 \\
\hline quenched & 3 & Pu35-42 & 3 & 18 & E68 & $<1.00$ & $<0.100$ & $<0.500$ & $<0.100$ & 1.59 & 0.83335 & 0.083335 & 0.416675 & 0.083335 & 2.650053 \\
\hline quenched & 3 & Pu35-36 & 3 & 19 & $\mathrm{E} 42$ & $<1.00$ & $<0.100$ & $<0.500$ & $<0.100$ & 1.07 & 0.83335 & 0.083335 & 0.416675 & 0.083335 & 1.783369 \\
\hline quenched & 3 & Pu35-39 & 3 & 20 & E36 & $<1.00$ & $<0.100$ & $<0.500$ & $<0.100$ & 1.77 & 0.83335 & 0.083335 & 0.416675 & 0.083335 & 2.950059 \\
\hline quenched & 3 & Pu35-46 & 3 & 21 & E28 & \begin{tabular}{|l|}
$<1.00$ \\
\end{tabular} & $<0.100$ & $<0.500$ & $<0.100$ & 0.634 & 0.83335 & 0.083335 & 0.416675 & 0.083335 & 1.0566878 \\
\hline quenched & 3 & Pu35-49 & 3 & 22 & E17 & $<1.00$ & $<0.100$ & $<0.500$ & $<0.100$ & 0.966 & 0.83335 & 0.083335 & 0.416675 & 0.083335 & 1.6100322 \\
\hline quenched & 3 & Pu35-47 & 3 & 23 & E66 & $<1.00$ & $<0.100$ & $<0.500$ & $<0.100$ & 0.525 & 0.83335 & 0.083335 & 0.416675 & 0.083335 & 0.8750175 \\
\hline quenched & 3 & Pu35-43 & 3 & 24 & E11 & $<1.00$ & $<0.100$ & $<0.500$ & $<0.100$ & 0.511 & 0.83335 & 0.083335 & 0.416675 & 0.083335 & 0.8516837 \\
\hline \multirow[t]{3}{*}{ quenched } & 3 & Pu35-45 & 3 & 25 & E19 & $<1.00$ & $<0.100$ & $<0.500$ & $<0.100$ & 0.759 & 0.83335 & 0.083335 & 0.416675 & 0.083335 & 1.2650253 \\
\hline & 3 & Soln Std & 3 & 26 & STD-13-3 & 19.7 & $<0.100$ & $<0.500$ & 83.8 & 49.4 & 19.7 & 0.05 & 0.25 & 83.8 & 49.4 \\
\hline & 1 & Soln Std & 1 & 1 & STD-11-1 & 20.5 & $<0.100$ & $<0.500$ & 83.7 & 49.9 & 20.5 & 0.05 & & 83.7 & 49.9 \\
\hline $\mathrm{ccc}$ & 1 & Pu35-01 & 1 & 2 & L62 & $<1.00$ & $<0.100$ & $<0.500$ & 1.2 & 1.34 & 0.83335 & 0.083335 & 0.416675 & 2.00004 & 2.233378 \\
\hline $\mathrm{ccc}$ & 1 & Pu35-06 & 1 & 3 & L45 & $<1.00$ & $<0.100$ & $<0.500$ & 1 & 2.06 & 0.83335 & 0.083335 & 0.416675 & 1.6667 & 3.433402 \\
\hline $\mathrm{ccc}$ & 1 & $\mathrm{Pu} 04-05$ & 1 & 4 & L49 & $<1.00$ & 0.562 & $<0.500$ & 0.658 & 0.407 & 0.83335 & 0.9366854 & 0.416675 & 1.0966886 & 0.6783469 \\
\hline $\mathrm{ccc}$ & 1 & Pu35-08 & 1 & 5 & L08 & $<1.00$ & $<0.100$ & $<0.500$ & $<0.100$ & 2.43 & 0.83335 & 0.083335 & 0.416675 & 0.083335 & 4.050081 \\
\hline $\mathrm{ccc}$ & 1 & $\mathrm{Pu} 04-04$ & 1 & 6 & L55 & $<1.00$ & $<0.100$ & $<0.500$ & 0.72 & 0.231 & 0.83335 & 0.083335 & 0.416675 & 1.200024 & 0.3850077 \\
\hline
\end{tabular}


Table E1. Laboratory Measurements of the PCT Solutions for the Pu Study Glasses As Reported (ar) and After the Appropriate Adjustments (in parts per million, ppm)

(continued)

\begin{tabular}{|c|c|c|c|c|c|c|c|c|c|c|c|c|c|c|c|}
\hline Heat Treament & Set & Glass ID & Block & Seq & SRNL-ML ID & B ar & Gd ar & Hf ar & Na ar & Si ar & B (ppm) & Gd (ppm) & Hf (ppm) & $\mathrm{Na}(\mathrm{ppm})$ & Si (ppm) \\
\hline $\operatorname{ccc}$ & 1 & Pu35-05 & 1 & 7 & L32 & $<1.00$ & $<0.100$ & $<0.500$ & 1.41 & 4.7 & 0.83335 & 0.083335 & 0.416675 & 2.350047 & 7.83349 \\
\hline $\mathrm{ccc}$ & 1 & blank & 1 & 8 & $\mathrm{~L} 21$ & $<1.00$ & $<0.100$ & $<0.500$ & 1.11 & $<0.100$ & 0.83335 & 0.083335 & 0.416675 & 1.850037 & 0.083335 \\
\hline $\mathrm{ccc}$ & 1 & Pu35-15 & 1 & 9 & L37 & $<1.00$ & $<0.100$ & $<0.500$ & 3.53 & 2.53 & 0.83335 & 0.083335 & 0.416675 & 5.883451 & 4.216751 \\
\hline $\mathrm{ccc}$ & 1 & Pu35-12 & 1 & 10 & L42 & $<1.00$ & $<0.100$ & $<0.500$ & 3.57 & 2.08 & 0.83335 & 0.083335 & 0.416675 & 5.950119 & 3.466736 \\
\hline $\mathrm{ccc}$ & 1 & Pu35-11 & 1 & 11 & $\mathrm{~L} 51$ & 1.17 & 0.495 & $<0.500$ & 1.02 & 2.29 & 1.950039 & 0.8250165 & 0.416675 & 1.700034 & 3.816743 \\
\hline $\mathrm{ccc}$ & 1 & Pu35-09 & 1 & 12 & L50 & $<1.00$ & 0.704 & $<0.500$ & 9.88 & 4.08 & 0.83335 & 1.1733568 & 0.416675 & 16.466996 & 6.800136 \\
\hline $\mathrm{ccc}$ & 1 & Soln Std & 1 & 13 & STD-11-2 & 20.8 & $<0.100$ & $<0.500$ & 84.8 & 50.7 & 20.8 & 0.05 & & 84.8 & 50.7 \\
\hline $\mathrm{ccc}$ & 1 & Pu35-04 & 1 & 14 & L24 & 1.05 & $<0.100$ & $<0.500$ & 1.98 & 2.36 & 1.750035 & 0.083335 & 0.416675 & 3.300066 & 3.933412 \\
\hline $\mathrm{ccc}$ & 1 & Pu35-10 & 1 & 15 & $\mathrm{~L} 23$ & $<1.00$ & $<0.100$ & $<0.500$ & 1.99 & 2.02 & 0.83335 & 0.083335 & 0.416675 & 3.316733 & 3.366734 \\
\hline $\mathrm{ccc}$ & 1 & Pu04-02 & 1 & 16 & $\mathrm{~L} 15$ & $<1.00$ & $<0.100$ & $<0.500$ & 3.39 & 0.314 & 0.83335 & 0.083335 & 0.416675 & 5.650113 & 0.5233438 \\
\hline $\mathrm{ccc}$ & 1 & Pu35-03 & 1 & 17 & $\mathrm{~L} 58$ & $<1.00$ & $<0.100$ & $<0.500$ & 1.53 & 3.75 & 0.83335 & 0.083335 & 0.416675 & 2.550051 & 6.250125 \\
\hline $\mathrm{ccc}$ & 1 & Pu35-02 & 1 & 18 & L11 & $<1.00$ & $<0.100$ & $<0.500$ & $<0.100$ & 2.5 & 0.83335 & 0.083335 & 0.416675 & 0.083335 & 4.16675 \\
\hline $\mathrm{ccc}$ & 1 & EA & 1 & 19 & L36 & 38.5 & 0.743 & $<0.500$ & 105 & 55.5 & 641.66795 & 12.383358 & 4.166675 & 1750.0035 & 925.00185 \\
\hline $\mathrm{ccc}$ & 1 & ARM-1 & 1 & 20 & L16 & 10.3 & $<0.100$ & $<0.500$ & 22 & 34.5 & 17.16701 & 0.083335 & 0.416675 & 36.6674 & 57.50115 \\
\hline $\mathrm{ccc}$ & 1 & Pu35-13 & 1 & 21 & L09 & $<1.00$ & 0.277 & $<0.500$ & 2.44 & 3.02 & 0.83335 & 0.4616759 & 0.416675 & 4.066748 & 5.033434 \\
\hline $\mathrm{ccc}$ & 1 & Pu35-14 & 1 & 22 & L29 & $<1.00$ & 0.143 & $<0.500$ & 0.62 & 1.94 & 0.83335 & 0.2383381 & 0.416675 & 1.033354 & 3.233398 \\
\hline $\mathrm{ccc}$ & 1 & Pu04-01 & 1 & 23 & L04 & $<1.00$ & 0.674 & $<0.500$ & 5.83 & 0.889 & 0.83335 & 1.1233558 & 0.416675 & 9.716861 & 1.4816963 \\
\hline $\mathrm{ccc}$ & 1 & Pu35-07 & 1 & 24 & L22 & $<1.00$ & $<0.100$ & $<0.500$ & 3.5 & 2.39 & 0.83335 & 0.083335 & 0.416675 & 5.83345 & 3.983413 \\
\hline $\mathrm{ccc}$ & 1 & $\mathrm{Pu} 04-03$ & 1 & 25 & L26 & $<1.00$ & 0.73 & $<0.500$ & 0.565 & 0.501 & 0.83335 & 1.216691 & 0.416675 & 0.9416855 & 0.8350167 \\
\hline $\mathrm{ccc}$ & 1 & Soln Std & 1 & 26 & STD-11-3 & 20 & $<0.100$ & $<0.500$ & 87.2 & 49.3 & 20 & 0.05 & & 87.2 & 49.3 \\
\hline $\mathrm{ccc}$ & 1 & Soln Std & 2 & 1 & STD-12-1 & 21.2 & $<0.100$ & $<0.500$ & 84.2 & 50.4 & 21.2 & 0.05 & & 84.2 & 50.4 \\
\hline $\mathrm{ccc}$ & 1 & Pu35-09 & 2 & 2 & L40 & 1.5 & 0.602 & $<0.500$ & 0.939 & 4.65 & 2.50005 & 1.0033534 & 0.416675 & 1.5650313 & 7.750155 \\
\hline $\mathrm{ccc}$ & 1 & Pu35-13 & 2 & 3 & $\mathrm{~L} 12$ & 1 & $<0.100$ & $<0.500$ & 1.83 & 3.5 & 1.6667 & 0.083335 & 0.416675 & 3.050061 & 5.83345 \\
\hline $\mathrm{ccc}$ & 1 & Pu35-07 & 2 & 4 & $\mathrm{~L} 35$ & $<1.00$ & \begin{tabular}{|l|}
0.463 \\
\end{tabular} & $<0.500$ & 11.5 & 3.19 & 0.83335 & 0.7716821 & 0.416675 & 19.16705 & 5.316773 \\
\hline $\mathrm{ccc}$ & 1 & Pu35-15 & 2 & 5 & $\mathrm{~L} 02$ & $<1.00$ & $<0.100$ & $<0.500$ & 1.78 & 3.01 & 0.83335 & 0.083335 & 0.416675 & 2.966726 & 5.016767 \\
\hline $\mathrm{ccc}$ & 1 & Pu04-04 & 2 & 6 & L53 & $<1.00$ & 1.019 & $<0.500$ & $<0.100$ & 1.28 & 0.83335 & 1.6983673 & 0.416675 & 0.083335 & 2.133376 \\
\hline $\mathrm{ccc}$ & 1 & Pu35-06 & 2 & 7 & $\mathrm{~L} 56$ & $<1.00$ & 0.77 & $<0.500$ & 0.611 & 2.6 & 0.83335 & 1.283359 & 0.416675 & 1.0183537 & 4.33342 \\
\hline $\mathrm{ccc}$ & 1 & Pu35-02 & 2 & 8 & L57 & $<1.00$ & 0.656 & $<0.500$ & 5.59 & 3.19 & 0.83335 & 1.0933552 & 0.416675 & 9.316853 & 5.316773 \\
\hline $\mathrm{ccc}$ & 1 & Pu35-11 & 2 & 9 & L47 & $<1.00$ & 0.441 & $<0.500$ & 5.14 & 3.05 & 0.83335 & 0.7350147 & 0.416675 & 8.566838 & 5.083435 \\
\hline $\mathrm{ccc}$ & 1 & Pu35-01 & 2 & 10 & L39 & $<1.00$ & $<0.100$ & $<0.500$ & 0.39 & 1.69 & 0.83335 & 0.083335 & 0.416675 & 0.650013 & 2.816723 \\
\hline $\mathrm{ccc}$ & 1 & Pu35-12 & 2 & 11 & L34 & $<1.00$ & 0.391 & $<0.500$ & 4.11 & 3.26 & 0.83335 & 0.6516797 & 0.416675 & 6.850137 & 5.433442 \\
\hline $\mathrm{ccc}$ & 1 & $\mathrm{Pu} 04-05$ & 2 & 12 & L03 & $<1.00$ & $<0.100$ & $<0.500$ & 1.41 & 0.7 & 0.83335 & 0.083335 & 0.416675 & 2.350047 & 1.16669 \\
\hline $\mathrm{ccc}$ & 1 & Soln Std & 2 & 13 & STD-12-2 & 20.5 & $<0.100$ & $<0.500$ & 86.6 & 50.8 & 20.5 & 0.05 & & 86.6 & 50.8 \\
\hline $\mathrm{ccc}$ & 1 & Pu35-08 & 2 & 14 & L17 & 1.07 & $<0.100$ & $<0.500$ & 2.27 & 3.29 & 1.783369 & 0.083335 & 0.416675 & 3.783409 & 5.483443 \\
\hline
\end{tabular}


Table E1. Laboratory Measurements of the PCT Solutions for the Pu Study Glasses As Reported (ar) and After the Appropriate Adjustments (in parts per million, ppm)

(continued)

\begin{tabular}{|c|c|c|c|c|c|c|c|c|c|c|c|c|c|c|c|}
\hline Heat Treament & Set & Glass ID & Block & Seq & SRNL-ML ID & B ar & Gd ar & Hf ar & Na ar & Si ar & B (ppm) & Gd (ppm) & Hf (ppm) & $\mathrm{Na}(\mathrm{ppm})$ & Si (ppm) \\
\hline $\operatorname{ccc}$ & 1 & Pu35-03 & 2 & 15 & L14 & 1.12 & 0.919 & $<0.500$ & 1.41 & 4.44 & 1.866704 & 1.5316973 & 0.416675 & 2.350047 & 7.400148 \\
\hline $\mathrm{ccc}$ & 1 & ARM-1 & 2 & 16 & L43 & 10.6 & 0.731 & $<0.500$ & 23.6 & 36.6 & 17.66702 & 1.2183577 & 0.416675 & 39.33412 & 61.00122 \\
\hline $\mathrm{ccc}$ & 1 & Pu35-10 & 2 & 17 & L33 & $<1.00$ & $<0.100$ & $<0.500$ & 1.95 & 2.53 & 0.83335 & 0.083335 & 0.416675 & 3.250065 & 4.216751 \\
\hline $\mathrm{ccc}$ & 1 & Pu35-14 & 2 & 18 & L46 & $<1.00$ & $<0.100$ & $<0.500$ & $<0.100$ & 2.56 & 0.83335 & 0.083335 & 0.416675 & 0.083335 & 4.266752 \\
\hline $\mathrm{ccc}$ & 1 & Pu04-01 & 2 & 19 & $\mathrm{~L} 41$ & $<1.00$ & 0.451 & $<0.500$ & $<0.100$ & 1.7 & 0.83335 & 0.7516817 & 0.416675 & 0.083335 & 2.83339 \\
\hline $\mathrm{ccc}$ & 1 & Pu35-05 & 2 & 20 & $\mathrm{~L} 60$ & $<1.00$ & 0.567 & $<0.500$ & $<0.100$ & 2.9 & 0.83335 & 0.9450189 & 0.416675 & 0.083335 & 4.83343 \\
\hline $\mathrm{ccc}$ & 1 & $\mathrm{Pu} 04-02$ & 2 & 21 & L27 & $<1.00$ & $<0.100$ & $<0.500$ & $<0.100$ & 0.695 & 0.83335 & 0.083335 & 0.416675 & 0.083335 & 1.1583565 \\
\hline $\mathrm{ccc}$ & 1 & EA & 2 & 22 & $\mathrm{~L} 05$ & 39.1 & 0.9 & $<0.500$ & 108 & 56 & 651.66797 & 15.00003 & 4.166675 & 1800.0036 & 933.3352 \\
\hline $\mathrm{ccc}$ & 1 & $\mathrm{Pu} 04-03$ & 2 & 23 & $\mathrm{~L} 65$ & $<1.00$ & $<0.100$ & $<0.500$ & $<0.100$ & 0.762 & 0.83335 & 0.083335 & 0.416675 & 0.083335 & 1.2700254 \\
\hline $\mathrm{ccc}$ & 1 & Pu35-04 & 2 & 24 & L38 & $<1.00$ & $<0.100$ & $<0.500$ & 0.709 & 2.58 & 0.83335 & 0.083335 & 0.416675 & 1.1816903 & 4.300086 \\
\hline $\mathrm{ccc}$ & 1 & Soln Std & 2 & 25 & STD-12-3 & 20.2 & $<0.100$ & $<0.500$ & 88.3 & 49.1 & 20.2 & 0.05 & & 88.3 & 49.1 \\
\hline $\mathrm{ccc}$ & 1 & Soln Std & 3 & 1 & STD-13-1 & 20.9 & $<0.100$ & $<0.500$ & 84.1 & 49.1 & 20.9 & 0.05 & & 84.1 & 49.1 \\
\hline $\mathrm{ccc}$ & 1 & Pu04-01 & 3 & 2 & L44 & $<1.00$ & $<0.100$ & $<0.500$ & 1.53 & 1.73 & 0.83335 & 0.083335 & 0.416675 & 2.550051 & 2.883391 \\
\hline $\mathrm{ccc}$ & 1 & ARM-1 & 3 & 3 & $\mathrm{~L} 28$ & 10.4 & \begin{tabular}{|l|}
0.854 \\
\end{tabular} & $<0.500$ & 22.9 & 35.5 & 17.33368 & 1.4233618 & 0.416675 & 38.16743 & 59.16785 \\
\hline $\mathrm{ccc}$ & 1 & Pu35-03 & 3 & 4 & $\mathrm{~L} 30$ & 1.08 & 0.151 & $<0.500$ & 7.43 & 4.4 & 1.800036 & 0.2516717 & 0.416675 & 12.383581 & 7.33348 \\
\hline $\mathrm{ccc}$ & 1 & blank & 3 & 5 & $\mathrm{~L} 63$ & $<1.00$ & $<0.100$ & $<0.500$ & 0.988 & $<0.100$ & 0.83335 & 0.083335 & 0.416675 & 1.6466996 & 0.083335 \\
\hline $\mathrm{ccc}$ & 1 & Pu35-13 & 3 & 6 & $\mathrm{~L} 68$ & $<1.00$ & $<0.100$ & $<0.500$ & 0.874 & 3.11 & 0.83335 & 0.083335 & 0.416675 & 1.4566958 & 5.183437 \\
\hline $\mathrm{ccc}$ & 1 & Pu35-15 & 3 & 7 & L07 & $<1.00$ & $<0.100$ & $<0.500$ & 5.71 & 2.52 & 0.83335 & 0.083335 & 0.416675 & 9.516857 & 4.200084 \\
\hline $\mathrm{ccc}$ & 1 & Pu35-01 & 3 & 8 & L67 & $<1.00$ & 0.105 & $<0.500$ & 0.689 & 1.54 & 0.83335 & 0.1750035 & 0.416675 & 1.1483563 & 2.566718 \\
\hline $\mathrm{ccc}$ & 1 & Pu35-04 & 3 & 9 & $\mathrm{~L} 52$ & $<1.00$ & 0.571 & $<0.500$ & 0.436 & 2.66 & 0.83335 & 0.9516857 & 0.416675 & 0.7266812 & 4.433422 \\
\hline $\mathrm{ccc}$ & 1 & Pu35-02 & 3 & 10 & L19 & $<1.00$ & $<0.100$ & $<0.500$ & 0.395 & 2.63 & 0.83335 & 0.083335 & 0.416675 & 0.6583465 & 4.383421 \\
\hline $\mathrm{ccc}$ & 1 & Pu35-12 & 3 & 11 & L20 & $<1.00$ & 0.417 & $<0.500$ & 3.94 & 2.54 & 0.83335 & 0.6950139 & 0.416675 & 6.566798 & 4.233418 \\
\hline $\mathrm{ccc}$ & 1 & Pu35-09 & 3 & 12 & L18 & $<1.00$ & $<0.100$ & $<0.500$ & 0.672 & 4.34 & 0.83335 & 0.083335 & 0.416675 & 1.1200224 & 7.233478 \\
\hline $\mathrm{ccc}$ & 1 & Soln Std & 3 & 13 & STD-13-2 & 20.1 & $<0.100$ & $<0.500$ & 86.9 & 50.5 & 20.1 & 0.05 & & 86.9 & 50.5 \\
\hline $\mathrm{ccc}$ & 1 & $\mathrm{Pu} 35-07$ & 3 & 14 & L25 & $<1.00$ & 0.206 & $<0.500$ & 0.467 & 2.21 & 0.83335 & 0.3433402 & 0.416675 & 0.7783489 & 3.683407 \\
\hline $\mathrm{ccc}$ & 1 & EA & 3 & 15 & L54 & 38 & $<0.100$ & $<0.500$ & 114 & 54.7 & 633.3346 & 0.833335 & 4.166675 & 1900.0038 & 911.66849 \\
\hline $\mathrm{ccc}$ & 1 & $\mathrm{Pu} 35-06$ & 3 & 16 & $\mathrm{~L} 31$ & $<1.00$ & 0.225 & $<0.500$ & 0.322 & 2.27 & 0.83335 & 0.3750075 & 0.416675 & 0.5366774 & 3.783409 \\
\hline $\mathrm{ccc}$ & 1 & Pu35-11 & 3 & 17 & L66 & $<1.00$ & $<0.100$ & $<0.500$ & $<0.100$ & 2.49 & 0.83335 & 0.083335 & 0.416675 & 0.083335 & 4.150083 \\
\hline $\mathrm{ccc}$ & 1 & Pu35-05 & 3 & 18 & L13 & $<1.00$ & $<0.100$ & $<0.500$ & 1.74 & 2.41 & 0.83335 & 0.083335 & 0.416675 & 2.900058 & 4.016747 \\
\hline $\mathrm{ccc}$ & 1 & Pu35-14 & 3 & 19 & L64 & $<1.00$ & 1.5 & $<0.500$ & 1.19 & 2.66 & 0.83335 & 2.50005 & 0.416675 & 1.983373 & 4.433422 \\
\hline $\mathrm{ccc}$ & 1 & $\mathrm{Pu} 04-03$ & 3 & 20 & L61 & $<1.00$ & $<0.100$ & $<0.500$ & 1.02 & 0.682 & 0.83335 & 0.083335 & 0.416675 & 1.700034 & 1.1366894 \\
\hline $\mathrm{ccc}$ & 1 & $\mathrm{Pu} 04-02$ & 3 & 21 & $\mathrm{~L} 48$ & $<1.00$ & $<0.100$ & $<0.500$ & 5.45 & 0.804 & 0.83335 & 0.083335 & 0.416675 & 9.083515 & 1.3400268 \\
\hline $\mathrm{ccc}$ & 1 & Pu35-08 & 3 & 22 & L01 & $<1.00$ & $<0.100$ & $<0.500$ & 0.848 & 2.47 & 0.83335 & 0.083335 & 0.416675 & 1.4133616 & 4.116749 \\
\hline $\mathrm{ccc}$ & 1 & Pu04-04 & 3 & 23 & L59 & $<1.00$ & $<0.100$ & $<0.500$ & 2.33 & 0.691 & 0.83335 & 0.083335 & 0.416675 & 3.883411 & 1.1516897 \\
\hline
\end{tabular}


Table E1. Laboratory Measurements of the PCT Solutions for the Pu Study Glasses As Reported (ar) and After the Appropriate Adjustments (in parts per million, ppm)

(continued)

\begin{tabular}{|c|c|c|c|c|c|c|c|c|c|c|c|c|c|c|c|}
\hline Heat Treament & Set & Glass ID & Block & Seq & SRNL-ML ID & B ar & Gd ar & Hf ar & Na ar & Si ar & B (ppm) & Gd (ppm) & Hf (ppm) & $\mathrm{Na}(\mathrm{ppm})$ & Si (ppm) \\
\hline $\operatorname{ccc}$ & 1 & Pu35-10 & 3 & 24 & L06 & $<1.00$ & $<0.100$ & $<0.500$ & 0.41 & 2.28 & 0.83335 & 0.083335 & 0.416675 & 0.683347 & 3.800076 \\
\hline $\mathrm{ccc}$ & 1 & Pu04-05 & 3 & 25 & L10 & $<1.00$ & $<0.100$ & $<0.500$ & $<0.100$ & 0.469 & 0.83335 & 0.083335 & 0.416675 & 0.083335 & 0.7816823 \\
\hline $\mathrm{ccc}$ & 1 & Soln Std & 3 & 26 & STD-13-3 & 20 & $<0.100$ & $<0.500$ & 90 & 50 & 20 & 0.05 & & 90 & 50 \\
\hline $\mathrm{ccc}$ & 2 & Soln Std & 1 & 1 & STD-11-1 & 20.8 & $<0.100$ & $<0.500$ & 82 & 49.5 & 20.8 & 0.05 & & 82 & 49.5 \\
\hline $\mathrm{ccc}$ & 2 & Pu35-17 & 1 & 2 & M47 & $<1.00$ & $<0.100$ & $<0.500$ & 0.498 & 2.86 & 0.83335 & 0.083335 & 0.416675 & 0.8300166 & 4.766762 \\
\hline $\mathrm{ccc}$ & 2 & Pu35-21 & 1 & 3 & M30 & $<1.00$ & $<0.100$ & $<0.500$ & 2.59 & 2.49 & 0.83335 & 0.083335 & 0.416675 & 4.316753 & 4.150083 \\
\hline $\mathrm{ccc}$ & 2 & Pu35-18 & 1 & 4 & M38 & $<1.00$ & $<0.100$ & $<0.500$ & 1.12 & 4.13 & 0.83335 & 0.083335 & 0.416675 & 1.866704 & 6.883471 \\
\hline $\mathrm{ccc}$ & 2 & blank & 1 & 5 & M21 & $<1.00$ & $<0.100$ & $<0.500$ & 4.19 & 0.176 & 0.83335 & 0.083335 & 0.416675 & 6.983473 & 0.2933392 \\
\hline $\mathrm{ccc}$ & 2 & Pu35-28 & 1 & 6 & M26 & $<1.00$ & $<0.100$ & $<0.500$ & 4.5 & 2.12 & 0.83335 & 0.083335 & 0.416675 & 7.50015 & 3.533404 \\
\hline $\mathrm{ccc}$ & 2 & Pu35-34 & 1 & 7 & M56 & $<1.00$ & $<0.100$ & $<0.500$ & 7.77 & 2.88 & 0.83335 & 0.083335 & 0.416675 & 12.950259 & 4.800096 \\
\hline $\mathrm{ccc}$ & 2 & Pu35-35 & 1 & 8 & M65 & $<1.00$ & $<0.100$ & 0.97 & 0.643 & 1.63 & 0.83335 & 0.083335 & 1.616699 & 1.0716881 & 2.716721 \\
\hline $\mathrm{ccc}$ & 2 & Pu35-24 & 1 & 9 & M12 & $<1.00$ & $<0.100$ & $<0.500$ & $<0.100$ & 2.25 & 0.83335 & 0.083335 & 0.416675 & 0.083335 & 3.750075 \\
\hline $\mathrm{ccc}$ & 2 & Pu35-30 & 1 & 10 & M10 & $<1.00$ & $<0.100$ & $<0.500$ & $<0.100$ & 3.06 & 0.83335 & 0.083335 & 0.416675 & 0.083335 & 5.100102 \\
\hline $\mathrm{ccc}$ & 2 & Pu35-27 & 1 & 11 & M03 & $<1.00$ & 0.46 & $<0.500$ & 0.125 & 2.51 & 0.83335 & 0.766682 & 0.416675 & 0.2083375 & 4.183417 \\
\hline $\mathrm{ccc}$ & 2 & Pu35-26 & 1 & 12 & M55 & $<1.00$ & $<0.100$ & $<0.500$ & 4.24 & 1.8 & 0.83335 & 0.083335 & 0.416675 & 7.066808 & 3.00006 \\
\hline $\mathrm{ccc}$ & 2 & Soln Std & 1 & 13 & STD-11-2 & 19.4 & $<0.100$ & $<0.500$ & 82.3 & 49.8 & 19.4 & 0.05 & & 82.3 & 49.8 \\
\hline $\mathrm{ccc}$ & 2 & Pu35-31 & 1 & 14 & M29 & $<1.00$ & $<0.100$ & $<0.500$ & 5.44 & 3.01 & 0.83335 & 0.083335 & 0.416675 & 9.066848 & 5.016767 \\
\hline $\mathrm{ccc}$ & 2 & Pu35-32 & 1 & 15 & M13 & $<1.00$ & $<0.100$ & $<0.500$ & $<0.100$ & 1.48 & 0.83335 & 0.083335 & 0.416675 & 0.083335 & 2.466716 \\
\hline $\mathrm{ccc}$ & 2 & Pu35-23 & 1 & 16 & M14 & $<1.00$ & $<0.100$ & $<0.500$ & 8.47 & 2.25 & 0.83335 & 0.083335 & 0.416675 & 14.116949 & 3.750075 \\
\hline $\mathrm{ccc}$ & 2 & ARM-1 & 1 & 17 & M63 & 9.54 & $<0.100$ & $<0.500$ & 30.4 & 35 & 15.900318 & 0.083335 & 0.416675 & 50.66768 & 58.3345 \\
\hline $\mathrm{ccc}$ & 2 & Pu35-16 & 1 & 18 & M46 & $<1.00$ & $<0.100$ & $<0.500$ & 1.36 & 1.2 & 0.83335 & 0.083335 & 0.416675 & 2.266712 & 2.00004 \\
\hline $\mathrm{ccc}$ & 2 & Pu35-25 & 1 & 19 & M16 & $<1.00$ & $<0.100$ & 0.674 & 11.7 & 3.42 & 0.83335 & 0.083335 & 1.123356 & 19.50039 & 5.700114 \\
\hline $\mathrm{ccc}$ & 2 & Pu35-33 & 1 & 20 & M02 & $<1.00$ & $<0.100$ & $<0.500$ & 5.64 & 1.84 & 0.83335 & 0.083335 & 0.416675 & 9.400188 & 3.066728 \\
\hline $\mathrm{ccc}$ & 2 & EA & 1 & 21 & M66 & 37.6 & $<0.100$ & $<0.500$ & 107 & 55.1 & 626.66792 & 0.833335 & 4.166675 & 1783.3369 & 918.33517 \\
\hline $\mathrm{ccc}$ & 2 & $\mathrm{Pu} 35-22$ & 1 & 22 & M33 & $<1.00$ & 0.324 & $<0.500$ & $<0.100$ & 2.74 & 0.83335 & 0.5400108 & 0.416675 & 0.083335 & 4.566758 \\
\hline $\mathrm{ccc}$ & 2 & Pu35-19 & 1 & 23 & M54 & $<1.00$ & $<0.100$ & $<0.500$ & $<0.100$ & 2.33 & 0.83335 & 0.083335 & 0.416675 & 0.083335 & 3.883411 \\
\hline $\mathrm{ccc}$ & 2 & Pu35-20 & 1 & 24 & M36 & $<1.00$ & $<0.100$ & $<0.500$ & 13.6 & 3.23 & 0.83335 & 0.083335 & 0.416675 & 22.66712 & 5.383441 \\
\hline $\mathrm{ccc}$ & 2 & Pu35-29 & 1 & 25 & M61 & $<1.00$ & $<0.100$ & $<0.500$ & 1.38 & 3.03 & 0.83335 & 0.083335 & 0.416675 & 2.300046 & 5.050101 \\
\hline $\mathrm{ccc}$ & 2 & Soln Std & 1 & 26 & STD-11-3 & \begin{tabular}{|l|}
19.7 \\
\end{tabular} & $<0.100$ & $<0.500$ & 87.2 & 48.8 & 19.7 & 0.05 & & 87.2 & 48.8 \\
\hline $\mathrm{ccc}$ & 2 & Soln Std & 2 & 1 & STD-12-1 & 20.1 & $<0.100$ & $<0.500$ & 81.3 & 49.3 & 20.1 & 0.05 & & 81.3 & 49.3 \\
\hline $\mathrm{ccc}$ & 2 & Pu35-29 & 2 & 2 & M43 & $<1.00$ & $<0.100$ & $<0.500$ & $<0.100$ & 2.06 & 0.83335 & 0.083335 & 0.416675 & 0.083335 & 3.433402 \\
\hline $\mathrm{ccc}$ & 2 & Pu35-19 & 2 & 3 & M20 & $<1.00$ & $<0.100$ & $<0.500$ & $<0.100$ & 1.29 & 0.83335 & 0.083335 & 0.416675 & 0.083335 & 2.150043 \\
\hline $\mathrm{ccc}$ & 2 & Pu35-27 & 2 & 4 & M62 & $<1.00$ & $<0.100$ & $<0.500$ & $<0.100$ & 0.227 & 0.83335 & 0.083335 & 0.416675 & 0.083335 & 0.3783409 \\
\hline $\mathrm{ccc}$ & 2 & Pu35-16 & 2 & 5 & M05 & $<1.00$ & $<0.100$ & $<0.500$ & $<0.100$ & 0.824 & 0.83335 & 0.083335 & 0.416675 & 0.083335 & 1.3733608 \\
\hline
\end{tabular}


Table E1. Laboratory Measurements of the PCT Solutions for the Pu Study Glasses As Reported (ar) and After the Appropriate Adjustments (in parts per million, ppm)

(continued)

\begin{tabular}{|c|c|c|c|c|c|c|c|c|c|c|c|c|c|c|c|}
\hline Heat Treament & Set & Glass ID & Block & Seq & SRNL-ML ID & B ar & Gd ar & Hf ar & Na ar & Si ar & B (ppm) & Gd (ppm) & Hf (ppm) & Na (ppm) & Si (ppm) \\
\hline $\mathrm{ccc}$ & 2 & Pu35-33 & 2 & 6 & M60 & $<1.00$ & $<0.100$ & $<0.500$ & 1.53 & 1.26 & 0.83335 & 0.083335 & 0.416675 & 2.550051 & 2.100042 \\
\hline $\mathrm{ccc}$ & 2 & Pu35-21 & 2 & 7 & M64 & $<1.00$ & $<0.100$ & $<0.500$ & $<0.100$ & 2.05 & 0.83335 & 0.083335 & 0.416675 & 0.083335 & 3.416735 \\
\hline $\mathrm{ccc}$ & 2 & Pu35-26 & 2 & 8 & M48 & $<1.00$ & $<0.100$ & $<0.500$ & 0.141 & 1.69 & 0.83335 & 0.083335 & 0.416675 & 0.2350047 & 2.816723 \\
\hline $\mathrm{ccc}$ & 2 & EA & 2 & 9 & M08 & 36.6 & $<0.100$ & $<0.500$ & 98.8 & 52.7 & 610.00122 & 0.833335 & 4.166675 & 1646.66996 & 878.33509 \\
\hline $\mathrm{ccc}$ & 2 & ARM-1 & 2 & 10 & M58 & 9.01 & $<0.100$ & $<0.500$ & 20.5 & 33 & 15.016967 & 0.083335 & 0.416675 & 34.16735 & 55.0011 \\
\hline $\mathrm{ccc}$ & 2 & Pu35-25 & 2 & 11 & M35 & $<1.00$ & $<0.100$ & $<0.500$ & 0.488 & 2.71 & 0.83335 & 0.083335 & 0.416675 & 0.8133496 & 4.516757 \\
\hline $\mathrm{ccc}$ & 2 & Pu35-20 & 2 & 12 & M22 & $<1.00$ & $<0.100$ & $<0.500$ & 1.37 & 2.82 & 0.83335 & 0.083335 & 0.416675 & 2.283379 & 4.700094 \\
\hline $\mathrm{ccc}$ & 2 & Soln Std & 2 & 13 & STD-12-2 & 19.1 & $<0.100$ & $<0.500$ & 80.8 & 48.4 & 19.1 & 0.05 & & 80.8 & 48.4 \\
\hline $\mathrm{ccc}$ & 2 & Pu35-30 & 2 & 14 & M27 & $<1.00$ & $<0.100$ & $<0.500$ & 0.751 & 2.84 & 0.83335 & 0.083335 & 0.416675 & 1.2516917 & 4.733428 \\
\hline $\mathrm{ccc}$ & 2 & Pu35-32 & 2 & 15 & M31 & $<1.00$ & $<0.100$ & $<0.500$ & $<0.100$ & 1.25 & 0.83335 & 0.083335 & 0.416675 & 0.083335 & 2.083375 \\
\hline $\mathrm{ccc}$ & 2 & Pu35-22 & 2 & 16 & M15 & $<1.00$ & $<0.100$ & $<0.500$ & 0.275 & 2.74 & 0.83335 & 0.083335 & 0.416675 & 0.4583425 & 4.566758 \\
\hline $\mathrm{ccc}$ & 2 & Pu35-24 & 2 & 17 & M06 & $<1.00$ & $<0.100$ & $<0.500$ & $<0.100$ & 2.14 & 0.83335 & 0.083335 & 0.416675 & 0.083335 & 3.566738 \\
\hline $\mathrm{ccc}$ & 2 & Pu35-18 & 2 & 18 & M67 & $<1.00$ & $<0.100$ & $<0.500$ & 1.08 & 3.99 & 0.83335 & 0.083335 & 0.416675 & 1.800036 & 6.650133 \\
\hline $\mathrm{ccc}$ & 2 & Pu35-34 & 2 & 19 & M04 & $<1.00$ & $<0.100$ & $<0.500$ & 1.32 & 2.75 & 0.83335 & 0.083335 & 0.416675 & 2.200044 & 4.583425 \\
\hline $\mathrm{ccc}$ & 2 & Pu35-35 & 2 & 20 & M52 & $<1.00$ & $<0.100$ & $<0.500$ & 0.63 & 1.57 & 0.83335 & 0.083335 & 0.416675 & 1.050021 & 2.616719 \\
\hline $\mathrm{ccc}$ & 2 & Pu35-28 & 2 & 21 & M19 & $<1.00$ & $<0.100$ & $<0.500$ & $<0.100$ & 1.97 & 0.83335 & 0.083335 & 0.416675 & 0.083335 & 3.283399 \\
\hline $\mathrm{ccc}$ & 2 & Pu35-23 & 2 & 22 & M42 & $<1.00$ & $<0.100$ & $<0.500$ & 0.819 & 2.23 & 0.83335 & 0.083335 & 0.416675 & 1.3650273 & 3.716741 \\
\hline $\mathrm{ccc}$ & 2 & Pu35-31 & 2 & 23 & M17 & $<1.00$ & $<0.100$ & $<0.500$ & 0.909 & 2.33 & 0.83335 & 0.083335 & 0.416675 & 1.5150303 & 3.883411 \\
\hline $\mathrm{ccc}$ & 2 & Pu35-17 & 2 & 24 & M68 & $<1.00$ & $<0.100$ & $<0.500$ & 0.396 & 2.48 & 0.83335 & 0.083335 & 0.416675 & 0.6600132 & 4.133416 \\
\hline $\mathrm{ccc}$ & 2 & Soln Std & 2 & 25 & STD-12-3 & 19.6 & $<0.100$ & $<0.500$ & 84.2 & 50.4 & 19.6 & 0.05 & & 84.2 & 50.4 \\
\hline $\mathrm{ccc}$ & 2 & Soln Std & 3 & 1 & STD-13-1 & 20.5 & $<0.100$ & $<0.500$ & 82.4 & 50 & 20.5 & 0.05 & & 82.4 & 50 \\
\hline $\mathrm{ccc}$ & 2 & EA & 3 & 2 & M09 & 36.5 & $<0.100$ & $<0.500$ & 100 & 53.2 & 608.33455 & 0.833335 & 4.166675 & 1666.67 & 886.66844 \\
\hline $\mathrm{ccc}$ & 2 & Pu35-18 & 3 & 3 & M24 & 1.34 & $<0.100$ & $<0.500$ & $<0.100$ & 4.28 & 2.233378 & 0.083335 & 0.416675 & 0.083335 & 7.133476 \\
\hline $\mathrm{ccc}$ & 2 & Pu35-25 & 3 & 4 & M01 & $<1.00$ & $<0.100$ & $<0.500$ & $<0.100$ & 3.05 & 0.83335 & 0.083335 & 0.416675 & 0.083335 & 5.083435 \\
\hline $\mathrm{ccc}$ & 2 & blank & 3 & 5 & M28 & $<1.00$ & $<0.100$ & $<0.500$ & $<0.100$ & 0.123 & 0.83335 & 0.083335 & 0.416675 & 0.083335 & 0.2050041 \\
\hline $\mathrm{ccc}$ & 2 & ARM-1 & 3 & 6 & M34 & 10.3 & $<0.100$ & $<0.500$ & 21.7 & 35.1 & 17.16701 & 0.083335 & 0.416675 & 36.16739 & 58.50117 \\
\hline $\mathrm{ccc}$ & 2 & Pu35-33 & 3 & 7 & M59 & $<1.00$ & $<0.100$ & $<0.500$ & $<0.100$ & 1.68 & 0.83335 & 0.083335 & 0.416675 & 0.083335 & 2.800056 \\
\hline $\mathrm{ccc}$ & 2 & Pu35-16 & 3 & 8 & M51 & $<1.00$ & $<0.100$ & $<0.500$ & $<0.100$ & 1.82 & 0.83335 & 0.083335 & 0.416675 & 0.083335 & 3.033394 \\
\hline $\mathrm{ccc}$ & 2 & Pu35-17 & 3 & 9 & M37 & $<1.00$ & $<0.100$ & $<0.500$ & $<0.100$ & 3.04 & 0.83335 & 0.083335 & 0.416675 & 0.083335 & 5.066768 \\
\hline $\mathrm{ccc}$ & 2 & Pu35-34 & 3 & 10 & M39 & $<1.00$ & $<0.100$ & $<0.500$ & $<0.100$ & 2.81 & 0.83335 & 0.083335 & 0.416675 & 0.083335 & 4.683427 \\
\hline $\mathrm{ccc}$ & 2 & Pu35-28 & 3 & 11 & M41 & $<1.00$ & $<0.100$ & $<0.500$ & $<0.100$ & 2.47 & 0.83335 & 0.083335 & 0.416675 & 0.083335 & 4.116749 \\
\hline $\mathrm{ccc}$ & 2 & Pu35-32 & 3 & 12 & M25 & $<1.00$ & $<0.100$ & $<0.500$ & $<0.100$ & 1.56 & 0.83335 & 0.083335 & 0.416675 & 0.083335 & 2.600052 \\
\hline $\mathrm{ccc}$ & 2 & Soln Std & 3 & 13 & STD-13-2 & 19.1 & $<0.100$ & $<0.500$ & 82.5 & 48.2 & 19.1 & 0.05 & & 82.5 & 48.2 \\
\hline $\mathrm{ccc}$ & 2 & Pu35-31 & 3 & 14 & M32 & $<1.00$ & $<0.100$ & $<0.500$ & $<0.100$ & 3.28 & 0.83335 & 0.083335 & 0.416675 & 0.083335 & 5.466776 \\
\hline
\end{tabular}


Table E1. Laboratory Measurements of the PCT Solutions for the Pu Study Glasses As Reported (ar) and After the Appropriate Adjustments (in parts per million, ppm)

(continued)

\begin{tabular}{|c|c|c|c|c|c|c|c|c|c|c|c|c|c|c|c|}
\hline Heat Treament & Set & Glass ID & Block & Seq & SRNL-ML ID & B ar & Gd ar & Hf ar & Na ar & Si ar & B (ppm) & Gd (ppm) & Hf (ppm) & $\mathrm{Na}(\mathrm{ppm})$ & Si (ppm) \\
\hline $\operatorname{ccc}$ & 2 & Pu35-26 & 3 & 15 & M18 & $<1.00$ & $<0.100$ & $<0.500$ & $<0.100$ & 1.83 & 0.83335 & 0.083335 & 0.416675 & 0.083335 & 3.050061 \\
\hline $\mathrm{ccc}$ & 2 & Pu35-19 & 3 & 16 & M40 & $<1.00$ & $<0.100$ & $<0.500$ & $<0.100$ & 2.76 & 0.83335 & 0.083335 & 0.416675 & 0.083335 & 4.600092 \\
\hline $\mathrm{ccc}$ & 2 & Pu35-22 & 3 & 17 & M45 & $<1.00$ & $<0.100$ & $<0.500$ & 1.86 & 3.02 & 0.83335 & 0.083335 & 0.416675 & 3.100062 & 5.033434 \\
\hline $\mathrm{ccc}$ & 2 & Pu35-21 & 3 & 18 & M23 & $<1.00$ & $<0.100$ & $<0.500$ & 1.4 & 2.68 & 0.83335 & 0.083335 & 0.416675 & 2.33338 & 4.466756 \\
\hline $\mathrm{ccc}$ & 2 & Pu35-23 & 3 & 19 & M57 & $<1.00$ & $<0.100$ & $<0.500$ & $<0.100$ & 2.44 & 0.83335 & 0.083335 & 0.416675 & 0.083335 & 4.066748 \\
\hline $\mathrm{ccc}$ & 2 & Pu35-35 & 3 & 20 & M49 & $<1.00$ & $<0.100$ & $<0.500$ & $<0.100$ & 1.89 & 0.83335 & 0.083335 & 0.416675 & 0.083335 & 3.150063 \\
\hline $\mathrm{ccc}$ & 2 & Pu35-20 & 3 & 21 & M07 & $<1.00$ & $<0.100$ & $<0.500$ & $<0.100$ & 2.91 & 0.83335 & 0.083335 & 0.416675 & 0.083335 & 4.850097 \\
\hline $\mathrm{ccc}$ & 2 & Pu35-27 & 3 & 22 & M11 & $<1.00$ & $<0.100$ & $<0.500$ & $<0.100$ & 2.62 & 0.83335 & 0.083335 & 0.416675 & 0.083335 & 4.366754 \\
\hline $\mathrm{ccc}$ & 2 & Pu35-30 & 3 & 23 & M53 & $<1.00$ & $<0.100$ & $<0.500$ & $<0.100$ & 3.39 & 0.83335 & 0.083335 & 0.416675 & 0.083335 & 5.650113 \\
\hline $\mathrm{ccc}$ & 2 & Pu35-24 & 3 & 24 & M50 & $<1.00$ & $<0.100$ & $<0.500$ & $<0.100$ & 2.49 & 0.83335 & 0.083335 & 0.416675 & 0.083335 & 4.150083 \\
\hline $\mathrm{ccc}$ & 2 & Pu35-29 & 3 & 25 & M44 & $<1.00$ & $<0.100$ & $<0.500$ & 0.306 & 2.89 & 0.83335 & 0.083335 & 0.416675 & 0.5100102 & 4.816763 \\
\hline $\mathrm{ccc}$ & 2 & Soln Std & 3 & 26 & STD-13-3 & 19.3 & $<0.100$ & $<0.500$ & 84.1 & 48.4 & 19.3 & 0.05 & & 84.1 & 48.4 \\
\hline $\mathrm{ccc}$ & 3 & Soln Std & 1 & 1 & STD-11-1 & 21.2 & $<0.100$ & $<0.500$ & 83.8 & 49.6 & 21.2 & 0.05 & & 83.8 & 49.6 \\
\hline $\mathrm{ccc}$ & 3 & Pu35-52 & 1 & 2 & N61 & 1 & $<0.100$ & $<0.500$ & 0.962 & 2.83 & 1.6667 & 0.083335 & 0.416675 & 1.6033654 & 4.716761 \\
\hline $\mathrm{ccc}$ & 3 & Pu35-36 & 1 & 3 & $\mathrm{~N} 23$ & 1.48 & $<0.100$ & $<0.500$ & 1.14 & 3.46 & 2.466716 & 0.083335 & 0.416675 & 1.900038 & 5.766782 \\
\hline $\mathrm{ccc}$ & 3 & blank & 1 & 4 & $\mathrm{~N} 21$ & $<1.00$ & $<0.100$ & $<0.500$ & 0.407 & $<0.100$ & 0.83335 & 0.083335 & 0.416675 & 0.6783469 & 0.083335 \\
\hline $\mathrm{ccc}$ & 3 & Pu35-49 & 1 & 5 & N04 & $<1.00$ & $<0.100$ & $<0.500$ & 1.57 & 2.56 & 0.83335 & 0.083335 & 0.416675 & 2.616719 & 4.266752 \\
\hline $\mathrm{ccc}$ & 3 & EA & 1 & 6 & N30 & 37.6 & $<0.100$ & $<0.500$ & 102 & 51.8 & 626.66792 & 0.833335 & 4.166675 & 1700.0034 & 863.33506 \\
\hline $\mathrm{ccc}$ & 3 & Pu35-40 & 1 & 7 & $\mathrm{~N} 41$ & $<1.00$ & $<0.100$ & $<0.500$ & 0.573 & 2.61 & 0.83335 & 0.083335 & 0.416675 & 0.9550191 & 4.350087 \\
\hline $\mathrm{ccc}$ & 3 & Pu35-51 & 1 & 8 & N67 & $<1.00$ & $<0.100$ & $<0.500$ & 0.983 & 2.49 & 0.83335 & 0.083335 & 0.416675 & 1.6383661 & 4.150083 \\
\hline $\mathrm{ccc}$ & 3 & ARM-1 & 1 & 9 & $\mathrm{~N} 46$ & 10.7 & $<0.100$ & $<0.500$ & 22 & 33.9 & 17.83369 & 0.083335 & 0.416675 & 36.6674 & 56.50113 \\
\hline $\mathrm{ccc}$ & 3 & Pu35-53 & 1 & 10 & N49 & $<1.00$ & $<0.100$ & $<0.500$ & 1.94 & 2.47 & 0.83335 & 0.083335 & 0.416675 & 3.233398 & 4.116749 \\
\hline $\mathrm{ccc}$ & 3 & Pu35-39 & 1 & 11 & N07 & $<1.00$ & $<0.100$ & $<0.500$ & 2.88 & 2.81 & 0.83335 & 0.083335 & 0.416675 & 4.800096 & 4.683427 \\
\hline $\mathrm{ccc}$ & 3 & Pu35-48 & 1 & 12 & N64 & $<1.00$ & $<0.100$ & $<0.500$ & 2 & 1.91 & 0.83335 & 0.083335 & 0.416675 & 3.3334 & 3.183397 \\
\hline $\mathrm{ccc}$ & 3 & Soln Std & 1 & 13 & STD-11-2 & 20.4 & $<0.100$ & $<0.500$ & 89.3 & 48.9 & 20.4 & 0.05 & & 89.3 & 48.9 \\
\hline $\mathrm{ccc}$ & 3 & Pu35-50 & 1 & 14 & N52 & $<1.00$ & $<0.100$ & $<0.500$ & 0.723 & 2.74 & 0.83335 & 0.083335 & 0.416675 & 1.2050241 & 4.566758 \\
\hline $\mathrm{ccc}$ & 3 & Pu35-41 & 1 & 15 & N34 & $<1.00$ & $<0.100$ & $<0.500$ & 0.864 & 2.76 & 0.83335 & 0.083335 & 0.416675 & 1.4400288 & 4.600092 \\
\hline $\mathrm{ccc}$ & 3 & Pu35-42 & 1 & 16 & $\mathrm{~N} 20$ & $<1.00$ & $<0.100$ & $<0.500$ & 1.17 & 3.2 & 0.83335 & 0.083335 & 0.416675 & 1.950039 & 5.33344 \\
\hline $\mathrm{ccc}$ & 3 & Pu35-43 & 1 & 17 & N03 & $<1.00$ & $<0.100$ & $<0.500$ & 0.852 & 2.04 & 0.83335 & 0.083335 & 0.416675 & 1.4200284 & 3.400068 \\
\hline $\mathrm{ccc}$ & 3 & Pu35-54 & 1 & 18 & N63 & $<1.00$ & $<0.100$ & $<0.500$ & 1.19 & 2.77 & 0.83335 & 0.083335 & 0.416675 & 1.983373 & 4.616759 \\
\hline $\mathrm{ccc}$ & 3 & Pu35-44 & 1 & 19 & $\mathrm{~N} 56$ & $<1.00$ & $<0.100$ & $<0.500$ & 0.939 & 2.15 & 0.83335 & 0.083335 & 0.416675 & 1.5650313 & 3.583405 \\
\hline $\mathrm{ccc}$ & 3 & $\mathrm{Pu} 35-47$ & 1 & 20 & N35 & $<1.00$ & $<0.100$ & $<0.500$ & 0.843 & 2.09 & 0.83335 & 0.083335 & 0.416675 & 1.4050281 & 3.483403 \\
\hline $\mathrm{ccc}$ & 3 & Pu35-45 & 1 & 21 & $\mathrm{~N} 22$ & $<1.00$ & $<0.100$ & $<0.500$ & 1.42 & 1.58 & 0.83335 & 0.083335 & 0.416675 & 2.366714 & 2.633386 \\
\hline $\mathrm{ccc}$ & 3 & Pu35-37 & 1 & 22 & N39 & $<1.00$ & $<0.100$ & $<0.500$ & 2.49 & 2.41 & 0.83335 & 0.083335 & 0.416675 & 4.150083 & 4.016747 \\
\hline
\end{tabular}


Table E1. Laboratory Measurements of the PCT Solutions for the Pu Study Glasses As Reported (ar) and After the Appropriate Adjustments (in parts per million, ppm)

(continued)

\begin{tabular}{|c|c|c|c|c|c|c|c|c|c|c|c|c|c|c|c|}
\hline Heat Treament & Set & Glass ID & Block & Seq & SRNL-ML ID & B ar & Gd ar & Hf ar & Na ar & Si ar & B (ppm) & Gd (ppm) & Hf (ppm) & $\mathrm{Na}(\mathrm{ppm})$ & Si (ppm) \\
\hline $\mathrm{ccc}$ & 3 & Pu35-55 & 1 & 23 & N15 & $<1.00$ & $<0.100$ & $<0.500$ & 0.833 & 2.56 & 0.83335 & 0.083335 & 0.416675 & 1.3883611 & 4.266752 \\
\hline $\mathrm{ccc}$ & 3 & Pu35-38 & 1 & 24 & N13 & $<1.00$ & $<0.100$ & $<0.500$ & 1.36 & 2.66 & 0.83335 & 0.083335 & 0.416675 & 2.266712 & 4.433422 \\
\hline $\mathrm{ccc}$ & 3 & Pu35-46 & 1 & 25 & N50 & $<1.00$ & $<0.100$ & $<0.500$ & 1.31 & 2.2 & 0.83335 & 0.083335 & 0.416675 & 2.183377 & 3.66674 \\
\hline $\mathrm{ccc}$ & 3 & Soln Std & 1 & 26 & STD-11-3 & 20.9 & $<0.100$ & $<0.500$ & 87.2 & 50.4 & 20.9 & 0.05 & & 87.2 & 50.4 \\
\hline $\mathrm{ccc}$ & 3 & Soln Std & 2 & 1 & STD-12-1 & 21.7 & $<0.100$ & $<0.500$ & 85.1 & 51.2 & 21.7 & 0.05 & & 85.1 & 51.2 \\
\hline $\mathrm{ccc}$ & 3 & Pu35-41 & 2 & 2 & N31 & 1.22 & $<0.100$ & $<0.500$ & 0.363 & 3.01 & 2.033374 & 0.083335 & 0.416675 & 0.6050121 & 5.016767 \\
\hline $\mathrm{ccc}$ & 3 & Pu35-53 & 2 & 3 & N37 & 1.07 & $<0.100$ & $<0.500$ & 23.5 & 3.11 & 1.783369 & 0.083335 & 0.416675 & 39.16745 & 5.183437 \\
\hline $\mathrm{ccc}$ & 3 & Pu35-39 & 2 & 4 & $\mathrm{~N} 33$ & $<1.00$ & $<0.100$ & $<0.500$ & 0.54 & 3.15 & 0.83335 & 0.083335 & 0.416675 & 0.900018 & 5.250105 \\
\hline $\mathrm{ccc}$ & 3 & ARM-1 & 2 & 5 & N01 & 11.3 & $<0.100$ & $<0.500$ & 20.9 & 35.9 & 18.83371 & 0.083335 & 0.416675 & 34.83403 & 59.83453 \\
\hline $\mathrm{ccc}$ & 3 & Pu35-45 & 2 & 6 & $\mathrm{~N} 40$ & $<1.00$ & $<0.100$ & $<0.500$ & 1.78 & 1.83 & 0.83335 & 0.083335 & 0.416675 & 2.966726 & 3.050061 \\
\hline $\mathrm{ccc}$ & 3 & Pu35-43 & 2 & 7 & N51 & $<1.00$ & $<0.100$ & $<0.500$ & 1.87 & 2.29 & 0.83335 & 0.083335 & 0.416675 & 3.116729 & 3.816743 \\
\hline $\mathrm{ccc}$ & 3 & Pu35-42 & 2 & 8 & $\mathrm{~N} 47$ & $<1.00$ & $<0.100$ & $<0.500$ & $<0.100$ & 3.23 & 0.83335 & 0.083335 & 0.416675 & 0.083335 & 5.383441 \\
\hline $\mathrm{ccc}$ & 3 & Pu35-55 & 2 & 9 & $\mathrm{~N} 48$ & $<1.00$ & $<0.100$ & $<0.500$ & 0.709 & 3.22 & 0.83335 & 0.083335 & 0.416675 & 1.1816903 & 5.366774 \\
\hline $\mathrm{ccc}$ & 3 & EA & 2 & 10 & $\mathrm{~N} 29$ & 37.5 & $<0.100$ & $<0.500$ & 103 & 52.6 & 625.00125 & 0.833335 & 4.166675 & 1716.6701 & 876.66842 \\
\hline $\mathrm{ccc}$ & 3 & Pu35-54 & 2 & 11 & $\mathrm{~N} 45$ & $<1.00$ & $<0.100$ & $<0.500$ & 1.36 & 3.42 & 0.83335 & 0.083335 & 0.416675 & 2.266712 & 5.700114 \\
\hline $\mathrm{ccc}$ & 3 & Pu35-48 & 2 & 12 & N60 & $<1.00$ & $<0.100$ & $<0.500$ & $<0.100$ & 2.3 & 0.83335 & 0.083335 & 0.416675 & 0.083335 & 3.83341 \\
\hline $\mathrm{ccc}$ & 3 & Soln Std & 2 & 13 & STD-12-2 & 20.7 & $<0.100$ & $<0.500$ & \begin{tabular}{|l|}
88.1 \\
\end{tabular} & 50 & 20.7 & 0.05 & & 88.1 & 50 \\
\hline $\mathrm{ccc}$ & 3 & Pu35-51 & 2 & 14 & N08 & $<1.00$ & $<0.100$ & $<0.500$ & 0.939 & 2.47 & 0.83335 & 0.083335 & 0.416675 & 1.5650313 & 4.116749 \\
\hline $\mathrm{ccc}$ & 3 & Pu35-50 & 2 & 15 & $\mathrm{~N} 27$ & $<1.00$ & $<0.100$ & $<0.500$ & 3.08 & 2.58 & 0.83335 & 0.083335 & 0.416675 & 5.133436 & 4.300086 \\
\hline $\mathrm{ccc}$ & 3 & Pu35-46 & 2 & 16 & $\mathrm{~N} 24$ & $<1.00$ & $<0.100$ & $<0.500$ & 0.215 & 2.63 & 0.83335 & 0.083335 & 0.416675 & 0.3583405 & 4.383421 \\
\hline $\mathrm{ccc}$ & 3 & Pu35-52 & 2 & 17 & $\mathrm{~N} 32$ & $<1.00$ & $<0.100$ & $<0.500$ & $<0.100$ & 2.63 & 0.83335 & 0.083335 & 0.416675 & 0.083335 & 4.383421 \\
\hline $\mathrm{ccc}$ & 3 & Pu35-49 & 2 & 18 & $\mathrm{~N} 43$ & $<1.00$ & $<0.100$ & $<0.500$ & $<0.100$ & 2.72 & 0.83335 & 0.083335 & 0.416675 & 0.083335 & 4.533424 \\
\hline $\mathrm{ccc}$ & 3 & Pu35-40 & 2 & 19 & $\mathrm{~N} 55$ & $<1.00$ & $<0.100$ & $<0.500$ & 0.489 & 2.9 & 0.83335 & 0.083335 & 0.416675 & 0.8150163 & 4.83343 \\
\hline $\mathrm{ccc}$ & 3 & Pu35-37 & 2 & 20 & N16 & $<1.00$ & $<0.100$ & $<0.500$ & 0.507 & 2.83 & 0.83335 & 0.083335 & 0.416675 & 0.8450169 & 4.716761 \\
\hline $\mathrm{ccc}$ & 3 & Pu35-44 & 2 & 21 & $\mathrm{~N} 53$ & $<1.00$ & $<0.100$ & $<0.500$ & 0.94 & 2.3 & 0.83335 & 0.083335 & 0.416675 & 1.566698 & 3.83341 \\
\hline $\mathrm{ccc}$ & 3 & Pu35-47 & 2 & 22 & N65 & $<1.00$ & $<0.100$ & $<0.500$ & 1.75 & 2.47 & 0.83335 & 0.083335 & 0.416675 & 2.916725 & 4.116749 \\
\hline $\mathrm{ccc}$ & 3 & Pu35-38 & 2 & 23 & N06 & $<1.00$ & $<0.100$ & $<0.500$ & 0.463 & 2.68 & 0.83335 & 0.083335 & 0.416675 & 0.7716821 & 4.466756 \\
\hline $\mathrm{ccc}$ & 3 & Pu35-36 & 2 & 24 & N12 & $<1.00$ & $<0.100$ & $<0.500$ & 0.737 & 3.73 & 0.83335 & 0.083335 & 0.416675 & 1.2283579 & 6.216791 \\
\hline $\mathrm{ccc}$ & 3 & Soln Std & 2 & 25 & STD-12-3 & 21 & $<0.100$ & $<0.500$ & 84.1 & 51.4 & 21 & 0.05 & & 84.1 & 51.4 \\
\hline $\mathrm{ccc}$ & 3 & Soln Std & 3 & 1 & STD-13-1 & 20.2 & $<0.100$ & $<0.500$ & 85.3 & 48.8 & 20.2 & 0.05 & & 85.3 & 48.8 \\
\hline $\mathrm{ccc}$ & 3 & Pu35-52 & 3 & 2 & N14 & $<1.00$ & $<0.100$ & $<0.500$ & $<0.100$ & 2.85 & 0.83335 & 0.083335 & 0.416675 & 0.083335 & 4.750095 \\
\hline $\mathrm{ccc}$ & 3 & $\mathrm{Pu} 35-44$ & 3 & 3 & $\mathrm{~N} 38$ & $<1.00$ & $<0.100$ & $<0.500$ & 0.434 & 2.24 & 0.83335 & 0.083335 & 0.416675 & 0.7233478 & 3.733408 \\
\hline $\mathrm{ccc}$ & 3 & Pu35-40 & 3 & 4 & $\mathrm{~N} 44$ & $<1.00$ & $<0.100$ & $<0.500$ & $<0.100$ & 2.41 & 0.83335 & 0.083335 & 0.416675 & 0.083335 & 4.016747 \\
\hline $\mathrm{ccc}$ & 3 & Pu35-51 & 3 & 5 & N10 & $<1.00$ & $<0.100$ & $<0.500$ & $<0.100$ & 2.05 & 0.83335 & 0.083335 & 0.416675 & 0.083335 & 3.416735 \\
\hline
\end{tabular}


Table E1. Laboratory Measurements of the PCT Solutions for the Pu Study Glasses As Reported (ar) and After the Appropriate Adjustments (in parts per million, ppm)

(continued)

\begin{tabular}{|c|c|c|c|c|c|c|c|c|c|c|c|c|c|c|c|}
\hline Heat Treament & Set & Glass ID & Block & Seq & SRNL-ML ID & B ar & Gd ar & Hf ar & Na ar & Si ar & B (ppm) & Gd (ppm) & Hf (ppm) & $\mathrm{Na}$ (ppm) & Si (ppm) \\
\hline $\mathrm{ccc}$ & 3 & EA & 3 & 6 & N62 & 37 & $<0.100$ & $<0.500$ & 100 & 53.4 & 616.6679 & 0.833335 & 4.166675 & 1666.67 & 890.00178 \\
\hline ccc & 3 & Pu35-50 & 3 & 7 & N05 & $<1.00$ & $<0.100$ & $<0.500$ & 0.164 & 3.03 & 0.83335 & 0.083335 & 0.416675 & 0.2733388 & 5.050101 \\
\hline $\mathrm{ccc}$ & 3 & Pu35-55 & 3 & 8 & N59 & $<1.00$ & $<0.100$ & $<0.500$ & $<0.100$ & 2.52 & 0.83335 & 0.083335 & 0.416675 & 0.083335 & 4.200084 \\
\hline $\mathrm{ccc}$ & 3 & ARM-1 & 3 & 9 & N26 & 10.4 & $<0.100$ & $<0.500$ & 21.7 & 35.3 & 17.33368 & 0.083335 & 0.416675 & 36.16739 & 58.83451 \\
\hline ccc & 3 & Pu35-48 & 3 & 10 & N58 & $<1.00$ & $<0.100$ & $<0.500$ & $<0.100$ & 2.22 & 0.83335 & 0.083335 & 0.416675 & 0.083335 & 3.700074 \\
\hline ccc & 3 & Pu35-37 & 3 & 11 & $\mathrm{~N} 25$ & $<1.00$ & $<0.100$ & $<0.500$ & 0.304 & 2.37 & 0.83335 & 0.083335 & 0.416675 & 0.5066768 & 3.950079 \\
\hline ccc & 3 & blank & 3 & 12 & N54 & $<1.00$ & $<0.100$ & $<0.500$ & 1.97 & $<0.100$ & 0.83335 & 0.083335 & 0.416675 & 3.283399 & 0.083335 \\
\hline $\mathrm{ccc}$ & 3 & Soln Std & 3 & 13 & STD-13-2 & 20.4 & $<0.100$ & $<0.500$ & 85.7 & 51.7 & 20.4 & 0.05 & & 85.7 & 51.7 \\
\hline ccc & 3 & Pu35-38 & 3 & 14 & N02 & $<1.00$ & $<0.100$ & $<0.500$ & 0.391 & 2.55 & 0.83335 & 0.083335 & 0.416675 & 0.6516797 & 4.250085 \\
\hline ccc & 3 & Pu35-41 & 3 & 15 & N18 & $<1.00$ & $<0.100$ & $<0.500$ & 0.253 & 2.72 & 0.83335 & 0.083335 & 0.416675 & 0.4216751 & 4.533424 \\
\hline ccc & 3 & Pu35-54 & 3 & 16 & N57 & $<1.00$ & $<0.100$ & $<0.500$ & 0.499 & 3.54 & 0.83335 & 0.083335 & 0.416675 & 0.8316833 & 5.900118 \\
\hline $\mathrm{ccc}$ & 3 & Pu35-53 & 3 & 17 & N09 & $<1.00$ & $<0.100$ & $<0.500$ & $<0.100$ & 3.13 & 0.83335 & 0.083335 & 0.416675 & 0.083335 & 5.216771 \\
\hline ccc & 3 & Pu35-42 & 3 & 18 & N68 & $<1.00$ & $<0.100$ & $<0.500$ & 2.8 & 3.59 & 0.83335 & 0.083335 & 0.416675 & 4.66676 & 5.983453 \\
\hline ccc & 3 & Pu35-36 & 3 & 19 & $\mathrm{~N} 42$ & $<1.00$ & $<0.100$ & $<0.500$ & 1.59 & 3.24 & 0.83335 & 0.083335 & 0.416675 & 2.650053 & 5.400108 \\
\hline ccc & 3 & Pu35-39 & 3 & 20 & N36 & $<1.00$ & $<0.100$ & $<0.500$ & $<0.100$ & 2.78 & 0.83335 & 0.083335 & 0.416675 & 0.083335 & 4.633426 \\
\hline $\mathrm{ccc}$ & 3 & Pu35-46 & 3 & 21 & $\mathrm{~N} 28$ & $<1.00$ & $<0.100$ & $<0.500$ & $<0.100$ & 2.71 & 0.83335 & 0.083335 & 0.416675 & 0.083335 & 4.516757 \\
\hline ccc & 3 & Pu35-49 & 3 & 22 & N17 & $<1.00$ & $<0.100$ & $<0.500$ & $<0.100$ & 2.47 & 0.83335 & 0.083335 & 0.416675 & 0.083335 & 4.116749 \\
\hline ccc & 3 & Pu35-47 & 3 & 23 & N66 & $<1.00$ & $<0.100$ & $<0.500$ & $<0.100$ & 2.04 & 0.83335 & 0.083335 & 0.416675 & 0.083335 & 3.400068 \\
\hline $\mathrm{ccc}$ & 3 & Pu35-43 & 3 & 24 & N11 & 1.49 & $<0.100$ & $<0.500$ & 10.2 & 1.86 & 2.483383 & 0.083335 & 0.416675 & 17.00034 & 3.100062 \\
\hline $\mathrm{ccc}$ & 3 & Pu35-45 & 3 & 25 & N19 & $<1.00$ & $<0.100$ & $<0.500$ & $<0.100$ & 1.5 & 0.83335 & 0.083335 & 0.416675 & 0.083335 & 2.50005 \\
\hline ccc & 3 & Soln Std & 3 & 26 & STD-13-3 & 20.1 & $<0.100$ & $<0.500$ & 87.4 & 50.8 & 20.1 & 0.05 & & 87.4 & 50.8 \\
\hline
\end{tabular}




\section{Exhibit E1. Laboratory PCT Measurements in Analytical Sequence for Quenched Study Glasses with and without EA, ARM, Blanks, and Solution Standards}

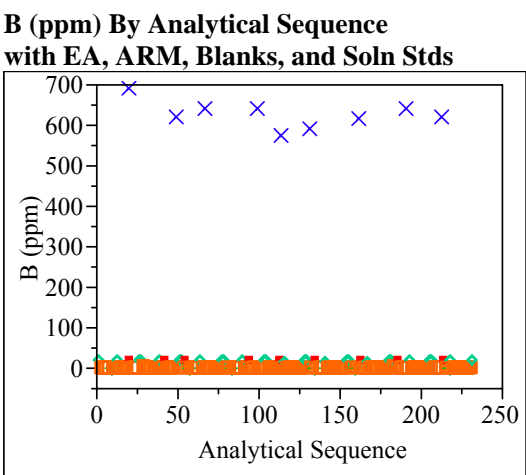

Gd (ppm) By Analytical Sequence with EA, ARM, Blanks, and Soln Stds

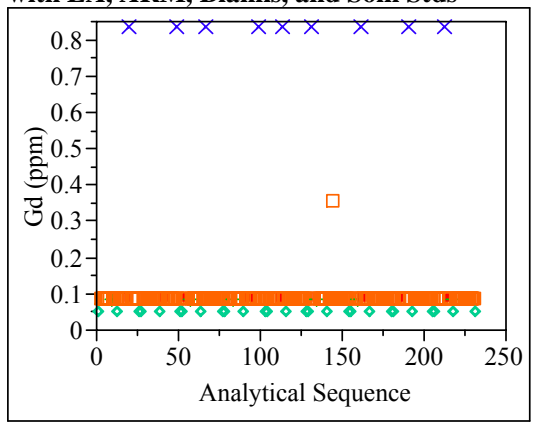

Hf (ppm) By Analytical Sequence with EA, ARM, Blanks, and Soln Stds

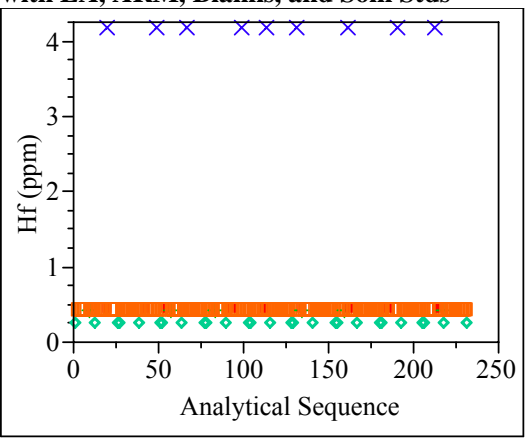

Na (ppm) By Analytical Sequence with EA, ARM, Blanks, and Soln Stds

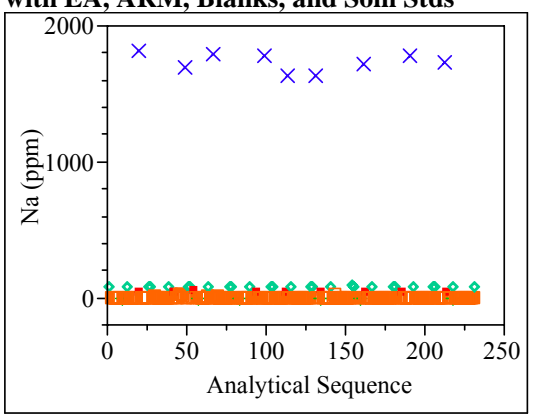

Si (ppm) By Analytical Sequence with Others with EA, ARM, Blanks, and Soln Stds

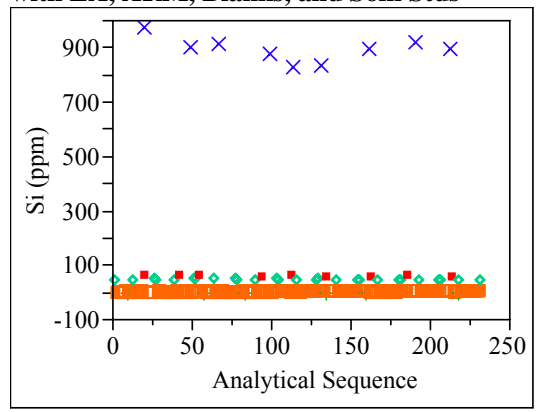

B (ppm) By Analytical Sequence without EA, ARM, Blanks, and Soln Stds

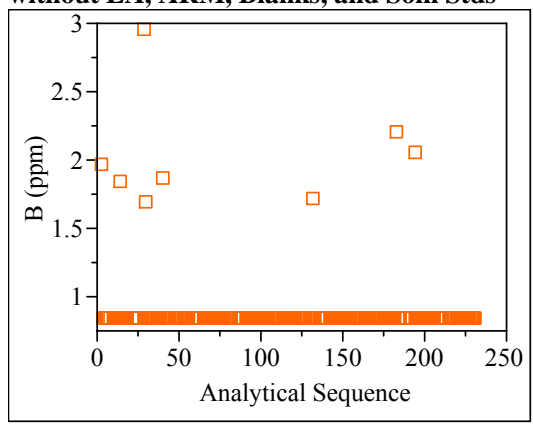

Gd (ppm) By Analytical Sequence without EA, ARM, Blanks, and Soln Stds

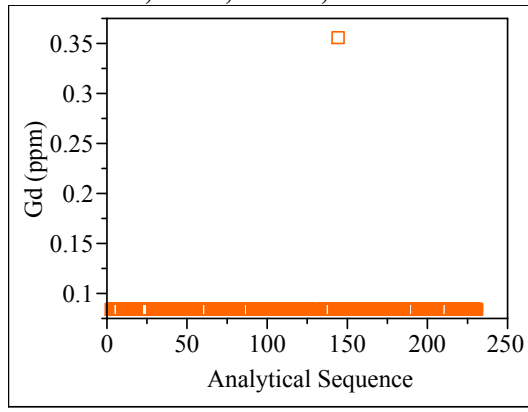

Hf (ppm) By Analytical Sequence without EA, ARM, Blanks, and Soln Stds

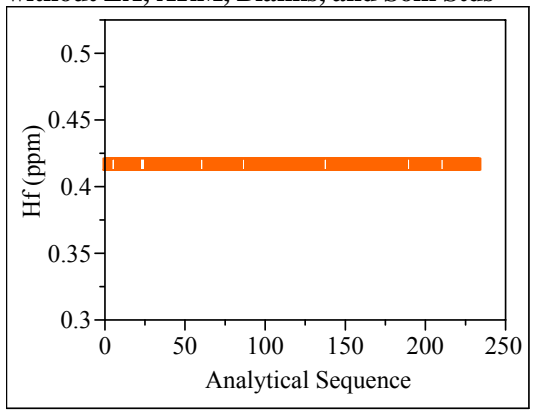

Na (ppm) By Analytical Sequence without EA, ARM, Blanks, and Soln Stds

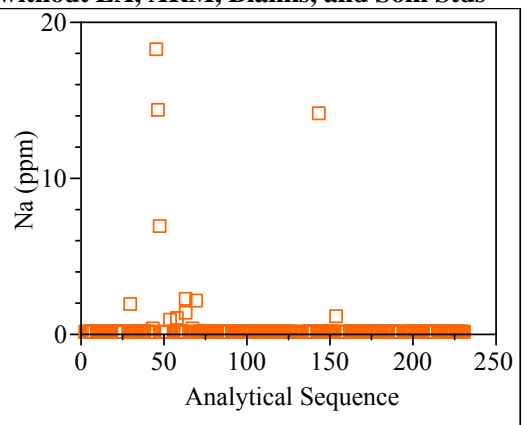

Si (ppm) By Analytical Sequence without EA, ARM, Blanks, and Soln Stds

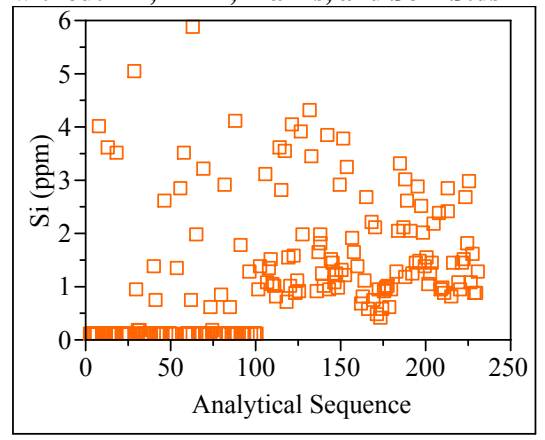




\section{Exhibit E2. Laboratory PCT Measurements in Analytical Sequence for CCC Study Glasses with and without EA, ARM, Blanks, and Solution Standards}

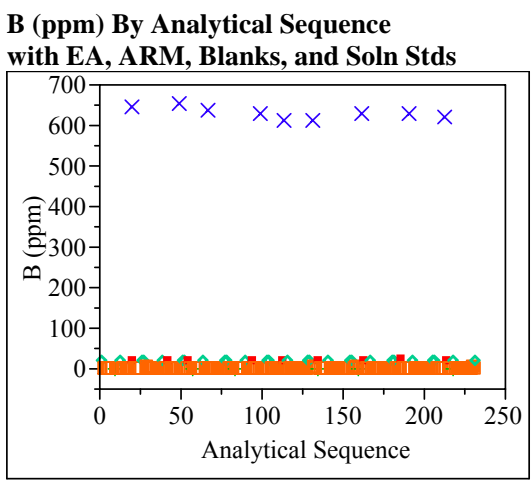

Gd (ppm) By Analytical Sequence with EA, ARM, Blanks, and Soln Stds

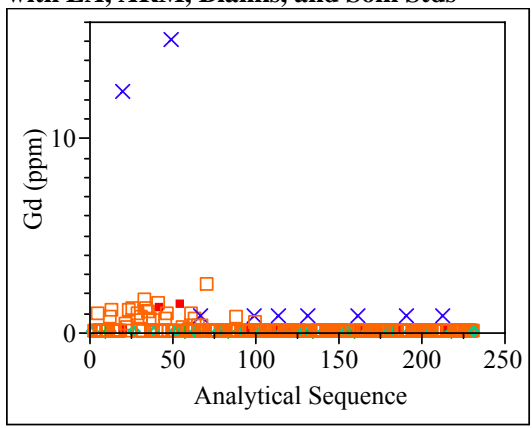

Hf (ppm) By Analytical Sequence with EA, ARM, Blanks, and Soln Stds

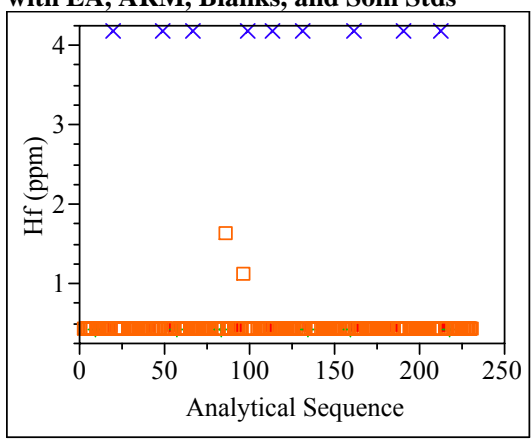

Na (ppm) By Analytical Sequence with EA, ARM, Blanks, and Soln Stds

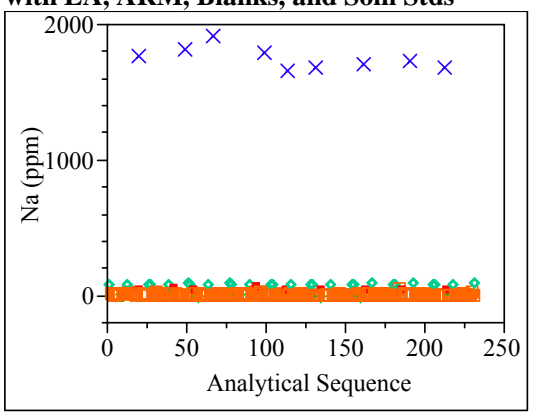

Si (ppm) By Analytical Sequence with EA, ARM, Blanks, and Soln Stds

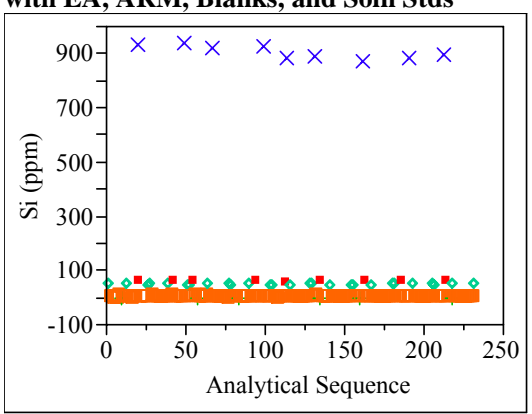

B (ppm) By Analytical Sequence without EA, ARM, Blanks, and Soln Stds

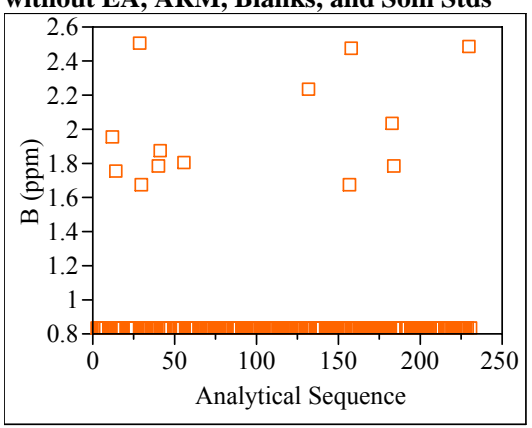

Gd (ppm) By Analytical Sequence without EA, ARM, Blanks, and Soln Stds

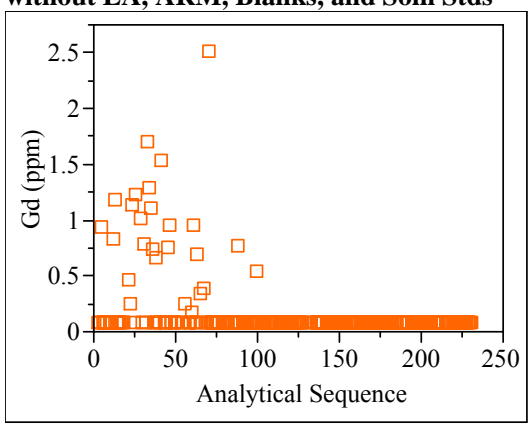

Hf (ppm) By Analytical Sequence without EA, ARM, Blanks, and Soln Stds

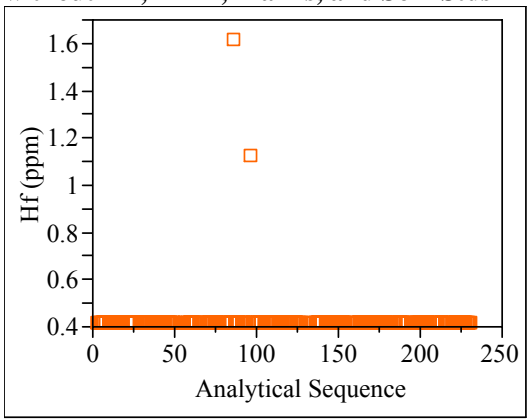

Na (ppm) By Analytical Sequence without EA, ARM, Blanks, and Soln Stds

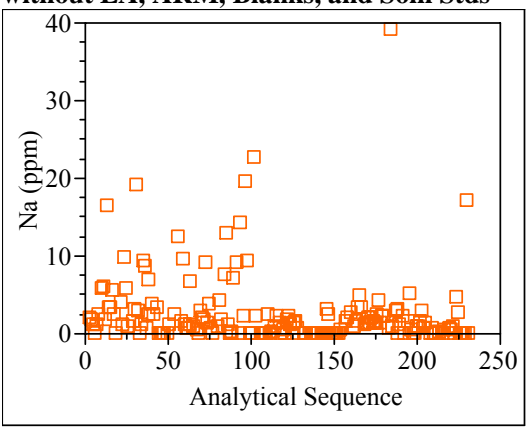

Si (ppm) By Analytical Sequence without EA, ARM, Blanks, and Soln Stds

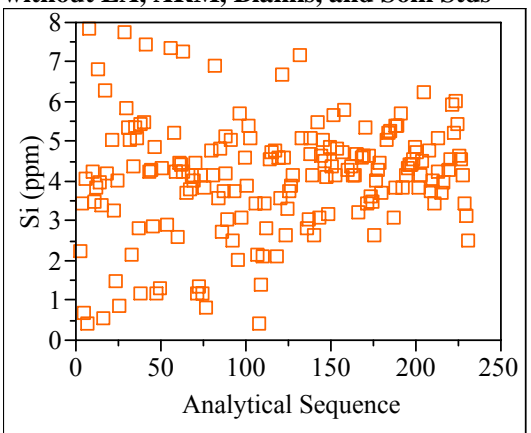




\section{Exhibit E3. Measurements of the Multi-Element Solution Standard by PCT Set} and ICP-AES Calibration Block for Quenched Glass Plans

(Note Gd and Hf are not in this Standard)

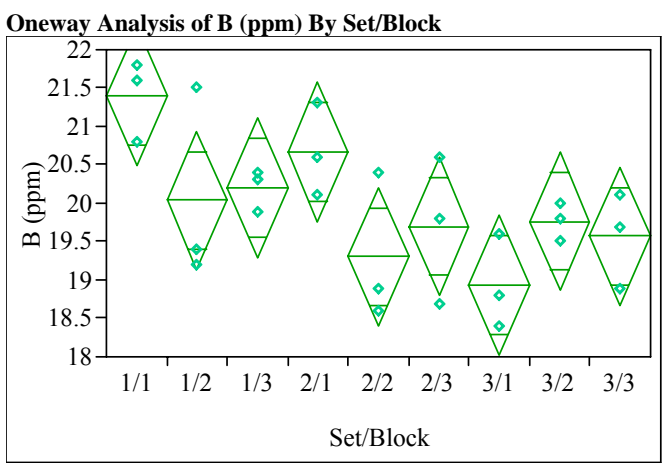

\section{Oneway Anova}

\section{Summary of Fit}

Rsquare

0.568766
0.377106

Root Mean Square Error $\quad 0.744362$

Mean of Response 19.95185

Observations (or Sum Wgts)

Analysis of Variance

Source DF Sum of Squares Mean Square F Ratio Prob $>$ F $\begin{array}{lrrrrr}\text { Set/Block } & 8 & 13.154074 & 1.64426 & 2.9676 & 0.0263\end{array}$

$\begin{array}{lrrr}\text { Error } & 18 & 9.973333 & 0.55407 \\ \text { C. Total } & 26 & 23.127407 & \end{array}$

Means for Oneway Anova

Level Number Mean Std Error Lower 95\% Upper 95\%

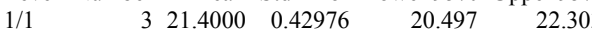

$\begin{array}{llllll}1 / 2 & 3 & 20.0333 & 0.42976 & 19.130 & 20.936 \\ 1 / 3 & 3 & 20.2000 & 0.42976 & 19.297 & 21.103\end{array}$

$\begin{array}{llllll}2 / 1 & 3 & 20.6667 & 0.42976 & 19.764 & 21.570\end{array}$

$\begin{array}{llllll}2 / 2 & 3 & 19.3000 & 0.42976 & 18.397 & 20.203\end{array}$

$\begin{array}{llllll}3 & 19.7000 & 0.42976 & 18.797 & 20.603 \\ 3 / 1 & 3 & 18.9333 & 0.42976 & 18.030 & 19.836\end{array}$

$\begin{array}{llllll}3 / 2 & 3 & 19.7667 & 0.42976 & 18.864 & 20.670\end{array}$

Std Error uses a pooled estimate of error variance

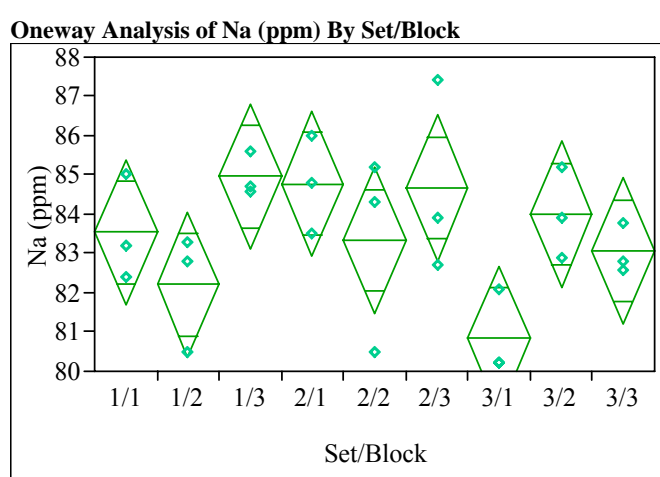

Oneway Anova

Summary of Fit

$\begin{array}{lr}\text { Rsquare } & 0.506698 \\ \text { Adj Rsquare } & 0.287453 \\ \text { Root Mean Square Error } & 1.527646 \\ \text { Mean of Response } & 83.48519 \\ \text { Observations (or Sum Wgts) } & 27\end{array}$

Observations (or Sum Wgts) 83.48519

Analysis of Variance

Source DF Sum of Squares Mean Square F Ratio Prob > F

$\begin{array}{lrrrrr}\text { Set/Block } & 8 & 43.147407 & 5.39343 & 2.3111 & 0.0667\end{array}$

Error $\quad 18 \quad 42.006667$

$\begin{array}{lll}5.39343 & 2.3111 & 0.0667 \\ 2.33370 & & \end{array}$

Means for Oneway Anova

Level Number Std Error Lower 95\% Upper 95\%

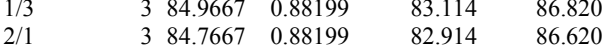

$\begin{array}{llllll}1 / 3 & 3 & 84.9667 & 0.88199 & 83.114 & 86.820 \\ 2 / 2 & 3 & 83.3637 & 0.88199 & 82.914 & 86.620 \\ 2 & 3 & 84.6667 & 0.8199 & 81.480 & 85.186\end{array}$

$\begin{array}{llllll}2 / 2 & 3 & 83.3333 & 0.88199 & 81.480 & 85.186 \\ 2 / 3 & 3 & 84.6667 & 0.88199 & 82.814 & 86.520\end{array}$

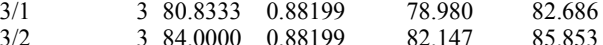

$\begin{array}{llllll}3 / 2 & 3 & 84.0000 & 0.88199 & 82.147 & 85.853 \\ 3 / 3 & 3 & 83.0667 & 0.88199 & 81.214 & 84.920\end{array}$

Std Error uses a pooled estimate of error variance
C. Total $26 \quad 85.154074$

$\begin{array}{llrrrr}1 / 1 & 3 & 83.5333 & 0.88199 & 81.680 & 85.386 \\ 1 / 2 & 3 & 82.2000 & 0.88199 & 80.347 & 84.053\end{array}$

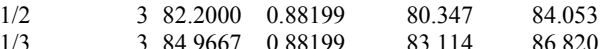

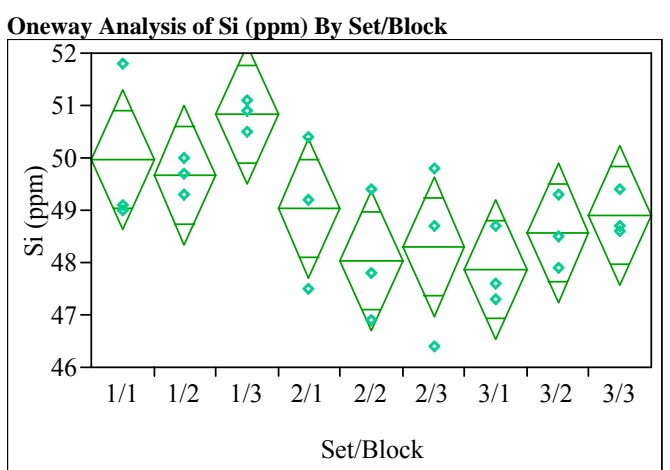

Oneway Anova

Summary of Fit

Rsquare

Adj Rsquare $\quad 0.517224$

Root Mean Square Error $\quad 0.302656$

Mean of Response $\quad 4901852$

$\begin{array}{lr}\text { Mean of Response } & 49.01852 \\ \text { Observations (or Sum Wgts) } & 27\end{array}$

Analysis of Variance

Source DF Sum of Squares Mean Square F Ratio Prob $>$ F $\begin{array}{lrrrrr}\text { Set/Block } & 8 & 22.934074 & 2.86676 & 2.4105 & 0.0577\end{array}$ $\begin{array}{llll}\text { Error } & 18 & 21.406667 & 1.18926\end{array}$

44.340741

Level Number Mean Std Error Lower 95\% Upper 95\%

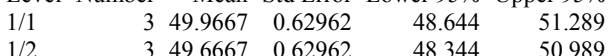

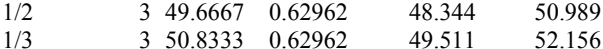

$\begin{array}{llllll}2 / 1 & 3 & 49.0333 & 0.62962 & 47.711 & 50.356\end{array}$

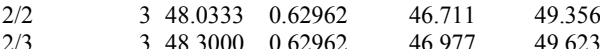

$\begin{array}{llllll}2 / 3 & 3 & 48.3000 & 0.62962 & 46.977 & 49.623 \\ 3 / 1 & 3 & 47.8667 & 0.62962 & 46.544 & 49.189\end{array}$

$\begin{array}{llllll}3 / 1 & 3 & 47.8667 & 0.62962 & 46.544 & 49.189 \\ 3 / 2 & 3 & 48.5667 & 0.62962 & 47.244 & 49.889\end{array}$

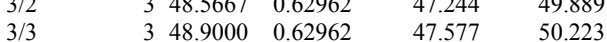

Std Error uses a pooled estimate of error variance 


\section{Exhibit E4. Measurements of the Multi-Element Solution Standard by PCT Set} and ICP-AES Calibration Block for CCC Glass Plans

(Note Gd and Hf are not in this Standard)

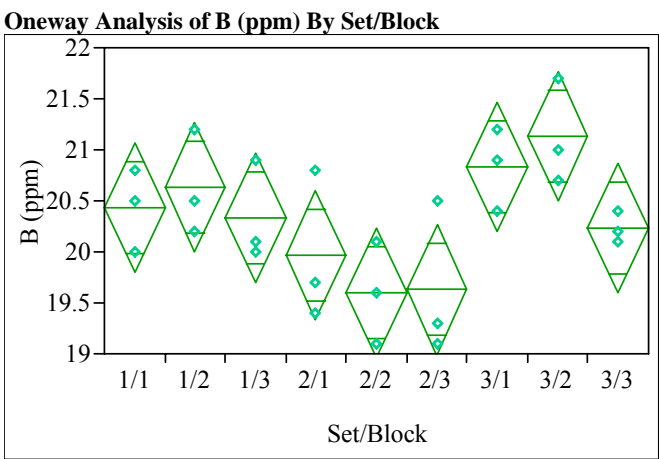

Oneway Anova
Summary of Fit

$\begin{array}{lr}\text { Rsquare } & 0.565521 \\ \text { Adj Rsquare } & 0.37242 \\ \text { Root Mean Square Error } & 0.525639 \\ \text { Mean of Response } & 20.31111 \\ \text { Observations (or Sum Wgts) } & 27\end{array}$

Observations (or Sum Wgts) 20.3111

\section{Analysis of Variance}

Source DF Sum of Squares Mean Square F Ratio Prob $>$ F $\begin{array}{lrllll}\text { Set/Block } & 8 & 6.473333 & 0.809167 & 2.9286 & 0.0278\end{array}$ $\begin{array}{lrr}\text { Error } & 18 & 4.973333 \\ \text { C. Total } & 26 & 11.446667\end{array}$

\section{Means for Oneway Anova}

Level Number Mean Std Error Lower 95\% Upper 95\% $\begin{array}{lllllr}1 / 1 & 3 & 20.4333 & 0.30348 & 19.796 & 21.071\end{array}$

$\begin{array}{llllll}1 / 2 & 3 & 20.6333 & 0.30348 & 19.996 & 21.271\end{array}$

$\begin{array}{llllll}1 / 3 & 3 & 20.3333 & 0.30348 & 19.696 & 20.971 \\ 2 / 1 & 3 & 19.9667 & 0.30348 & 19.329 & 20.604\end{array}$

$\begin{array}{llllll}1 / 3 & 3 & 19.9667 & 0.30348 & 19.329 & 20.604 \\ 2 / 2 & 3 & 19.6000 & 0.30348 & 18.962 & 20.238\end{array}$

$\begin{array}{llllll}2 / 3 & 3 & 19.6333 & 0.30348 & 18.996 & 20.271\end{array}$

$\begin{array}{llllll}3 / 1 & 3 & 20.8333 & 0.30348 & 20.196 & 21.471 \\ 3 / 2 & 3 & 21.1333 & 0.30348 & 20.496 & 21.771\end{array}$

$\begin{array}{llllll}3 / 3 & 3 & 20.2333 & 0.30348 & 19.596 & 20.871\end{array}$

Std Error uses a pooled estimate of error variance

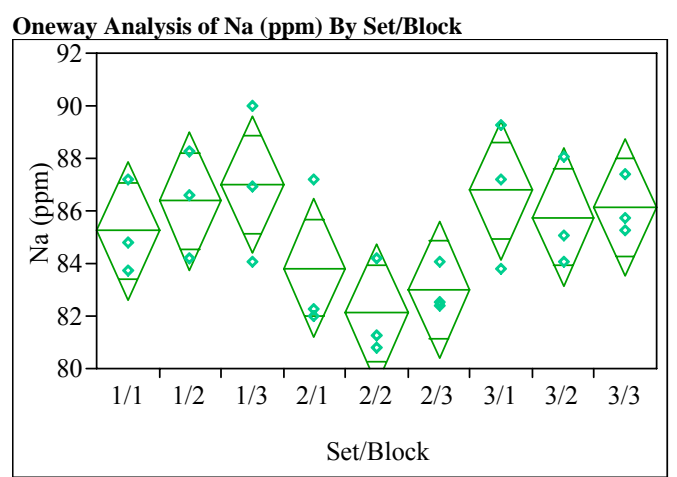

Oneway Anova

\section{Summary of Fi}

Rsquare

Adj Rsquare

Root Mean Square

Mean of Respons

0.227972

Observatios (or Sin wgts)

85.13333

Analysis of Variance

Source DF Sum of Squares Mean Square F Ratio Prob $>$ F $\begin{array}{lrrrrr}\text { Set/Block } & 8 & 73.58000 & 9.19750 & 1.9597 & 0.1124\end{array}$

C. Total $26 \quad 158.06000$

Means for Oneway Anova

Level Number Mean Std Error Lower 95\% Upper 95\%

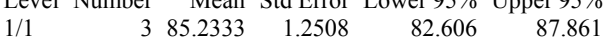

$\begin{array}{llllll}2 / 1 & 3 & 83.8333 & 1.2508 & 81.206 & 86.461 \\ 2 / 2 & 3 & 82.1000 & 1.2508 & 79.472 & 84.728\end{array}$

$\begin{array}{llllll}2 / 3 & 3 & 83.0000 & 1.2508 & 80.372 & 85.628 \\ 3 / 1 & 3 & 86.7667 & 1.2508 & 84.139 & 89.394\end{array}$

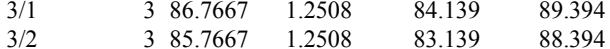

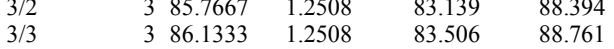

Std Error uses a pooled estimate of error variance $\begin{array}{lrrr}\text { Error } & 18 & 84.48000 & 4.69333\end{array}$

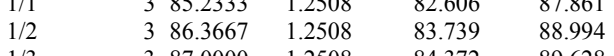

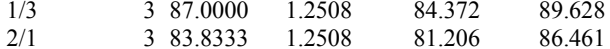

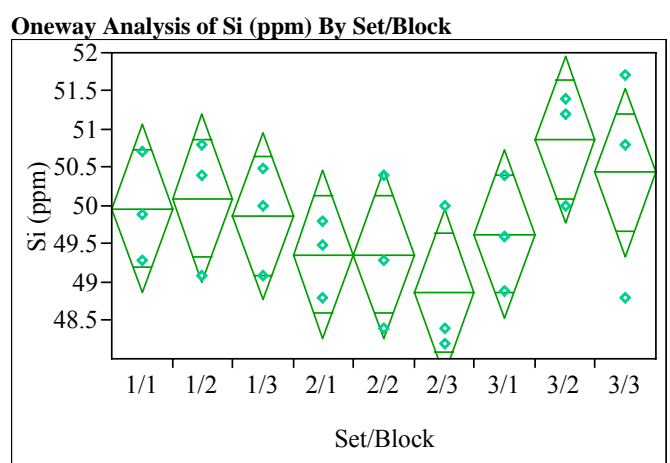

Oneway Anova

Summary of Fit

Adj Rsquare $\quad 0.09503$

Root Mean Square Error $\quad 0.90472$

Mean of Response 49.82963

Observations (or Sum Wgts)

Analysis of Variance

Source DF Sum of Squares Mean Square F Ratio Prob $>$ F

$\begin{array}{llllll}\text { Set/Block } & 8 & 8.782963 & 1.09787 & 1.3413 & 0.2861\end{array}$

$\begin{array}{llll}\text { Error } & 18 & 14.733333 & 0.81852\end{array}$

C. Total $26 \quad 23.516296$

Means for Oneway Anova
Level Number Mean Std Error Lower 95\% Upper 95\%

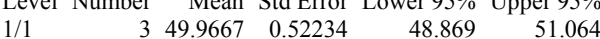

$\begin{array}{llllll}1 / 2 & 3 & 50.1000 & 0.52234 & 49.003 & 51.197\end{array}$

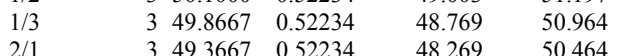

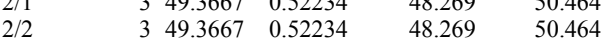

$\begin{array}{llllll}2 / 3 & 3 & 48.8667 & 0.52234 & 47.769 & 49.964\end{array}$

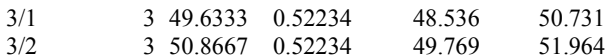

$\begin{array}{llllll}3 / 3 & 3 & 50.4333 & 0.52234 & 49.336 & 51.531\end{array}$

Std Error uses a pooled estimate of error variance 
WSRC-STI-2007-00477

Revision 0

Appendix E

\section{Exhibit E5. Laboratory PCT Measurements by Pu Glass ID for both Quenched and CCC Versions}

Glass ID=Pu04-01

Variability Chart for Concentration (ppm)

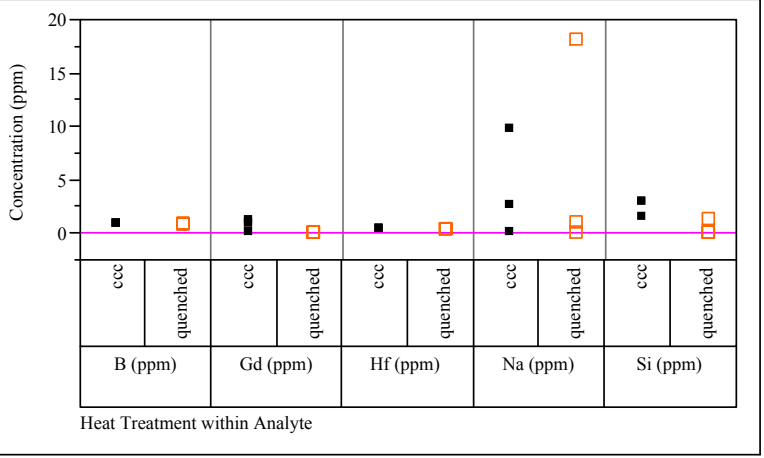

Glass ID=Pu04-02

Variability Chart for Concentration (ppm)

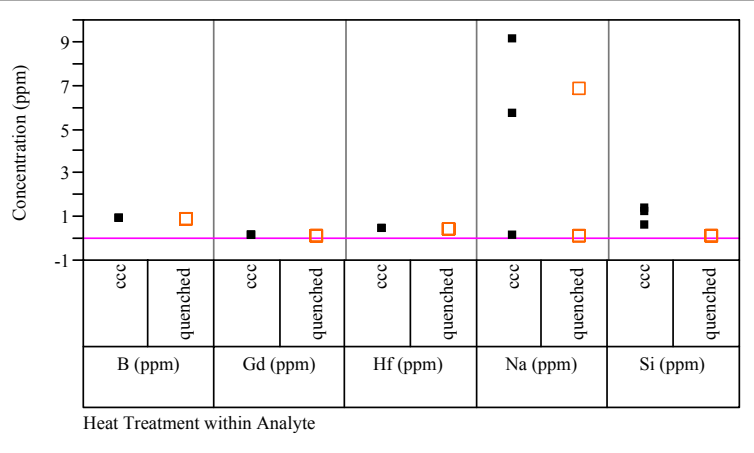

Glass ID=Pu04-03

Variability Chart for Concentration (ppm)

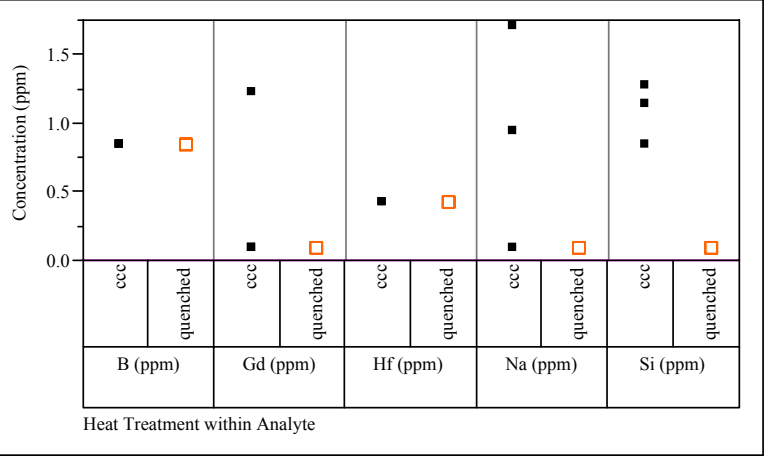

Glass ID=Pu04-04

Variability Chart for Concentration (ppm)

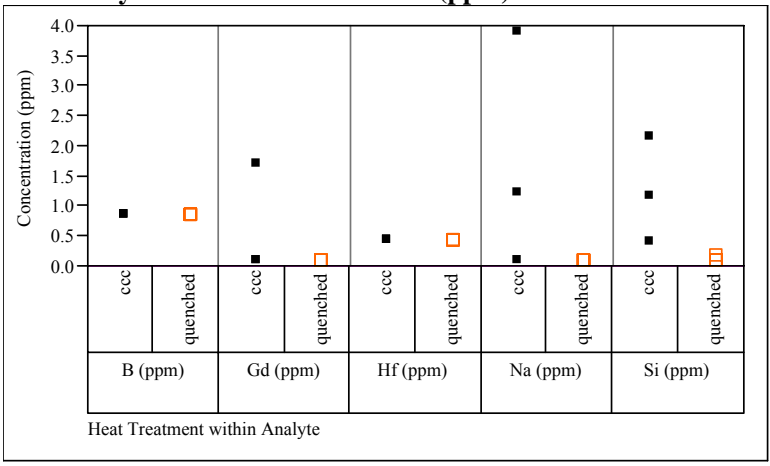

Glass ID=Pu04-05

Variability Chart for Concentration (ppm)

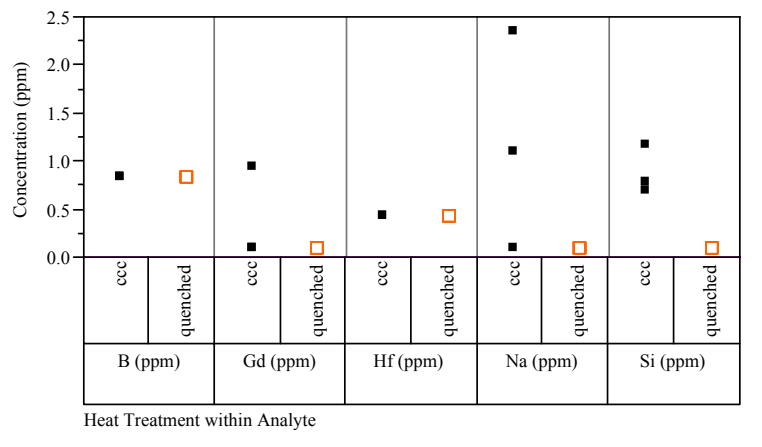

Glass ID=Pu35-01

Variability Chart for Concentration (ppm)

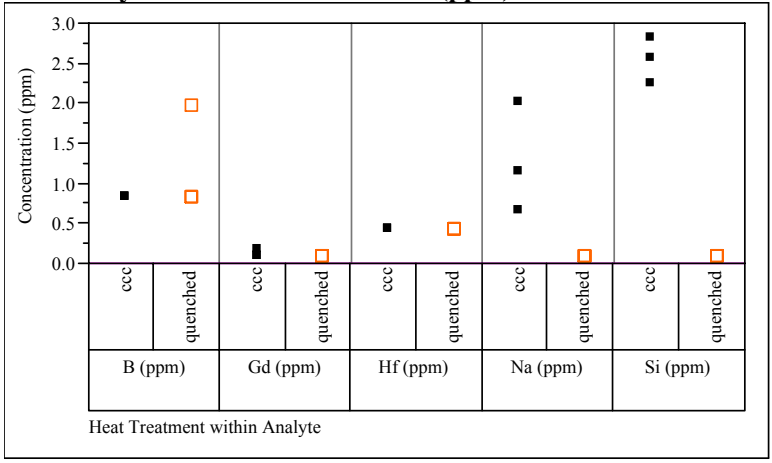




\section{Exhibit E5. Laboratory PCT Measurements by Pu Glass ID for both Quenched and CCC Versions (continued)}

Glass ID=Pu35-02

Variability Chart for Concentration (ppm)

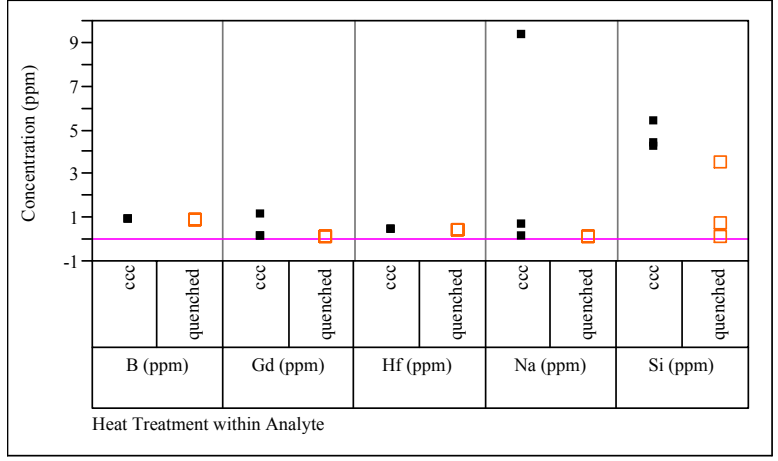

Glass ID=Pu35-03

Variability Chart for Concentration (ppm)

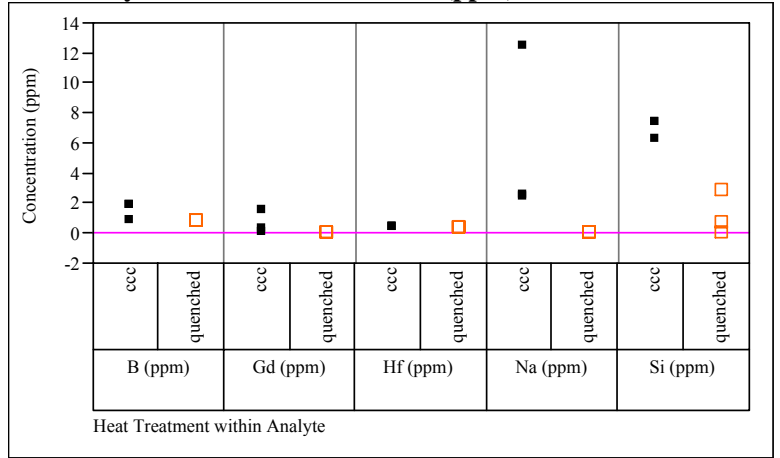

Glass ID=Pu35-04

Variability Chart for Concentration (ppm)

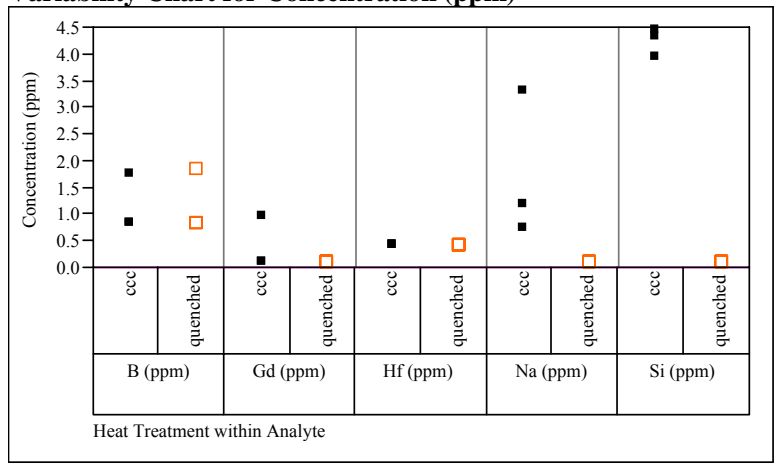

Glass ID=Pu35-05

Variability Chart for Concentration (ppm)

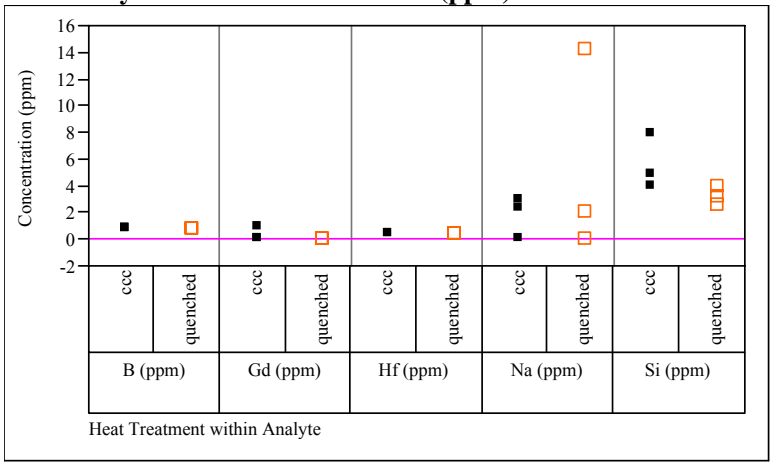

Glass ID=Pu35-06

Variability Chart for Concentration (ppm)

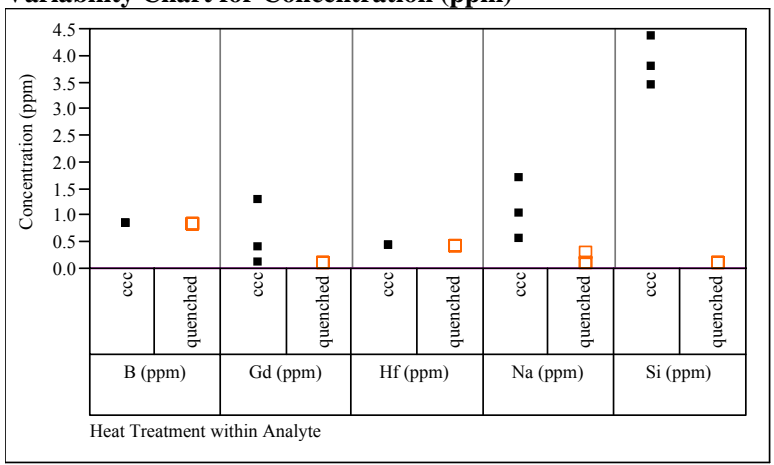

Glass ID=Pu35-07

Variability Chart for Concentration (ppm)

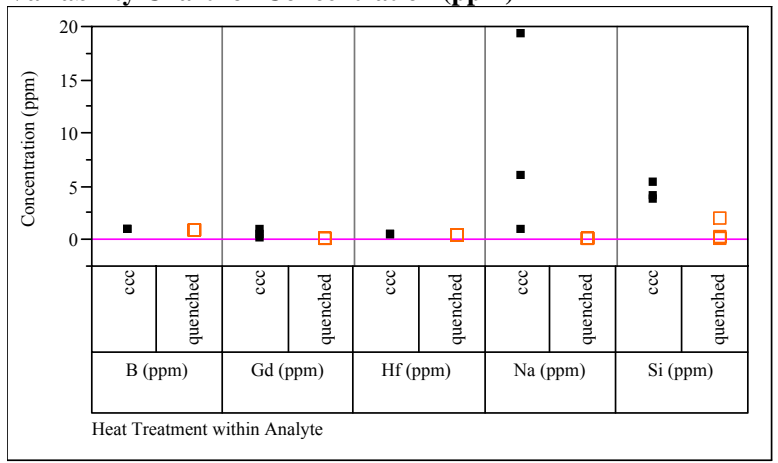


Exhibit E5. Laboratory PCT Measurements by Pu Glass ID for both Quenched and CCC Versions (continued)

Glass ID=Pu35-08

Variability Chart for Concentration (ppm)

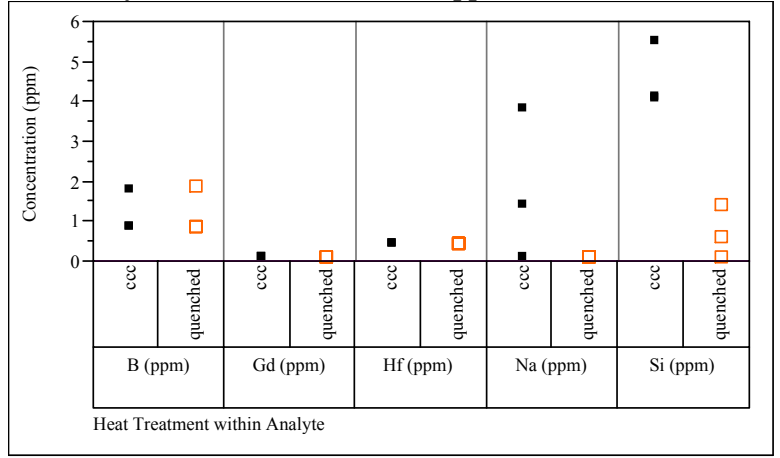

Glass ID=Pu35-09

Variability Chart for Concentration (ppm)

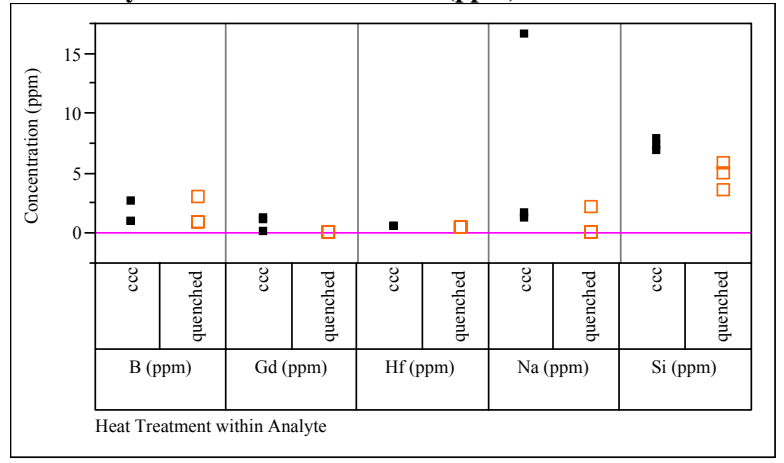

Glass ID=Pu35-10

Variability Chart for Concentration (ppm)

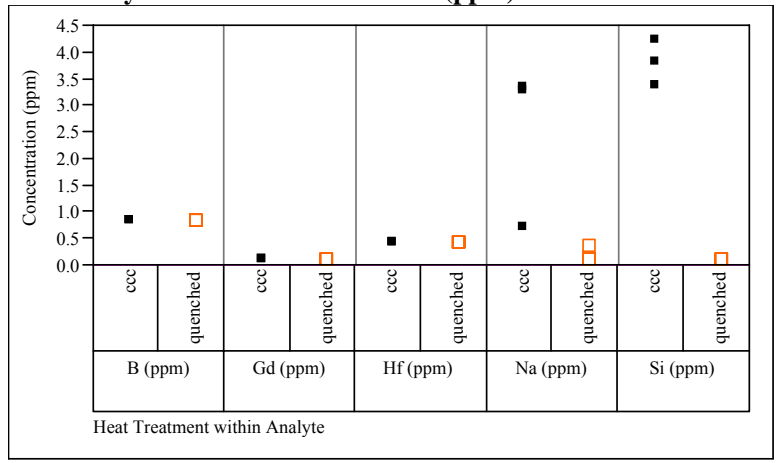

Glass ID=Pu35-11

Variability Chart for Concentration (ppm)

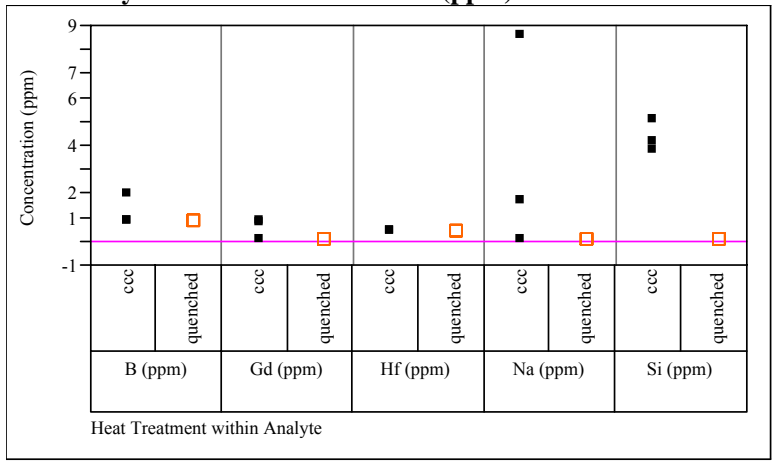

Glass ID=Pu35-12

Variability Chart for Concentration (ppm)

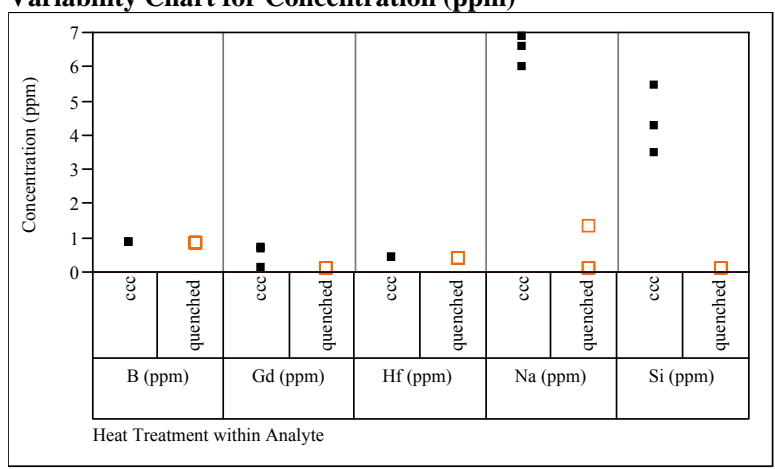

Glass ID=Pu35-13

Variability Chart for Concentration (ppm)

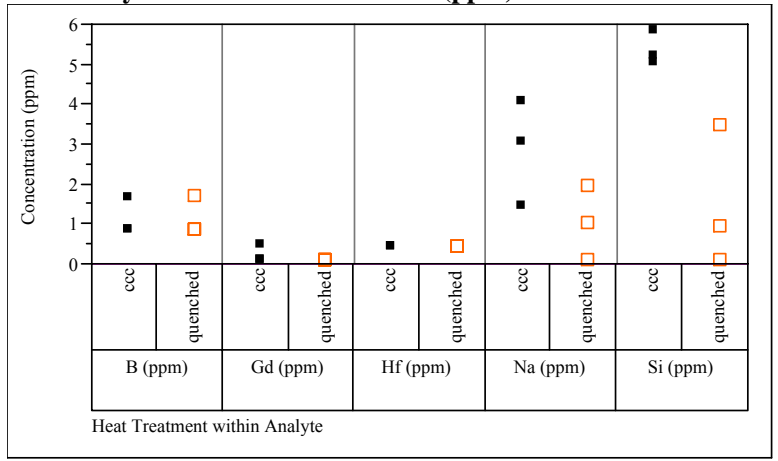




\section{Exhibit E5. Laboratory PCT Measurements by Pu Glass ID for both Quenched and CCC Versions (continued)}

Glass ID=Pu35-14

Variability Chart for Concentration (ppm)

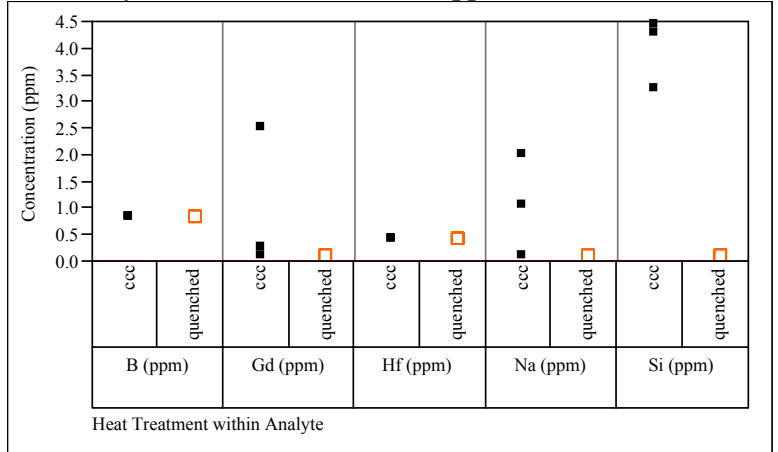

Glass ID=Pu35-15

Variability Chart for Concentration (ppm)

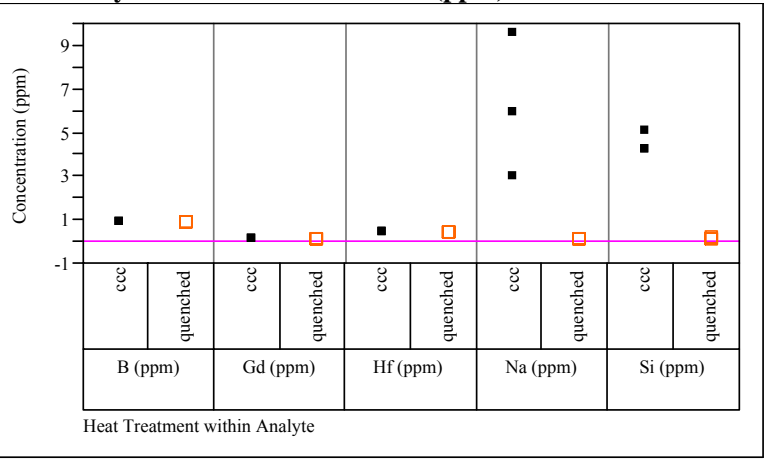

Glass ID=Pu35-16

Variability Chart for Concentration (ppm)

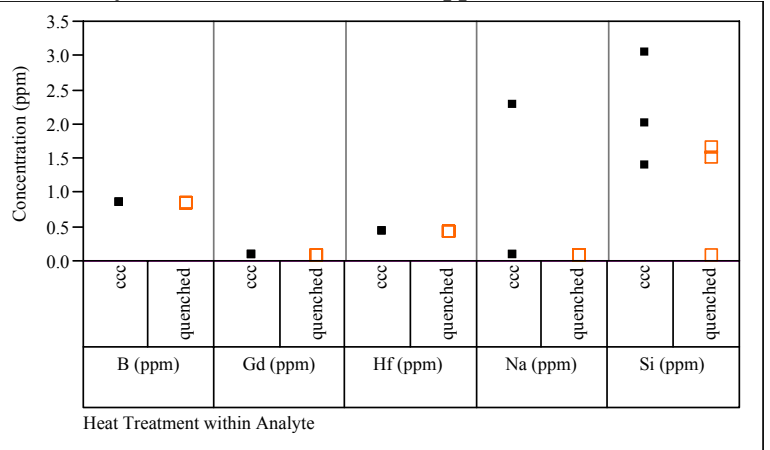

Glass ID=Pu35-17

Variability Chart for Concentration (ppm)

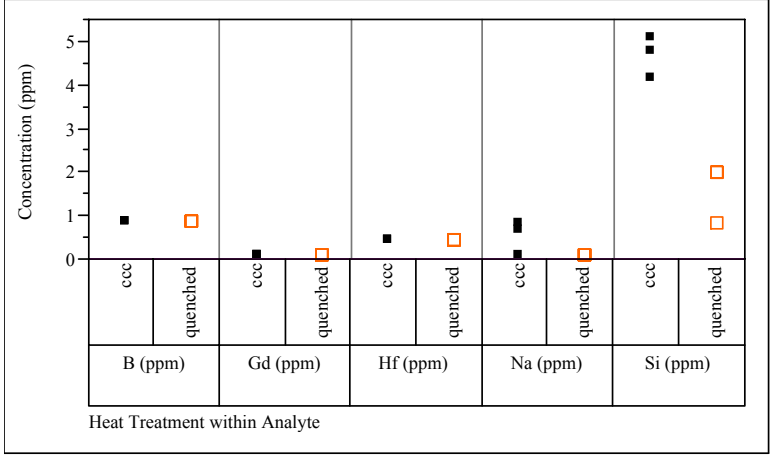

Glass ID=Pu35-18

Variability Chart for Concentration (ppm)

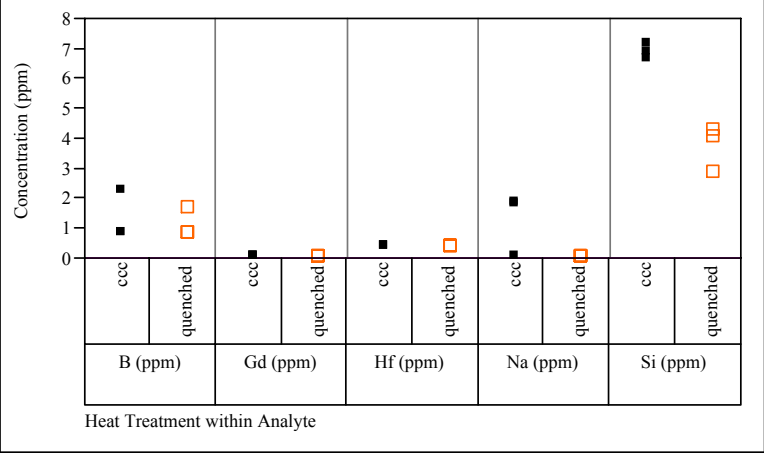

Glass ID=Pu35-19

Variability Chart for Concentration (ppm)

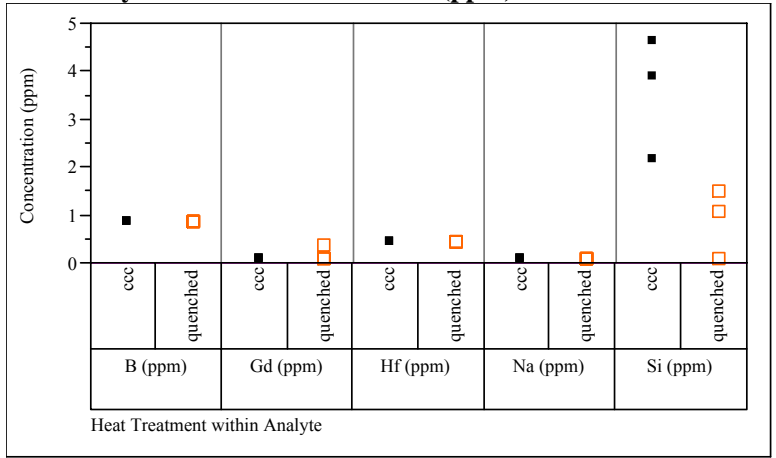




\section{Exhibit E5. Laboratory PCT Measurements by Pu Glass ID for both Quenched and CCC Versions (continued)}

Glass ID=Pu35-20

Variability Chart for Concentration (ppm)

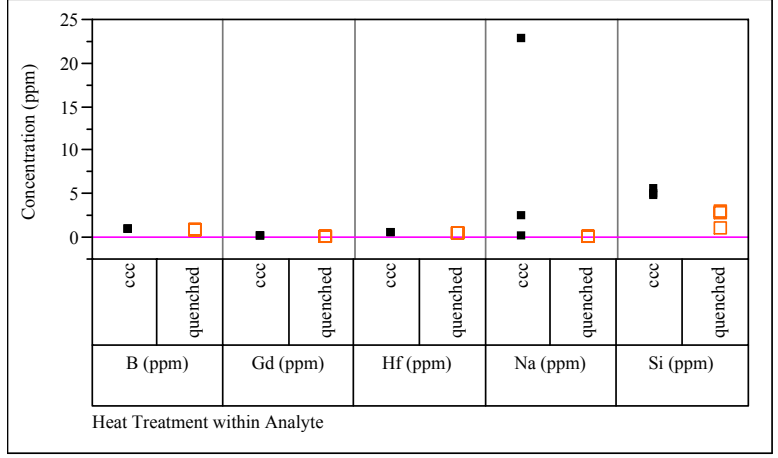

Glass ID=Pu35-21

Variability Chart for Concentration (ppm)

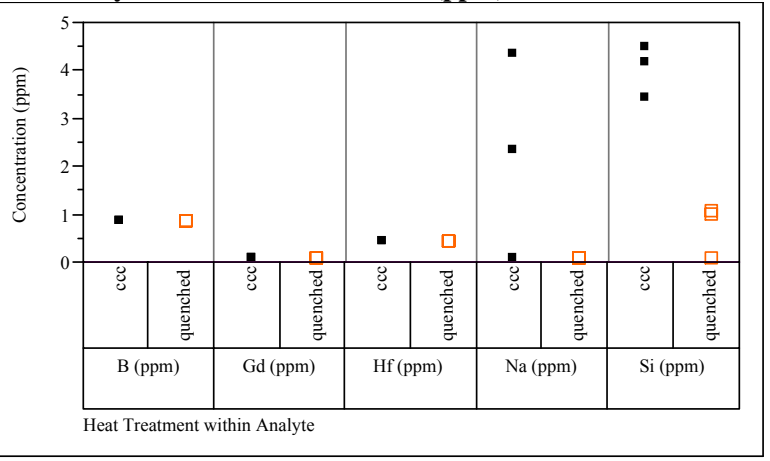

Glass ID=Pu35-22

Variability Chart for Concentration (ppm)

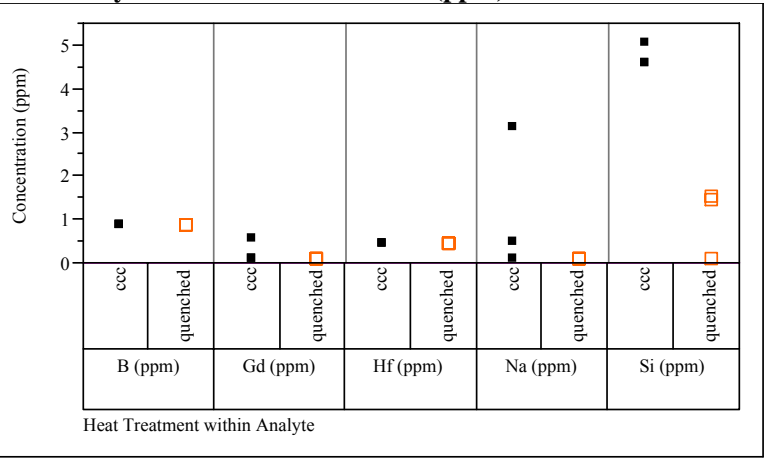

Glass ID=Pu35-23

Variability Chart for Concentration (ppm)

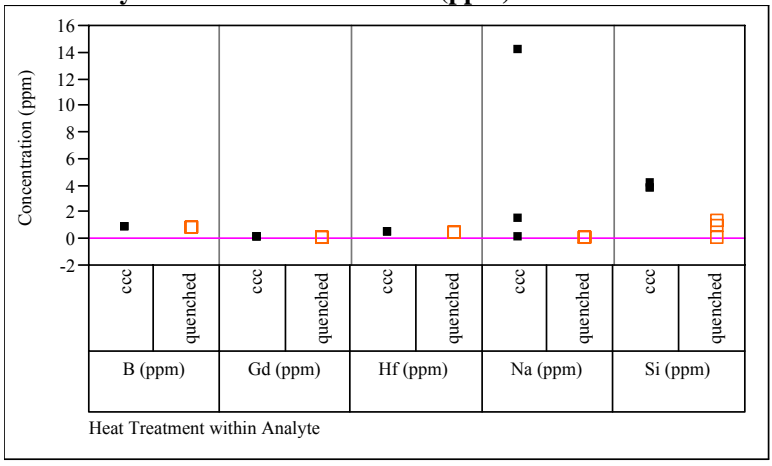

Glass ID=Pu35-24

Variability Chart for Concentration (ppm)

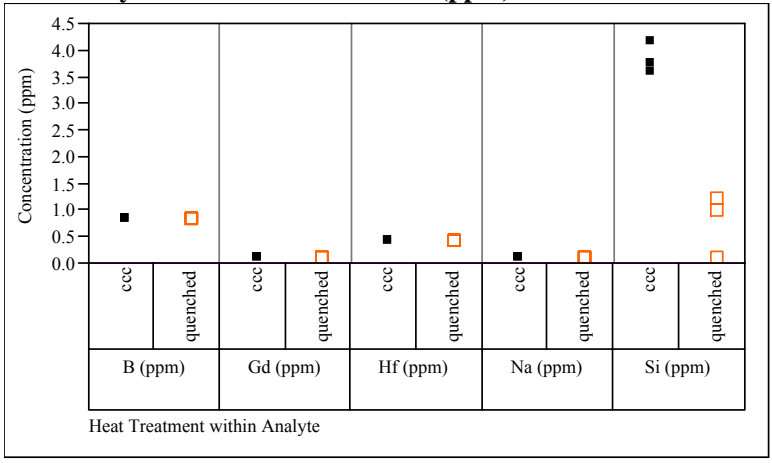

Glass ID=Pu35-25

Variability Chart for Concentration (ppm)

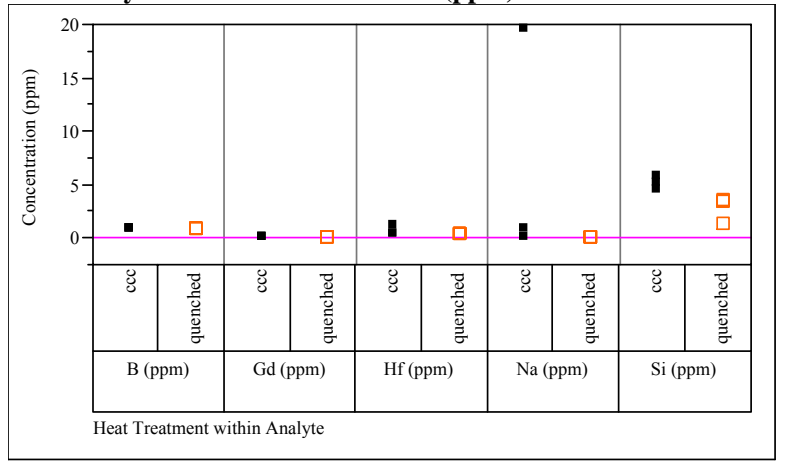




\section{Exhibit E5. Laboratory PCT Measurements by Pu Glass ID for both Quenched and CCC Versions (continued)}

Glass ID=Pu35-26

Variability Chart for Concentration (ppm)

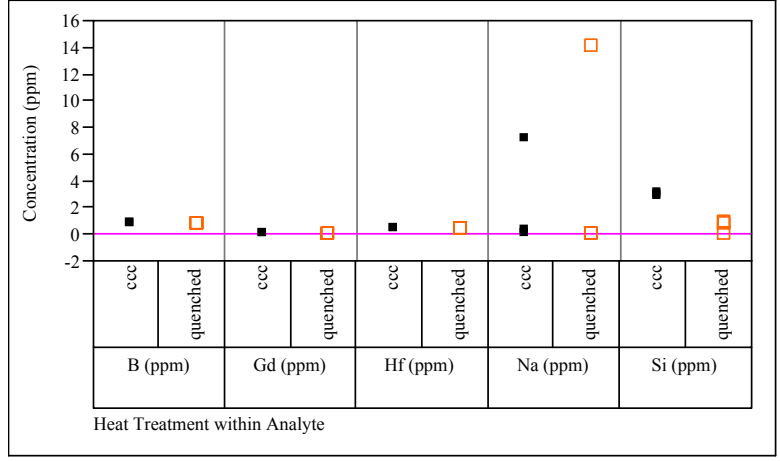

Glass ID=Pu35-27

Variability Chart for Concentration (ppm)

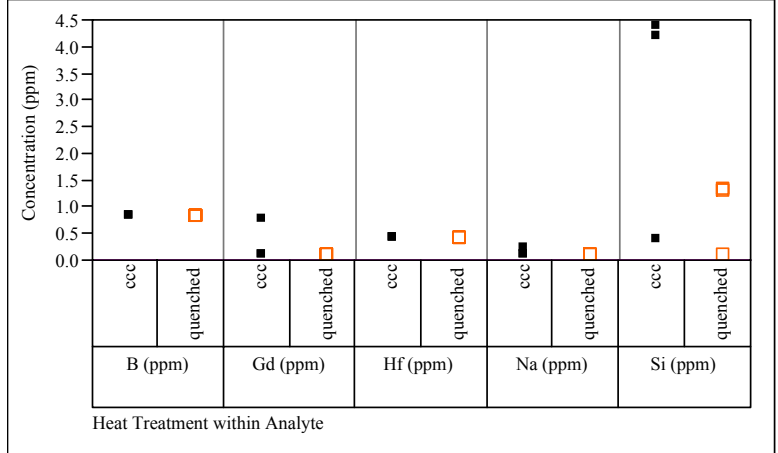

Glass ID=Pu35-28

Variability Chart for Concentration (ppm)

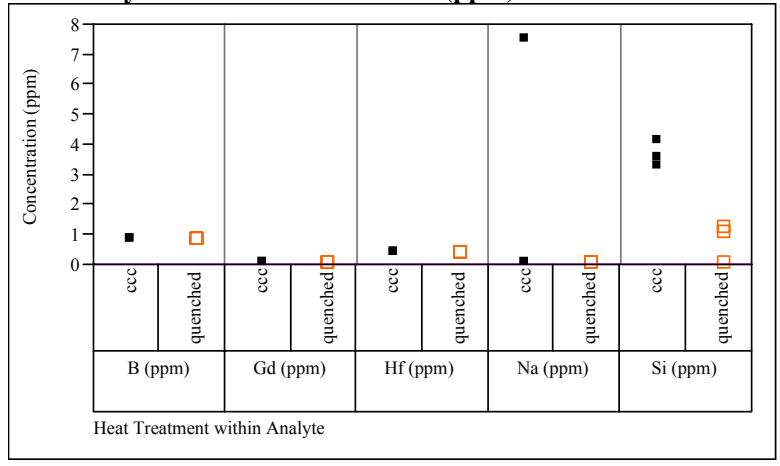

Glass ID=Pu35-29

Variability Chart for Concentration (ppm)

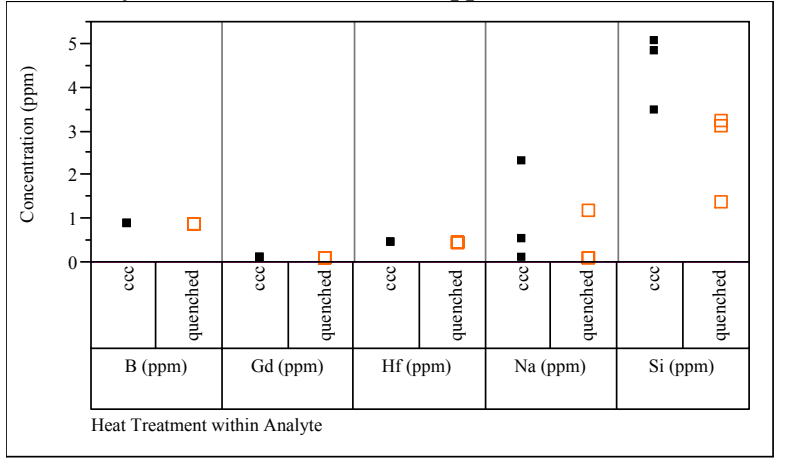

Glass ID=Pu35-30

Variability Chart for Concentration (ppm)

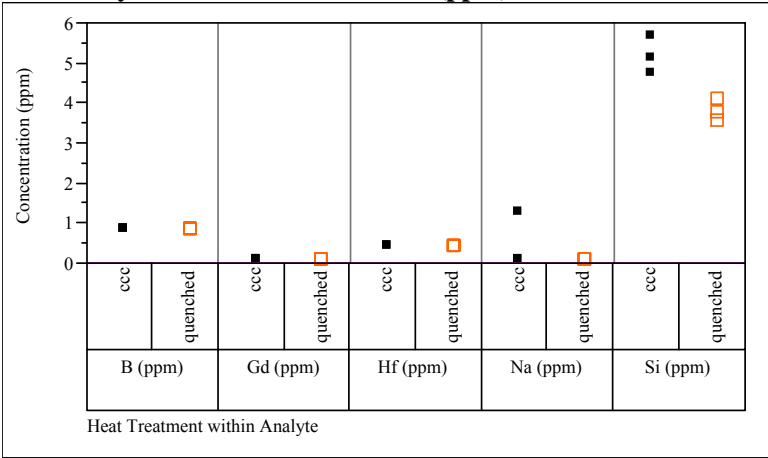

Glass ID=Pu35-31

Variability Chart for Concentration (ppm)

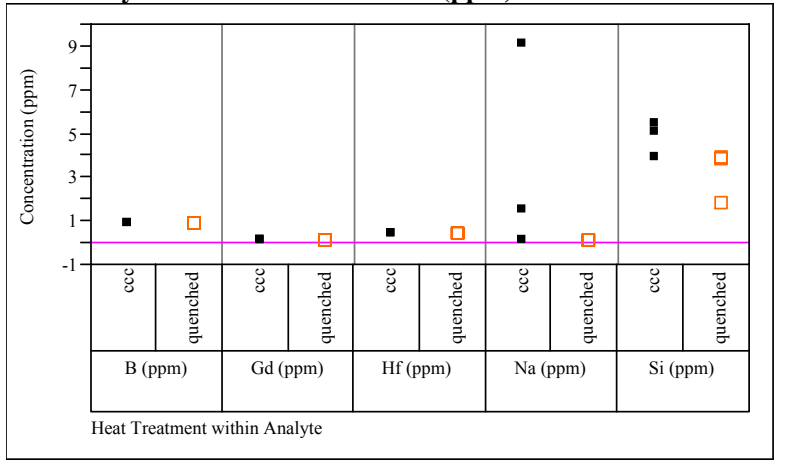




\section{Exhibit E5. Laboratory PCT Measurements by Pu Glass ID for both Quenched and CCC Versions (continued)}

Glass ID=Pu35-32

Variability Chart for Concentration (ppm)

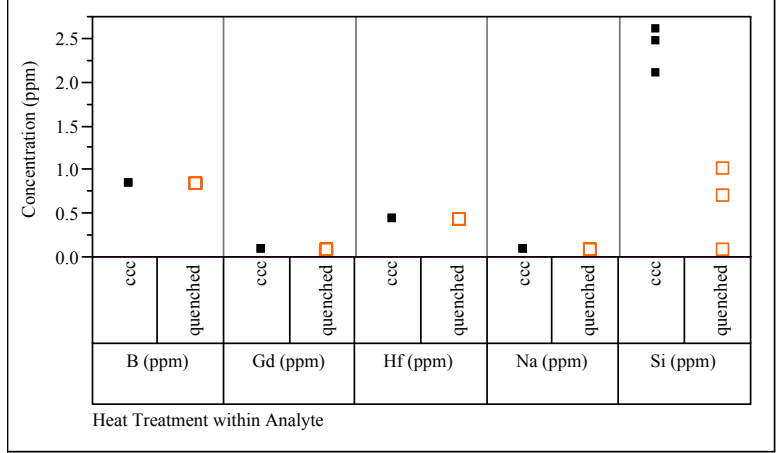

Glass ID=Pu35-33

Variability Chart for Concentration (ppm)

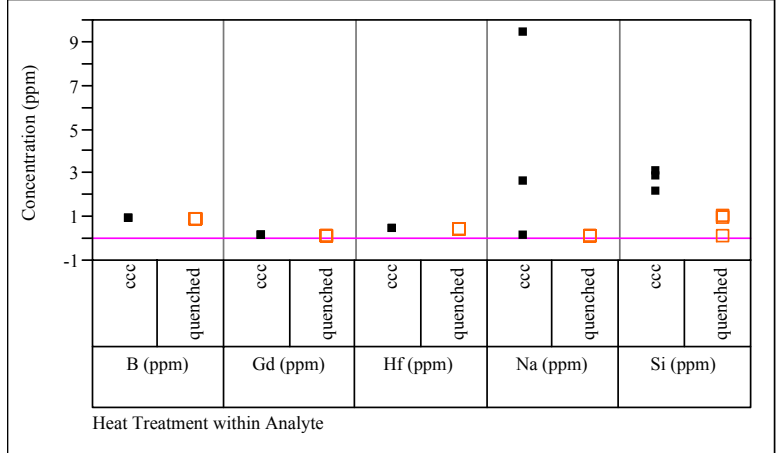

Glass ID=Pu35-34

Variability Chart for Concentration (ppm)

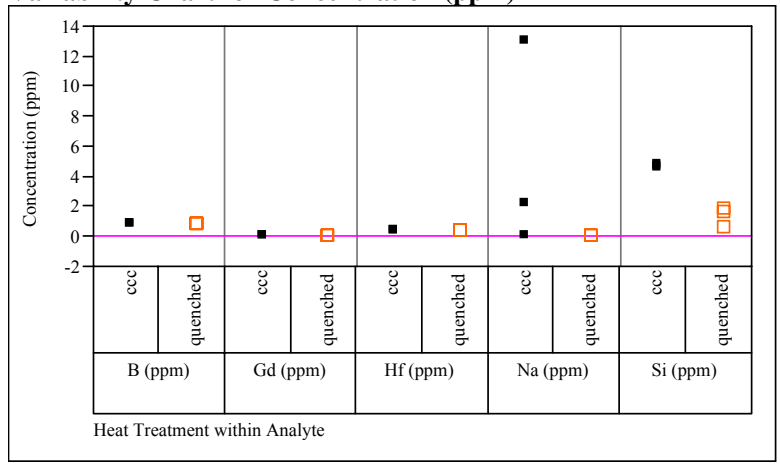

Glass ID=Pu35-35

Variability Chart for Concentration (ppm)

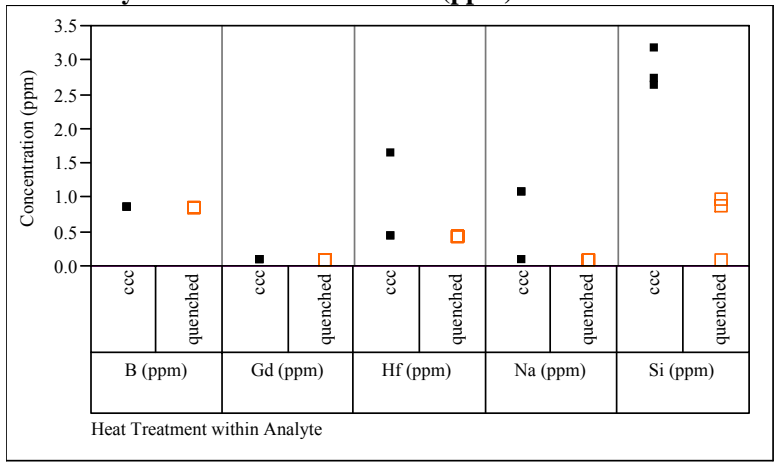

Glass ID=Pu35-36

Variability Chart for Concentration (ppm)

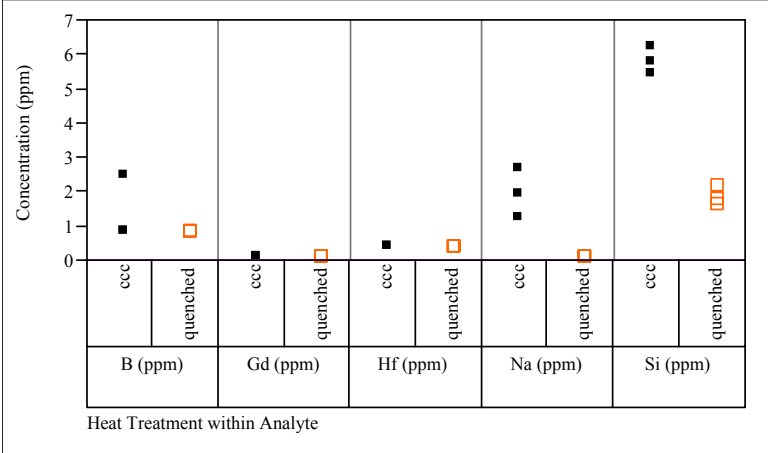

Glass ID=Pu35-37

Variability Chart for Concentration (ppm)

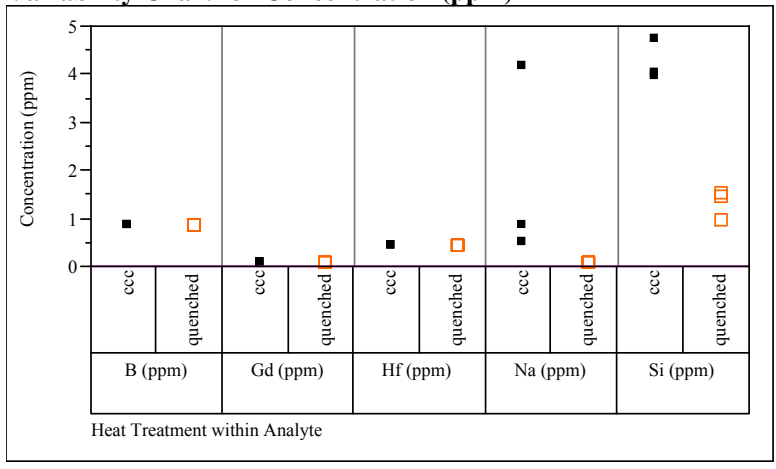




\section{Exhibit E5. Laboratory PCT Measurements by Pu Glass ID for both Quenched and CCC Versions (continued)}

Glass ID=Pu35-38

Variability Chart for Concentration (ppm)

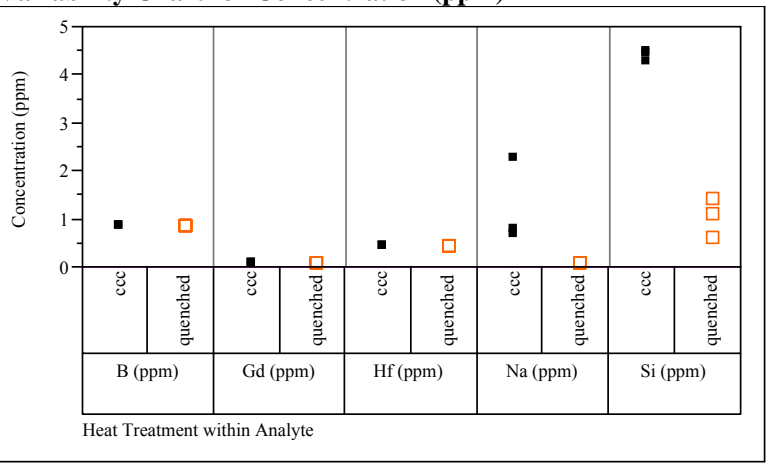

Glass ID=Pu35-39

Variability Chart for Concentration (ppm)

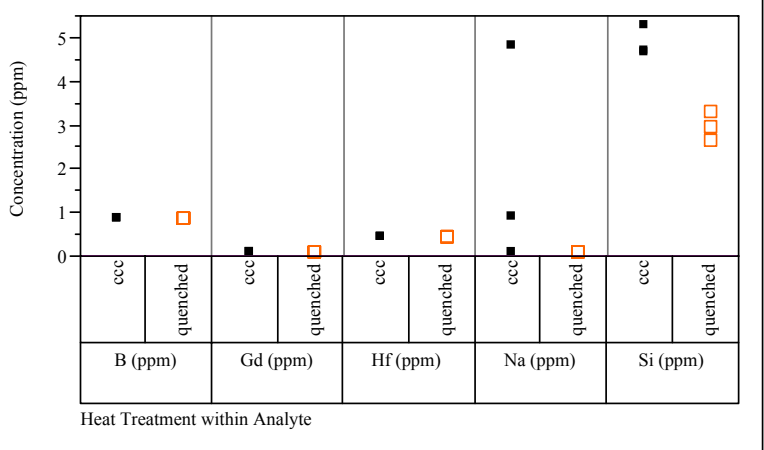

Glass ID=Pu35-40

Variability Chart for Concentration (ppm)

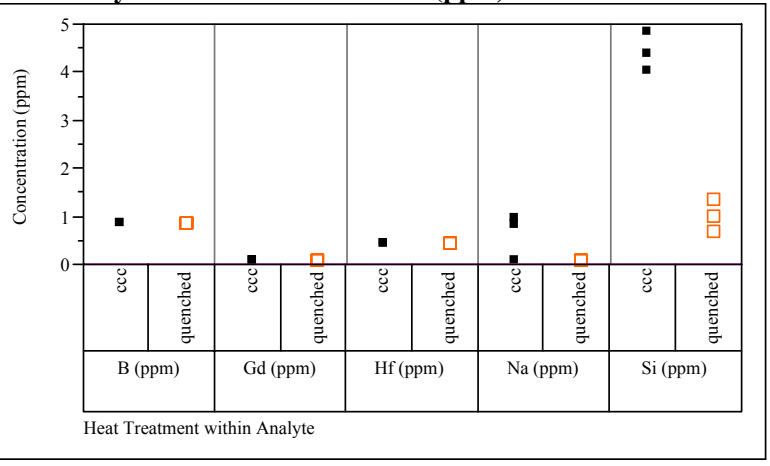

Glass ID=Pu35-41

Variability Chart for Concentration (ppm)

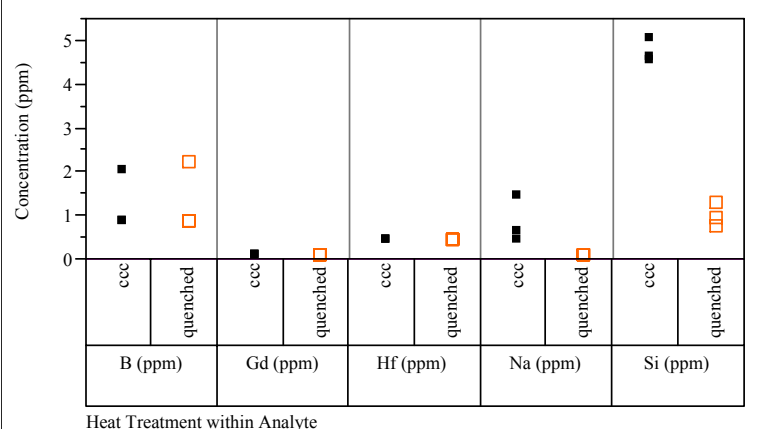

Heat Treatment within Analyte

Glass ID=Pu35-42

Variability Chart for Concentration (ppm)

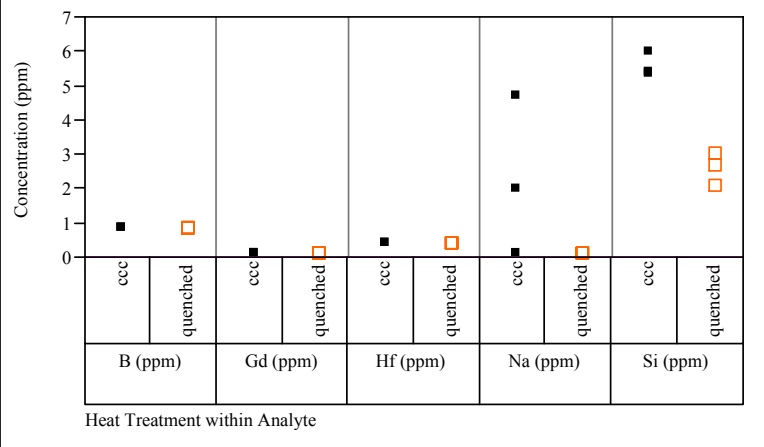

Glass ID=Pu35-43

Variability Chart for Concentration (ppm)

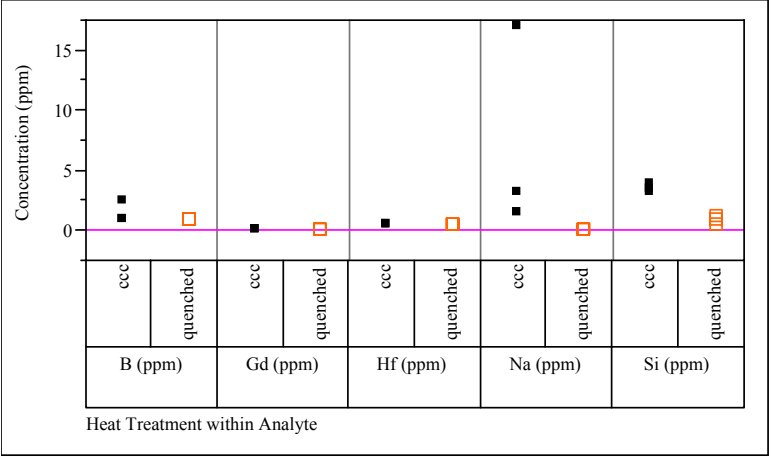




\section{Exhibit E5. Laboratory PCT Measurements by Pu Glass ID for both Quenched and CCC Versions (continued)}

Glass ID=Pu35-44

Variability Chart for Concentration (ppm)

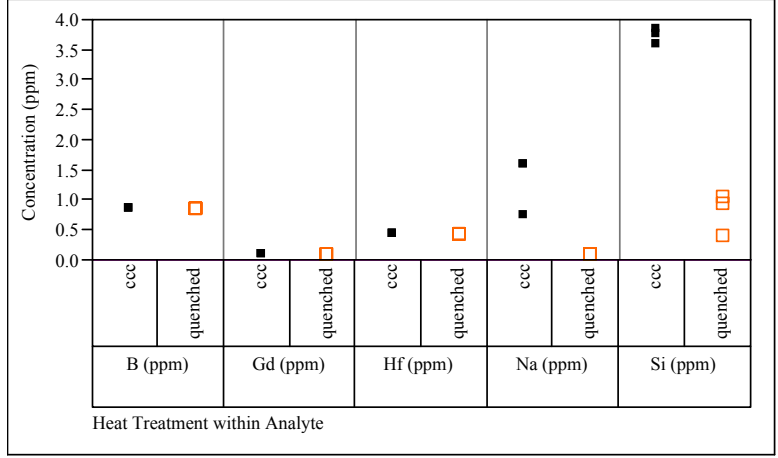

Glass ID=Pu35-45

Variability Chart for Concentration (ppm)

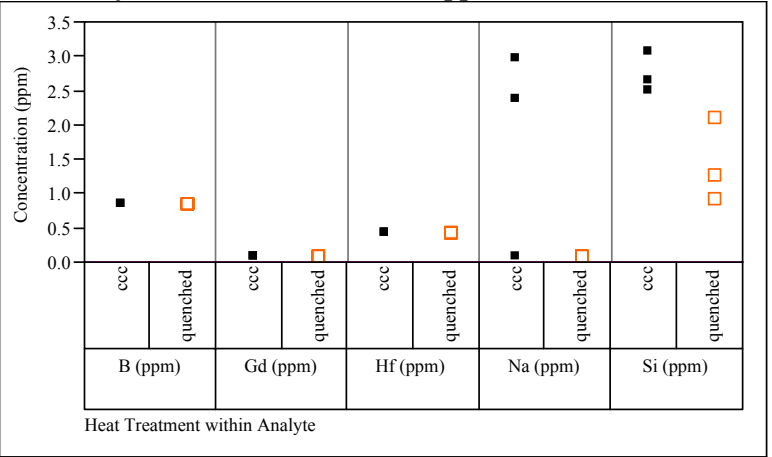

Glass ID=Pu35-46

Variability Chart for Concentration (ppm)

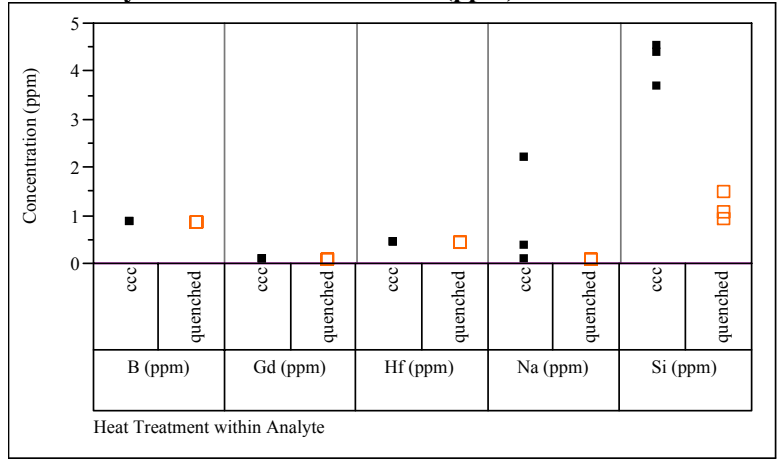

Glass ID=Pu35-47

Variability Chart for Concentration (ppm)

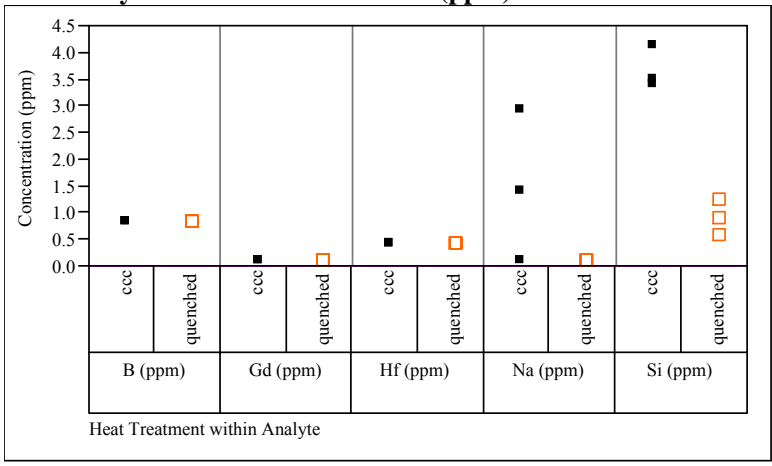

Glass ID=Pu35-48

Variability Chart for Concentration (ppm)

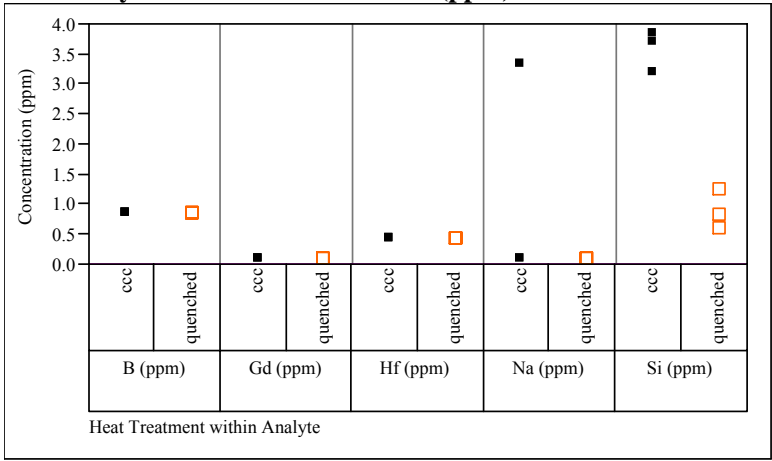

Glass ID=Pu35-49

Variability Chart for Concentration (ppm)

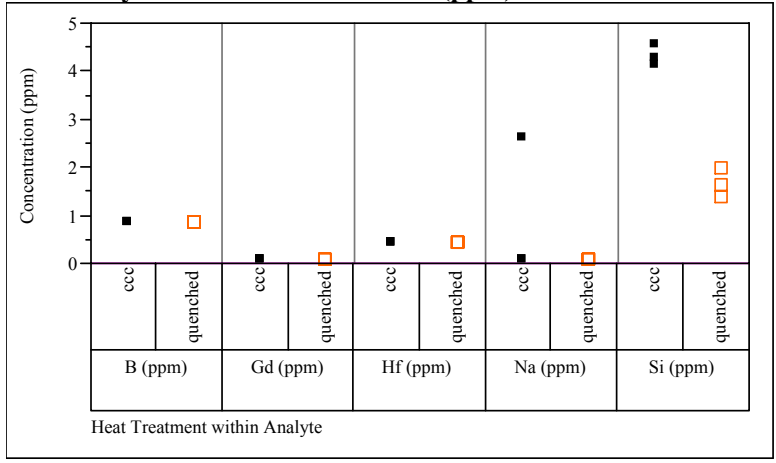




\section{Exhibit E5. Laboratory PCT Measurements by Pu Glass ID for both Quenched and CCC Versions (continued)}

Glass ID=Pu35-50

Variability Chart for Concentration (ppm)

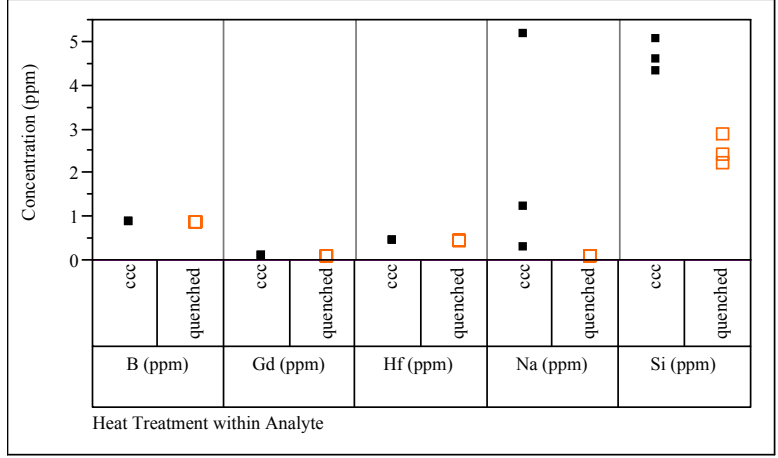

Glass ID=Pu35-51

Variability Chart for Concentration (ppm)

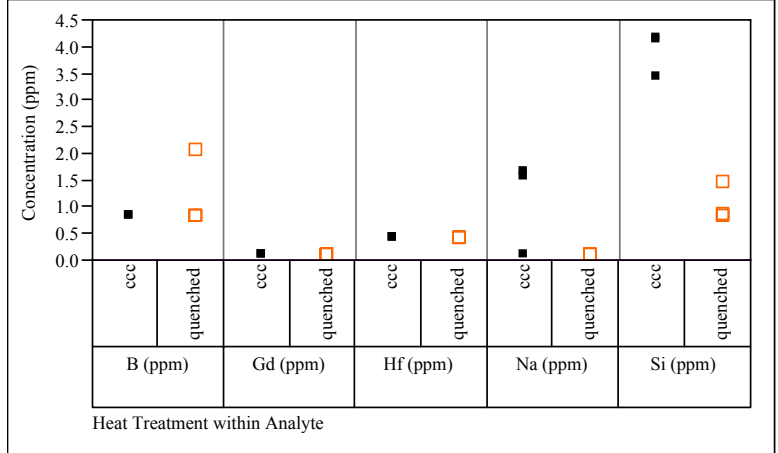

Glass ID=Pu35-52

Variability Chart for Concentration (ppm)

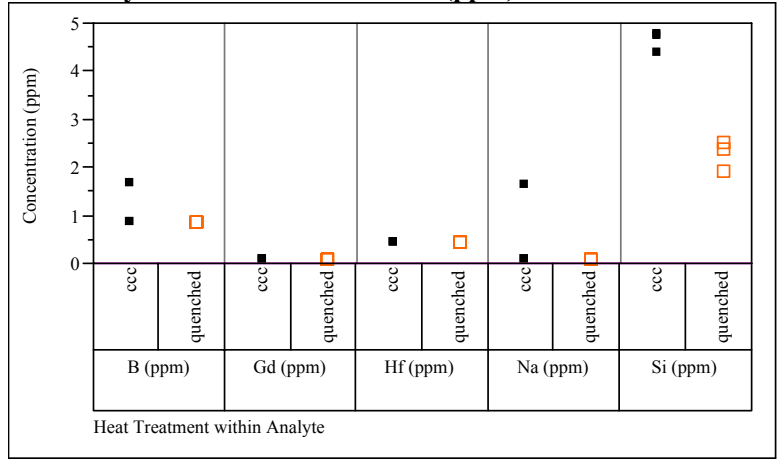

Glass ID=Pu35-53

Variability Chart for Concentration (ppm)

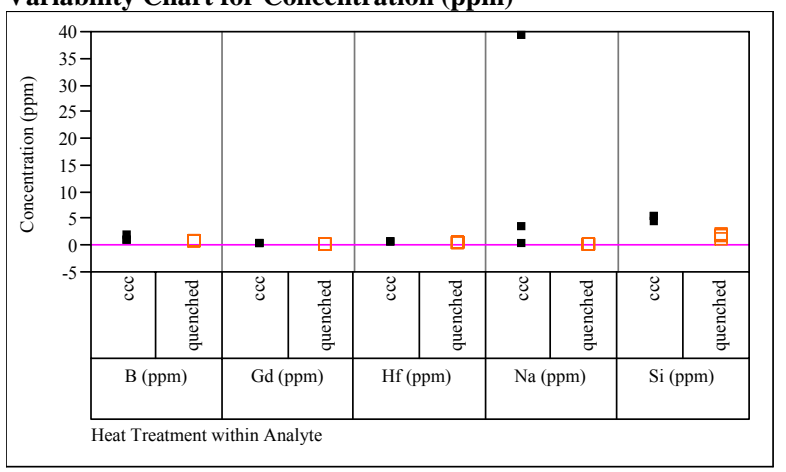

Glass ID=Pu35-54

Variability Chart for Concentration (ppm)

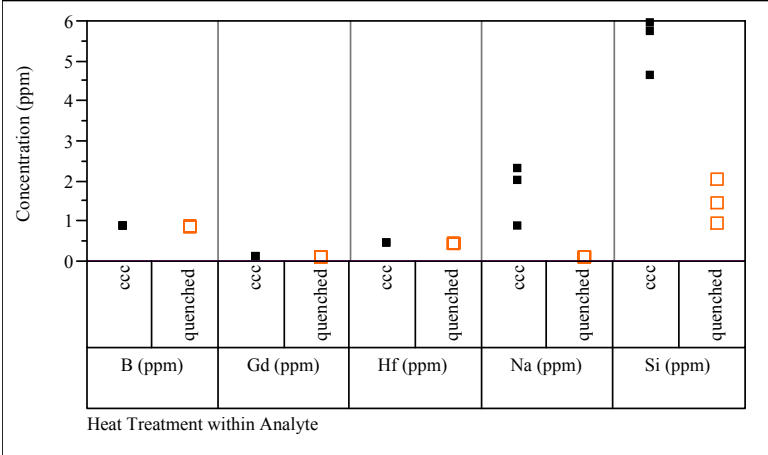

Glass ID=Pu35-55

Variability Chart for Concentration (ppm)

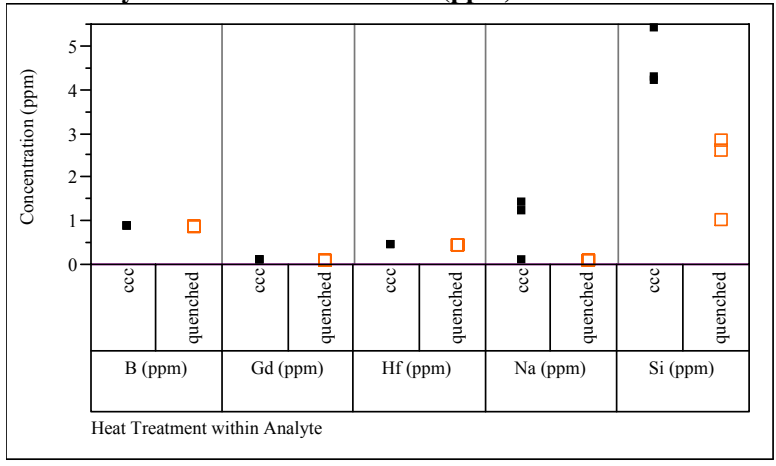




\title{
Appendix F
}

\author{
Laboratory Analysis Report: \\ Toxicity Characteristic Leaching Procedure Results
}


September 10, 2007

JAMES KOCH II

WASHINGTON SAVANNAH RIVER COMPANY

735-B, ROOM 133

AIKEN, SC 29804-6809

Report ID : AE2122

Page 1 of 16

Login Number :L07082202

Project Number :62664.00

Description :WSCR JOB 07239

Dear James Koch Ii:

We are pleased to provide the enclosed analytical results for the samples received by Davis \& Floyd, Inc. on August 21, 2007.

A formal Quality Assurance/Quality Control program is maintained by Davis \& Floyd, which is designed to meet or exceed the EPA, NELAC or other appropriate regulatory requirements. All analytical analyses for this project met QA/QC criteria and the results are within the $99 \%$ confidence interval for each method unless otherwise stated in the footnotes. This report is to be reproduced only in full.

Feel free to contact our Client Services Representative at (864) 229-4413 if further explanation of the analysis is required. Unless other arrangements have been made, samples will be disposed of or returned 14 days from the date of the report. We appreciate the opportunity to provide services to your firm.

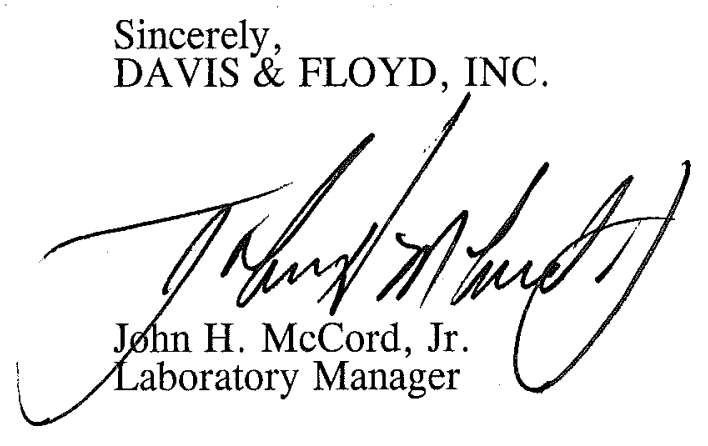




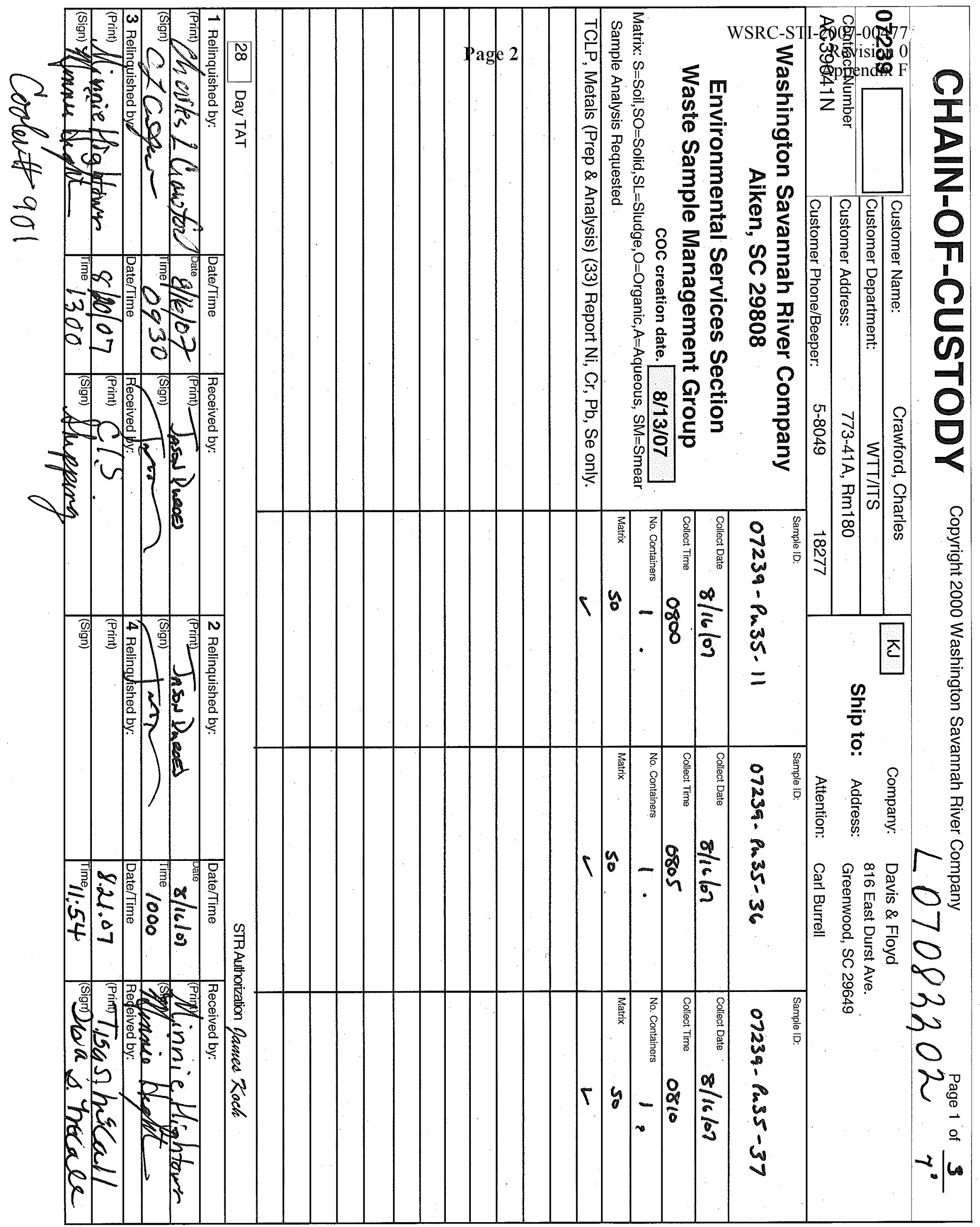




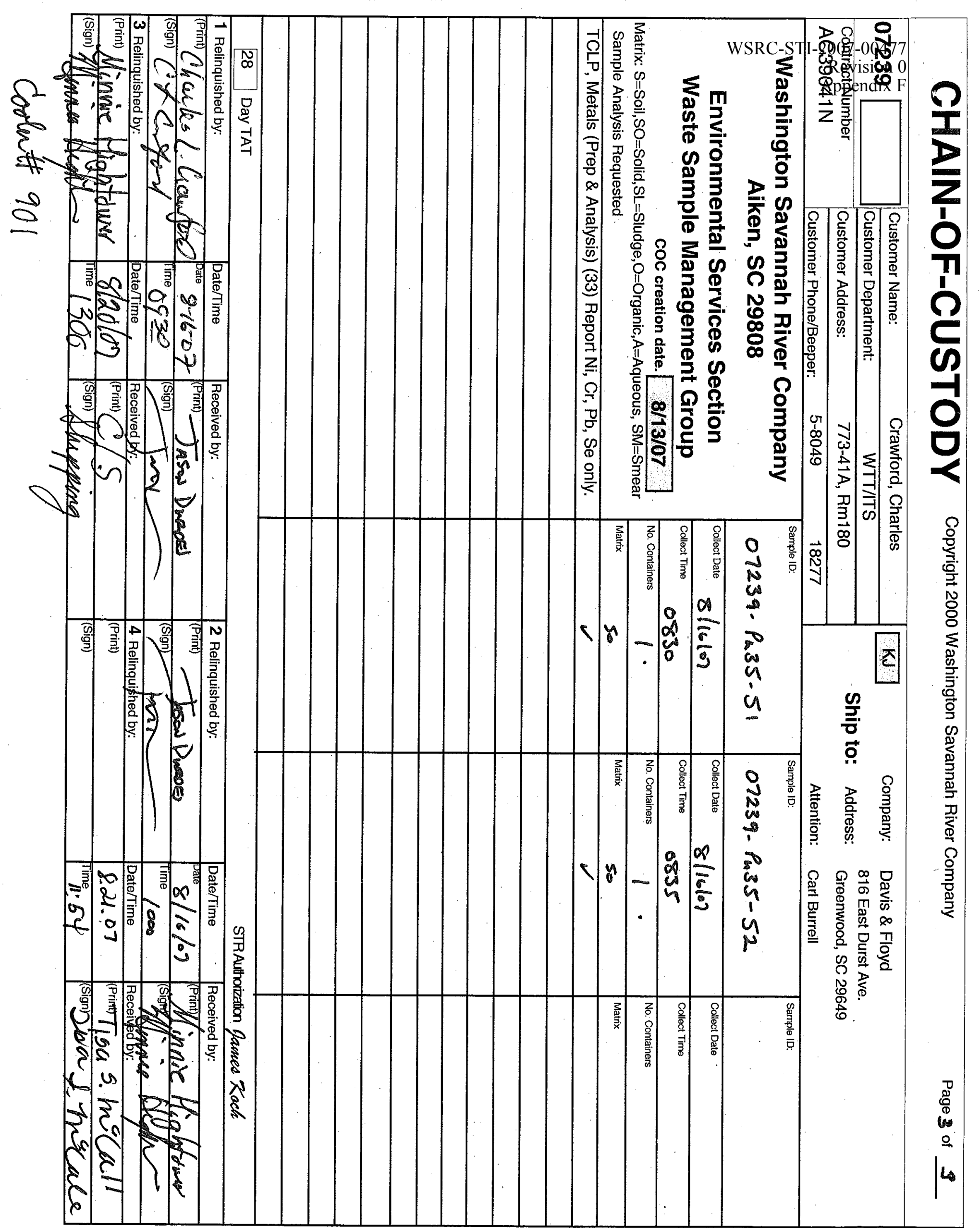




\title{
LABORATORY ANALYSIS REPORT
}

\author{
CASE NARRATIVE REPORT \\ For \\ Washington Savannah River Co. (WSRC) \\ Contract No. AC39041N \\ Job No. 07239
}

Date: September 10, 2007

\section{Laboratory Identification:}

Davis \& Floyd, Inc.

Summary:

Sample Receipt

On August 10,2007, the Davis \& Floyd, Inc. laboratory received eight solid wastesamples from the Washington Savannah River Co. The sample listed on the Chain-of-Custody (COC) form arrived in a cooler at a temperature of 7 degrees C. A twenty-eight day turnaround was requested on the COC.

The sample was logged into LIMS, labeled, and stored according to the D\&F Standard Operating Procedure (SOP) 20016_04.

The samples received were logged into LIMS as follows:

$\begin{array}{ll}\text { WSRC ID } & \text { D\&F Login Number } \\ \text { 07239-Pu35-11 } & \text { L07082202-01 } \\ 07239-P u 35-36 & \text { L07082202-02 } \\ 07239-P u 35-37 & \text { L07082202-03 } \\ 07239-P u 35-41 & \text { L07082202-04 } \\ 07239-P u 35-47 & \text { L07082202-05 } \\ \text { 07239-Pu35-50 } & \text { L07082202-06 } \\ \text { 07239-Pu35-51 } & \text { L07082202-07 } \\ \text { 07239-Pu35-52 } & \text { L07082202-08 }\end{array}$

\section{Case Narrative}

Sample analyses were conducted using methodology outlined in the appropriate D\&F Lab SOP. Any technical or administrative problems during analysis, data review, and reduction are written by analytical fraction in the enclosed narratives.

\section{Data Package}

The enclosed data package contains the following sections: Case Narrative, Certificate of Analysis, QC Summaries, Chain of Custody, Nonconformance Reports if applicable, and Electronic Data Hardcopy Report.

The Certificate of Analysis contains the following headings: 
Client ID:

Sample ID:

Matrix:

Date Collected:

Date Received:
Client sample Identification

D\&F laboratory identification number

Sample matrix

Date of sample collection

Date of sample receipt by laboratory

The detail on the Certificate includes the following:

$\begin{array}{ll}\text { Parameter: } & \text { Analyte or characteristic tested in sample } \\ \text { Result: } & \text { Final result of each parameter } \\ \text { Qual: } & \text { Qualifier used for data interpretation } \\ \text { RDL: } & \text { Report detection limit } \\ \text { MDL: } & \text { Method detection limit } \\ \text { Units: } & \text { Units of final result } \\ \text { Analyst: } & \text { Initials of analyst performing the test } \\ \text { Date: } & \text { Date of analysis } \\ \text { Time: } & \text { Time of analysis }\end{array}$

The QC Summary Report contains the following sections and headings:

QC Batch Report - Batch Sample List

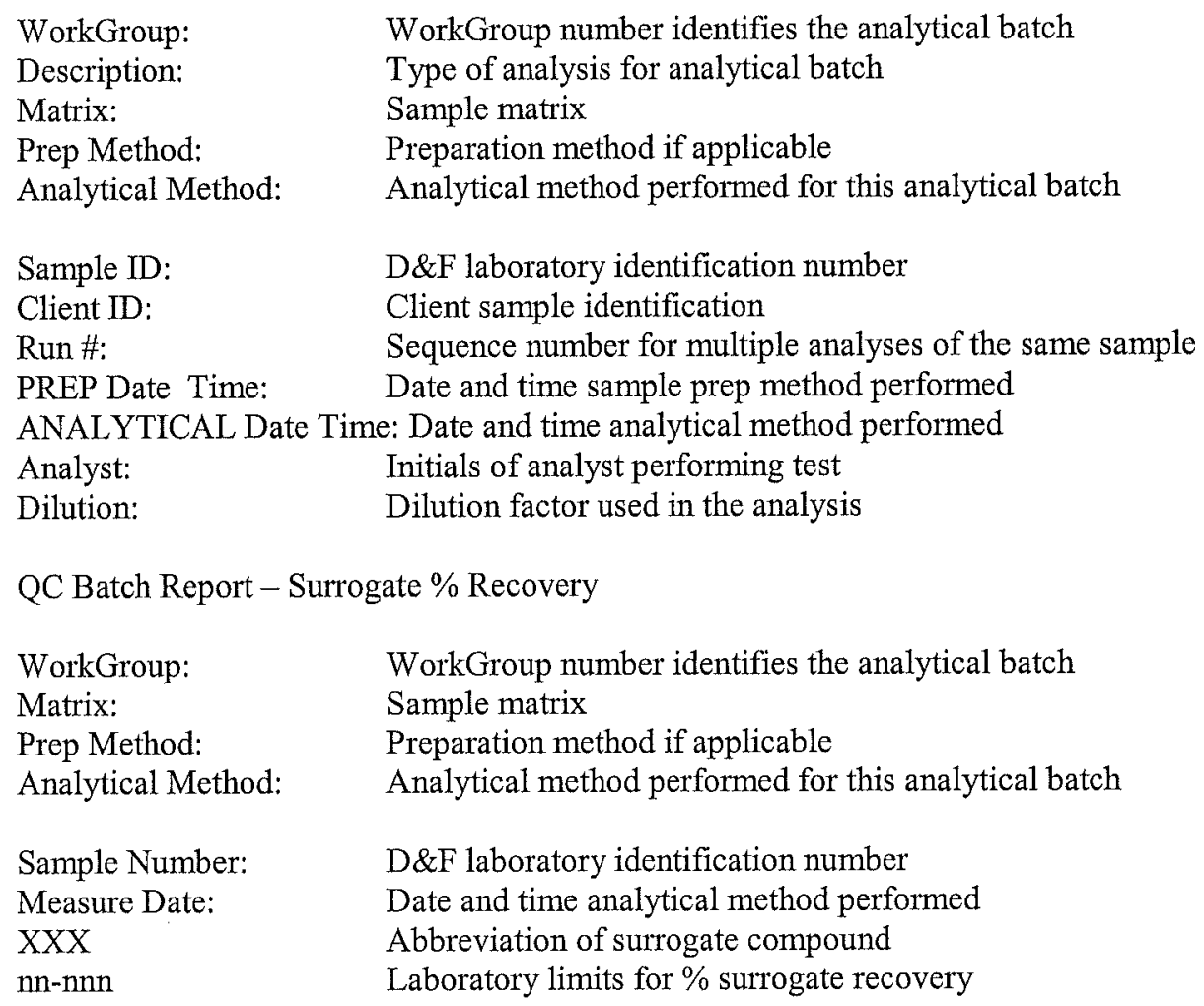


QC Batch Report - Method Blanks

$\begin{array}{ll}\text { WorkGroup: } & \text { WorkGroup number identifies the analytical batch } \\ \text { Blank: } & \text { Method blank identification number } \\ \text { Matrix: } & \text { Sample matrix }\end{array}$

Parameter: Analyte or characteristic tested in sample

Result: $\quad$ Final result of each parameter

Qual:

RDL:

Qualifier used for data interpretation

MDL:

Report detection limit

Units:

Method detection limit

Analyst:

Units of final result

Date:

Initials of analyst performing the test

Time:

Date of analysis

Time of analysis

QC Batch Report - Matrix Spikes and Duplicates

$\begin{array}{ll}\text { WorkGroup: } & \text { WorkGroup number identifies the analytical batch } \\ \text { MS/MSD: } & \text { Matrix spike \& matrix spike duplicate identification number } \\ \text { Matrix: } & \text { Sample matrix } \\ \text { Prep Method: } & \text { Preparation method if applicable } \\ \text { Analytical Method: } & \text { Analytical method performed for this analytical batch }\end{array}$

Matrix Spike

Parameter:

Spike Added:

Sample Conc:

MS Conc:

Units:

MS \% REC:

Limits \% REC:

Analyte or characteristic tested in sample

Concentration of spike added to the sample

Concentration of sample before spike added

Concentration of spiked sample analyzed

Units of final result

Calculated \% recovery of matrix spike

Laboratory established limits for $\%$ recovery

Matrix Spike Duplicate

Parameter:

Spike Added:

MSD Conc:

Units:

MSD \% REC:

$\%$ RPD

Limits \%RPD:

Limits \% REC:

Analyte or characteristic tested in sample

Concentration of spike added to the sample

Concentration of spiked sample analyzed

Units of final result

Calculated \% recovery of matrix spike

Relative percent difference between MS \& MSD

Laboratory established upper limits for \% RPD

QC Batch Report - Laboratory Control Standards and Duplicates

WorkGroup: WorkGroup number identifies the analytical batch 
LCS:

Matrix:

Prep Method:

Analytical Method:
Matrix spike \& matrix spike duplicate identification number

Sample matrix

Preparation method if applicable

Analytical method performed for this analytical batch
Parameter:

Spike Added:

LCS Conc:

Units:

LCS \% REC:

Limits \% REC:
Analyte or characteristic tested in sample

Concentration of spike added to the LCS

Concentration of spiked LCS analyzed

Units of final result

Calculated \% recovery of LCS

Laboratory established limits for LCS \% recovery

The following are definitions of report limits used by Davis \& Floyd, Inc.:

MDL Method Detection Limit: The minimum level of an analyte that can be determined (identified not quantified) with $99 \%$ confidence. The valued are normally achieved by preparing and analyzing seven aliquots of laboratory water spiked 1 to 5 times the estimated MDL, taking the standard deviation and multiplying it against the one-tailed t-statistic at $99 \%$. This computed value is then verified for reasonableness by repeating the study using the concentration found in the initial study, calculating an F-ratio, and computing the final limit. Sample preparation and dilution factors are applied to these limits when they are reported.

The MDL is the minimum concentration of a substance that can be identified, measured, and reported with $99 \%$ confidence that the analyte concentration is above zero. It answers the question "Is It Present".

RDL Report Detection Limit: The lowest concentration that can be reliably achieved within specified limits of precision and accuracy during routine laboratory operating conditions. The RDL is generally 5 to 10 times the calculated MDL. However, it may be nominally chosen within these guidelines to simplify data reporting. For many analytes the RDL analyte concentration is selected as the lowest non-zero standard in the calibration curve. Sample RDL's are highly matrix-dependant. Sample preparation and dilution factors are applied to these limits when they are reported.

The RDL is always $\geq \mathrm{MDL}$

The RDL is the lowest level at which a chemical substance may be accurately and reproducibly quantitated. It answers the question "How Much is Present".

Interpretation of RESULTS column on the Certificate of Analysis:

If the final concentration in the sample was found to be above the RDL, then the value reported is reported without a flag;

If the final concentration in the sample was found to be below the RDL but above the MDL, then the value reported is flagged with a " $\mathrm{J}$ "; 
If the final concentration in the sample was found to be below the MDL, the value reported is flagged with a "U".

Davis \& Floyd Inc. maintains acceptance criteria for QC samples through use of statistical process control (SPC). The SPC limits are used to qualify data usability. The flagging criterion identified in WSRC AN98 Format does not necessarily coincide with the laboratory SPC criteria. There may be instances where the Electronic Data Deliverable (EDD) has flagged data based on the AN98 criteria and the lab has not identified the data to be outside of the established control limits.

Those instances where the QC has not met laboratory SPC established criteria will be noted in the section case narratives that are included in this package.

This data package, to the best of my knowledge is in compliance with technical and administrative requirements.

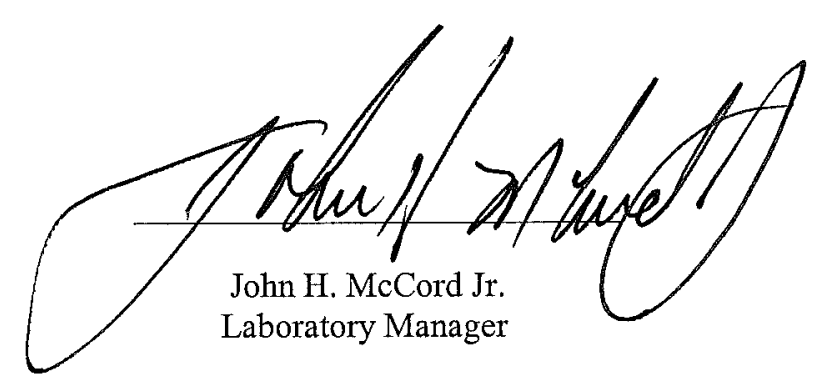




\author{
ICP-AE Trace Metals \\ Washington Savannah River Co (WSRC) \\ Job 07239
}

\title{
Method/Analysis Information
}

Procedure:

Trace Metals by Inductively-Coupled Plasma (ICP)

Analytical Method: $\quad$ SW846 6010B

Prep Method: $\quad$ SW846 1311, SW846 3010A

Analytical Batch Number: WG48646

\section{$\underline{\text { System Configuration }}$}

The analysis was performed on an inductively coupled plasma atomic emission spectrometer. The instrument is equipped with a Glass Expansion nebulizer, cyclonic spray chamber, internal standard, and lithium ionization suppressant. Operating conditions for the VARO ICP are set at a power level of 1000 watts. The instrument has a peristaltic pump flow rate of $15 \mathrm{RPM}$, argon gas flows of $1.5 \mathrm{~L} / \mathrm{min}$ for the auxiliary gas, $16.5 \mathrm{~L} / \mathrm{min}$ for the torch gas, and a pressure setting of $0.85 \mathrm{~L} / \mathrm{min}$ for the nebulizer.

\section{Sample Preparation}

All samples were prepared in accordance with the referenced SW-846 procedures.

\section{$\underline{\text { Sample Analysis }}$}

The following client and QC samples were analyzed to complete this sample delivery group using the methods referenced in the Analysis Information section:

\begin{tabular}{lc} 
Sample ID & Client ID \\
L07082202-01 & $07239-$ PU35-11 \\
\hline L07082202-02 & $07239-$ PU35-36 \\
\hline L07082202-03 & $07239-$ PU35-37 \\
\hline L07082202-04 & $07239-$ PU35-41 \\
\hline L07082202-05 & $07239-$ PU35-47 \\
\hline L07082202-06 & $07239-P U 35-50$ \\
\hline L07082202-07 & $07239-P U 35-51$ \\
\hline L07082202-08 & $07239-$ PU35-52 \\
\hline MB48646:1 & Method Blank (MB) \\
& JOB 07239-Metals (ICP) \\
& Page 1 of 3
\end{tabular}


LCS48646:1

MS07082202-08:48646

MSD07082202-08:48646

EB48646:1
Laboratory Control Sample (LCS)

07239-PU35-52 Matrix Spike

07239-PU35-52 Matrix Spike Duplicate

Extraction Blank (EB)

\section{Preparation/Analytical Method Verification}

Procedures for preparation, analysis, and reporting of analytical data are documented by the laboratory in SOP 45013_07, SOP 32101_08 and SOP 32302_08.

\section{Calibration Information}

\section{Initial Calibration}

Instrument calibrations are conducted using method and instrument manufacturer's specifications. All initial calibration requirements have been met for this analysis.

\section{CRDL Standard}

The CRDL standard recovery met the advisory limits.

\section{ICSA/ICSAB Requirements}

The interference check samples ICSA and ICSAB associated with this SDG met the established acceptance criteria.

\section{Continuing Calibration Blanks (CCB) Requirements}

All continuing calibration blanks (CCB) bracketing sample analyses associated with the SDG met the established acceptance criteria.

\section{Continuing Calibration Verification (CCV) Requirements}

All continuing calibration verification (CCV) standards bracketing sample analyses associated with this job met the recovery acceptance criteria.

\section{Quality Control (QC) Information}

\section{Method Blank Acceptance}

The Method Blank (MB) and the Extraction Blank (EB) analyzed with this job did not contain the analytes of interest at a concentration greater than the reporting limit.

\section{LCS Recovery Statement}

The LCS recoveries for this job were within the required acceptance limits.

\section{QC Sample Designation}

Sample L07082202-08 from job 07239 was designated as the quality control sample for the ICP batch WG48646. The batch included a Matrix Spike (MS) and a Matrix Spike Duplicate (MSD). 
MS/MSD Recovery Statement

The percent recoveries (\%R) obtained from the MS/MSD analyses are evaluated when the sample concentration is less than four times (4X) the spike concentration added. The TCLP aqueous sample and the MS and MSD were diluted by a factor of 10 prior to digestion. The laboratory normally dilutes all TCLP extracts by a factor of 10 so the matrix spike and matrix spike duplicate were evaluated even though they were diluted by a factor of more than 4. All applicable elements in the MS and MSD analyses met the established recovery acceptance criteria.

\section{MS/MSD RPD Statement}

The relative percent difference (RPD) between the MS and MSD analyses are not evaluated when the sample concentration is greater than four times $(4 \mathrm{X})$ the spike concentration added. The RPD for all analytes in this job were within the required acceptance limits.

\section{$\underline{\text { Technical Information }}$}

\section{Holding Time Specifications}

All of the samples were prepared and analyzed within the required holding time period.

\section{Sample Preservation and Integrity}

Sample integrity was met for all samples in this job.

\section{Sample Dilutions}

Dilutions are performed to minimize matrix interferences resulting from elevated mineral elements concentrations present in samples and/or to bring over range target analyte concentrations into the linear calibration range of the instrument. A $10 \mathrm{X}$ factor was introduced during preparation of all samples for this job due to the preparation procedure used for ICP analysis (SW846 3010A TCLP).

\section{$\underline{\text { Miscellaneous Information }}$}

\section{Nonconformance (NCR) Documentation}

Corrective Action Reports (CAR) are generated to document procedural anomalies that may deviate from reference SOP or contractual documents. No CARs were generated for this job.

\section{Review Validation}

The laboratory requires all analytical data to be verified by a qualified data validator. In addition, all data designated for CLP or CLP-like packaging will receive a third level validation upon completion of the data package.

The following data validator verified the information presented in this case narrative:

Reviewer: Mary P Mave Date: 04-10-07 


\section{LABORATORY ANALYSIS REPORT}

\section{Explanation of Symbols and Abbreviations}

The following defines common symbols and abbreviations used in reporting technical data:

\begin{tabular}{|c|c|c|c|}
\hline $\begin{array}{l}\text { RDL } \\
\text { TIC }\end{array}$ & $\begin{array}{l}\text { Report Detection Limit } \\
\text { Tentatively Identified } \\
\text { Compounds }\end{array}$ & $\begin{array}{l}\text { MDL } \\
\text { MSL }\end{array}$ & $\begin{array}{l}\text { Method Detection Limit } \\
\text { Mean Sea Level }\end{array}$ \\
\hline TNTC & Too Numerous To Count & MPN & Most Probable Number \\
\hline $\begin{array}{l}\text { BTU } \\
\text { C }\end{array}$ & $\begin{array}{l}\text { British Thermal Units } \\
\text { Degrees Centigrade }\end{array}$ & $\begin{array}{l}\text { NTU } \\
\text { F }\end{array}$ & $\begin{array}{l}\text { Nephelometric Turbidity Units } \\
\text { Degrees Fahrenheit }\end{array}$ \\
\hline $\begin{array}{l}\text { umhos } / \mathrm{cm} \\
\mathrm{kg}\end{array}$ & $\begin{array}{l}\text { micromhos/cm } \\
\text { kilogram(s) }\end{array}$ & meq & $\begin{array}{l}\text { milliequivalents } \\
\text { gram(s) }\end{array}$ \\
\hline $\mathrm{mg}$ & milligram(s) & ug & microgram(s) \\
\hline 1 & liter(s) & $\mathrm{ml}$ & milliliters(s) \\
\hline ul & microliter(s) & m3 & cubic meter(s) \\
\hline lb & pound(s) & $\mathrm{ft3}$ & cubic foot(feet) \\
\hline $\mathrm{ft}$ & foot(feet) & su & Standard Units \\
\hline
\end{tabular}

$\mathrm{mg} / \mathrm{l}, \mathrm{mg} / \mathrm{kg} \quad$ Units of concentration in milligrams per liter for liquids and milligrams per kilogram for solids. Also referred to as Parts Per Million or "ppm" when the assumption is made that the specific gravity or density is one $(1 \mathrm{~g} / \mathrm{ml})$.

ug/l, ug $/ \mathrm{kg} \quad$ Units of concentration in micrograms per liter for liquids and micrograms per kilograms for solids. Also referred to as Parts Per Billion or " $\mathrm{ppb}$ " when the assumption is made that the specific gravity or density is one $(1 \mathrm{~g} / \mathrm{ml})$.

$w t \% \quad$ Units of concentration expressed on a weight/weight basis (e.g. grams per 100 grams).

$<\quad$ Less Than - The number following the sign is the limit of quantitation, the smallest amount of analyte that can be reliably determined using this test.

$>\quad$ Greater Than

Data Qualifiers:

A TIC is a possible aldol-condensation product resulting from sample extraction, (Organics)

B Analyte also detected in the method blank.

C Amendable Cyanide is a negative value due to an unknown interference.

E Estimated concentration due to interference.

J Estimated value below RDL or estimated value for TIC. (Organics)

P Concentration difference between primary and confirmation columns $>25 \%$. (Organics) The lower result is reported.

U Final concentration is below the detection limit.

$\mathrm{X}$ Matrix interference which requires dilution or prevents the reporting of a result. Detection limits have been adjusted where applicable.

* Defined in report comments.

Solid samples (i.e. soil, sludge, and solid waste) are reported on a dry weight basis unless otherwise noted.

Test results relate only to the sample tested. Clients should be aware that a critical step in a chemical or biological analysis is the collection of the sample. Unless the sample analyzed is truly representative of the bulk of the material involved, the test results will be meaningless. If you have any questions regarding the proper techniques of collecting samples, please contact us. However, we cannot be held responsible for sample integrity unless sampling has been performed by a member of our staff.

REPRESENTATION AND LIMITATION OF LIABILITY - The accuracy of all analytical results for samples begins as it is received by the laboratory. Integrity of the sample begins at the time it is placed in the possession of authorized Davis \& Floyd, Inc. Laboratories personnel. All other warranties, expressed or implied, are disclaimed. Liability is limited to the cost of the analysis. 


\section{LABORATORY ANALYSIS REPORT}

NELAC Certification Number: E87633
Client : WASHINGTON SAVANNAH RIVER COMPANY
735-B, ROOM 133
AIKEN, SC 29804-6809
Contact : James Koch Ii
Project Number: 62664.00
Report Date : September 10, 2007
Page 3 of 16 Repoxt ID: AE2122

\section{Certificate of Analysis - 07239}

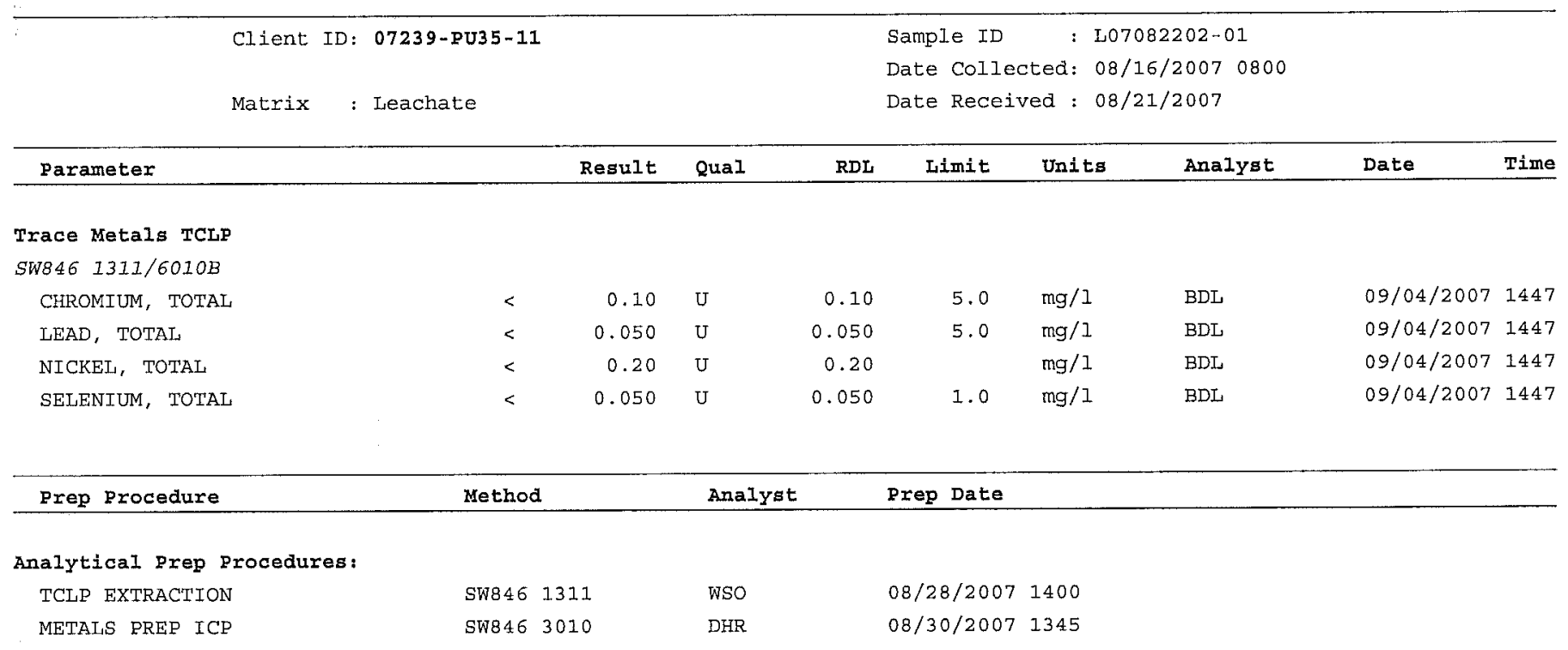




\section{LABORATORY ANALYSIS REPORT}

NELAC Certification Number: E87633
Client : WASHINGTON SAVANNAH RIVER COMPANY 735-B, ROOM 133
AIKEN， SC 29804-6809
Contact : James Koch Ii

\section{Certificate of Analysis - 07239}

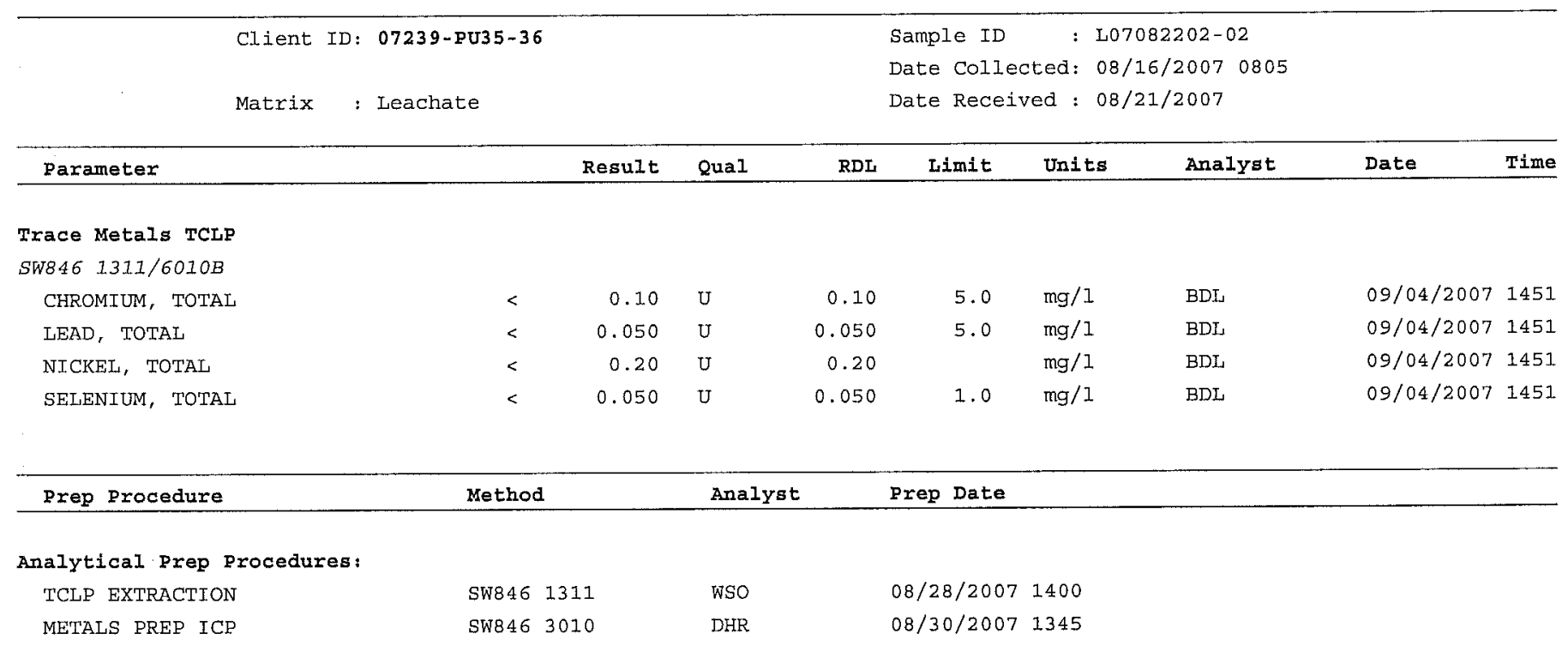




\section{DAVIS FLOYD}

\section{LABORATORY ANALYSIS REPORT}

NELAC Certification Number: E87633
Client : WASHINGTON SAVANNAH RIVER COMPANY
$735-B$, ROOM 133
ArKEN， SC 29804-6809
Contact : James Koch Ii

Project Number: 62664.00

Report Date : September 10, 2007

Page 5 of 16 Report ID: AE2122

Certificate of Analysis - 07239

\begin{tabular}{|c|c|c|c|c|c|c|c|c|c|c|}
\hline Client & : & $07239-$ PU35- 37 & & & & Sample ID & $:$ LO & $202-03$ & & \\
\hline & & & & & & Date Collec & cted: 08 & 20070810 & & \\
\hline Matrix & : & Leachate & & & & Date Receiv & ved : 08 & 2007 & & \\
\hline Parameter & & & Result & Qual & RDL & Limit & Units & Analyst & Date & Time \\
\hline Trace Metals TCLP & & & & & & & & & & \\
\hline SW846 1311/6010B & & & & & & & & & & \\
\hline CHROMIUM， TOTAL & & $<$ & 0.10 & $U$ & 0.10 & 5.0 & $\mathrm{mg} / 1$ & BDL & $09 / 04 / 2007$ & 1454 \\
\hline LEAD， TOTAL & & $<$ & 0.050 & U & 0.050 & 5.0 & $\mathrm{mg} / 1$ & $\mathrm{BDL}$ & $09 / 04 / 2007$ & 1454 \\
\hline NICKEL, TOTAL & & $<$ & 0.20 & $\mathrm{U}$ & 0.20 & & $\mathrm{mg} / 1$ & BDL & $09 / 04 / 2007$ & 1454 \\
\hline SELENIUM， TOTAI & & $<$ & 0.050 & $\mathrm{U}$ & 0.050 & 1.0 & $\mathrm{mg} / 1$ & BDL & $09 / 04 / 2007$ & 1454 \\
\hline Prep Procedure & & Method & & Analyst & & Prep Date & & & & \\
\hline Analytical Prep Procedur & & & & & & & & & & \\
\hline TCLP EXTRACTION & & SW846 & 1311 & wso & & $08 / 28 / 2007$ & 1400 & & & \\
\hline METALS PREP ICP & & SW846 & 3010 & $\mathrm{DHR}$ & & $08 / 30 / 2007$ & 1345 & & & \\
\hline
\end{tabular}




\section{LABORATORY ANALYSIS REPORT}

NELAC Certification Number: E87633
Client ; WASKINGTON SAVANNAH RIVER COMPANY
$735-B_{,}$ROOM 133
AIKEN, SC 29804-6809
Contact : James Koch $\mathrm{Ii}$

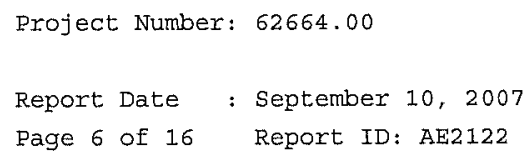

Project Number: 62664.00

Report Date : September 10,2007

Page 6 of 16 Report ID: AE2122

Certificate of Analysis - 07239

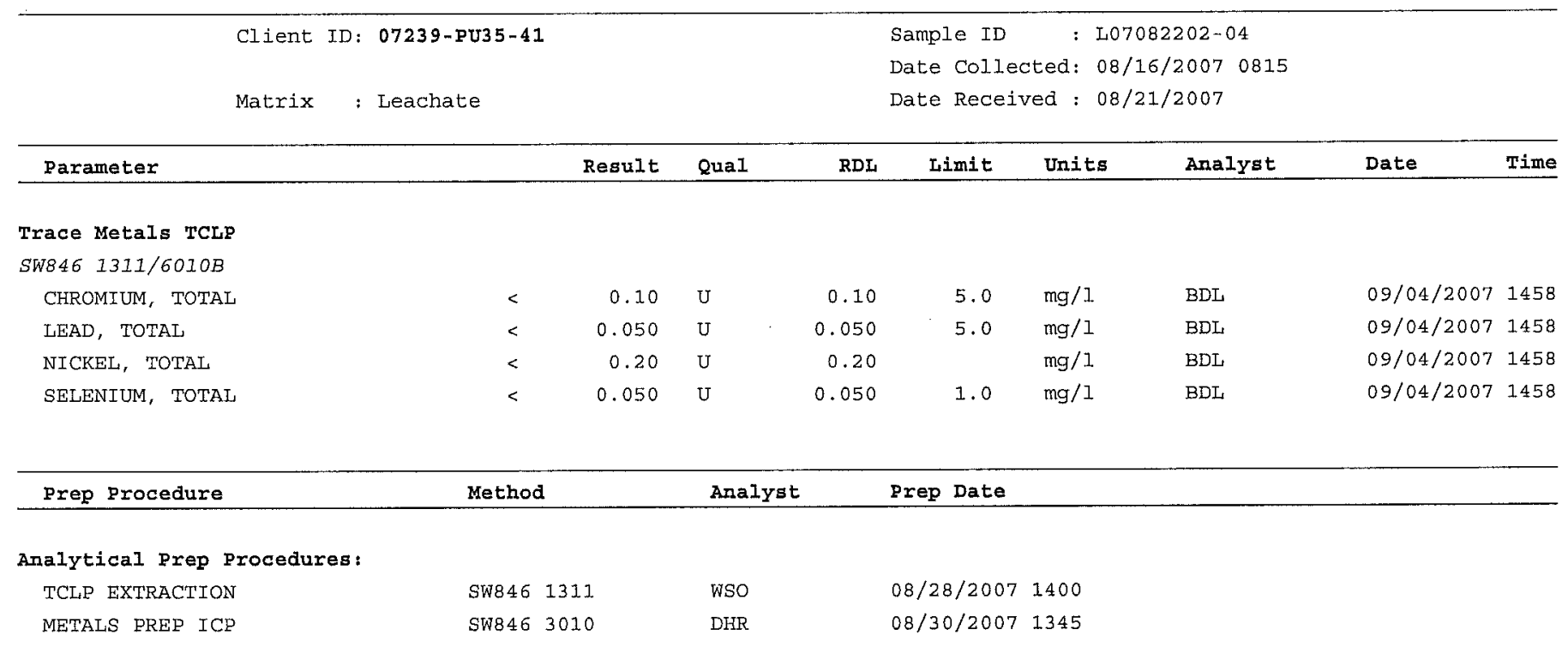




\section{LABORATORY ANALYSIS REPORT}

NELAC Certification Number: E87633
Client : WASHINGTON SAVANNAF RIVER COMPANY
$735-\mathrm{B}$, ROOM 133
AIKEN, SC 29804-6809
Contact : James Koch Ii

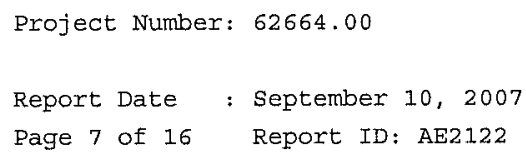

Project Number: 62664.00

Report Date : September 10, 2007

Page 7 of 16 Report ID: AE2122

\section{Certificate of Analysis - 07239}

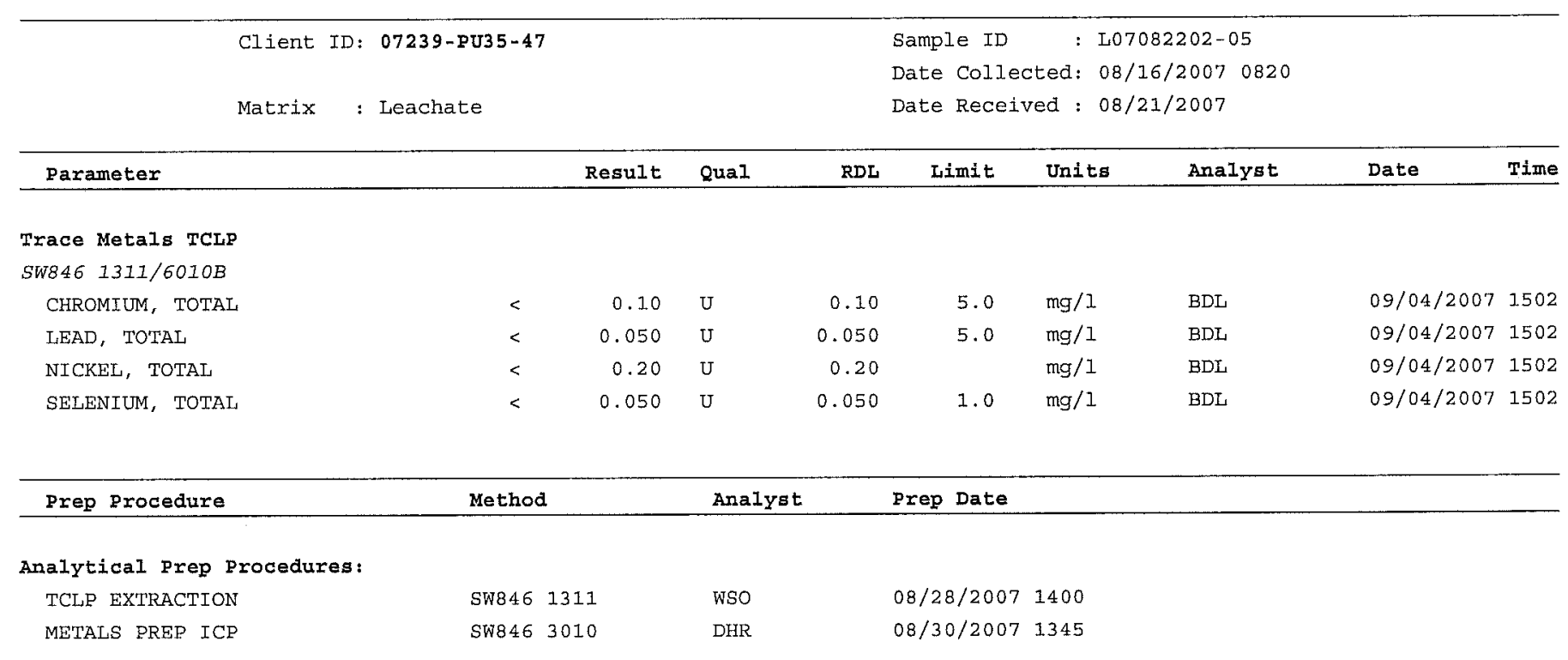




\section{DAVIS

\section{LABORATORY ANALYSIS REPORT}

NELAC Certification Number: E87633

$\begin{aligned} & \text { Client : WASHINGTON SAVANNAH RIVER COMPANY } \\ & 735-\mathrm{B}, \text { ROOM } 133 \\ & \text { AIKEN, SC 29804-6809 } \\ & \text { Contact : James Koch Ii }\end{aligned}$

Project Number: 62664.00

Report Date : September 10, 2007

Page 8 of 16 Report ID: AE2122

\section{Certificate of Analysis - 07239}

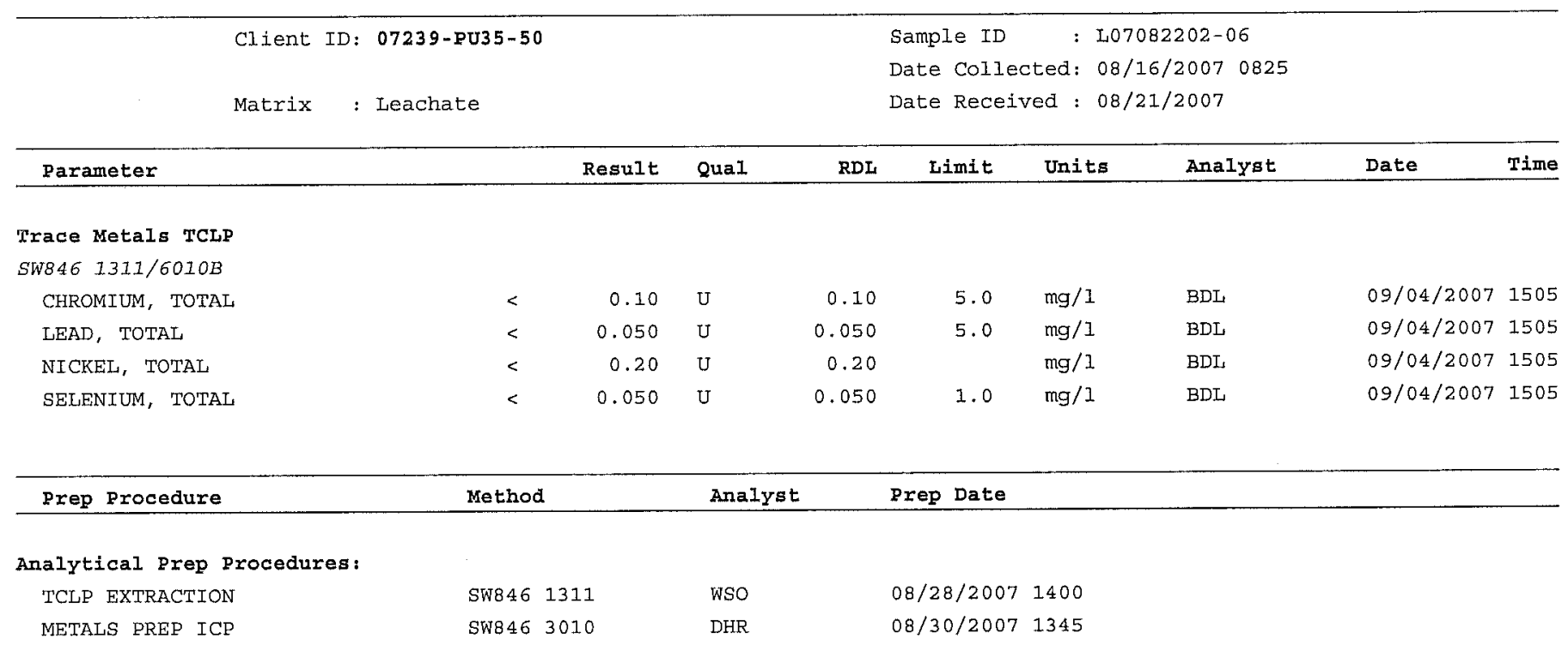




\section{LABORATORY ANALYSIS REPORT}

NELAC Certification Number: E87633
Client : WASHINGTON SAVANNAF RIVER COMPANY
$735-\mathrm{B}$, ROOM 133
AIKEN, SC 29804-6809
Contact : James Koch Ii

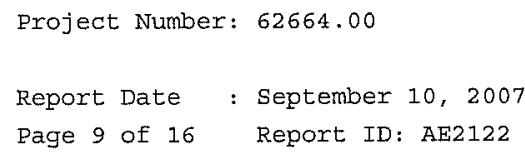

Project Number: 62664.00

Report Date : September 10, 2007

Page 9 of 16 Report ID: AF2122

Certificate of Analysis - 07239

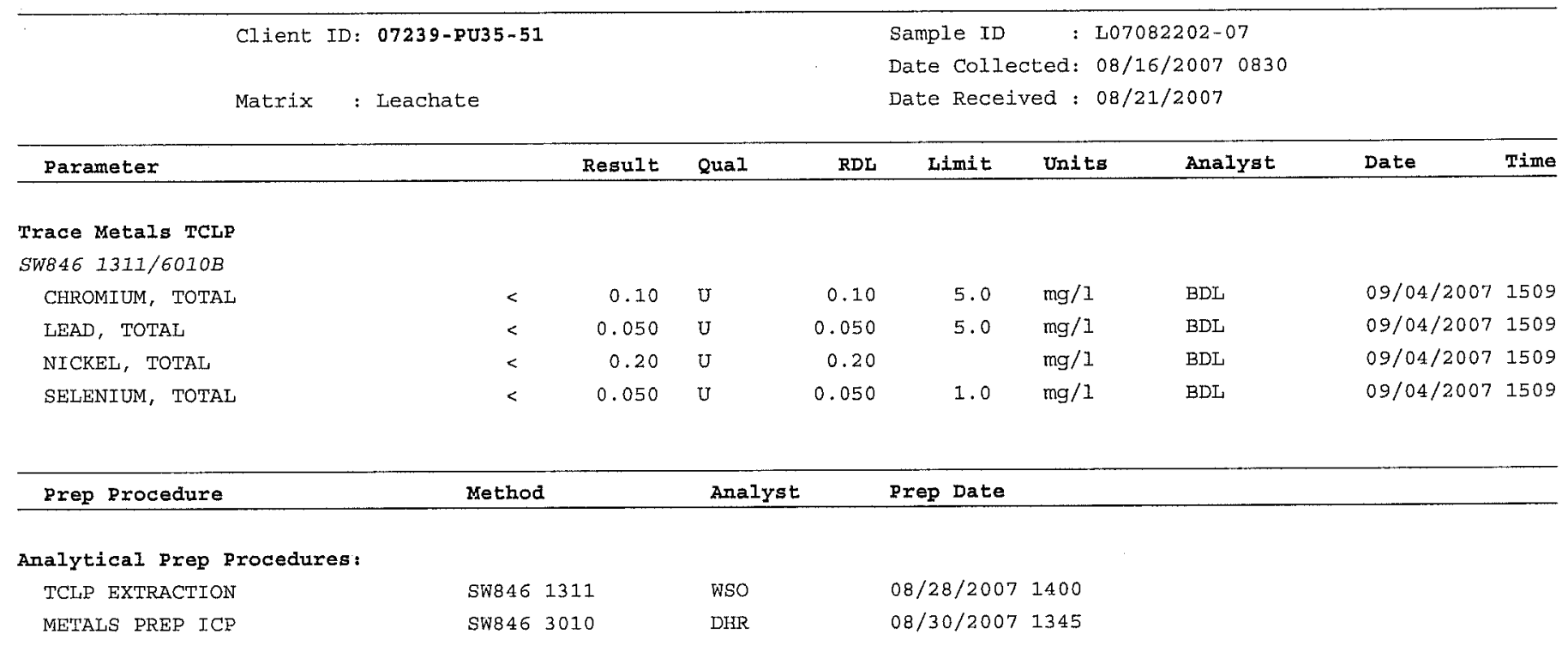




\section{LABORATORY ANALYSIS REPORT}

NELAC Certification Number: E87633
Client : WASHINGTON SAVAMNAH RIVER COMPANY 735-B, ROOM 133
AIKEN, SC 29804-6809
Contact : James Koch Ii

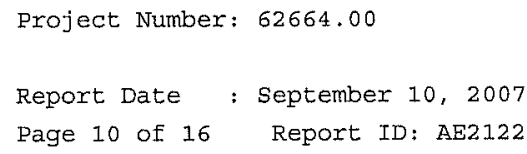

Project Number: 62664.00

Report Date ; September 10, 2007

Page 10 of 16 Report ID: AE2122

\section{Certificate of Analysis - 07239}

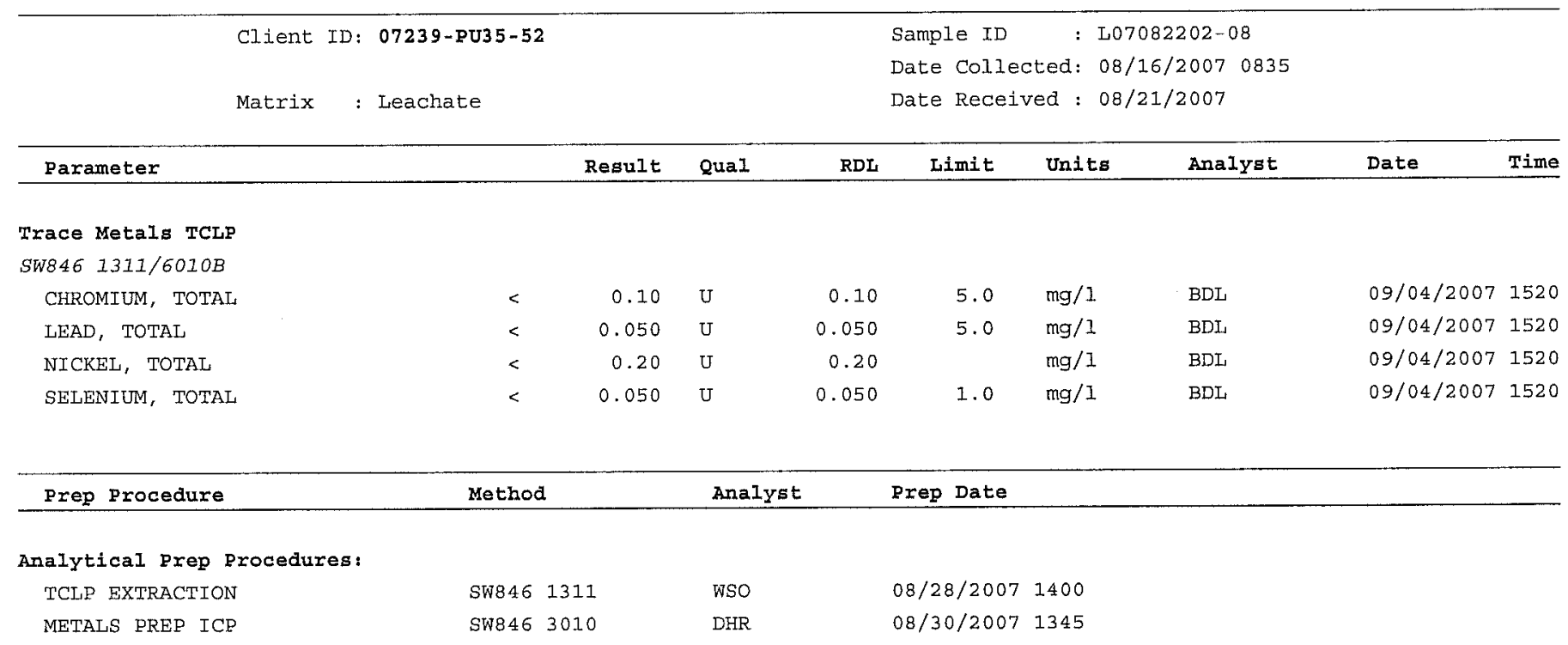




\section{LABORATORY ANALYSIS REPORT}

NELAC Certification Number: E87633

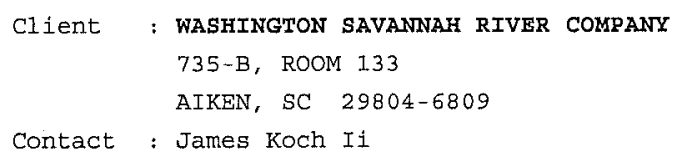

Project Number: 62664.00

Report Date : September 10, 2007

Page 11 of 16 Report ID: AE2122

\section{QC Summary Data}




\section{LABORATORY ANALYSIS REPORT}

NELAC Certification Number: $E 87633$
Client : WASHINGTON SAVANNAH RIVER COMPANY 735-B, ROOM 133
AIKEN, SC 29804-6809
Contact : James Koch Ii

\section{QC Batch Report - Batch Sample List}

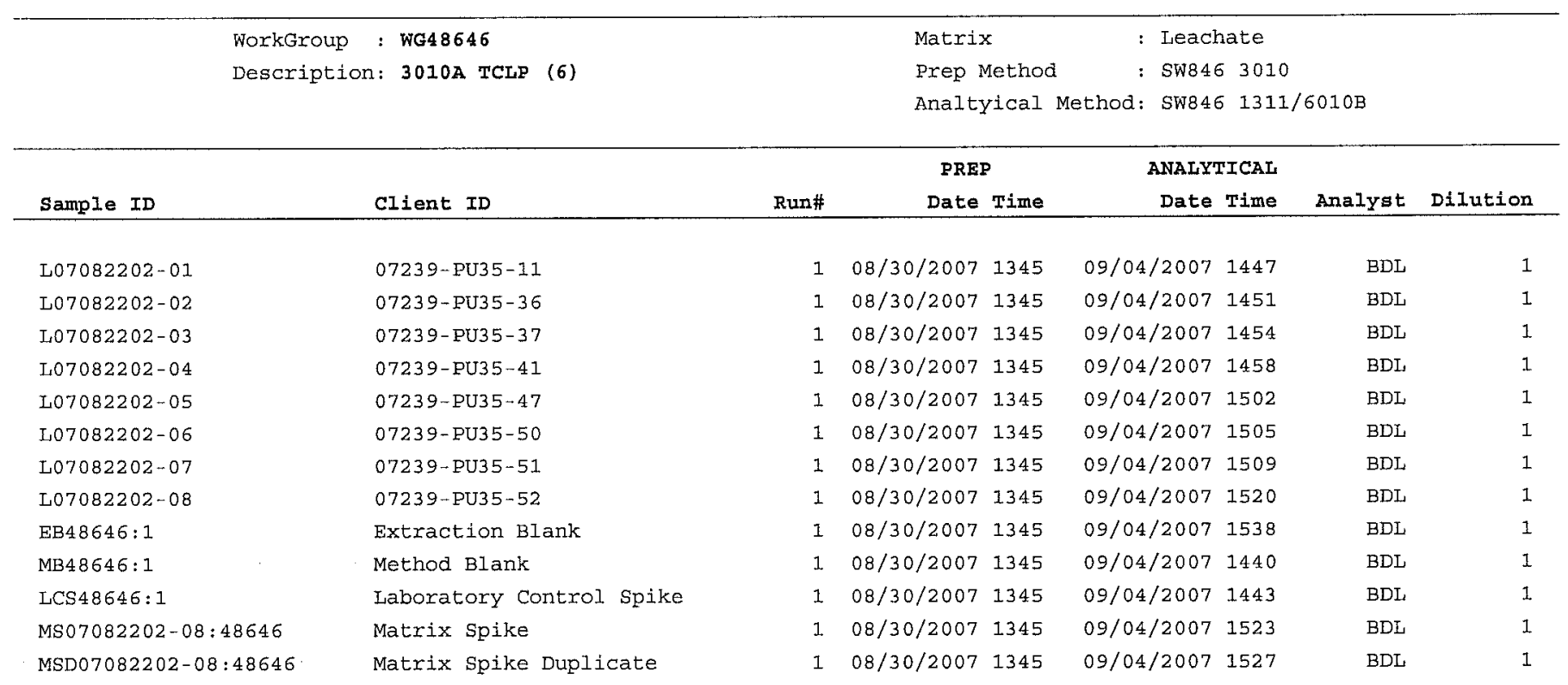




\section{LABORATORY ANALYSIS REPORT}

NELAC Certification Number: E87633
Client : WASHINGTON SAVANNAH RIVER COMPANY $735-B$, ROOM 133
AIKEN, SC 29804-6809
Contact : James Koch Ii

\section{QC Batch Report - Method Blanks}

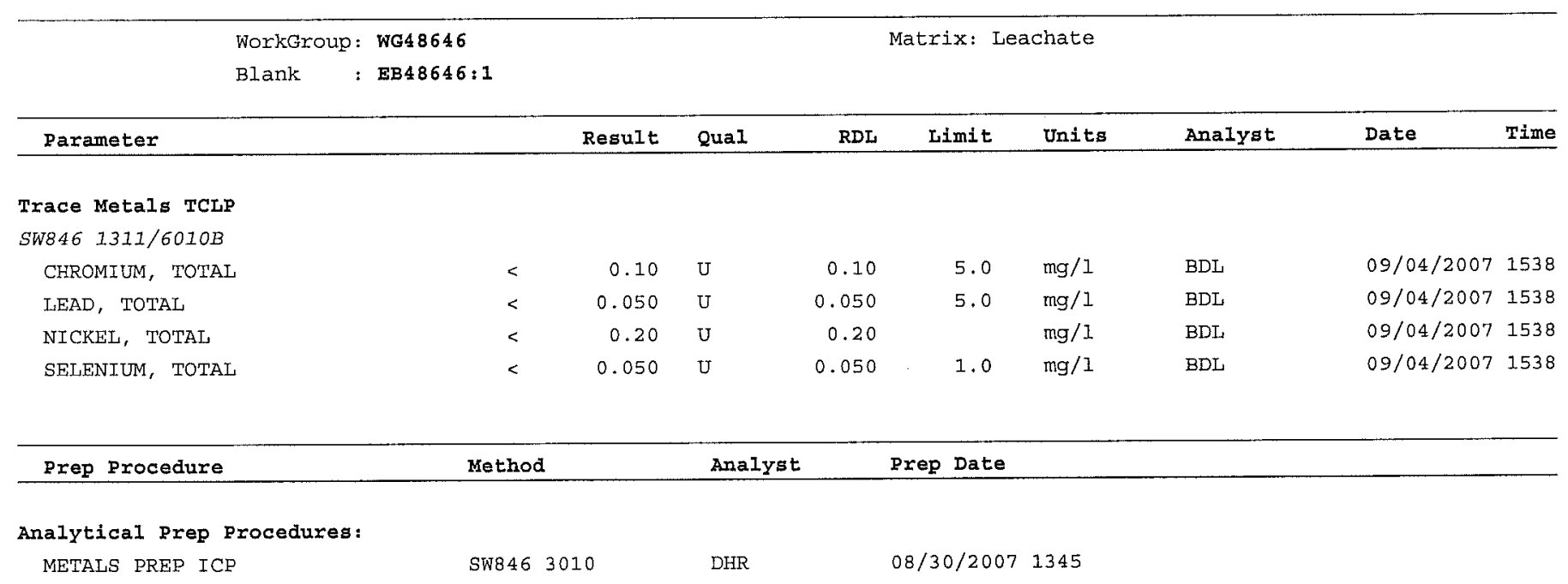




\section{LABORATORY ANALYSIS REPORT}

NELAC Certification Number: E87633
Client : WASHINGTON SAVANNAH RIVER COMPANY
735-B, ROOM 133
AIKEN, SC 29804-6809
Contact : James Koch Ii

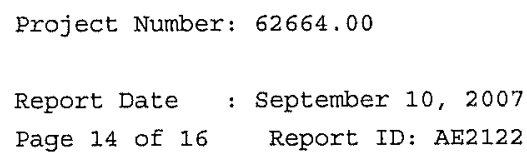

Project Number: 62664.00

Report Date : September 10, 2007

Page 14 of 16 Report ID: AE2122

\section{QC Batch Report - Method Blanks}

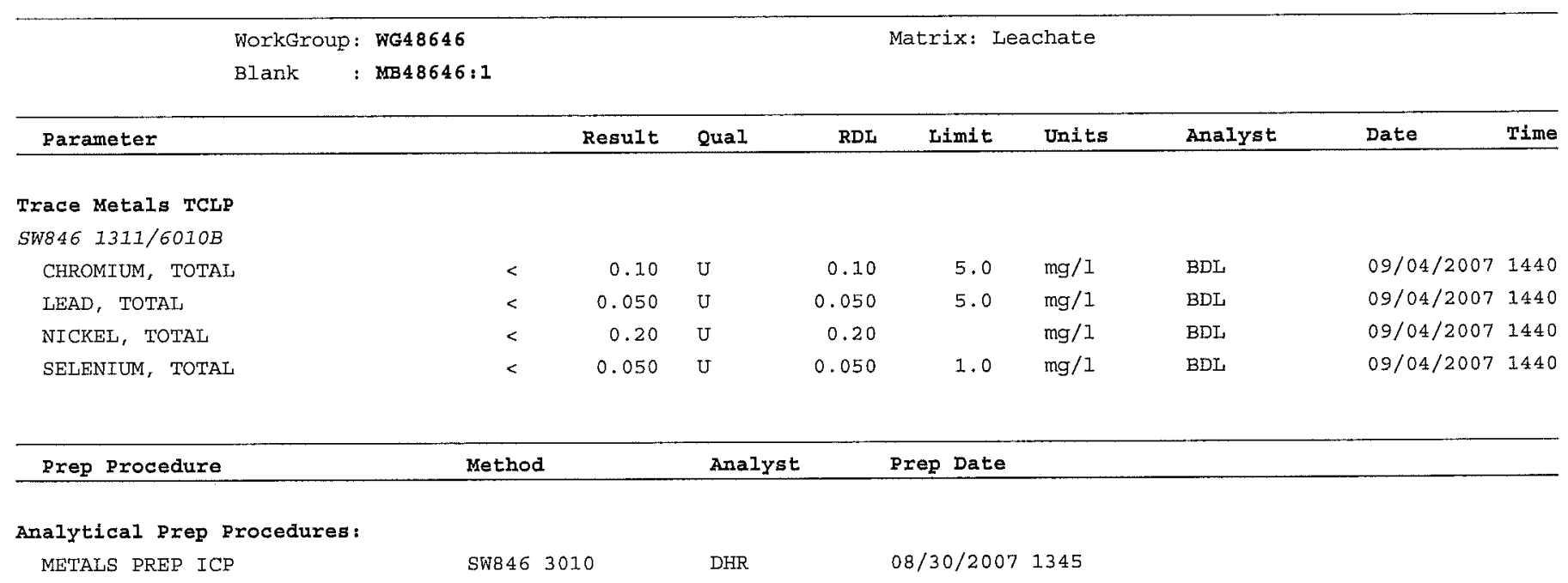




\title{
LABORATORY ANALYSIS REPORT
}

NELAC Certification Number: E87633
Client : WASHINGTON SAVANNAH RIVER COMPANY $735-\mathrm{B}$, ROOM 133
AIKEN, SC 29804-6809
Contact : James Koch Ii

\author{
Project Number: 62664.00 \\ Report Date : September 10, 2007 \\ Page 15 of 16 Report ID: AE2122
}

\section{QC Batch Report - Matrix Spikes and Duplicates}

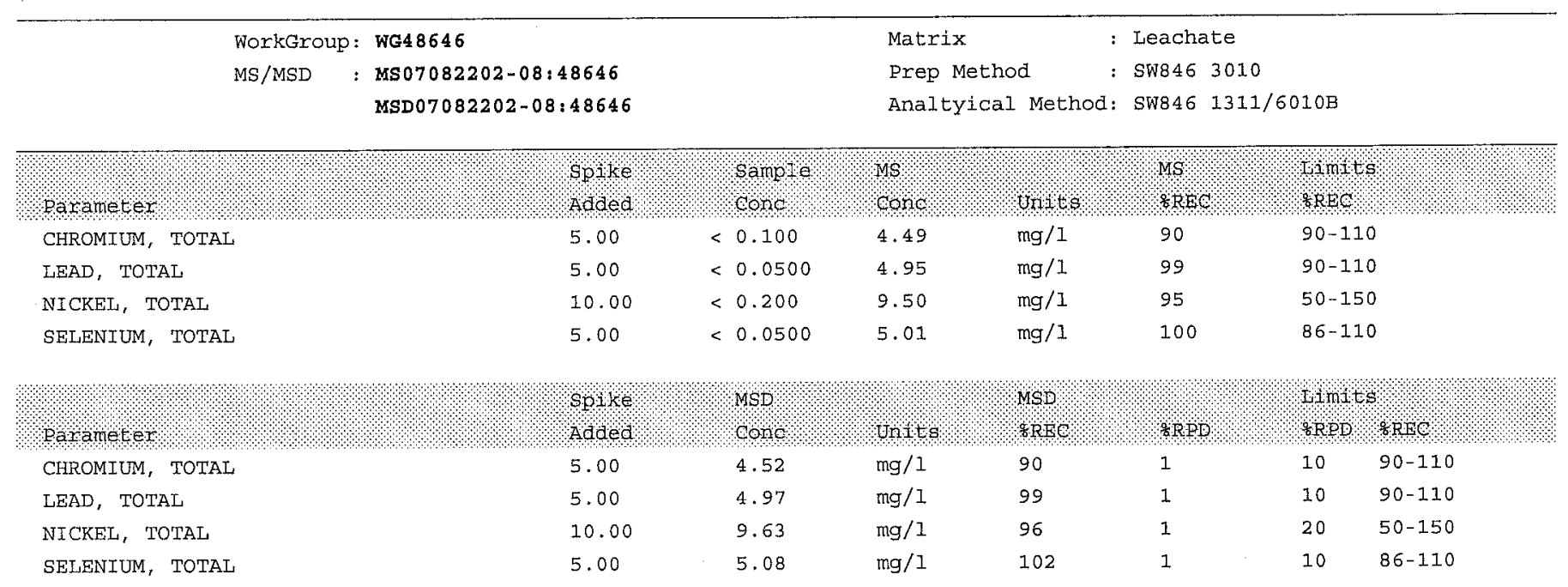

NOTE: MS/MSD $\frac{8}{8}$ recoveries are not evaluated if the sample concentration is greater than four times the spike added. 


\section{LABORATORY ANALYSIS REPORT}

NELAC Certification Number: E87633

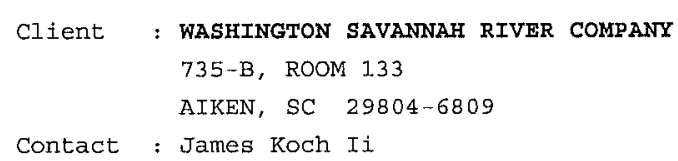

Project Number: 62664.00

Report Date : September 10, 2007

Page 16 of 16 Report ID: AE2122

\section{QC Batch Report - Laboratory Control Standards and Duplicates}

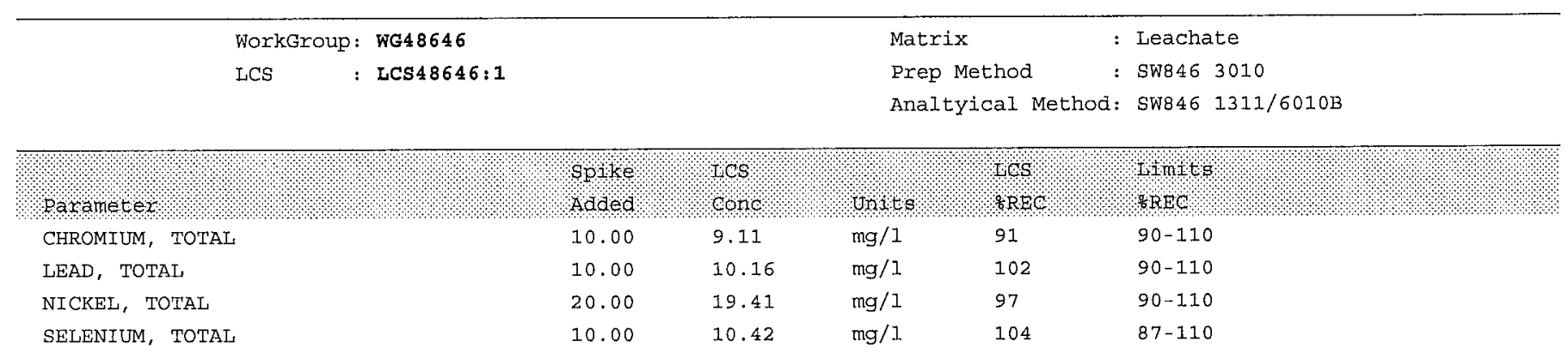


Page 28

DAVIS \& FLOYD, INC.

LOGIN REPORT ( $\ln 01$ )

August 22 2007, 08:36 am

Login Number: L07082202

AcCount: WASSAV WASHINGTON SAVANNAH RIVER COMPANY

Project: 62664.00 MISC. ANALYTICAL SERVICES
1.0.0. $0.0 \%$
1.1. 1010
0.0 .00 .
.). + .

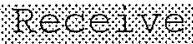
1.2.
1)
.1 .10 .10

$16-\mathrm{AUG}-2007$ 08*00 2 - AUG-2007 S 14 - SEP 2007 NON-RAD

Leachate

Leachate

Leachate

Leachate

Leachate

Leachate
P TM/TCLP+PREP

C OP/TCLP/EXT

C TM/CR/TCLP/6010

C TM/PB/TCLP/6010

C TM/SE/TCLP/6010

$\mathrm{S} T \mathrm{TM} / \mathrm{NI} / \mathrm{TCLP} / 6010$
- . . -

D018406

D018407

D018407

D018407

D018407

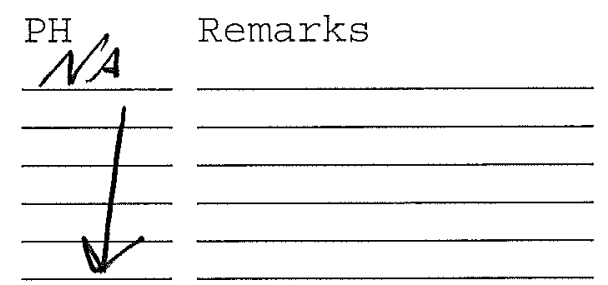

$1.6 \cdot \mathrm{AUG} 2007$. $08 \cdot 05$ 21 AUG $200 \%$ S $1.4-\mathrm{SEP}-2007$ NON-RAD

Leachate

Leachate

Leachate

Leachate

Leachate

Leachate
P TM/TCLP+PREP

C OP/TCLP/EXT

C TM/CR/TCLP/6010

C TM/PB/TCLP/6010

C TM/SE/TCLP/6010

S TM/NI/TCLP/6010
D018408
D018409
D018409
D018409
D018409

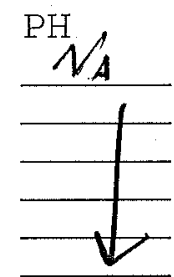

\section{To7 $082202-03$ NON-RAD}

Leachate

Leachate

Leachate

Leachate

Leachate

Leachate
$07239-2035-37$

$\begin{array}{ll}\mathrm{P} & \text { TM/TCLP+PREP } \\ \mathrm{C} & \mathrm{OP} / \mathrm{TCLP} / \mathrm{EXT} \\ \mathrm{C} & \mathrm{TM} / \mathrm{CR} / \mathrm{TCLP} / 6010 \\ \mathrm{C} & \mathrm{TM} / \mathrm{PB} / \mathrm{TCLP} / 6010 \\ \mathrm{C} & \mathrm{TM} / \mathrm{SE} / \mathrm{TCLP} / 6010 \\ \mathrm{~S} & \mathrm{TM} / \mathrm{NI} / \mathrm{TCLP} / 6010\end{array}$

$107082202 \cdot 04 \quad 07239$ PU35 41 NON-RAD

Leachate Leachate Leachate Leachate Leachate Leachate
P TM/TCLP+PREP

C OP/TCLP/EXT

C TM/CR/TCLP/6010

C TM/PB/TCLP/6010

C TM/SE/TCLP/6010

S TM/NI/TCLP/6010

16.AUG-2007\%08.100.21-AUG-2007 S. 14 -SPP-2007

$-\cdots$

D018410

D018411

D018411

D018411

D018411

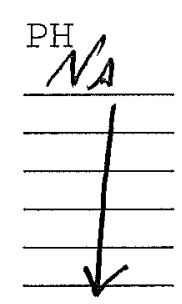

16. AUG $2007.08 \% 15$ 21-AUG 2007 S 14 - SPP 2007

Revision 0

Appendix F 
Page 29

DAVIS \& FLOYD, INC.

LOGIN REPORT (In01)

August 22 2007, 08:36 am

Login Number: L07082202

ACCount: WASSAV WASHINGTON SAVANNAH RIVER COMPANY

Project: 62664.00 MISC. ANALYTICAL SERVICES
1.*10.0. $0.0 .0 \% \%$

S.:1118.
\%1. $10.1 \%$

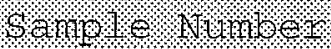

(.).

. .1 .0$.
WSRC-STI-2007-00477

Revision 0

Appendix F
107082202005 NON-RAD

Leachate

Leachate

Leachate

Leachate

Leachate

Leachate
07239 PUB 547

P TM/TCLP+PREP

C OP/TCLP/EXT

C TM/CR/TCLP/6010

C TM/PB/TCLP/6010

C TM/SE/TCLP/6010

S TM/NI/TCLP/6010

$16 \cdot A U G-2007: 08 \cdot 20$

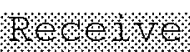

1.

$11 \mathrm{c}$

31.1 .100 .

$100708220206 \quad 07239-\mathrm{PU} 35=50$ NON-RAD

Leachate

Leachate

Leachate

Leachate

Leachate

Leachate
P TM/TCLP+PREP

C OP/TCLP/EXT

C TM/CR/TCLP/6010

C TM/PB/TCLP/6010

C TM/SE/TCLP/6010

$\mathrm{S} \mathrm{TM} / \mathrm{NI} / \mathrm{TCLP} / 6010$ $-\cdots$

D018414

D018415

D018415

D018415

D018415

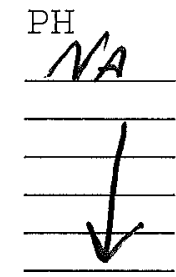

14.SFP 2007

$16 \cdot \mathrm{AUG}-200708 \cdot 25.21 \cdot \mathrm{AUG}-2007$ S 14 -SEP 2007

I07082202-07: $07239-2035-51$ NON-RAD

Ieachate

Leachate

Leachate

Leachate

Leachate

Leachate
$\mathrm{P}$ TM/TCLP+PREP

C OP/TCLP/EXT

C TM/CR/TCLP/6010

C TM/PB/TCLP/6010

C TM/SE/TCLP/6010

$\mathrm{S} T \mathrm{TM} / \mathrm{NI} / \mathrm{TCLP} / 6010$

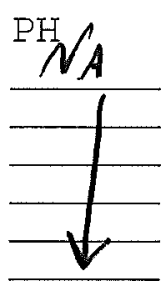

D018416
D018417
D018417
D018417
D018417

$16 . \mathrm{AUC}-2007$ 08.30.21-AUG-2007 S 14 -SPP-2007

- - - -

D018418

D018419

D018419

D018419

D018419

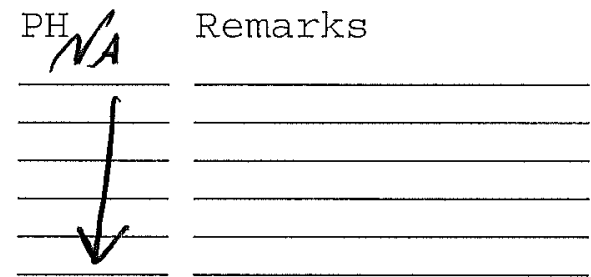

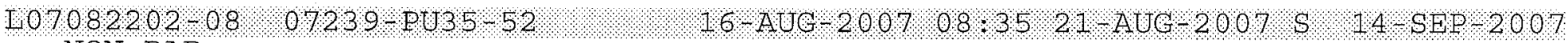
NON-RAD

Leachate

Leachate

Leachate

Leachate

Leachate

Leachate
P TM/TCLP+PREP

C OP/TCLP/EXT

C TM/CR/TCLP/6010

C TM/PB/TCLP/6010

C TM/SE/TCLP/6010

$\mathrm{S} \mathrm{TM} / \mathrm{NI} / \mathrm{TCLP} / 6010$
- - - -

D018420

D018421

D018421

D018421

D018421

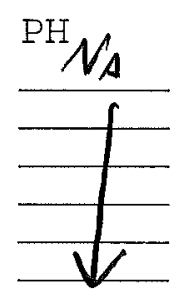




\section{DAYIS nigienting

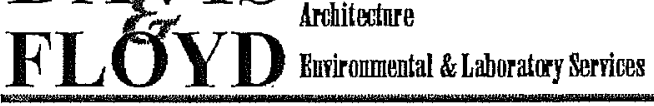

Date: 8.21 .07

Location: Sample receiving

Comments:

Time: $15: 09$

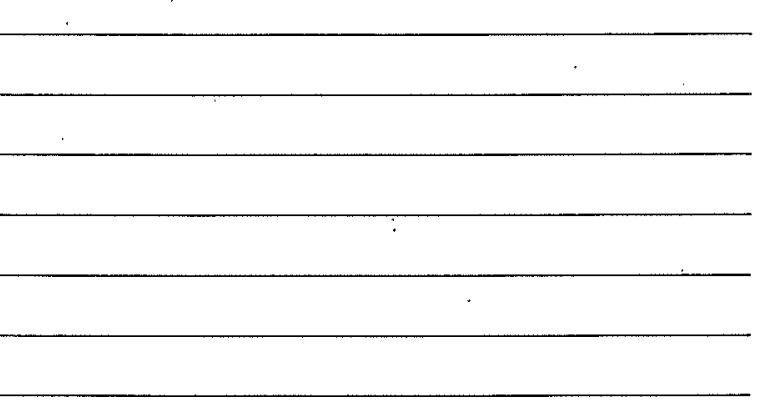

Survey Form

Surveyor: T/5a b. micall

\section{$\underline{\text { Instrument Data }}$}

\begin{tabular}{|c|c|}
\hline Mfg. $T_{e c}-3$ & Mfg. Tex -3 \\
\hline Model & Model \\
\hline Serial \# & Serial \# \\
\hline Cal Due 01.02 .08 & Cal Due 01.02 .08 \\
\hline Efficiency 85 & Efficiency 29.3 \\
\hline $\mathrm{MDA} \quad 18.0$ & MDA $\quad 233.7$ \\
\hline Mfg. & Mfg. \\
\hline Model & Mode1 \\
\hline Serial \# & Serial \# \\
\hline Cal Due & Cal Due \\
\hline Effficiency & Efficiency \\
\hline $\mathrm{MDA}$ & $\mathrm{MDA}$ \\
\hline
\end{tabular}

\section{SURVEY RESULTS}

\begin{tabular}{|c|c|c|c|c|c|c|c|}
\hline & & & ALPHA & & & BETA & \\
\hline SWIPE & LOCATION & Swipe & Direct & Wipe & Swipe & Direct & Wipe \\
\hline$\#$ & Sample Number & $\mathrm{dpm} / 100 \mathrm{~cm}^{2}$ & dpm/wipe & $\mathrm{dpm} / 100 \mathrm{~cm}^{2}$ & $\mathrm{dpm} / 100 \mathrm{~cm}^{2}$ & $\mathrm{dpm} / 100 \mathrm{~cm}^{2}$ & dpm/wipe \\
\hline 1 & outside of cooler OgOI & $\angle$ & & & $\angle$ & & \\
\hline 2 & Dutside of cooler 0529 & $\angle$ & & & $\angle$ & & \\
\hline 3 & bag containing paperwperk o5R & $9<$ & & & $<$ & & \\
\hline 4 & bag containing 5amples 0529 & $<$ & & & $<$ & & \\
\hline 5 & $06355-211 F-R 5-1 B 50 \mathrm{~g}$ & $<$ & & & $<$ & & \\
\hline 6 & $06355-3 \| 1 F-R 5-1 B$ Full & $\angle$ & & & $<$ & & \\
\hline 7 & bagcontaining paperwork ogol & $<$ & & & $<$ & & \\
\hline 8 & bag containing samples ogos & $<$ & & & $<$ & & \\
\hline 9 & $04339-P u 35-11$ & $\angle$ & & & $\angle$ & & \\
\hline 10 & $07339-P 435-36$ & $\angle$ & & & $\leqslant$ & & \\
\hline 11 & $0733 q-P u 35-37$ & $<$ & & & $<$ & & \\
\hline 12 & $07339-P u 35-41$ & $<$ & & & $<$ & & \\
\hline 13 & $0733 q-P u 35-47$ & $<$ & & & $\angle$ & & \\
\hline 14 & $0723 q-p u 35-50$ & $\angle$ & & & $<$ & & \\
\hline 15 & $07239 \cdot P 435-51$ & $<$ & & & $\angle$ & & \\
\hline
\end{tabular}

Reviewed by RSO:

Date:

Time: 
Survey Type: 5 wipe Location: 5 ample receiving

Purpose:

Comments:

\section{eiving}

com 


\section{Distribution:}

J.S. Allender, 705-A

A.B. Barnes, 999-W

D.R. Best, 786-1A

G.T. Chandler, 773-A

C.L. Crawford, 773-41A

D.A. Crowley, 999-W

R.E. Edwards, 773-A

T.B. Edwards, 999-W

D.P. Eisele, 730-1B

E.G. Estochen, 773-A
K.M. Fox, 999-W

E.N. Hoffman, 730-A

N.C. Iyer, 773-41A

J.C. Marra, 773-42A

E.N. Moore, 705-A

T.A. Nance, 773-42A

D.K. Peeler, 999-W

N. Shanmuganathan, 742-A

R.H. Smith, 730-1B

E.C. Tefft, 730-1B 